\title{
Struktur und Entwicklung der dialektalen Variation in der Campania
}

\section{Eine dialektometrische Analyse}

\author{
Dissertation \\ zur Erlangung des philosophischen Doktorgrades
}

an der Philosophischen Fakultät der Georg-August-Universität Göttingen

vorgelegt von

Sandra Hajek

aus Köln

Göttingen 2018 


\section{Danksagung}

Bei der vorliegenden Arbeit handelt es sich um die überarbeitete Version der Arbeit, die im Dezember 2016 an der Philosophischen Fakultät der Georg-August-Universität Göttingen als Dissertation im Fach Romanische Philologie (Romanische Sprachwissenschaft) angenommen wurde. Im Folgenden möchte ich den Menschen danken, die dazu beigetragen haben, dass die vorliegende Arbeit erstellt und als Leistung im Rahmen meiner Promotion anerkannt werden konnte.

Ein besonderer Dank gilt meinem Erstgutachter Prof. Dr. Guido Mensching, der mir stets mit Rat und Tat sowie seiner uneingeschränkten Loyalität und fachlichen Wertschätzung zur Seite stand und mir den erfolgreichen Abschluss meiner Promotion ermöglicht hat.

Meinem Zweitgutachter Prof. Dr. Hans Goebl danke ich für den verlässlichen Rückhalt, den intensiven fachlichen Austausch und die bedingungslose Unterstützung, die ich in allen Belangen und zu jeder Zeit erfahren durfte. Ihm und seinen Mitarbeitern Pavel Smečka und Bernhard Castellazzi danke ich ferner für die praktische Hilfestellung, die ich im Bereich der Verarbeitung und Präsentation der Daten erhalten habe.

Für ihre unschätzbare Hilfe bei der Durchführung der Dialektaufnahmen danke ich Michael Krause, Ansgar Huppertz, Rosario Boccione, Ciro Procentese und Gerardo Sista.

Meggi Altrock danke ich für ihre unermüdliche organisatorische Unterstützung und moralische Begleitung, die ich in allen Phasen des Arbeitsprozesses erfahren durfte.

Ich danke ferner meinen ehemaligen Doktoranden-Kollegen und -Kolleginnen der Universität Heidelberg für den wertvollen wissenschaftlichen Austausch und Sara Matrisciano zudem für das aufmerksame Lektorat. Meinen derzeitigen Kolleginnen und Kollegen von der Universität Göttingen danke ich für den täglichen Rückhalt während der bangen Wartezeit.

Nicht zuletzt möchte ich den Menschen in meinem privaten Umfeld für die moralische Unterstützung und das Verständnis danken, das mir stets entgegengebracht wurde. 


\section{Inhaltsverzeichnis}

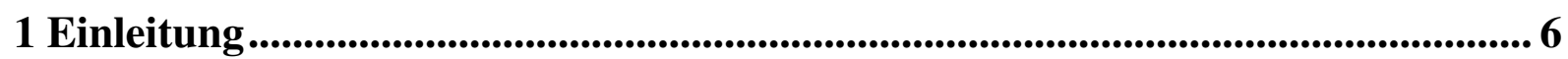

2 Italienisch, Dialekte und Koinai: Entwicklungstendenzen im italienischen Sprachraum..................................................................................................................................... 8

2.1 Die Umgestaltung des sprachlichen Repertoires......................................................... 8

2.2 Der Mythos des Dialektverfalls.............................................................................. 12

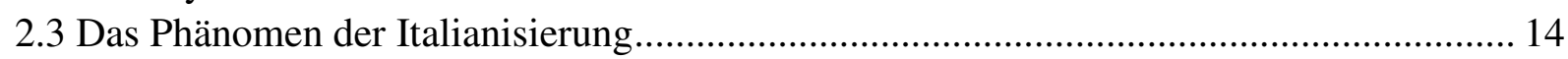

2.3.1 Die Italianisierung im wissenschaftlichen Diskurs ....................................................... 14

2.3.2 Einflüsse des Italienischen auf die dialektalen Sprachsysteme ....................................... 16

2.4 Diachronische Entwicklungen der diatopischen Variation: Koineisierung und

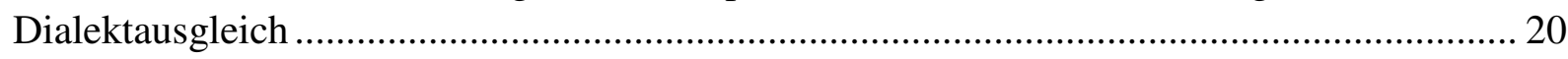

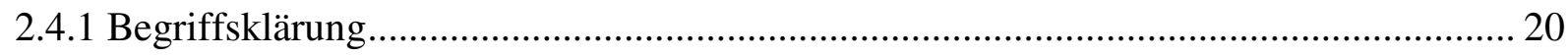

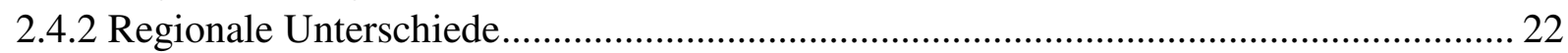

3 Eine (nicht nur) sprachlich komplexe Region: die Campania.................................. 25

3.1 Geographisches und demographisches Profil .......................................................... 25

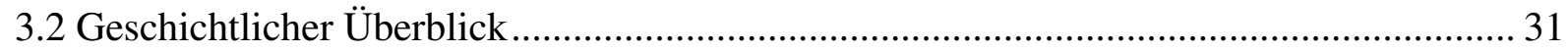

3.2.1 Die Campania von der vorrömischen Zeit bis zum Mittelalter ........................................ 31

3.2.2 Die Campania vom Mittelalter bis zur Neuzeit............................................................. 37

3.2.3 Die Rolle Neapels und des Neapolitanischen ………………………………............. 39

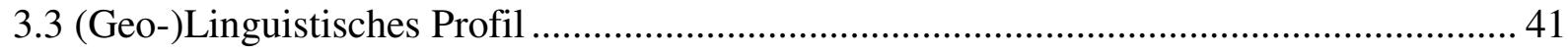

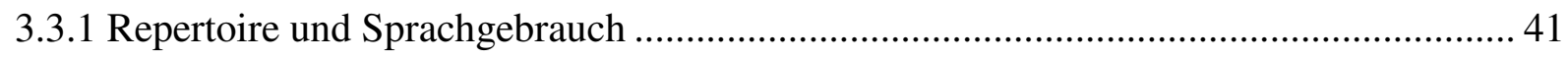

3.3.2 Zur kampanischen Dialektologie............................................................................. 42

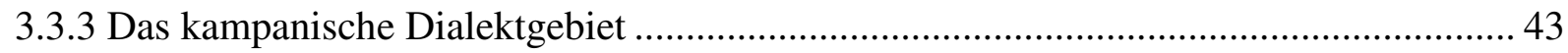

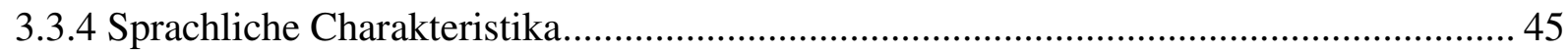

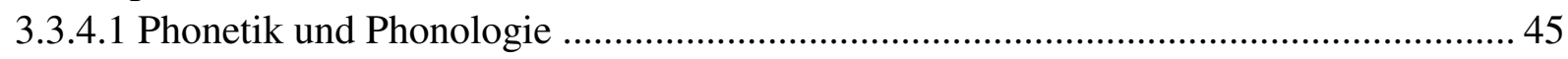

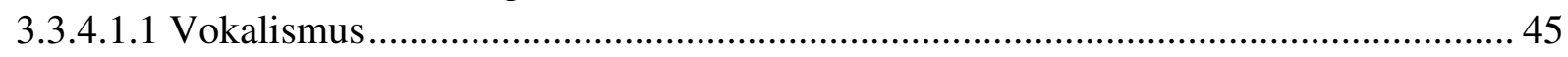

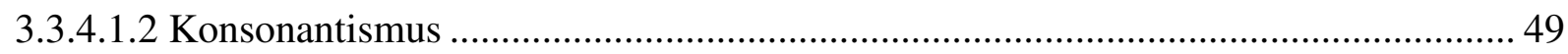

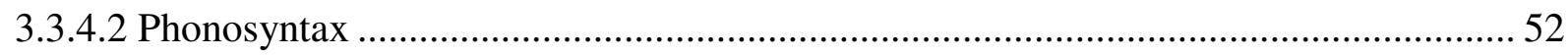

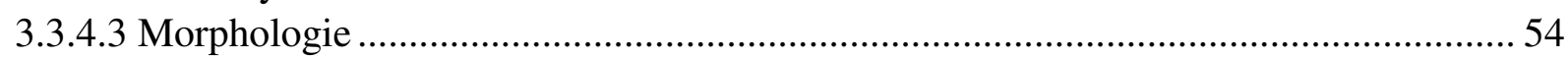

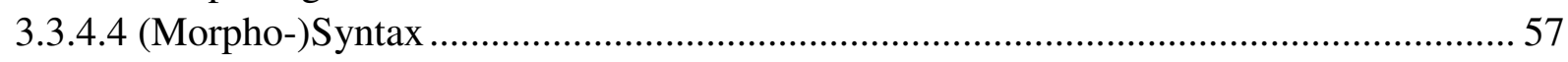

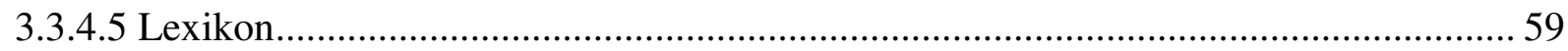

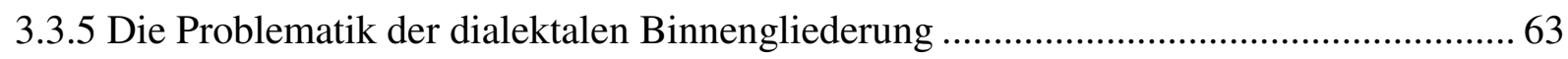

3.3.6 Die diachronische Entwicklung I: Italianisierungstendenzen ........................................ 75

3.3.6.1 Phonetik und Phonologie ........................................................................................ 75

3.3.6.2 Morphologie und (Morpho-)Syntax ........................................................................ 76

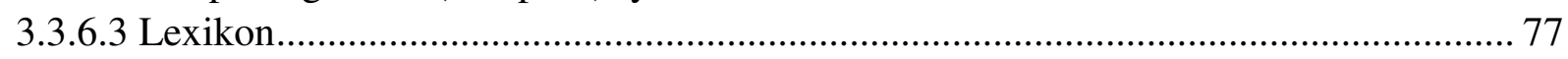

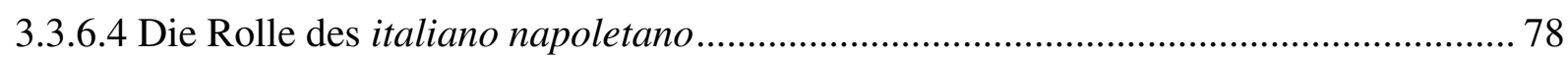

3.3.7 Die diachronische Entwicklung II: Koineisierung auf der Basis des Neapolitanischen? 79 


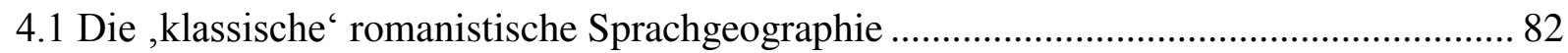

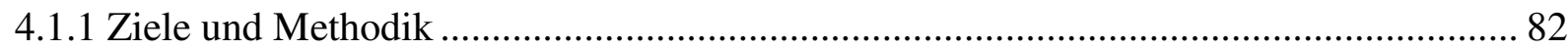

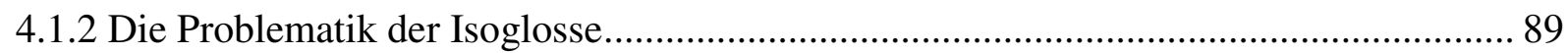

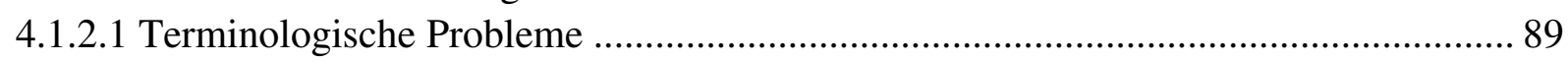

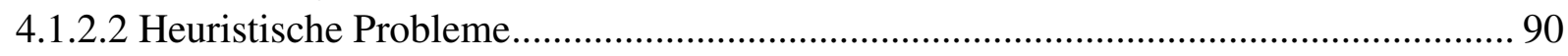

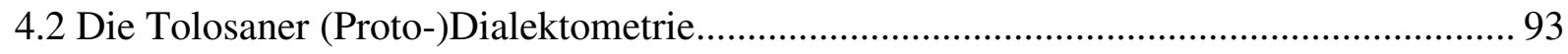

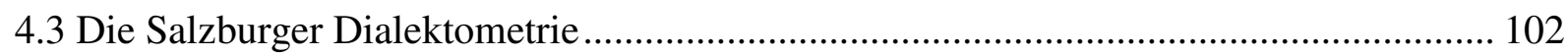

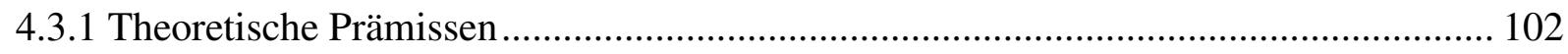

4.3.2 Epistemologische Grundlagen: die numerische Taxonomie ……………………….... 105

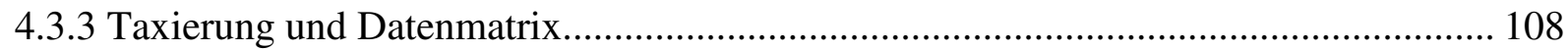

4.3.4 Erstellung der Ähnlichkeits- und Distanzmatrix ........................................................ 115

4.3.4.1 Relativer (ungewichteter) Identitäts- bzw. Distanzwert.......................................... 115

4.3.4.2 Gewichteter Identitäts- bzw. Distanzwert ............................................................ 118

4.3.5 Intervallisierung der Ähnlichkeits- bzw. Distanzwerte .............................................. 122

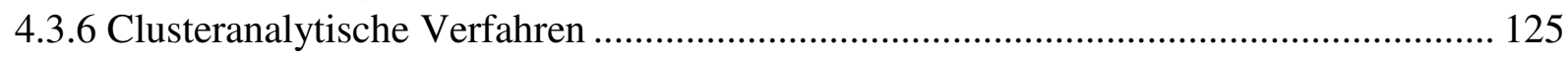

4.3.7 Kartographische Visualisierung und Interpretation …………………..................... 128

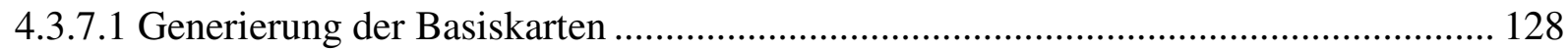

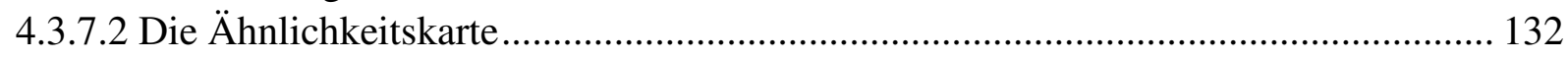

4.3.7.3 Die Kennwertsynopse der Maxima ......................................................................... 133

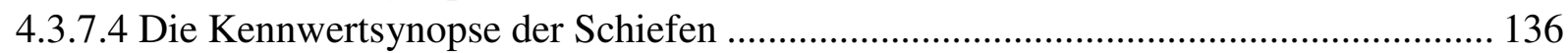

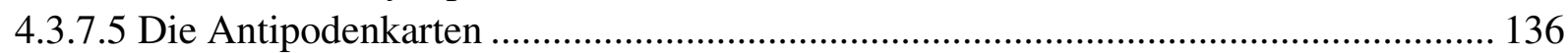

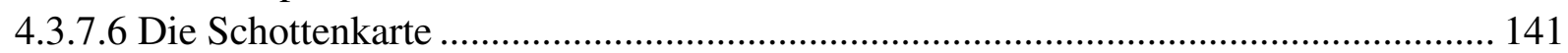

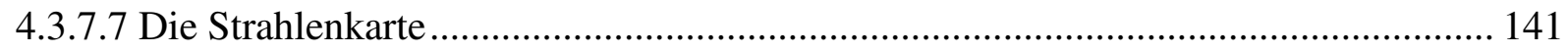

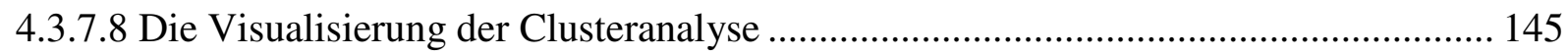

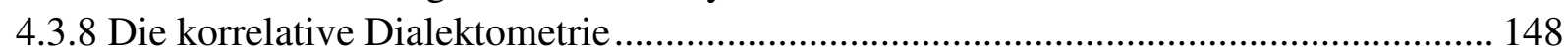

4.4 Zur Entstehung sprachlicher Raummuster ................................................................... 153

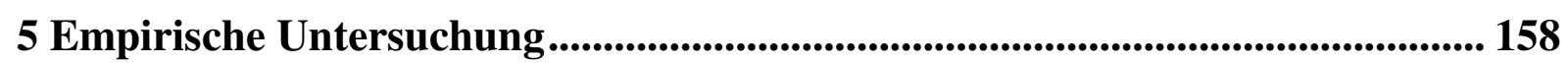

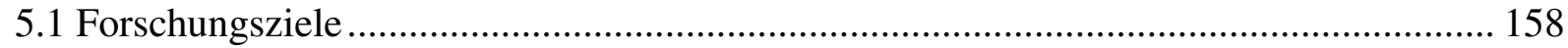

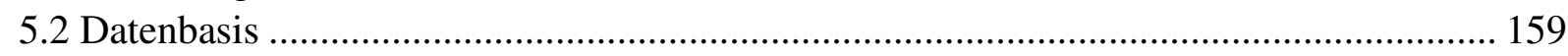

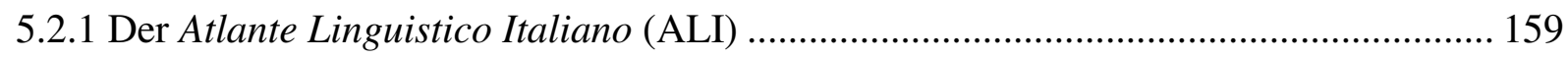

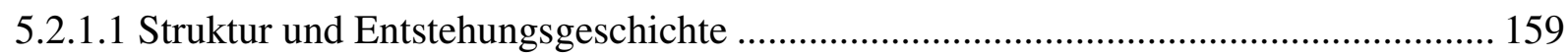

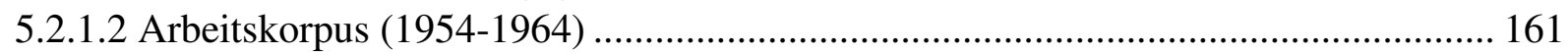

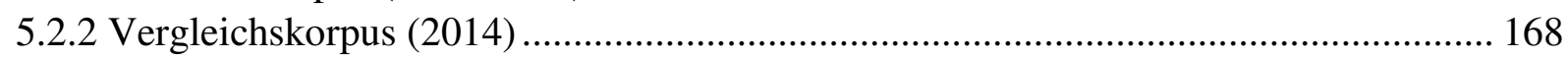

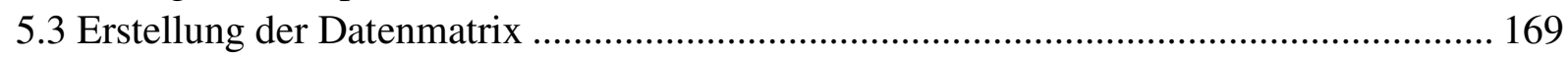

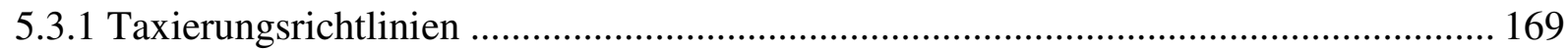

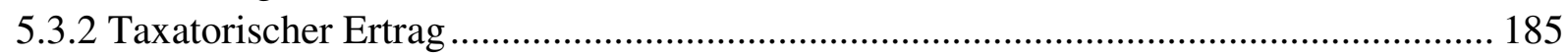

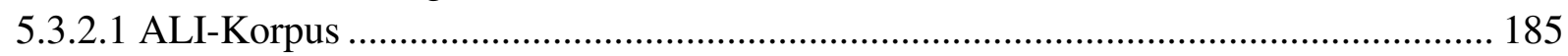

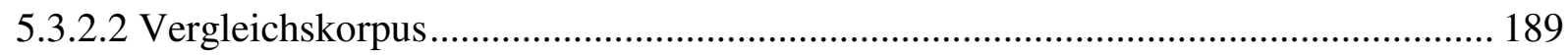

5.4 Dialektometrische Auswertung I: Das kampanische Dialektgebiet um 1960_................. 194

5.4.1 Klassifikation der kampanischen Dialekte ............................................................... 194

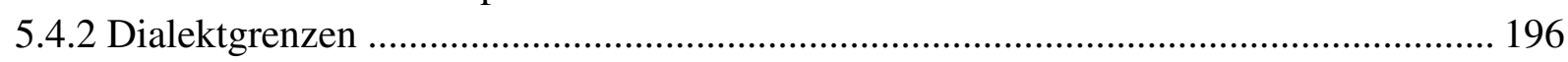

5.4.3 Dialektkerne und sprachliche ,Einzelgänger ‘............................................................ 199 


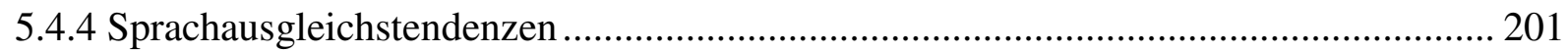

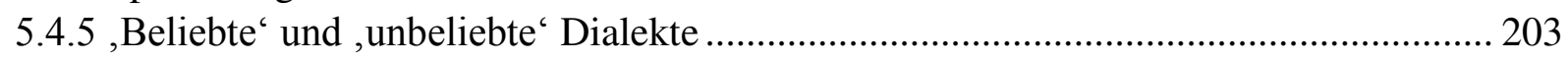

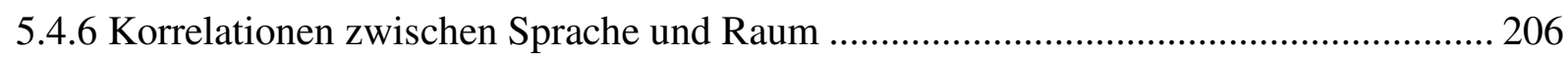

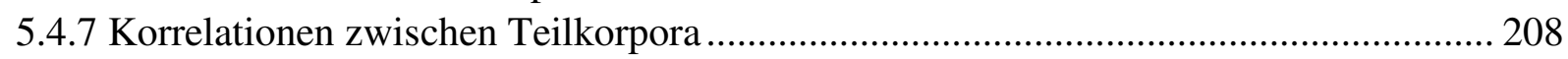

5.4.8 Die kampanischen Dialekte und das Standarditalienische ......................................... 210

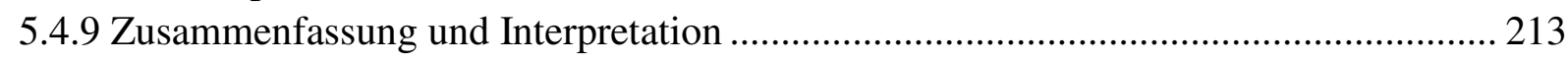

5.5 Dialektometrische Auswertung II: Das kampanische Dialektgebiet 2014..................... 216

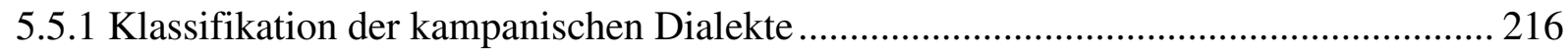

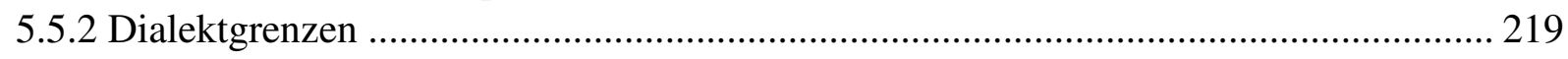

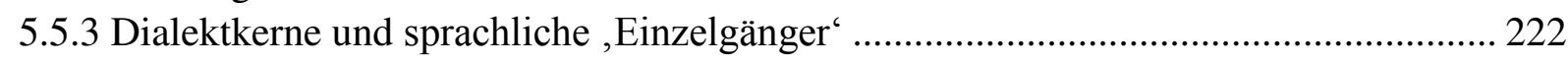

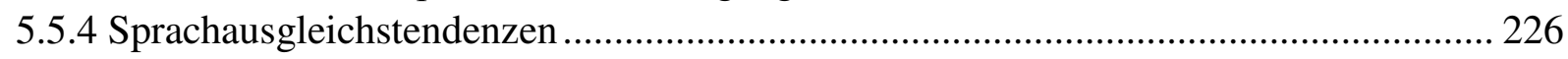

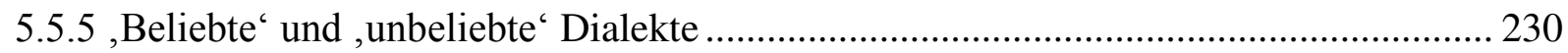

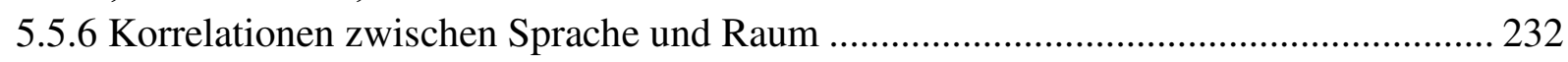

5.5.7 Veränderungen der sprachlichen Ähnlichkeitsprofile zwischen 1960 und 2014 ......... 236

5.5.8 Die kampanischen Dialekte und das Standarditalienische ......................................... 239

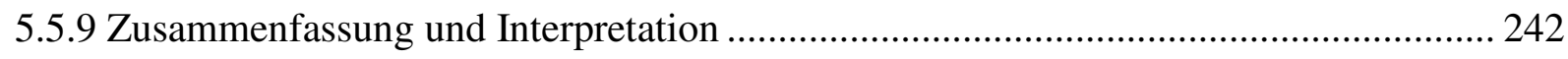

6 Forschungsbeitrag und Perspektiven............................................................................ 245

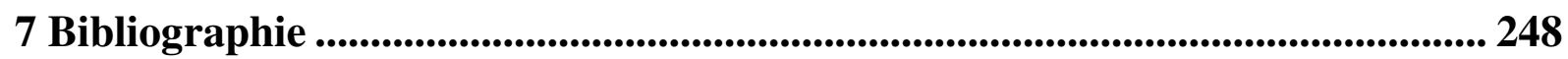

8 Verzeichnisse ……................................................................................................................ 266

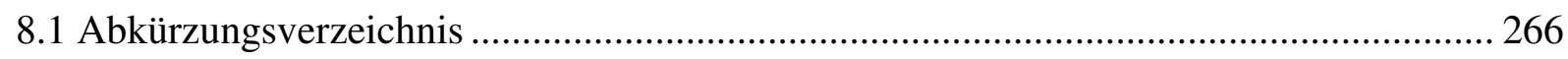

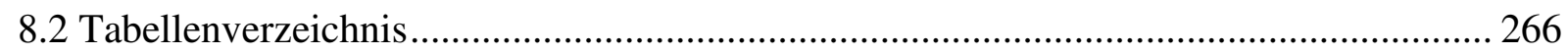

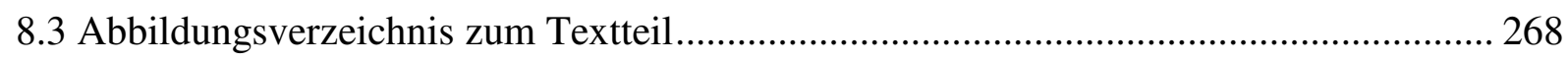

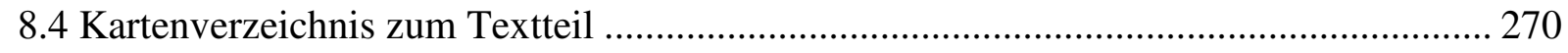

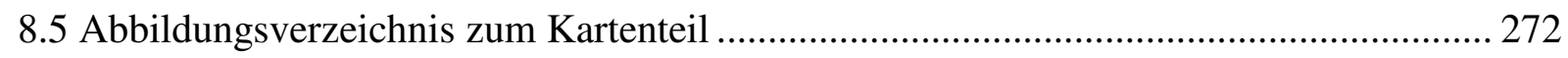

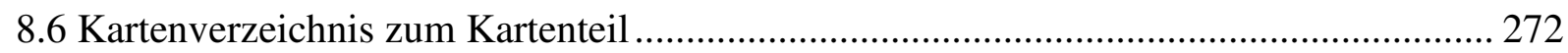

9 Kartenteil .......................................................................................................... 279 


\section{Einleitung}

Als elementarer Faktor der sprachlichen Variation hat der geographische Raum in der romanischen Sprachwissenschaft seit ihren Anfängen eine bedeutende Rolle gespielt. Das Interesse an der Dokumentation und Analyse der Beziehung zwischen Sprache und Raum kennzeichnete dabei neben der französischen insbesondere die italienische Linguistik, die die Entwicklung der romanistischen Sprachgeographie maßgeblich mitprägte.

Doch auch über ein Jahrhundert nach der Begründung der italienischen Dialektologie ist das diatopische Profil des italienischen Sprachraums nicht zufriedenstellend erforscht. Die vorliegende Literatur ist durch ein deutliches Ungleichgewicht in der Erforschung der verschiedenen Dialektareale gekennzeichnet: Während Beiträge zum norditalienischen Dialektgebiet ausreichend vorhanden sind, sind jene zur Struktur und Entwicklung der süditalienischen Dialekte und Dialektgebiete deutlich unterrepräsentiert. Die Notwendigkeit ergänzender geolinguistischer Forschung in diesem Bereich erhält eine besondere Dringlichkeit dadurch, dass sich die Entwicklungen im italienischen Sprachraum in den vergangenen 50 bis 60 Jahren stark beschleunigt haben: Die Umgestaltung des sprachlichen Repertoires und die Omnipräsenz des Standarditalienischen haben nicht nur Veränderungen im diatopischen Varietätengefüge (Bildung der italiani regionali) gezeitigt, sondern auch die strukturelle Entwicklung der italienischen Dialekte stark beeinflusst. Systematische Dokumentationen und Analysen der Veränderungen des diatopischen Profils und der dialektalen Sprachsysteme stehen insbesondere für den süditalienischen Dialektraum bis heute jedoch weitestgehend aus.

Auch im methodischen Bereich liegt die einst richtungsweisende italienische Geolinguistik heute zurück. Trotz der bekannten methodischen Nachteile und Unzulänglichkeiten der ,klassischen', qualitativen Sprachgeographie wird ein Übergang zur neueren, quantitativen geolinguistischen Methodik der Dialektometrie nicht für nutzbringend befunden. Gerade bei der Dokumentation und Analyse der internen Gliederung komplexer, durch starke diatopische Variation geprägter Dialektareale sind der qualitativen sprachgeographischen Methodik jedoch deutliche Grenzen gesetzt, sodass der wissenschaftliche Erkenntnisfortschritt nur durch die Öffnung gegenüber modernen, geeigneteren Methoden erfolgen kann. Eine solche findet sich in der italienischen Dialektologie bisher fast ausschließlich gegenüber den quantitativen Methoden der Soziolinguistik bzw. einer allgemeinen Variationslinguistik, deren Anwendung jedoch eine Verstellung des wissenschaftlichen Fokus bewirkt und eine primär geolinguistisch orientierte Forschung nicht ermöglicht.

Entsprechend der Situation, in der sich die italienische Geolinguistik zum heutigen Zeitpunkt befindet, ist das der vorliegenden Arbeit zugrunde liegende Forschungsinteresse ein zweifaches. Zum Einen soll durch die Analyse des komplexen Dialektgebietes der italienischen Region Kampanien (Campania) ein Beitrag zur Erweiterung der Kenntnisse über die dialektale Variation in den süditalienischen Regionen geleistet werden. Neben der ursprünglichen basilektalen Gliederung werden dabei die Entwicklung der geolinguistischen Strukturen sowie die Veränderung des strukturellen Verhältnisses zwischen den kampanischen Dialekten und dem Standarditalienischen in den vergangenen 50 Jahren analysiert und diskutiert.

Durch den Einsatz einer dialektometrischen Methodik - der Salzburger Dialektometrie - soll die Arbeit zum Anderen die Nutzbarkeit und auch die Notwendigkeit des Einsatzes moderner geolinguistischer Verfahren bei der Analyse sprachlicher Raumstrukturen in Gebieten aufzeigen, die mit qualitativen sprachgeographischen Mitteln nicht adäquat beschrieben und analysiert werden können. 
Die Arbeit beginnt mit einem einführenden Teil (Kap. 2), in dem die Entwicklungen, die den italienischen Sprachraum im vergangenen Jahrhundert gekennzeichnet haben und teilweise heute noch kennzeichnen, d.h. der Wandel des Repertoires der italienischen Sprachgemeinschaft und die dadurch bedingten Veränderungen des diatopischen Varietätengefüges und der Struktur der italienischen Dialekte überblickshaft dargestellt werden. Daneben erfolgt hier die Einführung und Klärung der im weiteren Verlauf der Arbeit relevanten Konzepte und Termini.

Das folgende Kapitel (Kap. 3) gibt zunächst grundlegende geographische und demographische Informationen zur Region Kampanien sowie einen Überblick über ihre (Siedlungs-)Geschichte. Einigen Angaben zum Sprachgebrauch und zur Stellung der Dialekte in der Region folgt eine Positionierung des kampanischen Dialektgebietes im süditalienischen Sprachraum sowie die Darstellung einiger Hauptmerkmale der kampanischen Dialekte in den verschiedenen sprachlichen Bereichen. Im Anschluss wird die Problematik der Beschreibung der dialektalen Struktur der Region mit den Mitteln der qualitativen Sprachgeographie illustriert. Eine Diskussion der Unzulänglichkeit der sprachgeographischen Forschung im Bereich der Analyse der diachronischen Entwicklung der diatopischen Variation in der Campania beschließt diesen Teil.

Der folgende Teil der Arbeit (Kap. 4) beinhaltet die Darstellung der in der empirischen Untersuchung eingesetzten geolinguistischen Methodik der Salzburger Dialektometrie im Hinblick auf ihre wissenschaftstheoretischen und -geschichtlichen Hintergründe, ihre epistemologischen Grundlagen und Ziele sowie die verschiedenen Schritte des dialektometrischen Verfahrens und die Heuristika der dialektometrischen Analyse.

Im Zentrum der Arbeit steht die empirische geolinguistische Untersuchung (Kap. 5). Hier werden zunächst Konzeption und Ziele der empirischen Arbeit und anschließend die Modalitäten der Erhebung des sprachlichen Datenmaterials erläutert. Es folgen die Darstellung der bei der dialektometrischen Verarbeitung der sprachlichen Rohdaten angewendeten Prinzipien und die Präsentation des dialektometrischen Ertrags. Den Hauptteil des Kapitels stellen die Analyse und Interpretation der Ergebnisse der dialektometrischen Auswertung anhand des entsprechenden Kartenmaterials dar.

Abgeschlossen wird die Arbeit mit einer Diskussion des durch die empirische Untersuchung geleisteten Forschungsbeitrags, verschiedener Möglichkeiten zur inhaltlichen Ergänzung und Weiterführung der Arbeit sowie der grundsätzlichen Desiderata, die sich daraus für die italienische Geolinguistik ergeben (Kap. 6). 


\section{Italienisch, Dialekte und Koinai: Entwicklungstendenzen im italienischen Sprachraum}

\subsection{Die Umgestaltung des sprachlichen Repertoires}

Die heutige Situation der italienischen Sprachgemeinschaft (in Italien) ist deutlich geprägt durch die Veränderungen, die das sprachliche Repertoire ${ }^{1}$ und mit ihm der Sprachgebrauch der Sprecher im Laufe der vergangenen 100 bis 150 Jahre erfahren haben. Die historische Situation des gesellschaftlichen Monolinguismus, in der die italienischen Dialekte ${ }^{2}$ den mündlichen Sprachgebrauch in allen Gesellschaftsschichten prägten, während die durch das literarische Werk der ,Tre Corone' (Dante, Boccaccio, Petrarca) im 14. bzw. 15. Jahrhundert zu Prestige gelangte Varietät des volgare toscanolfiorentino außerhalb der Toskana fast ausschließlich schriftlich und in gelehrten Kreisen gebraucht wurde, soll hier daher nur kurz in Erinnerung gerufen werden. Während die Sprecher aus den unteren, bildungsfernen Volksschichten noch bis Ende des 19. Jahrhunderts nicht oder nur sehr selten mit der geschriebenen Sprache in Kontakt kamen, orientierten sich die gebildeten (und damit alphabetisierten) Sprecher höherer sozialer Schichten bereits deutlich früher auch in der mündlichen Kommunikation an der toskanischen bzw. florentinischen Schriftsprache, sodass sich der mündliche Sprachgebrauch diastratisch stark differenzierte: ,[...] [I]n ogni Provincia vi son due linguaggi [...]: un che s'usa in parlando comunalmente, e senza studio alcuno, che noi chiamiamo imperfetto, il qual' ordinariamente si parla dal vulgo; l'altro che si cerca parlare, se pur non si parla, da gente civile, e noi chiamiamo perfetto, simile a quello, col qual si scrive“ (N. Amenta, Della lingua nobile d'Italia 1723-1724: I, 5). ${ }^{3}$

Zum Zeitpunkt der Gründung des italienischen Nationalstaates (Regno d'Italia) im Jahr 1861 bestand in den verschiedenen Teilen Italiens also eine Diglossie ohne (gesellschaftlichen) Bilinguismus: ${ }^{4}$ Die diatopisch stark diversifizierten Basisdialekte dienten in allen sozialen

\footnotetext{
${ }^{1}$ Der Begriff des sprachlichen Repertoires wird hier - wie auch in anderen, ähnlichen Darstellungen (vgl. etwa Sobrero 1996) - in einer erweiterten Bedeutung, d.h. unter Abstraktion von der interindividuellen Variation als Menge aller Register(-Typen) verstanden, die der Großteil einer Sprechergemeinschaft miteinander teilt. Verfügen zwei Sprecher etwa über die Möglichkeit, bei der Wahl der sprachlichen Ausdrucksform zwischen einem italoromanischen Dialekt und dem Italienischen zu wählen, so besitzen sie ein gemeinsames Repertoire.

${ }^{2}$ Der Arbeit zugrunde liegt ein Verständnis des Dialekts als autochthones Sprachsystem geringer geographischer Reichweite, das Teil eines horizontalen sprachlichen Kontinuums ist (und dementsprechend Ähnlichkeiten zu geographisch benachbarten dialektalen Systemen aufweist) und das von einer überregionalen, genetisch verwandten Standardsprache überdacht wird.

${ }^{3}$ Die vom ,einfachen Volk“ (vulgo) gebrauchte Varietät bezeichnet Amenta (ebd.) als ,lingua speciale“, die von gebildeten bzw. „bürgerlichen“ Sprechern (gente civile) verwendete Varietät als „lingua particolare“. Bei ersterer handelt es sich damit um den jeweiligen lokalen (italoromanischen) Dialekt und bei letzterer wohl um einen stark ,toskanisierten“ Dialekt oder eine Art ,Regional-Florentinisch' mit starken dialektalen Interferenzen. ${ }^{4}$ Die die möglichen Kombinationen von gesellschaftlichem (d.h. eine größere Anzahl an Individuen betreffenden) Bilinguismus und Diglossie beinhaltende Unterscheidung von vier potentiell in einer Gesellschaft anzutreffenden sprachlichen Situationen („Diglossie mit Bilinguismus“, „Diglossie ohne Bilinguismus“, „Bilinguismus ohne Diglossie“ und ,weder Diglossie noch Bilinguismus“) geht zurück auf Fishman (1967). Sie beruht auf dem den Fergusonschen (1959) Diglossie-Begriff erweiternden Verständnis ,that diglossia exists not only in multilingual societies which officially recognize several ,languages' but, also, in societies which are multilingual in the sense that they employ separate dialects, registers or functionally differentiated language varieties of whatever kind“ (Fishman 1967: 30). Diglossie mit Bilinguismus (+D, +B) findet sich demnach häufig in Sprachgemeinschaften, deren Mitglieder Zugang zu einer Vielzahl verschiedener und mit bestimmten sprachlichen Kodes verbundener sozialer Rollen und damit häufig ein breites sprachliches Repertoire haben. In diese Kategorie fallen viele moderne Sprachgemeinschaften, die gemeinhin als „,monolingual“ eingestuft werden. Diglossie ohne Bilinguismus $(+\mathrm{D},-\mathrm{B})$ ist meist ein Charakteristikum politisch geeinter Gesellschaften, die eine starke interne soziale (und damit auch sprachliche) Segregation, d.h. eine Vielzahl sozialer Gruppen mit (stark) beschränktem Zugang zu sozialen Rollen und entsprechend begrenzten sprachlichen Repertoires aufweisen. Damit kennzeichnet dieser
} 
Schichten als (primäres) Mittel zur Alltagskommunikation (L-Varietäten), ${ }^{5}$ während das ,klassische' Florentinisch die vorwiegend schriftlich gebrauchte National- und Literatursprache darstellte, deren Erwerb und Kenntnis nur durch einen (längeren) Schulbesuch zu erreichen und damit Angehörigen der intellektuellen (und politisch-ökonomischen) Elite vorbehalten war: „Al momento dell'unificazione, dunque, la popolazione italiana era per quasi 1' $80 \%$ priva della possibilità di venire a contatto con l'uso scritto dell'italiano, ossia [...] dell'italiano senz'altra specificazione“ (De Mauro 1986: 37).

Die italienische Einigung fungiert als Ausgangspunkt grundlegender Veränderungen im Repertoire der italienischen Sprachgemeinschaft: „L'unità d'Italia [...] fece sì che l'italiano, lingua parlata soltanto in Toscana e dalle persone colte del resto della Penisola, cominciasse a diffondersi presso l'intera popolazione italiana“ (Dardano/Trifone 2005: 39). Eine rasche Italianisierung vollzog sich jedoch zunächst nur in den an der Organisation des italienischen Nationalstaates, d.h. der Zentralisierung administrativer, politischer und militärischer Institutionen beteiligten Teilen der Bevölkerung; bei der Verbreitung des Italienischen in dem aus diesen Bereichen ausgeschlossenen Großteil der Bevölkerung des geeinten Staates handelte es sich um einen weit länger andauernden Prozess. Der Aufbau eines leistungsfähigen öffentlichen Bildungssystems zur flächendeckenden Alphabetisierung der Bevölkerung ging in den ersten Jahren und noch Jahrzehnte nach der Einigung nur langsam voran (1911 waren (gegenüber etwa $75 \%$ im Jahr 1861 $)^{6}$ noch etwa 40\% der Italiener Analphabeten, 1951 waren es noch etwa 14\%, vgl. De Mauro 1986: 95). Insbesondere zwischen städtischen und ländlichen Gebieten herrschten deutliche Unterschiede im Ausbau und in der Qualität der Schulbildung, die aufgrund der starken ländlichen Prägung der südlichen Regionen zu einem geographischen Ungleichgewicht im Hinblick auf die Alphabetisierung und den Erwerb des Italienischen führten: ${ }^{7},[\mathrm{D}]$ opo l'unità, " saper parlare italiano » è andato diventando sempre più un carattere tipico del Settentrione, mentre non sapere parlare italiano, cioè saper parlare soltanto dialetto, è andato diventando un contrassegno tipico delle popolazioni contadine del Sud“ (De Mauro 1986: 100). ${ }^{8}$

Typ etwa die auf dem Ständesystem aufgebauten europäischen Gesellschaften bis zum Aufkommen der Demokratie im 20. Jahrhundert sowie auch heutige Gesellschaftsformen, die auf sozialer Segregation - wie etwa dem Kastensystem - beruhen. Bilinguismus ohne Diglossie $(-D,+B)$ tritt in Gesellschaften auf, in denen die funktionale Differenzierung verschiedener Sprachen, Varietäten, Dialekte oder Register in Folge einer durch Prozesse wie Industrialisierung oder massive Immigration bedingten schwächeren Markierung sozialer Rollen bzw. Domänen verloren gegangen ist. Dieser Zustand sowie die dadurch hervorgerufenen sprachlichen Interferenzen und ,Mischvarietäten' haben meist Übergangscharakter und bestehen nur solange, bis sich die Sprache bzw. Varietät mit dem höheren Prestige gegenüber der bzw. den anderen durchsetzt. Der letzte Typus, d.h. weder Diglossie noch Bilinguismus (-D, -B), könnte sich theoretisch in sehr kleinen, sozial undifferenzierten und nach außen isolierten Sprachgemeinschaften finden lassen. Doch weisen alle bisher bekannten Sprachgemeinschaften soziale Bereiche mit beschränktem Zugang und ihre Mitglieder dementsprechend unterschiedliche sprachliche Repertoires auf. Da zudem die demographische und ökonomische Entwicklung einer (Sprach-)Gemeinschaft durch Exogamie, Handel oder Erweiterung des Territoriums zum Kontakt mit anderen (Sprach-)Gemeinschaften führen, ist der Fall (-D, -B) zum heutigen Stand als rein hypothetisch zu betrachten.

${ }^{5}$ Auch im teilweise bereits bilingualen Bildungsbürgertum war das Italienische noch bis Anfang des 20. Jahrhunderts nicht die lingua d'uso comune (De Mauro 1986: 137).

${ }^{6}$ An anderer Stelle (S. 36) spricht De Mauro (1986) von einem Anteil an Analphabeten von „oltre 78\%“; wahrscheinlich ist also ein Anteil zwischen 75\% und 80\% im Jahr 1861.

${ }^{7}$ Während etwa in Piemont der Anteil der Analphabeten zwischen 1861 und 1911 von 54\% auf 11\% und zwischen 1911 und 1951 auf 3\% sank, reduzierte sich der bereits zum Zeitpunkt der Einigung deutlich höhere Anteil der Analphabeten in Kalabrien von 86\% im Jahr 1861 nur auf 70\% im Jahr 1911 bzw. 32\% im Jahr 1951 (De Mauro 1986: 95).

${ }^{8}$ Soweit nicht anders angegeben, sind die graphischen Hervorhebungen in Zitaten aus dem jeweiligen Originaltext übernommen. 
Die wirtschaftlichen und gesellschaftlichen Umbrüche des ausgehenden 19. und beginnenden 20. Jahrhunderts - wachsende Industrialisierung, Urbanisierung und interne Migrationen (vgl. Grassi 2011: 280, Dardano/Trifone 2005: 40) - führten besonders in urbanen Regionen bald zu einer Verstärkung des Kontakts mit dem Italienischen auch außerhalb des Bildungssystems und somit zu einer Zunahme der Anzahl (potentiell) ${ }^{9}$ italophoner Sprecher. Die bedeutendsten Entwicklungen des Repertoires der italienischen Sprachgemeinschaft stehen jedoch im Zusammenhang mit den einschneidenden sozioökonomischen Veränderungen in der zweiten Hälfte des 20. Jahrhunderts. In dieser Zeit führte einerseits die weiter wachsende geographische und soziale bzw. sozioökonomische Mobilität zu einer Zunahme der sozialen und sprachlichen Heterogenität (Bruni 1984: 83) und damit zu einer weiteren Intensivierung des Sprach- bzw. Dialektkontakts und der Vermischung von Formen und Funktionen verschiedener sprachlicher Varietäten. Andererseits bewirkte das Aufkommen moderner Medien der Masseninformation bzw. -kommunikation (insbesondere Radio und Fernsehen) eine „,forte espansione della lingua standard in tutti gli ambiti d'impiego sotto la spinta dei mutamenti sociali, politici, economici, culturali“ (Berruto 1989: 107, vgl. auch Pellegrini 1990: 6).

Unter diesen Bedingungen entwickelte sich die heute beobachtbare komplexe soziolinguistische Situation, in der häufig gesellschaftlicher Bilinguismus und Diglossie nebeneinander bestehen (societal bilingualism with diglossia): ${ }^{10}$,The majority of the population knows (to varying degrees [...]) both a dialect and Italian and uses them in complementary distribution, along a relatively stable division of the respective contexts and domains“ (Mioni/ArnuzzoLanszweert 1979: 93). ${ }^{11}$ Hinsichtlich der Kommunikationsdomänen, in denen jeweils das Italienische und die lokalen Dialekte verwendet werden sowie hinsichtlich der Struktur des diatopischen Varietätengefüges bestehen jedoch deutliche regionale Unterschiede. Um diese berücksichtigen zu können, führte Trumper (1977) die Unterscheidung zwischen Makrodiglossie (oder „echter“ Diglossie) und Mikrodiglossie (oder „Pseudo-Diglossie“) ein, die sich anhand der Parameter „Kommunikationsdomänen der Kodes“, „Präsenz einer Koine“, „Funktion der Kodes“ und „Präsenz gemischtsprachiger Äußerungen“ charakterisieren und unterscheiden lassen (vgl. Trumper/Maddalon 1982: 13f.). So ist die Situation der Makrodiglossie - wie sie etwa im Veneto vorliegt - dadurch gekennzeichnet, dass neben dem Italienischen und den Dialekten eine regionale Koine (vgl. Kap. 2.4) existiert, die „Druck“ auf die lokalen Dialekte ausübt. Sowohl die dialektalen Varietäten als auch das Italienische werden in vielen Bereichen der Kommunikation verwendet und überlappen sich in ihren Funktionen weitestgehend. Dementsprechend häufig kommt es zu gemischtsprachigen Äußerungen (enunciati mistilingui) bzw. Interferenzerscheinungen im Allgemeinen (vgl. Trumper 1977: 263-265).

\footnotetext{
9, ,[M]olto inferiore, invece, era il numero di coloro che usavano realmente l'italiano nella vita quotidiana: probabilmente costoro, gli italofoni effetivi, non superavano i 5 milioni di individui“ (De Mauro 1986: 128, zur Situation Anfang des 20. Jahrhunderts).

${ }^{10}$ Die soziolinguistische Situation eines (societal) bilingualism without diglossia $(-\mathrm{D},+\mathrm{B})$ findet sich häufig in den Gebieten, die das Ziel interner Migrationsbewegungen sind (Rom und die hochindustrialisierten Gebiete Norditaliens um Mailand, Turin und Genua). Hier finden sich keine dialektal homogenen Gemeinschaften: Aufgrund der unterschiedlichen Herkunftsgebiete der Immigranten sind die Unterschiede zwischen den im Repertoire der einzelnen Sprecher vorhandenen Dialekte zu groß, als dass diese Teil des Repertoires der gesamten Gesellschaft werden könnten. Während die autochthone Bevölkerung hier häufig auf die regionale Koine zurückgreift (vgl. Kap. 2.4), verwenden Immigranten fast ausschließlich eine regionale Varietät des Italienischen, die häufig Interferenzen aus dem Herkunftsdialekt aufweist (Mioni/Arnuzzo-Lanszweert 1979: 95).

${ }^{11}$ Berruto (2010) führt zur Beschreibung der Situation, die heute einen Großteil des italienischen Sprachraums kennzeichnet, den Begriff der Dilalie (dilalia) ein: „La dilalia si differenzia fondamentalmente dalla diglossia perché il codice A è usato, almeno da una parte della comunità, anche nel parlato conversazionale usuale, e perché $[\ldots]$ vi sono impieghi e domini in cui vengono usati di fatto, ed è normale usare, sia l'una che l'altra varietà, alternativamente o congiuntamente“" (ebd.: 207).
} 
Im Unterschied zur Makrodiglossie ist der Gebrauch der lokalen Dialekte in der Mikrodiglossie auf wenige Domänen - v.a. auf die Kommunikation innerhalb der Familie und der peer group - beschränkt, sodass es nur hier zur funktionalen Überlappung mit dem Italienischen und dementsprechend selten zu gemischtsprachigen Äußerungen kommt (vgl. Trumper 1977: 265ff.). In mikrodiglossischen Situationen liegen die Voraussetzungen für die Bildung einer regionalen Koine nicht vor. Die lokalen Dialekte der kleineren Städte beeinflussen sich hier weder in einem entsprechenden Maße untereinander, noch stehen sie unter dem Einfluss des städtischen Dialekts des ökonomisch dominierenden regionalen Zentrums: ,[N]essun dialetto di un grosso centro urbano, come ad esempio Bologna o Modena, dominerebbe linguisticamente, né servirebbe da modello per il proprio circondario“ (Trumper 1977: 267). Diese Verhältnisse lassen sich unter anderem in der Emilia-Romagna, in den Marken und im südlichen Piemont beobachten (vgl. Mioni/Arnuzzo-Lanszweert 1979: 94). ${ }^{12}$

Durch die Entwicklung des gesellschaftlichen Bilinguismus sowie die funktionalen Überlappungen zwischen den Kodes kommt es zu mannigfaltigen Kontaktphänomenen zwischen dem Italienischen und den Dialekten in Form von „Interferenzen, gegenseitigen Einflüssen und Vermischungen der Systeme und Gebrauchsmuster“ (Berruto 1989: 107), welche zu strukturellen Veränderungen in den bereits bestehenden sowie zur Bildung neuer Varietäten im Kontinuum zwischen Basisdialekten und Standardvarietät führen. So haben sich durch die Integration dialektaler (d.h. lautlicher, grammatischer sowie lexikalischer) Elemente in das gesprochene Italienisch verschiedene italiani regionali gebildet, die nach Pellegrini (1975) mit den dialetti regionali/koinái dialettali den ,mittleren Bereich“ des Repertoires eines Großteils der italophonen Sprecher bilden (s. Abb. 1). ${ }^{13}$

\section{1) italiano comune/standard}

\section{LINGUA}

2) italiano regionale

3) dialetto regionale/koiné dialettale

\section{DIALETTO}

\section{4) dialetto locale}

Abbildung 1. Die vier „tastiere“ des sprachlichen Repertoires der italienischen Sprechergemeinschaft nach Pellegrini (1975: 40). ${ }^{14}$

\footnotetext{
12 „Stupisce tuttavia un po’ che Trumper chiami ,vera diglossia“ la situazione di macrodiglossia, e definisca pseudo-diglossia la situazione di microdiglossia, quando la natura dei rapporti fra i codici nei due casi riporterebbe piuttosto alla caratterizzazione contraria, con la microdiglossia a presentare tratti da ritenere tipici di un rapporto diglottico in senso fergusoniano, e in particolare la complementarità di distribuzione fra A e B“" (Berruto 2010: 200).

13 ,[U]na posizione del tutto particolare presentano ovviamente i Toscani per i quali le quattro sezioni si riducono di norma a due, e si ha, per lo più, una contrapposizione di vernacolo toscano (delle città e del contado, con differenziazione locale) a lingua“ (Pellegrini 1975: 12).

${ }^{14}$ Die entgegengesetzten Pole (italiano comune/standard und dialetto locale) weisen laut Pellegrini (ebd.) eine relativ hohe Einheitlichkeit auf, während der „settore mediano“ durch eine hohe Variabilität gekennzeichnet ist. Dementsprechend ist der Terminus italiano regionale als Abstraktion zu verstehen, als ,una definizione di comodo che peraltro sottende un concetto ben riconoscibile qualora si sappia individuare al suo interno una indiscutibile graduazione dovuta a vari fattori“ (Pellegrini 1990: 6). Auch den Begriff koiné verwendet Pellegrini
} 
Andere Modelle zur Beschreibung des sprachlichen Repertoires der italienischen Sprachgemeinschaft beziehen weitere Ebenen der sprachlichen Variation mit ein. So unterscheidet etwa Sabatini (1985: 176) unter Berücksichtigung des diastratischen Faktors ein italiano regionale delle classi istruite und ein italiano regionale delle classi popolari. Trumper/Maddalon (1982: 19) identifizieren im Bereich der diaphasischen Variation ein italiano regionale formale, ein italiano regionale informale und ein italiano regionale trascurato, fortemente interferito.

\subsection{Der Mythos des Dialektverfalls}

Die grundlegenden Veränderungen im Repertoire der italienischen Sprachgemeinschaft haben funktionale und strukturelle Veränderungen auf der Ebene der Dialekte verursacht, die aus verschiedenen Perspektiven betrachtet werden können. Eine Betrachtungsweise ist dabei jene, die die Entwicklungstendenzen in der italienischen Sprachgemeinschaft typischerweise mit dem Begriff des „Dialektverfalls“ (regressione dialettale) bzw. des „Dialekttods“ (morte dei dialetti) beschreibt (vgl. De Mauro 1986: 141). ${ }^{15}$ Explizite oder implizite Hinweise auf ein vermeintlich bevorstehendes „Dialektsterben“ finden sich in fast allen italienischen Wörterbüchern des 20. Jahrhunderts, wobei vor dem Hintergrund der Funktion des Dialekts als Teil des patrimonio culturale der „Dialektverfall“ auf ideologischer Ebene immer auch als Verfall lokaler kultureller Traditionen verstanden wird (Radtke 1995: 44). Als „Symptome“ dieser Entwicklung werden einerseits die „strukturelle Reduktion“ der dialektalen Sprachsysteme durch Anpassung an das Standarditalienische (vgl. Kap. 2.3.2) und andererseits die Reduktion der Anzahl der (nativen) Dialektsprecher durch den Rückgang des Dialektgebrauchs gesehen (vgl. Berruto 1994: 33). Bei genauerer Betrachtung stellt sich die Situation in Bezug auf den Sprachgebrauch jedoch weitaus differenzierter dar, als es die genannten, negativ konnotierten Schlagwörter vermitteln.

Mitte des 20. Jahrhunderts, als die flächendeckende Alphabetisierung in den norditalienischen Regionen fast erreicht war, verwendete etwa ein Drittel (ca. 35\%) der italienischen Bevölkerung den Dialekt nicht mehr als ausschließliches Kommunikationsmittel. Er war jedoch weiterhin für etwa $80 \%$ der Bevölkerung Teil des alltäglichen Sprachgebrauchs und für etwa zwei Drittel (ca. 64\%) ,l'idioma d'uso normale nel parlare in ogni circostanza“ (De Mauro 1986: 131). Neben ca. 19\% ausschließlich das Italienische und 13\% ausschließlich den Dialekt verwendenden Sprechern gebrauchte bereits zu diesem Zeitpunkt der Großteil der italienischen Bevölkerung in der Alltagskommunikation sowohl das Italienische als auch den Dialekt (vgl. De Mauro 1986: 135, Daten aus Rüegg 1956).

In die sich hier bereits andeutende Richtung geht auch die Entwicklung des Dialektgebrauchs in den letzten Jahrzehnten des 20. Jahrhunderts. So lässt sich zwar feststellen, dass der ausschließliche Dialektgebrauch (dialettofonia esclusiva) in der italienischen Sprachgemein-

\footnotetext{
„,solo per comodità e per rispetto alla tradizione [...]; la parlata regionale con caratteri comuni uniformi è ovviamente una astrazione poiché essa è nella realtà assai variabile“ (Pellegrini 1975: 12). Zum Phänomen der (regionalen) Koine vgl. Kap. 2.4.1.

${ }^{15}$ Die Vorstellung vom „Verfall“ oder „Tod“ einer Sprache geht auf die Anfänge der Philologie im 19. Jahrhundert zurück, die Sprache in Anlehnung an die in der damaligen biologischen Forschung vorherrschenden Konzepte als lebenden Organismus versteht, der einen Kreislauf von Leben und Tod durchläuft (vgl. Whitney 1875).
} 
schaft zwischen 1988 und 2000 auch im familiären Umfeld deutlich (um ca. 13\%) zurückgegangen ist (Berruto 2006: 102, Daten des Istituto nazionale di Statistica (IStat)). ${ }^{16}$ Es lässt sich jedoch andererseits keine entsprechend starke Zunahme des ausschließlichen Gebrauchs des Italienischen beobachten (italofonia esclusiva, Zunahme ca. 2\%). Gekennzeichnet ist die Entwicklung vor allem durch den Anstieg der alternativen Verwendung von Dialekt und Italienisch (Zunahme um ca. 8\%): ,[U]na parte considerevole della dialettofonia che va costantemente diminuendo non sparisce semplicemente dalla scena, ma da esclusiva si trasferisce nel campo dell'uso alternato o frammisto di italiano e dialetto" (Berruto 2006: 103).

Das Ausbleiben des ,Dialektsterbens ‘ ist in Verbindung damit zu sehen, dass in den vergangenen zwanzig Jahren vor allem in Süditalien eine Veränderung der noch in den 1950er Jahren zu beobachtenden, negativen Bewertung des Dialekts durch die Sprecher ${ }^{17}$ stattgefunden hat: „Il dialetto oggi non risulta più o non è più vissuto come codice tipico dei ceti bassi, simbolo di ignoranza e di esclusione dal mondo moderno, legato allo svantaggio sociale e culturale [...]. Non è più stigmatizzato socialmente come varietà unicamente bassa [...]" (Berruto 2006: 121). ${ }^{18}$ Ist der Dialekt - wie heute bei nahezu allen Sprechern - eine von mehreren Varietäten, über die ein Sprecher verfügt, so wird er als Bereicherung des sprachlichen Repertoires gesehen: ,[S]apere un dialetto è un valore positivo, una possibilità in più nel repertorio comunicativo individuale, da sfruttare per i suoi valori particolari quando sia il caso" (ebd.). Stellt der Dialekt hingegen die Varietät dar, in der der Sprecher die höchste Kompetenz aufweist, so wird er nach Zenaro (2004: 52) zum ,indice di ignoranza“ und als solcher stigmatisiert. Wahrscheinlicher ist allerdings, dass das ,Stigma“ in diesem Fall nicht dem Dialekt (bzw. der Dialektkompetenz des Sprechers), sondern der fehlenden Italienischkompetenz als Zeichen fehlender Bildung und Kultiviertheit anhaftet.

Insgesamt bleibt festzuhalten, dass das in den vergangenen Jahrzehnten zu beobachtende ,adattamento dei parlanti a una nuova realtà linguistica“ (Radtke 1995: 44) keine ,Verdrängung' des Dialekts aus dem sprachlichen Repertoire nach sich zieht, sondern in erster Linie zu einer Umstrukturierung der Kriterien für die Sprachwahl und einer Veränderung der Spracheinstellungen führt. Die von Mioni/Arnuzzo-Lanszweert (1979: 96) postulierte Entwicklung eines „standard monolingualism“ in der italienischen Sprachgemeinschaft bleibt damit bis heute hypothetisch.

\footnotetext{
${ }^{16}$ Ein entsprechender Rückgang findet sich zwischen 1988 und 2000 sowohl in den nördlichen als auch in den südlichen Regionen. Dadurch, dass der Dialektgebrauch im Nordwesten Italiens (insbesondere in Piemont) jedoch bereits seit der zweiten Hälfte des 20. Jahrhunderts stark zurückgegangen ist, ist der ausschließliche Dialektgebrauch in der Familie im Jahr 2000 im Norden weitaus geringer (Lombardei und Piemont ca. 11\%) als im Süden (Kampanien 30,5\% und Apulien 17,7\%, vgl. ebd.).

${ }^{17}$ Nach Lüdtke (1956: 126) gab es damals bei den süditalienischen Dialektsprechern „kein meridionales Selbstbewusstsein, keinen Lokalpatriotismus“. Dementsprechend war auch die Einstellung dem eigenen Dialekt gegenüber negativ. Die Mundart galt als ,hässlich“, ,verderbt“ und „,vulgär“" oder wurde sogar verleugnet: „Auf eine harmlose Frage nach dem Ortsdialekt versuchen die Einheimischen zunächst dem Fremden einzureden, dass es so etwas gar nicht gäbe und dass man im Dorfe nur Italienisch spräche“ (ebd.).

${ }^{18}$ In Norditalien hat der Dialekt nie eine entsprechende Stigmatisierung erfahren: ,[N]ördlich des Apennin steht die Mundart fast überall in hohem Ansehen und wird auch von den Gebildeten im Verkehr untereinander gesprochen“ (Lüdtke 1956: 125). Dies kann in Verbindung damit gesehen werden, dass die Alphabetisierung und damit auch die Italianisierung eines Großteils der Bevölkerung in den norditalienischen Regionen deutlich schneller vonstatten ging als im Mezzogiorno (vgl. Kap. 2.1) und sich die ausschließliche Beherrschung des Dialekts (und damit die fehlende Italienischkompetenz) nicht zu einem diastratischen Marker entwickeln konnte.
} 


\subsection{Das Phänomen der Italianisierung}

\subsubsection{Die Italianisierung im wissenschaftlichen Diskurs}

Die andere, terminologisch weniger konnotierte Perspektive, aus der die Entwicklung der Dialekte und ihrer Stellung im Varietätengefüge betrachtet wird, ist jene der „Italianisierung“ (italianizzazione), die seit mehreren Jahrzehnten eines der zentralen Themen in der italienischen Dialektologie ist. Bei einem Großteil der wissenschaftlichen Beiträge zum Thema handelt es sich jedoch um Einzelstudien auf lokaler Ebene, die häufig nur bestimmte Phänomene (meist lexikalischer und phonetischer Art) in den Blick nehmen. Betrachtungen, die das Phänomen in einem weiteren Blickwinkel und damit auch unter Einbeziehung regionaler Unterschiede betrachten oder in einem theoretischen Rahmen diskutieren, liegen nur wenige vor (vgl. Berruto 2006: 105f.).

Das Phänomen der Italianisierung manifestiert sich auf drei verschiedene Arten (Berruto 1984: 127): als ,soziale oder demographische Italianisierung“ durch die wachsende Anzahl der Sprecher, die das Italienische als Muttersprache haben, als ,diaphasische oder situationelle Italianisierung“ durch den Gebrauch des Italienischen (anstelle des Dialekts) in immer mehr Kommunikationssituationen und als ,strukturelle oder innere Italianisierung“ durch den Einfluss bzw. die Übernahme von Formen und Strukturen des Standarditalienischen auf bzw. in die dialektalen Sprachsysteme. Die letztgenannte Erscheinungsform, die zu einer Reduktion der strukturellen Distanz zwischen dem Standarditalienischen und den italoromanischen Dialekten führt, ist dabei „,viel weniger und in viel unsystematischerer Weise erforscht worden, als die demographische oder die situationelle Italianisierung“ (ebd.: 128). ${ }^{19}$ Klar ist jedoch, dass nicht alle sprachlichen Ebenen in gleichem Maße von dem Phänomen der Italianisierung betroffen sind (vgl. Kap. 2.3.2) und diese sich in den verschiedenen sprachlichen Bereichen über unterschiedliche Zeiträume erstreckt. So handelt es sich in den strukturellen Bereichen der Phonetik/Phonologie und der Morphosyntax um einen langfristigen Prozess, der bereits seit der Entwicklung des Bilinguismus in den bildungsnahen gesellschaftlichen Schichten (vgl. Kap. 2.1) im Gange ist (vgl. Berruto 2006: 107). In neuerer Zeit - insbesondere seit der zweiten Hälfte des 20. Jahrhunderts - lässt sich neben der weiterhin langsam fortschreitenden Italianisierung der strukturellen Bereiche eine starke Zunahme der Italianisierung auf lexikalischer Ebene, insbesondere in Form der Übernahme italienischer Lehnwörter in die dialektalen Lexika beobachten. Bedingt ist diese dadurch, dass aus der grundlegenden Transformation von Gesellschaft, Politik und Wirtschaft (Demokratisierung, Industrialisierung, Technisierung, Tertiärisierung etc.) eine Vielzahl neuer semantischer Bereiche erwachsen sind, „per le quali i dialetti non avevano le risorse lessicali adatte e in cui quindi dipendono totalmente da prestiti dall'italiano (a sua volta spesso debitore dell'inglese)“ (Berruto 2006: 108).

Auch hinsichtlich der außersprachlichen Bedingungen der strukturellen Italianisierung, d.h. der Wege oder ,Kanäle‘, über die diese verläuft, lassen sich deutliche Veränderungen feststellen. Für die Zeit, in der die Situation im italienischen Sprachraum mehrheitlich durch „Diglossie ohne Bilinguismus“ gekennzeichnet war (vgl. Kap. 2.1), wird der Verlauf der Italianisierung meist entsprechend der Theorie der „Diffusionszentren“ (vgl. Kap. 4.4) dargestellt.

\footnotetext{
19 ,[G]li storici della lingua comune accennano ad esso come a un fenomeno imponente, parlano di « sfasciarsi » dei dialetti, ma lasciano da parte ogni analisi particolare, forse ritenendola di pertinenza della dialettologia; senonché la dialettologia tradizionale, impegnata nella ricerca delle forme dialettali ritenute più tipiche, [...] sdegna gli italianismi dialettali, ai quali in genere accenna soltanto per rimpiangere che, con la loro introduzione, si vengano cancellando i tratti più caratteristici di questo o quel dialetto“ (De Mauro 1986: 140).
} 
Als Ausgangspunkt werden die dem Einfluss des Italienischen am stärksten ,ausgesetzten“ Großstädte gesehen, die die italianisierten Formen und Strukturen an mittelgroße Städte weitergeben, welche diese wiederum an Provinzzentren übertragen, die diese wiederum an Kleinstädte oder kleine Orte transferieren (vgl. Sobrero 1997: 413). ${ }^{20}$ Durch die Verbreitung neuer Informationskanäle (v.a. der Massenmedien Radio und Fernsehen) verlieren die städtischen Zentren insbesondere in der zweiten Hälfte des 20. Jahrhunderts ihre Bedeutung als ,Mittler im Kontakt zwischen den Dialekten und dem Standarditalienischen. Die neue Situation des gesellschaftlichen Bilinguismus ist durch einen direkten Kontakt zwischen dem Italienischen und den Dialekten gekennzeichnet:

[I]l contatto non passa più attraverso la mediazione dei centri leader delle aree linguistiche, ma diventa un contatto diretto: in ogni dominio, in ogni situazione, in ogni interazione, in ogni parlante $\mathrm{i}$ due codici vengono, o possono venire, a contatto. (Grassi/Sobero/Telmon 1998: 173)

Die rapide Zunahme der (insbesondere lexikalischen) Italianisierung im 20. Jahrhundert hat in Kombination mit der Entstehung regionaler Varietäten des Italienischen - im linguistischen Diskurs zu meist düsteren Prognosen über die Zukunft der italoromanischen Dialekte geführt. Immer wieder wurde und wird die Position vertreten, die Dialekte würden durch ihre Annäherung an das Italienische von den italiani regionali, absorbiert': ,[È] probabile che in un futuro più $\mathrm{o}$ meno lontano $[\ldots]$ anche $\mathrm{i}$ dialetti italiani si annacquino ulteriormente $\mathrm{e}$ finiscano per trasformarsi in vari italiani regionali fortemente intrinsi di dialettismi di ogni specie" (G.B. Pellegrini in Della Monica 2011: 118). Differenziertere Sichtweisen, die den Wandel der Dialekte nicht mit einer strukturellen ,Auflösung' gleichsetzen, sind deutlich seltener: „[...] [P]er effetto della crescente diffusione dell'italiano, i dialetti piuttosto che scomparire si modificano. Infatti essi restano vitali, come è noto, anche nelle metropoli, solo che non si tratterà più del dialetto arcaico [...], ma di un idioma sensibilmente diverso" (Bruni 1984: 83). Bei näherer Untersuchung des tatsächlichen Einflusses des Italienischen auf den Wandel der italoromanischen Dialekte zeigt sich zwar auf den ersten Blick, dass „die Italianisierung der Mundarten sehr ausgeprägt ist [...]“ (Berruto 1984: 139). Bei näherer Betrachtung lässt sich jedoch feststellen, dass ,die Mundarten heute zwar nicht mehr strukturell vital, ${ }^{21}$ aber doch noch widerstandsfähig sind. Mit anderen Worten: die Mundarten sind unproduktiv, nur noch rezeptiv; sie haben sich beachtlich gewandelt und standardisiert, sie sind aber in ihrer Struktur noch hinreichend intakt"“ (ebd., vgl. auch Berruto 2006: 118).

\footnotetext{
${ }^{20}$ Beispielhaft illustriert wird der Verlauf dieser ,indirekten Italianisierung“ (De Mauro 1986: 150) in der Studie Berrutos (1970) zur Sprachentwicklung im Valle d'Adorno (Piemont), wo „Italienisch und die Mundart von Turin die Mundart von Biella, dem Hauptort des Gebietes, zusammen beeinflußten, und wo diese wiederum die Mundarten der Dörfer des Tales mit radialer Wirkung beeinflußte“ (Berruto 1984: 128).

${ }^{21}$ Auf den Verlust der Vitalität der Dialekte weist eine einzige Erscheinung hin, ,nämlich die Abwesenheit von autonomen Neubildungen in der Entwicklung des Wortschatzes. Von diesem Gesichtspunkt aus scheinen die Mundarten sozusagen alt und fossilisiert“ (Berruto 1984: 138). Andere charakteristische Merkmale eines „Sprachtods“ wie Monostylismus, Zunahme von Polysemien („Bedeutungsvagheit“) oder Verlust der entsprechenden sprachlichen Identität (vgl. Schlieben-Lange 1976) lassen sich hier jedoch nicht finden (Berruto 1984: 139).
} 


\title{
2.3.2 Einflüsse des Italienischen auf die dialektalen Sprachsysteme
}

Die Annäherung der Dialekte an das Italienische, die in der dialektologischen Forschung häufig als Prozess der Sprach- bzw. Dialektkonvergenz bezeichnet wird, ${ }^{22}$ betrifft die verschiedenen Ebenen der dialektalen Sprachsysteme nicht im gleichen Ausmaß. Als „lo strato più esterno e quello, quindi, a più diretto contatto con l'extralinguistico e meno significativo per cogliere le dinamiche interne del sistema“" (Berruto 2006: 108) ist die lexikalische Ebene am stärksten vom Einfluss des Italienischen betroffen. ${ }^{23}$ Am weitaus häufigsten manifestiert sich dieser in Form der Übernahme italienischer Lexeme in die dialektalen Lexika. ${ }^{24}$ In semantisch-funktionaler Perspektive können lexikalische Entlehnungen (Italianismen) in zwei Gruppen eingeteilt werden.

\begin{abstract}
${ }^{22}$ Nach Sanga (1984: 147) handelt es sich bei der „,convergenza linguistica“ um ein „,avvicinamento strutturale a una lingua-guida e g e m o n e (LE) da parte di lingue s u b a 1 t e r n e (LS)“, das über die „,creazione di una rete di parallelis mi morfofo nologi ci“" zu einer, ,trasformazione fonologica, grammaticale, lessicale delle LS secondo il modello della LE“ führt. Die Verwendung des Begriffs „Konvergenz“ für Prozesse, in denen sprachliche Merkmale, seien es Formen, Funktionen oder Bedeutungen von einer Varietät aus einer anderen, koexistierenden Varietät übernommen werden, ist jedoch problematisch. Berücksichtigt man die etymologische Wortbedeutung (,Kon-vergenz“ < lat. con- (com-) , gemeinsam, zusammen“ + vergere ,neigen, wenden'), so ist unter dem Terminus die gegenseitige Annäherung zweier Sprachen bzw. Varietäten aneinander zu verstehen, durch die es zur „Ausbildung einer neuen Variante aufgrund einer formalen oder inhaltlichen Vermischung der Ausgangs- und der Zielvariante" kommt (Mattheier 1996: 34). Mit einer solchen Definition ist jedoch der Prozess der Italianisierung nicht adäquat charakterisiert, da keine strukturelle Annäherung des italiano standard an die Dialekte vorliegt, aus der - bei gleichzeitiger Annäherung der Dialekte an das italiano standard - eine „Vermischung“ beider Systeme (und damit eine „neue“ Grammatik und ein „,neues“ Lexikon) entstehen könnte (vgl. Berruto 1989: 116). Bei der Entwicklung der italiani regionali als Varietäten in der „,ffera media" (Radtke 1998a) zwischen Dialekt und Standarditalienisch handelt es sich um eine Zunahme der Variabilität im Bereich des Italienischen und nicht um strukturelle Veränderungen des standardsprachlichen Systems in Richtung der Dialekte. Zur Bescheibung der Italianisierung der Dialekte wäre der von Mattheier (1996) vorgeschlagene Terminus Advergenz adäquater, der die „bloße formale oder semantische Annäherung einer Varietät an eine andere dadurch, daß eigene Formen durch andere ersetzt werden“ (Mattheier 1996: 34) bezeichnet.

${ }^{23}$ Beim Kontakt zwischen dem Standarditalienischen und den italoromanischen Dialekten handelt es sich zwar nicht um einen Sprachkontakt im ,klassischen' Sinne (Wechselwirkungen zwischen sozial ,gleichwertigen Sprachsystemen), sondern um die „Wirkung des übergeordneten Sekundärsystems gegenüber den untergeordneten Primärsystemen“ (Berruto 1984: 131), d.h. um eine Art „vertikalen Sprachkontakt“ (Berruto 1997: 17). Die von der Sprachkontaktforschung in unterschiedlichen Formen (vgl. Wilkins 1996: 112, 114) präsentierte „Hierarchie“ der Sprachkontaktphänomene, die die ,Anfälligkeit“ und vice versa die Resistenz der sprachlichen Subsysteme gegenüber kontaktinduzierten Veränderungen widerspiegelt, kann jedoch auch hier als grundlegend betrachtet werden. Nach Thomason/Kaufman (1991: 50, 74ff.) ist die Ebene des Lexikons (genauer: der Bereich der „Inhaltswörter“) bereits bei gelegentlichem Sprachkontakt von Veränderungen betroffen. Mit der Intensivierung des Sprachkontakts kommt es neben weiteren lexikalischen Entlehnungen (nun auch aus dem Bereich der „Funktionswörter“) auch zu strukturellen Übertragungen, die sich zunächst auf der Ebene der Phonetik/Phonologie sowie der Syntax und schließlich (unter „starkem kulturellem Druck“) auch im Bereich der Morphologie manifestieren. Berruto (1997: 26) zufolge lässt sich die Situation der italienischen Sprachgemeinschaft in der Typologie von Thomason/Kaufman auf der Stufe des ,intensiven Kontaktes“ verorten, die durch eine hohe Anzahl lexikalischer Entlehnungen sowie „mäßige bis starke“ strukturelle Entlehnungsvorgänge vor allem in den Bereichen der Phonologie und der Syntax gekennzeichnet ist. Auf der letzten Stufe, auf der es nach Thomason/Kaufman durch „overwhelming long-term cultural pressure from source-language speaker group“ zu „massiven grammatischen Ersetzungen“ in der Empfängersprache kommt, sieht er die Entwicklung in der italienischen Sprachgemeinschaft noch nicht angekommen. Es sei allerdings noch zu diskutieren, ob es sich im Falle der italienischen Situation überhaupt um ein „mantenimento di lingua“ (Berruto 1997: 27) oder nicht vielmehr um einen (zumindest beginnenden) Sprachenwechsel handele (vgl. ebd.). ${ }^{24}$ Andere lexikalische Kontaktphänomene wie semantische Kalkierungen (gen. ghidun, ven. liganbi ,link', gen. picché, piem. sgnaché ,cliccare', lomb. ciciàra ,chat', vgl. Patrucco 2001, zit. in Berruto 2006: 114) und Hybridbildungen bzw. „Kreuzungen“ (kal. botteria ,batteria di fuochi d'artificio“ aus ital. batteria und dial. botta ,grande esplosione', rotamobuli , automobile“ aus ital. automobile und dial. rota ,ruota', vgl. Sobrero 1997: 414)
\end{abstract} finden sich weitaus seltener. 
Bei den Elementen der ersten Gruppe handelt es sich um sog. prestiti di necessità (vgl. Grassi/Sobrero/Telmon 1998: 173), d.h. um Lexeme, die aufgrund von Neuerungen in der auBersprachlichen Realität zur lexikalischen Bedarfsdeckung in die Dialekte entlehnt werden. So finden sich etwa in den meisten italienischen Dialekten bereits seit längerer Zeit und meist in phonetisch adaptierter Form die italienischen Lexeme radio, cinema, televisione, antenna, ministro, ferroviere, dentifricio, liceo, università (Grassi 2011: 300). Italianismen jüngeren Datums stammen unter anderem aus dem Bereich der elektronischen Kommunikation: ${ }^{25}$ lomb. messagg, piem. messagi , messaggio', lomb./piem. interativ, interattivo', lomb. informatiga, informatica', piem. telefonin ,telefonino', infraross ,infrarosso', telematich ,telematico' etc. (Patrucco 2001, zit. in Berruto 2006: 114). Die Elemente der zweiten Gruppe stellen sog. prestiti di lusso (Como 2007: 250) dar, d.h. Entlehnungen, die nicht aus Gründen der lexikalischen Bedarfsdeckung, sondern vor dem Hintergrund des Prestiges der Quellsprache (hier: Standarditalienisch) stattgefunden haben. Hierbei handelt es sich um ,Alltagswörter' mit hoher Frequenz, die Konzepte bezeichnen, für die bereits ein dialektales Lexem vorhanden ist, sodass es zur Bildung von Synonymenpaaren ${ }^{26}$ kommt: lomb. grembial neben bigaröl ,grembiule‘, piem. sista neben kavanja ,cesta' (Sobrero 1997: 415), bol. truvè neben katè ,trovare' (Foresti 1977: 242), kal. vestitu neben kustumi, vestito' und fazzulettu neben mukkaturi,fazzoletto ' (Falcone 1977: 292, 293), siz. cicatrici neben settu ,cicatrice' und macchia neben tacca ,macchia di sporco su un indumento“ (Tropea 1991: 176) etc. In einigen Fällen kommt es zu etymologisch identischen Wortpaaren (Dubletten), die jedoch von den Dialektsprechern nicht als solche wahrgenommen werden (vgl. Sobrero 1997: 415): piem. aqua neben lautgeschichtlichem eva ,aqua', sorèla neben seurî ,sorella', fratèllfradèl neben frèl ,fratello“ (De Mauro 1986: 376), kal. vespa neben véjsa ,vespa' und cugnatu/cognatu neben kanatu ,cognato' (Falcone 1977: 296), kamp. gomətə/vomatə neben (v)utə/(g)oveto ,gomito' (<CUBITU(M)) und sangue neben sank/sangə , sangue' (ALCam) etc.

Die aus dem Italienischen übernommenen Lehnwörter, die ein dialektales semantisches Äquivalent haben, werden zunächst - häufig in phonetisch bereits angepasster Form - parallel zu den entsprechenden dialektalen Lexemen gebraucht. In dieser Phase ,ist der italienische Terminus als neu und Standard markiert, während der mundartliche Terminus als eher archaisch und lokal markiert ist“ (Berruto 1984: 135). Die Verwendung beider Lexeme unterliegt teilweise Beschränkungen durch den situativen Kontext. ${ }^{27}$ Im weiteren Verlauf bleibt die synonyme Verwendung von Dialektismus und Italianismus häufig nicht bestehen. ${ }^{28}$ Es kommt in

\footnotetext{
${ }^{25}$ Die lokalen Dialekte, aus denen die jeweiligen Beispiele stammen, werden hier der Übersichtlichkeit halber nicht angegeben. Siehe dazu die Ortsangaben in den entsprechenden Quellen.

${ }^{26}$ In einigen Fällen handelt es sich nach Tropea (1991: 196) um „,falsche Synonyme“, „,in quanto l'italianismo esprime una realtà parzialmente diversa rispetto al vocabolo tradizionale. Mentre parrucca e pilucca sono, infatti, perfettamente sinonimi, parruchera e pilucchera sono due figure piuttosto diverse designando pilucchera, a differenza della moderna parruchiera, la ,parucchiera delle case signorili di un tempo"." Ähnlich verhält es sich

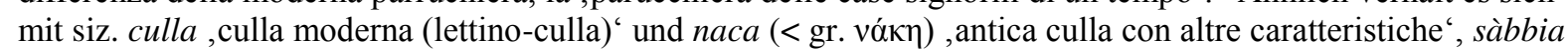
,sabbia di colore biancastro ottenuta dalla frantumazione di materiale calcareo e adoperata nell'impasto per la realizzazione dell'intonaco liscio“ und rrina ,sabbia tradizionale' oder prosciùttu ,il prosciutto che si compra oggi nelle salumerie“ und prisuttu ,prosciutto fino a un cinquantennio addietro realizzato artigianalmente dal macellaio del posto“" (ebd.).

${ }^{27}$ Teilweise bestehen auch Beschränkungen hinsichtlich des sprachlichen (syntagmatischen) Kontexts. So ist die Verwendung von Italianismen in idiomatischen (häufig metaphorischen) Ausdrücken oder Redewendungen ausgeschlossen: siz. jittari a pruuligghia nta-ll'occhji, gettare la polvere negli occhi', aber *jittar'a cipria ntall'occhji (siz. pruuligghia ,cipria', Tropea 1991: 197).

${ }^{28}$ Die von Berruto (1984: 135f.) in der Klasse der „Neologismen, die bereits bestehende entsprechende Termini von ganz verschiedener Form und Etymologie in der Mundart ersetzen“ in synchroner Perspektive unterschiedenen „Fälle“ stellen in diachronischer Perspektive häufig verschiedene Phasen eines Prozesses dar. So sind die
} 
der Folge entweder zu einer Ersetzung des dialektalen Terminus durch das italienische Lehnwort $^{29}$ oder zur Spezialisierung eines Lexems oder beider Lexeme. Spezialisiert sich ein Lexem, handelt es sich meist um den Dialektismus: piem. radìz,radice“ vs. rèiz ,torso, grande radice', ven. fornèr ,fornaio' vs. pèk ,colui che cuoce il pane, aiutante del fornaio', kadéna ,catena (dell'ancora)' vs. kaìna ,catena del camino“ (Berruto 1984: 136). In selteneren Fällen spezialisieren sich sowohl das dialektale als auch das dem Italienischen stammende Lexem: milan. söl ,pavimento sporco o dell'osteria' vs. paviment ,pavimento pulito o di casa' (Massariello Merzagora 1985: 432), kal. gjombaru, gomitolo di confezione artigianale' vs. gomitulu, gomitolo di confezione industriale' (Falcone 1977: 296).

Die phonetische Integration von Lehnwörtern kann Veränderungen im phonologischen System der Dialekte auslösen (vgl. Sobrero 1997: 417 sowie Weinreich 1977: 47f.). Dies geschieht besonders leicht in den Fällen, in denen der Italianismus und der Dialektismus etymologisch identisch sind (Dubletten, s.o.) und damit einen Teil des phonetischen Materials gemeinsam haben. Die Restrukturierung des phonologischen Systems kann auf verschiedenen Wegen verlaufen (vgl. Berruto 1984: 129f.). In den weitaus meisten Fällen handelt es sich um Veränderungen der Distribution dialektaler Phoneme nach italienischem Muster, die aufgrund des konservativen Charakters des Standarditalienischen teilweise zu einer ,Umkehrung ' sprachhistorischer Entwicklungen in den innovativeren Dialekten führen (nach De Mauro (1986: 154) „regressione verso fasi arcaiche“). So lässt sich etwa in den lombardischen und piemontesischen Dialekten die (Wieder-)Einführung von intervokalischem [t] (z.B. [fra't $t$ l] ,fratello') beobachten, das im Laufe der Lautentwicklung zunächst sonorisiert und im Anschluss durch Synkopierung getilgt worden war ([frel] $)$. In das Romanesco finden der intervokalische Konsonantennexus [mb] ([ko'lomba], colomba') anstelle von dial. [mm] und [1] vor Konsonant (['kaltsa] ,calza') anstelle von dial. [r] wieder Eingang (Sobrero 1997: 417). Im Mailändischen hat durch die Integration italienischer Lexeme, die $[\mathrm{u}]<\mathrm{o}<\breve{\mathrm{U}}$ (z.B. lungo, fungo, pungere) haben - zunächst in den mailändischen Pendants und dann allgemein eine Ersetzung von $[\mathrm{o}]<\breve{U}$ durch [u] stattgefunden: [lonk], [fontf], [spontf] > [luyk], [funtf], [spuntf] (Molinari 1976: 416). Auch auf silbenstruktureller Ebene können sich durch die Übernahme italienischer Lexeme, die im Dialekt ein lautgeschichtlich entwickeltes Äquivalent haben, Veränderungen in den Dialekten ergeben, wie die Wiederherstellung des unbetonten Vokals in lautgeschichtlich synkopierten

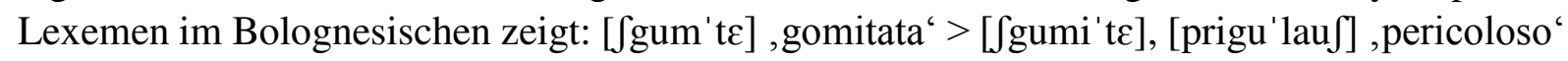
$>$ [periku'lauf] etc. (Foresti 1977: 243).

Neben der Ersetzung von dialektalen Phonemen bzw. Phonemkombinationen durch italienische Varianten kommt es auch zur Einführung von Phonemen des Italienischen, die die Dialekte nicht kennen (und nie gekannt haben), so etwa des Phonems $[\Lambda]$ in die norditalienischen Dialekte, die an seiner Statt lauthistorisch [j] haben: tess. [czaba' Kon] ,zabaglione' statt [czaba'jon], lomb. [ma'Kon] ,maglione‘ statt [ma'jon] (Berruto 1984: 130).

Eine dritte Art der phonologischen Restrukturierung ist die Ersetzung dialektaler Phoneme oder phonetischer Varianten, die im Italienischen nicht vorhanden sind, durch solche, die

von Berruto als Teile scheinbar stabiler Synonymenpaare klassifizierten lombardischen Dialektismen erbiũ ũ ,piselli“ und cifüũ ,comodino“ laut Sanga (1984: 21) bereits ,in via di completa sostituzione con piséi e cumudĩ , mentre resistono ancora bene erburĩ , prezzemolo', tumàtes ,pomodori', caròtul ,carote‘ e naturalmente cúu ,testa“." Auch Weinreich (1977: 77) geht davon aus, dass die „V e r m i s c h u n g d e r G e b r a u c h s we is e n oder auch vollständige Übereinstimmung des Inhalts zwischen altem und neuem Wort [...] wahrscheinlich auf die frühen Phasen des jeweiligen Sprachkontaktes beschränkt" ist.

${ }^{29} \mathrm{Im}$ Falle lexikalischer Serien wie etwa der Wochentage betrifft die Übernahme aus dem Italienischen alle Lexeme der Serie: siz. luneddì, marteddì, mercoleddì/mercoldì, ggiovedì, vennerdì/vernerdì statt luni, marti, mèrcuri, jovi, venniri, die zunächst durch lunidìa, martidia, mercuridìa etc. ersetzt wurden (Tropea 1991: 194f., venniri taucht in seiner Liste nicht auf, lässt sich aber anhand der dort genannten Form venniridìa ergänzen). 
dem korrespondierenden italienischen Laut näher stehen oder entsprechen. Dies ist etwa bei der Ersetzung der dentalen Frikative [ $\theta]$ und [ð] durch [s] bzw. [z] in den Dialekten des Veneto der Fall: [' $\theta$ ento] > ['sento] ,cento', ['meðo] > ['mezo] ,mezzo“ (Berruto 1984: 130f.). Im Turinerischen und Mailändischen lässt sich eine Ersetzung von betontem [p] durch [a] (['kplt] > ['kalt] ,caldo', ['kpsa] (sic) > ['kalsa] ,calza', Sobrero 1997: 417) beobachten. Das dem Italienischen unbekannte Phonem / $3 /$ ist im Mailändischen weitestgehend durch den stimmlosen Sibilanten /S/ ersetzt worden und findet sich nur noch in einzelnen Termini und insbesondere in Französismen wie [zam'bon], prosciutto' (Massariello Merzagora 1985: 431). Als natives Phonem wird $/ \mathrm{J} /$ wiederum dort, wo das Italienische im entsprechenden Lexem $/ \mathfrak{g} /$ aufweist, durch dieses ersetzt: lomb. [' $\left.\int \varepsilon n d e r\right]>$ ['t हner] , cenere' (ebd.: 435).

Die (Morpho-)Syntax der italoromanischen Dialekte ist deutlich weniger , anfällig' für Annäherungen an das System des Standarditalienischen als das Lexikon und der Bereich der Phonetik/Phonologie. Zudem sind die hier beobachtbaren Veränderungen nicht immer (ausschließlich) struktureller Natur: ,[...] [S]pesso la modificazione della sintassi dialettale è più propriamente, o almeno è contemporaneamente, una innovazione lessicale-semantica" (Grassi 2011: 291). So geht die native Periphrase aus der lat. Konstruktion ,HABEO + Infinitiv“ (agu d'andà dal dutùr ,devo andare dal dottore') im Mailändischen (und anderen galloitalienischen Dialekten) zugunsten der standarditalienischen Konstruktion aus lat. DEBEO + Infinitiv (deu nò mangià ,non devo mangiare') zurück (Massariello Merzagora 1985: 431). Im Lombardischen findet sich eine Negationsstruktur, die sowohl dialektale als auch italienische Elemente beinhaltet: non so mia tant bon ,non sono tanto capace' (ital. präverbale Partikel non + lomb. postverbale Partikel mia, vgl. Patrucco 2001, zit. in Berruto 2006: 115f.). In den norditalienischen Dialekten führt der Einfluss des Italienischen zur Tilgung des Elementes $k e$ aus den Doppelkonjunktionen mentre ke, kume ke, kwan ke etc. (Berruto 1984: 134).

Die stärkste Resistenz gegen den Einfluss des Standarditalienischen findet sich im Bereich der Morphologie, die durch ihre paradigmatische Organisation grundsätzlich die höchste Stabilität aller sprachlichen Subsysteme gegenüber äußeren Einflüssen aufweist. Gerade diese feste Struktur führt jedoch dazu, dass im Falle von Veränderungen meist nicht einzelne Elemente, sondern ganze Serien (Artikel, Pronomen etc.) betroffen sind: „Proprio la compattezza della microstruttura può dunque favorire, contraddittoriamente, l'ingresso dell'innovazione, che coinvolge tutta la serie nel suo insieme e non soltanto un suo elemento isolato" (Grassi 2011: 298). Ein typisches Beispiel ist die Ersetzung des Paradigmas der Possessivpronomen, die in vielen norditalienischen Dialekten zu beobachten ist: mè, tò, sò > mio, tuo, suo. Hier handelt es sich nicht nur um einen morphologischen, sondern auch um einen lexikalischen Wechsel (Berruto 1984: 134). Ein häufig anzutreffendes Kontaktphänomen an der Schnittstelle zwischen Phonologie und Morphologie ist die Aufgabe der metaphonischen Pluralbildung - die das Italienische nicht kennt - in verschiedenen italoromanischen Dialekten. In den piemontesischen Dialekten verliert sich diese etwa bei Paaren wie [bu'tuy]/[bu't $\varepsilon y g]$, bottone/-i' (Sobrero 1997: 418), [gat]/[get] ,gatto/-i`, [tət']/[titf] ,tetto/-i`, im Venetischen beispielsweise im Falle von ['tozo]/['tuzi] ,ragazzo/-i', [mo'rozo]/[mu'ruzi] ,fidanzato/-i'. Der Verlust der internen Flexion durch Aufgabe der Metaphonie findet sich auch in verbalen Paradigmen: ven. ['kuri] > ['kori] ,corri', ['sinti] > ['senti] ,senti' (Berruto 1984: 132). Im Lombardischen, in den Dialekten des Salento (Bruni 1984: 84) und auch in den kampanischen Dialekten (vgl. Kap. 3.3.4.3) lässt sich ein starker Rückgang der Pluralbildung mit dem lateinischen Suffix -ORA (lomb. campo - càmpora ,campo - campi`, prato - pràtora ,prato - prati', fico - ficora ,fico - fichi`, Grassi 2011: 297), zugunsten der italienischen Pluralbildung auf $-i$ beobachten. 
Im Bereich der Wortbildung kommt es in den Dialekten teilweise zur Übernahme italienischer Affixe: So wird der Superlativ im Mailändischen heute nicht mehr allein mit der Konstruktion multu + Adjektiv (die ihrerseits die Konstruktion tant + Adjektiv ersetzt hat), sondern auch durch Affigierung der Adjektive mit dem Suffix -ísim (< ital. -issimo) ausgedrückt: ütilísim ,utilissimo', pùtentísim ,potentissimo“ (Massariello Merzagora 1985: 431, 433). In Lexemen, die italienische Entsprechungen aufweisen, kommt es zur Ersetzung von dialektalen Präfixen oder Suffixen durch die entsprechenden italienischen Morpheme: bol. arnaser ,rinascere' > rinaser, lavuradaura, lavoratrice' > lavuratríz (Foresti 1977: 243).

\subsection{Diachronische Entwicklungen der diatopischen Variation: Koineisierung und Dialektausgleich}

\subsubsection{Begriffsklärung}

Als Entwicklungstendenz der diatopischen Variation im italienischen Sprachraum wird häufig die Entstehung regionaler Koinai genannt. Einer Diskussion der diesbezüglich vorhandenen Beiträge soll hier eine terminologische Klärung vorausgehen, die zur adäquaten Behandlung der Thematik unerlässlich ist.

Unter Berücksichtigung seines Entstehungskontextes ${ }^{30}$ kann der Begriff Koine definiert werden als ,the stabilized result of mixing of linguistic subsystems such as regional or literary dialects“" (Siegel 1985: 363). Hauptmerkmale einer (regionalen) Koine ${ }^{31}$ sind demnach ihre Stabilität (informelle Standardisierung und zumindest teilweise Nativisierung), die Basiertheit auf einem bestimmten Dialekt bei gleichzeitiger Beteiligung von Merkmalen aus verschiedenen anderen Dialekten, ihre Funktion als regionale lingua franca und eine strukturelle Reduktion bzw. Simplifizierung (ebd.: 362$).{ }^{32}$

Während der Terminus Koine über eine lange Geschichte verfügt, findet sich der prozessuale Begriff Koineisierung erst in jüngerer Zeit. Trudgill (1986: 107) beschreibt das Phänomen als Kombination aus einem „levelling out of minority or otherwise marked speech forms“ und und einer ,simplification, which involves, crucially, a reduction in irregularities.“ Koineisierung beinhaltet damit immer auch den Prozess des Dialektausgleichs (dialect levelling), d.h. einen Abbau (stark) markierter Merkmale in verschiedenen lokalen Dialekten, der zur Reduktion interdialektaler Differenzen führt (Dillard 1972: 300, vgl. auch Trudgill 1986: 98) ${ }^{33}$ Eine Identifikation beider Prozesse - wie sie in der wissenschaftlichen Literatur häufig indirekt in Form fehlender terminologischer Abgrenzungen anzutreffen ist - greift phänomenologisch jedoch aus wenigstens zwei Gründen zu kurz. Zum Einen findet Dialektausgleich - im Gegensatz zur Koineisierung - regelmäßig in Situationen statt, in denen Sprecher verschiedener Dialekte

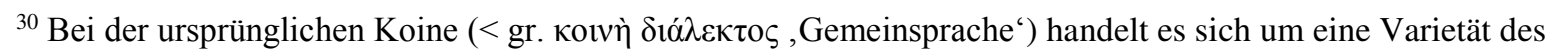
Griechischen, die in der griechisch-römischen Antike als lingua franca im östlichen Mittelmeerraum gesprochen wurde und sich durch Dialektkontakt in der Metropole Athen entwickelte, die Ziel vieler Immigranten aus verschiedenen Teilen des griechischen Territoriums war: „,T]he Hellenistic Koine [...] was mainly Attic but included many elements drawn from Ionic and some from the other dialects“" (Thomson 1960: 34).

${ }^{31}$ Von der „regional koine“ unterscheidet Siegel (1985) die ,immigrant koine“, die sich in Migrationssituationen durch das Zusammentreffen von Sprechern verschiedener (genealogisch verwandter) Dialekte manifestiert.

${ }^{32}$ Ebd. findet sich auch eine Synopse zu den Vorkommen der genannten Merkmale in verschiedenen wissenschaftlichen Beiträgen zum Phänomen der Koine.

${ }^{33}$ Für strukturelle Anpassungsprozesse zwischen Dialekten wird in der dialektologischen Forschung häufig wie im Fall der Annäherung der Dialekte an das Standarditalienische - auch der Terminus der ,(Dialekt-)Konvergenz" verwendet (vgl. Kap. 2.3.2).
} 
miteinander in Kontakt kommen (Dillard 1972: 300). ${ }^{34}$ Zudem führt Dialektausgleich nicht zwangsläufig zur Bildung eines neuen, einheitlichen Sprachsystems (,compromise dialect“", Siegel 1985: 365), wie es einer Koine zugrunde liegt. Bei der Koineisierung handelt es sich also in gewissem Sinne um einen ,Spezialfall` des Dialektausgleichs bzw. um eine über den Dialektausgleich hinaus gehende Entwicklung, zu deren Wirksamwerden bestimmte zusätzliche soziale Gegebenheiten vorliegen müssen - insbesondere eine (häufig auf politische, wirtschaftliche, soziale oder demographische Veränderungen zurückzuführende) intensive Interaktion zwischen Sprechern verschiedener Varietäten und eine Bereitschaft zur (sozialen und damit auch sprachlichen) Uniformisierung (Thomson 1960: 34).

Bei der Verwendung des Begriffs der ,regionalen Koine“ in der italienischen Dialektologie (in verschiedenen Formen wie „koiné dialettale“, „koiné regionale“, „dialetto di koiné“ etc. $)^{35}$ steht insbesondere die Prägung durch den Dialekt eines städtischen Zentrums im Vordergrund. Pellegrini (1975: 12) zufolge handelt es sich bei der koiné dialettale im italienischen Sprachraum um einen ,dialetto depurato dai tratti locali più vistosi e che accoglie, di norma, suoni e forme dei grandi centri regionali, con la sostituzione di vocaboli dialettali peregrini e marginali mediante quelli usati nei grandi centri e con quelli corrispondenti italiani, spesso in veste fonetica vernacolare.“ Das jeweilige städtische Zentrum hat dabei „la funzione di città guida, di capitale economica, sociale e culturale“ (Pellegrini 1990: 16), der städtische Dialekt verfügt über ein größeres Prestige als die Dialekte der ländlichen Umgebung, die häufig als archaisch und als Symbol sozialer und kultureller Rückständigkeit gelten. Typische Beispiele für in diesem Sinne definierte Koinai sind die in den Einzugsbereichen der norditalienischen Metropolen Mailand (koiné milanese), Turin (koiné torinese) und Venedig (koiné veneziana) entstandenen diatopischen Varietäten (vgl. Kap. 2.4.2). Der metalinguistische Kontext, in dem eine Koine entsteht, wird häufig dadurch charakterisiert, dass „,nelle aree vicine ai grandi, ai medi e a volte anche ai piccoli centri, il dialetto locale, confrontato con il dialetto ,civile' o con l'italiano della città, è concepito come inferiore“ (Sobrero/Miglietta 2006: 172). Die negative Bewertung des eigenen Dialekts führt demnach dazu, dass die Sprecher im geographischen Umfeld der Stadt die am deutlichsten markierten Merkmale ihres Dialekts vermeiden, um einer sozialen Stigmatisierung zu entgehen und stattdessen die Merkmale des prestigereicheren städtischen Dialekts übernehmen.

Das Phänomen der Koineisierung soll hier im Verständnis der italienischen Geolinguistik als durch das Prestige eines dialetto guida motivierte und aus Situationen des Dialektkontakts erwachsende Übernahme von Merkmalen eines Stadtdialekts in die Dialekte des ländlichen Umkreises definiert werden. ${ }^{36}$ Koineisierungstendenzen werden in der italienischen Dialektologie meist weder terminologisch noch phänomenologisch von dialektalen Ausgleichsprozessen abgegrenzt, ${ }^{37}$ Anmerkungen zum Inklusionsverhältnis zwischen beiden Phänomenen

\footnotetext{
${ }^{34}$ Ein sozio- bzw. pragmalinguistisches Erklärungsmodell hierfür bieten die Speech Accomodation Theory (SAT) bzw. die Communication Accomodation Theory (CAT), vgl. Niedzielski/Giles (1996).

${ }^{35}$ Vàrvaro (1991: 69) differenziert nach G. R. Cardona drei Verwendungsweisen des Begriffs „,koinè“: „quello di risultato della imposizione verticale, sia pure - naturalmente - con adattamenti, di una varietà su altre ([...] l'esempio del veneziano o del romanesco), quello del risultato di reciproci adattamenti orizzontali ([...] esempi africani) e, terza possibilità, il riferimento ad una koinè scritta, letteraria, poetica [...].“

${ }^{36}$ Da städtische Dialekte wie das Mailändische oder das Turinerische meist neben Dialektismen auch Elemente oder Merkmale an die umgebenden Dialekte ,weitergeben“, die aus dem Italienischen bereits in den jeweiligen Stadtdialekt übernommen worden sind (vgl. Kap. 2.3.1), beinhaltet der Prozess der Koineisierung teilweise eine (indirekte) Italianisierung der ruralen Dialekte.

${ }^{37}$ Ein Ansatz zur Differenzierung der beiden Phänomene findet sich bei Sobrero (1996) in der Dichotomie ,aktive Koine“ vs. ,passive Koine“. Letztere entsteht Sobrero zufolge, ,when - as a consequence of the pressure of
} 
finden sich nur sehr selten. ${ }^{38}$ Hinweise darauf, dass die Entwicklung der diatopischen Variation in der Italoromania auch durch, the disappearance of local differences [...] as a result of the levelling effects of forms of wider diffusion“ (Mioni/Arnuzzo-Lanszweert 1979: 92) gekennzeichnet ist, ohne dass ein Prozess der Koineisierung im Gange ist, sind nur schwer zu finden. Systematische empirische Untersuchungen zum Phänomen des Dialektausgleichs und insbesondere dazu, in welchem Maße der Dialektausgleich, d.h. die strukturelle Annäherung verschiedener Dialekte aneinander über die Ersetzung (stark) markierter dialektaler Merkmale durch Merkmale aus dem (Regional-)Italienischen, d.h. über die strukturelle Italianisierung der Dialekte verläuft, stehen aus.

\subsubsection{Regionale Unterschiede}

Im Hinblick auf die Entwicklung der diatopischen Variation und insbesondere auf die Bildung von Koinai bestehen im italoromanischen Sprachraum interregionale Unterschiede. Das wohl am häufigsten zitierte Beispiel einer koiné regionale ist die auf den starken sprachlich-kulturellen Einfluss Venedigs auf einen großen Teil des Veneto zurückzuführende koiné veneziana, „usata in tutta l'area in cui sono parlate varietà indigene appartenenti al gruppo dialettale veneto“ (Berruto 1989: 111, vgl. auch Trumper/Maddalon 1988: 234ff.). ${ }^{39}$ Im Westen der Lombardei hat sich eine Koine auf der Basis des Dialekts der ökonomisch und kulturell dominanten Metropole Mailand gebildet. Die koiné milanese ,accoglie le isoglosse ${ }^{40}$ comuni ai dialetti della zona, elimina i tratti locali più vistosi e per il resto si riferisce al dialetto del centro principale, che è anche il dialetto più italianizzato“" (Sanga 1984: 25). Der sprachliche Einfluss des Mailändischen erstreckt sich nach Trumper/Maddalon (1988: 233) etwa $60 \mathrm{~km}$ nach Westen, $30 \mathrm{~km}$ nach Südwesten und $60 \mathrm{~km}$ nach Norden. ${ }^{41}$ Im nördlichen Piemont ist eine auf dem torinese basierende regionale Koine in Gebrauch, die sich als Verkehrs- und Handelssprache bis in das frankoprovenzalische Aosta-Tal hinein erstreckt. Sie koexistiert mit den jeweiligen lokalen Dialekten, die (besonders in ländlichen Gebieten) weiterhin gebraucht werden (Berruto 1989: $111) .^{42}$

Koineisierungstendenzen sind im italienischen Sprachraum jedoch nicht überall vorhanden. Sie fehlen überall dort, wo sich kein (Stadt-)Dialekt durch ein größeres Prestige von den

\footnotetext{
Italian - the most marked dialectal differences in a certain area vanish, and dialects undergo processes of convergence - not guided by an urban center - tending to non-differentiated forms, generally italianized and re-phonetized according to the phonetics of the area" (Sobrero 1996: 107). Abgesehen von der scheinbar obligatorischen Bindung an den Prozess der Italianisierung weist eine ,passive Koine“ damit die Charakteristika eines Dialektausgleichs auf.

${ }^{38}$ Vgl. Berruto (1997: 17): „Nel livellamento dialettale può entrare la formazione di koinài dialettali regionali o subregionali $[\ldots]^{\text {“ }}$ (kursiv S.H.).

${ }^{39}$ Das impliziert jedoch nicht, dass die Dialekte hier historisch oder aktuell weniger Gewicht (gehabt) hätten: „,[T]he model of Veneto language behaviour and evolution over time is a general convergence model which, however, does not lead to the death of dialect but to the maintenance of a status quo between codes felt in some sense to be on equal terms“" (Trumper/Maddalon 1988: 253).

${ }^{40}$ Der Begriff Isoglosse bezeichnet hier nicht die Linien, die Gebiete begrenzen, in dem sich jeweils ein bestimmtes sprachliches Merkmale vorrangig findet, sondern die jeweiligen sprachlichen Merkmale selbst (vgl. Kap. 4.1.2.1).

${ }^{41}$ In den Gebieten um größere Städte wie Bergamo, Brescia oder Pavia fungiert nicht das milanese, sondern der jeweilige Stadtdialekt als sprachliches Modell (vgl. Berruto 1989: 111).

${ }^{42} \mathrm{Im}$ südwestlichen Piemont und in der östlichen Lombardei finden sich hingegen Gebiete, die zwar durch dialektale Ausgleichsprozesse, nicht aber durch die Entwicklung einer Koine gekennzeichnet sind (vgl. Sobrero/Miglietta 2006: 173).
} 
koexistierenden Dialekten abhebt und die Funktion des dialetto guida übernimmt. In der italophonen Schweiz (Kanton Tessin), die durch städtischen Plurizentrismus und durch starke lokale Unterschiede im Verhältnis der städtischen Dialekte zu jenen ihres ländlichen Einzugsbereichs gekennzeichnet ist, sind die Bedingungen für die Bildung einer Koine auf regionaler (kantonaler) Ebene nicht gegeben. Die größeren Städte (insbesondere Lugano, Locarno und Bellinzona) fungieren als kulturelle und sprachliche Knotenpunkte, in denen der durch ein starkes Pendlertum bedingte Kontakt zwischen verschiedenen basilektalen Varietäten zur Bildung von „Ausgleichsdialekten“ (varietà di dialetto livellato) führt (Petrini 1988: 51). Da die von der sozialen Gruppe der Pendler als (stark) markiert wahrgenommenen Merkmale des jeweiligen städtischen Dialekts in diese „Ausgleichsdialekte“ keinen Eingang finden (ebd.: 48), handelt es sich - aufgrund des Fehlens eines dialetto guida - im hiesigen Verständnis nicht um Koineisierungstendenzen, sondern um ,einfache' dialektale Ausgleichsprozesse.

In Mittel- und Süditalien sind Prozesse ,di formazione di dialetto regionale o sovramunicipale o interprovinciale“ (Pellegrini 1990: 17) deutlich seltener zu beobachten als in Norditalien. Ein häufig genanntes Beispiel für eine Region ohne Koineisierungstendenzen (und damit einen typischen Fall von Mikrodiglossie, vgl. Kap. 2.1) stellt die Emilia-Romagna dar, in der „every province presents a maximum of dialect divergence between urban and rural, rural and rural dialect circuits“" (Trumper/Maddalon 1988: 232). Foresti (1988: 571) verweist allerdings auf ,alcune evoluzioni subite anche in passato dai dialetti di località minori a fronte dell'influenza esercitata da centri più sviluppati economicamente e di più forte prestigio“ (Sassuolo, Modena, Piacenza, Faenza), die er im Falle von Piacenza als Hinweis auf die Entstehung einer „,coinè a livello provinciale“ (nach Sobrero/Miglietta 2006: 173 „,coinè locali“) interpretiert. Auch in den im Süden an die Emilia-Romagna grenzenden Marken existiert keine regionale Koine. ${ }^{43}$ In den Abruzzen sind die Bedingungen für die Entstehung einer regionalen Koine ebenfalls nicht gegeben, da keine Stadt eine wirtschaftliche und/oder kulturelle Vorrangstellung besitzt und die Dialekte in den kleineren Städten auch in bildungsnahen Schichten noch sehr vital sind (Pellegrini 1990: 17f.). Sobrero/Miglietta (2006: 174) identifizieren jedoch eine „micro-coinè“ im Gebiet des Gran Sasso (Zone zwischen L'Aquila und Rieti in der Provinz Latium) sowie eine zweite in der Marsica (um Avezzano).

In der Toskana - die aufgrund der strukturellen Nähe der Dialekte zum Standarditalienischen den anderen Regionen gegenüber eine Sonderstellung aufweist (vgl. Kap. 2.1) - ordnet Giannelli (1988: 604) allen größeren Städten einen sprachlichen Einflussbereich zu (,zona di influenza fiorentina“, „,zona di influenza pistoiese“, „zona di influenza lucchese“, ,zona di influenza senese“ etc.), macht jedoch keine Angaben zum Vorliegen entsprechender Koinai.

Für Kampanien wird die Existenz einer prestigereichen ,coinè a base napoletana“ postuliert (Pellegrini 1990: 18 und Grassi/Sobrero/Telmon 1998: 171), der teilweise ein über die Grenzen der Region hinaus reichender Einfluss zugesprochen wird (Sobrero/Miglietta 2006: 174), ${ }^{44}$ Trumper/Maddalon (1988: 232) weisen allerdings darauf hin, dass hier eine komplexe Situation vorliegt, die einer detaillierten Studie bedarf. In Nord- bzw. Mittelapulien wird im Gebiet um Bari - der hinter Neapel größten und wirtschaftlich bedeutendsten Stadt in Süditalien - eine „coinè dialettale barese“ identifiziert, die mit den lokalen Dialekten koexistiert (Sobrero/Miglietta 2006: 174). Das Salento weist zwar drei sprachlich-kulturell hegemoniale

\footnotetext{
${ }^{43}$ Die von Sobrero/Miglietta (2006: 173f.) identifizierte „,coinè dell’u finale“ im Gebiet um Camerino (Provinz Macerata), der „,sezione più tipicamente marchigiana, in quanto corrisponde all'area dialettale più arcaizzante“, kann aufgrund ihrer expliziten Beschränkung auf ein sprachliches Merkmal nicht als Koine im hiesigen Sinne gelten.

${ }^{44}$ Zur Evaluation dieser Annahme vgl. Kap. 3.3.7.
} 
Stadtzentren (Lecce, Taranto, Brindisi) auf, dennoch ist die Entwicklung der diatopischen Variation mehr durch eine Italianisierung der verschiedenen Lokaldialekte als durch die Entstehung eines „dialetto provinciale o sopramunicipale“ geprägt (Pellegrini 1990: 19). In der Basilicata (Lucania) existiert kein „parler directeur“ (Lüdtke 1979: 8), kein „,centro irradiatore di modelli linguistici“ und damit auch keine regionale Koine. Auch in Kalabrien, ,, region which presents an extremely high degree of dialect fragmentariness and divergence" (Trumper/Maddalon 1988: 245), lassen sich auf regionaler Ebene keine Koineisierungstendenzen beobachten. ${ }^{45}$ Sowohl in der Basilicata als auch in Kalabrien lassen sich zwar sprachlich-kulturelle Einflussbereiche größerer Städte wie Potenza, Matera, Cosenza, Catanzaro, Crotone oder Reggio Calabria identifizieren. Diese „urban-rural circuits“ sind jedoch nicht mit jenen der norditalienischen Metropolen Mailand oder Venedig vergleichbar: „In the Calabrian situation circuits do not in general exceed a diameter of $20 \mathrm{kms}$, linguistic models have no long term effects and large towns or cities did and do not influence other urban conglomerations" (ebd.: 233f.). Auf Sizilien liegt trotz der sprachlich und kulturell prestigereichen Metropolen Palermo und Catania und trotz der ehemaligen Verbreitung eines „palermitano illustre“ keine „coinè regionale generale siciliana“ vor: „,[A]lmeno sul versante orientale dell'Etna si osserva anche negli strati mediobassi un certo avvicinamento al dialetto di Catania, mediante alcuni adeguamenti soprattutto fonetici“" (Tropea, ohne weitere Angabe zit. in Pellegrini 1990: 19).

Es wird deutlich, dass der Versuch, die Entwicklung der diatopischen Variation in Mittel- und Süditalien wie jene in den hochurbanisierten Zonen Norditaliens auf Koineisierungsprozesse zurückzuführen, nicht zu zufriedenstellenden Ergebnissen führt. Bereits Lüdtke (1956: 126) weist darauf hin, dass das diatopische Profil des süditalienischen Sprachraums sich von jenem in Norditalien besonders dadurch unterscheidet, dass es keine „Regionalsprachen“ gibt, die von den Sprechern neben dem lokalen Dialekt und dem Italienischen verwendet werden. ${ }^{46}$ Die diatopische Entwicklung lässt sich hier - selbst unter dem Einsatz terminologisch eigenwilliger Konzepte wie dem der „micro-coinè“ oder der „coinè locale“ - mit der Verbreitung eines prestigereichen dialetto guida nicht adäquat charakterisieren. Die italienische Geolinguistik muss sich hier von dem Konzept der Koineisierung lösen und andere mögliche Formen der diatopischen Entwicklung in das Zentrum entsprechender Studien stellen.

\footnotetext{
${ }^{45}$ Unter Rückgriff auf Parlangèli (1960: 52ff.) führen Trumper/Maddalon (1988) die Situation in Lukanien (und auch in Apulien) auf die Konservierung soziolinguistischer Verhältnisse zurück, die in die Zeit vor der Entstehung des Regno di Napoli, d.h. in die Epoche der politisch-administrativen Opposition zwischen den langobardischen und den byzantinischen Teilen Süditaliens (vgl. Kap. 3.2) zurückreichen: „[T]he Kingdom of Naples [...] was an enormous territory, [...] that included many internal zones that were physically inaccessible, cut off from normal communication networks and difficult to administer, which of course permitted the conservation or further consolidation of preceeding sociolinguistic situations“" (ebd.: 231).

${ }^{46}$ Er identifiziert zwar „,regionale sprachliche Ausstrahlungszentren“ wie Neapel, Bari oder Tarent, denen er einen Einfluss auf die sie umgebenden Gebiete zuspricht, betont jedoch, „dass hier niemals, wenigstens in den letzten hundert Jahren, Ortsmundart und Regionalsprache als selbständige Sprachgebilde nebeneinander gestanden haben [...]“ (Lüdtke 1956: 127).
} 


\section{Eine (nicht nur) sprachlich komplexe Region: die Campania}

\subsection{Geographisches und demographisches Profil}

Die Campania ist eine Region im Südwesten Italiens, die im Norden an die Regionen Latium und Molise, im Osten an die Region Apulien und im Süden an die Region Basilicata grenzt. Sie beinhaltet die fünf Provinzen Avellino (AV), Benevento (BN), Caserta (CE), Neapel (Napoli, NA) und Salerno (SA) mit gleichnamigen Provinzhauptstädten (s. Karte 1). Mit einer Gesamtbevölkerung von 5.769.750 Einwohnern (Dezember 2012, vgl. Tab. 1) ist sie eine der bevölkerungsreichsten Regionen Italiens. ${ }^{47}$ Die Campania ist eine extrem kontrastreiche Region ,per quanto riguarda sia l'ambiente naturale, sia la distribuzione della popolazione e il suo modo di abitare, la ripartizione della proprietà e del reddito nelle varie parti della regione e tra le classi sociali, l'intensità delle colture e la concentrazione delle industrie, le vie di comunicazione e il traffico. Alla base di tali contrasti vi sono cause naturali e fattori umani [...]" (Ruocco 1976: 4). Geographisch stehen sich ein überwiegend flaches Küstengebiet mit mildem Klima (pianura), das die Provinz Neapel, den Westen der Provinz Caserta sowie das Küstengebiet südlich von Salerno umfasst und ein durch Erhebungen und Gebirge gekennzeichnetes, klimatisch schroffes Landesinnere (montagna) entgegen, durch das die Provinzen Benevento und Avellino, der östliche Teil der Provinz Caserta und ein Großteil der Provinz Salerno geprägt werden (s. Karte 2).

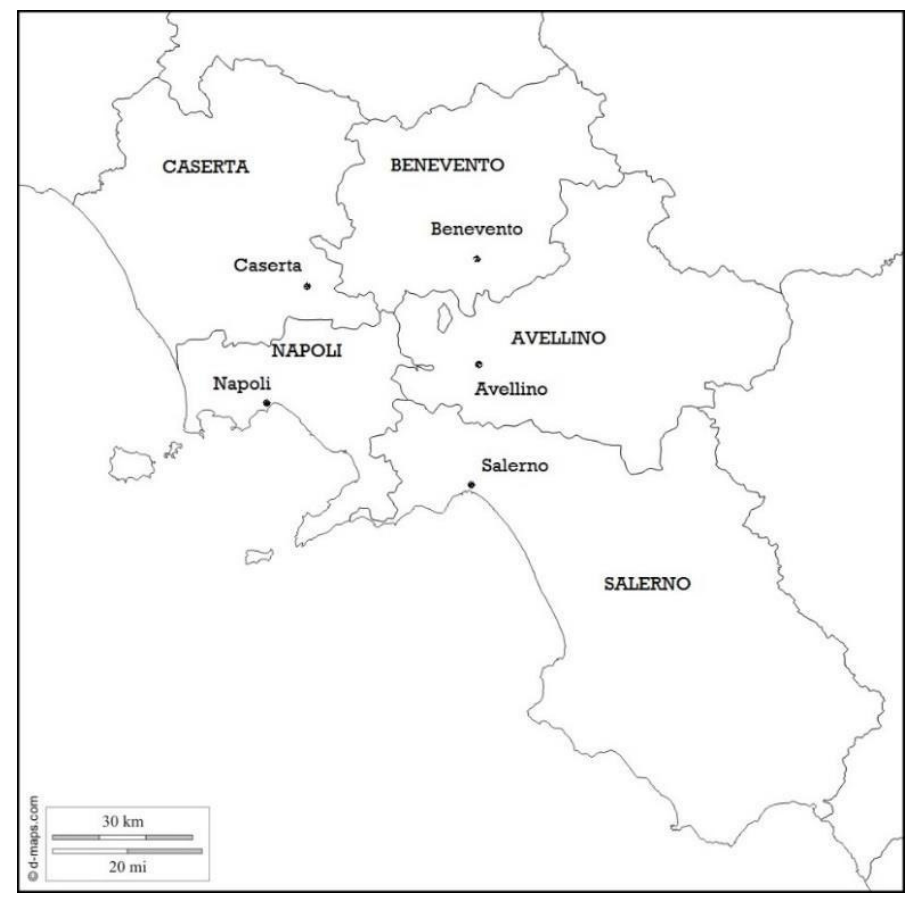

Karte 1. Provinzen und Provinzhauptstädte in der Region Kampanien (Quelle: d-maps.com).

Auch in demographischer Hinsicht ist die Campania eine Region mit starken Gegensätzen. Die flächenmäßig kleinste Provinz Neapel weist den größten Bevölkerungsanteil (53\%) und die höchste Bevölkerungsdichte auf (s. Tab. 1). Die Fläche der Provinz Caserta entspricht

\footnotetext{
${ }^{47}$ Trotz der mit 422,04 Einwohnern je $\mathrm{Km}^{2}$ (vgl. Tab. 1) ebenfalls verhältnismäßig hohen durchschnittlichen Bevölkerungsdichte kann die Campania aufgrund des großen demographischen Ungleichgewichts (s.u.) nicht pauschal als dicht besiedelte Region bezeichnet werden.
} 
in etwa jener der Provinz Avellino, die Bevölkerungsdichte ist in der Provinz Caserta jedoch mehr als doppelt so hoch. Auch die Bevölkerungsdichte der flächenmäßig größten Provinz Salerno ist deutlich geringer als jene der Provinz Caserta, die nur etwas mehr als die Hälfte der Fläche jener aufweist. Derartige statistische Unterschiede zwischen den Provinzen liefern erste Hinweise auf die demographische Verteilung innerhalb der Region, machen jedoch keine Aussage in Bezug auf die historisch gewachsene demographische Gesamtstruktur der Region, die sich erst bei kartographischer Betrachtung offenbart und bei der die administrativen Grenzen allenfalls eine untergeordnete Rolle spielen. ${ }^{48}$

\begin{tabular}{|l|c|c|c|}
\hline Provinz & Größe $\mathbf{( k m}^{\mathbf{2}}$ ) & $\begin{array}{l}\text { Bevölkerungszahl im Dez. } \\
\mathbf{2 0 1 2} \text { (Anteil an der Gesamtbe- } \\
\text { völkerung) }\end{array}$ & $\begin{array}{l}\text { Bevölkerungs- } \\
\text { dichte (Einwoh- } \\
\text { ner/km }{ }^{2} \text { ) }\end{array}$ \\
\hline Caserta & $2.651,35$ & $908.784(15,8 \%)$ & 342,76 \\
\hline Benevento & $2.080,44$ & $283.651(4,9 \%)$ & 136,34 \\
\hline Napoli & $1.178,93$ & $3.055 .339(53 \%)$ & 2591,62 \\
\hline Avellino & $2.806,07$ & $428.523(7,4 \%)$ & 152,71 \\
\hline Salerno & $4.954,16$ & $1.093 .453(19 \%)$ & 220,71 \\
\hline Gesamt & $\mathbf{1 3 . 6 7 0 , 9 5}$ & $\mathbf{5 . 7 6 9 . 7 5 0}$ & $\mathbf{4 2 2 , 0 4}$ \\
\hline
\end{tabular}

Tabelle 1. Demographische Verteilung in der Region Kampanien nach Provinzen. ${ }^{49}$

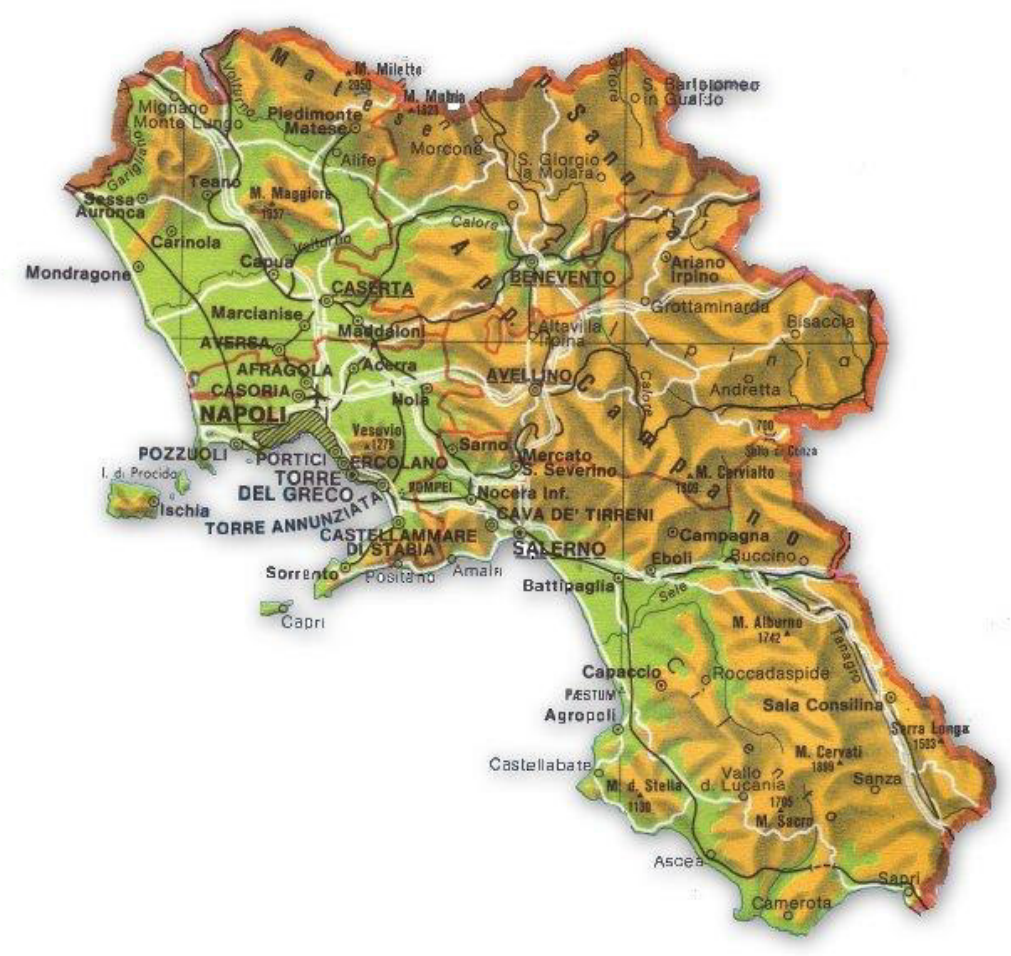

Karte 2. Geographisches Profil der Region Kampanien. ${ }^{50}$

\footnotetext{
${ }^{48}$ Wenn im Folgenden auf die administrativen Einheiten, d.h. die Provinzen verwiesen wird, so erfolgt dies lediglich zur Erleichterung der geographischen Orientierung des Lesers.

${ }^{49}$ Quelle: IStat (http://www.istat.it/it/archivio/82599, Dati comunali e provinciali und http://demo.istat.it/bilmens2012gen/index.html, zuletzt abgerufen am 11.07.2015).

${ }^{50}$ Quelle: http://www.cittacapitali.it/italia-da-vedere/campania/cartina-campania.htm, zuletzt abgerufen am 11.07.2015.
} 
Die demographische Struktur der Region spiegelt grob gesehen die bereits genannte geographische Zweiteilung wider. Die Bevölkerung konzentriert sich in der kampanischen Küstenebene, d.h. in der Provinz Neapel, im südlichen Teil der Provinz Caserta und im neapolitanischen Hinterland zwischen Caserta und Salerno sowie in den Küstengebieten südlich von Salerno, während die Gebirgsregionen - d.h. die Provinzen Avellino und Benevento mit Ausnahme der jeweiligen Provinzhauptstädte sowie große Teile der Provinz Salerno - dünn besiedelt sind (s. Karte 3). Insbesondere seit der zweiten Hälfte des 20. Jahrhunderts manifestiert sich in der kampanischen Küstenebene ein massives Wachstum der Bevölkerung (s. Tab. 2). ${ }^{51}$ Durch die wachsende Industrialisierung und Tertiärisierung der Gebiete am neapolitanischen und salernitanischen Golf, um Salerno und Caserta sowie anderer Städte des Hinterlands (Sarno, Nola) wurde in den vergangenen fünfzig Jahren eine stetig wachsende Zuwanderung aus den primär agrarwirtschaftlich geprägten Teilen der Region (Provinzen Benevento, Avellino und ländliche Gebiete der Provinz Salerno) hervorgerufen: „Si è verificata una discesa dal monte al mare e alla pianura, dove sono sorti nuovi agglomerati, [...] centri nuovi e vere città (Battipaglia) o si sono ingrandite e differenziate economicamente alcuni di quelli vecchi (Mondragone, Aversa, Casoria, Pontecagnano)“ (Ruocco 1976: 230). Der nunmehr dicht besiedelte Bereich stellt seit dem Jahr 2000 eine der neun italienischen Metropolregionen (aree metropolitane) dar, die als solche ,rapporti di stretta integrazione territoriale e in ordine alle attività economiche, ai servizi essenziali alla vita sociale, nonché alle relazioni culturali e alle caratteristiche territoriali“" aufweisen (Decreto Legislativo n. 267, Art. 22, 1, vom 18.08.2000). ${ }^{52}$

Das Bevölkerungswachstum in der Metropolregion Neapel erklärt sich jedoch nicht nur durch den demographischen Zustrom aus den ländlichen Teilen der Region. Tab. 3 zeigt, dass der Anteil aller urbanen Zentren - insbesondere aber Neapels und Salernos - an der Bevölkerung der entsprechenden Provinzen in den vergangenen drei Jahrzehnten deutlich zurückgegangen ist. Die demographische Entwicklung ist in allen Teilen der Campania, insbesondere aber in den Provinzen Neapel und Salerno durch eine Umsiedlung vieler Einwohner aus den großen Stadtgebieten in die ländlichen Einzugsgebiete gekennzeichnet. Während seit den 1990er Jahren sowohl in der Provinz Neapel als auch in der gesamten Region ein Bevölkerungswachstum zu verzeichnen ist, zeigt sich auf kommunaler Ebene (Neapel-Stadt) ein kontinuierlicher Bevölkerungsrückgang (s. Tab. 4). Im Vergleich mit den übrigen italienischen Metropolregionen zeigt sich hier eine ähnliche Situation wie in Cagliari und Palermo, während die nord- und mittelitalienischen Metropolen (mit Ausnahme Venedigs) sowie die süditalienische Metropole Bari ebenso wie die sie umgebenden Provinzen ein demographisches Wachstum verzeichnen (s. Abb. 2). Während ein Großteil der italienischen Metropolregionen also (weiterhin) eine zentripetale demographische Entwicklung aufweist, kann man im Falle der Metropolregion Neapel von einer zentrifugalen Entwicklung sprechen.

\footnotetext{
${ }^{51}$ Die agrarwirtschaftliche Krise, die die süditalienischen Regionen in den 1870er Jahren getroffen hatte, hatte dazu geführt, dass zwischen 1876 und 1925 über 1,5 Millionen Süditaliener ins europäische Ausland oder nach Nordamerika auswanderten. In der Campania konzentrierte sich die verbliebene Bevölkerung - insbesondere ab 1931 - in der nordwestlichen Küstenebene (Provinz Caserta), in der Peripherie Neapels sowie im Küstenstreifen zwischen Neapel und Salerno (vgl. Ruocco 1976: 596, 598). Das Bevölkerungswachstum in der Region, das sich zwischen 1871 und 1921 aufgrund der Emigrationswelle nur auf 34\% belief, erholte sich allmählich und lag zwischen 1921 und 1971 bei $51 \%$ (ebd.: 229).

52 Bei den aree metropolitane handelt es sich nicht um administrative Einheiten. Die Gemeinden haben jedoch die Möglichkeit, sich zu einer città metropolitana zusammenzuschließen, die dann die Funktion der jeweiligen Provinz übernimmt. Zur Definition des möglichen administrativen Gebietes der area metropolitana di Napoli existieren verschiedene Vorschläge (vgl. Smarazzo 1999), bisher ist es hier jedoch nicht zu einer Einigung zwischen den Gemeinden gekommen.
} 


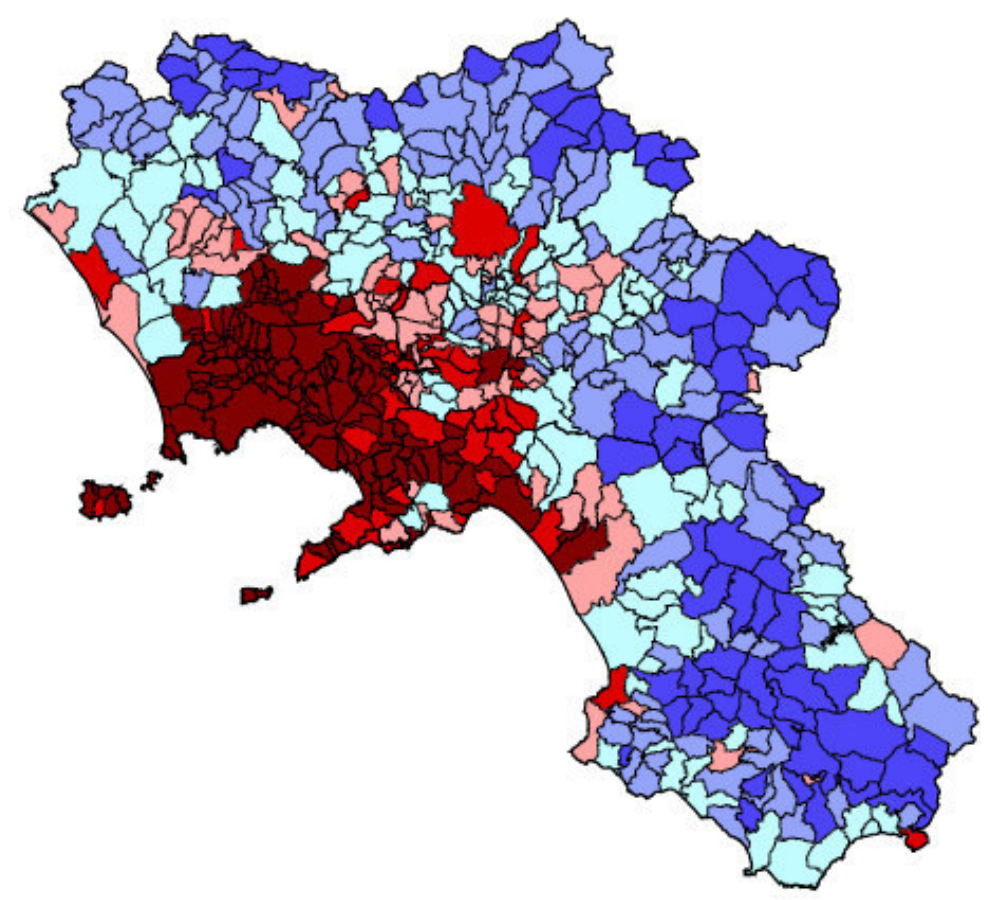

bis 50

50 bis 100

100 bis 200

200 bis 400

400 bis 800

über 800

Karte 3. Bevölkerungsdichte (Einwohner pro $\mathrm{km}^{2}$ ) in der Region Kampanien 2008 (Atlante Nazionale del Territorio Rurale: Regione Campania 2010: 101).

\begin{tabular}{|l|c|c|c|c|c|c|c|}
\hline Provinz & $\mathbf{1 9 5 1}$ & $\mathbf{1 9 6 1}$ & $\mathbf{1 9 7 1}$ & $\mathbf{1 9 8 2}$ & $\mathbf{1 9 9 2}$ & $\mathbf{2 0 0 1}$ & $\mathbf{2 0 1 2}$ \\
\hline Caserta & 601.372 & 649.327 & 677.959 & 756.169 & 816.144 & 852.230 & 908.784 \\
\hline $\begin{array}{l}\text { Bene- } \\
\text { vento }\end{array}$ & 333.203 & 314.253 & 287.613 & 288.997 & 292.817 & 287.539 & 283.651 \\
\hline Napoli & 2.081 .119 & 2.421 .243 & 2.709 .929 & 2.969 .298 & 3.017 .137 & 3.062 .897 & 3.055 .339 \\
\hline Avellino & 493.742 & 463.671 & 426.395 & 433.866 & 438.722 & 430.344 & 428.523 \\
\hline Salerno & 836.828 & 912.265 & 957.452 & 1.014 .280 & 1.066 .839 & 1.075 .127 & 1.093 .453 \\
\hline Gesamt & $\mathbf{4 . 3 4 9 . 5 0 0}$ & $\mathbf{4 . 7 6 8 . 9 0 1}$ & $\mathbf{5 . 0 6 5 . 4 0 6}$ & $\mathbf{5 . 4 6 2 . 6 1 0}$ & $\mathbf{5 . 6 3 1 . 6 5 9}$ & $\mathbf{5 . 7 0 8 . 1 3 7}$ & $\mathbf{5 . 7 6 9 . 7 5 0}$ \\
\hline
\end{tabular}

Tabelle 2. Demographische Entwicklung der kampanischen Provinzen von 1951 bis $2012 .{ }^{53}$

\footnotetext{
${ }^{53}$ Quelle: Istat (http://dati.istat.it/Index.aspx und http://demo.istat.it/bilmens2012gen/index.html, zuletzt abgerufen am 11.07.2015).
} 


\begin{tabular}{|l|c|c|c|c|}
\hline Provinzhauptstadt & $\mathbf{1 9 8 2}$ & $\mathbf{1 9 9 2}$ & $\mathbf{2 0 0 1}$ & $\mathbf{2 0 1 2}$ \\
\hline Caserta & $8,9 \%$ & $8,5 \%$ & $8,8 \%$ & $8,2 \%$ \\
\hline Benevento & $22,2 \%$ & $21,4 \%$ & $21,5 \%$ & $21,4 \%$ \\
\hline Neapel & $41 \%$ & $35,5 \%$ & $32,8 \%$ & $31,4 \%$ \\
\hline Avellino & $13,4 \%$ & $12,7 \%$ & $12,3 \%$ & $12,8 \%$ \\
\hline Salerno & $15,7 \%$ & $13,9 \%$ & $12,9 \%$ & $12,1 \%$ \\
\hline Gesamt & $\mathbf{2 8 , 7} \%$ & $\mathbf{2 5 \%}$ & $\mathbf{2 3 , 4} \%$ & $\mathbf{2 2 , 2} \%$ \\
\hline
\end{tabular}

Tabelle 3. Prozentualer Anteil der kampanischen Provinzhauptstädte an der Einwohnerzahl der jeweiligen Provinzen 1982-2012. ${ }^{54}$

\begin{tabular}{|l|c|c|c|}
\hline Zeitraum & Neapel-Stadt & Provinz Neapel & Region Kampanien \\
\hline $1991-2000$ & $-6,09 \%$ & $1,52 \%$ & $1,36 \%$ \\
\hline $2001-2007$ & $-3,13 \%$ & $0,75 \%$ & $1,93 \%$ \\
\hline
\end{tabular}

Tabelle 4. Entwicklung der Bevölkerung in Neapel-Stadt, in der Provinz Neapel und in der Region Kampanien (nach Crespi/Filippetti 2008: 29).

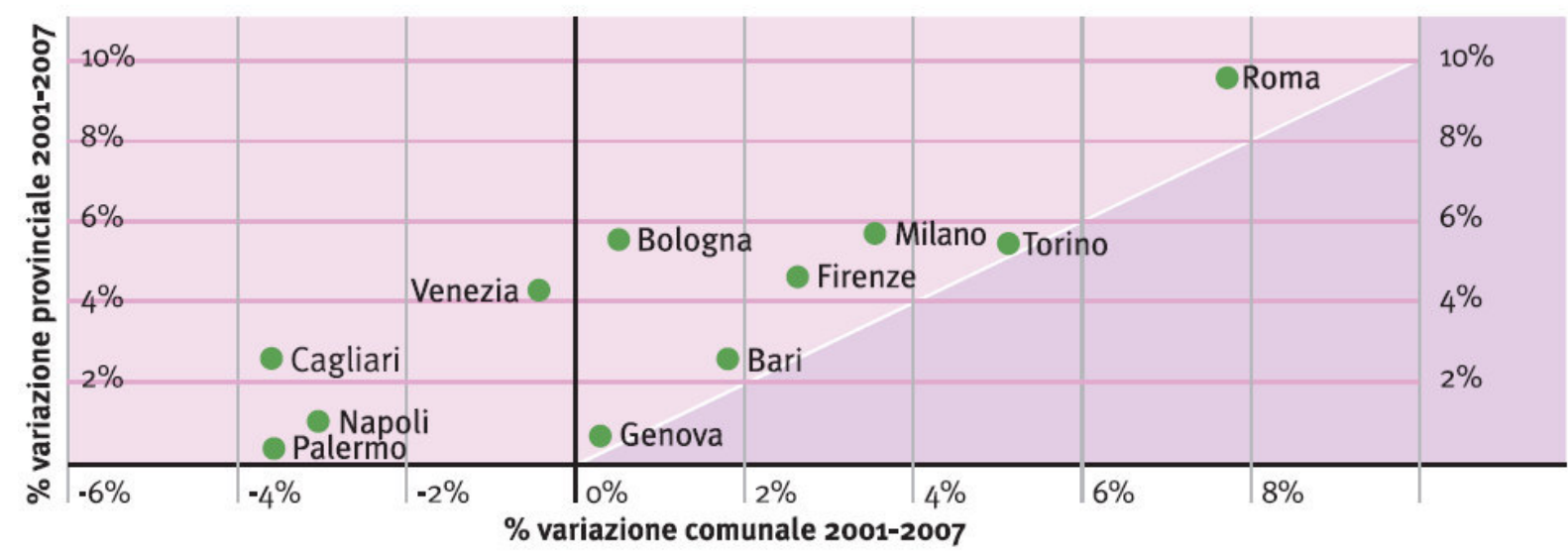

Abbildung 2. Entwicklung der Bevölkerung der italienischen Metropolen (x-Achse) und der entsprechenden Provinzen (y-Achse) zwischen 2001 und 2007 (Crespi/Filippetti 2008: 29).

Einer von Van den Berg/Drewett/Klaassen (1981) begründeten Theorie zur Entwicklung städtischer Agglomerationen zufolge ist der „Lebenszyklus“ von Metropolen durch die Abfolge expansiver Phasen (mit Bevölkerungswachstum) und rezessiver Phasen (mit Bevölkerungsreduktion) gekennzeichnet. Auf der Basis der Bevölkerungsentwicklung (Verhältnis von Ein- und Auswanderungsquoten) im Stadtkern (core) und in der städtischen Peripherie (ring) werden vier Phasen unterschieden: Die expansiven Phasen der Urbanisierung und der Suburbanisierung und die rezessiven Phasen der Deurbanisierung und der Reurbanisierung. Während in der Phase der Urbanisierung das Bevölkerungswachstum insbesondere im Stadtkern stattfindet, wächst die Bevölkerung in der Phase der Suburbanisierung vor allem in der städtischen Peripherie. In der ersten rezessiven Phase, der Deurbanisierung, verringert sich die Bevölkerung

\footnotetext{
${ }^{54}$ Quelle: IStat (http://dati.istat.it/?lang=it und http://demo.istat.it/bilmens2012gen/index.html, zuletzt abgerufen am 11.07.2015).
} 
im Stadtkern und in der Peripherie, während in der Phase der Reurbanisierung das demographische Wachstum im städtischen Kern wieder zunimmt (,Gentrifizierung“, vgl. Giecillo/La Nave 2009: 17f.). Bei der Anwendung dieses Modells auf die Entwicklung der italienischen Metropolen zeigt sich, dass sich, gemessen an der Bevölkerungsentwicklung von Kern und Peripherie zwischen 2002 und 2008, der Großteil der Metropolen - etwa Turin, Mailand, Genua und Venedig in Nord- oder Rom und Bologna in Mittelitalien - in der Phase der Suburbanisierung befindet (s. Tab. 5). Neapel und Palermo zeigen hingegen Merkmale der Deurbanisierung und weisen damit - neben Reggio Calabria, das sich in der Phase der Urbanisierung befindet - einen Sonderstatus unter den italienischen Metropolen auf.

Die Deurbanisierung Neapels wird begleitet von einer Relokalisierung der wirtschaftlichen Aktivität im industriellen und tertiären Sektor, die dazu führt, dass sich die Bevölkerung nicht mehr (nur) an der Metropole, sondern immer stärker (auch) an externen, kleineren Stadtzentren orientiert und das Verkehrsaufkommen (und hier insbesondere der Pendlerverkehr) in Richtung der Stadt abnimmt (vgl. Allulli 2010: 14f. und Giecillo/La Nave 2009: 19). Bei der zentrifugalen Entwicklung der Metropolregion Neapel handelt es sich also um einen langfristigen sozialgeographischen Strukturwandel, der als solcher naturgemäß eine Veränderung der sozialen und damit auch der sprachlich-kommunikativen Strukturen des Gebietes nach sich zieht.

\begin{tabular}{l|c|c|c|c}
\multirow{2}{*}{} & \multicolumn{3}{|c|}{ Tasso migratorio 2002-2008 } & \multirow{2}{*}{$\begin{array}{c}\text { Modello } \\
\text { di riferimento }\end{array}$} \\
\cline { 2 - 5 } Bari & core & ring & area metropolitana & Suburbanizzazione \\
\hline Bologna & $0,6 \%$ & $1,6 \%$ & $1,4 \%$ & Suburbanizzazione \\
\hline Cagliari & $4,7 \%$ & $11,0 \%$ & $2,6 \%$ & Suburbanizzazione \\
\hline Catania & $-1,9 \%$ & $4,5 \%$ & $1,4 \%$ & Suburbanizzazione \\
\hline Firenze & $-4,9 \%$ & $4,0 \%$ & $7,1 \%$ & Suburbanizzazione \\
\hline Genova & $6,0 \%$ & $7,7 \%$ & $5,2 \%$ & Suburbanizzazione \\
\hline Messina & $4,5 \%$ & $6,7 \%$ & $0,3 \%$ & Suburbanizzazione \\
\hline Milano & $-2,3 \%$ & $1,8 \%$ & $4,9 \%$ & Suburbanizzazione \\
\hline Napoli & $4,1 \%$ & $5,5 \%$ & $-2,3 \%$ & Disurbanizzazione \\
\hline Palermo & $-4,7 \%$ & $-1,2 \%$ & $-0,5 \%$ & Disurbanizzazione \\
\hline Reggio Calabria & $-5,1 \%$ & $5,3 \%$ & $0,4 \%$ & Urbanizzazione \\
\hline Roma & $3,0 \%$ & $-0,8 \%$ & $10,3 \%$ & Suburbanizzazione \\
\hline Torino & $7,0 \%$ & $17,2 \%$ & $6,6 \%$ & Suburbanizzazione \\
\hline Trieste & $6,3 \%$ & $6,7 \%$ & $2,9 \%$ & Suburbanizzazione \\
\hline Venezia & $2,7 \%$ & $3,9 \%$ & $6,0 \%$ & Suburbanizzazione \\
\hline
\end{tabular}

Tabelle 5. Bevölkerungsentwicklung in den italienischen Metropolen und Metropolregionen zwischen 2002 und 2008 (Giecillo/La Nave 2009: 18). 


\subsection{Geschichtlicher Überblick}

\subsubsection{Die Campania von der vorrömischen Zeit bis zum Mittelalter}

Die Siedlungsgeschichte der Campania ist geprägt durch das Aufeinanderfolgen und die Koexistenz vieler verschiedener Völker, „una sequenza che è propriamente una successione di egemonie, in cui nessun popolo a rigore scaccia quello che lo ha preceduto, ma piuttosto, senza annientarlo, gli si sovrappone“ (Colonna 1981: 66).

Die ersten historisch zuordenbaren Siedlungen sind jene ,protoitalischer' Volksstämme, darunter die Siedlungen der Ausoner im Nordwesten der heutigen Campania, die sich im Süden bis zum Fluss Volturno erstreckten sowie die Siedlungen der Opiker (gr. Opikoi) ${ }^{55} \mathrm{Im}$ 9. Jh. v. Chr. drangen die Etrusker von Norden (heute Region Latium) in die kampanische Küstenebene ein, wo sie zahlreiche Siedlungen gründeten (neben dem wichtigen Handelszentrum Capua (ca. 800 v. Chr.) u.a. Nola und Nocera), die sich im Süden vereinzelt bis zum Fluss Sele erstreckten (Pontecagnano). Ab dem 8. Jh. v. Chr. wurde die neapolitanische Küstenregion durch die Griechen (Euboer) kolonialisiert. ${ }^{56}$ Als älteste griechische Gründung im westlichen Mittelmeer gilt Pithecussa $^{57}$ (heute Ischia, ca. 770 v. Chr.), der auf dem Festland 750 v. Chr. Kyme (heute Cuma), ca. 700 v. Chr. Parthenope (im Gebiet des heutigen neapolitanischen Stadtteils San Ferdinando), 531 v. Chr. Dicearchia (heute Pozzuoli) und ca. 480-470 v. Chr. Neapolis (Neapel) folgten. ${ }^{58}$ Das griechische Volk lebte in friedlicher Koexistenz mit der autochthonen Bevölkerung und pflegte einen intensiven wirtschaftlichen und kulturellen Austausch mit den im Hinterland angesiedelten Etruskern. ${ }^{59}$

Auch im Süden der Region gründeten die griechischen Kolonisatoren strategisch wichtige Küstenstädte, darunter Poseidonia (ca. 625 v. Chr., heute Paestum), Palinuro (heute Centola, ca. 547 v. Chr.), Elea (ca. 530 v. Chr., lat. Velia, heute Ruinenstätte nahe Ascea) und Pyxous (ca. 470 v. Chr., lat. Buxentum, heute Santa Marina am Golf von Policastro) ${ }^{60}$ Hier unterhielten die griechischen Siedler ebenfalls gute wirtschaftliche Beziehungen zu den nördlich des Sele angesiedelten Etruskern. Als wirtschaftliche Umschlagplätze auf der Route zwischen Etrurien und den ionischen Städten erfuhren insbesondere Poseidonia und Elea wirtschaftlichen Wohlstand und demografisches Wachstum.

\footnotetext{
${ }^{55}$ Die folgenden Ausführungen orientieren sich mehrheitlich an Ruocco (1976: 6ff.).

${ }^{56}$ Zur (Kultur-)Geschichte der Magna Graecia vgl. De Palma (1980).

${ }^{57}$ Das Toponym bezeichnete in griechischer Zeit sowohl die auf dem Monte di Vico errichtete Stadt als auch die gesamte Insel.

${ }^{58}$ Die Prägung Neapels durch die griechische Sprache und Kultur wird unter anderem darin deutlich, dass die Stadt zur Zeit der römischen Herrschaft als « quasi Graecam urbem » (Tacitus, Annalen XV, 33) betrachtet wurde. In byzantinischer Zeit hatte das Griechische (als Sprache der Septuaginta und der oströmischen Kirche) in Neapel insbesondere im religiösen Bereich eine zentrale Bedeutung: ,[N]on mancavano in città insediamenti di monaci di rito greco, e almeno nelle funzioni religiose era piuttosto usuale il ricorso al greco accanto al latino“ (Bianchi/De Blasi/Librandi 2002: 631).

59 ,[G]li Etruschi ritrovano, come nella Padania, la vocazione di mediatori tra i Greci e i Barbari. Il conflitto sul mare, il conflitto per la talassocrazia con Cuma è tutt'altra cosa, riguarda le poleis costiere dell'Etruria propria, non influisce sui destini dell'Etruria campana“"(Colonna 1981: 72).

${ }^{60} \mathrm{Ob}$ die Gründung von Agropoli (< gr. 'Aкро́ $\left.\pi о \lambda ı \varsigma\right)$ ebenfalls in der griechischen Antike stattgefunden hat, ist unklar. Erstmals belegt ist Agropoli im Jahr 592 in einem Brief von Gregorio Magno an den Bischof von Agropoli (vgl. Rohlfs 1988: 114). Rohlfs schließt daraus, dass die Gründung bereits weit früher stattgefunden haben muss: „Poiché si tratta di una sede vescovile, non è molto probabile che la città sia stata fondata nel breve periodo del dominio bizantino, che inizia solo nel 552“(ebd.).
} 
Im 5. Jahrhundert v. Chr. drangen die oskischsprachigen Samniten (osk. *Safinèis) von Norden und Nordosten in die Campania ein und unterwarfen die dort siedelnden Opiker. ${ }^{61}$ Das Volk der Samniten bestand aus verschiedenen Stämmen, die im militärischen Bund der Lega sannitica miteinander verbunden waren. Ihr Siedlungsgebiet (lat. Samnium < osk. Safinim) erstreckte sich im Norden bis zum Fluss Sangro, im Süden bis zu den Flüssen Sele und Ofanto und im Osten bis zum Gebiet der Apulier und Frentaner (s. Karte 4). ${ }^{62}$ Während die Careciner im nördlichsten Teil des Samnium südlich des Sangro (heute Regionen Abruzzo und Molise) siedelten, erstreckte sich das Gebiet der Pentrer von Isernia (heute Region Molise) im Norden bis auf die Höhe des Volturno in die Campania hinein und umfasste zudem Gebiete östlich der heutigen Campania (bis Lucera). ${ }^{63}$ Südlich schloss sich etwa auf der Höhe des Flusses Calore das Siedlungsgebiet der Hirpiner an (lat. Irpini < osk. (h)irpus ,Fuchs', vgl. Galasso 2005: 67). ${ }^{64}$ (Süd-)westlich des Gebietes des Pentrer, an der Grenze zur kampanischen Küstenebene, siedelten die Caudiner. ${ }^{65}$ Südlich des Sele (heute Provinz Salerno) lebten die ebenfalls oskischsprachigen, jedoch nicht zum Volk der Samniten gehörigen Lukaner, deren Gebiet sich im Süden bis zum ionischen Meer erstreckte (lat. Lucania, heute Region Basilicata).

Die Samniten drangen Ende des 5. Jahrhunderts bis in die Küstenregion um Neapel vor, wo sie 423 v. Chr. ${ }^{66}$ Capua und 421 v. Chr. Cuma eroberten. Kurze Zeit später - im 4. Jh. v. Chr. - eroberten die Lukaner den Kernbereich des Cilento ${ }^{67}$ (um Vallo di Diano), mit Ausnahme

\footnotetext{
${ }^{61}$ Die samnitische und auch im Lateinischen gebräuchliche Bezeichnung Osci $(<$ osk. *Ops-ci aus dem Thema ops-, vgl. osk. opsaom ,lavorare“) stellt wohl eine an die Sprache der Samniten (heute „oskisch“) phonetisch angepasste Form des griechischen Terminus Opikoi an dar (vgl. Devoto 1951: 112). Durch die Einbürgerung der Bezeichnung „oskisch“ (in „oskisch-umbrisch“) für einen Zweig der italischen Sprachfamilie ist heute die Unterscheidung zwischen den ethnischen Termini und den dazugehörigen Sprachbezeichnungen wichtig: ,[L]'antico nome di Opici appartenesse allo strato più antico di Indoeuropei e la forma Osci rappresenti l'adattamento dello stesso nome agli Italici sopraggiunti. Sicché ,opico“ può continuare a significare un popolo affine agli Ausoni, ,osco ‘ un popolo italico, con le rispettive lingue, la « opica » protolatina, la « osca » italica [...]“ (Devoto 1951: 139).

${ }^{62}$ Zur Siedlungsgeschichte des Samnium vgl. Salmon (1985).

${ }^{63}$ Das entsprechende Gebiet innerhalb der Campania, das einen Großteil der Provinz Benevento umfasst, wird heute auch als Sannio Beneventano bezeichnet. In der vorliegenden Arbeit wird synonym auch die Kurzform ,Sannio' verwendet.

${ }^{64}$ Die historische Region, die in etwa die heutige Provinz Avellino umfasst, wird heute als Irpinia bezeichnet.

${ }^{65}$ Von der Besiedelung durch die oskischsprachigen Stämme zeugen in den heutigen Provinzen Benevento und Avellino zahlreiche Toponyme, die zum Teil auf das Volk der Samniten (Gioia Sannitica, Cerreto Sannita, Colle Sannita etc.) und zum Teil auf einzelne Stämme (Ariano Irpino, Bagnoli Irpino, Valle Caudina etc.) zurückgehen. In der Strataforschung werden einzelne strukturelle Merkmale bestimmter kampanischer Dialekte auf das oskisch-samnitische Substrat zurückgeführt, im phonologischen Bereich etwa die Präsenz von /f/ anstelle von lat. /b/ oder /v/ in aneap., irp. und cil. ottufra (lat. OCTOBER), ottobre', tufa (lat. TÜBA), corno ricavato da una conchiglia ed usato dai pastori‘ oder neap. rafaniélla ,ravanelli‘ (Avolio 1995: 8, vgl. auch Rohlfs 1971: 41). Im Bereich der Morphologie wird unter anderem angenommen, dass den kampanischen Perfektformen der 2. und 3. Konjugation (facèttə ,fece', rurmèttə ,dormì etc.) das oskisch-umbrische Perfekt auf -tt- zugrunde liegt: osk. dadíkatted (lat. DǏCĀVIT), prúfatted (lat. PRŎBĀVIT) etc. (Avolio 1995: 10). Zur sprachlichen und kulturellen Stellung des Samnitischen zwischen dem 6. und dem 4. Jh. v. Chr. vgl. Prosdocimi (1981).

${ }^{66}$ Als Zeitpunkt der Eroberung von Capua wird häufig das Jahr 445 v. Chr. angegeben. Nach Salmon handelt es sich dabei jedoch um eine Fehlinterpretation eines Passus bei Diodoros, der hier lediglich beschreibt ,,che nel 445 i Campani si affermarono come nazione separata e distinta (a Capua, o nelle vicinanze, a giudicare dal loro nome)“ (Salmon 1985: 39).

${ }^{67}$ Der Terminus Cilento (lat. Cis-Alentum ,diesseits des (Flusses) Alento') bezeichnete ursprünglich nur das Gebiet um Agropoli und Castellabate, das im Besitz der Abtei von Cava dei Tirreni war und später aufgrund seiner strategisch vorteilhaften Position von Byzanz und den Langobarden umkämpft und mehrmals (821 und 882 n. Chr.) von den Sarazenen besetzt wurde. Heute werden mit dem historisch-geographischen Terminus meist die Gebirgsregionen zwischen der Ebene des Sele und dem Golf von Policastro bezeichnet (vgl. Ruocco 1976: 203).
} 
von Elea. Die griechische Kultur blieb in den eroberten Gebieten jedoch bestehen und existierte fortan neben der lukanischen. ${ }^{68}$

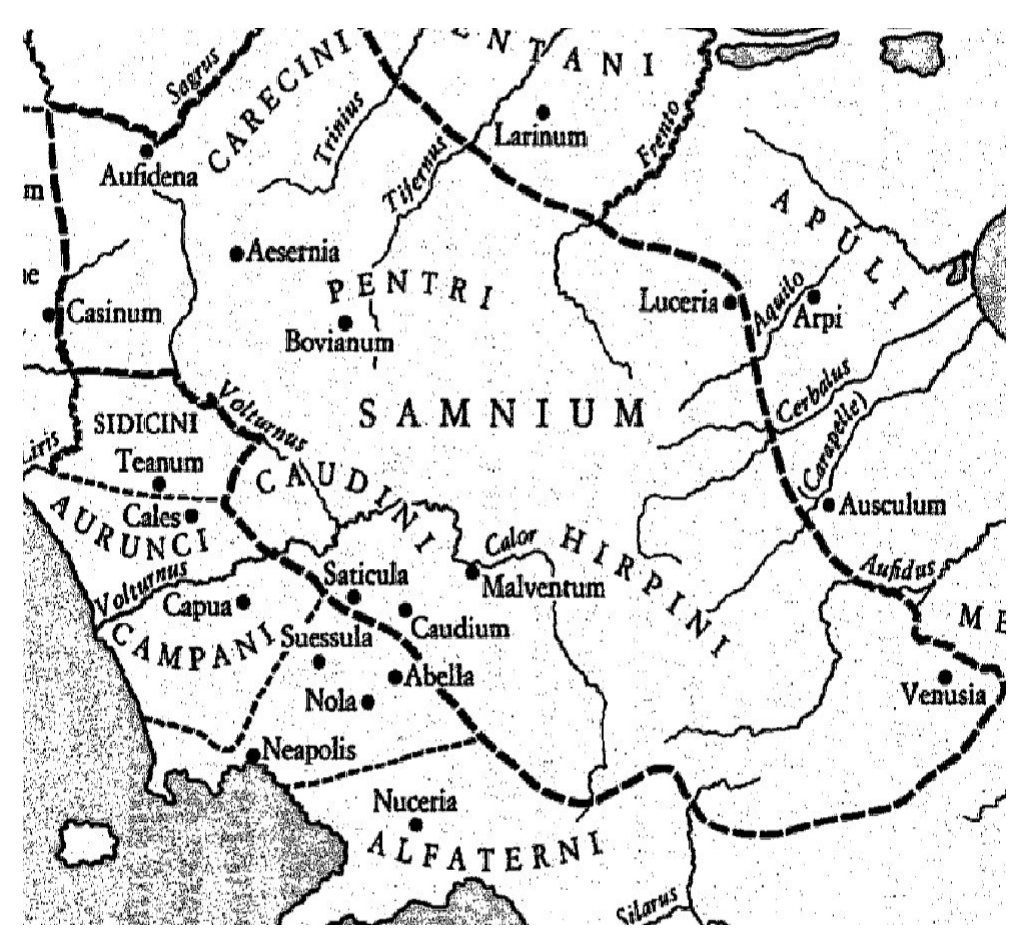

Karte 4. Das Samnium um 350 v. Chr (Salmon 1985: 27).

Etwa zur Zeit der samnitischen und lukanischen Eroberungen begann die Expansion des römischen Reiches im südlichen Teil der Apenninen-Halbinsel. Als die römischen Truppen die Campania erreichten, kam es - begünstigt durch das Hilfeersuchen der gegen die samnitische Besetzung rebellierenden Städte Capua und Teano an das römische Reich - 343 v. Chr. zum ersten Samnitenkrieg (bis 341 v. Chr.), dem zwei weitere (327 bis 304 v. Chr. und 298 bis 290 v. Chr.) folgten und der mit der Vertreibung der Samniten aus dem Gebiet der römischen Campania $^{69}$ endete. Im Rahmen der administrativen Neuordnung des nun erweiterten Imperium Romanum wurde das samnitische Siedlungsgebiet zerschlagen: Die römische Region IV (Samnium) umfasste den Norden des ursprünglichen Samnium, d.h. die Siedlungsgebiete der Careciner und der Pentrer, während das Siedlungsgebiet der Hirpiner der Region II (Apulia et Calabria) zugeteilt und das Siedlungsgebiet der Caudiner Teil der Region I (Latium et Campania) wurde.

Die innerhalb der Campania (insbesondere im vorrömischen Samnium) bereits vorhandene Infrastruktur wurde zu einem Teil des zu militärischen und wirtschaftlichen Zwecken genutzten römischen Straßennetzes umgebaut und erweitert. Von der Via Appia, die Rom mit der Stadt Brindisium (heute Brindisi) verband und von Westen nach Osten durch die Campania verlief (s. Karte 5), zweigte in Capua die Via Popilia ab (auch Via Annia, s. Karte 6) ab, die von dort parallel zur tyrrhenischen Küste durch die Region Kalabrien bis nach Reggio (lat.

\footnotetext{
${ }^{68}$ Die Besetzer profitierten dabei von der hochentwickelten griechischen Kultur: Das (Oskisch-)Lukanische wurde unter anderem mittels des griechischen Alphabets verschriftlicht (vgl. Avolio 1995: 5).

${ }^{69}$ Der Terminus Campania bezeichnete zu römischer Zeit die Ebene zwischen dem Massiv des Roccamonfia, dem Subappennino campano und dem Vesuv. Aufgrund der hohen Fruchtbarkeit des Bodens, der Milde des Klimas und der üppigen Vegetation trug die Campania bei den klassischen Autoren den Beinamen felix. Über die Via Popilia und die Via Appia (s.u.) belieferte sie das römische Reich mit Produkten aus dem Fischfang, dem Obst- und Gemüseanbau sowie der Ölgewinnung (vgl. Rohlfs 1933: 257).
} 
Reghium) führte (daher auch Via Capua-Reghium). Unter Kaiser Traian wurde mit der Via Traiana eine zweite Verbindung zwischen Rom und Brindisi eingerichtet, die in Benevento (lat. Beneventum $)^{70}$ von der Via Appia abzweigte (s. Karte 5), sodass schließlich drei der wichtigsten Viae Romanae durch die Campania verliefen und diese als infrastruktureller Knotenpunkt fungierte.

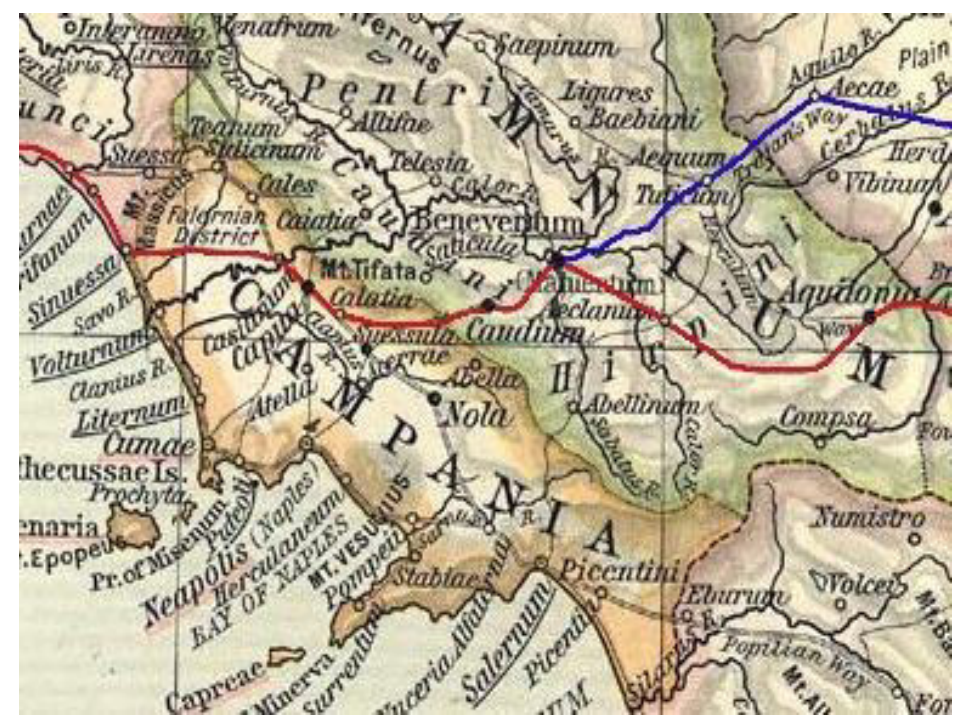

Karte 5. Verlauf der Via Appia (rot) und der Via Traiana (blau) im Gebiet der heutigen Campania (Ausschnitt aus Shepherd (1923: 30-31): „Reference Map of Ancient Italy. Southern Part“).

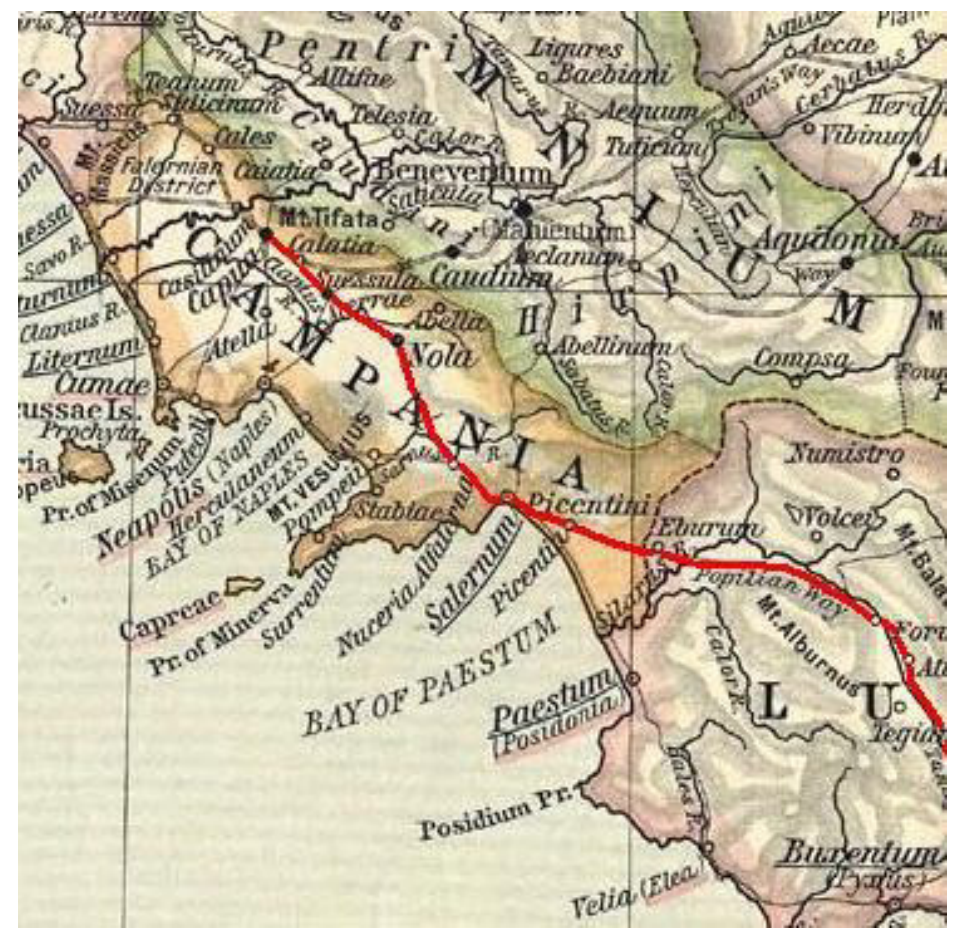

Karte 6. Verlauf der Via Popilia im Gebiet der heutigen Campania (Ausschnitt aus Shepherd (1923: 3031): „Reference Map of Ancient Italy. Southern Part“).

\footnotetext{
${ }^{70}$ Das ehemalige samnitische Zentrum, dessen (latinisierter) Name Mal(e)ventum lautete, war nach der Eroberung durch das römische Reich (275 v. Chr.) römische Kolonie geworden und trug ab 268 v. Chr. den Namen Beneventum (vgl. Galasso 2005: 73).
} 
Nach dem Zusammenbruch des römischen Reiches wurde Kampanien 493 n. Chr. von den Ostgoten erobert, die jedoch den Krieg um die Vorherrschaft im Jahr 553 gegen Byzanz verloren. Im Jahr 570 besetzten die Langobarden, die zuvor schon weite Gebiete Nord- und Mittelitaliens unter ihre Herrschaft gebracht hatten, das Samnium und eroberten von dort aus Kampanien, Lukanien sowie große Teile Apuliens (bis auf das Salento) und Kalabriens. ${ }^{71}$ In den folgenden Jahrhunderten bestimmten die politische Zweiteilung in einen griechischen (zum Exarchat von Italien gehörigen) und einen langobardischen Herrschaftsbereich (Ducato di Benevento, s. Karte 7) und die damit einhergehenden politischen Spannungen und militärischen Auseinandersetzungen die Geschichte Süditaliens und damit auch Kampaniens. ${ }^{72}$ Während das kampanische Inland mit Benevento als Zentrum des Ducato und auch die südlichen Küstengebiete bis einschließlich Salerno im Norden unter langobardischer Herrschaft waren, standen die griechischen Gründungen am Golf von Neapel und am Golf von Salerno - auch wenn sie sich bereits Mitte des 9. Jahrhunderts zu mehr oder weniger autonomen Ducati (Ducato di Gaeta, Ducato di Napoli ${ }^{73}$, Ducato di Amalfi, Ducato di Sorrento) entwickelt hatten - weiterhin in politischer Verbindung mit dem byzantinischen Reich und sicherten sich durch enge maritime Handelsbeziehungen zu Byzanz wirtschaftliches Wachstum. Das langobardische Siedlungsgebiet war dagegen in erster Linie durch Agrarwirtschaft und kleinere Siedlungs- und Handelszentren gekennzeichnet. ${ }^{74}$ Die somit nicht nur politisch, sondern auch ökonomisch motivierten zahlreichen Versuche der Eroberung Neapels (816-836) blieben vergeblich. ${ }^{75}$

\footnotetext{
${ }^{71}$ Mit dem Ducato di Spoleto, das Teile der Abruzzen, der Marken, Latiums und Umbriens umfasste, bildete das Ducato di Benevento die sog. Langobardia Minor. Die Langobardia Maior war hingegen das Siedlungsgebiet der Langobarden in Norditalien (mit Hauptstadt Pavia). Zur Geschichte der Langobardia Minor vgl. Gay (1904), Cilento (1966) und Peduto (2004).

${ }^{72}$ Parlangèli (1960) betont die Bedeutung der politisch-administrativen Opposition zwischen langobardischen und griechischen Gebieten für die Entstehung des sprachlichen Profils des Meridione und weiterer Teile Italiens: ,[L]à dove si formò un confine politico, amministrativo e militare fra territori langobardi e territori bizantini, là si formò anche un importante confine linguistico“ (Parlangèli 1960: 55). Insbesondere im Salento stellt er eine „straordinaria corrispondenza fra evoluzione linguistica e storia politico-amministrativa“ (ebd.: 52) fest. Die Bedeutung der langobardischen Besetzung großer Teile Italiens und der dadurch entstandenen Zweiteilung der Apenninenhalbinsel in einen langobardischen und einen griechischen Teil für die Entwicklung des sprachlichen Profils betont bereits Schürr (1933: 227) im Hinblick auf die Dialektgrenze zwischen dem Romagnolischen und dem Toskanischen.

${ }^{73}$ Neapel hatte bereits 661 den Status eines Ducato vom byzantinischen Kaiser Konstans II. erhalten.

${ }^{74}$ Auch Spuren der langobardischen Besiedelung finden sich in der Campania in vielen Toponymen (Sabatini 1963: 146ff.): Casa Cafaggio (BN), Gaio (villaggio, SA) < langob. *gahagi, terreno (bosco, pascolo o altro) riservato; bandita'; Fara (contrada in Ailano, BN), Grotta di Farinnola (bei Sala Consilina, SA) < langob. fara ,piccolo nucleo demografico e fondiario‘, Gaudi (villaggio, CE), Gaudello (frazione von Acerra, NA), Monte Gaudello (BN), Gaudo (villaggio, SA), Galdo (fraz. von Pòllica, SA) u.a. < langob. *wald , bosco', Sala Consilina (SA), Sala (fraz. von Caserta, CE), Sala (villaggio, BN), La Sala (fraz. von Montoro, AV), Sala (fraz. von Serino, AV), Sala (fraz. von Corbara, SA) etc. < langob. sala ,casa per la residenza padronale', dann ,casa di campagna', Atripalda (AV) < langob. Tripald (männl. Eigenname), Pontelandolfo (BN) < langob. Landulf (männl. Eigenname, De Blasi 2006: 16). Avolio (1995: 24) führt das Element guardia in Guardia Sanframondi (BN) und Guardia dei Lombardi (AV) auf langob. ward, got. wardja (< germ. wardon, waron ,prestare attenzione“) zurück. Sein Verweis auf die „Wichtigkeit“ der Spezifikation dei Lombardi lässt vermuten, dass er den Terminus Lombardi auf Longobardi zurückführt. Beide Toponyme finden sich bei Sabatini (1963: 165) nicht unter denjenigen, die langob. ward weiterführen. Seiner Position zufolge verweist die Form Lombardi nicht auf die Longobardi, sondern auf die lombardischen Siedler, die aus dem Norden Italiens mit den Normannen nach Süden kamen (s.u.). Damit ist für ihn wohl auch die Rückführung von guardia auf langob. ward ausgeschlossen. Allerdings räumt er ein, dass nicht auszuschließen ist, dass ,, i n q u a $1 \mathrm{c}$ h e c a s o la forma allogena lombardo si sia sovrapposta nel Sud alla forma originaria longobardo" (ebd.: 160).

${ }^{75}$ Zur Verteidigung gegen die langobardischen Eroberungszüge nahm Neapel (wie auch Gaeta) die militärische Hilfe der Sarazenen in Anspruch, die insbesondere im 9. Jahrhundert immer wieder Teile Süditaliens besetzten und erst 915 (unter Mithilfe Neapels) endgültig aus der Campania (Gebiete um den Garigliano und Agropoli) vertrieben werden konnten (Gay 1904: 239).
} 
Nach einem Bürgerkrieg kam es im Jahr 849 zur Teilung des Ducato di Benevento in das Principato di Benevento (mit Haupstadt Benevento), das das Gebiet im Nordosten und das Principato di Salerno (mit Hauptstadt Salerno), das die Gebiete im Süden und Westen umfasste (s. Karte 8). Im Jahr 860 kam es zur Abspaltung des Contea di Capua (ab 900 als Principato di Capua mit dem Principato di Benevento in Personalunion regiert), dessen Zentrum das nach seiner Zerstörung durch die Sarazenen (841) am Ufer des Volturno auf den Ruinen Casilinums im Jahr 856 neu erbaute Capua wurde.

$\mathrm{Zu}$ einer weiteren militärischen und politischen Schwächung der zeitweilig wiedervereinten langobardischen Territorien kam es im 9. und 10. Jahrhundert durch den fortdauernden Krieg mit Byzanz, dem es gelang, große Teile Apuliens ${ }^{76}$, Lukaniens (bis zum südlichen Cilento) und Kalabriens zurückzuerobern und - neben anderen Städten in der Campania - im Jahr 891 sogar Benevento zu besetzen, das 892 bis 894 Hauptstadt des griechischen Themas Langobardia war. ${ }^{77}$

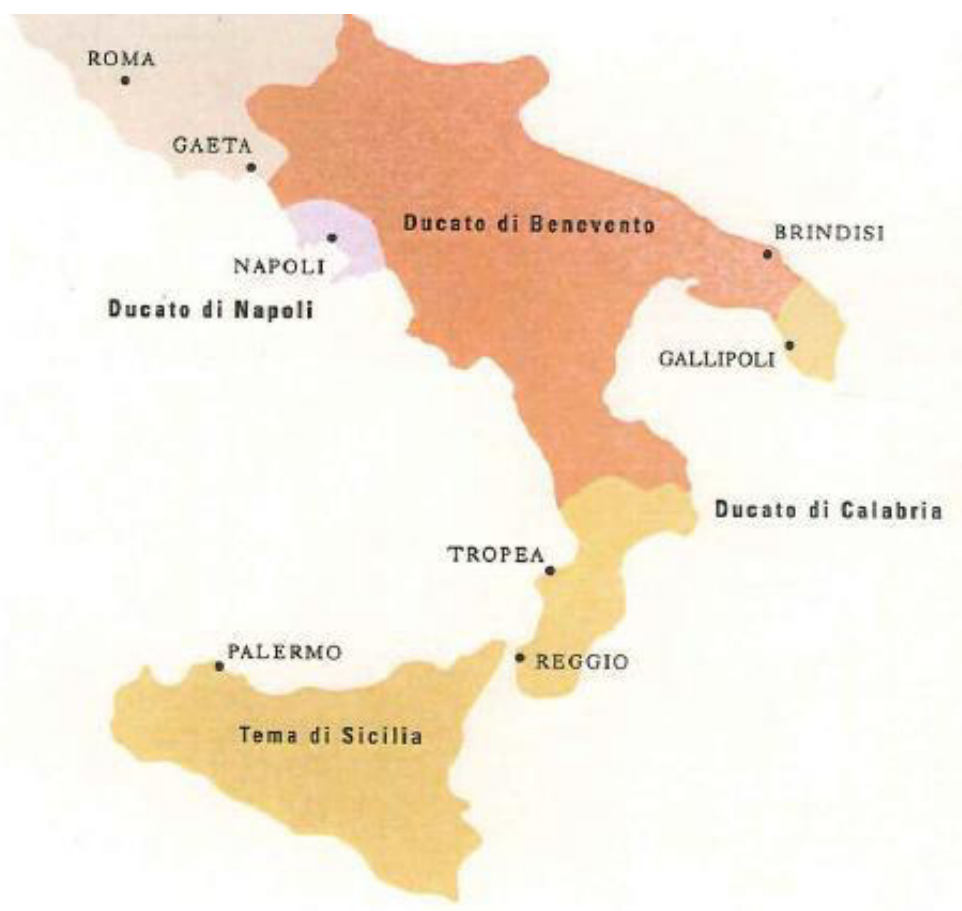

Karte 7. Das Ducato di Benevento in seiner maximalen Ausdehnung um 750 n. Chr (Cilento 2005: 49).

\footnotetext{
${ }^{76}$ Besonders umstritten waren einerseits immer wieder die strategisch und wirtschaftlich bedeutenden adriatischen Hafenstädte (insbesondere Siponto) und andererseits - vor allem im 10. Jahrhundert - die byzantinischlangobardische Grenzlinie, die von Bovino über Ascoli Satriano, Acerenza und Tricarico bis zur Nordgrenze des Themas Calabria (s.u.) führte. Bovino wurde unter anderem 908 und 969/970 umkämpft und wechselte mehrmals die politische Zugehörigkeit (vgl. Falkenhausen 1967: 31).

${ }^{77}$ Die Themata (Thema Langobardia, Thema Calabria, Thema Sikelia (Sizilien)) waren die Verwaltungseinheiten, in die der byzantinische Herrschaftsbereich in Süditalien Ende des 9. Jahrhunderts eingeteilt worden war. Zur Geschichte der byzantinischen Herrschaft in Süditalien im Früh- und Hochmittelalter vgl. Falkenhausen (1967) und Gay (1904).
} 


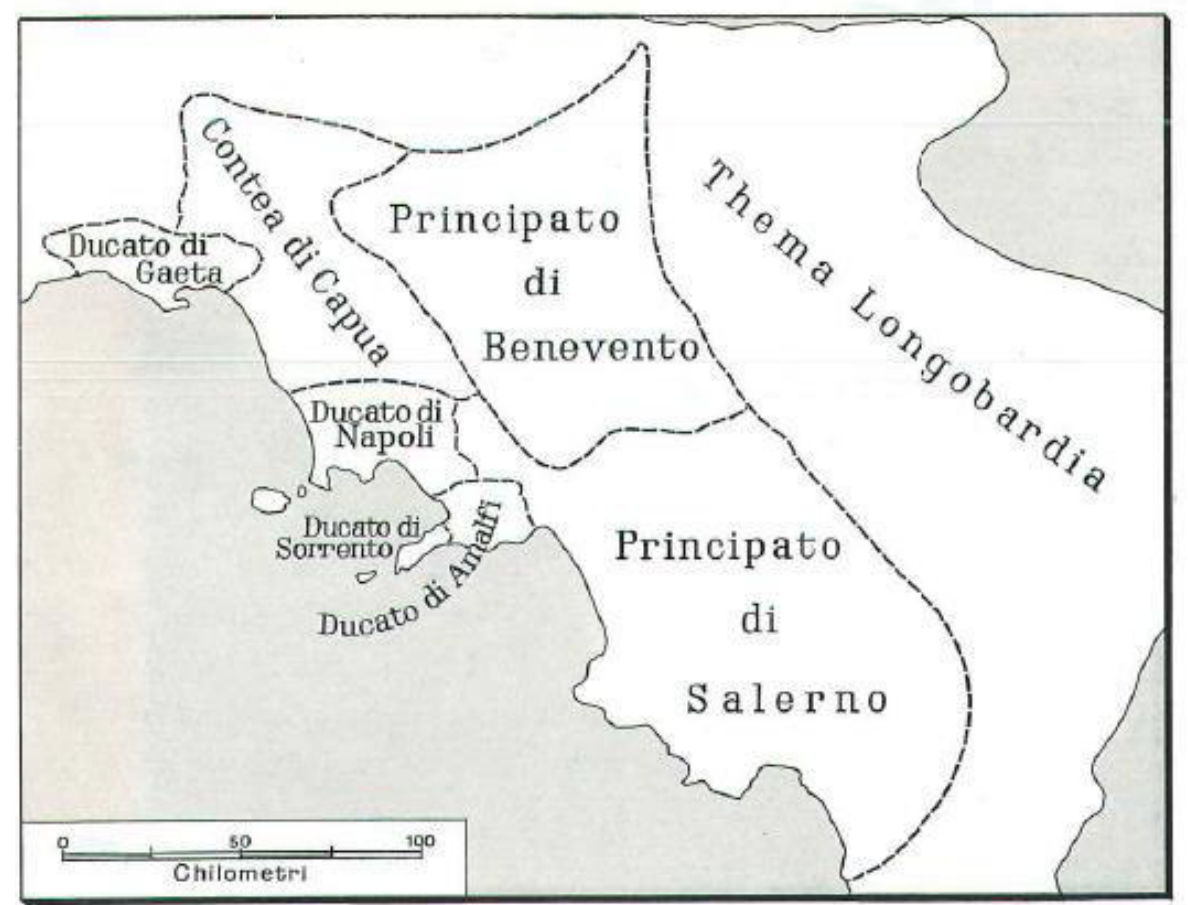

Karte 8. Politische Gliederung der Campania im 10. Jahrhundert (Ruocco 1976: 10).

\subsubsection{Die Campania vom Mittelalter bis zur Neuzeit}

Die Eroberung Süditaliens und Siziliens durch die Normannen, die 1026 Aversa, 1062 Capua, 1077 Salerno und 1140 Neapel unterwarfen, brachte das Ende der langobardischen und der byzantinischen Herrschaft in Süditalien (sowie der Herrschaft der Sarazenen auf Sizilien, die Byzanz dort verdrängt hatten). Die Besetzung Kampaniens durch die Normannen dauerte etwa 150 Jahre und brachte insbesondere Salerno, das nach seiner Eroberung Sitz des Hofes wurde, wirtschaftlichen und kulturellen Aufschwung.

1189 fiel die Campania an das Haus Hohenstaufen unter Heinrich VI, der sie mit großen Teilen Süditaliens und Sizilien zum Regno di Sicilia zusammenschloss, dessen Hauptstadt Palermo war: „Cominciò allora un periodo di gravi torbidi nell'Italia meridionale, e a Napoli in particolare, per l'odio esploso contro gli Svevi, perchè (sic) vi si erano insediati con prepotenza e vi facevano gravare un regime di oppressione fiscale“ (Ruocco 1976: 48). Die Rebellion endete erst im Jahre 1266 mit der Machtübernahme durch Karl I aus dem französischen Haus Anjou, der Neapel zur Hauptstadt des Reiches machte und damit dessen Blütezeit einleitete (s. Kap. 3.2.3). 1282 kam es nach einem Aufstand in Palermo (Vespri siciliani) und dem Eingreifen von Peter III von Aragón zur Abspaltung Siziliens vom kontinentalen Teil des Reiches.

Unter Karl II wurden im Jahr 1297 auf den Gebieten der ehemaligen langobardischen Principati (vgl. 3.2.1) zwei neue administrative Einheiten geschaffen: das Principatus Citra Serras Montorii (,Principato Citeriore“) und das Principatus Ultra Serras Montorii („Principato Ulteriore“", s. Karte 9). Mit den Gebieten Terra di Lavoro und Neapel bildeten diese fortan die politisch-administrative Gliederung des Regno di Napoli auf dem Gebiet der heutigen Campania, die - bis auf kleinere Änderungen in der Zeit der französischen Herrschaft Anfang des 19. Jahrhunderts - bis zur italienischen Einigung im Jahr 1860 bestehen blieb. 


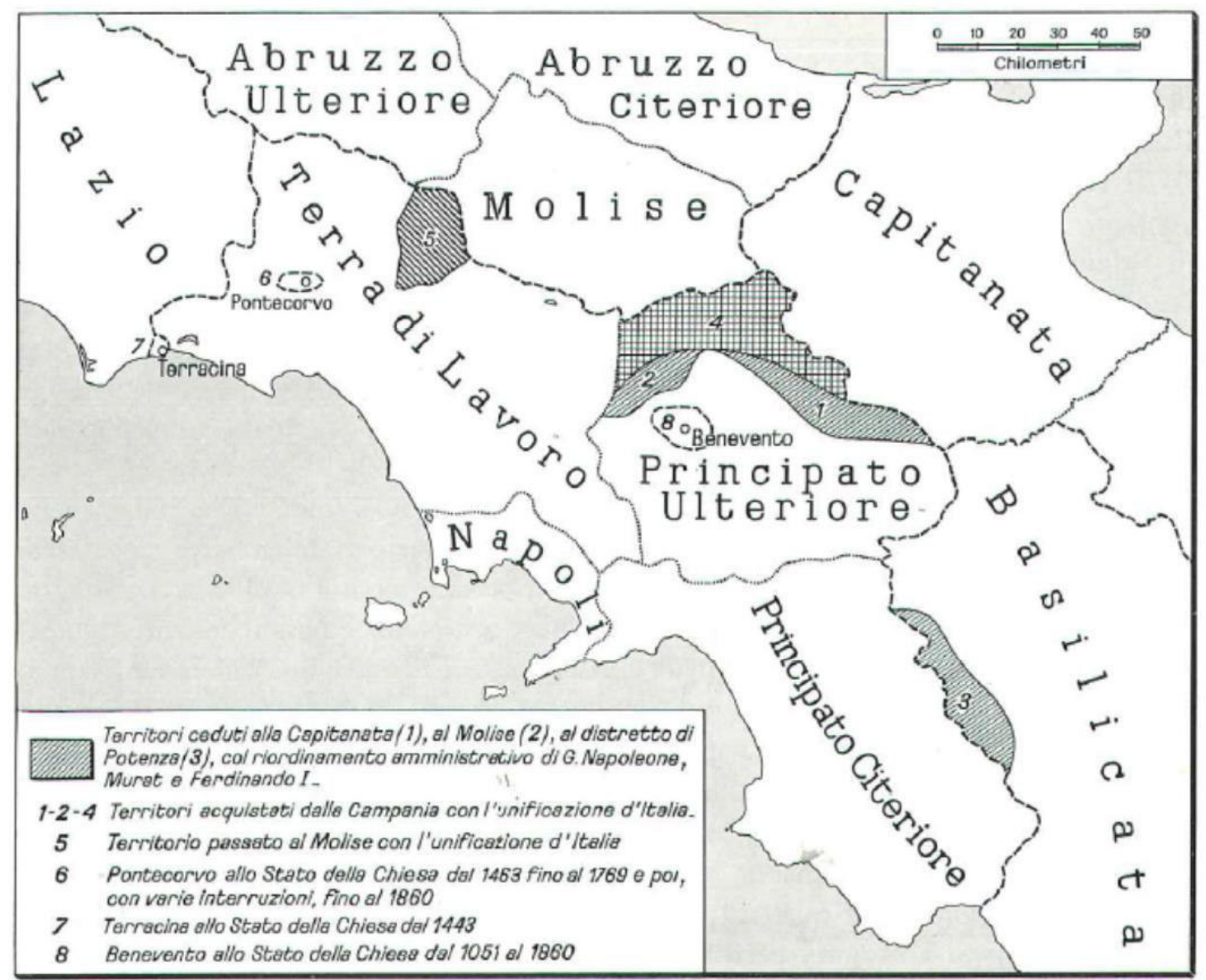

Karte 9. Politisch-administrative Gliederung Süditaliens im Regno di Napoli (aus Ruocco 1976: 9).

Die angevinische Herrschaft endete 1442 mit der Eroberung des Königreichs Neapel unter König Alfons V von Aragón, der damit das Regno di Napoli und das Regno di Sicilia politisch wieder vereinte. Nach einer kurzen Besetzung durch den französischen König Ludwig XII, der als Nachfahre des Hauses Anjou Ansprüche auf das Königreich erhob und von Gonzalo Fernandéz de Cordoba 1503 geschlagen wurde, verlor das Königreich Neapel seine Unabhängigkeit. Ferdinand II von Aragón erklärte es zu einem Gebiet der spanischen Krone, unter der es (als Regno di Sicilia citeriore) zusammen mit dem Königreich Sizilien (Regno di Sicilia ulteriore) durch den vom spanischen Thron eingesetzten Viceré regiert wurde.

Die lange Epoche des Viceregno spagnolo endete erst mit dem spanischen Erbfolgekrieg, in dessen Zuge das Königreich Neapel 1713 an die Habsburger Monarchie fiel, die es jedoch bereits 1734 wieder an Karl III aus dem Hause der spanischen Bourbonen verlor. 1799 kam es unter dem Einfluss der Französischen Revolution in Neapel zu einem Volksaufstand, in dessen Zuge die Repubblica Partenopea ausgerufen wurde. 1806 wurde das Königreich Neapel Teil des napoleonischen Reiches (zunächst unter Joseph Bonaparte, ab 1808 unter dessen Schwager Joachim Murat), bis es mit dem Wiener Kongress 1815 an Spanien zurückfiel. Im Jahr 1816 vereinte Ferdinand I das Königreich Neapel (Sicilia Citeriore) mit dem Königreich Sizilien (Sicilia Ulteriore) zum Regno delle Due Sicilie. Das Volk zeigte sich jedoch bald erneut unzufrieden mit der bourbonischen Herrschaft: 1820 kam es in Nola und 1848 - ähnlich wie im übrigen Europa - in verschiedenen Teilen des Reiches zu Aufständen der Arbeiter- und Bauernklasse. 1860 unterstützte das Volk Garibaldi in seinem Marsch auf Rom, sodass dieser nach 
seinem Triumph in der Schlacht am Volturno (1.-2. Oktober 1860) zusammen mit Vittorio Emmanule II, König von Sardinien und Piemont, am 26. Oktober 1860 in Teano die Integration des Königreiches in das Regno d'Italia beschließen konnte.

Die administrative Strukturierung des Regno d'Italia war die Geburtsstunde der Regione (bzw. des Compartimento) di Campania. Diese beinhaltete die Provinzen Neapel, Caserta (mit einem Großteil des Gebietes der Terra di Lavoro), Avellino (mit einem Großteil des Principato Ulteriore), Salerno (mit dem Principato Citeriore und einem Teil des Principato Ulteriore) sowie die - unter Einbeziehung von Teilen der Terra di Lavoro, des Molise, des Principato Ulteriore, der Capitanata (Region Apulien) und der ehemals vatikanischen Gebiete um die Stadt Benevento - neu geschaffene Provinz Benevento. Die nächsten administrativen Veränderungen brachte die Verwaltungsreform des faschistischen Regimes am 2. Januar 1927. Diese beschloss die Auflösung der Provinz Caserta unter Abgabe des Gebietes nördlich des Garigliano an die Region Latium (Fondi und Gaeta gingen an die Provinz Rom, Sora, Pontecorvo und Cassino an die Provinz Frosinone) und des nordwestlichen Teils des Matese sowie des Gebietes um Cercemaggiore an die Region Molise (Provinz Campobasso). Die verbliebenen Gebiete wurden auf die Provinzen Neapel und Benevento aufgeteilt. Im Osten (Subappennino Sannita) musste die Campania Orsara und Accadia und später auch Anzano und Monteleone (1929) sowie Rocchetta Sant'Antonio (1939) an die Provinz Foggia (Region Apulien) abtreten. Die Isole Ponziane (vor Gaeta) wurden nach mehrfacher Revision 1937 endgültig der Region Latium angegliedert. 1945 wurde die Provinz Caserta restituiert und das nordwestliche Matese wieder in die Region Kampanien integriert, während das Gebiet nördlich des Garigliano Teil des Lazio blieb.

\subsubsection{Die Rolle Neapels und des Neapolitanischen}

Mit der angevinischen Herrschaft, die Neapel zur Hauptstadt des Regno di Napoli machte, begann dessen Aufstieg zum politischen, wirtschaftlichen und kulturellen Zentrum, der auch unter der aragonesischen Herrschaft und im Viceregno anhielt. ${ }^{78}$ Die Stadt entwickelte sich zum wichtigen Umschlagplatz für nationale und internationale Handelsbewegungen ${ }^{79}$ und erhielt zahlreiche wirtschaftliche und steuerliche Privilegien, was zu einem Wachstum des Wohlstands sowie zu einem steten demographischen Zustrom aus wirtschaftlich starken Bevölkerungsgruppen (Kaufleuten und Aristokraten) aus dem gesamten Gebiet des Reiches führte. ${ }^{80}$ Mit der Gründung der Universität im Jahr 1224 - die für fast 600 Jahre die einzige in ganz Süditalien blieb - entwickelte sich Neapel zum intellektuellen Zentrum des Meridione, das insbesondere im 14. Jahrhundert auch die kulturelle Elite Italiens anzog (u.a. Aufenthalte von Giovanni Boccaccio und Francesco Petrarca). Während der aragonesischen Herrschaft und im Viceregno war die Stadt zunächst ein wichtiges Zentrum der Renaissance und des Humanismus ${ }^{81}$ und später der italienischen (und europäischen) Aufklärung. ${ }^{82}$

\footnotetext{
${ }^{78} \mathrm{Zu}$ den folgenden Ausführungen vgl. Galasso (2003).

${ }^{79}$ Hierzu trug in wichtigem Maße die Verlegung der Residenz des Hofes nach Castel Nuovo unter Karl I bei, die eine Verlagerung des städtischen Schwerpunktes in die Küstenzonen bewirkte.

${ }^{80}$ In den Jahrzehnten nach der Ernennung zur Hauptstadt verdoppelte sich die Einwohnerzahl Neapels von 30.000 auf 60.000, stieg während der aragonesischen Herrschaft auf 100.000 (Anfang des 16. Jh.) und erreichte Ende des 16. Jahrhunderts 250.000. Mitte des 17. Jahrhunderts (im Vorfeld der Pest-Epidemie von 1656) war Neapel mit über 350.000 Einwohnern nach Paris die zweitgrößte Stadt Westeuropas (vgl. Galasso 2003: 126). ${ }^{81}$ Unter anderem wirkten hier die Philosophen Bernardino Telesio (1508/1509-1588), Giordano Bruno (15481600) und Tommaso Campanella (1568-1639).

82 Über die Grenzen Italiens hinaus bekannte Philosophen des Illuminismo waren unter anderem Antonio Genovesi (1712-1768), der 1754 in Neapel den europaweit ersten Lehrstuhl für Wirtschaftspolitik erhielt, Gaetano
} 
Neapel hat sich seiner Zeit als Hauptstadt des Regno immer über seine Funktion als „struttura statale e nazionale“ (Galasso 2003: 130) und die damit verbundene politisch-administrative und wirtschaftliche Bedeutung für den Mezzogiorno definiert und nie einen „spirito comunale“ (ebd.) entwickelt. Als kulturelles und intellektuelles Zentrum war die Stadt immer ein ,„centro di irradiazione“ der jeweiligen Schrift- und Literatursprache, d.h. zunächst des Lateinischen und dann des Italienischen (Florentinischen), welches nicht nur im schriftlichen Sprachgebrauch eine wichtige Stellung einnahm:

[N]ella capitale del Regno il riconoscimento del primato del toscano non restò un dato meramente dottrinale [...]: attraverso la pratica della vita forense [...], mentre altrove l'uso parlato dell'italiano veniva ritenuto una « affettazione volgare » [...] si costituì così una tradizione di uso non solo scritto ma anche parlato dell'italiano [...].

(De Mauro 1986: 304)

Das volgare napoletano wurde - abgesehen von seiner Verwendung in notariellen Dokumenten und öffentlichen Bekanntmachungen - fast ausschließlich in der mündlichen Kommunikation gebraucht. Eine Loyalität dem lokalen Dialekt gegenüber hat sich - vor dem Hintergrund der nicht vorhandenen städtischen Identität - historisch nicht entwickelt. ${ }^{83}$

Im Gegensatz zu Venedig, Genua oder Florenz war Neapel nie eine „città dominante“ (Galasso 2003: 130), sondern immer vor allem ein Ort der ethnischen und sozialen Synthese. Auf sprachlicher Ebene kam es dementsprechend nicht zu einer Verbreitung des Neapolitanischen in der geographischen Umgebung, sondern viel mehr zur Festigung bestimmter sprachlicher Gemeinsamkeiten, die sich im Laufe der Geschichte zwischen den verschiedenen Dialekten des Mezzogiorno herausgebildet hatten (De Blasi 2006: 71). Gegen eine ,Ausstrahlung، des Neapolitanischen in das geographische Umfeld und weitere Teile der Region wirkt(e) insbesondere eine durch den historischen kulturellen Bruch zwischen Küstenzone und Hinterland (vgl. Kap. 3.2) bedingte (reziproke) ,sensazione di distanza“ zwischen den Bewohnern der Stadt und jenen des Landesinneren, ,che non poteva non riguardare anche il modo di parlare (insieme con il modo di vivere e di pensare)“ (De Blasi/Fanciullo 2003: 628). Die nicht nur in weiter entfernten Teilen der Region, sondern insbesondere in der direkten Umgebung (besonders in Pozzuoli im Norden sowie in Torre Annunziata im Süden) noch heute beobachtbaren starken sprachlichen und insbesondere phonetischen Unterschiede zum Neapolitanischen ${ }^{84}$ zeigen, dass die ,homogenisierende“ Funktion der Hauptstadt auf sprachlicher Ebene auf eine ,parziale diffusione di un lessico comune“"(De Blasi/Fanciullo 2003: 628) beschränkt geblieben ist.

Filangieri (1752-1788, La scienza della legislazione (1780-1785)) und Ferdinando Galiani (Abbé Galiani, 17281787).

${ }^{83}$ Vor dem Hintergrund des literarischen Aufstiegs des volgare toscano in Florenz kam lediglich unter gebildeten Florentinern Interesse am volgare napoletano auf: „[I]n assenza di una classe sociale napoletana che ritenesse utile o vantaggioso identificarsi con il volgare del luogo [...] furono degli esponenti della compagine fiorentina a cogliere, prima degli stessi napoletani, le peculiarità del volgare locale“ (Bianchi/De Blasi/Librandi 2002: 635). In diesem Kontext ist der erste in einem volgare napoletano verfasste Prosatext, die Epistola napoletana (1339) von Giovanni Boccaccio, zu sehen, die viele auch im heutigen Neapolitanischen noch anzutreffende phonetische, morphologische und syntaktische Charakteristika sowie in der mittelalterlichen neapolitanischen Umgangssprache gebräuchliche Lexeme enthält (vgl. De Blasi 2012: 27).

${ }^{84}$ Die Dialekte im direkten Umfeld der Stadt, die nach der Theorie der Diffusionszentren (vgl. Kap. 4.4) über die Jahrhunderte stark von der Phonetik/Phonologie des Neapolitanischen beeinflusst worden und dieser somit sehr ähnlich sein müssten, zeigen phonetische Merkmale (etwa die Palatalisierung von [a] zu [ $\varepsilon$ ] oder die Kakuminalisierung von [1l] zu [dd] bzw. weiter zu [r]), die nie Teil des Neapolitanischen waren: ,Si tratta sempre di processi innovativi, mentre Napoli assume la funzione di un freno o addirittura di un blocco a tali forze innovative“" (Radtke 1998b: 567). 
Als Neapel mit der Integration des Regno in den italienischen Nationalstaat im Jahre 1860 seine politische Funktion als Hauptstadt verlor und sich angesichts des Wachstums anderer Zentren im Mezzogiorno (z.B. Bari) auch seine zentripetale Wirkung verringerte, musste die Stadt ihre Stellung im Mezzogiorno neu definieren:

\begin{abstract}
Allora Napoli si sarebbe trovata di fronte al problema, che non ha ancora risolto, di non essere più vittima della sua stessa storia; di recuperare una sua identità più congeniale $\mathrm{e}$ adeguata alle sue possibilità; di trasformarsi da capitale privilegiata, ma congestionata [...], in grande metropoli moderna con più proprie e meglio fondate ragioni di vita (Galasso 2003: 130).
\end{abstract}

In diesem Zuge entwickelte sich das Neapolitanische zum Symbol einer (neuen) städtischen Identität, der napoletanità (vgl. Matrisciano i. Vorb., Signorelli 2009). Ende des 19. und im Laufe des 20. Jahrhunderts gelangte es insbesondere in durch Mündlichkeit geprägten kulturellen Bereichen (Musik, Theater, Film) ${ }^{85}$ und durch die Verbreitung über moderne Massenmedien (Radio, Fernsehen) zu nationaler und internationaler Bekanntheit.

\title{
3.3 (Geo-)Linguistisches Profil
}

\subsubsection{Repertoire und Sprachgebrauch}

Der Mitte bis Ende des 20. Jahrhunderts weit verbreiteten Auffassung zur Entwicklung des Dialektgebrauchs in Italien (vgl. Kap. 2.2) zufolge haben die Veränderungen im Repertoire der Sprecher sowie die Verbreitung des Italienischen in vielen Domänen der (formellen und informellen) Kommunikation zu einer Verdrängung der Dialekte aus Repertoire und Sprachgebrauch geführt, die häufig - nicht nur im laienlinguistischen Diskurs - mit dem Schlagwort des „Dialektsterbens“ (morte dei dialetti) belegt wird: „Il dialetto muore: a Procida come ovunque“ (Parascandola 1976: XVII). Dass - wie bereits Radtke (1988: 659) bemerkte - für die Campania „die extreme Position des Dialektverfalls kaum aufrechterhalten werden kann“, haben in den vergangenen Jahren soziolinguistische Untersuchungen bestätigt, die ein weitaus differenzierteres Bild der Stellung des Dialekts im sprachlichen Repertoire und im Sprachgebrauch der kampanischen Bevölkerung zeichnen.

Den durch das IStat erhobenen Daten zum Sprachgebrauch innerhalb der Familie zufolge ist der ausschließliche Gebrauch des Dialekts in der familiären Kommunikation zwischen 1988 und 2000 zwar deutlich (um ca. 12\%) zurückgegangen (Berruto 2006: 102). ${ }^{86}$ Demgegenüber manifestiert sich jedoch keineswegs eine Zunahme des ausschließlichen Gebrauchs des Italienischen - dieser bleibt in der Campania stabil bei ca. 22\%. Es wächst vielmehr die alternative Verwendung von Dialekt und Italienisch (Zunahme von 34,4\% auf 46,7\%). Auch Bianchi/Maturi (2006) zeigen, dass die Verbreitung des Italienischen zwar zu einer Reduktion des

\footnotetext{
${ }^{85}$ Das teatro napoletano wurde in dieser Zeit insbesondere durch Eduardo De Filippo (1900-1984), Raffaele Viviani (1888-1950) und Eduardo Scarpetta (1853-1925), die italienische Filmkomödie vor allem von Totò (Antonio de Curtis Gagliardi Ducas Comneno di Bisanzio, 1898-1967) geprägt. Im Bereich der Musik gelangte die canzone napoletana zu internationaler Bekanntheit.

${ }^{86}$ Mit 30,5\% ist der ausschließliche Gebrauch des Dialekts im familiären Umfeld in der Campania aber auch nach dieser Entwicklung noch deutlich höher als in anderen, sowohl nördlichen (Piemont 11,4\%, Lombardei $10,7 \%$ ) als auch südlichen Regionen (Apulien 17,7\%, ebd.).
} 
Dialektgebrauchs, nicht jedoch zu einer kompletten Aufgabe des Dialektes geführt hat. Sie unterscheiden vier Entwicklungstendenzen (vgl. ebd.: 2):

1) Allgemeine Reduktion des Dialektgebrauchs in sozialen Schichten mit mittlerem bis hohem Bildungsgrad in der Stadtbevölkerung von Neapel und anderer größerer regionaler Zentren zugunsten einer Verbreitung eines italiano di uso medio, bei gleichzeitiger Bewahrung der passiven Dialektkompetenz.

2) Gefestigte Diglossie-Situation in kleineren Stadtzentren mit dem Dialekt als low variety und der italienischen Varietät als high variety, bei gleichzeitiger Bewahrung sowohl der passiven als auch der aktiven Dialektkompetenz in allen sozialen Schichten.

3) Diffuse Dilalie in städtischen Bevölkerungsschichten mit mittlerem bis niedrigem Bildungsgrad, bei aktiver (muttersprachlicher) Dialektkompetenz.

4) Fast ausschließliche Verwendung des Dialekts in der älteren Generation und in sozialen Schichten mit geringer Schulbildung.

De Blasi (2006) stellt in einer Studie zum Sprachgebrauch in Neapel fest, dass der Dialekt von $70 \%$ aller Befragten gewohnheitsmäßig verwendet wird. In $30 \%$ aller Familien ist das Neapolitanische dabei Muttersprache, ,mentre tutti gli altri che non apprendono il dialetto hanno continue occasioni, nelle normali interazioni comunicative della vita quotidiana, di entrare a stretto contatto con esso e anche di apprenderlo come seconda lingua (nei gruppi giovanili, sul lavoro ecc.)" (De Blasi 2006: 106). Auch in den übrigen Teilen der Campania werden die lokalen Dialekte parallel zum Italienischen (italiano regionale) gebraucht. Die Sprachwahl ist hier vor allem vom außersprachlichen Kontext abhängig. Der Eindruck eines Rückgangs des Dialektgebrauchs entsteht nach De Blasi (ebd.) vermutlich dadurch, dass die Betrachtung auf bestimmte soziokulturelle oder kommunikative Kontexte beschränkt wird, in denen der Gebrauch des Italienischen überwiegt.

Insgesamt zeigt sich eine komplexe und vielschichte Situation, „nella quale italiano e dialetti si contendono lo spazio degli usi parlati informali con modalità molto differenziate in funzione di diverse dimensioni sociolinguistiche" (Bianchi/Maturi 2006: 1). Die Entwicklung des sprachlichen Profils der Campania wird also nicht vom ,Dialektsterben', sondern viel mehr vom Ausbau der „sfera media“ zwischen Dialekt und Standarditalienisch geprägt (vgl. Radtke 1998a).

\subsubsection{Zur kampanischen Dialektologie}

In der italienischen Dialektologie sind die Dialekte der Campania - auch im Vergleich zu anderen süditalienischen Dialekten wie etwa den sizilianischen - weitestgehend vernachlässigt worden (vgl. Radtke 1993: 444). Während sich in Norditalien bereits seit dem 19. Jahrhundert (G.I. Ascoli) an den Lehrstühlen für Glottologie (Turin, Padua u.a.) eine wissenschaftliche Dialektologie herausgebildet hatte, konzentrierte man sich an der Università di Napoli auf das Neapolitanische als Literatursprache: ${ }^{87}$ „Di creare un insegnamento di «Dialettologia» non se ne parlava proprio: si sarebbero opposti sia il docente di «Glottologia» che quello di «Filosofia di Linguaggio»" (Vàrvaro 2005: 177). Die Beschäftigung mit den (lokalen) Dialekten blieb in der Campania lange Zeit Sache interessierter Laien und umfasste insbesondere die Produktion von Dialektwörterbüchern und teilweise auch Dialektgrammatiken, sodass „le conoscenze

\footnotetext{
${ }^{87}$ Eine Ausnahme bildet Sornicola (1977).
} 
acquisite e lo stato delle ricerche raggiunto per il napoletano non sono assolutamente comparabili con quelle relative alle restanti varietà locali“ (Radtke 1997a: 15).

Die heute verfügbaren wissenschaftlich fundierten Beiträge zu den kampanischen Dialekten sind in ihrer Anzahl dementsprechend überschaubar. Als einschlägige Beiträge zu den Dialekten der Irpinia sind De Salvio (1913) und Marano Festa (1928), zu den Dialekten des Cilento Rohlfs (1937) und Ondis (1996 [1932]) und zu den Dialekten des Sannio Beneventano Iannace (1983) und Maturi (2002) zu nennen. ${ }^{88}$ Zum (gesprochenen) Neapolitanischen vgl. u.a. Vaughan (1910, 1915), Iannucci (1948-1950) und in neuerer Zeit Andalò (1991), Bafile (1997) und Del Puente (1995, 1998). Die einschlägige Darstellung zum Ischitanischen stammt von Freund (1933). Wissenschaftliche (Überblicks-)Darstellungen des gesamten kampanischen Dialektgebietes finden sich u.a. in Devoto/Giacomelli (1972), Radtke (1988, 1997a), Sornicola (1997) und De Blasi (2006). Seit Ende des 20. Jahrhunderts stehen - im Rahmen einer soziolinguistisch geprägten Dialektologie - an der Universität Neapel verstärkt die Dialekte im engeren geographischen Umkreis der Metropole (area flegrea mit Monte di Pròcida, Bacoli und Pozzuoli) sowie jene der Inseln Ischia und Pròcida im Zentrum des Forschungsinteresses (vgl. u.a. Como 2007, Como/Milano 2000, Milano 2002a, b, Sornicola 2001). ${ }^{89}$

\subsubsection{Das kampanische Dialektgebiet}

Die kampanischen Dialekte gehören zur Gruppe der dialetti meridionali intermedi, die auch die Dialekte der süditalienischen Regionen Abruzzo und Molise, des südlichen Latium, Apuliens, der Basilicata und des nördlichen Kalabrien umfasst (vgl. Pellegrini 1977). Da die Dialekte Kampaniens einen Großteil ihrer sprachlichen Charakteristika mit den übrigen süditalienischen Dialekten und insbesondere den Dialekten des (südlichen) Latium, des Molise, (West-) Apuliens und der (nördlichen) Basilicata teilen (,panmeridionale Merkmale'), gestaltet sich die Abgrenzung der kampanischen Dialekte bzw. des kampanischen Dialektgebietes von den übrigen süditalienischen Dialekten bzw. Dialektgebieten in der (qualitativen) Sprachgeographie jedoch schwierig.

Westlich der Apenninen, im südlichen Latium trennt nur eine Isoglosse ${ }^{90}$ die dialetti mediani von den dialetti meridionali intermedi: Es handelt sich um die Isoglosse [pj-]/[kj-], die Radtke (1988: 653) nördlich von Gaeta und südlich von Itri, zwischen Frosinone und Sora lokalisiert (s. Karte 10). Die Entwicklung von lat. PL- zu [kj-] (vgl. Pellegrini 1977: 43) ${ }^{91}$ ist damit in diesem Gebiet das einzige Kriterium für die Klassifikation der Dialekte als meridionali. Zu diesen gehören danach auch die Dialekte des südlichen Latium: „,[È] certo che il laziale sta piuttosto con la Campania e tipico rappresentante ne è il dialetto di Sora (Frosinone)“ (ebd.: 31). Südlich der [pj-]/[kj-]-Isoglosse folgt ein Gebiet (campano settentrionale), das von den übrigen kampanischen Dialekten (campano meridionale) durch die lexikalische Isoglosse comperare (camp. sett.) vs. accattare (camp. merid.) ,comprare“

\footnotetext{
${ }^{88}$ Einschlägig ist daneben auch Merlos (1978 [1920]) Analyse der Phonologie des Dialektes von Sora, das bis 1927 Teil der Region Kampanien (Provinz Terra di Lavoro) war (vgl. Kap. 3.2.2) und heute zur Region Latium (Provinz Frosinone) gehört.

${ }^{89}$ Eine Sammlung von Dialektdaten aus den genannten Gebieten stellt das Archivio di parlato dei dialetti campani (ADICA, vgl. Sornicola 1999 und Como/Milano 1999) dar.

${ }^{90}$ Zur Problematik des Konzepts der Isoglosse vgl. Kap. 4.1.2.

${ }^{91}$ Daneben nennt Pellegrini (ebd.) in der Beschreibung der Isoglosse 21 auch die Entwicklung von lat. CL- zu [t5-] in den dialetti meridionali. Den AIS-Karten, die ihm als Basis für die Isoglosse dienen (Karten 1613 und 1665), lassen sich jedoch nur Angaben zu lat. PL- in PLUS ,più‘ entnehmen. Zu den ,anderen Quellen“, derer sich Pellegrini laut eigener Aussage bedient, macht er keine Angaben.
} 
abgegrenzt wird (Radtke 1988: 653, s. Karte 10). Als charakteristisch für das campano meridionale wird der Rhotazismus /d/ > /r/ gesehen, der sich im Norden Kalabriens (wie auch

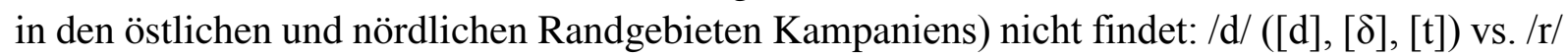
([r]) (kamp.) (ebd., s. Karte 10).

Die Problematik der Abgrenzung des kampanischen Dialektgebietes ,nach außen` ergibt sich auch daraus, dass die Identifizierung der sprachlichen Merkmale, die allen kampanischen Dialekten gemeinsam sind, äußerst schwierig ist. Denn die Campania präsentiert sich in dialektologischem Licht als wenig einheitlich: „Al livello della descrizione formale dei dialetti in questione non si manifesta né una ,campanità' né una ,napoletanità' quale criterio per l'identificazione dialettale“ (Radtke 1997a: 33). ${ }^{92}$ Die interne Differenzierung muss daher bei jeder (wenn auch - wie im Folgenden - nur überblickshaften) Darstellung des sprachlichen Profils der Campania berücksichtigt und verdeutlicht werden.

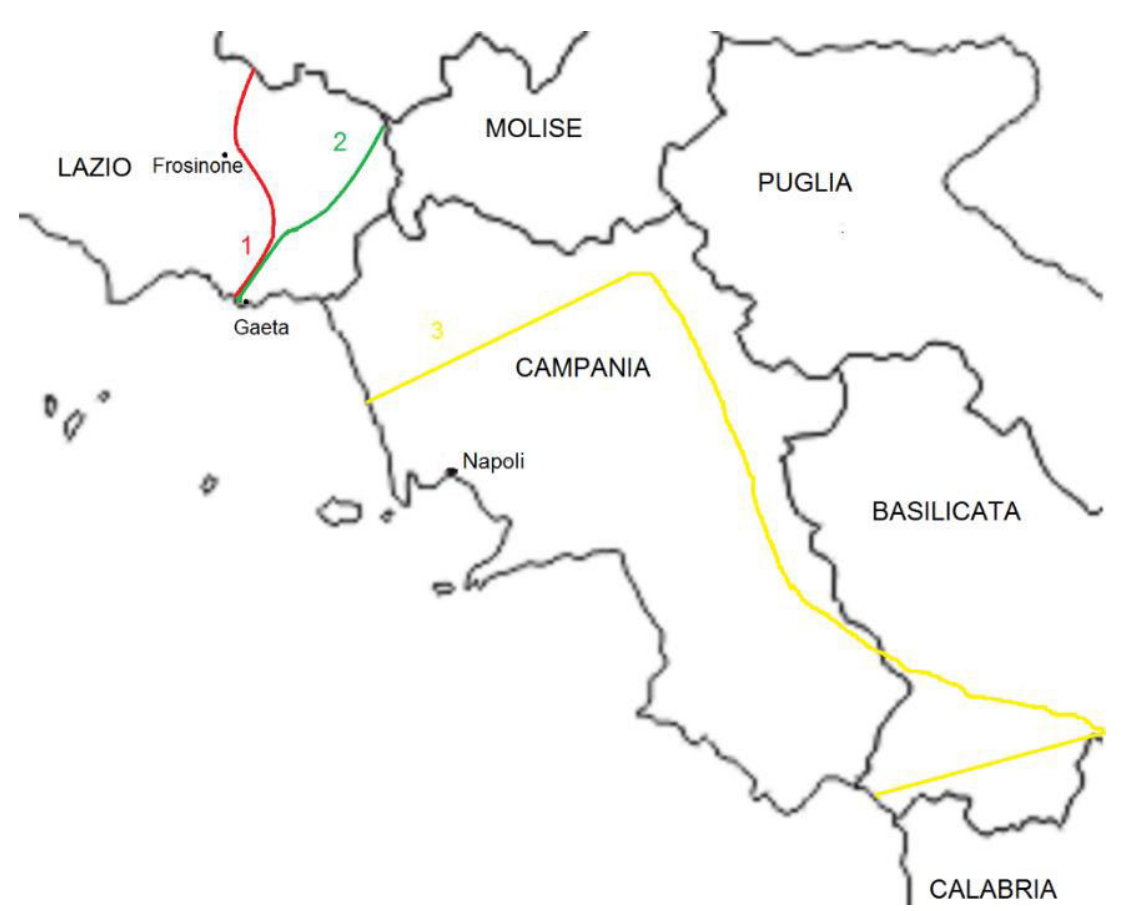

Karte 10. Isoglossen (nördlicher Teil / südlicher Teil) nach Radtke (1988: 653): [pj] / [kj] (1, rot), com-

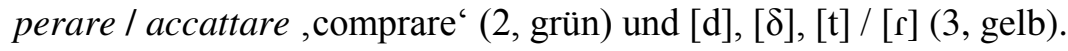

\footnotetext{
${ }^{92}$ Neben der ausgeprägten sprachlichen Variation, d.h. dem Vorliegen diatopisch, sozial oder kontextuell bedingter Varianten - als Ausdruck der sprachlichen Variabilität auf der Ebene der langue (Radtke 2001: 167f.) ist das sprachliche Profil der Campania auch durch einen starken Polymorphismus, d.h. die Koexistenz sprachlicher Varianten, die eine identische oder zumindest ähnliche Funktionalität aufweisen, gekennzeichnet (Radtke 1997a: 39ff.). Als Ausdruck der sprachlichen Variabilität auf der Ebene der parole (Radtke 2001: 167f.) wird der Polymorphismus in der vorliegenden Arbeit weitgehend unberücksichtigt gelassen.
} 


\subsubsection{Sprachliche Charakteristika}

\subsubsection{Phonetik und Phonologie}

\subsection{Vokalismus}

In betonter Stellung gilt in einem Großteil der kampanischen Dialekte ${ }^{93}$ das siebenteilige ,protoromanische“"Vokalsystem (Radtke 1997a: 53, vgl. auch Rohlfs 1966: 6):

$\begin{array}{ll}\text { lat. } & \overline{\mathrm{I}} \\ & \end{array}$

kamp. i

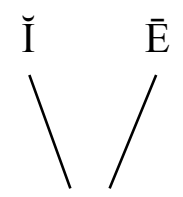

$\mathrm{e}$

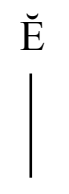

$\varepsilon$

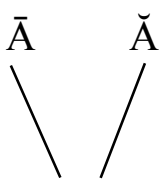

a

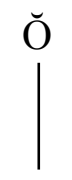

0

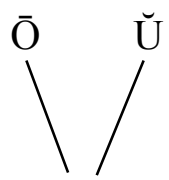

O

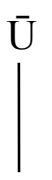

$\mathrm{u}$

Im südwestlichen Cilento (zwischen Sapri und Ascea) findet sich hingegen das fünfteilige „sizilianische" Vokalsystem, das auch in Kalabrien (Provinz Cosenza) und im südlichen Salento vorkommt und Formen generiert wie ['nivi] ,neve' und ['vuti] , voce' (Rohlfs 1966: 10): ${ }^{94}$
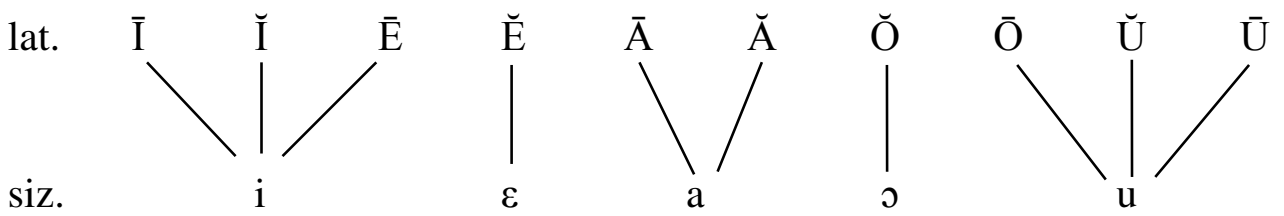

In unbetonter Stellung werden die Vokale in den kampanischen Dialekten (außerhalb des Cilento) häufig in abgeschwächter Form realisiert oder zu [ə] reduziert: ['stomm ${ }^{\mathrm{a}} \mathrm{k}$ ] ,stomaco', ['pek ${ }^{\mathrm{u}} \mathrm{r}$ ] ,pecora' (Freund 1933: 14), [vəl'likələ] (ALCam: Agerola), [pə'lus] ,peloso“ (ALCam: Ariano Irpino), [rə' nukkjə] , ginocchio' (ALCam: Castellamare di Stabia). ${ }^{95}$ Lat. $\overline{\mathrm{O}} / \breve{\mathrm{U}}$ wird daneben im Vorton oft zu [a] geöffnet: [ad'dorə] ,odore' (Radtke 1997: 62), [at'tfidə] ,uccidere' (ALCam: Ruviano). Auslautvokale werden in abgeschwächter Form realisiert, zu [ə] zentralisiert oder getilgt: ['dint $\left.{ }^{0}\right] /\left[{ }^{\prime} \operatorname{dint}^{\circ}\right] /\left[{ }^{\prime} \operatorname{dint}\right]$, dentro' (Radtke 1988: 655), am stabilsten ist [a]: ['koss], ['kossə] ,gamba' neben ['kossa] (ALCam). Dabei kann auch der vorausgehende Konsonant eine Rolle spielen: So erfordert z.B. der Nasal [n] die Realisierung des vokalischen Auslautes, vgl. ['lanə]/['lano] ,lamento“ (Radtke 1997a: 63). Zwischen apokopierten und nichtapokopierten Varianten eines Lexems scheint freie Variation zu bestehen: „[L]'elisione di [ə] non sembra stare in connessione né con lo spazio né con i ceti sociali dei parlanti né con le varie generazioni. Al limite si dovrà attribuire il suo uso / non-uso al contesto fonosintattico [...]“

\footnotetext{
${ }^{93}$ Die im Folgenden für die Dialekte der Campania oder bestimmter Teilgebiete genannten Merkmale sind nicht als ausnahmslos (d.h. für jeden einzelnen Lokaldialekt) geltend, sondern als in der Region bzw. in den entsprechenden Teilgebieten dominierend zu verstehen. Zum Problem der Diskontinuität der Verteilung der diatopischen Varianten vgl. Kap. 3.3.5.

${ }^{94}$ Bei den der Literatur entnommenen Beispielen werden die lokalen Dialekte, aus denen diese stammen, der Übersichtlichkeit halber nicht angegeben. Siehe dazu die Ortsangaben in den entsprechenden Quellen.

${ }^{95}$ Die stärkste Tendenz zur Reduktion der unbetonten Vokale zeigt das Neapolitanische: „In napoletano [...] sono generalmente escluse dalle sillabe atone tanto le vocali medio-alte $(e, o)$, che le vocali medio-basse $(\varepsilon, \supset)$. All'interno di questo quadro si osserva poi l'asimmetria fra sedi protoniche e sedi postoniche: a destra dell'accento è esclusa di solito anche l'occorenza delle vocali alte, per cui la gamma dei segmenti possibili si riduce a [a] (a volte [в]) e [ə]“ (Bafile 1997: 128).
} 
(Radtke 1997a: 48). ${ }^{96}$ In den Dialekten des Südcilento bleiben die Vokale in unbetonter Stellung und im Auslaut erhalten. Hier kommen (wie in Sizilien und Südkalabrien) wie auch in betonter Stellung [a], [i] und [u] vor: [tir'nikkju], setaccio', [fi'titula], beccafico', ['strummulu] ,trottola' (Rohlfs 1988: 86).

Eines der Hauptcharakteristika der kampanischen Dialekte - und der süditalienischen Dialekte im Allgemeinen - ist die Metaphonie der mittelhohen Vokale in betonter Stellung vor lat. I und $\breve{U}$ in der nachfolgenden Silbe, die unabhängig von der Silbenstruktur ist. ${ }^{97}$ Lat. $\breve{E}$ und Ŏ werden zu [je] bzw. [wo] diphthongiert, die häufig zu [je] und [wo] geschlossen werden: ['fjerro] ,ferro', ['tjjento] ,cento', ['kworpo] ,corpo', ['mworto] ,morto' (De Blasi 2006: 23). ${ }^{98}$ Lat. $\overline{\mathrm{E}}(\breve{\mathrm{I}})$ und $\overline{\mathrm{O}}(\breve{\mathrm{U}})$ werden zu [i] bzw. [u] angehoben: ['nirə] ,nero', ['sikkə] < SĬCCU(M) ,magro', ['russə] ,rosso', [nə'putə] ,nipote' (Rohlfs 1966: 83). Vor dem Hintergrund der Abschwächung der Auslautvokale zu [ə] (bzw. deren Tilgung) wird die Metaphonie in den kampanischen Dialekten in mehrfacher Hinsicht morphologisch relevant. ${ }^{99}$ So übernimmt sie bei Adjektiven und maskulinen Substantiven, die im Singular auf $-e$ und im Plural auf $-i$ enden, die Numerusdifferenzierung. ${ }^{100}$ Der Singularform ohne Metaphonie steht die Pluralform mit Metaphonie entgegen:

\begin{tabular}{|c|c|}
\hline Singular-Form & Plural-Form \\
\hline ['mesə],mese' & ['misə] ,mesi' \\
\hline ['Jorə], fiore' & ['Juro] ,fiori' \\
\hline ['vermə] ,verme' & ['vjermə], vermi' \\
\hline ['fortə] ,forte' & ['fwortə] ,forti' \\
\hline
\end{tabular}

Tabelle 6. Metaphonie als Pluralmarker (Beispiele aus De Blasi/Fanciullo 2003: 633 und Rohlfs 1966: 98).

Bei Adjektiven auf -o/- $a$ oder bei als Adjektiv gebrauchten Partizipien tritt die Metaphonie hingegen als Genusmarker auf. Sie kennzeichnet hier die maskulinen Formen (Endung auf $-u$ bzw. $-o$ im Sg. und auf $-i$ im Pl.) gegenüber den nicht-metaphonischen femininen Formen (Endung auf $-a$ im Sg. und $-e$ im Pl.):

\footnotetext{
${ }^{96}$ Die Elision des Auslautvokals geht häufig mit einer Desonorisierung des finalen Konsonanten einher: ['pwet] ,piede', ['det] ,dado، (De Blasi 2006: 57), ['sayk] ,sangue‘ (ALCam: Bagnoli Irpino).

${ }^{97}$ Die Metaphonie ist wohl ,,il fenomeno più caratteristico che inserisce i dialetti campani nel grande gruppo dei dialetti centro-meridionali“, zumindest jedoch „un tratto decisivo antitoscano“ (Devoto/Giacomelli 1972: 110, 112). Zur Metaphonie in den süditalienischen Dialekten vgl. Maiden (1985, 1991).

${ }^{98}$ Die in der vorliegenden Arbeit angegebenen Etyma sind - sofern es sich um (pan-)italienische Lexeme handelt - Cortelazzo/Zolli (2004) entnommen. Zur Etymologie der kampanischen Dialektismen vgl. D’Ascoli (1990, 1993).

${ }^{99}$ Fanciullo (1994: 574) macht darauf aufmerksam, dass die Metaphonie eine morphologische Funktion auch in den süditalienischen Dialekten übernimmt, in denen die unbetonten Auslautvokale erhalten sind, was etwa in den zentralen Dialekten des Salento in einigen Fällen zu einer redundanten morphologischen Markierung führt (z.B. ['pjertu] ,aperto' vs. ['perta] ,aperta'). Vor diesem Hintergrund ist für Fanciullo die morphologische Funktion der Metaphonie auch in den Dialekten primär (und keine „Folgeerscheinung“ phonetischer Entwicklungen), in denen - wie in der Campania - die unbetonten Auslautvokale reduziert oder getilgt werden.

${ }^{100}$ Bei den Substantiven wird der Numerus nicht allein durch die An- bzw. Abwesenheit der Metaphonie gekennzeichnet, sondern auch am Artikel sichtbar.
} 


\begin{tabular}{|c|c|}
\hline feminine Form & maskuline Form \\
\hline ['bonə], buona'/,buone' & ['bwono],buono"/,buoni“ \\
\hline ['rossə], rossa $\%$,rosse ${ }^{6}$ & ['russa],rosso $\%$,rossi ${ }^{6}$ \\
\hline ['nere], nera $\%$,nere 6 & ['nire] ,nero $\%$,neri ${ }^{6}$ \\
\hline [a'pertə] ,aperta $\%$,aperte 6 & [a'pjertə] ,aperto $\%$,aperti \\
\hline
\end{tabular}

Tabelle 7. Metaphonie als Genusmarker (Beispiele 1 und 3 aus Radtke (1988: 654), Beispiele 2 und 4 aus De Blasi/Fanciullo 2003: 630, 633).

Die Metaphonie übernimmt darüber hinaus die Funktion der internen Verbflexion, indem sie die 2. Pers. Sg. (Endung auf $-i$ ) von der 3. Pers. Sg. und häufig auch von der 1. Pers. Sg. differenziert:

\begin{tabular}{|c|c|c|c|}
\hline Infinitiv & 1. Pers. Sg. & 2. Pers. Sg. & 3. Pers. Sg. \\
\hline portà ,portare“ & ['portə],porto' & ['pwortə],porti & ['portə],porta ${ }^{6}$ \\
\hline $\begin{array}{l}\text { scénne(re) , scen- } \\
\text { dere }^{6}\end{array}$ & ['Jengə], scendo' & ['Jinnə], scendi“ & ['Jennə], scende \\
\hline córre $(r e)$,correre & ['korre] ,corro' & ['kurrə] ,corri' & ['korre] ,corre' \\
\hline $\begin{array}{l}\text { sènte }(r e) / \text { sentí , sen- } \\
\text { tire“ }\end{array}$ & ['scntə] , sento' & ['sjentə] ,senti' & ['scntə] , sente' \\
\hline
\end{tabular}

Tabelle 8. Metaphonie als interne Verbflexion (nach De Blasi 2006: 28).

Die metaphonische Entwicklung der betonten mittleren Vokale verläuft jedoch nicht in allen Teilen der Campania in gleicher Weise. In der (östlichen) Irpinia und im (Nord-)Cilento tritt häufig und in den übrigen Gebieten zumindest sporadisch eine Verschiebung des Akzents vom zweiten auf das erste Element des Diphthongs auf, welche mit einer Abschwächung des zweiten Elements zu [ə] oder dessen gänzlicher Tilgung einhergeht: ['miərk], medico“ (ALCam: Ariano Irpino u.a., neap. ['mjerəkə]), ['pittə] ,petto“ (ALCam: Vallata, neap. ['pjettə]), ['uəss] ,osso“ (ALCam: Oscata), ['ussə] (ALCam: Vallata, vgl. auch De Blasi 2006: 52). ${ }^{101} \mathrm{Im}$ Sannio werden die mittleren Vokale $[\varepsilon]$ und [ $\supset$ ] in betonter Stellung in aller Regel nicht diphthongiert, sondern zu [e] und [o] geschlossen: [ka'pello] ,capello', ['novo] ,nuovo', ['bono] ,buono“ (De Blasi 2006: 55). Im Südcilento fehlt die Diphthongierung ebenfalls in einzelnen Lokaldialekten: ['pettu] ,petto', ['Jssu] ,osso' etc. (Camerota, vgl. Rohlfs 1988: 81). ${ }^{102}$ Die stärkste Tendenz zur Diphthongierung von Vokalen in betonter Stellung zeigen die Dialekte der area flegrea (Gebiete um Monte di Pròcida und Pozzuoli) und der Inseln Ischia und Pròcida. Die Diphthongierung tritt hier nicht nur in metaphonischen Kontexten, sondern häufig auch ,spontan' auf. Dabei werden [i] und [e] zu [ai], [oi], [ci] oder [ei] diphthongiert: ['vaivərə] ,bere' (Rohlfs 1966: 85), [mi'foinə] ,micino, gattino“ (Radtke 1997a: 58), ['cjssə] ,essa‘ (Freund 1933: 9). Maskuline Lexeme, die im Singular [ai] aufweisen, haben im Plural [œi]: Sg. ['mailə] ,mela‘,

\footnotetext{
${ }^{101}$ In einigen Fällen dominiert in der gesamten Campania die Variante, in der der Akzent auf dem ersten Element des Diphthongs liegt. So kommen etwa die Varianten ['uəkkjə]/['uəkkç] deutlich häufiger vor als die Variante ['wokkjə] (vgl. ALCam).

${ }^{102}$ Rohlfs (1988: 81) zufolge könnte es sich bei den Orten des Cilento, deren Dialekte keine Diphthongierung aufweisen, um „Sprachinseln“ handeln, die sich durch Zuwanderung aus weiter südlichen Gebieten (Sizilien, Südkalabrien, südliche Terra d'Otranto) gebildet haben, welche seiner „Kontinuitätstheorie“ zufolge das Griechische (das keine derartige Diphthongierung aufweist) über die erste Phase der Romanisierung hinweg bis zu einer „Neoromanisierung“ im Mittelalter konserviert haben (vgl. Kap. 3.3.4.5, S. 72).
} 
['failə] ,filo‘, ['paifə] ,pesce‘ vs. ['mœilə] ,mele‘, ['foilə] ,fili‘, ['pœifə] ,pesci` (De Blasi 2006: 62). Betontes [o] wird zu [au] oder [ao] diphthongiert: ['nautə] ,noce', [nə'pautə] ,nipote“ (Rohlfs 1966: 99), ['raussə] ,rossa' (Freund 1933: 11), [yat'taonə] ,gattone' (Radtke 1997a: 58). In Pozzuoli findet sich auch die Variante [oø]: [stoø'pi], stupire‘, [si „noø'rinə] ,signorina' (ebd.: 55).

Eine weitere Form der Metaphonie in den vorgenannten Gebieten ist die Palatalisierung von betontem [a] zu [ $\varepsilon$ ]. Diese übernimmt eine morphologische Funktion als Genusmarker bei Adjektiven bzw. als Adjektiv gebrauchten Partizipien sowie bei Substantiven mit maskuliner und femininer Form: ${ }^{103}$

\begin{tabular}{|c|c|}
\hline feminine Form & maskuline Form \\
\hline ['kjatt], grossa' & ['kjett],grosso' \\
\hline [ma'lat], malata & [ma'let] ,malato“ \\
\hline ['patts],pazza' & ['petts],pazzo' \\
\hline ['jangə], bianca' & ['jeygə], bianco“ \\
\hline ['asəna] , asina' & ['Esənə], asino' \\
\hline
\end{tabular}

Tabelle 9. Die Palatalisierung von [a] als Genusmarker. Beispiele 1 - 3 aus Radtke (1997a: 57), Beispiele 4 und 5 aus Rohlfs (1966: 45).

In den übrigen Teilen der Campania findet sich diese Palatalisierung ,sporadicamente a macchia di leopardo [...], visto che tra Sannio, Terra di Lavoro e Cilento è possibile incontrare gerundi del tipo cantènno per cantando" (De Blasi 2001: 95). Im Sannio tritt sie nach Maturi (2002: 37) ,in modo abbastanza sistematico“ in Flexionsformen von Verben der 1. Konjugation (-à) sowie in Formen des Paradigmas von avé ,avere' auf: [tru'vennə] ,trovando',

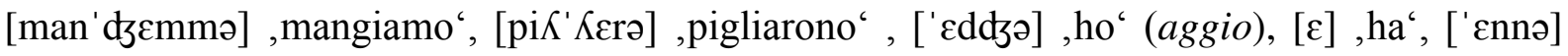
,hanno“ usw.

Ein weiteres Merkmal, das zur internen sprachlichen Differenzierung der Campania beiträgt, ist die Velarisierung von betontem [a]. Im Gebiet um Monte di Pròcida wird [a] in betontem Auslaut häufig zu [o] velarisiert: ['fo] ,fare', [bakka'lo] ,baccalà' (De Blasi 2006: 61). Weiter südlich, in der Umgebung von Neapel, kann die velare Realisierung von [a] (als [a]) vor Nasalkonsonanten und im Auslaut auch von einer Nasalierung begleitet sein: z.B. ['pãnts] ,pancia', ['nãnts] ,innanzi‘ (Radtke 1997a: 59), ['stã] ,sta', [k'kã] ,qua', [kan'tã] ,cantare' (Sornicola 1997: 332). ${ }^{104}$ Auch in der Provinz Caserta wird [a] zu [o] velarisiert: ['sottfə] ,(io) so “ (neap. ['sattə]), [tə 'stonnə], ci stanno', ['duə 'mojə], il 2 maggio' (Radtke 1997a: 55). Den in der Irpinia vorkommenden velaren Realisierungen [o] und [o] liegt wohl ein metaphonischer Effekt zugrunde, der von dem hohen velaren Vokal im maskulinen $(l u)$ und neutralen Artikel

\footnotetext{
${ }^{103}$ Vereinzelt tritt die Palatalisierung auch „spontan“ (also ohne Vorliegen eines Metaphonie auslösenden hohen Vokals in der nachfolgenden Silbe) auf: [a 'kspə] ,la testa' (la capa) (Radtke 1997a: 55). In anderen Fällen liegt wohl eine Analogie zur Palatalisierung im metaphonischen Kontext vor: ['kartə] ,carta' vs. ['kertə] ,carte', in Analogie zu ['kanə] ,cane‘ vs. ['kenə], cani‘ (Radtke 1997a: 55, 57).

${ }^{104}$ Die Velarisierung und Nasalierung von Vokalen sind im metasprachlichen Wissen der Sprecher stark stigmatisiert. Die Nasalierung von Vokalen vor Nasalkonsonanten oder im (durch Apokope entstandenen) Auslaut

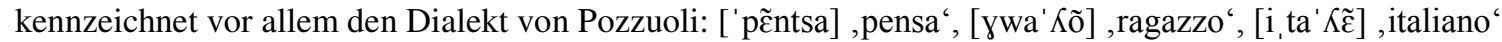
(Radtke 1997: 59).
} 
(ru) ausgeht: [ru l'bttə] ,il latte', [ru 'koso] ,il cacio', [ru 'solə] ,il sale', [lu 'korrə] ,il carro', [lu 'tokkə] ,il tacco', [lu 'sokkə], il sacco', [lu 'ponnə] ,il panno' (De Blasi 2006: 52f.). ${ }^{105}$

Als prägnant für den phonetischen Charakter der kampanischen Dialekte sind im Bereich des Vokalismus zuletzt zwei häufig auftretende silbenstrukturell relevante Phänomene zu nennen. Insbesondere, jedoch nicht ausschließlich bei Verben finden sich phonetische Varianten, die ein a protheticum aufweisen: ammozzecà ,mordere', arrattà ,grattare' (ALCam: Squille), arreposà ,riposare‘, accussì ,così‘, arò ,dove' (Radtke 1997a: 62) etc. Im Auslaut lässt sich die Verwendung von [ə] als paragogischem Vokal beobachten: ['majə] ,mai', [as'sajə], assai' (ebd.).

\subsection{Konsonantismus}

Ein Hauptcharakteristikum des Konsonantismus der kampanischen Dialekte (sowie eines Großteils der übrigen dialetti meridionali) ist die Art der Realisierung der stimmlosen lateinischen Plosive P, T und C [k]. Diese werden im Silbenanlaut und -inlaut grundsätzlich lenisiert oder sonorisiert: ['paț] ,padre' (Radtke 1997a: 70), ['gabə] capa ,testa' (ALCam: Siano). In den Nexus MP, NT und NC tritt die Sonorisierung der stimmlosen Plosive im Zuge einer partiellen progressiven Assimilation auf: ['tjembo] ,tempo' (De Salvio 1913: 365), ['kambə] ,campo', ['kwandə] ,quanto', [an'gorə] , ancora' (De Blasi/Fanciullo 2003: 634). Analog dazu kommt es in den Nexus MB und ND zu einer totalen Assimilation der stimmhaften Plosive: ['kwanno] ,quando' (Marano Festa 1928: 78), [kan'nela] ,candela', ['yamma] ,gamba' (Rohlfs 1988: 90), [tam'murro] ,tamburo‘ (De Salvio 1913: 365, vgl. auch Rohlfs 1966: 357, 360).

Auch andere Konsonantenverbindungen weisen in den kampanischen Dialekten Entwicklungen auf, die sich teilweise stark von jenen im Standarditalienischen unterscheiden. Hier sind zunächst die Nexus aus Konsonant(-en) + L zu nennen, deren Resultate häufig eine diatopische Differenzierung zeigen. Lat. CL (auch sekundär aus TL) wird in den meisten kampanischen Dialekten wie im Italienischen zu [kj] palatalisiert: ['kjavə] < CLĀVE(M) , chiave', ['wokkjo] < OC(U)LU(M) ,occhio' (Rohlfs 1966: 243, 349). In der Provinz Caserta findet sich jedoch - wie in den angrenzenden Gebieten des Latium ${ }^{106}$ - stellenweise eine stärkere Palatalisierung zu [ty]: ['tfave] ,chiave', ['wottfu] ,occhio' (De Blasi 2006: 60, vgl. auch ['uəttf], ALCam: Afragola), ['vjetti] < VECLI < VET(U)LI, vecchi' (Tommasino/Tommasino 2007: 15). Auch lat. PL ergibt in weiten Teilen der Campania [kj]: ['kjanta] < PLANTA(M), pianta', ['kjovere] < PLǓERE ,piovere' (Rohlfs 1966: 253), ['kju] < PLŪS ,più‘ (De Salvio 1913: 360). ${ }^{107}$ In der Provinz Caserta findet sich auch hier - wie im südlichen Latium ${ }^{108}$ - teilweise

\footnotetext{
105 Tuttle (1985) beschreibt dieses Phänomen, das er als der Metaphonie (assimilazione anticipatoria), ,entgegengesetzt“ einordnet, als assimilazione permansiva (non-anticipatoria), ,che implica la continuazione o la trasmissione d'un tratto da una sillaba a quella seguente“" (Tuttle 1985: 2f.). In dem von ihm beschriebenen Fall der Diphthongierung von betontem [a] zu [wa] handelt es sich um die Weitergabe der Merkmale [+ gerundet], [+ hoch] und [+ hinten] von dem Vokal /u/ (auch in seiner Realisierung als [ə]) einer vorangehenden Silbe an den Haupt- oder Nebentonvokal /a/. Dies geschieht häufig - wie in den für die Irpinia genannten Fällen - nach den Singular-Artikeln $r u$ und $\kappa u(\kappa \partial)$ und tritt in vielen süditalienischen Dialekten lediglich nach [k] im Silbenanlaut auf. Für Gallo in der Provinz Caserta belegt Tuttle (ebd.: 8) u.a. [ru 'kwapə] ,la testa (il capo)', [ru 'pwatrə] ,il padre', [ru fwalə'namə] ,il falegnamo', [ru kwalə'kajə] ,il calcagno', [ru 'rwamə] ,il ramo'.

${ }^{106}$ Vgl. Merlo (1978: 203).

${ }^{107}$ Ausnahmen, in denen PL wie im Toskanischen [pj] ergibt, sind piacere $<$ PLACĒRE und piatto $<*$ plattu $(m)$ (De Salvio 1913: 360, Radtke 1993: 446). Hier handelt es sich wohl um lautlich nicht integrierte Entlehnungen aus dem Italienischen (im ersten Fall möglicherweise aufgrund des gelehrten Charakters (PLACET), im zweiten Fall eventuell aufgrund dessen, dass gr. PLATÝS ,largo ‘ lautgeschichtlich kamp. chiatto, grasso“ ergeben hatte). ${ }^{108}$ Vgl. Merlo (1978: 205).
} 
die Palatalisierung zu [ty]: ['tyve] ,piove', ['tfu] ,più' (De Blasi 2006: 60). Lat. BL wird in der gesamten Campania zu [j]: ['janko] < germ. blank, bianco', ['junno] < germ. *blund ,biondo“ (Rohlfs 1966: 241). Lat. (F)FL wird in den Dialekten der Provinzen Neapel und Caserta sowie in Teilen des Sannio zu [S] palatalisiert: ['Jamma] < FLAMMA(M) ,fiamma' (Rohlfs 1966: 248), ['Jorə] < FLŌRE(M), fiore' (Radtke 1997a: 74), ['Jatə] < FLĀTU(M), fiato' (ALCam: Castellamare di Stabia u.a.), [ $\left.\int \mathrm{o} \int{ }^{\prime} \mathrm{J} a\right]<$ SUFFLARE , soffiare' (ALCam: Monte di Pròcida). In der Irpinia und im Cilento findet sich im Wortinlaut ebenfalls [S]: [u $\left.\int^{\prime} \int \mathrm{a}\right]$, soffiare', [a $\left.\int^{\prime} \int \mathrm{a}\right]<$ AFFLARE ,trovare' (Rohlfs 1988: 89). Im Wortanlaut wird FL hier hingegen zu [j]: ['jorə] ,fiore‘ (Rohlfs 1988: 89), ['jatə] ,fiato‘ (ALCam: Vallata). In lat. SCL ( ${ }^{*} s k j$ ) wird (bei gleichzeitiger Palatalisierung des Sibilanten, s.u.) der Lateral elidiert: [raf'ka] ,raschiare', ['ma $\mathrm{ku}$ ] < MASCULU(M) ,serratura', ['Jkuma] ,schiuma' (Rohlfs 1988: 89, 91), ['Jkaffo] ,schiaffo“ (Marano Festa 1928: 175).

Auch vorkonsonantisches L bleibt in den kampanischen Dialekten nur selten erhalten. Häufig findet sich hier ein Liquidentausch: [kur'tjello] ,coltello“ (Radtke 1988: 655), [kar'kano] ,calcagno', ['purpo] ,polpo', ['arba] ,alba' (Marano Festa 1928: 175). ${ }^{109}$ Vor [t, d, s, z] wird [1] häufig zu [u] vokalisiert, z.B. in ['auto] ,alto' (ALCam: Apollosa), ['fautso] ,falso“ (Radtke 1997a: 72). Vor [ts, dz] erfolgt eine Vokalisierung zu [i]: [ai'tsa] ,alzare‘ (ebd., vgl. auch Tommasino/Tommasino 2007: 28). Auf Ischia, Pròcida und in der area flegrea (Pozzuoli) wird [1] vor [t] zu [n]: [na b'bontə], una volta' (Radtke 1997a: 72).

Die Geminate LL zeigt diatopisch unterschiedliche Entwicklungen. Während sie in der Provinz Neapel erhalten ist (['killo] ,quello', [kur'tjello] ,coltello“ (Radtke 1988: 655), [ka'pillə] ,capelli“ (ALCam: Agerola)), hat sich in der Irpinia und im nördlichen Cilento aus dem Lateral [11] der Kakuminallaut [dd] entwickelt (Rohlfs 1966: 329): [ka'piddə] ,capelli‘, ['pedda],pelle' (ALCam: Trevico/Molini). ${ }^{110}$ Die (Weiter-)Entwicklung von [dd] zu [dd] findet sich in der Irpinia, im Cilento, auf den Inseln Ischia und Pròcida sowie in Monte Di Pròcida: ['voddə] ,bollire', [yad'dina], gallina' (Rohlfs 1988: 89), ['kwoddə]/['kwoddo] ,collo' (Freund 1933: 38, Parascandola 1976: 93), ['beddə] , bella‘ (Freund 1933: 39), ['kwiddu] ,quello‘ (Russo 1988: 39). In der Provinz Caserta ${ }^{111}$ sowie in Teilen des Sannio und der Irpinia wird [11] häufig zu [KK] palatalisiert: ['kiKKo] ,quello', ['beKKo] ,bello' (Tommasino/Tommasino 2007: 21, 23), [ka' piKKə] ,capelli‘ (ALCam: Teora, vgl. auch Rohlfs 1966: 327). Im Cilento kommt es in Pronomen bzw. Artikeln, die lat. ILLE/ILLA/ILLUD weiterführen, zum Rhotazismus [1l] > [r]: ['iro] ,egli', ['era] ,essa', ['kiro] ,quello', ['kera] ,quella' (Rohlfs 1988: 89). ${ }^{112}$ Der Rhotazismus findet sich auch auf Pròcida (['kire] ,quello', ['kera], quella' (Parascandola 1976: 74)), nicht jedoch auf Ischia, wo Freund (1933: 71) ['kiddə] ,quello‘ und ['kejddə], quella‘ belegt.

Auch die Entwicklungen anderer Konsonantennexus zeigen deutliche diatopische Unterschiede. Lat. CI wird in den Provinzen Neapel und Caserta wie im Standarditalienischen zu

\footnotetext{
${ }^{109}$ Auch im neutralen Singular-Artikel findet sich teilweise [r] statt [1], vgl. Kap. 3.3.4.3.

${ }^{110}$ In der Irpinia entwickelt sich [dd] sporadisch weiter zu [ddz]: [kan'neddzə] ,cannella', [au'tfeddzə] ,uccello“ (Melillo 1926: 5, Beispiele zit. in Rohlfs 1966: 329).

${ }^{111}$ Für das südliche Latium dokumentiert Merlo (1978: 199) als Resultat von lat. LL (vor İ, $\left.\bar{U}, \breve{U}\right)$ regelmäßig

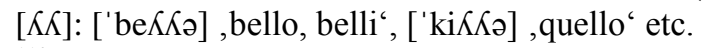

${ }^{112}$ De Blasi (2006: 51) nennt (ohne Lokalisierung) für die Irpinia die Varianten ['kwiro] ,quello“ und ['kwiri] ,quelli`. Hierbei kann es sich nur um sporadische Vorkommen im Grenzgebiet zum Cilento handeln. Warum allein die Pronomen in den süditalienischen Dialekten häufig die Variante $[\mathrm{r}]<\mathrm{LL}$ aufweisen, ist unklar. Nach Rohlfs (1988: 90) könnte es sich dabei um das Relikt einer früheren kakuminalen Aussprache [r] handeln, die sich als ,articolazione debole“ von [dd] bei der Realisierung der Pronomina in proklitischer Position entwickelt hat.
} 
[tt'] palatalisiert: ['fattfə] < FACIO, faccio', ['brattfə] < BRĀ(C)CHIU(M) ,braccio ‘. ${ }^{113}$ In Teilen des Sannio, in der Irpinia und im Cilento ergibt CI jedoch meist [tts]: ['fattso], ['brattso] etc. (Avolio 1989: 1ff.). ${ }^{114}$ Lat. NG ergibt in den Provinzen Neapel und Caserta sowie im westlichen Sannio [nn]: ['kjanjı] < PLĂNGERE , piangere' (Avolio 1989: 7, Iannace 1983: 30), [maj'na] ,mangiare' (De Blasi 2006: 53). Im östlichen Sannio, in der Irpinia und im Cilento findet sich hingegen wie im Italienischen [ndz]: [man'dza] (De Blasi 2006: 53), ['kjandzo] (Avolio 1989: 7, vgl. auch Kap. 3.3.5). Lat. QU (<CU) ist im östlichen Sannio und in der Irpinia bewahrt: ['kwiro]/['kwillə], quello' < ECCU ILLU(M) (ebenso die anderen Flexionsformen, vgl. De Blasi 2006: 51, Maturi 2002: 102), ['kwisto] ,questo' < ECCU ISTU(M) (ebenso die anderen Flexionsformen, vgl. De Salvio 1913: 360, Marano Festa 1928: 183), ['kwa] < ECCU HĀC (De Salvio 1913: 360). In den Provinzen Caserta und Neapel sowie im Cilento wird [kw] hingegen zu [k] reduziert: ['killo]/['kiro] ,quello' (De Salvio 1913: 360, Rohlfs 1988: 89), ['kisto] ,questo' (Parascandola 1976: 74), ['ka] ,qua' (Radtke 1997a: 74). Ein Charakteristikum der Dialekte der Provinz Neapel ist die Geminierung von intervokalischem M: [kan'tammo] ,cantiamo', ['ommo] ,uomo' ['kammera] ,camera' (De Blasi 2006: 64). ${ }^{115}$

Ein oft zitiertes Merkmal der kampanischen Dialekte stellt die Palatalisierung von S vor den lat. Plosiven P, T und C [k] dar. Tatsächlich findet sich diese jedoch nicht in allen kampanischen Dialekten und tritt je nach Gebiet in unterschiedlicher Distribution auf. In den Dialekten der Provinzen Neapel und Caserta wird S vor $\mathrm{C}$ und $\mathrm{P}$ regelmäßig, nicht jedoch vor $\mathrm{T}$ palatalisiert: ['Jkola] ,scuola', [Jpa'ra] ,sparare‘ (Radtke 1997a: 30), ['Jpartə] ,spartire', aber ['kisto] ,questo', [stu'ta] ,spegnere' (Freund 1933: 41f.). Auch im Cilento wird S vor C häufig palatalisiert: [Jkar'tellu] ,gobba', ['maJkara] , ascella' (Rohlfs 1988: 91), ['Jkatola] ,scatola“ (Ondis 1998: 66). Die Palatalisierung vor P ist hier seltener: Ondis (1998: 66) nennt insgesamt neun Beispiele, darunter ['Jposa] ,sposa', [Jpu'tare] (sic) ,sputare', ['vefpra] < VESPERA(M) ,pomeriggio/sera'. In der Irpinia und im östlichen Sannio bleibt $S$ nicht nur vor $T$, sondern auch vor C und P häufig erhalten: ['skola] ,scuola', ['spina] ,spina' (De Salvio 1913: 361), ['skaffə] ,schiaffo', [rə' spja」ə] , dispiace‘ (Maturi 2002: 94). An der Grenze zum Latium und zum Molise (nördliche Provinz Caserta und nördliches Sannio) findet sich die Palatalisierung von S nicht nur vor C und P, sondern häufig auch vor T: ['Jtupeto] ,stupido', ['Jtesso] ,stesso' (De Blasi 2006: 56), ['kefta] ,questa', ['Jtortə] ,storti' (Maturi 2002: 93). ${ }^{116}$

In den kampanischen Dialekten sind schließlich des öfteren Fälle von Metathese anzutreffen, die häufig (aber nicht ausschließlich) in Nexus mit R auftreten: ['frøvə] < FĔBRE(M) ,febbre', ['krapə] < CAPRA(M) ,capra', (Radtke 1997a: 75), ['frabbəkə] ,fabbrica' (Maturi 2002: 139), ['vritə] < VǏTRU(M), vetro' (Rohlfs 1966: 454) u.a. Regelmäßig tritt die Metathese in der lateinischen Endung-GǏNE(M) auf (Marano Festa 1928: 179): [sar'tanja] < *sartájina $<$ SARTAGĬNE(M) ,padella', [pe'tinja] < (IM)PETĪGǏNE(M) , scabbia', [fi' linja] < *filíjna < FULİĞNE(M) ,fuliggine' u.a. Reziproke Metathesen finden sich etwa in ['fetəkə] < FICATU(M), fegato“ (neben ['fekətə], Radtke 1997a: 75), [al'lordło] < HOROLŎGIU(M) ,orologio“ (Marano Festa 1928: 182), ['jirito] < DĬGITU(M), dito‘ (Rohlfs 1988: 88).

\footnotetext{
${ }^{113}$ De Blasi/Fanciullo (2003: 634) betrachten [tt] hingegen als italianisierte Variante, die in der neapolitanischen Küstenregion und an der Amalfiküste die dialektale Variante [tts] verdrängt hat.

${ }^{114}$ Vgl. auch Kap. 3.3.5.

${ }^{115}$ Die Geminierung tritt in anderen Teilen der Region nur lexemgebunden auf, z.B. im Cilento cimma, parte più fine del cavolo' (,cima'), auch in ncimma ,sopra' (,in cima') (Rohlfs 1988: 91). Letzteres findet sich auch in der Irpinia (Russo 1988: 112).

${ }^{116}$ Für das südliche Latium dokumentiert Merlo (1978: 192) eine regelmäßige Palatalisierung von S vor T: ['fefta], festa', ['kiftə] ,questo' etc.
} 


\subsubsection{Phonosyntax}

Die Realisierung vieler Konsonanten hängt in den kampanischen Dialekten vom phonosyntaktischen Kontext ab. Ein raddoppiamento (oder rafforzamento) fonosintattico (RS/RF) findet sich häufig dann, wenn einem einfachen Konsonanten im Wortanlaut eines der folgenden syntaktischen Elemente vorausgeht (De Blasi 2006: 29f, Maturi 2002: 109ff., s. auch Rohlfs 1966: 237): ${ }^{117}$

die Konjunktionen $e$ und $n e ́$,

die Negation $n u$,non',

die Präpositionen $a, \mathrm{a}^{\text {‘ }}, c o / c u$,con', pé ,per',

die Indefinitpronomina ognilogna ,ogni' und quacchelcacche ,qualche',

das Interrogativ- und Exklamativpronomen che,

die Adverbien accussì ,così‘ und chiù ,più',

das Numeralium tre,

die Artikel bzw. Pronomina o/lo/lu/ru, chello (neutr. Sg.) und e/i/la/rə/ri, cheste, chelle (fem. Pl.), in beiden Fällen mit Ausnahme des nördlichen Sannio (vgl. Maturi 2002: 136f.), ${ }^{118}$

die Verbform der 1. Pers. Sg. und 3. Pers. Pl. (so’), der 2. Pers. Sg. (si’) und der 3. Pers. Sg. (è) von èsse ,essere' sowie der 1. Pers. Sg. (sto) von stà ,stare‘. Die Form der 3. Pers. Sg. von avé , avere', $h a(<\mathrm{HA}(\mathrm{BE}) \mathrm{T}$, realisiert als [a] oder $[\varepsilon])$ löst im Sannio und im Cilento ein RS aus: [a f'fattə] , ha fatto' (Avolio 1995: 49), [a d'dittə]/[ $\varepsilon$ d'dittə] ,ha detto“ (vs. neap. [a 'rittə], Maturi 2002: 109).

Dort, wo die morphologische Funktion der Genusmarkierung aufgrund der Homonymie der entsprechenden Artikel durch diese nicht geleistet werden kann, wird das RS auch morphologisch relevant. So existiert im Neapolitanischen im Bereich der singularischen Artikel zwar eine Unterscheidung zwischen Maskulinum und Femininum ( $o$ vs. $a$ ), nicht jedoch zwischen Maskulinum und Neutrum (beide $o$ ). ${ }^{119} \mathrm{Im}$ Falle von Substantiven, die sowohl als Maskulina als auch als Neutra vorkommen (und entsprechende semantische Differenzierungen aufweisen), wird die Genusdifferenzierung allein vom RS übernommen:

\begin{tabular}{|c|c|}
\hline mask. Singular & neutr. Singular \\
\hline [o 'fjerro] , il ferro (utensile) ${ }^{6}$ & [o f'fjerro], il ferro (materiale) ${ }^{6}$ \\
\hline [o ka'fe], il caffè (locale) ${ }^{6}$ & [o kka'fe] ,il caffè (bevanda) ${ }^{6}$ \\
\hline [o 'russo] ,uomo con i capelli rossi' & [o r' russo], il rosso (colore) ${ }^{6}$ \\
\hline
\end{tabular}

Tabelle 10. Das raddoppiamento fonosintattico als Genusmarker im Singular (Beispiele 1 und 2 aus Iannucci 1948: 238, Beispiel 3 aus De Blasi/Imperatore 2000: 69).

Auch im Bereich des Plurals übernimmt das RS im Neapolitanischen eine morphologische Funktion. Der pluralische Artikel im Maskulinum lautet hier teilweise nicht $i$, sondern - wie im

\footnotetext{
${ }^{117}$ Sprachhistorisch geht das raddoppiamento fonosintattico auf die Assimilation eines lateinischen Auslautkonsonanten an den Anlautkonsonanten des folgenden Lemmas zurück (regressive Assimilation): [a k'kasa] < AD CASA(M).

${ }^{118}$ Im Falle des femininen Pluralartikels werden illas, *illaec und (hyperkorrektes) illes, im Falle des neutralen Singularartikels neben illŭd auch *illoc und *illod als Etyma diskutiert (vgl. Agostiniani 1975: 196f., Rohlfs 1968: 108, 110). Zu den heutigen Formen der Artikel vgl. Kap. 3.3.4.3.

${ }^{119}$ Zum Neutrum als drittem Genus vgl. Kap. 3.3.4.3.
} 
Femininum - $e$. Im Falle von Substantiven, die beide Genera aufweisen, welche durch den Artikel nicht unterschieden werden, wird die Genus- und damit auch die Bedeutungsdifferenzierung allein durch das RS geleistet:

\begin{tabular}{|c|c|}
\hline mask. Plural & fem. Plural \\
\hline [e 'fiאК弓] ,i figli' & [e f'fiKКə], le figlie ${ }^{6}$ \\
\hline [e 'primə], i primi' & [e p'primə], le prime“ \\
\hline [e 'pittsə], i posti' & [e p'pittsə], le pizze' \\
\hline [e 'pilə], i peli' & [e p'pilə], le batterie, le pile، \\
\hline [e 'tappə], i tappi' & [e t'tappo], le tappe, le soste \\
\hline
\end{tabular}

Tabelle 11. Das raddoppiamento fonosintattico als Genusmarker im Plural (Beispiele 1 und 2 aus Iannucci 1948: 239, Beispiele 3-5 aus De Blasi/Imperatore 2000: 75).

Einige konsonantische Phoneme unterliegen in den kampanischen Dialekten einer besonderen Art der kontextbedingten Variation, die nicht quantitative, sondern qualitative artikulatorische Veränderungen bedingt (variazione consonantica, vgl. De Blasi 2006: 30ff.). In „schwacher Stellung“" (posizione debole), d.h. im Anlaut nach einem Element, das kein RS auslöst sowie im Inlaut treten diese Phoneme in ihrer lauthistorischen Variante auf. Lat. B wird in den kampanischen Dialekten häufig als [v] realisiert („Betazismus“): ['vokka] ,bocca“, ['vattere] ,battere', ['vano] ,bagno' (Rohlfs 1966: 195). ${ }^{120}$ Daneben findet sich auch die Variante [ $\left.\beta\right]$ (['ßokkə] ,bocca' (ALCam: Amalfi)) oder die Tilgung des Lautes: ['כttə] ,botte' (Radtke 1997a: 68), ['okk] ,bocca' (ALCam: Oscata). ${ }^{121}$ Lat. D erfährt lauthistorisch meist einen Rhotazismus: ['ritə] ,dito', ['rendə] ,dente' (Rohlfs 1966: 204). Das Resultat [r] ${ }^{122}$ wird auf Ischia zu [1] (Liquidentausch): ['krulə] ,crudo', ['litə] ,dito' (Freund 1933: 25), ['pelə] ,piede', ['lendə] ,dente' (Rohlfs 1966: 204, 296). ${ }^{123}$ In der Provinz Caserta, im Sannio und im Norden der Irpinia bleibt /d/ (als [d] oder [ð]) häufig erhalten: ['beðə] (ALCam: Ruviano), ['pedə] (ALCam: Vallata). Sporadisch findet hier auch eine Tilgung statt: [i'Jimmo], diciamo ' (Como 2007: 228). In der Irpinia wird intervokalisches [d] teilweise zu [t] verhärtet: ['pete] ,piede',

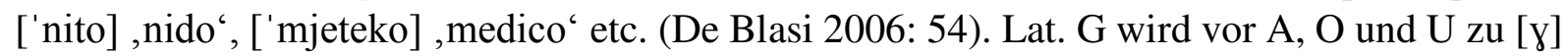

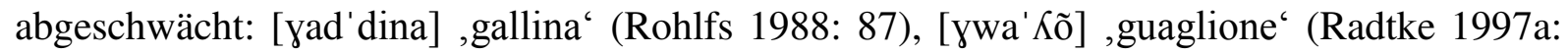
59). Häufig findet auch hier eine Tilgung statt: ['att] ,gatta', (Rohlfs 1966: 208), [waK'Kone] ,guaglione“ (De Blasi 2006: 31), [un'nella] < GUNNA ,gonna' (De Salvio 1913: 359). Nach

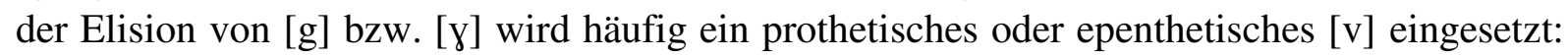
['vattə] ,gatto', ['vaאə], gallo“ (Rohlfs 1966: 208), [vaК'Konə], guagliona' (ALCam: Squille), ['fravola] ,fragola' (Altamura 1968: 137), ['vutə] < CUBITU(M) ,gomito“ (ALCam:

\footnotetext{
${ }^{120}$ Einige native Lexeme haben /bb/ anstelle von /v/: [b'bellə] ,bello', [b'bwonə] ,buono', [b'benə] ,bene': „Qui, però, /bb-/ può essere spiegato anche col fatto che raramente questi termini sono adoperati in iniziale assoluta, mentre lo sono molto spesso dopo raddoppiamento fonosintattico (è bbuóna, cha bbèlla ecc.); ciò potrebbe aver favorito una precoce generalizzazione della variante con /bb-/“" (Avolio 1995: 42).

${ }^{121}$ Dieselben Varianten weist kamp. [v] < lat. V auf: So finden sich für, voce' die Varianten ['vofə] (ALCam: Amalfi), ['ßofə] (ALCam: Torre del Greco) und ['ofə] (ALCam: Apollosa).

${ }^{122}$ In vielen Darstellungen wird das Resultat des Rhotazismus als Graphem $r$ angegeben. Es ist jedoch davon auszugehen, dass es sich in den allermeisten Fällen nicht - wie in den Fällen, in denen lat. R zugrunde liegt - um das (zweifach angeschlagene) [r], sondern um die (einfach angeschlagene) Variante [ $r$ ] handelt, die dementsprechend hier immer angegeben wird, wenn sich in der Quelle das Graphem $r$ für das Resultat von lat. D findet.

${ }^{123}$ Rohlfs (ebd.) zufolge gilt diese Entwicklung auch für Pròcida: ['kolə] ,coda'. Parascandola (1976: 145) belegt [1] für Pròcida einzig in [lut' trina] ,dottrina', als regelmäßig wird hier [r] angegeben: ['rito] ,dito', ['rwono] ,dono', ['pero] ,piede'.
} 
Agerola). ${ }^{124}$ Lat. G vor I und E sowie lat. DĬ werden zu [j]: [jə'la] < GELARE, ['jennərə] < GĚNERU(M) (Rohlfs 1966: 211), ['jworno] < DĬURNU(M), ['oj] < HŌDIE (Marano Festa 1928: 174), ['jirito] <* giditum < DĬGITU(M) (Rohlfs 1988: 88).

In ,starker Stellung“ (posizione forte), d.h. im Wortanlaut nach einem Element, das (im entsprechenden Dialekt) ein RS auslöst, finden /b/, /d/, /g/ in den geminierten Formen [bb] ${ }^{125}$, [dd] und [gg], während [j] - unabhängig vom ursprünglichen lateinischen Konsonanten(-Nexus) - zu [gj]/[ggj] wird: ${ }^{126}$

\begin{tabular}{|c|c|}
\hline ,schwache Stellung ${ }^{6}$ & ,starke Stellung ${ }^{6}$ \\
\hline [a 'rongo], la do' & [e d'dongo], le do' \\
\hline [nu 'allo], un gallo' & [tre g' galli], tre galli ${ }^{\circ}$ \\
\hline [a 'vortsa], la borsa' & [tre b'bortsə], tre borse' \\
\hline [na jur'nata], una giornata & ['ke ggjur'nata], Che giornata!' \\
\hline
\end{tabular}

Tabelle 12. Realisierungen der Phoneme /b/, /d/ und /g/ in starker und schwacher Stellung (Beipiele aus De Blasi 2006: 31f.).

\subsubsection{Morphologie}

Die kampanischen Dialekte zeigen eine komplexe, vom Standarditalienischen deutlich abweichende morphologische Struktur, die anhand ausgewählter Aspekte aus den Bereichen der Nominal- und Verbalflexion dargestellt werden soll. ${ }^{127}$ Eines der Hauptcharakteristika im Bereich der Nominalflexion ist die Existenz eines dritten Genus neben den in den romanischen Sprachen üblichen Genera Maskulinum und Femininum. Da es sich bei einigen der Substantive, die dieses Genus aufweisen, um lateinische Neutra handelt (SALE(M), MELE(M), LACTE(M), LARDU(M), FERRU(M) etc.), hat sich für dieses dritte Genus die Bezeichnung „Neutrum“ etabliert (z.B. De Blasi 2006: 34). Im Gegensatz zum lateinischen Neutrum ist das kampanische ,Neutrum‘ jedoch größtenteils semantisch motiviert: Es betrifft insbesondere nicht zählbare Substantive (,mass nouns“) und damit Singularia tantum wie o ppane, o mmele, o ssale, o llatte (Iannucci 1948: 238), o ggrano (Maturi 2002: 138), unter anderem auch solche, die im Lateinischen das maskuline Genus aufweisen (PANE(M), CASEU(M), SANGUE(M) etc., vgl. Rohlfs

\footnotetext{
${ }^{124}$ Epenthetisches [v] (+ [ə]) findet sich auch unabhängig von der variazione consonantica: [pa'vurə] ,paura“ (Radtke 1997a: 75), ['avətə] ,alto“ (ALCam: Agerola). Auch [g] und [y] kommen als prothetische und epenthetische Konsonanten häufig vor (nach Rohlfs (1988: 88) g inorganica): ['gauto]/['yautu] ,alto“ (ALCam: Bagnoli Irpino, Rohlfs 1988: 88), ['gavətə] ,alta' (Radtke 1997a: 75), [gu'rekkjə], orecchi‘ (ALCam: Vallata), [ga'la] < (H)ALARE ,sbadigliare', [diar'reya] , diarrea', [mi'leyu] ,frassino' (kal. milléu) (Rohlfs 1988: 88) etc. Sporadisch findet sich in dieser Funktion auch [b]: [bo'rekkjə], orecchi` (ALCam: Bagnoli Irpino).

${ }^{125}$ Auch kamp. [v] < lat. B, V, das in schwacher Stellung erhalten bleibt, als [ $\left.\beta\right]$ realisiert oder getilgt wird (s.o.), wird in starker Stellung zu [bb] (Betazismus im eigentlichen Sinne): [a 'vakkə] ,la vacca', aber [tre b'bakkə] ,tre vacche' (Radtke 1997: 69), ['vevərə] ,bere', aber [kə b'bivə] ,Che bevi?' etc. (Avolio 1995: 41f.). Daneben kommt in starker Stellung jedoch auch die Geminate [vv] vor: [e v'vene] ,le vene' (Tulleners-Bloemen 1983: 99).

${ }^{126}$ Sowohl neuere als auch ältere Lehnwörter sind von dieser Variation meist nicht betroffen (Tulleners-Bloemen 1983: 102).

${ }^{127}$ Aus Gründen der Lesbarkeit wird - wie bereits in Kap. 2.3.2 - in den Ausführungen zur Morphologie, zur (Morpho-)Syntax und zum Lexikon auf eine phonetische Schreibweise verzichtet; der Einheitlichkeit halber auch dann, wenn diese im Original vorliegt. Einzelne Kennzeichnungen - wie z.B. die des unbetonten Vokals [ə] (Schwa) - werden jedoch übernommen.
} 
1968: 109). ,Neutra' sind in den kampanischen Dialekten darüber hinaus substantivierte Formen (Pronomen, Adjektive, Adverbien, Verben) wie o nniro ,il nero', o vverde ,il verde', $o$ ddoce ,il dolce', o mmeglio ,il meglio', o nnuosto ,il nostro', o ccerto ,il certo ' (Iannucci 1948: 238), u mmangià ,il mangiare‘, o mmia ,il mio“ (Maturi 2002: 138) etc. ${ }^{128}$

Im Bereich der bestimmten Artikel weisen die kampanischen Dialekte eine hohe Differenzierung auf. Insbesondere im Inland können die Artikelsysteme von Ort zu Ort variieren. Der singularische Artikel für das Maskulinum lautet im Neapolitanischen $o$, während auf Ischia, Pròcida und Capri $u$ dominiert. In weiten Teilen des Inlands (Provinzen Neapel und Caserta, Sannio, westliche Irpinia) besteht Variation zwischen $o$ und $u$ (Radtke 1997a: 82). Die nicht aphäretischen Varianten lo/lu (selten $r u$ ) kommen sporadisch im Norden der Provinz Caserta (vgl. Rohlfs 1968: 109) und im Sannio (Nittoli 1984: 1), größtenteils jedoch in der Irpinia und im (Süd-)Cilento vor (De Blasi 1991: 17, Rohlfs 1988: 92). In der Provinz Caserta und im nordwestlichen Sannio findet sich - wie in den angrenzenden Gebieten des Latium und des Molise - stellenweise auch ju/gliu (De Blasi 2006: 60). ${ }^{129}$ Der singularische Artikel des Femininums tritt im westlichen Teil der Region (Provinzen Neapel und Caserta, sowie im westlichen Sannio) ebenfalls in aphäretischer Form (a) auf (Radtke 1997a: 81, Tommasino/Tommasino 2007: 36), während sich die Vollform la im östlichen Sannio, in der Irpinia und im Cilento findet (Maturi 2002: 139, De Blasi 1991: 17, Rohlfs 1988: 87). Der singularische Artikel der Neutra lautet in Neapel und Umgebung $o$. Variation besteht in der Provinz Caserta und im Sannio zwischen $o$ und $u$ und in der Irpinia und im Cilento zwischen lo/ro und lu/ru (De Blasi 1991: 17, Russo 1988: 22, Rohlfs 1988: 92). ${ }^{130}$

Beim maskulinen Plural-Artikel besteht in Neapel und Umgebung eine Variation zwischen den aphäretischen Formen $e$ (e figli ,i figli ${ }^{`}$, Radtke 1997a: 81) und $i$ ( $i$ sòrdi ,i soldi ${ }^{\star}, \mathrm{De}$ Blasi/Fanciullo 2003: 632). Während sich in der Provinz Caserta und im westlichen Sannio meist $i$ findet (Maturi 2002: 140, sporadisch, z.B. in Gallo auch ri, vgl. Rohlfs 1968: 110), dominiert im (östlichen) Sannio (Nittoli 1984: 1), in der Irpinia und im Cilento die Vollform li: li sòrdi (De Blasi 1991: 17), li riendi (Rohlfs 1988: 87). Der feminine Plural-Artikel lautet in der Provinz Neapel und im angrenzenden Bereich der Provinz Caserta $e$ (Radtke 1997a: 81). Im Norden der Provinz Caserta (Tommasino/Tommasino 2007: 36), im nördlichen Sannio (Maturi 2002: 142) und in der Irpinia findet sich die Vollform le/la (teilweise auch re, De Blasi 1991: 17, Russo 1988: 22). ${ }^{131}$ In den Dialekten des Cilento, die das fünfteilige Vokalsystem aufweisen (vgl. Kap. 3.3.4.1.1), ergibt sich durch den Zusammenfall von auslautendem - $e$ und $-i$ zu $-i$ auch für den femininen Plural der Artikel $l i$ (teilweise auch als lo realisiert, vgl. Rohlfs 1988: 87). Die Artikelsysteme der einzelnen Dialekte können (vor Konsonant) ${ }^{132}$ ausschließlich

\footnotetext{
${ }^{128}$ Zum RS nach dem neutralen Singular-Artikel vgl. Kap. 3.3.4.2.

${ }^{129} \mathrm{Im}$ Sannio (Cerreto Sannita) findet sich - womöglich durch Akzentverschiebung entwickelt aus ju (Maturi 2002: 135) - sporadisch $i$ : i muer, il mare', i puet, il piede', i fualegnèm, il falegname‘ (De Blasi 2006: 56, zum Phänomen der Diphthongierung zu [we] und [wa] vgl. Kap. 3.3.4.1.1).

${ }^{130} \mathrm{Im}$ Sannio (Cerreto Sannita, Gallo) und in der Irpinia finden sich stellenweise auch la bzw. rə (Maturi 2002: 137, De Blasi 2006: 55).

${ }^{131}$ Maturi (2002: 143) stellt fest, dass in einem Großteil des Sannio als femininer Plural-Artikel nicht die Form $e$, sondern die (als solche ebenfalls ein RS erzeugende) Variante $i$ dominiert, die für dieses Gebiet weder im AIS, noch in Rohlfs (1966-1969) belegt ist.

${ }^{132}$ Vor vokalischem Anlaut treten die Artikel immer in apokopierter Form auf (Radtke 1997a: 81, Russo 1988: 19): l'òmmə ,l'uomo' (ALCam: Afragola), r'òva ,le uova', gl'uortə ,l'orto' (Rohlfs 1968: 110) etc. Sporadisch finden sich auch die geminierte Form $l l$ ' bzw. die der Weiterentwicklung der Geminate (vgl. Kap. 3.3.4.1.2) folgenden Varianten $d d^{\prime}$ ' und ggj' [fJ]: ll'acqua ,l'aqua', ll'urmə ,gli olmi', tuttə ll'ossa ,tutte le ossa' (Neapel), dd'arə ,l'aia', dd'ésənə ,gli asini', dd'uórto ,l'orto' (Barano d'Ischia), ggj'érə ,l'aia', ggj'úortə ,l'orto', ggj'achə ,l'ago', ggj’úocchja ,gli occhi‘ (Forio, vgl. Rohlfs 1968: 110f.). Auf Ischia, Pròcida und in Monte di Pròcida lassen sich diese Varianten in der älteren Generation noch in den 1990er Jahren nachweisen: $(d) d$ 'uəssə
} 
aphäretische Formen (Neapel: $o, a, i, e$, vgl. De Blasi/Fanciullo 2003: 632), ${ }^{133}$ ausschließlich Vollformen (San Mango Sul Calore: lo, la, li, le, vgl. De Blasi 1991: 17), Trevico lu, la, li, ri, vgl. Rohlfs 1968: 110) oder aber eine Kombination aus aphäretischen Formen und Vollformen aufweisen (Sessa Aurunca: ru, a, ri, le, vgl. Tommasino/Tommasino 2007: 36).

Im Bereich der Nominalflexion findet sich noch selten und vor allem in ländlichen Gebieten eine Bewahrung des lateinischen Plurals auf -ORA (als -oral-era/-ere oder (mit Liquidentausch) als -ola/-ula/-ela), wenn Gruppen als Kollektiva verstanden werden: e ossere ,le ossa', e latere ,i lati' (Radtke 1997a: 84), ro ddetere ,le dita' (ALCam: Monte di Pròcida), màscure/màscule ,maschi', càsola ,case', múrola ,mura', détela ,dita', lèttela ,letti', chiòvela ,chiodi‘ (De Blasi 2006: 56).

Einige Substantive zeigen Genusvarianten, die häufig eine semantische Differenzierung übernehmen. Das feminine Genus kennzeichnet hierbei meist den größeren Gegenstand, vgl. auf Ischia cuccèro (m.) ${ }^{134}$,cucchiaio metallico (da mangiare) ${ }^{6}$ vs. cucciarə (f.) ,cucchiaio di legno (da cucinare) ${ }^{6}$, pignètə (m.) vs. pignatə (f.) ,pentola (di forme diverse) ${ }^{`}$ (Freund 1933: 68), in der Irpinia cucchiaro ,cucchiaio“ vs. cucchiara ,cazzuola (del muratore), mestolo“ (Russo 1988: 27, Acocella 2002: 45), saccu ,sacco“ vs. sacca ,tasca'(Russo 1988: 27), r'lloggi' ,orologio' vs. r'lloggia, orologio pubblico della torre di città' (Acocella 2002: 98) und im Neapolitanischen vracillo, ciottolino, ghiaia vagliata' vs. vracella, ciottolino di pietra viva (Altamura 1968: 379).

Im Bereich der Verbalmorphologie sind drei Flexionsklassen zu unterscheiden (Radtke 1997a: 86): Klasse I mit der Infinitivendung -à (< lat. -ĀRE), Klasse II mit den Infinitivendungen -'ere bzw. -é (< lat. -ĔRE/-ĒRE) und Klasse III mit der Infinitivendung -ì (lat $<$-İRE). Einige Verben können dabei sowohl nach Klasse II als auch nach Klasse III flektiert werden, vgl. etwa sèntere/sentì ,sentire', sàgliere/saglì ,salire', carélcarì ,cadere' (ALCam). ${ }^{135}$ Der Verbmodus ,Konjunktiv Präsens' existiert in den kampanischen Dialekten nicht. Die einzige Ausnahme bildet das Verb puté ,potere', das im Präsens Konjunktivformen aufweist, die in optativer Funktion gebraucht werden: puozze, (tu) possa' (Freund 1933: 72), pozza, (io/lui/lei) possa', puzzate ,possiate' (Radtke 1988: 657). Der Gebrauch des synthetischen Futurs aus Infinitiv + Form von avé ,avere' (z.B. lavarraggio ,laverò') ist in den kampanischen Dialekten selten. Stattdessen werden der Indikativ Präsens oder periphrastische Formen mit dem Verb $(j) \grave{\imath}$ ,andare', z.B. vaco a dicere ,dirò' verwendet (Radtke 1997a: 88). Bei der Wahl des Auxiliarverbs zur Konstruktion des Passato Prossimo (avé oder esse) existieren regionale Unterschiede: Während im Neapolitanischen - auch bei reflexiven Verben - überwiegend avé gebraucht wird (aggio fatto ,ho fatto', iti venuti (priesto), siete venuti (presto)' (De Blasi 2006: 57), m'aggio lavato ,mi sono lavato“, Radtke 1997a: 87), werden im Inland beide Varianten verwendet oder es dominiert (wie etwa im Sannio) èsse (so' fatto ,ho fatto', so' capito ,ho capito', vgl. Radtke 1997a: 87f.).

Im Bereich der Wortbildung (Derivation) ist für die kampanischen Dialekte - wie für die süditalienischen Dialekte insgesamt - das Suffix -illo (fem. -élla) charakteristisch: nənillo

,l'osso' - $(d)$ d'ossara ,le ossa', $(d)$ d'ogna ,l'unghia' - $(d) d$ 'ognara ,le unghie‘ (ALCam: Monte di Pròcida), $(d) d$ 'uassa ,l'osso“ - $(d) d$ 'òss ,le ossa', $(d) d$ 'òmma ,l'uomo' (ALCam: Pròcida), ggj'oss ,le ossa' (ALCam: Forio).

${ }^{133}$ Dass der Dialekt von Avellino ebenfalls die aphäretischen Formen $o, a, i, e$ aufweist (Russo 1988: 22) zeigt, dass hier - zumindest in diesem strukturellen Bereich - eine Nähe zu den (westlich angrenzenden) Dialekten der Provinz Neapel und deutliche Unterschiede zu den (östlich und südöstlich angrenzenden) Dialekten der Irpinia bestehen.

${ }^{134}$ Zur metaphonischen Palatalisierung von [a] zu [ع] vgl. Kap. 3.3.4.1.1.

${ }^{135}$ Einen Überblick über die Paradigmen regelmäßiger sowie frequenter unregelmäßiger Verben geben De Blasi/Imperatore (2000: 88ff.). Vgl. auch Bichelli (1974: 155ff.). 
$(<$ ninno ,bimbo')/nənélla, palillo (< pilo ,pelo“) (Iannace 1983: 51), ratilla (< rita ,dito', ALCam: Cava dei Tirreni), brudillo (< brudo ,brodo')/brudélla (Iannace 1983: 50). Es findet sich auch in der Form -lillo (fem. -lélla): ruzzulillo $(<$ ruzzo ,rozzo')/ruzzulélla, sturtulillo $(<$ stuórto ,storto')/sturtulélla (Iannace 1983: 51/52), autolillo, altetto' (< auto ,alto'), allegrolillo (Rohlfs 1969: 403). Typisch ist das Suffix auch bei der Bildung von Hypokoristika: Jasillo ,Biagio“, Jacolillo ,Giacomo“ (Rohlfs 1969: 404). Produktiv sind heute die Suffixe -iéllo, -èlla als adaptierte Formen der italienischen Suffixe -ello, -ella: ainiéllo (<àino ,montone')/ainèlla, mantiéllo (< manto ,manto')/mantèlla, paisiéllo (< paesa), panariéllo $(<$ panaro ,paniere')/panarèlla (Iannace 1983: 48/49), Franceschiello, Vincenzella (Radtke 1997a: 84). Als erweiterte Formen finden sich hier -ciéllo/-cèlla: limunciéllo (<limone)/limuncèlla, maccarunciéllo (< maccarona), wagliunciéllo (< wagliona ,ragazzo')/wagliuncèlla etc. (Iannace 1983: 53), -tiéllo/-tèlla: funcetiello, archetiello (Rohlfs 1969: 403), giarrotiello/giarrotèlla (< giarra ,anfora'), pescatiéllo (Iannace 1983: 53) etc. sowie -riéllo/-rèlla, vor dem die Basis regelmäßig auf -a endet: vantariéllo (< viénto), bunariéllo (< buóno)/bunarèlla etc. (Iannace 1983: 54).

\subsubsection{4 (Morpho-)Syntax}

Auch im Bereich der (Morpho-)Syntax zeigen die kampanischen Dialekte einige Besonderheiten, die im Folgenden kurz angesprochen werden sollen. Wie in den meisten süditalienischen Dialekten wird im Kampanischen tené statt avé (ital. avere, im Sinne von ,possedere') als Vollverb verwendet: Tengo a freva ,Ho la febbre“ (Rohlfs 1969: 126). In Konstruktionen mit Partizip Passiv übernimmt tené teilweise auch die Funktion eines Auxiliars: Saccio ca tiene lu fuoc' allumato ,So che hai acceso il fuoco' (Rohlfs 1969: 127). Eine Besonderheit im Bereich der Kopulaverben besteht darin, dass sich stà ,stare" nicht nur bei Angaben zu einer transitorischen, sondern auch zu einer permanenten Position im Raum belebter oder unbelebter Referenten findet und sich in dieser Funktion gegenüber èsse ,essere' bereits seit dem 16. Jh. vollständig durchgesetzt hat (Ledgeway 2009: 650): 'A montagna che sta addereto 'a cità ,La montagna che è/si trova dietro la città', Sto a Roma, steva a Milano ,Sono a Roma, ero a Milano' (ebd.). ${ }^{136}$

Statt der modalen Konstruktion dovere + Infinitiv wird in den kampanischen Dialekten häufig die Konstruktion avere + Präposition + Infinitiv gebraucht. Dabei haben die Flexionsformen von avere in allen Personen bis auf die 3. Pers. Sg. mit der Präposition $a$ agglutiniert: aggia (< aggəa) fà , ho da fare' = ,devo fare', aveva (< avevəa) fà , avevo da fare' etc., aber àdda $(<a$ da $)$ fà , ha da fare ${ }^{،}=$, deve fare‘ (De Blasi/Fanciullo 2003: 637). ${ }^{137}$ Zum Ausdruck des durativen Aspekts wird neben der Konstruktion stà ,stare‘ + Gerundium (Stó ppazziannə ,Sto scherzando', vgl. Avolio 1995: 73) auch die Konstruktion $i$, andare‘ + Gerundium verwendet, die neben der zeitlichen Dauer eine gleichzeitige Veränderung der Position im Raum ausdrückt: neap. Chə bbannə facènnə? ,Che stanno (lit.: vanno) facendo?' (ital. Che cosa stanno facendo così in giro?, ebd.: 55).

\footnotetext{
${ }^{136}$ Auch in existentieller Funktion findet sich stà statt èsse, d.h. cə sta(nnə) ,c'è/ci sono': Quanno int' 'o core nun ce sta cchiù ammore, Quando dentro al cuore non c'è più amore' (Ledgeway 2009: 650).

${ }^{137}$ Auffällig ist dabei, dass die Präposition $a$, die normalerweise ein RS auslöst (vgl. Kap. 3.3.4.2), dieses in der Agglutination mit avere nicht induziert (aggia fà, nicht *aggia ffà). Während nach Rohlfs (1969: 237) die Präposition $a$ kein RS auslöst, „quando serve a stabilire il legame tra un verbo modale e un infinito“, handelt es sich für De Blasi/Fanciullo (2003: 637) hier nicht um die Präposition $a$, sondern wie im Falle der 3. Pers. Sg. um die - in den süditalienischen Dialekten kein RS auslösende - Präposition $d a$,nella veste fonetica $a$ dappertutto, meno che alla $3^{\text {a }}$ singolare dell'indicativo presente (dove la $d$-della preposizione viene salvata e anzi rafforzata dal potere geminante di $a$, ha ' $<*$ HAT). " Hinsichtlich der Elision des Anlautkonsonanten von $d a$ (sowie dessen Verdoppelung in starker Stellung) verweisen De Blasi/Fanciullo (ebd.) auf die analoge Entwicklung der Präposition de ,di“ in den kampanischen Dialekten: e Nàpula e dde Saljernə ,di Napoli e di Salerno‘.
} 
Zur Referenz auf Mengen werden in den kampanischen Dialekten statt eines Teilungsartikels (ital.: $d i+$ best. Artikel) oft Numeralia oder Kollektiva verwendet, z.B. duje sciure ,dei fiori', M'accatto quatt'alice ,Vado a comprare delle alici', nu poco 'e caso ,del formaggio“ (Radtke 1997a: 83, nach De Blasi 1995: 60). Partitivkonstruktionen mit de (neap. rə) treten jedoch an anderer Stelle auf: n' amikə r'o mia , un mio amico' (lit.: , un amico del mio'), wobei das Pronomen in Genus und Numerus mit dem Kopf der NP kongruiert: n'amica r' a mia , una mia amica' (lit.: , una amica della mia', Sornicola 1997: 334). Der Anschluss eines Genitivattributs erfolgt teilweise ohne Präposition: lu peride la vernate ,il periodo dell'inverno' (Raucci 1993/1994: 120, zit. in Radtke 1997a: 92). ${ }^{138}$ Zu den besonderen morphosyntaktischen Charakteristika der kampanischen Dialekte gehört im nominalen Bereich auch die enklitische Verwendung der Possessivadjektive der 1. und 2. Person Singular bei Verwandtschaftsbezeichnungen, insbesondere wenn diese im Singular stehen: fràtemə ,mio fratello', sòrəmə ,mia sorella', pàt(r)əmə ,mio padre', màmmətə ,tua madre‘, marìtəmə ,mio marito“ etc. (Maturi 2002: 181, vgl. auch Iannace 1983: 55).

Des Weiteren finden sich in den kampanischen Dialekten spezielle Formen des Gebrauchs von Pronomina. Demonstrativpronomina können als semantisch leere Subjektpronomen (Sornicola (1997): dummy subjects) auftreten, die mit einer vollen Subjekt-NP koreferent und morphologisch kongruent sind, wobei das Demonstrativum und die Voll-NP adjazent sein können, aber nicht müssen: Chella ${ }_{i}$ 'a fibbia $s_{i}$ 'è rotta ,Quella fibbia s'è rotta' (lit. ,Quella la fibbia s'è rotta', Ledgeway 2011: 3), Chell' ${ }_{i}$ arrivaja a patrona ${ }_{i}$,Quella patrona arrivò (lit. ,Quella arrivò la patrona', Sornicola 1997: 335). ${ }^{139}$ Als Expletivpronomen, d.h. ohne Präsenz einer koreferenten Voll-NP, findet sich chello/chella (neutr. Sg.) ,quello“ häufig bei meteorologischen Verben: Chella chiove, Quello piove“ (ital. Piove, ebd.). Semantisch leere indirekte Objektklitika (Sornicola (1997): dummy objects), die mit einer vollen (indirekten) Objekt-NP morphologisch kongruent und koreferent sind, treten häufig dann auf, wenn diese dem flektierten Verb folgt und kein overtes Subjekt vorhanden ist: Coi cuntaja o fatt a la cummare $_{i}$,Raccontò il fatto alla vicina' (lit. ,Le raccontò il fatto alla vicina' ${ }^{140}$, Cəi purtaja nu rjalə a Mariai ,Portò un regalo a Mario“ (lit. ,Gli portò un regalo a Mario“, Sornicola 1997: 335, 336).

Auch im Bereich der Verbrektion weisen die kampanischen Dialekte einige Besonderheiten auf, die sie mit vielen süditalienischen Dialekten teilen. Ist ein proklitisches Pronomen der Kopf einer Objekt-NP, erscheint es häufig im Akkusativ (auch dort, wo das Verb im Italienischen den Dativ regiert): O telefunaja ,Gli telefonò ', A rètto na parata ,Le dette un calcio“ (ebd.: 336). ${ }^{141}$ In betonter (postverbaler) Stellung werden direkte Objekte in den kampanischen Dialekten mit der Präposition $a$ angeschlossen, wenn es sich um ein belebtes Objekt handelt (Differenzielle Objektmarkierung, vgl. Bossong 1991): ${ }^{142}$ Aspett' a Pietro ,Aspetto Pietro',

\footnotetext{
${ }^{138}$ Vgl. auch Rohlfs (1969: 5f.).

139 Vgl. auch Radtke (1997a: 83, 86) und Maturi (2002: 225ff.). Ledgeway (2011: 4f.) bekräftigt Sornicolas (1996: 326-327) Hypothese, dass im Falle von Adjazenz Pronomen und Voll-NP keine gemeinsame Konstituente bilden, mit der Beobachtung, dass bestimmte phonosyntaktische Regeln wie das raddoppiamento sintattico (vgl. Kap. 3.3.4.2) oder die Elision unbetonter Auslautvokale bei adnominalen Demonstrativa in diesen Fällen nicht greifen: „Chell[ə] $]_{\mathrm{i}}\left[\mathrm{DP}\left[\int\right]\right.$ ierti/*[tt $\left.\int\right]$ ierti mugliere $]_{\mathrm{i}}$ nun so' gelose“; „Chillo/*Chill' ${ }_{\mathrm{i}}[\text { Arturo }]_{\mathrm{i}} \mathrm{m}$ 'ha mannata na lettera“" (Ledgeway 2011: 4f.).

${ }^{140}$ Cummare bedeutet eigentlich ,Patentante“ (ital. madrina). Die hier wiedergegebene Übersetzung lautet jedoch „,she told TO-HER the fact to the neighbour woman“" (Sornicola 1997: 335).

${ }^{141}$ Hinsichtlich der Verben, die den Akkusativ statt des Dativs regieren, scheinen diatopische Unterschiede zu bestehen, vgl. neap. *o parlaja ,gli parlai` (c parlaja) vs. lu parléra gegu, io gli parlerei` (Teggiano (SA), AIS 1627, nach Sornicola 1997: 336).

142 „L'impiego della preposizione è certamente determinato dal bisogno di una più netta distinzione tra soggetto e oggetto [...]. Il fenomeno resta circoscritto agli esseri animati, perché di norma gli oggetti inanimati possono aver soltanto funzione d'oggetto [...]“ (Rohlfs 1969: 8).
} 
Èggio chiamat' a Maria ,Ho chiamato Maria' (Iannace 1983: 30), È vist' a u zì ,Ha visto lo zio', obbligav' a u fratella ,obbligava il fratello“ (Maturi 2002: 229, 230).

Wie in anderen süditalienischen Dialekten werden in den kampanischen Dialekten intransitive (meist unakkusative) Verben häufig transitiv gebraucht, wobei zwischen dem intransitiven und dem transitiven semantischen Kontext meist eine kausative Verbindung besteht: Sagliètte 'n coppə ,Salì sopra' neben Sagliètte o panarə 'n coppə ,Faceva salire sopra il paniere'; Scennètt' abbasciə ,Scese (giù)' neben Scennètt' o panare p' a fanèstz ,Faceva scendere il paniere giù attraverso la finestra'; Rumanètte sula ,Rimaneva solo' neben Ma rumanètte n'ammasciata pə’ tte ,Mi lasciò un messaggio per te' (Sornicola 1997: 337, vgl. auch Ledgeway 2009: 850f.).

Ein letztes strukturelles Phänomen der kampanischen Dialekte, das hier erwähnt werden soll, ist das che polivalente, bei dem die Partikel $c a$,che' in verschiedenen syntaktischen Funktionen gebraucht wird (Radtke 1997a: 92). Sie fungiert zum Einen als , universales` Relativpronomen: a vammana ch'aggio parlato ,l'ostetrica della quale/con la quale ho parlato', o farfariello ca tutte se mettono a paura, il folletto di cui tutti hanno paura' (Bichelli 1974: 153), ogni parte ca sò jutə ,ogni posto dove sono andata' (Maturi 2002: 112). Zum Anderen erscheint sie in adverbialen Nebensätzen als ,,passe-partout-Konjunktion“ (Koch/Oesterreicher 1990: 99), deren semantisch-logischer Wert (kausal, temporal, final etc.) ${ }^{143}$ allein durch den Kontext bestimmt wird (ebd.): ${ }^{144}$ Appila, ca nn'esce feccia ,Tappa, perché non esce la feccia' (D'Ambra 1873: 88), Nun chiamà tristu, ca peggiu te vene ,Non lamentarti perché può accaderti di peggio“ (Russo 1988: 148).

\subsubsection{Lexikon}

Auch hinsichtlich des Lexikons sind die kampanischen Dialekte - mit Ausnahme des Neapolitanischen - in der wissenschaftlichen Dialektologie wenig berücksichtigt worden: ,,[M]ancano quasi del tutto studi specifici non solo sull'insieme del lessico dialettale del Sud e del Centro della Penisola [italiana, S.H.], ma anche su specifici settori del patrimonio lessicale di aree relativamente omogenee o più ristrette, mentre i vocabolari dialettali di singoli comuni o città, spesso opera di studiosi dilettanti, si collocano su livelli assai diseguali““ (Avolio 1995: 56). Trotz dieser spärlichen wissenschaftlichen Forschungsgrundlage soll im Folgenden der Versuch eines Überblicks über die lexikalischen Besonderheiten der kampanischen Dialekte sowie ihr fremdsprachiges Lehnwortmaterial unternommen werden, wobei insbesondere die unterschiedlichen geographischen Verbreitungsgebiete der verschiedenen Lexeme bzw. Lexemgruppen im Vordergrund stehen.

Viele der dialektalen Lexeme, die in großen Teilen der Campania vorkommen, finden sich auch in den übrigen dialetti (centro-)meridionali und insbesondere in den Dialekten der angrenzenden Gebiete anderer Regionen (Molise, Südlatium, westliches Apulien und Basilicata): accattà ,comprare', assettarse ,sedersi', capa ,testa' (De Blasi 2006: 73), alluccà ,urlare', appiccià , accendere', cəcatə ,cieco', faticà ,lavorare', femmənə ,donna', ì , andare', mò

\footnotetext{
${ }^{143}$ D’Ambra (1873: 88) gibt die Bedeutungen ,perocché, conciossiacchè, dappoiché, poiché‘ an.

${ }^{144}$ Koch/Oesterreicher (1990: 99) analysieren das che polivalente als ,universales“ Merkmal des gesprochenen Italienisch - ,universal“ in dem Sinne, dass es auf die „universalen Kommunikationsbedingungen und Versprachlichungsstrategien“ (ebd.: 50) des Nähesprechens zurückzuführen ist. Auf der historisch-einzelsprachlichen Ebene liegt es jedoch nah, dass die semantische Flexibilität der dialektalen Konjunktion $c a$ zu einer Verfestigung des Phänomens im gesprochenen Italienisch der Region Kampanien (wie auch in anderen (süd-)italienischen Regionen) beigetragen hat.
} 
,adesso', patanə ,patata', pazzià ,scherzare', renə ,sabbia', sicchə ,magro', sor (i)cə ,topo ', sparagnà ,risparmiare' (Avolio 1995: 56ff.) etc. Die in weiten Teilen der Campania verbreiteten Lexeme finden sich insbesondere in den in der Alltagskommunikation frequenten semantischen Bereichen ,Körper/Gesundheit' (mola ,dente molare', catarro ,raffreddore' (De Blasi 2006: 80), coscia ,gamba', rine (P1.) ,schiena', faccia ,guance (P1.)‘ (Radtke 1997a: 97) etc.), ,Nutzpflanzen und ihre Produkte' (cocuzza ,zucchina', mulignana ,melanzana', pastenaca ,carota gialla', accio ,sedano', cerasa ,ciliegia' (Radtke 1997a: 97), crìsceto ,lievito', vrenna ,crusca', vasenècola ,basilico“ (De Blasi 2006: 80) etc.), ,Bewegungen/Äußerungen“ (appilà ,otturare‘, azzeccà ,appiccicare', 'ntuppà ,urtare', scetarsi ,svegliarsi', ebd.). Ein typisch westkampanisches Lexem ist 'ncoppa ,sopra', dem in der Irpinia und im Cilento 'ngimma, in cima' und im Cilento zusätzlich 'nguodde ,in collo' entsprechen (De Blasi 2006: 80, Russo 1988: 112).

Daneben finden sich lexikalische Elemente, deren Verbreitung auf bestimmte kompakte Gebiete innerhalb der Region beschränkt ist. Hier zeigt sich insbesondere die Sonderstellung der Metropolregion Neapel, wo sich viele Lexeme und Kollokationen finden, die in den übrigen Teilen der Region deutlich weniger verbreitet sind oder überhaupt nicht vorkommen. Diese stammen insbesondere aus den Bereichen Gastronomie, Kultur und Gesellschaft: prussiana ,tipo di dolce', pàccaro ,schiaffo' (Pl.: ,tipo di pasta'), basso ,terraneo usato come abitazione‘, 'nturzato ,gonfio', Vaco 'n freve ,Perdo la calma', 'a copp'a mano ,di rimando, prontamente', pane cafone ,pane proveniente dai paesi del circondario e cotto nel forno a legna', sapunaro ,straccivendolo', scugnizzo ,piccolo giovanissimo delinquente‘ (De Blasi 2006: 82), pezzottato/pezzotto ,fasullo, taroccato, falso ‘ (De Blasi 2001: 96), tenere 'o ggenio ,avere voglia' (De Blasi/Fanciullo 2003: 640) etc.

Neben Lexemen, die auf das (Vulgär-)Lateinische zurückgehen, findet sich in den kampanischen Dialekten eine hohe Anzahl von Lehnwörtern aus den in den unterschiedlichen Siedlungs- und Herrschaftsepochen präsenten Super- und Adstratsprachen. ${ }^{145}$ Als weit über tausendjähriges Kulturadstrat hat vor allem das Griechische in den kampanischen Dialekten deutliche Spuren hinterlassen. ${ }^{146}$ Über die gesamte Region verteilt finden sich u.a. folgende Gräzismen (Rohlfs 1988: 108f., 1933: 249f., vgl. auch Avolio 1995: 22):

abbragátu/abbrugátə ,rauco“ < gr. $\beta \rho \alpha \gamma \chi o ́ \varsigma,{ }^{147}$

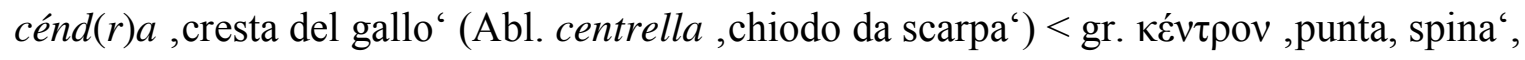

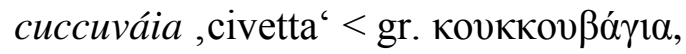

\footnotetext{
${ }^{145}$ An dieser Stelle wird das auf Walther von Wartburg (1950) zurückgehende Verständnis des Begriffs Superstrat (als Komplement zu dem von G. I. Ascoli geprägten Terminus Substrat) zugrunde gelegt; eine Diskussion der wissenschaftlichen Tauglichkeit der Begriffe kann hier nicht vorgenommen werden (vgl. dazu Dietrich 2005). Zu den kampanischen Toponymen, in denen sich Spuren der Superstrate erhalten haben vgl. Kap. 3.2.2, FN 74. Zu den Spuren der Substratsprachen in den kampanischen Dialekten vgl. Kap. 3.2.1, FN 65.

${ }^{146}$ Viele Gräzismen teilen die kampanischen Dialekte mit anderen dialetti meridionali: „Una gran parte di questi grecismi che in origine dovevano limitarsi alle regioni di popolazione mista, trovarono ben presto accoglienza nella lingua comune dell'Italia meridionale“ (Rohlfs 1933: 248). Die Frage, inwiefern das Griechische in Süditalien nicht nur als Kulturadstrat, sondern (zu Zeiten der Magna Graecia, vgl. Kap. 3.2.1) auch als Substrat wirksam gewesen ist, ist bis heute nicht endgültig geklärt, da in vielen Fällen umstritten ist, auf welche Epoche die griechischen Elemente genau zu datieren sind (vgl. Hubschmid 1958: 412f.). Rohlfs (1988: 117f.) betont zwar, dass kein sicheres historisches Indiz existiert, das es erlaubt, die griechischen Lehnelemente (hier: in den Dialekten des Cilento) auf eine bestimmte Periode zurückzuführen, vertritt jedoch die These, dass diese ,überwiegend“ aus der Antike, d.h. aus vorrömischer Zeit stammen („Kontinuitätstheorie“ (Hubschmid 1958: 405), vgl. auch Rohlfs 1933). Alessio (1942/43) zufolge stammen die Gräzismen hingegen aus nachrömischer, d.h. byzantinischer Zeit (,teoria «bizantinistica»“"(Parlangèli 1960: 67), vgl. Morosi 1994 [1870]).

${ }^{147}$ Hier und im Folgenden gilt: Wird die Bedeutung des Etymons nicht angegeben, so ist diese identisch mit der des genannten kampanischen Lexems.
} 


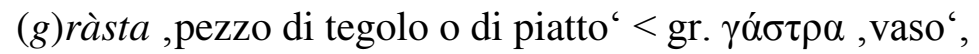
mátra ,madia'< gr. $\mu \alpha \kappa \tau \rho \alpha$,

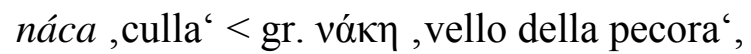
píro ,trottola' < gr. $\pi \tilde{\varepsilon i \rho o} \varsigma$,piuolo',

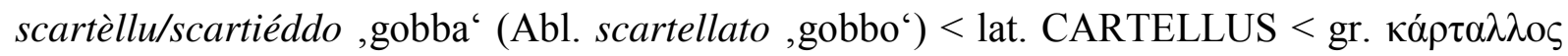
,tipo di cesta', spára ,cercine, cencio di cucina'< gr. $\sigma \pi \tilde{\varepsilon i \rho} \alpha$,cercine‘, strúmmulu ,trottola' < gr. $\sigma \tau \rho o ́ \mu \beta o \varsigma ~(* \sigma \tau \rho ́ ́ \mu \beta v \lambda o v)$,

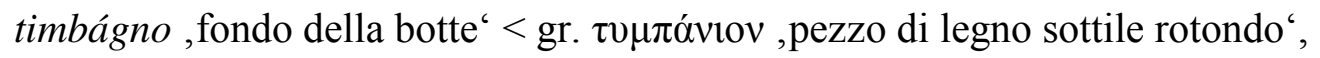
tropéa ,temporale d'estate di breve durata ‘ $<$ gr. $\tau \rho о \pi \alpha i ́ \alpha$,rivolgimento del vento“, vállini $<$, castagne lesse ${ }^{\text {' }}<$ gr. $\beta \alpha ́ \lambda \alpha v o \zeta$, ghianda, castagna', vòcola ,culla'< agr. $\beta \alpha v \kappa \alpha \lambda \alpha ́ \omega$, cullare',

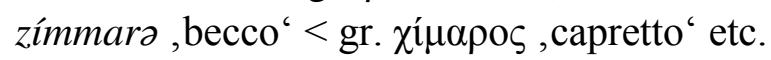

Andere griechische Elemente sind in ihrer Verbreitung hingegen (innerhalb der Campania) auf

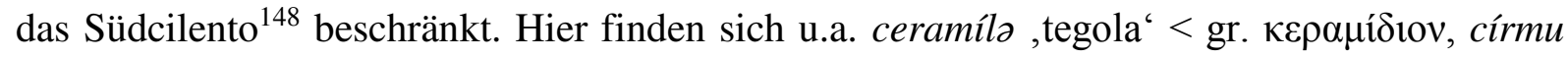

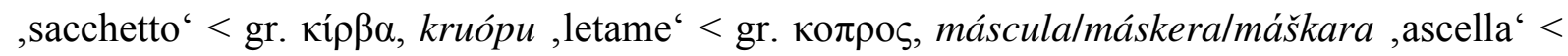

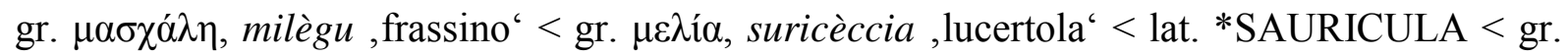

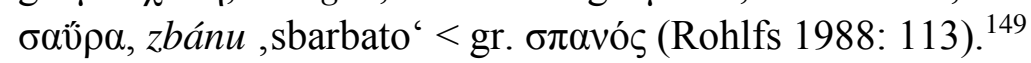

Die in den kampanischen Dialekten vorhandenen Germanismen sind größtenteils auf das langobardische Superstrat (6. - 11. Jh.) zurückzuführen, darunter

arraffà , afferrare con violenza' $<$ langob. *(h)raffōn, iéffula ,involto, ciocca' < langob. wîffa ,ciuffo di paglia come segnale, matassa', nocca , giuntura' < langob. *knohha (Sabatini 1963: 214ff.),

pacca, natica“ (Abl. pàccaro ,schiaffo') < langob. *pakka (D’Ascoli 1993: 499), prèdula ,sgabello'< langob. *bredil/predil/pretil,

rosta, Abl. rostina ,cespuglio“ < langob. *(h)rausta ,intreccio di frasche“, spaccà ,fendere, spezzare, dividere' < langob. *spahhan, squiglio ,germoglio' < langob. quillan ,sprizzare', staffone ,predellino o montatoio della carrozza $<$ langob. *staffa,stummo ,moncherino, storpio“ < langob. *stumb(al)/*stumpf, moncherino, tronco, ceppo“ (Sabatini 1963: 214ff.), vàfio/gàfio ,pianerottolo esterno ‘ < langob. *waif ,comune, non appartenente a nessuno (Bianchi/De Blasi/Librandi 2002: 631),

zizza ,mammella' < langob. *zizza (Sabatini 1963: 240).

Durch den Sprach- und Kulturkontakt zu den Sarazenen (vgl. Kap. 3.2.1) fanden im frühen Mittelalter zudem einige Arabismen Eingang in die kampanischen Dialekte: neap. cannacca ,collana (per donna) ${ }^{\prime}<$ ar. hannaqa ,monile, collana', neap. giarra , boccale per acqua' < ar. ğarra, neap. ziro ,grosso recipiente di terracotta o d'altro materiale per olio ‘ < ar. zir ,orcio',

\footnotetext{
${ }^{148}$ Die speziellen Gräzismen der Dialekte des Cilento finden sich auch in den angrenzenden Gebieten der Basilicata (südlicher Teil der Provinz Potenza) und in der nördlichen Calabria (nördlicher Teil der Provinz Cosenza): „,[L]a grecità del Cilento non rappresenta una particolarità di questa zona. Essa costituisce piuttosto un insieme organico con la grecità del territorio di confine calabro-lucano" (Rohlfs 1988: 114).

${ }^{149}$ Rohlfs (1988: 109) nennt hier auch gunúcciu ,ginocchio“ und denkt dabei an den Einfluss von gr. yóvv, ,se non si vuol ritenere che queste forme conservino una forma regionale di latino provinciale (*GONUCULUM), che aveva lo stesso grado di gr. yóvv.“
} 
neap. túmmulo ,tomolo (misura di capacità per aridi), una grande quantità, catafalco ‘ < ar. tumn ,un ottavo, misura di capacità‘ (mlat. tumülus/tumǐnus ,catafalco‘, D’Ascoli 1993). ${ }^{150}$

Während der normannischen Besetzung (11. Jh.) wurden einige Gallizismen in die kampanischen Dialekte übernommen: perciare , bucare' $(<$ frz. percer), davon abgeleitet perciante ,persona noiosa' und perciatielli, maccheroni lunghi', sowie vanella ,viuzza' $(<$ frz. venelle) (De Blasi 2006: 17). Der durch die angevinische Herrschaft zustande gekommene Kontakt mit der französischen Kultur und Sprache führte zur Integration von weiteren Gallizismen in die kampanischen Dialekte. Das prominenteste Beispiel ist hier wohl guaglione ,ragazzo“ (über Dissimilation aus guagnone ${ }^{151}<$ mfrz. wagnor , lavoratore dei campi ${ }^{`}$, vgl. Fanciullo 2002: 24), das sich bis heute sowohl in der maskulinen Form (auch als uaglione oder vaglione) ${ }^{152}$ als auch in der femininen Form ( $\left(\right.$ g)uagliona/vagliona ,ragazza $\left.{ }^{\circ}\right)$ in einem Großteil der kampanischen Dialekte findet (De Blasi 2009: 33, vgl. auch ALCam). ${ }^{153}$ Unter den im 13. und 14. Jahrhundert im Neapolitanischen gebräuchlichen Gallizismen, die insbesondere aus dem konzeptuellen Bereich des Rittertums (frz. chevalerie) stammen und häufig im Provenzalischen ihren Ursprung haben, finden sich u.a. astivamente , affrettatamente' $<$ afrz. hastivement, aprov. astivamen, bazellaria/pacillaria, coraggio cavalleresco' $<$ afrz. bacheler, giovane in attesa dell'investitura a cavaliere ${ }^{154}$, camaglio , cappuccio di maglia di ferro' < afrz. camail/aprov. capmalh, magagnare ,ridurre malconcio ‘ < aprov. maganhar, tropiello ,drappello' < aprov. tropel, stantale, stendardo' < afrz. estandart, arnese , armi ' < afrz. herneis (evtl. bereits in normannischer Zeit entlehnt, De Blasi 2012: 30ff.). Französischen Einfluss zeigen zudem zahlreiche Wortbildungen mit dem Suffix -anza (frz. -ance), etwa in amanza, certanza, delicanza, fidanza, lianza, moderanza, pietanza, speranza, venyanza (ebd.).

In der aragonesischen Herrschaftsperiode drangen durch die Immigration insbesondere katalanischer Siedler Katalanismen wie priarse ,rallegrarsi, gioire' < kat. prehar (D'Ascoli 1993: 561), tràstola ,traffico poco limpido“ < kat. traste ,masserizia, bagaglio“ und caracò ,scala a chiocciola' < kat. caracòl ,chiocciola' (De Blasi 2006: 18f.) in das Neapolitanische ein. Zur Integration einer großen Anzahl an Hispanismen führte der starke soziokulturelle Einfluss des Spanischen während des etwa dreihundertjährigen Viceregno. Unter den in dieser Zeit übernommenen spanischen Lehnwörtern sind u.a.:

ammuinà ,infastidire, annoiare‘ < span. amohinar (Beccaria 1985: 68),

attrassà ,lasciar sospeso, tralasciare, lasciare arretrato (un lavoro o.a.), ritardare (i pagamenti o.a.), rientrare (del latte, del sudore ecc.) ${ }^{6}<$ span. atrasar ,restare indietro' zu atrás ,dietro', Abl. attrasso ,rimanenza, residuo (di un lavoro)', attrassarse ,arrestarsi“ (D’Ascoli 1993: 92) $)^{155}$

\footnotetext{
${ }^{150}$ Aufgrund der wiederholten Besetzung verschiedener Teile Süditaliens durch die Sarazenen finden sich die genannten Arabismen auch in anderen süditalienischen Dialekten wieder (vgl. die Beispiele in Avolio 1995: 25). ${ }^{151}$ Guagnone findet sich heute insbesondere in der Basilicata in der Bedeutung ,giovane aiutante nel lavoro dei campi` (De Blasi 2009: 33).

${ }^{152}$ Zur Entwicklung von anlautendem G in den kampanischen Dialekten vgl. Kap. 3.3.4.1.2.

${ }^{153}$ In der Irpinia und in einem Teil der Provinz Salerno findet sich derselbe Wortstamm teilweise mit anderem Suffix: vagliotta (dim. vagliòttella), (g)uagnarda, uagnardazza (pej.), De Blasi (2006: 48).

${ }^{154}$ Das FEW (I, 198) belegt allerdings auch afrz. bachelerie ,qualités d'un bachelier, bravoure, habilité etc.; adolescence, jeunesse, guerrière', sodass es sich bei bazellarialpacillaria möglicherweise auch um eine direkte Entlehnung der Ableitung aus dem Französischen handelt.

${ }^{155} \mathrm{Ob}$ arrassà , allontanare, scostare' (Abl. arrasso ,lontano', arrassarse, allontanarsi ') auch auf span. atrasar zurückgeht, ist noch ungeklärt. Neben der direkten Weiterführung von lat. AD-RETRAXĀRE werden als weitere mögliche Etyma gr. rhassō ,battere, urtare', ar. arasa/harascia/harasa/arrada, allontanare', span. arrancar (u.a. ,allontanare, distogliere`) und gr. arássōo (verschiedene Bedeutungen) genannt (D’Ascoli 1993: 72).
} 
atturrà ,tostare' < span. turrar (Beccaria 1985: 69),

cantimbrora, vaso di stagno o di vetro con ghiaccio“ < span. cantimplora (D’Ascoli 1993: 142), coviglia ,sorta di semifreddo " < span. cubillo , secchiello per conservare le bevande fredde a tavola' (De Blasi 2006: 64),

guappo ,camorrista, bravaccio, gradasso“ < span. guapo ,mascalzone, ruffiano“ (D’Ascoli 1993: 330f.),

marvizzo ,tordo' < span. malvís (D’Ascoli 1993: 388),

'ngarrà ,indovinare, azzeccare, imbroccare' < span. engarrar ,ottenere, afferrare, conseguire (D’Ascoli 1993: 461),

'ngarzà ,commettere, calettare‘ < span. engarzar, incastonare, incatenare‘ (D’Ascoli 1993: 461),

làzzaro ,giovane volgare e impertinente, povero diavolo“ (Abl.: lazarone, lazariello) < span. làzaro ,lebbroso“ (D’Ascoli 1993: 352f.),

palià ,bastonare' < span. apalear (Beccaria 1985: 69),

scapece ,tipo di salsa piccante' < span. escabeche (D’Ascoli 1993: 637),

ufano/ofano, vano, vanaglorioso, ampolloso ‘ < span. ufano, Abl. ufanità/ofanità , vanagloria, boria, presunzione' (Beccaria 1985: 182) sowie das bei der Anrede männlicher Personen hohen sozialen Ranges dem Personennamen vorangestellte Don (D’Ascoli 1993: 262, Radtke 1997: 90).

Im 18. und 19. Jahrhundert wurden die kampanischen Dialekte erneut stark von der - in dieser Zeit in ganz Europa hegemonialen - französischen Kultur und Sprache beeinflusst. Unter den zahlreichen - insbesondere aus den Bereichen der Gastronomie und der Mode stammenden Französismen sind einige insbesondere in Neapel auch heute noch gebräuchlich: gattò ,pasticcio di patate' $<$ frz. gâteau, crocchè , polpettina di patate frittata' $<$ frz. croquette, sartù , timballo di riso' < frz. surtout, ra $(g) \grave{u}$, sugo di carne' < frz. ragoût (De Blasi/Fanciullo 2003: 629), buffè < frz. buffet (D'Ascoli 1993: 120). Im frühen 19. Jahrhundert dokumentiert sind u.a. frambuas ,lampone' < frz. framboise, gosce ,sguaiato' < frz. gauche, adruà , agile' < frz. adroit, garson ,scapolo' < frz. garçon, bisciù , gioielli' < frz. bijoux, tricotté , lavorare a maglia' < frz. tricoter (De Blasi 2012: 105).

\subsubsection{Die Problematik der dialektalen Binnengliederung}

In der bisherigen sprachgeographischen Forschung ist nicht nur das Problem der Abgrenzung des kampanischen Dialektgebietes nach außen, sondern auch die Frage der dialektalen Binnengliederung noch nicht geklärt worden. Die Feststellung, die bereits Pellegrini (1977, S. 31: „Manca una suddivisione scientifica dei dialetti campani [...]") und gut zehn sowie fünfzehn Jahre später Radtke (1988 und 1993, S. 445: „Eine solide Klassifikation der kampanischen Mundarten steht aus [... $\left.]^{*}\right)$ trafen, ist also nach wie vor aktuell. Die Schwierigkeit einer Klassifikation der kampanischen Dialekte ergibt sich insbesondere daraus, dass sich in der Region eine „komplexe[...], oftmals heterogene[...] Verteilung von dialektalen Besonderheiten“ (Radtke 1993: 444) zeigt, was angesichts der zahlreichen sprachlich-kulturellen Einflüsse, die im Laufe der Geschichte auf das sprachliche Profil der Campania eingewirkt haben (vgl. Kap. 3.2), nicht verwundert.

Pellegrini (1977: 31) unterscheidet in der Campania (einschließlich des heute zum südlichen Latium gehörenden Gebietes) zwar vier Dialektgruppen - das laziale meridionale (IVa), das irpino (IVb), das napoletano (IVc) und das cilentano (IVd) - gibt jedoch weder sprachliche 
Kriterien für diese Klassifikation noch entsprechende geographische Areale an. ${ }^{156}$ Andere Klassifikationen verzichten ganz auf eine Gliederung anhand bestimmter sprachlicher Merkmale und greifen ,aus Bequemlichkeit“ (De Blasi 2006: 45) auf geographische oder administrative Kriterien (Provinzgliederung) zurück.

Die Gesamtschau der geographischen Verbreitung verschiedener phonetisch-phonologischer, morphologischer und lexikalischer Varianten (vgl. Kap. 3.3.4) weist auf eine Zweiteilung des kampanischen Dialektgebietes hin, wobei ein Gebiet die heutigen Provinzen Neapel und Caserta sowie das westliche Sannio Beneventano umfasst (nach Radtke (1993: 447) die sprachlich ,ältere“ bzw. konservative Zone), während sich das zweite Gebiet über das östliche Sannio, die Irpinia und das Cilento erstreckt und sich im Osten bis nach Apulien und im Süden bis in die Basilicata hinein ausdehnt (ebd.: sprachlich ,jüngere“ bzw. innovative Zone). Als Grenze zwischen beiden Gebieten kann nach Radtke (ebd.) die von Avolio (1989) postulierte „Linie Salerno-Lucera“ gesehen werden, ein Isoglossenbündel, das zehn (drei phonetischphonologische, vier morphologische und drei lexikalische) Isoglossen beinhaltet, die sich zwischen Salerno und Eboli auffächern (s. Karte 11-13): 157

(1) Resultat von lat. CI: [ttg] (westl.) vs. [tts] (östl.) in braccio und faccio, dagegen [tts] (westl.) vs. [tt]] (östl.) in pazzo und zitto, ${ }^{158}$

(2) Resultat von lat. intervokal. LL: [11] (westl.) vs. [dd] / [dd] / [r] (östl.): [killul'la] vs. [kiddud'da]/[kwiddu'da]/[kirəd'da]/[kwirəd'da], quello là',

(3) Resultat von lat. NG vor vorderem Vokal: [nn] (westl.) vs. [nḑ] (östl.): ['kjannı] vs. ['kjandzə] ,piange',

(4) Flexionssuffix zur Markierung der 1. und 3. Pers. Sg. des indicativo imperfetto: -eva (veneva) (westl.) vs. -ìa (venia) (östl.),

(5) Tempus in der Apodosis (am Beispiel der Formen für die 1. und 3. Pers. Sg.): Nachfolger des lat. Konjunktiv Plusquamperfekts auf -ESSE (congiuntivo imperfetto: facessa) bzw. der Konstruktion FACERE + HABEBAM (condizionale presente: farrialfacciarì) (westl.) vs. Nachfolger des lat. Indikativ Plusquamperfekt auf -ERA (condizionale presente: facera) ${ }^{159}$ (östl.), ${ }^{160}$

\footnotetext{
${ }^{156}$ Den einzigen (vagen) Hinweis auf die Lokalisierung der Dialektgebiete stellt die Position der Nummern der Dialektgruppen auf der zugehörigen Karte dar: IVa (laziale meridionale) findet sich in der Region Latium, zwischen Frosinone und Sora (bei Isola d. Liri), IVb (irpino) bei Atripalda (AV), IVc (napoletano) bei Neapel und IVd (cilentano) bei Laurito (SA).

${ }^{157}$ Für Avolio stellt diese „Linie“ die westliche Grenze der lukanischen Dialekte dar (dementsprechend lautet der Titel des Aufsatzes von 1989 „Il limite occidentale dei dialetti lucani nel quadro del gruppo «altomeridionale»: considerazioni a proposito della linea Salerno-Lucera").

${ }^{158}$ Als „ungefähre“" nördliche Grenze des Gebietes, in dem [tts] dominiert, nennt bereits Rohlfs (1966: 389) die „Linie“ (hier im Sinne der Luftlinie) zwischen Salerno und Lucera. Da die Ost-West-Verteilung der Varianten jedoch nicht einheitlich ist (s.o.) und die Lexeme unterschiedliche Isoglossenverläufe zeigen, ist (abgesehen von den grundsätzlichen methodischen Unzulänglichkeiten des Konzepts der „Isoglosse“, vgl. Kap. 4.1.2) die Annahme einer einzigen Isoglosse hier jedoch (besonders) fragwürdig. Die kartographische Darstellung Avolios (1989: 19) zeigt dementsprechend auch nicht eine Isoglosse [ttg]/[ts] bzw. [tts]/[ttf], sondern den Isoglossenverlauf für jedes einzelne der berücksichtigten Lexeme (braccio, faccio, pazzo, zitto).

${ }^{159}$ In der 1. Konjugation (Infinitivendung -à) lautet die Endung der 1. und 3. Pers. Sg. im condizionale presente -ara, vgl. Marano Festa (1928: 184).

${ }^{160}$ Hierbei handelt es sich also eigentlich um die Kombination einer morphologischen Isoglosse (Flexionsendungen im condizionale presente) mit einer (morpho-)syntaktischen Isoglosse (consecutio temporum in hypothetischen Konstruktionen).
} 
(6) maskuline Form des Personalpronomens der 3. Pers. Sg.: issa < lat. İPSU(M) (westl.) vs. iddə < lat. İLLU(M) (östl.), ${ }^{161}$

(7) Form des Reflexivpronomens der 1. Pers. Pl.: $c ə<$ HINCE (westl.) vs. $n ə<$ INDE (östl.): ca verimma ,ci vediamo" vs. na verima,

(8) Bezeichnung von ,culla': cònnala (westl.) vs. naca (östl.),

(9) Bezeichnung von ,civetta': ciuciuvettala (westl.) vs. cuccuvaia (östl.),

(10) Bezeichnung von ,domani‘: rimanə (westl.) vs. craiə (<CRAS) (östl.). ${ }^{162}$

Vor allem die Isoglossen (1), (2) und (7) sind nach Radtke (1993: 447) ,geeignet, für einen Teil Süditaliens eine Binnengliederung vorzulegen“, aus der sich für Kampanien die genannte Zweiteilung ableitet (ebd.). Die Isoglossen (6), (7) und (10) verschieben sich nach Avolio (1989: 11) in jüngerer Zeit Richtung Osten, d.h. es liegt eine Vergrößerung des Verbreitungsgebietes der Formen isse ,quello', cə ,ci‘ und rimane ,domani“ und ein entsprechender Rückgang der Varianten idde ,quello', no , $\mathrm{ci}^{\text {‘ }}$ und craia ,domani ${ }^{`}$ vor. ${ }^{163}$

Beim visuellen Vergleich der Isoglossenkarten wird das Problem deutlich, das sich beim Versuch einer Klassifikation der kampanischen Dialekte bzw. einer Gliederung des kampanischen Dialektgebietes mittels der Isoglossenmethode ergibt: ,[L]e isoglosse [...] non forniscono sempre indicazioni tali da poterle considerare dei veri e propri confini dialettali. I fasci si rivelano in realtà spesso come un miscuglio non ordinato di coincidenze del tutto casuali“" (Radtke 1997a: 31, ähnlich auch Maturi 2002: 244). Avolio selbst verweist zwar auf die Inkongruenzen im Verlauf der von ihm identifizierten Isoglossen, sieht darin jedoch ein grundsätzliches Merkmal von Isoglossenbündeln, wie es auch die Linien La Spezia-Rimini und Rom-Ancona aufweisen: „Tuttavia, allo stesso modo delle importanti linee che suddividono l'Italia peninsulare in grandi gruppi dialettali (La Spezia-Rimini, Rom-Ancona) anche la Salerno-Lucera si presenta compatta, nelle sue varie isoglosse, solo in alcuni punti, mentre appare significativamente «sfilacciata» in altri“" (Avolio 1989: 1). Ein solcher Vergleich mit den ,großen“ Isoglossenbündeln La Spezia-Rimini und Rom-Ancona ist jedoch nicht unproblematisch, da bei der isoglossenbasierten Identifizierung von Dialektgrenzen ${ }^{164}$ fehlende Übereinstimmungen bzw. nicht vorhandene Parallelitäten zwischen verschiedenen Isoglossenverläufen umso mehr ins Gewicht fallen, je kleiner das entsprechende Gebiet ist. Hinzu kommt, dass sowohl De Blasi (2006) als auch Radtke (1988, 1997a) in ihren Aussagen bezüglich der Vorkommen bestimmter Varianten bzw. der jeweiligen Isoglossenverläufe stark von Avolio (1989) abweichen. Ein anschauliches Beispiel hierfür sind die Divergenzen zwischen den von Avolio (1989: 20) und Radtke (1997a: 73) gezeichneten Verläufen der Isoglosse [11] vs. [dd]/[dd] (bzw. [r], s. Karte 14).

\footnotetext{
${ }^{161}$ Die entsprechenden femininen Formen ess $>$ ĬPSA(M) und $i d d ə<\breve{I L L A}(\mathrm{M})$ zeigen dieselbe geographische Verteilung (Radtke 1997a: 85).

${ }^{162}$ In diesem Fall handelt es sich allerdings um eine Fehlinterpretation, da es sich nur bei crai um eine basilektale Variante handelt: „Domani ist eine Innovation, die ihren Ausgang von Neapel nimmt und die Küstenregion, die sich früher und schneller italianisiert, betrifft“ (Radtke 1993: 448). Die Variation zwischen domani und crai zeugt also nicht von basilektalen Unterschieden, sondern von einem Dialektwandel, der mit der Integration von domani in die Dialekte der Küstenregion im 19. Jahrhundert seinen Anfang genommen hat. Dies bestätigt die Verteilung der Varianten, wie sie im AIS (Bd. II, Karte 347) dokumentiert ist: ,domani : crai grenzt [...] die Golfregion von Neapel vom Hinterland ab“ (Radtke 1993: 448).

${ }^{163}$ Die Isoglosse (2) ist laut Avolio (1989: 11) ebenfalls „,in movimento“. Angaben zur Richtung der Verschiebung fehlen hier zwar, es ist jedoch anzunehmen, dass - analog zu den anderen Fällen - ebenfalls eine Ausdehnung der westlichen Variante [11] nach Osten gemeint ist.

${ }^{164}$ Vgl. Kap. 4.1.2.
} 
Inkonsistenzen dieser Art können mit der geringen Interkomparabilität der Aufnahmen Avolios zusammenhängen (Radtke 1997a: 32), ${ }^{165}$ sind jedoch mit Sicherheit auch durch die nicht nur in der Campania anzutreffende - Tatsache bedingt, dass die Verbreitungsgebiete verschiedener Varianten einer Variable einander häufig überlappen und/oder die Varianten in einigen Fällen geographisch diskontinuierlich verteilt sind. ${ }^{166}$ Eine ,exakte‘ Teilung des kampanischen Dialektgebietes in Areale, in denen jeweils ausschließlich eine Variante verwendet wird, ist häufig nicht möglich. Die auf der Basis von Daten aus dem Atlante Linguistico della Campania (ALCam) erstellten Karten 15, 16, 17 und 18 zeigen Beispiele für die diskontinuierliche Verteilung diatopischer Varianten aus dem phonetisch-phonologischen und dem lexikalischen Bereich.

In allen Fällen ist die Festlegung von Isoglossenverläufen zur Bestimmung von Verbreitungsgebieten sprachlicher Merkmale keine valide Methode. Doch auch ohne Rückgriff auf das Konzept der Isoglosse würde eine Gliederung des kampanischen Dialektgebietes anhand weniger sprachlicher Merkmale aufgrund der Inkongruenzen zwischen den Verbreitungsgebieten der jeweiligen Varianten eines Merkmals zu erheblichen methodischen Schwierigkeiten führen. Je nach Wahl des Merkmals entstünde ein unterschiedliches Bild der dialektalen Gliederung, sodass eine (subjektive) Gewichtung der Merkmale erforderlich würde, die unter Umständen ein sehr verzerrtes Abbild der tatsächlichen sprachlichen Verhältnisse erbringen könnte. Probleme dieser Art können zwar nie ganz vermieden werden, da keine Methode existiert, die es möglich macht, die gesamte sprachliche Realität in eine Analyse einzuschließen. Durch die Berücksichtigung einer größeren Anzahl sprachlicher Merkmale kann der subjektive Anteil der sprachgeographischen Analyse jedoch deutlich reduziert und damit eine höhere Reliabilität des Ergebnisses erreicht werden.

\footnotetext{
${ }^{165}$ Avolio selbst (1989: 1) spricht von seinen Daten als ,,alcuni dati provvisori raccolti personalmente, da fonti orali [...].“ In jedem Fall ist seine isoglossenbasierte Einteilung (zumindest in Bezug auf das kampanische Dialektgebiet) insofern unzureichend, als teilweise nicht alle dialektalen Varianten einer Variable angegeben werden. So erscheinen etwa weder die im Norden und Osten der Region vorkommenden phonetischen Varianten

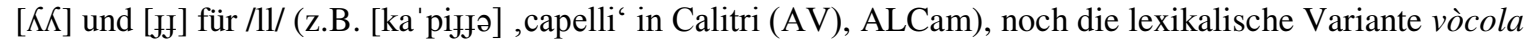
,culla', die vor allem in der Provinz Salerno (Cava dei Tirreni, Piano Vetrale u.a. (ALCam), vgl. auch Rohlfs 1988: 110) verbreitet ist.

166 Selbst in relativ kleinen Teilgebieten wie dem Sannio Beneventano zeigt sich, dass ,le varianti risultano distribuite in modo discontinuo sul territorio, con una disposizione , a macchia di leopardo“ assolutamente incompatibile con il concetto stesso di isoglossa“" (Maturi 2002: 244).
} 


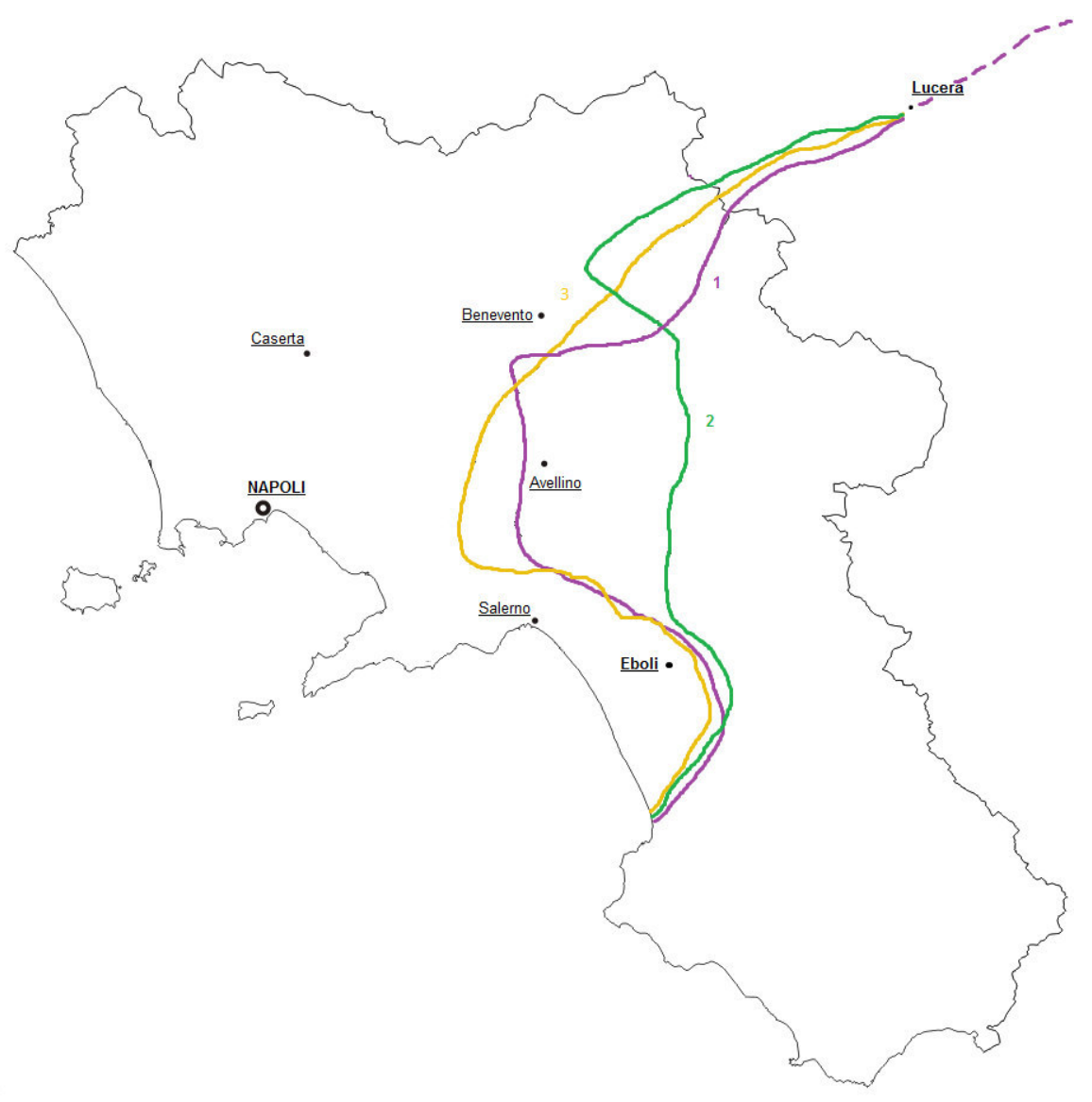

Karte 11. Phonetische Isoglossen nach Avolio (1989: 19f., westliche Variante vs. östliche Variante(n)): [ttf] vs. [tts] in faccio (1, violett), [11] vs. [dd]/[dd] bzw. [r] (2, grün) und [nn] vs. [nds] (3, gelb) (Hintergrundkarte: d-maps.com). 


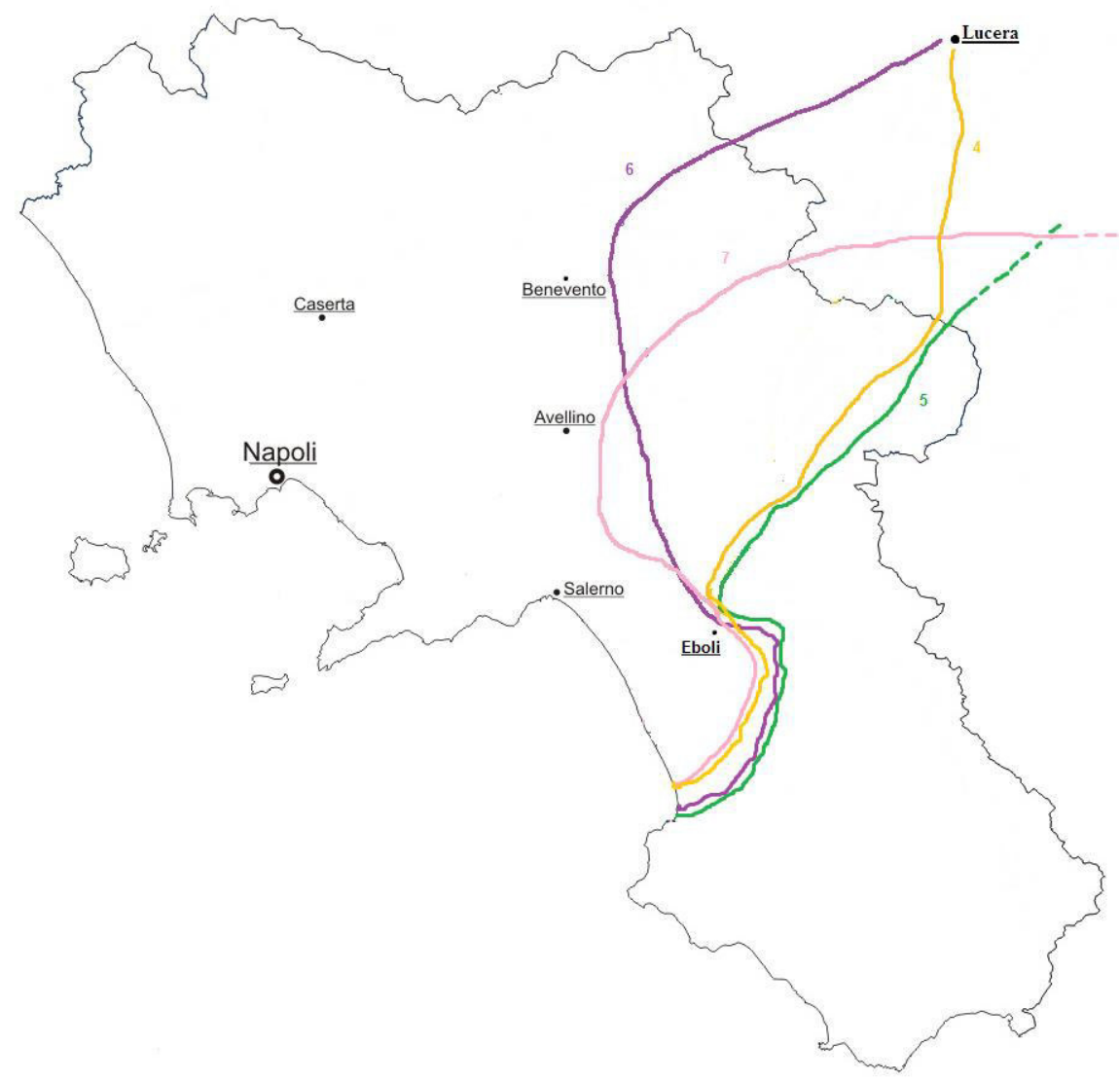

Karte 12. Morphologische Isoglossen nach Avolio (1989: 20, westliche Variante(n) vs. östliche Variante): Imp. -eva vs. -ìa (4, gelb), Cong. Imp. auf -essa oder Cond. auf -ìa vs. Cond. auf -era (5, grün), issa vs. iddə (6, violett), cə vs. nə (7, rosa) (Hintergrundkarte: d-maps.com). 


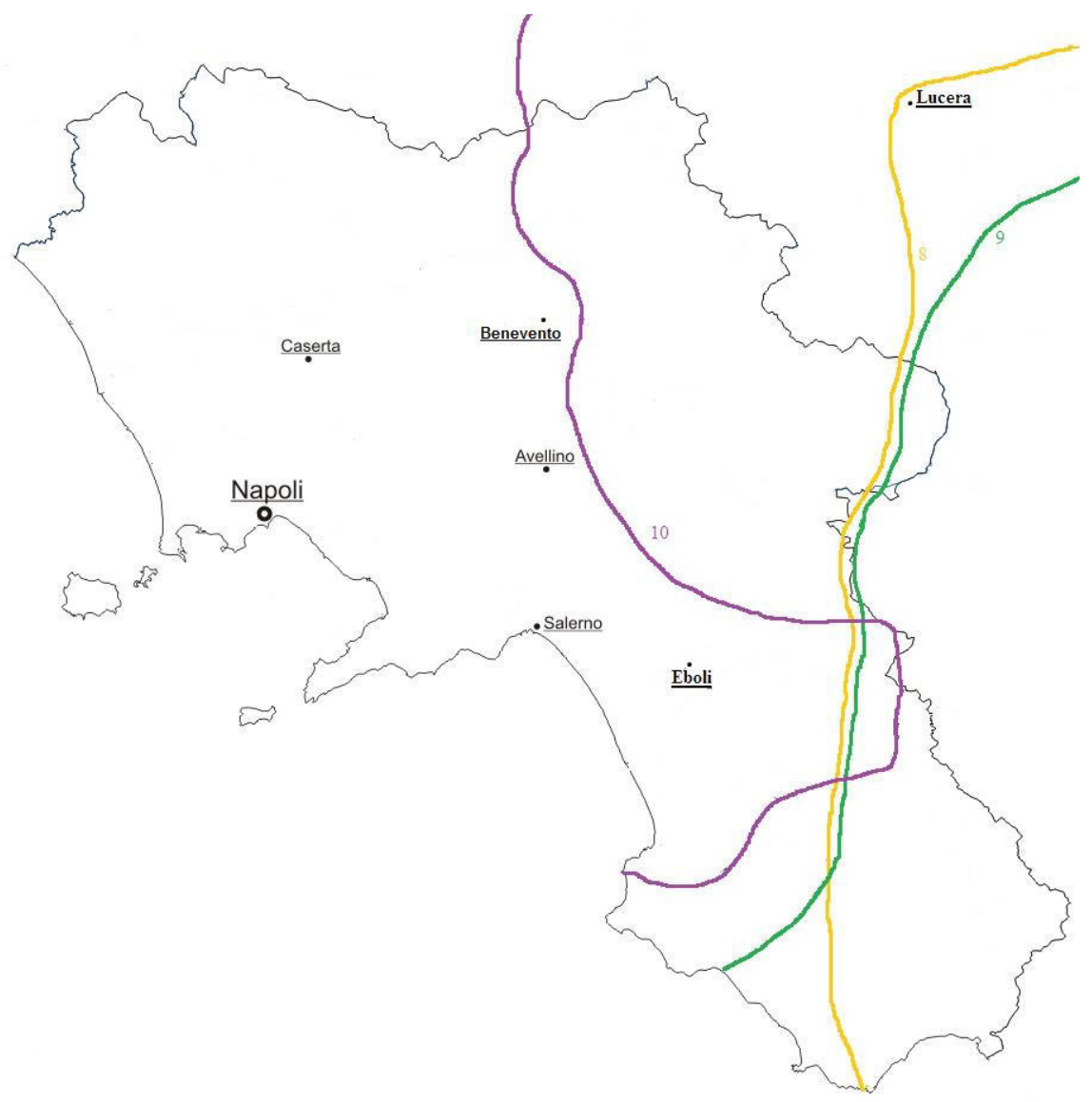

Karte 13. Lexikalische Isoglossen nach Avolio (1989: 21, westliche Variante vs. östliche Variante): cònnala vs. naca ,culla‘ (8, gelb), ciuciuvettala vs. cuccuvaia ,civetta‘ (9, grün), rimana vs. craiə ,domani` (10, violett) (Hintergrundkarte: d-maps.com). 


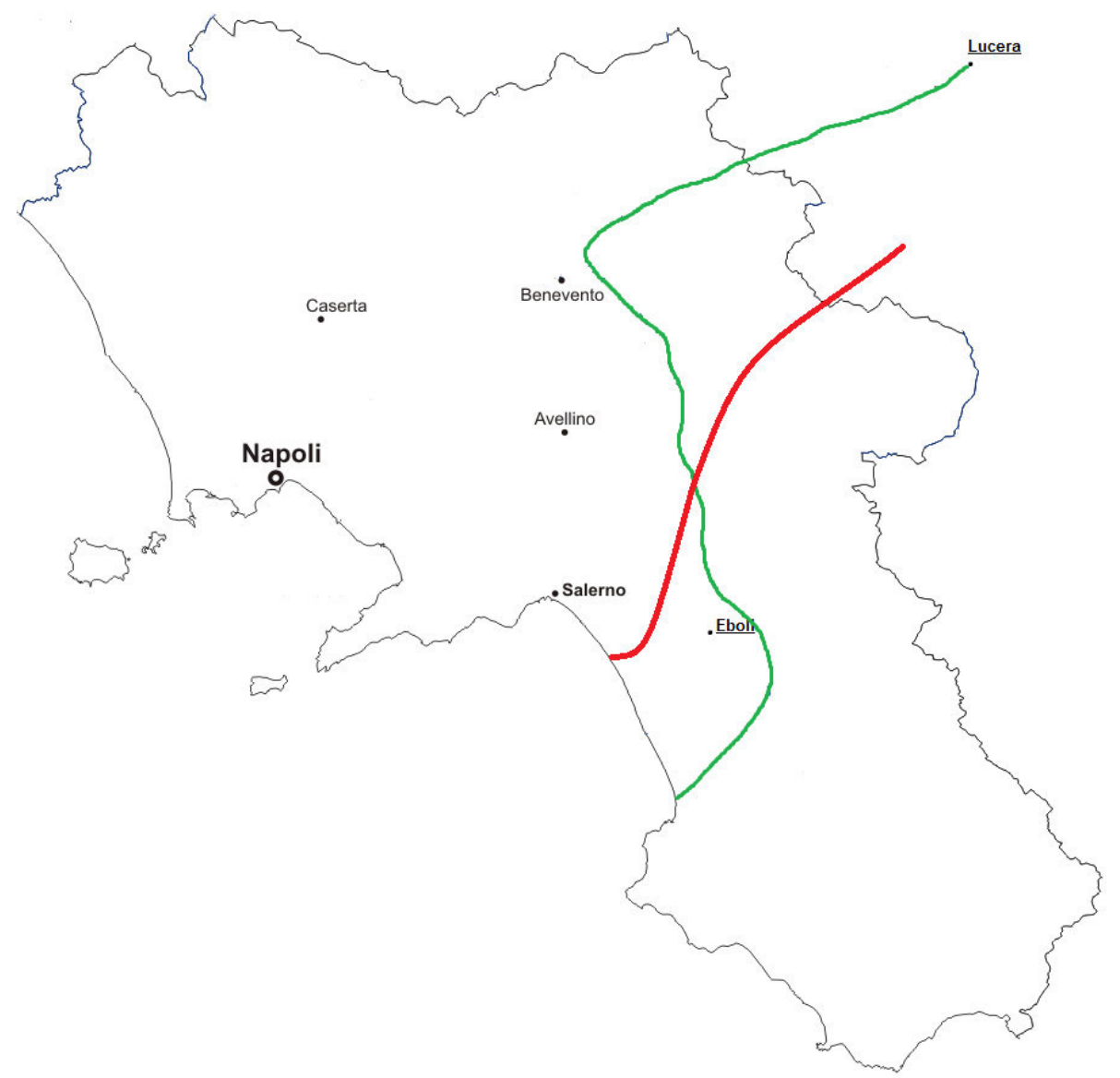

Karte 14. Verlauf der Isoglosse [11] (Westen) vs. [dd], [dd] (Osten) nach Avolio (1989: 29, grün) und nach Radtke (1997a: 73, rot) (Hintergrundkarte: d-maps.com). 


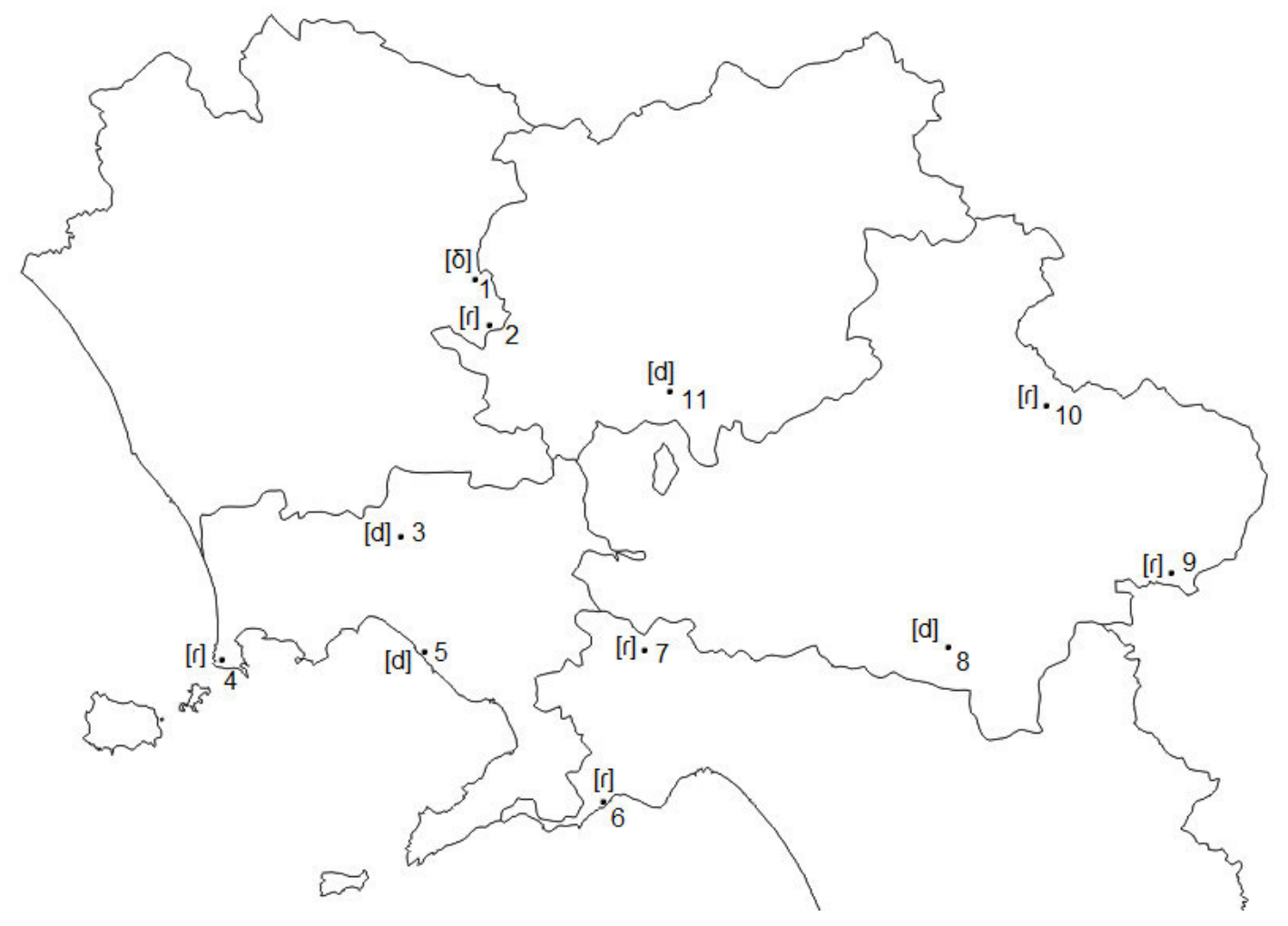

Legende

$\begin{array}{ll}1=\text { Ruviano } & 7=\text { Siano } \\ 2=\text { Squille } & 8=\text { Bagnoli Irpino } \\ 3=\text { Afragola } & 9=\text { Calitri } \\ 4=\text { Monte di Pròcida } & 10=\text { Molini } \\ 5=\text { Ercolano } & 11=\text { Apollosa } \\ 6=\text { Amalfi } & -=\text { Provinzgrenzen }\end{array}$

Karte 15. Realisierungen von /d/ in pede,piede“ im nördlichen Teil der Campania nach den Daten des ALCam (Hintergrundkarte: d-maps.com). 


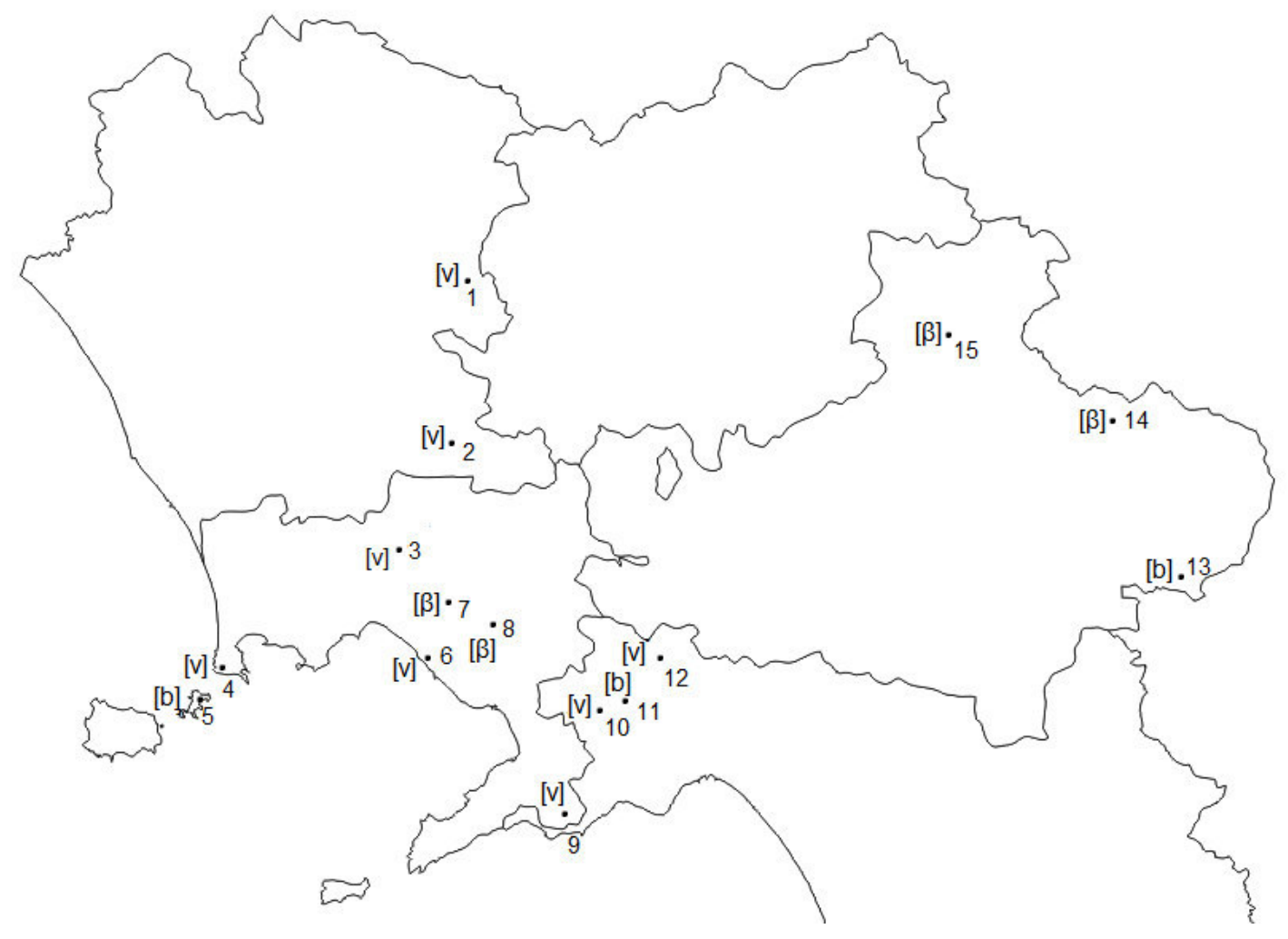

Legende

$$
\begin{aligned}
& 1=\text { Ruviano } \\
& 2=\text { San Marco Evangelista } \\
& 3=\text { Afragola } \\
& 4=\text { Monte di Pròcida } \\
& 5=\text { Pròcida } \\
& 6=\text { Ercolano } \\
& 7=\text { Sant'Anastasia } \\
& 8=\text { Ottaviano }
\end{aligned}
$$

$$
\begin{aligned}
& 9=\text { Amalfi } \\
& 10=\text { Pagani } \\
& 11=\text { Nocera } \\
& 12=\text { Siano } \\
& 13=\text { Calitri } \\
& 14=\text { Oscata } \\
& 15=\text { Ariano Irpino } \\
& -=\text { Provinzgrenzen }
\end{aligned}
$$

Karte 16. Realisierungen von /b/ in véve(re) ,bere‘ im nördlichen Teil der Campania nach den Daten des ALCam (Hintergrundkarte: d-maps.com). 


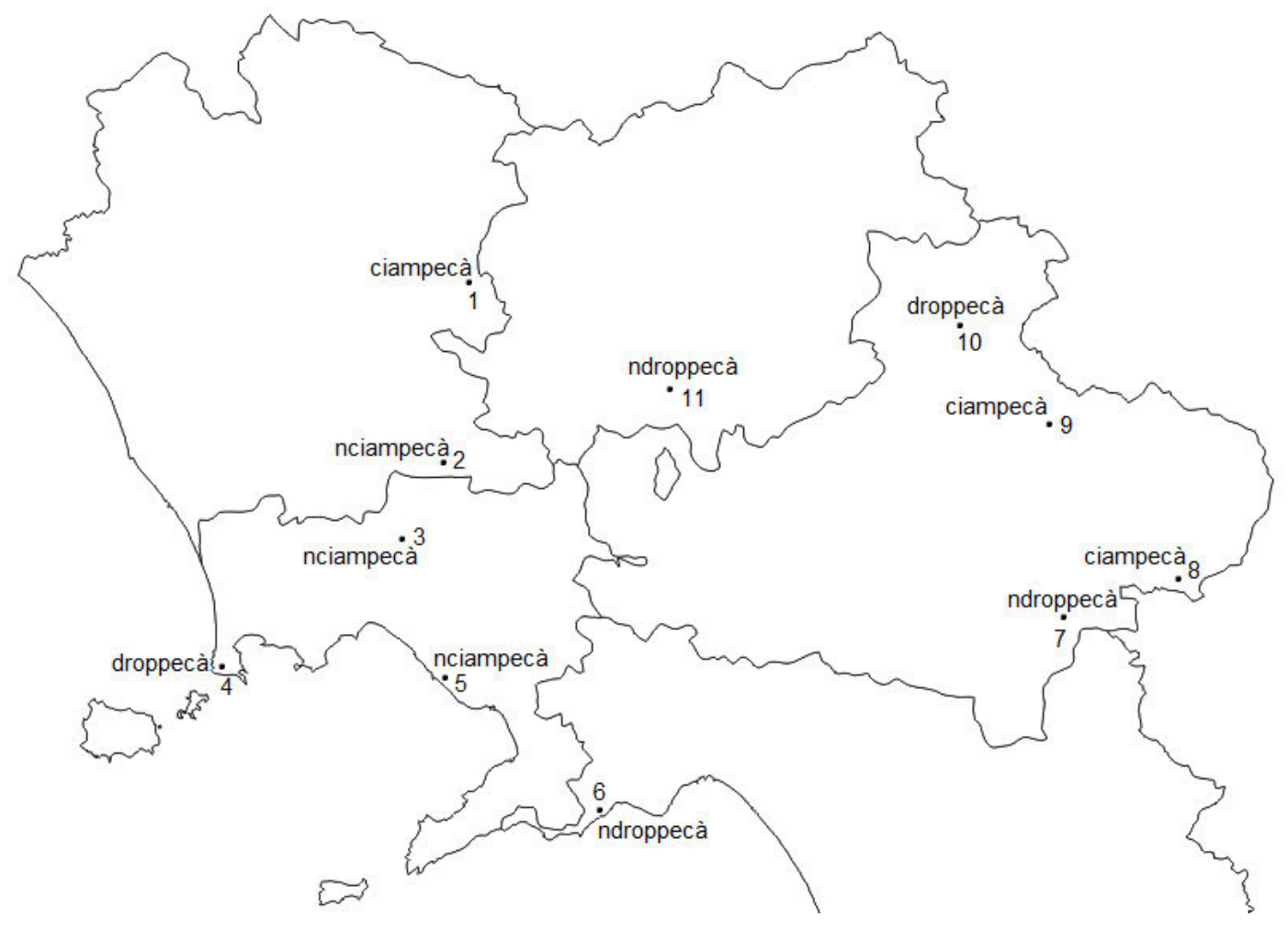

Legende

$$
\begin{array}{ll}
1=\text { Ruviano } & 7=\text { Teora } \\
2=\text { San Marco Evangelista } & 8=\text { Calitri } \\
3=\text { Afragola } & 9=\text { Carife } \\
4=\text { Monte di Pròcida } & 10=\text { Ariano Irpino } \\
5=\text { Torre del Greco } & 11=\text { Apollosa } \\
6=\text { Amalfi } & - \text { = Provinzgrenzen }
\end{array}
$$

Karte 17. Bezeichnungen für ,inciampare‘ im nördlichen Teil der Campania nach den Daten des ALCam (Hintergrundkarte: d-maps.com). 


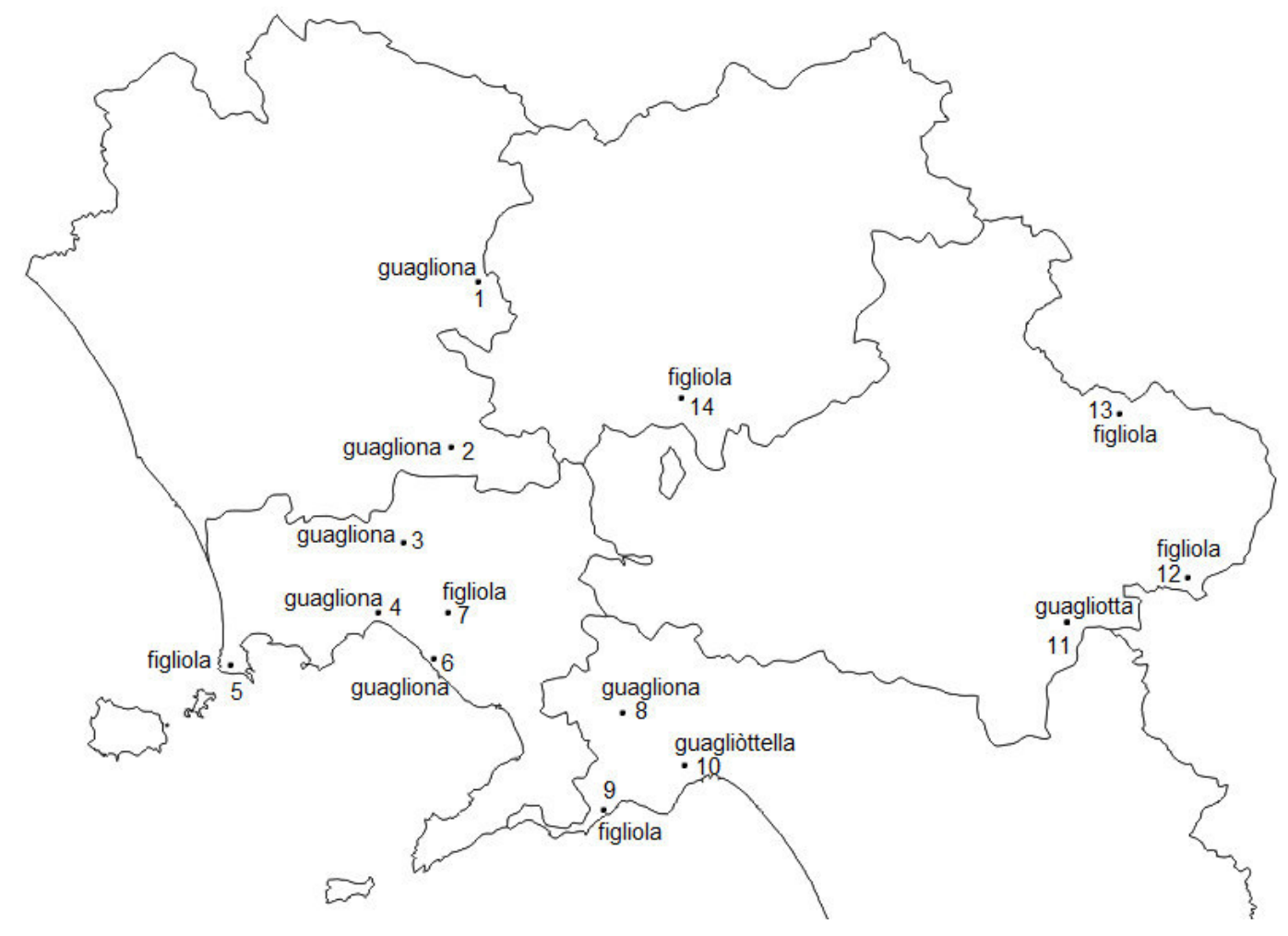

Legende

$1=$ Ruviano
$2=$ San Marco Evangelista
$3=$ Afragola
$4=$ Napoli
$5=$ Monte di Pròcida
$6=$ Ercolano
$7=$ Sant'Anastasia

$$
\begin{aligned}
& 8=\text { Nocera } \\
& 9=\text { Amalfi } \\
& 10=\text { Cava dei Tirreni } \\
& 11=\text { Teora } \\
& 12=\text { Calitri } \\
& 13=\text { Oscata } \\
& 14=\text { Apollosa }
\end{aligned}
$$

Karte 18. Bezeichnungen für ,ragazza‘ im nördlichen Teil der Campania nach den Daten des ALCam (Hintergrundkarte: d-maps.com). 


\subsubsection{Die diachronische Entwicklung I: Italianisierungstendenzen}

\subsubsection{Phonetik und Phonologie}

Auf phonetisch-phonologischer Ebene lassen sich in den kampanischen Dialekten einige Veränderungen beobachten, die ihren Ursprung in der phonologischen Integration von Lexemen aus dem Standarditalienischen haben. Durch den anhaltenden intensiven Kontakt mit dem Italienischen werden die bei der Integration der Lehnwörter entstandenen Distributionsmuster in der Folge auf native Lexeme - insbesondere jene mit italienischem Äquivalent - ausgedehnt. ${ }^{167}$ Dies betrifft zunächst die Realisierung der Phoneme, die in den kampanischen Dialekten der variazione consonantica unterworfen sind (vgl. Kap. 3.3.4.2). Da die einfachen stimmhaften Plosive in schwacher Stellung nicht vorkommen, wird zur Wiedergabe von ital. /b/ häufig die geminierte Variante [bb] verwendet (De Blasi/Fanciullo 2003: 636): [bban'nera] ,bandiera', [b'barkone] ,balcone', [ab'beto] ,abete' (Rohlfs 1966: 195f., 294), ['abbile] ,abile' (Radtke 1997a: 70). Bei der Wiedergabe von ital. /d/ findet sich die geminierte Variante häufig in Kombination mit prothetischem $a$ : [ad'dedeka] ,dedica', [ad'dosa] ,dose' (Rohlfs 1966: 204), [ad'do] (neben [ar'ro]), dove“ (Radtke 1988: 655). Im Fall von ital. /d/ kommt es jedoch auch - und bei der Wiedergabe von ital. /g/ regelmäßig - zur Realisierung der einfachen stimmhaften Variante und damit zur Einführung dieser in das dialektale phonologische System (De Blasi/Fanciullo 2003: 636).

Die mit der phonologischen Integration der Italianismen entstandenen neuen Distributionsmuster verursachen Veränderungen bei der Realisierung der Phoneme in nativen Lexemen und damit einen Wandel in diesem Bereich des phonologischen Systems: Insbesondere im Falle von /b/ tritt die geminierte Variante in schwacher Stellung zunehmend an die Stelle des lauthistorischen Ergebnisses, insbesondere in Lexemen, die ein standarditalienisches Äquivalent aufweisen: [b'barka] statt ['varka] ,barca' (ebd.). ${ }^{168}$ Eine deutliche Veränderung der phonologischen Systems nach italienischem Muster stellt die Ersetzung der Varianten [j] (in schwacher Stellung) und [ggj] (in starker Stellung, vgl. Kap. 3.3.4.2) dar, in deren Position sich im Italienischen die Affrikate /dz/ - als [d] oder [ddz] - findet. Da die kampanischen Dialekte nur die geminierte Variante kennen, tritt diese anstelle von [j] und [ggj] nicht nur dort auf, wo im Italienischen ebenfalls die geminierte Variante vorliegt, sondern auch dort, wo das Italienische die einfache Variante aufweist: ['əjə] > ['כddzə] , oggi ', aber auch ['jennərə] > [d'dz\&nnərə] ,genero“ (De Blasi/Fanciullo 2003: 636).

Als weiteres durch den Einfluss des Italienischen bedingtes Phänomen im phonetischphonologischen Bereich lässt sich eine Ersetzung von kamp. [ $]$ ] FL durch ital. [fj] beobachten: ['Jaykə] > ['fjaykə] , fianco' ${ }^{169}$ Einen Rückgang zeigt auch der Nexus [kj] < PL, der durch ital. [pj] ersetzt wird: ['kjummo] > ['pjummo] ,piombo' (De Blasi 2006: 65), ['kjanta] > ['pjanta] ,pianta', [kja'nella] > [pja'nella], pantofola'(Radtke 1997a: 74).

Im Bereich des Vokalismus beobachtet Como (2007: 236, 250) eine Zunahme der Realisierung der unbetonten Auslautvokale (vgl. Kap. 3.3.4.1.1): ['kisto] statt ['kistə] ,questo', ['ato] statt ['atə] ,altro', ['mare] statt ['marə] ,mare' (vgl. auch Maturi 2002: 148f.). Auch die

\footnotetext{
${ }^{167}$ Bei den im Folgenden aufgeführten Beispielen werden interindividuelle, oft durch Unterschiede in der Italienischkompetenz oder in den sprachlichen Gebrauchsmustern bedingte Differenzen nicht berücksichtigt. Vgl. dazu Como (2007) und Milano (2006).

${ }^{168}$ Teilweise ergeben sich dabei semantische Differenzierungen, etwa im Falle von [b'barba], ,barba' vs. (älteres) ['varva] ,mento“ (Rohlfs 1966: 196).

${ }^{169}$ In Einzelformen und festen Verbindungen erhält sich das lauthistorische Ergebnis jedoch: [' Jatə] ,fiato“ und

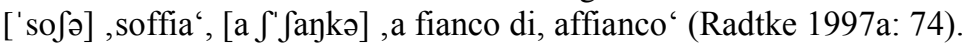


Realisierung vortoniger Vokale geschieht teilweise nach italienischem Muster: [for'kettə] statt [fur'kettə] ,forchetta' (Como 2007: 250).

Del Puente (1995) stellt einen Rückgang der Metaphonie im Neapolitanischen fest, der insbesondere maskuline Substantive betrifft, die (durch ein gemeinsames Etymon oder frühe Entlehnung) eine Entsprechung im Standarditalienischen haben. Hier lässt sich eine Tendenz zur Generalisierung derjenigen Variante - ob metaphonisch oder nicht - feststellen, die an entsprechender Stelle im Italienischen auftritt: [pja'tferə] (Sg.) vs. [pja'tfirə] (Pl.) > [pja'tferə] (Sg./Pl.) ,piacere/-i', ['prentfəpə] (Sg.) vs. ['printfəpə] (Pl.) > ['printfəpə] (Sg./Pl.) ,principe/-i' (Del Puente 1995: 57). ${ }^{170}$ Über den Artikel wird die Numerusmarkierung in diesen Fällen jedoch weiterhin gesichert. Deutlich stabiler ist die Metaphonie im Bereich der Adjektive, wo sie neben der Funktion der Numerusdifferenzierung (bei Adjektiven auf - $e$ ) auch jene der Genusdifferenzierung (bei Adjektiven auf - $o$ und adjektivisch gebrauchten Partizipien) übernimmt (vgl. Kap. 3.3.4.1.1). Auf der Ebene der Phonetik beschränken sich Italianisierungs-prozesse offenbar auf jene Bereiche, welche die Stabilität des morphologischen Systems nicht gefährden.

\subsubsection{Morphologie und (Morpho-)Syntax}

In den grammatischen Bereichen erweisen sich die kampanischen Dialekte - wie die italienischen Dialekte im Allgemeinen (vgl. Kap. 2.4.1) - als gegenüber externen Einflüssen deutlich stabiler als im Bereich der Phonetik/Phonologie und des Lexikons (vgl. Kap. 3.3.6.3). Die beobachtbaren Tendenzen zur strukturellen Angleichung an das Italienische sind weniger deutlich und betreffen häufig nur einzelne Formen oder Paradigmen.

Im Bereich der Verbalflexion lässt sich eine Ersetzung der dialektalen Flexionsendung der 1. Pers. Sg. Ind. (-cco) der Verben aspettare und mettere durch die Endung -tto beobachten (aspecco ,(io) aspetto'> aspetto, mecco, io metto ‘ metto, vgl. Radtke 1997a: 39f., 87), durch die sich ein paradigmatischer Ausgleich ergibt (2. Pers. Sg. aspiettə/miettz, 3. Pers. Sg. aspettə/mettว). ${ }^{171}$ Dieser ist zeitlich wie räumlich bereits relativ weit fortgeschritten - die dialektale Flexionsendung findet sich nur noch im kampanischen Hinterland ${ }^{172}$ und ausschließlich im Sprachgebrauch der älteren Generation. Auf Capri stellt sie ein Schibboleth-Merkmal des Dialekts von Anacapri dar (ebd.: 40). Eine ähnliche Entwicklung zeigt sich im Falle der Suppletivform saccio/sòccio,(io) so', die vor allem in städtischen Bereichen in der Provinz Caserta häufig durch ital. so ersetzt wird (Radtke 1997a: 48f.), sodass es auch hier zu einem paradigmatischen Ausgleich kommt (2. Pers. Sg. sai, 3. Pers. Sg. sa). In vielen anderen Fällen zeigen sich die Suppletivformen der 1. Pers. Sg. jedoch stabil: songo ,sono', dongo ,do', vanga ,vado', scengə ,scendo', vengo, vendo“ etc. (Radtke 1977a: 87).

Auf die Stabilität der internen Flexion (Metaphonie) bei Adjektiven und Partizipien ist oben (Kap. 3.3.6.1) bereits hingewiesen worden. Im Bereich der Nominalflexion ist zu beobachten, dass die dialektale Pluralendung aus lat. -ORA (vgl. Kap. 3.3.4.3) durch den italienischen Plural auf - $a$ ersetzt wird: l'ossa ,le ossa' (ALCam). Der alte Plural (l'osserall'ossera)

\footnotetext{
${ }^{170}$ Auch Como (2007: 257) konstatiert (vor allem bei hinteren Vokalen) eine „maggiore rarefazione dei fenomeni di metafonia [...], anche se va osservato che generalmente l'assenza della metafonia co-occorre con altri fenomeni di italianizzazione a livello lessicale.“

${ }^{171}$ Da paradigmatische Ausgleichsprozesse in Sprachsystemen regelmäßig auftreten, ist es hier jedoch unwahrscheinlich, dass es sich um ein ausschließlich durch den Einfluss des Italienischen induziertes Phänomen handelt.

${ }^{172}$ In Neapel und der neapolitanischen Küstenregion gilt die ursprüngliche Flexionsendung als Merkmal der parlata cafonesca, die den unteren sozialen Schichten und den ländlichen Gebieten zugeschrieben wird (Radtke 1997a: 40).
} 
findet sich nur noch sporadisch und meist in ländlichen Gegenden sowie in der area flegrea (Monte di Pròcida, vgl. ALCam).

Raucci (1993/1994: 104, zit. in Radtke 1997a: 85) beobachtet einen Rückgang des Reflexivpronomens der 1. Pers. Pl. ne zugunsten des italienischen Äquivalents $c i(c z)$, den bereits Avolio (1989) erwähnt (vgl. Kap. 3.3.5).

Hinsichtlich des Gebrauchs der Tempora und Modi lässt sich feststellen, dass das passato prossimo zunehmend Funktionen des passato remoto übernimmt, sodass dieses langsam aus dem Dialektgebrauch verschwindet: aggio sentuto statt sentètte ,ho sentito“ etc. (Radtke 1988: 657).

\subsubsection{Lexikon}

Am deutlichsten zu beobachten ist der Einfluss des Italienischen im lexikalischen Bereich. Hier kommt es einerseits zur Übernahme italienischer Lexeme, die der lexikalischen Bedarfsdeckung dienen, d.h. lexikalische ,Lücken“ im Dialekt füllen. Diese Lexeme stammen insbesondere aus den Bereichen ,Medizin' (terapia, anestesia, sonda, cardiologo, tendine, radioterapia, tintura di iodio (Como 2007: 219, 250), bronchite (Milano 2006: 276) etc.), , Telekommunikation und Medien' (telegramma, telefono, televisione, cinema (Como 2007: 225, 238) etc.), ,Politik, Wirtschaft, Bürokratie‘ (azienda, contributi (Milano 2006: 276) etc.) sowie, Wissenschaft und Technik': concime, ossidato, marconista, fonogramma, aviazione, binocolo, boccaporto, fotografia, bossolo (Como 2007: 214, 216, 236, 242).

Neben diesen ,prestiti di necessità“ findet sich eine weit höhere Anzahl an ,prestiti di lusso" (Como 2007: 250), d.h. italienischer Lehnwörter aus verschiedenen semantischen Bereichen der Alltagssprache, die synonym ${ }^{173}$ zu den entsprechenden dialektalen Lexemen verwendet werden. Der Grad der phonetischen Integration der Lexeme ist dabei unterschiedlich und kann auch bei ein und demselben Lexem variieren: ['pikkolə] neben ['pikkulə], piccolo' (ebd.). Im Folgenden findet sich eine Auswahl an Beispielen aus verschiedenen semantischen Bereichen (ohne Berücksichtigung der etymologischen Beziehung zwischen den jeweiligen Lexemen). ${ }^{174}$

a) ,Familie/Verwandtschaft"

madre (dial. mamma)

moglie (dial. mugliera)

fratello (dial. frate)

sorella (dial. sora)

cognato (dial. cainato)

suocero (dial. suocro) (Como 2007: 236, vgl. auch Milano 2006: 225, 276) ${ }^{175}$

b) ,Körper/Gesundheit

dottor' (dial. miéraka)

\footnotetext{
${ }^{173}$ Dies bedeutet jedoch nicht, dass in einem gegebenen außersprachlichen Kontext immer beide Lexeme nebeneinander zum Einsatz kommen. In ihrer Konnotation und ihren sozialen Funktionen können sich Italianismen und Dialektismen trotz (denotativer) Synonymität erheblich unterscheiden.

${ }^{174} \mathrm{Ob}$ oder inwieweit sich das italienische Lexem gegenüber dem dialektalen Lexem im Sprachgebrauch bereits durchgesetzt hat und welche Konnotationen oder kontextuellen Beschränkungen jeweils vorliegen, kann hier nicht im Einzelfall geklärt werden.

175 Die Stellung der Possessivadjektive folgt hier ebenfalls dem italienischen Muster: mia moglie statt muglièrema (Como 2007: 236).
} 
raffreddore (dial. catarro)

schiena (dial. rine $(\mathrm{Pl})$.

baffi (dial. mostacchi)

mento (dial. vàvera)

pomo d'adamo (dial. gannarone/nuozzo/zuzzunielle)

gomito (dial. vuto)

pollice (dial. radone)

mignolo (dial. radillo)

destra (dial. rorittz) ,mano destra“

sinistra (dial. mangina), mano sinistra' (ALCam)

incinta (dial. prena) (De Blasi 2006: 65)

c) ,Nutzpflanzen und ihre Produkte‘

arancia (dial. purtuallo)

albicocca (dial. crisuommelo)

mandorla (dial. ammènnola)

pesca (dial. piérzeco)

mela (dial. milo)

pera (dial. piro) (De Blasi 2006: 65)

lievito (dial. crísceto) (Como 2007: 250)

d) ,Tätigkeiten‘

sarto (dial. cosetore)

levatrice (dial. vammana)

ricevere (dial. abbuscà) (De Blasi 2006: 65)

comprare (dial. accattà)

lavorare (dial. faticà) (Como 2007: 216)

e) ,Zeit/Raum/Art und Weise“

rimanə (dial. crai) (Radtke 1993: 448, vgl. Kap. 3.3.5)

settimana (dial. semana)

stasera (dial. mosera)

così (dial. accussì) (Como 2007: 236, 238)

\subsubsection{Die Rolle des italiano napoletano}

Im Rahmen der Diskussion zur Italianisierung der kampanischen Dialekte stellt sich abschließend die Frage, welche Varietät des Italienischen im Repertoire der kampanischen Dialektsprecher verankert und damit Quelle der insbesondere lexikalischen und phonetischen Übernahmen in die kampanischen Dialekte ist. Entsprechend der allgemeinen Annahme, dass die Italianisierung der Dialekte sich zunächst in großen urbanen Zentren manifestiert und durch den Einfluss der städtischen Varietäten an mittlere und von diesen schließlich an kleine Stadtzentren ,weitergegeben' wird (vgl. Kap. 2.3.1) wird auch der Metropole Neapel eine führende Rolle im Prozess der Italianisierung und dem italiano di Napoli der Status einer ,Bezugsvarietät‘ für die verschiedenen italiani regionali campani zugeschrieben: ,[L]e differenze soprattutto fonetiche tra il parlato delle diverse province, e tra zone rurali e centri urbani [...] si appiattiscono nella tendenza verso un modello napoletano che nel suo prestigio sociolinguistico in molti casi funge 
da filtro verso lo standard“ (Bianchi/De Blasi/Librandi 1993: 199). Doch auch wenn Neapel als kulturelles und administratives Zentrum des Regno di Napoli lange Zeit als ,centro di irradiazione“ des Italienischen (wie vorher des Lateinischen) fungierte (vgl. Kap. 3.2.3), haben die dialektophonen Sprecher in anderen Teilen der Region vor allem ein ,italiano di sfumature locali in rapporto alla propria area di origine“ erworben (De Blasi 2001: 93). In jüngster Zeit lässt sich zudem ein Widerstand gegen die neapolitanische Varietät des Italienischen als Bezugsmodell beobachten, die in Zusammenhang mit der Überwindung der Stigmatisierung der lokalen Varietäten des Italienischen gebracht werden kann: „[L']utente odierno dell'italiano regionale non ritiene più automaticamente questa varietà una parlata inferiore rispetto ad altre varietà“ (Radtke 1998a: 191). ${ }^{176}$

Die verschiedenen italiani campani weisen - analog zu den Basisdialekten - insbesondere auf phonetischer Ebene eine hohe Diversifikation auf, die sich vor allem in Unterschieden in der Frequenz bestimmter phonetischer Merkmale (z.B. Lenisierung der stimmlosen intervokalischen Plosive, Palatalisierung von [s] vor [k, g, p, b] oder Rhotazismus, vgl. Radtke 1998a: 191) sowie in prosodischen Charakteristika (De Blasi 2001: 93) manifestiert. Auf lexikalischer Ebene zeigen die verschiedenen Varietäten des Italienischen in der Campania sicher eine stärkere Homogenität als im Bereich der Phonetik. Um festzustellen, ob bzw. inwieweit diese tatsächlich auf die Verbreitung von Lexemen aus dem italiano napoletano - und nicht auf den ,pankampanischen' Teil des in die verschiedenen italiani regionali einfließenden dialektalen Wortschatzes - zurückzuführen ist (vgl. Kap. 3.3.4.5), bedarf es jedoch einer detaillierten Untersuchung einer repräsentativen Anzahl an Lexemen, die bisher nicht vorliegt. Da die regionalen bzw. lokalen Varietäten des Italienischen in der Campania jedoch auch auf lexikalischer Ebene durchaus Unterschiede aufweisen (De Blasi 2001: 96f.), ist es jedoch auch hier nicht gerechtfertigt, die im Repertoire der dialektophonen Sprecher jeweils verankerte Varietät des Italienischen mit dem italiano di Napoli zu identifizieren. Von e i n e m italiano campano lässt sich in jedem Fall nur unter starker Abstraktion von den intraregionalen bzw. lokalen Differenzen sprechen (De Blasi 2001: 92).

\subsubsection{Die diachronische Entwicklung II: Koineisierung auf der Basis des Neapo- litanischen?}

Die Position der italienischen Geolinguistik im Hinblick auf die Entwicklung der diatopischen Variation in der Campania in jüngster Zeit (d.h. ab der zweiten Hälfte des 20. Jahrhunderts) ist auf den ersten Blick eindeutig. Der Metropole Neapel wird - wie den norditalienischen Metropolen Turin, Mailand und Venedig (vgl. Kap. 2.4.2) - der Status einer città guida und dem prestigereichen Neapolitanischen entsprechend die Funktion eines parler directeur (Radtke 2002a: 66) für die Dialekte der Region - und teilweise sogar darüber hinaus - zugesprochen: „Centro unificatore o meglio modello di alto prestigio per tante parlate non soltanto campane è rappresentato da Napoli, e, come si sa, qui si può parlare di espansione idiomatica del napoletano e di formazione di una specie di coinè italianizzante [...] fondata sul dialetto della metro-

\footnotetext{
${ }^{176}$ Die historische Stigmatisierung der (durch die Merkmale der zugrunde liegenden Dialekte geprägten) lokalen Varietäten des Italienischen ist als Konsequenz der Stigmatisierung der Dialekte gegenüber der italienischen Nationalsprache zu betrachten. Damit steht auch die Überwindung dieser Stigmatisierung in direktem Zusammenhang mit der Überwindung des Minderwertigkeitsgefühls der Sprecher in Bezug auf ihre Dialektophonie (vgl. 3.3.7).
} 
poli“ (Pellegrini 1990: 18). Aussagen wie die von Trumper/Maddalon (1988: 232), die im Kontext ihrer Analyse verschiedener italienischer Regionen im Hinblick auf sprachliche Konvergenzprozesse darauf hinweisen, dass ,,[t]he Neapolitan question requires a more detailed study than is here possible“ zeigen jedoch, dass die geolinguistische Situation und Entwicklung in der Campania durchaus nicht überall mit dem Hinweis auf das Vorliegen einer koiné napoletana als ausreichend charakterisiert betrachtet wird.

Es scheint außer Frage zu stehen, dass das Neapolitanische zumindest die Entwicklung der Dialekte in der direkten geographischen Umgebung beeinflusst: „La varietà napoletana si diffonde fuori Napoli e sta per omogeneizzare la parlata del Golfo“ (Radtke 1996: 158). Als Folge einer solchen - in Kombination mit der Italianisierung der Dialekte wirkenden - ,irradiazione del napoletano" (ebd.) wird etwa die Durchsetzung der neapolitanischen Variante [11] (< LL) auf der Insel Ischia beschrieben (Radtke 1996: 156ff.), die in der zweiten Hälfte des 20. Jahrhunderts auf Kosten der in den 1930er Jahren noch dominanten dialektalen Variante [dd] sowie der Varianten [JJ] und $[K \Lambda]$ stattgefunden hat, die entweder gänzlich verdrängt worden sind $([\Lambda K])$ oder nurmehr als ,residui“ vorkommen ([dd] in der älteren Generation in Barano d'Ischia und [JJ] in der älteren und mittleren Generation in Forio). Auch auf dem Festland - in der Provinz Caserta, im Sannio und im nördlichen Teil der Irpinia - wird der Rückgang der dialektalen Varianten $[K \kappa]$ und [J] mit der Verbreitung der neapolitanischen Variante [11] in Verbindung gebracht (Radtke 1997a: 72). Als Phänomene einer napoletanizzazione des Cilento werden die Abschwächung der Auslautvokale, die Verbreitung der Palatalisierung von [s] zu [S] vor [k] und [p] (Radtke 1997a: 63, 74) sowie die Ersetzung der autochthonen Varianten trezza ,treccia' und fazzo ,faccio' durch die neapolitanischen Varianten treccia und faccio (Radtke 1998a: 189) genannt. Die Verdrängung des Objektpronomens der 1. Pers. Sg. nə durch cə $(c i)$ im Cilento und in der Irpinia wird auf eine Kombination aus Neapolitanisierung und Italianisierung zurückgeführt (Radtke 1997a: 85).

De Blasi/Fanciullo (2003: 628) weisen darauf hin, dass die Neapolitanisierung der Dialekte möglicherweise auf jene Merkmale beschränkt ist, die das Neapolitanische mit dem Italienischen teilt und dass es sich somit etwa im Fall der Ersetzung von fazzo durch faccio im Cilento nicht um ein „,cedimento cilentano verso il napoletano“ (ebd.), sondern vielmehr um eine Durchsetzung der italienischen gegenüber der dialektalen Variante handelt. Selbiges könnte für die Verbreitung der Variante [11] und die Verdrängung des dialektalen Objektpronomens nə durch $c$ a $(c i)$ - wo der (verstärkende) Einfluss des Italienischen ja bereits festgestellt wurde (s.o.) - angenommen werden. Die These der napoletanizzazione kann jedenfalls (auf qualitativer Ebene) nur dadurch zweifelsfrei belegt werden, dass die Verbreitung von Merkmalen nachgewiesen wird, die ausschließlich im Neapolitanischen, d.h. weder im Italienischen noch in anderen kampanischen Dialekten zu finden sind. Solche Merkmale sind bisher jedoch nicht bekannt.

Auch auf metalinguistischer Ebene finden sich Hinweise, die eine kritische Überprüfung der These der Neapolitanisierung der kampanischen Dialekte nahelegen. Die (historisch-kulturell bedingte) ${ }^{177}$,incontrovertibile differenza fra i cittadini e gli altri“ (De Blasi/Fanciullo 2003: 629) spiegelt sich in einer reziproken „sensazione di distanza“ (ebd.: 628) wider, die neben anderen sozialen Aspekten auch den sprachlichen Bereich betrifft. In seiner direkten geographischen Umgebung hat das Neapolitanische zwar den Status eines ,modello normativo di prestigio“" (Radtke 2002a: 69), die sprecherseitige Einstellung gegenüber dem napoletano ist jedoch

\footnotetext{
177 Vgl. Kap. 3.2.
} 
entweder offenkundig negativ (Pozzuoli) ${ }^{178}$ oder „,reserviert“ (Hinterland, etwa Frattamaggiore, Radtke 2002a: 68f.). Die in Neapel zu den kulturellen Topoi gehörende Abwertung der Dialekte des Hinterlands als cafone (,provinciale, contadino') ist den Sprechern dieser Dialekte zwar bekannt, führt jedoch nicht zu einem gesteigerten Assimilationsbedürfnis: „I parlanti [...] non vogliono parlare come i napoletani, ma sanno che la loro parlata non piace ai napoletani“ (Radtke 2002a: 69). Vor diesem komplexen metalinguistischen Hintergrund ist eine Neapolitanisierung der im Hinterland der Metropole situierten Dialekte nicht ohne Weiteres anzunehmen.

In den weiter östlich und südöstlich im Landesinneren gelegenen Gebieten (etwa in der area circumvesuviana oder in der Irpinia) kommt dem napoletano in den Bewertungsmustern der Sprecher häufig keine besondere Stellung mehr zu: ,[R]imane in questo quadro una varietà neutra come le altre senza superiorità di prestigio“ (Radtke 2002a: 70). Diese Neutralität ist mit einem „superamento graduale della vergogna della propria dialettofonia“ (Radtke 1998a: 191) ${ }^{179}$ und einer damit einhergehenden Überwindung des sprachlichen Minderwertigkeitsgefühls gegenüber dem Neapolitanischen in Verbindung zu bringen. Geht man davon aus, dass gerade das Gefühl der sprachlichen Unterlegenheit gegenüber einem als prestigereich betrachteten städtischen Dialekt Voraussetzung für die Übernahme von Merkmalen aus diesem in den lokalen Dialekt und damit für eine Koineisierung ist (vgl. Kap. 2.4.1), ist auch eine Neapolitanisierung der im Osten der Region gelegenen Gebiete unwahrscheinlich. In den südlichen Gebieten (Cilento) wird das napoletano zwar - neben den lokalen Dialekten - als Teil des ,patrimonio culturale“ angesehen und meist positiv bewertet, ist jedoch nicht Teil der Dialektkompetenz der Sprecher (Radtke 2002a: 70). Hier stellt sich die Frage, auf welchem Wege eine Neapolitanisierung stattfinden soll, wenn die Sprecher der lokalen Dialekte nicht über eine (zumindest passive) Kompetenz im Neapolitanischen verfügen.

Die metalinguistische Situation in der Campania weist also einige Merkmale auf, die das Vorliegen einer Neapolitanisierung zwar nicht ausschließen, jedoch deutlich in Frage stellen. Nichtsdestotrotz wurde der Möglichkeit, dass der Orientierung der Dialekte ,verso un livello sovralocale“ (Radtke 1998a: 189) ein nicht auf den Einfluss des Neapolitanischen zurückzuführender Prozess, d.h. ein allgemeiner Dialektausgleich (dialect levelling, vgl. Kap. 2.4.1) zugrunde liegen könnte, bisher nicht nachgegangen. Doch erfordern nicht zuletzt die Unterschiede, die die demographische Entwicklung der Metropolregion Neapel zu jener der norditalienischen Metropolregionen aufweist (vgl. Kap. 3.1), eine kritische Überprüfung des Phänomens einer auf dem Neapolitanischen als dialetto guida basierenden Koineisierung.

Einzelne qualitative Studien weisen bereits darauf hin, dass die Entwicklung der dialektalen Variation in der Campania in Richtung der Entstehung eines „dialetto regionale o sovraregionale spesso fortemente italianizzato“ geht (Buonocore 2007: 84). Die Analyse einzelner sprachlicher Merkmale (seien sie auch struktureller Natur) reicht jedoch zu einer umfassenden Klärung der Frage nach der grundsätzlichen Natur dieser Veränderungen nicht aus. Um auszuschließen, dass es sich bei den festgestellten Entwicklungstendenzen um Einzelfälle handelt, bedarf es einer Analyse der Entwicklung der basilektalen Variation unter Einbeziehung einer größeren Anzahl sprachlicher Merkmale.

\footnotetext{
${ }^{178}$ Angesichts der starken Stigmatisierung des (v.a. im vokalischen Bereich innovativen) Dialekts von Pozzuoli (puteolano) durch die Sprecher des Neapolitanischen und der sich daraus ergebenden reziproken Antipathie (Radtke 2002a: 68) liegt hier jedoch eine spezielle, d.h. nicht repräsentative Situation vor.

${ }^{179}$ Vgl. Kap. 2.2, FN 17.
} 


\section{Zur Analyse der diatopischen Variation}

\subsection{Die ,klassische' romanistische Sprachgeographie}

\subsubsection{Ziele und Methodik}

[U]nter Sprachgeographie (bzw. Geolinguistik, geografia linguistica, geolinguistica, géographie linguistique, géolinguistique, linguistic geography, geolinguistics) [versteht man] seit mehr als einem Jahrhundert das systematische Bemühen um die empirische Erhebung, kartographische Darstellung und nachfolgende Analyse von möglichst vielen sprachlichen Einzelelementen (wie Wörtern, Lauten, Formen oder Satzteilen); dies alles mit stetem Blick auf ein ausgedehntes Netz von Ortsdialekten, welch letztere wiederum in genetischer Hinsicht einer territorial zusammenhängenden Sprachgemeinschaft wie dem Deutschen, Italienischen oder Französischen zuzuordnen sind. (Goebl 2007: 189) ${ }^{180}$

Die ,klassische' romanistische Sprachgeographie und alle epistemologisch an diese anknüpfenden modernen geolinguistischen Forschungsrichtungen ${ }^{181}$ beschränken sich mithin auf die Analyse der diatopischen - genauer: der basilektalen - Variation innerhalb einer Historischen Gesamtsprache. ${ }^{182}$

Der ,klassischen“ romanistischen Sprachgeographie liegen zwei voneinander unabhängige Forschungstraditionen zugrunde. Den geistesgeschichtlichen Hintergrund bildet die - von dem romantisch-nostalgischen Interesse am überlieferten, volkstümlichen Sprachgut ' begleitete - im 19. Jahrhundert in den philologischen Kreisen Europas entwickelte Überzeugung, „dass die wissenschaftliche Durchdringung [...] der überlieferten Hoch- und Kultursprachen Europas durch das mit allen Mitteln zu systematisierende Studium von deren Dialekten entscheidend zu verbessern sei“ (Goebl 2011: 7), aus der sich insbesondere das Interesse der Indogermanistik für den Sprach- bzw. Dialektvergleich speiste. ${ }^{183}$ Als theoretischer und gleichzeitig methodischer ,Nährboden“ fungierte die spezifisch französische Tradition der „Departement-Statistik“, die seit Beginn des 19. Jahrhunderts in Frankreich in einer Vielzahl systematischer Erhebungen in verschiedenen physio- und humangeographischen Bereichen erprobt und

180 Tappolet (1905: 388) unterscheidet zwei „Arten von Sprachgeographie“: die Sprachgeographie im engeren Sinne als Wissenschaft der räumlichen Verteilung von Sprachen bzw. Sprachfamilien (,ethnographische Sprachgeographie“) und die Sprachgeographie im weiteren Sinne als Wissenschaft der räumlichen Verteilung von Spracherscheinungen (,dialektische Sprachgeographie“). Der Begriff ,Sprachgeographie“ hat sich jedoch nur in der zweiten Bedeutung etabliert; der erstgenannten Bedeutung entspräche in der linguistischen Terminologie der Begriff, „Sprachengeographie“(Goebl 2007: 189).

181 Vgl. Kap. 4.3.

182 In dem Begriff der „Historischen Gesamtsprache“ führt Mattheier (1996) das Konzept der „Historischen Sprachen“ von E. Coseriu (1980) und jenes der „Gesamtsprache“ von H. Steger (1988) zusammen: „die Vorstellung von einem über sprachliche Verwandtschafts- und Ähnlichkeitsrelationen verbundenen Gesamtzusammenhang von Sprachvarietäten und Sprachstilen, die heutzutage häufig durch eine gemeinsame Standardvarietät überdacht sind, und die Vorstellung von einem sich über eine lange gemeinsame Entwicklungszeit herausbildenden Varietätenkomplex, der von der Sprachgemeinschaft, die ihn trägt, auch zur Identitätsbildung herangezogen wird" (Mattheier 1996: 32).

${ }^{183}$ Vor diesem Hintergrund entwickelten sich auch in der germanistischen Philologie die ersten Ansätze einer systematisch betriebenen Sprachgeographie. So begann der Marburger Bibliothekar Georg Wenker (1852-1911) bereits im Jahr 1876 mit der Erhebung von Sprachdaten anhand eines (von den Gewährspersonen schriftlich auszufüllenden) Fragebogens im Rheinland, welche im Sprach-Atlas der Rheinprovinz nördlich der Mosel sowie des Kreises Siegen, dem ersten deutschen Sprachatlas (Wenker 1878) veröffentlicht wurden (vgl. Herrgen 2001: 1520). 
optimiert worden war (vgl. Goebl 2011: 7f.). ${ }^{184}$ Dieser Praxis lag die Auffassung des Raumes als ein in allen unterschiedlichen Formen der Bewirtschaftung systematisch zu eruierendes zweidimensionales Gebilde zugrunde. Vorläufer der romanistischen Sprachgeographie waren insbesondere die Arbeiten des Diplomaten und Statistikers Charles-Etienne Coquebert de Montbret (1755-1831) und dessen Sohn Eugène-Barthélémy Coquebert de Montbret (17851849), die als erste systematisch und mittels eines standardisierten Verfahrens erhobene Sprachdaten in Form dialektaler Übersetzungen der Parabole de l'Enfant Prodigue aus Frankreich und allen von Frankreich besetzten Gebieten zusammentrugen (vgl. Goebl 2006a: 295).

Die systematische sprachgeographische Erfassung der gesamten Galloromania gelang Ende des 19. Jahrhunderts dem Schweizer Romanisten Jules Gilliéron (1854-1926), der mit dem Atlas Linguistique de la France (ALF, 1902-1910) in direkter Tradition der DepartementStatistik stand und den methodischen Grundstein für die klassische Sprachatlasarbeit in der Romanistik legte. ${ }^{185}$ Der Erhebung der Dialektdaten lag dabei ein Ortsnetz zugrunde, das entsprechend der erprobten humangeographischen Praxis - aus einer arbeitspraktisch zu bewältigenden, gleichzeitig aber statistisch ausreichenden Anzahl von $638^{186}$ in äquidistanter Weise im französischen Staatsgebiet verteilten Aufnahmeorten bestand. Ziel der empirischen sprachgeographischen Arbeit, die von Gilliérons Explorator Edmond Edmont (1849-1926) zwischen 1897 und 1901 in verschiedenen Etappen durchgeführt wurde, war die Sammlung von perfekt interkomparablem, ausschließlich basilektalem Sprachmaterial (vgl. Goebl 2011: 8, 12). Dabei nutzte Gilliéron bewusst den bereits damals weitestgehend vorhandenen Bilinguismus (lokaler Dialekt und Standardfranzösisch) der französischen Bevölkerung: So wurde - auf der Grundlage eines stark diversifizierten, d.h. verschiedene sprachliche Ebenen abdeckenden Fragebuchs (1421 Grundfragen $)^{187}$ - in auf Französisch geführten Aufnahmegesprächen die basilektale Kompetenz (und nur diese) der Gewährsleute elizitiert. ${ }^{188}$ Um dabei sowohl die Interkomparabilität als auch die Authentizität der Antworten zu maximieren, wurde grundsätzlich die erste,

\footnotetext{
${ }^{184}$ Dies umfasste nicht nur die Ausführung extensiver Umfragen aller Art, sondern ebenfalls deren statistische Auswertung sowie die Erprobung verschiedener Techniken der kartographischen Visualisierung der Ergebnisse. Wichtige Arbeiten stammen u.a. von Charles Dupin (1784-1873, Carte figurative de l'instruction populaire de la France, 1827), André-Michel Guerry (1802-1866, Statistique comparée de l'état de l'instruction et du nombre des crimes dans les divers Arrondissements des Académies et des Cours Royales de France, 1829) und Adolphe D’Angeville (1796-1856, Statistique de la Population française, 1836) (vgl. Goebl 2006a).

${ }^{185}$ Mit dem Motto „dictionnaire, cimetière“ (Roques 1926: 8) entschied sich Gilliéron bewusst gegen die damals vorherrschende Praxis der Dokumentation von Dialekten anhand von Wörterbüchern und Monographien. Bei seinen Arbeiten zum ALF konnte Gilliéron bereits auf die Erfahrungen im Bereich der Sprachatlasarbeit zurückgreifen, die er mit seinem 1881 erschienenen Petit Atlas phonétique du Valais roman (sud du Rhône) gemacht hatte. Zu Leben und Werk Gilliérons vgl. Pop/Pop (1959) und Lauwers/Simoni-Aurembou/Swiggers (2002). 186 Tatsächlich wurden die Aufnahmen zum ALF in 638 Orten (points d'enquête) durchgeführt. Da jedoch in Saint-Pol-sur-Ternoise (Picardie, ALF-Punkt 284), dem Geburtsort von E. Edmont, zwei Aufnahmen (enquêtes) gemacht wurden (eine in der Peripherie und eine im centre-ville), sprechen viele Darstellungen - darin wohl Gilliéron selbst (1902: 3) folgend - von 639 points d'enquête (statt korrekterweise von 639 enquêtes).

${ }^{187}$ Im Laufe der Erhebungen wurde das Fragebuch allerdings auf 1747 Fragen (Kartenserie B) bzw. 1920 Fragen (Kartenserie C) erweitert. Die erweiterten Varianten kamen nur im mittleren bzw. südlichen Teil Frankreichs zum Einsatz. Zur separaten Betrachtung der Kartenserie B vgl. Goebl/Smečka (2014).

${ }^{188}$ Im Gegensatz zu der ,klassischen“ germanistischen Sprachgeographie ist die romanistische Sprachgeographie nicht an der Erfassung des jeweils ,ältesten“, sondern des jeweils „ortstypischen“ Dialekts interessiert (Goebl 2011: 16). Der Erhebungspraxis liegt mithin die Annahme zugrunde, dass die jeweilige Ortsgemeinschaft sprachlich ausreichend homogen ist und dass die durch die - nach Kriterien wie Ortsstämmigkeit und Dialektkompetenz ausgewählte - Gewährsperson gelieferten Belege als „typisch“ für den jeweiligen Ortsdialekt gelten können.
} 
„spontane“ Antwort bevorzugt und jegliche Form des „Nachfragens“ (extorsion) möglichst vermieden (Goebl 2011: 13). ${ }^{189}$

Bei der Auswertung und Interpretation der erhobenen Sprach- bzw. Dialektdaten, die anhand der von der Druckerei des ALF in Mâcon zur Verfügung gestellten „stummen Karten“ von Gilliéron und den Mitgliedern seines wissenschaftlichen Zirkels in extensiver Form vorgenommen wurden (Goebl 2011: 9), verfolgte Gilliéron neben dem synchronen insbesondere auch ein diachrones Erkenntnisinteresse: die Rekonstruktion sprachhistorischer Prozesse ausgehend von den synchron beobachtbaren sprachgeographischen Gegebenheiten. Die synchrone sprachliche (und insbesondere lexikalische) Differenzierung eines Gebietes betrachtete er dabei als Spiegel der verschiedenen historischen Sprach- bzw. Wort-,,Schichten“ und damit als „Schlüssel“" zu den in der Vergangenheit abgelaufenen Sprachwandelprozessen:

Un mot a ses conditions géographiques précises qu'il importe avant tout de déterminer. Un fait géographique est souvent la clef de son histoire. De par les conditions géographiques, une étymologie, possible ailleurs, est impossible là. Si des couches de mots coexistent actuellement sur le sol, il y a lieu de montrer que l'une est par rapport à l'autre un sous-sol et ainsi de suite : nous devons réaliser d'abord une géographie ou géologie linguistique qui nous permettra de situer les mots chronologiquement, de définir leurs rapports, de reconstituer leur génèse. (Gilliéron/Mongin 1905: 3) ${ }^{190}$

Die Auswertung des im ALF enthaltenen sprachlichen Materials erfolgte insbesondere mit dem Ziel des Aufdeckens der ,stratigraphie des mots dans l'histoire des faits linguistiques“ (Gilliéron 1918: 1). Auf der Basis der Arbeiten entstanden Hypothesen zur relativen Chronologie verschiedener ,pathologischer“" sprachlicher Entwicklungen (z.B. lautliche Schrumpfung, Homonymenkollision, Entwicklung von Polysemie) und den darauf folgenden ,therapeutischen“ Reaktionen der Sprecher, in deren ,remèdes“ (z.B. phonetische Restaurierung, lexikalische Ersetzung, Volksetymologie) ihre Kreativität zum Ausdruck kommt (Desmet/Lauwers/Swiggers 2002: 38). ${ }^{191}$ Während dieser historische Fokus der Sprachgeographie größtenteils auf das Werk Gilliérons und seiner Adlaten beschränkt blieb, beeinflusste die seiner empirischen Arbeit zugrunde liegende Methodik der systematischen, d.h. flächendeckenden und standardisierten Erhebungsweise sprachlicher Daten die weitere Entwicklung der romanistischen Sprachgeographie maßgeblich. Aus der Anzahl der im Laufe des 20. Jahrhunderts publizierten und an den Gilliéronschen Prinzipien orientierten romanischen Sprachatlanten ${ }^{192}$ ist ins-

\footnotetext{
${ }^{189}$ Dabei war sich Gilliéron des „Augenblickscharakters“ der Antworten sehr wohl bewusst: „Ce caractère d'instantanéité est précisément ce à quoi nous tenions le plus, ce qui distingue le mieux l'Atlas de tous les autres matériaux utilisés jusqu'ici, ce qui est notre sauvegarde à nous qui l'utilisons“" (Gilliéron 1918: 4).

${ }^{190}$ Analog dazu bezeichnet Bartoli (1945: VIII) Sprachatlanten als ,telescopi, perché si scoprono le fasi anteriori, che sono talora molto lontane nei tempi: costellazioni già tramontate.“

${ }^{191}$ Entsprechend der in den Anfängen der philologischen Forschung häufig vertretenen Auffassung von Sprache als Organismus (Whitney 1875) ist Gilliérons Terminologie an der (Human-)Biologie und der Medizin orientiert: Sprachwandel wird als Abfolge von „Pathologie“ und „Therapie“ begriffen (vgl. Gilliéron 1921). Zur Kritik der Analyse und Interpretation der sprachgeographischen Daten durch Gilliéron vgl. u.a. Wartburg (1970: 143ff.) und Weinhold (1985: 13f.).

192 Die in Frankreich zwischen 1950 und 1997 erschienenen Atlanten des Projekts Nouvel Atlas Linguistique de la France (NALF, ab 1980 Atlas linguistique de la France par régions), die jeweils eine bestimmte Region abdecken, unterscheiden sich hingegen in ihrer Konzeption grundlegend vom ALF: Hier ging es primär darum, den sprachlichen Charakter verschiedener historischer Regionen möglichst umfassend zu dokumentieren und damit im Hinblick auf den Rückgang der Dialekte - zu konservieren. Auf methodischer Ebene ging damit - neben einer „Verfeinerung“ des Ortsnetzes - die Anpassung des Fragebogens an die regionalen (sprachlichen und
} 
besondere der Sprach- und Sachatlas Italiens und der Südschweiz (AIS, 1928-1940) herauszuheben, der in den 1920er Jahren unter der Leitung der Schweizer Romanisten (und Schüler Gilliérons) Karl Jaberg (1877-1958) und Jakob Jud (1882-1952) als zweiter, ähnlich umfangreicher (im Gegensatz zum ALF allerdings ethnographisch orientierter) romanischer Sprachatlas entstand und sich explizit an den Gilliéronschen Prinzipien der empirischen Sprachatlasarbeit orientierte (höchste Interkomparabilität der erhobenen Daten, Spontaneität der Antworten etc., vgl. Jaberg/Jud 1928: 175, 182 u.a.). ${ }^{193}$ Jaberg und Jud verweisen - wohl in Antizipation der Kritik, die zuvor an Gilliérons sprachgeographischer Erhebungspraxis geübt worden war ${ }^{194}$ - zudem explizit darauf, wie der dokumentarische Wert eines nach Gilliéronschem Muster erstellten Sprachatlasses einzuschätzen ist:

Ein Sprachatlas von der Art des unsrigen will nicht ein nach Vollständigkeit strebender Thesaurus sein etwa in dem Sinne, wie es die Wörterbücher größerer Dialektgebiete sind. Er verhält sich zum groß angelegten Wörterbuch wie $\mathrm{d}$ i e $\mathrm{S}$ k i z z e z u m B i $1 \mathrm{~d}$. Er will bloß charakteristische Proben der geographischen Verteilung des Wort- und Formenschatzes eines Sprachgebietes geben ; Proben, die reichlich genug sind, um von der Skizze auf das Bild schließen zu lassen. Es ist die Aufgabe von Regionalatlanten [...], die Détailsverhältnisse festzustellen. Eine Beschränkung auf eine Auswahl von Ortschaften war also nicht nur durch äußere Rücksichten, sondern auch durch das Prinzip des sprachlichen Ü b e r s i c h t s a t 1 a s s e s gegeben. (Jaberg/Jud 1928: 184)

Auch im Bereich der kartographischen Darstellung setzte Gilliéron mit dem ALF die Standards der romanistischen Sprachgeographie: So wird das erhobene sprachliche Datenmaterial in der romanistischen Sprachgeographie bis heute auf großformatigen Volltextkarten präsentiert, auf denen die sprachlichen Belege in einer phonetischen Transkription neben den mit Nummern gekennzeichneten Aufnahmeorten notiert werden (s. Karte 19). ${ }^{195}$

\footnotetext{
außersprachlichen) Gegebenheiten einher, mit der man einen nahezu kompletten Verlust der von Gilliéron postulierten Interkomparabilität der Daten in Kauf nahm (vgl. Goebl 2013d: 71).

${ }^{193}$ Der Einfluss Gilliérons zeichnet sich wohl in erster Linie bei der Gestaltung des Fragebuchs ab, zu der die Autoren bemerken: „Bis zu einem gewissen Grade waren wir auch durch den ALF gebunden, den wir zwar nicht kopieren, aber doch fortsetzen wollten“ (Jaberg/Jud 1928: 176). Im Hinblick auf die Gestaltung des Ortsnetzes weicht der AIS insbesondere durch die Integration städtischer Zentren vom ALF ab, in dem diese nicht berücksichtigt worden waren (vgl. Pop/Pop 1959: 72).

${ }^{194}$ Diese Kritik betraf u.a. die „Unvollständigkeit“ des Fragebuchs, die Großmaschigkeit des Ortsnetzes bzw. die gleichmäßige Verteilung der Orte auf den Sprachraum sowie einzelne Transkriptionsfehler Edmonts (vgl. Pop/Pop 1959: 70f., 72, 75f., Dauzat 1944: 9ff.) und mündete in der Forderung einer größeren „Authentizität“ der sprachgeographischen Daten (Goebl 2013d: 71).

195 In der germanistischen Sprachgeographie wird hingegen seit Beginn der kartographischen Darstellung (die die bis dahin übliche Darstellung von Sprachdaten in Tabellenform ablöste, vgl. Goebl 2011: 9) die (indirekte) Darstellung mittels Symbolkarten, bei der die verschiedenen sprachlichen Formen (Typen) jeweils durch ein bestimmtes Symbol auf der Karte illustriert werden und die somit eine vorherige Auswertung der Belege erfordert. Zurück geht diese kartographische Tradition auf die Auswertung des von Wenker gesammelten, extrem umfangreichen Datenmaterials, bei der die Technik der Symbol-Kodierung in erster Linie arbeitspraktischen Bedingungen geschuldet war: Das überaus feinmaschige Ortsnetz von bereits zu Anfang 36.000 Messpunkten (das sukzessive um 16.000 weitere deutschsprachige Orte in angrenzenden Ländern erweitert wurde, vgl. Goebl 2006: 9) ließ bei der kartographischen Visualisierung der Daten im Deutschen Sprachatlas (DSA, Teilpublikation 1927-1956) schlichtweg keine andere Darstellungsweise zu (Goebl 2011: 9). Einen Überblick über die Verfahren der kartographischen Darstellung von Sprachdaten liefert Putschke (1982).
} 


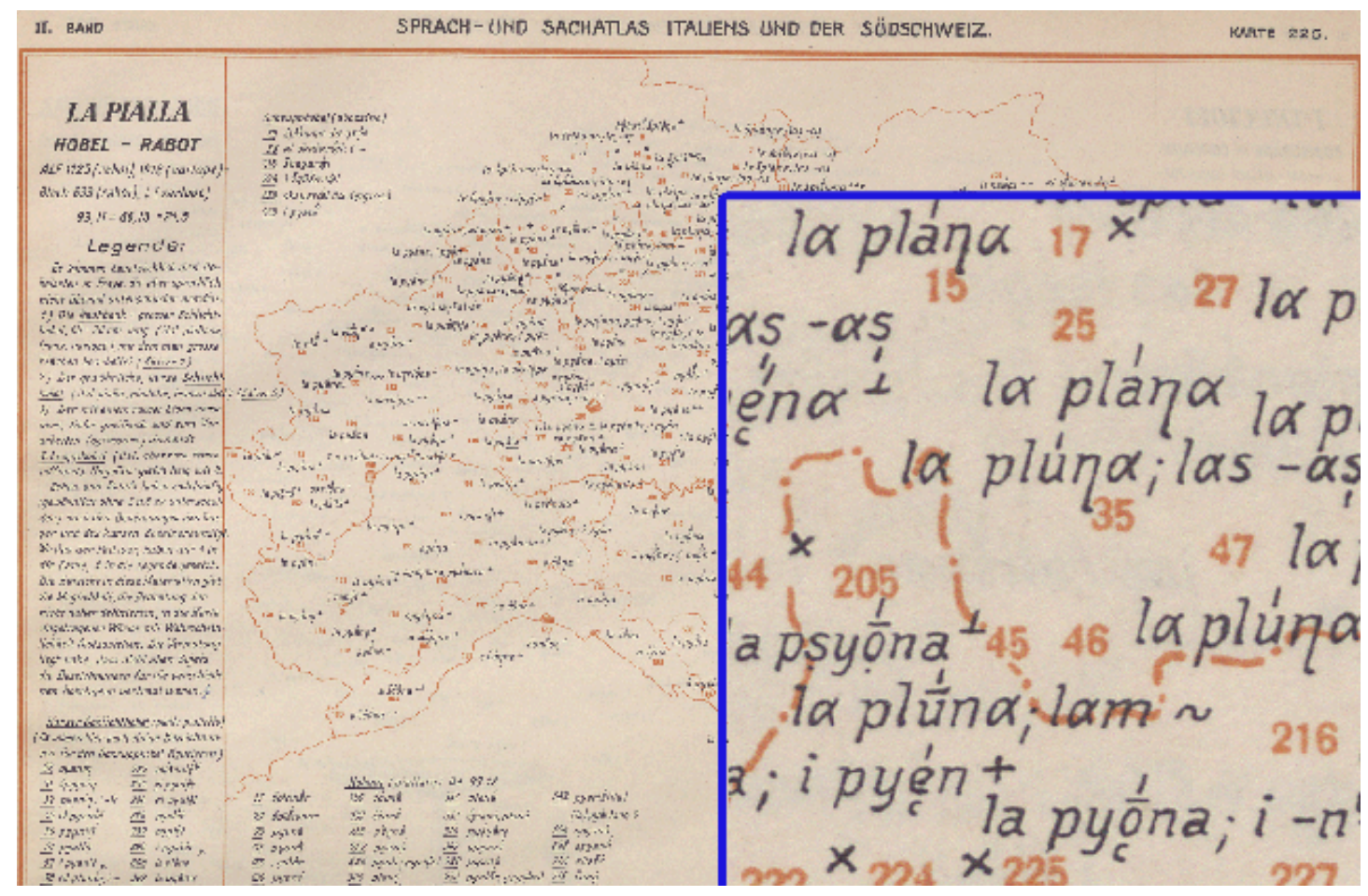

Karte 19. Karte 225 (la pialla) des AIS (nördliche Hälfte) mit vergrößertem Ausschnitt (Quelle: NavigAIS).

Das der Analyse des erhobenen sprachlichen bzw. dialektalen Datenmaterials zugrunde liegende Erkenntnisinteresse deckt sich in der ,post-Gilliéronschen' romanistischen Sprachgeographie hingegen nicht (mehr) mit dem ihres Begründers. Ziel der Analyse der synchronen sprachlichen Differenzierung des geographischen Raums ist nun nicht mehr die Rekonstruktion sprachhistorischer Prozesse, sondern die Bestimmung der Grenzen zwischen den Verbreitungsgebieten sprachlicher Varianten mit dem Ziel der synchronen Gliederung von Sprachräumen und Dialektgebieten. Das dabei verwendete Verfahren ist in der klassischen Sprachgeographie qualitativer Natur. Zur Visualisierung der dialektalen Unterschiede innerhalb eines Untersuchungsgebietes werden die Grenzen zwischen den Verbreitungsarealen verschiedener Varianten einer sprachlichen Form bzw. eines sprachlichen Merkmals (Isoglossen, vgl. Kap. 4.1.2) entsprechend der Verteilung der Belege auf der jeweiligen Sprachatlaskarte gezogen: „[A]n area is split up into subareas 1 and 2, because speakers in area 1 use form A while those in area 2 have form B for the same linguistic function“" (Schneider 1988: 176, vgl. Abb. 3). ${ }^{196}$

\footnotetext{
${ }^{196}$ Dadurch, dass sich die ,klassische` Sprachgeographie im Allgemeinen mehr für die Grenzen zwischen den Arealen als für die Areale selbst interessierte (Bauer 2009: 119), kam die zur Linienkarte komplementäre Flächenkarte als Heuristikum hier deutlich seltener zum Einsatz (Goebl 2004a: 528). Eine Ausnahme bildet die extensive Auswertung der Daten des ALF, bei der - entsprechend der kartographischen Tradition der DepartementStatistik (s.o.) - zu einem Großteil mit Flächenkarten gearbeitet wurde (ebd.: 529, vgl. etwa die Karte zu ,scier ${ }^{6}$ in Gilliéron/Mongin 1905).
} 


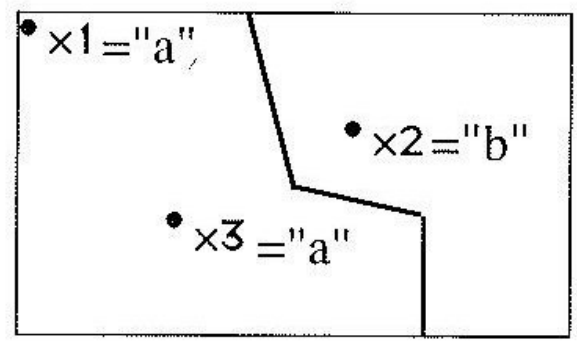

Abbildung 3. Schema zum Verlauf von Isoglossen (D’Agostino/Pennisi 1995: 17).

Durch das Aufbringen verschiedener Isoglossen auf ein und derselben Karte (Isoglossensynthese) können Gruppen von Isoglossen identifiziert werden, die grob gesehen einen ähnlichen bzw. parallelen Verlauf in einem bestimmten geographischen Areal nehmen (Isoglossenbündel, vgl. Stammerjohann 1975: 202). Diese werden meist als Indikatoren für die äußeren Grenzen eines Dialektgebietes ${ }^{197}$ gesehen:

Il y a donc chance pour que les lignes qui enserrent les groupes de localités où se produisent plusieurs innovations indépendantes viennent à coïncider entièrement, ou du moins se rapprochent et se suivent souvent de très près. Un ensemble de localités où se produit ainsi, de manière indépendante, une série de changements concordants, qui sont en conséquence enserrées par un certain nombre de lignes d'isoglosses et s'opposent par là aux parlers voisins, constitue un dialecte naturel. (Meillet 1908: 4) ${ }^{198}$

Auf diese Weise, d.h. anhand von Isoglossenbündeln bzw. der durch sie konstituierten Dialektgrenzen wurde und wird in der qualitativen Sprachgeographie die Gliederung von Sprachräumen bzw. Makroarealen in distinkte Dialektareale (s. Karte 20) und häufig auch die interne Gliederung dieser vorgenommen. Die bis heute ungebrochene ,Popularität ${ }^{`}$ der Methode darf jedoch nicht darüber hinwegtäuschen, dass die Isoglosse sowohl als sprachgeographischer Terminus als auch - weit wichtiger - als kartographisches Heuristikum (Goebl 2004a: 526) mit signifikanten Problemen behaftet ist, die die Adäquatheit der Verwendung von Isoglossen im Bereich der Sprachgeographie in Frage stellen und im Folgenden abrisshaft dargestellt werden.

\footnotetext{
${ }^{197}$ Bei Isoglossenbündeln zwischen Geotypen, die zu unterschiedlichen Sprachräumen gehören, handelt es sich entsprechend um Sprachgrenzen (vgl. die Isoglossensynthese zur Illustration der provenzalisch-piemontesischen Sprachgrenze in Rohlfs 1947: 7). Zur Metaphorik und Problematik des Begriffs der ,Sprachgrenze` vgl. Goebl (2003).

${ }^{198}$ Vgl. auch De Saussure (1995: 277f.).
} 


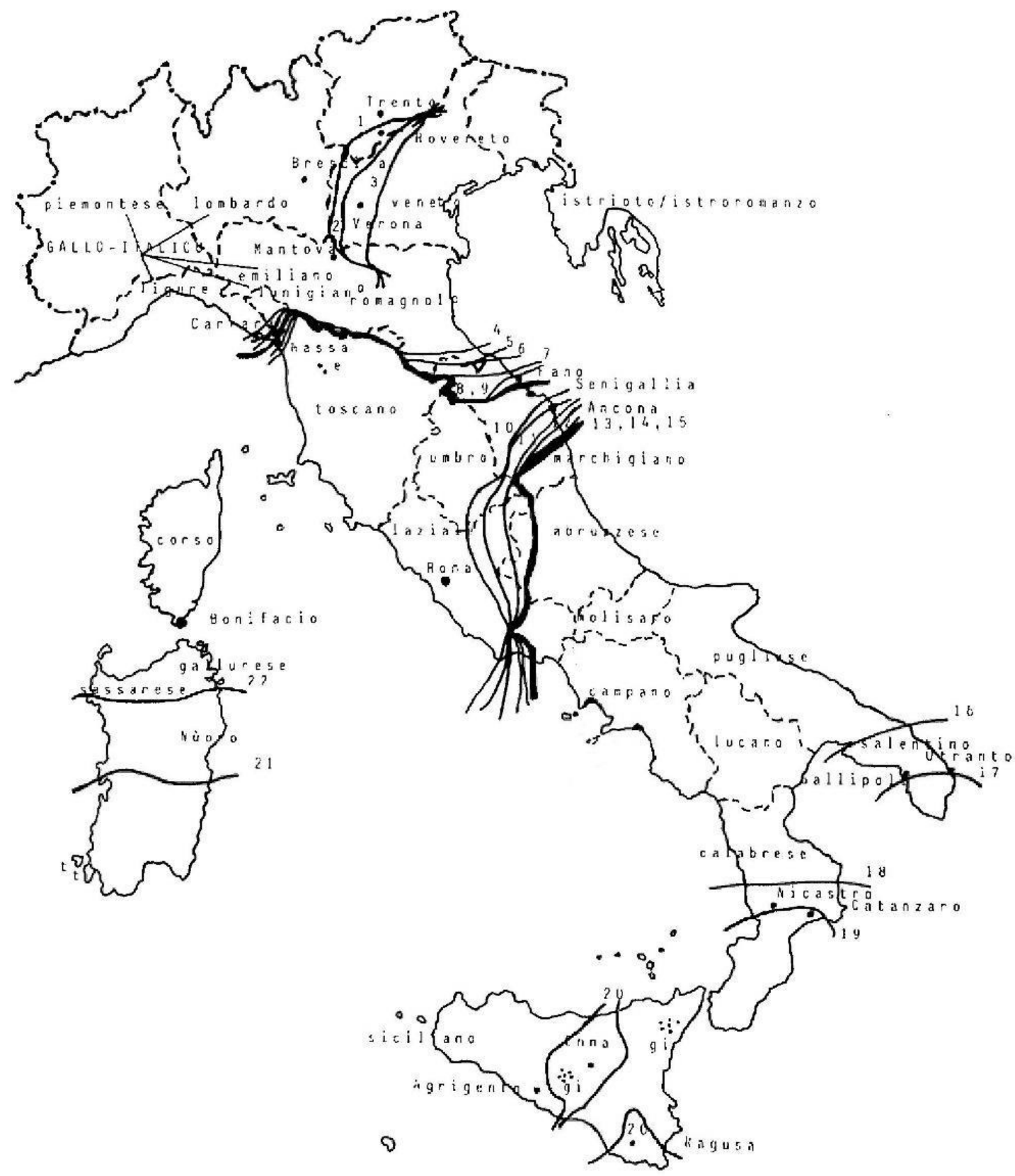

Karte 20. Isoglossen und Isoglossenbündel im italienischen Sprachraum, aus Blasco-Ferrer (1994: 204, dort mit Legende). Die Isoglossen 4 bis 9 bilden die Grenze zwischen dem norditalienischen und dem mittelitalienischen Dialektgebiet („Linie La Spezia-Rimini“), die Isoglossen 10 bis 15 die Grenze zwischen dem mittelitalienischen und dem süditalienischen Dialektgebiet („Linie Rom-Ancona“). 


\subsubsection{Die Problematik der Isoglosse}

\subsubsection{Terminologische Probleme}

Als Urheber des Begriffs Isoglosse gilt der Lettologe J. G. August Bielenstein (1826-1907), der diesen in Analogie zu dem meteorologischen Begriff Isotherme als Bezeichnung der „Verbreitungsgrenze für die einzelnen dialektischen Spracherscheinungen“" prägte (Bielenstein 1892: 391). ${ }^{199}$ In den darauf folgenden Jahrzehnten etablierte sich der Terminus in der allgemeinen und indogermanischen Sprachwissenschaft sowie in der romanistischen und in anderen Sprachgeographien. ${ }^{200}$ Heute finden sich in der sprachgeographischen bzw. dialektologischen Forschung hauptsächlich zwei Verwendungsweisen des Begriffs ,Isoglosse' bzw. des häufig synonym gebrauchten Terminus der sprachlichen ,Grenzlinie'.

Zum Einen erfolgt die Verwendung in der Bedeutung einer, Trennungslinie', die zwei Gebiete voneinander abgenzt, welche unterschiedliche sprachliche Merkmale aufweisen: „An ,isogloss' is a line on a linguistic map drawn between areas or localities where different forms occur, a dividing line which separates the two subareas, or dialect regions" (Schneider 1988: 176). Zum Anderen wird der Begriff ,Isoglosse“ in der Bedeutung einer ,Umgrenzungslinie“ gebraucht, die das Verbreitungsgebiet eines sprachlichen Merkmals um- bzw. eingrenzt: „,...] [A]n isogloss should never be regarded as a dividing line between two usages; rather it is an indication of the approximate outer limit of a single feature" (Atwood 1963: 15). ${ }^{201}$ Obwohl die zweite, der Bedeutung des meteorologischen Begriffs der ,Isotherme“ (eher) entsprechende Verwendungsweise des Begriffs deutlich weniger problematisch ist, da sie den in der Realität häufig anzutreffenden Fall der Überlappung der Verbreitungsgebiete verschiedener Varianten nicht ausschließt, findet sie sich in sprachgeographischen Beiträgen deutlich seltener. Häufig bildet sie jedoch die Grundlage der kartographischen Darstellung, wie etwa in Kurath (1949), der den Begriff in dem dazugehörigen Text hingegen in der Bedeutung ,Trennungslinie ' verwendet.

Mit der Verwendungsweise des Begriffs ,Isoglosse' zur Bezeichnung einer Trennungslinie, auf deren einer Seite ein sprachliches Merkmal in Variante A auftritt, während sich auf der anderen Seite Variante B findet, sind tiefgehende terminologische, heuristische und - durch die Verwendung von Isoglossenbündeln zur Abgrenzung von Dialektgebieten - schließlich

\footnotetext{
${ }^{199}$ Das fehlerhafte Verständnis der Isotherme, das Bielenstein, der den Begriff nicht in seinem eigentlichen, geowissenschaftlichen Sinn (d.h. als Verbindungslinie zwischen Orten mit gleichen Temperaturwerten), sondern ausgehend ,von den praktischen Auswirkungen der Isothermie auf die Flora“ (Freudenberg 1966: 227) - als Grenzen des Verbreitungsgebietes bestimmter Pflanzen auffasste, häufig vorgeworfen wird, ist in der Diskussion der terminologischen und heuristischen Problematik der Isoglosse zweitrangig.

${ }^{200}$ Vgl. De Saussure (1995 [1916]: 277): „On a appelé « lignes isoglosses » ou « d'isoglosses » les frontières des caractères dialectaux ; ce terme a été formé sur le modèle d'isotherme ; mais il est obscur et impropre, car il veut dire « qui a la même langue »; si l'on admet que glossème signifie « caractère idiomatique », on pourrait parler plus justement de lignes isoglossématiques, si ce terme était utilisable ; mais nous préférons encore dire : ondes d'innovation en reprenant une image qui remonte à J. Schmidt et que le chapitre suivant justifiera.“

${ }^{201}$ Freudenberg (1966: 220) spricht in seiner Definition des Begriffs zwar beide Verwendungsweisen an, grenzt diese jedoch nicht gegeneinander ab, sondern versteht die zweite Verwendungsweise als Spezifikation der ersten: „Im w e i t e r e n Sinn verstehen wir darunter eine gedachte Linie, die sprachliche Erscheinungen j e g l i c h e r A r t räumlich voneinander trennt; genauer: die e i n e Spracherscheinung umschließt und nach außen abgrenzt.“ Damit verkennt er den springenden Punkt, dass ,,[n]icht jede Begrenzungslinie auf Dialektkarten [...] auch eine T r e n n u n g s linie (oder S c h e i d e linie) in dem Sinne [ist], daß sie $\mathrm{z} \mathrm{u} \mathrm{g} \mathrm{l} \mathrm{e} \mathrm{i} \mathrm{c} \mathrm{h} \mathrm{z} \mathrm{w} \mathrm{e} \mathrm{i} \mathrm{unterschiedliche,} \mathrm{aber} \mathrm{aufgrund} \mathrm{eines} \mathrm{tertium} \mathrm{comparationis} \mathrm{vergleichbare} \mathrm{sprachliche} \mathrm{Er-}$ scheinungen begrenzt" (Händler/Wiegand 1982: 515).
} 
auch methodische Probleme verbunden. Terminologische Probleme ergeben sich daraus, dass dieses Verständnis des Terminus der Bedeutung der geowissenschaftlichen ,Iso-Linien“ genau entgegengesetzt ist: Während es sich bei Isothermen, Isobaren, Isohypsen etc. um Linien handelt, die Punkte verbinden, an denen gleiche Werte gemessen wurden („LINIEN GLEICHER $\mathrm{X}^{\text {“) }}$, sind Isoglossen in der Sprachgeographie hingegen meist ,gerade n i c h t (Verbindungs-) Linien gleicher Sprechweisen sondern Trennungslinien zwischen Räumen verschiedener Sprechweise“ (Händler/Wiegand 1982: 512). ${ }^{202}$ Obwohl diese Verwendungsweise des Terminus bereits vor über 50 Jahren moniert wurde (vgl. Goossens 1959: 48), ${ }^{203}$ konnten sich Bezeichnungen wie der von H. Kurath (1972) vorgeschlagene Terminus Heteroglosse in der sprachgeographischen Terminologie nicht durchsetzen. ${ }^{204} \mathrm{Im}$ Gegenteil: Durch die Bildung einer großen Anzahl weiterer ,Iso-Termini‘ (Huber (1909: 100) unterscheidet etwa Isophonen, Isomorphen, Isoformen, Isofixen, Isolexen, Isoglossen und Isosyntaxen) stieg die Anzahl der mit dieser terminologischen Problematik behafteten sprachgeographischen Begriffe in der weiteren Entwicklung der Sprachgeographie rapide an. Zu der uneinheitlichen Gebrauchsweise des Begriffs ,Isoglosse ${ }^{6}$ - die in vielen Fällen einer vorherigen (genauen) Definition entbehrt kommt überdies eine Polysemie, die meist nicht berücksichtigt oder deren Kenntnis vorausgesetzt wird: So bezeichnet der Begriff , Isoglosse' nicht nur die Linie, die das Verbreitungsgebiet eines sprachlichen Merkmals umgrenzt bzw. zwei Gebiete, die sich hinsichtlich eines Merkmals unterscheiden, voneinander trennt, sondern - insbesondere in der Indogermanistik - mitunter auch die sprachlichen Merkmale selbst. ${ }^{205}$ Dieser durch Metonymie entstandene , semantische Drift' findet sich bereits bei Meillet (1908) und wurde später insbesondere von italienischen Philologen wie V. Pisani (1939), G. Devoto (1958 [1924], vgl. Goebl 2004a: 531) oder auch G. Sanga (1984, vgl. Kap. 2.4.2) übernommen.

\subsubsection{Heuristische Probleme}

Das grundlegende heuristische Problem der Isoglosse ergibt sich aus der Kollision zwischen ihren geometrischen Eigenschaften und der sprachlichen Wirklichkeit, d.h. der tatsächlich beobachtbaren Verteilung sprachlicher Varianten im Raum. Isoglossen sind lineare Gebilde mit strikt binärer Aussage: Auf der einen Seite der Linie wird Variante A, auf der anderen Seite

\footnotetext{
${ }^{202}$ Vor diesem Hintergrund nimmt etwa Freudenberg (1966: 221f.) Anstoß an der Verwendungsweise des Begriffs der Isophone durch E. Zwirner (1959), der diesen als einer der wenigen im Sinne der geowissenschaftlichen ,Iso-Termini“ verwendet, wenn er als ,phonometrische Isophonen der Quantität“" die Linien bezeichnet, die Punkte verbinden, an denen gleiche Werte für das Verhältnis zwischen vokalischen Längen und Kürzen (d.h. gleiche Quotienten, bei Kürzen = 1) gemessen wurden. Die Definition des Terminus bei Porzig (1950: 168: „Linie zwischen den Punkten, die die eine und denen, die die andere Form aufweisen [...]“, Hervorhebung S.H.) lässt demgegenüber beide Lesarten (d.h. sowohl die geowissenschaftliche als auch die sprachgeographische) zu (vgl. Händler/Wiegand 1982: 512).

${ }^{203}$ Schneider (1988: 177) spricht von einer „funktionalen Überladung“ der Isoglosse.

${ }^{204}$ Auch die alternative (Wieder-)Verwendung des Terminus Sprachgrenze für Laut- bzw. Wortgrenzen (vgl. z.B. Ruoff 1980) leistet hier keine Abhilfe, da sie „kontraintuitiv, d.h. hier: entgegen der Wortbildungssemantik ist" (Händler/Wiegand 1982: 513) - denn dieser zufolge ist eine Sprachgrenze eben die ,Grenze einer Sprache“ bzw. eines Sprachraumes, d.h. ein ,raumteilende[s] und linienartig ausgeprägte[s] Phänomen[...]“ (Goebl 2003: 632), das in Form eines Bündels mehr oder weniger parallel verlaufender Grenzen sprachlicher (phonetischer, lexikalischer etc.) Einzelmerkmale auftritt.

${ }^{205}$ In einem Großteil der linguistischen Lexika bleibt diese zweite Bedeutung des Begriffs unberücksichtigt (vgl. Goebl 2004a: 531f.). Eine Ausnahme bildet H. Stammerjohanns Handbuch der Linguistik (1975), wo die Isoglosse als ,[g]leiche dialektale Erscheinung, die sich in einem $\rightarrow$ Sprachatlas als Linie nachzeichnen läßt" definiert wird.
} 
Variante B verwendet. Bei den ,Grenzen' zwischen Arealen, in denen unterschiedliche Varianten dominieren, handelt es sich jedoch meist nicht um lineare, sondern um disperse Grenzstrukturen (Bauer 2009: 121):

Unter dispersen Grenzstrukturen können Grenzbildungen verstanden werden, die nicht an einer Linie festgemacht werden können, sondern mehr und minder durchmischte Räume darstellen, in denen die sich abgrenzenden Objekte nebeneinander vorhanden sind. Man kann von „Grenzsäumen“ oder „Übergangsräumen“ sprechen. (Haubrichs 1993: 100)

In solchen „Mischzonen“ sind „Grenzlinien [...] ,instabil“, parameterabhängig“, Darstellungsvariablen: [D]ie Möglichkeit einer lokalen Determinierung ist von der Sache her eingeschränkt (Händler/Wiegand 1982: 522) ${ }^{206}$ Die Interpretation der Belegstruktur erfolgt in der „herkömmlichen Kartierungspraxis [...] visuell-intuitiv“ (ebd.), was insbesondere in den Fällen problematisch ist, in denen sich die Verbreitungsgebiete zweier (oder mehrerer) funktional gleicher sprachlicher Formen überlappen. Auch hier wird auf der Karte eine Linie gezogen, die den Eindruck kompakter Verbreitungsgebiete entstehen lässt - ungeachtet möglicher sporadischer Vorkommen einer oder mehrerer Formen auf der jeweils anderen Seite der Linie. ${ }^{207}$ Anmerkungen wie die Ruoffs (1980: 108) zum „statistischen Problem“ der Isoglosse (dort „Sprachgrenze“, s.o.) bleiben dabei häufig unberücksichtigt.

Mit Blick auf die Aussagekraft einzelner Isoglossen ergeben sich insbesondere im Bereich der Phonetik weitere Schwierigkeiten daraus, dass eine Isoglosse meist aufgrund der Realisierung eines phonetischen Merkmals in einem einzigen Lexem gezogen, ihre Gültigkeit aber häufig implizit für alle weiteren Vorkommen dieses Merkmals in den jeweiligen dialektalen Lexika postuliert wird: Es wird dann etwa in Bezug auf den italienischen Sprachraum von einer Isoglosse „lat. PL- > kj-“ (Pellegrini 1977: 43, vgl. Kap. 3.3.3) statt - mit Bezug auf die tatsächlich verwendeten sprachlichen Daten (verifizierbar hier: AIS-Karten 1613 und 1665) von einer ,più/chiù-Isoglosse“ gesprochen. ${ }^{208}$ Verallgemeinerungen dieser Art sind wissenschaftlich strenggenommen solange nicht haltbar, bis eine Überprüfung des Verlaufs der

\footnotetext{
${ }^{206}$ Wissenschaftlich (annähernd) valide Aussagen zum Verlauf von Isoglossen in (stark) durchmischten Zonen können somit nur auf der Basis einer statistischen Analyse von unter Berücksichtigung verschiedener Parameter erhobenen empirischen Daten getroffen werden. Abgesehen davon, dass die Möglichkeit einer solchen Analyse aufgrund der häufig nur qualitativen Natur der Belege in den meisten Fällen nicht gegeben ist, beeinträchtigt die Angabe der statistischen Verteilung der Varianten (vgl. etwa die Karten des ALM) die für kartographische Darstellungen essentielle Übersichtlichkeit sehr stark: „Für die exhaustive Kartendarstellung ergibt sich [...] die Notwendigkeit, zwischen Übersichtlichkeit und Genauigkeit zu wählen; innerhalb von Mischzonen ist das eine nur auf Kosten des anderen zu erreichen“ (Händler/Wiegand 1988: 522).

${ }^{207}$ Bereits Bielenstein (1892: 391f.) erkennt dieses Problem und kommt möglicher Kritik zuvor, indem er darauf hinweist, dass seine Isoglossen „nur ungefähr“ die Grenzen eines Gebietes markieren, in denen eine bestimmte sprachliche Erscheinung ,herrscht“, d.h. „massenhaft vorkommt“: „Es darf also von unseren Isoglossen nicht mehr gefordert werden, als sie leisten können, und wenn sie manchesmal eine Grenze angeben, über die hinaus Bezzenberger in seinen lettischen Dialektstudien Beispiele anführt, welche er sicher gehört hat, so wolle man auf Grund dessen meine Isoglossen noch nicht gleich als ungenau verwerfen.“ Er betont, dass A. Bezzenberger „Spuren einer dialektischen Sprachform zuweilen weiterhin nachweist, als ich [d.h. Bielenstein selbst, S.H.] mit der Isoglosse umschliessen durfte, da ich mich doch einigermassen auf die Grenze beschränken musste, bis wohin eine Spracheigenthümlichkeit zu herrschen schien“(ebd.: 393).

${ }^{208}$ Die Beschränkung der Isoglossen auf einzelne Token, d.h. das Vorkommen phonetischer Merkmale in einzelnen Lexemen (nach Freudenberg (1966: 220f.) Isoglossen ,im e n g e r e n Sinn“) findet sich in der germanistischen Sprachgeographie etwa im Falle der bekannten kartographischen Darstellung des Verbreitungsgebietes der althochdeutschen Lautverschiebung im Rheinland (,Rheinischer Fächer“ mit den Isophonen ik/ich, make/mache, Dorp/Dorf, dat/das, Appel/Apfel, vgl. Sturtevant 1947: 34). In der romanistischen Sprachgeographie findet sich ein entsprechendes Beispiel in der Darstellung der [tts]/[tt]]-Isophonen bei Avolio (1989: 19, vgl. Kap. 3.3.5).
} 
Grenze bei allen Token des Merkmals, d.h. bei allen Lexemen, die dieses Merkmal aufweisen, stattgefunden hat (vgl. auch Freudenberg 1966: 221), werden jedoch im Verhältnis dazu selten kritisch betrachtet. ${ }^{209}$

Auch auf der allgemein-typologischen Ebene, ${ }^{210}$ d.h. bei der Bestimmung von Dialektgrenzen auf der Basis von Isoglossenverläufen steht die klassische Sprachgeographie häufig vor einem heuristischen Problem. Isoglossen verlaufen selten parallel: Im günstigsten Fall nähern sie sich einander an und konstituieren lose Bündel, im ungünstigsten Fall schneiden sie sich und indizieren komplett unterschiedliche, widersprüchliche Dialekteinteilungen (vgl. Kessler 1995: 1). Während in Makroarealen - wie z.B. ganzen Sprachräumen - die Bedeutung einzelner Abweichungen bei Isoglossenverläufen durch die Präsenz einer größeren Anzahl von in etwa parallel verlaufenden Isoglossen (z.B. im Falle der „Linien“ La Spezia-Rimini oder Rom-Ancona, s. Karte 20) weniger ins Gewicht fällt, ${ }^{211}$ kann das Abweichen von Isoglossenverläufen in kleinräumigen Arealen soweit gehen, dass eine dialektale Einteilung nahezu unmöglich wird: „Dans quelques régions, en effet, les lignes se croisent et s'enchevêtrent actuellement à ce point qu'une délimitation des parlers y semble tout à fait i m p o s s i b 1 e“ (Rosenqvist 1919: 109). ${ }^{212}$ Soll dennoch eine Bestimmung von Dialektgrenzen mittels der Isoglossenmethode vorgenommen werden, wird eine Gewichtung der Relevanz einzelner sprachlicher Merkmale (bzw. der entsprechenden Isoglossen) notwendig, die nur in subjektiver Form, d.h. durch den jeweils analysierenden Sprachgeographen vorgenommen werden kann: „It is commonly admitted that this is a subjective method to be justified by the experience and factual knowledge of the respective dialectologist“ (Schneider 1988: 179). ${ }^{213}$ Da man jedoch „über den relativen Wert, der einer Spracherscheinung im Verhältnis zum Gesamtcharakter des betreffenden Idioms zukommt, sehr im Zweifel sein kann“ (Tappolet 1905: 391f.), erweist sich die Bildung eines fachlichen Konsenses über die Gewichtung von Isoglossen als sehr schwierig. ${ }^{214}$

\footnotetext{
${ }^{209}$ Eine Ausnahme bildet bereits sehr früh Gamillscheg (1928), der beispielhaft in Bezug auf die Entwicklung von lat. intervokalischem $\mathrm{T}$ in der Galloromania darauf hinweist, dass ,die Grenzlinien zwischen franz. roue und prov. roda, zwischen franz. couenne und prov. codena, zwischen franz. crier und prov. cridar auf weiten Strecken nicht zusammenfallen“ (Gamillscheg 1928: 6). Er schlussfolgert, dass man bereits auf der Ebene einzelner Lautgrenzen statt von „strengen Grenzlinien“ vielmehr von „Grenzzonen“ sprechen muss (ebd.).

${ }^{210}$ Die Unterscheidung zwischen partikulärer und allgemein-typologischer bzw. -klassifikatorischer Ebene folgt Goebl (2001, 2004a).

211, ,...] [D]ans plus d'un endroit, il y a des lignes détachées qui s'éloignent des faisceaux. [...] Ce fait négatif, c'est-à-dire rendant difficile la délimitation des dialectes, se constate un peu partout sans trop diminuer en général la netteté des faisceaux de lignes“" (Rosenqvist 1919: 108).

${ }^{212}$ Vgl. auch Dauzat (1944: 156f.). An dem Problem der Nicht-Übereinstimmung der Isoglossenverläufe und damit auch jener der von den jeweiligen Isoglossen umschlossenen Areale entzündete sich der Streit zwischen dem „Typophilen“ Graziadio Isaia Ascoli (1876) und den „Typophoben“ Paul Meyer (1875) und Gaston Paris (1888) um die „Existenz von Dialekten“ (vgl. Goebl 2004a: 528). Aus den o.g. Beobachtungen schloss die,,typophobe“ Seite auf die grundsätzliche Unmöglichkeit der Klassifikation von sprachgeographischen Daten zu Dialekten bzw. Geotypen und verkannte damit das grundlegende epistemologische Prinzip, „daß die räumliche Erstreckung einzelner Sprachmerkmale erkenntnistheoretisch auf der Ebene des Besonderen liegt, während die räumliche Erstreckung eines Typs (Dialekts, Geotyps etc.) auf jener des Allgemeinen angesiedelt ist" (Goebl 2001: 1477).

${ }^{213}$ Ein extremes Maß an Subjektivität entfaltet die Methode dann, wenn einzelne Isoglossen als stellvertretend für Grenzen zwischen zwei sprachlichen Makroarealen betrachtet werden. Ein bekanntes Beispiel aus der amerikanischen Sprachgeographie ist die pail/bucket-Isoglosse, die Kurath (1949: 12f.) als „,repräsentativen Indikator“ für die Grenze zwischen nördlichem (pail) und mittlerem amerikanischen Englisch (bucket) ansieht (Schneider 1988: 179).

${ }^{214}$ Von der verhältnismäßig hohen Subjektivität der Isoglossenmethode zu trennen die Tatsache, dass jede wissenschaftliche Methodik durch die Festlegung auf einen Anwendungsbereich bereits einen subjektiven Charakter trägt, wie jedes empirische Unterfangen a priori durch die Festlegung bzw. Erstellung der Datenbasis und die Wahl der Methode eine subjektive Komponente aufweist. Doch ermöglichen es quantitative Verfahren, durch die
} 
Vor dem Hintergrund der genannten Probleme lässt sich in der modernen Sprachgeographie die Ansicht antreffen, die Isoglosse sei ,no longer sufficiently scientific because it is unvalidatable as a research tool" (Kretzschmar 1991: 261). Dem ist für den Fall zuzustimmen, in dem Isoglossen als ,absolute Grenzen“ bzw. „Stufen eines Diskontinuums“ (Freudenberg 1966: 222) begriffen werden. Als kartographisches Arbeitsmittel, das einen sprachlichen Übergangsraum indiziert, kann die Isoglosse jedoch durchaus hilfreich sein:

The isogloss [...] does not mark a sharp switch for one word to the other, but the center of a transitional area where one comes to be favored somewhat over the other. The isogloss is a useful concept [...], but it must always be viewed as an abstraction and not a clear line on the land which one might step across from one dialect area into another. (Francis 1983: 5, Hervorhebung S.H.)

Bei der Bewertung dessen, was das Heuristikum der Isoglosse im Bereich der Sprachgeographie leisten kann, ist es essentiell, zu erkennen, dass die „räumliche Erstreckung eines einzelnen Sprachmerkmals einem qualitativen Begriff entspricht, während die räumliche Erstreckung eines Typs (Dialekts, Geotyps etc.) einem quantitativen Begriff gleichkommt“" (Goebl 2001: 1477). Die vorangegangenen Ausführungen haben gezeigt, dass der heuristische Wert der Isoglosse auf einzelne sprachliche Merkmale und damit auf die qualitativ-partikuläre Ebene begrenzt ist, die Verwendung der Isoglosse (bzw. von Isoglossenbündeln) mithin auf der quantitativen, d.h. der allgemein-typologischen Ebene (Bestimmung von Dialekten bzw. Geotypen) kein adäquates Verfahren darstellt. ${ }^{215}$ Vor diesem Hintergrund sind seit den 1970er Jahren alternative geolinguistisch-klassifikatorische Verfahren entwickelt worden, die ohne das Konzept der Isoglosse und die damit verbundenen heuristischen Probleme auskommen und in den folgenden Kapiteln in ihren Grundzügen dargestellt werden.

\subsection{Die Tolosaner (Proto-)Dialektometrie ${ }^{216}$}

Unter den mit dem Heuristikum der Isoglosse einhergehenden Problemen führten in der zweiten Hälfte des 20. Jahrhunderts besonders die Schwierigkeiten auf der global-typologischen Ebene zur Entwicklung alternativer kartographischer und methodischer Ansätze im Bereich der romanistischen Sprachgeographie. In Frankreich vollzog sich diese Weiterentwicklung insbesondere im wissenschaftlichen Kreis um den Tolosaner Sprachgeographen Jean Séguy (1914-1973), unter dessen Leitung als Teil des Nouvel Atlas Linguistique de la France ${ }^{217}$ der Atlas Linguistique de la Gascogne (ALG, 1954-1973) entstand. Bei den dazu durchgeführten Erhebungen zeigte sich, dass sowohl die zur Bezeichnung eines Konzepts verwendeten unterschied-

\footnotetext{
operationalisierte Verarbeitung von Massendaten (vgl. Kap. 4.3) die subjektive Komponente zumindest in späteren Phasen des Untersuchungsprozesses geringer zu halten und dadurch die Objektivität der Ergebnisse gegenüber rein qualitativen Verfahren deutlich zu steigern.

${ }^{215} \mathrm{Vgl}$. auch Séguy (1971: 335): „En dialectologie, on a l'habitude de comparer entre elles des aires phonologiques, phonétiques, lexicales, etc. [...] On dit alors que les deux aires comparées, si elles sont contiguës, sont séparées par une ligne isoglosse. Mais dès qu'on veut superposer plusieurs faits, c'est-à-dire quand on cherche à comparer deux aires en visant la totalité linguistique, les difficultés apparaissent et croissent suivant le nombre de faits rassemblés."

${ }^{216}$ Diesen Terminus übernehme ich aus Bauer (2009).

217 Vgl. Kap. 4.1.1, FN 196.
} 
lichen Lexeme als auch die Varianten phonetischer Merkmale häufig ohne erkennbare räumliche Ordnung auftraten und ihre Verteilung in der Regel nicht die von der traditionellen Sprachgeographie postulierten Dialektareale widerspiegelte:

La relève des vocables et des traitements phonétiques a lieu au saut du moindre ruisseau, entre deux bornes hectométriques, dans la cour commune de deux fermes contiguës, sans aucun respect pour les « cartes des dialectes » savamment dressées.

(Lalanne 1953: 263)

So konnten anhand von Isoglossen zwar die Verbreitungsgebiete einzelner sprachlicher Merkmale festgelegt werden; legte man jedoch zu verschiedenen sprachlichen Variablen generierte Isoglossenkarten übereinander, zeigten sich auf den so entstandenen cartes composites (dt. meist Isoglossensynthesen) statt der als Indikatoren für Dialektgrenzen erwarteten Isoglossenbündel stark abweichende und teilweise widersprüchliche Linienverläufe, die keinen Schluss auf kohärente Dialektgebiete zuließen:

[T] outes les isophones importantes (et deux ou trois grammaticales) qui traversent la Gascogne Maritime [...] la compartimentent, en détruisant toute unité et homogénéité continue. (Lalanne 1953: 268f., s. Karte 21)

Il faut le reconnaître, l'experience est décevante, et il semble inutile de la poursuivre. Les bourrelets attendus n'apparaissent nulle part [...].

(Lalanne 1949: 5f., zit. n. Guiter 1973: 63)

Man vermutete, dass zur ,Verbesserung' des Ergebnisses, d.h. zur Abbildung der erwarteten kohärenten Dialektgebiete eine umfassendere Auswertung der in den Sprachatlanten enthaltenen großen Datenmengen vonnöten sei, zu deren Durchführung es jedoch einer anderen, isoglossenunabhängigen Methodik bedurfte. Diese fand man in der Quantifizierung der sprachlichen Unterschiede zwischen je zwei benachbarten Orten:

La méthode consistait à observer les interpoints où un objet changeait de vocable [...]. Sur la ligne joignant deux points d'enquête on a fait autant d'encoches que l'on notait de ces oppositions lexicales. (Lalanne 1953: 266)

Aus diesem Grundprinzip, nach dem Lalanne (1953) auf der Basis der ersten 100 Karten des ALF die lexikalischen Abstände zwischen je zwei benachbarten Orten im okzitanischen Sprachgebiet (sowie auf zwei „Achsen“ im französischen Sprachgebiet) gemessen hatte, entwickelte Séguy eine Verfahrenskette, für die er (1973: 1) den Terminus dialectométrie prägte. 


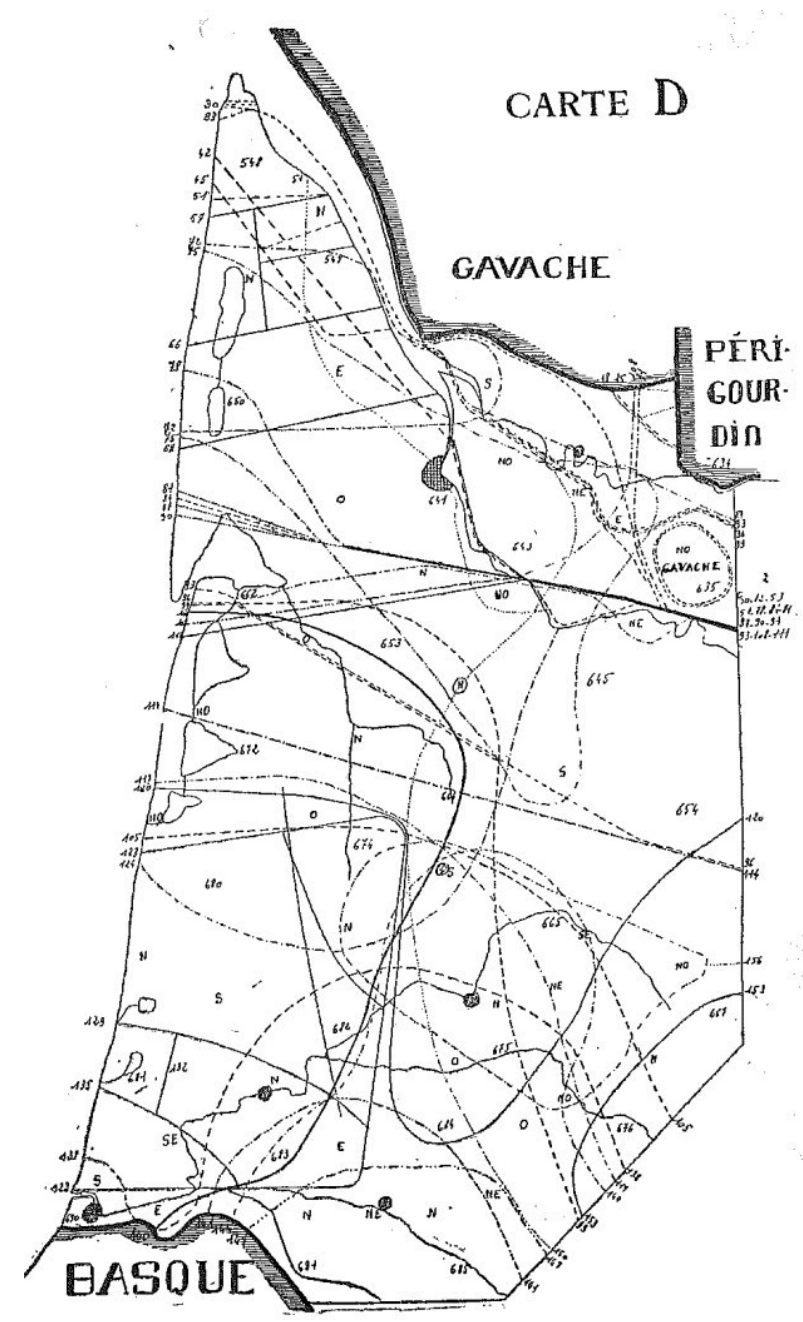

Karte 21. Phonetische Isoglossen in der Gascogne maritime. Carte composite aus Lalanne (1953: 269).

In einem ersten, die dialektometrische Messung vorbereitenden Schritt werden hier die Karten eines Sprachatlasses entsprechend der darauf vorliegenden sprachlichen Belege kodiert. ${ }^{218}$ Dabei werden (für Messungen auf lexikalischer Ebene) etymologisch unterschiedlichen Lexemen $^{219}$ und (für Messungen auf phonetisch-phonologischer und morphosyntaktischer Ebene) verschiedenen Varianten eines Merkmals unterschiedliche Ziffern zugeordnet. Im zweiten Schritt wird eine Datenmatrix (tableau dialectométrique) der Form Ortsdialekte (parlers) x Kriterien/Variablen (critères/variables) erstellt, in der die einzelnen Zellen die Ziffer der im jeweiligen Ortsdialekt für die betreffende sprachliche Variable anzutreffenden Variante bzw. des jeweils belegten Lexems enthalten:

\footnotetext{
${ }^{218}$ Guiter (1973) zeigt anhand statistischer Tests, dass eine Anzahl von 100 Karten zur Erlangung eines reliablen Ergebnisses ausreichend ist: „Nous devrons considérer comme peu sûres les données fournies par moins de 100 cartes [...]: à partir de 107 cartes, les résultats seraient les mêmes qu'avec 200“" (Guiter 1973: 80).

${ }^{219}$ In der Entscheidung, ab welchem Punkt die gemeinsame Etymologie zweier Lexeme aufgrund der phonetischen Entwicklung „,vraiment méconnaissable“ ist, sieht Séguy eine (bzw. die einzige, s.u.) subjektive Komponente seiner Methodik: „Le plus discutable de ces cas est évidemment celui où nous mettons sous plusieurs chiffres les continuateurs d'un même étymon: le procédé est nécessairement entaché de subjectivitéc (Séguy 1971: $340)$.
} 


\begin{tabular}{|l|l|l|l|l|l|}
\hline & $\mathrm{j}_{1}$ & $\mathrm{j}_{2}$ & $\mathrm{j}_{3}$ & $\mathrm{j}_{4}$ & $\mathrm{j}_{5}$ \\
\hline $\mathrm{i}_{1}$ & 1 & 0 & 1 & 0 & 0 \\
\hline $\mathrm{i}_{2}$ & 1 & 1 & 0 & 0 & 0 \\
\hline $\mathrm{i}_{3}$ & 1 & 1 & 0 & 0 & 1 \\
\hline
\end{tabular}

Abbildung 4. Beispiel einer Datenmatrix der Form Ortsdialekte $\left(i_{1}, i_{2}, i_{3}\right) x$ Variablen $\left(j_{1}-j_{5}\right)$, mit zwei sprachlichen Varianten $(0,1)$ nach Philps (1985: 277).

Beim eigentlichen dialektometrischen Messvorgang handelt es sich um eine Anwendung des Hamming-Abstands. ${ }^{220}$ Dabei werden die in der Datenmatrix enthaltenen Ortsvektoren jeweils paarweise und Variable für Variable miteinander verglichen, wobei bei jeder angetroffenen Differenz eine Einheit notiert wird. Durch Addition der notierten Einheiten ergibt sich die absolute Hamming-Distanz zwischen zwei Ortsvektoren bzw. den entsprechenden Dialekten, die durch Division durch die Anzahl der berücksichtigten Variablen in die relative Hamming-Distanz transformiert werden kann (vgl. Philps 1985: 277):

$\mathrm{dH}\left(\mathrm{i}_{1}, \mathrm{i}_{2}\right)=\frac{\mathrm{d}}{\mathrm{j}}$

wobei

$\mathrm{dH}=$ (relative) Hamming-Distanz zwischen den Ortsdialekten $\mathrm{i}_{1}$ und $\mathrm{i}_{2}$

$\mathrm{d}=$ Summe der Differenzen zwischen den Ortsdialekten $\mathrm{i}_{1}$ und $\mathrm{i}_{2}$

$\mathrm{j}=$ Summe der berücksichtigten Variablen

Für die Ortsdialekte der Datenmatrix in Abb. 4 lauten die (relativen) Hamming-Distanzen demnach wie folgt (ebd.):

$$
\begin{aligned}
& \mathrm{dH}\left(\mathrm{i}_{1}, \mathrm{i}_{2}\right)=\frac{2}{5}=0,4(40 \%) \\
& \mathrm{dH}\left(\mathrm{i}_{1}, \mathrm{i}_{3}\right)=\frac{3}{5}=0,6(60 \%) \\
& \mathrm{dH}\left(\mathrm{i}_{2}, \mathrm{i}_{3}\right)=\frac{1}{5}=0,2(20 \%)
\end{aligned}
$$

Die kartographische Darstellung der gemessenen sprachlichen Distanzwerte geschieht in der Tolosaner Dialektometrie mittels Karten, auf denen benachbarte Messpunkte jeweils durch eine Gerade verbunden sind, neben der die sprachliche (bzw. lexikalische, phonetische etc.) Distanz zwischen den Orten notiert ist (s. Karte 22). ${ }^{221}$ Als kartographisches Heuristikum fungiert in

\footnotetext{
${ }^{220}$ Der entsprechende Algorithmus geht auf den US-amerikanischen Mathematiker Richard W. Hamming (1915-1998) zurück, der diesen als Maß für die Unterschiede zweier binärer Zeichenketten gleicher Länge (codes) entwickelte (vgl. Hamming 1950). So unterscheiden sich die Codes

$\mathrm{X}=0010$ und

$\mathrm{Y}=1011$

an zwei Stellen, sodass der (absolute) Hamming-Abstand gleich 2 ist.

${ }^{221}$ Der Schritt zur Strahlenkarte als kartographischem Heuristikum wird hier jedoch (noch) nicht vollzogen. Vgl. dazu Kap. 4.3.7.7.
} 
der Tolosaner Dialektometrie eine Form der Waben- bzw. Zwischenpunktkarte (carte à interpoints $)^{222}$, auf der die sprachlichen Distanzverhältnisse in intervallisierter Form mittels verschieden gearteter, durch die Zwischenpunkte (d.h. orthogonal durch den Mittelpunkt der Verbindungsgeraden zweier Orspunkte) verlaufender Linien dargestellt werden. ${ }^{223}$ Jeder Linientyp repräsentiert hier ein Intervall der (meist in Prozentzahlen angegebenen) sprachlichen Distanzwerte (s. Karte 23). ${ }^{224}$

Die Aussage der auf der Basis des sprachlichen Materials aus dem ALG erstellten Wabenkarte erweist sich für ihre nach Bestätigung der Dialektgrenzen suchenden Autoren jedoch als sehr unbefriedigend:

Il n'en est rien: les « aires dialectales » que les frontières de cette carte semblent circonscrire ne sont que de fausses aires. Si, prenant deux points non contigus à l'intérieur de l'une de ces aires fallacieuses, on en calcule la distance linguistique, il résulte que cette distance atteint et le plus souvent dépasse celle de la frontière. [...] Les conclusions de Lalanne quant à l'inexistence des aires dialectales sont indestructibles. [...] [L]es bourrelets signifient qu'il existe une différence linguistique notable entre deux séries de localités contiguës, et ne signifient que cela. (Séguy 1973: 22)

\footnotetext{
${ }^{222}$ Dieser Kartentyp stellt einen Vorläufer des in der heutigen Dialektometrie allgemein als Schottenkarte bezeichneten Heuristikums dar (vgl. Kap. 4.3.7.6).

${ }^{223}$ Die Verwendung (gedachter) geometrischer Grenzlinien zwischen je zwei Ortspunkten zur Darstellung sprachlicher Unterschiede wurde bereits im Jahr 1898 von dem Germanisten und Romanisten Karl Haag (18601946) vorgeschlagen (vgl. Händler/Wiegand (1982: 509f.), die Haags methodisches Vorgehen nachzeichnen). Obwohl damit also bereits sehr früh eine Alternative zur Isoglossenmethode vorhanden war, die die heuristische „Isoglossenproblematik“ (vgl. Kap. 4.1.2) durch ,Aufspaltung“ der kontinuierlichen Linie in kleinstmögliche Segmente löste, fand das Verfahren nicht nur in die romanistische, sondern auch in die germanistische und anglistische Sprachgeographie erst deutlich später Eingang. Es dauerte über 50 Jahre, bis das Verfahren der ,intuitiven' Isoglossenziehung, in dem die qualitativen sprachlichen Unterschiede zwischen verschiedenen Arealen im Vordergrund standen (vgl. u.a. Kurath 1949), durch jenes Konkurrenz bekam, in dem die Anzahl der sprachlichen Unterschiede zwischen jeweils zwei benachbarten Orten addiert und ihre Synthese mittels einer nach dem Verfahren Haags konstruierten Zwischenpunktkarte (auch Kombinationskarte) kartographisch illustriert wurde (so u.a. in Frebel 1956, Baur 1967, Kurath 1972).

${ }^{224}$ Eine abweichende kartographische Darstellungsform findet sich bei dem ebenfalls dialektometrisch, aber unabhängig von Séguy arbeitenden Henri Guiter (1973), der mithilfe dialektometrischer Messungen im Gebiet der Pyrenäen (auf der Basis von je 200 Karten und den entsprechenden kartographischen Ausschnitten aus dem ALF, dem ALPI, dem ALC, dem (von ihm selbst erstellten) ALPO sowie dem Atlas Sacaze von J. Allières) den Status der sprachlichen Grenzen im Pyrenäengebiet und insbesondere den Status des Katalanischen und des Okzitanischen als Sprachen oder Dialekte zu definieren versucht. Die Basis für die Einstufung bilden im vorhinein (ohne erkennbare empirische Basis) festgelegte Intervalle: Bei einem sprachlichen Abstand zwischen benachbarten Orten von $20 \%$ bis $30 \%$ handelt es sich um unterschiedliche ,parlers“, bei Abständen zwischen $30 \%$ und 50\% um unterschiedliche ,sous-dialectes“, bei Abständen zwischen 50\% und 80\% um unterschiedliche „,dialectes“" und bei Abständen über 80\% um unterschiedliche „langues“ (Guiter 1973: 79). Der dialektometrischen Analyse zugrunde liegt bei Guiter zwar ein trianguliertes Ortsnetz, das jedoch nicht als kartographisches Heuristikum verwendet wird: Entsprechend der Methode der Abstandsmessung, die darin besteht, zu registrieren, „combien de fois chaque segment [d.h. jede Dreiecksseite, S.H.] était coupé par une ligne isoglosse“" (ebd.: 67) beruht die kartographische Darstellung auch hier auf den zwischen den Messpunkten verlaufenden und sich in Strichstärke und Linienart unterscheidenden Grenzsegmenten. Im Gegensatz zu den Wabenkarten Lalannes und Séguys werden hier jedoch die Grenzsegmente (durch Abrundung der durch die Schnittpunkte der Geraden entstandenen Kanten) zu kontinuierlichen Grenzlinien verbunden, sodass Guiters Karten eine Mischform zwischen Isoglossensynthesen und Wabenkarten darstellen (vgl. Bauer 2009: 18).
} 


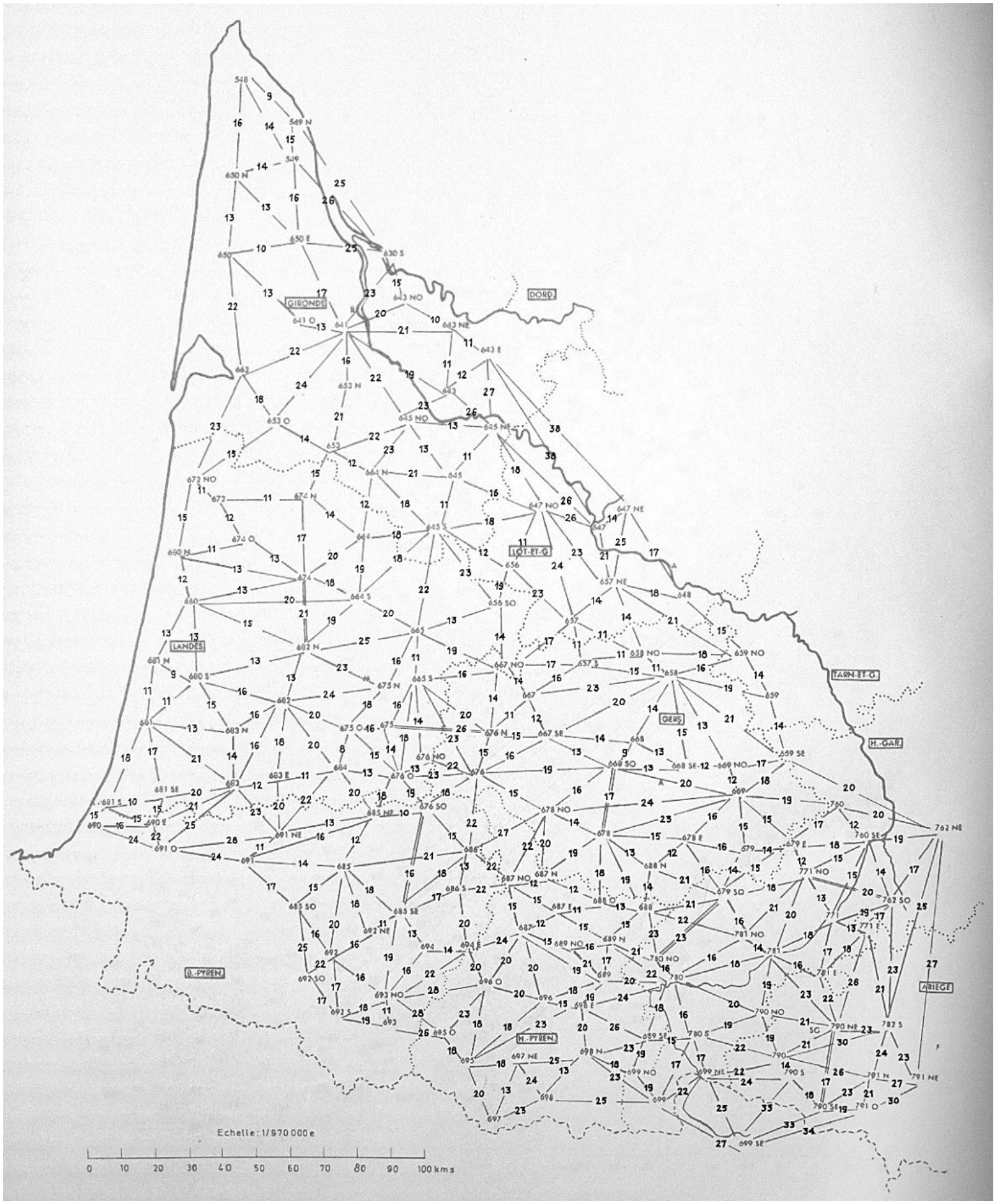

Karte 22. Kartographische Darstellung der (relativen) sprachlichen Abstände (in Prozent, kumuliert aus separaten Berechnungen für die Bereiche phonétique diachronique, phonologie, morpho-syntaxe, verbe, lexique) zwischen je zwei Orten im Gebiet der Gascogne (ALG-Karte 2524). 


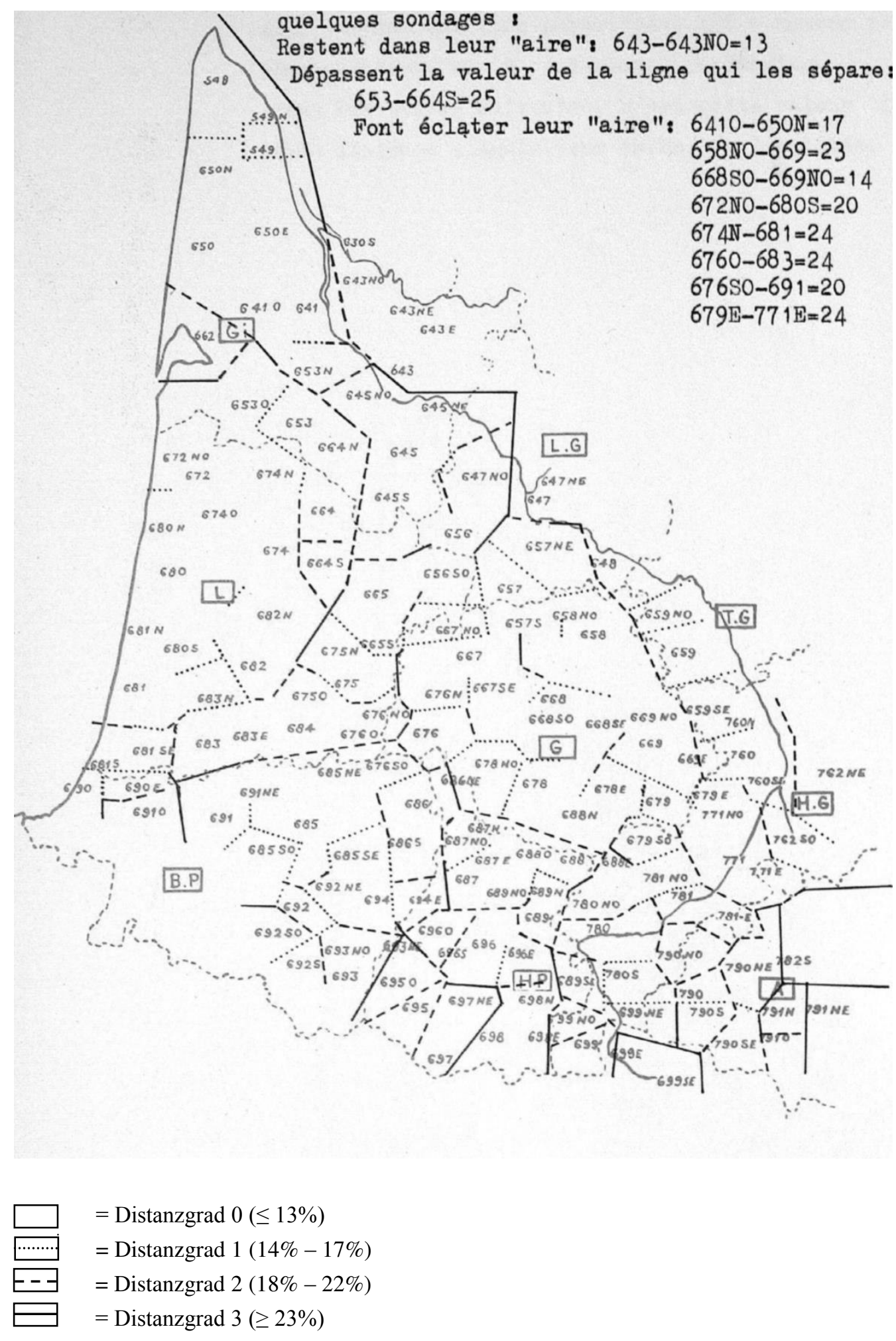

Karte 23. Dialektgrenzen im gaskognischen Sprachraum (ALG-Karte 2525). Die prozentualen sprachlichen Distanzwerte (s. Karte 22) zwischen je zwei benachbarten Orten sind in vier Intervalle eingeteilt, die verschiedenen Distanzgraden entsprechen und von denen jedes durch einen Linientyp repräsentiert wird. 
Aus diesem Umstand schließt Séguy (1973: 24), dass die raum- bzw. flächenbezogene Dialektometrie (dialectométrie bi-dimensionnelle, bei Séguy auch aréologie dialectale) nicht in der Lage ist, auf der Basis einer größeren Menge an Merkmalen ${ }^{225}$ kohärente Dialektgebiete sichtbar zu machen, da es eben diese Dialektgebiete (zumindest in der Gascogne) nicht gebe. Die grundsätzliche Unzulänglichkeit seines Verfahrens liegt Séguy zufolge darin, dass es auf die Messung der dialektalen Distanzen zwischen benachbarten Ortspunkten beschränkt bleibt. Das einzige Verfahren, das den paarweisen Vergleich aller Orte untereinander erlaubt, ist für ihn die lineare Dialektometrie (dialectométrie linéaire):

La comparaison irréfutable ne peut être que linéaire et de deux en deux ; dès qu'on infère de l'unidimensionnel au bidimensionnel, sans qu'il soit exclu de tomber juste, on s'expose à des erreurs. [...] Constater que tant d'isoglosses passent entre le point A et le point $\mathrm{B}$ est une certitude mathématique ; mais rien ne prouve que les points en deçà de $\mathrm{A}$ et ceux au delà de $\mathrm{B}$ soient séparés par les mêmes isoglosses. Cela arrive d'ailleurs, et même souvent, mais la démonstration n'est pas faite tant que la comparaison n'a pas été pratiquée entre tous les points du plan pris deux à deux. (Séguy 1971: 336)

In der linearen Dialektometrie Séguys wird die sprachliche (bzw. lexikalische, phonetische etc.) Distanz zwischen je zwei aus einer Reihe von Orten ermittelt, die auf einem imaginären „Pfad“ (parcours) zwischen einem Ausgangspunkt A und einem Endpunkt B liegen, wobei einerseits der sprachliche Abstand jedes Ortes zum Ausgangspunkt A, d.h. die Distanzen $A-a, A-b, A-$ $c, \ldots, A-B$ und andererseits die sprachlichen Abstände zwischen den entlang der Verbindungslinie zwischen A und B liegenden Punkten $a$ bis $n$ (points intermédiaires), d.h. die Distanzen $a$ $-b, b-c, \ldots, n-B$ gemessen werden. Diese Art der Dialektometrie erlaubt es ferner, das Verhältnis zwischen sprachlicher Distanz und geographischer Distanz zu ermitteln. In seiner Pionierarbeit von 1971 berechnet Séguy dazu auf einer Grundlage von je 100 (semantisch diversifizierten) lexikalischen Karten ${ }^{226}$ und unter Berücksichtigung ausgewählter Pfade ${ }^{227}$ aus den Sprachatlanten AIS, ALEA (dort: ALAn), ALC, ALF, ALG, ALLy, ALMC, ALPO und ALR die lexikalischen Abstände zwischen den Ortspunkten eines Pfades und dem jeweiligen Ausgangspunkt sowie zwischen den auf der Strecke liegenden Orten untereinander und notiert diese zusammen mit den entsprechenden geographischen Distanzen in Tabellenform (vgl. Séguy

\footnotetext{
${ }^{225}$ Dass Séguy (ebd.) die dialectométrie bi-dimensionnelle jedoch zur Analyse der Verbreitungsgebiete einzelner Merkmale für geeignet hält, mutet paradox an, da einer solchen Anwendung das (von Séguy selbst an erster Stelle genannte) zentrale Charakteristikum der Dialektometrie - die synthetisierende Verarbeitung einer großen Anzahl von Sprach- bzw. Dialektdaten - fehlt.

${ }^{226}$ Die Beschränkung auf Stichproben aus dem lexikalischen Bereich ist in erster Linie der manuellen Verarbeitungsweise der Daten geschuldet: „La totalité linguistique, intégrant tous les paramètres [...] est pratiquement inaccessible [...] à un chercheur qui ne dispose pas de moyens informatiques [...]. Certes, nous avons pu établir les distances linguistiques intégrales pour tous les points de l'ALG [...], mais au prix d'un travail de longue haleine, qu'il ne pouvait être question de refaire pour tous les atlas ici mis en œuvre [...]. Finalement, nous avons retenu un seul critère: le critère lexical, le plus facile à isoler“" (Séguy 1971: 338). Diese Beschränkung lässt sich jedoch ,glücklicherweise“ (ebd.) mit der besonderen Bedeutung des Lexikons für die sprachliche Verständigung begründen: „[D]ans l'intercompréhension, le primat du lexique est écrasant“ (ebd.). Gleichzeitig gibt Séguy (1971: 339) jedoch zu, dass auf sprachstruktureller Ebene morphologische und morphosyntaktische Charakteristika - vor phonetisch-phonologischen Merkmalen - an erster Stelle stehen, während hier dem Lexikon nur eine untergeordnete Rolle zukommt.

${ }^{227}$ Bei den Atlanten mit verhältnismäßig kleiner geographischer Fläche (ALC, ALLy, ALMC, ALPO) wird dabei nur ein Pfad berücksichtigt; bei allen anderen werden zwei Pfade aufgenommen, die orthogonal zueinander liegen (Séguy 1971: 339), beim ALG kommt ein dritter, diagonal verlaufender Pfad hinzu, während bim ALEA (ALAn) der zweite Pfad zusätzlich in umgekehrter Richtung aufgenommen wird.
} 
1971: 343f.). Unter Einbeziehung aller Werte zeigt sich, dass das Verhältnis zwischen der lexikalischen Distanz (y) und der geographischen Distanz (x) in jedem berücksichtigten Sprachbzw. Dialektgebiet der logarithmischen Funktion $y=a \sqrt{\log (x+1)}$ und damit bestimmten Regularitäten folgt (s. Abb. 5).

COURBE MOYENNE

$y=36 \sqrt{\log (x+1)}$

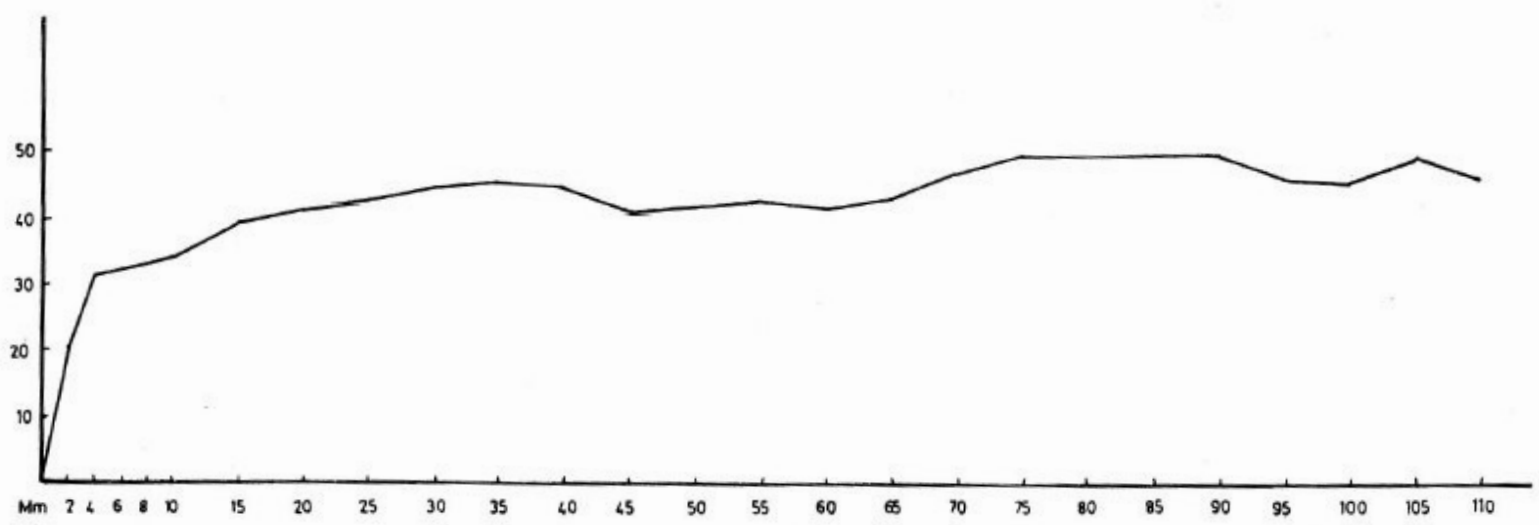

Abbildung 5. Graphische Darstellung des durchschnittlichen Verhältnisses zwischen geographischer Distanz ( $\mathrm{x}$-Achse, in myriamètres $(\mathrm{Mm})$, wobei $1 \mathrm{Mm}=10 \mathrm{~km}$ ) und (absoluter) lexikalischer Distanz (y-Achse, in Differenzen) zu einem Ausgangspunkt (hier: Nullpunkt des Koordinatensystems). Aus Séguy (1971: 349).

Die lineare Dialektometrie bedient damit unbestritten ein sprachgeographisches Erkenntnisinteresse $^{228}$, ist jedoch in ihrer heuristischen Kraft relativ begrenzt. Im Hinblick auf die Sprachgeographie als an der Beschreibung der Regularitäten der sprachlichen Variation im (zweidimensionalen) Raum aus unterschiedlichen Perspektiven orientierter Disziplin ist darum vor allem von Interesse, welche Bedeutung der raum- bzw. flächengebundenen Tolosaner Dialektometrie im Hinblick auf die Entwicklung sprachgeographischer Verfahren zuzuschreiben ist, die ohne das problematische Heuristikum der Isoglosse auskommen und eine Integration des quantitativ-numerischen Aspekts in die Analyse der diatopischen Variation ermöglichen. Laut Séguy (1973: 11) bietet die dialectométrie endlich die Möglichkeit, die Gesamtheit der im jeweiligen Atlas enthaltenen sprachlichen Informationen quantitativ zu verarbeiten. Tatsächlich ist dies Séguy jedoch - wohl insbesondere aufgrund seines Festhaltens an der manuellen Verarbeitungsweise ${ }^{229}$ - nie gelungen:

\footnotetext{
${ }^{228}$ Eine Fortführung der linearen Dialektometrie findet sich in Nerbonne (2010), wo anhand von (unter Verwendung des Levenshteinschen Sequenzabstandsmaßes durchgeführten) Messungen sprachlicher bzw. dialektaler Abstände der Versuch unternommen wird, die Stärke des Einflusses des geographischen Faktors auf die Verbreitung sprachlicher Phänomene und die mathematische Natur des Zusammenhangs zwischen sprachlicher und geographischer Distanz zu ermitteln. Distanzmessungen in sechs verschiedenen Sprachräumen (Bantu, Bulgarisch, Deutsch, Niederländisch, Norwegisch sowie Mittel- und Südamerika) bestätigen, ,that there is a simple, measurable and normally sublinear influence which geography exerts on aggregate linguistic differences" (Nerbonne 2010: 3825). Zur graphischen Darstellung des Verhältnisses zwischen sprachlicher Ähnlichkeit und räumlicher Distanz vgl. Goebl (2001: 1481).

${ }^{229}$ Séguy (1971: 338) begründet dies zunächst damit, dass er weder über „,moyens informatiques“ noch über entsprechende Kenntnisse verfüge. Später (1973: 12f.) erklärt er die Programmierung der dialektometrischen Berechnung für „,chimérique“, da die dazu erforderlichen zeitlichen und finanziellen Aufwendungen in einem geisteswissenschaftlichen Bereich wie der Dialektologie nicht zu erbringen seien. Dass zur selben Zeit andernorts
} 
[P]lusieurs fois, nous nous sommes trouvés aux limites des possibilités du calcul manuel, notamment en phonologie [...], les surfaces des cinq matrices couvrent deux mètres carrés [...]. Ceci pour un atlas de 154 points d'enquête seulement. (Séguy 1973: 12)

Die übrigen von Séguy (1973: 11f.) genannten Vorteile des Verfahrens - dessen Objektivität ${ }^{230}$, die Einfachheit der Berechnung sowie die Verifizierbarkeit der Ergebnisse auf jeder Stufe des Arbeitsprozesses - verlieren vor diesem Hintergrund jede praktische Relevanz. Die Tolosaner Dialektometrie scheitert daran, dass sie über die Stufe eines methodischen Konzepts nicht hinauskommt.

\subsection{Die Salzburger Dialektometrie}

\subsubsection{Theoretische Prämissen}

Die heute als Salzburger Dialektometrie (S-DM) bezeichnete Form der Dialektometrie wurde in ihren Grundzügen - und unabhängig von der Tolosaner dialectométrie - entwickelt durch den Romanisten Hans Goebl, in dessen Pionierarbeit - seiner dreibändigen Habilitationsschrift von 1984 - die Prinzipien und Verfahrensschritte der dialektometrischen Methode erläutert und auf der Basis sprachgeographischer Daten (aus ALF und AIS) illustriert werden.

Die Entwicklung der S-DM, die bereits Anfang der 1970er Jahre begann (vgl. Goebl/Winterleitner 1971) war motiviert durch das Bestreben, einen Ausweg aus der ,methodische[n] Insuffizienz" (Goebl 1984: 1) der klassischen, qualitativen Sprachgeographie im Bereich der global-synthetischen Erfassung der diatopischen bzw. dialektalen Variation (vgl. Kap. 4.1) zu schaffen. ${ }^{231}$ Mit Hilfe der sich entwickelnden Technik der elektronischen Datenverarbeitung und durch praktizierte Interdisziplinarität (Integration von Aspekten der Numerischen Taxonomie (s.u.), der Statistik, der Kartographie, der Quantitativen Geographie etc.) entstand in diesem Zuge ein global-induktives, synthetisierendes Verfahren der Sprachgeographie, des-

\footnotetext{
bereits die ersten dialektometrischen Experimente mithilfe von Techniken der elektronischen Datenverarbeitung vorgenommen wurden (vgl. Goebl/Winterleitner 1971), zeigt jedoch, dass es auch Séguy zumindest im Hinblick auf die zeitgenössischen technischen Möglichkeiten prinzipiell möglich gewesen wäre, seine Berechnungen mit elektronischer Unterstützung durchzuführen.

${ }^{230}$ Séguy verkennt hier, dass - wie in jeder wissenschaftlichen Methodik - auch in der Dialektometrie nie eine vollkommene Objektivität erreicht werden kann, da es sich bereits auf der Ebene der Datenquelle - d.h. bei dem mit einer bestimmten Datenmenge bestückten Atlas oder dem aus diesem gewählten Extrakt - immer um einen subjektiv (d.h. durch Autor(en) und Explorator(en)) festgelegten Ausschnitt aus der sprachlichen Realität handelt (Goebl 1984: 10).

${ }^{231}$ Ein oft als mit der Dialektometrie konkurrierend betrachteter, jedoch im Grunde komplementärer Ansatz zur Weiterentwicklung der romanischen Sprachgeographie entwickelte sich wenig später unter dem Namen der pluridimensionalen Geolinguistik, die der geolinguistischen Forschung einen erweiterten Variationsbegriff zugrunde legt. Im Zentrum steht hier die Integration weiterer Parameter (des diastratischen, des diasexuellen, des diagenerationellen und des diaphasischen) in die empirische Erforschung der diatopischen Variation, deren Arbeitsinstrument der atlante repertorio/atlante variazionale darstellt. Im Fokus stehen hier einerseits die südamerikanische Romania Nova (Atlas Lingüístico de México (ALM), Atlas Lingüístico Diatópico y Diastrático del Uruguay - Norte (ADDU-Norte) u.a.) und andererseits regionale Sprach- bzw. Dialektgebiete in Europa (atlanti regionali, zum spanischen Sprachraum z.B. der Atlas Lingüístico y Etnográfico de Aragón, Navarra y Rioja (ALEANR) oder der Atlas Lingüístico (y Etnográfico) de Castilla-La Mancha (ALECMan) und zum italienischen Sprachraum der Atlante Linguistico della Sicilia (ALS) oder der Atlante Linguistico della Campania (ALCam, vgl. Radtke 2002b)). Einen Überblick über die in diesem Kontext geleistete Sprachatlasarbeit geben Ruffino (1992) und AA.VV. (1989). Zu den theoretischen und methodischen Grundlagen der pluridimensionalen Geolinguistik vgl. Radtke/Thun (1996).
} 
sen Zweck ,die Erkennung von in den Sprachatlasdaten tiefer verborgenen Mustern und Strukturen aller Art“ ist (Goebl 2001: 1478). Trotz einiger methodischer Unterschiede, die insbesondere den Einsatz und die Bedeutung der (automatischen) Kartographie betreffen, übernahm Goebl für seine Methode den Terminus „,dialectométrie“von Séguy (vgl. Kap. 4.2) in der deutschen Form Dialektometrie in der Hoffnung, „daß unter der Decke des Namens ,Dialektometrie' allmählich jene methodologische Kompaktheit eintreten wird, die Vollmetrien wie Ökonometrie, Biometrie, Demometrie oder Psychometrie eigen ist" (Goebl 1984: 4). ${ }^{232}$

Die S-DM beruht auf der theoretischen Grundannahme der kulturellen - und damit auch sprachlichen - „Bewirtschaftung“ des Raumes durch den Menschen in seiner Eigenschaft als homo loquens. Dies bezeichnet den Umstand, dass der Mensch - will er im ihn umgebenden geographischen Raum überleben - gezwungen ist, seine sozialen Verhaltensweisen (und damit auch seine Sprechweise bzw. seine „Sprache“) den geographischen Gegebenheiten anzupassen: So wird mit in der geographischen Nachbarschaft angesiedelten Menschen grundsätzlich intensiver und damit anders kommuniziert als mit weiter entfernt lebenden Mitmenschen (Goebl 2005a: 68f.). ${ }^{233}$ Da es sich bei der so entstehenden räumlichen Variation um eine universale Eigenschaft natürlicher Sprachen handelt, ist auch die Frage nach den Gesetzmäßigkeiten, die ihre Entstehung und Entwicklung bestimmen, universaler Natur. Mit dem Ziel der Aufdeckung dieser Gesetzmäßigkeiten stellt sich die Dialektometrie in eine Reihe mit anderen Geisteswissenschaften (wie etwa der Anthropologie, der Ethnographie oder der Populationsgenetik), in denen die soziale und kulturelle „Bewirtschaftung“ des Raumes durch den Menschen eine zentrale Rolle spielt und ist damit von interdisziplinärer Relevanz (Goebl 2010b: 64). ${ }^{234}$

Als „direktes Kind“ bzw. „Fortsetzung“ der klassischen romanistischen Sprachgeographie (Goebl 2011: 22) folgt die Salzburger Dialektometrie einer auf das Erkennen räumlicher Strukturen bzw. Ordnungsmuster und Regularitäten ausgelegten theoretischen Konzeption, die mittels einer global-induktiven ${ }^{235}$, datenverdichtenden Methodik umgesetzt wird. Daraus ergeben sich bestimmte Anforderungen an die Struktur der Datenbasis: Zum Einen müssen die erhobenen Daten eine hohe Interkomparabilität aufweisen, was eine „standardisierte Erhebung der Sprachatlasdaten (definiert durch ein fixes Fragebuch und eine an allen besuchten Ortschaften gleichermaßen anzuwendende Abfragemethode)“ (Goebl 2007: 191) voraussetzt. ${ }^{236}$ Für eine dialektometrische Analyse eignen sich damit als Datenquellen nur nach klassischem, Gilliéronschem Muster erstellte Sprachatlanten oder vergleichbare Datensammlungen in Listenform, denen Erhebungen zugrunde liegen, bei denen nur ein Teil des Gesamtrepertoires der

\footnotetext{
${ }^{232}$ Goebl (1984: 2) weist explizit darauf hin, dass - wie für alle wissenschaftlichen Ansätze und Methoden - natürlich auch für die unter dem Namen der Dialektometrie vorgenommenen methodischen Neuerungen die Prinzipien der Vorläufigkeit und der relativen Bewährung gelten und an keiner Stelle eine wissenschaftliche Exklusivität postuliert wird.

${ }^{233}$ Die heute durch moderne Verkehrs- und Kommunikationsmittel stark erleichterte Überwindung des Naturraumes ist dabei insofern als „Oberflächenphänomen“ (Goebl 2005a: 69) zu begreifen, als sie zwar die physische, nicht aber die kognitive (und damit auch sprachliche) „Verankerung“ des Menschen in seinem ,,angestammten“ Naturraum außer Kraft zu setzen imstande ist.

${ }^{234}$ Zur Anwendung der S-DM auf (kultur-)anthropologische Daten (Patronyme) vgl. Goebl (2005a).

235 „Unter einer als ,global‘ bezeichneten Datenauswertung ist jede mehr als einen Merkmalsvektor (einer $\mathbf{N}$ mal p messenden Datenmatrix [...]) einbeziehende Auswertung von Sprachatlasdaten zu verstehen“ (Goebl 2001: 1478).

${ }^{236}$ Die atlanti variazionali bzw. atlanti repertorio (vgl. FN 231) scheiden damit als Datenbasis für eine dialektometrische Analyse aus: „Evidemment, une documentation faite sous le signe de l' « atlante repertorio » est plus authentique ou naturaliste qu'une enquête réalisée sur le modèle de l'ALF [...]. Mais [...] ces propos ne sauront jamais répondre aux exigences théoriques d'une base de données compilée à la gilliéronienne“" (Goebl 2013d: 74).
} 
Gewährspersonen erfasst wird, da „nur so die im Bewusstsein der Sprecher sehr prägnant verankerte basilektale Sprachkompetenz mit der nötigen Präzision und auch in möglichst ökonomischer Form erfasst werden kann“ (Goebl 2007: 191). ${ }^{237}$ Die zweite zentrale Anforderung, die die dialektometrische Methode an die auszuwertende Datenbasis stellt, ergibt sich aus dem im Einklang mit den Prinzipien der numerischen Taxonomie (s.u.) - angestrebten Ziel der Berücksichtigung einer möglichst großen Anzahl sprachlicher Merkmale:

Es hat sich nämlich gezeigt, daß bei kontinuierlicher Erhöhung der Merkmalsanzahl (stets zu einem vorgegebenen Taxandum) sich die Klassifikationsergebnisse allmählich zu stabilisieren beginnen und zwar eher aufgrund des Vorliegens einer bestimmten Menge als einer bestimmten Art von Merkmalen.

(Goebl 1984: 29)

Eine ausreichende Reliabilität der Ergebnisse wird in der Dialektometrie etwa ab einer Menge von 200 bis 300 Merkmalen - hier in Form räumlicher Verteilungen sprachlicher Realisierungsformen, sog. Arbeitskarten (AK) ${ }^{238}$ - erreicht (vgl. Goebl 2007: 199). Der Umfang der zugrunde liegenden Datenbasis (d.h. die Anzahl der Originalkarten des zugrunde gelegten Sprachatlasses) muss somit groß genug sein, um eine Extraktion dieser Mindestmenge an Arbeitskarten zu erlauben.

Die Salzburger Dialektometrie weist zentrale epistemologische und damit auch methodische Unterschiede zur Tolosaner Dialektometrie auf. Zum Einen stehen in der S-DM nicht die sprachlichen Unterschiede (und die daraus resultierenden sprachlichen Distanzen), sondern die sprachlichen Gemeinsamkeiten (bzw. die daraus resultierenden sprachlichen Ähnlichkeiten) zwischen den Messpunkten und damit auf klassifikatorischer Ebene nicht die Grenzen (also Linien) zwischen verschiedenen Dialektarealen, sondern diese Areale selbst (also Flächen) im Vordergrund. ${ }^{239}$ Bei der Visualisierung der Ergebnisse kommt dem ,interaktive[ $\left.n\right]$ Moment zwischen dem Betrachter und der Karte“ (Goebl 2007: 205) eine zentrale Bedeutung zu. Um die aus den Messergebnissen resultierenden Raumstrukturen aus möglichst vielen verschiedenen Blickwinkeln betrachten und ihre Bedeutung möglichst integral erfassen zu können, kommen verschiedene kartographische Heuristika ${ }^{240}$ zum Einsatz. Ihre besondere Bedeutung für die methodische Weiterentwicklung der Sprachgeographie erhält die S-DM schließlich durch die umfassende Operationalisierung des Verfahrens in dem von E. Haimerl entwickelten Programmpaket VisualDialectoMetry (VDM) ${ }^{241}$, mit dem dialektometrische Berechnungen in realistischen Zeiträumen und mit überschaubarem Arbeitsaufwand durchgeführt und die Ergebnisse mittels einer Vielzahl kartographischer Heuristika visualisiert werden können.

\footnotetext{
${ }^{237}$ Bei den Erhebungen zu allen „klassischen“ Sprachatlanten werden „prinzipiell mindestens zweisprachige Gewährsleute (Basisdialekt und jeweilige Schul- bzw. Hochsprache) befragt [...], also Leute, die imstande sind, die meistens in der Standardsprache gestellten Fragen des Explorators gezielt auf Ihre [sic] Grundmundart zu beziehen“ (Goebl 2007: 191). Vgl. Kap. 4.1.

${ }^{238}$ Vgl. Kap. 4.3.3.

${ }^{239}$ Vor dem Hintergrund, dass „Ähnlichkeit und Distanz [...] komplementäre Aspekte eines einzigen Konzeptes“ sind (Vogel 1975: 82) handelt es sich also um eine andere Perspektive auf ein und denselben Untersuchungsgegenstand.

${ }^{240}$ Vgl. Kap. 4.3.7.2 - 4.3.7.8.

${ }^{241}$ Vgl. Haimerl (2000), Goebl (2004b) und Bauer (2009: 201ff.).
} 
Der Beitrag der S-DM zur Entwicklung einer modernen romanistischen Sprachgeographie liegt nicht nur in den im ,Salzburger Zirkel' selbst durchgeführten dialektometrischen Auswertungen einer Vielzahl romanischer und nicht-romanischer Sprachatlanten. ${ }^{242}$ Sie gab auch den Impuls zu zahlreichen dialektometrischen Studien sowie der Entwicklung alternativer dialektometrischer Methoden innerhalb und außerhalb der Romanistik. ${ }^{243}$

\subsubsection{Epistemologische Grundlagen: die numerische Taxonomie}

Die Salzburger Dialektometrie versteht sich als Anwendung der Prinzipien der numerischen Taxonomie bzw. Taxometrie (engl. numerical taxonomy bzw. taxometrics) ${ }^{244}$ auf die Sprachgeographie. Diese geht in ihrer modernen Form auf die US-amerikanischen Biologen P. H. A. Sneath und R. R. Sokal (1963) ${ }^{245}$ zurück und steht als quantitatives Klassifikationsverfahren der qualitativen, essentialistisch ausgerichteten Typologie ${ }^{246}$ gegenüber. Während es sich bei letzterer um ein konzeptuell-deduktives (top-down) Klassifikationsverfahren handelt, arbeitet die numerische Taxonomie induktiv (bottom-up), d.h. auf der Basis real beobachtbarer Objekte

\footnotetext{
${ }^{242} \mathrm{Zu}$ nennen sind hier u.a. der Atlas Linguistique de la France (ALF, vgl. u.a. Goebl 1984, 1993a), der Sprachund Sachatlas Italiens und der Südschweiz (AIS, vgl. u.a. Goebl 1984, 2007), der Atlas Lingüístico de la Península Ibérica (ALPI, vgl. Goebl 2013a), der Atlas Lingüístic del Domini Català (ALDC, vgl. Goebl 2013b), der Computer Developed Linguistic Atlas of England (CLAE, vgl. Goebl 1997a, b), der Sprachatlas der Deutschen Schweiz (SDS, vgl. Goebl/Scherrer/Smečka 2013) sowie der am Fachbereich Romanistik der Universität Salzburg selbst erstellte Atlant linguistich dl ladin dolomitich y di dialec vejins (ALD I, vgl. u.a. Bauer 2004, 2005, 2009). In einer Erweiterung des ursprünglichen Forschungskonzepts wurden daneben auch metasprachliche Daten zur subjektiv empfundenen dialektalen Ähnlichkeit dialektometrisch ausgewertet und das Ergebnis mit jenem der dialektometrischen Analyse objektiver Sprachdaten verglichen (vgl. Goebl 1993b, 1995, 2002, 2006b).

${ }^{243}$ Vgl. dazu Goebl (1993c: 277f.) und Bauer (2009: 85f.).

${ }^{244}$ Synonym dazu werden u.a. die Termini numerische Klassifikation/numerical classification (z.B. Vogel 1975, Sneath/Sokal 1973) und automatische Klassifikation (z.B. Bock 1974) verwendet. Unter dem Begriff ,Klassifikation“ kann sowohl der Prozess der Klassenbildung als auch als das Ergebnis dieses Prozesses verstanden werden. Stehen die verwendeten numerischen Klassifikationstechniken im Vordergrund, wird der Terminus numerische Taxonomie teilweise auch mit dem Begriff der Clusteranalyse (cluster analysis) gleichgesetzt (Bauer 2009: 7).

${ }^{245}$ Die der taxometrischen Klassifikation zugrunde liegenden Prinzipien (vgl. Sneath/Sokal 1973: 5) finden sich in ihren Grundzügen bereits bei dem französischen Botaniker Michel Adanson (1727-1806), der häufig als „Vater" der numerischen Taxonomie angesehen wird (vgl. Sneath 1964). Die moderne numerische Taxonomie, deren Entwicklung in den 1950er Jahren begann und die von der fortschreitenden (Weiter-)Entwicklung elektronischer Rechenanlagen profitieren konnte (vgl. Vogel 1975: 19), geht jedoch über die Ideen Adansons hinaus: ,[T]o have to rely on Adanson's views for a validation of modern numerical phenetics seems as irrelevant as to rely on Mendel's writings for a validation of the findings of the molecular geneticists“" (Sneath/Sokal 1973: 24). ${ }^{246}$ Die klassische Typologie geht mit Aristoteles davon aus, dass sicheres Wissen von den Dingen nur über die Kenntnis ihres Wesens bzw. ihrer Essenz gewonnen werden kann. Die Klassifikation von Objekten geschieht hier auf der Basis der logischen Division, die die Definition der Essenz eines Objektes, die Bestimmung seines Genus, d.h. desjenigen Teils der Definition, in dem diese mit den Definitionen anderer Objekte übereinstimmt und der Differentia, d.h. des Teils der Definition, der für andere Objekte nicht gilt, umfasst (vgl. Cain 1958: 145). Einer der bekanntesten Anwendungsfälle der klassischen Typologie sind die Klassifikationen des schwedischen Botanikers Carl von Linné (1707-1778), in denen er die bis heute verwendete wissenschaftliche Nomenklatur in der Botanik und der Zoologie einführte. Die Merkmale, die der Klassifikation im Bereich der Sprachentypologie zugrunde gelegt werden, sind häufig morphologischer Natur (Unterscheidung zwischen ,flektierenden“, „,agglutinierenden“, ,,isolierenden“, ,,introflektierenden“ und „,polysynthetischen“ Sprachen). Das Hauptproblem einer auf dem Prinzip der logischen Division beruhenden Sprachentypologie besteht darin, dass sich die Klassifikation hier auf wenige Merkmale beschränkt, ,von denen [...] nicht einmal gezeigt werden kann, dass sie tatsächlich wesentlich sind [...]“ (Altmann/Lehfeldt 1973: 22).
} 
und gehört damit zu den empirischen Wissenschaften (vgl. Sneath/Sokal 1973: 5). ${ }^{247} \mathrm{Im} \mathrm{Ge}-$ gensatz zur klassischen Typologie - bei der alle einer Klasse angehörenden Objekte alle Merkmale besitzen, durch die die Klasse definiert ist - werden in der numerischen Taxonomie diejenigen Objekte oder Gegenstände zu einer Klasse zusammengefasst, die eine große Anzahl gemeinsamer Merkmale aufweisen oder bei denen viele Merkmale ähnlich ausgeprägt sind (vgl. Altmann/Lehfeldt 1973: 27). ${ }^{248}$ Ziel der numerischen Taxonomie ist es mithin, „eine Menge von $n$ Objekten, die durch m Merkmale charakterisiert sind, so in disjunkte Teilmengen, die Klassen genannt werden, zu zerlegen, daß die eine Klasse bildenden Objekte einander hinsichtlich aller m Merkmale in einem bestimmten Sinne möglichst ähnlich sind“"(Vogel 1975: 347). ${ }^{249}$ Die zugrunde liegende Annahme ist dabei, dass „,im zu klassifizierenden Datensatz ein System von Ähnlichkeiten existiert, das durch geeignete Verfahren erkannt werden kann“ (ebd.).

Die numerische Klassifikation liefert den übrigen empirischen Wissenschaften - und damit auch der Dialektometrie - das methodische „Handwerkszeug“, „um aus einer vorgegebenen Objekt- und Merkmalskonstellation abstrakte Integrate, eben Typen, abzuleiten" (Goebl 1984a: 13). Die das Verfahren konstituierenden Etappen sind

a) (kontrollierte) Datenreduktion (und damit -verdichtung),

b) Mustererkennung,

c) Klassenbildung und

d) Gewinnung und Überprüfung von Hypothesen und Theorien (ebd.). ${ }^{250}$

\footnotetext{
247, ,L]es sciences expérimentales sont très loin de pouvoir connaître parfaitement l'essence des choses qu'elles étudient. Elles ne peuvent pas en effet parvenir à une notion proprement distincte de cette essence, elles n'en ont jamais qu'une notion confuse ou purement descriptive, et ne la connaissent pour ainsi dire qu'à l'aveugle, grâce à des signes indirects“" (Maritain 1987: 200). Wissenschaftsgeschichtlich geht der Gegensatz zwischen der essentialistisch-deduktiven und der empirisch-induktiven Forschungsperspektive zurück bis zum mittelalterlichen „Universalienstreit” zwischen Anhängern des Platonismus („,das Allgemeine existiert unabhängig vom Menschen: universale ante rem“, Goebl 1984: 13f.) und des Nominalismus („,das Allgemeine existiert nur als Abstraktion des menschlichen Geistes: universale post rem“, ebd.).

${ }^{248}$ In dieser Beschreibung wird - wie auch in anderen Beiträgen zur numerischen Taxonomie - der Terminus ,Merkmal' in ambiger Weise verwendet, d.h. er bezeichnet sowohl die Kategorien, im Hinblick auf welche die Objekte klassifiziert werden, als auch die Ausprägungen, die die verschiedenen Objekte im Hinblick auf eine Kategorie aufweisen. In der vorliegenden Arbeit werden beiden Bedeutungen terminologisch unterschieden (s.u.).

${ }^{249}$ Dieses Prinzip wird auch als „Natürlichkeit“ der Klassen und eine solche Klassen generierende Klassifikation als „natürliche Klassifikation“ bezeichnet. Die Idee der Bildung „natürlicher Klassen“ (natural system), die bereits die typologische Arbeit Linnés kennzeichnete (vgl. Cain 1958: 154ff.), wurde in der taxonomischen Forschung insbesondere von Gilmour (1937 u.a.) diskutiert. Einen Überblick geben Sneath/Sokal (1973: 18ff.). ${ }^{250}$ Wie jede andere Klassifikationsmethode beinhaltet auch eine numerische Klassifikation ein subjektives Element: „Sie wird im Hinblick auf ein vorher festgesetztes Forschungsziel von einem Wissenschaftler konstruiert, wobei dessen theoretischer Standpunkt und Erudition ausschlaggebend sind“ (Altmann/Lehfeldt 1973: 50). Die Tatsache, dass Klassifikationen immer in Abhängigkeit von der zugrunde liegenden Theorie bzw. im Hinblick auf ein bestimmtes Forschungsziel durchgeführt werden, hat den elementaren Umstand zur Folge, dass (auch bei gleicher Zielsetzung) unterschiedliche Klassifikationsverfahren zu unterschiedlichen Resultaten führen können. Dies bedeutet wiederum, dass ,,jedes Klassifikationsergebnis nur im Hinblick auf den Zweck oder das Ziel, das damit erreicht werden soll, beurteilt und verstanden werden kann“ (Vogel 1975: 15): „,Richtige“ oder ,falsche“ Klassifikationsergebnisse gibt es (in der Regel) nicht, sondern nur mehr oder weniger ,brauchbare““(ebd.). Will man eine möglichst allgemeine Klassifikation erstellen, so muss sie so gestaltet sein, dass sie eine möglichst große Anzahl an Merkmalen berücksichtigt und die generierten Klassen ein Maximum an Information über die klassifizierten Objekte enthalten (Sneath/Sokal 1973: 5).
} 
In der Dialektometrie handelt es sich bei den zu klassifizierenden Elementen bzw. Objekten um die Messpunkte eines Sprachatlasses (bzw. im abstrakteren Sinn um die jeweiligen lokalen Dialekte) und bei den Merkmalen bzw. Eigenschaften um die sprachlichen Kategorien bzw. Phänomene, im Hinblick auf welche die Messpunkte klassifiziert werden, während die an den jeweiligen Messpunkten notierten sprachlichen (d.h. phonetischen, lexikalischen, morphologischen oder (morpho-)syntaktischen) Realisierungsformen die Merkmalsausprägungen darstellen. Ziel der dialektometrischen Analyse ist es, durch die Synthese einer möglichst großen Menge sprachlicher Einzeldaten die Beziehungen - d.h. die gesamtsprachlichen (bzw. phonetischen, lexikalischen, morphologischen und/oder (morpho-) syntaktischen) Ähnlichkeitsverhältnisse - zwischen den Messpunkten eines Sprachatlasses bzw. den jeweiligen Dialekten herauszuarbeiten und durch deren Visualisierung „zur Freilegung bzw. Entdeckung höherrangiger (i.e. sprachtypologisch relevanter) quantitativer Raummuster zu gelangen [...]" (Goebl 2007: 194). Möglich wird dies dadurch, dass Sprachatlasdaten durch ihren matrizenartigen Aufbau ( $n$ Messpunkte x $p$ Atlaskarten) Massendaten darstellen und damit Tiefenstrukturen enthalten, die mittels numerisch-taxonomischer Verfahren an die Oberfläche gebracht werden können (Goebl 2011: 23). Die einzelnen Schritte der dialektometrischen Verfahrenskette, wie sie sich in der SDM etabliert hat (s. Abb. 6) werden in den folgenden Kapiteln erläutert.

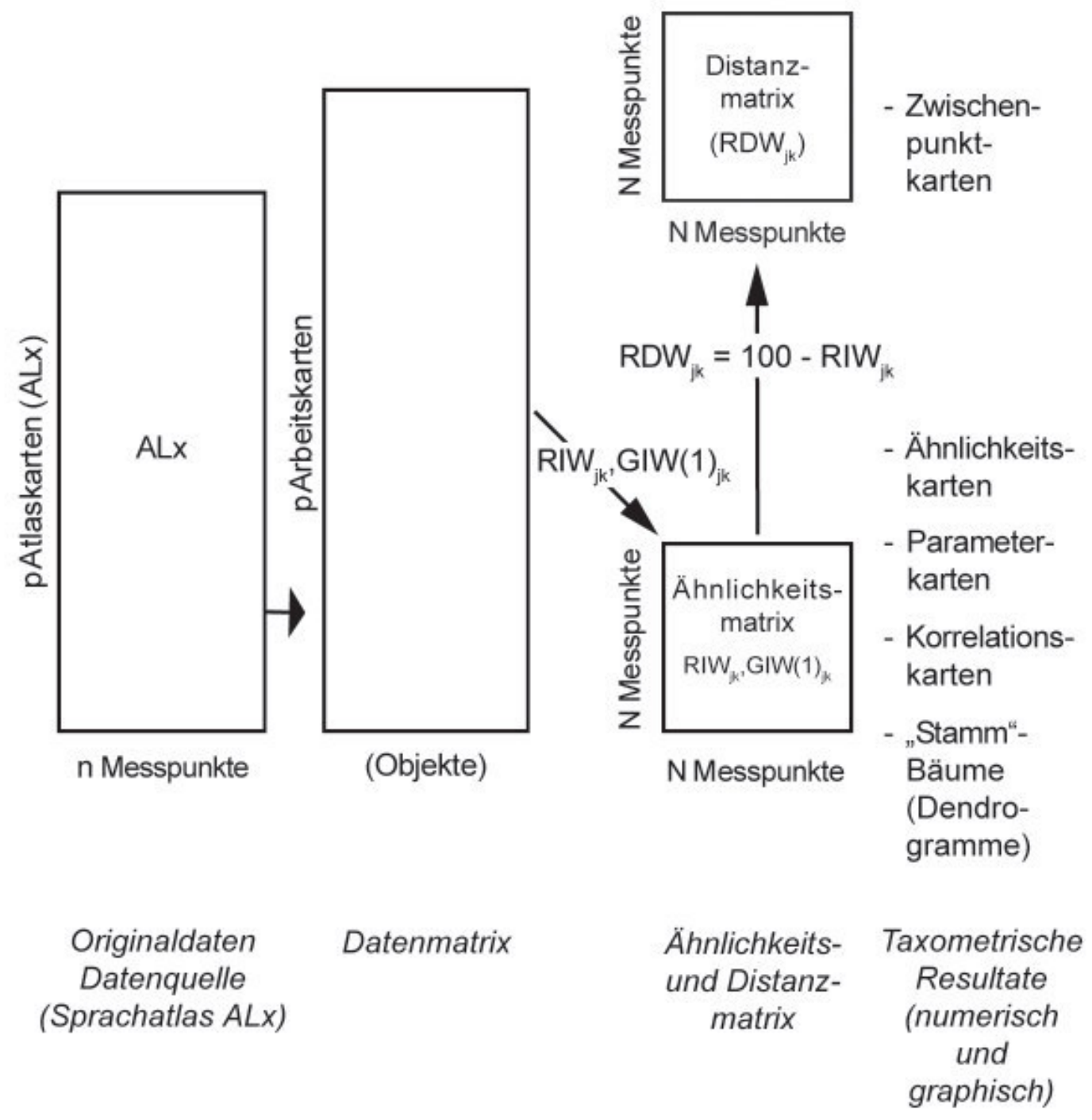

Abbildung 6. Flussdiagramm der dialektometrischen Verfahrenskette (Goebl 2007: 197). 


\subsubsection{Taxierung und Datenmatrix}

Die dialektometrische Arbeit an einem sprachlichen Korpus, d.h. den Karten eines Sprachatlasses oder einer ähnlich strukturierten Datensammlung in Listenform, erfordert zunächst eine Aufbereitung der (als Ausschnitt aus der sprachlichen Objektwelt) gewählten Original- bzw. Rohdaten (Taxandum). Ziel dieser Datenaufbereitung ist die Generierung einer zweidimensionalen, nominalen Datenmatrix des Typs $n$ (Elemente, hier: Messpunkte, d.h. Aufnahmepunkte des Sprachatlasses) x $p$ (sprachliche Merkmale bzw. Arbeitskarten, s. Abb. 7).

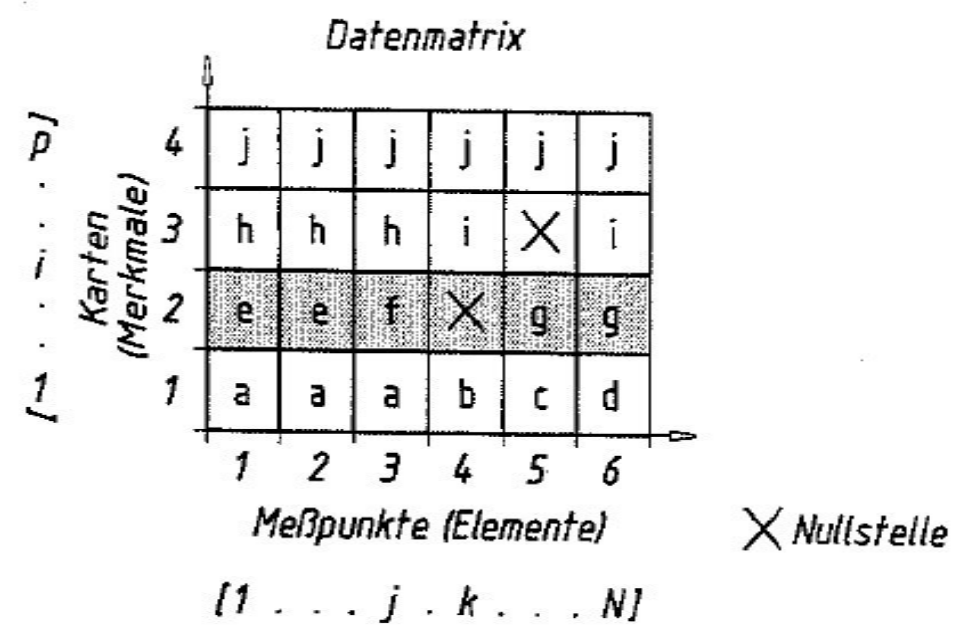

Abbildung 7. Schema einer dialektometrischen Datenmatrix in der S-DM (Goebl 1984: 16). Grau unterlegt: Merkmalsvektor 2, d.h. Ausprägungen (e, f, g) eines sprachlichen Merkmals (2) an den berücksichtigten Messpunkten (1-6).

Die Erstellung der dialektometrischen Datenmatrix läuft über den Prozess der Taxierung (auch: Typisierung) der Originaldaten, d.h. einer „nach gewissen linguistischen Prinzipien vorzunehmende[n], klassifizierende[n] Zusammenfassung der auf den Originalkarten des betreffenden Sprachatlasses anzutreffenden, lautschriftlich festgehaltenen Dialekt-Antworten in voneinander disjunkte Gruppen“ (Goebl 2007: 199). ${ }^{251}$ Die Taxierung erfolgt für jede Sprachatlas-Karte separat und kann auf verschiedenen sprachlichen Ebenen (Lexikon, Phonetik/Phonologie, Morphologie, (Morpho-)Syntax) durchgeführt werden, sodass eine Atlaskarte je nach der dort vorliegenden Belegstruktur mehrfach taxiert werden kann. Der Taxierungsvorgang umfasst folgende Schritte (vgl. ebd.: 198f.):

1) Zunächst wird jede Karte im Hinblick auf ihre Tauglichkeit für eine taxatorische Erfassung auf den jeweils berücksichtigten sprachlichen Ebenen überprüft. Dabei wird zum Einen die in der Belegstruktur für jedes potentielle (lexikalische, phonetische etc.) Merkmal vorliegende diatopische Differenzierung untersucht: Da die Analyse sprachlicher Variation das Vorhandensein mindestens zweier als unterschiedlich betrachteter Merkmalsausprägungen (Typen,

\footnotetext{
${ }^{251}$ Die mit der Taxierung vorgenommene Filterung der sprachlichen Roh- bzw. Originaldaten ist ,eine notwendige und unabdingbare Voraussetzung für die Erstellung der Datenmatrix in ihrer orthogonalen Form und hat zur Folge, daß die in der Datenmatrix enthaltenen Informationen [...] aus «objektiven» (d.h. der Objektwelt verpflichteten) und «subjektiven» (d.h. dem Taxonomen bzw. dessen Objektschau oder Theorie verpflichteten) Anteilen bestehen“ (Goebl 1984: 17).
} 
in der S-DM: Taxate) ${ }^{252}$ voraussetzt, werden mononyme ${ }^{253}$ Atlaskarten, d.h. Atlaskarten, auf denen alle Messpunkte für das jeweilige Merkmal dieselbe Ausprägung aufweisen, bei der Taxierung nicht berücksichtigt. ${ }^{254}$ Zum Anderen wird bei der Evaluierung der Eignung einer Karte der Besatz mit Nullstellen, d.h. Datenlücken (fehlende Belege) geprüft. Um eine zu große Beeinträchtigung des Messergebnisses zu verhindern, muss - in Abhängigkeit von Struktur und Ergiebigkeit der Originaldaten und somit für jede dialektometrische Untersuchung individuell - eine maximale Anzahl an Messpunkten (je Karte) festgelegt werden, die Datenlücken aufweisen dürfen. Alle Atlaskarten, die mehr als die maximale Anzahl an Datenlücken enthalten, werden aus der Taxierung ausgeschlossen. Da die Taxierung einer Karte im Hinblick auf ein oder mehrere phonetische Merkmale nur im Falle lexikalisch mononymer Karten möglich ist (Goebl 2007: 200), muss hier zudem sicher gestellt werden, dass die Anzahl der Messpunkte, die lexikalisch unterschiedliche (und damit als Nullstellen zu wertende) Belege aufweisen, zusammen mit den eigentlichen Datenlücken den festgelegten maximalen Prozentsatz an Nullstellen nicht übersteigt.

2) Im zweiten Schritt werden die taxatorische(n) Kategorie(n) der Karte (lexikalisch, phonetisch, morphologisch, (morpho-)syntaktisch) sowie die Merkmale, im Hinblick auf welche die Taxierung jeweils stattfinden soll, auf einem Erfassungsformular festgehalten. ${ }^{255} \mathrm{Im}$ lexikalischen Bereich handelt es sich bei den ,Merkmalen' um die abgefragten Lexeme (d.h. die Kartentitel bzw. bei Karten, die mehrere Lexeme enthalten, die entsprechenden Teile der Kartentitel), die je nach Erkenntnisinteresse auf der Basis semantischer, grammatischer oder etymologischer Kriterien in verschiedene Kategorien eingeteilt und entsprechend kodiert werden können. In den strukturellen Bereichen wird auf im Vorfeld erstellte Merkmalskataloge mit entsprechenden Kodierungen zurückgegriffen. ${ }^{256}$

Die phonetische Taxierung kann auf der Makro- wie auf der Mikroebene erfolgen (vgl. Bauer 2009: 182). Bei der makrophonetischen Taxierung werden die vorliegenden Daten bzw. Antwortlemmata im Hinblick auf bestimmte (für das Untersuchungsgebiet typische) Lautentwicklungen im jeweiligen Etymon taxiert (etwa Diphthongierung von lat. Ŏ, Palatalisierung von lat. $\mathrm{C}$ vor A/O/U), während bei der mikrophonetischen Taxierung das Etymon in seine phonetischen Teilnexus zerlegt wird, deren in den jeweiligen Antwortlemmata vorliegenden Resultate taxiert werden (Goebl 2014: 243):

\footnotetext{
${ }^{252}$ In der Biologie werden die als hinreichend verschieden betrachteten Merkmalsausprägungen, die jeweils eine Gruppe von Einzeldaten generieren, als „Taxa“ (Sg. „Taxon“) bezeichnet. Die Wahl der Bezeichnung „Taxat“ in der S-DM soll (in Analogie zur Bezeichnung „Taxandum“ für die Gesamtheit der zugrunde gelegten (noch untaxierten) sprachlichen Rohdaten), unter Rückgriff auf die der lateinischen Wortbildung innewohnende Semantik den letztendlich provisorischen bzw. fließenden Charakter des Taxierens betonen und damit terminologisch auf die Notwendigkeit hinweisen, Messungen bzw. Taxierungen nie als definitiv zu betrachten“ (Goebl 1984: 31 ). ${ }^{253}$ Zur Nomenklatur vgl. FN 263.

${ }^{254}$ Je nach Umfang der Datenbasis kann es sinnvoll sein, eine Minimalvariation vorauszusetzen, die die Anzahl von zwei Taxaten übersteigt. Dadurch kann insbesondere vermieden werden, dass isoliert auftretende Merkmalsausprägungen, die „oft auf Verlegenheitsantworten oder sachliche und/oder sprachliche Unsicherheiten seitens der Informanten zurückzuführen [sind]“ (Bauer 2009: 180), das Messergebnis beeinträchtigen.

${ }^{255}$ Muster für die bei einer Taxierung im Rahmen der S-DM verwendeten unterschiedlichen Erfassungsformulare finden sich in Kap. 5.3.1.

${ }^{256}$ Vgl. Kap. 5.3.1, Tabelle 20.
} 


\begin{tabular}{ll}
\multirow{4}{*}{ intervokalisches } & C im Anlaut vor A \\
& A im Vorton vor Nasalkonsonant \\
& NT \\
Á im Hauptton und in offener Silbe \\
R \\
& E im Auslaut
\end{tabular}

Unter den Merkmalen im Bereich der morphologischen bzw. morphosyntaktischen Taxierung sind (im Falle romanischer Sprachatlanten) häufig die Realisierung und Form des bestimmten Artikels (differenziert nach Genus und Numerus) und der Subjektpronomina, die Pluralbildung von Substantiven und Adjektiven und verschiedene Aspekte der Verbalmorphologie (Bauer 2009: 186). Eine hypothetische, drei Messpunkte enthaltende Atlaskarte mit dem Titel „quando mio figlio“ (vgl. AIS I, Karte 9) und den Belegen kwan al me mat in Messpunkt 1, kan ke mun fey in Messpunkt 2 und kwan me fyöl in Messpunkt 3 kann also hinsichtlich dreier Merkmale taxiert werden, nämlich der Realisierungsform der temporalen Konjunktion quando (Syntax), der Form des maskulinen Possessivpronomens der 1. Pers. Sg. (mio, Morphosyntax) und der Realisierung des Konzepts ,figlio‘ (Lexikon, vgl. Goebl 1984: 19).

3) Im nächsten Schritt werden für jedes Merkmal die zueinander disjunkten Merkmalsausprägungen bzw. Taxate erfasst und kodiert. Da ein universal gültiges System für die Taxatbildung bis heute weder in der Dialektometrie noch in anderen taxonomischen Anwendungsbereichen existiert, ${ }^{257}$ müssen für jedes dialektometrische Vorhaben stets indivuelle Taxierungsrichtlinien geschaffen werden, die jedoch gewissen grundlegenden methodischen Anforderungen - z.B. der prinzipiellen Vergleichbarkeit von Objekten auf der Basis ihrer Merkmale, der Relevanz und Repräsentativität der gewählten Merkmale, der Genauigkeit der Taxierung (Mikro- bzw. Makroanalyse) - genügen müssen (Bauer 2009: 161). ${ }^{258}$

4) Den letzten - und zentralen - Taxierungsschritt bildet die Erfassung der an den Messpunkten in den jeweiligen Belegen vorliegenden Merkmalsausprägungen. Bei in kartographischer Form vorliegenden Originaldaten werden auf die Karten (bzw. den Kartenteil, der das interessierende geographische Teilareal abbildet) sog. Prüfpfade aufgebracht, um dem Taxierenden das Zurechtfinden auf der Karte zu erleichtern und Fehler zu vermeiden. ${ }^{259}$ Die Erfassung erfolgt dann über das ,Abgehen' der erstellten Prüfpfade und die Eintragung der Taxatzugehörigkeit der an den Messpunkten notierten sprachlichen Belege in Form der im Vorfeld zugeordneten Taxat-Kodes auf das Erfassungsformular. Dabei wird in den Fällen, in denen für einen Messpunkt mehrere Belege vorliegen, grundsätzlich nur die erste Nennung berücksichtigt. ${ }^{260}$ Nach Abschluss der Taxierungsarbeit werden die Inhalte aller Erfassungsformulare in

\footnotetext{
${ }^{257}$ Bei den zwei konkurrierenden Taxierungsprinzipien spricht man von splitting und lumping: ,[D]er ,splitter strebt an, aber auch jede Andeutung von Verschiedenheit und jede Ebene von Verwandtschaftsbeziehung durch die formale Anerkennung gesonderter Taxa auszudrücken und dies in aufwendig abgestufte Kategorien umzusetzen. Demgegenüber hält es der ,lumper' für ideal, in der Klassifikation die Tatsache zum Ausdruck zu bringen, daß höhere Taxa und Kategorien Ausdruck von Verwandtschaft sind, und daß eine zu weitgehende [sic] Aufgliederung der Taxa zu einer nicht vertretbaren Gedächtnisbelastung führt“" (Mayr 1975: 217f.).

${ }^{258}$ Von besonderer Bedeutung sind diese Kriterien insbesondere in Fällen, in denen aus arbeitspraktischen Gründen das Taxandum nicht der Gesamtheit der Datenquelle (d.h. dem gesamten Datenmaterial eines Sprachatlasses) entsprechen kann und Entscheidungen hinsichtlich der Auswahl insbesondere struktureller Merkmale getroffen werden müssen.

${ }^{259}$ Für in Listenform vorliegende Originaldaten sind entsprechend ,Prüflisten` (durch Festlegung der Reihenfolge der zu überprüfenden Messpunkte) zu erstellen.

${ }^{260}$ Der (bewusste) Ausschluss von Mehrfachantworten bzw. -nennungen (multiple responses, kurz MRs) stellt wohl einen der am häufigsten genannten Kritikpunkte der S-DM dar (vgl. etwa Schneider 1984: 324), der auch dann nicht restlos aufgelöst wird, wenn statt der ersten die im Merkmalsvektor am häufigsten vertretene Antwort
} 
eine elektronische Datenbank ${ }^{261}$ übertragen und so die entsprechende Datenmatrix erstellt, die die Basis für die dialektometrischen Berechnungen mit Hilfe des Programms VDM bildet.

Die Resultate der Taxierung der Originalkarten werden in der S-DM als Arbeitskarten (AK) bezeichnet (Goebl 2014: 245). ${ }^{262} \mathrm{Zu}$ ihrer kartographischen Visualisierung werden jedem Taxat eine eigene Farbe zugeordnet und eine im Vorfeld erstellte „stumme“ Polygonkarte (vgl. Kap. 4.3.7.1) entsprechend der vorgenommenen Zuordnung der Messpunkte eingefärbt (s. Karte 24 und 25). Die Anzahl der auf den polynymen Arbeitskarten ${ }^{263}$ jeweils aufscheinenden Taxate (Taxatbesatz, Polynymie) kann zwischen 2 (bi-nyme Arbeitskarten) und N (n-nyme Arbeitskarten) variieren (Goebl/Smečka 2014: 445). Die graphische Umlegung der Häufigkeitsverteilung der Arbeitskarten im Hinblick auf ihre jeweiligen Taxatbesätze mittels eines Säulendiagramms (vgl. Abb. 8) zeigt in allen bisher durchgeführten dialektometrischen Untersuchungen das Bild einer exponentiell abfallenden Kurve (Goebl 2014: 246), die je nach Datenquelle mehr oder weniger prototypisch sein kann. ${ }^{264}$ Bereits die Analyse der Häufigkeitsverteilung der Taxatbesätze ${ }^{265}$ weist also darauf hin, dass die sprachliche Bewirtschaftung des Raumes durch den Menschen nach bestimmten Regularitäten verläuft. Es lässt sich zeigen, dass es sich dabei um Gesetzmäßigkeiten handelt, die mit den Zipfschen Gesetzen bzw. Kräften aus der Text- bzw. Korpuslinguistik $^{266}$ vergleichbar sind bzw. deren „geolinguistisches Pendant“ darstellen

gewählt wird (etwa in dem von Schiltz (1996) eingeführten Ähnlichkeitsmaß RIW ). In der Kontroverse um die Berücksichtigung von MRs in dialektometrischen Berechnungen werden jedoch die dafür eigentlich maßgeblichen Punkte meist nicht berücksichtigt. Hier ist zunächst der Umstand zu nennen, dass (nach Gilliéronschen Prinzipien erstellte) romanische Sprachatlanten - im Gegensatz zu deutschen oder englischen Sprachatlanten, wo der Anteil an MRs bis zu 7\% betragen kann - im Allgemeinen eine sehr geringe Anzahl an Mehrfachnennungen aufweisen (Schiltz 1997: 662), sodass ihre Berücksichtigung in der romanistischen Dialektometrie von geringerer Relevanz ist. Den gewichtigeren Punkt stellt jedoch die epistemologische Bewertung von MRs dar, d.h. die Frage, ob Mehrfachantworten im Rahmen der jeweiligen geolinguistischen Theorie grundsätzlich den „Wert“ der Forschungsergebnisse erhöhen oder aber verringern (Goebl 1997a: 23). Da Mehrfachnennungen mehr soziolinguistische als eigentlich geolinguistische Information enthalten (ebd.: 28), ist ihre Berücksichtigung von geringem erkenntnistheoretischen Nutzen, wenn der durchzuführenden dialektometrischen Berechnung ein genuin geolinguistisches Ziel, d.h. die Erkennung sprachlicher Raumstrukturen zugrunde liegt. Steht hingegen der soziolinguistische Wandel - als eines dessen Zeichen MRs im Allgemeinen gelten können im Zentrum des Forschungsinteresses, so können Ähnlichkeitsmaße, mit denen sich Mehrfachnennungen berücksichtigen lassen (wie etwas das in Goebl (1997a) verwendete Ähnlichkeitsmaß VBOM VB $_{j}$ den „,Wert“ des dialektometrischen Ergebnisses steigern (Schiltz 1997: 666).

${ }^{261}$ Zur Struktur der dialektometrischen Datenbank vgl. Kap. 5.3.1., Tabelle 21.

${ }^{262}$ Der Begriff, Arbeitskarte ' bezeichnet zwar im eigentlichen Sinne die kartographische Visualisierung der Taxierungsergebnisse, hat sich jedoch auch für die entsprechenden Taxatlisten etabliert, die in VDM neben der kartographischen Darstellung ebenfalls eingesehen werden können.

${ }^{263}$ Die Angabe des Taxatbesatzes einer Arbeitskarte erfolgt durch das Einsetzen griechischer oder lateinischer Präfixe für die jeweilige Taxatzahl: Eine Arbeitskarte mit drei Taxaten wird als tri-nym, eine Arbeitskarte mit zehn Taxaten als deka-nym etc. bezeichnet. Für die Bezeichnung verschiedener Stufen des Taxatbesatzes haben sich die Termini oligo-nym (AK mit niedriger Taxatzahl), meso-nym (AK mit mittlerer Taxatzahl) und poikilonym Arbeitskarten (AK mit hoher Taxatzahl) etabliert (vgl. Goebl 2014: 245, Goebl/Smečka 2014: 445).

${ }^{264}$ Die Tatsache, dass sich unter den Untersuchungsergebnissen auch solche befinden, bei denen die Taxierungsarbeit von bis zu 11 verschiedenen, unterschiedlichen Klassifikationsrichtlinien folgenden Personen vorgenommen wurde (vgl. Goebl/Smečka 2016: 118ff.), zeigt, dass die Regularitäten mitnichten auf die individuelle ,geolinguistic bias“ des Taxierenden (ebd.: 119) zurückgehen können.

${ }^{265}$ Eine ähnliche Kurve ergibt sich für die Verteilung der Taxate nach der Anzahl der Polygone (Messpunkte), in denen das jeweilige Taxat auftritt (Taxatareale) und die zwischen 1 und N-1 variiert (vgl. Kap. 5.3.2, Abb. 2325 und Abb. 29-31). Das dahinter stehende, universale Phänomen wird in der Dialektometrie als ,,spezielle Verzahnung“ (engl. special entanglement, frz. enchevêtrement particulier) der Taxatareale bezeichnet (vgl. Goebl/Smečka 2016, 2017).

${ }^{266}$ Bei dem nach dem amerikanischen Linguisten George K. Zipf (1902-1950) benannten „Zipfschen Gesetz“ handelt es sich um einen - unabhängig von Textsorte sowie Alter und Sprache des Textes gültigen - ,gesetzlichen Zusammenhang zwischen der Verwendungshäufigkeit von Wörtern in einzelnen Texten bzw. bei einzelnen Sprechern/Autoren und ihrem Rangplatz auf einer Liste ihrer generellen Auftretenshäufigkeit: Die Logarithmen 
(Goebl/Smečka 2014: 448). ${ }^{267}$ Wie sich im Folgenden zeigen wird, werden diese in der diatopischen Diversifikation wirksamen Regularitäten auch im weiteren Verlauf der dialektometrischen Verfahrenskette sichtbar.

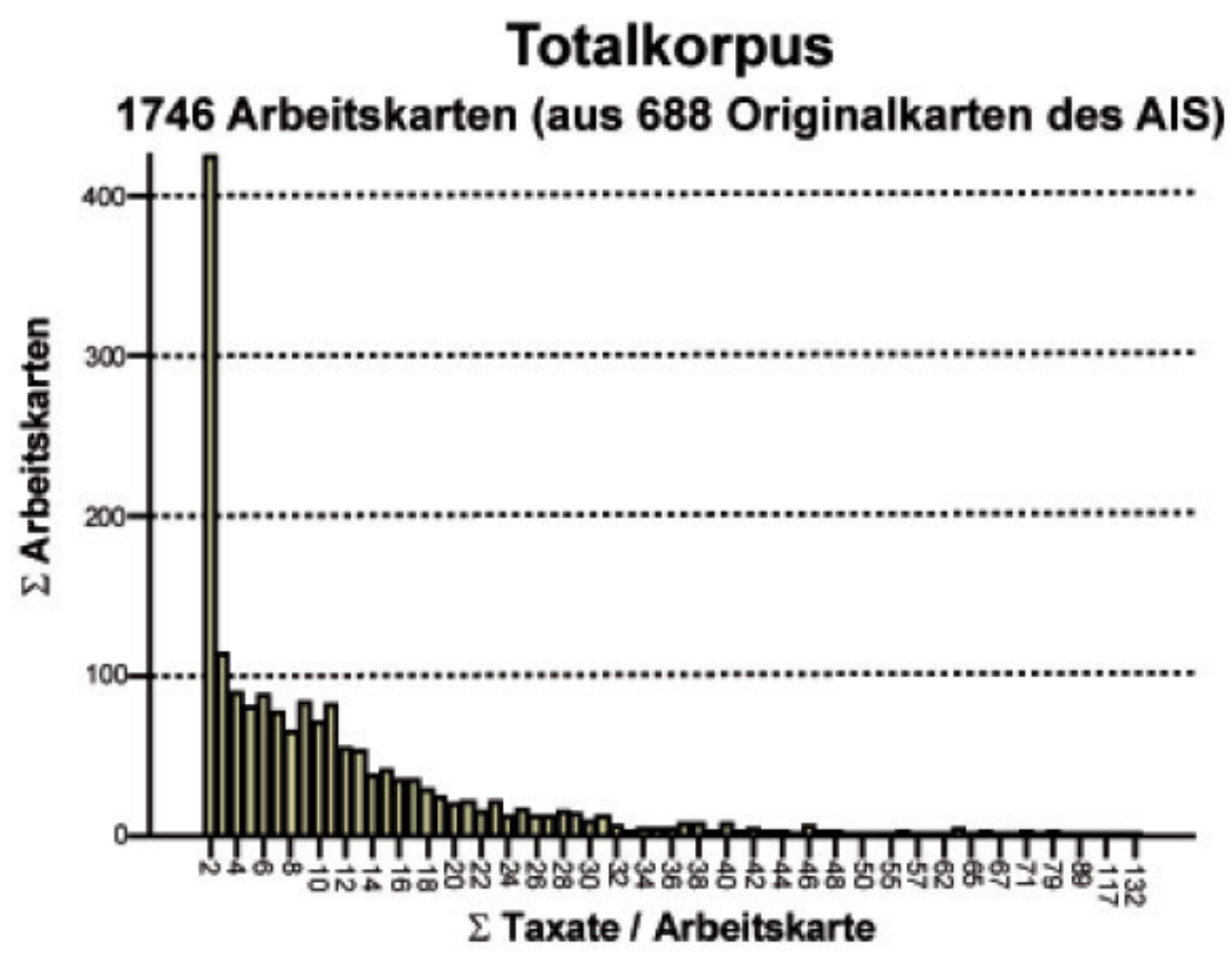

Abbildung 8. Histogramm (Goebl 2007: 203): Verteilung von 1746 aus dem AIS extrahierten Arbeitskarten (y-Achse) nach der Anzahl der auf ihnen aufscheinenden Taxate (x-Achse, Polynymie hier: 2 bis 132).

dieser beiden Variablen stehen in einer konstanten Relation zueinander, d.h. das Produkt aus einem Rangplatz und der Verwendungshäufigkeit ist konstant“ (Bußmann 2002: 763). Vgl. Zipf (1965 [1935]).

${ }^{267}$ Den mathematischen Nachweis dazu erbringt Altmann (1985) auf der Basis von Daten aus Goebl (1984). In Analogie zum Zipfschen Gesetz prägt Altmann (ebd.: 155) für die Gesetzmäßigkeiten der diatopischen Variation den Begriff des „Goeblschen Gesetzes“. 


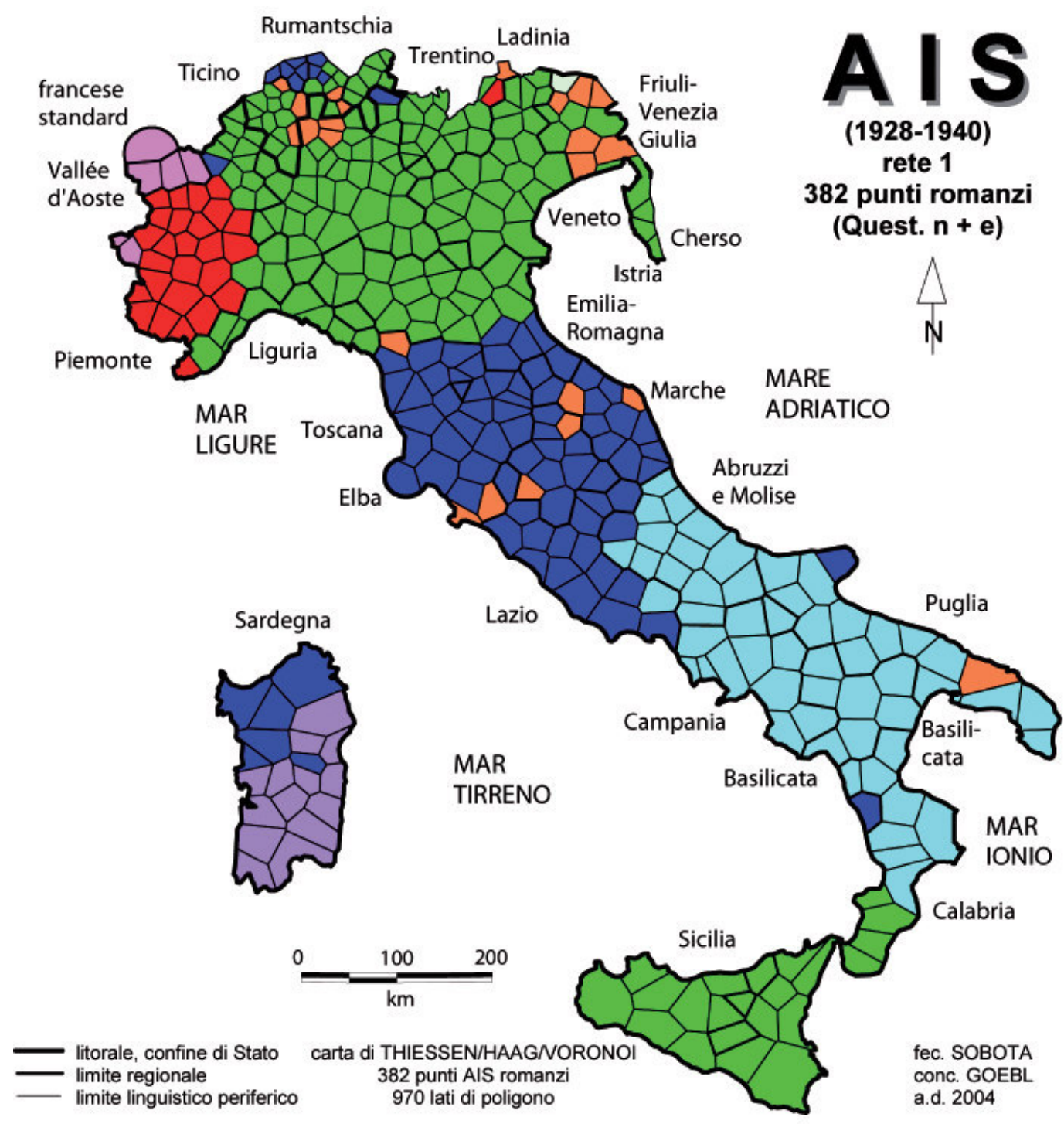

\section{Bezeichnungen für "blind"}

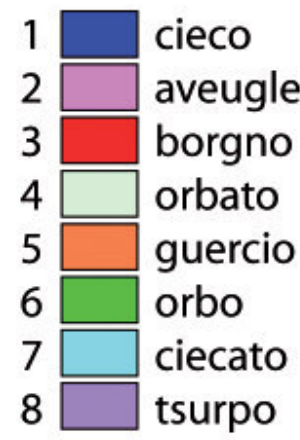

$$
\overline{\Sigma=382}
$$

Karte 24. Lexikalisch relevante Arbeitskarte (Goebl 2007: 237). Geographische Verteilung der Bezeichnungen für ,blind“ anhand der Karte 188 ,cieco' des AIS. Hinter den Taxaten ist in Klammern die Anzahl der Orte notiert, die den jeweiligen lexikalischen Typ aufweisen. 


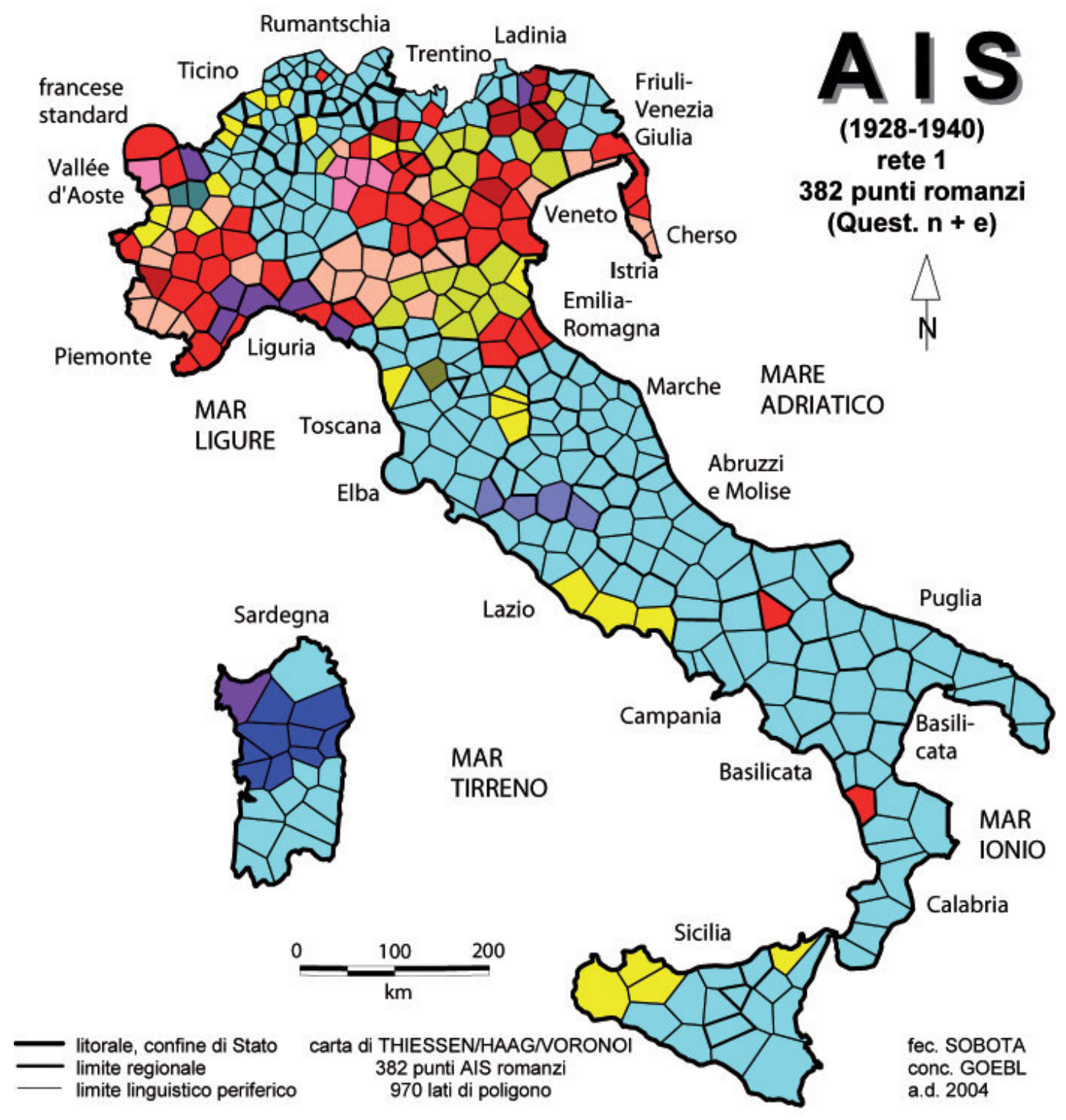

Resultate von $\mathrm{C}+$ E̊́ in CÉNNTU

\begin{tabular}{|c|c|c|}
\hline & $\dot{c}$ & (225) \\
\hline 2 & $s$ & (47) \\
\hline 3 & $t s$ & (8) \\
\hline 4 & $c^{\prime} c ́$ & (4) \\
\hline 5 & $\underline{s}$ & (26) \\
\hline & $\check{s}$ & (24) \\
\hline
\end{tabular}

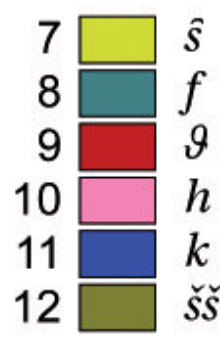

Karte 25. Phonetisch relevante Arbeitskarte (Goebl 2007: 236). Geographische Verteilung der Resultate von lat. C vor bet. $\check{E}$ in CĚNTU anhand der Karte 304 , cento' des AIS. Hinter den Taxaten ist in Klammern die Anzahl der Orte notiert, die den jeweiligen phonetischen Typ aufweisen. 


\subsubsection{Erstellung der Ähnlichkeits- und Distanzmatrix}

\subsubsection{Relativer (ungewichteter) Identitäts- bzw. Distanzwert}

Im Zentrum der dialektometrischen Analyse steht die Ermittlung der sprachlichen Beziehungen, d.h. der sprachlichen Ähnlichkeiten bzw. Distanzen zwischen den Messpunkten des Untersuchungsnetzes. ${ }^{268}$ Diese verläuft über den jeweils paarweise ausgeführten Vergleich der Messpunktvektoren der nominalen Datenmatrix, wobei verschiedene Ähnlichkeits- bzw. Distanzmaße zur Verfügung stehen. Für die metrischen Eigenschaften dieser Maße gelten dabei wie für alle taxonomischen Ähnlichkeits- bzw. Distanzmaße ${ }^{269}$ - dieselben Bedingungen wie für geometrische (euklidische) Distanzen (nach Bauer 2009: 93f.):

1) Positivdefiniertheit: $s_{j k} \geq 0$ bzw. $d_{j k} \geq 0$

Die zwischen zwei Punkten $j$ und $k$ gemessenen Ähnlichkeits- $\left(\mathrm{s}_{j k}\right)$ bzw. Distanzwerte $\left(\mathrm{d}_{j k}\right)$ dürfen nicht negativ sein.

2) Reflexivität: $\mathrm{s}_{k k}=1$ (bzw. 100\%), $\mathrm{d}_{k k}=0$ (bzw. 0\%)

Die Ähnlichkeit eines Punktes zu sich selbst ist immer 1 (bzw. 100\%), die Distanz eines Punktes zu sich selbst ist immer 0 (bzw. 0\%).

3) Symmetrie: $\mathrm{s}_{k j}=\mathrm{s}_{j k}$ bzw. $\mathrm{d}_{k j}=\mathrm{d}_{j k}$

Die Ähnlichkeit bzw. Distanz zwischen zwei Punkten $j$ und $k$ ist numerisch identisch mit der Ähnlichkeit bzw. Distanz zwischen den Punkten $k$ und $j$. Das Ergebnis ist also unabhängig von der Messrichtung.

4) Dreiecksungleichung: $\mathrm{d}_{j i}+\mathrm{d}_{i k} \geq \mathrm{d}_{j k}$

Die Distanz zwischen zwei Punkten $j$ und $i$ über einen weiteren Punkt $k$ darf nicht kürzer sein als die direkte Distanz zwischen den Punkten $j$ und $k$.

Das in der S-DM am häufigsten verwendete Maß zur Ermittlung der Ähnlichkeit zwischen zwei Messpunktvektoren ist der Relative Identitätswert $\left(\mathrm{RIW}_{j k}\right)^{270}$, bei dem „,die paarweisen Übereinstimmungen zwischen den qualitativen Merkmalsausprägungen (a, b, c, d etc.) im Inneren der Datenmatrix erfasst und zur Gesamtmenge der in den betreffenden Paarvergleich überhaupt einbeziehbaren Ausprägungs-Paare in Relation“ gesetzt werden (Goebl 2007: 195). Mit anderen Worten, es werden je zwei Vektoren der Datenmatrix im Hinblick auf die Anzahl von

\footnotetext{
268 Die Messung der Beziehungen zwischen den Objekten einer Klassifikation wird in der numerischen Taxonomie als $Q$-Analyse bezeichnet. Demgegenüber spricht man bei der Ermittlung von Zusammenhängen zwischen den Klassifikationsmerkmalen von R-Analyse (Sneath/Sokal 1973: 114). In der Dialektometrie wird häufig eine etwas abgewandelte R-Analyse verwendet, die auf Q-analytischen Messungen basiert, ,wobei aber merkmalsseitig systematische Datenrestriktionen bzw. - manipulationen vorgenommen werden, um solcherart festzustellen, inwieweit ein bestimmter Q-analytischer Meßertrag von R-analytisch relevanten Ordnungsstrukturen abhängig ist" (Goebl 1984: 197). Das bedeutet, dass die dialektometrischen Ergebnisse bzw. die kartographisch aufscheinenden Ordnungsstrukturen verschiedener Teilkorpora (z.B. des phonetischen und des lexikalischen Teilkorpus oder aber des vokalischen und des konsonantischen Teilkorpus) miteinander verglichen werden, um Informationen über die Korpus-Sensibilität des Messergebnisses zu erhalten (vgl. Kap. 4.3.8).

269 Vgl. Vogel (1975: 82-84) und Bock (1974: 24-26).

${ }^{270}$ Die Indizes $j$ und $k$ stehen für zwei verschiedene Messpunktvektoren der Datenmatrix. Im Französischen wird der $\mathrm{RIW}_{j k}$ als Indice Relatif d'Identité (IRI $\left.{ }_{j k}\right)$ und im Englischen als Relative Identity Value $\left(\mathrm{RIV}_{j k}\right)$ bezeichnet.
} 
Koidentitäten (übereinstimmende Merkmalsausprägungen/Taxate) und Kodifferenzen (divergierende Merkmalsausprägungen/Taxate) miteinander verglichen, wobei keine unterschiedliche Gewichtung der Taxate erfolgt, alle Taxate also mit gleichem Gewicht in die Berechnung eingehen (Goebl 1984: 76). ${ }^{271}$ Nullstellen werden in der S-DM generell nicht in den Vergleich einbezogen, um zu gewährleisten, ,dass zwei- oder mehrmaliges Auftreten von Nullstellen innerhalb eines Merkmalsvektors beim paarweisen Vergleich der Ortsvektoren nicht als Ko-Iden-

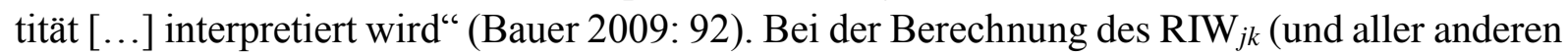
Ähnlichkeitsmaße) wird also die Anzahl der bei dem Vergleich insgesamt zu berücksichtigenden Merkmale (Arbeitskarten) für jede Ortspaarung neu definiert. ${ }^{272}$

Der Relative Identitätswert RIW ${ }_{j k}$ ergibt sich daraus, dass die Summe der Koidentitäten (Absoluter Identitätswert $\mathrm{AIW}_{j k}$ ) in Bezug zur Summe aller messbaren Koidentitäten und Kodifferenzen, d.h. aller berücksichtigten Merkmale gesetzt und mit dem Faktor 100 multipliziert wird (vgl. Goebl 1984: 76):

$$
\operatorname{RIW}_{\mathrm{jk}}=100 \cdot \frac{\sum_{\mathrm{i}=1}^{\mathrm{p}}\left(\mathrm{KOI}_{\mathrm{jk}}\right)_{\mathrm{i}}}{\sum_{\mathrm{i}=1}^{\mathrm{p}}\left(\mathrm{KOI}_{\mathrm{jk}}\right)_{\mathrm{i}}+\sum_{\mathrm{i}=1}^{\mathrm{p}}\left(\mathrm{KOD}_{\mathrm{jk}}\right)_{\mathrm{i}}}
$$

wobei

RIW $_{\mathrm{jk}} \quad \mathrm{Maß}$ für die Ähnlichkeit zwischen den Messpunktvektoren $\mathrm{j}$ und $\mathrm{k}$ $\left(0 \leq \mathrm{RIW}_{\mathrm{jk}} \leq 100\right)$

$\sum_{\mathrm{i}=1}^{\mathrm{p}}\left(\mathrm{KOI}_{\mathrm{jk}}\right)_{\mathrm{i}} \quad$ Summe aller beim Vergleich der Messpunktvektoren j und k festgestellten Koidentitäten (i ... p = berücksichtigte Merkmale)

$\sum_{\mathrm{i}=1}^{\mathrm{p}}\left(\mathrm{KOD}_{\mathrm{jk}}\right)_{\mathrm{i}} \quad$ Summe aller beim Vergleich der Messpunktvektoren j und k festgestellten Kodifferenzen (i ... p = berücksichtigte Merkmale)

So ergibt etwa ein anhand der Merkmale 1 bis 4 durchgeführter Vergleich der Messpunktvektoren 5 und 6 aus Abb. 7 bei drei insgesamt zu berücksichtigenden Merkmalspaaren zwei Koidentitäten (j/j, g/g) und eine Kodifferenz (c/d). Durch Einsetzen in obige Formel erhält man:

$$
\operatorname{RIW}_{5,6}=100 \cdot \frac{2}{2+1}=66,67(\%)^{273}
$$

Die anhand der vorliegenden Datenbasis zu ermittelnde sprachliche Ähnlichkeit zwischen den Messpunkten 5 und 6 liegt demnach etwa bei vollen $66 \%$ (vgl. Abb. 9).

\footnotetext{
${ }^{271}$ In der taxonomischen Fachsprache werden Ähnlichkeitsmaße, bei denen alle Merkmale gleich gewichtet werden, als isokratische oder - nach Michel Adanson (vgl. Kap. 4.3.2) - als adansonistische Ähnlichkeitsmaße bezeichnet (vgl. Goebl 1984: 83, Bauer 2009: 92).

${ }^{272}$ Dabei handelt es sich um ein in der numerischen Taxonomie gängiges Verfahren: „Wenn in der Matrix $\left(x_{k i}\right)$ einige Daten $x_{k i}$ nicht bekannt oder verfügbar sind, müssen die genannten Ähnlichkeits- und Distanzmaße modifiziert werden. Man geht dann zweckmäßig von einem Maß $s_{j k}$ bzw. $d_{j k}$ aus, bei dem jedes einzelne Merkmal einen additiven Beitrag liefert und das bzgl. der Anzahl der Merkmale normiert ist (Division durch $p$ ): In der entsprechenden Summe berücksichtigt man dann nur jene Komponenten von $x_{j}$ und $x_{k}$, die in beiden Vektoren bekannt sind, und dividiert durch die Anzahl $\tilde{p}$ dieser Komponenten [...]“ (Bock 1974: 75).

${ }^{273}$ Ergebnis auf die zweite Kommastelle gerundet.
} 
Der paarweise Vergleich aller Messpunktvektoren im Hinblick auf Koidentitäten und Kodifferenzen generiert eine symmetrische Ähnlichkeitsmatrix vom Typ N (Messpunkte) mal N (Messpunkte), die als solche (abzüglich der 100\%igen Ähnlichkeit jedes Messpunktes zu sich selbst) $\mathrm{N} / 2 \cdot(\mathrm{N}-1)$ verwertbare Ähnlichkeitswerte enthält und deren Diagonale durch die Zellen mit reflexiven Ähnlichkeitswerten $\left(\mathrm{RIW}_{j j}=100\right)$ konstituiert wird (vgl. Abb. 9). Heuristisch gesehen stellt sie „ein nach bestimmten Kriterien erstelltes quantitatives Abbild der qualitativen Information (bzw. der darin enthaltenen Variation) der Datenmatrix“ dar (Goebl 2007: 196).

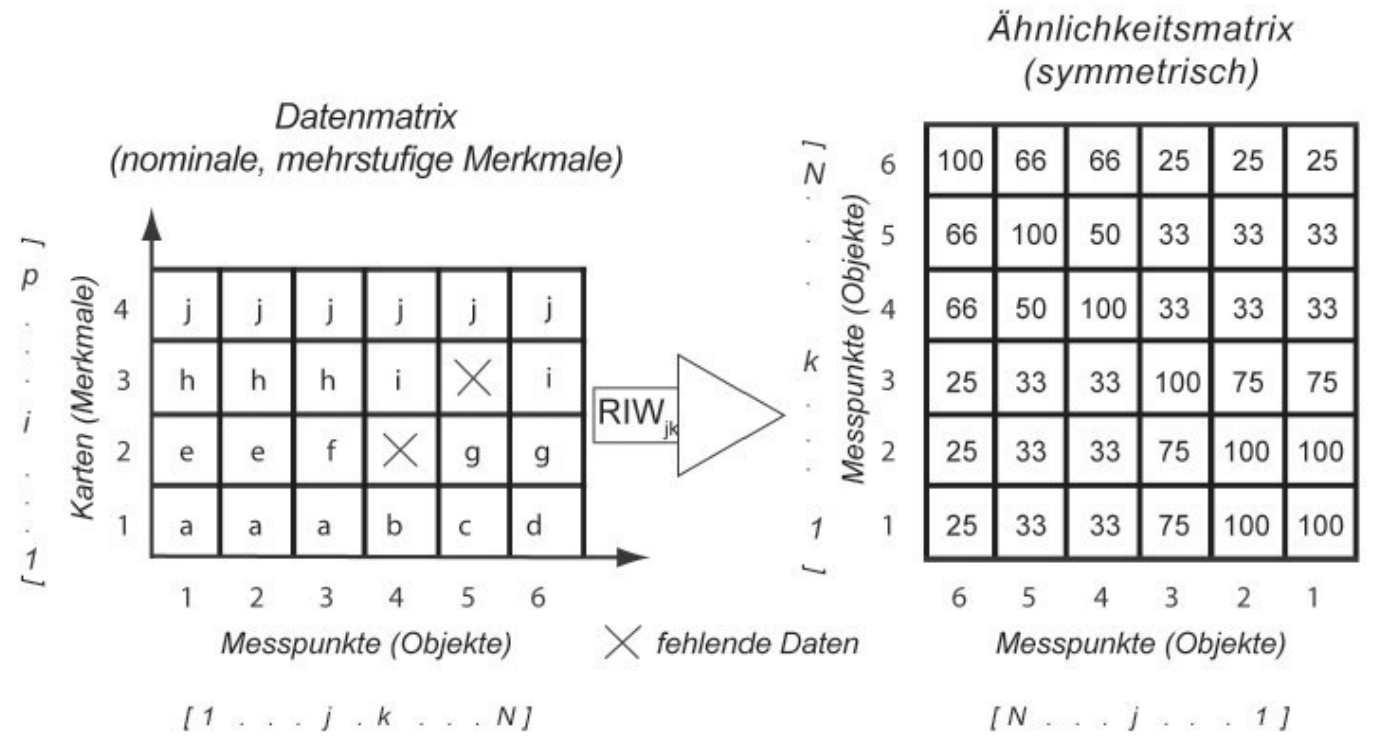

Abbildung 9. Generierung einer (metrischen) Ähnlichkeitsmatrix aus einer (nominalen) Datenmatrix mittels des Relativen Identitätswertes (RIW ${ }_{j k}$, Goebl 2007: 196).

Obgleich in der S-DM die sprachlichen Ähnlichkeiten zwischen den Messpunkten im Zentrum des Forschungsinteresses stehen (vgl. Kap. 4.3.1), lassen sich hier auch die sprachlichen $A b$ stände bzw. Distanzen zwischen diesen auf einfache Weise (und mittels VDM automatisch) ermitteln. Die Relativen Distanzwerte $\left(\mathrm{RDW}_{j k}\right)$, die die Messpunkte zueinander aufweisen, sind zu den entsprechen Relativen Ähnlichkeitswerten komplementär und werden über folgende Formel errechnet (Bauer 2009: 96):

$$
\mathrm{RDW}_{\mathrm{jk}}=100-\mathrm{RIW}_{\mathrm{jk}}
$$

Analog zu den Ähnlichkeitswerten werden die ermittelten Distanzwerte in einer (symmetrischen) Distanzmatrix ${ }^{274}$ zusammengefasst, die (wie die Ähnlichkeitsmatrix) N/2 $\cdot(\mathrm{N}-1)$ dialektometrisch relevante Werte enthält und deren Diagonale durch die Zellen mit reflexiven Distanzwerten $\left(\mathrm{RDW}_{j j}=0\right)$ konstituiert wird (s. Abb. 10).

\footnotetext{
${ }^{274}$ Ein Teil der in der Distanzmatrix gespeicherten Werte wird in der S-DM zur Generierung von Schottenkarten verwendet (vgl. Kap. 4.3.7.6).
} 


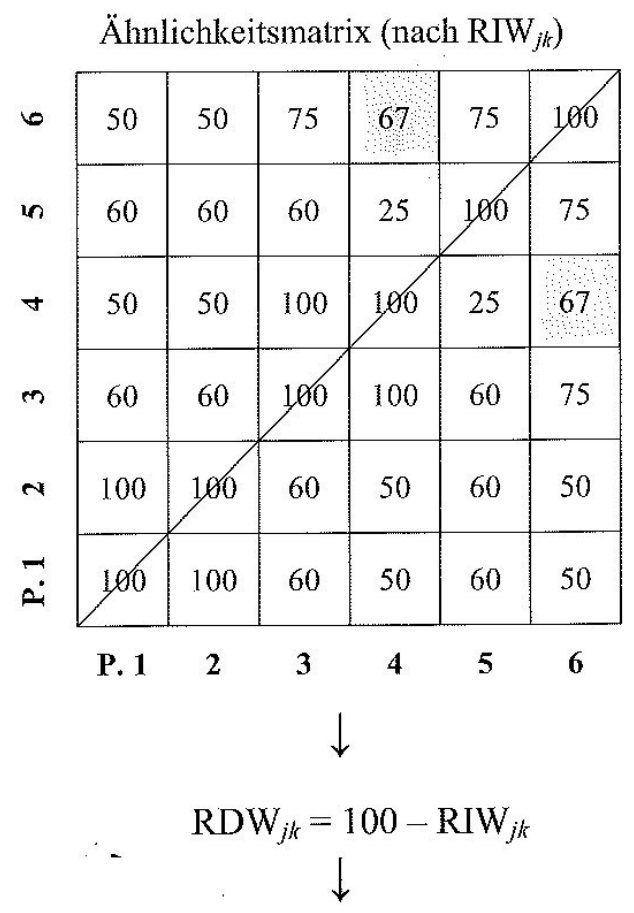

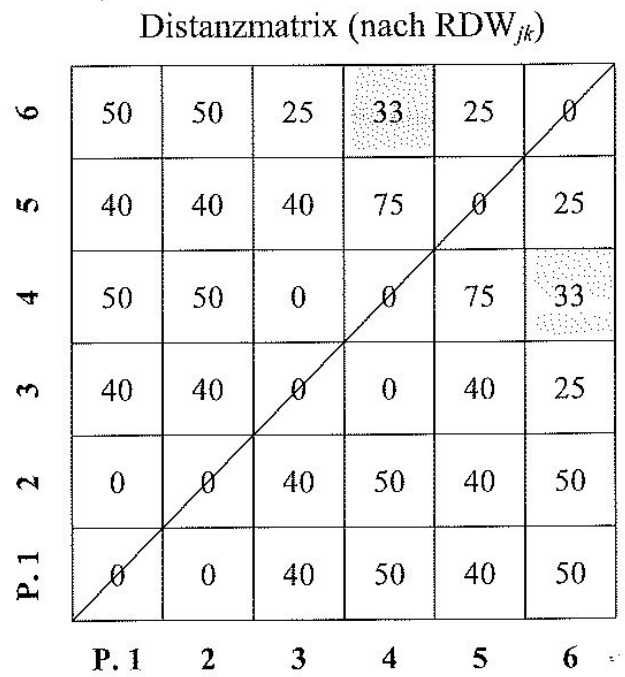

Abbildung 10. Erzeugung einer Distanzmatrix nach $\mathrm{RDW}_{j k}($ Bauer 2009: 97).

\subsubsection{Gewichteter Identitäts- bzw. Distanzwert}

Beim isokratischen Ähnlichkeitsmaß $\mathrm{RIW}_{j k}$ werden die Merkmalsausprägungen bzw. Taxate unabhängig von der Häufigkeit, mit der sie jeweils innerhalb eines Merkmalsvektors auftreten, gleich gewichtet. Für das Resultat der Ähnlichkeitsmessung bedeutet dies, dass ein in einem Merkmalsvektor hochfrequentes Taxat zum numerischen Gesamtertrag in diesem Merkmalsvektor stärker beiträgt als ein seltenes Taxat (Bauer 2009: 96). Gegen die Gleichgewichtung von Merkmalsausprägungen - die immerhin ein grundsätzliches Prinzip der numerischen Taxonomie nach Adanson darstellt (vgl. Sneath/Sokal 1973: 5) - ist in der modernen Taxonomie und ihren verschiedenen Anwendungsbereichen der Einwand erhoben worden, ,that agreement among rare character states is a less probable event than agreement for frequent character states 
and should therefore be weighted more heavily“ (Sneath/Sokal 1973: 140). Für die Sprachgeographie bedeutet dies, „daß onomasiologisch homogenen Straten großer Ausdehnung und den dort anzusetzenden Taxaten ein geringeres taxometrisches Gewicht beigemessen wird als nur punktuell auftretenden Residual- oder Innovationsformen“ (Goebl 1983a: 13). In der S-DM wurde mit dem sog. Gewichteten Identitätswert $\left(\mathrm{GIW}_{j k}\right.$, vgl. Goebl 1983a) ein Ähnlichkeitsmaß eingeführt, das es ermöglicht, ,den Normalwert jeder Koidentität, nämlich 1, von der Häufigkeit des die Koidentität generierenden Taxats gewichten zu lassen“ (Goebl 1984: 83), während der Wert jeder Kodifferenz unverändert bei 1 bleibt. ${ }^{275}$ Die Werte der Koidentitäten sind umso geringer, je häufiger das die Koidentität generierende Taxat im jeweiligen Merkmalsvektor auftritt und berechnen sich wie folgt (ebd.: 84):

$$
\begin{aligned}
& \left(\mathrm{KOI}_{\mathrm{jk}}\right)_{\mathrm{i}}=1-\frac{\mathrm{f}\left(\mathrm{TAX}_{\mathrm{jk}}\right)_{\mathrm{i}}-1}{\mathrm{n}_{\mathrm{i}} \cdot \mathrm{w}} \\
& \text { wobei } \\
& \left(\mathrm{KOI}_{\mathrm{jk}}\right)_{\mathrm{i}} \quad \text { Wert der Koidentität zwischen den Messpunktvektoren } \mathrm{j} \text { und } \mathrm{k} \text { im i-ten } \\
& \text { Merkmalsvektor }\left(0<\left(\mathrm{KOI}_{\mathrm{jk}}\right)_{\mathrm{i}}<1\right) \\
& \mathrm{f}\left(\mathrm{TAX}_{\mathrm{jk}}\right)_{\mathrm{i}} \quad \text { (absolute) Frequenz des die Koidentität zwischen den Messpunktvekto- } \\
& \text { ren } \mathrm{j} \text { und } \mathrm{k} \text { im i-ten Merkmalsvektor generierenden Taxats } \\
& \left(2 \leq \mathrm{f}\left(\mathrm{TAX}_{\mathrm{jk}}\right)_{\mathrm{i}} \leq \mathrm{n}_{\mathrm{i}}\right)
\end{aligned}
$$

$\mathrm{n}_{\mathrm{i}}$

Anzahl der insgesamt berücksichtigten Einträge im i-ten Merkmalsvektor (ohne Nullstellen, $\mathrm{n}_{\mathrm{i}} \leq \mathrm{N}$ )

$\mathrm{W}$

Gewicht (kann auf einen Wert zwischen 1 und $\infty$ festgelegt werden)

Zur Berechnung der Werte der Koidentitäten zwischen den Messpunktvektoren 5 und 6 in Abb. 9 im Hinblick auf die Merkmale 2 und 4 muss also in die Formel folgendermaßen eingesetzt werden $(\mathrm{w}=1)$ :

$$
\begin{aligned}
& \left(\mathrm{KOI}_{5,6}\right)_{2}=1-\frac{2-1}{5 \cdot 1}=1-\frac{1}{5}=\frac{4}{5}(0,8) \\
& \left(\mathrm{KOI}_{5,6}\right)_{4}=1-\frac{6-1}{6 \cdot 1}=1-\frac{5}{6}=\frac{1}{6}(0,16)
\end{aligned}
$$

Der Wert der Koidentität zwischen den Messpunktvektoren 5 und 6 ist in Merkmalsvektor 2, wo das übereinstimmende Taxat eine geringere Frequenz (2) aufweist, also deutlich höher als der Wert der Koidentität in Merkmalsvektor 4, wo das übereinstimmende Taxat eine höhere Frequenz (6) aufweist.

\footnotetext{
${ }^{275}$ In der numerischen Taxonomie bestehen zwei grundsätzlich unterschiedliche Verwendungsweisen der von Sokal/Michener (1958) für mit Mittelwerten operierende Methoden eingeführten Termini ,gewichtet“/,gewogen“ (engl. weighted) und „ungewichtet“/,ungewogen“ (engl. unweighted). Im Hinblick auf die Art des Ähnlichkeitsmaßes werden Verfahren, bei denen die Werte unterschiedlich gewichtet werden, als gewichtet und solche, bei denen keine unterschiedliche Gewichtung der Werte vorgenommen wird, als ungewichtet bezeichnet (so in der hier verwendeten dialektometrischen Terminologie). Im Hinblick auf die resultierende Klassifikation wird hingegen - in der Tradition von Sokal/Michener - bei Verfahren, die gewichtete Werte verwenden, von ungewichteten und bei solchen, die ungewichtete Werte verwenden, von gewichteten Verfahren gesprochen (vgl. Vogel 1975: 305).
} 
Zur Berechnung der metrischen Ähnlichkeitsmatrix mittels GIW wird zunächst eine metrische Zwischenmatrix im Format $n$ (Messpunkte) mal $p$ (Merkmale) erstellt, deren Zellen die Werte enthalten, die sich für die Koidentitäten auf der Basis der jeweiligen Taxate ergeben (s. Abb. 11). Auf der Basis dieser Zwischenmatrix werden die Ähnlichkeiten zwischen den Messpunktvektoren dann anhand folgender Formel berechnet (vgl. Bauer 2009: 98): 276

$$
\begin{aligned}
& \operatorname{GIW}(w)_{j k}=100 \cdot \frac{\sum_{i=1}^{\mathrm{p}}\left(1-\frac{\mathrm{f}\left(\mathrm{TAX}_{\mathrm{jk}}\right)_{\mathrm{i}}-1}{\mathrm{n}_{\mathrm{i}} \cdot \mathrm{w}}\right) \mathrm{i}}{\sum_{\mathrm{i}=1}^{\mathrm{p}}\left(1-\frac{\mathrm{f}\left(\mathrm{TAX}_{\mathrm{jk}}\right)_{\mathrm{i}}-1}{\mathrm{n}_{\mathrm{i}} \cdot \mathrm{w}}\right) \mathrm{i}+\sum_{\mathrm{i}=1}^{\mathrm{p}}\left(\mathrm{KOD}_{\mathrm{jk}}\right)_{\mathrm{i}}} \\
& \text { wobei } \\
& \text { GIW(w) })_{j k} \quad \text { Maß für die Ähnlichkeit zwischen den Messpunktvektoren j und k bei } \\
& \text { einem Gewicht von w } \\
& \sum_{\mathrm{i}=1}^{\mathrm{p}}\left(1-\frac{\mathrm{f}\left(\mathrm{TAX}_{\mathrm{jk}}\right)_{\mathrm{i}}-1}{\mathrm{n}_{\mathrm{i}} \cdot \mathrm{w}}\right) \mathrm{i} \quad \text { Summe der Werte aller beim Vergleich der } \\
& \text { Messpunktvektoren j und } \mathrm{k} \text { festgestellten Koiden- } \\
& \text { titäten } \\
& \text { (i ....p = berücksichtigte Merkmale) } \\
& \sum_{\mathrm{i}=1}^{\mathrm{p}}\left(\mathrm{KOD}_{\mathrm{jk}}\right)_{\mathrm{i}} \\
& \text { Summe aller beim Vergleich der } \\
& \text { Messpunktvektoren } \mathrm{j} \text { und } \mathrm{k} \text { festgestellten Kodiffe- } \\
& \text { renzen } \\
& \text { (i ....p = berücksichtigte Merkmale) }
\end{aligned}
$$

Für die Ähnlichkeit zwischen den Messpunkten 5 und 6 aus Abb. 7 (bzw. Abb. 9) ergibt sich somit $(\mathrm{w}=1)$ :

$$
\operatorname{GIW}(1)_{5,6}=100 \cdot \frac{\frac{4}{5}+\frac{1}{6}}{\frac{4}{5}+\frac{1}{6}+1}=100 \cdot \frac{24+5}{24+5+30}=100 \cdot \frac{29}{59}=49,15(\%)
$$

Der deutliche Unterschied, den dieser Wert zu dem mittels RIW ju $_{j k}$ berechneten Ähnlichkeitswert $(66,67 \%$, s.o.) aufweist, ist dem geringen Wert von w geschuldet. Generell gilt: „Je größer w gewählt wird, desto kleiner werden die jeder Koidentität aufgelasteten Gewichte und desto mehr nähert sich GIW an RIW an“ (Goebl 1984: 85). Im vorliegenden Beispiel wird eine ungefähre Übereinstimmung von $\mathrm{GIW}_{j k}$ mit $\mathrm{RIW}_{j k}$ erreicht, wenn $\mathrm{w}=100$ gewählt wird. Das numerische Resultat der dialektometrischen Berechnungen mittels GIW $_{j k}$ hängt also erheblich von der Wahl der Gewichte ab. Da eine objektive Bestimmung der Gewichte im Allgemeinen nicht möglich ist und die Gefahr der Manipulation des Klassifikationsergebnisses durch die Wahl ,passender“ Gewichte besteht (Bock 1974: 76), ist „,im Zusammenhang mit Gruppierungsproblemen [...] eine a priori festgelegte, konstante Gewichtung i. a. nicht angebracht" (ebd.). Bei der Wahl des Ähnlichkeitsmaßes muss es jedoch in der Dialektometrie wie auch in anderen Anwendungsbereichen der numerischen Taxonomie letztlich darum gehen, in jedem Einzelfall das „,brauchbarste“ Ähnlichkeitsmaß zu finden, „,denn das Maß, welches

\footnotetext{
${ }^{276}$ Die zu den Gewichteten Ähnlichkeitswerten komplementären Gewichteten Distanzwerte $\left(\mathrm{GDW}_{j k}\right)$ werden analog zu den Relativen Distanzwerten $\left(\mathrm{RDW}_{j k}\right.$, s.o.) berechnet: $\mathrm{GDW}_{j k}=100-\mathrm{GIW}_{j k}$.
} 
alle Arten von Ähnlichkeitsbeziehungen in einer allgemeingültigen Form zu messen imstande ist, gibt es nicht“" (Vogel 1975: 80).

$$
\begin{aligned}
& \text { Datenmatrix }
\end{aligned}
$$

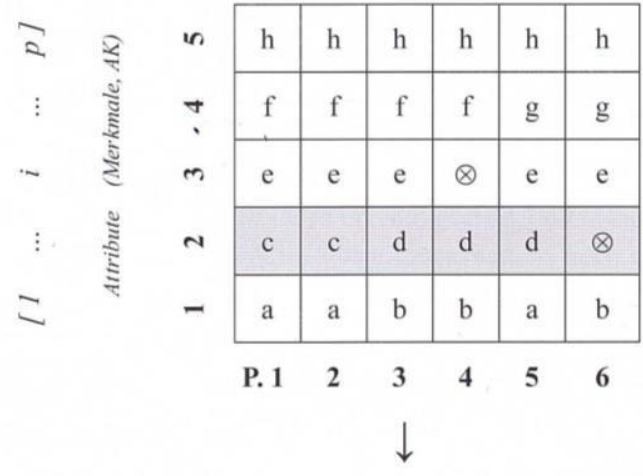

$$
\begin{aligned}
& \sum_{i=1}^{\tilde{p}}\left(1-\frac{f\left(\operatorname{TAX}_{j k}\right) i-1}{n_{i} \cdot w}\right) i \\
& \downarrow
\end{aligned}
$$

\begin{tabular}{|c|c|c|c|c|c|}
\hline 50,8 & 50,8 & 50,8 & 45,5 & 100 & 101 \\
\hline 34,1 & 34,1 & 62 & 58,9 & 100 & 100 \\
\hline 57,1 & 57,1 & 100 & 100 & 58,9 & 45,5 \\
\hline 60,5 & 60,5 & 100 & 100 & 62 & 50,8 \\
\hline 100 & 18 & 60,5 & 57,1 & 34,1 & 50,8 \\
\hline 100 & 100 & 60,5 & 57,1 & 34,1 & 50,8 \\
\hline
\end{tabular}

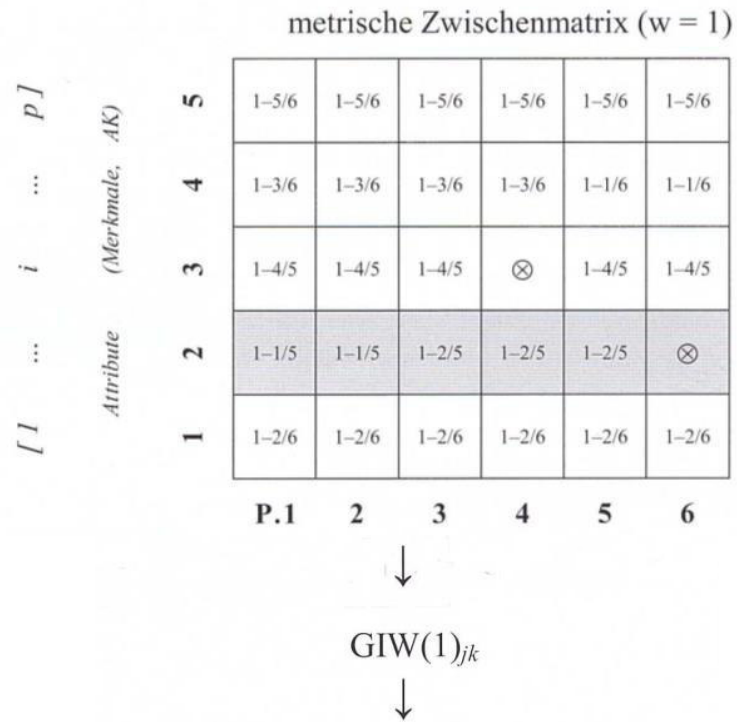

$\begin{array}{llllll}\text { P. } 1 & 2 & 3 & 4 & 5 & 6\end{array}$

Abbildung 11. Generierung einer dialektometrischen Ähnlichkeitsmatrix mittels GIW(1) $)_{j k}$ (Bauer 2009: 100f.). 


\subsubsection{Intervallisierung der Ähnlichkeits- bzw. Distanzwerte}

In der aus dem paarweisen Vergleich der Ortsvektoren resultierenden Ähnlichkeits- bzw. Distanzmatrix liegen zu jedem Messpunkt $\mathrm{N}-1$ dialektometrisch relevante Werte vor, die jeweils eine bestimmte Spannweite aufweisen. Die Häufigkeitsverteilung der Ähnlichkeitswerte innerhalb dieser Spannweite wird in der Dialektometrie auch als das Ähnlichkeitsprofil eines Messpunktes bezeichnet. Zur kartographischen Darstellung dieses Ähnlichkeitsprofils (vgl. Kap. 4.3.7.2) werden die Ähnlichkeitswerte in disjunkte Wertklassen bzw. Intervalle eingeteilt. ${ }^{277}$ Eine auf rein subjektiv festgelegten Wertklassen basierende Intervallisierung hat dabei den großen Nachteil, „dass Häufigkeitsverteilungen zu verschiedenen Messpunkten nur mehr schwer miteinander verglichen werden können, da sich die Bandbreite an jeweils gemessenen Werten von Punkt zu Punkt ändert“ (Bauer 2009: 102). Objektiver und praktikabler ist eine Lösung, bei der „die Wertklassenbildung (Intervalleinteilung) durch einen mathematischen Algorithmus an die statistischen Kennwerte der jeweils vorliegenden empirischen Häufigkeitsverteilung“ gebunden wird (Goebl 1984: 93). ${ }^{278}$

Die Klassenanzahl kann dabei unterschiedlich eingestellt werden, wobei der visuelle Eindruck um so komplexer und das Auffinden der entsprechenden höherrangigen räumlichen Ordnungsstrukturen um so schwieriger ist, je größer die Anzahl der Wertklassen gewählt wird. Bei der Wahl der Wertklassenzahl muss mithin die begrenzte Leistungsfähigkeit des menschlichen Sehsinns berücksichtigt werden: Generell ist die serielle Verarbeitung von mehr als acht Farbstufen für das menschliche Auge problematisch, sodass ein wirksamer globaler Eindruck bei einer Anzahl von mehr als acht Klassen nicht mehr gewährleistet ist (Goebl 1984: 92, Bauer 2009: 103). ${ }^{279}$ Ein sowohl im Hinblick auf die visuelle Verarbeitung als auch im Hinblick auf den heuristischen Gehalt optimaler Karteneindruck wird meist mit einer 6-fachen Intervalleinteilung erreicht.

Bei der Wertklassenbildung kommen in der S-DM die Algorithmen MINMWMAX, MEDMW und MED zum Einsatz (vgl. Goebl 1984: 94ff.).

1) Der Algorithmus MINMWMAX basiert auf dem Minimum (diskreter Wert), dem arithmetischen Mittel bzw. Mittelwert (stetiger Wert) ${ }^{280}$ und dem Maximum (diskreter Wert) der jeweiligen Häufigkeitsverteilung. Dabei werden die (numerischen) Spannweiten zwischen dem Minimum und dem Mittelwert einerseits und dem Maximum und dem Mittelwert andererseits gebildet und jeweils in eine bestimmte Anzahl gleich breiter Klassen eingeteilt (Tab. 13). Der Algorithmus MINMWMAX zeichnet sich dadurch aus, dass hier vor allem die mittleren Wertklassen stark besetzt sind, sodass die statistisch am stärksten vertretenen mittleren Ähnlichkeitsverhältnisse und damit die Übergangsräume zwischen extremen dialektalen Ähnlichkeiten (mit Messpunkten im direkten geographischen Umfeld) und extremen dialektalen Distanzen (zu Messpunkten in geographisch entfernten Gebieten) gut visualisiert werden.

\footnotetext{
${ }^{277}$ Bei Vorliegen einer Distanzmatrix wird analog vorgegangen.

${ }^{278}$ Das subjektive Moment manifestiert sich hier „,nur“ noch in der Wahl des Intervallalgorithmus. Gänzlich lässt es sich aufgrund des subjektiven Charakters jeder Klassifikation - die ja in Abhängigkeit vom jeweiligen Forschungsziel geschieht (vgl. Kap. 4.3.2) - einsichtigerweise nicht „auflösen“.

${ }^{279}$ Um Einsicht in die Detailstruktur der Ähnlichkeitsverteilungen zu erlangen, kann auch eine größere Anzahl an Wertklassen (in VDM bis zu 20) gewählt werden (Bauer 2009: 103).

${ }^{280}$ Das arithmetische Mittel kann, muss jedoch nicht in der Häufigkeitsverteilung der Ähnlichkeitswerte vorkommen (Bauer 2009: 103).
} 


\begin{tabular}{|c|c|c|c|c|}
\hline \multirow{2}{*}{$\begin{array}{l}\text { Wertklasse } \\
\text { Intervall) }\end{array}$} & \multicolumn{2}{|c|}{ RIW237,k } & Wertklassenbreite & $\begin{array}{l}\text { Anzahl der } \\
\text { Messpunkte } \\
\text { pro Klasse }\end{array}$ \\
\hline$[1]$ & $45,953(\mathrm{MIN})$ & 53,975 & 8,021 & $10+6=16$ \\
\hline$[2]$ & $>53,975$ & 61,995 & 8,021 & $11+4=15$ \\
\hline$[3]$ & $>61,995$ & $70,016(\mathrm{MW})$ & 8,021 & $21+59=80$ \\
\hline$[4]$ & $>70,016$ & 76,555 & 6,5386 & $55+36=91$ \\
\hline$[5]$ & $>76,555$ & 83,093 & 6,5386 & $24+12=36$ \\
\hline$[6]$ & $>83,093$ & $89,632(\mathrm{MAX})$ & 6,5386 & $9+3=12$ \\
\hline
\end{tabular}

Tabelle 13. Wertklassenbildung zum AIS-Messpunkt 237 (Gromo (Lombardei), Ähnlichkeitswerte zu 250 norditalienischen Messpunkten) mittels MINMWMAX, 6-fach (nach Goebl 1984: 94, MIN = Minimum, MW = arithmetisches Mittel, MAX = Maximum). Die zu beiden Seiten des Mittelwertes gelegenen Wertklassen mit der gleichen Spannweite sind mit derselben Farbe unterlegt. Die hier (und in den folgenden Tabellen) durch Addition dargestellte nochmalige Aufteilung der Messpunkte jeder Klasse in zwei Untergruppen liegt der Darstellung der Häufigkeitsverteilung im Histogramm zugrunde (s.u.).

2) Der Algorithmus MEDMW basiert ebenfalls auf dem Minimum, dem arithmetischen Mittel und dem Maximum der jeweiligen Häufigkeitsverteilung. Hier werden die zu einem Messpunkt vorhandenen Ähnlichkeitswerte, die zwischen dem Minimum und dem Mittelwert einerseits und dem Maximum und dem Mittelwert andererseits liegen, zunächst ihrer Größe nach geordnet und danach zu beiden Seiten des Mittelwertes in eine bestimmte Anzahl von Klassen eingeteilt, die jeweils etwa dieselbe Anzahl an Werten (bzw. Messpunkten) enthalten (Tab. 14). Die mittleren Wertklassen sind damit hier nicht stärker besetzt als die Wertklassen mit extrem

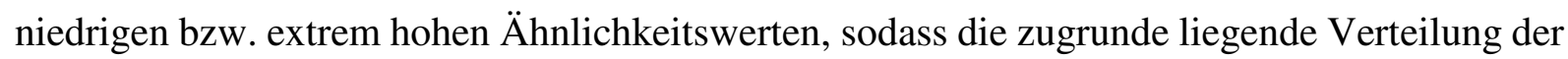
Werte nicht zum Vorschein kommt.

\begin{tabular}{|c|c|c|c|c|}
\hline \multirow{2}{*}{$\begin{array}{l}\text { Wertklasse } \\
\text { Intervall) }\end{array}$} & \multicolumn{2}{|c|}{ RIW237,k } & Wertklassenbreite & $\begin{array}{l}\text { Anzahl der } \\
\text { Messpunkte } \\
\text { pro Klasse }\end{array}$ \\
\hline$[1]$ & $45,853(\mathrm{MIN})$ & 64,084 & 18,131 & $18+18=36$ \\
\hline$[2]$ & $>64,084$ & 67,826 & 3,742 & $18+19=37$ \\
\hline$[3]$ & $>67,826$ & $70,058(\mathrm{MW})$ & 2,232 & $19+19=38$ \\
\hline$[4]$ & $>70,058$ & 72,393 & 2,335 & $23+23=46$ \\
\hline$[5]$ & $>72,393$ & 76,700 & 4,307 & $23+23=46$ \\
\hline$[6]$ & $>76,700$ & $89,632(\mathrm{MAX})$ & 12,932 & $24+23=47$ \\
\hline
\end{tabular}

Tabelle 14. Wertklassenbildung zum AIS-Messpunkt 237 (Gromo (Lombardei), Ähnlichkeitswerte zu 250 norditalienischen Messpunkten) mittels MEDMW, 6-fach (nach Goebl 1984: 95, MIN = Minimum, MW $=$ arithmetisches Mittel, MAX = Maximum). Die zu beiden Seiten des Mittelwertes gelegenen Wertklassen mit einer jeweils etwa gleich großen Anzahl an Messpunkten sind mit derselben Farbe unterlegt.

3) Bei dem Algorithmus MED werden lediglich das Minimum und das Maximum der jeweiligen Häufigkeitsverteilung berücksichtigt; das arithmetische Mittel spielt keine Rolle. Alle zu einem Messpunkt vorhandenen Ähnlichkeitswerte werden ihrer Größe nach sortiert und danach 
zu beiden Seiten des Medians ${ }^{281}$ in eine bestimmte Anzahl von Klassen eingeteilt, die jeweils etwa dieselbe Anzahl an Werten (bzw. Messpunkten) enthalten (Tab. 15). Auch hier wird die Dominanz der mittleren Ähnlichkeitswerte innerhalb der Gesamtverteilung nicht sichtbar. Zudem erzeugen MEDMW und MED bei der kartographischen Visualisierung ,einen größeren Bildkonstrast bzw. einen unruhigeren Flächeneindruck“ als MINMWMAX (Bauer 2009: 105), sodass sich letzterer zur Visualisierung einzelner Ähnlichkeitsprofile besser eignet. ${ }^{282}$

\begin{tabular}{|c|c|c|c|c|}
\hline \multirow{2}{*}{$\begin{array}{l}\text { Wertklasse } \\
\text { Intervall) }\end{array}$} & \multicolumn{2}{|c|}{ RIW237,k } & Wertklassenbreite & $\begin{array}{l}\text { Anzahl der } \\
\text { Messpunkte } \\
\text { pro Klasse }\end{array}$ \\
\hline$[1]$ & $45,935(\mathrm{MIN})$ & 64,544 & 18,591 & $20+21=41$ \\
\hline$[2]$ & $>64,544$ & 68,413 & 3,869 & $21+21=42$ \\
\hline$[3]$ & $>68,413$ & $70,852(\mathrm{MED})$ & 2,439 & $21+21=42$ \\
\hline$[4]$ & $>70,852$ & 73,333 & 2,481 & $21+21=42$ \\
\hline$[5]$ & $>73,333$ & 77,631 & 4,298 & $21+21=42$ \\
\hline$[6]$ & $>77,631$ & $89,632(\mathrm{MAX})$ & 12,001 & $20+21=41$ \\
\hline
\end{tabular}

Tabelle 15. Wertklassenbildung zum AIS-Messpunkt 237 (Gromo (Lombardei), Ähnlichkeitswerte zu 250 norditalienischen Messpunkten) mittels MED, 6-fach (nach Goebl 1984: 96, MIN = Minimum, MED $=$ Median, MAX = Maximum). Die zu beiden Seiten des Medians gelegenen Wertklassen mit einer jeweils etwa gleich großen Anzahl an Messpunkten sind mit derselben Farbe unterlegt.

Auf der dialektometrischen Ähnlichkeitskarte ist die Häufigkeitsverteilung der Ähnlichkeitswerte zum jeweiligen Messpunkt in Form eines Säulendiagramms (Histogramms) dargestellt, das meist (d.h. bei einer 6-fachen Intervalleinteilung) 12 Stäbe enthält, von denen jeweils zwei (identisch eingefärbte) Stäbe eine Wertklasse repräsentieren, sodass jeder einzelne Stab die Hälfte der jeweiligen Wertklassenbreite umfasst (Goebl 1984: 97) ${ }^{283}$ Vor dem Histogramm ist die Kurve der Gaußschen Normalverteilung eingeblendet, sodass die Art der Abweichung der jeweiligen Ähnlichkeitsverteilung von dieser auf einen Blick erfasst werden kann (vgl. Abb. 12). Je nach Verteilung der Ähnlichkeitswerte können die Ähnlichkeitsprofile der Messpunkte mehr oder weniger symmetrisch ausfallen. Die Symmetrie des Ähnlichkeitsprofils eines Messpunktes wird dadurch bestimmt, wie groß der Anteil der Ähnlichkeitswerte ist, die über bzw. unter dem Mittelwert (MW) liegen: Je größer die Differenz zwischen den Anteilen über und unter dem Mittelwert ist, desto asymmetrischer ist das Ähnlichkeitsprofil. Häufig ist zu beobachten, dass asymmetrische (linkslastige) Ähnlichkeitsprofile (oberes Beispiel in Abb. 12) eher in Orten auftreten, die sich in peripheren Gebieten des untersuchten geographischen Raums befinden, während symmetrische Verteilungen (unteres Beispiel in Abb. 12) meist in zentral gelegenen Orten zu finden sind (Goebl 2001: 1482).

\footnotetext{
${ }^{281}$ Der Median bzw. Zentralwert bezeichnet in der Statistik einen (diskreten) Wert, der dadurch definiert ist, dass ,jeweils mindestens 50\% der Beobachtungen $\mathrm{x}_{1}, \ldots, \mathrm{x}_{\mathrm{n}}$ einen Wert größer oder gleich bzw. kleiner oder gleich dem Median annehmen“ (Hartung/Elpelt/Klösener 2005: 32).

${ }^{282}$ Bei kartographischen Heuristika, bei denen auf die gesamte Ähnlichkeitsmatrix (d.h. alle N/2 · (N - 1) Werte) zurückgegriffen wird (vgl. Kap. 4.3.7.4, 4.3.7.8 und 4.3.8), kann die Verwendung von MEDMW oder MED hingegen zur Optimierung des visuellen Eindrucks beitragen (Bauer 2009: 105).

${ }^{283}$ Die Höhe des Histogrammstabs ergibt sich aus dem Quotient $\left(\frac{\mathrm{p}_{\mathrm{j}}}{\mathrm{d}_{\mathrm{j}}}\right)$ aus der relativen Häufigkeit $\left(\mathrm{p}_{\mathrm{j}}\right)$ der in der durch den Histogrammstab umfassten Wertklasse (j) enthaltenen Messwerte und der numerischen Breite des betreffenden Histogrammstabs $\left(\mathrm{d}_{\mathrm{j}}\right)$, vgl. ebd.
} 

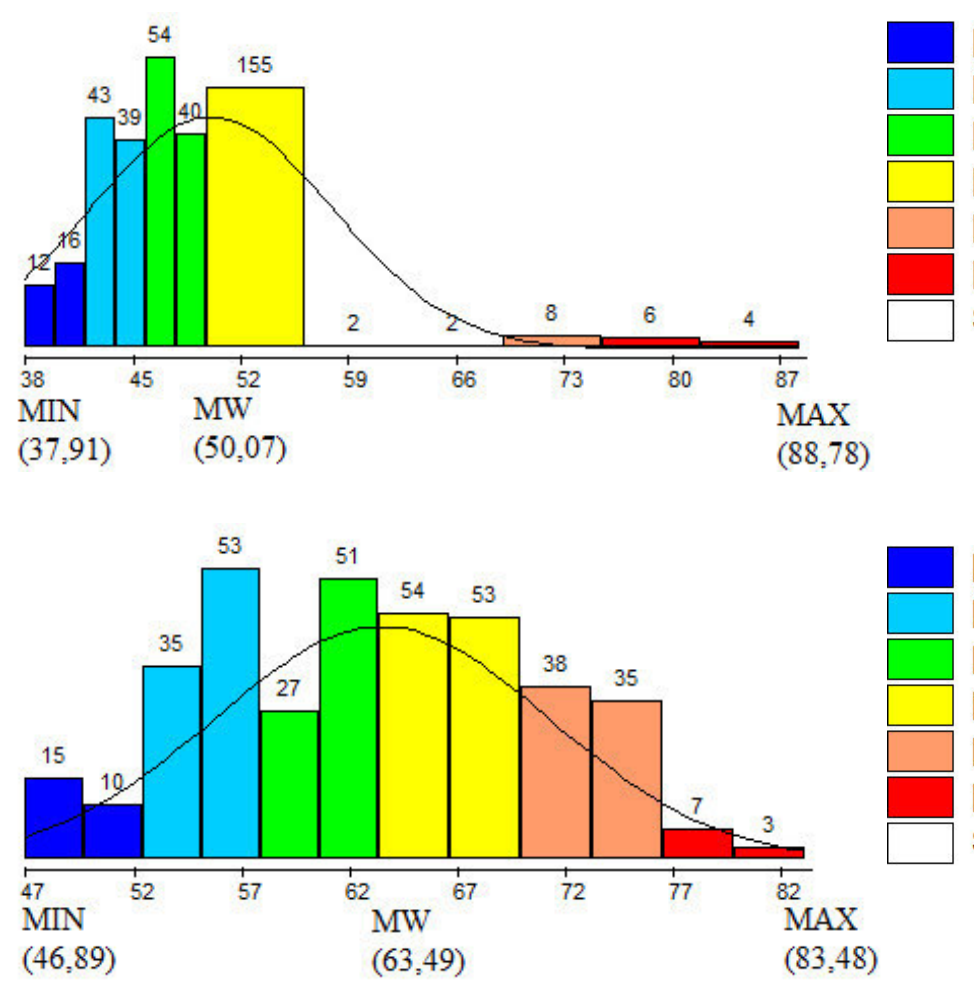

[1] von 37.91 bis $41.96(n=28)$

[2] bis $46.02(n=82)$

[3] bis $50.07(n=94)$

[4] bis $62.96(n=157)$

[5] bis $75.85(n=10)$

[6] bis $88.74(n=10)$

Summe der Elemente: 381

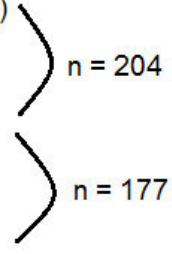

$\left\{\begin{array}{l}n=204 \\ n=177\end{array}\right.$
[1] von 46.89 bis $52.42(n=25)$

[2] bis $57.95(n=88)$

[3] bis $63.49(n=78)$

[4] bis $70.15(n=107)$

[5] bis $76.82(n=73)$

[6] bis $83.48(n=10)$

Summe der Elemente: 381

Abbildung 12. Ähnlichkeitsprofile zu verschiedenen AIS-Messpunkten (aus der VDM-Projektdatei zum AIS, Ähnlichkeitsmaß RIW R $_{j k}$ Intervallalgorithmus MINMWMAX).

Oben: Ähnlichkeitsprofil zum AIS-Messpunkt 10 (Camischolas (Tujetsch), Graubünden (Schweiz)) mit zugehöriger Intervalleinteilung.

Unten: Ähnlichkeitsprofil zum AIS Messpunkt 285 (Pescarolo, Lombardei) mit zugehöriger Intervalleinteilung.

Symbolisierung: MIN = Minimum, MW = Mittelwert, $\mathrm{MAX}=$ Maximum.

\subsubsection{Clusteranalytische Verfahren}

Neben der direkten, wertklassenbasierten Visualisierung bedient sich die Dialektometrie der multivariaten Klassifikation der in der Ähnlichkeits- bzw. Distanzmatrix enthaltenen Werte in Form clusteranalytischer Verfahren. Dabei haben sich insbesondere solche Methoden als geeignet erwiesen, die in der numerischen Taxonomie mit dem Sigel SAHN beschrieben werden (vgl. Sneath/Sokal 1973: 214). Das bedeutet, sie sind

sequenziell, d.h. die Objekte werden nacheinander in einem rekursiven Vorgang verarbeitet, agglomerativ, d.h. die Klassifikation geht von einer Menge separater Einheiten aus, die Schritt für Schritt zu immer größeren Clustern zusammengefügt werden, bis sich alle Objekte in einem einzigen Cluster befinden (vgl. ebd.: 202f., 208f.),

hierarchisch, d.h. die Klassen jeder Clusterstufe (Partition) r werden aus den Klassen der vorangehenden Partition r- 1 gebildet (vgl. Vogel 1975: 234), sodass die Anzahl der Cluster von Partition zu Partition immer mehr abnimmt ${ }^{284}$ und

\footnotetext{
${ }^{284}$ Hierarchische Clusterverfahren haben gegenüber iterativen Clusterverfahren den Vorteil, dass die Anzahl der Klassen nicht im Vorfeld festzulegen ist, jedoch den Nachteil, dass die Zuordnung von Elementen zu Clustern nicht rückgängig gemacht werden kann, wenn sich im Laufe des Klassifikationsprozesses die Eigenschaften der Cluster ändern (vgl. Vogel 1975: 349f.).
} 
nicht-überlappend, d.h. in jeder Partition schließen sich die Cluster gegenseitig aus, sodass jedes Element in einer Partition immer nur genau einem Cluster angehört (vgl. Sneath/Sokal 1973: 207f.).

Hierarchisch-agglomerative Verfahren gehen also von einer maximalen Anzahl an Clustern (d.h. so vielen Clustern wie Elementen) aus und lassen diese auf der Basis ihrer Abstände Schritt um Schritt zu größeren Clustern fusionieren. Die Klassifikation erfolgt also „,von unten nach oben“ (bottom-up). ${ }^{285}$ Als zentrale Prinzipien der Fusionierung gelten dabei, dass „die Variation innerhalb eines Clusters (Intra-Group-Distanz) immer möglichst gering gehalten werden soll“" und dass „die Unterschiede zwischen den Clustern (Inter-Group-Distanz) mit fortschreitender Agglomerierung immer größer werden“ (Bauer 2009: 149). In jedem Klassifikationsschritt werden zunächst diejenigen zwei Cluster fusioniert, die die geringste Distanz bzw. die größte Ähnlichkeit zueinander aufweisen (Pair-Group-Methoden). ${ }^{286}$ Nach jeder Fusion werden die Distanzen zwischen den neuen Clustern und den unveränderten Clustern mithilfe eines geeigneten Algorithmus bestimmt und eine aktualisierte Datenmatrix erstellt, die gegenüber der vorigen in ihrer Größe reduziert ist. Dann folgt der nächste Klassifikationsschritt. Dieser Vorgang wird so lange wiederholt, bis alle Elemente einem gemeinsamen Cluster angehören (Bock 1974: 385f.).

Zur Aktualisierung der Datenmatrix können unterschiedliche Verfahren bzw. Algorithmen verwendet werden (vgl. Sneath/Sokal 1973: 218ff.). In der Salzburger Dialektometrie kommen die Verfahren Single Linkage, Complete Linkage, Average Linkage (WPGMA, UPGMA) sowie die Methode nach Ward zum Einsatz. ${ }^{287}$

1) Bei dem Verfahren Single Linkage (Nearest Neighbour oder auch Minimum Method) ${ }^{288}$ entspricht der Abstand zwischen zwei Clustern J und K dem Abstand zwischen den am nächsten zueinander liegenden Elementen dieser Cluster (Bock 1974: 387):289

$$
d(\mathrm{~J}, \mathrm{~K})=\operatorname{Min}\left\{d_{j, k}\right\} \quad \text { wobei } \mathrm{j} \in \mathrm{J} \text { und } \mathrm{k} \in \mathrm{K}
$$

Charakteristisch für Single Linkage ist die Tendenz zur „Verkettung“ von Elementen über sog. „,intermediates“, die nah beieinander am Rand zweier Cluster liegen und diese so miteinander verbinden (Vogel 1975: 298). „Ausreißer“, d.h. Elemente, die zu allen übrigen einen großen Abstand aufweisen, treten hier erst sehr spät in ein Cluster ein und können daher mit dieser Methode leicht identifiziert werden.

2) Beim Complete Linkage (Furthest Neighbour oder auch Maximum Method) entspricht der Abstand zwischen zwei Clustern J und $\mathrm{K}$ dem Abstand zwischen den am weitesten voneinander entfernt liegenden Elementen beider Cluster (Bock 1974: 392):

$$
d(\mathrm{~J}, \mathrm{~K})=\operatorname{Max}\left\{d_{j, k}\right\} \quad \text { wobei } \mathrm{j} \in \mathrm{J} \text { und } \mathrm{k} \in \mathrm{K}
$$

\footnotetext{
${ }^{285}$ Im Gegensatz zu agglomerativen Verfahren gehen divisive Verfahren von einem Gesamtcluster aus, das alle Elemente enthält und gliedern aus diesem Schritt für Schritt einzelne Elemente aus, bis die Anzahl der Cluster der Anzahl der Elemente entspricht (top-down-Verfahren, vgl. Vogel 1975: 349f.).

${ }^{286}$ In sog. Variable Group-Methoden können hingegen auf jeder Clusterstufe mehrere Klassen miteinander fusioniert werden (vgl. Vogel 1975: 304).

${ }^{287}$ Im Hinblick auf die Auswirkungen der Clusterverfahren auf den metrischen Raum spricht man nach Lance/Williams (1967) bei Single Linkage von einem kontrahierenden und bei Complete Linkage von einem dilatierenden Verfahren. Bei Average Linkage und der Methode nach Ward handelt es sich um konservierende Verfahren (vgl. Sneath/Sokal 1973: 219).

${ }^{288} \mathrm{Vgl}$. Sneath/Sokal (1973: 218).

${ }^{289}$ Die Symbolisierung weicht hier - wie in den folgenden Algorithmen - von jener der zitierten Quellen ab.
} 
Das Verfahren hat den Vorteil, dass es die bei Single Linkage auftretende Verkettung vermeidet, da die Anforderungen für eine Fusion zweier Cluster sehr hoch sind. Es erzeugt somit kompakte Klassen, die einen relativ großen Abstand zueinander aufweisen (vgl. Bock 1974: 394, Sneath/Sokal 1973: 222).

3) Bei der Weighted Pair Group Method using Arithmetic Averages (WPGMA) entspricht der Abstand zwischen zwei Clustern dem Mittelwert der Abstände zwischen allen Elementen des Clusters. Bei der Berechnung des Abstands zwischen zwei Clustern werden hier die einzelnen Elemente in Abhängigkeit von ihrer internen Struktur unterschiedlich gewichtet (vgl. Sneath/Sokal 1973: 218):

$$
d(\mathrm{~J}, \mathrm{~K})=\sum_{j, k} w_{j} w_{k} d_{j, k} \quad \text { wobei } \mathrm{j} \in \mathrm{J} \text { und } \mathrm{k} \in \mathrm{K}
$$

sowie $w_{j}=\frac{1}{2^{C_{j}}}$ und $C_{\mathrm{j}}$ die Anzahl der von $\mathrm{j}$ bereits durchlaufenen Clusterstufen

bzw. $w_{k}=\frac{1}{2^{C_{k}}}$ und $\mathrm{C}_{\mathrm{k}}$ die Anzahl der von $k$ bereits durchlaufenen Clusterstufen

4) Die Unweighted Pair Group Method using Arithmetic Averages (UPGMA) gehört zu den in der numerischen Taxonomie am häufigsten verwendeten Verfahren. Wie bei der WPGMA kommt hier ebenfalls das arithmetische Mittel zur Berechnung des Abstands zwischen zwei Clustern zum Einsatz. Im Unterschied zur WPGMA werden hier jedoch die einzelnen Elemente bzw. Cluster unabhängig von ihrer Struktur gleichberechtigt in die Berechnung des Abstands zu einem anderen Element bzw. Cluster einbezogen (vgl. Bock 1974: 402):

$$
d(\mathrm{~J}, \mathrm{~K})=\frac{1}{n_{J} n_{K}} \times \sum_{j, k} d_{j, k} \quad \text { wobei } \mathrm{j} \in \mathrm{J} \text { und } \mathrm{k} \in \mathrm{K}
$$

sowie $n_{J}$ die Anzahl der Elemente in Cluster J und $n_{k}$ die Anzahl der Elemente in Cluster K

5) Bei der Ward-Methode (Minimale Varianz) ${ }^{290}$ handelt es sich um ein Verfahren, das grundsätzlich anders funktioniert als die bisher beschriebenen Algorithmen. Hier entspricht der Abstand zwischen zwei Clustern dem Heterogenitätszuwachs ${ }^{291}$ - Ward (1963) selbst spricht von „Informationsverlust“, der sich durch eine Fusion dieser Cluster ergibt. Bei einer Klassifikation mittels der Ward-Methode werden mithin immer diejenigen Cluster fusioniert, bei denen sich der geringste Heterogenitätszuwachs ergibt, sodass sehr homogene Klassen generiert werden. Allerdings tendiert das Verfahren dazu, ,die Klassen kompakter erscheinen zu lassen als sie sind“ (Vogel 1975: 323) und den Daten damit „eine bestimmte Struktur aufzuzwingen“ (ebd.: $325)$.

Die Darstellung des Ergebnisses einer hierarchischen Clusteranalyse erfolgt in Form eines Dendrogramms (vgl. Kap. 4.3.7.8) ${ }^{292}$ Im Allgemeinen wird angenommen, dass eine Klassifikation dann optimal ist, wenn sie so genau wie möglich die ursprünglichen Ähnlichkeitsbzw. Distanzverhältnisse zwischen den untersuchten Objekten wiedergibt (,natural concept“",

\footnotetext{
${ }^{290}$ Benannt ist diese Methode nach dem US-amerikanischen Statistiker Joe H. Ward, Jr., der sie 1963 einführte.

${ }^{291}$ Das Maß für die Heterogenität einer Klasse K ist dabei die Fehlerquadratsumme $E_{k}$, d.h. ,die Summe der $n_{k}$ quadrierten euklidischen Distanzen der Objekte einer Klasse zum Centroid dieser Klasse“ (Vogel 1975: 315). Zum Algorithmus vgl. ebd. sowie Bock (1974: 407f.).

${ }^{292}$ Sneath/Sokal (1973) verwenden synonym auch den englischen Terminus phenogram.
} 
vgl. Sneath/Sokal 1973: 278f.). Zur Ermittlung der Korrelationen zwischen einer Ähnlichkeitsmatrix S bzw. der dazu komplementären Distanzmatrix D und einem auf dieser basierenden Klassifikationsergebnis werden die Distanzen zwischen den Elementen im resultierenden Dendrogramm in kophenetische Werte ,übersetzt“ und aus diesen eine Matrix C gebildet. Über die Berechnung der Korrelation zwischen dieser Matrix und der ursprünglichen Distanzmatrix D mittels eines geeigneten kophenetischen Korrelations-Koeffizienten (meist abgekürzt als $r_{\text {coph }}$ oder $r_{\mathrm{c}}$ ) kann dann festgestellt werden, wie genau das Klassifikationsergebnis die ursprünglichen Ähnlichkeits- bzw. Distanzverhältnisse wiedergibt (vgl. ebd.).

\subsubsection{Kartographische Visualisierung und Interpretation}

\subsubsection{Generierung der Basiskarten}

Die als Grundlage für die Visualisierung der Ergebnisse der dialektometrischen Ähnlichkeitsmessung dienenden Basiskarten werden in der S-DM mit den Methoden der Triangulierung und Polygonisierung von Messpunktnetzen konstruiert. Das zugrunde liegende geometrische Konstruktionsverfahren ist in der Mathematik nach den russischen Mathematikern Georgi Feodosjewitsch Voronoi (1868-1908) und Boris Nikolajewitsch Delaunay (1890-1980) als Delaunay-Voronoi-Methode bekannt, während es in der Geographie und Kartographie nach dem USamerikanischen Meteorologen Alfred H. Thiessen (1872-1956) - der die polygonisierte Darstellung geographischer Gebiete im Jahre 1911 als Verfahren zur Gestaltung von Niederschlagskarten vorschlug - meist als Thiessen-Methode bezeichnet wird (vgl. Goebl 2001: 1478). ${ }^{293}$

Durch die Polygonisierung der Messpunktnetze soll in der Dialektometrie erreicht werden, ,dass die a priori disjunkten Raumausschnitte, die von isolierten Sprachatlaspunkten belegt werden, nicht mehr mit voneinander durch Leerräume getrennten Punktsymbolen signiert werden, sondern durch einen pseudo-kontinuierlichen bzw. kohärenten, überlappungsfreien Gesamtraum ersetzt werden können“ (Bauer 2009: 105). Durch die Schaffung „künstlicher“ sprachgeographischer Kontinua wird der visuelle Eindruck des Betrachters somit nicht durch leere Flächen ,gestört“ bzw. ,unterbrochen“ und die zur Erkennung räumlicher Ordnungsmuster so wichtige Übertragung der ikonischen Information optimiert (vgl. ebd.). ${ }^{294}$

Die Methode der Triangulierung und anschließenden Polygonisierung von Messpunktnetzen umfasst folgende Schritte (vgl. Bauer 2009: 107f.):

1) Bei der Triangulierung wird jeder Messpunkt mit den ihm direkt benachbarten übrigen Messpunkten durch Geraden verbunden, sodass ein Netz aus direkt aneinander angrenzenden Dreiecken entsteht. Diese Prozedur generiert eine Isarithmen- bzw. Zwischenpunktkarte (isarithmic

\footnotetext{
${ }^{293}$ Anwendungen des Prinzips der Polygonisierung finden sich bereits bei dem deutschen Mathematiker Johann Peter Gustav Lejeune Dirichlet (1805-1859), nach dem die resultierenden Polygone auch als Dirichlet-Regionen oder Dirichlet tesselations bezeichnet werden.

${ }^{294}$ Die Visualisierung der dialektometrischen Ergebnisse mittels polygonisierter Netze impliziert mithin die Annahme, dass die an den einzelnen Messpunkten ermittelten Werte ebenso für die jeweilige unmittelbare Umgebung, die kartographisch durch das umgebende Polygon dargestellt wird, gelten, mit anderen Worten, dass das durch das Polygon umfasste Gebiet sprachlich ausreichend homogen ist, um durch den ausgewählten Messpunkt hinreichend repräsentiert werden zu können. Eine dadurch bedingte etwaige Minderung der Validität der Messung kann jedoch durch die Wahl eines entsprechend dichten Ortsnetzes (d.h. eines geringen durchschnittlichen geographischen Abstands zwischen den einzelnen Messpunkten) und die dadurch zu erreichende Verkleinerung der Polygonflächen auf ein Minimum reduziert werden.
} 
bzw. interpoint map $)^{295}$ die in der S-DM als Basis für das Heuristikum der Strahlenkarte ${ }^{296}$ fungiert (s. Abb. 13 und Abb. 14, linke Seite).

2) Zur Polygonisierung des Messpunktnetzes werden auf den Dreiecksseiten die Streckensymmetralen (Mittellote) konstruiert, deren Schnittpunkt den Umkreismittelpunkt des jeweiligen Dreiecks darstellt und fallweise auch außerhalb dessen liegen kann (s. Abb. 13).

3) Die Umkreismittelpunkte der verschiedenen Dreiecke werden nun über die Streckensymmetralen miteinander verbunden, sodass ein Netz aus sich nicht überlappenden Polygonflächen entsteht, in dem die Umkreismittelpunkte der Dreiecke die Ecken und die jeweiligen Teile der Streckensymmetralen die Seiten der Polygone darstellen (s. Abb. 13 und Abb. 14, rechte Seite). Das Polygonnetz wird in der S-DM zur Generierung einer weiteren Form der Isarithmenkarte, der Schottenkarte ${ }^{297}$, verwendet und dient zudem der Erstellung von Choroplethenkarten (auch Flächenmosaikkarten, vgl. Goebl 2007: 204), die in der S-DM bei der Gestaltung der Ähnlichkeits-, Parameter- , Korrelations- und Clusterkarte ${ }^{298}$ zum Einsatz kommen.

Die noch keine Daten visualisierende, also ,leere‘ Polygonkarte des Messpunktnetzes wird in der Dialektometrie als stumme Karte bezeichnet. Sie enthält zusätzlich zu dem Polygonnetz die in den Polygonflächen notierten Ortsnummern der Messpunkte sowie verschiedene Kartenelemente, wie etwa den Kartentitel (meist Sigel und Erscheinungsjahr der Datenquelle), Angaben zum Urheber der Karte, geographische Informationen, Angaben zu Kunstpunkten sowie Zeichenerklärungen (s. Karte 26). ${ }^{299}$

\footnotetext{
${ }^{295}$ Der zugrunde liegende französische Terminus interpoint geht auf T. Lalanne zurück (vgl. Kap. 4.2).

296 Vgl. Kap. 4.3.7.7.

${ }^{297}$ Vgl. Kap. 4.3.7.6.

${ }^{298}$ Vgl. Kap. 4.3.7.2 bis 4.3.7.5 sowie Kap. 4.3.7.8 und 4.3.8.

${ }^{299}$ Alle im Folgenden verwendeten dialektometrischen Karten bzw. Abbildungen zum AIS stammen aus der VDM-Projektdatei, die im Zuge der Dialektometrisierung der AIS-Daten generiert wurde und für deren Bereitstellung ich Prof. Hans Goebl und seinen Mitarbeitern herzlich danke.
} 


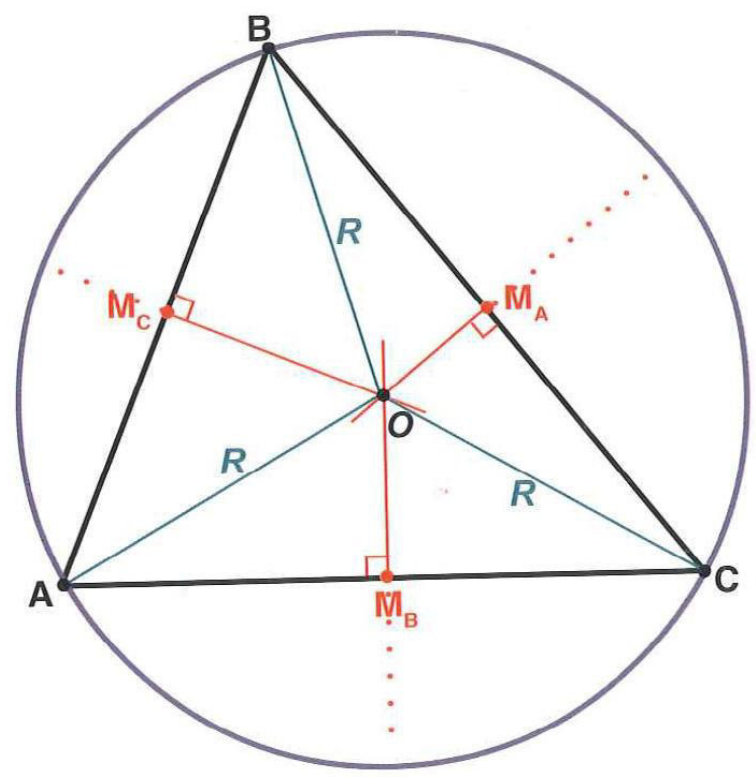

A, B, C: Eckpunkte des Dreiecks (= Messpunkte)

$\mathrm{M}_{\mathrm{A}}, \mathrm{M}_{\mathrm{B}}, \mathrm{M}_{\mathrm{C}}$ : Mittelpunkte der Dreiecksseiten

O: Umkreismittelpunkt (= Ecke der Polygonseiten)

R: Radius des Umkreises

schwarz: Dreiecksseiten

rot: Streckensymmetralen (= Polygonseiten)

türkis: Radien

blau: Umkreis

Abbildung 13. Triangulierung und Konstruktion des Umkreismittelpunktes (Bauer 2009: 108).
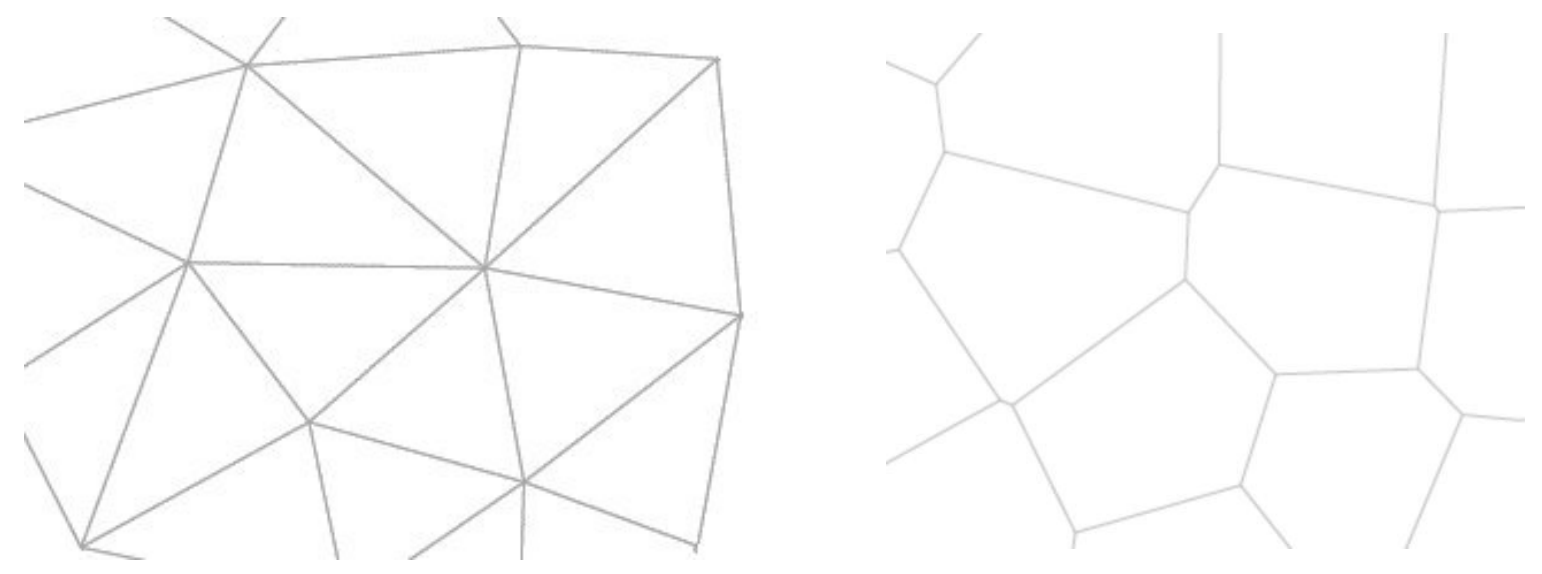

Abbildung 14. Links: Delaunay-Triangulation einer Menge von Messpunkten. Rechts: Voronoi-Diagramm (Polygonnetz) mit derselben Menge von Messpunkten. 


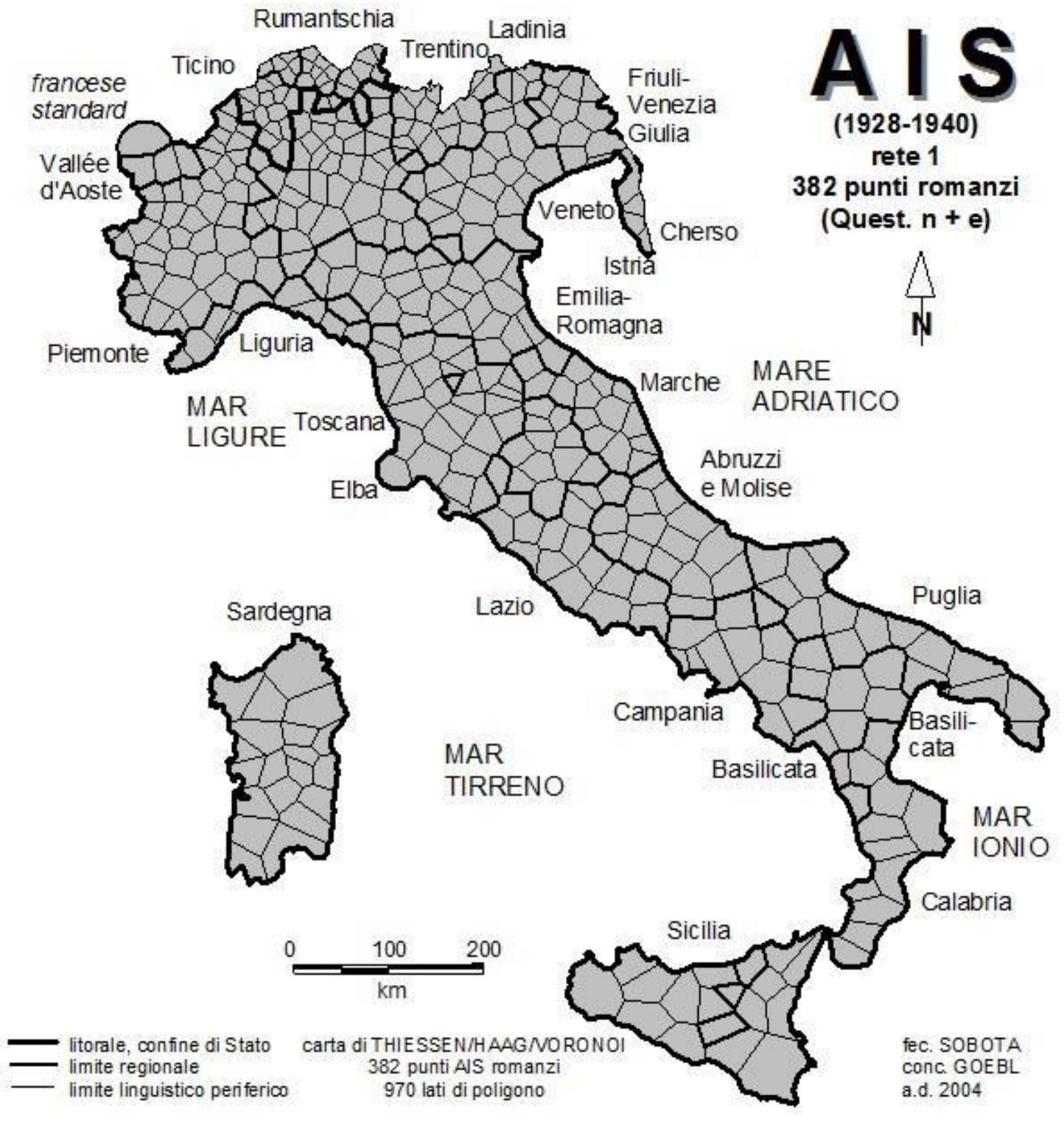

Karte 26. Stumme Polygonkarte zum AIS. 


\subsubsection{Die Ähnlichkeitskarte}

Die kartographischen Heuristika der Salzburger Dialektometrie visualisieren jeweils verschiedene Aspekte der dialektometrischen Messergebnisse und bedienen sich dazu der zugrunde liegenden Ähnlichkeits- bzw. Distanzmatrix in unterschiedlicher Weise. ${ }^{300} \ddot{A}$ hnlichkeitskarten beruhen jeweils auf einem der N Messpunktvektoren der Ähnlichkeitsmatrix, sodass einer Ähnlichkeitsmatrix N Ähnlichkeitskarten entnommen werden können (vgl. Goebl 2007: 207). ${ }^{301}$ Ähnlichkeitskarten visualisieren - auf der Basis der Choroplethenkarte - jeweils das sprachliche Ähnlichkeitsprofil eines der N Messpunkte, der jeweils als Referenzpunkt bzw. als Prüfbezugspunkt (PBP) bezeichnet wird. Die um die N - 1 übrigen Messpunkte konstruierten Polygone sind entsprechend des zum jeweiligen Prüfbezugspunkt vorliegenden Ähnlichkeitswertes eingefärbt, während der PBP durch ein weißes Polygon symbolisiert wird (s. Karte 27). Die Einfärbung der N - 1 Polygone richtet sich dabei nach den Intervallen, denen die jeweiligen Ähnlichkeitswerte angehören und denen die Farben des Sonnenspektrums zugeordnet werden. Ähnlichkeitswerte, die in Intervalle unterhalb des Mittelwertes bzw. des Medians fallen, werden in kalten Farben, Ähnlichkeitswerte in Intervallen oberhalb des Mittelwertes bzw. des Medians in warmen Farben visualisiert: Bei einer 6-fachen Intervallisierung mit MINMWMAX werden etwa den drei Klassen unterhalb des Mittelwertes standardmäßig die Farben dunkelblau, hellblau und grün und den drei Klassen oberhalb des Mittelwertes die Farben gelb, orange und rot zugeordnet. Je wärmer ein Polygon also eingefärbt ist, desto größer ist die sprachliche Ähnlichkeit des jeweiligen Messpunktes zum Referenzpunkt. ${ }^{302}$ Der Messpunkt, der die höchste Ähnlichkeit zum Referenzpunkt aufweist, wird durch weiße Schraffur des jeweiligen Polygons gekennzeichnet (s. Karte 27).

Ähnlichkeitskarten bestehen - wie Distanzkarten und Parameterkarten - jeweils aus drei Teilen (vgl. Goebl 2010a: 442):

1) der entsprechend kolorierten Choroplethenkarte selbst,

2) einer Intervallskala (vgl. Kap. 4.3.5), die den verwendeten Intervallalgorithmus, die jeweilige numerische Spannweite der Intervalle sowie dahinter in Klammern die Anzahl $n$ der in das jeweilige Intervall fallenden Messpunkte (und darunter deren Gesamtsumme) enthält (unten links) und

3) einem Histogramm (vgl. Kap. 4.3.5), in dem die Häufigkeitsverteilung der metrischen Werte in graphischer Form dargestellt ist (unten rechts).

Die Kartenunterschrift enthält alle wichtigen Basis-Informationen, die der Betrachter zum Verständnis der Karte benötigt, d.h. Angaben zum Kartentypus, zur Datenquelle, zur zugrunde liegenden Datenmatrix (Anzahl der einbezogenen Arbeitskarten und Messpunkte, ggfs. sprachlicher Teilbereich), zum Messmoment (Ähnlichkeits- bzw. Distanzmaß), ggfs. zur Clustermethode und zum Korrelationskoeffizienten sowie bei Ähnlichkeitskarten den Namen und die Nummer des Prüfbezugspunktes.

Der visuelle Eindruck einer Ähnlichkeits-, Distanz-, Parameter- oder Korrelationskarte beruht nicht auf der absoluten Höhe der N - 1 Ähnlichkeitswerte zu einem PBP, sondern auf relativen Höhe, d.h. ihrer Stellung im Verhältnis zueinander. In dieser kartographischen Praxis

\footnotetext{
${ }^{300}$ In den folgenden Kapiteln werden lediglich einige der gängigsten dialektometrischen Heuristika präsentiert Zur Gesamtheit der in VDM verfügbaren Heuristika vgl. Bauer (2009). Zur exhaustiven Beschreibung der für eine Ähnlichkeitsmatrix messbaren Parameter vgl. Goebl (1984).

${ }^{301}$ Dem komplementären Heuristikum der Distanzkarte liegt entsprechend jeweils ein Messpunktvektor der Distanzmatrix zugrunde.

${ }^{302}$ Für Distanzkarten gilt entsprechend: Je wärmer ein Polygon eingefärbt ist, desto größer ist die sprachliche Distanz (d.h. desto geringer die sprachliche Ähnlichkeit) des jeweiligen Messpunktes zum PBP.
} 
spiegelt sich der epistemologische Vorrang, den das Erkennen globaler sprachlicher Raumstrukturen in der S-DM vor der Betrachtung der einzelnen metrischen Ähnlichkeitswerte hat. ${ }^{303}$

Ähnlichkeitskarten liefern Einblicke in die Stellung bzw. Positionierung des jeweiligen Ortsdialekts innerhalb des durch das Messpunktnetz abgedeckten Dialektgebietes. In der Regel nimmt dabei mit wachsender räumlicher Entfernung die sprachliche Ähnlichkeit der Messpunkte zum Prüfbezugspunkt ab, was ,,auf die Existenz räumlich verankerter, aber sprachlich relevanter Gesetzmäßigkeiten hin[weist]“" (Goebl 2007: 206). ${ }^{304}$ Bei Ähnlichkeitsprofilen, die eine unregelmäßige Struktur aufweisen, ist anzunehmen, dass die reguläre sprachliche Bewirtschaftung des Raumes durch externe Faktoren in irgendeiner Weise gestört bzw. unterbrochen worden ist.

\subsubsection{Die Kennwertsynopse der Maxima}

Neben den jeweils die Ähnlichkeitswerte eines Messpunktvektors visualisierenden Ähnlichkeitskarten werden in der S-DM Kartentypen verwendet, mit denen bestimmte Parameter der Gesamtheit der in der Ähnlichkeitsmatrix enthaltenen metrischen Werte visualisiert werden können (Parameterkarten). Einer dieser Parameter sind die maximalen Ähnlichkeitswerte (Maximalwerte bzw. Maxima) der N Messpunktvektoren, die intervallisiert und auf der Basis der Choroplethenkarte synoptisch visualisiert werden, sodass jede Karte N Maximalwerte abbildet. Die die Messpunkte umgebenden Polygone sind - wie im Falle der Ähnlichkeitskarte - entsprechend der Höhe ihres Maximalwertes bzw. entsprechend des Intervalls, in das dieser fällt, eingefärbt: Bei einer 6-fachen Intervallisierung weisen also dunkel- und hellblau eingefärbte Polygone einen sehr niedrigen bzw. niedrigen, orange und rot eingefärbte Polygone hingegen einen hohen bzw. sehr hohen Maximalwert auf; in grün und gelb gehalten sind die Messpunkte mit mittleren Maximalwerten, die bei Verwendung des Intervallalgorithmus MINMWMAX die Mehrheit bilden. Die Messpunkte, die den höchsten bzw. niedrigsten Maximalwert aufweisen, werden durch Schraffur der jeweiligen Polygone gekennzeichnet (s. Karte 28).

Die Höhe des Maximalwertes, den ein Messpunkt aufweist, gibt Auskunft über dessen sprachliche Integration in sein geographisches Umfeld. Messpunkte mit hohen Maxima weisen enge sprachliche Verbindungen zu den umliegenden Messpunkten auf und formen damit kompakte Dialektgebiete, die auch als Dialektkerne bezeichnet werden (Goebl 2010a: 447). Dialekte mit niedrigen Maximalwerten sind mit ihrem sprachlichen Umfeld hingegen nur lose verbunden und bisweilen von diesem sogar weitgehend isoliert. ${ }^{305}$ Bei Gebieten mit durchweg niedrigen Maxima handelt es sich dementsprechend um wenig kompakte Dialektgebiete (vgl. Bauer 2009: 131), in denen die Dialekte in ihrer Entwicklung eher eigene Wege gehen. ${ }^{306}$

\footnotetext{
${ }^{303}$ In VDM kann jedoch bei Bedarf durch Bewegen des Mauszeigers auf das jeweilige Polygon der exakte Ähnlichkeitswert zum PBP abgerufen werden. Dies gilt auch für die auf den Parameter- und Korrelationskarten visualisierten Werte (s.u.).

${ }^{304}$ Vgl. Kap. 4.3.3 (,Goeblsches Gesetz“).

${ }^{305}$ Bei Ortsdialekten, die einer anderen Sprachfamilie als die umgebenden Dialekte zuzuordnen sind, handelt es sich um Sprachinseln. Dies ist etwa der Fall bei den Dialekten der in Süditalien liegenden AIS-Punkte 715 (Faeto, frankoprovenzalisch) und 760 (Guardia Piemontese, provenzalisch), die durch ihre Zugehörigkeit zur galloromanischen Sprachfamilie von ihrem italienischsprachigen Umfeld isoliert sind und dementsprechend niedrige Maxima aufweisen (s. Karte 28 und vgl. Goebl 2007: 208, 239).

${ }^{306}$ Analog zu den Maximalwerten können auch die Minimalwerte der N verschiedenen Messpunktvektoren auf der Basis einer Choroplethenkarte synoptisch visualisiert werden. Diese Kennwerte sind jedoch weitaus schwieriger zu interpretieren als die Maximalwerte und werden somit nur selten in die dialektometrische Analyse einbezogen. $\mathrm{Zu}$ einer möglichen Interpretation der Kennwertsynopse der Minima vgl. Bauer (2009: 133f.).
} 


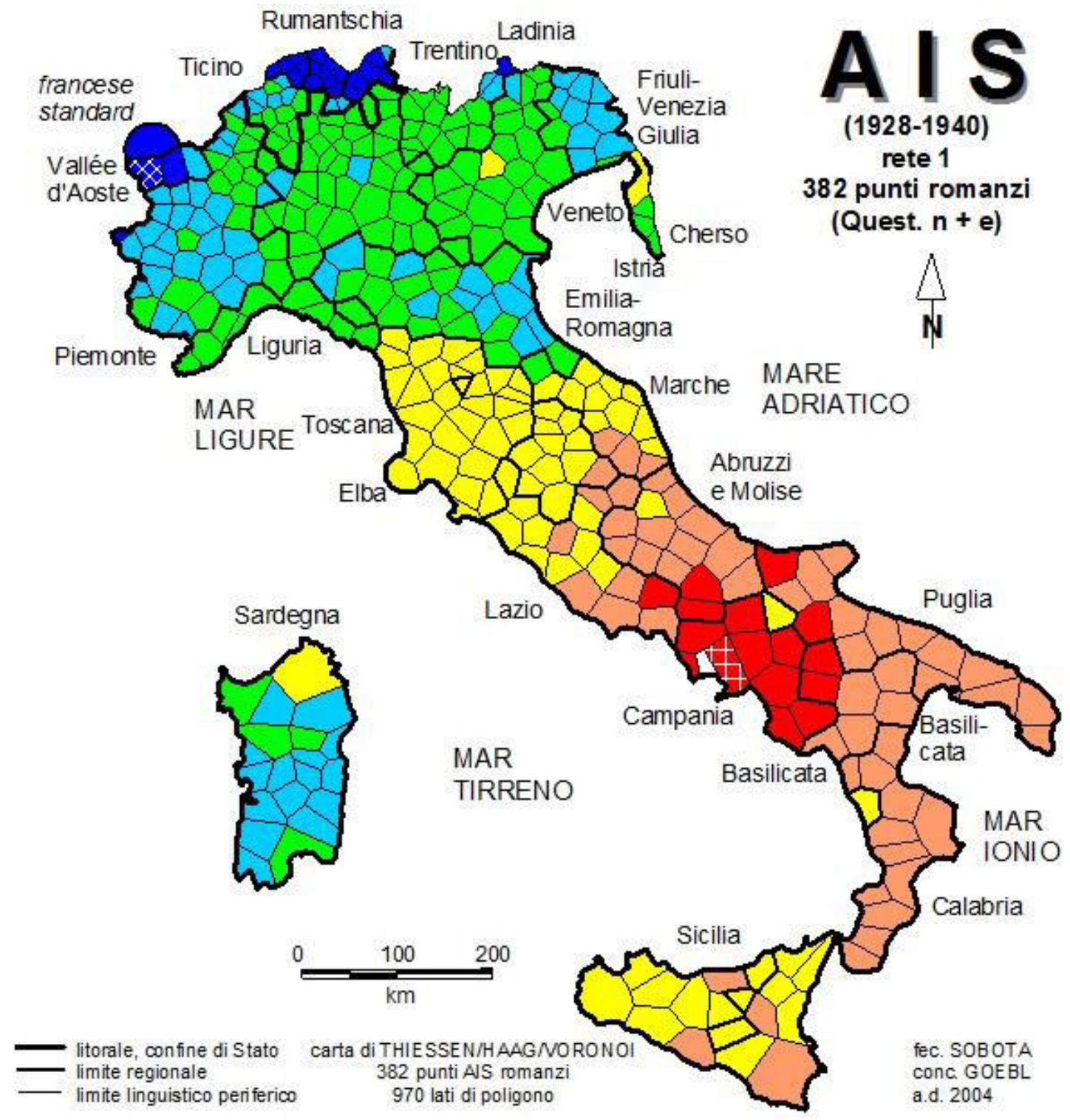

Legende, MINMWMAX, 6-fach

Häufigkeitsverteilung, MINMWMAX, 12-fach

[1] von 40.58 bis $46.58(n=23)$

[2] bis $52.58(n=74)$

[3] bis $58.58(n=134)$

[4] bis $67.10(n=78)$

[5] bis $75.62(n=56)$

[6] bis $84.14(n=16)$

Summe der Elemente: 381

$\mathrm{MIN}=40.58$ (P. 121)

$\mathrm{MW}=58.58$

MED $=55.82$

$\operatorname{MAX}=84.14(P .722)$

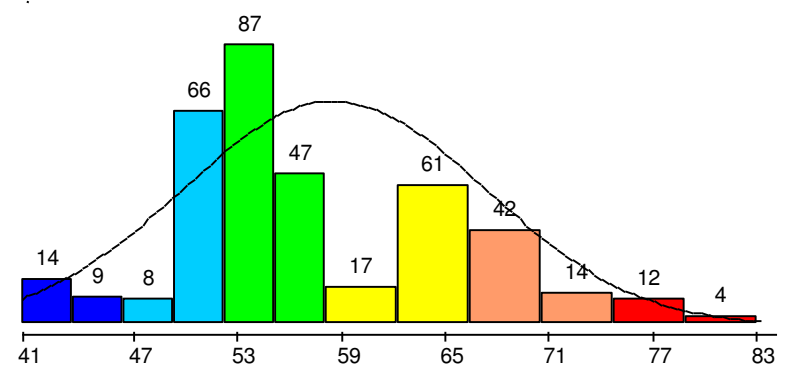

Karte 27. Ähnlichkeitskarte zum AIS-Messpunkt 721 (Neapel, weiß). Totalkorpus (3.911 AK), Ähnlichkeitsmaß RIW $_{j k}$. 


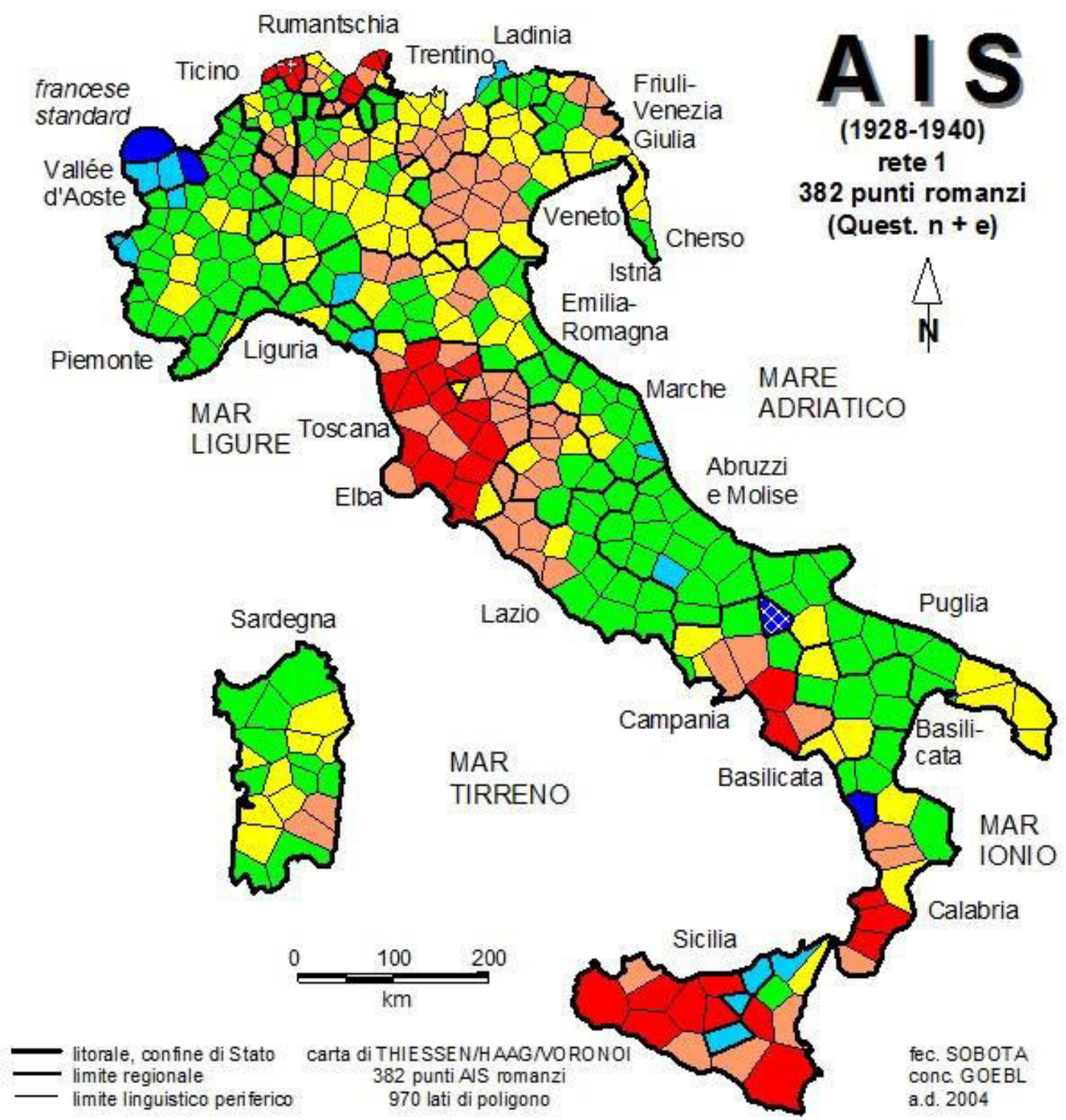

Legende, MINMWMAX, 6-fach

Häufigkeitsverteilung, MINMWMAX, 12-fach

[1] von 63.33 bis $69.70(n=4)$

[2] bis $76.08(n=15)$

[3] bis $82.45(n=160)$

[4] bis $84.90(n=94)$

[5] bis $87.36(n=72)$

[6] bis $89.81(n=37)$

Summe der Elemente: 382

MIN $=63.33$ (P. 715)

$\mathrm{MW}=82.45$

$\mathrm{MED}=82.71$

MAX $=89.81$ (P. 1; 11)

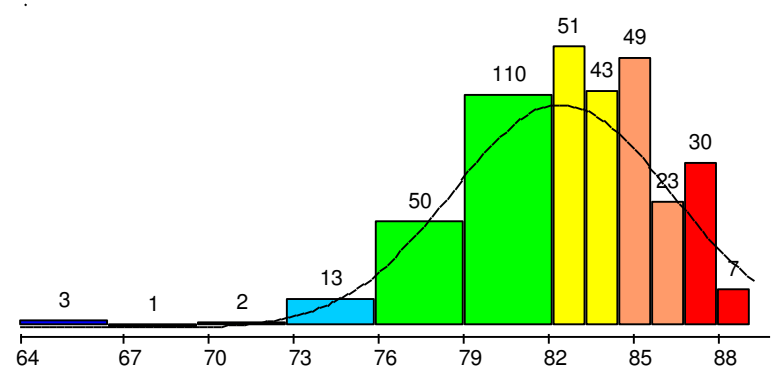

Karte 28. Synopse der Maximalwerte zum AIS. Totalkorpus (3.911 AK), Messmoment RIW R $_{j k}$ 


\subsubsection{Die Kennwertsynopse der Schiefen}

Ein weiterer Parameter der N Ähnlichkeitsverteilungen, der mithilfe eines kartographischen Heuristikums in der S-DM visualisiert werden kann, ist die Schiefe (engl. skewness). Dabei handelt es sich um einen statistischen Kennwert, anhand dessen sich die Symmetrie (bzw. Asymmetrie) einer Häufigkeitsverteilung genau bestimmen lässt (vgl. Goebl 2007: 215). ${ }^{307}$ Ist diese exakt symmetrisch, d.h. befindet sich genau die Hälfte der Messwerte oberhalb und unterhalb des Mittelwertes, nimmt die Schiefe den Wert 0 an. Eine asymmetrische Verteilung, in der der größere Teil der Werte zwischen dem Maximal- und dem Mittelwert liegt, generiert negative Schiefewerte, während sich im umgekehrten Fall, d.h. wenn der größere Teil der Werte zwischen dem Minimal- und dem Mittelwert liegt, positive Werte ergeben (vgl. ebd.). ${ }^{308} \mathrm{Im}$ Gegensatz zu der Ähnlichkeitskarte und den Parameterkarten der Maxima, der Minima und der Antipoden (sowie zu den im Folgenden noch zu besprechenden Zwischenpunktkarten) berücksichtigt die Kennwertsynopse der Schiefen die zugrunde liegende Ähnlichkeitsmatrix also in ihrer Gesamtheit. ${ }^{309}$ Zur kartographischen Darstellung werden den aus der (hier 6-fachen) Intervallisierung der N Schiefewerte resultierenden Wertklassen die bekannte Farbskala von dunkelblau (niedrigste Schiefewerte) bis rot (höchste Schiefewerte) zugeordnet und die N Polygone entsprechend koloriert (s. Karte 29).

Die kartographische Visualisierung der Kennwertsynopse der Schiefen wird in der SDM vor allem im Hinblick auf den Grad der Beteiligung verschiedener geographischer Zonen am allfälligen Sprachausgleich, d.h. der „Durchmischung von Sprachmerkmalen“" (Goebl 2007: 216, Goebl 2010a: 446) ${ }^{310}$ interpretiert. Kalt eingefärbte Polygone, die verhältnismäßig niedrige Schiefewerte und damit überdurchschnittlich hohe Ähnlichkeitswerte zu vielen Messpunkten aufweisen, stehen dabei für dialektale Übergangsgebiete, d.h. Gebiete, in denen ein starker Austausch sprachlicher Merkmale stattgefunden hat bzw. in denen grundsätzlich eine ,große Bereitschaft zum Sprachausgleich" besteht (Bauer 2009: 283). Bei den in warmen Farben gehaltenen Zonen, die verhältnismäßig hohe Schiefewerte und damit unterdurchschnittlich niedrige Ähnlichkeitswerte zu vielen Messpunkten aufweisen, handelt es sich hingegen um Gebiete, die nur eine geringe Tendenz zum Sprachausgleich zeigen bzw. sich verhältnismäßig gut gegen sprachliche Dynamiken auf diatopischer Ebene ,,abschirmen“ können (Bauer 2009: 139). Diese Gebiete befinden sich häufig in der Peripherie des Messpunktnetzes und weisen nur schwache sprachliche Verbindungen zu den übrigen Teilen des Netzes auf.

\subsubsection{Die Antipodenkarten}

Ein mit der Kennwertsynopse der Maxima und jener der Minima verbundenes dialektometrisches Heuristikum sind die sog. Antipodenkarten. Während die Kennwertsynopse der Maxima (bzw. Minima) den jeweils höchsten (bzw. niedrigsten) Ähnlichkeitswert berücksichtigt, den

\footnotetext{
${ }^{307}$ Eine groben Eindruck der Symmetrie bzw. Asymmetrie eines Ähnlichkeitsprofils liefert bereits das dazugehörige Histogramm, vgl. Kap. 4.3.5.

${ }^{308}$ Die Berechnung der Schiefewerte fußt auf dem durch den britischen Statistiker Sir Ronald A. Fisher (18901962) eingeführten Ähnlichkeitskoeffizienten, der im Französischen als Coefficient d'Asymétrie de Fisher (CAF) bezeichnet wird (Bauer 2009: 137). Zur mathematischen Formel vgl. Goebl (1984: 150).

${ }^{309}$ Bauer (2009: VII) spricht hier von ,integraler“ (und bei den vorgenannten Heuristika von ,partieller“) Nutzung der Ähnlichkeits- bzw. Distanzmatrizen.

${ }^{310} \mathrm{Im}$ Folgenden wird (wie auch bereits in Kap. 2 und 3) der Terminus ,Merkmal‘ in seiner geläufigen Bedeutung, d.h. zur Bezeichnung sprachlicher Varianten bzw. Typen (denen in der Terminologie der S-DM die Merkmalsausprägungen bzw. Taxate entsprechen, vgl. Kap. 4.3.3) verwendet.
} 
jeder Messpunkt zuweist, werden auf der Antipodenkarte ausschließlich diejenigen Messpunkte dargestellt, die von mindestens einem der übrigen Messpunkte mit dem maximalen (Antipodenkarte der Maxima) bzw. minimalen Ähnlichkeitswert (Antipodenkarte der Minima) belegt werden (Bauer 2009: 124).

Bei der Antipodenkarte handelt es sich um eine Form der Choroplethenkarte, auf der die als Empfänger von Maximal- bzw. Minimalwerten in Frage kommenden Messpunkte bzw. die sie umfassenden Polygone entsprechend der Anzahl der Messpunkte koloriert sind, die ihnen jeweils Maxima bzw. Minima zuweisen (s. Karte 30 und Karte 31). Die in der Legende zur Karte angegebenen Intervalle konstituieren sich also aus der jeweiligen Anzahl der Messpunkte, die den Messpunkten der entsprechenden Wertklasse Maximal- bzw. Minimalwerte $z u-$ weisen. Daneben wird - wie im Falle der bisher genannten Heuristika auch - in Klammern die Anzahl $n$ der Messpunkte angegeben, die in die entsprechende Wertklasse fallen, hier also die jeweilige Anzahl an Maxima bzw. Minima erhalten. Die als Empfänger von Maxima bzw. Minima in Frage kommenden Messpunkte bzw. Polygone sind im Allgemeinen in umso kälteren Farben koloriert, je weniger Maximal- bzw. Minimalwerte sie erhalten. ${ }^{311}$ Durch Anwählen der als Empfänger in Frage kommenden Messpunkte (vgl. weiß schraffierte Polygone auf den Karten 30 und 31) können in VDM diejenigen Messpunkte identifiziert werden, welche dem angewählten Messpunkt ihren Maximal- bzw. Minimalwert zuweisen (vgl. schwarz schraffierte Polygone auf den Karten 30 und 31).

In der geolinguistischen Interpretation der Antipodenkarten hat sich in der S-DM seit Goebl (1994) eine sozialpsychologische Metaphorik etabliert, in der das Netz aus N Messpunkten bzw. Ortsdialekten als ein Netz aus N sozial interagierenden Individuen begriffen wird (vgl. Goebl 1997c: 183). ${ }^{312}$ So wird bei demjenigen Messpunkt bzw. Dialekt, der von einem anderen mit dessen Maximalwert belegt wird, vom „besten Freund“ bzw. „bevorzugten Kommunikationspartner" des zuweisenden Messpunktes und bei demjenigen Messpunkt, der von einem anderen dessen Minimalwert erhält, vom ,schlimmsten Feind“ bzw. „Hauptgegner“ des zuweisenden Messpunktes gesprochen. Die Dialekte, die - in Form von Minimalwerten - mehrere „Antipathien“ auf sich ziehen, stellen für die Gruppe der Dialekte, die diese Minima zuweisen, die „Außenseiter“, „Prügelknaben“ oder „Sündenböcke“ dar, mit denen jegliche ,friedliche“ Kommunikation möglichst gemieden wird. ${ }^{313}$

Hinsichtlich der geographischen Verteilung und der Anzahl der Messpunkte, die als „,beste Freunde“ oder aber als „Sündenböcke“ infrage kommen, lassen sich bestimmte Regularitäten erkennen. Während ein Großteil der Messpunkte zumindest für einen, meist benachbarten Dialekt als „,bester Freund“ fungiert, ist die Anzahl der Messpunkte, die innerhalb eines dialektalen Netzes als „Sündenböcke“ in Frage kommen, deutlich geringer. Die „Aversionen“ des Großteils der Netzmitglieder konzentrieren sich in einer Art „kollektiven Konsenses“ im Allgemeinen auf wenige, häufig in der Peripherie des dialektalen Netzes befindliche Dialekte (Goebl 1994: 74).

\footnotetext{
${ }^{311}$ Messpunkte, die nicht als Empfänger von Maximal- bzw. Minimalwerten in Frage kommen, sind auf der Antipodenkarte grau unterlegt.

${ }^{312}$ Angedeutet und in ihrer interdisziplinären Relevanz hervorgehoben wird diese Analogie allerdings bereits in Goebl (1984: 143-148 und 164-166).

${ }^{313} \mathrm{Zu}$ den zitierten metaphorischen Begriffen vgl. Goebl (1994), Goebl (1997b, c), Bauer (2004, 2009). Die sozialpsychologische Metaphorik ist hier auch Teil der Aufsatztitel, vgl. „,Spannungsverhältnisse in dialektalen Netzen [...]“"(Goebl 1994), ,,Es kracht im Gebälk des CLAE... [...]“(Goebl 1997b), ,Wenn Dialekte miteinander streiten...“(Goebl 1997c), „Dialekte, Dialektmerkmale, dialektale Spannungen - Von ,Cliquen“, ,Störenfrieden“ und ,Sündenböcken' [...]“" (Bauer 2004).
} 
Weisen sich zwei Dialekte gegenseitig ihre Minimalwerte zu, so können sie als „Streithähne“ begriffen werden, die „Spannungen“ im dialektalen Netz erzeugen und innerhalb der Gemeinschaft oft polarisieren. Gruppen von Dialekten, die sich hingegen - in Form von Maximalwerten - gegenseitig „Sympathien“ zuweisen, formen dialektale „Cliquen“, die in ihrer Kommunikation jeweils vorwiegend unter sich bleiben.

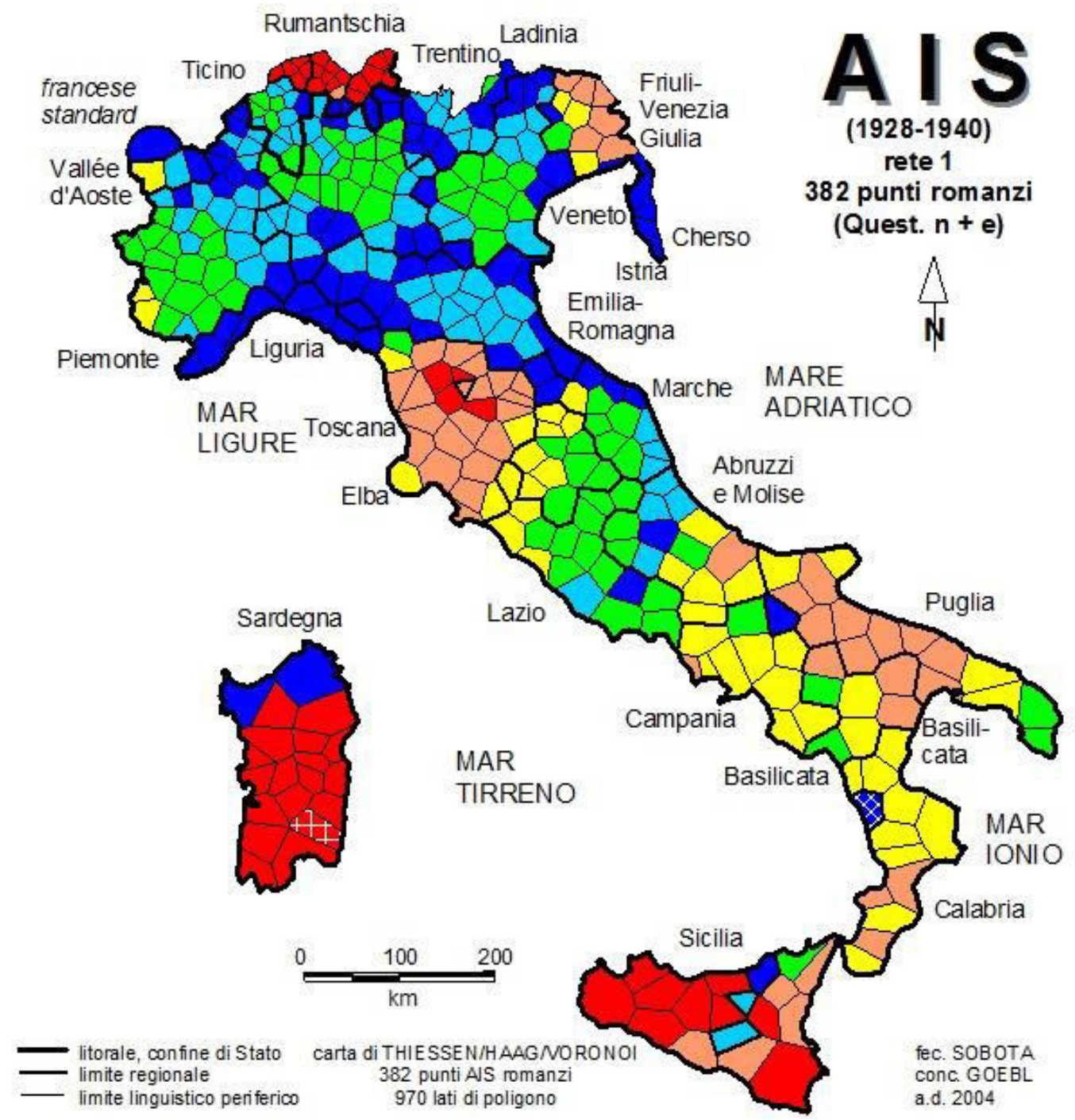

Legende, MEDMW, 6-fach

Häufigkeitsverteilung, MEDMW,12-fach

[1] von -1.72 bis $-0.01(n=79)$

[2] bis $0.13(n=78)$

[3] bis $0.40(n=78)$

[4] bis $0.58(n=49)$

[5] bis $0.92(n=49)$

[6] bis $2.43(n=49)$

Summe der Elemente: 382

$\mathrm{MIN}=-1.72(P .760)$

$\mathrm{MW}=0.40$

MED $=0.2$

$\operatorname{MAX}=2.43(P .967)$

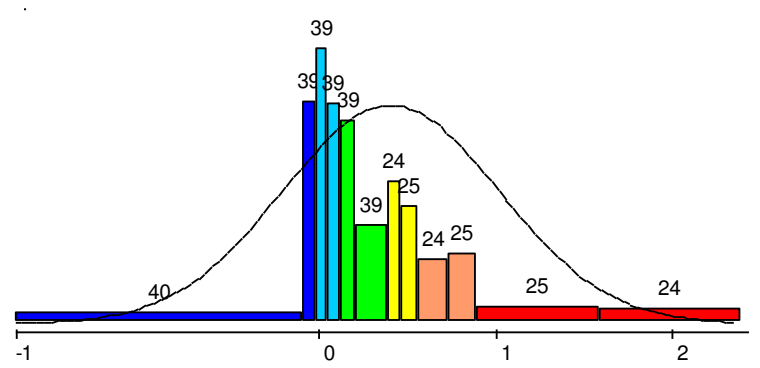

Karte 29. Synopse der Schiefewerte zum AIS. Totalkorpus (3.911 AK), Messmoment RIW ${ }_{j k}$. 


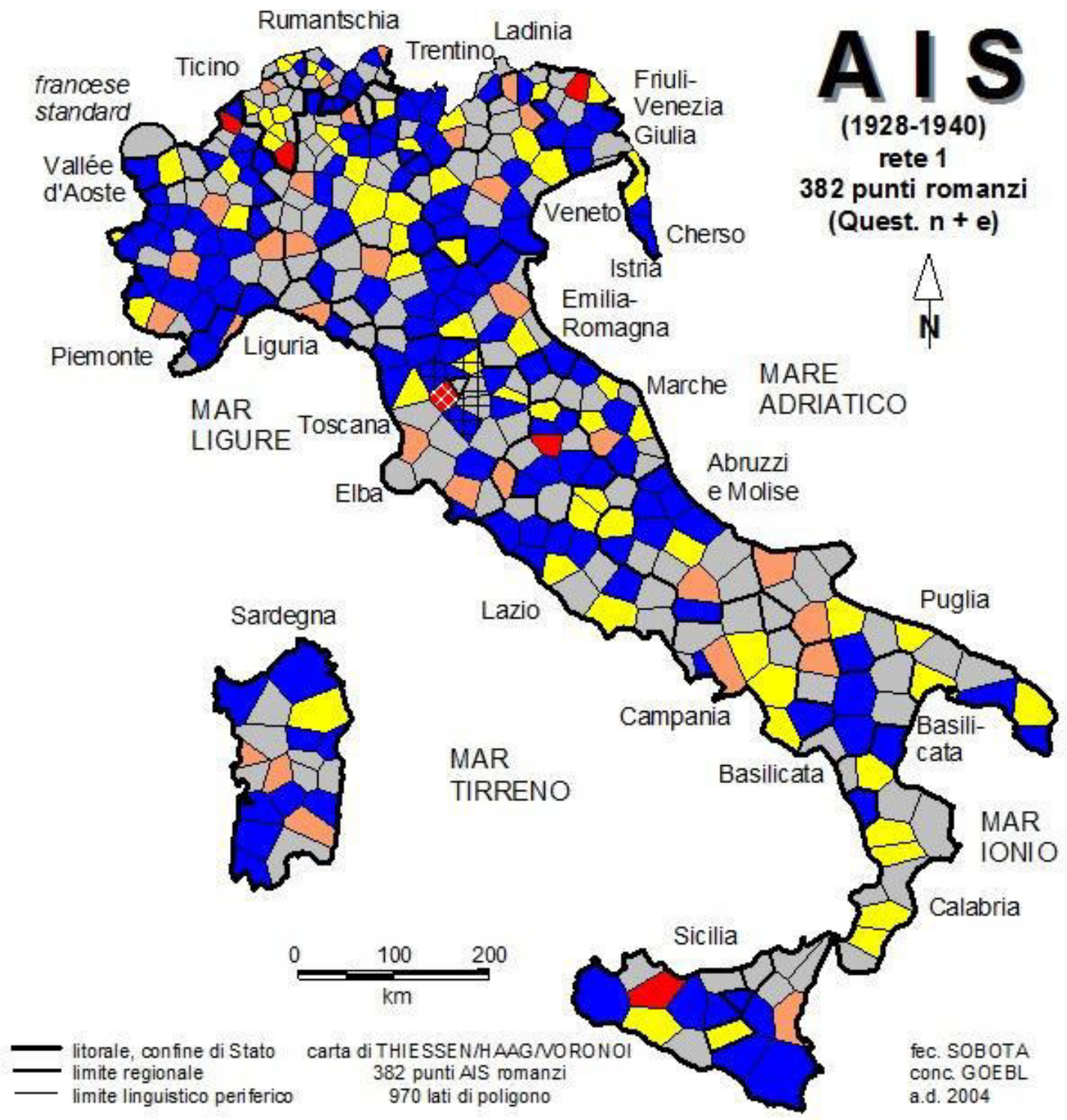

Legende, MINMWMAX, 6-fach

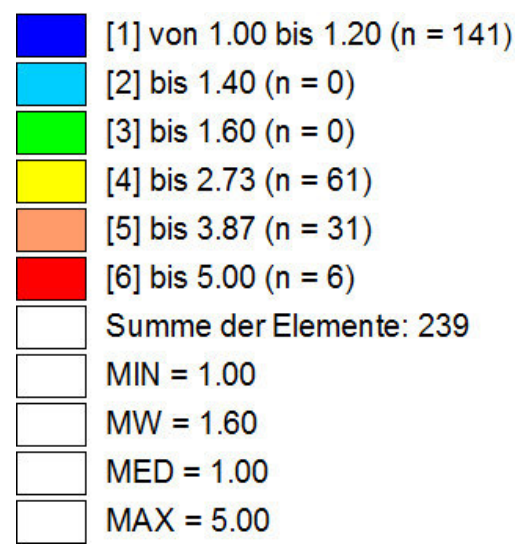

Häufigkeitsverteilung, MINMWMAX, 12-fach

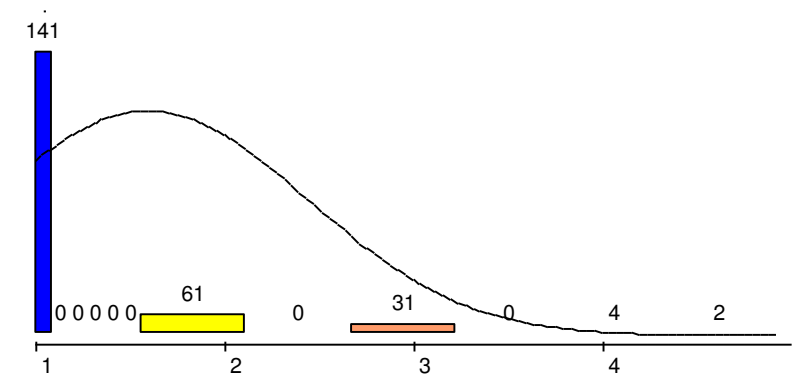

Karte 30. Antipodenkarte der Maxima zum AIS (Totalkorpus (3.911 AK), Messmoment RIW RW $_{j k}$. Weiße Schraffur: AIS-Messpunkt 532 (Montespertoli, Toscana), schwarze Schraffur: AIS-Messpunkte $(\mathrm{n}=5)$, von denen dieser Punkt Maximalwerte erhält. 


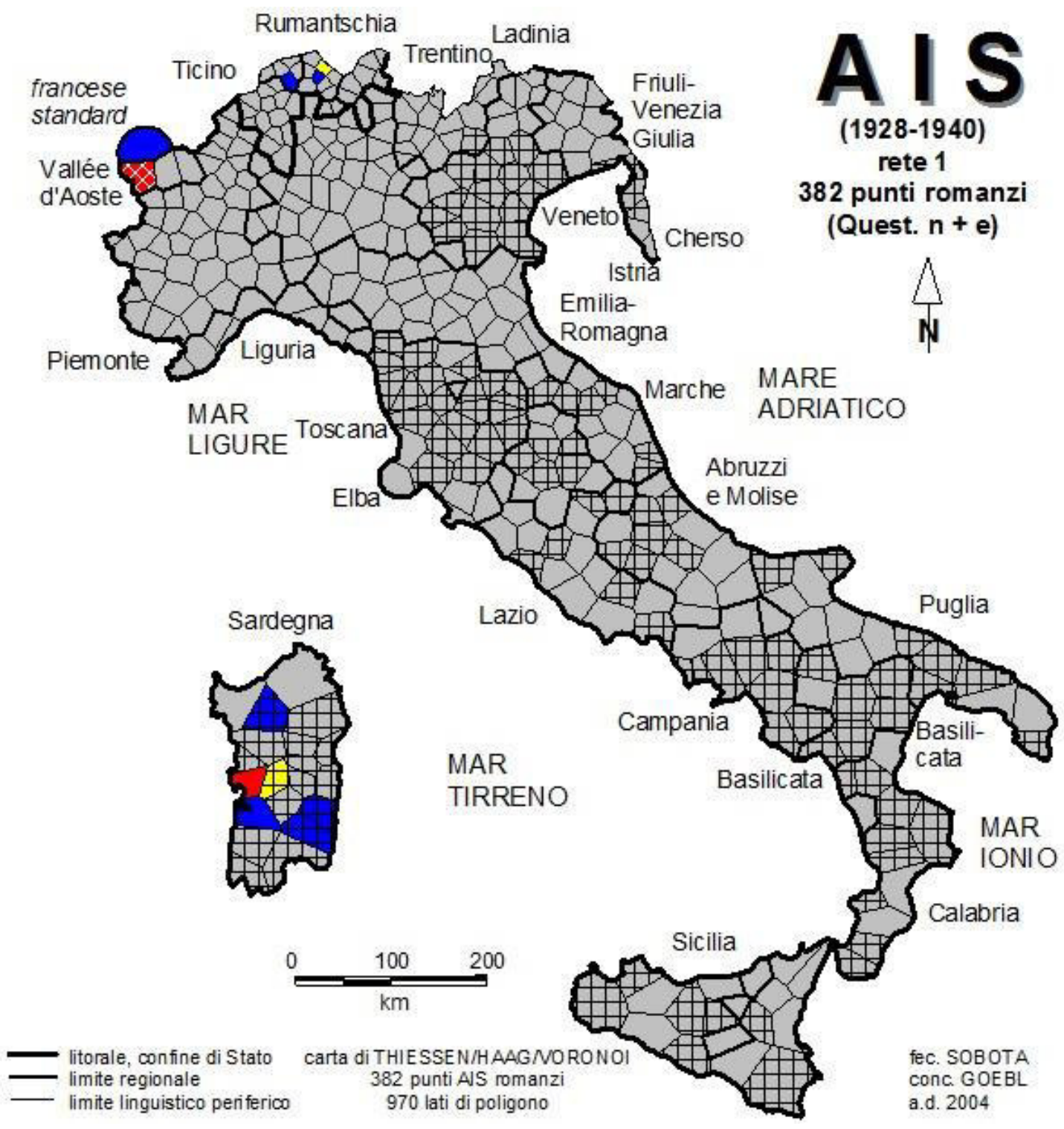

Legende, MINMWMAX, 6-fach

Häufigkeitsverteilung, MINMWMAX, 12-fach
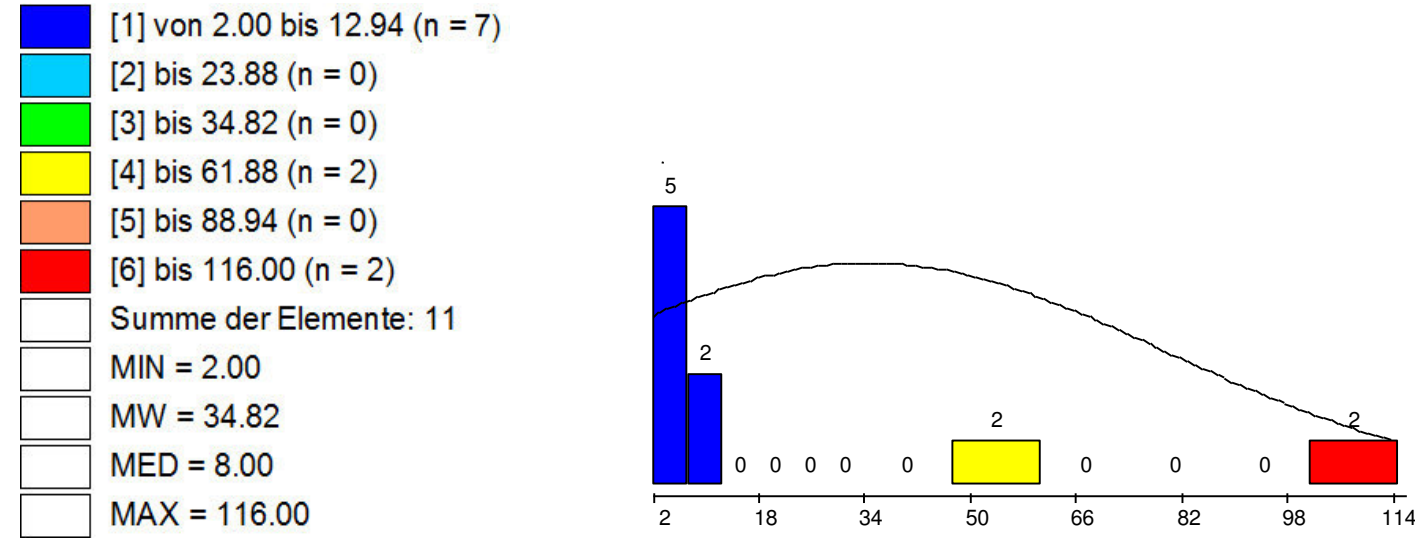

Karte 31. Antipodenkarte der Minima zum AIS (Totalkorpus (3.911 AK), Messmoment RIW R $_{j k}$ ). Weiße Schraffur: AIS-Messpunkt 121 (Rhêmes-St-Georges, Aostatal), schwarze Schraffur: AIS-Messpunkte $(\mathrm{n}=116)$, von denen dieser Punkt Minimalwerte erhält. 


\subsubsection{Die Schottenkarte}

Bei der Schottenkarte - auch „Grenzsegment-“ oder „Wabenkarte“ (engl. honeycomb map) genannt $^{314}$ - handelt es sich um eine Form der Zwischenpunkt- bzw. Isarithmenkarte, die auf der polygonisierten Form des Messpunktnetzes (vgl. Kap. 4.3.7.1) beruht. Im Gegensatz zur Choroplethenkarte werden hier jedoch nicht die Flächen, sondern die Seiten der Polygone zur Darstellung der dialektometrischen Messergebnisse verwendet.

Die in der S-DM eingesetzte Form der Schottenkarte entspricht vom Prinzip her dem in den proto-dialektometrischen Arbeiten von Lalanne (1953) und Séguy (1973b) verwendeten Kartentypus ${ }^{315}$ : Die (gedachten) Zwischenpunkte übernehmen hier ,la fonction discriminatoire pour signaler des différences (dissemblances, dissimilarités, distances) linguistiques“ (Goebl 1983b: 354). Dementsprechend greift die Schottenkarte nicht auf die zugrunde liegende Ähnlichkeitsmatrix, sondern auf die zu dieser komplementäre - anhand von $\mathrm{RDW}_{j k}$ oder $\mathrm{GDW}_{j k}{ }^{316}$ berechnete - Distanzmatrix zu, wobei jedoch nur diejenigen Distanzwerte berücksichtigt werden, die die Relation zwischen zwei Messpunkten angeben, die eine gemeinsame Polygonseite aufweisen. Die Darstellung der (intervallisierten) Distanzwerte erfolgt über die Farbe und Strichstärke der entsprechenden Linien: Je größer die sprachliche Distanz zwischen den zu beiden Seiten des Grenzsegments liegenden Messpunkten ist, desto kälter ist die Färbung und desto dicker die Markierung der Polygonseiten. Bei einer 6-fachen Intervalleinteilung der Distanzwerte weisen dicke und blau bzw. hellblau eingefärbte Grenzsegmente also auf hohe und dünn und rot bzw. orange gefärbte Polygonseiten auf niedrige sprachliche Abstände zwischen den jeweiligen Messpunkten hin (s. Karte 32).

Die sprachgeographische Botschaft der Schottenkarten stimmt häufig grob mit der Aussage von im entsprechenden Gebiet durchgeführten Isoglossensynthesen überein (vgl. Goebl 2010a: 448, Goebl 2007: 217). Wenn jedoch Aneinanderreihungen von in Blau- und Grüntönen eingefärbte Schotten hier als „Dialektgrenzen“ bezeichnet werden, so sind darunter nicht exakt lokalisierbare (bzw. lokalisierte) Grenzlinien, sondern dialektale Grenz- bzw. Übergangsräume zu verstehen. ${ }^{317}$ Gebiete, in denen kalt eingefärbte Segmente dominieren, verweisen somit auf sprachlich sehr heterogene Zonen, während Räume, in denen sich warm eingefärbte Polygonseiten aneinanderreihen, für sprachlich verhältnismäßig homogene bzw. kompakte Gebiete stehen, in denen die dialektalen Übergänge deutlich ,weicher' sind.

\subsubsection{Die Strahlenkarte}

Die Strahlenkarte (engl. beam map) stellt das heuristische Komplement zur Schottenkarte dar: Während die der kartographischen Darstellung zugrunde liegenden (gedachten) Zwischenpunkte dort die sprachlichen Distanzen zwischen zwei benachbarten Messpunkten abbilden,

\footnotetext{
${ }^{314}$ Die auch verwendete Bezeichnung „Isoglossenkarte“ ist leicht irreführend, da es sich bei den Elementen auf der Schottenkarte im Gegensatz zu den Isoglossen (vgl. Kap. 4.1) eben nicht um (Teile von) Grenzlinien, sondern um voneinander unabhängige Grenzsegmente handelt, die lediglich (bei ähnlicher Einfärbung) den visuellen Eindruck von Kontinuität vermitteln können.

315 Vgl. Kap. 4.2, Karte 23.

${ }^{316}$ Vgl. Kap. 4.3.4.

${ }^{317}$ An der Tatsache, dass sich die in Blautönen eingefärbten und dick markierten Schotten häufig in denselben Gebieten finden, die in der Darstellung der Schiefewerte blau markiert, d.h. durch einen hohen Sprachausgleich gekennzeichnet sind, erkennt man ,die essentielle Doppelnatur des Phänomens der ,Grenze‘, welch letztere vom parallelen Wirksamwerden von Informationsdurchfluss und Informationssperre gekennzeichnet ist" (Goebl 2007: 218).
} 
haben sie hier „la fonction communicative pour signaler des identités (similarités, ressemblances, similitudes) linguistiques“ (Goebl 1983b: 354). ${ }^{318}$ Visualisiert werden hier dementsprechend die Ähnlichkeitswerte zwischen jeweils zwei benachbarten Messpunkten. Die geometrische Basis ist dabei die triangulierte Form des Messpunktnetzes (vgl. Kap. 4.3.7.1): Die dialektalen Ähnlichkeiten werden in der Gestaltung der direkten Verbindungslinien zwischen zwei benachbarten Messpunkten, d.h. der Dreiecksseiten des triangulierten Ortsnetzes sichtbar. Die verschiedenen Wertklassen werden durch unterschiedliche Farbe und Strichstärke der Linien symbolisiert. So weisen dicke, rot oder orange gefärbte Linien auf hohe, dagegen dünne, in Blautönen eingefärbte Verbindungen auf niedrige dialektale Ähnlichkeiten hin (s. Karte 33)..$^{319}$

Die heuristische Leistung von Strahlenkarten liegt in der Visualisierung der zwischen benachbarten Messpunkten eines dialektalen Netzes verlaufenden Kontakt- und Interaktionsflüsse (vgl. Goebl 2007: 218). In Analogie zur Verkehrsgeographie können dicke und warm eingefärbte, d.h. hohe dialektale Ähnlichkeitswerte symbolisierende Linien als „,mobilitätsbzw. kommunikationsfördernde ,Autobahnen“ “, dünne und kalt eingefärbte und entsprechend niedrige dialektale Ähnlichkeiten illustrierende Verbindungen als „Nebenstraßen“ oder „Bergstraßen“ begriffen werden (Bauer 2009: 115).

Konzentrationen von dicken, rot oder orange eingefärbten Linien stehen für Gebiete, innerhalb derer starke kommunikative und damit auch soziale Vernetzungen bestehen. Ihnen entsprechen auf verkehrsgeographischer Ebene häufig infrastrukturell gut erschlossene Gebiete. Bei den Gebieten, in denen in Blautönen eingefärbte Verbindungslinien dominieren, handelt es sich hingegen oft um Areale, die auch infrastrukturell schlechter vernetzt sind (ebd.: 117).

\footnotetext{
${ }^{318}$ Vgl. ebd. zur graphischen Gegenüberstellung der unterschiedlichen Funktionen von Zwischenpunkten. ${ }^{319}$ Obwohl die Triangulierung von Ortsnetzen bereits in proto-dialektometrischen Arbeiten (so etwa in Guiter 1973) vorgenommen wurde und triangulierte Ortsnetze als kartographische Basis zum Einsatz kamen (vgl. Kap. 4.2), wurde das heuristische Potential dieses Kartentyps erst in der Entwicklung der S-DM (Goebl 1983b) erkannt: „Il semble bien que les difficultés graphiques voire cartographiques auxquelles toutes les synthèses isoglottiques se sont heurtées jusqu'alors aient empêché les dialectologues de pousser plus avant leurs recherches relatives à l'autre versant du principe interponctuel“" (ebd.: 355).
} 


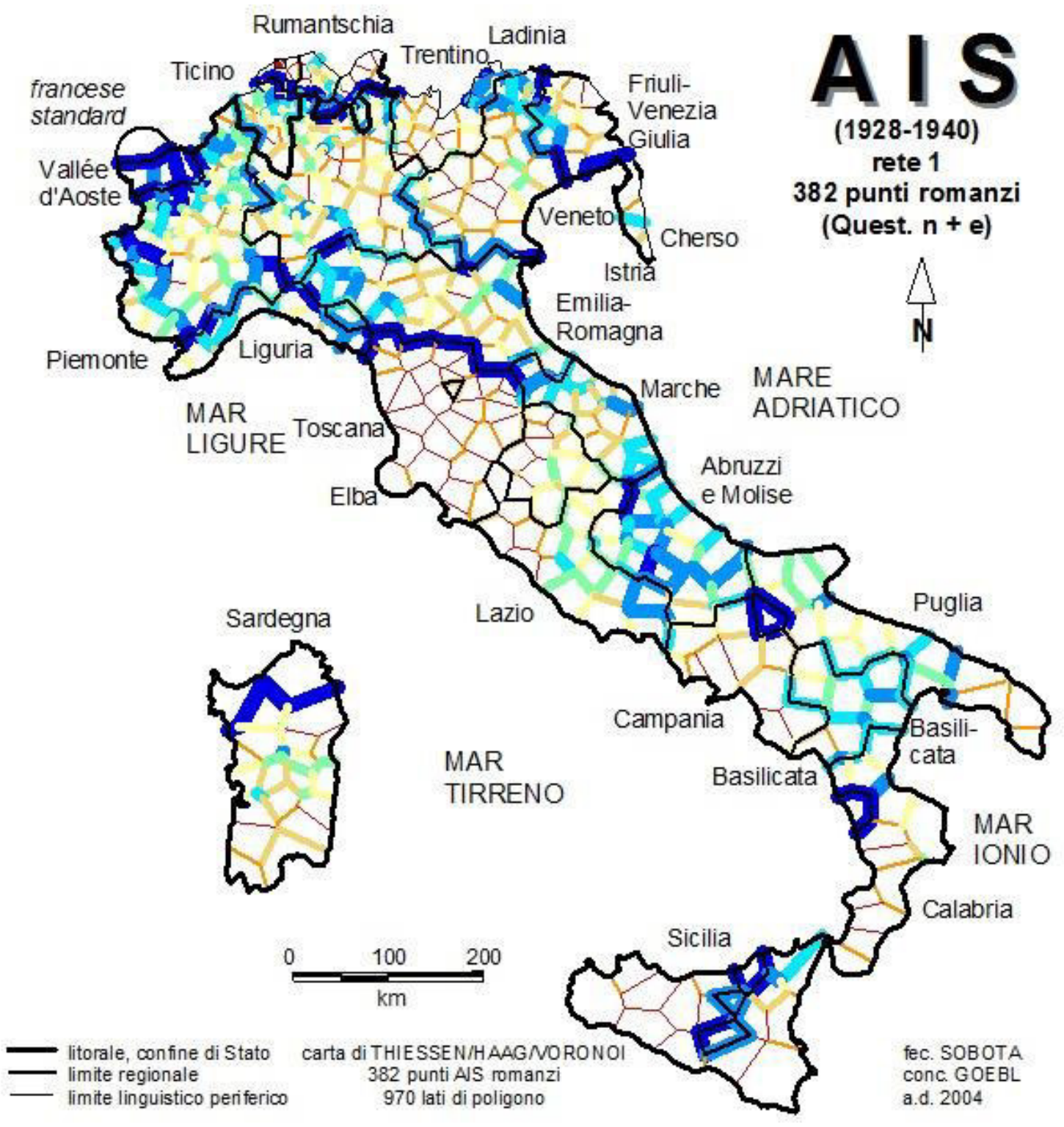

Legende, MEDMW, 8-fach

Häufigkeitsverteilung, MEDMW, 16-fach

[1] von 10.19 bis $16.11(n=139)$

[2] bis $18.20(n=139)$

[3] bis $19.90(n=139)$

[4] bis $21.82(n=139)$

[5] bis $23.40(n=103)$

[6] bis $25.08(n=104)$

[7] bis $28.89(n=104)$

[8] bis $47.52(n=103)$

Summe der Elemente: 970

$\mathrm{MIN}=10.19$ (PP. $1-11)$

$M W=21.81$

MED $=20.80$

$\operatorname{MAX}=47.52($ PP. $13-32)$

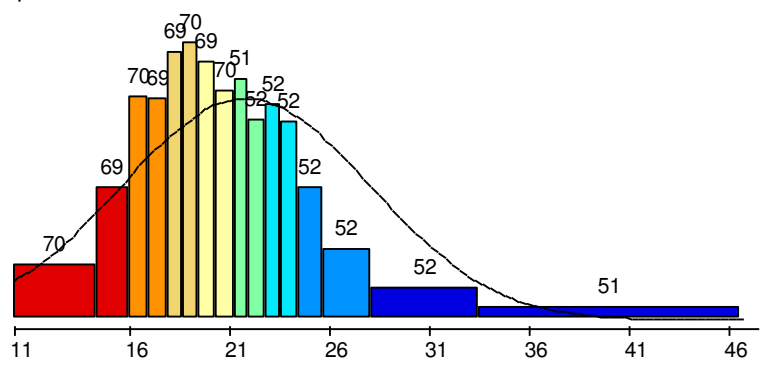

Karte 32. Schottenkarte zum AIS. Totalkorpus (3.911 AK), Messmoment RDW $j k$. 


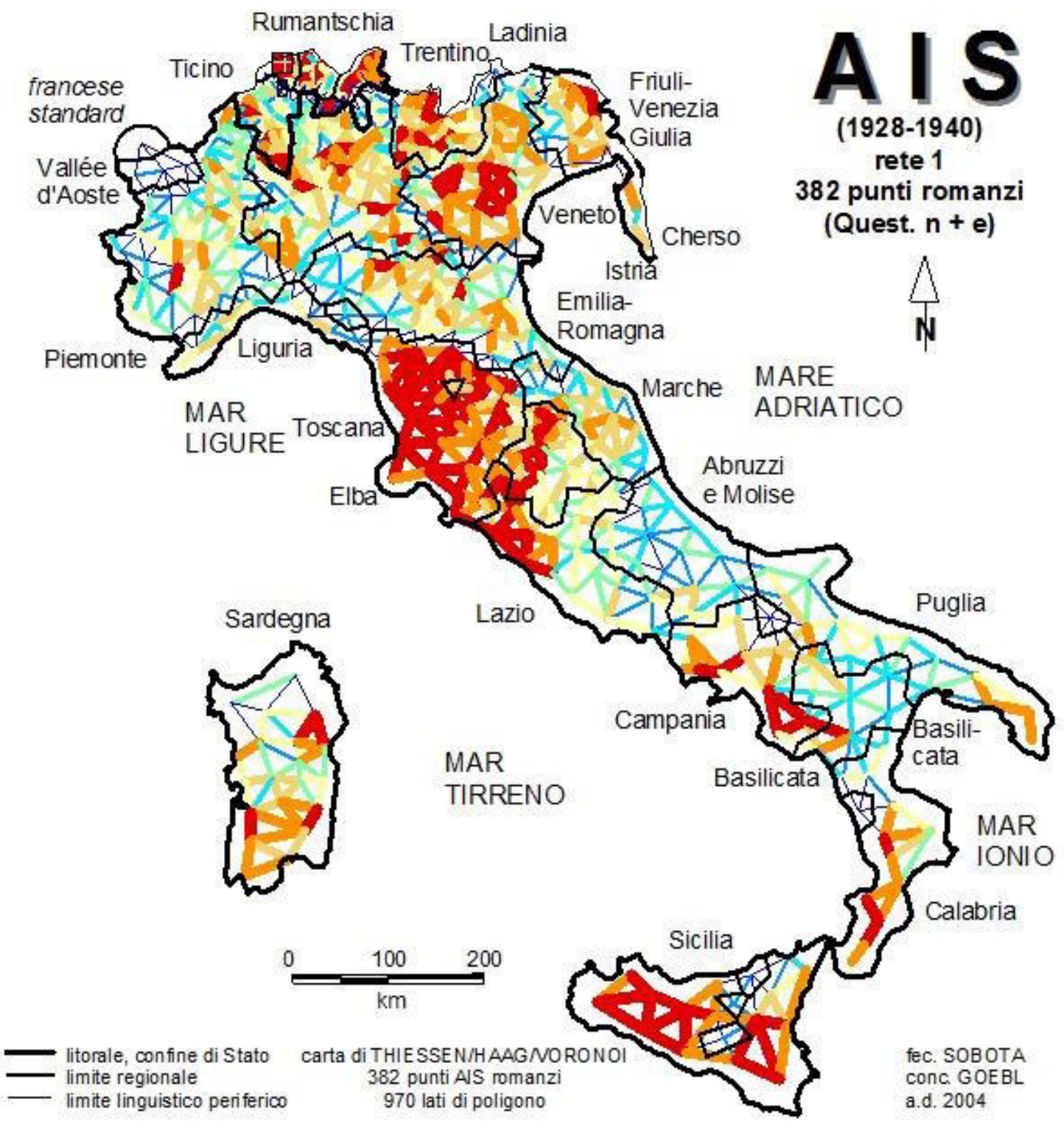

\section{Legende, MEDMW, 8-fach}

[1] von 52.48 bis $71.11(n=104)$

[2] bis $74.92(n=104)$

[3] bis $76.60(n=104)$

[4] bis $78.19(n=104)$

[5] bis $80.10(n=138)$

[6] bis $81.80(n=139)$

[7] bis $83.89(n=139)$

[8] bis $89.81(n=138)$

Summe der Elemente: 970

$\mathrm{MIN}=52.48$ (PP. 13 - 32)

$\mathrm{MW}=78.19$

MED $=79.21$

MAX $=89.81$ (PP. $1-11)$
Häufigkeitsverteilung, MEDMW, 16-fach

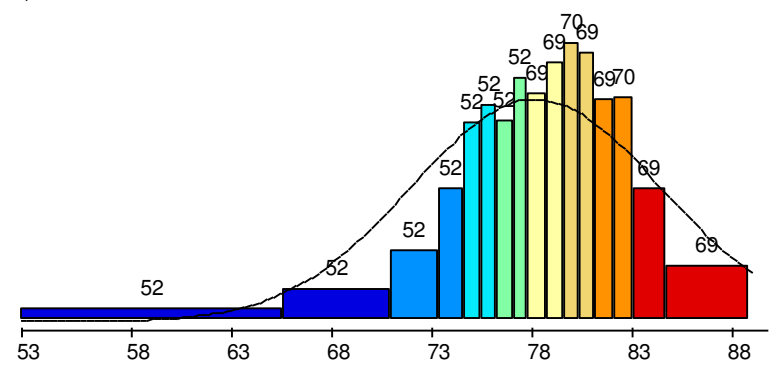

Karte 33. Strahlenkarte zum AIS. Totalkorpus (3.911 AK), Messmoment RIW $j k$. 


\subsubsection{Die Visualisierung der Clusteranalyse}

Die Visualisierung der Clusteranalyse erfolgt in der S-DM - wie auch in der numerischen Taxonomie $^{320}$ - üblicherweise anhand eines Dendrogramms, das einerseits den Prozess der Klassenbildung (sukzessive Fusion kleinerer zu größeren Clustern, vgl. Kap. 4.3.6) und andererseits das Ergebnis dieser, d.h. die Hierarchie der Cluster abbildet. Optisch ähnelt das Dendrogramm einem (umgekehrten) Baum (daher auch Baumdiagramm), dessen ,Blätter' die zu Beginn der Klassifikation unverbundenen N Objekte (hier: Messpunkte bzw. Dialekte) und dessen (binäre) ,Astgabeln“ die sukzessiven Fusionsschritte darstellen (s. Abb. 15). Das Cluster, in dem alle Objekte nach der letzten Fusionsstufe vereint sind, entspricht damit dem ,Stamm“ oder der ,Wurzel' des Baumes. Da im Laufe des Klassifikationsprozesses die Heterogenität der generierten Cluster immer weiter zunimmt, weisen die (großen) Cluster, die sich in der Nähe des Stamms befinden, eine größere Heterogenität auf als die (kleinen) Cluster, die sich in der Nähe der ,Blätter' befinden (vgl. Goebl 2010a: 452). ${ }^{321}$

Während die Klassifikation der Messpunkte bzw. der Dialekte agglomerierend, d.h. von den ,Blättern` zur ,Wurzel', erfolgt, wird in der sprachgeographischen Analyse der ,Baum` meist in umgekehrter Richtung, d.h. von der, Wurzel' zu den ,Blättern` betrachtet (Bauer 2009: 154), wobei die dabei aufscheinende hierarchische Struktur auf zwei verschiedene Arten analysiert und interpretiert werden kann. Bei der diachronen Interpretation wird die von der, Wur-

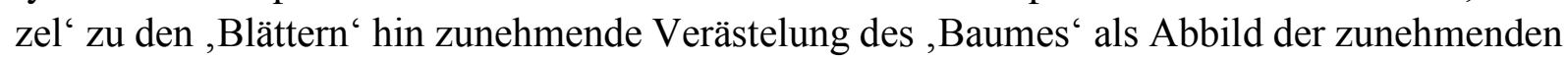
dialektalen Fragmentierung des untersuchten Sprach- bzw. Dialektgebietes im Laufe der Geschichte gesehen (vgl. Goebl 2010a: 452). ${ }^{322}$ Gegenstand der synchronen Analyse ist hingegen die zum Zeitpunkt der Datenerhebung bestehende „dialektale Fraktionierung“ eines Sprachbzw. Dialektgebietes (Bauer 2009: 155), die anhand der Anzahl und Größe der Cluster, ihrer Zusammensetzung und der Abstände, die sie untereinander aufweisen, beschrieben werden kann.

Bei der Beschreibung der hierarchischen Struktur eines Dendrogramms mit dem Ziel der Erkenntnis von Ordnungsmustern innerhalb der Menge der klassifizierten Objekte macht es wenig Sinn, der zunehmenden Fragmentierung von der letzten Partition bis zur Ausgangspartition zu folgen, in der die Anzahl der Klassen der Anzahl der Objekte entspricht. Es muss daher immer eine Partition oberhalb der ersten Fusionsstufe bestimmt werden, auf der der Analyseprozess beendet wird und die bis dahin ausgegliederten Cluster als strukturell relevant betrachtet werden (Hierarchiequerschnitt, s. Abb. 15). Die zu einem bestimmten Hierarchiequerschnitt vorhandenen Cluster (in der S-DM auch Dendreme genannt) werden in VDM automatisch koloriert, können jedoch in ihrer Farbe jederzeit manuell angepasst werden (s.u.).

Wie bereits bemerkt, stehen in der S-DM die durch die Visualisierung der Ähnlichkeitsbzw. Distanzwerte zum Vorschein kommenden sprachlichen Raumstrukturen im Zentrum des Interesses. Dementsprechend ist auch bei der Visualisierung der Clusteranalyse insbesondere die räumliche Projektion (,Spatialisierung“) des Dendrogramms von heuristischem Wert (vgl.

\footnotetext{
${ }^{320}$ Zur Verwendung des Dendrogramms in der numerischen Taxonomie vgl. Vogel (1975: 237) und Bock (1974: 383f.).

${ }^{321}$ In der numerischen Taxonomie wird das Dendrogramm häufig von einer senkrecht zur Grundlinie stehenden Messskala begleitet, auf der die numerische Ähnlichkeit (Abnahme der Werte in Richtung Stamm) bzw. Distanz (Zunahme der Werte in Richtung Stamm) gekennzeichnet sind. Daran kann abgelesen werden, welcher numerische Ähnlichkeits- bzw. Distanzwert den verschiedenen Fusionsstufen entspricht, d.h. welche Ähnlichkeit bzw. welchen Distanz die auf der entsprechenden Stufe fusionierenden Cluster zueinander aufweisen. Graphisch entspricht diesem Abstand die Länge der, Äste‘ des Dendrogramms (Vogel 1975: 239).

${ }^{322}$ Die Verwendung von Baumdiagrammen zur Darstellung linguistischer Genealogien geht auf Schleicher (1863) zurück (Stammbaumtheorie), vgl. Bauer (2009: 153).
} 
Goebl 2010b: 72). Diese geschieht in VDM auf der Basis der Polygonkarte, indem die bei dem gewählten Hierarchiequerschnitt aufscheinenden Dendreme in entsprechend kolorierte Polygone, sog. Choreme umgelegt werden und damit eine räumliche Ausdehnung erhalten (s. Karte 34). Um die visuelle Erfassung der Verhältnisse zwischen den Dialektclustern zu optimieren, können in VDM die Farben der Cluster manuell angepasst, d.h. etwa die ein größeres Cluster bildenden Dendreme (und damit die entsprechenden Choreme auf der Clusterkarte) in ähnlichen Farben koloriert werden (vgl. Bauer 2009: 155). Durch Veränderungen des Hierarchiequerschnitts im Dendrogramm können in der synchronen Analyse die durch die Choreme symbolisierten dialektalen Haupt- und Untergruppen geographisch verortet und Einblicke in die interne Organisation des untersuchten Sprach- bzw. Dialektgebietes gewonnen werden. In diachroner Perspektive ermöglicht es der kartographische Vergleich verschiedener Partitionen, die räumlichen Implikationen des Prozesses der dialektalen Ausgliederung im untersuchten Gebiet nachzuvollziehen.

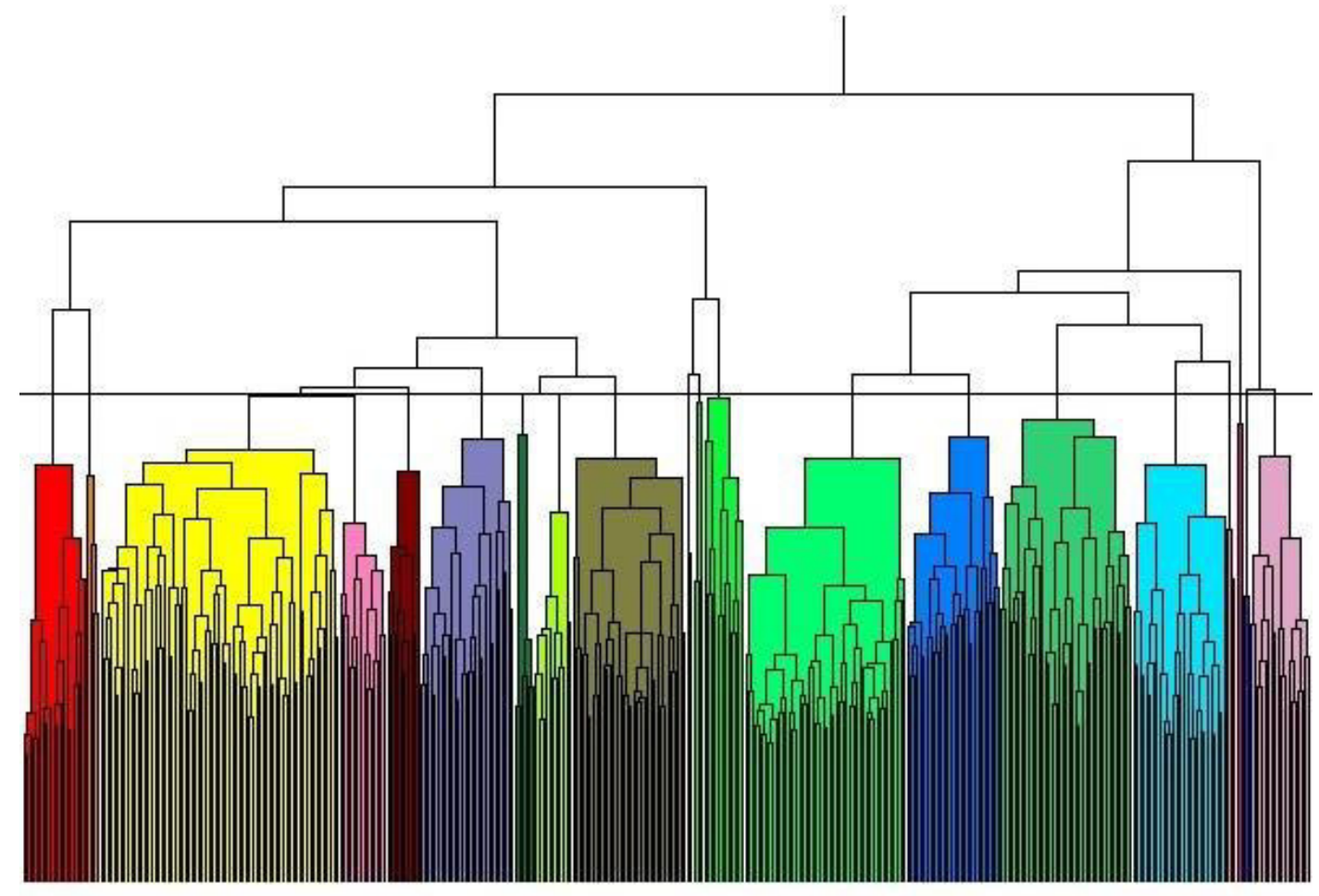

Abbildung 15. Dendrogramm zum AIS. Totalkorpus (3.911 AK), Messmoment RIW ${ }_{j k}$, Clusteralgorithmus Complete Linkage. Hierarchiequerschnitt bei 19 eingefärbten Dendremen. 


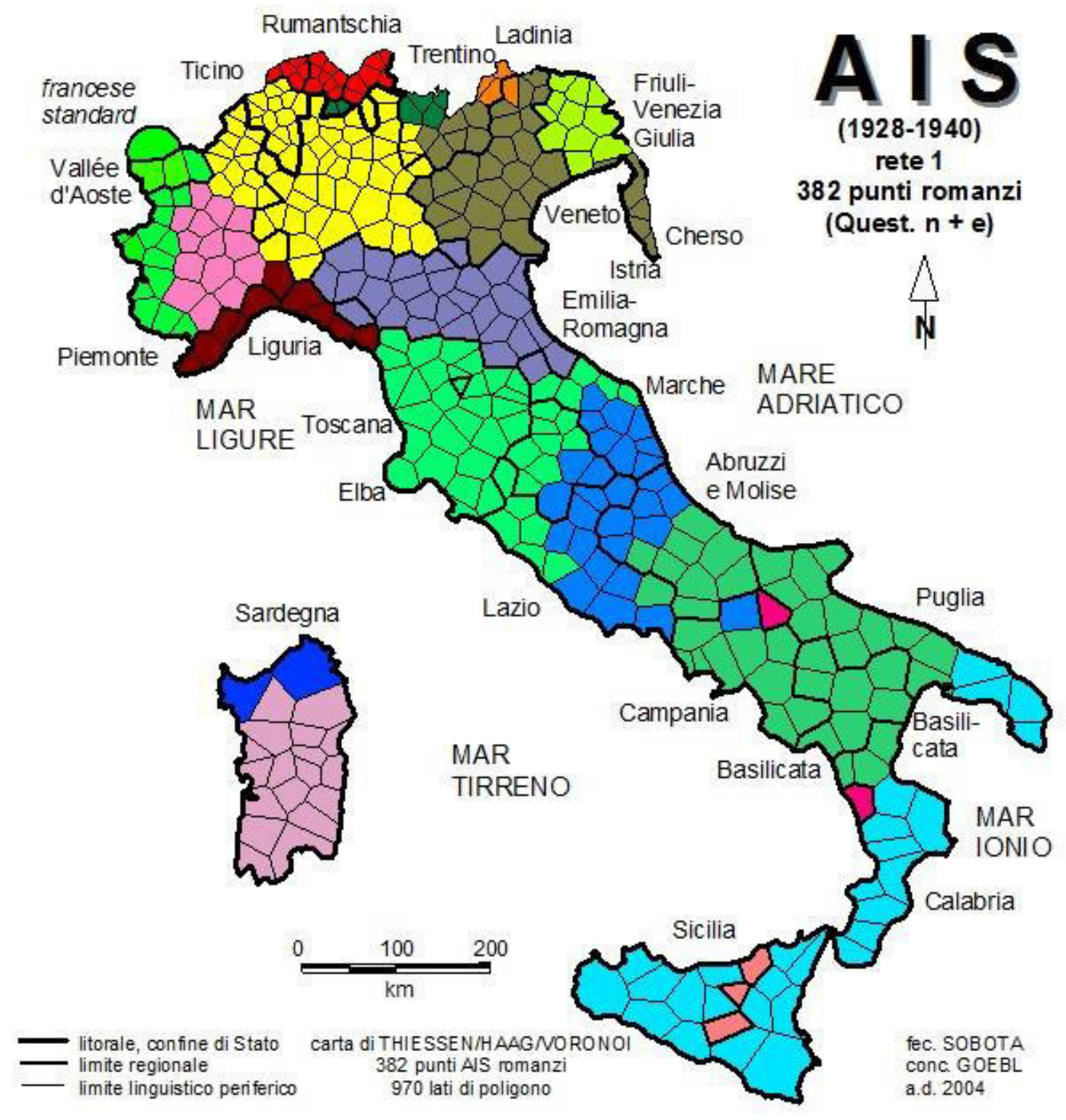

Karte 34. Räumliche Projektion des Dendrogramms aus Abb. 15. Clusterkarte mit 19 eingefärbten Choremen. 


\subsubsection{Die korrelative Dialektometrie}

Die seit 2004 als Teilbereich der S-DM existierende korrelative Dialektometrie entstand vor dem Hintergrund der Frage, ,,in welcher Weise die auf allen Ähnlichkeitskarten gut beobachtbare Abnahme der linguistischen Ähnlichkeiten im Raum tatsächlich mit der Zunahme der geographischen Entfernung vom Prüfbezugspunkt zusammenhängt“" (Goebl 2007: 220). ${ }^{323}$ Um Einblicke in das Verhältnis zwischen Sprache und Raum im jeweils untersuchten Gebiet zu erhalten, muss neben dem sprachlichen Ähnlichkeitsprofil der dialektometrischen Messpunkte auch das geographische Ähnlichkeitsprofil jedes Messpunktes berechnet werden. Dazu wird nach der Formel des Pythagoras die geographische Proximität aller N - 1 Messpunkte zu dem jeweiligen Prüfbezugspunkt berechnet. Daraus resultiert eine geographische Ähnlichkeitsmatrix, die dieselbe Struktur (N x N) aufweist wie die mittels RIW $_{j k}$ oder GIW $_{j k}$ berechnete sprachliche Ähnlichkeitsmatrix. Das geographische Ähnlichkeitsprofil jedes Messpunktes kann dann genau wie die sprachliche Ähnlichkeitsverteilung (vgl. Kap. 4.3.7.2) auf der Basis einer Polygonkarte dargestellt und so bereits optisch mit dem entsprechenden sprachlichen Ähnlichkeitsprofil verglichen werden (s. Karten 35 und 36).

Einen globalen, also das gesamte Untersuchungsgebiet umfassenden Eindruck des Verhältnisses zwischen sprachlicher Ähnlichkeit und geographischer Proximität erlaubt jedoch erst die statistische Korrelation beider Ähnlichkeitsmatrizen. ${ }^{324}$ Ein hierzu in der S-DM häufig verwendetes $\mathrm{Ma} ß$ ist der Produktmoment-Korrelationskoeffizient nach Bravais/Pearson (abgekürzt $r(\mathrm{BP})$ oder PMK). ${ }^{325}$ Aus dem Vergleich der beiden zu jedem Messpunkt vorliegenden Vektoren aus N - 1 Ähnlichkeitswerten resultiert ein einziger Wert, der zwischen -1 und +1 liegen kann. Positive Werte (zwischen 0 und +1) weisen dabei auf einen $\mathrm{Zu}$ sammenhang zwischen den korrelierten Variablen im Sinne einer proportionalen Entwicklung hin (je größer A, desto größer B), wobei dieser umso stärker ist, je näher der Wert an 1 liegt. Ist der Wert gleich 0, existieren keine Interdependenzen zwischen den Variablen. Negative Werte (zwischen 0 und -1) weisen hingegen auf eine negative Korrelation der Variablen und damit auf eine antiproportionale Entwicklung hin (je größer A, desto kleiner B, vgl. Goebl 2005b: 330, Bauer 2009: 143). Im vorliegenden Fall weisen positive Korrelationswerte also darauf hin, dass mit abnehmender räumlicher Proximität (bzw. mit wachsender räumlicher Distanz) der Messpunkte von einem Referenzpunkt auch die sprachliche Ähnlichkeit zu diesem abnimmt, während negative Werte eine Situation widerspiegeln, in der mit abnehmender räumlicher Proximität (bzw. mit wachsender räumlicher Distanz) die sprachliche Ähnlichkeit zu einem Referenzpunkt zunimmt.

Die Korrelationswerte der N Messpunkte werden wie üblich zu Wertklassen zusammengefasst und kartographisch auf der Basis der Polygonkarte dargestellt (s. Karte 37). Die Farbgebung erfolgt dabei ebenfalls in bekannter Weise, sodass in Blautönen eingefärbte Polygone

\footnotetext{
${ }^{323}$ Hierbei handelt es sich also um dieselbe Frage, die zur Entwicklung der ,linearen Dialektometrie“(vgl. Kap. 4.2) geführt hat. Während dort jedoch in Form der Analyse einzelner Pfade nur ,Zufallsstichproben“ (Goebl 2005b: 324f.) des Verhältnisses zwischen Sprache und Raum genommen werden, wird dieses in der korrelativen Dialektometrie in globaler Perspektive betrachtet.

${ }^{324}$ Voraussetzung dafür ist - neben der identischen Struktur der korrelierten Ähnlichkeitsmatrizen - dass die Werte der geographischen Ähnlichkeitsmatrix in derselben Größenordnung liegen wie jene der sprachlichen Ähnlichkeitsmatrix. Dazu müssen die geographischen Ähnlichkeitswerte im Vorfeld der Korrelation gegebenenfalls numerisch transformiert werden (vgl. Goebl 2005b: 330).

${ }^{325}$ Zur Formel vgl. Goebl (2005b: 329). In VDM können zur Berechnung von Korrelationen alternativ die Durchschnittliche Manhattan Metrik (DMM, auch Cityblock-Metrik) und die Durchschnittliche Euklidische Metrik (DEM) ausgewählt werden.
} 
für niedrige (aber nicht notwendigerweise negative) Korrelationswerte und in rot bzw. orange gehaltene Polygone für hohe Korrelationswerte stehen.

Die Korrelation sprachlicher und geographischer Ähnlichkeitsverhältnisse ermöglicht Einblicke in das Verhältnis zwischen Sprach- und Naturraum. Da die Progression der geographischen Proximität linear und damit stabil ist, ist es insbesondere von Interesse, inwieweit die nicht raumzeitlich vorgegebene, sondern sozial bedingte Progression der sprachlichen Ähnlichkeit von dieser abweicht (d.h. schneller bzw. langsamer verläuft) und damit zu Beeinträchtigungen der Konvergenz zwischen Sprache und Raum führt (vgl. Goebl 2007: 221). Nimmt man an, dass im ,Ur-Zustand‘, d.h. zu Beginn der sprachlichen Tätigkeit des Menschen im geographischen Raum, eine vollkommene ,Harmonie‘ zwischen sprachlicher Ähnlichkeit und geographischer Proximität bestanden hat, indizieren rot bzw. orange eingefärbte Polygone auf der Korrelationskarte Gebiete, in denen diese über die Zeit hinweg gut erhalten geblieben ist. In Blautönen eingefärbte Polygone, die verhältnismäßig niedrige Korrelationswerte und damit die stärksten Abweichungen von einer optimalen Konvergenz (= Korrelationswerte nahe 1) zwischen Sprache und Raum symbolisieren, stehen demnach für Gebiete, ,,in denen es im Laufe der Sprachgeschichte bedingt durch externe (politische, soziale, historische u.a.) Faktoren zu einem Bruch des ursprünglich vorhandenen Gleichgewichts Sprache vs. Naturraum gekommen ist“" (Bauer 2009: 148). ${ }^{326}$ Es ist jedoch mit dialektometrischen Mitteln nicht möglich, festzustellen, welcher der beiden möglichen, zu einer Diskordanz zwischen Sprache und Raum führenden Fälle zu einem gegebenen Zeitpunkt vorliegt, d.h. ob die Progression der sprachlichen Ähnlichkeit schneller oder langsamer als die Progression der geographischen Proximität vonstatten geht (vgl. Goebl 2007: 221).

Eine zweite Variante der korrelativen Dialektometrie besteht in dem Vergleich der sich bei einer Reduktion der zugrunde liegenden Datenmatrix auf verschiedene Teilkorpora ergebenden Ähnlichkeitsverhältnisse bzw. Raumstrukturen (z.B. jener in den Bereichen Phonetik und Lexikon oder in den Bereichen Konsonantismus und Vokalismus). Über einen Vergleich der auf der Basis des Totalkorpus ermittelten Ähnlichkeitsverhältnisse mit jenen, die sich auf der Basis einzelner Teilkorpora ergeben, lässt sich zudem feststellen, inwieweit die verschiedenen Subkorpora das dialektometrische Gesamtergebnis beeinflussen. ${ }^{327}$ Die Korrelation der (hier in beiden Fällen mit einem dialektometrischen Ähnlichkeitsmaß erstellten) Ähnlichkeitsmatrizen und die Visualisierung der Korrelationswerte (s. Karte 38) erfolgen dabei in der bereits für die Korrelation zwischen Sprach- und Naturraum beschriebenen Weise.

Dem Vergleich der sich für verschiedene sprachliche Ebenen separat ergebenden Ähnlichkeitsverhältnisse liegt die bereits in der traditionellen Sprachgeographie oft gestellte Frage zugrunde, inwieweit die auf verschiedenen sprachlichen Ebenen generierten dialektalen Strukturen einander entsprechen (vgl. Goebl 2007: 222). In der S-DM stehen kalt eingefärbte Polygone (d.h. niedrige Korrelationswerte) für Gebiete, in denen die „Bewirtschaftung des Raumes“ in den korrelierten sprachlichen Bereichen unterschiedlich verlaufen ist, sodass die resultierenden Raumstrukturen verhältnismäßig stark voneinander abweichen, warm eingefärbte Polygone (d.h. hohe Korrelationswerte) hingegen für Zonen, in denen eine gleichschrittige Entwicklung stattgefunden hat und die resultierenden Raumstrukturen entsprechend kongruent sind.

\footnotetext{
${ }^{326}$ Brüche dieser Art zeigen sich damit grundsätzlich in Gebieten, die Sprachinseln darstellen (wie etwa die galloromanischen Sprachinseln in Süditalien, s. Karte 37), d.h. überall dort, wo die ursprüngliche sprachliche Bewirtschaftung des Raumes durch Migrationsprozesse überdeckt worden ist.

${ }^{327}$ Dabei spielt einsichtigerweise der Anteil, den die entsprechenden Arbeitskarten am Gesamtkorpus haben, eine entscheidende Rolle (vgl. Bauer 2009: 340).
} 


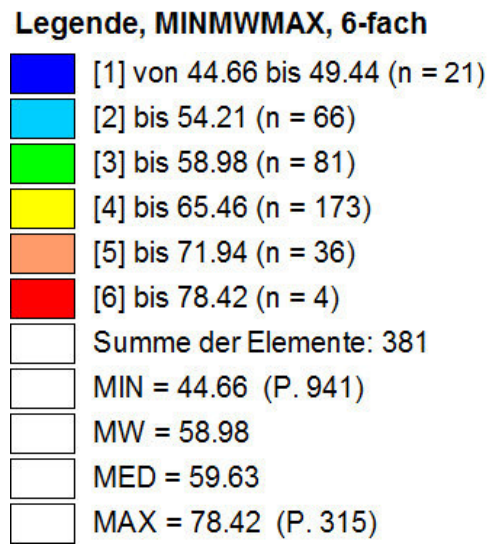

Häufigkeitsverteilung, MINMWMAX, 12-fach
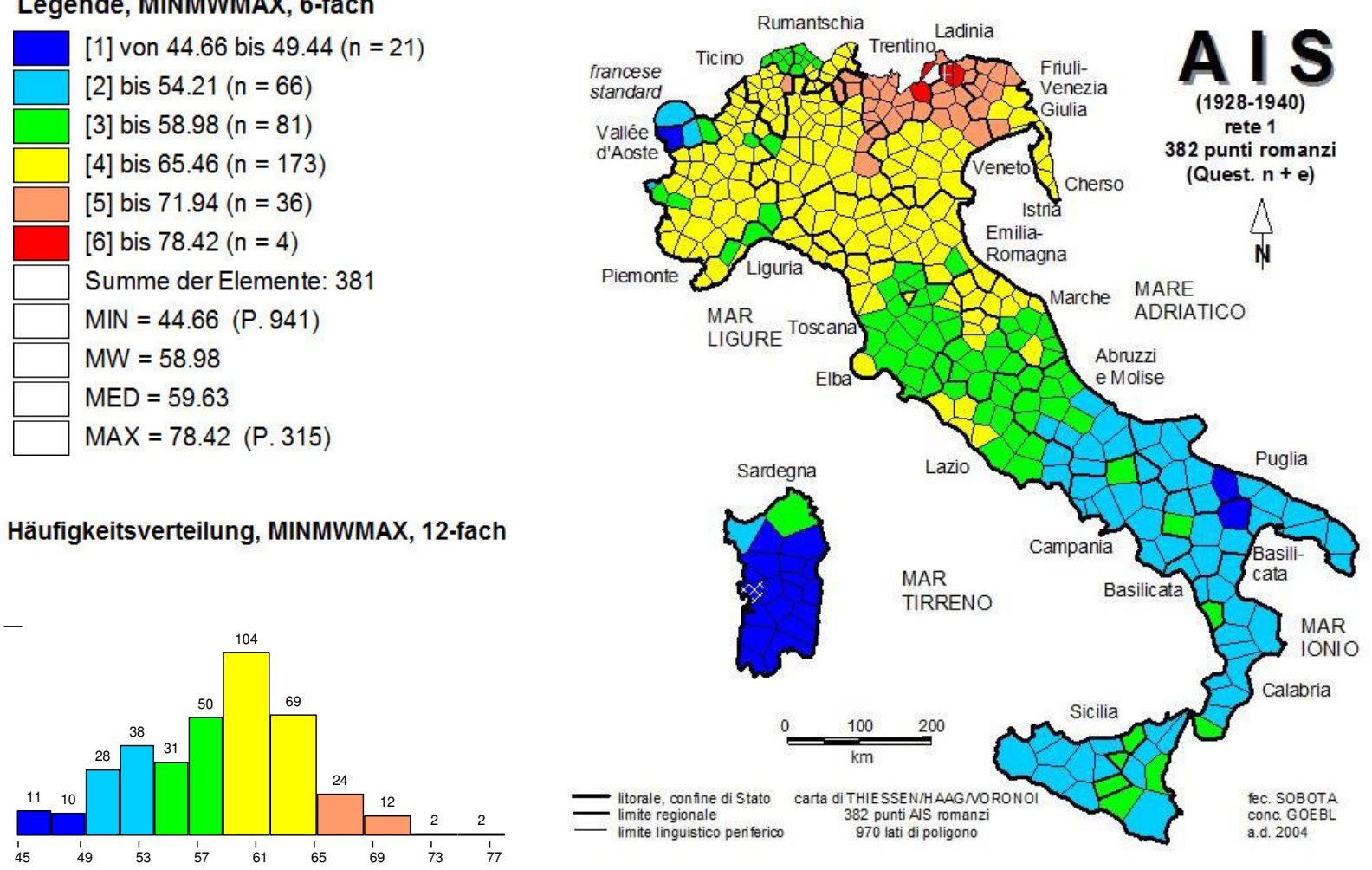

Karte 35. Sprachliches Ähnlichkeitsprofil (Totalkorpus (3.911 AK), Messmoment RIW $\mathrm{R}_{j k}$ ) zum AISMesspunkt 313 (Penía (Trentino), weiß).

\section{Legende, MINMWMAX, 6-fach}

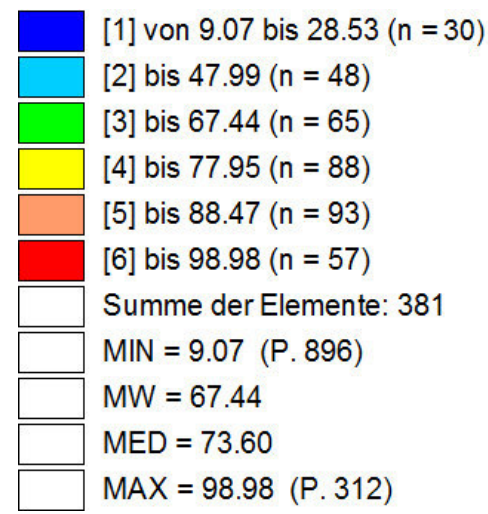

Häufigkeitsverteilung, MINMWMAX, 12-fach

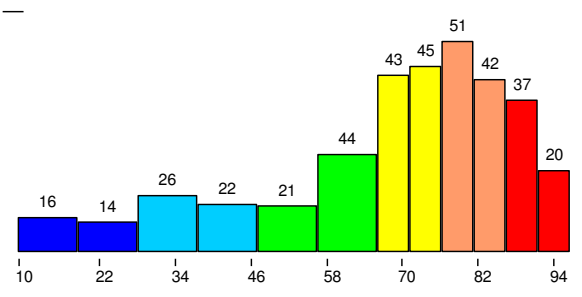

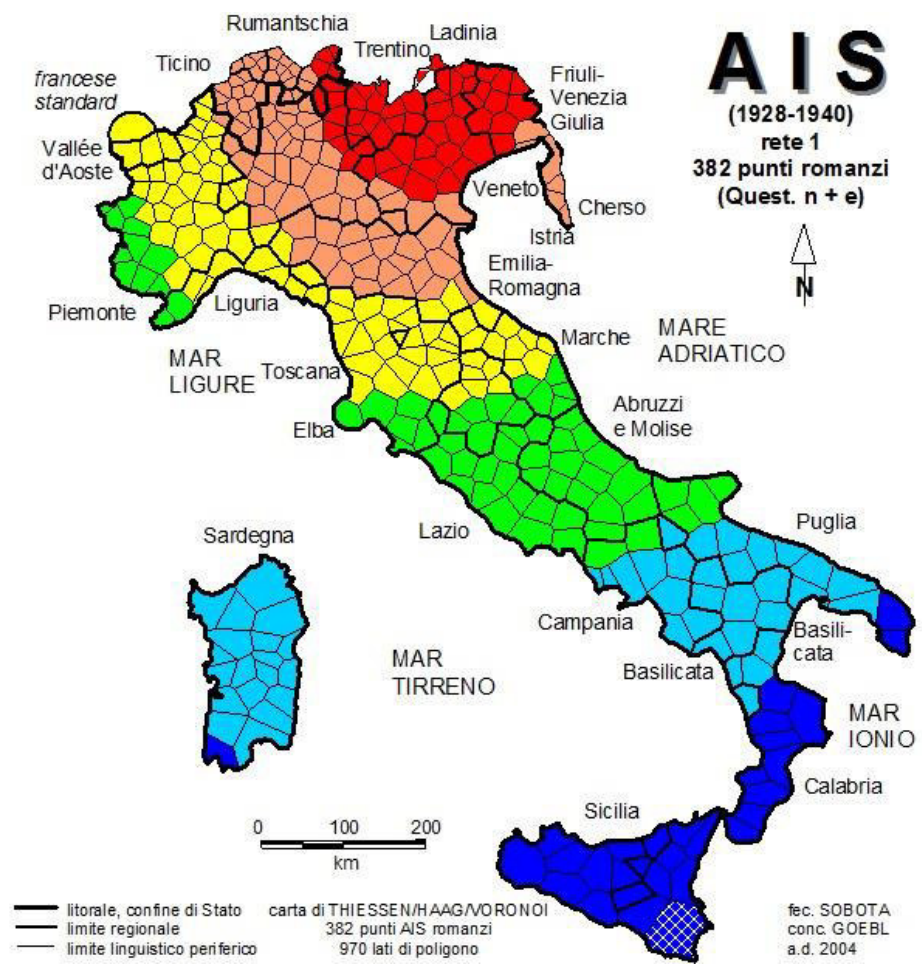

Karte 36. Geographische (euklidische) Proximität zum AIS-Messpunkt 313 (Penía (Trentino), weiß). 


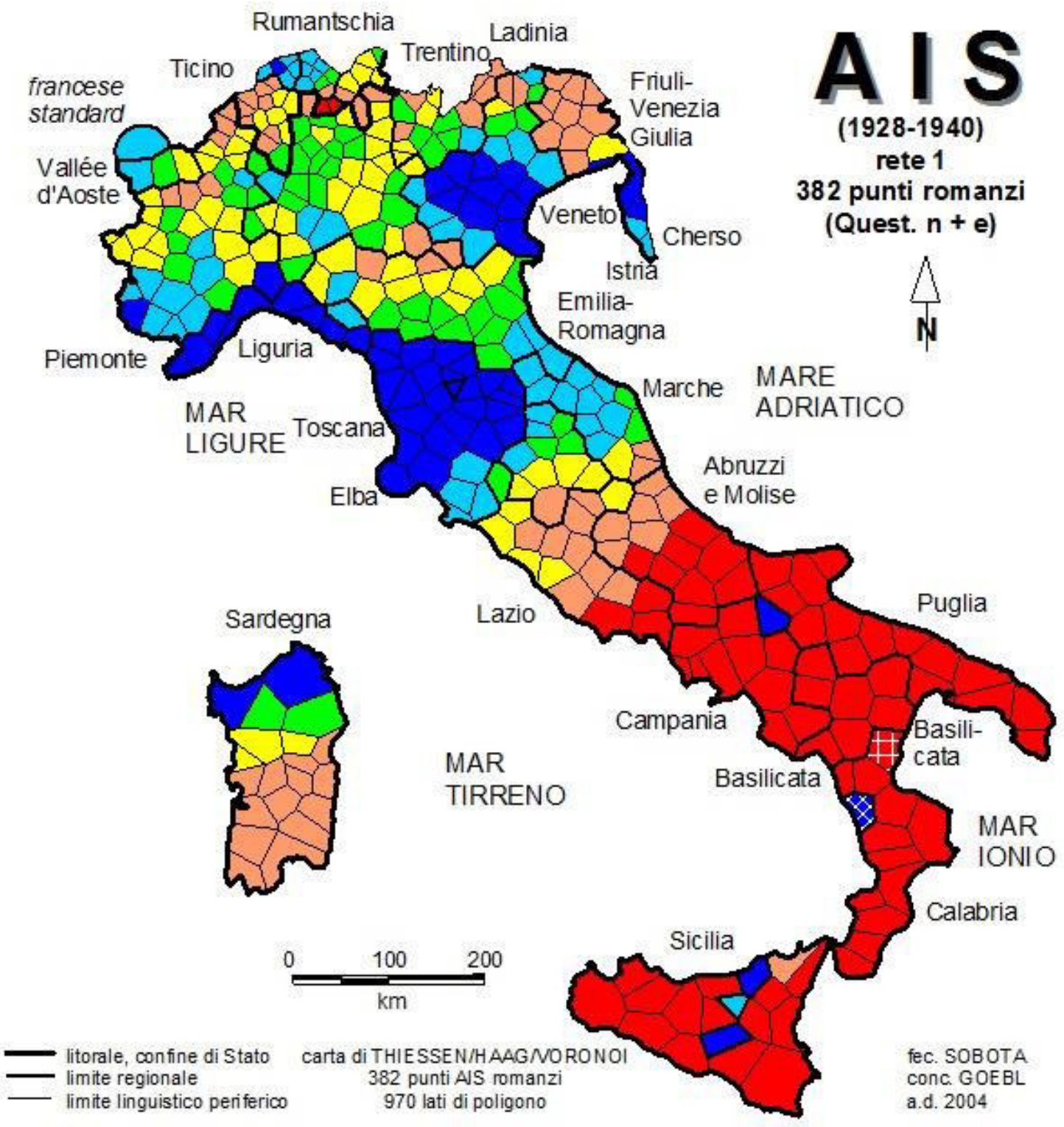

\section{Legende, MEDMW, 6-fach}
[1] von 0.04 bis $0.66(n=56)$
[2] bis $0.71(n=56)$
[3] bis $0.74(n=56)$
[4] bis $0.76(n=71)$
[5] bis $0.84(n=72)$
[6] bis $0.91(n=71)$
Summe der Elemente: 382
$\mathrm{MIN}=0.04$ (P. 760)
$\mathrm{MW}=0.74$
MED $=0.75$
MAX $=0.91$ (P. 745)

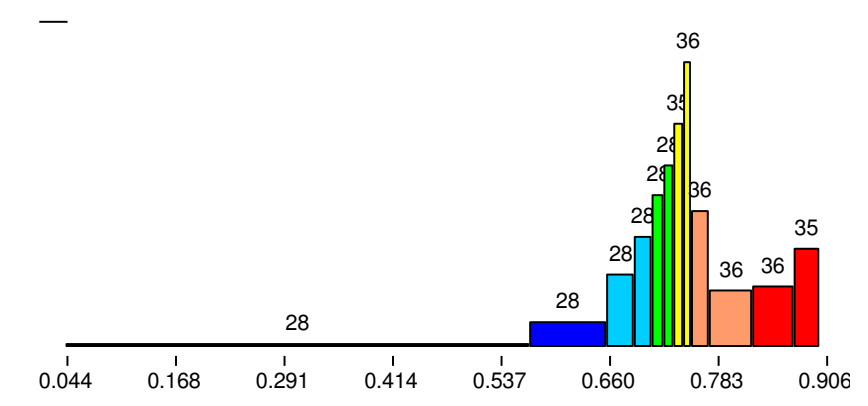

Karte 37. Korrelationskarte zum AIS. Korrelation zwischen sprachlicher Ähnlichkeit (Totalkorpus (3.911 AK, Messmoment RIW ${ }_{j k}$ ) und geographischer (euklidischer) Proximität (Produktmoment-Korrelationskoeffizient nach Bravais/Pearson). 


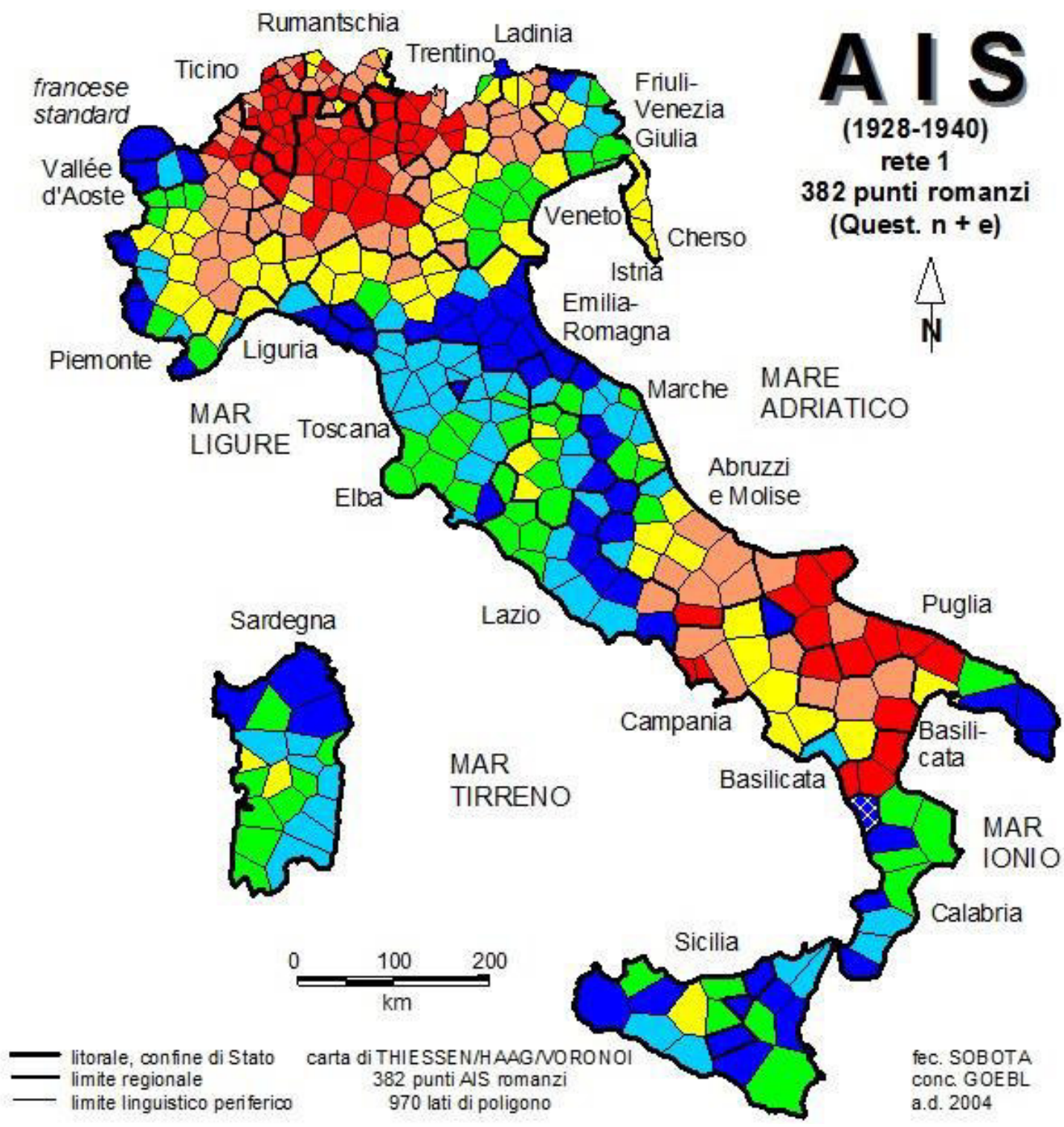

Legende, MEDMW, 6-fach

Häufigkeitsverteilung, MEDMW,12-fach
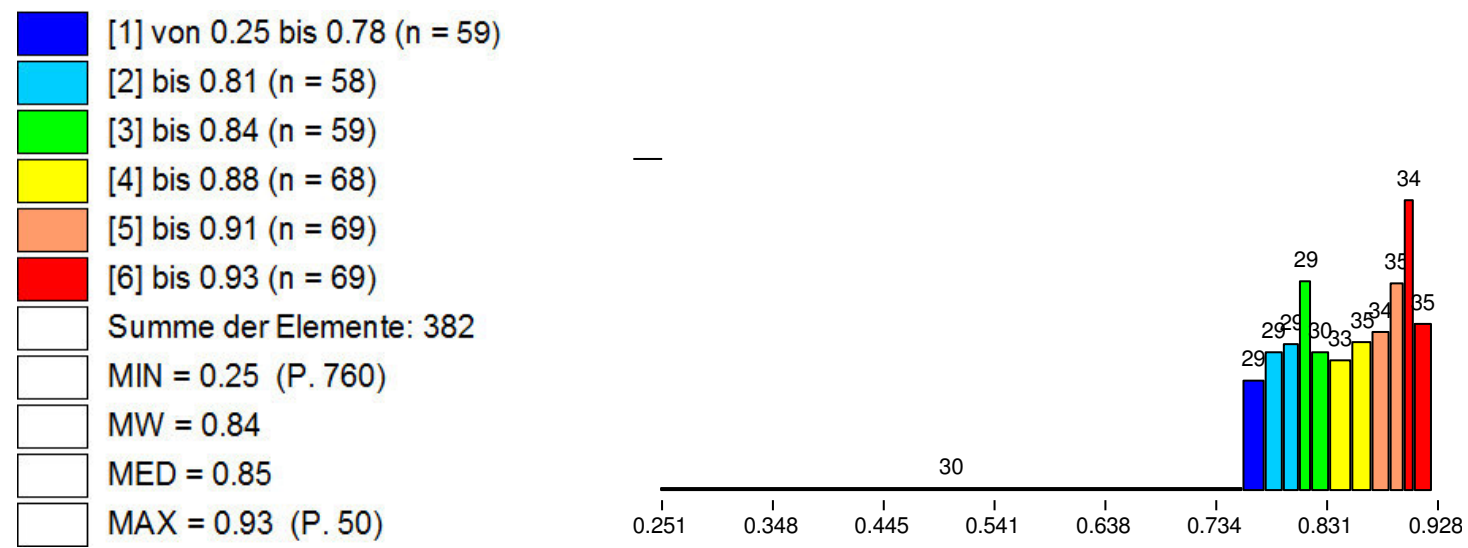

Karte 38. Korrelationskarte zum AIS. Korrelation zwischen phonetischem Teilkorpus (1.766 AK) und lexikalischem Teilkorpus (1.225 AK). Messmoment jeweils RIW $_{j k}$, Produktmoment-Korrelationskoeffizient nach Bravais/Pearson. 


\subsection{Zur Entstehung sprachlicher Raummuster}

Die Ausdehnung von Dialektgebieten und insbesondere ihre Grenzen zueinander werden in der Sprachgeographie häufig mit Bezug auf Korrelationen zwischen diesen und außersprachlichen Grenzverläufen unterschiedlichster Art zu erklären versucht (vgl. u.a. Tappolet 1905, Morf 1911, Rosenqvist 1919, Haag 1930):

[I]l doit exister plusieurs causes qui ont empêché les idiomes de se confondre. Peutêtre les limites de diocèse fournissent-elles une explication satisfaisante pour beaucoup de régions et les frontières politiques pour d'autres : quoi qu'il en soit, il y a des cas $[\ldots]$, où ce sont les considérations d'ordre topographique et économique qui nous aident en première ligne à éclaircir la question. (Rosenqvist 1919: 117)

Allen so gearteten Erklärungsansätzen zugrunde liegt die Auffassung, dass es sich bei Dialektund Sprachgrenzen um „Grenzen historischer Kommunikationsräume“ (Putschke 1982: 244) handelt, die durch geographische, historisch-politische, ethnographische ${ }^{328}$ oder - insbesondere in kleinräumigen Arealen - konfessionelle bzw. kirchlich-administrative Grenzen geformt worden sind. ${ }^{329}$ Die entsprechenden Hypothesen und die damit verbundenen Datierungen der Dialektareale werden grundsätzlich umso eher akzeptiert, je größer die Anzahl der „dialektalen Isolinien“ und je länger die „Koinzidenzstrecke“ (ebd.) mit der entsprechenden außersprachlichen Grenze ist. Zudem ist die Anzahl der im jeweiligen Kontext beigebrachten sprachhistorischen Belege von Relevanz (vgl. ebd.). Die Adäquatheit des bei der Erklärung sprachlicher Grenzen durch außersprachliche Grenzen implizit zugrunde gelegten strengen Kausalitätsprinzips wird hingegen im Allgemeinen nicht hinterfragt. Da aber sprachliche Phänomene nicht allein von außersprachlichen bestimmt werden, sondern „soziale Phänomene neben ihnen“ (Weinhold 1985: 253) sind, ist auf wissenschaftlicher Ebene eine „simple Gleichsetzung sprachlicher, ökonomischer, volkskundlicher und anderer Areale“ (ebd.: 180) in aller Regel nicht möglich. Aufgrund der Überschneidungen zwischen den den menschlichen Lebensraum strukturierenden „Kräftegruppen“ (nach Wirth (1969) wirtschaftliche, soziale ${ }^{330}$ und staatliche Kräfte) kann jedoch „eine nicht idealtypisch konstruierte, sondern empirisch vorgefundene

\footnotetext{
${ }^{328}$ Um eine Grenze als ethnographisch bedingt zu charakterisieren, bedarf es des Nachweises, ,,daß eine längere auffallende Dialektgrenze, die weder durch natürliche noch politisch-kulturelle Schranken irgend wie [sic] erklärbar ist, mit einer sicher belegten Stammesgrenze wirklich zusammenfällt"“ (Tappolet 1905: 413). Da historisch-politische Gliederungen jedoch häufig ,,alte Stammesgrenzen“ (ebd.) fortführen, kann die Rolle des ethnographischen Aspekts nicht immer abschließend geklärt werden.

${ }^{329}$ Doch manifestiert sich nicht jede Verkehrsgrenze zwingend in einer Dialektgrenze oder einer Grenze zwischen verschiedenen Sprachräumen. Als Beispiele für Fälle, in denen geographische Verkehrsgrenzen keine Grenzen zwischen Sprachräumen darstellen, führt Tappolet (1905: 386f.) das Mont Blanc-Massiv an, das die sprachlich ähnlichen Gebiete des Aostatals und des Savoyen geographisch (und politisch) voneinander trennt, den Alpengipfel Monte Rosa, der zwischen den in Italien liegenden deutschsprachigen Walsergemeinden und ihrem schweizerdeutschen „Mutterland“ liegt, sowie den Monte Viso als geographische und politische Grenze zwischen der okzitanischsprachigen Provence und den okzitanischsprachigen Gemeinden in der italienischen Region Piemont.

${ }^{330}$ Unter ,,sozialen Kräften“ versteht Wirth (1969: 170) „Phänomene wie Gewohnheit, Tradition, Neigung zur Beharrung, Sozialprestige, Mode, Nachahmung, Gruppennorm, social control und ähnliche“, die ,als meist ungeschriebene Verhaltensnormen und Wertsysteme Gültigkeit haben“ und „gleichsam unbeabsichtigt räumlich differenzierend“ wirken. Gegenüber den anderen beiden Kräftegruppen sind die sozialen Kräfte deutlich schwerer fassbar: „Soziologie und Sozialpsychologie haben bisher noch kein System sozialer Kräfte aufgestellt, welches sich ohne Bruch und erhebliche Korrekturen in eine allgemeine kulturgeographische Kräftelehre einbringen ließe“ (ebd.).
} 
räumliche Gliederung nach zwei der drei Kräftegruppen [...] nicht ohne Aussagewert auch für die dritte sein“ (Weinhold 1985: 180).

Goebl (1984: 160) weist darauf hin, dass nicht nur in der Physik, sondern auch in den Sozial- und Geowissenschaften längst eine Abwendung von einem kausalen hin zu einem statistisch-probabilistischen Gesetzesbegriff zu beobachten ist, welcher durchaus auch in der Sprachgeographie, d.h. zur Beschreibung von Korrelationen zwischen sprachlichen und historischen Raumstrukturen nutzbar gemacht werden könnte: „Ein derartiges statistisches Gesetz könnte [...] etwa besagen, daß man erwarten kann, daß sich in x von y Fällen historische Raumstrukturen in linguistischen abbilden“" (ebd.). ${ }^{331}$

Abseits der Aufdeckung der sprachexternen Faktoren, die Struktur und Umfang konkreter Dialektgebiete bzw. den Verlauf der entsprechenden Dialektgrenzen bedingen, stellt sich die Frage nach möglichen allgemeinen Gesetzmäßigkeiten der räumlichen Verbreitung sprachlicher Phänomene, deren Verteilung den anzutreffenden sprachlichen Raumstrukturen zugrunde liegt. Das älteste dazu entwickelte Modell ist wohl die Wellentheorie ${ }^{332}$, nach der „sprachliche Erscheinungen von einem Ausgangspunkte aus sich in teils beschränkterer, teils weiterer Ausdehnung wellenförmig über die benachbarten Gebiete ausbreiten“ (Huber 1909: 107). ${ }^{333}$ Die Isoglosse ist somit als ,le bord extrême d'une inondation qui se répand, et qui peut aussi refluer" zu interpretieren (De Saussure 1995: 282, vgl. auch Porzig 1950: 251, der von Isoglossen als „Wellenringen“ spricht). ${ }^{334}$

Das grundsätzliche epistemologische Problem des Wellenmodells besteht darin, dass es „als Überwindung von Distanz schematisiert, was in Wahrheit soziale Interaktion zwischen Menschen ist" (Weinhold 1985: 169). Dadurch, dass es eine gleichmäßige Verteilung der Bevölkerung über den Raum sowie die Abwesenheit von physiogeographischen und humangeographischen Barrieren jeglicher Art voraussetzt, kann es einer ,,sozialpsychologischen Raumvorstellung“ (ebd.: 181), wie sie der Human- und damit auch der Sprachgeographie zugrunde

\footnotetext{
${ }^{331}$ Goebl (1984: 159) beschreibt sprachgeographische Messpunktnetze - und damit die entsprechenden dialektalen Netze - als „,Schaltungsnetzwerke“, deren ,innere Verbindungsleitungen in bestimmter Weise geschaltet sind“, wobei „eine bestimmte Menge Schalter an bestimmten Verzweigungsstellen in den Positionen ,aus“ und/oder ,ein“ vor[liegen].“ Den Einstellungen der „Schalter“ liegen kommunikative Tätigkeiten zugrunde, die die Verbindungen zu einem bestimmten historischen Zeitpunkt entweder schaffen bzw. verstärken oder aber unterbrechen. Die Geschichte eines dialektalen Netzes entspricht damit der Abfolge solcher „Aktivierungen“ bzw. „Deaktivierungen“, sodass die zu einem bestimmten Zeitpunkt vorliegenden Verschaltungen auf ,markante“ historische Konstellationen zurückbezogen werden können (ebd.: 160).

${ }^{332}$ Bekannt wurde die Wellentheorie vor allem durch den Indogermanisten J. Schmidt (1872). Hinweise auf das Prinzip der wellenförmigen Ausbreitung sprachlicher Innovationen finden sich jedoch bereits einige Jahre zuvor bei Schuchardt (1868, III: 34, Hervorhebung S.H.): „Denken wir uns die Sprache in ihrer Einheit als ein Gewässer mit glattem Spiegel; in Bewegung gesetzt wird dasselbe dadurch, dass an verschiedenen Stellen desselben sich Wellencentra bilden, deren Systeme, je nach der Intensivität der treibenden Kraft von grösserem oder geringerem Umfange, sich durchkreuzen."

${ }^{333}$ Eine weiter entwickelte Form der Wellentheorie ist die aus der Botanik (Willis 1922) übernommene - und die Basis für M. Bartolis (1925, 1945) Arealnormen bildende - Age-and-Area-Hypothese, die auf der Annahme beruht, alle geographischen Diffusionsprozesse verliefen grundsätzlich mit gleicher Geschwindigkeit. Im Falle sprachlicher Innovationen bedeutet dies: Je größer die räumliche Verbreitung eines sprachlichen Phänomens ist, desto älter ist dieses. Demnach werden ältere sprachliche Merkmale häufig in isolierten (Inseln) oder randständigen Gebieten konserviert, während zentrale Gebiete meist jüngere Merkmale aufweisen. Zu einer kritischen Prüfung der Age-and-Area-Hypothese vgl. Hodgen (1942).

${ }^{334}$ In der sprachtypologischen Forschung steht das Wellenmodell bis heute in Konkurrenz zur Stammbaumtheorie (Schleicher 1863). Dass beide Erklärungsmodelle und damit auch die zugehörigen Methaphern der „Welle“ und des „Stammbaums“ einander jedoch keineswegs ausschließen, sondern vielmehr verschiedene Betrachtungsperspektiven auf ein und denselben Ausschnitt aus der sprachlichen Realität und damit komplementäre sprachgeographische und -typologische Heuristika darstellen, zeigt Goebl (1983a).
} 
liegt, ${ }^{335}$ nicht gerecht werden. Bereits Sapir (1916: 26f.) weist darauf hin, dass es sich bei der kontinuierlichen Diffusion kultureller (und damit eben auch sprachlicher) Elemente um einen idealtypischen Prozess handelt, der durch verschiedene Faktoren „gestört“ werden kann. So können geographische oder soziokulturelle Barrieren dazu führen, dass der Diffusionsprozess nicht in allen Richtungen mit gleicher Geschwindigkeit verläuft, sodass das ,,kulturelle Zentrum“ (d.h. der Ort, in dem das kulturelle Element zuerst aufgetreten ist) weit entfernt vom aktuellen geographischen Diffusionszentrum oder sogar in der Peripherie des Verbreitungsgebietes der Innovation liegen kann. Darüber hinaus können Bevölkerungsbewegungen bzw. die damit einhergehenden Relokalisierungen der kulturellen Elemente zu einer „Verschleierung“ der ursprünglichen Diffusionsmuster führen. Schließlich kann die historisch älteste Form eines kulturellen Elements in ihrem Zentrum erheblichen Veränderungen unterlegen gewesen sein, sodass sich die ,typische“ Form nicht mehr dort, sondern in einem anderen, eventuell weit entfernten Ort findet. Bei der geographischen Diffusion kultureller Merkmale sind nach Sapir einerseits die infrastrukturelle Vernetzung und andererseits die (mit dieser in Zusammenhang stehende) Intensität der sozialen Interaktion zwischen verschiedenen Bevölkerungsgruppen maßgeblich:

[I]t makes all the difference whether the tribes observed to have a certain feature in common lie along a well established trade route or not; further, whether or not they are in the habit of meeting periodically, or at least frequently, for exchange of goods and participation in common activities (ceremonies, amusements). (Sapir 1916: 35)

In eine ähnliche Richtung gehen die Ausführungen Dauzats (1944), der zur räumlichen Verbreitung sprachlicher Innovationen bemerkt, dass diese oft nicht kontinuierlich, sondern ,ppar sauts brusques“" (ebd.: 174) verläuft und dass größere Siedlungszentren als Knotenpunkte der sozialen Interaktion eine besondere Rolle im Diffusionsprozess spielen: ${ }^{336}$

Les courants linguistiques ne circulent pas au hasard et ne sont pas seulement subordonnés aux conditions géographiques : ils obéissent à l'impulsion des centres sociaux et des grands foyers de civilisation [...]. D'une façon générale, chaque centre social est un foyer d'irradiation. [...] Les métropoles constituent de puissants foyers d'expansion linguistique, qui rayonnent sur un territoire très vaste, jusqu'aux confins de leur influence sociale [...] par l'intermédiaire des centres secondaires et des petits centres [...]. (Dauzat 1944: 191f.) $)^{337}$

\footnotetext{
${ }^{335}$ Die „Räume, mit denen es die Geographie des Menschen zu tun hat (etwa der vorgestellte, ,perzipierte“ Raum, in dem wir erleben und planen), [sind] nicht euklidisch. Sie sind vielfach weder isotrop (sondern haben bevorzugte und weniger bevorzugte Richtungen), noch kontinuierlich (sondern sind durch schwer und leicht passierbare Stellen strukturiert), noch homogen (es gibt vielmehr Stellen, die mehr, und andere, die weniger ,wert ${ }^{\text {" }}$ sind)“(Hard 1973: 183).

${ }^{336}$ Ein ähnlicher Hinweis findet sich bereits bei Tappolet (1905: 387): „Gegenüber den natürlichen Verkehrshindernissen werden im Allgemeinen die verkehrsfördernden Momente zu wenig berücksichtigt. Vor allem sind zu nennen die politischen oder wirtschaftlichen Centren, wie Hauptstädte oder Marktflecken, die auf die Umgegend ausgleichend wirken; dann die Straßen- und neuerdings die Eisenbahn.“

${ }^{337}$ Bei Dauzat gilt dieses Modell der räumlichen Diffusion in uneingeschränkter Form jedoch nur für lexikalische Innovationen; auf phonetischer Ebene stellen sich die Verhältnisse für ihn wesentlich komplexer dar, wie es die Beobachtung des archaischen Charakters einiger nordfranzösischer Stadtmundarten mit innovativerem ländlichem Umfeld zeigt (vgl. Dauzat 1944: 193). Dauzat schlussfolgert, dass Bildung und Entwicklung lexikalischer und phonetischer Verbreitungsgebiete „nicht denselben Gesetzen zu gehorchen scheinen“ (ebd.: 194). Die Frage nach möglichen Unterschieden in den Regularitäten der räumlichen Verteilung von Merkmalen auf den unterschiedlichen sprachlichen Ebenen ist in der Sprachgeographie bisher nicht allgemeingültig beantwortet worden.
} 
Überlegungen dieser Art führten in der Sprachgeographie zur Übernahme des Modells der Hierarchie der Diffusionszentren (hierarchy/cascade model of diffusion) aus der Human- bzw. Sozialgeographie. ${ }^{338} \mathrm{Im}$ Kontext der Analyse der räumlichen Diffusion sozialer Innovationen war dort insbesondere die Arbeit T. Hägerstrands (1952, 1965, 1967, 1968) maßgeblich, der zunächst empirisch nachwies, dass die Diffusion technischer und sozialer Innovationen nicht ungeordnet, sondern nach bestimmten Gesetzmäßigkeiten verläuft:

A closer analysis shows that the spread along the initial 'frontier' is led through the urban hierarchy. The point of introduction in a new country is its primate city; sometimes some other metropolis. Then centers next in rank follow. Soon, however, this order is broken up and replaced by one where the neighborhood effect ${ }^{339}$ dominates over the pure size succession. (Hägerstrand 1965: 40)

In einer mathematisch-statistischen Simulation der räumlichen Diffusion (Monte Carlo-Simulationsmodell) zeigte sich, dass auch unter Annahme einer gleichmäßigen geographischen Verteilung der Bevölkerung über ein bestimmtes Gebiet der Diffusionsprozess dieses nicht etwa gleichmäßig überzieht, sondern - ähnlich wie in der empirischen Studie - von bestimmten Zentren ausgeht (vgl. Hägerstrand 1968: 375). Unter Verzicht auf die Annahme einer homogenen Bevölkerungsdichte und bei Berücksichtigung der Auswirkungen geographischer „Grenzen“ (barriers) zwischen Siedlungen (z.B. dichte Wälder, Moore oder große Seen) auf die Konfiguration der sozialen Netzwerke ergaben sich in der Simulation schließlich Diffusionsstrukturen, die den empirisch beobachteten sehr ähnlich waren (vgl. ebd.: 377). Die Signifikanz des neighbourhood effect zeigt, ,that the links between individuals in circles of acquaintances and friendship play a remarkably important role for directing information and influence" (Hägerstrand 1965: 28); gleichzeitig ist der Einfluss der Massenmedien - als Instantiierungen ortsunabhängiger Informations- und Kommunikationsübertragung - nicht zu überschätzen (vgl. Hägerstrand 1968: 370). Die Diffusionsmuster soziokultureller oder technischer Innovationen sind somit in erster Linie durch die Intensität der sozialen Interaktion bzw. die Konfiguration der sozialen Kontakte zwischen den beteiligten Individuen bedingt, bei der unter anderem geographische Faktoren eine wichtige Rolle spielen.

In der Sprachgeographie finden sich analoge Beobachtungen zur Diffusion sprachlicher Innovationen. So stellt Trudgill (1974: 221) fest, dass sich ein und dieselbe Innovation von

\footnotetext{
Im Kontext dialektometrischer Untersuchungen konnte jedoch bereits festgestellt werden, dass die Arbeitskarten mit den höchsten Taxatbesätzen (d.h. der höchsten Anzahl unterschiedlicher Typen) stets lexikalischer Natur sind, während der taxatorische Ertrag im Bereich der Phonetik meist deutlich geringer ist, was sich auf die prinzipiell unendliche Variabilität des Lexikons bzw. die durch die geschlossene Klasse der basalen Einheiten vorgegebene variationelle Beschränktheit des phonetischen Bereichs zurückführen lässt (vgl. Goebl/Smečka 2014: 447). Während die räumliche Diffusion phonetischer Merkmale also maßgeblich von strukturellen Faktoren abhängt und die Typenvielfalt damit von diesen beschränkt wird, scheinen der Diffusion von Lexemen und damit der lexikalischen Vielfalt von sprachstruktureller Seite aus keine Grenzen gesetzt zu sein, sodass die hierfür maßgeblichen Faktoren im außersprachlichen Bereich liegen und mögliche ,Gesetze` dort gesucht werden müssen.

${ }^{338}$ Die dem hierarchy model of diffusion zugrunde liegende Idee der räumlichen Organisation der menschlichen Besiedelung (Europas) nach ,zentralen Orten“, die jeweils den ökonomischen und infrastrukturellen Mittelpunkt eines Gebietes darstellen und hierarchisch angeordnet sind, stammt von W. Christaller (1968 [1933], 1950).

${ }^{339}$ Als ,neighborhood effect“" bezeichnet Hägerstrand (1965: 28) das Phänomen, ,that a new adoption is more likely to occur in the vicinity of existing adoptions than further out from them." Dem entspricht auf allgemeiner Ebene genau die der S-DM zugrunde liegende Annahme, dass „mit in der geographischen Nachbarschaft angesiedelten Menschen grundsätzlich intensiver und damit anders kommuniziert [wird] als mit weiter entfernt lebenden Mitmenschen (Goebl 2005a: 68f., vgl. Kap. 4.3.1).
} 
ihrem „Kern“ aus fallweise nicht nur auf dem ,hierarchischen“ Weg, d.h. von größeren zu kleineren Stadtzentren ,,springend“, sondern auch in geographischer Kontinuität - und damit entsprechend dem Nachbarschaftseffekt, also über die sozialen Beziehungen der Sprecher in ihrem geographischen Umfeld - verbreitet (vgl. auch Chambers/Trudgill 1998: 175). Aus einem humangeographischen Gravity Model, das die Interaktion zwischen zwei Siedlungszentren als Funktion der Faktoren ,geographische Distanz' und ,Siedlungsgröße' darstellt, entwickelt Trudgill (1974: 233f.) einen Algorithmus, anhand dessen sich die Stärke des sprachlichen Einflusses eines städtischen Zentrums auf ein anderes ermitteln lässt. Auch hier ist die Frequenz bzw. die Intensität der Interaktion (bzw. des Kontaktes) zwischen Sprechern aus verschiedenen Orten von zentraler Bedeutung:

[T]he gravity model assumes that all influence weakens with increasing distance. It seems most likely that this weakening of influence is not due to psychological or social factors so much as the frequency of contact among speakers of the two cities. The assumption underlying this is Bloomfield's principle of density (1933: 476) that people automatically and inevitably influence each other's language each time they speak to each other. (Labov 2003: 15, Hervorhebung S.H.)

Die räumliche Distanz ist zwar ein wichtiger, jedoch nicht der einzige Faktor, der bei der Intensität der sozialen bzw. sprachlichen Interaktion eine Rolle spielt: So können sich enge soziale Bindungen trotz großer geographischer Entfernung in einem hohen Maß an sprachlicher Interaktion zwischen den Beteiligten widerspiegeln, soziale Barrieren jedoch auch auf kürzeste Distanz große kommunikative Hindernisse darstellen (Weinhold 1985: 172). Aufgrund der Pluralität der Funktionen von ,Sprache‘ ist die Diffusion sprachlicher Innovationen gegenüber jener anderer soziokultureller Neuerungen jedoch von einer erhöhten Komplexität: Zum Einen ist sie eine „Begleiterscheinung der Diffusion neuer Gegenstände und neuer außersprachlicher Verhaltensweisen“ (ebd.: 204), zum Anderen ,über die bloße [sic] informierende, die Symbolfunktion, hinaus selbst soziales Verhalten und unterliegt, wie jedes andere, der Bewertung und entsprechender Motivation, diese zu beeinflussen“ (ebd.). Dementsprechend merkt Trudgill (1974: 241) an, dass ein adäquates Modell der Verbreitung sprachlicher Innovationen weiteren, insbesondere soziolinguistischen Faktoren (Spracheinstellungen, Prestige, soziale Markierung sprachlicher Merkmale etc.) Rechnung tragen muss.

Für die Ausbreitung sprachlicher Innovationen im Raum ist festzuhalten, dass diese weder ausschließlich eine Funktion der räumlichen Distanz ist, noch gänzlich unabhängig von dieser verläuft. Die für die Diffusionsstrukturen bzw. -räume maßgeblichen Faktoren sind jene, die die soziale bzw. sprachliche Interaktion zwischen in verschiedenen Orten angesiedelten Sprechern bestimmen. Dabei sind ,die bisher von der Sprachgeographie genutzten Faktoren (politisch-administrative, kirchliche, sonstige kulturelle Grenzen) nur die am leichtesten fassbaren, aber vielleicht nicht einmal die wichtigsten“ (Weinhold 1985: 255). 


\section{Empirische Untersuchung}

\subsection{Forschungsziele}

[A] dialectologist is obliged to state explicitly what he wants to find and how he wants to find it - then he is entitled to use the most appropriate method [...] to achieve the desired result. Or, to put it pointedly: method determines the result.

(Schneider 1988: 196)

Die vorliegende Untersuchung soll einen Beitrag zum Verständnis der Entwicklung der sprachlichen - genauer: der diatopischen - Variation in der Region Kampanien leisten, mit dem die bisherigen Forschungsergebnisse auf quantitativer Basis überprüft und ergänzt werden. Während im aktuellen wissenschaftlichen Fokus insbesondere die Dokumentation der Variationsdynamik im Kontinuum zwischen Dialekt und Standarditalienisch anhand ausgewählter Phänomene und Orte steht, beschränkt sich die hier unternommene Analyse auf die Variation auf dialektaler Ebene, berücksichtigt jedoch eine größere Anzahl an Variationsphänomenen und umfasst die gesamte Region. Sie versteht sich somit als makroanalytisches Komplement der vorliegenden mikroanalytischen Untersuchungen.

Die Studie dient der Bearbeitung einiger im Bereich der Analyse der diatopischen Variation in der Campania bestehender Forschungsdesiderata (vgl. Kap. 3.3.5 - 3.3.7). Erstes Ziel der empirischen Untersuchung ist eine isoglossenunabhängige Analyse der basilektalen Gliederung der Campania auf der Basis einer statistisch relevanten, in den 1960er Jahren erhobenen Datenmenge, bei der die sprachlichen Ebenen der Phonetik/Phonologie und des Lexikons berücksichtigt werden. Hierbei wird ein sprachgeographisches Verfahren verwendet, mit dem Ähnlichkeitsverhältnisse zwischen Dialekten und damit die sprachlichen Raummuster bzw. Ordnungsstrukturen eines Gebietes sichtbar gemacht werden können. Als in der epistemologischen Tradition der klassischen romanischen Sprachgeographie stehende Methodik eignet sich die Salzburger Dialektometrie (S-DM, vgl. Kap. 4.3) im gegebenen (romanistischen) Forschungskontext besser als in anderen Kontexten entwickelte Verfahren. Zudem liegt mit dem Softwarepaket VDM eine EDV-technische Implementierung des Salzburger Verfahrens vor, die nicht nur die automatische Berechnung der sprachlichen Ähnlichkeitswerte ermöglicht, sondern durch die Integration verschiedener Heuristika auch verschiedene Möglichkeiten zur Visualisierung der Ergebnisse bereitstellt. Neben dem Gesamtkorpus können hier auch einzelne Teilkorpora separat ausgewertet und die geographische Verteilung der sprachlichen Varianten anhand von Arbeitskarten eingesehen werden.

Zweites Ziel der Arbeit ist die Analyse der Entwicklung der sprachlichen Raumstrukturen in der Campania in der zweiten Hälfte des 20. Jahrhunderts, anhand derer die Hypothesen, die sich bezüglich der Entwicklung der diatopischen Variation in der Campania finden lassen (Italianisierung und ,Neapolitanisierung' der Dialekte, vgl. Kap. 3.3.6 und 3.3.7), auf quantitativer Basis überprüft werden sollen. Dies geschieht durch die dialektometrische Auswertung eines zweiten, identisch strukturierten, jedoch jüngeren Sets von Dialektdaten und durch den Vergleich der resultierenden sprachlichen Raumstrukturen mit jenen des ersten, älteren Datensets. ${ }^{340}$ Anhand des diachronischen Vergleichs soll zudem die Entwicklung des strukturellen

\footnotetext{
${ }^{340}$ Der Vergleich zweier zu verschiedenen historischen Zeitpunkten erhobener, identisch strukturierter Datensets (bzw. der bei der räumlichen Umlegung der Daten entstehenden Karten) entspricht dem von Lalanne (1953: 274) formulierten Desiderat nach der Integration der zeitlichen Dimension in die sprachgeographische Forschung: „Nos cartes ne connaissent que la longitude et la latitude : il nous manque la troisième dimension de notre objet,
} 
Verhältnisses der kampanischen Dialekte zum Standarditalienischen untersucht werden. Auch wenn eine solche Analyse über die eigentliche Zielsetzung der (romanistischen) Dialektometrie (Messung von Ähnlichkeitsverhältnissen zwischen Dialekten zur Sichtbarmachung sprachlicher Raummuster, vgl. Kap. 4.3.1) hinausgeht, soll angesichts der wissenschaftlichen Aktualität des Themas (Italianisierung der Dialekte, vgl. Kap. 2.3 und 3.3.6) versucht werden, auch auf dialektometrischem Wege Erkenntnisse über die strukturelle Annäherung der kampanischen Dialekte an das Italienische zu gewinnen. ${ }^{341}$

Die genannten Arbeitsziele und die daran geknüpfte Methodik können nur dann erreicht bzw. angewandt werden, wenn das zugrunde liegende Datenmaterial bestimmte Anforderungen erfüllt. Oberstes Kriterium bei der Erstellung einer dialektometrischen Datenbasis ist stets die Interkomparabilität der Daten, die deren systematische Erhebung voraussetzt. Bei den in der Analyse verwendeten Datensets handelt es sich einerseits um eine Auswahl an Karten und Ortspunkten aus dem Atlante Linguistico Italiano (ALI) und andererseits um ein auf der Basis eines aus den ausgewählten Karten (bzw. den entsprechenden Lemmata) zusammengestellten Fragebuchs in denselben Ortspunkten erhobenes Vergleichskorpus.

\subsection{Datenbasis}

\subsubsection{Der Atlante Linguistico Italiano (ALI)}

\subsubsection{Struktur und Entstehungsgeschichte}

Der Atlante Linguistico Italiano (ALI) ist ein zwischen 1995 und 2008 in insgesamt 8 Bänden (831 Karten) vom Istituto dell'Atlante Linguistico Italiano (Turin) herausgegebener Sprachatlas Italiens. ${ }^{342}$ Die Erhebungen der Sprachdaten fanden in Norditalien im Zeitraum zwischen 1925 und 1943 und in Mittel- und Süditalien zwischen 1952 und 1965 statt. Das Ortsnetz des Atlasses besteht aus 1036 Messpunkten, von denen 993 innerhalb Italiens und 43 außerhalb Italiens (davon 10 in Slowenien, 32 in Kroatien, 1 in Frankreich) liegen. Das Fragebuch (Questionario) umfasst im Hauptteil (Parte Generale) die Lemmata 1-3544 und im Zusatzteil (Parte Speciale) die Lemmata 3545-7659. ${ }^{343}$

Der ALI wurde im Jahr 1924 auf die Initiative der Società Filologica Friulana Graziadio Isaia Ascoli (Udine) hin am Lehrstuhl für Linguistik (später Glottologie) der Università degli Studi di Torino unter der Leitung von Matteo Giulio Bartoli (1873-1946) ins Leben gerufen. ${ }^{344}$ Ziel war die Erstellung eines ,,atlante unitario e totalitario, conforme alla realtà linguistica unitaria e totalitaria d'Italia, cioè alla evidente realtà nazionale“ (Vidossi 1933: 19), der

\footnotetext{
je veux dire la profondeur ou le temps. [.... La superposition de ces cartes en profondeur serait encore plus féconde, sous beaucoup d'aspects, que l'étude de nos atlas pelliculaires.“

${ }^{341}$ Da die Beziehungen, die die italienischen Dialekten und das Standarditalienische zueinander aufweisen, nicht auf der räumlichen bzw. horizontalen, sondern auf der vertikalen Achse der sprachlichen Variation liegen, handelt es hier also nicht um eine Analyse sprachlicher Raumstrukturen, sondern um die Analyse der (numerischen) Ähnlichkeit - und ihrer Entwicklung - zwischen den dialektalen Sprachsystemen auf der einen und dem standarditalienischen Sprachsystem auf der anderen Seite.

${ }^{342} \mathrm{Ab} 1933$ erschien (mit mehreren Unterbrechungen) als zugehörige Zeitschrift das Bollettino dell'Atlante Linguistico Italiano (BALI) mit Beiträgen zur Dialektologie, Linguistik, Philologie und Ethnographie.

${ }^{343}$ In den Messpunkten wurden teilweise unterschiedliche Ausschnitte aus beiden Teilen abgefragt, vgl. Bartoli/Pellis (1995).

${ }^{344}$ Sofern nicht anders indiziert, basieren die Angaben zum Verlauf des Projektes auf den auf der Homepage des ALI (http://www.atlantelinguistico.it, zuletzt konsultiert am 11.07.2015) in der Rubrik „Il Progetto“ verfügbaren Informationen.
} 
insbesondere die sprachliche ,attualità“, d.h. die „fenomeni della vita del linguaggio“ (Vidossi 1933: 19) widerspiegeln sollte. ${ }^{345}$ Von großer Bedeutung war für die Initiatoren dabei insbesondere die Abgrenzung vom Sprach- und Sachatlas Italiens und der Südschweiz (AIS) der Schweizer Romanisten Karl Jaberg und Jakob Jud ${ }^{346}$ - zu dem die Erhebungen seit Ende 1919 liefen - „1) per l'ampiezza del questionario; 2) per il numero dei punti d'assaggio; 3) per i criteri seguiti nella compilazione del questionario e nella scelta dei punti d'assaggio; ${ }^{347}$ 4) per il modo come fu concepito da studiosi italiani come opera italiana; 5) per l'inclusione di tutti i territori italiani situati fuori dei confini del Regno; 6) per l'inclusione di tutte le «penisole e isole alloglottiche » che si trovano nei confini del Regno, nonché dei gerghi che vi si parlano“ (Vidossi 1933: 6). Beiden Atlasprojekten gemein sind jedoch die methodischen Grundprinzipien der ,unicità del raccoglitore ${ }^{\text {“348 }}$ und der ,,uniformità delle domande“ (ebd.), die die Einheitlichkeit und Vergleichbarkeit der Daten garantieren sollten.

Als Explorator gewann Bartoli den Philologen und Präsidenten der Società Filologica Friulana, Ugo Pellis (1882-1943), der neben einer ,profonda conoscenza teorica e [...] ampia esperienza pratica, in fatto d'analisi fonetica di parlate italiane e alloglottiche" (Vidossi 1933: 9) über „doti notevoli di comprensione e di intuizione psicologica“ (Terracini 1955: 6) verfügte und ein ausgeprägtes Interesse an der ethnographischen und linguistischen Forschung zeigte (ebd.: 5f.). Pellis führte zwischen 1925 und 1943 insgesamt 727 Befragungen in Nord- und Mittelitalien sowie auf Sardinien durch - die von ihm zusammengetragenen Materialien wurden in Udine archiviert.

Die Realisierung des Atlasprojektes war von Beginn an durch „,croniche gravi difficoltà economiche e organizzative“ (Massobrio 1992: 291) geprägt. Die mit dem Eintritt Italiens in den Zweiten Weltkrieg zum Erliegen gekommenen Arbeiten konnten nach dem Tod von Ugo Pellis im Jahr 1943 und jenem Matteo Bartolis im Jahr 1946 zunächst nicht wieder aufgenommen werden. Durch den Einsatz des verbliebenen Komitee-Mitglieds Giuseppe Vidossi (18781969) konnte schließlich im Jahre 1947 der aus seinem argentinischen Exil zurückgekehrte Benvenuto Terracini (1886-1968) für die Weiterführung des Projektes gewonnen werden. ${ }^{349}$ Um die verbleibenden Erhebungen in Mittel- und Süditalien so schnell wie möglich durchführen zu können, wurden diese auf verschiedene Exploratoren ${ }^{350}$ verteilt und konnten im Jahr 1965 abgeschlossen werden.

\footnotetext{
${ }^{345}$ Damit unterschied sich Bartolis Konzeption des Sprachatlasses von der seines Lehrers Gilliéron, der auch dem sprachhistorischen Gehalt der synchronen Dokumentation der Dialekte eine hohe Bedeutung beigemessen hatte: „Un atlante, scrisse Bartoli, deve essere uno strumento di lavoro e non soltanto un museo di antichità“ (Terracini 1955: 4).

${ }^{346}$ Vgl. Kap. 4.1.1. Zur Konzipierung des AIS vgl. Jaberg/Jud (1928). Aufgrund der geringen Anzahl der Aufnahmeorte auf dem (heutigen) Gebiet der Region Kampanien (11 Punkte) eignet dieser sich nicht als Datenbasis für eine Analyse der dialektalen Gliederung mit dialektometrischen Mitteln.

${ }^{347}$ Im Hinblick auf die Zusammenstellung des Fragebuchs finden sich Unterschiede in Auswahl, Anordnung, Formulierung und Verbindung der Fragen (vgl. Vidossi 1933: 5) gegenüber dem für den Questionario des AIS maßgeblichen Gilliéronschen Muster. Die Auswahl der Aufnahmeorte des ALI erfolgte „,con riguardo ai criteri economico, culturale, ecclesiastico [...] e [...] in quanto possibile, con riguardo alla norma dell'equidistanza“" (ebd.: 16).

${ }^{448}$ Das aus der Gilliéronschen Konzeption übernommene Prinzip des „esploratore unico“ konnte jedoch weder bei den Aufnahmen für den AIS (neben Paul Scheuermeier (1888-1973) erhoben Gerhard Rohlfs (1892-1986) und Max Leopold Wagner (1880-1962)), noch bei jenen für den ALI (Ugo Pellis starb vor Beendigung der Aufnahmen, s.u.) eingehalten werden.

${ }^{349}$ Die Arbeit Vidossis und Terracinis an der Weiterführung des ALI folgte strikt dem einst von Bartoli erstellten Plan, ,facendo tacere ogni velleità di innovazione che esca dal quadro generale che è stato tracciato una volta per tutte“" (Terracini 1955: 8).

${ }^{350}$ Es waren dies Raffaele Giacomelli (1952-1956, Mittelitalien, Latium, Kampanien), Corrado Grassi (1955-

1957, Kalabrien, Apulien, Basilicata), Giorgio Piccitto (1956-1957, Sizilien), Temistocle Franceschi (1958-1964,
} 
Mit dem Tod von Benvenuto Terracini im Jahr 1968 kam das Projekt ein weiteres Mal zum Stillstand. Zwar übernahm Corrado Grassi (1969-1982) die Leitung; Lösungen für die andauernden gravierenden strukturellen und finanziellen Probleme konnten jedoch erst gegen Ende der 1980er Jahre unter Arturo Genre (1983-1989) und insbesondere unter Lorenzo Massobrio (seit 1990) gefunden werden. Ein Meilenstein war hierbei die rechtliche Anerkennung des Istituto dell'Atlante Linguistico Italiano als „Centro autonomo di ricerca dell'Università degli Studi di Torino“"im Jahr 1987.

Nachdem mit dem Istituto Poligrafico e Zecca dello Stato (Rom) ein Verleger für die ersten Bände des Atlaswerkes gefunden war, konnte die Publikation - nach der Erprobung verschiedener Techniken zur Erstellung einer elektronischen Datenbank für die sprachlichen Materialien und zur computergesteuerten Kartographie - im Jahr 1995 beginnen. Tab. 16 zeigt die konzeptuelle Anordnung der auf insgesamt acht Bände verteilten Atlaskarten.

\begin{tabular}{|c|c|c|}
\hline Band & Titel (konzeptuelle Bereiche) & Karten \\
\hline $\mathrm{I}$ & $\begin{array}{l}\text { Il corpo umano: anatomia, qualità e } \\
\text { difetti fisici, protesi popolari }\end{array}$ & $1-93$ \\
\hline II & $\begin{array}{l}\text { Il corpo umano: funzioni principali, } \\
\text { malesseri e affezioni patologiche co- } \\
\text { muni, malattie principali }\end{array}$ & $94-202$ \\
\hline III & Indumenti e abbigliamento & $203-297$ \\
\hline IV & $\begin{array}{l}\text { La casa e l'arredamento: l'esterno, } \\
\text { l'interno e l'arredo (il tinello, la } \\
\text { camera da letto) }\end{array}$ & $298-392$ \\
\hline $\mathrm{V}$ & La casa e l'arredamento: la cucina & $393-524$ \\
\hline VI & L'alimentazione & $525-614$ \\
\hline VII & $\begin{array}{l}\text { La famiglia e le età dell'uomo: la } \\
\text { vita in famiglia; il bimbo e il ragazzi- } \\
\text { no }\end{array}$ & $615-724$ \\
\hline VIII & $\begin{array}{l}\text { Le età dell'uomo: la scuola, } i \\
\text { giovani, il matrimonio, adulti e } \\
\text { anziani, parentela }\end{array}$ & $725-831$ \\
\hline
\end{tabular}

Tabelle 16. Struktur des ALI. ${ }^{351}$ Die Zusammenstellung der Karten im Atlas weicht von der Reihenfolge der Lemmata im Questionario ab.

\subsubsection{Arbeitskorpus (1954-1964)}

Auf dem (heutigen) Gebiet der Region Kampanien wurden die Erhebungen der Sprachdaten für den ALI zwischen 1954 und 1964 von den Exploratoren Raffaele Giacomelli (18781956) und Temistocle Franceschi $(* 1928)$ in insgesamt 37 Messpunkten durchgeführt. ${ }^{352}$ Bei

\footnotetext{
Toskana, Emilia-Romagna, Kampanien, Kalabrien, Basilicata), Giovanni Tropea (1960-1964, Sizilien) und Michele Melillo (1961-1964, Apulien, Basilicata).

${ }^{351}$ Zum Datenmaterial des Atlas gehören darüber hinaus etwa 10.000 ethnographische Fotografien.

${ }^{352}$ Bei den Erhebungen wurden je Ort ein bis zwei primäre Gewährspersonen und eine Kontroll-Gewährsperson befragt. Antworten der Kontroll-Gewährspersonen sind auf den Karten mit ai (=altro informatore) gekennzeichnet. Die primären Gewährspersonen gehörten zu verschiedenen Altersgruppen (vgl. Bartoli/Pellis 1995).
} 
der Festlegung des der Analyse zugrunde zu legenden Ortsnetzes wurden - neben der albanischen Sprachinsel Greci (817) - jene Punkte ausgeschlossen, in denen das Datenmaterial des ALI für eine dialektometrische Untersuchung zu lückenhaft ist (Atrani (853) an der Amalfiküste sowie Camerota (879) und San Giovanni a Piro (880) im Cilento). Auf der anderen Seite wurden dem Ortsnetz zwei Messpunkte - Bovino (819) und Candela (827) ${ }^{353}$ - hinzugefügt, die zwar jenseits der heutigen Grenze der Region Kampanien zur Region Apulien, in der Provinz Foggia liegen, jedoch enge historische Verbindungen zur Campania aufweisen (vgl. Kap. 3.2). ${ }^{354}$ Integriert wurde zudem der künstliche Prüfbezugspunkt italiano standard/Standarditalienisch (900), sodass das Ortsnetz der dialektometrischen Untersuchung insgesamt 36 Messpunkte umfasst (s. Tab. 17). Karte 39 zeigt die stumme Karte des Ortsnetzes, die mittels des Programms ArcGIS 9.3 generiert und - mithilfe des von B. Castellazzi (2010) erstellten Leitfadens - in das Programm VDM exportiert wurde.

Im zweiten Schritt der Festlegung des Taxandums wurden die Originalkarten ${ }^{355}$ bzw. die dem Ortsnetz entsprechenden Kartenausschnitte des ALI im Hinblick auf ihre Eignung für eine taxatorische Erfassung überprüft. Karten, die (im ausgewählten Ausschnitt) mehr als 7 (= 20\%) Nullstellen enthielten, wurden aus der Taxierung ausgeschlossen. ${ }^{356}$ Für die phonetische Taxierung wurden nur solche Karten ausgewählt, deren Daten eine Variation im Hinblick auf die berücksichtigten phonetischen Merkmale (s. Tab. 21) aufwiesen. Um einen überdurchschnittlich hohen Einfluss einzelner Lexeme auf das Messergebnis zu vermeiden, wurde bei Vorliegen mehrerer Flexionsformen eines Lexems mit demselben phonetischen Merkmal (z.B. Entwicklung von bet. $\check{E}$ in [ka'pjellə] ,capello', ,capelli`) nur jeweils eine Form im Hinblick auf dieses Merkmal taxiert.

Damit erfolgte die Taxierung zunächst für 207 Originalkarten. Um eine exakte Vergleichbarkeit zwischen dem auf der Basis des ALI erstellten Korpus und dem selbst erhobenen Vergleichskorpus zu gewährleisten, musste diese Menge jedoch im Anschluss an die eigene Datenerhebung um jene Karten reduziert werden, für die das Vergleichskorpus keine Taxierung zuließ (vgl. Kap. 5.2.2). Das endgültige dem ALI entnommene Arbeitskorpus umfasst 189 Originalkarten (s. Tab. 18).

\footnotetext{
${ }^{353}$ In diesen beiden Punkten waren die Erhebungen von Michele Melillo (1915-2004) durchgeführt worden.

354 Das Gebiet, in denen beide Orte liegen (der Subappennino Dauno) ist sprachgeographisch schwer einzuordnen: Nach Pellegrini (1977, Kartenlegende) handelt es sich um eine ,area mista di complessa classificazione“.

${ }^{355}$ Entsprechend dem in der Dialektometrie etablierten Gebrauch ist mit dem Begriff ,Originalkarte " nicht die (gegenständliche) Atlaskarte, sondern die Gesamtheit der zu einem Lemma eingetragenen Belege gemeint, die häufig nur einen Teil der auf einer Atlaskarte notierten Daten darstellen.

${ }^{356}$ Der im Vergleich zu anderen dialektometrischen Untersuchungen relativ hohe Anteil an tolerierten Nullstellen ist der in Süditalien im Allgemeinen und im Untersuchungsareal im Besonderen vergleichsweise großen Lückenhaftigkeit der Daten des ALI geschuldet.
} 


\begin{tabular}{|c|c|c|c|}
\hline Gemeinde (Kürzel Provinz) & ALI-Nr. & Explorator & Jahr der Erhebung \\
\hline Alfano (SA) & 873 & R. Giacomelli & 1955 \\
\hline Anacapri (NA) & 851 & R. Giacomelli & 1955 \\
\hline Avellino (AV) & 838 & T. Franceschi & 1960 \\
\hline Barano d'Ischia (NA) & 833 & R. Giacomelli & 1955 \\
\hline Benevento (BN) & 825 & R. Giacomelli & 1956 \\
\hline Bovino (FG) & 819 & M. Melillo & 1962 \\
\hline Cairano (AV) & 841 & T. Franceschi & 1964 \\
\hline Candela (FG) & 827 & M. Melillo & 1963 \\
\hline Capaccio (SA) & 863 & T. Franceschi & 1961 \\
\hline Casal di Prìncipe (CE) & 823 & R. Giacomelli & 1955 \\
\hline Casaletto Spartano (SA) & 874 & R. Giacomelli & 1955 \\
\hline Castel Volturno (CE) & 822 & T. Franceschi & 1960 \\
\hline Fontegreca $(\mathrm{CE})$ & 810 & R. Giacomelli & 1954 \\
\hline Ginestra degli Schiavoni (BN) & 816 & T. Franceschi & 1964 \\
\hline Gioia Sannìtica (CE) & 814 & T. Franceschi & 1961 \\
\hline Laurino (SA) & 864 & T. Franceschi & 1961 \\
\hline Limàtola $(\mathrm{BN})$ & 824 & T. Franceschi & 1961 \\
\hline Maiori (SA) & 854 & T. Franceschi & 1960 \\
\hline Melito Irpino (AV) & 826 & T. Franceschi & 1964 \\
\hline Montella (AV) & 839 & T. Franceschi & 1964 \\
\hline Monte San Giacomo (SA) & 865 & R. Giacomelli & 1955 \\
\hline Napoli (NA) & 835 & R. Giacomelli & 1955 \\
\hline Olèvano sul Tusciano (SA) & 856 & T. Franceschi & 1961 \\
\hline Pòllica (SA) & 872 & T. Franceschi & 1961 \\
\hline Postiglione (SA) & 857 & T. Franceschi & 1962 \\
\hline Pròcida (NA) & 834 & R. Giacomelli & 1955 \\
\hline Reìno (BN) & 815 & T. Franceschi & 1962 \\
\hline Rocca d'Evandro (CE) & 809 & T. Franceschi & 1961 \\
\hline Roccaraìnola (NA) & 836 & T. Franceschi & 1961 \\
\hline Salerno (SA) & 855 & R. Giacomelli & 1956 \\
\hline Salvitelle (SA) & 858 & T. Franceschi & 1962 \\
\hline Sarno (SA) & 837 & T. Franceschi & 1960 \\
\hline Senerchia (AV) & 840 & T. Franceschi & 1962 \\
\hline Sorrento (NA) & 852 & R. Giacomelli & 1956 \\
\hline Teano $(\mathrm{CE})$ & 813 & R. Giacomelli & 1956 \\
\hline
\end{tabular}

Tabelle 17. Basisdaten zu den für den ALI vorgenommenen sprachlichen Erhebungen im Messpunktnetz. 


\section{ALI (1995-2008) - Campania}

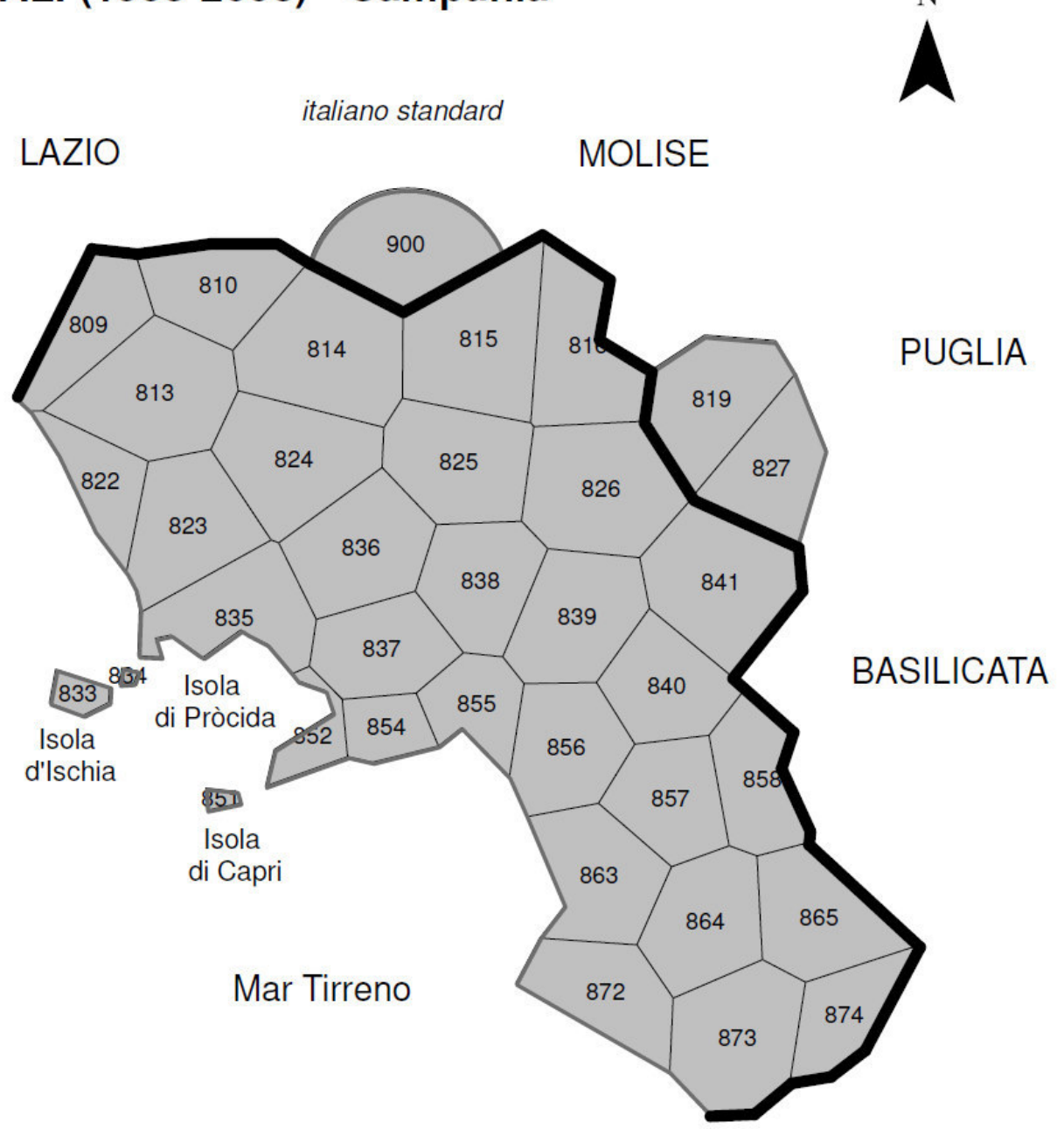

fec. S. Hajek

adiuv. H. Goebl et P. Smečka

adiuv. B. Castellazzi

a.d. 2013 carta di THIESSEN/HAAG/VORONOI 35 punti d'inchiesta + italiano standard

Karte 39. Stumme Karte des der Untersuchung zugrunde liegenden Ortsnetzes. 


\begin{tabular}{|l|l|l|l|}
\hline Originalkarten & \multicolumn{2}{l|}{ ALI } \\
\hline Nr. & Titel & Karten-Nr. & Band \\
\hline 1 & osso & 2 & I \\
\hline 3 & pelle & 6 & I \\
\hline 4 & cervello & 10 & I \\
\hline 5 & capelli & 11 & I \\
\hline 7 & occhio & 19 & I \\
\hline 8 & orecchio & 22 & I \\
\hline 9 & baffi & 27 & I \\
\hline 10 & bocca & 28 & I \\
\hline 11 & labbro & 29 & I \\
\hline 12 & dente & 30 & I \\
\hline 13 & mento & 36 & I \\
\hline 14 & collo & 37 & I \\
\hline 15 & spalla & 40 & I \\
\hline 16 & braccio & 41 & I \\
\hline 17 & destra & 42 & I \\
\hline 18 & gomito & 43 & I \\
\hline 19 & dito & 47 & I \\
\hline 20 & mignolo & 48 & I \\
\hline 21 & petto & 50 & I \\
\hline 22 & mamella & 51 & I \\
\hline 23 & ventre & 58 & I \\
\hline 24 & ombelico & 60 & I \\
\hline 25 & fianco & 62 & I \\
\hline 26 & gamba & 67 & I \\
\hline 27 & ginocchio & 68 & I \\
\hline 28 & piede & 71 & I \\
\hline 29 & calcagno & 72 & I \\
\hline 30 & grasso & 75 & I \\
\hline 33 & neo & 90 & I \\
\hline 34 & occhiali & 91 & I \\
\hline 35 & stampelle & 92 & I \\
\hline 36 & vedere & 94 & II \\
\hline 37 & guardate & 96 & II \\
\hline 38 & piangi & 97 & II \\
\hline 39 & puzza & 101 & II \\
\hline 40 & pulirti il naso & 103 & II \\
\hline 41 & fiato & 104 & II \\
\hline 42 & buono & 109 & II \\
\hline 43 & sbadiglio & 111 & II \\
\hline 44 & state zitti & 115 & II \\
\hline 45 & io) fischio & 118 & \\
\hline & & & \\
\hline
\end{tabular}

\begin{tabular}{|c|c|c|c|}
\hline \multicolumn{2}{|c|}{ Originalkarten } & \multicolumn{2}{|l|}{ ALI } \\
\hline Nr. & Titel & Karten-Nr. & Band \\
\hline 46 & sputare & 121 & II \\
\hline 47 & solletico & 130 & II \\
\hline 48 & dormire & 132 & II \\
\hline 49 & sonno & 135 & II \\
\hline 50 & peto & 144 & II \\
\hline 51 & sudore & 146 & II \\
\hline 53 & rauco & 157 & II \\
\hline 54 & geloni & 161 & II \\
\hline 55 & callo & 162 & II \\
\hline 56 & diarrea & 163 & II \\
\hline 57 & febbre & 169 & II \\
\hline 58 & pallido & 170 & II \\
\hline 59 & grattarsi & 172 & II \\
\hline 60 & piaga & 175 & II \\
\hline 61 & morbillo & 178 & II \\
\hline 63 & orecchioni & 184 & II \\
\hline 64 & vermi & 190 & II \\
\hline 65 & pazzo & 200 & II \\
\hline 66 & cappello & 203 & III \\
\hline 67 & cuffietta & 208 & III \\
\hline 68 & sciarpa & 210 & III \\
\hline 69 & $\begin{array}{l}\text { bavero della } \\
\text { giacca }\end{array}$ & 212 & III \\
\hline 71 & $\begin{array}{l}\text { corpetto da } \\
\text { uomo }\end{array}$ & 221 & III \\
\hline 72 & calzoni & 228 & III \\
\hline 73 & gonna & 235 & III \\
\hline 74 & sottana & 236 & III \\
\hline 75 & grembiule & 237 & III \\
\hline 76 & mutande & 238 & III \\
\hline 77 & guanti & 239 & III \\
\hline 78 & calzino & 242 & III \\
\hline 79 & $\begin{array}{|ll|}\text { calza } & \text { da } \\
\text { donna } & \\
\end{array}$ & 244 & III \\
\hline 80 & scarpa & 246 & III \\
\hline 81 & suola & 250 & III \\
\hline 82 & stringhe & 258 & III \\
\hline 83 & zoccoli & 261 & III \\
\hline 84 & mantello & 265 & III \\
\hline 85 & $\begin{array}{l}\text { cappuccio del } \\
\text { mantello }\end{array}$ & 266 & III \\
\hline 86 & orecchini & 268 & III \\
\hline
\end{tabular}




\begin{tabular}{|c|c|c|c|}
\hline \multicolumn{2}{|c|}{ Originalkarten } & \multicolumn{2}{|l|}{ ALI } \\
\hline Nr. & Titel & Karten-Nr. & Band \\
\hline 87 & anello & 269 & III \\
\hline 88 & fede & 270 & III \\
\hline 89 & orologio & $\begin{array}{l}273 \quad \sim \quad \text { di } \\
\text { tasca })\end{array}$ & III \\
\hline 91 & ventaglio & 278 & III \\
\hline 92 & vestito & 279 & III \\
\hline 93 & nuovo & 280 & III \\
\hline 94 & vecchio & 281 & III \\
\hline 95 & sporco & 283 & III \\
\hline 96 & macchia & 287 & III \\
\hline 97 & strappato & \begin{tabular}{|ll}
288 & (intig- \\
nati) & \\
\end{tabular} & III \\
\hline 99 & nudo & 293 & III \\
\hline 100 & serratura & 314 & IV \\
\hline 101 & chiave & 317 & IV \\
\hline 102 & lucchetto & 323 & IV \\
\hline 103 & tegola & 336 & IV \\
\hline 104 & fumaiolo & 338 & IV \\
\hline 105 & $\begin{array}{l}\text { fiamma della } \\
\text { candela }\end{array}$ & 367 & IV \\
\hline 106 & letto & 370 & IV \\
\hline 107 & lettuccio & 371 & IV \\
\hline 108 & specchio & 385 & IV \\
\hline 109 & cassettone & 390 & IV \\
\hline 110 & $\begin{array}{|ll|}\begin{array}{l}\text { fuoco } \\
\text { focolare }\end{array} & \text { sul } \\
\end{array}$ & 411 & V \\
\hline 111 & fiammifero & 413 & V \\
\hline 112 & brace & 422 & V \\
\hline 113 & fumo & 426 & V \\
\hline 114 & si spegne & 427 & $\mathrm{~V}$ \\
\hline 115 & tagliere & 435 & V \\
\hline 116 & coperchio & 442 & $\mathrm{~V}$ \\
\hline 117 & $\begin{array}{l}\text { ramaiolo per } \\
\text { pentola }\end{array}$ & 443 & $\mathrm{~V}$ \\
\hline 118 & padella & 448 & V \\
\hline 119 & \begin{tabular}{|l|}
$\begin{array}{l}\text { macinino da } \\
\text { caffè }\end{array}$ \\
\end{tabular} & 455 & V \\
\hline 122 & panca & 467 & $\mathrm{~V}$ \\
\hline 123 & sgabello & 468 & $\mathrm{~V}$ \\
\hline 124 & cucchiaio & 474 & $\mathrm{~V}$ \\
\hline 125 & forchetta & 475 & $\mathrm{~V}$ \\
\hline 126 & coltello & 476 & $\mathrm{~V}$ \\
\hline
\end{tabular}

\begin{tabular}{|c|c|c|c|}
\hline \multicolumn{2}{|c|}{ Originalkarten } & \multicolumn{2}{|l|}{ ALI } \\
\hline Nr. & Titel & Karten-Nr. & Band \\
\hline 128 & fiasco & 483 & $\mathrm{~V}$ \\
\hline 129 & turacciolo & 484 & $\mathrm{~V}$ \\
\hline 130 & $\begin{array}{l}\text { cucchiaino da } \\
\text { caffè }\end{array}$ & 497 & V \\
\hline 131 & si lava & 506 & $\mathrm{~V}$ \\
\hline 132 & calda & 507 & $\mathrm{~V}$ \\
\hline 133 & granata & 511 & $\mathrm{~V}$ \\
\hline 134 & \begin{tabular}{|l} 
spazzola da \\
vestiti
\end{tabular} & 522 & V \\
\hline 135 & colazione & 525 & VI \\
\hline 136 & fame & 531 & VI \\
\hline 137 & digiuno & 533 & VI \\
\hline 138 & mi piace più & 534 & VI \\
\hline 139 & $\begin{array}{|ll|}\begin{array}{l}\text { crosta del } \\
\text { pane }\end{array} & \\
\end{array}$ & 536 & VI \\
\hline 140 & $\begin{array}{l}\text { mollica del } \\
\text { pane }\end{array}$ & 537 & VI \\
\hline 141 & duro & 544 & $\mathrm{VI}$ \\
\hline 142 & fetta & 546 & VI \\
\hline 143 & crusca & 550 & VI \\
\hline 144 & brodo & 558 & $\mathrm{VI}$ \\
\hline 145 & spaghetti & 562 & VI \\
\hline 146 & uovo & 571 & VI \\
\hline 147 & $\begin{array}{l}\text { guscio } \\
\text { dell'uovo }\end{array}$ & 572 & VI \\
\hline 148 & salame & 581 & $\mathrm{VI}$ \\
\hline 149 & salsiccia & 582 & VI \\
\hline 150 & insipida & 590 & VI \\
\hline 151 & olio & 592 & VI \\
\hline 152 & grasso & 595 & VI \\
\hline 153 & cotto & 601 & $\mathrm{VI}$ \\
\hline 154 & bollire & 604 & VI \\
\hline 155 & cruda & 605 & VI \\
\hline 156 & $\begin{array}{ll}\begin{array}{l}\text { schiuma } \\
\text { sapone }\end{array} \\
\end{array}$ & 618 & VII \\
\hline 157 & schizzò & 620 & VII \\
\hline 159 & forbici & 625 & VII \\
\hline 161 & pidocchi & 627 & VII \\
\hline 162 & pulce & 628 & VII \\
\hline 163 & cimice & 629 & VII \\
\hline 164 & s'è guardata & 632 & VII \\
\hline
\end{tabular}




\begin{tabular}{|l|l|l|l|}
\hline \multicolumn{2}{|l|}{ Originalkarten } & ALI \\
\hline Nr. & Titel & Karten-Nr. & Band \\
\hline 166 & stanco & 634 & VII \\
\hline 167 & mi svegliò & 635 & VII \\
\hline 168 & alzarci/levarci & 638 & VII \\
\hline 169 & oggi & 639 & VII \\
\hline 170 & tutto il giorno & 641 & VII \\
\hline 171 & di buon'ora & 643 & VII \\
\hline 172 & ieri mattina & 644 & VII \\
\hline 173 & domani & 646 & VII \\
\hline 174 & dopo domani & 648 & VII \\
\hline 175 & doglie & 656 & VII \\
\hline 178 & gemelli & 669 & VII \\
\hline 179 & culla & 679 & VII \\
\hline 180 & giocare & 693 & VII \\
\hline 181 & scuola & 725 & VIII \\
\hline 182 & lavagna & 726 & VIII \\
\hline 183 & cartella & 729 & VIII \\
\hline 184 & stracciato & 732 & VIII \\
\hline 185 & temperino & 734 & VIII \\
\hline 186 & scrivere & 740 & VIII \\
\hline
\end{tabular}

\begin{tabular}{|l|l|l|l|}
\hline \multicolumn{2}{|l|}{ Originalkarten } & ALI & \\
\hline Nr. & Titel & Karten-Nr. & Band \\
\hline 187 & numero & 743 & VIII \\
\hline 188 & maestro & 744 & VIII \\
\hline 190 & schiaffo & 754 & VIII \\
\hline 191 & calcio & 755 & VIII \\
\hline 192 & giovane & 764 & VIII \\
\hline 193 & amico & 765 & VIII \\
\hline 194 & $\begin{array}{l}\text { mazzo di } \\
\text { fiori }\end{array}$ & 770 & VIII \\
\hline 195 & vuol bene & 771 & VIII \\
\hline 196 & mi baci & 774 & VIII \\
\hline 197 & $\begin{array}{l}\text { facciamo } \\
\text { l'amore }\end{array}$ & 778 & VIII \\
\hline 198 & dote & 787 & VIII \\
\hline 199 & sposo & 789 & VIII \\
\hline 200 & $\begin{array}{l}\text { velo da } \\
\text { sposa }\end{array}$ & 790 & VIII \\
\hline 201 & si sposa & 795 & VIII \\
\hline 202 & uomini & 800 & VIII \\
\hline 203 & vedovo & 803 & VIII \\
\hline 204 & mio padre & 805 & VIII \\
\hline 205 & parenti & 811 & VIII \\
\hline 206 & nonno & 812 & VIII \\
\hline 207 & figlioccio & 827 & VIII \\
\hline & & & \\
\hline
\end{tabular}

Tabelle 18. Taxierte Originalkarten mit Angabe der Nummer im Vergleichskorpus und der entsprechenden ALI-Kartennummer. 


\subsubsection{Vergleichskorpus (2014)}

Das für den diachronischen Vergleich benötigte Vergleichskorpus weist dieselbe Struktur auf wie das aus dem ALI extrahierte Korpus. Die Erhebung der Daten fand von April bis Mai 2014 mit einer Ausnahme ${ }^{357}$ in denselben Ortspunkten statt, in denen die Daten für den ALI erhoben worden waren. Als Gewährspersonen wurden dabei nach gängiger sprachgeographischer Pra$\mathrm{xis}^{358}$ bilinguale Sprecher (Beherrschung des Italienischen und des jeweiligen lokalen Dialekts) ausgewählt, die möglichst im jeweiligen Ort geboren, in jedem Fall aber aufgewachsen bzw. primär sozialisiert worden sein sollten. Um einen möglichst aktuellen Sprachstand zu dokumentieren, wurden dabei bevorzugt Sprecher im Alter zwischen 20 und 35 Jahren $^{359}$ ausgewählt. Dabei wurde auf ein ungefähres Gleichgewicht zwischen weiblichen (19) und männlichen Gewährspersonen (16) geachtet. Die Akquisition der Gewährspersonen erfolgte an öffentlichen Orten, wo meist auch in direktem Anschluss die Interviews durchgeführt wurden.

Der in allen besuchten Orten gleichermaßen abgefragte Questionario bestand aus insgesamt 207 Lemmata, die den Titeln der aus dem ALI extrahierten Originalkarten entsprachen. ${ }^{360}$ Zur eindeutigen semantischen Identifizierung des erfragten Lemmas (und zur Vermeidung von Missverständnissen und dadurch bedingte Beeinträchtigungen der Interkomparabilität) wurden den Gewährspersonen zu einem Großteil der substantivischen Lemmata visuelle Stimuli, d.h. Bilder des erfragten Gegenstands und zu einem Großteil der Verben, Adjektive und Adverbien ein Satzkontext präsentiert, in dem das Lemma realisiert bzw. wiederholt werden sollte. ${ }^{361}$ Die Gewährspersonen wurden angewiesen, für die jeweiligen italienischen Lemmata die dialektale Entsprechung zu nennen, die sie a) selbst und b) üblicherweise in der Alltagskommunikation verwenden. Damit sollte die Nennung von Dialektismen vermieden wer-

\footnotetext{
${ }^{357}$ In Falle des Messpunktes 840 musste aufgrund fehlender Disponibilität von Gewährspersonen im ursprünglichen Ort (Senerchia) das eigene Interview im $5 \mathrm{~km}$ entfernten Nachbarort Quaglietta durchgeführt werden. Eine Anpassung des Polygonnetzes, welches ohnehin nur minimale Abweichungen von dem für die Auswertung des ALI-Korpus generierten Netz gezeigt hätte, konnte zu diesem Zeitpunkt nicht mehr vorgenommen werden. ${ }^{358}$ Vgl. Kap. 4.1.1.

${ }^{359}$ In den Fällen, in denen keine geeignete Gewährsperson in der angegebenen Altersklasse zur Verfügung stand, wurde diese nach oben erweitert. In keinem Fall wurde jedoch ein Alter von 43 Jahren überschritten.

Die Untergrenze von 20 Jahren (die lediglich einmal leicht unterschritten wurde), wurde festgelegt, um a) ausreichendes Verständnis für den Zweck der Untersuchung und entsprechende Seriosität bei der Beantwortung der Fragen und b) ein ausreichendes konzeptuelles Wissen auf Seiten der Gewährspersonen zu gewährleisten. ${ }^{360}$ Zur Vermeidung von Verständnisschwierigkeiten wurden bei folgenden Lemmata Änderungen vorgenommen:

(Vestiti) intignati ,Lumpen, (von Motten) zerfressene Kleidung'(ALI 288): Da das Lexem intignato ,zerlumpt, (von Motten) zerfressen' heute nicht mehr bekannt ist, wurde stattdessen nach (vestito) strappato, zerrissene Kleidung' gefragt.

L'orologio di tasca ,Taschenuhr“ (ALI 273): Da in den Daten des ALI lediglich das Hyperonym ,orologio“ realisiert wird und das Konzept ,Taschenuhr' durch cipollone (ALI 275) bereits abgedeckt ist, wurde nur nach ,orologio' gefragt.

Il bricco del caffè ,Kaffeekanne“ (ALI 456): Da das Objekt in Italien nicht zum Ausschank von Kaffee, sondern allenfalls zum Ausschank von Tee oder heißer Schokolade verwendet wird, wurde lediglich nach il bricco ,Kanne' gefragt. Die im ALI häufig vorliegende Antwort cioccolatèra lässt darauf schließen, dass die Situation zum damaligen Aufnahmezeitpunkt vielerorts ähnlich war.

Levarsi ,sich erheben“ (ALI 638) ist im heutigen Italienischen deutlich weniger geläufig als das Synonym alzarsi, daher wurde letzteres gefragt. Auf der ALI-Originalkarte findet sich bei der Angabe des syntaktischen Kontextes, in dem das Lemma gefragt wurde, ,dobbiamo levarci (alzarci)“. Auch hier wurde also bereits auf das geläufigere Verb ausgewichen.

${ }^{361}$ Um Beeinträchtigungen bei der phonetischen Taxierung (vgl. Kap. 5.3.1) zu vermeiden, wurde bei der Auswahl der Satzkontexte für die abgefragten Lemmata auf die Vermeidung von Kontexten geachtet, in denen in den kampanischen Dialekten häufig ein raddoppiamento sintattico stattfindet (vgl. Kap. 3.3.4.2).
} 
den, die den Gewährspersonen - etwa durch die Kommunikation mit Personen älterer Generationen, die diese verwenden - zwar bekannt sind, in ihrem alltäglichen aktiven Dialektgebrauch jedoch nicht mehr vorkommen. Die für die empirische Untersuchung relevanten akustischen Daten wurden unter Verwendung des International Phonetic Alphabet (IPA, 2005) transkribiert und gemeinsam mit den zum Punkt italiano standard (900) ergänzten Daten in einer Matrix des Typs $N$ (36 Messpunkte) x $p$ (207 Originalkarten) ${ }^{362}$ zusammengefasst.

Im Vorfeld der Taxierung musste die Anzahl der Originalkarten um jene reduziert werden, die entweder aufgrund einer zu hohen Anzahl an Nullstellen keine Taxierung zuließen oder mononyme und damit dialektometrisch nicht relevante Arbeitskarten ergeben hätten. Bei den aufgrund einer zu hohen Anzahl an Nullstellen (>7) nicht taxierbaren Originalkarten handelt es sich um folgende: ${ }^{363}$,midollo dell'osso“ (ALI 3), ,chierica‘ (ALI 15), ,gobbo‘ (ALI 85), ,gozzo“ (ALI 86), ,itterizia‘ (ALI 183), ,occhiello‘ (ALI 218), ,cipollone‘ (ALI 275), ,bricco del caffè‘ (ALI 456), , setaccio‘ (ALI 457), , lendini‘ (ALI 626) und ,levatrice‘ (ALI 659). Die aufgrund von Mononymität (sowohl auf der lexikalischen als auch auf der phonetischen Ebene) nicht taxierbaren Originalkarten waren: ,forfora' (ALI 149), ,stretta' (ALI 290), ,bicchiere“ (ALI 481), , pettinare‘ (ALI 623), ,riposare‘ (ALI 633), ,vivo“ (ALI 664) und, a memoria‘ (ALI 748). Die verbleibenden 189 Originalkarten (s. Tab. 18) und ihre aus dem ALI gewonnenen älteren Äquivalente wurden nach bestimmten Richtlinien taxiert, die im folgenden Abschnitt dargestellt werden.

\subsection{Erstellung der Datenmatrix}

\subsubsection{Taxierungsrichtlinien}

Die Taxierung der Originalkarten wurde sowohl für das aus dem ALI extrahierte Korpus als auch für das Vergleichskorpus auf lexikalischer sowie auf phonetischer Ebene vorgenommen. In beiden Bereichen wurden im Vorfeld der Taxierung verschiedene Kategorien (,Typen“) $)^{364}$ eingerichtet und jedem Typ ein eigener Kode zugewiesen. Im lexikalischen Bereich stellen die Typen verschiedene grammatische Kategorien (s. Tab. 19), im phonetischen Bereich verschiedene historische Lautentwicklungen dar, die unter Berücksichtigung von für das Untersuchungsgebiet typischen Variations- bzw. Lautwandelphänomenen (vgl. Kap. 3.3.4.1) festgelegt und zwei verschiedenen „Typbereichen“ - Konsonantismus (KONS) und Vokalismus (VOK) - zugeordnet wurden (s. Tab. 20). Zur Systematisierung des Erfassungsvorgangs wurden - unter Orientierung an der administrativen Zugehörigkeit (Provinzgliederung) und der geographischen Lage der Messpunkte - auf Kopien der Atlaskarten Prüfpfade verzeichnet und die in Listenform vorliegenden Daten des Vergleichskorpus diesen Prüfpfaden entsprechend geordnet.

\footnotetext{
${ }^{362}$ Auch wenn die Originaldaten im Falle des Vergleichskorpus nicht in Form von Karten, sondern in Form von Listen vorliegen, wird - entsprechend der in der Dialektometrie etablierten Terminologie - der Terminus ,Originalkarte' (OK) verwendet.

${ }^{363}$ Zur besseren Vergleichbarkeit wird als Referenz die Nummer der Karte angegeben, auf der die Daten der jeweiligen Originalkarte im ALI verzeichnet sind.

${ }^{364}$ Die hiesige Verwendung des Begriffs „Typ“ im Sinne von „Merkmal“ steht im Zusammenhang mit der entsprechenden Tabelle der dialektometrischen Datenbank (vgl. Tabelle 22) und ist zu unterscheiden von der weitaus geläufigeren Verwendungsweise des Terminus im Sinne von „Taxat“ (vgl. Kap. 4.3.3, vgl. dort auch „Typisierung“ im Sinne von ,Taxierung“).
} 


\begin{tabular}{|l|l|l|c|c|}
\hline Kode & $\begin{array}{l}\text { Ebene } \\
\text { (Typbe- } \\
\text { reich) }\end{array}$ & $\begin{array}{l}\text { grammatische Ka- } \\
\text { tegorie (Typ) }\end{array}$ & $\begin{array}{l}\text { Frequenz (AK) } \\
\text { im ALI-Korpus }\end{array}$ & $\begin{array}{l}\text { Frequenz (AK) im } \\
\text { Vergleichskorpus }\end{array}$ \\
\hline 1 & LEX & Substantiv & 78 & 86 \\
\hline 2 & LEX & Adjektiv & 10 & 11 \\
\hline 3 & LEX & Verb & 13 & 11 \\
\hline 4 & LEX & Adverb + Sonst. & 4 & 4 \\
\hline
\end{tabular}

Tabelle 19. Lexikalische Typen und ihre Frequenzen im ALI-Korpus und im Vergleichskorpus.

\begin{tabular}{|c|c|c|c|c|}
\hline Kode & $\begin{array}{l}\text { Ebene } \\
\text { (Typ- } \\
\text { bereich) }\end{array}$ & Merkmal (Typ) & $\begin{array}{l}\text { Frequenz } \\
\text { (AK) im } \\
\text { ALI-Korpus }\end{array}$ & $\begin{array}{l}\text { Frequenz } \\
\text { (AK) im } \\
\text { Vergleichs- } \\
\text { korpus }\end{array}$ \\
\hline 10 & KONS & Lautentwicklung von $\mathrm{D}^{365}$ & 17 & 15 \\
\hline 11 & KONS & Lautentwicklung von B & 23 & 20 \\
\hline 12 & KONS & Lautentwicklung von $\mathrm{G}$ & 4 & 8 \\
\hline 13 & KONS & Lautentwicklung von LL & 19 & 16 \\
\hline 14 & KONS & Lautentwicklung von L $(\backslash \mathrm{KONS})^{366}$ & 4 & 6 \\
\hline 15 & KONS & Lautentwicklung von $\mathrm{S}(\mathrm{IP}, \mathrm{T}, \mathrm{K})$ & 15 & 18 \\
\hline 16 & KONS & Lautentwicklung von FL & 3 & 4 \\
\hline 17 & KONS & Lautentwicklung von PL & 4 & 2 \\
\hline 18 & KONS & Lautentwicklung von CL & 11 & $0^{367}$ \\
\hline 19 & KONS & Lautentwicklung von TS & 2 & 3 \\
\hline 20 & KONS & Lautentwicklung von $\mathrm{C}(\mathrm{I}, \mathrm{E})$ & 6 & 4 \\
\hline 21 & KONS & Lautentwicklung von L (\I, E) & 2 & 4 \\
\hline 22 & KONS & Lautentwicklung von D ( II) & 2 & 3 \\
\hline 23 & KONS & Lautentwicklung von S ( II) & 2 & 2 \\
\hline 24 & KONS & Lautentwicklung von intervok. M & 7 & 7 \\
\hline 25 & KONS & Metathese & 3 & 4 \\
\hline 26 & KONS & Sonstige kons. Lautentwicklungen & 5 & 9 \\
\hline 27 & VOK & $\begin{array}{l}\text { Lautentwicklung von bet. } \breve{E} \\
\text { (lauslaut. } \overline{\mathrm{I}}, \breve{\mathrm{U}} \text { ) }\end{array}$ & 14 & 16 \\
\hline 28 & VOK & $\begin{array}{l}\text { Lautentwicklung von bet. Ǒ } \\
\text { (lauslaut. } \overline{\mathrm{I}}, \breve{\mathrm{U}} \text { ) }\end{array}$ & 14 & 16 \\
\hline 29 & VOK & Lautentwicklung von bet. A & 6 & 7 \\
\hline 30 & VOK & Aphärese & 2 & 4 \\
\hline 31 & VOK & Synkope & 2 & 2 \\
\hline 32 & VOK & Sonstige vok. Lautentwicklungen & 2 & 2 \\
\hline
\end{tabular}

\footnotetext{
${ }^{365}$ Großbuchstaben stehen für die im jeweiligen (nicht notwendigerweise lateinischen) Etymon vorliegenden Laute.

${ }^{366}$ Folgt dem taxierten Nexus eine Klammer, so gibt diese das jeweils relevante phonetische Umfeld an. Der Schrägstrich wird hierbei im Sinne von, vor ' verwendet. Werden die dahinter genannten Nexus durch ein Komma getrennt, so ist dies im Sinne von ,oder' zu interpretieren.

${ }^{367}$ Keine Taxierung möglich, da alle Originalkarten mononym (s. Tab. 21, S. 214f.).
} 


\begin{tabular}{|l|l|l|l|l|}
\hline 33 & VOK & Sonstige vok. Lautentwicklungen & & 1 \\
\hline
\end{tabular}

Tabelle 20. Phonetische Merkmale (Typen) und ihre Frequenzen im ALI-Korpus und im Vergleichskorpus.

Im ersten Taxierungsschritt wurde(n) die taxatorische(n) Kategorie(n) der ausgewählten Originalkarten (lexikalisch und/oder phonetisch, mitsamt der jeweiligen Merkmale) anhand des Formulars $\alpha$ (Taxierungs-Leitblatt, s. Abb. 16) erfasst. ${ }^{369}$ Eine phonetische Taxierung lexikalisch relevanter Karten wurde nur in den Fällen vorgenommen, in denen nicht mehr als 7 (= 20\%) der Messpunkte etymologisch unterschiedliche Taxate aufwiesen. Diese wurden bei der phonetischen Taxierung als Nullstellen gezählt.

Im zweiten Schritt wurden für jede Originalkarte die dort $\mathrm{zu}$ den verschiedenen Merkmalen jeweils vorhandenen Antwortbelege zu Taxaten zusammengefasst und diese anhand der Erfassungsformulare $\beta$ (phonetische Taxierung, s. Abb. 17) und $\gamma$ (lexikalische Taxierung, s. Abb. 18) registriert. Nebenstehend wurden - für Phonetik und Lexikon separat die dadurch generierten Arbeitskarten fortlaufend nummeriert.

Die Bildung der Taxate erfolgte auf der Basis allgemeiner Richtlinien, die im lexikalischen und im phonetischen Bereich jeweils um spezielle Richtlinien ergänzt wurden. Folgende Richtlinien galten allgemein:

1) Unter den vorhandenen Antwortlemmata werden lediglich jene berücksichtigt, die der primären Gewährsperson zuzuordnen sind. Die Antwort einer zweiten Gewährsperson (Kennzeichen im ALI: $a i=$ altro informatore) wird nur in den Fällen berücksichtigt, in denen keine Antwort der primären Gewährsperson vorliegt oder die Antwort nicht verwertbar ist (s.u.). ${ }^{370}$

2) Gibt die primäre Gewährsperson mehrere Antworten, so ist grundsätzlich nur die erste Antwort relevant. ${ }^{371}$ Ausnahmen zu dieser Regel stellen die folgenden Fälle dar:

a) Im Falle einer Autokorrektur der Gewährsperson wird nicht die zuerst gegebene Antwort, sondern die Korrektur taxiert.

b) Wird im ALI die Transkription der Erstantwort gefolgt von dem Zeichen [ ? ], welches die Unsicherheit der Gewährsperson bezüglich der Richtigkeit der Antwort markiert, wird - soweit vorliegend - ebenfalls die Zweitantwort taxiert.

c) Ist die Erstantwort nicht verwertbar (z.B. aufgrund unterschiedlicher Etymologie, s.u.) und liegen alternative Antworten vor, werden diese bei entsprechender Eignung taxiert.

3) Das für das Standarditalienische jeweils anzusetzende Taxat entspricht dem Titel der Originalkarte. Für die Taxierung auf phonetischer Ebene wird die im Grande Dizionario Italiano dell'Uso (De Mauro 2000) vermerkte lautliche Realisierung zugrunde gelegt.

\footnotetext{
${ }^{368}$ Dieses Merkmal wurde hinzugefügt, um die vokalische Mehrfachtaxierung der Karte ,orologio“ (ALI 273) in der Kategorie „Sonstige vok. Lautentwicklungen“ (Taxierung von O ( $\backslash R)$ und O ( $(L)$ ) ohne Schlüsselverletzungen in die Datenbank einfügen zu können.

${ }^{369}$ Die Erfassungsformulare wurden nach dem in der S-DM etablierten Muster erstellt (s. Bauer 2009: 164ff.).

${ }^{370}$ Da bei den Erhebungen zum Vergleichskorpus neben der Exploratorin und der primären Gewährsperson häufig weitere Personen während der Aufnahme zugegen waren, liegen auch im Vergleichskorpus teilweise mehrere Antwortlemmata vor. Zur Vermeidung von diachronischen Verzerrungseffekten wurde in diesem Fall die Antwort einer zweiten Gewährsperson (bei fehlender Antwort der primären Gewährsperson) nur dann taxiert, wenn das Alter der Person nicht offensichtlich die festgelegte Obergrenze überstieg.

${ }^{371}$ Vgl. Kap. 4.3.3, FN 260. Durch die häufige Beschränkung auf eine primäre Gewährsperson pro Ortspunkt weisen sowohl das aus dem ALI extrahierte Korpus als auch das Vergleichskorpus eine überschaubare Anzahl von Mehrfachantworten auf.
} 
Für die lexikalische Taxierung galten zusätzlich folgende Prinzipien (zu 1) bis 3) vgl. Goebl 1984: 34):

1) Antwortlemmata mit unterschiedlichen Etyma bilden je ein eigenes Taxat (z.B. gilè vs. cammisòla ,corpetto' (ALI 221)). ${ }^{372}$

2) Antwortlemmata, die (im Basiswort) dasselbe Etymon haben, aber wortbildungstechnisch voneinander verschieden sind (Präfigierung, Suffigierung, Infigierung und auch Nullableitung), bilden je ein eigenes Taxat (z.B. cuffietta vs. cuffia ,cuffietta da bambini' (ALI 208)).

3) Antwortlemmata, die dasselbe Etymon haben, jedoch hinsichtlich des Wortakzents voneinander verschieden sind, bilden je ein eigenes Taxat (z.B. sciápita vs. sciapíta, insipida' (ALI 590)).

4) Verbale Antwortlemmata, die sich nur hinsichtlich der Reflexivität unterscheiden, bilden ein gemeinsames Taxat (z.B. se cuccà und cuccà, dormire').

5) Paraphrasen (z.B. l'uomo che tiene una gobba für ,il gobbo') zählen als Nullstellen.

6) Antworten, die eine andere grammatische Kategorie als das erfragte Lemma aufweisen, zählen als Nullstellen. ${ }^{373}$

7) Antworten, die die scherzhafte Verwendung eines Wortes beinhalten, z.B. cernicchio (eig. ,crivello') für ,cervello' (Vergleichskorpus, Cairano (841)), zählen als Nullstellen.

Auf der phonetischen Ebene waren die Taxate - mit Ausnahme der Merkmale ,Aphärese‘, ,Synkope‘ und ,Metathese‘ (Taxat Nr. 1) ja: Präsenz, Taxat Nr. 2) nein: Absenz des jeweiligen Phänomens) - nicht vordefiniert, sondern es wurden die als ausreichend verschieden betrachteten phonetischen Varianten - als lauthistorische Resultate des im Etymon jeweils zugrunde liegenden lateinischen Nexus - zu Taxaten zusammengeführt (s. Tab. 21). ${ }^{374}$ Für die Bildung dieser Taxate galten folgende Richtlinien:

1) Antworten mit unterschiedlichen Etyma zählen als Nullstellen. ${ }^{375}$ Ist die erste Antwort oder die Korrektur etymologisch verschieden und liegt gleichzeitig eine etymologisch identische Antwort vor, wird letztere taxiert. Derivate eines Lexems werden nur dann taxiert, wenn sich der betreffende Nexus in der Wurzel befindet und die Betonungsverhältnisse mit jenen der Basis identisch sind. ${ }^{376}$

\footnotetext{
372 Phonetische Varianten eines Lexems - etwa tellechià und teddechià ,fare il solletico“(ALI 130) - bilden damit ein gemeinsames lexikalisches Taxat. Aus Gründen der Übersichtlichkeit wird bei der Referenz auf ein lexikalisches Taxat immer stellvertretend nur eine phonetische Variante genannt.

${ }^{373}$ Eine separate Regelung galt für die lexikalische Taxierung von il solletico (ALI 130) und von (lo) sbadiglio (ALI 111), da die Mehrheit der Dialektantworten hier verbalen Charakter aufweist (z.B. cellechià ,fare il solletico“ oder alà ,fare uno sbadiglio“). Zur Vereinheitlichung der grammatischen Kategorie wurden alle substantivischen Antwortlemmata sowie die im Kartentitel enthaltenen substantivischen Lemmata in ihrer verbalen Konstruktion mit fare taxiert (ital. fare il solletico bzw. fare uno sbadiglio).

${ }^{374}$ Die damit zustande kommende Mischform aus makro- und mikrophonetischer Taxierungsweise (vgl. Kap. 4.3.3) wurde gewählt, um trotz der (durch den zur Verfügung stehenden Zeitrahmen bedingten) Beschränkung auf bestimmte Nexus ein möglichst feines Taxierungsergebnis und damit eine möglichst genaue Klassifikation der kampanischen Dialekte zu erhalten. Zudem können die qualitativen Informationen, die die Angabe der verschiedenen phonetischen Varianten bietet, für zukünftige Beiträge zur dialektalen Variation in der Campania von Nutzen sein.

${ }^{375}$ Der künstliche Prüfbezugspunkt italiano standard (900) weist also in den Fällen Nullstellen auf, in denen sich das italienische Lemma etymologisch von dem zu taxierenden (dialektalen) Lemma unterscheidet.

${ }^{376}$ Dies gilt jedoch nicht für Fälle, in denen ein Nexus im An- oder Auslaut des Wortstamms taxiert wird, dessen lautgeschichtliche Entwicklung durch einen Wortbildungsprozess beeinflusst worden ist (z.B. Geminierung infolge von Präfigierung mit der Präposition $a(<\mathrm{AD})$ in Fällen wie addurmì , dormire` oder avvasà ,baciare‘). In diesen Fällen wird eine Nullstelle eingetragen.
} 
2) Um den Unterschieden im Hörempfinden der Transkriptoren ${ }^{377}$ Rechnung zu tragen, werden in Form von hoch- bzw. tiefergestellten Lautzeichen transkribierte, d.h. nur schwach bis sehr schwach hörbare Laute nicht berücksichtigt. ${ }^{378}$

3) Wird eine Karte im Hinblick auf einen konsonantischen Nexus im Wortanlaut taxiert, so wird in den Fällen, in denen das (erste) Antwortlemma (etwa aufgrund von Abweichungen in der Flexionsform oder im Satzkontext) im Anlaut ein RS aufweist, dieses nicht taxiert, da hier die Vergleichbarkeit im Hinblick auf die historische Lautentwicklung nicht gegeben ist. Liegt eine alternative Antwort ohne RS vor, wird diese taxiert, ist dies nicht der Fall, wird eine Nullstelle eingetragen.

4) Wird ein (maskulines) adjektivisches oder substantivisches Lemma im Hinblick auf die Entwicklung von bet. $\breve{E}$ bzw. Ŏ vor auslautendem I oder Ŭ taxiert, so wird in Fällen, in denen das Antwortlemma ein feminines Genus (d.h. im Etymon den für Lautentwicklungen im Hauptton nicht relevanten Auslaut - A) aufweist, die Antwort als Nullstelle gezählt (z.B. [a Jər'vella] statt [o for'vjello], il cervello').

5) Bei allen anderen phonetischen Merkmalen werden etymologisch identische Antworten auch dann in die Taxierung aufgenommen, wenn sie ein anderes Genus als das erfragte Lemma aufweisen (z.B. Lautentwicklung von L (\KONS) in ['kauro] ,caldo ' (Vergleichskorpus, Avellino (838)), statt erfragtem ,calda'). Entsprechend werden bei der phonetischen Taxierung von Verben auch Antworten, die in einer anderen als der erfragten Flexionsform vorliegen, in die Taxierung aufgenommen (z.B. Lautentwicklung von G in ['warda], guarda' als Antwort auf erfragtes , guardate'). ${ }^{379}$

6) Der neutrale Vokal [ə] (Schwa) wird in unbetonter Position hinter Vollvokalen bei der Taxierung nicht berücksichtigt (z.B. in ['uəkkjə] , occhio“ (ALI 19) $\rightarrow$ Taxat [u]). Trägt er hingegen den Akzent, z.B. in ['wəkkjə] (ALI-Korpus: Castel Volturno (822)), wird ein separates Taxat (hier: [wə]) angenommen.

Zur Maximierung der Vergleichbarkeit der beiden Datensets wurde bei der Festlegung der phonetischen Taxate allgemein eher nach dem Prinzip des lumping ${ }^{380}$ verfahren. In diesem Kontext stehen folgende Prinzipien:

7) Folgende Allophone bilden je ein gemeinsames Taxat: ${ }^{381}$

a) alle Varianten des Phonems $/ \mathrm{r} /{ }^{382}$,

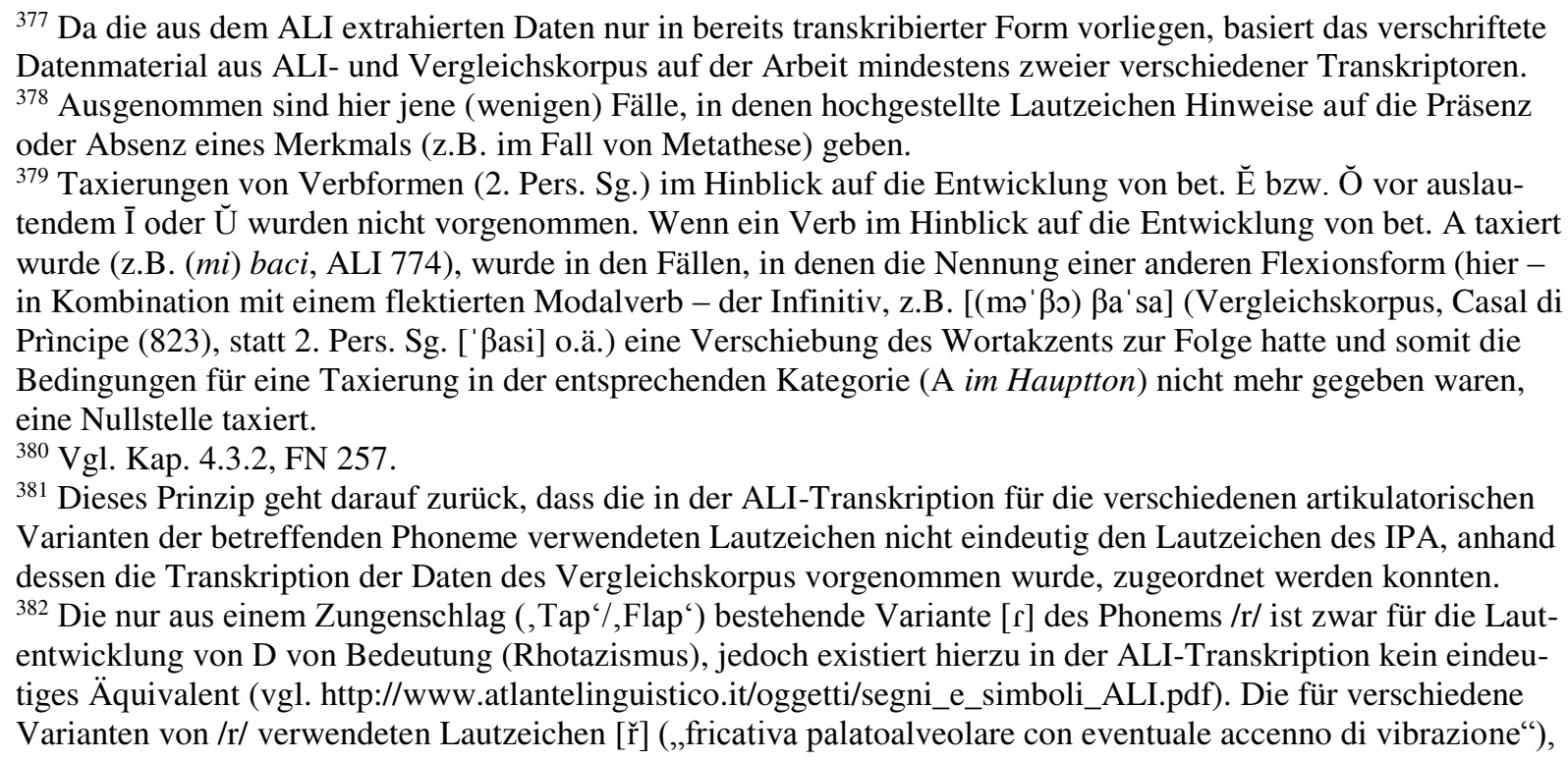


b) alle Varianten des Phonems /s/ - in der ALI-Transkription z.B. [s] oder [ $\dot{\mathrm{s}}]$,

c) alle Varianten des Phonems / $/ \mathfrak{g} /$ - in der ALI-Transkription z.B. [č] oder [ç] und

d) alle Varianten des Phonems / $/ \varepsilon$ - in der ALI-Transkription [è] und [ä].

8) Phonetische Realisierungen, die sich nur durch die artikulatorische Länge (bzw. bei Plosiven durch den Zeitpunkt der Lösung des Verschlusses) unterscheiden, bilden ein gemeinsames Taxat (z.B. [tg]/[ttf] bzw. [kj]/[kkj] oder [a]/[aa])..$^{383}$

9) Phonetische Realisierungen, die sich nur durch die Stimmhaftigkeit unterscheiden, bilden ein gemeinsames Taxat (z.B. [dz]/[t'] aus NG). ${ }^{384}$

10) Bei mittleren Vokalen wird lediglich zwischen einer offenen ([ع] bzw. [o]) und einer geschlossenen Variante ([e] bzw. [o]) unterschieden. Die in der ALI-Transkription (sporadisch) anzutreffende ,neutrale' Variante (dort [é] bzw. [ó]) bildet mit der jeweiligen geschlossenen Variante ein gemeinsames Taxat.

11) Die in der Transkription der ALI-Daten vorgenommene Unterscheidung zwischen den

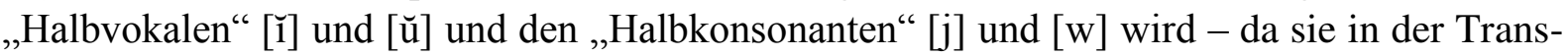
kription des Vergleichskorpus nicht vorgenommen wurde - nicht berücksichtigt. In beiden Fällen bilden der „Halbvokal“" und der „Halbkonsonant“ ein gemeinsames Taxat.

Nach der Festlegung der Taxate fand im dritten und letzten Taxierungsschritt das ,Abgehen“ der Messpunkte anhand der erstellten Prüfpfade bzw. -listen und die Eintragung der Nummern der jeweils vorliegenden Taxate in das Erfassungsformular $\delta$ (Taxatnummernblatt, s. Abb. 19) statt. Nach Abschluss des Taxierungsvorgangs wurde der Inhalt aller Erfassungsformulare beider Datensets in je eine nach dem in der S-DM etablierten Muster strukturierte Microsoft Access (2013)-Datenbank übertragen (s. Tab. 22). Über Tabellenabfragen wurden dialektometrisch relevante Angaben zu den Korpora (Anzahl der Arbeitskarten in den verschiedenen Subkorpora, Anzahl der Taxate auf den einzelnen Arbeitskarten (Polynymie) etc.) ergänzt. Auf der Basis der nun vorliegenden vollständigen Datenbanken wurden mittels des Programmpakets VDM die Ähnlichkeitsmessungen und die Clusteranalysen jeweils für das Totalkorpus, den lexikalischen Bereich, den phonetischen Bereich, den Bereich des Konsonantismus und den Bereich des Vokalismus durchgeführt.

\footnotetext{
[ $\mathbf{Z}$ ] (,fricativa alveolodentale sorda“, ,fricativa alveolodentale sonora“), [r] (nicht in der Liste der Lautzeichen

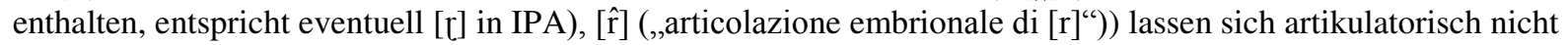
eindeutig interpretieren, sodass ein entsprechendes Zeichen in der IPA-Transkription nicht bestimmt werden kann. Zur Sicherung der Vergleichbarkeit der beiden Datensets werden in der Taxierung eines Lemmas hinsichtlich des Phänomens ,Lautentwicklung von D` die verschiedenen Allophone des Phonems /r/ (im Vergleichskorpus nur $[\mathrm{r}]$ und $[r]$ ) - und zur Wahrung der artikulatorischen Verhältnisse analog dazu auch jene des Phonems /d/ ([d], [ð]) - zu einem Taxat zusammengefasst.

${ }^{383}$ Dies gilt nicht für die Taxierung im Hinblick auf die Entwicklung von intervokalischem M, da es sich hier bei der konsonantischen Länge um das phonetische Merkmal handelt, das die Taxate voneinander unterscheidet (s. Tab. 21).

${ }^{384}$ Dies ist besonders im Hinblick auf die Tatsache sinnvoll, dass in den kampanischen Dialekten (wie in den süditalienischen Dialekten allgemein) stimmlose Plosive und Affrikaten in den meisten Fällen lenisiert oder sonorisiert werden, z.B. [ka'pilli] , capelli‘ (Vergleichskorpus: Montella (839)), [ka'tşctt] ,calza‘ (Vergleichskorpus: Salerno (855)).
} 


\section{ALI (1995-2008) / Hajek (2014) - KODIERUNG}

TAXIERUNGS-LEITBLATT

ALI-Kartennr.

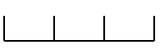

ALI-Kartentitel

Anzahl der insgesamt extrahierten Arbeitskarten

1) Lexikalische Taxierung: Kodierungsspielraum: $000-099$

Arbeitskarten

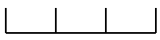

\llcorner

1

$\llcorner\perp \perp$

\llcorner

2

$\llcorner\perp \perp \perp$

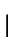

2) Phonetische Taxierung: Kodierungsspielraum: 100 - 199

$$
\text { L }
$$

$\llcorner\perp \perp$

$\llcorner\perp \perp$

$$
\llcorner
$$

$$
\text { L }
$$

Abbildung 16. Erfassungsformular $\alpha$ (Taxierungsleitblatt). 


\section{ALI (1995-2008) / Hajek (2014) - KODIERUNG}

PHONETISCHE TAXIERUNG: Typenblatt

ALI-Kartennr.

$\downarrow \perp \perp$
ALI-Kartentitel

Etymon

Nr. Arbeitskarte:
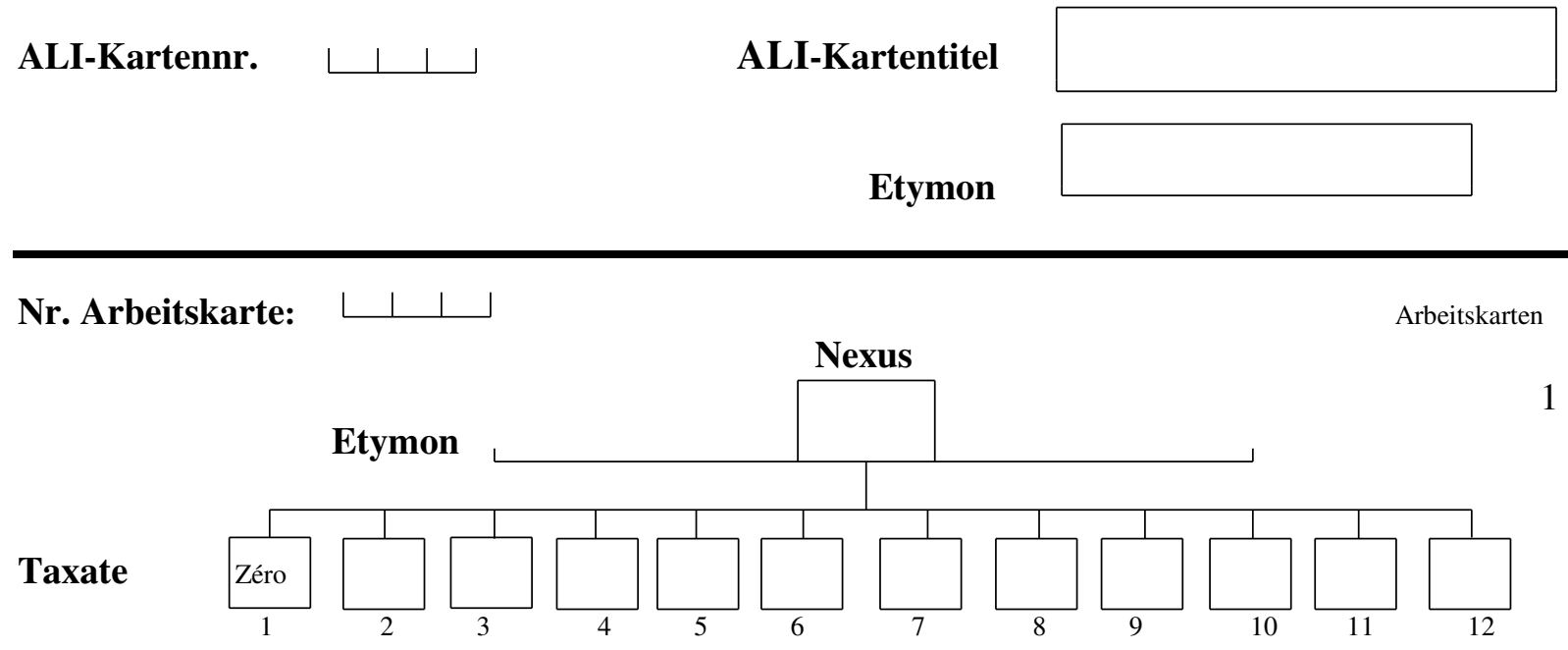

Nr. Arbeitskarte:

Arbeitskarten

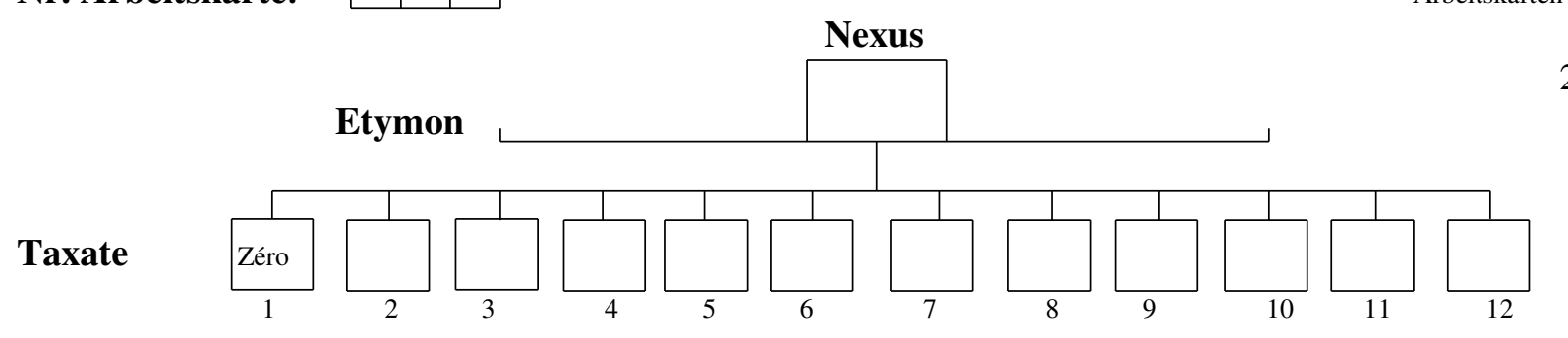

Nr. Arbeitskarte:

Arbeitskarten

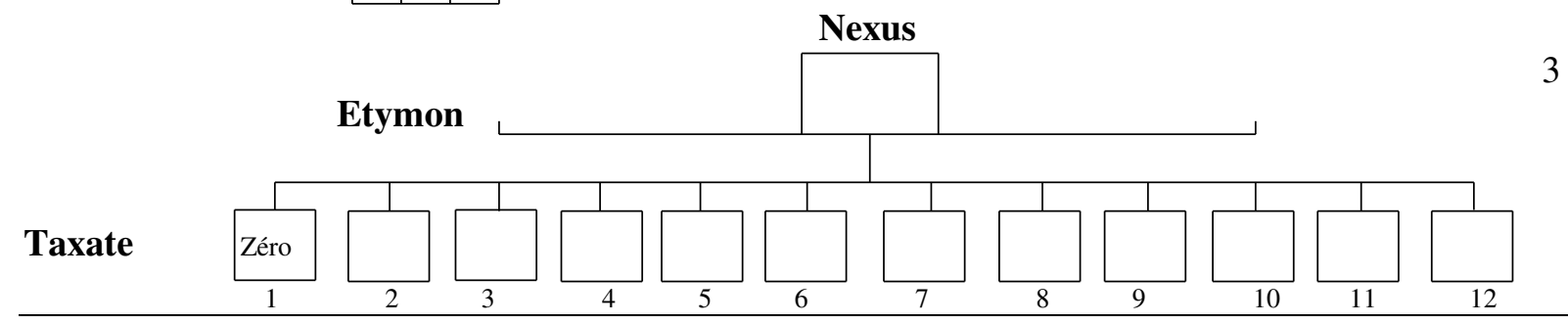

Nr. Arbeitskarte: $\downarrow \downarrow \downarrow \mid \downarrow$

Arbeitskarten

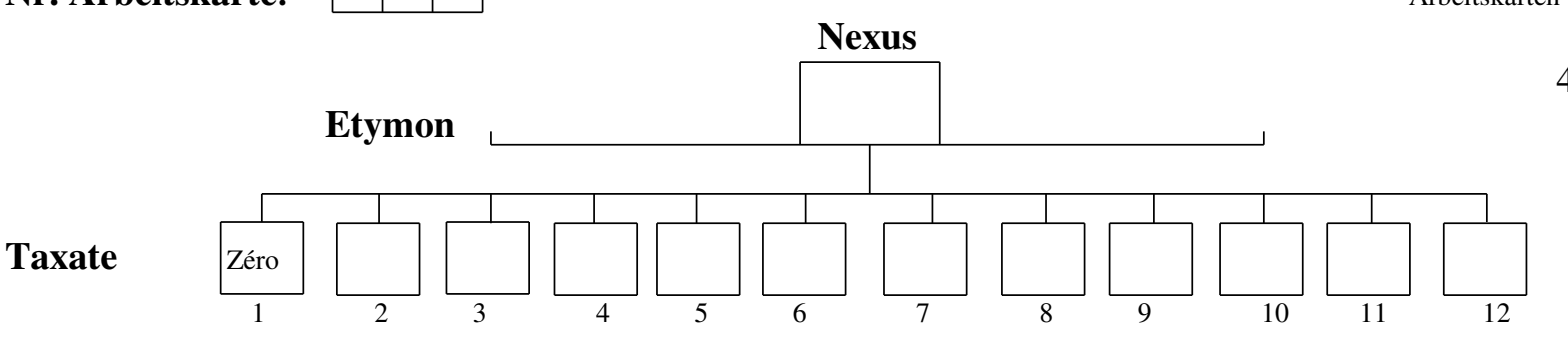




\section{ALI (1995-2008) / Hajek (2014) - KODIERUNG}

LEXIKALISCHE TAXIERUNG: Typenblatt

ALI-Kartennr.

$\downarrow \perp \perp$

Nr. Arbeitskarte

$\downarrow \perp \perp$
ALI-Kartentitel

Lexem

\begin{tabular}{|c|c|c|c|}
\hline Taxat - Kode & Taxate & $\begin{array}{l}\text { spezielle } \\
\text { men }\end{array}$ & Einzelfor- \\
\hline \multicolumn{4}{|c|}{1 (Standarditalienisch) } \\
\hline \multicolumn{4}{|l|}{2} \\
\hline \multicolumn{4}{|l|}{3} \\
\hline \multicolumn{4}{|l|}{4} \\
\hline \multicolumn{4}{|l|}{5} \\
\hline \multicolumn{4}{|l|}{6} \\
\hline \multicolumn{4}{|l|}{7} \\
\hline \multicolumn{4}{|l|}{8} \\
\hline \multicolumn{4}{|l|}{9} \\
\hline \multicolumn{4}{|l|}{10} \\
\hline \multicolumn{4}{|l|}{11} \\
\hline \multicolumn{4}{|l|}{12} \\
\hline \multicolumn{4}{|l|}{13} \\
\hline \multicolumn{4}{|l|}{14} \\
\hline \multicolumn{4}{|l|}{15} \\
\hline 16 & & & \\
\hline
\end{tabular}

Abbildung 18. Erfassungsformular $\gamma$. 


\section{ALI (1995-2008) / Hajek (2014) - KODIERUNG}

\section{TAXAT-NUMMERNBLATT}

Nr. Arbeitskarte

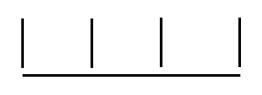

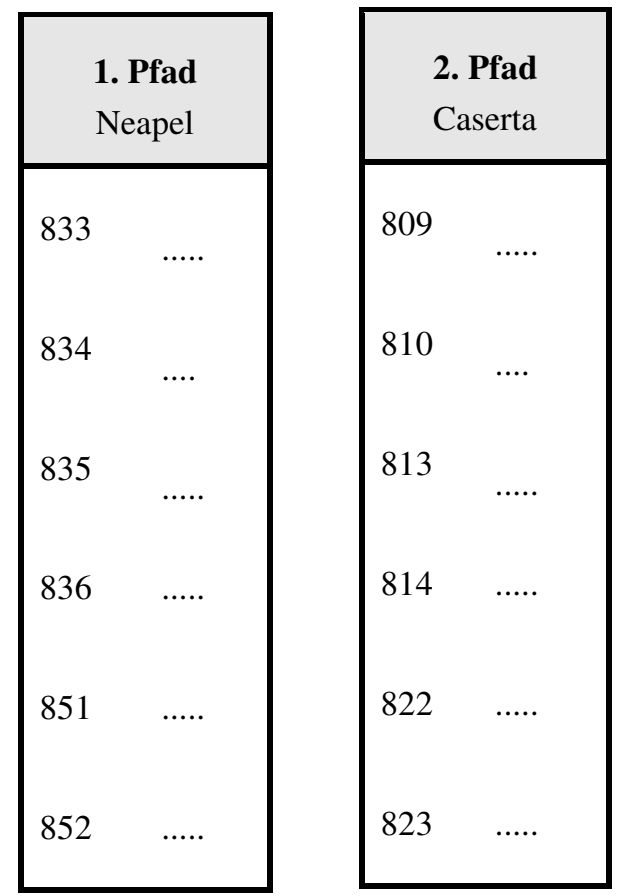

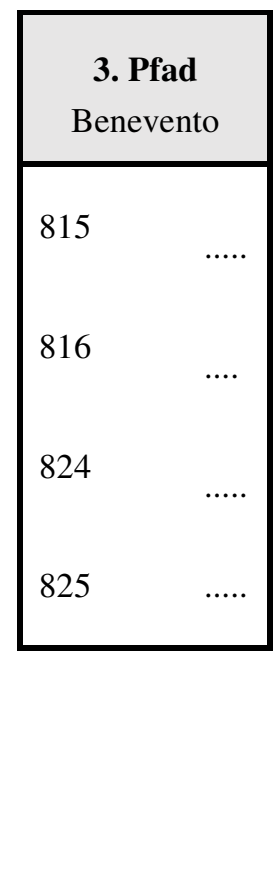

\begin{tabular}{|cc|}
\hline $\begin{array}{c}\text { 4. Pfad } \\
\text { Avellino }+ \\
\text { Foggia }\end{array}$ \\
\hline 826 & $\ldots .$. \\
838 & $\ldots$. \\
839 & $\ldots .$. \\
840 & $\ldots .$. \\
841 & $\ldots .$. \\
827 & $\ldots .$. \\
\hline 819 & $\ldots .$. \\
\hline
\end{tabular}

\begin{tabular}{|cc|}
\hline \multicolumn{2}{|c|}{$\mathbf{5 . P f a d}$} \\
Salerno
\end{tabular}

Abbildung 19. Erfassungsformular $\delta$ (Taxatnummernblatt). 


\begin{tabular}{|c|c|c|c|c|}
\hline Kode & $\begin{array}{l}\text { Ebene (Typ- } \\
\text { bereich) }\end{array}$ & Merkmal (Typ) & $\begin{array}{l}\text { Taxate }^{385} \text { im ALI- } \\
\text { Korpus }\end{array}$ & $\begin{array}{l}\text { Taxate im } \\
\text { Vergleichs- } \\
\text { korpus }\end{array}$ \\
\hline 10 & KONS & Lautentwicklung von D & $\begin{array}{l}\text { 1) zéro } \\
\text { 2) } d \\
\text { 3) } d / d \\
\text { 4) } d / t \\
\text { 5) } \mathrm{r} / \mathrm{f}^{387} \\
\text { 6) } \mathrm{r} \text { (und andere } \\
\text { Varianten }{ }^{388} \\
\text { 7) } 1 \\
\text { 8) } \mathrm{j} \text { (vereinzelt) } \\
\text { 9) } \mathrm{p} \text { (vereinzelt) } \\
\text { 10) } \mathfrak{t} / \mathrm{d} \text { (verein- } \\
\text { zelt) } \\
\text { 11) } \int \text { (vereinzelt) }\end{array}$ & $\begin{array}{l}\text { 1) zéro } \\
\text { (vereinzelt) } \\
\text { 2) } d \\
\text { 3) } d / t \\
\text { 4) } \mathrm{r} / \mathrm{c} \\
\text { 5) } \mathrm{l} \\
\text { 6) ds } \\
\text { 7) (l)l (vereinzelt) } \\
\text { 8) } \mathrm{r} \text { (vereinzelt) } \\
\text { 9) } \mathrm{d} / \text { (t)t (verein- } \\
\text { zelt) } \\
\text { 10) g (vereinzelt) } \\
\text { 11) } \beta \text { (vereinzelt) } \\
\text { 12) } \int \text { (vereinzelt) }\end{array}$ \\
\hline 11 & KONS & $\begin{array}{l}\text { Lautentwicklung von } \\
\text { B/V }\end{array}$ & $\begin{array}{l}\text { 1) zéro } \\
\text { 2) } \mathrm{b} \\
\text { 3) } \beta \\
\text { 4) } \mathrm{v} \\
\text { 5) } \mathrm{v} / \mathrm{f} \\
\text { 6) } \mathrm{m} \\
\text { 7) } \mathrm{b} / \mathrm{p} \text { (vereinzelt) } \\
\text { 8) } \mathrm{w} \text { (vereinzelt) } \\
\text { 9) } \mathrm{g} \text { (vereinzelt) } \\
\text { 10) j (vereinzelt) } \\
\text { 11) } 1 \text { (vereinzelt) }\end{array}$ & $\begin{array}{l}\text { 1) zéro } \\
\text { 2) b } \\
\text { 3) (b)b } \\
\text { 4) } \beta \\
\text { 5) } \mathrm{v} \\
\text { 6) } \mathrm{m} \\
\text { 7) } \mathrm{w} \\
\text { 8) v / f (verein- } \\
\text { zelt) } \\
\text { 9) j (vereinzelt) } \\
\text { 10) r (vereinzelt) }\end{array}$ \\
\hline 12 & KONS & Lautentwicklung von $\mathrm{G}$ & $\begin{array}{l}\text { 1) zéro } \\
\text { 2) } \mathrm{g} \\
\text { 3) } \mathrm{g} / \mathrm{k} \\
\text { 4) } \mathrm{\gamma} \\
\text { 5) } \beta \\
\text { 6) } \mathrm{v} \\
\text { 7) j } \\
\text { 8) } \mathrm{m} \text { (vereinzelt) }\end{array}$ & $\begin{array}{l}\text { 1) zéro } \\
\text { 2) g } \\
\text { 3) } \mathrm{g} \\
\text { 4) } \mathrm{v} \\
\text { 5) ds } \\
\text { 6) j (vereinzelt) }\end{array}$ \\
\hline 13 & KONS & Lautentwicklung von LL & $\begin{array}{l}\text { 1) zéro } \\
\text { 2) ll }\end{array}$ & $\begin{array}{l}\text { 1) } 11 \\
\text { 2) (1)1 }\end{array}$ \\
\hline
\end{tabular}

385 Die Angabe erfolgt in IPA-Zeichen. Zu jedem Phänomen werden alle Taxate angegeben, die im jeweiligen Gesamtkorpus vorkommen, die Reihenfolge entspricht nicht der Häufigkeit der einzelnen Taxate (lediglich Taxate, die mit weniger als 5 Token im Gesamtkorpus vorkommen, werden mit dem Vermerk ,vereinzelt“ gekennzeichnet). Das bedeutet nicht, dass jede Arbeitskarte, die im Hinblick auf das jeweilige Phänomen taxiert wurde, auch alle diese Taxate aufweist (dies ist teilweise ohnehin ausgeschlossen, da auf den einzelnen Arbeitskarten nach den o.g. Richtlinien bestimmte Varianten zu einem gemeinsamen Taxat zusammengefasst werden). Welche Taxate auf den einzelnen Arbeitskarten mit welcher Häufigkeit vorkommen, kann in den zum Projekt erstellten VDM-Datenbanken eingesehen werden.

386 Schwund des Nexus.

387 Taxat im Vergleichskorpus.

388 Taxat im ALI-Korpus, vgl. FN 382. 


\begin{tabular}{|c|c|c|c|c|}
\hline & & & $\begin{array}{l}\text { 3) } \mathrm{dd} \\
\text { 4) } \mathrm{dd} \\
\text { 5) } \mathrm{K} \Lambda \\
\text { 6) } \mathrm{nn} \text { (vereinzelt) } \\
\text { 7) } \mathrm{nn} \text { (vereinzelt) }\end{array}$ & $\begin{array}{l}\text { 3) dd } \\
\text { 4) dd } \\
\text { 5) } \mathrm{KK} \\
\text { 6) JJ } \\
\text { 7) nn (vereinzelt) } \\
\text { 8) nn (vereinzelt) } \\
\text { 9) dds (vereinzelt) }\end{array}$ \\
\hline 14 & KONS & $\begin{array}{l}\text { Lautentwicklung von L } \\
\text { (\KONS) }\end{array}$ & $\begin{array}{l}\text { 1) zéro } \\
\text { 2) } 1 \\
\text { 3) } \mathrm{u} \\
\text { 4) } \mathrm{v} \\
\text { 5) } \beta \\
\text { 6) n (vereinzelt) } \\
\text { 7) o (vereinzelt) }\end{array}$ & $\begin{array}{l}\text { 1) zéro } \\
\text { 2) } \mathrm{l} \\
\text { 3) } \mathrm{u} \\
\text { 4) } \mathrm{v} \\
\text { 5) } \mathrm{j} / \mathrm{i} \\
\text { 6) } \mathrm{o} \text { (vereinzelt) } \\
\text { 7) } \mathrm{r} \text { (vereinzelt) }\end{array}$ \\
\hline 15 & KONS & $\begin{array}{l}\text { Lautentwicklung von } \mathrm{S} \\
(\mathrm{P}, \mathrm{T}, \mathrm{K})\end{array}$ & $\begin{array}{l}\text { 1) zéro (vereinzelt) } \\
\text { 2) } s \\
\text { 3) } \int\end{array}$ & $\begin{array}{l}\text { 1) } \mathrm{s} \\
\text { 2) } \mathrm{S}\end{array}$ \\
\hline 16 & KONS & Lautentwicklung von FL & $\begin{array}{l}\text { 1) zéro (vereinzelt) } \\
\text { 2) } \mathrm{fj} \\
\text { 3) } \mathrm{j} \\
\text { 4) } \mathrm{J}\end{array}$ & $\begin{array}{l}\text { 1) } f j \\
\text { 2) } j \\
\text { 3) } \int \\
\text { 4) } t g \text { (vereinzelt) }\end{array}$ \\
\hline 17 & KONS & Lautentwicklung von PL & $\begin{array}{l}\text { 1) zéro (vereinzelt) } \\
\text { 2) } \mathrm{kj} \\
\text { 3) } \mathrm{kj} / \mathrm{kkj} \\
\text { 4) } \mathrm{kj} / \mathrm{gj} \\
\text { 5) } \mathrm{pj} \\
\text { 6) } \mathrm{g} / \mathrm{ttg} \\
\text { 7) } \mathrm{g} \\
\text { 8) } \mathrm{g} / \mathrm{d}\end{array}$ & $\begin{array}{l}\text { 1) } \mathrm{kj} \\
\text { 2) } \mathrm{kj} / \mathrm{kkj} \\
\text { 3) } \mathfrak{g} \\
\text { 4) } \mathrm{pj} \text { (vereinzelt) }\end{array}$ \\
\hline 18 & KONS & $\begin{array}{l}\text { Lautentwicklung von } \\
\text { CL }\end{array}$ & $\begin{array}{l}\text { 1) zéro } \\
\text { 2) } \mathrm{kj} \\
\text { 3) } \mathrm{kkj} \\
\text { 4) } \mathfrak{g} \\
\text { 5) } \mathrm{tt} f\end{array}$ & $\begin{array}{l}\text { kj bzw. kkj (Mo- } \\
\text { nonymie) }\end{array}$ \\
\hline 19 & KONS & Lautentwicklung von TS & $\begin{array}{l}\text { 1) ts / dz } \\
\text { 2) } \mathrm{t} / \mathrm{dt} \\
\text { 3) tts } \\
\text { 4) } \mathrm{tt}\end{array}$ & $\begin{array}{l}\text { 1) } \mathrm{ts} / \mathrm{dz} \\
\text { 2) } \mathrm{tt} \\
\text { 3) } \mathrm{g} \\
\text { 4) } \mathrm{tts} \\
\text { 5) } \mathrm{s} / \mathrm{z} \text { (verein- } \\
\text { zelt) } \\
\text { 6) } \int \text { (vereinzelt) } \\
\text { 7) } \mathrm{kkj} \text { (vereinzelt) }\end{array}$ \\
\hline 20 & KONS & $\begin{array}{l}\text { Lautentwicklung von } \mathrm{C} \\
(\mathrm{I}, \mathrm{E})\end{array}$ & $\begin{array}{l}\text { 1) zéro } \\
\text { 2) } \mathrm{tts} \\
\text { 3) } \mathrm{t} / \mathrm{tt} \\
\text { 4) } \mathrm{tg}\end{array}$ & $\begin{array}{l}\text { 1) } \mathrm{tts} \\
\text { 2) } \mathrm{tt} \\
\text { 3) } \mathrm{t} / \mathrm{tt} \\
\text { 4) } \int\end{array}$ \\
\hline
\end{tabular}




\begin{tabular}{|c|c|c|c|c|}
\hline & & & $\begin{array}{l}\text { 5) } \mathrm{kkj} \\
\text { 6) } \int \text { (vereinzelt) }\end{array}$ & 5) $\mathrm{kkj}$ \\
\hline 21 & KONS & $\begin{array}{l}\text { Lautentwicklung von L } \\
\text { (II, E) }\end{array}$ & $\begin{array}{l}\text { 1) zéro (vereinzelt) } \\
\text { 2) } K \kappa \\
\text { 3) } \mathrm{JJ} \\
\text { 4) } \mathrm{jj} \text { (vereinzelt) }\end{array}$ & $\begin{array}{l}\text { 1) } \mathrm{KK} \\
\text { 2) } \mathrm{jj} \\
\text { 3) } \mathrm{JJ}\end{array}$ \\
\hline 22 & KONS & $\begin{array}{l}\text { Lautentwicklung von D } \\
\text { (II) }\end{array}$ & $\begin{array}{l}\text { 1) zéro } \\
\text { 2) } \mathrm{tg} / \mathrm{dd} \\
\text { 3) ḋ (vereinzelt) } \\
\text { 4) } K K \text { (vereinzelt) }\end{array}$ & $\begin{array}{l}\text { 1) zéro } \\
\text { 2) } t \mathrm{t} / \mathrm{dd} \\
\text { 3) } d \mathrm{~s} \\
\text { 4) } \int \text { (vereinzelt) }\end{array}$ \\
\hline 23 & KONS & $\begin{array}{l}\text { Lautentwicklung von } \mathrm{S} \\
\text { (II) }\end{array}$ & $\begin{array}{l}\text { 1) zéro (vereinzelt) } \\
\text { 2) } \mathrm{s} \\
\text { 3) } \int \\
\text { 4) } \mathrm{ts} \\
\text { 5) } \mathfrak{t} / \mathrm{d} \\
\text { 6) } \mathfrak{t} \text { (vereinzelt) } \\
\text { 7) } \mathrm{j} \text { (vereinzelt) }\end{array}$ & $\begin{array}{l}\text { 1) } s \\
\text { 2) } t s \\
\text { 3) } t \mathrm{t} \\
\text { 4) } \int \\
\text { 5) } d \text { (vereinzelt) } \\
\text { 6) } j \text { (vereinzelt) }\end{array}$ \\
\hline 24 & KONS & $\begin{array}{l}\text { Lautentwicklung von } \\
\text { intervok. M }\end{array}$ & $\begin{array}{l}\text { 1) zéro } \\
\text { 2) } \mathrm{m} \\
\text { 3) } \mathrm{mm}\end{array}$ & $\begin{array}{l}\text { 1) } \mathrm{m} \\
\text { 2) } \mathrm{mm}\end{array}$ \\
\hline 25 & KONS & Metathese & $\begin{array}{l}\text { 1) ja } \\
\text { 2) nein }\end{array}$ & $\begin{array}{l}\text { 1) ja } \\
\text { 2) nein }\end{array}$ \\
\hline 26 & KONS & $\begin{array}{l}\text { Sonstige kons. Lautent- } \\
\text { wicklungen }\end{array}$ & div. & div. \\
\hline 27 & VOK & $\begin{array}{l}\text { Lautentwicklung von } \\
\text { bet. } \breve{\mathrm{E}}(\mathrm{I}, \mathrm{I}, \mathrm{U})\end{array}$ & $\begin{array}{l}\text { 1) } \varepsilon \\
\text { 2) } \mathrm{e} \\
\text { 3) } \mathrm{i} \\
\text { 4) je } \\
\text { 5) je (vereinzelt) } \\
\text { 6) we (vereinzelt) }\end{array}$ & $\begin{array}{l}\text { 1) } \varepsilon \\
\text { 2) } \mathrm{e} \\
\text { 3) } \mathrm{i} \\
\text { 4) je } \\
\text { 5) } \mathrm{j} \varepsilon \\
\text { 6) } \mathrm{ji} \\
\text { 7) } \mathrm{o} \varepsilon \text { (vereinzelt) }\end{array}$ \\
\hline 28 & VOK & $\begin{array}{l}\text { Lautentwicklung von } \\
\text { bet. } \breve{O}(\overline{\mathrm{I}}, \breve{\mathrm{U}})\end{array}$ & $\begin{array}{l}\text { 1) o } \\
\text { 2) o } \\
\text { 3) u } \\
\text { 4) wo } \\
\text { 5) wo } \\
\text { 6) we (vereinzelt) } \\
\text { 7) wə (vereinzelt) }\end{array}$ & $\begin{array}{l}\text { 1) o } \\
\text { 2) o } \\
\text { 3) u } \\
\text { 4) wo } \\
\text { 5) wo } \\
\text { 6) wə } \\
\text { 7) ou (vereinzelt) }\end{array}$ \\
\hline 29 & VOK & $\begin{array}{l}\text { Lautentwicklung von } \\
\text { bet. A }\end{array}$ & $\begin{array}{l}\text { 1) a } \\
\text { 2) } \varepsilon \\
\text { 3) a (vereinzelt) } \\
\text { 4) e (vereinzelt) }\end{array}$ & $\begin{array}{l}\text { 1) a } \\
\text { 2) } \varepsilon \\
\text { 3) a (vereinzelt) }\end{array}$ \\
\hline 30 & VOK & Aphärese & $\begin{array}{l}\text { 1) ja } \\
\text { 2) nein }\end{array}$ & $\begin{array}{l}\text { 1) ja } \\
\text { 2) nein }\end{array}$ \\
\hline 31 & VOK & Synkope & $\begin{array}{l}\text { 1) ja } \\
\text { 2) nein }\end{array}$ & $\begin{array}{l}\text { 1) ja } \\
\text { 2) nein }\end{array}$ \\
\hline
\end{tabular}




\begin{tabular}{|l|l|l|l|l|}
\hline 32 & VOK & $\begin{array}{l}\text { Sonstige vok. Lautent- } \\
\text { wicklungen }\end{array}$ & div. & div. \\
\hline 33 & VOK & $\begin{array}{l}\text { Sonstige vok. Lautent- } \\
\text { wicklungen }\end{array}$ & div. & div. \\
\hline
\end{tabular}

Tabelle 21. Phonetische Merkmale und dazugehörige Taxate im ALI-Korpus und im Vergleichskorpus.

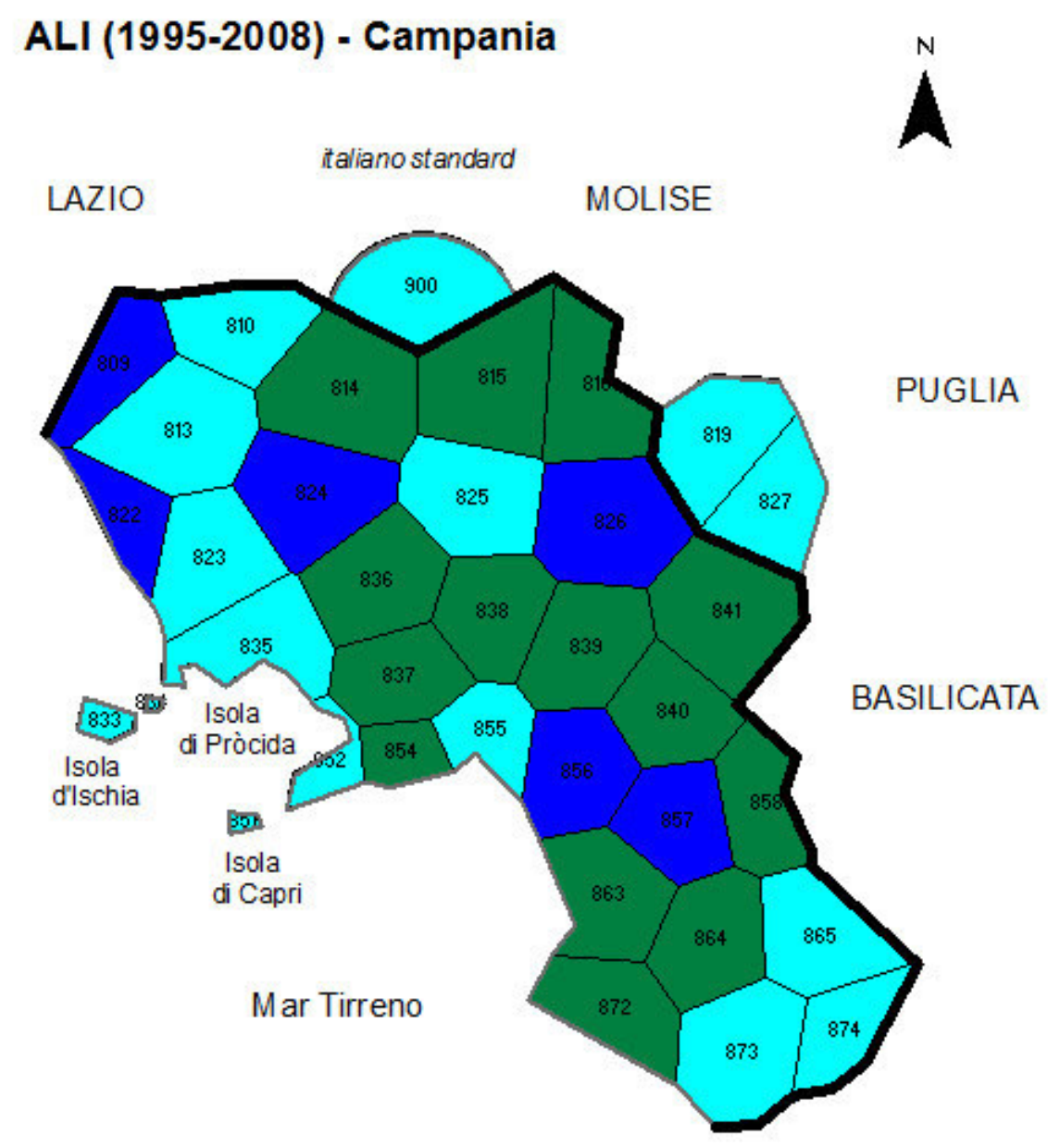

fec. S. Hajek

adiuv. H. Goebl et P. Smečka

adiuv. B. Castellazzi

a.d. 2013

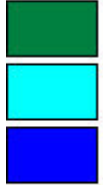

1: zéro [14]

2: [V] [16]

3: $[\beta][6]$ carta di THIESSENHAAGNORONOI

35 punti d'inchiesta + italiano standard

limite di regione

Karte 40. Phonetisch relevante Arbeitskarte: Resultate von lat. V in ŎVU(M) (ALI-Korpus, Karte 571). 


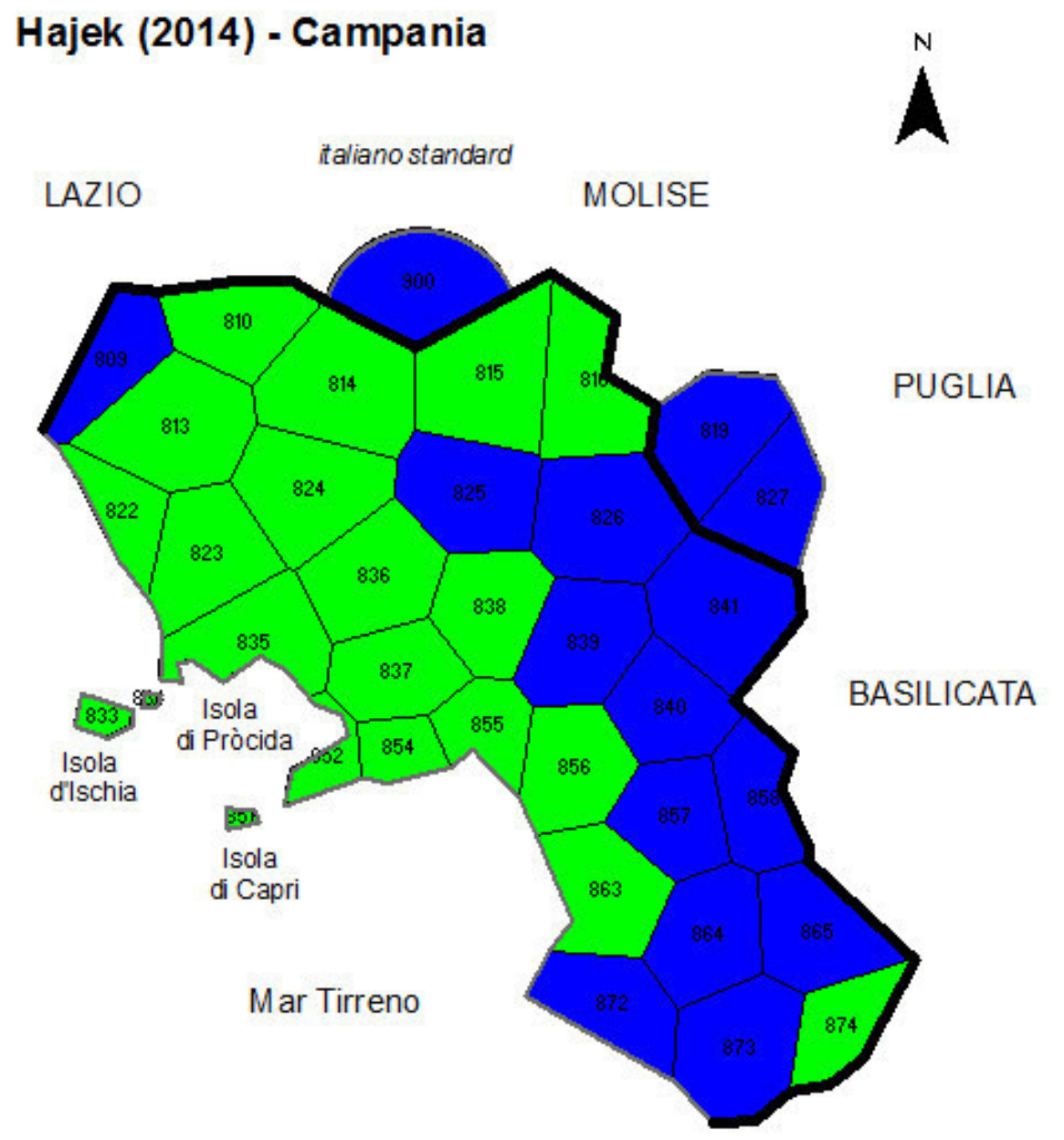

fec. S. Hajek

adiuv. H. Goebl et P. Smečka

adiuv. B. Castellazzi

a.d. 2013

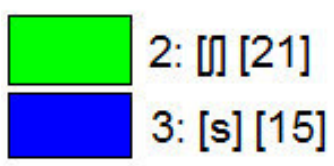

carta di THIESSENHAAGNORONOI 35 punti d'inchiesta + italiano standard

Karte 41. Phonetisch relevante Arbeitskarte: Resultate von lat. S in SPĔC(U)LU(M) (Vergleichskorpus, Karte 385). 


\begin{tabular}{|c|c|}
\hline Tabellenname & Tabelleninhalt \\
\hline Atlas Title & $\begin{array}{l}\text { Gesamtheit der berücksichtigten Originalkar- } \\
\text { ten, mit Angabe von Nummer und Titel so- } \\
\text { wie des entsprechenden Atlasbandes }{ }^{389}\end{array}$ \\
\hline Title & $\begin{array}{l}\text { Gesamtheit der extrahierten Arbeitskarten, } \\
\text { mit Angabe von Nummer und Titel der zu- } \\
\text { grunde liegenden Originalkarte und des je- } \\
\text { weiligen (phonetischen bzw. lexikalischen) } \\
\text { Merkmals in kodierter Form }{ }^{390}\end{array}$ \\
\hline Typbereich & $\begin{array}{l}\text { linguistische Teilkorpora und dazugehörige } \\
\text { Kodierung (hier: Lexikon, Phonetik - Konso- } \\
\text { nantismus, Phonetik - Vokalismus) sowie die } \\
\text { jeweilige Anzahl der Arbeitskarten (Typbe- } \\
\text { reich-Frequenz) im Totalkorpus }\end{array}$ \\
\hline Type & $\begin{array}{l}\text { berücksichtigte phonetische Merkmale und } \\
\text { lexikalische Kategorien („Typen“) mit zuge- } \\
\text { hörigen Kodes sowie Angabe des Typbe- } \\
\text { reichs (Teilkorpus) und der Anzahl der Ar- } \\
\text { beitskarten (Typ-Frequenz) im Totalkorpus }\end{array}$ \\
\hline Taxats & $\begin{array}{l}\text { Gesamtheit der gebildeten Taxate, mit Anga- } \\
\text { be der jeweiligen Arbeitskarte (als Kombina- } \\
\text { tion aus der Nummer der Originalkarte und } \\
\text { dem Kode des taxierten Merkmals) sowie der } \\
\text { Frequenz des Taxats auf der Arbeitskarte }\end{array}$ \\
\hline Data & $\begin{array}{l}\text { eigentliche Datenmatrix mit Zuordnung der } \\
\text { Taxate zu den Messpunkten }\end{array}$ \\
\hline Locations & $\begin{array}{l}\text { Gesamtheit der Messpunkte, mit Angabe zu } \\
\text { Ortsnummer und -name }{ }^{391} \text { sowie den jeweili- } \\
\text { gen Polygonecken }\end{array}$ \\
\hline Neighbours & $\begin{array}{l}\text { zu jedem Messpunkt Angabe der Polygonsei- } \\
\text { ten und des (geometrischen) Polygonzent- } \\
\text { rums sowie der benachbarten Messpunkte } \\
\text { (und der entsprechenden Polygonzentren) }\end{array}$ \\
\hline
\end{tabular}

Tabelle 22. Zentrale Tabellen der dialektometrischen Datenbank (vgl. Bauer 2009: 199ff.).

\footnotetext{
${ }^{389}$ In der für das Vergleichskorpus erstellten Datenbank enthält die Tabelle ,Atlas Title` zusätzlich eine Spalte mit den entsprechenden Nummern der Lemmata in dem Fragebuch, mit dem die Daten für das Vergleichskorpus erhoben wurden.

${ }^{390}$ In der Spalte ,KarteTitle ‘ werden die Originalform des jeweiligen Lemmas sowie ggfs. in runden Klammern die bei der Erhebung des Vergleichskorpus verwendete Form angegeben. Sind auf einer Atlaskarte Antworten zu mehreren Lemmata vermerkt, so werden alle Elemente des Kartentitels außer dem für die Taxierung jeweils relevanten Lemma in eckigen Klammern angegeben. Zur direkten Vergleichbarkeit der Datensets hinsichtlich der Taxat-Verteilung auf den einzelnen Arbeitskarten in VDM wird in der Spalte ,KarteNr` auch in der Datenbank zum Vergleichskorpus die entsprechende ALI-Kartennummer angegeben.

${ }^{391}$ Der Ortsname von P 840 (Senerchia) wurde in der Datenbank zum Vergleichskorpus durch den Namen des benachbarten Ortes (Quaglietta) ersetzt, wo die Vergleichsdaten erhoben wurden (vgl. Kap. 5.2.2, FN 357).
} 


\subsubsection{Taxatorischer Ertrag}

\subsubsection{ALI-Korpus}

Aus den 189 berücksichtigten Originalkarten (OK) des ALI konnten insgesamt 275 Arbeitskarten (AK, d.h. durchschnittlich ca. 1,5 AK je OK) extrahiert werden, von denen 105 AK lexikalisch und $170 \mathrm{AK}$ phonetisch relevant sind (s. Tab. 23). Von den phonetisch relevanten Arbeitskarten fallen $129 \mathrm{AK}$ in den Bereich des Konsonantismus und $41 \mathrm{AK}$ in den Bereich des Vokalismus. ${ }^{392}$

\begin{tabular}{|l|c|c|c|c|c|}
\hline Kategorie & $\sum$ AK & $\sum$ Taxate $^{\mathbf{3 9 3}}$ & $\begin{array}{l}\emptyset \text { Taxate/ } \\
\text { AK }^{\mathbf{3 9 4}}\end{array}$ & $\begin{array}{l}\text { Variationsbreite } \\
\text { Taxate/AK }\end{array}$ & $\begin{array}{l}\emptyset \text { Messpunkte/ } \\
\text { Taxatareal }\end{array}$ \\
\hline Totalkorpus & 275 & 1038 & 3,8 & von 2 bis 13 & 9,2 \\
\hline Lexikon & 105 & 452 & 4,3 & von 2 bis 13 & 8,3 \\
\hline Phonetik & 170 & 586 & 3,4 & von 2 bis 7 & 10,1 \\
\hline Konsonantismus & 129 & 440 & 3,4 & von 2 bis 7 & 10,0 \\
\hline Vokalismus & 41 & 146 & 3,6 & von 2 bis 6 & 9,8 \\
\hline
\end{tabular}

Tabelle 23. Synopse des Ertrages der dialektometrischen Auswertung des ALI-Korpus $(\mathrm{N}=36)$.

Die Taxierung der Originalkarten erbrachte eine Gesamtsumme von 1038 Taxaten, von denen 452 auf den lexikalischen Bereich und 586 auf den phonetischen Bereich entfallen. Die durchschnittliche Anzahl der Taxate je Arbeitskarte, die für einen direkten Vergleich der Teilkorpora im Hinblick auf den Taxatbesatz maßgeblich ist, liegt im lexikalischen Korpus höher als im phonetischen Korpus. Die kampanischen Dialekte zeigen in den 1960er Jahren also im lexikalischen Bereich eine höhere Diversifikation als im phonetischen Bereich. ${ }^{395}$ In den phonetischen Teilbereichen (Konsonantismus und Vokalismus) ist die diatopische Differenzierung hingegen in etwa gleich stark ausgeprägt. Die Abbildungen 20, 21 und 22 zeigen die Häufigkeitsverteilung der unterschiedlichen Taxatbesätze (Polynymie) im Hinblick auf die Gesamtheit der Arbeitskarten (TOT), im Lexikon (LEX) und im phonetischen Bereich (PHON). Sowohl im Totalkorpus als auch im lexikalischen und phonetischen Teilkorpus weicht der Verlauf der Kurve im statistisch relevanten Bereich (2 - 4 Taxate) von den in anderen dialektometrischen Untersuchungen festgestellten Regularitäten (vgl. Kap. 4.3.3) ab. Zwar fällt die Kurve nach Überschreitung des Maximums in typischer Weise exponentiell ab, das Maximum selbst liegt jedoch statt bei den binymen bei den tetranymen Arbeitskarten. Dies weist auf eine im Vergleich zu anderen Sprach- bzw. Dialektgebieten hohe diatopische Diversifikation im untersuchten Areal

\footnotetext{
${ }^{392}$ Die im Vergleich zum Konsonantismus deutlich geringere Anzahl der Arbeitskarten im Bereich des Vokalismus muss im Verhältnis zu der im Vokalismus ebenfalls deutlich geringeren Anzahl der berücksichtigten Merkmale (s. Tab. 20) gesehen werden. Das Verhältnis zwischen Konsonantismus und Vokalismus ist sowohl im Bereich der Arbeitskarten (129 zu 41) als auch im Bereich der ausgewählten Merkmale (ohne die Kategorien „Sonstige“ 15 zu 5) ca. 3 zu 1.

${ }^{393}$ Keine Taxate sind Nullstellen (Taxat Nr. 0) und nullfrequentes zéro (Wegfall des Nexus, standardmäßig Taxat Nr. 1 bei phonetischer Taxierung).

${ }^{394}$ Ergebnisse auf die erste Kommastelle gerundet.

${ }^{395}$ Damit kann die in den bisherigen dialektometrischen Arbeiten gemachte Beobachtung der allgemein größeren taxatorischen Vielfalt, die der lexikalische Bereich im Vergleich zum phonetischen Bereich aufweist (vgl. Kap. 4.4, FN 337), bestätigt werden.
} 
hin und bestätigt die Ergebnisse der qualitativen Untersuchungen zum kampanischen Dialektgebiet (vgl. Kap. 3.3.3 - 3.3.5). ${ }^{396}$

Das Verhältnis zwischen den sprachlichen Teilbereichen im Hinblick auf die Ausprägung der diatopischen Diversifikation findet sich auf der Ebene der Taxatareale wieder. Die durchschnittliche Anzahl der Messpunkte je Taxat ist im lexikalischen Bereich (ca. 8 Messpunkte) geringer und das durchschnittliche Taxatareal damit kleiner als im phonetischen Bereich (ca. 10 Messpunkte), wo Konsonantismus und Vokalismus im Durchschnitt etwa gleich große Taxatareale zeigen. Die „basilektale Bewirtschaftung des Raumes durch den homo loquens" (Goebl 1993d: 277) greift also in der Campania im phonetischen Bereich tendenziell weiträumiger aus und generiert damit gröbere Raumstrukturen als im Lexikon. Die Abbildungen 23, 24 und 25 zeigen die Häufigkeitsverteilung der unterschiedlich großen Taxatareale im Hinblick auf die Gesamtheit der Taxate (TOT), im Lexikon (LEX) und im phonetischen Bereich (PHON). Hier folgt die exponentiell abfallende Kurve im lexikalischen Bereich deutlich den der diatopischen Diversifikation zugrunde liegenden Gesetzmäßigkeiten, während sich im phonetischen Bereich vor allem im mittleren Abschnitt (11 - 20 Messpunkte je Taxat) deutliche Abweichungen finden. Mit der Kleinräumigkeit der Taxatareale korreliert im Lexikon also eine stärkere Regularität der „,sprachlichen Bewirtschaftung“ der Campania, während das weiträumigere Ausgreifen der Taxaträume im phonetischen Bereich Abweichungen vom typischen Verlauf der sprachlichen Diversifikation im Raum begünstigt.

\footnotetext{
${ }^{396} \mathrm{Ob}$ und wenn ja, inwieweit die Abweichungen in der Taxatverteilung durch die Modalitäten der Datenerhebung für den ALI (d.h. abweichende Erhebungsmethoden durch verschiedene Exploratoren, vgl. Kap. 5.2.1.2) bedingt sind, muss hier dahin gestellt bleiben.
} 
ALI (1995-2008) - Campania - TOT (275 AK)

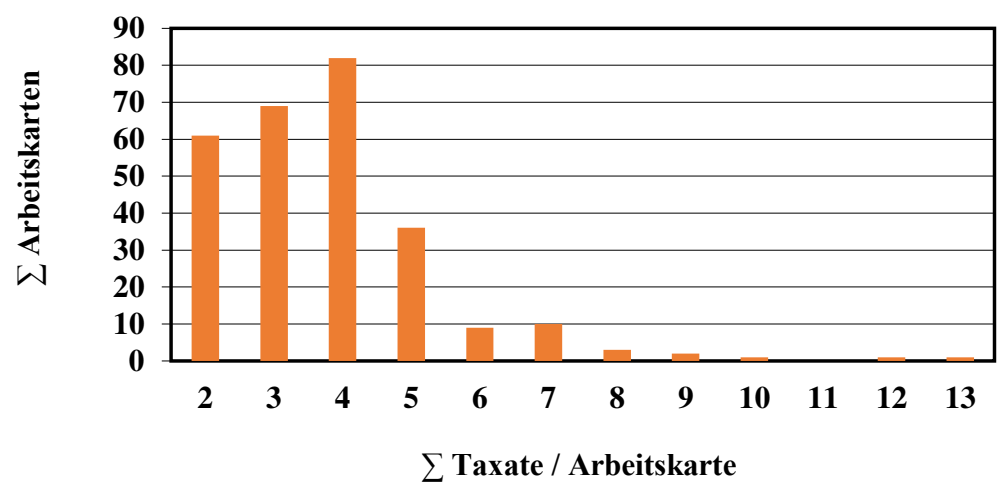

Abbildung 20. Verteilung der Arbeitskarten nach Anzahl der Taxate je Arbeitskarte im Totalkorpus.

\section{ALI (1995-2008) - Campania - LEX (105 AK)}

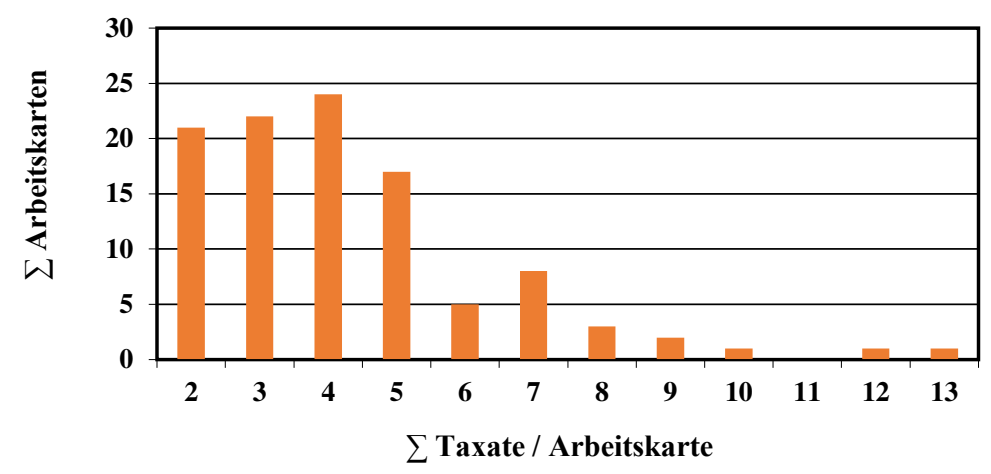

Abbildung 21. Verteilung der Arbeitskarten nach Anzahl der Taxate je Arbeitskarte im lexikalischen Teilkorpus.

\section{ALI (1995-2008) - Campania - PHON (170 AK)}

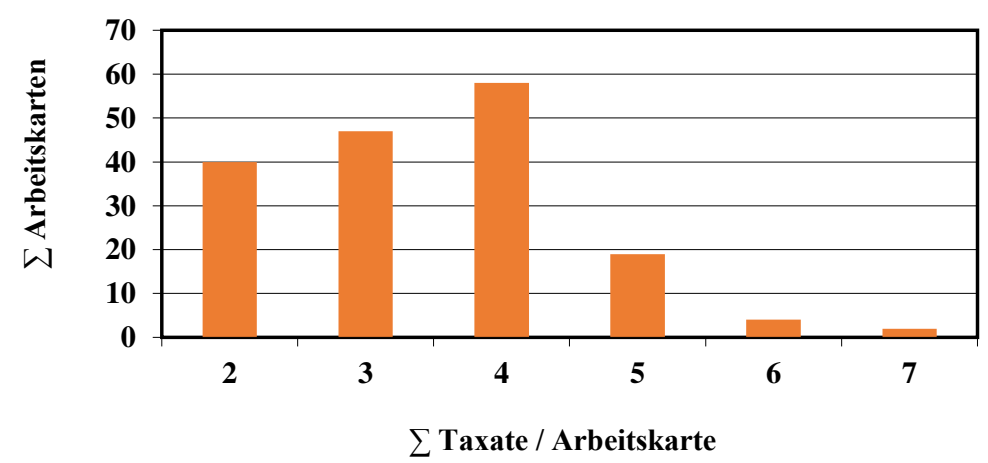

Abbildung 22. Verteilung der Arbeitskarten nach Anzahl der Taxate je Arbeitskarte im phonetischen Teilkorpus. 
ALI (1995-2008) - Campania - TOT

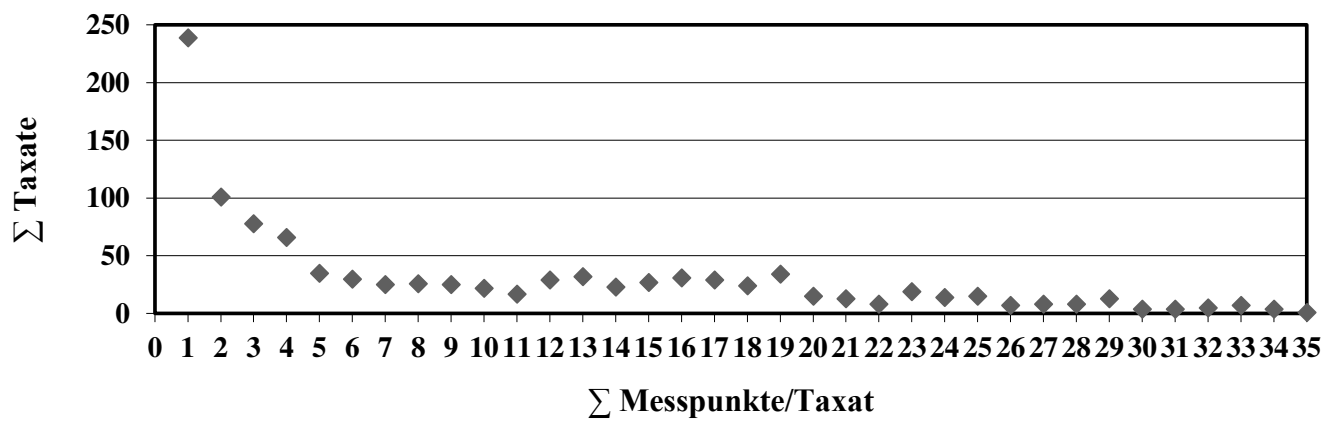

Abbildung 23. Verteilung der Taxate nach der Größe der Taxatareale im Totalkorpus (1038 Taxate).

\section{ALI (1995-2008) - Campania - LEX}

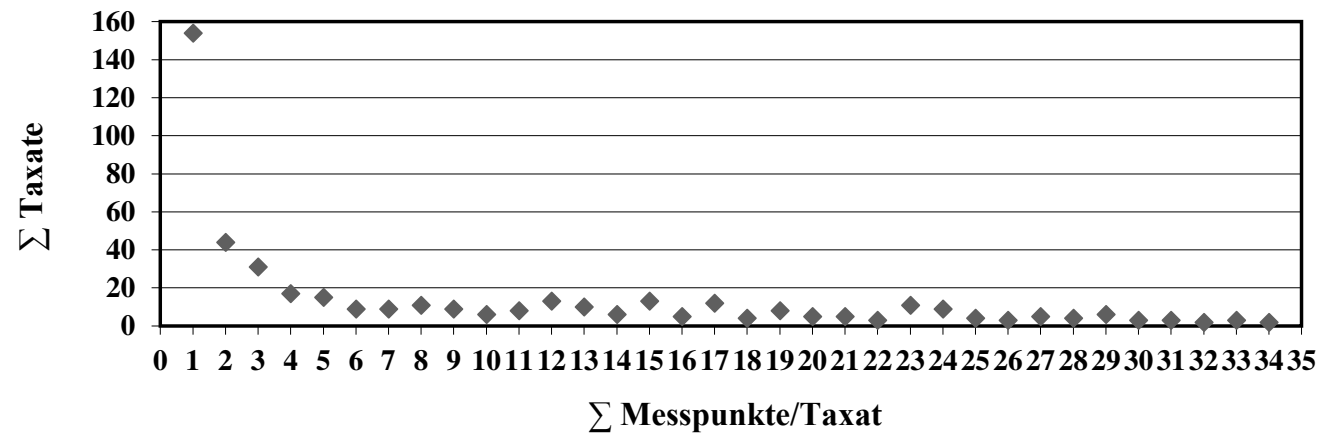

Abbildung 24. Verteilung der Taxate nach der Größe der Taxatareale im lexikalischen Teilkorpus (452 Taxate).

\section{ALI (1995-2008) - Campania - PHON}

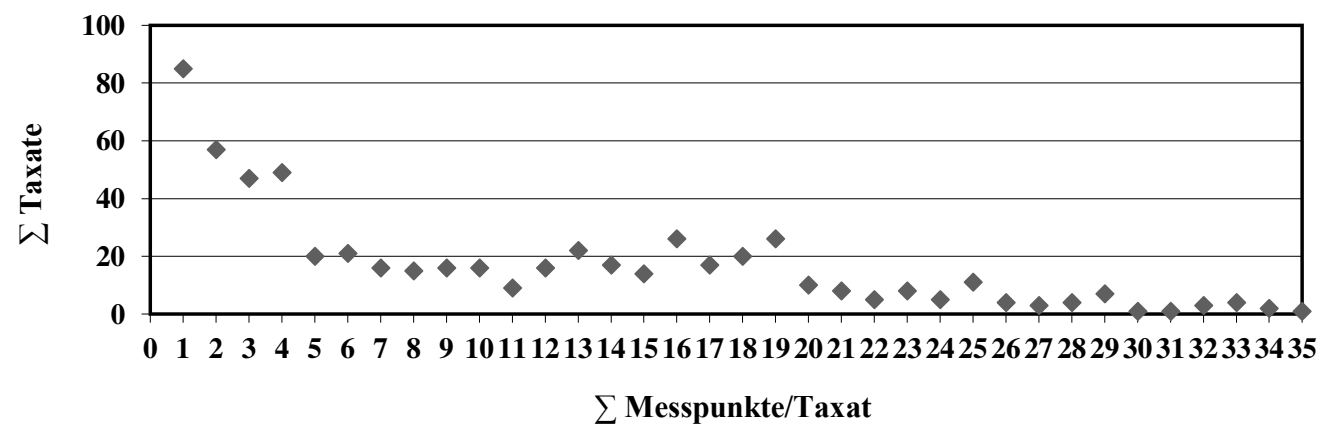

Abbildung 25. Verteilung der Taxate nach der Größe der Taxatareale im phonetischen Teilkorpus (586 Taxate). 


\subsubsection{Vergleichskorpus}

Im Vergleichskorpus (Hajek 2014) konnten aus den (nach Ausschluss der OK mit mehr als 7 Nullstellen sowie der mononymen OK) endgültig berücksichtigten 189 Originalkarten 285 Arbeitskarten (d.h. durchschnittlich 1,5 Arbeitskarten pro Originalkarte) extrahiert werden, von denen 112 AK lexikalisch und 173 AK phonetisch relevant sind. Im phonetischen Bereich fallen $125 \mathrm{AK}$ in den Bereich des Konsonantismus und $48 \mathrm{AK}$ in den Bereich des Vokalismus (s. Tab. 24). ${ }^{397}$

\begin{tabular}{|l|c|c|c|c|c|}
\hline Kategorie & $\sum$ AK & $\sum$ Taxate $^{\mathbf{3 9 8}}$ & $\emptyset$ Taxate/AK & $\begin{array}{l}\text { Variationsbreite } \\
\text { Taxate/AK }\end{array}$ & $\begin{array}{l}\text { Messpunkte/ } \\
\text { Taxatareal }\end{array}$ \\
\hline TOT & 285 & 912 & 3,2 & von 2 bis 9 & 10,9 \\
\hline LEX & 112 & 416 & 3,7 & von 2 bis 9 & 9,5 \\
\hline PHON & 173 & 496 & 2,9 & von 2 bis 7 & 12,1 \\
\hline KONS & 125 & 339 & 2,7 & von 2 bis 7 & 12,8 \\
\hline VOK & 48 & 157 & 3,3 & von 2 bis 6 & 10,7 \\
\hline
\end{tabular}

Tabelle 24. Synopse des Ertrages der dialektometrischen Auswertung des Vergleichskorpus $(\mathrm{N}=36)$.

Insgesamt ergab sich bei der Taxierung der Originalkarten eine Anzahl von 912 Taxaten, von denen 416 Taxate auf den lexikalischen und 496 Taxate auf den phonetischen Bereich entfallen. Die durchschnittliche Anzahl der Taxate je Arbeitskarte ist damit im lexikalischen Bereich höher als im phonetischen Bereich. Gleichzeitig ist die durchschnittliche Anzahl der Messpunkte je Taxatareal im Lexikon geringer als in der Phonetik. Die diatopische Diversifikation der kampanischen Dialekte ist also auch gegenwärtig im Lexikon stärker ausgeprägt und zeigt feinere Raumstrukturen als im phonetischen Bereich. Innerhalb des phonetischen Teilkorpus zeigen sich im Vergleichskorpus jedoch sowohl hinsichtlich des durchschnittlichen Taxatbesatzes als auch hinsichtlich der durchschnittlichen Größe der Taxatareale Unterschiede zwischen Konsonantismus und Vokalismus. Während die durchschnittliche Anzahl der Taxate je Arbeitskarte im Konsonantismus leicht geringer ist als im Vokalismus, zeigen sich im Konsonantismus im Schnitt größere Taxatareale. Vor dem Hintergrund, dass die diatopische Diversifikation im ALI-Korpus im konsonantischen und im vokalischen Bereich etwa gleich ausgeprägt ist (vgl. Tab. 25), deutet die Analyse des Taxatbesatzes also darauf hin, dass in der Zeit zwischen den Erhebungszeitpunkten, d.h. in der zweiten Hälfte des 20. Jahrhunderts in der phonetischen Diversifikation des kampanischen Dialektgebietes Veränderungen stattgefunden haben, die die im Vergleichskorpus zu beobachtenden Abweichungen zwischen Konsonantismus und Vokalismus bedingen.

Tabelle 25 zeigt, dass die Gesamtzahl der Taxate im ALI-Korpus deutlich höher ist als im Vergleichskorpus. Dies gilt auch für alle Teilkorpora bis auf den Vokalismus, wo der Taxatertrag im Vergleichskorpus leicht höher liegt. Die für den direkten Vergleich der

\footnotetext{
${ }^{397}$ Damit ergibt sich hier gegenüber dem Ergebnis im ALI-Korpus eine geringe Abweichung des Verhältnisses zwischen Konsonantismus und Vokalismus im Bereich der Arbeitskarten (2,6 zu 1) von jenem im Bereich der Merkmale (3 zu 1).

${ }^{398}$ Keine Taxate sind Nullstellen (Taxat Nr. 0) und nullfrequentes zéro (Wegfall des Nexus, standardmäßig Taxat Nr. 1 bei phonetischer Taxierung).

${ }^{399}$ Ergebnisse auf die erste Kommastelle gerundet.
} 
Taxaterträge relevante durchschnittliche Anzahl der Taxate je Arbeitskarte ${ }^{400}$ ist im Vergleichskorpus insgesamt sowie in allen Teilkorpora - und insbesondere im Konsonantismus - geringer als im ALI-Korpus. In der Zeit zwischen den Erhebungszeitpunkten hat also im lexikalischen wie im phonetischen (und hier insbesondere im konsonantischen) Bereich eine Reduktion der diatopischen Diversifikation im kampanischen Dialektgebiet stattgefunden. Dementsprechend lässt sich im Hinblick auf die durchschnittliche Größe der Taxatareale im diachronischen Vergleich ein deutliches Wachstum erkennen, das im phonetischen Bereich ausgeprägter ist als im Lexikon und sich insbesondere im Konsonantismus manifestiert. Die sprachlichen Raummuster sind also heute deutlich grobmaschiger als noch in den 1960er Jahren.

\begin{tabular}{|c|c|c|c|c|c|c|}
\hline \multirow[t]{2}{*}{ Kategorie } & \multicolumn{2}{|c|}{$\sum$ Taxate } & \multicolumn{2}{|c|}{ ø Taxate/AK } & \multicolumn{2}{|c|}{$\begin{array}{l}\text { ø Messpunkte/ } \\
\text { Taxatareal }\end{array}$} \\
\hline & $\begin{array}{c}\text { ALI } \\
(1960)\end{array}$ & $\begin{array}{l}\text { Hajek } \\
(2014)\end{array}$ & $\begin{array}{c}\text { ALI } \\
(1960)\end{array}$ & $\begin{array}{l}\text { Hajek } \\
(2014)\end{array}$ & $\begin{array}{c}\text { ALI } \\
(1960)\end{array}$ & $\begin{array}{l}\text { Hajek } \\
(2014)\end{array}$ \\
\hline TOT & 1038 & 912 & 3,8 & 3,2 & 9,2 & 10,9 \\
\hline LEX & 452 & 416 & 4,3 & 3,7 & 8,3 & 9,5 \\
\hline PHON & 586 & 496 & 3,4 & 2,9 & 10,1 & 12,1 \\
\hline KONS & 440 & 339 & 3,4 & 2,7 & 10,0 & 12,8 \\
\hline VOK & 146 & 157 & 3,6 & 3,3 & 9,8 & 10,7 \\
\hline
\end{tabular}

Tabelle 25. Synopse des Taxatertrages der dialektometrischen Auswertung des ALI-Korpus (1960) ${ }^{401}$ und des Vergleichskorpus (2014).

Die Abbildungen 26, 27 und 28 zeigen die Häufigkeitsverteilung der verschiedenen Taxatbesätze im Vergleichskorpus im Hinblick auf alle extrahierten Arbeitskarten (TOT) sowie im lexikalischen (LEX) und im phonetischen Bereich (PHON). Es fällt auf, dass der Verlauf der Kurve hier sowohl im Totalkorpus als auch in den Teilkorpora deutlich stärker mit den allgemeinen Gesetzmäßigkeiten kongruiert als im ALI-Korpus (Erreichen des Maximums bei den binymen Arbeitskarten mit anschließender exponentieller Abnahme). Die diatopische Differenzierung des kampanischen Dialektgebietes weist also heute ,typischere' Charakteristika auf als noch vor fünfzig Jahren. Auch die Häufigkeitsverteilung der Taxatareale nach ihrer Größe (s. Abb. 29, 30 und 31) zeigt im Vergleichskorpus sowohl im Hinblick auf die Gesamtheit der Taxate als auch in den Teilbereichen eine typische Struktur. Zwar existieren auch hier im phonetischen Bereich an mehreren Stellen Unregelmäßigkeiten; diese sind jedoch weit weniger ausgeprägt als im ALI-Korpus (vgl. Abb. 25). Die sprachliche Bewirtschaftung des Raumes verläuft also insbesondere im phonetischen Bereich heute regulärer als in den 1960er Jahren, gleichzeitig jedoch nach wie vor weniger regelmäßig als im Lexikon. Obwohl also innerhalb des phonetischen Bereichs Veränderungen stattgefunden haben, ist das Verhältnis zwischen Lexikon und Phonetik im Hinblick auf die Ausprägung der diatopischen Diversifikation stabil geblieben.

\footnotetext{
${ }^{400}$ Die Variationsbreite der Anzahl der Taxate je Arbeitskarte bildet keine adäquate Grundlage für den Vergleich beider Korpora, da hier die Häufigkeitsverteilung der verschiedenen Taxatbesätze nicht deutlich wird (so weisen etwa im ALI-Korpus nur drei Arbeitskarten mehr als neun Taxate auf). Ein Vergleich der Diagramme zur Taxatverteilung im ALI-Korpus (Abb. 20-22) und im Vergleichskorpus (Abb. 26-28) liefert in dieser Hinsicht ein besseres Bild.

${ }^{401}$ Da der Erhebungszeitraum der Daten für den ALI etwa zehn Jahre beträgt (1954-1964), wird hier zur besseren Übersicht ein mittlerer Zeitpunkt (1960) angegeben.
} 
Aus dem Vergleich der Taxierungserträge der beiden Korpora lässt sich also festhalten, dass

a) zwischen den Erhebungszeitpunkten - d.h. zwischen ca. 1960 und 2014 - eine Reduktion der sprachlichen Diversifikation in der Campania stattgefunden hat, die sich vor allem im Konsonantismus manifestiert und mit einer Vergröberung der Raummuster einhergeht,

b) die „,basilektale Bewirtschaftung des Raumes“ heute deutlich gesetzmäßiger verläuft als in den 1960er Jahren und

c) das Verhältnis zwischen Lexikon und Phonetik im Hinblick auf die Ausprägung der diatopischen Diversifikation diachronisch stabil ist.

In welcher Form sich die von den numerischen Taxierungsergebnissen bereits angedeuteten diachronischen Veränderungen in der sprachlichen Raumordnung der Campania genau darstellen und welche geographischen Bereiche besonders von der Umgestaltung betroffen sind, zeigt die Analyse der dialektometrischen Heuristika in Kap. 5.4 und 5.5. 
Hajek (2014) - Campania - TOT (285 AK)

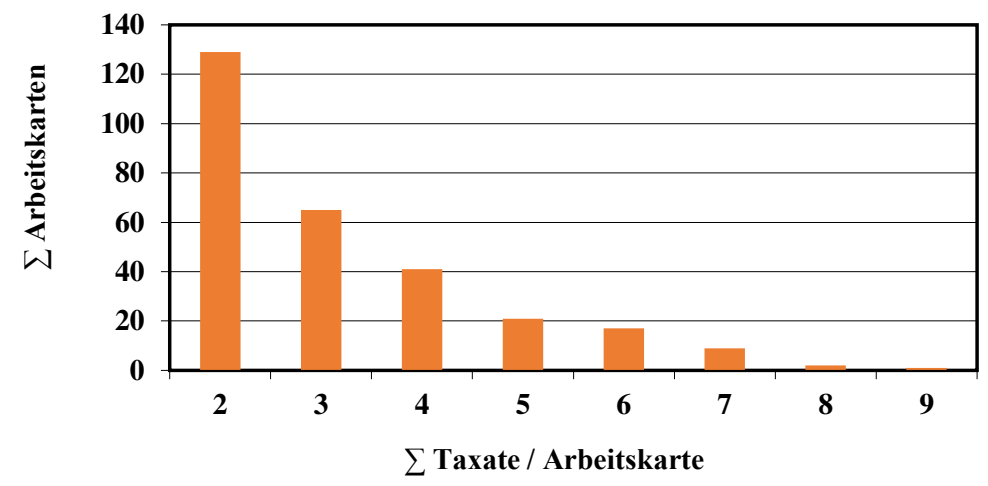

Abbildung 26. Verteilung der Arbeitskarten nach Anzahl der Taxate je Arbeitskarte im Totalkorpus.

Hajek (2014) - Campania - LEX (112 AK)

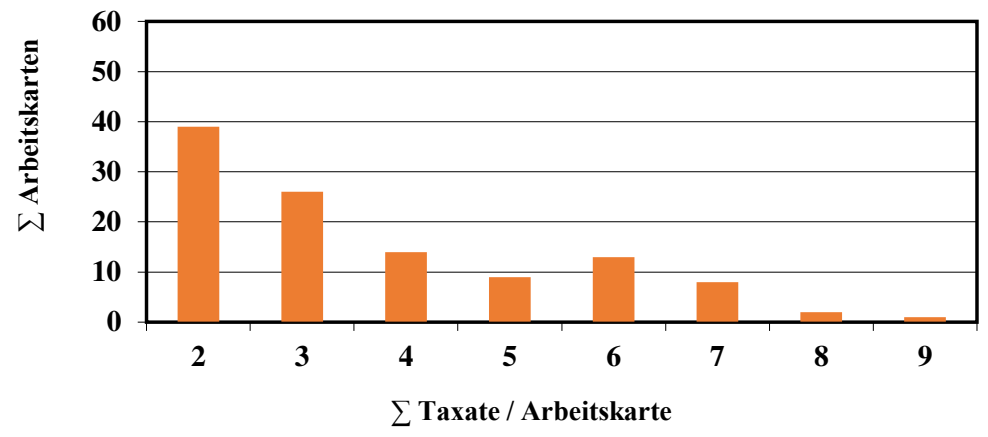

Abbildung 27. Verteilung der Arbeitskarten nach Anzahl der Taxate je Arbeitskarte im lexikalischen Teilkorpus.

Hajek (2014) - Campania - PHON (173 AK)

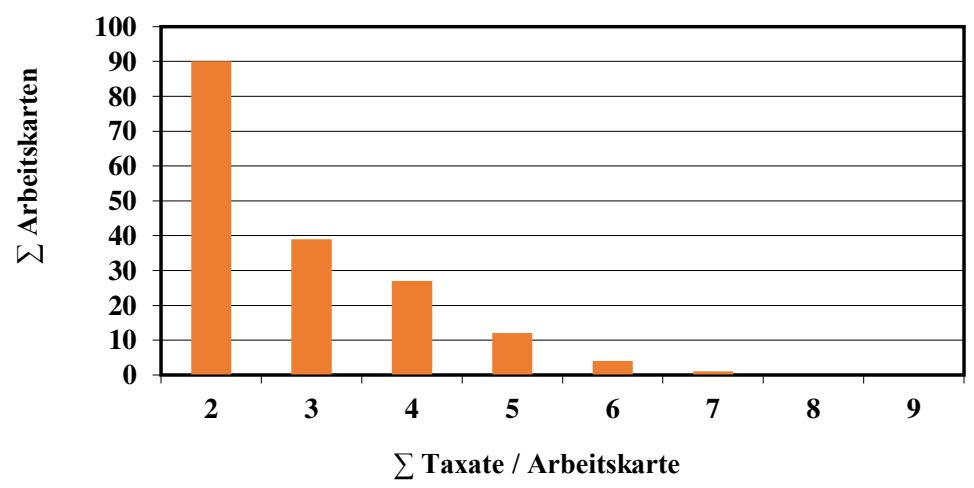

Abbildung 28. Verteilung der Arbeitskarten nach Anzahl der Taxate je Arbeitskarte im phonetischen Teilkorpus. 
Hajek (2014) - Campania - TOT

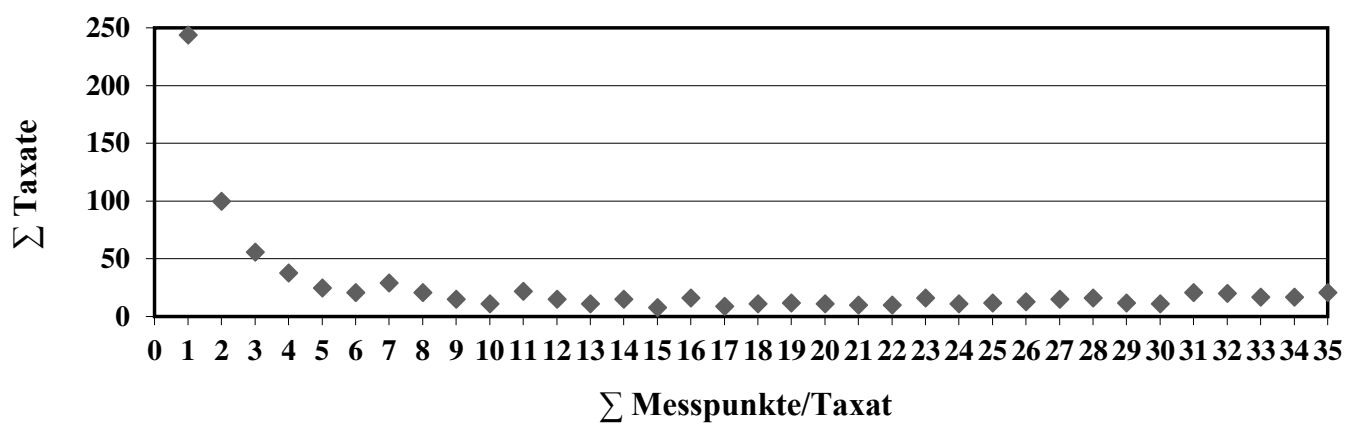

Abbildung 29. Verteilung der Taxate nach Größe der Taxatareale im Totalkorpus (912 Taxate).

Hajek (2014) - Campania - LEX

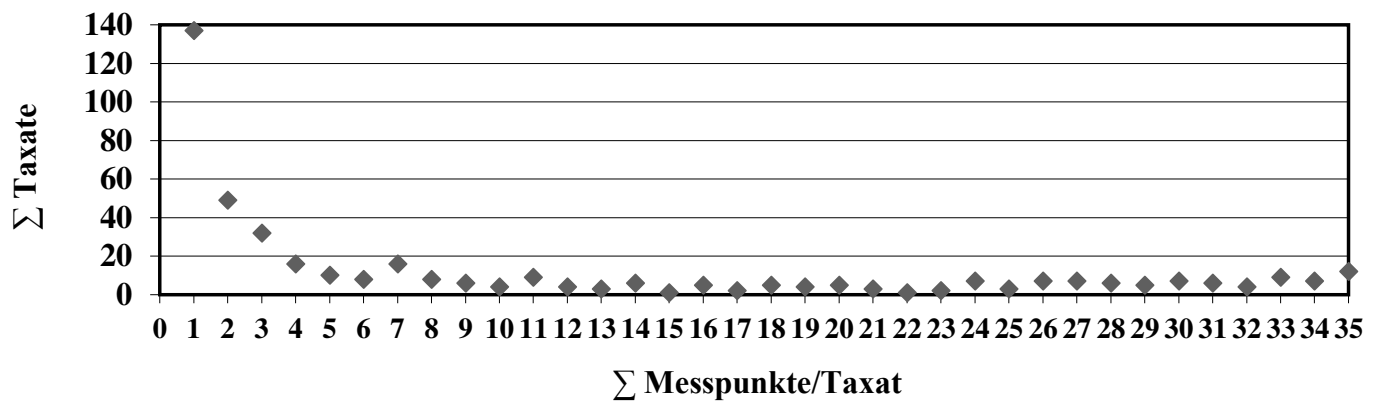

Abbildung 30. Verteilung der Taxate nach Größe der Taxatareale im lexikalischen Teilkorpus (416 Taxate).

\section{Hajek (2014) - Campania - PHON}

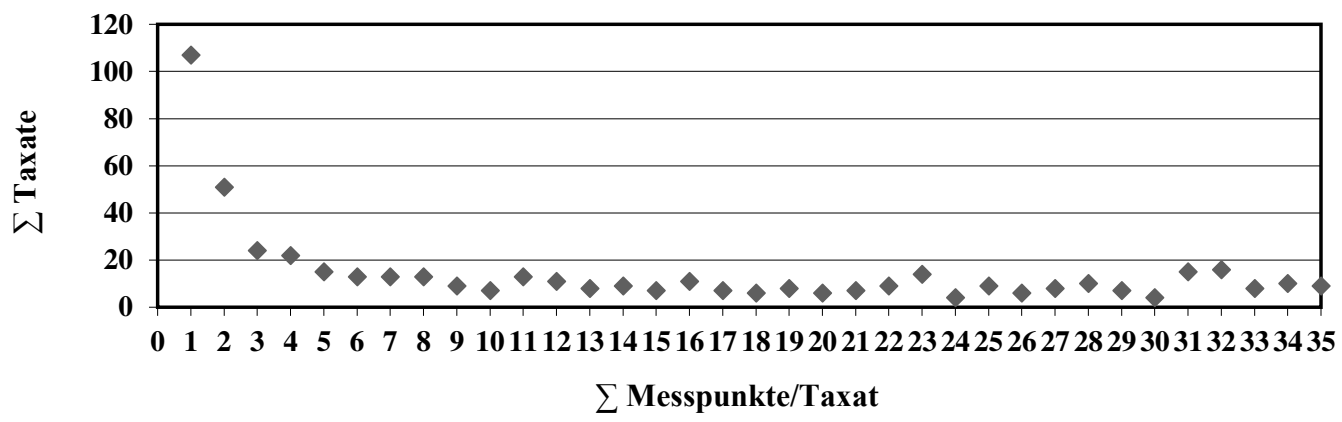

Abbildung 31. Verteilung der Taxate nach Größe der Taxatareale im phonetischen Teilkorpus (496 Taxate). 


\title{
5.4 Dialektometrische Auswertung I: Das kampanische Dialektgebiet um 1960
}

\subsubsection{Klassifikation der kampanischen Dialekte}

\author{
S. Kartenteil, Abb. A1 - A4 und Karten A1 - A4
}

Aufschluss über die interne Gliederung des kampanischen Dialektgebietes ${ }^{402}$ gibt das Ergebnis der auf der Basis der dialektometrisch (mittels RIW $_{j k}$ ) gemessenen Ähnlichkeitswerte durchgeführten hierarchisch-agglomerativen Clusteranalyse. Das resultierende Dendrogramm wird im Folgenden in umgekehrter Richtung, d.h. in Richtung der Ausgliederung der verschiedenen Untercluster aus dem alle Elemente beinhaltenden Gesamtcluster (also von oben nach unten) gelesen und sowohl für das Totalkorpus (TOT) als auch für die Teilkorpora Lexikon (LEX), Konsonantismus (KONS) und Vokalismus (VOK) separat betrachtet. Die Ergebnisse basieren auf der Clustermethode des Complete Linkage. ${ }^{403}$

Im Totalkorpus lassen sich zwei Hauptcluster identifizieren (s. Abb. A1): Eines, das die Cluster A, B, C und D und damit den Großteil der Dialekte im kampanischen Inland, d.h. in der Terra di Lavoro ${ }^{404}$, im Sannio, in der Irpinia und im Nordcilento umfasst und eines, das die Cluster E, F und G und damit die Dialekte in der Metropolregion Neapel ${ }^{405}$ (Casal di Prìncipe (823), Neapel (835), Sorrento (852), Barano d'Ischia (833), Pròcida (834) und Anacapri (851)), die Provinzhauptstädte Benevento (825) und Salerno (855) sowie die Dialekte in der Region Apulien (Bovino (819), Candela (827)) und im Südcilento (Monte San Giacomo (865), Alfano (873), Casaletto Spartano (874)) enthält. Räumlich entsprechen diese Hauptcluster zwei großen dialektalen Makrogebieten bzw. Dialektblöcken, wobei der kompakte Block, der die Dialekte im kampanischen Inland, d.h. in der Terra di Lavoro, im Sannio, in der Irpinia und im Nordcilento enthält (warm eingefärbte Choreme und grünes Chorem), von dem zweigeteilten Block eingefasst wird, der die in der Peripherie des Gebietes liegenden Dialekte im Westen der Region Apulien, im Südcilento und in der Metropolregion Neapel umfasst (blau eingefärbte Choreme).

Innerhalb der beiden großen Dialektblöcke lassen sich folgende kleinere dialektale ,Verbünde‘ bzw. Geotypen identifizieren (s. Karte A1): ${ }^{406}$

\footnotetext{
${ }^{402}$ Wann immer nicht anders angegeben, werden hierunter die Dialekte aller in der empirischen Analyse berücksichtigten Messpunkte - also auch jene der außerhalb der Region Kampanien liegenden Messpunkte - verstanden. Das als ,kampanisches Dialektgebiet' bezeichnete Areal wird somit als kongruent mit dem (polygonisierten) Ortsnetz angesehen. Die synonym dazu verwendeten Begriffe ,Region Kampanien“ bzw. ,Campania ‘ sind dementsprechend nicht im administrativen Sinn zu verstehen.

${ }^{403}$ Bei der Analyse der sprachlichen Raumstrukturen (Kap. 5.4.1 - 5.4.7) werden die Werte des künstlichen Prüfbezugspunktes italiano standard (900) nicht berücksichtigt. Der Analyse (wie den entsprechenden dialektometrischen Karten) liegt hier also eine reduzierte Ähnlichkeitsmatrix von 35 x 35 Messpunkten zugrunde. Das Ähnlichkeitsprofil zum Referenzpunkt italiano standard wird in Kap. 5.4.8 separat behandelt. Entsprechendes gilt für die dialektometrische Analyse des Vergleichskorpus (Kap. 5.5).

${ }^{404}$ Dieser Terminus bezeichnet hier nicht das gesamte historisch-geographische Gebiet der Terra di Lavoro, sondern lediglich den Teil, der in der heutigen Region Kampanien liegt.

${ }^{405}$ Vgl. Kap. 3.1.

${ }^{406}$ Für die Clusteranalyse in der vorliegenden Arbeit gilt, dass die für die Klassifikation der Dialekte entscheidende Partition bzw. die Anzahl an relevanten Clustern dann erreicht ist, wenn alle auf der Schottenkarte (Kap. 5.4.2 und 5.5.2) aufscheinenden kompakten Dialektareale (im Sinne von Räumen, in denen die Dialekte hohe bis sehr hohe Ähnlichkeiten zueinander aufweisen) und Dialektgrenzen (im Sinne von Übergangsräumen zwischen diesen Dialektarealen) mit den bis dahin ausgegliederten Clustern bzw. mit den Umrissen der entsprechenden Choreme in Zusammenhang gebracht werden können. Das bedeutet jedoch nicht, dass sich alle der bis dahin ausgegliederten Cluster als nach außen abgegrenzte Dialektareale bzw. deren Umrisse sich als deutliche Dialektgrenzen (d.h. in Blau- und Grüntönen) auf der jeweiligen Schottenkarte manifestieren müssen. Bei Klassen, die sich erst relativ spät ausgliedern, sind die Abstände zu geographisch angrenzenden Dialektgruppen (d.h. die
} 
1) die Dialekte in der Terra di Lavoro (Cluster A), ${ }^{407}$

2) die Dialekte im neapolitanischen Hinterland (Cluster B),

3) die Dialekte im Sannio Beneventano (Cluster C),

4) die Dialekte im Gebiet Nordcilento-Irpinia (Cluster D), ${ }^{408}$

5) die Dialekte im Gebiet Bovino-Candela (Cluster E),

6) die Dialekte im Südcilento (Cluster F),

7) die Dialekte in der Metropolregion Neapel (einschließlich der geographisch nicht adjazenten ${ }^{409}$ Dialekte von Benevento (825) und Salerno (855), Cluster G). ${ }^{410}$

Im lexikalischen Bereich erbringt die Clusteranalyse eine etwas andere dialektale Klassifikation als im Totalkorpus (s. Abb. A2 und Karte A2). Zunächst fällt hier auf, dass die Dialekte in der Irpinia im Lexikon eine eigene Gruppe bilden (Cluster F). Die Dialekte in der Region Apulien (Cluster E) und im Südcilento (Cluster H) bilden eine Gruppe mit den Dialekten im kampanischen Inland und nicht - wie im Totalkorpus - mit den Dialekten in der Metropolregion Neapel (Cluster B). Die Beziehung zwischen diesen und den peripheren Dialekten im Süden und Osten besteht also primär auf der Ebene der Phonetik. Auffallend ist im Lexikon zudem die Sonderstellung des Dialektes von Olèvano Sul Tusciano (856), der eine große geographische Distanz zu den übrigen Dialekten von Cluster A, die sich in der Terra di Lavoro befinden, aufweist. ${ }^{411}$

Wie angesichts der Dominanz des konsonantischen Teilkorpus im Gesamtkorpus zu erwarten, entsprechen die Ergebnisse der Klassifikation im konsonantischen Bereich weitgehend jenen im Totalkorpus (bzw. umgekehrt, s. Abb. A3 und Karte A3). Unterschiede zum Totalkorpus liegen darin, dass die Isole Flegree (mit den Messpunkten Barano d'Ischia (833) und Pròcida (834)) im Konsonantismus eine eigene Dialektgruppe (Cluster G) bilden und die Dialekte von Roccarainola (836) und Capaccio (863) ,Sonderlinge' sind, die sich keinem Geotyp in ihrer Umgebung anschließen, sondern zusammen ein separates Cluster bilden.

Im Vokalismus weicht die Klassifikation der kampanischen Dialekte sowohl von jener im Totalkorpus bzw. Konsonantismus als auch von jener im Lexikon ab: Hier treten die größeren Cluster in der Spatialisierung des Klassifikationsergebnisses nicht als kompakte Verbünde zu Tage, sondern bestehen aus mehreren räumlich disjunkten Kleingruppen (s. Abb. A4 und Karte A4). Das erste Hauptcluster - bestehend aus den Clustern A, B, C, D und E - beinhaltet

sprachlichen Abstände zwischen den ,Nachbarn') häufig relativ gering, sodass auf der Schottenkarte keine deutlichen Grenzen sichtbar werden.

${ }^{407}$ Die Bezeichnungen der Dialektklassen wurden nach den Bezeichnungen der (historisch-)geographischen Gebiete gewählt, in denen sich jeweils die meisten Messpunkte befinden. Bei einigen Messpunkten (z.B. Maiori (854) oder Olèvano Sul Tusciano (856)) muss bei der Zugehörigkeit zur jeweiligen Dialektklasse von der geographischen Position des Messpunktes abstrahiert werden.

${ }_{408}$ Die Dialekte von Postiglione (857) und Salvitelle (858) konstituieren dabei den Übergang zwischen den Dialekten des nördlichen Cilento und den Dialekten der Irpinia.

${ }^{409}$ In der vorliegenden Arbeit werden zwei Messpunkte bzw. Dialekte als ,adjazent‘ bezeichnet, wenn die entsprechenden Polygone adjazent sind, d.h. eine gemeinsame Seite aufweisen. Rein geographische Trennungen (wie etwa zwischen den Inseln im Golf von Neapel und dem kampanischen Festland) werden hierbei nicht berücksichtigt (so gehören z.B. die insularen Dialekte von Barano d'Ischia (833), Pròcida (834) und Anacapri (851) trotz ihrer geographischen Trennung vom Festland zur Gruppe der Dialekte in der Metropolregion Neapel).

${ }^{410}$ In der Analyse der Daten aus dem ALI sind - soweit nicht anders gekennzeichnet - grundsätzlich die geographisch nicht adjazenten Messpunkte Benevento (825) und Salerno (855) als Teil der Dialektklasse bzw. des Dialektgebietes in der „Metropolregion Neapel“ zu verstehen.

${ }^{411}$ Auch wenn einzelne Messpunkte in der betrachteten Partition zu keinem Cluster gehören - also eine große Distanz zu allen in den übrigen Clustern zusammengefassten Messpunkten aufweisen - bestehen sprachliche Beziehungen zum geographischen Umfeld, die sich häufig in anderen Heuristika manifestieren (s.u.). 
die Dialekte im neapolitanischen Hinterland, im Sannio, in der Irpinia, im Nordcilento und in Apulien, das zweite Hauptcluster (Cluster F, G und H) umfasst die Dialekte in der Metropolregion Neapel (hier bis nach Rocca d'Evandro (809) in der Terra di Lavoro), die Dialekte der Provinzhauptstädte Benevento (825) und Salerno (855), die Dialekte im Südcilento sowie die peripheren nördlichen Dialekte von Gioia Sannìtica (814) und Reìno (815). Zudem zeigen sich hier einzelne Dialekte mit Sonderstellung im Süden (Casaletto Spartano (874)) und Osten (Bovino (819), Candela (827)). ${ }^{412}$ Die im Totalkorpus erkennbare Beziehung zwischen den Dialekten in der Provinz Foggia und den Dialekten in der Metropolregion Neapel manifestiert sich im Vokalismus also nicht und ist damit auf die sprachliche Nähe zurückzuführen, die diese Gebiete im konsonantischen Bereich zueinander aufweisen.

Für die dialektale Gliederung der Region Kampanien in den 1960er Jahren kann festgehalten werden, dass im Totalkorpus mehrere kleinräumige Geotypen aufscheinen, die sich in den Klassifikationen im konsonantischen und lexikalischen Teilkorpus zum Großteil wiederfinden. Auffällig ist besonders die Nähe der Dialekte der Provinzhauptstädte Benevento (825) und Salerno (855) zu den Dialekten der Metropolregion Neapel sowie die Ähnlichkeit, die letztere (im Konsonantismus und im Vokalismus) zu den Dialekten im Südcilento und (nur im Konsonantismus) zu den Dialekten in der Provinz Foggia aufweisen.

\subsubsection{Dialektgrenzen}

\section{S. Kartenteil, Karten A5 - A8}

Anhand der Analyse der Schottenkarte ${ }^{413}$ sollen im Folgenden die ,Bruchstellen“ innerhalb des kampanischen Dialektgebietes, d.h. die Dialektgrenzen ${ }^{414}$ identifiziert und die Kompaktheit ${ }^{415}$ der von diesen umschlossenen dialektalen Teilareale diskutiert werden.

\footnotetext{
${ }^{412}$ Dies zeigt allerdings nur, dass die meisten anderen Dialekte einander im Vokalismus näher sind als den genannten und lässt keine Rückschlüsse darauf zu, ob bzw. welche sprachlichen Ähnlichkeiten zwischen den ,Außenseitern“ und ihrem geographischen Umfeld bestehen. Vgl. dazu Kap. 5.4.3.

${ }^{413}$ Da beide Typen der Zwischenpunktkarte (Schottenkarte und Strahlenkarte) denselben Ausschnitt der zugrunde liegenden Ähnlichkeits- bzw. der zu dieser komplementären Distanzmatrix abbilden (vgl. Kap. 4.3.7.6 und 4.3.7.7) wird im Folgenden (und analog dazu auch in der dialektometrischen Analyse des Vergleichskorpus) auf die Analyse der Strahlenkarten verzichtet. Die dort ,direkt' symbolisierten Interaktionsflüsse lassen sich ,indirekt‘ auch aus der Schottenkarte ablesen (vgl. die Ausführungen zur „Doppelnatur“ des Phänomens ,Grenze‘, Kap. 4.3.7.6, FN 317).

${ }^{414}$ In der vorliegenden Analyse wird der Terminus ,Dialektgrenze“ immer im Sinne eines (durch die Koexistenz sprachlicher Varianten charakterisierten) Übergangsraumes und das ,Dialektgebiet` dementsprechend als ein von Übergangsräumen zu anderen Dialektgebieten umschlossenes sprachgeographisches Areal verstanden (vgl. Kap. 4.1 und 4.3.7.6). Als Indikatoren für Dialektgrenzen werden in Grün- und Blautönen gefärbte Schotten begriffen. Diese finden sich teilweise auch zwischen zwei Messpunkten, die auf den entsprechenden Ähnlichkeitskarten eine verhältnismäßig hohe sprachliche Ähnlichkeit (d.h. Werte in den Klassen 5 und 6) zueinander aufweisen. Dies beruht auf der unterschiedlichen Art und Anzahl der in den Heuristika berücksichtigten Werte (vgl. Kap. 4.3.7.2 und Kap. 4.3.7.6) und ist immer dann der Fall, wenn die Ähnlichkeit zwischen zwei Polygonnachbarn zwar im Verhältnis zur Ähnlichkeit jedes der beiden Messpunkte zu allen übrigen (N - 2) Messpunkten hoch, aber im Vergleich zu der sprachlichen Ähnlichkeit, die alle übrigen Polygonnachbarn zueinander aufweisen, niedrig ist.

${ }^{415}$ Unter ,kompakten Dialektarealen“ werden in der vorliegenden Arbeit Agglomerationen von Messpunkten verstanden, die jeweils eine hohe bis sehr hohe sprachliche Ähnlichkeit (Wertklassen [4], [5] und [6] auf der Ähnlichkeitskarte, Wertklassen [1], [2] und [3] auf der Schottenkarte) zueinander aufweisen und sich deutlich d.h. durch verhältnismäßig hohe sprachliche Distanzen (Wertklassen [1], [2] und [3] auf der Ähnlichkeitskarte, Wertklassen [4], [5] und [6] auf der Schottenkarte) - von umgebenden Gebieten abgrenzen.
} 
Bei der Betrachtung der auf der Basis des Totalkorpus generierten Schottenkarte (s. Karte A5) $)^{416}$ ergibt sich ein klares Bild der dialektalen Grenzen in der Campania. Im Westen der Region lässt sich die Grenze zwischen dem - sich im Norden bis an die Grenze der Region erstreckenden - Dialektgebiet der Metropolregion Neapel und dem Dialektgebiet im neapolitanischen Hinterland ausmachen, die allerdings zwischen Sorrento (852) und Sarno (837) bzw. Maiori (854) verblasst. ${ }^{417}$ Das Dialektgebiet im neapolitanischen Hinterland wird im Osten klar von dem Dialektgebiet Nordcilento-Irpinia und dem Dialektgebiet im Sannio durch eine mitten durch die Region verlaufende Grenze getrennt. Der Verlauf dieser Grenze zeigt eine Kongruenz (im Sinne einer ungefähren Deckungsgleichheit der durch die Grenzen indizierten Übergangsräume) mit dem Verlauf der Isoglossen [ttg]/[tts] und [nn]/[ndł] nach Avolio (1989), ${ }^{418}$ die im südlichen Teil (östlich der Messpunkte Olèvano Sul Tusciano (856) und Avellino (838)) stärker ist als im nördlichen (zwischen den Polygonen um Melito Irpino (826) und Montella (839) bzw. Cairano (841)). ${ }^{419}$ Dies kann als Hinweis darauf gewertet werden, dass die mit Avolios (phonetischen) Isoglossen korrespondierenden sprachlichen Merkmale eine typologische Relevanz aufweisen.

Im Nordosten der Campania indiziert der südlich von Melito Irpino (826) verlaufende Teil der genannten Dialektgrenze den Übergangsraum zwischen dem Dialektgebiet Nordcilento-Irpinia und dem Dialektgebiet im Sannio. Östlich davon zeigt sich - in Form von blau eingefärbten Grenzsegmenten - deutlich die Grenze zwischen dem Dialektgebiet im Sannio bzw. dem Dialektgebiet Nordcilento-Irpinia und den in der apulischen Provinz Foggia liegenden Dialekten von Bovino (819) und Candela (827). Im Süden der Region manifestiert sich die Grenze zwischen dem Dialektgebiet Nordcilento-Irpinia und dem Dialektgebiet im Südcilento, die nördlich von Alfano (873) und Monte San Giacomo (865) verläuft. Neben den Grenzen zwischen dialektalen Teilgebieten wird auf der Schottenkarte zudem die sprachliche Isolation $^{420}$ einzelner Orte von ihrem geographischen Umfeld deutlich: jene von Castel Volturno (822) an der kampanischen Küste, von Gioia Sannìtica (814) im äußersten Norden an der Grenze zwischen der Terra di Lavoro und dem Sannio und insbesondere jene von Benevento (825), die durch die sprachliche Nähe zu den Dialekten der Metropolregion Neapel (vgl. Kap. 5.4.1) bedingt ist.

Im lexikalischen Bereich ist die sprachliche Raumstruktur der Region Kampanien durch eine Zweiteilung in einen westlichen und einen östlichen Teil geprägt. Die Grenze zwischen

\footnotetext{
${ }^{416}$ Da die Polygone um die Messpunkte Barano d'Ischia (833), Pròcida (834) und Anacapri (851) zur Wiedergabe der geographischen Verhältnisse bei der Generierung der Basiskarte an die Umrisse der Inseln angepasst wurden, weisen sie keine gemeinsamen Seiten mit den Polygonen auf dem Festland auf. Die Dialektabstände zwischen den insularen Messpunkten und den jeweils benachbarten Messpunkten auf dem Festland können damit auf der Schottenkarte nicht dargestellt und hier somit auch nicht in die Analyse einbezogen werden.

${ }^{417}$ In VDM erscheinen die Ortsnummern auf den Choroplethenkarten, aber nicht auf den Zwischenpunktkarten. Zur Identifikation der Messpunkte bzw. Polygone s. Karte 39.

${ }^{418}$ Vgl. Kap. 3.3.5, Karte 11.

${ }^{419}$ Die Kongruenz zwischen dialektometrisch ermittelten Dialektgrenzen und ,klassischen“ Isoglossenbündeln kann selbstredend nur eine grobe sein, da es sich bei den dialektometrischen Grenzsegmenten um geometrisch konstruierte Elemente handelt, die (im Gegensatz zu Isoglossen) keine kontinuierlichen (und erst recht keine ,scharfen') Grenzen indizieren (sollen).

${ }^{420}$ Die Begriffe der (sprachlichen), Isolation“ bzw. ,Abschottung“ sind hier - wie in der gesamten Datenanalyse - im Sinne einer sehr großen sprachlichen Distanz (Wertklassen [5] und [6] auf der Schottenkarte) zum geographischen Umfeld zu verstehen. Sprachliche Isolation eines Ortes im eigentlichen Sinn kann nur dann vorliegen, wenn - etwa bedingt durch vollkommene geographische Abschottung - zu keinem Zeitpunkt der Geschichte eine Interaktion mit den Sprechergemeinden im geographischen Umfeld bestand. Dies ist in der Campania nicht der Fall.
} 
beiden Teilen verläuft dabei östlich der Punkte Gioia Sannìtica (814), Benevento (825), Avellino (838) und Salerno (855) (s. Karte A6). Olèvano Sul Tusciano (856) befindet sich also im Lexikon östlich der zentralen Dialektgrenze und ist somit Teil des Dialektgebietes NordcilentoIrpinia, während es im Totalkorpus westlich der Grenze liegt und damit zum Dialektgebiet im neapolitanischen Hinterland gehört. Im westlichen Teil der Region, d.h. in der kampanischen Küstenebene scheint zwischen den dialektalen Teilarealen aus dem Totalkorpus (Dialektgebiet in der Terra di Lavoro, in der Metropolregion Neapel und im neapolitanischen Hinterland) im Lexikon keine Grenze auf, sodass der Eindruck eines großflächigen, den Großteil der kampanischen Ebene umfassenden Dialektgebietes entsteht. Diesem steht im Osten der Region ein sprachlich relativ zerklüftetes Areal gegenüber, dass durch verhältnismäßig hohe Abstände zwischen den einzelnen Dialekten gekennzeichnet ist. Besonders auffällig ist die sprachliche Abgrenzung von Senerchia (840) innerhalb der Irpinia, die bewirkt, dass im Lexikon zwei geographisch getrennte Dialektgebiete - das Dialektgebiet Sannio-Irpinia und das Dialektgebiet im Nordcilento - aufscheinen, die sich in dieser Form im Totalkorpus nicht manifestieren. Weiterhin zeigt sich, dass - im Gegensatz zum Totalkorpus - die Dialekte von Bovino (819) und Candela (827) im Lexikon in das Dialektareal Sannio-Irpinia integriert sind und damit kein eigenes dialektales Gebiet darstellen (vgl. Kap. 5.4.1). Stabil ist im Lexikon hingegen die sprachliche Abschottung des Dialektgebietes im Südcilento nach Norden. Darüber hinaus zeigt sich auch hier die Isolation einzelner Dialekte - Castel Volturnos (822), Beneventos (825), nicht aber Gioia Sannìticas (814) - von ihrem geographischen Umfeld.

Die im konsonantischen Bereich aufscheinenden Raumstrukturen (s. Karte A7) entsprechen weitgehend jenen im Totalkorpus. Kleine Abweichungen zeigen sich im Falle von Benevento (825), das hier in südlicher Richtung sprachlich nicht isoliert ist. Auch die Grenze zwischen dem Dialektgebiet im Südcilento und dem Dialektgebiet Nordcilento-Irpinia ist im Konsonantismus weniger stark ausgeprägt als im Totalkorpus.

Im Vokalismus zeigen sich in der Region Kampanien andere sprachliche Raumstrukturen als in den übrigen Teilkorpora (s. Karte A8). Dominiert wird das Raumprofil einerseits durch die sprachliche Abschottung der ein eigenes Gebiet bildenden Dialekte in der nördlichen Peripherie (Gioia Sannìtica (814) und Reìno (815)) von ihrem geographischen Umfeld im Süden, Westen und Osten und andererseits durch die Dialektgrenze zwischen Bovino (819) und Candela (827) in der Region Apulien. Bovino (819) ist dabei im Vokalismus weniger gegenüber seinem geographischen Umfeld im Westen (Sannio) abgeschottet als im Totalkorpus, während Candela (827) klar zum Dialektgebiet Nordcilento-Irpinia gehört. Wie im Totalkorpus, im Konsonantismus und im Lexikon manifestiert sich im Vokalismus die Grenze zwischen dem Dialektgebiet Nordcilento-Irpinia und dem Dialektgebiet im Südcilento, dem sich hier jedoch Casaletto Spartano (874) nicht anschließt. Sprachlich isoliert ist im vokalischen Korpus zudem wie im Totalkorpus und im Lexikon - Castel Volturno (822) an der kampanischen Küste. Auffällig ist schließlich die Aufweichung der Grenze zwischen dem Dialektgebiet NordcilentoIrpinia und dem Dialektgebiet im Sannio, die den Eindruck eines großflächigen kompakten Dialektgebietes im Osten der Region entstehen lässt. Insgesamt zeigt sich im Vokalismus eine geringere Fragmentierung des kampanischen Dialektgebietes als in den übrigen (Teil-)Korpora.

Es kann festgehalten werden, dass das sprachliche Raumprofil der Region Kampanien in erster Linie durch die Zweiteilung in einen westlichen (Küstenebene) und einen östlichen Teil (Gebirgsregionen) bestimmt wird, von dem die geographischen Randgebiete im Süden (Südcilento) und im Osten (Gebiete um Bovino (819) und Candela (827)) sprachlich abgeschottet sind. Im Lexikon zeichnet sich das dialektale Areal westlich der Hauptgrenze durch eine größere Kompaktheit und jenes östlich der Hauptgrenze durch eine größere Fragmentierung als 
im Totalkorpus aus. Deutliche Abweichungen von den Raumstrukturen im Totalkorpus finden sich im Vokalismus, wo sich der östliche Teil der Region ebenfalls als kompaktes Dialektgebiet präsentiert und die peripheren nördlichen Dialekte aus Gioia Sannìtica (814) und Reìno (815) ein eigenes Areal bilden.

\subsubsection{Dialektkerne und sprachliche ,Einzelgänger}

\section{S. Kartenteil, Karten A9 - A12}

Um einen Einblick in den Grad der Kohäsion zwischen benachbarten Dialekten in der Campania zu erhalten, d.h. dialektale Kerngebiete auf der einen und sprachliche ,Einzelgänger' auf der anderen Seite zu identifizieren, wird im Folgenden die Synopse der Maximalwerte betrachtet.

Im Totalkorpus zeigen sich drei Gebiete mit hohen bis sehr hohen Maximalwerten (Wertklassen [5] und [6]), und damit drei kompakte Dialektkerne (s. Karte A9). ${ }^{421}$ Im Zentrum des Dialektkerns in der Metropolregion Neapel stehen die drei Dialekte Neapels (835), Sorrentos (852) und Salernos (855), die alle den höchsten Maximalwert in der gesamten Region aufweisen (s. Tab. 26). Bis auf Casal di Prìncipe (823) zeigen alle übrigen Messpunkte im Dialektgebiet in der Metropolregion Neapel ebenfalls hohe Maximalwerte (Wertklasse [5]). Im neapolitanischen Hinterland findet sich ein weiterer (kleinerer) Dialektkern mit hohen Maximalwerten (Wertklasse [5]) im Gebiet um Sarno (837) und Maiori (854). ${ }^{422}$ Der dritte Dialektkern liegt im Südcilento und umfasst das Gebiet um Alfano (873) und Monte San Giacomo (865), die jeweils sehr hohe Maximalwerte (Wertklasse [6]) aufweisen.

Dialekte mit sehr niedrigen bis niedrigen Maximalwerten (Wertklassen [1] und [2]) liegen einerseits in peripheren Gebieten im Norden (Gioia Sannìtica $(814, \mathrm{MIN})^{423}$, Reìno (815)), im Osten (Bovino (819), Candela (827)), im (Nord-)Westen (Rocca d'Evandro (809), Castel Volturno (822)) sowie im Süden (Casaletto Spartano (874)). Eine zweite Gruppe von Dialekten mit niedrigen Maximalwerten umfasst solche, die in dialektalen Übergangsräumen liegen. An der westlichen Grenze des Dialektgebietes Nordcilento-Irpinia sind dies Olèvano Sul Tusciano (856) und Avellino (838), im Grenzraum zwischen dem Nordcilento und der Irpinia ist es Senerchia (840) und an der Grenze zwischen dem Dialektgebiet der Terra di Lavoro, dem Dialektgebiet der Metropolregion Neapel und dem Dialektgebiet im neapolitanischen Hinterland betrifft es Limàtola (824).

Im Lexikon liegen der durchschnittliche Maximalwert und die Spannweite der Werte auf einem ähnlichen Niveau wie im Totalkorpus (s. Tab. 26). ${ }^{424}$ In der räumlichen Umlegung

\footnotetext{
${ }^{421}$ Im Vergleich zu anderen Korpora, in denen die Maxima in dialektalen Kerngebieten „meist deutlich über 90\%“ (Bauer 2009: 131) liegen, ist der höchste Maximalwert mit 75,64\% hier relativ niedrig. Dies spricht für eine gemessen an anderen Sprach- bzw. Dialektgebieten relativ hohe Heterogenität des kampanischen Dialektgebietes in den 1960er Jahren.

${ }^{422}$ Dass es sich hier um einen eigenständigen Dialektkern handeln muss, zeigt die Clusteranalyse (Kap. 5.5.1), in der das neapolitanische Hinterland sich als autonomes Dialektgebiet manifestiert.

${ }^{423}$ Die Abkürzungen MAX und MIN stehen für den höchsten bzw. niedrigsten Wert, der sich unter den jeweils berücksichtigten Werten der Ähnlichkeitsmatrix (also hier unter den Maximalwerten aller Messpunktvektoren) finden lässt. Analog gilt dies für alle anderen Heuristika.

${ }^{424}$ Von dem Vergleich der verschiedenen (Teil-)Korpora in Bezug auf ihre statistischen Kennwerte (MIN, MW, MAX) heuristisch zu trennen ist die Analyse der Verhältnisse (bzw. ihrer räumlichen Umlegung) innerhalb eines (Teil-)Korpus bzw. der Vergleich der Verhältnisse innerhalb der verschiedenen Teilkorpora. Hier wird nicht auf die Höhe der einzelnen Werte, sondern auf die auf der Skala abzulesende Ausprägung einer Eigenschaft (z.B. Maximalwert, Schiefe) in einem Messpunkt im Verhältnis zur Ausprägung dieses Phänomens in den übrigen Messpunkten Bezug genommen (sehr hoch = Wertklasse [6], sehr niedrig = Wertklasse [1]). Wenn also z.B. die
} 
(s. Karte A10) zeigen sich jedoch Unterschiede, die vor allem darin liegen, dass sowohl die dialektalen Kerngebiete als auch die Gebiete, die sprachliche ,Einzelgänger' beinhalten, im Lexikon großflächiger sind als im Totalkorpus. Ein großflächiges dialektales Kerngebiet mit hohen bis sehr hohen Maximalwerten (Wertklassen [5] und [6]) umfasst die Dialekte in der kampanischen Küstenregion - d.h. in der Terra di Lavoro, in der Metropolregion Neapel und im neapolitanischen Hinterland (mit Ausnahme von Castel Volturno (822) und Anacapri (851)) und erstreckt sich bis in das Cilento hinein (Capaccio (863), Laurino (864)). Im Zentrum dieses dialektalen Großraumes stehen Neapel (835) und Salerno (855), die beide das höchste Maximum der gesamten Region aufweisen. Dem westlichen Dialektkern steht ein großflächiges Gebiet mit sehr niedrigen Maximalwerten (Wertklasse [1]) im kampanischen Gebirgsland gegenüber, das sprachliche ,Einzelgänger' im Sannio (Reìno (815), Ginestra degli Schiavoni (816), Melito Irpino (826)), in der Irpinia (Senerchia (840, MIN), Montella (839), Cairano (841)) und die apulischen Orte Bovino (819, MIN) und Candela (827) umfasst. Ein weiteres, kleineres Gebiet mit sprachlichen ,Einzelgängern' findet sich im Cilento (Monte San Giacomo (865), Pòllica (872, MIN), Alfano (873) und Casaletto Spartano (874)). Der im Totalkorpus (s.o.) aufscheinende Dialektkern im Südcilento manifestiert sich im lexikalischen Bereich also nicht und ist somit auf phonetische Merkmale zurückzuführen.

Im Konsonantismus finden sich ein etwas höherer durchschnittlicher Maximalwert und eine deutlich höhere Spannweite als im Lexikon (s. Tab. 26). Die räumliche Verteilung der Dialektkerne und der ,Einzelgänger' spiegelt jene im Totalkorpus wider, zeigt allerdings auch kleine Abweichungen (s. Karte A11). Neben den Dialektkernen in der Metropolregion Neapel und im Südcilento (Monte San Giacomo (865), Alfano (873)) manifestiert sich ein Dialektkern in der Irpinia (Montella (839), Cairano (841)). Darüber hinaus liegt das höchste Maximum nicht mehr in der Metropolregion Neapel, sondern im Südcilento (MAX in Alfano (873) und Casaletto Spartano (874)). Die Dialekte mit niedrigen Maximalwerten liegen wie im Totalkorpus in peripheren Gebieten im Norden (Gioia Sannìtica (814, MIN), Reìno (815)) und im (Nord-)Westen (Rocca d'Evandro (809), Castel Volturno (822)), dazu an der östlichen Grenze der Metropolregion Neapel (Limàtola (824), Roccaraìnola (836)) sowie an der westlichen Grenze des Dialektgebietes Nordcilento-Irpinia (Olèvano Sul Tusciano (856), Capaccio (863)).

Im Vokalismus ergeben sich ein deutlich höherer Mittelwert und eine größere Spannweite als in den übrigen Teilkorpora (s. Tab. 26). Hier sind die Dialekte also allgemein deutlich besser in das Gesamtgebiet integriert als in den übrigen Teilkorpora, während gleichzeitig die Abweichungen in einzelnen Dialekten deutlicher ausgeprägt sind. Dass das kampanische Dialektgebiet im Vokalismus die höchste Kompaktheit aufweist, zeigt sich besonders darin, dass die Ähnlichkeitswerte eines Großteils der Dialekte sehr nah beieinander (d.h. in den Wertklassen [3] und [4], vgl. Karte A12) liegen. Die verhältnismäßig hohe Spannweite ergibt sich aus den extremen Abweichungen der Maxima im unteren Wertebereich, die sich in einzelnen Dialekten der südlichen (Casaletto Spartano (874, MIN)) und östlichen Peripherie (Bovino (819) und Candela (827)) finden. Im Hinblick auf die räumliche Verteilung der Dialekte mit hohen Maximalwerten fällt auf, dass neben dem dialektalen Kerngebiet in der Metropolregion Neapel (MAX in Sorrento (852) und Benevento (825)) und jenem im Südcilento (Monte San Giacomo

\footnotetext{
Synopse der Maximalwerte im vokalischen Teilkorpus im Vergleich zum konsonantischen Teilkorpus deutlich niedrigere statistische Kennwerte aufweist, so ist die Integration der Dialekte im Vokalismus insgesamt schwächer ausgeprägt als im Konsonantismus. Nichtsdestotrotz gibt es im Vokalismus Messpunkte, die einen verhältnismäßig - d.h. im Vergleich zu den übrigen Messpunkten - hohen Maximal- oder Schiefewert zeigen. Wenn einige Messpunkte hinsichtlich ihrer Position auf der Skala (d.h. ihrer Wertklasse) Unterschiede zwischen den verschiedenen Teilkorpora aufweisen, so manifestiert sich dies in der räumlichen Umlegung in unterschiedlichen Raumstrukturen.
} 
(865) und Alfano (873)) ein weiteres kompaktes Dialektgebiet am Übergang zwischen dem Nordcilento und der Irpinia (Olèvano Sul Tusciano (856), Postiglione (857) und Salvitelle (858)) sichtbar wird.

Die Ergebnisse der Synopse der Maximalwerte zeigen die Zweiteilung des kampanischen Dialektgebietes aus der Perspektive der sprachlichen Kohäsion benachbarter Orte: Dem von der Metropolregion Neapel dominierten dialektalen Kerngebiet im Westen, das im lexikalischen Bereich besonders großflächig ist, steht ein sprachlich zerklüftetes östliches Gebiet gegenüber, in dem fast jeder Ort - insbesondere im Lexikon - sprachlich eigene Wege geht.

\begin{tabular}{|c|c|c|c|c|c|}
\hline Kennwert & TOT & LEX & PHON & KONS & VOK \\
\hline MIN & 57,45 & 60,00 & 53,53 & 55,81 & 43,90 \\
\hline MW & 67,42 & 66,10 & 69,92 & 69,52 & 78,95 \\
\hline MAX & 75,64 & 73,33 & 81,18 & 79,84 & 92,68 \\
\hline
\end{tabular}

Tabelle 26. Statistische Kennwerte der Synopse der Maxima im ALI-Korpus. Messmoment RIW ${ }_{j k}$.

\subsubsection{Sprachausgleichstendenzen}

\section{S. Kartenteil, Karten A13 - A16}

Einen Einblick in die in den 1960er Jahren in der Region Kampanien bestehenden Tendenzen zum Sprach- bzw. Dialektausgleich ${ }^{425}$ gibt die Analyse der Kennwertsynopse der Schiefen.

Im Totalkorpus liegt der durchschnittliche Schiefewert im niedrigen positiven Bereich (0,29, vgl. Tab. 27), was auf eine insgesamt relativ schwache Integration der kampanischen Dialekte bzw. eine relativ geringe Bereitschaft zum Sprachausgleich in den berücksichtigten Dialekten hinweist. Niedrige Schiefewerte (Wertklassen [1] und [2]) und damit die verhältnismäßig höchste Bereitschaft zum Sprachausgleich finden sich erwartungsgemäß in dialektalen Grenz- bzw. Übergangsräumen (s. Karte A13). Hier handelt es sich um Dialekte an der Grenze zum Dialektgebiet in der Metropolregion Neapel (Castel Volturno (822), Limàtola (824, MIN), Roccaraìnola (836)) sowie am Übergang zum Dialektgebiet Nordcilento-Irpinia (Melito Irpino (826), Avellino (838), Olèvano Sul Tusciano (856)). Eine hohe sprachliche Durchmischung zeigen auch die im Norden dieses Gebietes gelegenen Orte Postiglione (857) und Senerchia (840). Hohe bis sehr hohe Schiefewerte (Wertklassen [5] und [6]) zeigen Monte San Giacomo (865) und Casaletto Spartano (874, MAX) im Südcilento sowie der insulare Dialekt Barano d'Ischias (833). Hierbei handelt es sich um Dialekte, die durch ihre periphere (und im Falle Barano d'Ischias auch geographisch isolierte) Lage gegenüber den sprachlichen Ausgleichsprozessen in der Region weitgehend resistent sind.

Im Lexikon liegen die Kennwerte der Schiefen insgesamt leicht höher als im Totalkorpus (s. Tab. 27). Die Dialekte mit niedrigen Schiefewerten (Wertklassen [1] und [2]) und damit (sehr) hohen Sprachausgleichstendenzen formen ein großflächiges Gebiet in der kampanischen Küstenebene, das sich im Norden bis Teano (813) in der Terra di Lavoro, im Osten bis Montella (839) in der Irpinia und im Süden bis Olèvano Sul Tusciano (856, MIN) erstreckt (s. Karte A14) und damit fast den gesamten dialektalen Großraum umfasst. Zonen mit hohen bis sehr hohen

\footnotetext{
${ }^{425}$ Aufgrund seiner Etablierung in der dialektometrischen Forschung wird der Terminus Sprachausgleich $(=$ sprachlicher Ausgleich bzw. Nivellierung der sprachlichen Unterschiede innerhalb eines Gebietes) hier neben bzw. synonym zu jenem des ,Dialektausgleichs“(vgl. Kap. 2.4.1) verwendet.
} 
Schiefewerten (Wertklassen [5] und [6]) finden sich auch hier in peripheren Gebieten: Gegenüber sprachlichen Nivellierungsprozessen auf lexikalischer Ebene resistent sind das Südcilento (Monte San Giacomo (865), Alfano (873), Casaletto Spartano (874, MAX)), sowie die nördliche Terra di Lavoro (Rocca d'Evandro (809), Fontegreca (810)). Auffällig ist hier, dass auch Senerchia (840) in der Irpinia gegen sprachliche Ausgleichsprozesse relativ gut abgeschirmt ist, während es sich im Totalkorpus unter den Dialekten mit verhältnismäßig starker Bereitschaft zum Sprachausgleich befindet. Im Verhältnis zu den übrigen Dialekten findet sich hier also eine deutliche Diskrepanz zwischen der Entwicklung im Totalkorpus, die eher in Richtung Sprachausgleich geht und jener im lexikalischen Bereich, die von einer vergleichsweise hohen Resistenz gegenüber sprachlicher Durchmischung geprägt ist. In ähnlicher, wenn auch weniger deutlicher Weise gilt dies auch für den südlichen ,Nachbarn' Postiglione (857, Wertklasse [2] im Totalkorpus, hingegen Wertklasse [4] im lexikalischen Teilkorpus). Die Bereitschaft zum Sprachausgleich konzentriert sich in diesen Dialekten also auf den phonetischen Bereich.

Im Konsonantismus sind die Integration der Dialekte und die Bereitschaft zum Sprachausgleich in der Region Kampanien stärker ausgeprägt als im Lexikon (s. Tab. 27). Bei der räumlichen Umlegung der Schiefewerte zeigen sich ähnliche Verhältnisse wie im Totalkorpus, die sich jedoch durch eine stärkere geographische Kohärenz der Dialekte auszeichnen (s. Karte A15). Ein großflächiges Gebiet mit verhältnismäßig niedrigen Schiefewerten, d.h. starken Tendenzen zur sprachlichen Nivellierung (Wertklassen [1] und [2]), umfasst zusätzlich zu den in Grenzzonen gelegenen Dialekten (s. Totalkorpus) die Punkte Gioia Sannìtica (814) und Reìno (815) in der nördlichen Peripherie, die Provinzhauptstadt Benevento (825) sowie Sarno (837) im neapolitanischen Hinterland. Ein Gebiet mit (sehr) hohen Schiefewerten - also ein gegenüber der sprachlichen Durchmischung verhältnismäßig resistentes Areal (Wertklassen [5] und [6]) - liegt wie im Totalkorpus im Südcilento, umfasst hier allerdings auch Laurino (864) und Alfano (873), sodass ein kompakter ,Block' entsteht. Auch die peripheren Dialekte im Osten (Bovino (819) und Candela (827)) sowie die zentralen Dialekte der Irpinia (Montella (839) und Cairano (841)) sind im Konsonantismus gut gegen sprachliche Ausgleichsprozesse abgeschirmt. Einzelne, an den sprachlichen Nivellierungstendenzen nicht partizipierende Dialekte finden sich (wie im Lexikon) in Rocca d'Evandro (809) und (wie im Totalkorpus) in Barano d'Ischia (833).

Der Vokalismus ist der Bereich, in dem die Integration der Dialekte und die Bereitschaft zum Sprachausgleich in der Region Kampanien am höchsten sind, während gleichzeitig in einzelnen Dialekten starke Abweichungen bestehen (s. Tab. 27). Dialekte mit sehr niedrigen bis niedrigen Schiefewerten (Wertklassen [1] und [2]), die also starke Tendenzen zur sprachlichen Angleichung aufweisen, liegen hier einerseits (wie im Totalkorpus) im Grenzgebiet zur Metropolregion Neapel (Castel Volturno (822), Limàtola (824), Maiori (854)) und andererseits in einem Gebiet, das das (nord-)westliche Cilento (Capaccio (863), Pòllica (872), Laurino (864)) umfasst und sich im Norden über Olèvano Sul Tusciano (856) bis in die Irpinia hinein (Montella (839) und Cairano (841, MIN)) erstreckt (s. Karte A16). Dabei fällt auf, dass es sich bei den letztgenannten um genau die Dialekte handelt, die im Konsonantismus eine verhältnismäßig geringe Bereitschaft zum Sprachausgleich zeigen, sodass hier die Tendenzen im Vokalismus und im Konsonantismus deutlich differieren. Ähnlich divergierende Tendenzen finden sich in einzelnen Dialekte in der nördlichen (Rocca d'Evandro (809)) und in der südlichen Peripherie (Casaletto Spartano (874), vgl. Karte A15 und A16).

Die einzigen Dialekte mit sehr hohen Schiefewerten (Wertklasse [6]) sind jene von Gioia Sannìtica (814) und Reìno (815, MAX) in der nördlichen Peripherie. Dass die Resistenz 
dieser Dialekte gegenüber den sprachlichen Nivellierungsprozessen im Vokalismus ausgeprägter ist als jene der Dialekte mit den höchsten Schiefewerten im Konsonantismus bzw. im Lexikon, zeigt sich darin, dass hier in Wertklasse [5] keine Messpunkte zu liegen kommen, sodass der Abstand der Messpunkte in Wertklasse [6] zu den folgenden Messpunkten (Wertklasse [4]) entsprechend groß ist. Nicht zuletzt manifestiert sich hier einmal mehr die Kompaktheit der Dialektgebiete in der Metropolregion Neapel und im Südcilento (Monte San Giacomo (865), Alfano (873)): Nur in diesen Gebieten befinden sich alle Messpunkte in derselben Wertklasse (Wertklasse [3]).

\begin{tabular}{|c|c|c|c|c|c|}
\hline Kennwert & TOT & LEX & PHON & KONS & VOK \\
\hline MIN & $-0,27$ & $-0,21$ & $-0,28$ & $-0,31$ & $-0,95$ \\
\hline MW & 0,29 & 0,33 & 0,22 & 0,23 & 0,06 \\
\hline MAX & 1,31 & 1,17 & 0,81 & 0,85 & 3,14 \\
\hline
\end{tabular}

Tabelle 27. Statistische Kennwerte der Synopse der Schiefen im ALI-Korpus. Messmoment RIW $j k$.

Die Synopse der Schiefewerte zeigt, dass in den 1960er Jahren die Bereitschaft zum Sprachausgleich in der Campania insbesondere in dialektalen Grenz- bzw. Übergangszonen besteht (Grenzgebiet zur Metropolregion Neapel und Übergangsgebiet zum Dialektgebiet NordcilentoIrpinia), während periphere Gebiete im Süden (Südcilento), Osten (Dialektgebiet BovinoCandela), Norden (nördliche Terra di Lavoro) sowie (vor allem im Konsonantismus) die Isole Flegree von der sprachlichen Nivellierung weitgehend unberührt bleiben. Die im Vokalismus aufscheinende Zone mit starken Tendenzen zur sprachlichen Angleichung im (nord-) westlichen Cilento scheint sich auf den ersten Blick nicht in dieses Bild einzufügen. Die Analyse des Vergleichskorpus wird jedoch zeigen, dass es sich auch bei dieser nicht um ein , $\mathrm{Zu}$ fallsprodukt', sondern um eine Art ,Vorboten' der sprachgeographischen Entwicklung in der Region Kampanien handelt.

\subsection{5 ,Beliebte' und ,unbeliebte ${ }^{6}$ Dialekte}

\section{S. Kartenteil, Karten A17 - A24}

Während die Synopse der Maximalwerte Auskunft darüber gibt, wie sich die Position der verschiedenen Dialekte innerhalb des Gebietes aus ihrer eigenen, Sicht' darstellt, lässt sich auf der Basis des Heuristikums der Antipodenkarten Kenntnis darüber erlangen, welcher Status einem Dialekt aus der , Sicht` der übrigen Dialekte zugewiesen wird. ${ }^{426}$

Im Totalkorpus fällt zunächst auf, dass mehr als zwei Drittel der Dialekte (25) mindestens ein Maximum - vorwiegend von ihren direkten ,Nachbarn“ - erhalten (s. Karte A17), was die kleinräumige Struktur des kampanischen Dialektgebietes in den 1960er Jahren illustriert. Der insgesamt ,beliebteste‘ Dialekt ist jener von Sarno (837) im neapolitanischen Hinterland: Er erhält vier Maxima, die aus seinem geographischen Umfeld (Roccaraìnola (836), Avellino (838) und Maiori (854)) und vom Dialekt aus Castel Volturno (822) kommen, der zwar geo-

\footnotetext{
${ }^{426}$ Auch wenn die Breite der Wertklassen im Bereich der Antipoden in VDM ebenfalls in Dezimalwerten angegeben wird (vgl. die im folgenden genannten Karten), werden diese - wie in der Dialektometrie üblich und entsprechend der kartographischen Visualisierung bei Anwahl der Antipoden - bei der Analyse auf ganze Zahlen gerundet. Dies gilt analog für Kap. 5.5.5.
} 
graphisch entfernt ist, aber ebenfalls dieser Dialektgruppe angehört (vgl. Kap. 5.4.1). ${ }^{427}$ An zweiter Stelle folgt - als , beliebtester' Dialekt des Dialektgebietes in der Metropolregion Neapel - jener von Sorrento (852), das seine drei Maxima von den Dialekten aus Salerno (855), Benevento (825) und Anacapri (851) erhält. Bei den ,beliebtesten' Dialekten handelt es sich also um die Zentren der kompakten Dialektgebiete in der Metropolregion Neapel und im neapolitanischen Hinterland. Die Kompaktheit des Dialektgebietes im Cilento manifestiert sich darin, dass drei ,benachbarte ' Dialekte (Postiglione (857), Laurino (864) und Monte San Giacomo (865)) jeweils zwei Maxima von ihren direkten ,Nachbarn' erhalten. Bei der Verteilung der als ,beste Freunde“ in Frage kommenden Dialekte fällt auf, dass die Wertklassen [2] und [3] unbesetzt bleiben, die Kluft zwischen der relativ kleinen Gruppe der größten ,Sympathieträger' und den übrigen Dialekten also sehr groß ist.

Als ,Sündenböcke‘ infrage kommen im Totalkorpus 14 Dialekte (s. Karte A18), die sich vor allem im Dialektgebiet der Metropolregion Neapel, im Dialektgebiet im neapolitanischen Hinterland, im Dialektgebiet des Nordcilento und im Dialektgebiet des Südcilento befinden und sich häufig wechselseitige ,Antipathien` zuweisen: Dabei sind die Dialekte des Nordcilento die ,größten Feinde ‘ der Dialekte in der Metropolregion Neapel (und umgekehrt) und die Dialekte des Südcilento die ,größten Feinde' des Dialektgebietes im neapolitanischen Hinterland (und umgekehrt). Der in der Campania mit Abstand ,unbeliebteste' Dialekt ist jener aus Barano d'Ischia (833), der acht Minima und diese fast ausschließlich von den Dialekten im Gebiet Nordcilento-Irpinia (,Streit‘ mit Postiglione (857)) erhält. Es folgt der Dialekt aus Monte San Giacomo (865) im Südcilento, der seine sechs Minima insbesondere aus dem Dialektgebiet im neapolitanischen Hinterland erhält und im ,Streit' mit dem Dialekt Gioia Sannìticas (814) liegt.

Im Lexikon kommen als , beste Freunde‘ ebenso viele Dialekte infrage wie im Totalkorpus (25), von denen etwa die Hälfte - meist von ihren geographischen Nachbarn - jeweils ein Maximum erhält (s. Karte A19). Der ,beliebteste“ Dialekt ist hier jener aus Neapel (835): Er erhält vier Maxima, die alle aus dem Dialektgebiet der Metropolregion Neapel kommen. Dahinter folgt - als sprachliches Zentrum des neapolitanischen Hinterlands - mit drei Maxima der Dialekt aus Sarno (837). Als ,Sündenböcke‘ infrage kommen im lexikalischen Bereich 18 Dialekte, die sich größtenteils im Norden und Osten der Region befinden (s. Karte A20). Hier gibt es drei Dialekte, die als ,größte Feinde' fungieren: Die Dialekte von Barano d'Ischia (833) und Pròcida (834) erhalten beide jeweils sechs Minima, insbesondere aus dem Dialektgebiet Nordcilento-Irpinia (,Streit‘ zwischen Barano d'Ischia (833) und Laurino (864)) und aus dem Dialektgebiet im Sannio. Der Dialekt aus Casaletto Spartano (874) im Südcilento erhält ebenfalls sechs Minima - insbesondere aus dem Dialektgebiet im neapolitanischen Hinterland - und liegt im ,Streit‘ mit dem am gegenüberliegenden Rand der Region lokalisierten Dialekt aus Gioia Sannìtica (814).

Im Konsonantismus zeigt sich eine ähnliche Verteilung der ,Sympathieträger' und der ,Sündenböcke' wie im Totalkorpus. Als ,beste Freunde‘ infrage kommen 24 Dialekte, die sich - mit Ausnahme eines Gebietes im nördlichen Zentrum (um Benevento) - auf die gesamte Region verteilen (s. Karte A21). Der im Konsonantismus ,beliebteste' Dialekt ist jener aus Sarno, der vier Maxima aus dem eigenen Dialektgebiet erhält. Dahinter folgen Laurino (864) im Dia-

\footnotetext{
${ }^{427} \mathrm{Da}$ auf den Antipodenkarten nur jeweils zu einem als , bester Freund‘ bzw. ,größter Feind‘ in Frage kommenden Messpunkt (weiße Schraffur) die ihre Maxima bzw. Minima jeweils zuweisenden Dialekte (schwarze Schraffur) angezeigt werden können, wird dies auf den hier präsentierten Karten nur für den jeweils die meisten Maxima bzw. Minima erhaltenden Messpunkt (bzw. bei mehreren für einen von diesen) vorgenommen. Dies gilt analog für Kap. 5.5.5.
} 
lektgebiet Nordcilento-Irpinia und Anacapri (851) im Dialektgebiet der Metropolregion Neapel, die jeweils drei Maxima aus ihrem geographischen Umfeld erhalten. Wie im Totalkorpus handelt es sich also auch im Konsonantismus bei den ,beliebtesten' Dialekten um die Zentren der kompakten und stabilsten Dialektgebiete. Als ,unbeliebteste“ Dialekte infrage kommen im konsonantischen Bereich 15 Dialekte aus unterschiedlichen Teilen der Region (s. Karte A22). Der größte ,Sündenbock“ ist auch hier der Dialekt aus Barano d'Ischia (833), der neun Minima und diese zum Großteil aus dem Dialektgebiet Nordcilento-Irpinia erhält, wo er mit Postiglione (857) im ,Streit` liegt. Dahinter folgen der Dialekt aus Monte San Giacomo (865) und (in Abweichung vom Totalkorpus) auch der Dialekt aus Capaccio (863), die beide jeweils fünf Minima erhalten. Dabei bekommt Monte San Giacomo (865) diese aus dem Dialektgebiet im neapolitanischen Hinterland zugewiesen, während Capaccio (863) aus Sicht der Dialekte in der Metropolregion Neapel den ,unbeliebtesten` Dialekt des Gebietes Nordcilento-Irpinia darstellt.

Im Vokalismus kommen (wie im Konsonantismus) insgesamt 24 von 35 Dialekten als ,beste Freunde“ in Frage (s. Karte A23). Die ,beliebtesten“ Dialekte finden sich auch hier wieder in den kompakten Dialektgebieten in der Metropolregion Neapel (Sorrento (852), fünf Maxima) und im neapolitanischen Hinterland (Limàtola (824), vier Maxima), aus denen sie ihre Maxima auch größtenteils erhalten. Im Gegensatz zu den anderen Teilkorpora und zum Totalkorpus gibt es im Vokalismus unter den ,besten Freunden' auch (und nicht wenige) Dialekte, die in Wertklasse [3] zu liegen kommen, sodass die interdialektale Verteilung der ,Sympathien“ insgesamt ausgeglichener ist als in den übrigen Teilkorpora. Dies spiegelt die in den vorigen Analyseschritten bereits konstatierte verhältnismäßig große Kompaktheit des kampanischen Dialektgebietes im vokalischen Bereich wider. Diese manifestiert sich auch darin, dass lediglich 10 von 35 Dialekten als ,Sündenböcke“ in Frage kommen, die alle an der Peripherie des Untersuchungsgebietes liegen (s. Karte A24). Der im Hinblick auf den Vokalismus , unbeliebteste ' Dialekt ist der bereits als vokalisch ,speziell' aufgefallene Dialekt von Reìno (815), ${ }^{428}$ der 15 Minima - von allen Dialekten im Gebiet Nordcilento-Irpinia, von den beiden Dialekte in der Region Apulien sowie von vielen Dialekten im neapolitanischen Hinterland - erhält. Dahinter folgen die vokalisch ebenfalls , auffälligen“ Dialekte aus Gioia Sannìtica (814) und Bovino (819), die sechs bzw. sieben Minima (meist aus dem Dialektgebiet in der Metropolregion Neapel) erhalten und sich diese auch gegenseitig zuweisen.

Die Analyse der Antipoden im ALI-Korpus erbringt klare Ergebnisse. Die kleinräumige Gliederung des kampanischen Dialektgebietes geht mit einer Vielzahl sprachlicher ,Sympathieträger' einher, die für das jeweilige dialektale Mikroareal, das sie umgibt oder aber auch nur für einen der benachbarten Dialekte die ,Bezugspunkte‘ darstellen. Dies gilt auch für die Metropole Neapel, die nur innerhalb des Dialektgebietes der Metropolregion und nur im lexikalischen Bereich als ,Bezugspunkt' fungiert. Die kulturelle Vormachtstellung Neapels hat also keineswegs zu einer Implementierung des Neapolitanischen als ,Leitvarietät ${ }^{6}$ - weder im Hinblick auf die gesamte Campania noch in der kampanischen Küstenebene - geführt.

Das Verhältnis zwischen den kompakten Dialektgebieten ist von gegenseitigen ,Antipathien' geprägt. Als ,Streithähne' erweisen sich auf der einen Seite das Dialektgebiet in der Metropolregion Neapel und das Dialektgebiet im Nordcilento und auf der anderen Seite das Dialektgebiet im neapolitanischen Hinterland und das Dialektgebiet im Südcilento. Die größten ,Sündenböcke' sind jedoch meist bestimmte peripher verortete Dialekte im Südcilento (Lexikon, Konsonantismus), im Sannio (Vokalismus) oder auf den Isole Flegree (Lexikon, Konso-

\footnotetext{
${ }^{428}$ Vgl. Kap. 5.4.1 und Kap. 5.4.2.
} 
nantismus). Die relativ niedrige Anzahl der Dialekte, die im Bereich des Vokalismus als ,unbeliebteste' Dialekte infrage kommen, weist erneut darauf hin, dass die sprachlichen Differenzen innerhalb der Campania in diesem Bereich am geringsten sind.

\subsubsection{Korrelationen zwischen Sprache und Raum}

\section{S. Kartenteil, Karten A25 - A30}

Im Folgenden wird der Frage nachgegangen, wie sich die in den vorangegangenen Abschnitten aufgezeigten sprachlichen Raumstrukturen in der Region Kampanien im Verhältnis zu den geographischen Raumstrukturen verhalten. Dazu werden die Korrelationen zwischen sprachlicher Ähnlichkeit und geographischer (euklidischer) Proximität (GEO Prox) sowohl für das Totalkorpus als auch für die verschiedenen Teilkorpora untersucht, wobei als Korrelationsmaß der Produktmoment-Korrelationskoeffizient nach Bravais/Pearson (PMK) verwendet wird (vgl. Kap. 4.3.8).

Bei dem Vergleich zwischen den auf der Basis des Totalkorpus ermittelten sprachlichen Ähnlichkeitswerten und der geographischen Proximität zeigen sich nur positive Korrelationswerte (s. Tab. 28). Es liegt also in keinem Messpunkt ein gegenläufiges Verhältnis von Sprachund Naturraum vor. Ein großflächiges Gebiet mit hohen bis sehr hohen Korrelationswerten (Wertklassen [5] und [6]) - und damit einer ausgeprägten Harmonie zwischen sprachlicher und räumlicher Nähe - umfasst einen Großteil der Messpunkte im östlichen Teil der Region (Nordcilento, Irpinia, Sannio, s. Karte A25). Im Westen sind neben Sarno (837, MAX) und Maiori (854) vor allem die insularen Messpunkte (Barano d'Ischia (833), Pròcida (834) und Anacapri (851)) durch ein harmonisches Verhältnis zwischen Sprache und Raum gekennzeichnet, was darauf hinweist, dass ihre geographisch isolierte Lage sie historisch gesehen gegenüber äußeren Einflüssen abgeschirmt hat. Eine starke Disharmonie zwischen Sprache und Raum findet sich zum Einen in der östlichen Peripherie der Region, wo die Messpunkte Bovino (819) und Candela (827) eine starke sprachliche Abschottung gegenüber ihrem geographischen Umfeld im Westen aufweisen (vgl. Kap. 5.4.2 bzw. Karte A5), die auf geschichtliche Besonderheiten zurückgeführt werden kann (vgl. Kap. 3.2) und sich - sicherlich auch begünstigt durch die geographischen Verhältnisse - über die Zeit erhalten hat. Auch die Messpunkte im Südcilento (insbesondere Alfano (873)) weisen relativ niedrige Korrelationswerte (Wertklassen [2] bis [3]) auf, welche sich durch die sprachliche Abgrenzung nach Norden ergeben (s. Karte A5). Die stärksten Störungen des Verhältnisses zwischen sprachlicher Nähe und räumlicher Proximität finden sich in den Provinzhauptstädten Salerno (855, MIN) und Benevento (825), wo die Orientierung am Neapolitanischen zu einer sprachlichen Isolation vom geographischen Umfeld geführt hat (im Falle von Salerno nur in östlicher Richtung, vgl. Kap. 5.4.2). Durch seine Grenzlage bzw. die starke Abgrenzung von den geographisch adjazenten Messpunkten im Osten (s. Karte A5) weist auch Olèvano Sul Tusciano (856) eine Störung des Verhältnisses zwischen Sprache und Raum auf. Ein direkter visueller Vergleich zwischen geographischem und sprachlichem Ähnlichkeitsprofil veranschaulicht am Beispiel von Benevento (825) deutlich die Diskrepanzen, die in Messpunkten mit extrem niedrigen Korrelationswerten zwischen Sprach- und Naturraum bestehen (s. Karten A27 und A28).

Im Lexikon ergibt sich beim Vergleich zwischen sprachlicher Ähnlichkeit und geographischer Proximität die im Durchschnitt stärkste Korrelation zwischen Sprache und Raum (s. 
Tab. 28). Dabei zeigen die bei der Spatialisierung der Korrelationswerte aufscheinenden Raumstrukturen (s. Karte A26) deutliche Unterschiede zu jenen im Totalkorpus. Das größte Gebiet mit ausgeprägter Harmonie zwischen Sprach- und Naturraum (Wertklassen [5] und [6]) findet sich nicht im östlichen Teil der Region, sondern in der lexikalisch kompakten kampanischen Küstenebene (MAX in Pròcida (834)). ${ }^{429}$ Hier kommen die Korrelationswerte fast aller Messpunkte in einer deutlich höheren Wertklasse zu liegen als im Totalkorpus (Wertklasse [6] statt Wertklasse [3]). Im östlichen Teil der Region finden sich hohe Korrelationswerte im Zentrum und Norden des Dialektgebietes Nordcilento-Irpinia (Laurino (864), Salvitelle (858) und Cairano (841)). Gravierende Störungen des Verhältnisses zwischen Sprache und Raum (Wertklasse [1]) weisen - wie auch schon im Totalkorpus - die sprachlich vor allem nach Osten isolierten Provinzhauptstädte Benevento (825) und Salerno (855) auf. Daneben finden sich niedrige Korrelationswerte auch in den übrigen Messpunkten, die entlang der von Norden nach Süden verlaufenden Dialektgrenze (Montella (839), Olèvano Sul Tusciano (856), vgl. Karte A5) oder an der Dialektgrenze zwischen dem Nord- und dem Südcilento (Pòllica (872)) liegen.

Im Konsonantismus zeigen sich - bis auf eine Abweichung im niedrigen Wertebereich (s. Tab. 28) - im Hinblick auf das Verhältnis zwischen Sprache und Raum weder in numerischer, noch in räumlicher Hinsicht relevante Unterschiede zum Totalkorpus (vgl. Karte A25 und Karte A29). Die Harmonie zwischen Sprach- und Naturraum ist somit im Konsonantismus schwächer als im Lexikon.

Im Vokalismus finden sich eine im Durchschnitt deutlich niedrigere Korrelation zwischen sprachlicher und räumlicher Nähe und eine deutlich höhere Spannweite der Korrelationswerte als im Totalkorpus und in den übrigen Teilkorpora (s. Tab. 28). Der vokalische Bereich weist also unter allen (Teil-)Korpora die stärksten Störungen im Verhältnis zwischen Sprache und Raum auf. Bedingt ist dies durch die verhältnismäßig starke sprachliche Kompaktheit des kampanischen Dialektgebietes im Vokalismus, die dazu führt, dass die sprachliche Ähnlichkeit zwischen den Messpunkten teilweise deutlich höher ist, als vor dem Hintergrund der entsprechenden geographischen Proximität zu erwarten wäre. Die verhältnismäßig hohen Korrelationswerte bedecken im Vokalismus ein weites Gebiet, das den größten Teil der Messpunkte im Nordcilento, in der Irpinia und im Sannio umfasst, sowie ein kleineres Gebiet um die Messpunkte in der Metropolregion Neapel (Neapel (835), Barano d'Ischia (833), Pròcida (834) und Anacapri (851, MAX), s. Karte A30). Die geringe Harmonie zwischen Sprache und Raum, die die Provinzhauptstädte Benevento (825) und Salerno (855) aufweisen, zeigt sich im Vokalismus besonders deutlich: In Benevento (825) findet sich hier sogar ein negativer Korrelationswert $(-0,04)$ und damit ein leicht gegenläufiges Verhältnis zwischen sprachlicher Ähnlichkeit und geographischer Proximität. Diskordanzen zwischen Sprach- und Naturraum (Wertklassen [1] und [2]) zeigen sich darüber hinaus im Südcilento (Alfano (873), Monte San Giacomo (865)) und in der südlichen Terra di Lavoro (Castel Volturno (822), Teano (813), Limàtola (824)).

Die Auswirkungen der Kompaktheit des kampanischen Dialektgebietes bzw. des verhältnismäßig starken Sprachausgleichs im Bereich des Vokalismus auf das Verhältnis zwischen Sprache und Raum lassen sich am Beispiel der Position Bovinos (819) illustrieren. Dieses be-

\footnotetext{
${ }^{429}$ In den Fällen, in denen die insularen Messpunkte (Barano d’Ischia (833), Pròcida (834) oder Anacapri (851)) Maxima bzw. Minima aufweisen, wird dies auf der entsprechenden Karte meist nicht genau sichtbar, da die Fläche der Insel-Polygone um Pròcida (834) und Anacapri (851) kleiner und die des Polygons um Barano d'Ischia (833) nur geringfügig größer ist als die Maschen der Schraffierung, mit denen die Maxima bzw. Minima in VDM gekennzeichnet werden.
} 
findet sich im Vokalismus (s. Karte A30) unter den Messpunkten mit den höchsten Korrelationswerten (Wertklasse [5]), während es im Totalkorpus (s. Karte A25) und im Konsonantismus (s. Karte A29) im Vergleich zu den übrigen Messpunkten sehr niedrige Korrelationswerte zeigt (Wertklasse [2] bzw. [1]). Im vokalischen Bereich führt also die verhältnismäßig starke Kompaktheit des kampanischen Dialektgebietes dazu, dass sich (zumindest im östlichen Teil der Region) die Unterschiede zwischen den Messpunkten im Hinblick auf das Verhältnis zwischen Sprache und Raum nivellieren. Dies manifestiert sich auch darin, dass die oberen Wertklassen im Vokalismus stärker besetzt sind als im Totalkorpus und im Konsonantismus.

\begin{tabular}{|c|c|c|c|c|c|}
\hline Kennwert & TOT/GEO & LEX/GEO & PHON/GEO & KONS/GEO & VOK/GEO \\
\hline MIN & 0,29 & 0,46 & 0,16 & 0,19 & $-0,04$ \\
\hline MW & 0,62 & 0,68 & 0,56 & 0,58 & 0,36 \\
\hline MAX & 0,79 & 0,83 & 0,76 & 0,80 & 0,59 \\
\hline
\end{tabular}

Tabelle 28. Statistische Kennwerte der Korrelation zwischen sprachlicher Ähnlichkeit und geographischer Proximität in den verschiedenen Teilkorpora des ALI-Korpus. Produktmoment-Korrelationskoeffizient nach Bravais/Pearson.

Aus der Analyse des Verhältnisses zwischen Sprache und Raum in der Campania der 1960er Jahre lässt sich im Hinblick auf das Gesamtkorpus festhalten, dass sich insbesondere in den sprachlich an der Metropolregion Neapel orientierten Provinzhauptstädten Benevento (825) und Salerno (855) und daneben auch häufig in peripheren Gebieten und Messpunkten deutliche Störungen manifestieren. Im kampanischen Inland und in den geographisch abgeschotteten insularen Gebieten ist das Verhältnis zwischen Sprache und Raum hingegen verhältnismäßig harmonisch. Im Lexikon zeigen sich entsprechend der Unterschiede in den Raumstrukturen andere Verhältnisse als im Totalkorpus und in den phonetischen Teilkorpora: Durch die lexikalische Kompaktheit des westkampanischen Dialektgebietes manifestiert sich im Westen der Region flächendeckend eine starke Harmonie zwischen dem sprachlichen und dem geographischen Raum, wohingegen die Korrelationen in den östlichen und südlichen Gebieten deutlich schwächer ausfallen. Im Vokalismus führen die Kompaktheit des kampanischen Dialektgebietes bzw. der verhältnismäßig starke Sprachausgleich innerhalb der Region zu einer im Durchschnitt sehr schwachen, aber gleichmäßiger verteilten Harmonie zwischen Sprache und Raum. Bis auf wenige Ausnahmen in der Peripherie des Gebietes haben sich die Dialekte im Vokalismus also am weitesten aufeinander zu und damit von ihrer ursprünglichen geographischen Verortung weg ,bewegt'.

\subsubsection{Korrelationen zwischen Teilkorpora}

\section{S. Kartenteil, Karten A31 - A36}

Im Folgenden soll kurz der die sprachgeographische Forschung immer wieder beschäftigenden Frage nach den Unterschieden und Gemeinsamkeiten zwischen den Raumstrukturen in verschiedenen sprachlichen Bereichen nachgegangen werden. Dazu werden die Korrelationen zwischen den dialektometrischen Messergebnissen der verschiedenen Teilkorpora untersucht, die sich als sprachliche Subsysteme jeweils auf einer Ebene befinden. 
Im Hinblick auf die Korrelation zwischen den Ergebnissen im lexikalischen und im phonetischen Bereich sind ähnliche Werte zu beobachten wie in anderen $\operatorname{Sprachräumen~}^{430}$ (s. Tab. 29). Die Messpunkte, in denen sich die niedrigsten Korrelationswerte (Wertklassen [1] und [2]) finden, liegen - mit Ausnahme von Limàtola (824) - alle in der Peripherie des kampanischen Dialektgebietes (s. Karte A31): Fontegreca (810, MIN) im Norden, Ginestra degli Schiavoni (816) und Candela (827) im Nordosten, Monte San Giacomo (865) im Südosten und Salerno (855) im Westen. In diesen Punkten sind die Entwicklungen der Raumstrukturen im Bereich der Phonetik und im Lexikon historisch also sehr unterschiedlich (wenn auch längst nicht ,gegeneinander") verlaufen. Karte A33 und A34 illustrieren dies am Beispiel des Ähnlichkeitsprofils von Fontegreca (810), das im phonetischen Bereich eine hohe Ähnlichkeit zu den Dialekten der Metropolregion Neapel aufweist, im lexikalischen Bereich jedoch in dem kleinräumigen ,Dialektverbund“ in der Terra di Lavoro verortet ist.

Die Messpunkte, die hohe bis sehr hohe Korrelationswerte (Wertklassen [5] und [6]) aufweisen, formen - mit Ausnahme von Reìno (815) - zwei kompakte Gebiete: Eines stellen die Isole Flegree mit den Punkten Barano d'Ischia (833) und Pròcida (834) dar, das andere findet sich im Cilento (Postiglione (857), Capaccio (863), Laurino (864), Monte San Giacomo (865)). Hier haben sich die Raumstrukturen im Bereich der Phonetik und im Lexikon also weitgehend konform entwickelt, was die Beobachtungen (vgl. Kap. 5.4.4) bestätigt, dass beide Gebiete sich gut von allfälligen Sprachausgleichstendenzen - und den dadurch bedingten ,Störungen' einer kongruenten Sprachentwicklung - haben abschotten können, was v.a. im Falle der insularen Dialekte, aber auch im Cilento durch geographische Faktoren begünstigt worden sein dürfte.

Im Hinblick auf die Korrelation zwischen den phonetischen Teilkorpora - also den Ergebnissen im konsonantischen und jenen im vokalischen Bereich - fällt auf, dass die Korrelationswerte im Durchschnitt deutlich niedriger liegen und gleichzeitig eine deutlich höhere Spannweite aufweisen als im Falle der Korrelation zwischen phonetischem und lexikalischem Teilkorpus (s. Tab. 29). Die historischen Entwicklungen der Raumstrukturen im Bereich des Konsonantismus und im Bereich des Vokalismus weisen also größere Unterschiede auf. Die verhältnismäßig höchsten Korrelationswerte (Wertklassen [5] und [6]) finden sich in zwei kompakten Gebieten (s. Karte A32): in der Metropolregion Neapel - insbesondere auf den Isole Flegree (Barano d'Ischia (835), Pròcida (834, MAX)) - sowie am Übergang zwischen der Irpinia und dem Cilento (Capaccio (863), Postiglione (857), Salvitelle (858), Senerchia (840)). Es sind dies also die Gebiete, in denen die historischen Entwicklungen von Konsonantismus und Vokalismus weitgehend konform verlaufen sind.

\begin{tabular}{|c|c|c|}
\hline $\begin{array}{c}\text { Kenn- } \\
\text { wert }\end{array}$ & LEX/PHON & KONS/VOK \\
\hline MIN & 0,69 & 0,22 \\
\hline MW & 0,81 & 0,65 \\
\hline MAX & 0,92 & 0,87 \\
\hline
\end{tabular}

Tabelle 29. Statistische Kennwerte der Korrelationen zwischen verschiedenen sprachlichen Bereichen im ALI-Korpus. Messmoment RIW ${ }_{j k}$, Produktmoment-Korrelationskoeffizient nach Bravais/Pearson.

\footnotetext{
${ }^{430}$ Vgl. etwa zum italienischen Sprachraum Goebl (2007: 267) und zum französischen Sprachraum Goebl (2006c: 435).
} 
Die deutlichsten Abweichungen zwischen den konsonantischen und den vokalischen Raumstrukturen (Wertklassen [1] und [2]) finden sich in Messpunkten, die bereits durch ihren besonderen Vokalismus aufgefallen sind: Bovino (819, MIN), Monte San Giacomo (865), Sarno (837) und Montella (839). Im Falle Monte San Giacomos (865) geht dies darauf zurück, dass der Dialekt zwar im Vokalismus, nicht aber im Konsonantismus eine starke Ähnlichkeit zu den Dialekten in der Metropolregion Neapel aufweist (vgl. Karte A35 und A36). Die verhältnismäßig großen Unterschiede zwischen den konsonantischen und den vokalischen Raumstrukturen haben hier in allen Fällen ein außersprachliches Korrelat in der dialektalen Grenzlage der Messpunkte: Bovino (819) liegt im Grenzgebiet zwischen den kampanischen und den apulischen Dialekten, Monte San Giacomo (865) im Grenzraum zwischen den kampanischen Dialekten und jenen der Basilicata, Sarno (837) befindet sich im Grenzraum zu dem Dialektgebiet in der Metropolregion Neapel und Montella (839) im Übergangsgebiet zwischen Sannio und Irpinia.

\subsubsection{Die kampanischen Dialekte und das Standarditalienische}

\section{S. Kartenteil, Karten A37 - A40}

In Erweiterung des usuellen Anwendungsbereiches der Dialektometrie soll auf der Basis der vorliegenden Daten neben dem Verhältnis der kampanischen Dialekte untereinander auch ihr Verhältnis zur Standard- bzw. Nationalsprache (italiano standard (900)) analysiert werden. ${ }^{431}$ Die Ergebnisse der Analyse des ALI-Korpus dienen darüber hinaus als Bezugsgröße für die Analyse der diachronischen Entwicklung des Verhältnisses der kampanischen Dialekte zum Standarditalienischen (vgl. Kap. 5.5.8).

Die durchschnittliche Ähnlichkeit der kampanischen Dialekte zum Standarditalienischen ist - bedingt durch die ,typisch kampanische ' bzw. ,meridionale' Phonetik und Lexik ${ }^{432}$ - erwartungsgemäß sowohl im Totalkorpus als auch in den verschiedenen Teilkorpora relativ gering (s. Tab. 30). Die geringsten Ähnlichkeitswerte zum italiano standard (Wertklasse [1]) weisen im Gesamtkorpus die Dialekte von Barano d'Ischia (833, MIN), Pròcida (834) und Casal di Prìncipe (823) auf (s. Karte A37), dahinter (Wertklasse [2]) finden sich einige Dialekte im Cilento (Capaccio (863), Laurino (864)) sowie der Dialekt von Anacapri (851). Im Falle der insularen Dialekten geht die geringe Ähnlichkeit zum Standarditalienischen darauf zurück, dass hier spezielle, besonders standardferne phonetische Merkmale und Lexeme vorliegen, deren Konservierung durch die geographische Abschottung vom kampanischen Festland begünstigt wurde. Die Tatsache, dass sich auch das festländische Casal di Prìncipe (823) in dieser Gruppe findet, weist darauf hin, dass der Ort zu den Dialekten in der Metropolregion Neapel gehört, die - ähnlich wie Pozzuoli (vgl. Kap. 3.3.4.1) - besondere dialektale Merkmale aufweisen. Im Falle der cilentanischen Dialekte spiegelt die geringe Ähnlichkeit die verhältnismäßig großen strukturellen Unterschiede zum Standarditalienischen wider, die vor allem den Vokalismus kennzeichnen (vgl. Kap. 3.3.4.1).

Die (verhältnismäßig) höchsten Ähnlichkeitswerte zum Standarditalienischen (Wertklasse [1]) finden sich in Neapel (835) und in Candela (827, MAX), dahinter folgen vier Dialekte, die ein kompaktes Gebiet zwischen Sannio (Reìno (815), Benevento (825)) und Irpinia (Avellino (838), Melito Irpino (826)) aufspannen. Hier manifestieren sich die in Kap. 3.3.4.1

\footnotetext{
${ }^{431}$ Die Basis der dialektometrischen Analyse stellt hier die komplette Ähnlichkeitsmatrix von 36 x 36 Messpunkten dar. Dies gilt auch für Kap. 5.5.8.

${ }^{432}$ Vgl. Kap. 3.3.4.1 und 3.3.4.5.
} 
diskutierten, mit der Randständigkeit der Gebiete korrelierenden, v.a. phonetisch speziellen Charakteristika der Dialekte des Sannio und der Irpinia, die häufig von den ,typisch kampanischen` Merkmalen abweichen und offensichtlich näher am Standarditalienischen liegen als jene.

Im Lexikon ergibt sich eine etwas höhere durchschnittliche Ähnlichkeit der kampanischen Dialekte zum Standarditalienischen als im Totalkorpus (s. Tab. 30). Bei der Betrachtung der Synopsekarte (s. Karte A38) zeigt sich, dass vor allem die verhältnismäßig hohe Ähnlichkeit, die der Dialekt von Neapel (835) im Gesamtkorpus zum Standarditalienischen aufweist, auf das lexikalische Teilkorpus zurückgeht, wo sich in Neapel (835, MAX) die innerhalb der Region höchste Ähnlichkeit zum Standarditalienischen überhaupt findet. Angesichts dessen, dass der Einfluss des Standarditalienischen in Neapel durch den hier stattfindenden - und insbesondere das Lexikon ${ }^{433}$ betreffenden - Sprachkontakt stärker ausgeprägt ist als in Orten mit geringerer Bevölkerungsgröße und -fluktuation, verwundert dies nicht. Vor dem Hintergrund der sprachlichen Orientierung Beneventos (825) an Neapel erklärt sich dadurch mittelbar auch der hohe Ähnlichkeitswert, den Benevento (Wertklasse [2]) zum italiano standard aufweist. Schwieriger und wohl nur durch genaue Beleuchtung des jeweiligen soziokulturellen Hintergrunds zu erklären sind die hohen Ähnlichkeitswerte, die sich in Sarno (837) im neapolitanischen Hinterland, in Rocca d'Evandro (809) in der Terra di Lavoro sowie in Monte San Giacomo (865) im Südcilento finden.

Die geringste lexikalische Ähnlichkeit zum Standarditalienischen findet sich in Anacapri (851, MIN), wo die geographische Abschottung wie im Falle der Isole Flegree (Ischia, Pròcida, s.o.) eine Konservierung dialektaler, hier v.a. lexikalischer Merkmale begünstigt hat. Daneben finden sich drei kleine Gebiete mit geringer Ähnlichkeit zum italiano standard (Wertklassen [1] bis [2]): das Gebiet um Casal di Prìncipe (823) und Limàtola (824) im neapolitanischen Hinterland, das Gebiet um Salvitelle (858) und Senerchia (840) am Übergang zwischen Nordcilento und Irpinia sowie das Gebiet um Reìno (815), Ginestra degli Schiavoni (816) und Melito Irpino (826) im Sannio. Letzteres entspricht in etwa jenem Areal, das im Totalkorpus eine verhältnimäßig hohe Ähnlichkeit zum Standarditalienischen aufweist. Diese nur scheinbar widersprüchlichen Verhältnisse ergeben sich aus ein und derselben Entwicklungstendenz: der durch die geographische Randständigkeit der Dialekte im Sannio begünstigten Bewahrung der basilektalen (dem Italienischen nahe stehenden) Phonetik bzw. Phonologie und der (vom Italienischen deutlich abweichenden) basilektalen Lexik, welch letztere sich auch in den übrigen genannten Dialekten mit hoher lexikalischer Distanz zum italiano standard findet.

Im Konsonantismus liegt die durchschnittliche Ähnlichkeit der kampanischen Dialekte zum Standarditalienischen auf ähnlichem Niveau wie im Totalkorpus und ist damit niedriger als im Lexikon (s. Tab. 30). Die bei der Betrachtung der Synopsekarte sichtbaren Raumstrukturen (s. Karte A39) weisen nur kleine Abweichungen von jenen im Totalkorpus auf. Diese betreffen zunächst die Position von Neapel (835), das sich im Konsonantismus nicht (wie im Totalkorpus) unter den Dialekten mit verhältnismäßig hoher Ähnlichkeit zum Standarditalienischen findet, d.h. hier stärker von standardfernen Merkmalen geprägt ist. Umgekehrt kommt Casal di Prìncipe (823) nicht (wie im Totalkorpus) in einer der niedrigsten Wertklassen zu liegen, sodass sich hier also weniger große Abweichungen vom Standarditalienischen manifestieren als im lexikalischen Bereich. Zu dem Gebiet mit geringer sprachlicher Ähnlichkeit zum italiano standard im Nordcilento gehört im Konsonantismus neben Capaccio (863) und Laurino (864) zusätzlich Pòllica (872). Im Vergleich zum Gesamtkorpus geringere Ähnlichkeiten zum

${ }^{433}$ Vgl. Kap. 2.3.2 und 3.3.4.5. 
Standarditalienischen weisen auch die Dialekte von Roccaraìnola (836) und Maiori (854) im neapolitanischen Hinterland auf.

Im Vokalismus ist die durchschnittliche Ähnlichkeit zum italiano standard geringer als in den übrigen Teilkorpora (s. Tab. 30). Die auf der Synopsekarte zu Tage tretenden Raumstrukturen (s. Karte A40) weisen deutliche Unterschiede zu jenen im Totalkorpus bzw. im Konsonantismus und jenen im Lexikon auf. Die größte Ähnlichkeit zum Standarditalienischen (Wertklasse [6]) findet sich im peripheren südlichen Dialekt von Casaletto Spartano (874, MAX), dessen Sonderstellung im Vokalismus bereits deutlich geworden ist (vgl. Kap. 5.4.1 und Kap. 5.4.2). Verhältnismäßig hohe Ähnlichkeiten zum Standarditalienischen (Wertklasse [5]) zeigen auch die Dialekte von Avellino (838) und Gioia Sannìtica (814). Bei letzterem handelt es sich um einen peripheren nördlichen Dialekt an der Grenze zwischen der Terra di Lavoro und dem Sannio, dessen sprachliche - dem Italienischen näher als dem ,prototypisch`Kampanischen stehende - Besonderheiten nur im Vokalismus noch sichtbar werden, wo es gemeinsam mit seinem ,Nachbarn' Reìno (815) vom Rest des Dialektgebietes abgeschottet ist (vgl. Kap. 5.4.1 und 5.4.2). Die geringsten Ähnlichkeiten zum italiano standard (Wertklasse [1]) weisen (wie im Totalkorpus) die Dialekte von Barano d'Ischia (833, MIN), Casal di Prìncipe (823, MIN) und Pròcida (834) auf, wo also auch im vokalischen Bereich die dialektalen Merkmale gut bewahrt worden sind. Ein weiteres Minimum findet sich in Bovino (819, MIN), dessen Sonderstellung im Vokalismus bereits zu Tage getreten ist (vgl. Kap. 5.4.1 und 5.4.2). Auffällig ist darüber hinaus, dass 28 von 35 Dialekten eine mittlere Ähnlichkeit (Wertklassen [3] und [4]) zum Standarditalienischen aufweisen, während Wertklasse [2] leer bleibt. Im Vokalismus ist also auch hinsichtlich der Ähnlichkeit zum Standarditalienischen eine deutlich größere Homogenität innerhalb des Dialektgebietes festzustellen als in den übrigen (Teil-)Korpora. Die verhältnismäßig hohe Spannweite der Werte ergibt sich hier lediglich durch die - geographisch immer peripher gelegenen - ,Ausreißer' an beiden Enden der Skala.

\begin{tabular}{|c|c|c|c|c|c|}
\hline Kennwert & TOT & LEX & PHON & KONS & VOK \\
\hline MIN & 23,64 & 28,57 & 16,47 & 17,05 & 14,63 \\
\hline MW & 33,53 & 36,41 & 31,75 & 32,74 & 28,64 \\
\hline MAX & 42,91 & 46,67 & 47,06 & 53,49 & 46,34 \\
\hline
\end{tabular}

Tabelle 30. Statistische Kennwerte der Ähnlichkeiten der kampanischen Dialekte zum Standarditalienischen im ALI-Korpus (Messmoment RIW $_{j k}$ ).

Für das Verhältnis zwischen den kampanischen Dialekten und dem Standarditalienischen in den 1960er Jahren ist festzuhalten, dass die Ähnlichkeit insgesamt verhältnismäßig gering ist, d.h. fast immer deutlich unter 50\% liegt, wobei sich die im Durchschnitt höchste Ähnlichkeit zum italiano standard im Lexikon und die geringste durchschnittliche Ähnlichkeit im Vokalismus ergibt. Für die ,Resistenz' der dialektalen Subsysteme gegenüber der Übernahme von Elementen bzw. Merkmalen aus dem Standarditalienischen (vgl. Kap. 2.4.3) ergibt sich also die Reihenfolge (Resistenz abnehmend): Vokalismus > Konsonantismus > Lexikon.

Im Bereich der räumlichen Verteilung der in den oberen und unteren Wertklassen liegenden Dialekte zeigen sich deutliche Unterschiede zwischen den im Totalkorpus dominanten Teilkorpora. Während die Dialekte mit verhältnismäßig hoher bzw. geringer Ähnlichkeit zum Standarditalienischen im (strukturellen) konsonantischen Bereich kompakte Gebiete bilden, sind sie im Bereich des Lexikons, in dem das Verhältnis zum Standarditalienischen nicht durch 
strukturelle, sondern durch metalinguistische und soziokulturelle Faktoren bestimmt wird, häufig diskontinuierlich in der Region verteilt.

\subsubsection{Zusammenfassung und Interpretation}

Die dialektometrische Analyse des aus dem ALI extrahierten Korpus hat gezeigt, dass das sprachliche Raumprofil der Campania in den 1960er Jahren durch eine kleinräumige dialektale Gliederung geprägt ist, die durch sieben dialektale ,Verbünde' bestimmt wird: das Dialektgebiet in der Terra di Lavoro, das Dialektgebiet im neapolitanischen Hinterland, das Dialektgebiet im Sannio, das Dialektgebiet Nordcilento-Irpinia, das Dialektgebiet Bovino-Candela, das Dialektgebiet im Südcilento und das Dialektgebiet in der Metropolregion Neapel, zu dem ebenfalls die geographisch nicht adjazenten Provinzhauptstädte Benevento (825) und Salerno (855) gehören. Im lexikalischen Bereich bilden das Dialektgebiet in der Metropolregion Neapel, das Dialektareal im neapolitanischen Hinterland sowie ein Großteil des Dialektgebietes in der Terra di Lavoro einen dialektalen Großraum im Westen der Region.

Die kleinräumige Gliederung des kampanischen Dialektgebietes geht mit einer Vielzahl ,beliebter' Dialekte, d.h. sprachlicher ,Bezugspunkte‘ einher, deren jeweilige ,Einzugsbereiche' entsprechend klein sind. Auch die Metropole Neapel ist nur für ihre geographische Umgebung und hier auch nur im lexikalischen Bereich ein sprachlicher Bezugspunkt. Daraus lässt sich schlussfolgern, dass nicht nur im Hinblick auf die gesamte Region, sondern auch im Bereich der Küstenebene historisch keine ,Neapolitanisierung', d.h. keine Übernahme von Merkmalen aus dem Neapolitanischen in die übrigen Dialekte stattgefunden hat.

Unter den kompakten Dialektgebieten finden sich vier, Streithähne', von denen jeweils zwei durch wechselseitige ,Antipathien' gegenüber dem anderen gekennzeichnet sind. Gegenüber stehen sich einerseits das Dialektgebiet in der Metropolregion Neapel und das Dialektgebiet im Nordcilento und andererseits das Dialektgebiet im neapolitanischen Hinterland und das Dialektgebiet im Südcilento.

Die deutlichste Dialektgrenze verläuft in der Campania in den 1960er Jahren von Gioia Sannìtica (814) im Norden nach Olèvano Sul Tusciano (856) im Süden und trennt das Dialektgebiet somit in einen sprachlich (insbesondere lexikalisch) kompakten westlichen und einen sprachlich (insbesondere lexikalisch) zerklüfteten östlichen Teil. Im Vokalismus sind die Raumstrukturen in erster Linie durch die Abschottung peripherer dialektaler Mikroareale bzw. einzelner peripherer Dialekte von einem insgesamt kompakten dialektalen Binnenareal gekennzeichnet. Somit spiegeln sich in den sprachlichen Raumstrukturen geographische Gegebenheiten wie die Zweiteilung der Campania in Küstenebene (pianura) und Gebirgsregionen (montagna, vgl. Kap. 3.1) und die Randlage (bzw. im Falle der Inseln die geographische Abschottung) bestimmter Gebiete bzw. Ortspunkte wider.

In den 1960er Jahren finden sich in der Campania drei Dialektkerne: das Dialektgebiet der Metropolregion Neapel mit den Zentren Neapel (835), Sorrento (852) und Salerno (855), das Dialektgebiet im neapolitanischen Hinterland mit dem Zentrum Sarno (837) und das Dialektgebiet im Südcilento um Alfano (873) und Monte San Giacomo (865). Die Tatsache, dass die sprachlichen Maxima im Verhältnis zu anderen dialektometrischen Untersuchungen relativ niedrig liegen, spricht für eine gemessen an anderen Sprach- bzw. Dialektgebieten relativ hohe Heterogenität des kampanischen Dialektareals. ,Einzelgänger', d.h. relativ schlecht integrierte Dialekte finden sich in der nördlichen (Gioia Sannìtica (814), Reìno (815)), der östlichen (Bovino (819), Candela (827)), der nordwestlichen (Rocca d'Evandro (809), Castel Volturno (822)) sowie der südlichen Peripherie (Casaletto Spartano (874)). 
Die Bereitschaft zum Sprachausgleich, die sich in den 1960er Jahren im kampanischen Dialektgebiet zeigt, ist relativ schwach und manifestiert sich am deutlichsten im Vokalismus. Die Zonen, die die stärksten Sprachausgleichstendenzen aufweisen, finden sich vor allem entlang von Dialektgrenzen, d.h. östlich des Dialektgebietes der Metropolregion Neapel, am Übergang zwischen dem Dialektgebiet im Nordcilento und der Irpinia und zwischen dem Dialektgebiet der Irpinia und dem Sannio. Im Vokalismus zeigt sich eine weitere Sprachausgleichszone, die sich im Norden bis in die Irpinia hinein ausdehnt, im Westcilento. Von den sprachlichen Nivellierungsprozessen in der Region weitgehend abgeschirmt sind periphere und geographisch isolierte Areale. Im Lexikon ist dies vor allem das Südcilento, im Konsonantismus sind es das Südcilento, die Dialekte in der Provinz Foggia und die Isole Flegree (Barano d'Ischia (833)) und im Vokalismus ist es das nördliche Sannio (Gioia Sannìtica (814), Reìno (815)).

Im Hinblick auf die Korrelation zwischen Sprach- und Naturraum zeigen sich im kampanischen Dialektgebiet große Unterschiede zwischen den Verhältnissen im konsonantischen und vokalischen Bereich und jenen im Lexikon. Während im Konsonantismus und im Vokalismus das Verhältnis zwischen Sprache und Raum insbesondere in den kampanischen Gebirgsregionen sowie den geographisch abgeschotteten insularen Gebieten verhältnismäßig harmonisch ist, manifestieren sich im lexikalischen Bereich die stärksten Kongruenzen zwischen Sprach- und Naturraum in der kampanischen Küstenebene. Störungen des Verhältnisses zwischen Sprache und Raum betreffen einerseits die sprachlich an der Metropolregion Neapel orientierten - und dadurch von ihrem geographischen Umfeld sprachlich isolierten - Provinzhauptstädte Benevento (825) und Salerno (855) und andererseits periphere Gebiete im Osten (Bovino (819), Candela (827)) und Süden (Südcilento) sowie (v.a. im lexikalischen Bereich) das Westcilento. Im Vokalismus führen die besonders hohe Kompaktheit des kampanischen Dialektgebietes bzw. der verhältnismäßig starke Sprachausgleich innerhalb der Region zu einer im Vergleich zu den übrigen Korpora sehr geringen, aber gleichmäßiger verteilten Harmonie zwischen Sprache und Raum.

Im Hinblick auf die Frage nach dem Verhältnis zwischen den Raumstrukturen, die in den sich gegenüber stehenden sprachlichen Teilbereichen vorliegen, hat die Analyse der Korrelationen zwischen den verschiedenen Teilkorpora ergeben, dass in der Tat davon auszugehen ist, dass die Entwicklung der Raumstrukturen im Bereich der Phonetik grundsätzlich anders verläuft als im Bereich des Lexikons. Noch größere Unterschiede bzw. noch geringere Korrelationen zeigen sich in der Campania überraschenderweise zwischen den Raumstrukturen im konsonantischen und im vokalischen Bereich, was mit der Sonderstellung des letzteren zusammenhängt. Worauf diese allerdings zurückzuführen ist, kann im Rahmen einer dialektometrischen Analyse nicht geklärt werden.

Die Analyse der sprachlichen Raumstrukturen in der Campania der 1960er Jahre lässt Rückschlüsse auf die in dieser Zeit bestehenden sozialen und sprachlichen Interaktionsflüsse zu. Die hohe Anzahl kompakter Dialektgebiete mit entsprechend geringer Fläche verweist auf einen durch die räumlichen Gegebenheiten eingeschränkten Kommunikations- und Interaktionsradius der Sprecher. Dort, wo die räumlichen Gegebenheiten die sprachliche und soziale Interaktion nicht bzw. weniger behindern - in der kampanischen Küstenebene - hat sich auf der Ebene des Lexikons ein dialektales Makroareal entwickelt.

Bei den beobachtbaren sprachlichen Raumstrukturen handelt es sich nicht um zufällige, sondern um historisch gewachsene Konstellationen, die am Ende einer kontinuierlichen Entwicklung der auf die Anfänge der sprachlichen „Bewirtschaftung“ der Region zurückgehenden Ordnungsmuster stehen. Die verhältnismäßig hohe Heterogenität des kampanischen Dialektge- 
bietes findet eine Parallele in der Vielzahl der Besiedlungsphasen und den damit einhergehenden unterschiedlichen sprachlich-kulturellen Einflüssen, die die Region im Laufe der Geschichte geprägt haben (vgl. Kap. 3.2). ${ }^{434}$ Deutlich hervor tritt die sprachliche Sonderstellung der Gebiete am neapolitanischen Golf, die historisch (spätestens) von der griechischen Eroberung an eine ethnische und vor allem während des rund 600-jährigen Bestehens des Regno di Napoli als eigentlich neapolitanischer Teil (s. Karte 9) auch eine soziopolitische Einheit bildeten. Wann genau die soziale Abgrenzung dieses Gebietes nach außen auch sprachlich, d.h. in Form der heute beobachtbaren Dialektgrenze wirksam geworden ist, kann nur anhand von detaillierten sprachhistorischen Untersuchungen geklärt werden. Gleiches gilt für die Frage, inwieweit die beobachtete Ähnlichkeit zwischen den Dialekten im Südcilento, den Dialekten im Westen der Region Apulien und den Dialekten in der Metropolregion Neapel im 20. Jahrhundert - d.h. mehr als 2500 Jahre nach Beginn der griechischen Besiedelung Kampaniens - noch durch das griechische Sub- bzw. Adstrat (vgl. Kap. 3.2) bedingt ist. In jedem Fall ist anzunehmen, dass auch der Verlauf der römischen - und in den nachfolgenden Epochen weiter genutzten und ausgebauten - Verkehrsachsen (d.h. der Via Popilia im neapolitanischen Hinterland und der Via Appia im Norden der Region, s. Karte 5 und 6) bei der historischen Entwicklung der sprachlichen Raumstrukturen eine Rolle gespielt hat.

Die Tatsache, dass die Metropole Neapel nur für ihre geographische Umgebung und hier auch nur im lexikalischen Bereich ein sprachlicher Bezugspunkt ist, spiegelt die Ergebnisse der kultur- und sprachhistorischen Forschung zur Stellung Neapels wider (vgl. Kap. 3.2.3): Historisch gesehen hat das Fehlen eines ,spirito comunale“ (Galasso 2003: 130) einer Verbreitung der Merkmale des Neapolitanischen und damit einer Koineisierung in der Region entgegengewirkt. In der Autonomie des Dialektgebietes im neapolitanischen Hinterland bzw. in dessen Abgrenzung gegenüber dem Dialektgebiet in der Metropolregion Neapel manifestieren sich wiederum der historische kulturelle Bruch und die dadurch bedingte ,sensazione di distanza“ (De Blasi/Fanciullo 2003: 628) zwischen den Bewohnern des städtischen Einzugsbereichs und jenen des Hinterlands (vgl. Kap. 3.2.3).

Das Verhältnis, das die kampanischen Dialekte in den 1960er Jahren zum Standarditalienischen aufweisen, ist durch eine verhältnismäßig geringe Ähnlichkeit von durchschnittlich weit unter 50\% gekennzeichnet. Dabei bestehen sowohl deutliche intraregionale Unterschiede als auch Diskrepanzen zwischen den im Totalkorpus dominanten Teilkorpora: Während sich die Dialekte mit hoher bzw. geringer Ähnlichkeit zum Standarditalienischen im konsonantischen Bereich in bestimmten Gebieten konzentrieren, sind sie im Bereich des Lexikons meist diskontinuierlich in der Region verteilt. Während das Verhältnis zum Standarditalienischen auf der strukturellen Ebene des Konsonantismus also raumgebunden ist, sind im nicht-strukturellen, lexikalischen Bereich metalinguistische und (sozio-)kulturelle Faktoren ausschlaggebend.

\footnotetext{
${ }^{434}$ Angesichts der großen Zeitspanne und der dadurch bedingten Menge an (sprach-)historischen Entwicklungen, die zwischen dem sprachlichen Profil der Region in frühen Besiedlungsphasen und jenem in den 1960er Jahren liegen, kann für etwaige Zusammenhänge jedoch lediglich Potentialität beansprucht werden.
} 


\title{
5.5 Dialektometrische Auswertung II: Das kampanische Dialektgebiet 2014
}

\subsubsection{Klassifikation der kampanischen Dialekte}

\author{
S. Kartenteil, Abb. A5 - A8 und Karten A41 - A52
}

Die Veränderungen, die in der Campania zwischen 1960 und 2014 im Bereich der dialektalen Gliederung stattgefunden haben, werden durch Betrachtung der auf der Basis des Vergleichskorpus vorgenommenen Clusteranalyse ${ }^{435}$ und durch den direkten Vergleich zwischen dieser und der für das ALI-Korpus vorliegenden Klassifikation sichtbar.

Im Totalkorpus finden sich zwei Hauptcluster (s. Abb. A5), die in der räumlichen Umlegung zwei kompakte Dialektblöcke bilden: Den Dialekten im Westen und im Norden der Region (Cluster A, B, C, D und E), d.h. in der Metropolregion Neapel (inklusive der Provinzhauptstädte Benevento (825), Avellino (838) und Salerno (855)), in der Terra di Lavoro, im Sannio und im westlichen Cilento stehen die Dialekte im Osten der Region (Cluster F, G und H), d.h. jene im östlichen Cilento, in der Irpinia und in der apulischen Provinz Foggia gegenüber. Innerhalb dieser dialektalen Makroareale lassen sich folgende Geotypen identifizieren (s. Karte A41): ${ }^{436}$

1) die Dialekte im (Nord-)Westen der Region (Cluster A),

2) die Dialekte im Westcilento ${ }^{437}$ (Cluster B),

3) die Dialekte im Sannio (Cluster C),

4) die Dialekte in der apulischen Provinz Foggia (Cluster F) und

5) die Dialekte im Gebiet Cilento-Irpinia (Cluster G).

Die Dialekte von Fontegreca (810, Cluster D) in der Terra di Lavoro, von Casal di Prìncipe (823, Cluster E) in der Metropolregion Neapel und von Casaletto Spartano (874, Cluster H) im Südcilento weisen jeweils eine Sonderstellung auf.

Damit unterscheidet sich die aus der Clusteranalyse des Vergleichskorpus resultierende dialektale Klassifikation deutlich von jener, die sich auf der Basis des ALI-Korpus ergeben hat (vgl. Karte A42 und A43). Diachronisch stabil sind nur zwei Geotypen: die Klasse der Dialekte im Sannio und die Gruppe der Dialekte in der Provinz Foggia. Die in den 1960er Jahren noch separate Klassen bildenden Dialekte in der Terra di Lavoro, im neapolitanischen Hinterland und in der Metropolregion Neapel bilden 2014 eine gemeinsame und räumlich entsprechend weit ausgreifende Dialektgruppe (Cluster A), die - bis auf Fontegreca (810) und Casal di Prìncipe (823) - alle Dialekte in der kampanischen Küstenebene umfasst. Dies weist darauf hin, dass in diesem Gebiet in der zweiten Hälfte des 20. Jahrhunderts eine strukturelle Annäherung zwischen den Dialekten stattgefunden hat. Eine ähnliche Entwicklung zeigt sich im Süden bzw.

\footnotetext{
${ }^{435}$ Auch hier wurde die Clustermethode des Complete Linkage verwendet.

${ }^{436}$ Die Färbung der Dendreme bzw. Choreme in den Abbildungen der Ergebnisse des Vergleichskorpus orientiert sich nicht an der Einfärbung in den Abbildungen der Ergebnisse des ALI-Korpus. Bei der Farbgebung wurden - soweit möglich - für das Auge gut differenzierbare und die Zugehörigkeit zu den Hauptclustern möglichst verdeutlichende Grundfarben gewählt. Übereinstimmende Farben verweisen also nicht per se auf etwaige diachronische Zusammenhänge zwischen den jeweiligen Dialektgebieten. So ist etwa die farbliche Übereinstimmung zwischen dem großflächigen westkampanischen Dialektgebiet im Vergleichskorpus (s. Karte A43) und dem Dialektgebiet in der Terra di Lavoro im ALI-Korpus (s. Karte A42) zufällig und nicht als eine ,Erweiterung' des letzteren zu interpretieren.

${ }^{437}$ Bei der Bezeichnung ist von der geographischen Lage einiger Ortspunkte (hier: Montella (839), Olèvano Sul Tusciano (856), die geographisch nicht im Cilento liegen) zu abstrahieren.
} 
im Südosten der Region, wo sich die in den 1960er Jahren noch einen separaten Verbund bildenden Dialekte des Südcilento (Monte San Giacomo (865), Alfano (873)) der Dialektklasse im Gebiet Cilento-Irpinia angeschlossen haben (Cluster G). Auf der anderen Seite haben sich die Dialekte im Südwesten von dieser abgespalten und eine eigene Klasse gebildet (Cluster B). Die Dialekte, die gegenwärtig eine Sonderstellung aufweisen, haben sich einerseits aus der Gruppe der Dialekte in der Metropolregion Neapel (Fontegreca (810) und Casal di Prìncipe (823)) und andererseits aus der Klasse der Dialekte im Südcilento (Casaletto Spartano (874)) ausgegliedert. Bei der Betrachtung der Hauptcluster fällt auf, dass sich die engen Beziehungen, die in den 1960er Jahren zwischen den Dialekten in der Metropolregion Neapel einerseits und den peripheren Dialekten im Südcilento und in der Region Apulien andererseits bestanden haben, fünfzig Jahre später nicht mehr manifestieren (vgl. Abb. A1 und Abb. A5).

Im lexikalischen Bereich (s. Abb. A6 und Karte A44) weist das Clusterergebnis deutliche Unterschiede zum Totalkorpus auf. Übereinstimmung besteht grob gesehen in der großen Dialektgruppe in der kampanischen Küstenebene (Cluster A); bei genauerer Betrachtung ergeben sich jedoch auch hier kleine Abweichungen. So ist Casal di Prìncipe (823), das im Gesamtkorpus eine Sonderstellung aufweist, im Lexikon Teil des westkampanischen Dialektgebietes. Umgekehrt verhält es sich mit den Dialekten von Castel Volturno (822) und Pròcida (834), die sich im Lexikon der zweiten großen Dialektgruppe anschließen (Cluster D), welche darüber hinaus die Dialekte im Westcilento sowie einige separate Dialekte im Norden (Reìno (815)), im Zentrum (Avellino (838)) und im Osten (Postiglione (857), Salvitelle (858)) beinhaltet. Durch die Zugehörigkeit der beiden letztgenannten Dialekte zu dieser Klasse zerfällt die Gruppe der Dialekte im Gebiet Cilento-Irpinia (Cluster G) geographisch in einen nördlichen und einen südlichen Teil. Die Dialekte im Sannio und die Dialekte in der Provinz Foggia bilden im Lexikon keine gemeinsamen Klassen. Auffällig ist auch die sprachliche Sonderstellung Beneventos (825), die sich im Totalkorpus nicht manifestiert.

Die diachronischen Unterschiede im Bereich der Klassifikation der kampanischen Dialekte stellen sich im westlichen Teil der Region im Lexikon ähnlich dar wie im Totalkorpus. Die in den 1960er Jahren eine eigene Klasse bildenden Dialekte in der Terra di Lavoro haben sich in den vergangenen fünfzig Jahren mit den Dialekten in der Metropolregion Neapel und den Dialekten im neapolitanischen Hinterland zu einer große Gruppe vereint (vgl. Karte A45 und A46). Im Südwesten hat sich auch im Lexikon eine neue Dialektklasse gebildet (Cluster D), zu der jedoch auch weiter im Norden lokalisierte Dialekte gehören. Im östlichen Teil der Region finden sich im Lexikon besondere Entwicklungen, die in Richtung einer Fragmentierung der vormals kompakten Dialektklassen gehen. Die Dialekte von Bovino (819), Candela (827) und Cairano (841) bilden 2014 keine gemeinsame Klasse mehr: Bovino (819) weist eine Sonderstellung auf, Candela bildet eine Klasse mit Melito Irpino (826, Cluster F) und Cairano formt eine Gruppe mit Quaglietta (840) und zwei Dialekten im Cilento (Cluster G). Auch die ehemals kohäsiven Dialekte im Sannio gehören nun zu verschiedenen Klassen, die jeweils diskontinuierlich verteilte Dialekte beinhalten.

Im konsonantischen Bereich spiegelt das Ergebnis der Clusteranalyse (s. Abb. A7) im Westen der Region jenes im Totalkorpus wider (bzw. umgekehrt). Im Osten ergeben sich jedoch einige Abweichungen, die insbesondere darin bestehen, dass die im Totalkorpus aufscheinenden kompakten Dialektgebiete hier in kleinere Verbünde zerfallen (vgl. Karte A47 und A41). Im Norden gehört Melito Irpino (826) im Konsonantismus nicht zur Gruppe der Dialekte im Sannio, sondern bildet (wie im lexikalischen Teilkorpus) eine eigene Klasse mit Candela (827), sodass auch das Dialektgebiet in der Provinz Foggia zerfällt (Bovino (819) bleibt jedoch 
durch seine Verbindung zu den räumlich entfernten Dialekten im Cilento (Cluster F) im Hinblick auf die gesamte Region kein ,Außenseiter ${ }^{6}$ ). Dadurch, dass die Dialekte von Cairano (841) und Quaglietta (840) in der Irpinia eine eigene Klasse bilden und Postiglione (857) sich dem Dialektgebiet im Westcilento anschließt, reduziert sich das große Dialektgebiet (blaues Chorem), das sich im Totalkorpus vom Südcilento bis in die Irpinia erstreckt, im Konsonantismus auf ein kompaktes Gebiet im Cilento, dem sich allerdings Casaletto Spartano (874) und Pòllica (872) anschließen.

Hinsichtlich der diachronischen Entwicklung der dialektalen Gliederung im Konsonantismus lässt sich für den westlichen Teil der Region feststellen, dass sich dem entstandenen dialektalen Großraum, der bereits im Totalkorpus sichtbar geworden ist, auch die Dialekte der Isole Flegree, die in den 1960er Jahren in konsonantischer Hinsicht noch eine separate Klasse bildeten, angeschlossen haben (vgl. Karte A48 und Karte A49). Im Osten der Region hat in den vergangenen fünfzig Jahren eine grundlegende Umordnung der dialektalen Verbünde stattgefunden. Das ehemals kompakte Dialektgebiet Nordcilento-Irpinia (dunkelgrünes Chorem auf Karte A48) hat sich regelrecht in seine Einzelteile ,aufgelöst': Montella (839) und Postiglione (857) sind heute Teil des Dialektgebietes im Westcilento, Quaglietta (840) und Cairano (841) bilden zusammen eine eigene Klasse. Die verbleibenden Dialekte (Salvitelle (858), Laurino (864) und Pòllica (872)) haben sich mit den Dialekten im Südcilento zu einer gemeinsamen Klasse vereint. Im Norden ist aus den ehemals zu den kompakten Verbünden im Sannio und in der Provinz Foggia gehörenden Dialekten aus Melito Irpino (826) und Candela (827) eine neue, kleine Gruppe entstanden.

Im Vokalismus zeigt sich auch im Vergleichskorpus eine grundlegend andere dialektale Klassifikation als im Totalkorpus bzw. im Konsonantismus und im Lexikon (s. Abb. A8 und Karte A50). Der auffälligste Unterschied besteht darin, dass sich im Vokalismus im Westen der Region kein dialektales Großcluster manifestiert, sondern die Dialekte in der kampanischen Küstenebene stattdessen zu drei verschiedenen Klassen gehören. In allen drei Klassen (Cluster A, B und C) bilden die Dialekte je zwei größere geographische ,Verbünde', sodass es sich zwar nicht um historische Dialektgebiete, jedoch auch nicht um sprachgeographisch ,unmotivierte“ Strukturen handeln kann. Abseits davon zeichnet sich die dialektale Gliederung der Campania im Vokalismus durch die Sonderstellung einzelner Dialekte in der nördlichen (Reìno (815)), östlichen (Bovino (819), Candela (827)) und südlichen Peripherie (Casaletto Spartano (874)) aus.

Auch im vokalischen Bereich haben in den vergangenen fünfzig Jahren deutliche Veränderungen der dialektalen Gliederung in der Campania stattgefunden, die insgesamt in Richtung einer größeren Kompaktheit des kampanischen Dialektgebietes gehen (vgl. Karte A51 und A52). Die Dialekte im (West-)Cilento und in der Irpinia, die in den 1960er Jahren noch zu drei verschiedenen Klassen gehörten, bilden heute eine gemeinsame Klasse (rotes Chorem auf Karte A52). In der kampanischen Küstenebene bilden die Dialekte in der Metropolregion Neapel (blaues Chorem auf Karte A51) heute hingegen keine gemeinsame Gruppe mehr. Stattdessen stehen sich ein nördlicher ,Verbund' (Fontegreca (810), Teano (813), Casal di Prìncipe (823)) und ein südlicher ,Verbund‘ (Barano d'Ischia (833), Pròcida (834), Neapel (835), Anacapri (851), Sorrento (852), Salerno (855)) gegenüber. Diachronische Kontinuität zeigt sich im Bereich der sprachlichen ,Einzelgänger': Fast alle Dialekte, die in den 1960er Jahren im Bereich des Vokalismus eine Sonderstellung aufwiesen, haben diese über die Zeit hinweg bewahrt (Casaletto Spartano (874), Bovino (819), Candela (827) und Reìno (815)). 
Die Unterschiede zwischen den dialektalen Gruppierungen von 1960 und 2014 weisen darauf hin, dass in der Campania in den vergangenen fünfzig Jahren tiefgreifende Veränderungen der sprachlichen Raumordnung stattgefunden haben. Die Verbindung kompakter Dialektklassen zu größeren Gruppen lässt auf eine gegenseitige strukturelle Annäherung der Dialekte, d.h. auf einen Sprach- bzw. Dialektausgleich insbesondere im westlichen Teil der Region schließen. Dialekte, die an diesem Prozess nicht teilgenommen haben (v.a. Casal di Prìncipe (823) und Fontegreca (810)), sind dadurch (zum Teil nur innerhalb ihres geographischen Umfelds) zu ,Außenseitern“ geworden. Die Dialekte in der Peripherie der Region, die (vor allem im Vokalismus) bereits in den 1960er Jahren eine Sonderstellung aufwiesen, haben diese ungeachtet der sprachgeographischen Veränderungen in der Region über die Zeit hinweg meist konserviert.

Die Veränderungen der Beziehungen zwischen den Dialekten haben im Süden der Region unter anderem zur Bildung einer ,neuen“ Dialektgruppe im Westcilento geführt. Über die Hintergründe dieser Entwicklung und die Beziehungen dieser Klasse zu den übrigen Dialekten wird die Analyse weiterer kartographischer Heuristika Aufschluss geben.

\subsubsection{Dialektgrenzen}

\section{S. Kartenteil, Karten A53 - A60}

Anhand der diachronisch vergleichenden Analyse der Schottenkarten der Gesamt- sowie der verschiedenen Teilkorpora werden im Folgenden die diachronischen Unterschiede in der sprachlichen Raumordnung der Campania im Hinblick auf den Verlauf der Dialektgrenzen sowie die Kompaktheit der von diesen ,umschlossenen' dialektalen Teilareale analysiert.

Im Vergleichskorpus zeigt die Schottenkarte auf der Basis des Totalkorpus (s. Karte A54) eine klare sprachgeographische Zweiteilung der Region: Einem großflächigen, kompakten Dialektgebiet im Westen, das im südlichen Teil bis in das Cilento hineinreicht, steht ein kleineres, durch eine vergleichsweise hohe sprachliche Fragmentierung gekennzeichnetes Gebiet im Osten der Region gegenüber. Die Grenze zwischen diesen beiden Arealen verläuft dabei von Reìno (815) im Sannio über Benevento (825), Montella (839) und Quaglietta (840) nach Salvitelle (858) südlich der Irpinia. Abseits davon manifestieren sich deutlich die sprachliche Abschottung von Fontegreca (810) in der nördlichen Peripherie, von Casal di Prìncipe (823) im Westen und von Casaletto Spartano (874) in der südlichen Peripherie.

Der Vergleich mit der Schottenkarte zum ALI-Korpus zeigt deutlich die diachronischen Veränderungen der dialektalen ,Bruchstellen' und der von diesen umgrenzten Areale (vgl. Karte A53 und A54). Im Westen der Region hat eine Nivellierung der sprachlichen Distanzen zwischen dem Dialektgebiet in der Metropolregion Neapel, dem Dialektgebiet im neapolitanischen Hinterland und den Dialekten im Westcilento stattgefunden, infolge derer sich die ehemals voneinander abgegrenzten Areale gegenwärtig als ein dialektaler Großraum präsentieren. Auch zwischen dem nordöstlichen und dem südlichen Cilento hat in den vergangenen fünfzig Jahren eine Aufhebung der Dialektgrenze bzw. eine ,Fusion“ der Dialektgebiete stattgefunden. Während die Dialekte in Monte San Giacomo (865) und Alfano (873) in den 1960er Jahren noch gemeinsam mit Casaletto Spartano (874) ein kompaktes, nach Norden klar abgegrenztes Dialektgebiet im Südcilento bildeten, formen sie gegenwärtig ein gemeinsames Dialektgebiet mit den Dialekten im nordöstlichen Cilento (Laurino (864), Salvitelle (858), Postiglione (857)), das allerdings im Norden bereits südlich der Irpinia (Quaglietta (840)) endet und in sich weniger 
homogen ist als der dialektale Großraum im Westen. Die ehemals kompakten Dialektgebiete im Sannio, in der apulischen Provinz Foggia und zwischen Nordcilento und Irpinia sind heute durch die Fragmentierung des östlichen Teils der Region nahezu aufgelöst. Im Hinblick auf das Gesamtbild lässt sich feststellen, dass sich die auf der Basis des ALI-Korpus und die auf der Basis des Vergleichskorpus generierte Clusterkarte in den durch die Ausprägungen der sprachlichen Distanzen generierten ikonischen Mustern stark unterscheiden. Während der globale Eindruck der sprachlichen Raumstrukturen in der Campania im Falle des ALI-Korpus von den in Blautönen gefärbten Polygonseiten bestimmt wird, die sich im Zentrum der Region aneinander reihen und so den Fokus auf die sprachlichen Distanzen zwischen nur je zwei Messpunkten bzw. Polygonen lenken, liegt der visuelle Schwerpunkt der auf der Basis des Vergleichskorpus erstellten Clusterkarte - aufgrund des Fehlens stark ausgeprägter dialektaler Distanzen innerhalb der Region - auf der Unterschiedlichkeit der sprachlichen Kohäsion innerhalb verschiedener Areale (Homogenität im Westen, Fragmentierung im Osten).

Abseits der für den globalen Raumeindruck relevanten Veränderungen der dialektalen Teilareale zeigen sich im diachronischen Vergleich auch Unterschiede hinsichtlich der Abschottung einzelner (peripherer) Dialekte von ihrem geographischen Umfeld. Castel Volturno (822) weist gegenwärtig keine sprachliche Abschottung mehr auf, sondern ist Teil des westkampanischen Dialektkontinuums. In Casal di Prìncipe (823) und Fontegreca (810) hat dagegen die umgekehrte Entwicklung stattgefunden: Sie sind 2014 sprachlich von ihrem geographischen Umfeld zwar nicht abgeschottet, aber doch sichtbar distanziert, während sie um 1960 noch Teil kompakter Dialektgebiete (Dialektgebiet in der Metropolregion Neapel bzw. Dialektgebiet in der Terra di Lavoro) waren. ${ }^{438}$ Casaletto Spartano (874) schließlich ist 2014 nicht nur (wie noch um 1960) im Vokalismus (s. Karte A8), sondern auch insgesamt von seinen geographischen ,Nachbarn' im Norden sprachlich abgeschottet und repräsentiert damit den sprachlichen ,AuBenseiter' im Süden der Campania.

Im lexikalischen Bereich zeigen sich auf der Schottenkarte ähnliche Raumstrukturen wie im Totalkorpus (s. Karte A56). Abweichungen betreffen lediglich einzelne Dialekte, die jedoch angesichts der Kleinräumigkeit des Ortsnetzes bereits den visuellen Gesamteindruck etwas verändern und daher kurz angesprochen werden sollen. Insgesamt dehnt sich der dialektale Großraum im lexikalischen Bereich sowohl im Norden als auch im Süden der Region weiter nach Osten aus als im Totalkorpus. Als östlichste Punkte umfasst er dabei im Norden Reìno (815) und im Süden Monte San Giacomo (865). Durch die geringere sprachliche Distanz zwischen Montella (839) und Melito Irpino (826) ist die Dialektgrenze zwischen dem westlichen und dem östlichen Teil der Region hier ebenfalls aufgehoben. Das sprachlich zerklüftete Gebiet im Osten der Region ist im lexikalischen Bereich auf die (östliche) Irpinia und das apulische Gebiet beschränkt. Bezüglich der Stellung der peripheren Dialekte ergeben sich im lexikalischen Bereich ebenfalls einige Änderungen gegenüber dem Ergebnis im Totalkorpus. Auf der einen Seite ist Casal di Prìncipe (823) im Bereich des Lexikons nicht von seinem geographischen Umfeld isoliert, sodass die dort heute anzutreffenden sprachlichen Besonderheiten dem phonetischen Bereich zugeordnet werden können. Auf der anderen Seite weist Sorrento (852) im Lexikon eine Sonderstellung und dementsprechend hohe Abstände zu den Dialekten in seinem geographischen Umfeld (Maiori (854), Sarno (837), Neapel (835)) auf. Der Dialekt im peripheren südlichen Punkt Casaletto Spartano (874) ist lexikalisch nicht isoliert: Er weist nur eine sehr geringe Distanz zum im Nordwesten benachbarten Dialekt von Alfano (873) auf, sodass seine Abschottung im Gesamtkorpus primär phonetisch bedingt ist.

\footnotetext{
${ }^{438}$ Im Falle Fontegrecas (810) könnte es sich dabei um den ,Rest‘ des Dialektgebietes in der Terra di Lavoro handeln. Dies kann jedoch nur im Rahmen einer qualitativen, diachronen (Mikro-)Analyse festgestellt werden.
} 
Die Unterschiede zwischen den Raumstrukturen aus den 1960er Jahren und jenen von 2014 (vgl. Karte A55 und A56) sind im lexikalischen Bereich insgesamt weniger ausgeprägt als im Totalkorpus. Dies ist insbesondere darauf zurückzuführen, dass das großflächige Dialektgebiet in der kampanischen Küstenebene, d.h. die ,Fusion' der kompakten Dialektgebiete in der Metropolregion Neapel, im neapolitanischen Hinterland und in der Terra di Lavoro bereits um 1960 sichtbar geworden ist. Bei genauer Betrachtung wird jedoch deutlich, dass sich der lexikalische Großraum in den vergangenen fünfzig Jahren durch den Wegfall verschiedener Dialektgrenzen insbesondere über Olèvano Sul Tusciano (856) deutlich ausgeweitet hat: Durch die Annäherung zwischen diesem Dialekt und dem Dialekt von Salerno (855) einerseits sowie dem Dialekt von Montella (839) andererseits erstreckt sich das lexikalisch homogene Gebiet heute im Süden bis in das Südcilento und im Osten bis in die Irpinia hinein. Im Norden ist durch lexikalische Annäherung zudem Reìno (815) integriert worden. Durch diese Entwicklungen sind es heute nur die an der östlichen Peripherie des Untersuchungsgebietes liegenden Dialekte (Ginestra degli Schiavoni (816), Bovino (819), Candela (827), Cairano (841), Quaglietta (840), Salvitelle (858)), die noch eine ausgeprägte lexikalische Individualität aufweisen.

Die Raumstrukturen, die im Bereich des Konsonantismus sichtbar werden (s. Karte A58), unterscheiden sich nur marginal von jenen im Totalkorpus. Das Gebiet um die Dialekte im nördlichen Sannio (Reìno (815) und Ginestra degli Schiavoni (816)) ist hier Teil des westkampanischen Dialektkontinuums im Westen der Region. Dieses schließt darüber hinaus auch die Provinzhauptstadt Benevento (825) ein, die im Totalkorpus auch im Westen von ihrem geographischen Umfeld abgeschottet ist. Die sprachliche Abschottung Beneventos ist also in erster Linie lexikalisch bedingt. Zudem zeigen sich kleine Unterschiede hinsichtlich der Isolation der peripheren Dialekte: Fontegreca (810) ist weniger, Casal di Prìncipe (823) stärker vom geographischen Umfeld abgeschottet als im Totalkorpus, sodass sich dessen ,Außenseiterposition “ vor allem durch Besonderheiten im Konsonantismus erklärt. Im diachronischen Vergleich der Raumstrukturen (vgl. Karte A57 und A58) ist die bereits bei den Totalkorpora beobachtete ,Fusion' der ehemaligen Dialektgebiete in der Terra di Lavoro, in der Metropolregion Neapel und im neapolitanischen Hinterland zu einem großflächigen - und um das Westcilento erweiterten - Dialektkontinuum gut zu beobachten. Auch die starke Fragmentierung des östlichen Teils der Region (Irpinia, Apulien und östliches Cilento) tritt deutlich hervor.

Im Vokalismus zeigen sich auch zum gegenwärtigen Zeitpunkt Raumstrukturen, die deutliche Unterschiede zu jenen im Totalkorpus und in den übrigen Teilkorpora aufweisen (s. Karte A60). Die gesamte Region präsentiert sich hier als kompaktes Dialektgebiet, in welches nur einzelne periphere Dialekte nicht integriert sind. Als solche erweisen sich die Punkte Castel Volturno (822) im Westen, Reìno (815) im Norden, Bovino (819), Candela (827) und Cairano (841) im Osten sowie Casaletto Spartano (874) im Süden. Der diachronische Vergleich der Raumstrukturen im Vokalismus (vgl. Karte A59 und Karte A60) zeigt, dass die gegenwärtig aufscheinende Kompaktheit des Dialektgebietes das Ergebnis dialektaler Nivellierungsprozesse ist, die sich schon vor fünfzig Jahren im Vokalismus abzeichneten. Während in den 1960er Jahren besonders der östliche Teil der Region im Vokalismus eine auffällige Kompaktheit aufwies, sind heute auch die dialektalen Distanzen in der kampanischen Küstenebene nivelliert. Die stärkste diachronische Entwicklung zeigt sich im Punkt Gioia Sannìtica (814) in der nördlichen Peripherie der Region. Dieser hat seinen besonderen Vokalismus, durch den er ehemals gemeinsam mit dem benachbarten Reìno (815) ein sprachlich stark abgeschottetes dialektales Mikro-Areal bildete, in den vergangenen fünfzig Jahren aufgegeben und ist heute in den dialektalen Großraum integriert. Im Gegensatz dazu haben die übrigen Dialekte, die um 1960 eine Sonderstellung im Bereich des Vokalismus aufwiesen - Castel Volturno (822), Reìno (815), 
Bovino (819) und Casaletto Spartano (874) - diese über die Zeit bewahrt, sodass - vor dem Hintergrund der in den übrigen Gebieten weiter vorangeschrittenen sprachlichen Annäherung - ihre Abschottung vom dialektalen Großraum gegenwärtig besonders deutlich aufscheint. Eine Tendenz zur stärkeren Abgrenzung im Hinblick auf den Vokalismus lässt sich in den peripheren östlichen Punkten Cairano (841) und Candela (827) beobachten, die in den 1960er Jahren noch Teil des kompakten Dialektgebietes im Osten der Region waren.

Insgesamt bleibt festzuhalten, dass die Nivellierung der sprachlichen Distanzen, die sich in den vergangenen fünfzig Jahren im kampanischen Dialektgebiet vollzogen hat, in den statistisch dominanten Teilkorpora (Lexikon und Konsonantismus) zur Ablösung der kleinräumigen, , polyzentrischen' Struktur durch ein großräumiges Ordnungsmuster des Typs ,Zentrum - Peripherie' geführt hat. Im Vokalismus hat die bereits in den 1960er Jahren bestehende hohe Kompaktheit des Dialektgebietes durch die Nivellierung der dialektalen Distanzen im Westen der Region deutlich zugenommen, sodass lediglich die bereits um 1960 sprachlich speziellen Dialekte (bis auf Gioia Sannìtica (814)) außerhalb des dialektalen Großraums verbleiben.

\subsubsection{Dialektkerne und sprachliche ,Einzelgänger'}

\section{S. Kartenteil, Karten A61 - A68}

Die in ihren Grundzügen bereits dargestellte diachronische Entwicklung der sprachlichen Raumordnung in der Campania soll im Folgenden im Hinblick auf die Kohäsion benachbarter Dialekte, d.h. auf Unterschiede im Bereich der Dialektkerne und sprachlichen ,Einzelgänger“ weiter analysiert werden. Im Totalkorpus (s. Karte A62) zeigt sich ein Gebiet mit hohen bis sehr hohen Maximalwerten (Wertklassen [5] und [6]), das die Metropolregion Neapel umfasst und sich im Süden über Olèvano Sul Tusciano (856) bis nach Capaccio (863) im Westcilento ausdehnt. Zentren dieses dialektalen Kerngebietes sind Salerno (855, MAX) und Maiori (854, MAX), während Sorrento (852) und Pròcida (834, beide Wertklasse [4]) etwas schlechter integriert sind als die übrigen Dialekte. Geographisch vom dialektalen Kern getrennt sind die ebenfalls hohe Maximalwerte aufweisenden Dialekte aus Castel Volturno (823) und Teano (813) in der Terra di Lavoro. Dem Dialektkern gegenüber steht ein Gebiet mit sehr niedrigen bis niedrigen Maximalwerten (Wertklassen [1] und [2]), das alle Dialekte im Sannio, Cairano (841) in der Irpinia und die Dialekte im westlichen Apulien (MIN in Bovino (819)) umfasst. ,Einzelgänger' sind darüber hinaus die peripheren Dialekte Fontegreca (810) im Norden, Casaletto Spartano (874) im Süden und Casal di Prìncipe (823) im Westen der Region.

Der diachronische Vergleich zwischen den kartographisch umgelegten Kennwertsynopsen der Maxima (vgl. Karte A61 und A62) erbringt deutliche Unterschiede, die die bereits konstatierten diachronischen Entwicklungen in der sprachlichen Raumordnung vor allem im Westen der Region widerspiegeln. Das primäre dialektale Kerngebiet befindet sich zwar nach wie vor im Bereich der kampanischen Küstenebene, ist jedoch im Vergleich zu seiner ehemaligen Lokalisierung nach Süden verschoben: Während in den 1960er Jahren Fontegreca (810) den nördlichsten und Salerno (855) den südlichsten Punkt des kompakten Gebietes darstellten, erstreckt sich das Gebiet heute von Roccaraìnola (836) im Norden bis nach Capaccio (863) im Süden. Entsprechend dieser Entwicklung liegen die zentralen Punkte des Dialektkerns nicht mehr wie noch um 1960 an der Küste des Golfs von Neapel (MAX in Neapel (835), Sorrento (852) und Salerno (855)), sondern ausschließlich an der Küste des Golfs von Salerno (MAX in Maiori (854) und Salerno (855)). Die ,Einzelgänger', d.h. die Dialekte mit sehr niedrigen bis 
niedrigen Maximalwerten (Wertklassen [1] und [2]) sind gegenwärtig nicht mehr diskontinuierlich in der Region verteilt, sondern liegen - abgesehen von den sprachlich speziellen Dialekten im Westen, Norden und Süden (s.o.) - in einem kompakten Gebiet im Nordosten (Sannio, Irpinia, Provinz Foggia), wo sich bereits in den 1960er Jahren relativ niedrige Maximalwerte finden ließen. Die dialektale Kohäsion des Südcilento (Monte San Giacomo (865), Alfano (873)) ist gegenüber jener in der Metropolregion Neapel in den vergangenen fünfzig Jahren zurückgegangen: Beide Dialekte weisen heute ähnlich niedrige Maximalwerte auf wie die übrigen Dialekte im Osten der Region. Die ehemaligen ,Einzelgänger' im Westen der Region (Castel Volturno (822), Rocca d'Evandro (809), Gioia Sannitica (814), Limàtola (824), Roccaraìnola (836), Avellino (838), Olèvano Sul Tusciano (856) und Capaccio (863)) sind heute hingegen alle deutlich stärker in ihr Umfeld integriert als in den 1960er Jahren. Der in den vergangenen fünfzig Jahren in der Campania abgelaufene Dialektausgleich wird also auch in dieser Perspektive deutlich.

Der diachronische Vergleich der statistischen Kennwerte der Maxima zeigt einen leichten, aber sichtbaren Anstieg des Durchschnittswertes (s. Tab. 31). ${ }^{439}$ Insgesamt ist also in den vergangenen fünfzig Jahren zwischen den kampanischen Dialekten eine deutliche strukturelle Annäherung zu beobachten, die sich jedoch im Bereich der Raumstrukturen nur dort manifestiert, wo sie zwischen benachbarten - und somit bereits in den 1960er Jahren hohe Maximalwerte aufweisenden - Dialekten bzw. Dialektgebieten stattgefunden hat, d.h. im westlichen Teil der Region. Auch wenn im (Nord-)Osten teilweise eine Annäherung einzelner Dialekte an den dialektalen Großraum im Westen stattgefunden hat, ${ }^{440}$ gehören diese gegenwärtig (noch) nicht zum dialektalen Kerngebiet.

Auf lexikalischer Ebene zeigt das kampanische Dialektgebiet eine ähnliche Kompaktheit wie im Totalkorpus (s. Tab. 31). Auch die Raumstrukturen (s. Karte A64) weisen nur marginale Unterschiede zu jenen im Totalkorpus auf. Die auffälligste Abweichung findet sich in Casal di Prìncipe (823), das im Lexikon in das dialektale Kerngebiet in der kampanischen Küstenebene integriert ist, sodass seine Sonderstellung (wie bereits in den vorigen Analyseteilen deutlich geworden ist) sich auf den phonetischen (bzw. konsonantischen) Bereich beschränkt. Im Falle Casaletto Spartanos (874) ist die Integration in das geographische Umfeld im lexikalischen Bereich besser, in Quaglietta (840) hingegen schlechter als im Gesamtkorpus. Beim diachronischen Vergleich der Maxima im Bereich des Lexikons zeigt sich (wie auch schon im Totalkorpus) ein leicht erhöhter Durchschnittswert (s. Tab. 31). Auch hier manifestiert sich also

\footnotetext{
${ }^{439}$ Auch im diachronischen Vergleich ist die heuristische Trennung zwischen dem Vergleich eines (Teil-)Korpus von 2014 und dem entsprechenden (Teil-)Korpus aus den 1960er Jahren in Bezug auf ihre statistischen Kennwerte (MIN, MW, MAX) und dem Vergleich der Verhältnisse bzw. der Raumstrukturen innerhalb der (unterschiedlich ,alten`) Teilkorpora zu berücksichtigen. Wenn also z.B. die Synopse der Maximalwerte des Totalkorpus von 2014 einen höheren Durchschnittswert (MW) aufweist als im Totalkorpus von 1960, so ist die Integration der Dialekte im Vokalismus insgesamt deutlich angestiegen. Von dieser grundsätzlichen Entwicklung zu trennen ist die Veränderung der Stellung eines Dialekts innerhalb der gesamten Dialektgruppe (konkret: die Veränderung der Position eines Messpunktes auf der Skala, d.h. die Wertklasse, in der er zu liegen kommt). Bei einigen Messpunkten ist diese drastisch, bei anderen weniger stark und bei wiederum anderen nicht zu beobachten. Aus der Gesamtschau der Unterschiede in der Stellung der Dialekte ergeben sich die im diachronischen Vergleich zu beobachtenden Veränderungen der sprachlichen Raumstrukturen. Auch wenn heute also insgesamt eine stärkere Integration der Dialekte besteht als in den 1960er Jahren, so existieren doch innerhalb der heutigen Dialektlandschaft ebenfalls Dialekte, die eine Sonderstellung bzw. eine Abschottung von den übrigen aufweisen. Diese Abschottung ist (numerisch betrachtet) dann jedoch im Verhältnis zu der Abschottung anderer (oder derselben) Dialekte in den 1960er Jahren meist von geringerem Ausmaß.

${ }^{440}$ Beispielhaft lässt sich dies anhand der Ähnlichkeitswerte des Ortspaares Ginestra degli Schiavoni (816) im Sannio und Capaccio (863) im Cilento illustrieren, deren sprachliche Ähnlichkeit von 42,18\% (Wertklasse [3]) in den 1960er Jahren auf 60,35\% (Wertklasse [5]) im Jahr 2014 gestiegen ist.
} 
die in den vergangenen fünfzig Jahren zu beobachtende sprachliche Annäherung der kampanischen Dialekte aneinander. Da das großflächige dialektale Kerngebiet im Westen der Region im Lexikon bereits in den 1960er Jahren vorhanden ist (s. Karte A63), sind die diachronischen Unterschiede in der Verortung der dialektalen Kerngebiete und der sprachlichen ,Einzelgänger im lexikalischen Bereich geringer als im Totalkorpus. Auch die Tendenz zur sprachlichen Fragmentierung im östlichen Teil der Region wird in den 1960er Jahren bereits deutlich sichtbar. Tendenzen zur sprachlichen ,Abkopplung' vom geographischen Umfeld finden sich in der Terra di Lavoro (Fontegreca (810) und - in schwächerer Form - Gioia Sannìtica (814)), aber auch in der Metropolregion Neapel (Sorrento (852)) sowie im Cilento (Laurino (864), vgl. Karte A63 und Karte A64). Die umgekehrte Entwicklung - also eine sprachliche Annäherung an das geographische Umfeld - findet sich einerseits in der Peripherie der Metropolregion Neapel (Castel Volturno (822), Anacapri (851)) und andererseits im Gebiet der östlichen und südlichen ,Erweiterung ' des westkampanischen Dialektgebietes (Montella (839), Pòllica (872)). In diesen Punkten macht sich also die Bildung des dialektalen Großraums im Westen der Campania im lexikalischen Bereich besonders bemerkbar.

Im Konsonantismus zeigt sich ein höherer durchschnittlicher Maximalwert und damit eine insgesamt bessere Integration der Dialekte in ihr geographisches Umfeld als im Lexikon (s. Tab. 31). Hinsichtlich der bei der räumlichen Umlegung der Werte sichtbaren Raumstrukturen (s. Karte A66) zeigen sich nur wenige Unterschiede zu jenen im Totalkorpus, unter denen einige jedoch besonders hervortreten. Am auffälligsten sind die Differenzen im Bereich des dialektalen Zentrums des westkampanischen Dialektgebietes (vgl. Karte A62 und A66): Während dieses im Totalkorpus von Salerno (855) und Maiori (854) gebildet wird, liegt es im Konsonantismus weiter nördlich in Roccaraìnola (836) und Sarno (837). Eine weitere Abweichung betrifft die Stellung Neapels (835), das im Konsonantismus schlechter in den westlichen dialektalen Großraum integriert ist als im Totalkorpus. In der Terra di Lavoro ist Rocca d'Evandro (809) im Konsonantismus - ebenso wie sein ,Nachbar‘ Fontegreca (810) - sprachlicher ,Einzelgänger‘. Die sprachliche Sonderstellung Casal di Prìncipes (823) ist im Konsonantismus am ausgeprägtesten: Es läuft hier Bovino (819) als Punkt mit dem niedrigsten Maximalwert im gesamten Untersuchungsgebiet den Rang ab.

Hinsichtlich der diachronischen Entwicklung ist zu beobachten, dass in den vergangenen fünfzig Jahren die sprachliche Kompaktheit der Campania im Konsonantismus deutlicher zugenommen hat als im Lexikon (s. Tab. 31). Die Annäherung der (west-)kampanischen Dialekte aneinander hat sich also in diesem Zeitraum insbesondere im konsonantischen Bereich vollzogen. Der diachronische Vergleich der Raumstrukturen zeigt hier deutliche Veränderungen der dialektalen Kerngebiete (vgl. Karte A65 und A66): Der ehemalige Dialektkern im Südcilento, wo in den 1960er Jahren noch die höchsten Maxima zu finden waren, ist - ähnlich wie das kleine kohäsive Gebiet in der Irpinia - fünfzig Jahre später von der dialektometrischen Karte ,verschwunden', sodass die Maxima nun wie in den übrigen Teilkorpora allein in der kampanischen Küstenebene liegen. Dort werden die Bildung des dialektalen Großraumgebietes und dessen Erweiterung in Richtung des Cilento in einem Anstieg der sprachlichen Integration vieler Dialekte - besonders deutlich in Gioia Sannìtica (814), Castel Volturno (822) und Roccaraìnola (836) - sichtbar.

Im vokalischen Teilkorpus finden sich auch im Vergleichskorpus der höchste Durchschnittswert und die größten Spannweite der Maximalwerte (s. Tab. 31). Ersteres verdeutlicht, dass auch heute der Vokalismus der Bereich ist, in dem das kampanische Dialektgebiet die größte Kompaktheit aufweist. Die hohe Spannweite ergibt sich durch einzelne ,Ausreißer' im niedrigen Wertebereich. Bei der räumlichen Verteilung der Dialektkerne und der sprachlichen 
,Einzelgänger` im Vokalismus (s. Karte A68) fällt zunächst auf, das dialektale Kerngebiet deutlich großflächiger ist als in den übrigen (Teil-)Korpora, indem es neben den Dialekten im westlichen Großraum (MAX in Barano d'Ischia (833), Salerno (855) und Olèvano Sul Tusciano (856)) auch einen Großteil der Dialekte im Cilento und in der Irpinia beinhaltet. Insgesamt weisen 15 (also ca. 43\%) der Dialekte Maximalwerte in den beiden höchsten Wertklassen auf. Sprachliche ,Einzelgänger" (Wertklassen [1] und [2]) finden sich hingegen nur vereinzelt in den peripheren Zonen der Region (Casaletto Spartano (874, MIN) im Süden, Reìno (815, MIN) im Norden und Bovino (819) sowie Candela (827) im Osten).

Der diachronische Vergleich der räumlichen Verteilung der Maximalwerte zeigt, dass das dialektale Kerngebiet im Vokalismus heute deutlich weiter ausgreift als in den 1960er Jahren (vgl. Karte A67 und Karte A68): Die vor allem im neapolitanischen Hinterland in Form von schwächer integrierten Dialekten bestehenden ,Lücken' zwischen den ehemals noch disparaten dialektalen Kerngebieten haben sich geschlossen, während sich der Dialektkern im Cilento nach Norden in die Irpinia hinein ausgedehnt hat. Entsprechend der Ausdehnung nach Osten und Südosten hat sich auch der dialektale ,Schwerpunkt' nach Salerno (855) und Olèvano Sul Tusciano (856) verschoben (ein weiteres Maximum weist Barano d'Ischia (833) auf, was die starke Kompaktheit des Gebietes bestätigt). Unter den sprachlichen ,Einzelgängern“ finden sich im Vokalismus im Süden und Osten dieselben Dialekte wie in den 1960er Jahren (Casaletto Spartano (874), Bovino (819) und Candela (827)). Daneben ist Reìno (815) in der nördlichen Peripherie durch die Bewahrung seiner vokalischen Besonderheiten in den letzten fünfzig Jahren hier ebenfalls zum ,Einzelgänger' geworden. Im numerischen Bereich zeigt sich gegenwärtig ein gegenüber den 1960er Jahren kaum veränderter durchschnittlicher Maximalwert. Die bereits in den 1960er Jahren starke Kohäsion des kampanischen Dialektgebietes ist also diachronisch stabil. In der deutlich verringerten Spannweite, die insbesondere durch ein höheres Minimum zustande kommt, zeigt sich eine Verbesserung der Integration der sprachlichen ,Ausreißer' in das großflächige dialektale Kerngebiet.

\begin{tabular}{|c|c|c|c|c|c|c|c|c|c|c|}
\hline \multirow{2}{*}{$\begin{array}{c}\text { Kenn- } \\
\text { wert }\end{array}$} & \multicolumn{2}{|c|}{ TOT } & \multicolumn{2}{c|}{ LEX } & \multicolumn{2}{c|}{ PHON } & \multicolumn{2}{c|}{ KONS } & \multicolumn{2}{c|}{ VOK } \\
\cline { 2 - 11 } & 1960 & 2014 & 1960 & 2014 & 1960 & 2014 & 1960 & 2014 & 1960 & 2014 \\
\hline MIN & 57,45 & 60,35 & 60,00 & 63,39 & 53,53 & 61,85 & 55,81 & 64,00 & 43,90 & 54,17 \\
\hline MW & 67,42 & 72,85 & 66,10 & 71,79 & 69,92 & 75,61 & 69,52 & 77,30 & 78,95 & 77,92 \\
\hline MAX & 75,64 & 81,40 & 73,33 & 77,68 & 81,18 & 84,97 & 79,84 & 88,00 & 92,68 & 87,50 \\
\hline
\end{tabular}

Tabelle 31. Statistische Kennwerte der Synopse der Maxima im ALI-Korpus (1960) und im Vergleichskorpus (2014). Messmoment jeweils $\mathrm{RIW}_{j k}$.

Der deutliche Anstieg der durchschnittlichen Maximalwerte im Totalkorpus zeigt, dass in der Campania in den vergangenen fünfzig Jahren eine strukturelle Annäherung der verschiedenen Ortsdialekte aneinander stattgefunden hat. Diese manifestiert sich auf der räumlichen Ebene vor allem im Konsonantismus und zeitigt Veränderungen im Bereich der Raumstrukturen. Während im Westen und Südwesten der Region die Annäherung benachbarter Dialekte im Konsonantismus zur Bildung eines großflächigen dialektalen Kerngebietes führt, weisen die Dialekte in den östlichen Gebieten einen deutlich geringeren Zusammenhalt auf. Die Entwicklung ist hier nicht durch ein Zusammenwachsen der kompakten Dialektgebiete, sondern durch die Annäherung einzelner Dialekte an den dialektalen Großraum im Westen der Region gekennzeichnet. Da im lexikalischen Bereich die Bildung des heutigen dialektalen Kerngebietes in der kampanischen Küstenebene bereits in den 1960er Jahren abgeschlossen war, manifestiert 
sich die interdialektale Annäherung in der Campania hier nicht in räumlich sichtbarer Form. Im Vokalismus ist die diachronische Entwicklung insbesondere durch die weitere Ausdehnung des bereits in den 1960er Jahren kompakten Dialektgebietes gekennzeichnet.

\subsubsection{Sprachausgleichstendenzen}

\section{S. Kartenteil, Karten A69 - A76}

Um einen Einblick in die gegenwärtig in der Campania bestehende Bereitschaft zum Sprachausgleich und die Unterschiede zu den Verhältnissen in den 1960er Jahren zu erhalten, werden im Folgenden die Schiefewerte sowie die in der sprachlichen Umlegung aufscheinenden Raumstrukturen separat und im Vergleich zu jenen im ALI-Korpus analysiert.

Bei der Betrachtung der räumlichen Umlegung der Synopse der Schiefewerte im Totalkorpus (s. Karte A70) fällt zunächst auf, dass sich die Bereitschaft zur sprachlichen Angleichung in einem großflächigen Gebiet im Norden und Westen - d.h. in dem Bereich, in dem in den vergangenen Jahrzehnten die Bildung des großräumigen Dialektareals stattgefunden hat gegenwärtig auf einem mittleren Niveau, eingependelt' hat (20 Messpunkte liegen in Wertklasse [3]). Eine relativ starke Tendenz zum Sprachausgleich weisen drei Dialekte im Nordosten der Region (Reìno (815), Melito Irpino (826, MIN) und Candela (827), alle Wertklasse [1]) sowie der insulare Dialekt aus Pròcida (834, Wertklasse [2]) auf. Dabei handelt es sich um die Dialekte, die sich in den vergangenen fünfzig Jahren sprachlich gegenüber dem dialektalen Großraum im Westen der Region geöffnet haben. Im südlichen Teil der Region findet sich hingegen ein Areal, das gegenüber sprachlichen Angleichungsprozessen verhältnismäßig resistent ist und bis auf Capaccio (863), Pòllica (872) und Casaletto Spartano (874) alle Dialekte im Cilento beinhaltet. Es stellt damit die letzte ,Bastion“ gegen die im kampanischen Dialektgebiet vorherrschenden dialektalen Nivellierungstendenzen dar.

Der gegenwärtig im Vergleich zum ALI-Korpus deutlich niedrigere durchschnittliche Schiefewert (s. Tab. 32) zeigt, dass in der Campania heute insgesamt eine deutlich höhere Bereitschaft zum Sprachausgleich besteht als noch in den 1960er Jahren. Dabei sind es heute andere Dialekte bzw. Dialektgebiete, die eine besondere Tendenz zur sprachlichen Angleichung bzw. eine Abschirmung gegenüber Sprachausgleichsprozessen aufweisen. Die Zonen entlang der ehemaligen Dialektgrenze zwischen dem Dialektgebiet in der Metropolregion Neapel und dem Dialektgebiet im neapolitanischen Hinterland, die in den 1960er Jahren noch einen starke Tendenz zum Sprachausgleich zeigten (s. Karte A69), sind entsprechend der Veränderungen in der sprachlichen Raumordnung gegenwärtig größtenteils auf demselben Stand wie die übrigen Dialekte im Westen der Region. Im oberen Wertebereich ist zu beobachten, dass die beiden peripheren Dialekte aus Pròcida (834) und Casaletto Spartano (874), die in den 1960er Jahren noch eine starke Abschirmung gegenüber dialektalen Ausgleichstendenzen zeigten, heute in die sprachliche Nivellierungsdynamik eingebunden sind.

Im Lexikon ist die durchschnittliche Bereitschaft zum Sprachausgleich insgesamt stärker ausgeprägt als im Totalkorpus (vgl. Tab. 32). Auch die räumliche Verteilung der Dialekte mit hohen und niedrigen Schiefewerten (s. Karte A72) weicht deutlich von jener im Totalkorpus ab. Die Dialekte, die verhältnismäßig starke Tendenzen zur sprachlichen Angleichung aufweisen (Wertklassen [1] und [2]), liegen im lexikalischen Bereich vor allem entlang der Grenze zwischen dem westlichen dialektalen Großraum und den sprachlich schlechter integrierten Gebieten der östlichen Peripherie (vgl. Kap. 5.5.2). Neben dieser Zone, die sich von Melito Irpino (826) in der Irpinia bis Pòllica (872) im Cilento erstreckt, weisen einzelne Dialekte im Westen 
des Großraums - Castel Volturno (822) in der Terra di Lavoro sowie die insularen Dialekte in Pròcida (834) und Anacapri (851) - eine verhältnismäßig starke Bereitschaft zur sprachlichen Angleichung auf. Gut gegen die sprachliche Nivellierungsdynamik abgeschirmte Zonen (Wertklassen [5] und [6]) finden sich einerseits in der Terra di Lavoro (Rocca d'Evandro (809), Fontegreca (810), Gioia Sannìtica (814)) und andererseits in der Region Apulien (Bovino (819), Candela (827)). Daneben weisen einzelne Dialekte in der Irpinia (Quaglietta (840)), im Cilento (Alfano (873, MAX)) sowie an der Amalfiküste (Maiori (854)) eine starke Resistenz gegenüber sprachlichen Ausgleichstendenzen auf. Quaglietta (840) und Alfano (873) stellen dabei ,Inseln“ inmitten eines durch (starke) Bereitschaft zum Sprachausgleich gekennzeichneten Gebietes dar.

Die Unterschiede, die das lexikalische Teilkorpus im Bereich der Schiefewerte zum Totalkorpus aufweist, werden in einigen Dialekten, insbesondere im Cilento und in der Region Apulien besonders deutlich. Im Cilento und am Übergang zur Irpinia weist ein Großteil der Dialekte im lexikalischen Bereich deutlich niedrigere Schiefewerte und damit stärkere Sprachausgleichstendenzen auf als im Totalkorpus, sodass sich der Status des Cilento als ,Bastion“ gegenüber den von Norden kommenden sprachlichen Nivellierungstendenzen auf den phonetischen Bereich beschränkt. In der Region Apulien zeigen sich hingegen umgekehrte Verhältnisse. Hier weisen beide Dialekte eine verhältnismäßig hohe Resistenz gegenüber einer sprachlichen Angleichung an das Dialektgebiet im Westen auf, was im Falle Candelas (827) der hohen Bereitschaft zur sprachlichen Angleichung im Totalkorpus (s. Karte A70) entgegenläuft, welche somit auf den phonetischen Bereich zurückgeführt werden kann.

Insgesamt ist die Bereitschaft zum Sprachausgleich in der Region Kampanien im Bereich des Lexikons gegenwärtig deutlich höher als noch in den 1960er Jahren (s. Tab. 32). Hinsichtlich der Dialekte, die starke Sprachausgleichstendenzen aufweisen, sind die Profile der Schiefen des Vergleichskorpus und des ALI-Korpus weitestgehend komplementär (vgl. Karte A71 und A72): Während das Gebiet mit starken dialektalen Nivellierungstendenzen in den 1960er Jahren fast die gesamte kampanische Küstenebene umfasst und sich bis in die Irpinia hinein ausdehnt, erstreckt sich das entsprechende Areal gegenwärtig entlang der östlichen Grenze dieser Zone, wobei Montella (839) in der Irpinia die ,Schnittstelle ${ }^{6}$ zwischen beiden Gebieten darstellt. Im lexikalischen Bereich lässt sich also das räumliche Fortschreiten der Bereitschaft zur sprachlichen Angleichung von Westen nach Osten besonders gut beobachten. Im oberen Wertebereich wird deutlich, dass einige Dialekte, die in den 1960er Jahren im Lexikon hohe bis sehr hohe Schiefewerte und damit eine deutliche Resistenz gegenüber sprachlichen Ausgleichsprozessen aufwiesen, diese bis heute bewahrt haben. Besonders deutlich zeigt sich die ehemalige Resistenz gegenüber sprachlicher Angleichung heute noch in Rocca d'Evandro (809) und Fontegreca (810) in der Terra di Lavoro, in Quaglietta (840) in der Irpinia und in Alfano (873) im Südcilento.

Die Verhältnisse im Konsonantismus sind geprägt durch eine geringere durchschnittliche Bereitschaft der Dialekte zur sprachlichen Angleichung als im Lexikon (s. Tab. 32). Die bei der räumlichen Umlegung der Schiefewerte sichtbaren Strukturen (vgl. Karte A74) zeigen nur leichte Abweichungen von jenen im Totalkorpus. Die Dialekte mit den niedrigsten Schiefewerten und damit den stärksten Sprachausgleichstendenzen finden sich auch hier im Nordosten des kampanischen Dialektgebietes, wobei sich Candela (827, MIN) als einziger Dialekt in Wertklasse [1] von Melito Irpino (826) und Benevento (825, beide Wertklasse [2]) absetzt. Der insulare Dialekt von Pròcida (834) zeigt im Konsonantismus die gleiche Tendenz zum Sprachausgleich (Wertklasse [3]) wie die übrigen Dialekte im Westen der Region. Wie im Totalkorpus manifestiert sich im Konsonantismus das gegenüber sprachlicher Angleichung resistente Gebiet 
im Süden der Region; maximale Resistenz weist hier jedoch nicht Quaglietta (840) in der Irpinia, sondern Alfano (873) im Südcilento auf. In der Region Apulien zeigt im konsonantischen Bereich auch Bovino (819) eine gute Abschirmung gegenüber sprachlichen Ausgleichsprozessen (Wertklasse [6]), während es im Totalkorpus Teil des von der Nivellierungsdynamik erfassten Gebietes ist (Wertklasse [3]).

Im diachronischen Vergleich zeigt sich die erhöhte Bereitschaft zur sprachlichen Angleichung in der Region Kampanien im Konsonantismus in einem heute gegenüber 1960 deutlich geringeren mittleren Schiefewert (s. Tab. 32). Im Hinblick auf die geographische Verteilung der Dialekte mit niedrigen bzw. hohen Schiefewerten fällt zunächst auf, dass sich - ähnlich wie im Totalkorpus - die Bereitschaft zum Sprachausgleich im Zentrum der Region, das in den 1960er Jahren eine Zone mit starken Sprachausgleichstendenzen konstituierte, gegenwärtig auf einem mittleren Niveau ,eingependelt' hat (vgl. Karte A73 und A74). Da die Tendenz zum Sprachausgleich in der Metropolregion Neapel verhältnismäßig stabil geblieben ist, manifestiert sich im Westen der Region heute ein großflächiges, im Hinblick auf die sprachliche Nivellierungsdynamik homogenes Gebiet. Die größte Veränderung im Hinblick auf die Bereitschaft zum Sprachausgleich zeigt Candela (827, MIN) in der Region Apulien, das gegenwärtig eine hohe Bereitschaft zur sprachlichen Angleichung zeigt, während es vor fünfzig Jahren (wie das benachbarte Bovino (819)) noch eine ausgeprägte sprachliche Resistenz zeigte. Die sprachliche ,Einsiedelei' Candelas ist also zumindest im Konsonantismus in den letzten fünfzig Jahren einer Öffnung gegenüber den von Westen kommenden Nivellierungstendenzen gewichen. In eine ähnliche Richtung geht die Entwicklung in Montella (839) in der Irpinia, das heute im Hinblick auf die sprachliche Durchmischung auf dem gleichen Stand ist wie der Großteil der übrigen Dialekte, während es in den 1960er Jahren noch durch eine starke sprachliche Abschirmung gekennzeichnet war. Im Westen der Region haben schließlich die Dialekte in Barano d'Ischia (833) und Rocca d'Evandro (809) ihren Widerstand gegenüber sprachlichen Nivellierungsprozessen aufgegeben. Das gegenüber sprachlicher Durchmischung resistente Gebiet im Cilento manifestiert sich gegenwärtig in stärkerem Maße (Wertklasse [6] statt [5]) und erstreckt sich weiter nach Norden (bis Quaglietta (840)) als in den 1960er Jahren. Casaletto Spartano (874) ist jedoch gegenwärtig nicht mehr Teil dieses Gebietes, sondern zeigt Tendenzen zur sprachlichen Angleichung.

Im Bereich des Vokalismus ist die Bereitschaft zum Sprachausgleich in der Campania gegenwärtig am stärksten (s. Tab. 32). Bei der räumlichen Umlegung der Schiefewerte (s. Karte A76) zeigen sich deutliche Unterschiede zum Totalkorpus. Zunächst fällt auf, dass im Vokalismus deutlich mehr Dialekte von starken Sprachausgleichstendenzen (Wertklassen [1] und [2]) gekennzeichnet sind. Bis auf Benevento (825, MIN) finden diese sich alle in Randgebieten (Castel Volturno (822) und Rocca d'Evandro (809) im Nordwesten, Gioia Sannìtica (814) im Norden, Bovino (819), Cairano (841), Salvitelle (858) und Monte San Giacomo (865) im Osten und Capaccio (863) und Salerno (855) im Südwesten), was der für den Vokalismus typischen Zweiteilung in einen zentralen Bereich und dessen Peripherie entspricht. Die gegenüber der sprachlichen Nivellierungsdynamik abgeschirmten Dialekte, die im Totalkorpus ein kompaktes Gebiet im Cilento formen, zeigen im Vokalismus entweder nur eine sehr schwache Resistenz oder deutliche Sprachausgleichstendenzen (Salvitelle (858), Monte San Giacomo (865)). Der Dialekt des peripheren südlichen Casaletto Spartano (874, MAX), der im Totalkorpus (schwache) Sprachausgleichstendenzen aufweist, ist dagegen im Vokalismus (als einziger Dialekt in Wertklasse [6]) gut gegenüber den sprachlichen Angleichungsprozessen in der Campania abgeschirmt. Als im Vokalismus ebenfalls resistent erweist sich auch Pròcida (834, Wertklasse [5]), das hier andere Wege geht als im Lexikon und im Konsonantismus, wo es verhältnismäßig 
starke bzw. durchschnittliche Tendenzen zur sprachlichen Angleichung zeigt (vgl. Karte A72 und A74).

Die verhältnismäßig starke Bereitschaft zum Sprachausgleich, durch die die kampanischen Dialekte im Vokalismus bereits in den 1960er Jahren gekennzeichnet waren, hat sich in den vergangenen fünfzig Jahren noch einmal erhöht (vgl. Tab. 32). Gleichzeitig sind die Abweichungen im oberen Wertebereich, d.h. die besondere Resistenz einzelner Dialekte geringer geworden. Die bei der räumlichen Umlegung der Schiefewerte zu Tage tretenden Raummuster zeigen deutliche diachronische Unterschiede (vgl. Karte A75 und A76). In dem sich vom Westcilento bis in die Irpinia erstreckenden Gebiet, das in den 1960er Jahren die meisten Dialekte mit relativ starker Neigung zur sprachlichen Angleichung umfasste, haben sich die Sprachausgleichstendenzen gegenwärtig fast überall auf einem mittleren Niveau stabilisiert (Ausnahmen sind Capaccio (863) und Cairano (841), die nach wie vor starke Tendenzen zur sprachlichen Angleichung aufweisen). In den ehemals eine verhältnismäßig hohe Bereitschaft zum Sprachausgleich zeigenden Dialekten in der Terra di Lavoro (Rocca d'Evandro (809) und Castel Volturno (822)) macht sich diese hingegen auch heute noch bemerkbar. Am auffälligsten sind die diachronischen Unterschiede im Hinblick auf die Bereitschaft zum Sprachausgleich in den peripheren Gebieten im Norden und Süden der Region. Der Dialekt des peripheren nördlichen Gioia Sannìtica (814) hat seine ehemals starke Resistenz gegenüber sprachlichen Ausgleichsprozessen aufgegeben und zeigt - nach seiner Integration in den dialektalen Großraum im Westen (vgl. Kap. 5.5.2) - heute stattdessen eine starke Bereitschaft zur (weiteren) sprachlichen Angleichung. Die umgekehrte Entwicklung hat im Dialekt des peripheren südlichen Casaletto Spartano (874) stattgefunden, der um 1960 noch von relativ hohen Sprachausgleichstendenzen gekennzeichnet war, heute jedoch als einziger Dialekt eine starke Resistenz gegenüber der sprachlichen Nivellierungsdynamik aufweist.

Im Hinblick auf die in der Campania gegenwärtig bestehende Bereitschaft zum Sprachausgleich und ihre diachronische Entwicklung lässt sich Folgendes festhalten. Im Westen der Region haben sich die in den 1960er Jahren noch verhältnismäßig starken sprachlichen Ausgleichstendenzen gegenwärtig auf einem mittleren Niveau ,eingependelt ${ }^{6}$, sodass ein großer Teil der Region hinsichtlich der Bereitschaft zur sprachlichen Durchmischung heute homogen ist. Die Zonen mit der stärksten Neigung zum Sprachausgleich liegen heute - insbesondere im Lexikon - an der östlichen Grenze dieses großflächigen, homogenen Areals, sodass das räumliche Fortschreiten der dialektalen Nivellierungsprozesse von Westen nach Osten im kartographischen Vergleich gut sichtbar wird. Im Konsonantismus zeigt sich im Cilento gegenwärtig eine letzte ,Bastion“ gegen die den Großteil der Region prägenden sprachlichen Nivellierungstendenzen. Im Vokalismus haben sich die Tendenzen zum Sprachausgleich im Gebiet zwischen Westcilento und Irpinia ebenfalls auf einem mittleren Niveau stabilisiert - hohe Sprachausgleichstendenzen manifestieren sich hier vorwiegend in den peripheren Gebieten der Region.

\begin{tabular}{|c|c|c|c|c|c|c|c|c|c|c|}
\hline \multirow{2}{*}{$\begin{array}{c}\text { Kenn- } \\
\text { wert }\end{array}$} & \multicolumn{2}{|c|}{ TOT } & \multicolumn{2}{c|}{ LEX } & \multicolumn{2}{c|}{ PHON } & \multicolumn{2}{c|}{ KONS } & \multicolumn{2}{c|}{ VOK } \\
\cline { 2 - 11 } & 1960 & 2014 & 1960 & 2014 & 1960 & 2014 & 1960 & 2014 & 1960 & 2014 \\
\hline MIN & $-0,27$ & $-0,84$ & $-0,21$ & $-0,74$ & $-0,28$ & $-1,22$ & $-0,31$ & $-1,15$ & $-0,95$ & $-1,75$ \\
\hline MW & 0,29 & $-0,07$ & 0,33 & $-0,21$ & 0,22 & $-0,13$ & 0,23 & $-0,12$ & 0,06 & $-1,01$ \\
\hline MAX & 1,31 & 0,75 & 1,17 & 0,35 & 0,81 & 0,65 & 0,85 & 0,63 & 3,14 & 0,42 \\
\hline
\end{tabular}

Tabelle 32. Statistische Kennwerte der Synopse der Schiefen im ALI-Korpus (1960) und im Vergleichskorpus (2014). Messmoment jeweils $\mathrm{RIW}_{j k}$. 


\subsection{5 ,Beliebte' und ,unbeliebte' Dialekte}

\section{S. Kartenteil, Karten A77 - A92}

Im Folgenden sollen das derzeitige Erscheinungsbild und die diachronische Entwicklung der sprachlichen Raumstrukturen im Hinblick auf die Ausprägung sowie die räumliche Verteilung der sprachlichen Antipoden, d.h. der ,beliebtesten' und ,unbeliebtesten“ Dialekte in der Campania analysiert werden.

Im Totalkorpus kommen gegenwärtig etwa die Hälfte aller Dialekte (18) - und damit deutlich weniger als in den 1960er Jahren (25) - als ,beste Freunde“ in Frage (vgl. Karte A77 und Karte A78). Unter diesen erhalten jedoch deutlich mehr Dialekte mehr als ein Maximum (14 statt 8). Die Verteilung der interdialektalen ,Sympathien“'ist also insgesamt deutlich weniger ausgeglichen als noch vor fünfzig Jahren. Der ,beliebteste“ kampanische Dialekt ist gegenwärtig der Dialekt aus Salerno (855), der neun Maxima - und diese nicht nur von Dialekten in der näheren geographischen Umgebung (Olèvano Sul Tusciano (856), Maiori (854), Sorrento (852)), sondern auch aus weiter entfernten Teilen der Region (u.a. Castel Volturno (822) und Teano (813) in der Terra di Lavoro, Limàtola (824) und Reìno (815) im Sannio) - erhält. Damit bekommt der salernitanische Dialekt von mehr als doppelt so vielen Ortsdialekten Maxima zugewiesen wie der mit vier Maxima in den 1960er Jahren ,beliebteste' Dialekt aus Sarno (837). Die Anzahl der Dialekte, die als ,Sündenböcke‘ in Frage kommen, hat sich parallel zu der Anzahl der ,besten Freunde" in den letzten fünfzig Jahren ebenfalls deutlich (von 14 auf 9) verringert (vgl. Karte A79 und A80). Die Rolle des ,unbeliebtesten“ Dialekts, die vor fünfzig Jahren der Dialekt aus Barano d'Ischia (833) innehatte, ist auf den Dialekt in Bovino (819) in der Region Apulien übergegangen, der 12 Minima und diese aus der Terra di Lavoro, von den Isole Flegree sowie aus dem neapolitanischen Hinterland und aus der westlichen Irpinia erhält. Die ,kollektive Abneigung' der kampanischen Dialekte gegenüber dem bovinese ist somit deutlich stärker, als dies in den 1960er Jahren gegenüber dem ischitano (acht Minima) der Fall war. Dem Dialekt in Bovino folgen mit jeweils neun Minima die Dialekte von Casal di Prìncipe (823) und Alfano (873). Letzterer stellt damit - vor allem aus der ,Sicht' der Dialekte im Westen der Region - den ,prototypischen' Dialekt des Cilento dar, das bereits in den 1960er Jahren als dialektales Kerngebiet mit den Dialekten im (Nord-)Westen der Region im ,Streit' lag (Monte San Giacomo (865) erhielt sechs Minima aus der Metropolregion Neapel, vgl. Kap. 5.4.5). In Bezug auf die Verhältnisse im Bereich der Antipoden lassen sich also insgesamt deutliche diachronische Unterschiede feststellen: War die Situation in den 1960er Jahren noch durch interindividuelle ,Sympathien“ und ,Antipathien“ gekennzeichnet, so geht sie gegenwärtig in Richtung einer ,kollektiven Sympathie' gegenüber einzelnen Dialekten innerhalb des dialektalen Großraums sowie einer ,kollektiven Aversion“ gegenüber einzelnen, peripher verorteten Dialekten.

Im lexikalischen Bereich kommen gegenwärtig ebenfalls weniger Dialekte (19, s. Karte A82) als ,Sympathieträger' in Frage als noch in den 1960er Jahren (25, s. Karte A81). Die Rolle des ,besten Freundes' teilen sich nun mit jeweils fünf Maxima der Dialekt aus Pòllica (872) als ,beliebtester' Dialekt im (West-)Cilento und in der Irpinia - und der Dialekt aus Salerno (855) - als ,beliebtester' Dialekt im westkampanischen Großraum. Das Neapolitanische, das im Lexikon in den 1960er Jahren mit vier Maxima noch als ,bester Freund' der Dialekte in der Metropolregion Neapel fungierte, hat diese Rolle also in den vergangenen fünfzig Jahren abgegeben. Als ,größte Feinde“ kommen im lexikalischen Bereich nur gut halb so viele Dialekte in Frage wie noch vor fünfzig Jahren (10 statt 18, vgl. Karte A83 und A84). Die Rolle des größten 
,Sündenbocks‘ besetzt dabei mit neun Minima der Dialekt von Alfano (873), der damit den Dialekt von Casaletto Spartano (874) als polarisierender, ,prototypisch ‘ cilentanischer Dialekt abgelöst hat. Es folgt der in der östlichen Peripherie gelegene Dialekt von Bovino (819), der sich - wie jener von Alfano - auch im Totalkorpus unter den, unbeliebtesten' Dialekten findet.

Im Konsonantismus kommen als ,Sympathieträger' gegenwärtig 20 Dialekte - und damit ebenfalls weniger als in den 1960er Jahren - infrage, während die Zahl der Dialekte, die mehr als ein Maximum erhalten, deutlich gestiegen ist (von 8 auf 13, vgl. Karte A85 und A86). Die die diachronische Entwicklung im Totalkorpus charakterisierende Entwicklung in Richtung einer Konzentration der interdialektalen ,Sympathien` zeigt sich hier also besonders deutlich. Der , beliebteste' Dialekt der Campania ist im Konsonantismus nicht (wie im Totalkorpus) der Dialekt aus Salerno, sondern der Dialekt aus Roccaraìnola (836) im neapolitanischen Hinterland, der neun Maxima aus dem Westen der Region erhält. Es folgen der Dialekt des ,benachbarten“ Sarno (837) sowie jener von Gioia Sannìtica (814) mit jeweils fünf Maxima. Die Anzahl der Dialekte, die im Konsonantismus als ,größte Feinde“ in Frage kommen, ist gegenwärtig ebenfalls geringer als in den 1960er Jahren (12 statt 15, vgl. Karte A87 und A88). Den größten ,Sündenbock` stellt im konsonantischen Bereich der Dialekt aus Casal di Prìncipe (823) dar, der 11 Minima - vor allem aus dem Osten der Region - erhält und bereits durch seine Sonderstellung im Konsonantismus aufgefallen ist. Der Dialekt aus Alfano (873) hat auch hier die Rolle des ,prototypisch“ cilentanischen Dialektes (diesmal von Monte San Giacomo (865)) übernommen und steht mit acht Minima in der Rangfolge der ,Sündenböcke' an zweiter Stelle. Der Dialekt aus Barano d'Ischia (833) hingegen, dem 1960 noch die meisten Minima zugewiesen wurden, ist fünfzig Jahre später im konsonantischen Bereich so gut in das (west-)kampanische Dialektgebiet integriert, dass er kein einziges Minimum mehr erhält.

Im Vokalismus kommen - der guten Integration der einzelnen Dialekte in ihr geographisches Umfeld entsprechend (vgl. Kap. 5.5.3) - als ,Sympathieträger' gegenwärtig die meisten Dialekte in Frage (22), doch auch hier liegt eine leichte Reduktion gegenüber dem Stand in den 1960er Jahren vor (vgl. Karte A89 und A90). Der , beliebteste' Dialekt ist (wie im Totalkorpus) jener von Salerno (855): Er erhält mit 13 Maxima mehr als doppelt so viele wie der in den 1960er Jahren , beliebteste' Dialekt von Sorrento (852). Die Tatsache, dass die Maxima aus fast allen Teilen der Region (neapolitanisches Hinterland, Irpinia, Cilento) kommen, spiegelt die den Vokalimus kennzeichnende Kompaktheit des kampanischen Dialektgebietes wider. Als ,Sündenböcke‘ kommen insgesamt nur vier Dialekte - und damit weniger als halb so viele wie in den 1960er Jahren - in Frage (vgl. Karte A91 und A92). Es sind dies die bereits für ihre Sonderstellung im Vokalismus bekannten, geographisch peripheren Dialekte von Reìno (815), Bovino (819), Candela (829) und Casaletto Spartano (874). Die Rolle des größten ,Sündenbocks' ist dabei in den vergangenen fünfzig Jahren von Reìno (815, 14 Minima) auf Casaletto Spartano (874, 23 Minima) übergegangen, dessen Position sich damit gegenüber dem Stand in den 1960er Jahren (drei Minima) deutlich verschlechtert hat. Diachronisch stabil sind hingegen die Anzahl der Minima, die der Dialekt von Reìno (815) erhält (14 bzw. 15) sowie die wechselseitige ,Antipathie‘ zwischen den Dialekten von Reìno und Bovino (819, drei Minima).

Die Ergebnisse der Antipodenmessung stützen die bisher gemachten Beobachtungen zur diachronischen Entwicklung der sprachlichen Raumstrukturen in der Campania. Die Ablösung der wechselseitigen ,Sympathien' zwischen geographisch benachbarten Dialekten durch eine ,kollektive Sympathie‘ zu einzelnen Dialekten, die dadurch zu Hauptbezugspunkten werden, spiegelt die in den vorangegangenen Analyseschritten dargestellte, durch dialektale Ausgleichsprozesse bedingte Entwicklung der kleinräumigen Gliederung mit vielen sprachlichen Bezugspunkten zu einer großräumigen Gliederung des Typs ,Zentrum - Peripherie“ wider. 
Diese ,Großräumigkeit‘ ist dabei im konsonantischen und im vokalischen Bereich (jeweils ein Hauptbezugspunkt) ausgeprägter als im lexikalischen Bereich (zwei Hauptbezugspunkte). Die Tatsache, dass die Metropole Neapel heute selbst für ihr geographisches Umfeld als sprachlicher Bezugspunkt nicht mehr relevant ist, zeigt, dass es sich bei der diatopischen Entwicklung in den vergangenen fünfzig Jahren nicht um eine ,Neapolitanisierung', d.h. eine Verbreitung der Merkmale des Neapolitanischen handeln kann. Stattdessen hat ein allgemeiner Dialektausgleich stattgefunden, aus dem - als sprachliche ,Kompromisszentren“ - neue, kollektive dialektale Bezugspunkte hervorgegangen sind.

Die Verringerung der Anzahl der Dialekte, die als ,Sündenböcke' in Frage kommen, ist ein weiterer Reflex der sprachlichen Nivellierungsprozesse. Die allgemeine sprachliche Angleichung hat dazu geführt, dass sich gegenwärtig nur noch wenige Dialekte durch Abweichungen auszeichnen, welche entsprechend große ,Konflikte' mit den angepassten Dialekten zeitigen. Dadurch sind die in den 1960er Jahren bestehenden wechselseitigen ,Antipathien“ zwischen einzelnen Dialekten aufgelöst und bei einem Großteil der Dialekte durch eine, kollektive Antipathie' gegenüber ein und demselben dialektalen ,Außenseiter' ersetzt worden.

\subsubsection{Korrelationen zwischen Sprache und Raum}

\section{S. Kartenteil, Karten A93 - A100}

Um Einblicke in die Veränderungen zu erhalten, die sich durch die diachronischen Veränderungen im Ähnlichkeitsprofil der Dialekte im Verhältnis zwischen Sprache und Raum in der Campania ergeben haben, sollen im Folgenden die verschiedenen Bereiche des Vergleichskorpus im Hinblick auf die Korrelationen ${ }^{441}$ zwischen sprachlicher Ähnlichkeit und geographischer (euklidischer) Proximität analysiert und die Ergebnisse im Vergleich mit jenen des ALIKorpus betrachtet werden.

Im Totalkorpus erbringt die Korrelation zwischen sprachlicher Ähnlichkeit und geographischer Proximität nur positive Werte (s. Tab. 33). Es findet sich also in keinem Punkt eine gegenläufige Entwicklung von Sprache und Raum. Niedrige Korrelationswerte weisen die Messpunkte im Dialektgebiet des Westcilento, in der Irpinia, im Sannio, in der Region Apulien sowie Casaletto Spartano (874) im Südcilento auf (s. Karte A94). Diese Störungen im Verhältnis zwischen Sprache und Raum können mit den sprachgeographischen Veränderungen in Zusammenhang gebracht werden, die in den vergangenen fünfzig Jahren in der Campania stattgefunden haben bzw. gegenwärtig noch stattfinden (vgl. Kap. 5.5.2): Im Falle der Gebiete in der Irpinia und im Sannio sowie in Candela (827) hat die ,Auflösung' der vormals kompakten dialektalen Mikro-Areale zu einer sprachlichen Fragmentierung geführt, sodass die Dialekte nicht (mehr) die Ähnlichkeit aufweisen, die man aufgrund der geographischen Proximität der jeweiligen Messpunkte erwarten würde. Im Falle des Westcilento hat der Anschluss an den dialektalen Großraum zu einem Anstieg der sprachlichen Ähnlichkeit zu geographisch entfernten Arealen geführt und Casaletto Spartano (874) hat sich durch seine besondere Entwicklung sprachlich (weiter) von seinen ,Nachbarn“ im Cilento entfernt. Der niedrigste Korrelationswert liegt in Olèvano Sul Tusciano (856, MIN), das durch seine Lage an der Grenze zur kampanischen Küstenebene den ,Ausgangspunkt ${ }^{`}$ der südlichen Erweiterung des dialektalen Großraums darstellt. Der diachronische Vergleich der Raumstrukturen (vgl. Karte A93 und A94) zeigt, dass

${ }^{441}$ Das eingesetzte Korrelationsmaß ist hierbei (wie auch im ALI-Korpus) der Produktmoment-Korrelationskoeffizient nach Bravais/Pearson (vgl. Kap. 4.3.8). 
sich durch die sprachlichen Ausgleichsprozesse das Verhältnis zwischen sprachlicher und räumlicher Nähe besonders im östlichen und südlichen Teil der Region (Sannio, Irpinia, Nordcilento) in den letzten fünfzig Jahren deutlich verschlechtert hat.

Im Bereich der hohen Korrelationswerte (Wertklassen [5] und [6]) lassen sich gegenwärtig zwei Areale identifizieren, von denen eines die Dialekte der kampanischen Küstenebene und der Inseln (MAX in Barano d'Ischia (833)) und das andere das Zentrum des Dialektgebietes im Cilento (Alfano (873), Monte San Giacomo (865) und Laurino (864)) umfasst. In beiden Fällen hat sich die ,Fusion' benachbarter Dialektgebiete (Dialektgebiet in der Metropolregion Neapel und Dialektgebiet im neapolitanischen Hinterland bzw. Dialektgebiet im Nordcilento und Dialektgebiet im Südcilento, vgl. Kap. 5.5.2) positiv auf das Verhältnis zwischen Sprache und Raum ausgewirkt. Dies gilt auch für die in den 1960er Jahren noch durch äußerst niedrige Korrelationswerte gekennzeichneten Provinzhauptstädte Benevento (825) und Salerno (855), die heute ein etwas harmonischeres Verhältnis zwischen Sprach- und Naturraum zeigen. Sowohl die durchschnittliche Korrelation zwischen sprachlicher und räumlicher Nähe als auch die Spannweite der Korrelationswerte sind jedoch diachronisch stabil geblieben (dabei liegen allerdings sowohl der Minimal-, als auch der Maximalwert im Vergleichskorpus höher als im ALI-Korpus, s. Tab. 33).

Im Lexikon zeigt sich gegenwärtig eine schwächere durchschnittliche Korrelation zwischen sprachlicher Ähnlichkeit und räumlicher Proximität als im Totalkorpus (s. Tab. 33). Dies ist darauf zurückzuführen, dass der ,Zusammenschluss' der Dialektgebiete im Westen der Region - die im Totalkorpus (und im Konsonantismus, s.u.) eine Zunahme der Harmonie zwischen Sprache und Raum bewirkt hat - im Lexikon bereits in den 1960er Jahren zu beobachten ist (vgl. Kap. 5.4.2). Somit wirkt sich lediglich die sprachliche Annäherung einzelner östlicher Punkte an den dialektalen Großraum im Westen auf die Entwicklung des Verhältnisses zwischen Sprache und Raum aus. Die sich bei der räumlichen Umlegung der Korrelationswerte ergebenden Strukturen (s. Karte A96) sind im lexikalischen Teilkorpus ähnlich wie im Totalkorpus. Ein auffälliger Unterschied findet sich jedoch im Südcilento, wo Casaletto Spartano (874) aufgrund seiner besseren sprachlichen Integration (vgl. Kap. 5.5.2 und 5.5.3) im Lexikon dasselbe (relativ harmonische) Verhältnis zwischen Sprach- und Naturraum aufweist wie die benachbarten Messpunkte.

Im Gegensatz zum Totalkorpus treten im Lexikon auch im numerischen Bereich diachronische Unterschiede zu Tage. So ist - bedingt durch die vor allem in den östlichen Messpunkten unterschiedliche Entwicklung des Verhältnisses zwischen Sprache und Raum - die durchschnittliche Harmonie zwischen Sprache und Raum deutlich schwächer und die Spannweite der Korrelationswerte (vor allem durch ein niedrigeres Minimum) deutlich größer als noch vor fünfzig Jahren (s. Tab. 33). Diejenigen Messpunkte, in denen sich die stärkste Veränderung des Verhältnisses zwischen sprachlicher und räumlicher Nähe manifestiert, liegen am Übergang zwischen dem Nordcilento und der Irpinia (Cairano (841), Salvitelle (858), Postiglione (857), vgl. Karte A95 und Karte A96). Hier hat sich das in den 1960er Jahren noch harmonische Verhältnis zwischen Sprach- und Naturraum (Wertklassen [4] und [5]) in den vergangenen fünfzig Jahren deutlich verschlechtert (Wertklassen [1] und [2]), was im Falle von Salvitelle (858) und Postiglione (857) durch die starke lexikalische Angleichung an das Westcilento bedingt ist (vgl. Kap. 5.5.1). Im Hinblick auf das Verhältnis zwischen Sprache und Raum diachronisch stabil ist die Position der Messpunkte in der kampanischen Küstenebene, wo der dialektale Großraum sich im lexikalischen Bereich bereits in den 1960er Jahren herausgebildet und eine entsprechende Harmonie zwischen Sprach- und Naturraum erzeugt hatte, und andererseits in den Gebieten mit dialektaler Grenzlage (Montella (839), Olèvano Sul Tusciano (856), 
Pòllica (872)), die sich damals wie heute unter den Punkten befinden, in denen die Harmonie zwischen Sprache und Raum am geringsten ist.

Im Konsonantismus ist die durchschnittliche Korrelation zwischen sprachlicher Ähnlichkeit und geographischer Proximität höher als im Lexikon (s. Tab. 33). Die Raumstrukturen (s. Karte A98) spiegeln über weite Strecken jene im Totalkorpus wider. Kleine Abweichungen finden sich insbesondere im (nord-)östlichen Teil der Region (Sannio, Irpinia), wo die Störungen im Verhältnis zwischen Sprache und Raum in einigen Messpunkten (Reìno (815), Ginestra degli Schiavoni (816), Melito Irpino (826), Cairano (841)) im Konsonantismus deutlich schwächer sind als im Totalkorpus. Im diachronischen Vergleich zeigt sich ein leichter Anstieg der durchschnittlichen Harmonie zwischen Sprache und Raum (s. Tab. 33). Hier wirken sich die sprachlichen Nivellierungsprozesse, die in den vergangenen fünfzig Jahren im Westen der Campania stattgefunden haben, also positiv auf das allgemeine Verhältnis zwischen Sprachund Naturraum aus. Die sprachliche Annäherung einzelner östlicher Messpunkte an den dialektalen Großraum fällt hier deutlich weniger ins Gewicht. ${ }^{442}$

Im Vokalismus ist die durchschnittliche Korrelation zwischen sprachlicher Ähnlichkeit und geographischer Proximität in der Campania gegenwärtig am geringsten (s. Tab. 33). Hier spiegelt sich - wie schon in den 1960er Jahren - die stärkere sprachliche Kompaktheit des kampanischen Dialektgebietes wider, die dazu führt, dass die sprachliche Ähnlichkeit zwischen geographisch entfernten Messpunkten teilweise deutlich höher ist, als es die entsprechende geographische Proximität erwarten ließe. ${ }^{443}$ Durch die Besonderheiten einzelner peripherer Dialekte ergibt sich auch der umgekehrte Fall, dass die sprachliche Ähnlichkeit zwischen zwei Messpunkten teilweise deutlich geringer ist, als sich vor dem Hintergrund der geographischen Proximität vermuten ließe (s.u.). Dementsprechend ist die Störung im Verhältnis zwischen Sprache und Raum in den Messpunkten mit niedrigen Korrelationswerten deutlich stärker (d.h. das Minimum deutlich niedriger) und die Harmonie zwischen Sprache und Raum in den Messpunkten mit hohen Korrelationswerten deutlich schwächer (d.h. das Maximum deutlich niedriger) als in den übrigen Teilkorpora.

Hinsichtlich der bei der räumlichen Umlegung der Korrelationswerte aufscheinenden Strukturen (s. Karte A100) finden sich im Vokalismus einige deutliche Unterschiede zum Totalkorpus, die die bereits dargestellten Besonderheiten der sprachlichen Raumstrukturen widerspiegeln. Äußerst starke Störungen des Verhältnisses zwischen Sprache und Raum finden sich im Südcilento (Laurino (864), Monte San Giacomo (865), Alfano (873)), dessen Dialekte teilweise hohe Ähnlichkeitswerte zu weiter entfernten bzw. sogar peripheren nördlichen Dialekten, ${ }^{444}$ gleichzeitig jedoch eine sehr hohe Distanz zum ihrem ,Nachbarn' Casaletto Spartano (874) - und im Falle von Alfano (873) auch zu Pòllica (872) - aufweisen (vgl. Kap. 5.5.2). Auch der nördliche Teil des neapolitanischen Hinterlands (Roccaraìnola (836), Limàtola (824)) zeigt im Vokalismus Störungen im Verhältnis zwischen sprachlicher und räumlicher Nähe, die im Totalkorpus nicht sichtbar werden. Dies ist darauf zurückzuführen, dass die Nähe zwischen den Dialekten in der Metropolregion Neapel und den Dialekten im neapolitanischen Hinterland

\footnotetext{
${ }^{442} \mathrm{Da}$ im ALI-Korpus die Raumstrukturen im konsonantischen Bereich ebenfalls kongruent mit jenen im Totalkorpus sind, wird auf den diachronischen Vergleich der Raumstrukturen (vgl. Karte A97 und A98) an dieser Stelle verzichtet (s. Vergleich der Totalkorpora).

${ }^{443}$ Am deutlichsten wird dies in Cairano (841), das den niedrigsten Korrelationswert überhaupt aufweist $(0,14)$. Hier liegt die geographische Proximität zum am weitesten entfernten Messpunkt Rocca d'Evandro (809) bei $33,28 \%$, während die sprachliche Ähnlichkeit im Vokalismus mehr als doppelt so hoch ist $(68,75 \%)$.

${ }^{444}$ Beispielhaft anführen lassen sich hier die Ähnlichkeitswerte zwischen Alfano (873) und Fontegreca (810) $(68,75 \%)$, zwischen Laurino (864) und Melito Irpino (826) (77,08\%) und zwischen Monte San Giacomo (865) und Castel Volturno (822) (70,83\%).
} 
im Vergleich zu jener im konsonantischen und insbesondere im lexikalischen Bereich im Vokalismus noch relativ ,jung' und dementsprechend wenig stabil ist. In einigen Messpunkten am Übergang zum Cilento (Olèvano Sul Tusciano (856), Capaccio (863), Postiglione (857)) sowie in den Provinzhauptstädten Salerno (855) und Avellino (838) hat die Kompaktheit des kampanischen Dialektgebietes im Vokalismus einen positiven Einfluss auf das Verhältnis zwischen Sprache und Raum.

Die durchschnittliche Harmonie zwischen Sprach- und Naturraum ist im Vokalismus in den vergangenen fünfzig Jahren leicht gestiegen (s. Tab. 33). Hinsichtlich der räumlichen Konstellationen zeigen sich teilweise deutliche diachronische Unterschiede (vgl. Karte A99 und A100), die die in den vergangenen fünfzig Jahren abgelaufenen Entwicklungen im Bereich der sprachlichen Raumstrukturen widerspiegeln. Im westlichen Teil der Region zeigt sich - bedingt durch die ,Fusion“ der Dialektgebiete und die Verschiebung des dialektalen ,Schwerpunkts“ in der kampanischen Küstenebene - eine deutliche Erhöhung der Korrelationswerte in den Punkten Sarno (837) und Salerno (855). Auch in der um 1960 sprachlich von ihrem geographischen Umfeld isolierten Provinzhauptstadt Benevento (825) hat sich (wie im Totalkorpus und im Lexikon) in den vergangenen fünfzig Jahren das Verhältnis zwischen Sprache und Raum im Vokalismus deutlich harmonisiert. In den meisten Messpunkten im Sannio, in der Irpinia und im Nordcilento haben sich die Verstärkung der Kompaktheit des kampanischen Dialektgebietes einerseits und die diachronisch stabile Sonderstellung einiger benachbarter peripherer Dialekte andererseits (vgl. Kap. 5.5.2) hingegen negativ auf das Verhältnis zwischen sprachlicher und räumlicher Nähe ausgewirkt.

\begin{tabular}{|c|c|c|c|c|c|c|c|c|}
\hline \multirow{2}{*}{$\begin{array}{c}\text { Kenn- } \\
\text { wert }\end{array}$} & \multicolumn{2}{|c|}{ TOT/GEO } & \multicolumn{2}{c|}{ LEX/GEO } & \multicolumn{2}{c|}{ KONS/GEO } & \multicolumn{2}{c|}{ VOK/GEO } \\
\cline { 2 - 9 } & 1960 & 2014 & 1960 & 2014 & 1960 & 2014 & 1960 & 2014 \\
\hline MIN & 0,29 & 0,36 & 0,46 & 0,20 & 0,19 & 0,24 & $-0,04$ & 0,14 \\
\hline MW & 0,62 & 0,62 & 0,68 & 0,48 & 0,58 & 0,64 & 0,36 & 0,42 \\
\hline MAX & 0,79 & 0,86 & 0,83 & 0,80 & 0,80 & 0,84 & 0,59 & 0,74 \\
\hline
\end{tabular}

Tabelle 33. Statistische Kennwerte der Korrelationen zwischen sprachlicher Ähnlichkeit (verschiedene Teilkorpora) und geographischer Proximität im ALI-Korpus (1960) und im Vergleichskorpus (2014). Messmoment jeweils RIW R $_{j k}$ jeweils Produktmoment-Korrelationskoeffizient nach Bravais/Pearson.

Die in den verschiedenen Teilkorpora unterschiedlich ausgeprägten sprachlichen Nivellierungsprozesse, die in den vergangenen fünfzig Jahren in der Campania stattgefunden haben, spiegeln sich also in unterschiedlichen Entwicklungen des Verhältnisses zwischen Sprache und Raum wider. Während sich in der Zunahme der Harmonie zwischen Sprach- und Naturraum in den phonetischen Teilkorpora (und hier insbesondere im Konsonantismus) die Bildung des dialektalen Großraums im Westen der Region manifestiert, spiegelt die im Lexikon zu beobachtende allgemeine Verschlechterung des Verhältnisses zwischen Sprach- und Naturraum die sprachliche Angleichung der östlichen Dialekte an den dialektalen Großraum im Westen der Region wider. Dadurch, dass sich die in den verschiedenen Teilkorpora gegensätzlichen Tendenzen der Entwicklung des Verhältnisses zwischen sprachlicher und räumlicher Nähe im Totalkorpus ausgleichen, ergeben sich bei der durchschnittlichen Harmonie zwischen Sprache und Raum insgesamt keine diachronischen Veränderungen. 


\title{
5.5.7 Veränderungen der sprachlichen Ähnlichkeitsprofile zwischen 1960 und 2014
}

\author{
S. Kartenteil, Karten A101 - A112
}

Nachdem in den vorangegangenen Abschnitten die diachronischen Veränderungen der sprachlichen Raumstrukturen in der Campania anhand des Vergleiches verschiedener kartographischer Heuristika betrachtet wurden, soll nun eine Analyse der Korrelationen zwischen den Ergebnissen der Ähnlichkeitsmessungen im kampanischen Dialektgebiet von 1960 und 2014 zeigen, welche Dialekte in ihrem Ähnlichkeitsprofil die stärksten Veränderungen erfahren haben und in welchen Gebieten das Verhältnis zu den übrigen Dialekten relativ stabil geblieben ist.

Im Totalkorpus (s. Karte A101) finden sich die Dialekte, deren Ähnlichkeitsprofile diachronisch stabil geblieben sind (Wertklassen [5] und [6]) im Westen der Terra di Lavoro (Castel Volturno (822) und Rocca d'Evandro (809)), im neapolitanischen Hinterland (Sarno (837) und Maiori (854)) sowie im Gebiet (Nord-)Cilento-Irpinia (MAX in Laurino (864)). Bei letzteren handelt es sich um die Dialekte, die in den 1960er Jahren das Dialektgebiet Nordcilento-Irpinia darstellten (vgl. Kap. 5.4.1 bzw. Karte A1) und heute eine hohe Resistenz gegenüber sprachlichen Ausgleichsprozessen zeigen (vgl. Kap. 5.5.4 bzw. Karte A70). Im Falle der Dialekte von Sarno (837) und Maiori (854) spiegeln die hohen Korrelationswerte die unverändert gute sprachliche Integration in das geographische Umfeld wieder. Die Stabilität des sprachlichen Ähnlichkeitsprofils von Bovino (819) zeigt, dass der Dialekt nach wie vor den ,Außenseiter“ unter den kampanischen Dialekten darstellt. Relativ unberührt von den sprachgeographischen Umwälzungen sind auch die Ähnlichkeitsprofile der peripheren Dialekte in der Terra di Lavoro geblieben.

Die schwächsten Korrelationen zwischen den sprachlichen Ähnlichkeitsprofilen von 1960 und 2014 (Wertklassen [1] und [2]) finden sich in fast allen Punkten des ehemaligen Dialektgebietes in der Metropolregion Neapel (Barano d'Ischia (833), Pròcida (834, MIN), Neapel (835), Anacapri (851), Salerno (855), Benevento (825)). Ein Vergleich der Karten A105 und A106 zeigt am Beispiel von Neapel, dass die Veränderungen in den Ähnlichkeitsprofilen dieser Dialekte durch eine heute deutlich höhere Ähnlichkeit zu den Dialekten im neapolitanischen Hinterland einerseits und den Dialekten im Osten der Region andererseits zustande kommen. In der Entwicklung der Ähnlichkeitsprofile der Dialekte in der Metropolregion Neapel manifestieren sich also die Bildung des dialektalen Großraumes in der kampanischen Küstenebene und dessen Ausdehnung in die östlichen und südwestlichen Bereiche der Region (vgl. Kap. 5.5.2) in besonderem Maße. ${ }^{445}$

Starke Veränderungen der Ähnlichkeitsprofile (s. Karte A101) zeigen sich jedoch nicht nur im Gebiet der Metropolregion Neapel. Auch Capaccio (863) im Nordcilento weist einen niedrigen Korrelationswert auf, der die beobachtete sprachliche ,Abkopplung ' vom Dialektgebiet Nordcilento-Irpinia und die gleichzeitige sprachliche Annäherung an den dialektalen Großraum im Westen der Region (vgl. Kap. 5.5.2) widerspiegelt. In dem veränderten Ähnlichkeitsprofil des Dialektes aus Alfano (873) manifestieren sich die Integration in das Dialektgebiet Cilento-Irpinia und die gleichzeitige Reduktion der Ähnlichkeit zu den Dialekten der Metropolregion Neapel (vgl. Kap. 5.5.1). Die niedrigen Korrelationswerte im peripheren nördlichen

\footnotetext{
${ }^{445}$ Dies ist nicht im Sinne eines kausalen Zusammenhangs (der nicht vorliegt, da auch die direkte Korrelation der Ähnlichkeitsprofile lediglich eine andere Perspektive auf ein und dieselbe Entwicklung darstellt), sondern lediglich als Brückenschlag zu den in den vorhergehenden Analyseschritten zur Entwicklung der sprachlichen Raumstrukturen in der Campania gemachten Beobachtungen zu verstehen.
} 
Fontegreca (810) illustrieren, dass der Dialekt nicht länger eine hohe Ähnlichkeit zu den Dialekten der Metropolregion Neapel, sondern eine sprachliche Sonderstellung aufweist (vgl. Kap. 5.5.1).

Im lexikalischen Bereich entspricht die durchschnittliche Stabilität der Ähnlichkeitsprofile der kampanischen Dialekte jener im Totalkorpus (s. Tab. 34). Im Bereich der Raumstrukturen (s. Karte A102) ergeben sich allerdings einige Abweichungen. Im Westen der Region weisen nicht nur die Dialekte von Sarno (837) und Maiori (854), sondern auch alle übrigen Dialekte im neapolitanischen Hinterland (im Norden bis nach Gioia Sannìtica (814)) diachronisch stabile Ähnlichkeitsprofile (Wertklassen [5] und [6]) auf. Dies ergibt sich daraus, dass die Dialekte nach wie vor Teil des kompakten Gebietes in der kampanischen Küstenebene sind (vgl. Kap. 5.5.1 und 5.5.2) und sich zudem ihr Verhältnis zu den Dialekten im östlichen Teil der Region nur marginal verändert hat. ${ }^{446}$ Die Tatsache, dass alle Dialekte in der Metropolregion Neapel (außer Pròcida (834)) im lexikalischen Bereich (teilweise deutlich) höhere Korrelationswerte aufweisen als im Totalkorpus, zeigt, dass die Veränderungen der sprachlichen Raumstrukturen im Westen der Region in den vergangenen fünfzig Jahren insbesondere auf phonetischer Ebene stattgefunden haben. Im Dialektgebiet (Nord-)Cilento-Irpinia ist die diachronische Stabilität der Ähnlichkeitsprofile im lexikalischen Bereich geringer als im Totalkorpus. Die auffällig großen Veränderungen in den Ähnlichkeitsprofilen von Postiglione (857) und Salvitelle (858) illustrieren die lexikalische Annäherung an das Westcilento, die sich in der dialektalen Klassifikation bereits in ihrer, Auskopplung' aus der Gruppe der Dialekte im Gebiet Cilento-Irpinia gezeigt hat (vgl. Kap. 5.5.1). Auch die Punkte Reìno (815) im Sannio sowie Melito Irpino (826) und Montella (839, MIN) in der Irpinia weisen im lexikalischen Bereich äußerst niedrige Korrelationswerte auf. In den Veränderungen der Ähnlichkeitsprofile dieser Dialekte manifestiert sich ihre Annäherung an den westkampanischen Großraum (vgl. Kap. 5.5.2), die teilweise eine ,Abkopplung' von benachbarten Dialekten zur Folge hat. Ein Vergleich der Karten A107 und A108 illustriert diese Entwicklung am Beispiel des Ähnlichkeitsprofils von Melito Irpino (826).

Im Konsonantismus zeigt das numerische Ergebnis der diachronischen Korrelation der Ähnlichkeitsprofile einen im Vergleich zum lexikalischen Teilkorpus deutlich niedrigeren Durchschnittswert (s. Tab. 34). Dies bestätigt die aus der Analyse der Heuristika hervorgegangene Folgerung, dass die diachronischen Veränderungen der sprachlichen Raumordnung im Bereich des Konsonantismus in stärkerem Maße stattgefunden haben als im Lexikon. Die Ergebnisse der räumlichen Umlegung der Korrelationswerte (s. Karte A103) spiegeln - entsprechend der statistischen Dominanz des konsonantischen Bereichs - größtenteils jene im Totalkorpus wider. Starke Veränderungen der Ähnlichkeitsprofile (Wertklassen [1] und [2]) finden sich bei vielen Dialekten im Westen der Region, d.h. in der kampanischen Küstenebene (MIN in Neapel (835)), auf den Inseln und im Westcilento und damit in dem Bereich, wo sich in den vergangenen fünfzig Jahren der dialektale Großraum gebildet hat. Der Vergleich der Karten A109 und A110 illustriert die Entwicklung des Ähnlichkeitsprofils des Neapolitanischen, die sich durch einen starken Anstieg der Ähnlichkeit zu beinahe allen Dialekten in der kampanischen Küstenebene auszeichnet. Die starken Veränderungen im Verhältnis des Neapolitanischen zu den Dialekten im Südcilento und in der Region Apulien illustrieren das ,Aufweichen“ der engen Beziehungen, die in den 1960er Jahren zwischen diesen Gebieten bestanden haben

\footnotetext{
${ }^{446}$ Etwas stärkere Veränderungen finden sich im Verhältnis zwischen den Dialekten der Metropolregion Neapel und den Dialekten im Osten der Region, sodass erstere etwas geringere Korrelationswerte als die Dialekte im neapolitanischen Hinterland aufweisen.
} 
(vgl. Kap. 5.5.1). Schwache Korrelationen zwischen den Ähnlichkeitsprofilen finden sich darüber hinaus in der Peripherie der Region (s. Karte A103): Zusätzlich zu den auch im Totalkorpus vertretenen Orten Fontegreca (810) und Alfano (873) finden sich hier Reìno (815) und Candela (827), die sich - im Falle Candelas (827) unter Aufgabe der exklusiven sprachlichen Nähe zur Metropolregion Neapel - an den dialektalen Großraum angenähert haben. Diachronisch sehr stabile Ähnlichkeitsprofile (Wertklassen [5] und [6]) finden sich hingegen im Dialektgebiet Cilento-Irpinia (MAX in Laurino (864)), in Sarno (837) sowie in den peripheren Orten Rocca d'Evandro (809), Ginestra degli Schiavoni (816) und Bovino (819).

Im Vokalismus zeigt der gegenüber den anderen Teilkorpora deutlich geringere durchschnittliche Korrelationswert (s. Tab. 34), dass - wie vor allem bei der Analyse der Maxima und der Schiefewerte (Kap. 5.5.3 und 5.5.4) zu beobachten war - in diesem Teilbereich in den vergangenen fünfzig Jahren mit Abstand die (numerisch) stärksten Veränderungen der Ähnlichkeitsverhältnisse zwischen den kampanischen Dialekten stattgefunden haben. Das Ergebnis der räumlichen Umlegung der Korrelationswerte (s. Karte A104) zeigt - wie für den Vokalismus typisch - gegenüber den statistisch dominanten Teilkorpora (Lexikon und Konsonantismus) einige Besonderheiten. Die stärkste Veränderung des sprachlichen Ähnlichkeitsprofils findet sich in Gioia Sannìtica (814), das sich sprachlich von seinem Nachbarn Reìno (815) mit dem es in den 1960er Jahren noch ein nach Süden abgeschottetes dialektales Mikroareal bildete (vgl. Kap. 5.4.2) - , abgekoppelt' hat und heute Teil des dialektalen Großraums im Westen der Region ist (vgl. Kap. 5.5.2). Der Vergleich der Karten A111 und A112 illustriert die diachronischen Unterschiede im Ähnlichkeitsprofil des Dialekts. Deutliche Veränderungen des Ähnlichkeitsprofils (s. Karte A104, Wertklassen [1] und [2]) weisen darüber hinaus einige Dialekte in der Metropolregion Neapel auf (Pròcida (834), Anacapri (851), Sorrento (852), Salerno (855)). Hier zeigt sich insbesondere, dass die relativ großen Distanzen, die hier in den 1960er Jahren noch zu den benachbarten Dialekten im neapolitanischen Hinterland bestanden (vgl. Kap. 5.4.2), im Zuge der wachsenden sprachlichen Kompaktheit der Campania in den vergangenen fünfzig Jahren nivelliert worden sind.

Die geringsten Veränderungen (Wertklassen [5] und [6]) haben im vokalischen Bereich einerseits die Ähnlichkeitsprofile der peripheren Dialekte von Reìno (815) im Norden, Bovino (819) im Osten und Casaletto Spartano (874, MAX) im Süden erfahren, die im vokalischen Bereich nach wie vor eine Sonderstellung unter den kampanischen Dialekten einnehmen. Dass sich auch in mehreren Punkten innerhalb des dialektalen Großraums - insbesondere in der Irpinia (Cairano (841), Quaglietta (840), Montella (839)) und im Westen der Terra di Lavoro (Castel Volturno (822), Rocca d'Evandro (809)) - nur verhältnismäßig geringe Veränderungen der sprachlichen Ähnlichkeitsprofile zeigen, spiegelt die heute wie damals hohe Kompaktheit des kampanischen Dialektgebietes im Vokalismus wider.

Aus dem diachronischen Vergleich der Ähnlichkeitsprofile der kampanischen Dialekte bleibt folgendes festzuhalten. Diachronisch stabil sind einerseits die Ähnlichkeitsprofile der Dialekte im neapolitanischen Hinterland, die ihre Position im Zentrum eines kompakten Dialektraums über die Zeit hinweg behalten haben und andererseits die Ähnlichkeitsprofile im Dialektgebiet Cilento-Irpinia, das seine Rolle als ,Gegenpol‘ - ehemals zum Dialektgebiet in der Metropolregion Neapel, heute zum großen Dialektraum im Westen der Region - bewahrt hat. Starke Veränderungen der Ähnlichkeitsprofile finden sich insbesondere bei den Dialekten der Metropolregion Neapel sowie in Benevento (825) und Salerno (855), deren Distanzen zu den Dialekten im neapolitanischen Hinterland sich in den vergangenen fünfzig Jahren nivelliert haben, bei den Dialekten des Westcilento, die sich an den nördlich angrenzenden dialektalen Großraum angenähert haben sowie bei denjenigen östlichen Dialekten, in denen eine solche 
Annäherung ebenfalls stattgefunden hat. Die Ähnlichkeitsprofile der peripheren Dialekte haben sich zum Teil über die Zeit hinweg wenig, zum Teil jedoch drastisch verändert, wobei die Entwicklung in den sprachlichen Teilbereichen teilweise unterschiedlich verlaufen ist.

\begin{tabular}{|c|c|c|c|c|c|}
\hline Kennwert & TOT & LEX & PHON & KONS & VOK \\
\hline MIN & 0,62 & 0,59 & 0,39 & 0,48 & 0,05 \\
\hline MW & 0,77 & 0,77 & 0,60 & 0,67 & 0,55 \\
\hline MAX & 0,93 & 0,91 & 0,83 & 0,92 & 0,78 \\
\hline
\end{tabular}

Tabelle 34. Statistische Kennwerte der Korrelationen zwischen den jeweiligen Teilkorpora im ALIKorpus (1960) und im Vergleichskorpus (2014). Messmoment jeweils RIW K $_{j k}$, Produktmoment-Korrelationskoeffizient nach Bravais/Pearson.

\subsubsection{Die kampanischen Dialekte und das Standarditalienische}

\section{S. Kartenteil, Karten A113 - A120}

Im Anschluss an die Analyse der diachronischen Entwicklung der sprachlichen Raumstrukturen in der Campania sollen im Folgenden die dialektometrisch beobachtbaren Veränderungen im Verhältnis zwischen den kampanischen Dialekten und dem Standarditalienischen diskutiert werden.

Im Totalkorpus finden sich Dialekte mit hoher Ähnlichkeit zum Standarditalienischen (Wertklassen [5] und [6]) gegenwärtig in verschiedenen Teilen des Untersuchungsgebietes (s. Karte A114): im Sannio (Reìno (815)), in der Irpinia (Melito Irpino (826), Montella (839)), am Übergang zum Cilento (Olèvano Sul Tusciano (856), Salvitelle (858)), im Westcilento (Pòllica (872)), auf den Inseln (Pròcida (834) und Anacapri (851)) sowie im Westen der Terra di Lavoro (Rocca d'Evandro (809)). Die geringste Ähnlichkeit zum Standarditalienischen weist heute der Dialekt von Casal di Prìncipe (823, MIN) auf. Dies spiegelt die in den vorigen Analyseschritten bereits festgestellte Sonderstellung des Dialektes im Gebiet der Metropolregion Neapel wider (vgl. Kap. 5.5.2). Eine geringe Ähnlichkeit zum Standarditalienischen (Wertklasse [2]) findet sich darüber hinaus in weiteren peripheren Dialekten: im Norden in Fontegreca (810), im Osten in Bovino (819) und Quaglietta (840), im Süden in Alfano (873) und im Westen in Sorrento (852).

Der diachronische Vergleich der statistischen Kennwerte ergibt, dass in den kampanischen Dialekten in den vergangenen fünfzig Jahren eine deutliche Annäherung an das Standarditalienische stattgefunden hat (deutlicher Anstieg der durchschnittlichen Ähnlichkeitswerte, s. Tab. 35). Der Vergleich der Karten A113 und A114 zeigt, dass sich diese mit Abstand am stärksten in den insularen Dialekten (Barano d'Ischia (833), Pròcida (834), Anacapri (851)) manifestiert und auch in Pòllica (872), Olèvano Sul Tusciano (856) und Montella (839) relativ stark ausgeprägt ist. Wirft man einen Blick zurück auf die Analyse der Entwicklung der Raumstrukturen, zeigen sich auffällige Übereinstimmungen: Bei den Dialekten, die die stärkste Annäherung an das Italienische zeigen, handelt es sich größtenteils um jene, in denen in den vergangenen fünfzig Jahren eine Angleichung an den dialektalen Großraum im Westen stattgefunden hat, die in Montella (839), Pòllica (872) und Anacapri (851) vor allem das Lexikon (vgl. Karten A63 und A64) und in Barano d'Ischia (833) und Pròcida (834) den Konsonantismus 
betrifft (vgl. Karten A73 und A74). In diesen Dialekten ist also die Annäherung an das Standarditalienische parallel zu den sprachlichen Angleichungsprozessen - und letztere damit zumindest zum Teil über erstere - verlaufen. Dieser Zusammenhang wird durch die geographische Verteilung der Dialekte am unteren Ende des Wertebereichs bestätigt: Bei den Dialekten, die heute die geringste Ähnlichkeit zum Standarditalienischen aufweisen, handelt es sich um solche, die im Lexikon (Fontegreca (810), Sorrento (852), Alfano (873), Quaglietta (840), Bovino (819), s. Karte A56) und/oder im Konsonantismus (Casal di Prìncipe (823), Quaglietta (840), Bovino (819), s. Karte A58) und/oder im Vokalismus (Bovino (819), s. Karte A60) heute nicht zum dialektalen Großraum gehören. Das bedeutet nicht, dass hier keine Italianisierungsprozesse stattgefunden hätten - alle Punkte weisen heute höhere Ähnlichkeitswerte zum Standarditalienischen auf als in den 1960er Jahren. Aber den Teil der Italianisierung, der im Zusammenhang mit den dialektalen Ausgleichsprozessen steht, die in den vergangenen fünfzig Jahren in der Campania stattgefunden haben, haben die genannten Gebiete nicht durchlaufen.

Im Lexikon weisen die kampanischen Dialekte gegenwärtig eine deutlich höhere durchschnittliche Ähnlichkeit zum Standarditalienischen auf als im Totalkorpus (s. Tab. 35). Besonders auffällig ist hier, dass fast ein Drittel der Dialekte (10) eine verhältnismäßig geringe Ähnlichkeit zum Standarditalienischen (Wertklasse [1]) aufweist und sich numerisch deutlich von den folgenden Dialekten abhebt (Wertklasse [2] bleibt leer, s. Karte A116). Unter den standardfernen Dialekten, die sich über die gesamte Region verteilen, weisen gleich drei Dialekte (Bovino (819), Quaglietta (840), Casal di Prìncipe (823)) den minimalen Ähnlichkeitswert auf alle sind Dialekte, die bereits bei der Analyse der interdialektalen Beziehungen durch ihre Sonderstellung aufgefallen sind. Sie sind also auch die Dialekte, die ihre lexikalischen Besonderheiten besonders gut gegen Übernahmen aus dem italiano standard abschirmen können. Die Gründe für diese ausgeprägte Resistenz gegenüber der Übernahme lexikalischer Elemente aus dem Standarditalienischen sind im metalinguistischen bzw. im soziokulturellen Bereich (Spracheinstellungen, Sprachbewusstsein, Sprachloyalität etc.) zu verorten. Die Dialekte, die die höchsten Ähnlichkeitswerte zum Italienischen (Wertklassen [5] und [6]) und damit die stärkste Bereitschaft zur Übernahme von Italianismen aufweisen, sind ebenfalls über das gesamte Gebiet verteilt: Sie finden sich in der Terra di Lavoro (Rocca d'Evandro (809), Castel Volturno (822)), auf den Isole Flegree (Barano d'Ischia (833), Pròcida (834)), im Westcilento (Pòllica (872)), am Übergang zwischen Cilento und Irpinia (Postiglione (857), Salvitelle (858)) sowie in der Irpinia selbst (Montella (839)). Quaglietta (840) in der Irpinia stellt eine gegen die Übernahme von Italianismen resistente ,Insel' inmitten von relativ ,italianismen-freundlichen“ Gebieten dar. Dies korreliert mit der bei der Analyse der Maxima im lexikalischen Bereich gemachten Beobachtung zum ,Inselcharakter' des Ortes (vgl. Kap. 5.5.3).

Der diachronisch vergleichende Blick auf das Verhältnis der kampanischen Dialekte zum Standarditalienischen zeigt, dass im Lexikon in den vergangenen fünfzig Jahren die deutlichste Annäherung der kampanischen Dialekte an das Standarditalienische stattgefunden hat (s. Tab. 35), was die bezüglich der Hierarchie der Sprachkontaktphänomene im Allgemeinen bzw. zur ,Anfälligkeit‘ der sprachlichen Teilbereiche gegenüber Einflüssen aus dem Italienischen im Speziellen getätigten Aussagen (vgl. Kap. 2.3.2) bestätigt. Unter den Dialekten, die nach wie vor eine verhältnismäßig hohe Resistenz gegenüber lexikalischen Einflüssen aus dem Standarditalienischen aufweisen (Wertklassen [1] und [2] sowohl in den 1960er Jahren als auch 2014) finden sich Quaglietta/Senerchia (840) in der Irpinia, Ginestra degli Schiavoni (816) im Sannio und Casal di Prìncipe (823) in der Metropolregion Neapel (vgl. Karten A115 und A116).

Im Konsonantismus spiegelt das Ähnlichkeitsprofil des Standarditalienischen sowohl im numerischen Bereich als auch hinsichtlich der Raumstrukturen über weite Strecken jenes im 
Totalkorpus wider. Die auffälligste numerische Abweichung findet sich dabei im unteren Wertebereich, wo sich die bereits bei der Analyse der interdialektalen Verhältnisse aufgefallenen konsonantischen Besonderheiten des Dialekts von Casal di Prìncipe (823, MIN, s. Karte A118) in einer extrem geringen Ähnlichkeit zum italiano standard manifestieren (s. Tab. 35). Die diachronische Entwicklung ist - den Parallelen im Totalkorpus entsprechend - auch im Konsonantismus durch eine deutliche Annäherung der kampanischen Dialekte an das Standarditalienische geprägt, die sich am deutlichsten in Pròcida (834) beobachten lässt (Wertklasse [1] $\rightarrow$ Wertklasse [5], vgl. Karte A117 und A118). Es fällt auf, dass sich fast alle Dialekte, die in den 1960er Jahren noch zu den standardfernsten zählten (Wertklassen [1] und [2], d.h. die Dialekte der Isole Flegree, im neapolitanischen Hinterland (Roccaraìnola (836), Maiori (854)) und im Westcilento, heute in den mittleren Wertklassen finden, sich also in den vergangenen fünfzig Jahren im Hinblick auf die Standardnähe an den Großteil der kampanischen Dialekte angeglichen haben (in Pròcida (834) ist die Annäherung an das Standarditalienische über diese Angleichung hinausgegangen). Die Tatsache, dass es sich hier - wie im Totalkorpus - um genau die Gebiete handelt, in denen im gleichen Zeitraum (besonders im Konsonantismus) starke interdialektale Ausgleichsprozesse stattgefunden haben (vgl. Kap. 5.5.4), weist darauf hin, dass insbesondere im Konsonantismus ein Zusammenhang zwischen dem Prozess der Annäherung an das Standarditalienische und dem Prozess des Dialektausgleichs besteht.

Im Vokalismus sind die durchschnittliche Ähnlichkeit der kampanischen Dialekte zum Standarditalienischen geringer und - wie im Falle der interdialektalen Verhältnisse - die Spannweite der Werte deutlich größer als in den übrigen (Teil-)Korpora (s. Tab. 35). Die höchsten Ähnlichkeiten zum italiano standard (Wertklassen [5] und [6]) finden sich in den bereits durch ihren besonderen Vokalismus aufgefallenen peripheren Dialekten von Casaletto Spartano (874, MAX) im Süden und Reìno (815) im Norden der Region (s. Karte A120). Die Dialekte, die die geringsten Ähnlichkeiten zum Standarditalienischen aufweisen (Wertklassen [1] und [2]), liegen - mit Ausnahme von Benevento (825) - in der Peripherie (MIN in Bovino (819)) und sind größtenteils identisch mit jenen im Totalkorpus. In der Auffälligkeit, dass sowohl in der nördlichen als auch in der südlichen Peripherie von zwei benachbarten Dialekten jeweils einer (Reìno (815) und Casaletto Spartano (874)) eine verhältnismäßig hohe und einer (Gioia Sannìtica (814) und Alfano (873)) eine sehr geringe Ähnlichkeit zum Italienischen aufweist, werden die - zwischen Alfano und Casaletto Spartano bereits in den 1960er Jahren, zwischen Gioia Sannìtica und Reìno erst heute beobachtbaren - strukturellen Unterschiede zwischen den jeweiligen Dialekten deutlich.

Der diachronische Vergleich zeigt, dass in den kampanischen Dialekten im Vokalismus insgesamt lediglich eine marginale Annäherung an das Standarditalienische stattgefunden hat (s. Tab. 35). Im vokalischen Bereich zeigen die Dialekte also eine große inhärente Stabilität, die die Übernahme von Merkmalen aus dem Standarditalienischen größtenteils verhindert. Der einzige deutliche Unterschied findet sich im Bereich des Maximums, wo sich im Dialekt von Casaletto Spartano (874) die Ähnlichkeit zum Italienischen deutlich vergrößert hat. Im Bereich der Raumstrukturen (vgl. Karte A119 und A120) zeigt sich größtenteils diachronische Stabilität, teilweise lassen sich aber auch (drastische) Entwicklungen beobachten. Erstere findet sich einerseits im Dialekt von Casaletto Spartano (874), der über die Zeit hinweg seine Position als kampanischer Dialekt mit der größten Standardnähe erhalten hat und andererseits in den Dialekten von Bovino (819) und Casal di Prìncipe (823), die nach wie vor sehr geringe Ähnlichkeitswerte zum Italienischen aufweisen. Eine deutliche Annäherung an das Standarditalienische zeigt sich in Pròcida (834, Wertklasse [1] $\rightarrow$ Wertklasse [4]), das eine ähnliche Entwicklung bereits im konsonantischen Bereich gezeigt hat (s.o.). Die größte Veränderung im Verhältnis 
zum Standarditalienischen findet sich jedoch in Gioia Sannìtica (814), dessen Dialekt in den 1960er Jahren zu jenen mit den größten Ähnlichkeiten zum Italienischen gehörte und heute durch eine verhältnismäßig große Standardferne gekennzeichnet ist. Diese Entwicklung ist auf die Aufgabe vokalischer Besonderheiten zurückzuführen, die bereits in der Integration in den dialektalen Großraum im Westen der Region deutlich geworden ist (vgl. Kap. 5.5.2).

\begin{tabular}{|c|c|c|c|c|c|c|c|c|c|c|}
\hline \multirow{2}{*}{$\begin{array}{c}\text { Kenn- } \\
\text { wert }\end{array}$} & \multicolumn{2}{|c|}{ TOT } & \multicolumn{2}{c|}{ LEX } & \multicolumn{2}{c|}{ PHON } & \multicolumn{2}{c|}{ KONS } & \multicolumn{2}{c|}{ VOK } \\
\cline { 2 - 11 } & 1960 & 2014 & 1960 & 2014 & 1960 & 2014 & 1960 & 2014 & 1960 & 2014 \\
\hline MIN & 23,64 & 34,74 & 28,57 & 50,89 & 16,47 & 24,28 & 17,05 & 24,00 & 14,63 & 16,67 \\
\hline MW & 33,53 & 50,23 & 36,41 & 60,15 & 31,75 & 43,80 & 32,74 & 48,37 & 28,64 & 31,90 \\
\hline MAX & 42,91 & 60,35 & 46,67 & 77,68 & 47,06 & 57,23 & 53,49 & 62,40 & 46,34 & 60,42 \\
\hline
\end{tabular}

Tabelle 35. Statistische Kennwerte der Ähnlichkeiten der kampanischen Dialekte zum Standarditalienischen im ALI-Korpus (1960) und im Vergleichskorpus (2014). Messmoment jeweils RIW $j k$.

Die Analyse der Entwicklung des Verhältnisses der kampanischen Dialekte zum Standarditalienischen hat gezeigt, dass in den vergangenen fünfzig Jahren eine deutliche Annäherung der Dialekte an das Italienische stattgefunden hat, die sich insbesondere im lexikalischen Bereich manifestiert. Während die Annäherung an das Standarditalienische im Konsonantismus zwar geringer als im Lexikon, jedoch noch deutlich sichtbar ist, zeigt sich der Vokalismus gegenüber einer Annäherung an das italiano standard resistent. Die dialektometrischen Ergebnisse bestätigen damit die auf qualitativer Basis vorgenommenen Analysen zum Prozess der Italianisierung der kampanischen Dialekte (vgl. Kap. 3.3.6) und spiegeln gleichzeitig die Unterschiede im Bereich der inhärenten Stabilität der sprachlichen Bereiche wider (vgl. Kap. 2.3.2). In der besonders im Konsonantismus zu beobachtenden - Kongruenz zwischen den Gebieten, in denen ein deutlicher Anstieg einer vormals relativ geringen Ähnlichkeit zum Standarditalienischen zu beobachten ist, und den Gebieten, in denen in den vergangenen fünfzig Jahren sprachliche Angleichungsprozesse stattgefunden haben, wird der Zusammenhang zwischen dem Prozess der Italianisierung (im Sinne einer Annäherung der Dialekte an das Italienische) und dem Prozess des Sprach- bzw. Dialektausgleichs dialektometrisch sichtbar.

\subsubsection{Zusammenfassung und Interpretation}

Die vergleichende dialektometrische Analyse des aus den 1960er Jahren stammenden ALIKorpus und des 2014 erhobenen Vergleichskorpus hat deutliche Aufschlüsse über die diachronische Entwicklung der interdialektalen Ähnlichkeitsverhältnisse und der damit verbundenen sprachlichen Raumstrukturen in der Campania sowie über jene des Verhältnisses zwischen den kampanischen Dialekten und dem Standarditalienischen gegeben. In der Campania ist in den vergangenen fünfzig Jahren eine interdialektale Annäherung zu beobachten, die zu einer Verbesserung der sprachlichen Integration der Dialekte und damit zu einer stärkeren Kompaktheit des Dialektgebietes geführt hat.

Die Bildung des dialektalen Großraums im Westen der Region, die im Lexikon bereits in den 1960er Jahren abgeschlossen war, hat sich in den vergangenen fünfzig Jahren auch im Konsonantismus vollzogen. Die Verlagerung der sprachlichen Bezugspunkte von der Küste in 
das neapolitanische Hinterland bzw. nach Salerno zeigt, dass es sich hier nicht um eine Neapolitanisierung, d.h. um eine Übernahme der Merkmale des Neapolitanischen in die übrigen Dialekte, sondern um einen Ausgleich zwischen diesen, d.h. eine Durchmischung ihrer Merkmale (vgl. Kap. 4.3.7.4) handelt. Da Neapel jedoch für die weiter entfernten Gebiete der Region (Sannio, Irpinia, Cilento) auch ehemals nicht und für seine engere geographische Umgebung nur im lexikalischen Bereich die Rolle eines Bezugspunkts innehatte, kann - zumindest im Hinblick auf die gesamte Region - von einem ,Verblassen` der sprachlichen ,Ausstrahlung' der Metropole keine Rede sein. Bei der Entwicklung der dialektalen Variation in der Campania sind sowohl in jüngster Zeit als auch historisch gesehen schlicht andere ,soziale Kräfte‘ (vgl. Kap. 4.4) als der Status des Neapolitanischen bestimmend (gewesen).

Parallel zur interdialektalen Angleichung bzw. zur Nivellierung der dialektalen Differenzen in der kampanischen Küstenebene lässt sich im Westcilento eine sprachliche Angleichung an den nördlich gelegenen dialektalen Großraum beobachten. Diese hat sich bereits in den 1960er Jahren dadurch angedeutet, dass (insbesondere im Vokalismus) in den entsprechenden Dialekten eine verhältnismäßig hohe Bereitschaft zum Sprachausgleich bestand. Die heute aufscheinenden Raummuster sind also keine einer ungeordneten Variation entspringenden $\mathrm{Zu}$ fallsprodukte, sondern nach bestimmten Gesetzmäßigkeiten gewachsene Strukturen. Auch in einigen Dialekten im Osten der Region fand und findet - vor allem in den Bereichen des Konsonantismus und des Lexikons - eine Angleichung an den dialektalen Großraum statt, die ,auf Kosten' der sprachlichen Kohäsion in den ehemaligen dialektalen Mikro-Arealen (Sannio, Nordcilento-Irpinia) geschieht. Dadurch, dass andere Dialekte ihre (konsonantischen und/oder lexikalischen) Besonderheiten stärker konservieren, weist das Gebiet östlich des dialektalen Großraums in diesen sprachlichen Bereichen heute eine verhältnismäßig hohe Fragmentierung auf. Im Vokalismus zeigt sich aufgrund der abweichenden Ausgangslage - d.h. der bereits in den 1960er Jahren bestehenden verhältnismäßig hohen Kompaktheit des kampanischen Dialektgebietes - eine andere diachronische Entwicklung, die - vor allem im Westen der Region von einem weiteren Anwachsen der Kohäsion im Großraum und dem Erhalt der Raumstruktur ,Zentrum - Peripherie' gekennzeichnet ist. Obwohl auch in den peripheren Dialekten Tendenzen zur Annäherung an den sprachlichen Großraum bestehen, haben diese ihre Sonderstellung den übrigen Dialekten gegenüber meist gut konserviert und nur in Einzelfällen aufgegeben.

Die Entwicklung der sprachlichen Raumstrukturen, die in den vergangenen fünfzig Jahren im kampanischen Dialektgebiet stattgefunden hat, zeichnet sich insgesamt dadurch aus, dass kleinräumige, durch starke ,Sympathien` zwischen benachbarten Dialekten und wechselseitige ,Antipathien` zwischen kompakten Dialektgebieten geprägte Raummuster großräumigeren Strukturen gewichen sind, die durch gemeinsame sprachliche ,Sympathieträger' einerseits und kollektive ,Abneigung' gegenüber sprachlichen, meist peripher situierten ,Außenseitern' andererseits bestimmt werden. Es handelt sich also um die Ablösung einer kleinräumigen, ,polyzentrischen' Ordnung durch eine großräumige Ordnung vom Typ ,Zentrum - Peripherie‘. Dabei treten als neue ,Sympathieträger' bzw. Bezugspunkte diejenigen Dialekte hervor, in denen zwischen konkurrierenden dialektalen Varianten offensichtlich der beste Kompromiss gefunden werden konnte.

Die räumliche Progression der sprachlichen Ausgleichsprozesse - und damit der Integration der Dialekte in den sprachlichen Großraum - wird besonders im lexikalischen Bereich gut sichtbar. Während sich im Westen der Region die in den 1960er Jahren noch verhältnismäBig starken sprachlichen Ausgleichstendenzen auf einem mittleren Niveau ,eingependelt', die Dialekte also ihren neuen Platz innerhalb der Dialektlandschaft gefunden haben, hat die sprachliche Nivellierungsdynamik gegenwärtig die Gebiete an der östlichen Grenze des dialektalen 
Großraums erreicht. Im Konsonantismus zeigt sich im Cilento eine letzte kompakte ,Bastion“ gegenüber den die übrigen Gebiete prägenden sprachlichen Ausgleichsprozessen. Im Vokalismus ist die Integration der Dialekte im Westcilento und in der Irpinia abgeschlossen und beginnt nun in den peripheren Gebieten mit besonders speziellem Vokalismus.

Die diachronischen Entwicklungen der interdialektalen Ähnlichkeiten zeitigen Veränderungen im Verhältnis zwischen Sprach- und Naturraum. Während im Konsonantismus die Bildung des dialektalen Großraums im Westen der Region am stärksten ins Gewicht fällt, sodass sich eine Zunahme der Harmonie zwischen Sprach- und Naturraum beobachten lässt, führt die Angleichung der östlichen Dialekte an den westlichen dialektalen Großraum im Lexikon wo dieser bereits in den 1960er Jahren existierte - zu einer allgemeinen Verschlechterung des Verhältnisses zwischen sprachlicher und räumlicher Nähe. Im Vokalismus manifestiert sich die Kompaktheit des kampanischen Dialektgebietes heute wie damals in einer geringen Korrelation zwischen den sprachlichen und den geographischen Ähnlichkeitsprofilen der Messpunkte.

Die diachronischen Entwicklungen der sprachlichen Raumordnung sind sprachgeographische Reflexe der Veränderungen, die sich im Bereich der sprachlichen Interaktions- bzw. Kommunikationsstrukturen in der Campania vollzogen haben. Diese wiederum können (unter anderem) in Zusammenhang gebracht werden mit den demographischen Entwicklungen, die in der Campania in den vergangenen Jahrzehnten stattgefunden haben. So können die Bildung des dialektalen bzw. kommunikativen Großraums in der kampanischen Küstenebene und im Westcilento und die damit einhergehende Verlagerung des dialektalen, Zentrums ' mit dem Prozess der Deurbanisierung (vgl. Kap. 3.1) und dem demographischen Wachstum im neapolitanischen Hinterland und an der Küste der Provinz Salerno in Verbindung gebracht werden. Die heute in Richtung Osten fortschreitende Angleichung der peripheren Dialekte an den westlichen Großraum weist auf eine (wenn auch langsam) fortschreitende Eingliederung der östlichen Teile der Region in den kommunikativen Großraum hin.

Neben den durch den Dialektausgleich bedingten Veränderungen im Bereich der sprachlichen Raumstrukturen lässt sich in der diachronischen Entwicklung der kampanischen Dialekte eine Annäherung an das Standarditalienische beobachten, die vor allem den (nichtstrukturellen) lexikalischen Bereich, aber auch den (strukturellen) konsonantischen Bereich betrifft. Die Parallelität der Prozesse des Sprachausgleichs und der Italianisierung lässt den Schluss zu, dass die Differenzen zwischen den verschiedenen Basisdialekten unter anderem durch die Ersetzung von (lokal unterschiedlichen) Dialektismen bzw. dialektalen konsonantischen Merkmalen durch Italianismen bzw. konsonantische Merkmale des Italienischen nivelliert werden. Weitestgehend unberührt von dem Prozess der Annäherung an das Standarditalienische bleibt bisher der kampanische Vokalismus, der sich als stabiles und damit gegenüber äußeren Einflüssen gut abgeschirmtes sprachliches Teilsystem erweist. 


\section{Forschungsbeitrag und Perspektiven}

Ziel der vorliegenden Arbeit war es zum Einen, durch eine quantitative, dialektometrische Analyse der diatopischen Variation und ihrer diachronischen Entwicklung in der Region Kampanien einen Beitrag zur Ergänzung der bisher dazu vorliegenen Forschung zu leisten. Hinsichtlich der basilektalen Gliederung, die vor dem Wirksamwerden der grundlegenden soziolinguistischen Veränderungen in der zweiten Hälfte des 20. Jahrhunderts bestand, konnte die bereits in qualitativen Studien postulierte starke Heterogenität des kampanischen Dialektgebietes bestätigt werden. Es wurde deutlich, dass die diatopische Variation in den 1960er Jahren eine auffällig kleinräumige Ordnung aufwies, die mit historischen (Siedlungs-) Grenzen in Zusammenhang gebracht werden kann. Das Desiderat einer wissenschaftlichen, quantitativen Klassifikation der kampanischen Dialekte konnte für die Bereiche der Phonetik und des Lexikons erfüllt werden.

Im Hinblick auf die diachronische Entwicklung der diatopischen Variation in der Campania widerlegen die Ergebnisse der Untersuchung die Annahmen der qualitativen sprachgeographischen Forschung. Die diachronisch vergleichende dialektometrische Analyse hat gezeigt, dass die Entwicklung der diatopischen Variation in der Campania in den vergangenen fünfzig bis sechzig Jahren nicht durch eine (zentripetale) ,Neapolitanisierung', d.h. die Bildung einer regionalen Koine auf der Basis des neapolitanischen Dialekts, sondern durch (zentrifugale) dialektale Ausgleichstendenzen gekennzeichnet ist, welche die demographische Entwicklung insbesondere im Westen der Region widerspiegeln. Für die italienische Geolinguistik ergibt sich daraus, dass die Entwicklung der diatopischen Variation in einem bestimmten Dialektgebiet immer im Einzelfall und vor allem auch unter Berücksichtigung der jeweiligen demographischen Entwicklung analysiert werden muss und die in Norditalien beobachteten Tendenzen der Bildung von Koinai auf der Basis von (italianisierten) städtischen Dialekten nicht pauschal auf das süditalienische Dialektgebiet übertragen werden dürfen.

Die Arbeit hat zudem Hinweise darauf geliefert, dass der in den vergangenen Jahrzehnten beobachtbare Dialektausgleich vor allem im lexikalischen Bereich parallel zur Italianisierung der Dialekte verläuft, während sich der kampanische Vokalismus den Einflüssen des Standardtalienischen gegenüber als resistent erweist. In Ergänzung der vorgenommenen global-synthetischen Auswertung kann hier eine qualitative und quantitativ-statistische Analyse der erhobenen Daten - also eine Untersuchung der Entwicklung der Frequenz und der diatopischen Verteilung der einzelnen phonetischen Varianten bzw. Lexeme - detaillierte Einblicke in den Prozess der Ersetzung dialektaler Merkmale und Lexeme durch standarditalienische Äquivalente geben. Andererseits können dadurch auch diejenigen dialektalen Merkmale und Lexeme identifiziert werden, die sich im Zuge des Dialektausgleichs in einem größeren Gebiet verbreitet haben und damit - in einer sprachprognostischen Perspektive - hinsichtlich einer Ersetzung durch die entsprechende italienische Variante als weniger, gefährdet' gelten können. Zur Überprüfung und Ergänzung des dialektometrischen Ergebnisses wäre eine Ausdehnung der globalsynthetischen Analyse auf den Bereich der Morphologie und der (Morpho-)Syntax wünschenswert. Eine solche Erweiterung könnte zudem wichtige Hinweise darauf liefern, ob und wenn ja, inwieweit sich der Einfluss des Italienischen in den ,inneren', gegenüber externen Einflüssen am besten ,geschützten' sprachlichen Bereichen bemerkbar macht. Zur Weiterführung der Arbeit bieten sich darüber hinaus die Erhebung und dialektometrische Auswertung metasprachlicher Daten, d.h. subjektiver Beurteilungen der sprachlichen (lexikalischen bzw. phonetischen) Ähnlichkeiten im Dialektgebiet Kampanien (mental maps) und ein Vergleich der Ergebnisse mit den objektiv gemessenen Ähnlichkeitswerten der vorliegenden Analyse an. Eine solche 
Studie gäbe Aufschluss darüber, inwieweit die in den vergangenen Jahrzehnten beobachtbaren Entwicklungen der sprachlichen Raumstrukturen bereits Eingang in die Wahrnehmung der Sprecher gefunden haben und böte im Falle von Diskrepanzen zwischen den Ergebnissen der vorliegenden und jenen der metasprachlichen Untersuchung Anlass zu Studien zu den soziolinguistischen Hintergründen der von den tatsächlichen sprachgeographischen Verhältnissen differierenden subjektiven Bewertungen.

Auch wenn die Sichtbarmachung sprachlicher Raumstrukturen mit einem Ortsnetz durchschnittlicher Dichte in kleinräumigen Arealen aufgrund der größeren Relevanz von Abweichungen in einzelnen Messpunkten um einiges schwieriger ist als in geographischen Großräumen, hat die vorliegende Untersuchung doch gezeigt, dass der Einsatz einer dialektometrischen Methodik bei der Analyse sprachlicher Raumstrukturen in Dialektgebieten, die mit den Mitteln der qualitativen Sprachgeographie nicht adäquat beschrieben werden können, von hohem heuristischem Wert ist. Der Verzicht auf das methodisch unzulängliche Konzept der Isoglosse und die Berücksichtigung einer Vielzahl sprachlicher Merkmale ermöglichen eine Steigerung der Objektivität und Reliabilität bei der Analyse und Klassifikation komplexer Dialektgebiete. Auch hinsichtlich der Analyse der diachronischen Entwicklung sprachlicher Raumstrukturen hat sich der Einsatz der Dialektometrie als fruchtbar erwiesen.

Die Ergebnisse der Analyse der diachronischen Entwicklung des Verhältnisses zwischen den kampanischen Dialekten und dem Standarditalienischen zeigen ferner, dass es mithilfe der Dialektometrie auch möglich ist, nicht raumgebundene Entwicklungen in der Struktur von Dialekten (hier: Italianisierungstendenzen) sichtbar zu machen. Bei weiteren Untersuchungen dieser Art wird jedoch zu berücksichtigen sein, dass die (numerischen) Resultate aller Wahrscheinlichkeit nach mit der Wahl der Varietät des Italienischen (grob gesehen: schriftlich (italiano scritto) oder mündlich (italiano parlato) konzipiertes Italienisch), der die Daten für die Bezugsgröße italiano standard (= Kartentitel bzw. abgefragte Items) entnommen werden, variieren. Es ist ersichtlich, dass sich bei der Wahl von Varianten, die nur oder auch im italiano parlato vorkommen, eine größere durchschnittliche Ähnlichkeit zwischen den Dialekten und dem Italienischen ergeben wird als bei der Wahl von Varianten, die sich vorrangig oder nur im italiano scritto finden lassen (vgl. z.B. primär schriftlich gebrauchtes ventre vs. mündlich gebrauchtes pancia; schriftliches stringhe vs. mündliches lacci, schriftliches turacciolo vs. mündliches tappo etc.). Die Wahl von Varianten aus dem italiano parlato ist im Hinblick auf die sprachliche Realität sicherlich von Vorteil. Angesichts der Tatsache, dass nahezu jede Form des gesprochenen Italienischen zumindest phonetisch leicht regional markiert ist, birgt die Identifikation überregionaler Merkmale jedoch Schwierigkeiten. Dies führt insbesondere dann zu Problemen, wenn ein Vergleich verschiedener Dialektareale im Hinblick auf das Vorliegen von Italianisierungstendenzen mit dem italiano parlato als Bezugsgröße erfolgen soll, welcher nicht nur von sprachgeographischem, sondern auch von dialektologischem und soziolinguistischem Interesse wäre.

In einem größeren Rahmen betrachtet zeigen die Ergebnisse der vorliegenden Arbeit, dass eine Öffnung der italienischen Geolinguistik gegenüber dialektometrischen Verfahren dringend notwendig ist. Die Erforschung komplexer Dialektgebiete wie der Campania kann nur dann zu einem zufriedenstellenden Ergebnis führen, wenn die Beiträge verschiedener mit sprachlicher Variation befasster Disziplinen wie Dialektometrie, pluridimensionale Geolinguistik und Soziolinguistik als komplementär und nicht als antagonistisch begriffen werden. Die Ergänzung der Ergebnisse soziolinguistischer bzw. variationswissenschaftlicher Studien durch primär geolinguistisch orientierte, dialektometrische Untersuchungen, die in wissenschaftlichem Austausch mit Disziplinen wie der Humangeographie, der Kulturanthropologie oder der 
6 Forschungsbeitrag und Perspektiven

Ethnographie stehen, sollte daher künftig in stärkerem Maße von der italienischen Varietätenlinguistik verfolgt werden. 


\section{Bibliographie}

\section{Quellen}

Plinius Secundus, Gaius: C. Plini Secundi Naturalis Historiae. Libri XXXVII. Ed. Carolus Mayhoff. Vol. III. Libri XVI - XXII. Lipsiae: Teubner, 1967. Ed. stereotypa ed. prioris (1892).

Tacitus, Cornelius: Annalen. Lateinisch - Deutsch. Hg. von Erich Heller. Mit einer Einführung von Manfred Fuhrmann. München/Zürich: Artemis \& Winkler, ${ }^{6} 2010$.

\section{Sekundärliteratur}

AA.VV. (1989): Atlanti regionali: aspetti metodologici, linguistici e etnografici. Atti del XV Convegno des C.S.D.I. Pisa: Pacini.

Acocella, G. ( $\left.{ }^{2} 2002\right)$ : Dizionario del dialetto calitrano. Plano, Texas (USA).

ADDU-Norte = Thun, H./Elizaincín, A. (2000): Atlas lingüístico Diatópico y Diastrático del Uruguay - Norte. Kiel: Westensee.

Agostiniani, L. (1975): „Rafforzamento sintattico e articolo in alcuni dialetti meridionali“. Archivio Glottologico Italiano 60, 192-200.

AIS = Jaberg, K./Jud, J. (1928-1940): Sprach- und Sachatlas Italiens und der Südschweiz. Zofingen: Ringier.

ALC = Griera, A. (1923-1964): Atlas Lingüístic de Catalunya . Barcelona: Institut d'Estudis Catalans.

ALCam = Radtke, E. (1997ff.): Atlante Linguistico della Campania .

ALD I = Goebl, H. (1998): Atlant linguistich dl ladin dolomitich y di dialec vejins, la pert / Atlante Linguistico del ladino dolomitico e dei dialetti limitrofi, la parte / Sprachatlas des Dolomitenladinischen und angrenzender Dialekte, 1. Teil. Wiesbaden: Reichert.

ALDC = Veny, J./Pons i Griera, L. (2001-2010): Atles Lingüístic del Domini Català. Barcelona: Institut d'Estudis Catalans.

ALEA = Alvar, M. (1961-1973): Atlas lingüístico y etnografico de Andalucia. Grenada: Universidad de Granada.

ALEANR = Alvar, M. (1979-1983): Atlas Lingüístico y Etnográfico de Aragón, Navarra y Rioja. Madrid: Ed. La Muralla.

ALECMan = García Mouton, P./Moreno Fernández, F. (1987ff.): Atlas Lingüístico (y etnográfico) de Castilla - La Mancha. Alcalá: Universidad de Alcalá.

Alessio, G. (1942/1943): „L'elemento latino e quello greco nei dialetti del Cilento“. Rendiconti dell'Istituto Lombardo di Scienze e Lettere 76, 341-360.

$\mathrm{ALF}=$ Gilliéron, J./Edmont, E. (1902-1910): Atlas Linguistique de la France. Paris: Champion.

ALG = Séguy, J. (1954-1973): Atlas Linguistique et ethnographique de la Gascogne. Paris: C.N.R.S.

ALI = Bartoli, M. G./Pellis, U. et al. (1995-2008): Atlante Linguistico Italiano. Rom: Istituto Poligrafico e Zecca dello Stato.

Allières, J. (1960-1961): Petit atlas linguistique basque-français ,Sacaze؛ Toulouse: Université de Toulouse Le Mirail.

Allulli, M. (2010): La riforma metropolitana e i suoi dilemmi. Rapporto Cittalia 2010. http://www.anci.it/Contenuti/Allegati/La\%20riforma\%20metropolitana.pdf 
ALLy = Gardette, P. (1950-1976): Atlas linguistique et ethnographique du Lyonnais. Paris: C.N.R.S.

ALM = Lope Blanch, J. M. (1990-2000): Atlas Lingüístico de México. Mexiko: Colegio de México [u.a.].

ALMC = Nauton, P. (1957-1963): Atlas linguistique et ethnographique du Massif Central. Paris: C.N.R.S.

ALPI = Consejo Superior de Investigaciones Científicas (1962): Atlas Lingüístico de la Península Ibérica. I. Fonética. Madrid.

ALPO = Guiter, H. (1966): Atlas Linguistique des Pyrénées Orientales. Paris: C.N.R.S.

ALR = Academia Republicii Populare Romîne, Institutul de Lingvistică (1956-1972): Atlasul Lingvistic Romîn. Serie nouă. Cluj.

ALS = Ruffino, G. (1996ff.): Atlante Linguistico della Sicilia.

Altamura, A. $\left({ }^{2} 1968\right)$ : Dizionario dialettale napoletano. Neapel: Fiorentino.

Altmann, G. (1985): „Die Entstehung diatopischer Varianten: Ein stochastisches Modell“. Zeitschrift für Sprachwissenschaft 4/2, 139-155.

Altmann, G./Lehfeldt, W. (1973): Allgemeine Sprachtypologie. Prinzipien und Meßverfahren. München: Fink.

Amenta, N. (1723-1724): Della lingua nobile d'Italia, E del modo di leggiadramente scrivere in essa, non che di perfettamente parlare. 2 Bände. Neapel: A. Muzio.

Andalò, A. (1991): „Il raddoppiamento sintattico nel dialetto di Napoli.“ In: Gianelli, L./ Maraschio, N./Poggi Salani, T./Vedovelli, M. (Hg.): Tra Rinascimento e strutture attuali. Saggi di linguistica italiana. Turin: Rosenberg \& Sellier, 241-251.

Ascoli, G. I. (1876): „P. Meyer e il franco-provenzale“. Archivio Glottologico Italiano 2, $385-$ 395.

Atlante Nazionale del Territorio Rurale. Regione Campania (2010). Herausgegeben vom Ministero delle Politiche Agricole, Alimentari e Forestali.

http://www.reterurale.it/atlante/campania/pdf/pdf_monografia/s_monografia_campani a.pdf

Atwood, E. B. (1963): „The methods of American Dialectology.“ Zeitschrift für Mundartforschung 30 (1), 1-30.

Avolio, F. (1989): „Il limite occidentale dei dialetti lucani nel quadro del gruppo «altomeridionale»: considerazioni a proposito della linea Salerno-Lucera“. L'Italia Dialettale. Rivista di dialettologia italiana 52, 1-21.

Avolio, F. (1995): Bommèspra. Profilo linguistico dell'Italia centro-meridionale. San Severo: Gerni.

Bafile, L. (1997): „L'innalzamento vocalico in napoletano: un caso di interazione tra fonologia e morfologia." In: Agostiniani, L. et al. (Hg.): Atti del III Convegno della Società Internazionale di Linguistica e Filologia Italiana. Neapel: Edizioni Scientifiche Italiane, Bd. I, 127-148.

BALI = Istituto dell'Atlante Linguistico Italiano (1933ff.): Bollettino dell'Atlante Linguistico Italiano. Turin.

Bartoli, M. G. (1925): Introduzione alla neolinguistica. Principi - scopi - metodi. Genf: Olschki.

Bartoli, M. G. (1945): Saggi di linguistica spaziale. Turin: Bona.

Bartoli, M. G./Pellis, U. (1995): Verbali delle inchieste. 2 Bände. Turin: Istituto Poligrafico e Zecca dello Stato. 
Bauer, R. (2004): „Dialekte - Dialektmerkmale - dialektale Spannungen. Von ,Cliquen“, ,Störenfrieden“ und ,Sündenböcken' im Netz des dolomitenladinischen Sprachatlasses ALD-I.“ Ladinia XXVIII, 201-242.

Bauer, R. (2005): „La classificazione dialettometrica dei basiletti altoitaliani e ladini rappresentati nell'Atlante linguistico del ladino dolomitico e dei dialetti limitrofi (ALD I)“. In: Guardiano, C. et al. (Hg.): Lingue, istituzioni, territori. Riflessioni teoriche, proposte metodologiche ed esperienz di politica linguistica. Atti del XXXVIII Congresso Internazionale di Studi della Società di Linguistica Italiana (SLI): Modena, 23-25 settembre 2004. Rom: Bulzoni, 347-365.

Bauer, R. (2009): Dialektometrische Einsichten. Sprachklassifikatorische Oberflächenmuster und Tiefenstrukturen im lombardo-venedischen Dialektraum und in der Rätoromania. San Martin de Tor: Istitut Ladin Micurà de Rü.

Baur, G. W. (1967): Die Mundarten im nördlichen Schwarzwald. Marburg: Elwert. (Reihe Deutsche Dialektgeographie: Untersuchungen zum Deutschen Sprachatlas, 55)

Beccaria, G. L. (1985): Spagnolo e spagnoli in Italia. Riflessi ispanici sulla lingua italiana del Cinque e del Seicento. Turin: Giappichelli.

Berruto, G. (1970): Dialetto e società industriale nella Valle d'Andorno. Note per una sociologia dei sistemi linguistici. Turin. (Supplement zu Bolletino dell'Atlante Linguistico Italiano, 1)

Berruto, G. (1984): „Zur Italianisierung der Mundarten in Italien im zwanzigsten Jahrhundert.“ Italienische Studien 7, 127-139.

Berruto, G. (1989): „Tra italiano e dialetto.“ In: Holtus, G./Metzeltin, M./Pfister, M. (Hg.): La dialettologia italiana oggi. Studi offerti a Manlio Cortelazzo. Tübingen: Narr.

Berruto, G. (1994): „Scenari sociolinguistici per 1'Italia del Duemila“. In: Holtus, G./Radtke, E. (op. cit.), 23-45.

Berruto, G. (1997): „Linguistica del contatto e aspetti dell'italianizzazione dei dialetti: appunti di creolistica casalinga“. In: Holtus, G./Kramer, J./Schweickard, W. (Hg.): Italica et Romanica. Festschrift für Max Pfister zum 65. Geburtstag. Tübingen: Niemeyer, 13-29.

Berruto, G. (2006): „Quale dialetto per l'Italia del Duemila? Aspetti dell'italianizzazione e risorgenze dialettali in Piemonte (e altrove)“. In: Sorbrero, A. A./Miglietta, A. (Hg.): Lingua e Dialetto nell'Italia del Duemila (Atti del convegno - Procida, 27-29 maggio 2004). Galatina: Congedo, 101-128.

Berruto, G. ( $\left.{ }^{5} 2010\right)$ : Fondamenti di sociolinguistica. Rom/Bari: Laterza (Reihe Manuali di base, 9).

Bianchi, P./De Blasi, N./Librandi, R. (1993): Storia della lingua a Napoli e in Campania. I’ te vurria parlà. Neapel: Pironti.

Bianchi, P./De Blasi, N./Librandi, R. ( $\left.{ }^{2} 2002\right)$ : „La Campania“. In: Bruni, F. (Hg.): L'italiano nelle regioni: Storia della lingua italiana. Bd. II. Turin: UTET, 190-263.

Bianchi, P./Maturi, P. (2006): „Dialetto e italiano negli usi linguistici dei parlanti di Napoli e della Campania“. In: De Blasi, N./Marcato, C. (Hg.): Lo spazio del dialetto in città. Neapel: Liguori, 1-21.

Bichelli, P. (1974): Grammatica del dialetto napoletano. Bari: Pégaso.

Bielenstein, J. G. A. (1892): Die Grenzen des lettischen Volkstammes und der lettischen Sprache in der Gegenwart und im 13. Jahrhundert. St. Petersburg: Eggers.

Blasco-Ferrer, E. (1994): Handbuch der italienischen Sprachwissenschaft. Berlin: E. Schmidt. Bloomfield, L. (1933): Language. New York: Holt, Rhinehart and Winston. 
Bock, H. H. (1974): Automatische Klassifikation. Theoretische und praktische Methoden zur Gruppierung und Strukturierung von Daten (Cluster-Analyse). Göttingen: Vandenhoeck \& Ruprecht.

Bossong, G. (1991): „Differential object marking in Romance and beyond“. In: Wanner, D./ Kibbee, D. A. (Hg.): New analyses in Romance linguistics. Amsterdam/Philadelphia: Benjamins, 143-170.

Bruni, F. (1984): L'italiano. Elementi di storia della lingua e della cultura. Turin: UTET.

Buonocore, A. (2007): Varietà dialettale microareale della costiera amalfitana. Dissertation (Manuskript), Universität Heidelberg.

Bußmann, H. (Hg.) ( $\left.{ }^{3} 2002\right)$ : Lexikon der Sprachwissenschaft. Stuttgart: Kröner.

Cain, A. J. (1958): „Logic and Memory in Linnaeus's System of Taxonomy“. In: Proceedings of the Linnean Society of London 169/1-2, 144-163.

Caprio, A./Giordano, A./Natale, M. (2003): Terra di Lavoro. Neapel: Alfredo Guida Editore.

Castellazzi, B. (2010): Guide to export Thiessen maps from ArcGIS 9.3 to VDM. Manuskript, Fachbereich Romanistik der Universität Salzburg.

Chambers, J. K./Trudgill, P. (1984): Dialectology. Cambridge: University Press.

Christaller, W. (1950): Das Grundgerüst der räumlichen Ordnung in Europa: die Systeme der europäischen zentralen Orte. Frankfurt a.M.: Kramer. (Reihe Frankfurter Geographische Hefte 24, 1)

Christaller, W. (1968 [1933]): Die zentralen Orte in Süddeutschland: eine ökonomisch-geographische Untersuchung über die Gesetzmäßigkeit der Verbreitung und Entwicklung der Siedlungen mit städtischen Funktionen. Darmstadt: Wiss. Buchgesellschaft.

Cilento, A. (2005): Bisanzio in Sicilia e nel sud dell'Italia. Udine: Magnus Edizioni SpA.

Cilento, N. (1966): Italia meridionale longobarda. Mailand [u.a.]: Ricciardi.

CLAE (1991-1997): The Computer Developed Linguistic Atlas of England. Herausgegeben von W. Viereck. 2 Bände. Tübingen: Niemeyer.

Colonna, G. (1981): „Gli Etruschi.“ In: Maetzke, G. (op. cit.), 65-72.

Como, P. (22007): La variabilità del dialetto: uno studio su Monte di Pròcida. Neapel: Liguori.

Como, P./Milano, E. (1999): „L'archivio di parlato dei dialetti campani: un esperimento di rappresentazione della variazione linguistica“" In: Marcato, G. (Hg.): Dialetti oggi. Tra lingua, cultura, società. Dialettologia sociologica. Atti del convegno di studi - Sappada/Plodn (BL), 1-4 luglio 1998. Padua: Unipress, 123-132.

Como, P./Milano, E. (2000): „La dinamica interna di fenomeni fonetici e morfosintattici a Procida e Monte di Procida“. In: Actes du XXIIe Congrès International de Linguistique et de Philologie Romanes, Bruxelles, 23-28 juillet 1998. Vol. 3: Vivacité et diversité de la variation linguistique. Tübingen: Niemeyer, 123-133.

Cortelazzo, M./Zolli, P. (1988): Dizionario etimologico della lingua italiana. Bologna: Zanichelli.

Coseriu, E. (1980): „Historische Sprache und Dialekt“. In: Göschel, J. et al. (Hg.): Dialekt und Dialektologie. Ergebnisse des Internationalen Symposions ,Zur Theorie des Dialekts“, Marburg 1977. Wiesbaden: Steiner, 106-115.

Crespi, F./Filippetti, A. (2008): „Le dinamiche della popolazione: re-urbanizzazione, immigrazione e mercato immobiliare“. In: Tortorella, W./Chiodini, L. (Hg.): Ripartire dalle città. Rapporto Cittalia 2008, 25-60.

http://www.cittalia.it/images/file/Cittalia2008.pdf?phpMyAdmin=95af31fc7e586d80e 7d664a36f07b8b6\&phpMyAdmin=3dc56f06dc02f3f7ac2bf9bdd4ec9b2f 
D’Agostino, M./Pennisi, A. (1995): Per una sociolinguistica spaziale. Modelli e rappresentazioni della variabilità linguistica nell'esperienza dell'ALS. Palermo: Centro di studi filologici e linguistici siciliani.

D'Ambra, R. (1873): Vocabolario napolitano-toscano domestico di arti e mestieri. Neapel: Selbstverlag.

Dardano, M./Trifone, P. (2005): La lingua italiana: morfologia, sintassi, fonologia, formazione delle parole, lessico, nozioni di linguistica e sociolinguistica. Bologna: Zanichelli.

D’Ascoli, F. (1990): Nuovo dizionario etimologico napoletano con appendice di aggiunte e correzioni. Neapel: Gallina.

D’Ascoli, F. (1993): Nuovo vocabolario dialettale napoletano. Neapel: Gallina.

Dauzat, A. ( $\left.{ }^{2} 1944\right):$ La géographie linguistique. Paris: Flammarion.

De Blasi, L. (1991): Dizionario dialettale di San Mango sul Calore (Avellino). Potenza: Il Salice.

De Blasi, N. (1995): „'O motorino. 'O gliommero p'a giunta 'e Bassolino“. In: AA.VV. (Hg.): Forse Napoli. Un libro per una città. Neapel: Pironti, 55-61.

De Blasi, N. (2001): „Usi e riusi dell'italiano napoletano e campano“. In: Fusco, F./Marcato, C. (Hg.): L'italiano e le regioni. Atti del convegno di studi, Udine, 15-16 giugno 2001. Università degli studi di Udine: Centro internazionale sul plurilinguismo, 89-109. (Reihe Plurilinguismo. Contatti di lingue e culture, 8)

De Blasi, N. (2006): Profilo linguistico della Campania. Rom/Bari: Laterza. (Reihe Manuali Laterza, 224)

De Blasi, N. (2009): Parole nella storia quotidiana. Studi e note lessicali. Neapel: Liguori.

De Blasi, N. (2012): Storia linguistica di Napoli. Rom: Carocci.

De Blasi, N./Fanciullo, F. (2003): „La Campania“. In: Cortelazzo, M. et al. (Hg.): I dialetti italiani. Storia, struttura, uso. Turin: Utet, 628-678.

De Blasi, N./Imperatore, L. ( $\left.{ }^{2} 2000\right)$ : Il napoletano parlato e scritto. Neapel: Dante \& Descartes.

Decreto Legislativo n. 267 (18.08.2000): „Testo unico delle leggi sull'ordinamento degli enti locali“. Gazzetta Ufficiale 227 (28.09.2000) (Supplemento Ordinario 162). http://www.camera.it/parlam/leggi/deleghe/00267dl.htm

Della Monica, W. (2011): I dialetti e l'Italia. Inchiesta fra scrittori, poeti, sociologi, specialisti. Cesena: Il Ponte Vecchio.

Del Puente, P. (1995): „La metafonia napoletana. Un tentativo di analisi sociolinguistica“. L'Italia Dialettale. Rivista di dialettologia italiana 58, 49-67.

Del Puente, P. (1998): „Appunti sulla situazione di avere e tenere nel dialetto napoletano“. In: Atti del Sodalizio Glottologico Milanese XXXVII-XXXVIII, 165-174.

De Mauro, T. ( ${ }^{3} 1986$ [1963]): Storia linguistica dell'Italia unita. Bari: Laterza.

De Palma, C. (1980): La Magna Grecia. Storia e civiltà dell'Italia meridionale dalle origini alla conquista romana. Rom: Newton Compton Editori.

De Salvio, A. (1913): „Studies in the Irpino dialect“. Romanic Review 4/3, 352-380.

De Saussure, F. $\left({ }^{4} 1995\right.$ [1967]): Cours de linguistique générale. Édition critique préparée par Tullio de Mauro. Paris: Payot.

Desmet, P./Lauwers, P./Swiggers, P. (2002): „Le développement de la dialectologie avant et après Gilliéron“. In: Lauwers, P./Simoni-Aurembou, M.-R./Swiggers, P. (Hg.) : Géographie linguistique et biologie du langage: Autour de Jules Gilliéron. Leuven/Paris/Dudley (MA): Peeters, 17-64. (Orbis, Supplementa 20)

Devoto, G. ( $\left.{ }^{2} 1951\right)$ : Gli antichi italici. Florenz: Vallecchi. 
Devoto, G. (1958 [1924]): „Ricostruzione e storia di lingue“. In: Devoto, G. (1958): Scritti minori. Bd. I. Florenz: Le Monnier, 29-39.

Devoto, G./Giacomelli, G. (1972): I dialetti delle regioni d'Italia. Florenz: Sansoni.

Dietrich, W. (2005): „Substrat, Superstrat, Adstrat, Interstrat. Zum Sprachwandel durch Sprachkontakt in der Neuen Romania.“ In: Stehl, T. (Hg.): Unsichtbare Hand und Sprecherwahl : Typologie und Prozesse des Sprachwandels in der Romania. Beiträge zur Sektion 1a des XXIV. Deutschen Romanistentags in Münster 1995. Tübingen: Narr, 123-152.

Dillard, J. L. (1972): Black English: Its history and usage in the United States. New York: Random House.

DSA (1927-1956): Deutscher Sprachatlas. Auf der Grundlage des „Sprachatlasses des Deutschen Reiches“"von G. Wenker. Begonnen von F. Wrede, fortgesetzt und herausgegeben von W. Mitzka und B. Martin. 128 Karten. Marburg: Elwert.

Falcone, G. (1977): „Innovazione e conservazione nei dialetti calabresi““. In: Dal dialetto alla lingua. Atti del IX Convegno per gli Studi Dialettali Italiani (Lecce, 28 settembre - 1 ottobre 1972). Pisa: Pacini, 283-306. (Reihe Centro di Studio per la Dialettologia Italiana, 3)

Falkenhausen, V. von (1967): Untersuchungen über die byzantinische Herrschaft in Süditalien vom 9. bis ins 11. Jahrhundert. Wiesbaden: Harrassowitz (Reihe Schriften zur Geistesgeschichte des östlichen Europa, 1)

Fanciullo, F. (1994): „Morfo-metafonia“. In: Cipriano, P./Di Giovine, P./Mancini, M. (Hg.): Miscellanea di studi linguistici in onore di Walter Belardi. Rom: Il Calamo, 571-592.

Fanciullo, F. (2002): Etimologie dell'Italo-romània. Alessandria: Edizioni dell'Orso.

FEW = Wartburg, Walther von (1922-2002): Französisches Etymologisches Wörterbuch. Eine Darstellung des galloromanischen Sprachschatzes. 25 Bände. Bonn/Leipzig/Basel: Klopp/Teubner/Zbinden.

Fishman, J. A. (1967): „Bilingualism with and without Diglossia; Diglossia with and without Bilingualism“. Journal of Social Issues 23 (2), 29-38.

Foresti, F. (1977): „Cenni sull'italianizzazione del dialetto bolognese con particolare riferimento all'aspetto lessicale“. In: Dal dialetto alla lingua. Atti del IX Convegno per gli Studi Dialettali Italiani (Lecce, 28 settembre - 1 ottobre 1972). Pisa: Pacini, 239-245. (Reihe Centro di Studio per la Dialettologia Italiana, 3)

Foresti, F. (1988): „Aree linguistiche. Emilia e Romagna“. In: Holtus, G./Metzeltin, M./Schmitt, C. (op. cit.), Bd. IV, 569-593.

Francis, W. N. (1983): Dialectology: An Introduction. London: Longman.

Frebel, P. (1957): Die Mundarten des westlichen Sauerlandes zwischen Ebbegebirge und Arnsberger Wald. Marburg: Elwert. (Reihe Deutsche Dialektgeographie: Untersuchungen zum Deutschen Sprachatlas, 45)

Freudenberg, R. (1966): „Isoglosse: Prägung und Problematik eines sprachwissenschaftlichen Terminus“. Zeitschrift für Mundartforschung 33, 219-232.

Freund, I. (1933): Beiträge zur Mundart von Ischia. Leipzig: Noske.

Galasso, G. (2003): Napoli capitale. Identità politica e identità cittadina. Studi e ricerche 12661860. Neapel: Electa Napoli.

Galasso, G. (2005): Storia dell'Irpinia antica. Avellino: De Angelis.

Gamillscheg, E. (1928): Die Sprachgeographie und ihre Ergebnisse für die allgemeine Sprachwissenschaft. Bielefeld/Leipzig: Van Velhagen \& Klasing. 
Gay, J. (1904): L'Italie méridionale et l'Empire byzantin. Bd. I. New York: Burt Franklin.

Gianelli, L. (1988): „Aree linguistiche. Toscana“. In: Holtus, G./Metzeltin, M./Schmitt, C. (op. cit.), Bd. IV, 594-606.

Giecillo, L./La Nave, M. (2009): „Mobilità e città. Aspetti generali e tendenze al movimento in ambito metropolitano“". In: Tortorella, W./Andreani, V. (Hg.): Città mobili. Rapporto Cittalia 2009, 17-87.

http://www.astrid-online.it/static/upload/protected/Citt/Cittalia_Citt-mobili_rapporto_15_12_09.pdf

Gilliéron, J. (1881): Petit Atlas phonétique du Valais roman (sud du Rhône). Paris: Champion.

Gilliéron, J. (1902): Atlas Linguistique de la France. Notice servant à l'intelligence des cartes. Paris: Champion.

Gilliéron, J. (1918): Généalogie des mots qui désignent l'abeille d'après l'atlas linguistique de la France. Paris: Champion.

Gilliéron, J. (1921): Pathologie et thérapeutique verbales. Paris: Champion.

Gilliéron, J./Mongin, J. (1905): Étude de géographie linguistique. ,Scier 'dans la Gaule romane du sud et de l'est. Paris: Champion.

Gilmour, J. S. L. (1937): „A taxonomic problem“. Nature 139, 1040-1042.

Goebl, H./Winterleitner, N. (1971): „Projekt einer sprachstatistischen Auswertung von in Sprachatlanten gespeicherter linguistischer Information mit Hilfe elektronischer Rechenanlagen“. Linguistische Berichte 14, 60-61.

Goebl, H. (1983a): , ,Stammbaum‘ und ,Welle‘. Vergleichende Betrachtungen aus numerischtaxonomischer Sicht“. Zeitschrift für Sprachwissenschaft 2, 3-44.

Goebl, H. (1983b): „Parquet polygonal et treillis triangulaire: les deux versants de la dialectométrie interponctuelle“. Revue de linguistique romane 47, 353-412.

Goebl, H. (1984): Dialektometrische Studien. Anhand italoromanischer, rätoromanischer und galloromanischer Sprachmaterialien aus AIS und ALF. 3 Bände. Tübingen: Niemeyer.

Goebl, H. (1993a): „Analyse dialectométrique des structures de profondeur de 1'ALF“. Revue de linguistique romane $66,5-63$.

Goebl, H. (1993b): „Die dialektale Gliederung Ladiniens aus der Sicht der Ladiner. Eine Pilotstudie zum Problem der geolinguistischen ,Mental Maps“ “. Ladinia XVII, 59-95.

Goebl, H. (1993c): „Dialectometry. A Short Overview of the Principles and Practice of Quantitative Classification of Linguistic Data“. In: Köhler, R./Rieger, B. B. (Hg.): Contributions to Quantitative Linguistics. Dordrecht: Kluwer, 277-315.

Goebl, H. (1994): „Spannungsverhältnisse in dialektalen Netzen. Ein Hinweis zur disziplinübergreifenen Diskussion“. In: Klenk, U. (Hg.): Computatio linguae II. Aufsätze zur algorithmischen und quantitativen Analyse von Sprache. Stuttgart: Steiner, 63-83.

Goebl, H. (1995): „Geolinguistische ,Mental Maps‘. Zum Problem der subjektiven Dialektverwandtschaft (anhand einer Fallstudie aus Ladinien)“. In: Sornig, K./Halwachs, D. W./Penzinger, Ch./Ambrosch, G. (Hg.): Linguistics with a Human Face. Festschrift für Norman Denison zum 70. Geburtstag. Graz: Treffpunkt Sprachen der Karl-FranzensUniversität, Forschungsbereich Plurilingualismus, 97-111. (Reihe Grazer Linguistische Monographien, 10)

Goebl, H. (1997a): „Some Dendrographic Classifications of the Data of CLAE 1 and CLAE 2“. In: Viereck, W./Ramisch, H./Händler, H./Marx, C. (Hg.): The Computer Developed Linguistic Atlas of England 2, Tübingen: Niemeyer, 23-32. 
Goebl, H. (1997b): „, Es kracht im Gebälk des CLAE...' Dialektometrische Beobachtungen zu eigenartigen Polarisierungseffekten in sprachgeographischen Netzen“. In: Ramisch, H./Wynne, K. (Hg.): Language in Time and Space. Studies in Honour of Wolfgang Viereck on the Occasion of his 60th Birthday. Stuttgart: Steiner, 100-108.

Goebl, H. (1997c): „Wenn Dialekte miteinander streiten...“ In: Gather, A./Werner, H. (Hg.): Semiotische Prozesse und natürliche Sprache. Festschrift für Udo L. Figge zum 60. Geburtstag. Stuttgart: Steiner, 183-191.

Goebl, H. (2001): „Arealtypologie und Dialektologie“. In: Haspelmath, M. et al. (Hg.): Language Typology and Language Universals. An International Handbook. Vol. 2. Berlin/New York: de Gruyter, 1471-1486.

Goebl, H. (2002): „Il trattamento dialettometrico della coscienza (meta)linguistica nella Ladinia dolomitica“. In: Cini, M./Regis, R. (Hg.): Che cosa ne pensa oggi Chiaffredo Roux? Percorsi della dialettologia percezionale all'alba del nuovo millennio. Atti del Convegno Internazionale, Bardonecchia 25-27 maggio 2000. Alessandria: Edizioni dell'Orso, 189-204.

Goebl, H. (2003): „Entwicklung der romanischen Sprachgrenzen: Italoromania und Ostalpenraum“. In: Ernst, G. et al. (Hg.): Romanische Sprachgeschichte. Ein internationales Handbuch zur Geschichte der romanischen Sprachen. 1. Teilband. Berlin/New York: de Gruyter, 631-645 (Handbücher zur Sprach- und Kommunikationswissenschaft, 23.1).

Goebl, H. (2004a): „Eine Glosse zu Isoglosse“. In: Krisch, T./Lindener, T./Müller, U. (Hg.): Analecta Homini Universali Dictata. Arbeiten zu Indogermanistik, Linguistik, Philologie, Politik, Musik und Dichtung. Festschrift für Oswald Panagl zum 65. Geburtstag. Stuttgart: H.-D. Heinz, 525-537. (Reihe Stuttgarter Arbeiten zur Germanistik, 421).

Goebl, H. (2004b): „VDM - Visual Dialectometry. Vorstellung eines dialektometrischen Software-Pakets auf CD-Rom (mit Beispielen zu ALF und Dees 1980)“. In: Dahmen, W. et al. (Hg.): Romanistik und neue Medien. Tübingen: Narr, 209-241.

Goebl, H. (2005a): „Dialekte und Familiennamen in Frankreich. Ein interdisziplinärer Vergleich mit den Mitteln der Dialektometrie“. In: Hauska, G. (Hg.): Gene, Sprachen und ihre Evolution. Wie verwandt sind die Menschen - Wie verwandt sind ihre Sprachen? Regensburg: Universitätsverlag, 68-99. (Schriftenreihe der Universität Regensburg, 29).

Goebl, H. (2005b): „La dialectométrie corrélative. Un nouvel outil pour l'étude de l'aménagement dialectal de l'espace par l'homme“. Revue de linguistique romane 69, 321-367.

Goebl (2006a): „Warum die Dialektometrie nur in einem romani(st)ischen Forschungskontext entstehen konnte“. In: Dahmen, W. et al. (Hg.): Was kann eine vergleichende romanische Sprachwissenschaft heute (noch) leisten? Romanistisches Kolloquium XX. Tübingen: Narr, 291-317.

Goebl, H. (2006b): „(Meta)Sprachliche Kon- und Divergenzen im Bereich der Sprachlandschaft Ladinien. Ein dialektometrischer Vergleich anhand subjektiver und objektiver Dialektdaten“. Ladinia XXX, 223-283.

Goebl, H. (2006c): „Recent Advances in Salzburg Dialectometry“. Literary and Linguistic Computing 21/4, 411-435.

Goebl, H. (2007): „Dialektometrische Streifzüge durch das Netz des Sprachatlasses AIS“. Ladinia XXXI, 187-271.

Goebl, H. (2010a): „Dialectometry and quantitative mapping“. In: Lameli, A./Kehrein, R./Rabanus, S. (Hg.): Language and Space. An International Handbook of Linguistic Variation. Vol. 2: Language Mapping. Berlin/New York: de Gruyter, 433-457. 
Goebl, H. (2010b): „Dialectometry: Theoretical Prerequisites, Practical Problems, and Concrete Applications (mainly with examples drawn from the ,Atlas Linguistique de la France“, 1902-1910)“. Dialectologia. Special Issue I, 63-77.

Goebl, H. (2011): „Quo vadis, atlas linguistice? Einige wissenschaftshistorische und zeitgeistkritische Reflexionen zur atlasgestützten Geolinguistik“. In: Schlaak, C./Busse, L. (Hg.): Sprachkontakte, Sprachvariation und Sprachwandel. Festschrift für Thomas Stehl zum 60. Geburtstag. Tübingen: Narr Francke Attempto, 5-27.

Goebl, H. (2013a): „La dialectometrización del ALPI: rápida presentación de los resultados“. In: Casanova Herrero, E./Calvo Rigual, C. (Hg.): Actas del XXVI Congreso Internacional de Lingüística y de Filología Románicas (Valencia 2010). Berlin [u.a.]: de Gruyter, Bd. VI, 143-154.

Goebl, H. (2013b): „La dialectometrització dels quatre primers volums de 1'ALDC“. Estudis Romànics 35, 87-116.

Goebl, H. (2013d): „Le Baiser de la Belle au bois dormant ou: des péripéties encourues par la géographie linguistique depuis Jules Gilliéron“. In: Caprini, R. (Hg.): Dialectologie. Corpus, atlas, analyses. Alessandria: Edizioni dell'Orso, 61-84. (Reihe Corpus, 12)

Goebl, H. (2014): „L'impact de la polynymie des cartes d'atlas sur le résultat de calculs dialectométriques“. In: Bednarczuk, L. et al. (Hg.): Linguistique romane et linguistique indoeuropéenne. Mélanges offerts à Witold Mańczak à l'occasion de son $90^{e}$ anniversaire. Krakau: Polska Akademia Umiejetnosci, Instytut Filologii Romanskiej Uniwersytetu Jagiellonskiego, 243-260.

Goebl, H./Scherrer, Y./Smečka, P. (2013): „Kurzbericht über die Dialektometrisierung des Gesamtnetzes des ,Sprachatlasses der deutschen Schweiz‘ (SDS)“. In: Schneider-Wiejowski, K./Kellermeier-Rehbein, B./Haselhuber, J. (Hg.): Vielfalt, Variation und Stellung der deutschen Sprache. Berlin/Boston: de Gruyter, 153-175.

Goebl, H./Smečka, P. (2014): „L'analyse dialectométrique des cartes de la série B de l'ALF“. Revue de linguistique romane 78, 439-497.

Goebl, H./Smečka, P. (2016): „The Quantitative Nature of Working Maps (WM) and Taxatorial Areas (TA)“. In: Kelih, E. et al. (Hg.): Issues in Quantitative Linguistics, 4. Dedicated to Reinhard Köhler on the occasion of his 65th birthday. Lüdenscheid: RAM, 113-127.

Goebl, H./Smečka, P. (2017): „Zur Rolle der Polynymie im Rahmen der Salzburger Dialektometrie. Am Beispiel des italienischen Sprachatlasses AIS“. In: Gerstenberg, A. et al. (Hg.): Romanice loqui. Festschrift für Gerald Bernhard zu seinem 60. Geburtstag. Tübingen: Stauffenburg, 137-154.

Goossens, J. (1959): „Relictgebieden“. Leuvense Bijdragen 48, 1-47.

Grassi, C. (2011): „Italiano e dialetti“. In: Sobrero, A. A. (op. cit.), 279-310.

Grassi, C./Sobrero, A. A./Telmon, T. $\left({ }^{2} 1998\right)$ : Fondamenti di dialettologia italiana. Rom/Bari: Laterza.

Guiter, H. (1973): „Atlas et frontières linguistiques“. In: Straka, G./Gardette, P. (Hg.): Les dialectes romans de France à la lumière des atlas régionaux. Strasbourg 24 - 28 mai 1971. Paris: C.N.R.S., 61-109.

Gurreri, F. (1991): „Immagini statistiche del Lazio dall'unificazione nazionale ai nostri giorni““. In: Caracciolo, A. (Hg.): Il Lazio. Turin: Einaudi, 597-653. (Reihe Storia d'Italia. Le regioni dall'Unità a oggi, 10) 
Haag, K. (1898): Die Mundarten des oberen Neckar- und Donaulandes (schwäbisch-alemannisches Grenzgebiet: Baarmundarten). Reutlingen. (Beilage zum Programm der Königlichen Realanstalt zu Reutlingen)

Haag, K. (1930): „Die Sprachlandschaften Oberitaliens“. Germanisch-Romanische Monatsschrift 18, 458-478.

Hägerstrand, T. (1952): The propagation of innovation waves. Lund: Royal University of Lund, Dept. of Geography. (Reihe Lund studies in geography: Series B, Human geography, 4).

Hägerstrand, T. (1965): „Aspects of the spacial structure of social communication and the diffusion of information“. In: Papers of the Regional Science Association 16, $27-42$.

Hägerstrand, T. (1967): Innovation diffusion as a spatial process. Chicago [u.a.]: University of Chicago Press.

Hägerstrand T. (1968): „A Monte Carlo approach to diffusion“. In: Berry, J. L./Marble, D.F. (Hg.): Spatial Analysis. A Reader in Statistical Geography. Englewood Cliffs, N.J.: Prentice-Hall, 368-384.

Haimerl, E. (2000): „Computer Aided Evaluations of Linguistic Atlases: From Automatic Classification to Dialectometry“. In: Decker, R./Gaul, W. (Hg.): Classification and Information Processing at the Turn of the Millenium. Berlin/Heidelberg: Springer, 469-478.

Hamming, R. W. (1950): „Error Detecting and Error Correcting Codes“. The Bell System Technical Journal, 29 (2), 147-160.

Händler, H./Wiegand, H. E. (1982): „Das Konzept der Isoglosse: methodische und terminologische Probleme“. In: Besch, W./Knoop, U. /Putschke, W./Wiegand, H. E. (Hg.): Dialektologie. Ein Handbuch zur deutschen und allgemeinen Dialektforschung. Berlin [u.a.]: de Gruyter, 501-527.

Hard, G. (1973): Die Geographie. Eine wissenschaftstheoretische Einführung. Berlin: de Gruyter. (Sammlung Göschen, 9001)

Hartung, J./Elpelt, B./Klösener, K.-H. ( $\left.{ }^{14} 2005\right):$ Statistik. Lehr- und Handbuch der angewandten Statistik. München/Wien: Oldenbourg.

Haubrichs, W. (1993): „Über die allmähliche Verfertigung von Sprachgrenzen. Das Beispiel der Kontaktzonen von Germania und Romania“" In: Haubrichs, W./Schneider, R. (Hg.): Grenzen und Grenzregionen / Frontières et régions frontalières / Borders and Border Regions. Saarbrücken: Saarbrücker Druckerei und Verlag, 99-129.

Herrgen, J. (2001): „Die Dialektologie des Deutschen“. In: Auroux, S. et al. (Hg.): Geschichte der Sprachwissenschaften. 2. Teilband, Artikel 182. Berlin/New York: de Gruyter, 1513-1535. (HSK 18.2)

Hodgen, M. T. (1942): „Geographical diffusion as a criterion of age“. American Anthropologist 44, 345-368.

Holtus, G./Metzeltin, M./Schmitt, C. (Hg.) (1988-2005): Lexikon der romanistischen Linguistik (LRL). 12 Bände. Tübingen: Niemeyer.

Holtus, G./Radtke, E. (Hg.) (1985): Gesprochenes Italienisch in Geschichte und Gegenwart. Tübingen: Narr.

Holtus, G./Radtke, E. (Hg.) (1994): Sprachprognostik und das ,italiano di domani '. Prospettive per una linguistica, prognostica'. Tübingen: Narr.

Huber, J. (1909): „Sprachgeographie. Ein Rückblick und Ausblick“. Bulletin de dialectologie romane I, 89-117. 
Hubschmid, J. (1958): „Zum Griechentum Süditaliens“. Zeitschrift für romanische Philologie $74,405-413$.

Iannace, G. (1983): Interferenza linguistica ai confini fra Stato e Regno. Il dialetto di San Leucio del Sannio. Ravenna: Longo.

Iannucci, J. E. (1948-1950): „Gemination of initial consonants and its semantic function in Neapolitan“. Romance Philology 2, 237-239.

Jaberg, K./Jud, J. (1928): Der Sprachatlas als Forschungsinstrument. Kritische Grundlegung und Einführung in den Sprach- $u$. Sachatlas Italiens und der Suedschweiz. Halle (Saale): Niemeyer.

Kessler, B. (1995): „Computational dialectology in Irish Gaelic“. In: Proceedings of the seventh conference on European chapter of the Association for Computational Linguistics. San Francisco: Morgan Kaufmann, 60-66.

Koch, P./Oesterreicher, W. (1990): Gesprochene Sprache in der Romania: Französisch, Italienisch, Spanisch. Berlin u.a.: de Gruyter.

Kretzschmar, W. A., Jr. (1991): [Unbetitelter Beitrag]. In: Alinei, M. (Hg.): Quaderni di semantica, 12 (2): Dove va la dialettologia? Bologna: Ed. CLUEB, 257-262.

Kurath, H. (1949): A Word Geography of the Eastern United States. Ann Arbor: University of Michigan Press.

Kurath, H. (1972): Studies in Area Linguistics. Bloomington: Indiana University Press.

Labov, W. (2003): „Pursuing the cascade model““. In: Britain, D./Cheshire, J. (Hg.): Social Dialectology: In Honor of Peter Trudgill. Amsterdam: Benjamins, 9-22.

Lalanne, T. (1953): „Indice de polyonymie. Indice de polyphonie“. Le français moderne 21, 263-274.

Lance, G. N./Williams, W. T. (1967): „A general theory of classificatory sorting strategies. I. Hierarchical systems“. Computer Journal 9, 373-380.

Ledgeway, A. (2009): Grammatica diacronica del napoletano. Tübingen: Niemeyer. (Beihefte zur Zeitschrift für romanische Philologie, 350)

Ledgeway, A. (2011): „The Neapolitan Double-Subject Construction“. In: Benincà, P./ Murano, N. (Hg.): Mapping the Left Periphery: The Cartography of Syntactic Structures, Volume 5. Oxford Scholarship Online. http://opac.vimaru.edu.vn/edata/EBook/TAILIEUSO/Oxford/Full/58.MappingtheLeft Periphery.pdf

Lüdtke, H. (1956): „Die soziologische Stellung der Mundart in Portugal und in Süditalien: ihre Bedeutung für die Sprachgeschichte“. Orbis 5, 123-130.

Lüdtke, H. (1979): Lucania. Pisa: Pacini. (Reihe Profilo dei dialetti italiani, 17)

Maetzke, G. (1992) (Hg.): La Campania fra il VI e il III secolo A.C. Atti del XIV Convegno di Studi Etruschi e Italici, Benevento, 24 - 28 giugno 1981. Galatina: Congedo.

Maiden, M. (1985): „,Displaced“ metaphony and the morphologisation of metaphony“. Romance Philology 39 (1), 22-43.

Maiden, M. (1991): Interactive Morphonology. Metaphony in Italy. London/New York: Routledge.

Maiden, M./Parry M. (1997) (Hg.): The Dialects of Italy. London: Routledge.

Marano Festa, O. (1928): „Il dialetto irpino di Montella“. L'Italia dialettale. Rivista di dialettologia italiana 4, 168-185. 
Maritain, J. (1987): „Introduction générale à la philosophie“. In: Allion, J.-M. et al. (Hg.): Jacques et Rä̈ssa Maritain. Oeuvres complètes. Vol II. Freiburg (Schweiz): Éditions Universitaires Fribourg Suisse/Éditions Saint-Paul Paris.

Massariello Merzagora, G. (1985): „Fenomeni di italianizzazione del dialetto nell'area lombarda“. In: Agostiniani, L./Bellucci Maffei, P./Paoli, M. (Hg.): Linguistica storica e cambiamento linguistico. Atti del XVI. congresso internazionale di studi; Firenze 7 - 9 maggio 1982. Rom: Bulzoni, 427-438.

Massobrio, L. (1992): „Lo stato attuale dei lavori e le prospettive future dell'Atlante Linguistico Italiano (ALI)“. In: Ruffino, G. (op. cit.), 291-298.

Matrisciano, S. (i.Vorb.): Wahrnehmungs- und Gebrauchsmuster sprachlicher Variation in der Metropole Neapel. Dissertation, Universität Heidelberg.

Mattheier, K. J. (1996): „Varietätenkonvergenz. Überlegungen zu einem Baustein einer Theorie der Sprachvariation“. Sociolinguistica 10, 31-52.

Maturi, P. (2002): Dialetti e substandardizzazione nel Sannio Beneventano. Frankfurt [u.a.]: Peter Lang. (Reihe Vario Lingua, 16)

Mayr, E. (1975): Grundlagen der zoologischen Systematik. Hamburg/Berlin: Paul Parey.

Meillet, A. (1908): Les dialectes indo-européens. Paris: Champion. (Reihe Collection Linguistique, 1)

Melillo, G. (1926): Gli esiti della vibrante L in alcuni dialetti irpini. Avellino: Tip. Pergola.

Merlo, C. (1978 [1920]): Fonologia del dialetto di Sora. Pisa: Mariotti.

Meyer, P. (1875): „Rezension zu: Ascoli (1873)“. Romania 4, 293-296.

Milano, E. (2002a): „La dinamica dei fenomeni di palatalizzazione della a tonica a Monte di Procida“. Bollettino Linguistico Campano 1, 197-236.

Milano, E. (2002b): „I luoghi della palatalizzazione: uno studio sincronico della variazione testuale a Procida e a Monte di Procida“. In: Krefeld, T. (Hg.): Spazio vissuto e dinamica linguistica. Frankfurt a.M.: Peter Lang, 75-92.

Milano, E. (2006): „Tra lingua e dialetto: affinità e discrepanze nel parlato bilingue e monolingue dei testi di alcuni parlanti di area flegrea“. In: Sobrero, A./Miglietta, A. (Hg.): Lingua e Dialetto nell'Italia del Duemila (Atti del convegno - Procida, 27 - 29 maggio 2004). Galatina: Congedo, 265-288.

Mioni, A. M./Arnuzzo-Lanszweert, A. M. (1979): „Sociolinguistics in Italy“. International Journal of the Sociology of Language, 81-107.

Molinari, M. V. (1976): „Fenomeni di evoluzione e conservazione nella fonetica del dialetto milanese dal Salvioni ai giorni nostri“‘. In: Pisani, V./Santoro, C. (Hg.): Italia linguistica nuova ed antica. Studi linguistici in memoria di Oronzo Parlangèli. Bd. I. Galatina: Congedo, 407-423.

Morf, H. (1911): „Zur sprachlichen Gliederung Frankreichs“. In: Abhandlungen der Königl. Preuß. Akademie der Wissenschaften, Phil.-hist. Classe, Mem. II, 3-37.

Morosi, G. (1994 [1870]): Studi sui dialetti greci della terra d'Otranto. Sala Bolognese: Forni.

NavigAIS: AIS Digital Atlas and Navigation Software. Graziano G. Tisato, Istituto di Scienze e Tecnologie della Cognizione (ISTC), Consiglio Nazionale delle Ricerche (CNR), Dipartimento di Discipline Linguistiche Comunicative e dello Spettacolo, Archivio Generale del Comune di Padova.

http://www3.pd.istc.cnr.it/navigais/navigais-index

Nerbonne, J. (2010): „Measuring the diffusion of linguistic change“. In: Philosophical Transactions of the Royal Society 365, 3821-3828. 
Niedzielski, N./Giles, H. (1996): „Linguistic accomodation“. In: Goebl, H./Nelde, P. H./Starý, Z./Wölck, W. (Hg.): Kontaktlinguistik. Ein internationales Handbuch zeitgenössischer Forschung. 1. Halbband. V. Grundbegriffe der Kontaktlinguistik. Berlin/New York: de Gruyter, 332-342.

Nittoli, S. ( $\left.{ }^{2} 1984\right)$ : Vocabolario di vari dialetti del Sannio. Sala Bolognese: Forni.

Ondis, L. A. (1996 [1932]): Fonologia del dialetto cilentano. Casalvelino Scalo: Galzerano.

Parascandola, V. (1976): Vèfio. Folk-glossario del dialetto procidano. Neapel: Berisio.

Paris, G. (1888): „Les Parlers de France“. In: Paris, G. (1909): Mélanges linguistiques, publiés par Mario Roques. Paris: Champion, 432-448.

Parlangèli, O. (1960): Storia linguistica e storia politica nell'Italia meridionale. Florenz: Le Monnier.

Patrucco, E. (2001): Dialetto on line. Osservazioni sulla presenza dei dialetti nord-occidentali in Internet. Tesi di laurea inedita, Facoltà di Lettere e Filosofia dell'Università di Torino.

Peduto, P. (2004): „Insediamenti longobardi del ducato di Benevento (secc. VI-VIII)“. In: Gasparri, S. (Hg.): Il regno dei Longobardi in Italia: archeologia, società e istituzioni. Spoleto: Centro Italiano di Studi sull'Alto Medioevo, 367-441.

Pellegrini, G. B. (1975): Saggi di linguistica italiana. Storia, struttura, società. Turin: Boringhieri.

Pellegrini, G. B. (1977): Carta dei dialetti d'Italia. Pisa: Pacini.

Pellegrini, G. B. (1990): „Tra italiano regionale e coinè dialettale“. In: Banfi, E./Cordin, P. (Hg.): Storia dell'italiano e forme dell 'italianizzazione. Atti del XXIII Congresso SLI. Rom: Bulzoni, 5-26.

Petrini, D. (1988): La koinè ticinese. Livellamento dialettale e dinamiche innovative. Bern: Francke. (Reihe Romanica Helvetica, 105)

Philps, D. (1985): Atlas dialectométrique des Pyrénées centrales. 2 Bände. Thèse de doctorat d'État, Université de Toulouse - Le Mirail.

Pisani, V. (1939): Geolinguistica e indoeuropeo. Rom. (Memorie della Reale Accademia nazionale dei Lincei CCCXXXVI, serie VI, vol. IX, fasc. II)

Pop, S./Pop. R. D. (1959): Jules Gilliéron: vie, enseignement, élèves, auvres, souvenirs. Louvain: Centre international de dialectologie générale.

Porzig, W. (1950): Das Wunder der Sprache. Probleme, Methoden und Ergebnisse der Sprachwissenschaft. Bern: Francke.

Prosdocimi, A. L. (1981): „Note su ,Italico“ e ,Sannita“.”In: Maetzke, G. (op. cit.), 119-148.

Putschke, W. (1982): „Theoriebildung der klassischen Dialektologie“. In: Besch, W. (Hg.): Dialektologie: ein Handbuch der deutschen und allgemeinen Dialektforschung. New York: de Gruyter, 232-247.

Radtke, E. (1988): „Areallinguistik IX. Kampanien, Kalabrien“. In: Holtus, G./Metzeltin, M./ Schmitt, C. (op. cit.), Bd. IV, 652-668.

Radtke, E. (1993): „Zur Klassifizierung der kampanischen Mundarten“. In: Viereck, W. (Hg.): Verhandlungen des Internationalen Dialektologenkongresses Bamberg 1990, Bd.1. Stuttgart: Steiner, 444-457.

Radtke, E. (1995): „Il problema della regressione dialettale“. In: Romanello, M. T./Tempesta, I. (Hg.): Dialetti e lingue nazionali. Atti del XXVII Congresso della SLI. Rom: Bulzoni, 43-53. 
Radtke, E. (1996): „Spostamenti di isoglosse dovuti a differenziazioni generazionali“. In: Radtke, E./Thun, H. (Hg.): Neue Wege der romanischen Geolinguistik. Akten des Symposiums zur empirischen Dialektologie (Heidelberg/Mainz 21.-24.10.1991). Kiel: Westensee, 149-163.

Radtke, E. (1997a): I dialetti della Campania. Rom: Il Calamo.

Radtke, E. (1997b): „Tortorella - eine bisher unbekannte galloitalienische Sprachkolonie im Cilento“. Zeitschrift für romanische Philologie 113, 82-109.

Radtke, E. (1998a): „Napoli, ma non solo Napoli. Gli italiani regionali in Campania“. Italiano \& Oltre XIII/3-4, 189-197.

Radtke, E. (1998b): „Quant'è innovativa la dialettologia tradizionale? Il caso della dialettologia campana“. In: Ruffino, G. (Hg.): Actes du XXI congrès international de la Société de Linguistique et Philologie Romanes, Palerme, 18-24 septembre 1995. Tübingen: Niemeyer, 563-574.

Radtke, E. (2001): „Il polimorfismo come categoria della linguistica variazionale“. In: Orioles, V. (Hg.): Dal ,paradigma ' alla parola. Riflessioni sul metalinguaggio della linguistica. Atti del Convegno Udine-Gorizia, 10 - 11 febbraio 1999. Rom: Il Calamo, 161-176.

Radtke, E. (2002a): „Il napoletano - varietà di prestigio o varietà stigmatizzata fuori Napoli?““ In: Krefeld, T. (Hg.): Spazio vissuto e dinamica linguistica. Varietà meridionali in Italia $e$ in situazione di extraterritorialità. Frankfurt a.M.: Peter Lang, 61-74.

Radtke, E. (2002b): „La dinamica variazionale nella Campania linguistica. I fondamenti dell'Atlante linguistico della Campania (ALCam)“. Bollettino Linguistico Campano 1, 1-39.

Radtke, E./Thun, H. (1996): „Neue Wege der romanischen Geolinguistik. Eine Bilanz“. In: Radtke, E./Thun, H. (Hg.): Neue Wege der romanischen Geolinguistik. Akten des Symposiums zur empirischen Dialektologie (Heidelberg/Mainz 21.-24.10.1991). Kiel: Westensee, 1-24.

Rando, C. ( 2000$)$ : Napoli e la Campania. Mailand: TCI. (Reihe Guide d'Italia)

Raucci, S. (1993-94): Lingua e dialetto a Trevico: Studio del continuum sociolinguistico. Tesi di laurea, Università di Napoli Federico II.

Rohlfs, G. (1933): Scavi linguistici nella Magna Grecia. Rom: Collezione Meridionale Editrice.

Rohlfs, G. (1937): „Mundarten und Griechentum des Cilento“. Zeitschrift für romanische Philologie 57, 421-461. (ital. Übersetzung in Rohlfs 1988 (op. cit.), 77-118)

Rohlfs, G. (1941): „Galloitalienische Sprachkolonien am Golf von Policastro“. Zeitschrift für romanische Philologie 61, 97-113. (ital. Übersetzung in Rohlfs 1988 (op. cit.), 39-76)

Rohlfs, G. (1947): Sprachgeographische Streifzüge durch Italien. München: Verlag der Bayerischen Akademie der Wissenschaften. (Sitzungsberichte der Bayerischen Akademie der Wissenschaften, Philosophisch-historische Klasse Jahrgang 1944/46, Heft 3)

Rohlfs, G. (1966): Grammatica storica della lingua italiana e dei suoi dialetti. Volume 1: Fonetica. Turin: Einaudi.

Rohlfs, G. (1968): Grammatica storica della lingua italiana e dei suoi dialetti. Volume 2: Morfologia. Turin: Einaudi.

Rohlfs, G. (1969): Grammatica storica della lingua italiana e dei suoi dialetti. Volume 3: Sintassi e formazione delle parole. Turin: Einaudi.

Rohlfs, G. (1971): Romanische Sprachgeographie. Geschichte und Grundlagen, Aspekte und Probleme mit dem Versuch eines Sprachatlas der romanischen Sprachen. München: C. H. Beck. 
Rohlfs, G. (1988): Studi linguistici sulla Lucania e sul Cilento. Galatina: Congedo.

Roques, M. (1926): „Jules Gilliéron“. In: École pratique des Hautes Études, Section des sciences historiques et philologiques. Annuaire 1926-1927, 3-22.

Rosenqvist, A. (1919): „Limites administratives et division dialectale de la France“. Neuphilologische Mitteilungen 20, 87-119.

Rüegg, R. (1956): Zur Wortgeographie der italienischen Umgangssprache. Köln: Romanisches Seminar der Universität zu Köln. (Reihe Kölner Romanistische Arbeiten, 7)

Ruffino, G. (Hg.) (1992): Atlanti linguistici italiani e romanzi: esperienze a confronto. Atti del Congresso Internazionale, Palermo, 3-7 ottobre 1990. Palermo: Centro Studi Filologici.

Ruocco, D. (1976): Le Regioni d'Italia. Vol. 13. Campania. Turin: UTET.

Ruoff, A. (1980): „Probleme der Sprachgrenzen und -übergänge“. In: König, W./Stopp, H. (Hg.): Historische, geographische und soziale Übergänge im alemannischen Sprachraum. München: Vögel, 93-109.

Russo, A. (1989): Grammatica di un dialetto irpino. Nusco: Poligrafica Irpina.

Sabatini, F. (1963): Riflessi linguistici della dominazione longobarda nell'Italia mediana e meridionale. Florenz: Olschki.

Sabatini, F. (1985): „L', italiano dell'uso medio“: una realtà tra le varietà linguistiche italiane“. In: Holtus, G./Radtke, E. (op. cit.), 154-184.

Salmon, E. T. (1985): Il Sannio e i Sanniti. Turin: Einaudi.

Sanga, G. (1984): Dialettologia lombarda. Lingue e culture popolari. Pavia: Aurora.

Sapir, E. (1916): Time perspective in aboriginal american culture. Ottawa: Government Printing Bureau.

Schiltz, G. (1996): Der Dialektometrische Atlas von Südwest-Baden (DASB). Konzepte eines dialektometrischen Informationssystems. 4 Bände. Marburg: Elwert.

Schiltz, G. (1997): „Current Trends in Dialectometry: The Handling of Synonym Feature Realizations“. In: Klar, R./Opitz, O. (Hg.): Classification and knowledge organization. Berlin/Heidelberg/New York: Springer, 661-668.

Schleicher, A. (1863): Die Darwinsche Theorie und die Sprachwissenschaft. Offenes Sendschreiben an Herrn Dr. Ernst Haeckel, o. Professor der Zoologie und Direktor des zoologischen Museums an der Universität Jena. Weimar.

Schlieben-Lange, B. (1976): „A propos de la mort des langues“. In: Atti del XIV Congresso internazionale di linguistica e filologia romanza. Neapel/Amsterdam: Macchiaroli-Benjamins, Bd. 2, 381-388.

Schmidt, J. (1872): Die Verwantschaftsverhältnisse der indogermanischen Sprachen. Weimar: Böhlau.

Schneider, E. W. (1984): „Methodologische Probleme der Dialektometrie“. In: Goebl, H. (Hg.): Dialectology. Bochum: Brockmeyer, 314-335. (Reihe Quantitative Linguistics, 21)

Schneider, E. W. (1988): „Qualitative vs. Quantitative Methods of Area Delimitation in Dialectology: A Comparison Based on Lexical Data from Georgia and Alabama“. Journal of English Linguistics 21, 175-222.

Schuchardt, H. (1866-1868): Der Vokalismus des Vulgärlateins. 3 Bände. Leipzig: Teubner.

Schürr, F. (1933): „La posizione storica del Romagnolo fra i dialetti contermini“. Revue de Linguistique Romane 9, 209-228.

SDS (1962-1997): Sprachatlas der Deutschen Schweiz. Herausgegeben von Rudolf Hotzenköcherle und Rudolf Trüb. 8 Bände. Bern/Basel: Francke. 
Séguy, J. (1971): „La relation entre la distance spatiale et la distance lexicale“. Revue de Linguistique romane $35,335-357$.

Séguy, J. (1973): „La dialectométrie dans l'Atlas Linguistique de la Gascogne“. Revue de Linguistique romane $37,1-24$.

Shepherd, W. J. (1923): Historical Atlas. New York: Henry Holt and Company. http://www.lib.utexas.edu/maps/historical/history_shepherd_1923.html

Siegel, J. (1985): „Koines and koineization“. Language in Society 14, 357-378.

Signorelli, A. (2009): „Napoletanità. Stereotype und Widersprüche“. In: Pisani, S./Siebenmorgen, K. (Hg.): Neapel. Sechs Jahrhunderte Kulturgeschichte. Berlin: Reimer.

Smarazzo, D. (1999): „Documenti e Studi per una definizione dell'area Metropolitana di Napoli“. In: AA.VV (Hg.): Pianificazione urbanistica ed ambientale. Santarcangelo di Romagna: Maggioli. (Collana Strumenti) http://users.libero.it/domenico.smarrazzo/studio.PDF

Sneath, P. H. A. (1964): „Mathematics and classification from Adanson to the present“. In: Lawrence, G. H. M. (Hg.): Adanson. The Bicentennial of Michel Adanson's ,Familles des plantes '. Pittsburgh: Hunt Botanical Library, Carnegie Institute of Technology, 471498.

Sneath, P. H. A./Sokal, R. R. (1963): Principles of Numerical Taxonomy. San Francisco, CA: W. H. Freeman and Company.

Sneath, P. H. A./Sokal, R.R. (1973): Numerical Taxonomy. San Francisco, CA: W. H. Freeman and Company.

Sobrero, A. A. (1996): „Italianization and Variations in the Repertoire: The Koinai'“. Sociolinguistica 10, 105-111.

Sobrero, A. A. (1997): „Italianization of the Dialects“. In: Maiden, M./Parry M. (op. cit.), 412418.

Sobrero, A. A. (Hg.) ( $\left.{ }^{14} 2011\right)$ : Introduzione all'italiano contemporaneo. La variazione e gli usi. Bari: Laterza.

Sobrero, A. A./Miglietta, A. (2006): Introduzione alla linguistica italiana. Rom/Bari: Laterza.

Sokal, R. R./Michener, C. D. (1958): „A statistical method for evaluating systematic relationships“. The University of Kansas Science Bulletin 38, 1409-1438.

Sornicola, R. (1977): Lingua e dialetto a Napoli oggi. Premesse. Neapel: Università di Napoli.

Sornicola, R. (1996): „Alcune strutture con pronome espletivo nei dialetti italiani meridionali“. In: Benincà, P./Cinque, G./De Mauro, T./Vincent, N. (Hg.): Italiano e dialetti nel tempo. Saggi di Grammatica in onore di G. Lepschy. Rom: Bulzoni, 323-340.

Sornicola, R. (1997): „Campania“. In: Maiden, M./Parry, M. (op. cit.), 330-337.

Sornicola, R. (1999): „La variazione dialettale nell'area costiera napoletana. Il progetto di un Archivio di testi dialettali parlati“. In: Marcato, G. (Hg.): Dialetti oggi. Tra lingua, cultura, società. Dialettologia sociologica. Atti del convegno di studi Sappada/Plodn, 1-4 luglio 1998. Padova: Unipress, 103-122.

Sornicola, R. (2001): „Alcune recenti ricerche sul parlato: le dinamiche vocaliche di (e) nell'area flegrea e le loro implicazioni per una teoria della variazione“. In: Dardano, M./Pelo, A./Stefinlongo, A. (Hg.): Scritto e parlato. Metodi, testi e contesti. Atti del Colloquio Internazionale di Studi (Roma, 5-6 febbraio 1999). Rom: Aracne, 239-264.

Stammerjohann, H. (1975): Handbuch der Linguistik. Allgemeine und angewandte Sprachwissenschaft. München: Nymphenburger. 
Steger, H. (1988): „Erscheinungsformen der deutschen Sprache“. Deutsche Sprache 16, 289319.

Sturtevant, E. H. (1947): An Introduction to Linguistic Science. New Haven: Yale University Press.

Tappolet, E. (1905): „Über die Bedeutung der Sprachgeographie, mit besonderer Berücksichtigung französischer Mundarten“. In: Aus romanischen Sprachen und Literaturen: Festschrift Heinrich Morf zur Feier seiner fünfundzwanzigjährigen Lehrtätigkeit von seinen Schülern dargebracht. Halle: Niemeyer, 385-416.

Terracini, B. (1955): „L'Atlante linguistico italiano nell'opera di Matteo Bartoli e Ugo Pellis“. Bollettino dell'Atlante Linguistico Italiano (Nuova Serie) 1, 3-9.

Thiessen, A. H. (1911): „Precipitation averages for large areas“. Monthly Weather Review, 39 (7), 1082-1084.

Thomason, S./Kaufman, T. (1991): Language contact, creolization, and genetic linguistics. Berkeley [u.a.]: University of California Press.

Thomson, G. (1960): The Greek language. Cambridge: Heffer.

Tommasino, F./Tommasino, W. (2007): Grammatica del dialetto della zona aurunca. Marina di Minturno: Caramanica.

Tropea, G. (1976): Italiano di Sicilia. Palermo: Aracne.

Tropea, G. (1991): „Su alcuni aspetti dell'italianizzazione lessicale in Sicilia“. In: Orioles, V. (Hg.): Innovazione e conservazione nelle lingue. Atti del Convegno della Società Italiana di Glottologia (Messina, 9-11 novembre 1989). Pisa: Giardini, 171-200.

Trudgill, P. (1974): „Linguistic change and diffusion: description and explanation in sociolinguistic dialect geography“. Language in Society 2, 215-246.

Trudgill, P. (1986): Dialects in Contact. Oxford: Blackwell.

Trumper, J. (1977): „Ricostruzione nell'Italia settentrionale: sistemi consonantici. Considerazioni sociolinguistiche nella diachronia“. In: Simone, R./Vignuzzi, U. (Hg.): Problemi della ricostruzione in linguistica. Rom: Bulzoni, 259-310.

Trumper, J./Maddalon, M. (1982): L'italiano regionale tra lingua e dialetto. Presupposti ed analisi. Cosenza: Brenner.

Trumper, J./Maddalon, M. (1988): „Converging Divergence and Diverging Convergence: The Dialect-Language Conflicting and Contrasting Evolutionary Trends in Modern Italy“. In: Auer, P./Di Luzio, A. (Hg.): Variation and Convergence. Studies in Social Dialectology. Berlin/New York: de Gruyter, 216-258.

Tulleners-Bloemen, M. (1983): „Il betacismo nell'Italia meridionale. Analisi sincronica sulla base dei dati AIS“. Rivista Italiana di Dialettologia 7, 97-117.

Tuttle, E. F. (1985): „Assimilazione ,permansiva“ negli esiti centro-meridionali di A tonica“. L'Italia Dialettale. Rivista di dialettologia italiana 48, 1-34.

Van den Berg, L./Drewett, R./Klaassen, L. H. (1981): Urban Europe. A Study on Growth and Decline. Oxford: Pergamon.

Vàrvaro, A. (1991): „Koinè nell'Italia meridionale“. In: Sanga, G. (Hg.): Koinè in Italia dalle origini al Cinquecento. Atti del Convegno di Milano e Pavia (25-26 settembre 1987). Bergamo: Minerva Italica, 69-78.

Vàrvaro, A. (2005): „Sul ritardo della dialettologia in Campania“. Bollettino linguistico campano $7 / 8,183-188$.

Vaughan, H. H. (1910): „A brief study of the phonology of the Neapolitan dialect“. Revue Romane 1, 159-180. 
Vaughan, H. H. (1915): The dialects of Central Italy. Philadelphia.

Vidossi, G. (1933): „L'Atlante linguistico italiano: questioni di metodo e di fini“. Bollettino dell'Atlante Linguistico Italiano (BALI) 1, 4-27.

Vogel, F. (1975): Probleme und Verfahren der numerischen Klassifikation. Unter besonderer Berücksichtigung von Alternativmerkmalen. Göttingen: Vandenhoeck \& Ruprecht.

Ward, J. H., Jr. (1963): „Hierarchical Grouping to Optimize an Objective Function“. Journal of the American Statistical Association 58, 236-244.

Wartburg, W. von (1950): Die Ausgliederung der romanischen Sprachräume. Berlin: A. Francke.

Wartburg, W. von $\left({ }^{3} 1970\right)$ : Einführung in die Problematik und Methodik der Sprachwissenschaft. Tübingen: Niemeyer.

Weinhold, N. (1985): Sprachgeographische Distribution und chronologische Schichtung: Untersuchungen zu M. Bartoli und neueren geographischen Theorien. Hamburg: Buske. (Reihe Romanistik in Geschichte und Gegenwart, 17)

Weinreich, U. (1977 [1953]): Sprachen in Kontakt: Ergebnisse und Probleme der Zweisprachigkeitsforschung. München: C. H. Beck.

Wenker, G. (1878): Sprach-Atlas der Rheinprovinz nördlich der Mosel sowie des Kreises Siegen. Nach systematisch aus ca. 1.500 Orten gesammeltem Material. Marburg.

Whitney, W. D. (1875): The Life and Growth of Language: an outline of linguistic science. London.

Wilkins, D. (1996): „Morphology“. In: Goebl, H./Nelde, P. H./Starý, Z./Wölck, W. (Hg.): Kontaktlinguistik. Ein internationales Handbuch zeitgenössischer Forschung. 1. Halbband. III. Bedingungsfaktoren der Kontaktlinguistik III: Kontaktfaktoren sprachlicher Ebenen. Berlin/New York: de Gruyter, 109-117.

Willis, J. C. (1922): Age and area. A study in geographical distribution and origin of species. Cambridge: University Press.

Wirth, E. (1969): „Zum Problem einer allgemeinen Kulturgeographie. Raummodelle - kulturgeographische Kräftelehre - raumrelevante Prozesse - Kategorien“. Die Erde 100, 155193.

Zenaro, T. (2004): Parlare dialetto a Rivoli (TO): un'inchiesta sociolinguistica. Tesi di laurea inedita. Facoltà di Lettere e Filosofia dell'Università di Torino.

Zipf, G. K. (1965 [1935]): The psycho-biology of language. An introduction to dynamic philology. Cambridge, Mass.: MIT Press.

Zweifel, M. (1921): Untersuchung über die Bedeutungsentwicklung von Langobardus-Lombardus mit besonderer Berücksichtigung französischer Verhältnisse. Halle (Saale): Karras, Kröber \& Nietschmann.

Zwirner, E. (1959): „Phonometrische Isophonen der Quantität der deutschen Mundarten“. Phonetica 4, Supplement, 93-125. 


\section{Verzeichnisse}

\subsection{Abkürzungsverzeichnis}

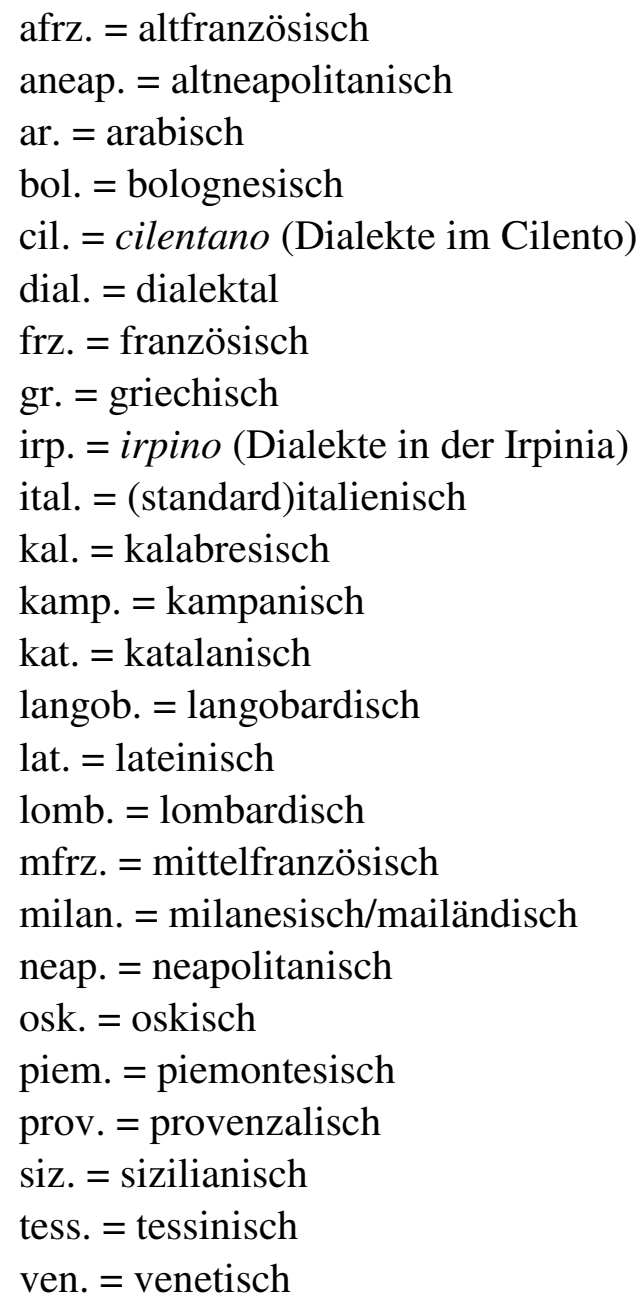

\subsection{Tabellenverzeichnis}

Tabelle 1. Demographische Verteilung in der Region Kampanien nach Provinzen..............26

Tabelle 2. Demographische Entwicklung der Provinzen von 1951 bis 2012 ...................... 28

Tabelle 3. Prozentualer Anteil der kampanischen Provinzhauptstädte an der Einwohnerzahl der jeweiligen Provinzen 1982-2012.

Tabelle 4. Entwicklung der Bevölkerung in Neapel-Stadt, in der Provinz Neapel und in der Region Kampanien....

Tabelle 5. Bevölkerungsentwicklung in den italienischen Metropolen zwischen 2002 und 2008 
Tabelle 7. Metaphonie als Genusmarker

Tabelle 8. Metaphonie als interne Verbflexion

Tabelle 9. Die Palatalisierung von [a] als Genusmarker

Tabelle 10. Das raddoppiamento fonosintattico als Genusmarker im Singular 52

Tabelle 11. Das raddoppiamento fonosintattico als Genusmarker im Plural 53

Tabelle 12. Realisierungen der Phoneme /b/, /d/ und /g/ in starker und schwacher

Stellung.

Tabelle 13. Wertklassenbildung zum AIS-Messpunkt 237 (Gromo, Lombardei) mittels MINMWMAX, 6-fach 123

Tabelle 14. Wertklassenbildung zum AIS-Messpunkt 237 (Gromo, Lombardei) mittels MEDMW, 6-fach

Tabelle 15. Wertklassenbildung zum AIS-Messpunkt 237 (Gromo, Lombardei) mittels MED, 6-fach.

Tabelle 16. Struktur des ALI

Tabelle 17. Basisdaten zu den für den ALI vorgenommenen sprachlichen Erhebungen im Messpunktnetz.

Tabelle 18. Taxierte Originalkarten

Tabelle 19. Lexikalische Typen und ihre Frequenzen im ALI-Korpus und im Vergleichskorpus

Tabelle 20. Phonetische Merkmale (Typen) und ihre Frequenzen im ALI-Korpus und im Vergleichskorpus

Tabelle 21. Phonetische Merkmale und dazugehörige Taxate im ALI-Korpus und im Vergleichskorpus.

Tabelle 22. Zentrale Tabellen der dialektometrischen Datenbank

Tabelle 23. Synopse des Ertrages der dialektometrischen Auswertung des ALI-Korpus.... 185

Tabelle 24. Synopse des Ertrages der dialektometrischen Auswertung des

Vergleichskorpus

Tabelle 25. Synopse des Taxatertrages der dialektometrischen Auswertung des ALI-Korpus und des Vergleichskorpus (2014) 
Tabelle 26. Statistische Kennwerte der Synopse der Maxima im ALI-Korpus 201

Tabelle 27. Statistische Kennwerte der Synopse der Schiefen im ALI-Korpus 203

Tabelle 28. Statistische Kennwerte der Korrelation zwischen sprachlicher Ähnlichkeit und geographischer Proximität in den verschiedenen Teilkorpora des ALI-Korpus. 208

Tabelle 29. Statistische Kennwerte der Korrelationen zwischen verschiedenen sprachlichen Bereichen im ALI-Korpus (ohne italiano standard (900))

Tabelle 30. Statistische Kennwerte der Ähnlichkeiten der kampanischen Dialekte zum Standarditalienischen im ALI-Korpus

Tabelle 31. Statistische Kennwerte der Synopse der Maxima im ALI-Korpus und im Vergleichskorpus

Tabelle 32. Statistische Kennwerte der Synopse der Schiefen im ALI-Korpus und im Vergleichskorpus

Tabelle 33. Statistische Kennwerte der Korrelationen zwischen sprachlicher Ähnlichkeit (verschiedene Teilkorpora) und geographischer Proximität im ALI-Korpus und im Vergleichskorpus

Tabelle 34. Statistische Kennwerte der Korrelationen zwischen den jeweiligen Teilkorpora im ALI-Korpus und im Vergleichskorpus

Tabelle 35. Statistische Kennwerte der Ähnlichkeiten der kampanischen Dialekte zum

Standarditalienischen im ALI-Korpus und im Vergleichskorpus

\subsection{Abbildungsverzeichnis zum Textteil}

Abbildung 1. Die vier „tastiere” des sprachlichen Repertoires nach Pellegrini (1975) ......... 11

Abbildung 2. Entwicklung der Bevölkerung der italienischen Metropolen im Vergleich zu den entsprechenden Provinzen zwischen 2001 und 2007

Abbildung 3. Schema zum Verlauf von Isoglossen

Abbildung 4. Beispiel einer Datenmatrix der Form Ortspunkte x Variablen in der Tolosaner Dialektometrie

Abbildung 5. Graphische Darstellung des durchschnittlichen Verhältnisses zwischen geographischer Distanz und lexikalischer Distanz....

Abbildung 6. Flussdiagramm der dialektometrischen Verfahrenskette 
Abbildung 8. Histogramm: Verteilung von 1746 aus dem AIS extrahierten Arbeitskarten nach der Anzahl der auf ihnen aufscheinenden Taxate.

Abbildung 9. Generierung einer (metrischen) Ähnlichkeitsmatrix aus einer (nominalen)

Datenmatrix mittels $\mathrm{RIW}_{j k}$

Abbildung 10. Erzeugung einer Distanzmatrix nach $\mathrm{RDW}_{j k}$

Abbildung 11. Generierung einer dialektometrischen Ähnlichkeitsmatrix mittels

$\operatorname{GIW}(1)_{j k}$

Abbildung 12. Ähnlichkeitsprofile zu verschiedenen AIS-Messpunkten 125

Abbildung 13. Triangulierung und Konstruktion des Umkreismittelpunktes 130

Abbildung 14. Delaunay-Triangulation und Voronoi-Diagramm (Polygonnetz) 130

Abbildung 15. Dendrogramm zum AIS (Totalkorpus)

Abbildung 16. Erfassungsformular $\alpha$ (Taxierungsleitblatt)

Abbildung 17. Erfassungsformular $\beta$

Abbildung 18. Erfassungsformular $\gamma$

Abbildung 19. Erfassungsformular $\delta$ (Taxatnummernblatt)

Abbildung 20. Verteilung der Arbeitskarten nach Anzahl der Taxate je Arbeitskarte im ALI-Korpus (Totalkorpus)

Abbildung 21. Verteilung der Arbeitskarten nach Anzahl der Taxate je Arbeitskarte im ALI-Korpus (lexikalisches Teilkorpus)

Abbildung 22. Verteilung der Arbeitskarten nach Anzahl der Taxate je Arbeitskarte im ALI-Korpus (phonetisches Teilkorpus)

Abbildung 23. Verteilung der Taxate nach Größe der Taxatareale im ALI-Korpus (Totalkorpus)

Abbildung 24. Verteilung der Taxate nach Größe der Taxatareale im ALI-Korpus (lexikalisches Teilkorpus)

Abbildung 25. Verteilung der Taxate nach Größe der Taxatareale im ALI-Korpus

(phonetisches Teilkorpus) 
Abbildung 26. Verteilung der Arbeitskarten nach Anzahl der Taxate je Arbeitskarte im Vergleichskorpus (Totalkorpus)

Abbildung 27. Verteilung der Arbeitskarten nach Anzahl der Taxate je Arbeitskarte im Vergleichskorpus (lexikalisches Teilkorpus)

Abbildung 28. Verteilung der Arbeitskarten nach Anzahl der Taxate je Arbeitskarte im Vergleichskorpus (phonetisches Teilkorpus)

Abbildung 29. Verteilung der Taxate nach Größe der Taxatareale im Vergleichskorpus (Totalkorpus)

Abbildung 30. Verteilung der Taxate nach Größe der Taxatareale im Vergleichskorpus

(lexikalisches Teilkorpus)

Abbildung 31. Verteilung der Taxate nach Größe der Taxatareale im Vergleichskorpus (phonetisches Teilkorpus)

\subsection{Kartenverzeichnis zum Textteil}

Karte 1. Provinzen und Provinzhauptstädte in der Region Kampanien ................................25

Karte 2. Geographisches Profil der Region Kampanien ...................................................26

Karte 3. Bevölkerungsdichte (Einwohner pro $\mathrm{km}^{2}$ ) in der Region Kampanien 2008 ............28

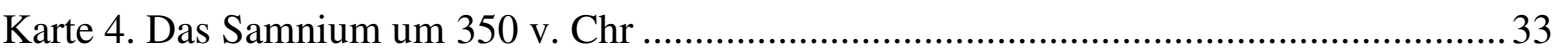

Karte 5. Verlauf der Via Appia und der Via Traiana im Gebiet der heutigen Campania .......34

Karte 6. Verlauf der Via Popilia im Gebiet der heutigen Campania .................................... 34

Karte 7. Das Ducato di Benevento in seiner maximalen Ausdehnung (um 750 n. Chr)........ 36

Karte 8. Politische Gliederung der Campania im 10. Jahrhundert ....................................... 37

Karte 9. Politisch-administrative Gliederung Süditaliens im Regno di Napoli...................... 38

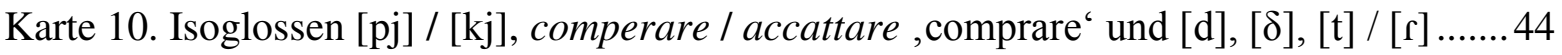

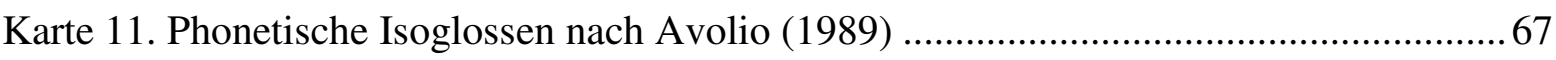

Karte 12. Morphologische Isoglossen nach Avolio (1989)...................................................68

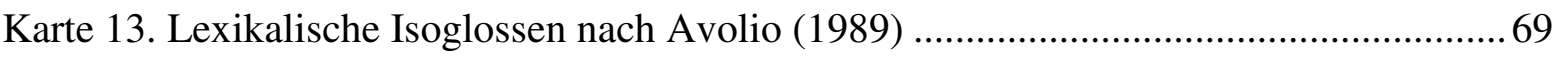


Karte 14. Verlauf der Isoglosse [11] / [dd], [dd]

Karte 15. Realisierungen von /d/ in piede im nördlichen Teil der Campania ....................... 71

Karte 16. Realisierungen von /b/ in be(ve)re im nördlichen Teil der Campania ................... 72

Karte 17. Bezeichnungen für ,inciampare‘ im nördlichen Teil der Campania ..................... 73

Karte 18. Bezeichnungen für ,ragazza‘ im nördlichen Teil der Campania............................ 74

Karte 19. Karte 225 (la pialla) des AIS (nördliche Hälfte) mit vergrößertem

Ausschnitt 86

Karte 20. Isoglossen und Isoglossenbündel im italienischen Sprachraum........................... 88

Karte 21. Phonetische Isoglossen in der Gascogne maritime 95

Karte 22. Kartographische Darstellung der (relativen) sprachlichen Abstände im Gebiet

Karte 23. Dialektgrenzen im gaskognischen Sprachraum (ALG-Karte 2525) .....

Karte 24. Lexikalisch relevante Arbeitskarte: Bezeichnungen für ,blind‘

Karte 25. Phonetisch relevante Arbeitskarte: Resultate von lat. C vor bet. $\check{E}$ in CĚNTU ... 114

Karte 26. Stumme Polygonkarte zum AIS

Karte 27. Ähnlichkeitskarte (Totalkorpus) zum AIS-Messpunkt 721 (Neapel) 134

Karte 28. Synopse der Maximalwerte zum AIS (Totalkorpus)

Karte 29. Synopse der Schiefewerte zum AIS (Totalkorpus) 138

Karte 30. Antipodenkarte der Maxima zum AIS (Totalkorpus)

Karte 31. Antipodenkarte der Minima zum AIS (Totalkorpus) 140

Karte 32. Schottenkarte zum AIS (Totalkorpus)

Karte 33. Strahlenkarte zum AIS (Totalkorpus)

Karte 34. Räumliche Projektion des Dendrogramms aus Abb. 15

Karte 35. Sprachliches Ähnlichkeitsprofil (Totalkorpus) zum AIS-Messpunkt 313 (Penía)150

Karte 36. Geographische (euklidische) Proximität zum AIS-Messpunkt 313 (Penía) 150 
Karte 37. Korrelationskarte zum AIS: sprachliche vs. geographische (euklidische)

Proximität

Karte 38. Korrelationskarte zum AIS: phonetisches vs. lexikalisches Teilkorpus 152

Karte 39. Stumme Karte des der Untersuchung zugrunde liegenden Ortsnetzes. 164

Karte 40. Phonetisch relevante Arbeitskarte: Resultate von lat. V in ŎVU(M)

(ALI-Korpus, Karte 571)

Karte 41. Phonetisch relevante Arbeitskarte: Resultate von lat. S in SPĔC(U)LU(M)

(Vergleichskorpus, Karte 385)

\subsection{Abbildungsverzeichnis zum Kartenteil}

Abbildung A1. Dendrogramm zum ALI-Korpus, Totalkorpus...................................... 280

Abbildung A2. Dendrogramm zum ALI-Korpus, Lexikon...............................................2 281

Abbildung A3. Dendrogramm zum ALI-Korpus, Konsonantismus ..................................2282

Abbildung A4. Dendrogramm zum ALI-Korpus, Vokalismus .........................................283

Abbildung A5. Dendrogramm zum Vergleichskorpus, Totalkorpus ................................. 302

Abbildung A6. Dendrogramm zum Vergleichskorpus, Lexikon ........................................ 304

Abbildung A7. Dendrogramm zum Vergleichskorpus, Konsonantismus ........................... 306

Abbildung A8. Dendrogramm zum Vergleichskorpus, Vokalismus ....................................308

\subsection{Kartenverzeichnis zum Kartenteil}

Karte A1. Räumliche Umlegung des Dendrogramms aus Abb. A1: Clusterkarte zum ALI-Korpus, Totalkorpus

Karte A2. Räumliche Umlegung des Dendrogramms aus Abb. A2: Clusterkarte zum ALI-Korpus, Lexikon.

Karte A3. Räumliche Umlegung des Dendrogramms aus Abb. A3: Clusterkarte zum ALI-Korpus, Konsonantismus

Karte A4. Räumliche Umlegung des Dendrogramms aus Abb. A4: Clusterkarte zum ALI-Korpus, Vokalismus .... 
Karte A5. Schottenkarte zum ALI-Korpus, Totalkorpus 284

Karte A6. Schottenkarte zum ALI-Korpus, Lexikon 284

Karte A7. Schottenkarte zum ALI-Korpus, Konsonantismus 285

Karte A8. Schottenkarte zum ALI-Korpus, Vokalismus 285

Karte A9. Kennwertsynopse der Maxima zum ALI-Korpus, Totalkorpus 286

Karte A10. Kennwertsynopse der Maxima zum ALI-Korpus, Lexikon 286

Karte A11. Kennwertsynopse der Maxima zum ALI-Korpus, Konsonantismus 287

Karte A12. Kennwertsynopse der Maxima zum ALI-Korpus, Vokalismus 287

Karte A13. Kennwertsynopse der Schiefewerte zum ALI-Korpus, Totalkorpus 288

Karte A14. Kennwertsynopse der Schiefewerte zum ALI-Korpus, Lexikon 288

Karte A15. Kennwertsynopse der Schiefewerte zum ALI-Korpus, Konsonantismus . 289

Karte A16. Kennwertsynopse der Schiefewerte zum ALI-Korpus, Vokalismus 289

Karte A17. Antipodenkarte der Maxima zum ALI-Korpus, Totalkorpus 290

Karte A18. Antipodenkarte der Minima zum ALI-Korpus, Totalkorpus 290

Karte A19. Antipodenkarte der Maxima zum ALI-Korpus, Lexikon 291

Karte A20. Antipodenkarte der Minima zum ALI-Korpus, Lexikon 291

Karte A21. Antipodenkarte der Maxima zum ALI-Korpus, Konsonantismus. 292

Karte A22. Antipodenkarte der Minima zum ALI-Korpus, Konsonantismus 292

Karte A23. Antipodenkarte der Maxima zum ALI-Korpus, Vokalismus 293

Karte A24. Antipodenkarte der Minima zum ALI-Korpus, Vokalismus. 293

Karte A25. Korrelationskarte zum ALI-Korpus: Totalkorpus und geographische Proximität 294

Karte A26. Korrelationskarte zum ALI-Korpus: Lexikon und geographische Proximität .. 294

Karte A27. Geographische Proximität zum Referenzpunkt Benevento (825) 295 
Karte A28. Sprachliches Ähnlichkeitsprofil zum Referenzpunkt Benevento (825) 295

Karte A29. Korrelationskarte zum ALI-Korpus: Konsonantismus und geographische Proximität

Karte A30. Korrelationskarte zum ALI-Korpus: Vokalismus und geographische Proximität 296

Karte A31. Korrelationskarte zum ALI-Korpus: Lexikon und Phonetik

Karte A32. Korrelationskarte zum ALI-Korpus: Konsonantismus und Vokalismus 297

Karte A33. Ähnlichkeitsprofil zum Referenzpunkt Fontegreca (810): ALI-Korpus, Phonetik.

Karte A34. Ähnlichkeitsprofil zum Referenzpunkt Fontegreca (810): ALI-Korpus,

Lexikon.

Karte A35. Ähnlichkeitsprofil zum Referenzpunkt Monte San Giacomo (865):

ALI-Korpus, Konsonantismus

Karte A36. Ähnlichkeitsprofil zum Referenzpunkt Monte San Giacomo (865):

ALI-Korpus, Vokalismus

Karte A37. Synopse der Ähnlichkeitswerte zum Referenzpunkt italiano standard (900):

ALI-Korpus, Totalkorpus 300

Karte A38. Synopse der Ähnlichkeitswerte zum Referenzpunkt italiano standard (900):

ALI-Korpus, Lexikon 300

Karte A39. Synopse der Ähnlichkeitswerte zum Referenzpunkt italiano standard (900):

ALI-Korpus, Konsonantismus

Karte A40. Synopse der Ähnlichkeitswerte zum Referenzpunkt italiano standard (900):

ALI-Korpus, Vokalismus

Karte A41. Räumliche Umlegung des Dendrogramms aus Abb. A5: Clusterkarte zum Vergleichskorpus, Totalkorpus

Karte A42. Clusterkarte zum ALI-Korpus, Totalkorpus

Karte A43. Clusterkarte zum Vergleichskorpus, Totalkorpus

Karte A44. Räumliche Umlegung des Dendrogramms aus Abb. A6: Clusterkarte zum Vergleichskorpus, Lexikon

Karte A45. Clusterkarte zum ALI-Korpus, Lexikon 
Karte A46. Clusterkarte zum Vergleichskorpus, Lexikon

Karte A47. Räumliche Umlegung des Dendrogramms aus Abb. A7: Clusterkarte zum

Vergleichskorpus, Konsonantismus

Karte A48. Clusterkarte zum ALI-Korpus, Konsonantismus

Karte A49. Clusterkarte zum Vergleichskorpus, Konsonantismus

Karte A50. Räumliche Umlegung des Dendrogramms aus Abb. A8: Clusterkarte zum

Vergleichskorpus, Vokalismus

Karte A51. Clusterkarte zum ALI-Korpus, Vokalismus

Karte A52. Clusterkarte zum Vergleichskorpus, Vokalismus

Karte A53. Schottenkarte zum ALI-Korpus, Totalkorpus

Karte A54. Schottenkarte zum Vergleichskorpus, Totalkorpus

Karte A55. Schottenkarte zum ALI-Korpus, Lexikon

Karte A56. Schottenkarte zum Vergleichskorpus, Lexikon

Karte A57. Schottenkarte zum ALI-Korpus, Konsonantismus

Karte A58. Schottenkarte zum Vergleichskorpus, Konsonantismus

Karte A59. Schottenkarte zum ALI-Korpus, Vokalismus

Karte A60. Schottenkarte zum Vergleichskorpus, Vokalismus

Karte A61. Kennwertsynopse der Maxima zum ALI-Korpus, Totalkorpus

Karte A62. Kennwertsynopse der Maxima zum Vergleichskorpus, Totalkorpus.

Karte A63. Kennwertsynopse der Maxima zum ALI-Korpus, Lexikon

Karte A64. Kennwertsynopse der Maxima zum Vergleichskorpus, Lexikon.

Karte A65. Kennwertsynopse der Maxima zum ALI-Korpus, Konsonantismus.

Karte A66. Kennwertsynopse der Maxima zum Vergleichskorpus, Konsonantismus

Karte A67. Kennwertsynopse der Maxima zum ALI-Korpus, Vokalismus

Karte A68. Kennwertsynopse der Maxima zum Vergleichskorpus, Vokalismus 
Karte A69. Kennwertsynopse der Schiefewerte zum ALI-Korpus, Totalkorpus 318

Karte A70. Kennwertsynopse der Schiefewerte zum Vergleichskorpus, Totalkorpus ........318

Karte A71. Kennwertsynopse der Schiefewerte zum ALI-Korpus, Lexikon

Karte A72. Kennwertsynopse der Schiefewerte zum Vergleichskorpus, Lexikon

Karte A73. Kennwertsynopse der Schiefewerte zum ALI-Korpus, Konsonantismus 320

Karte A74. Kennwertsynopse der Schiefewerte zum Vergleichskorpus, Konsonantismus. 320

Karte A75. Kennwertsynopse der Schiefewerte zum ALI-Korpus, Vokalismus 321

Karte A76. Kennwertsynopse der Schiefewerte zum Vergleichskorpus, Vokalismus 321

Karte A77. Antipodenkarte der Maxima zum ALI-Korpus, Totalkorpus 322

Karte A78. Antipodenkarte der Maxima zum Vergleichskorpus, Totalkorpus 322

Karte A79. Antipodenkarte der Minima zum ALI-Korpus, Totalkorpus 323

Karte A80. Antipodenkarte der Minima zum Vergleichskorpus, Totalkorpus 323

Karte A81. Antipodenkarte der Maxima zum ALI-Korpus, Lexikon 324

Karte A82. Antipodenkarte der Maxima zum Vergleichskorpus, Lexikon 324

Karte A83. Antipodenkarte der Minima zum ALI-Korpus, Lexikon 325

Karte A84. Antipodenkarte der Minima zum Vergleichskorpus, Lexikon 325

Karte A85. Antipodenkarte der Maxima zum ALI-Korpus, Konsonantismus 326

Karte A86. Antipodenkarte der Maxima zum Vergleichskorpus, Konsonantismus 326

Karte A87. Antipodenkarte der Minima zum ALI-Korpus, Konsonantismus 327

Karte A88. Antipodenkarte der Minima zum Vergleichskorpus, Konsonantismus 327

Karte A89. Antipodenkarte der Maxima zum ALI-Korpus, Vokalismus 328

Karte A90. Antipodenkarte der Maxima zum Vergleichskorpus, Vokalismus 328

Karte A91. Antipodenkarte der Minima zum ALI-Korpus, Vokalismus 329

Karte A92. Antipodenkarte der Minima zum Vergleichskorpus, Vokalismus 329 
Karte A93. Korrelationskarte zum ALI-Korpus: Totalkorpus und geographische Proximität

Karte A94. Korrelationskarte zum Vergleichskorpus: Totalkorpus und geographische Proximität

Karte A95. Korrelationskarte zum ALI-Korpus: Lexikon und geographische Proximität .. 331

Karte A96. Korrelationskarte zum Vergleichskorpus: Lexikon und geographische

Proximität

Karte A97. Korrelationskarte zum ALI-Korpus: Konsonantismus und geographische Proximität

Karte A98. Korrelationskarte zum Vergleichskorpus: Konsonantismus und geographische

Proximität

Karte A99. Korrelationskarte zum ALI-Korpus: Vokalismus und geographische

Proximität

Karte A100. Korrelationskarte zum Vergleichskorpus: Vokalismus und geographische

Proximität

Karte A101. Korrelationskarte zu den Totalkorpora: ALI-Korpus und Vergleichskorpus.. 334

Karte A102. Korrelationskarte zum Lexikon: ALI-Korpus und Vergleichskorpus 334

Karte A103. Korrelationskarte zum Konsonantismus: ALI-Korpus und

Vergleichskorpus

Karte A104. Korrelationskarte zum Vokalismus: ALI-Korpus und Vergleichskorpus ....... 335

Karte A105. Ähnlichkeitsprofil zum Referenzpunkt Neapel (835):

ALI-Korpus, Totalkorpus

Karte A106. Ähnlichkeitsprofil zum Referenzpunkt Neapel (835): Vergleichskorpus, Totalkorpus.

Karte A107. Ähnlichkeitsprofil zum Referenzpunkt Melito Irpino (826):

ALI-Korpus, Lexikon

Karte A108. Ähnlichkeitsprofil zum Referenzpunkt Melito Irpino (826):

Vergleichskorpus, Lexikon

Karte A109. Ähnlichkeitsprofil zum Referenzpunkt Neapel (835):

ALI-Korpus, Konsonantismus 
Karte A110. Ähnlichkeitsprofil zum Referenzpunkt Neapel (835):

Vergleichskorpus, Konsonantismus

Karte A111. Ähnlichkeitsprofil zum Referenzpunkt Gioia Sannìtica (814):

ALI-Korpus, Vokalismus

Karte A112. Ähnlichkeitsprofil zum Referenzpunkt Gioia Sannìtica (814):

Vergleichskorpus, Vokalismus

Karte A113. Synopse der Ähnlichkeitswerte zum Referenzpunkt italiano standard (900):

ALI-Korpus, Totalkorpus

Karte A114. Synopse der Ähnlichkeitswerte zum Referenzpunkt italiano standard (900):

Vergleichskorpus, Totalkorpus

Karte A115. Synopse der Ähnlichkeitswerte zum Referenzpunkt italiano standard (900):

ALI-Korpus, Lexikon

Karte A116. Synopse der Ähnlichkeitswerte zum Referenzpunkt italiano standard (900):

Vergleichskorpus, Lexikon

Karte A117. Synopse der Ähnlichkeitswerte zum Referenzpunkt italiano standard (900):

ALI-Korpus, Konsonantismus

Karte A118. Synopse der Ähnlichkeitswerte zum Referenzpunkt italiano standard (900):

Vergleichskorpus, Konsonantismus

Karte A119. Synopse der Ähnlichkeitswerte zum Referenzpunkt italiano standard (900):

ALI-Korpus, Vokalismus

Karte A120. Synopse der Ähnlichkeitswerte zum Referenzpunkt italiano standard (900):

Vergleichskorpus, Vokalismus 
9 Kartenteil 


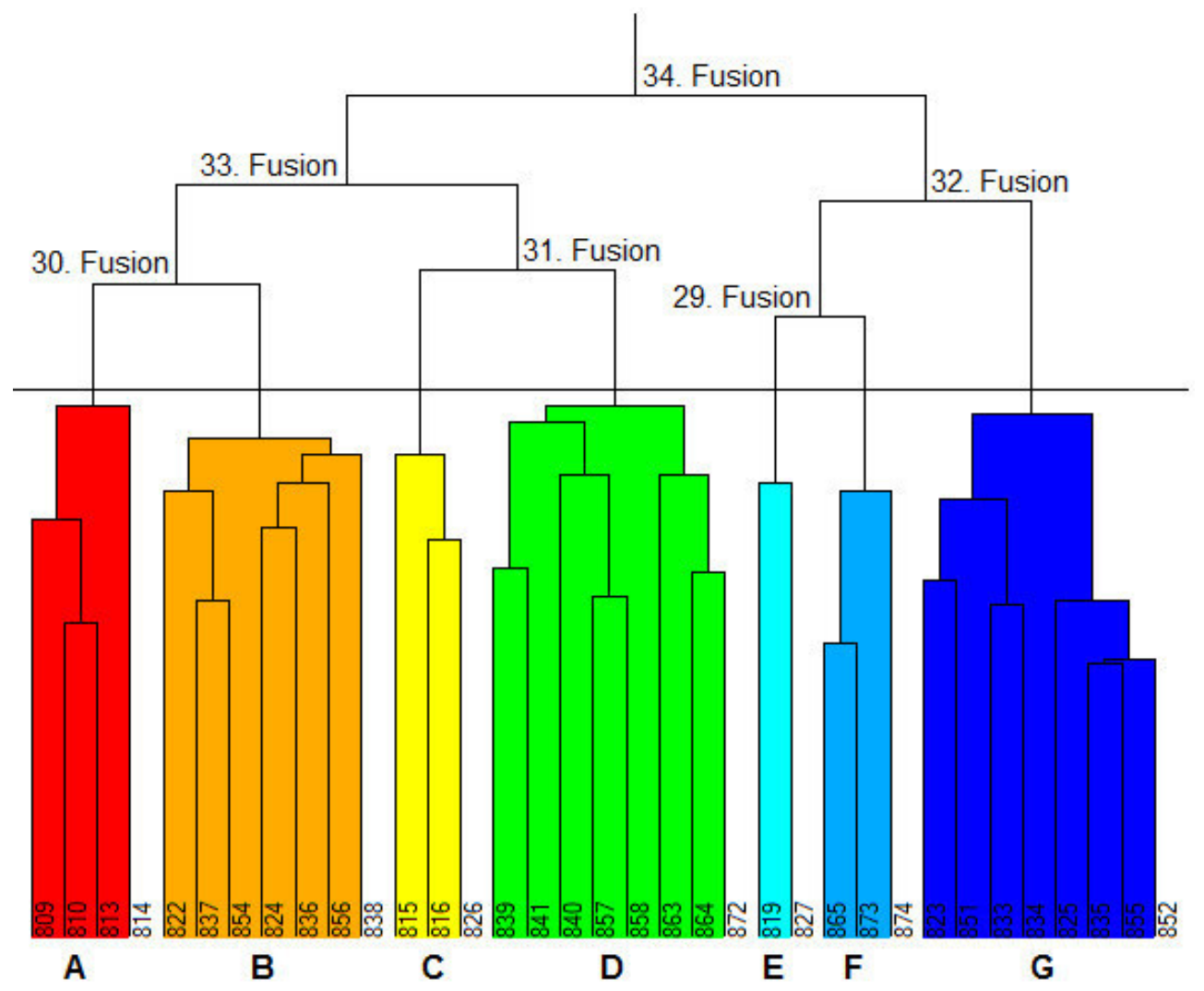

Abbildung A1. Dendrogramm der Clusteranalyse mit sieben eingefärbten Dendremen. ALI-Korpus, Totalkorpus (275 $\mathrm{AK}) . \mathrm{N}=35$, Messmoment $\mathrm{RIW}_{j k}$, Clustermethode Complete Linkage.

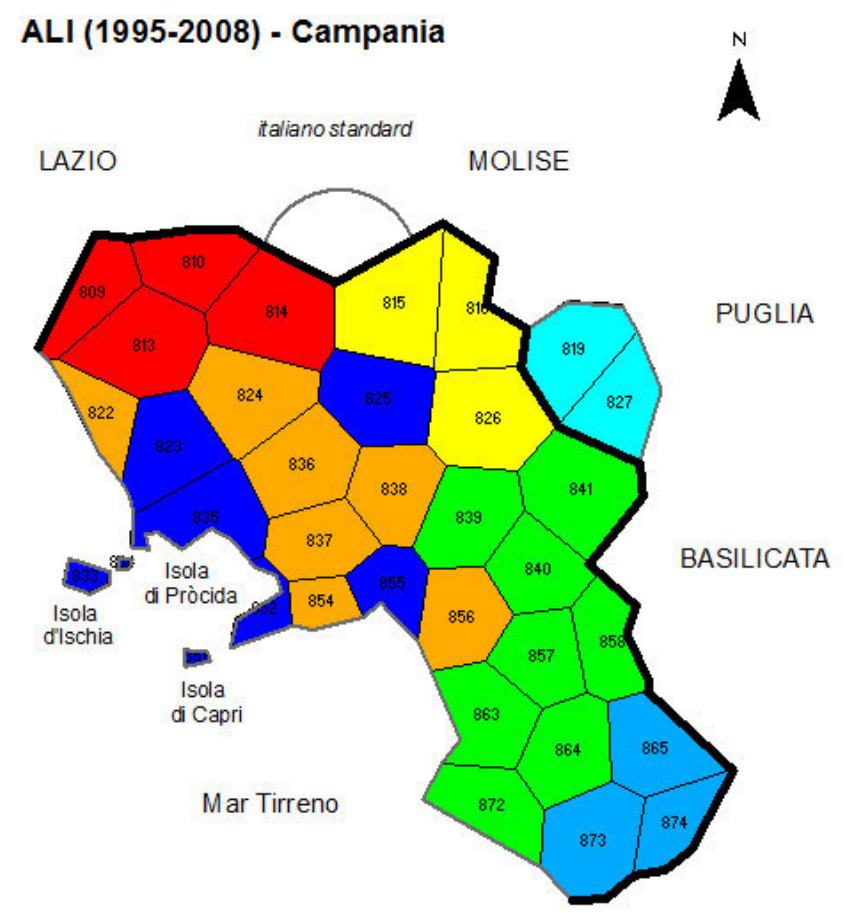

fec S. Hajek

adiuv. H. Goebl et P. Smečka

adiuv. B. Castellazzi

carta di THIESSENHAAGNORONOI 35 punti d'inchiesta + italiano standard

a.d. 2013

limite di regione

Karte A1. Räumliche Umlegung des Dendrogramms aus Abb. A1: Clusterkarte mit sieben Choremen. 


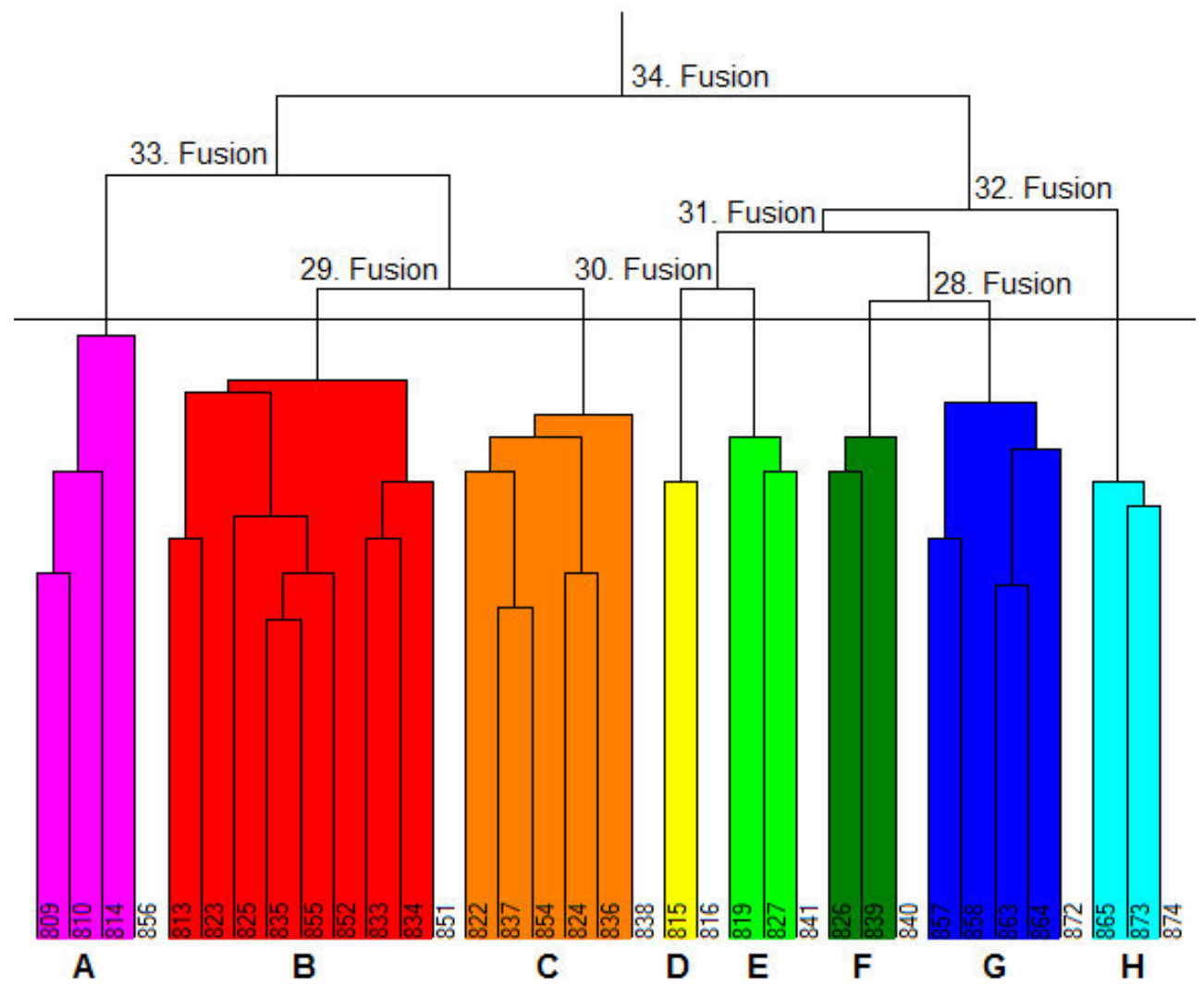

Abbildung A2. Dendrogramm der Clusteranalyse mit acht eingefärbten Dendremen. ALI-Korpus, Lexikon (105 AK). $\mathrm{N}=35$, Messmoment $\mathrm{RIW}_{j k}$, Clustermethode Complete Linkage.
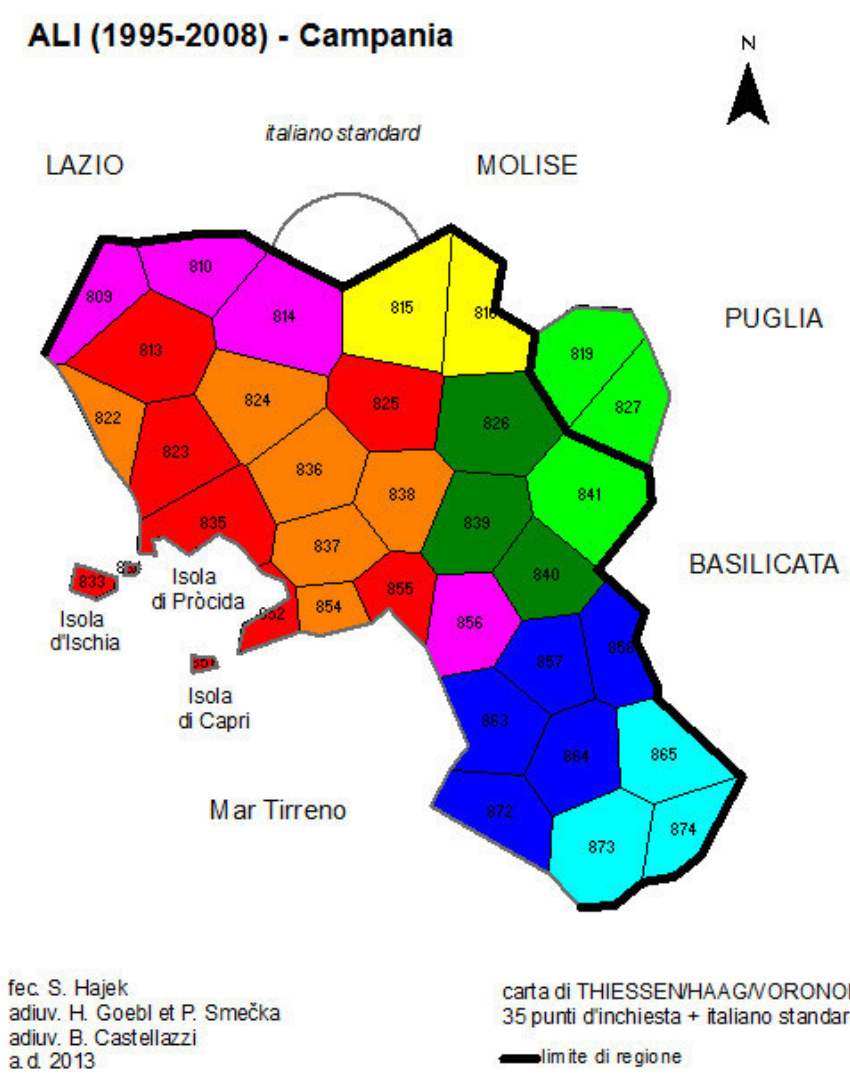

limite di regione

Karte A2. Räumliche Umlegung des Dendrogramms aus Abb. A2: Clusterkarte mit acht Choremen. 


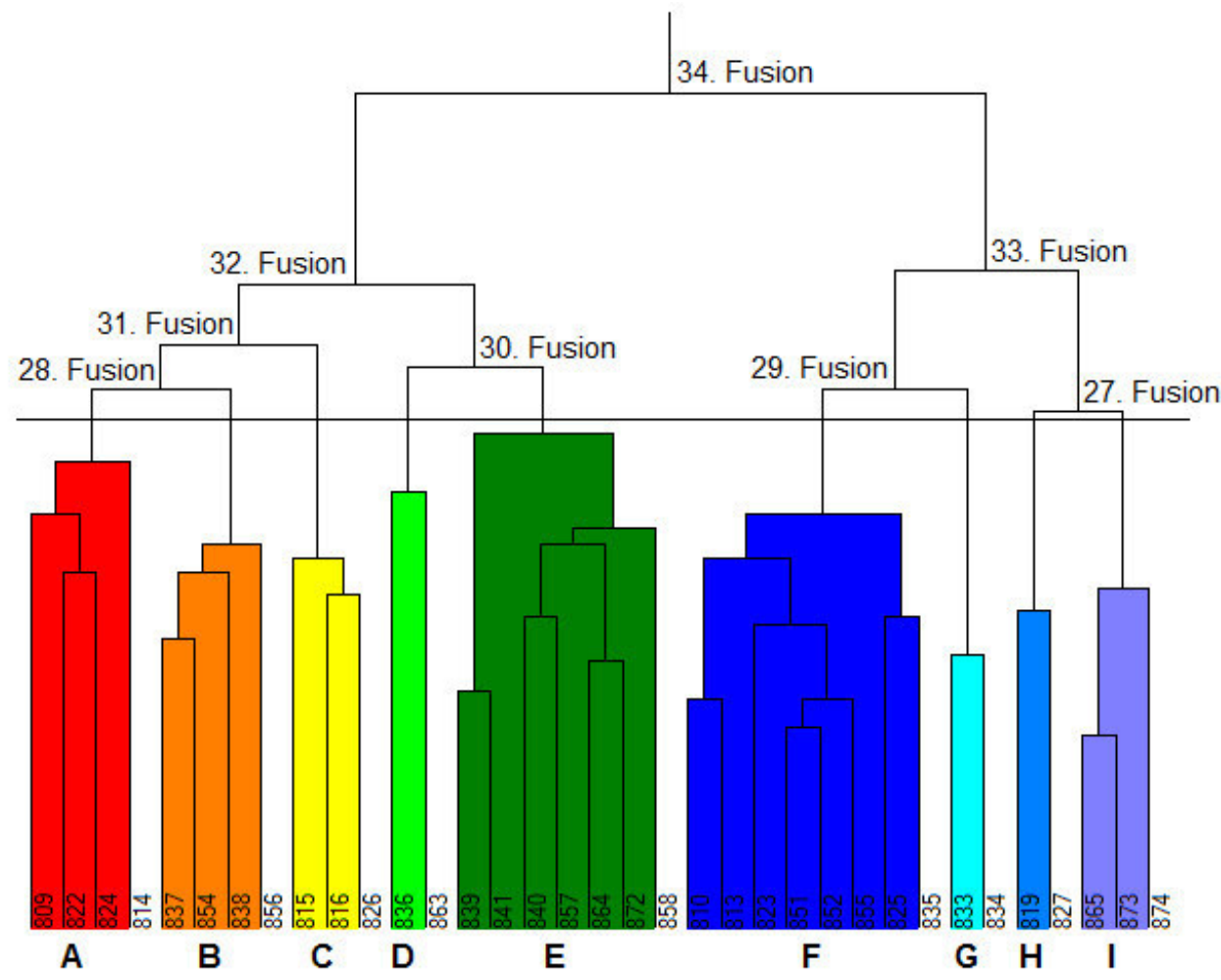

Abbildung A3. Dendrogramm der Clusteranalyse mit neun eingefärbten Dendremen. ALI-Korpus, Konsonantismus (129 AK). $\mathrm{N}=35$, Messmoment $\mathrm{RIW}_{j k}$, Clustermethode Complete Linkage .

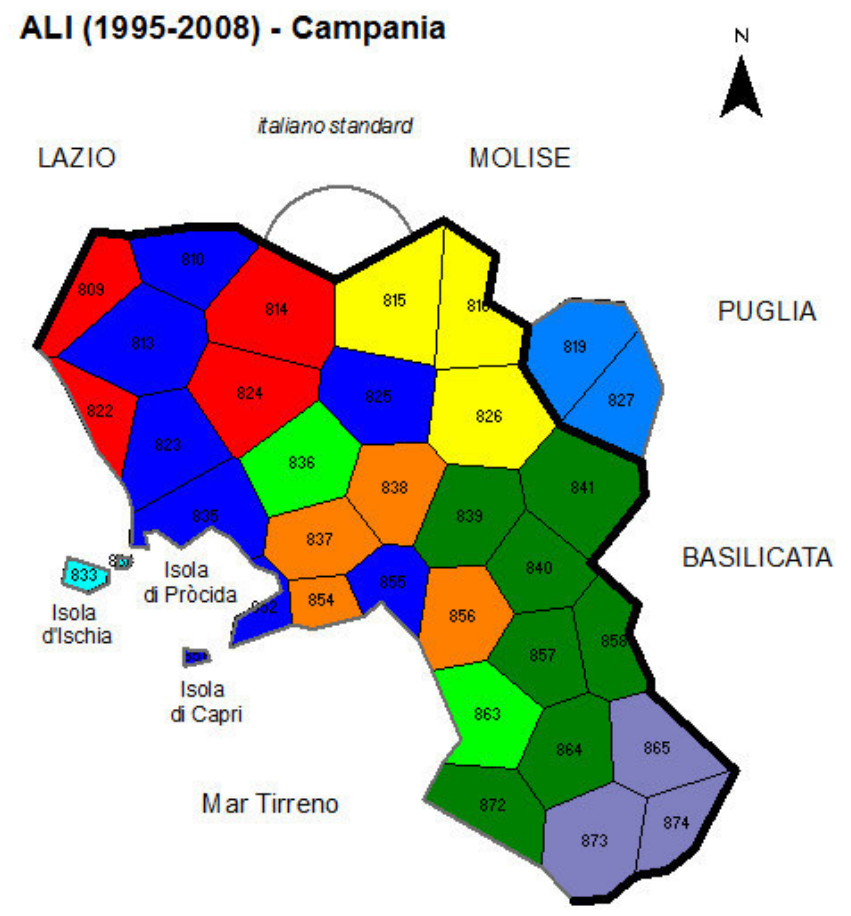

fec. S. Hajek

adiuv. H. Goebl et P. Smečka

adiuv. B. Castellazzi

carta di THIESSENHAAGNORONOI 35 punti d'inchiesta + italiano standard

a.d. 2013

limite di regione

Karte A3. Räumliche Umlegung des Dendrogramms aus Abb. A3: Clusterkarte mit neun Choremen. 


\section{Kartenteil}

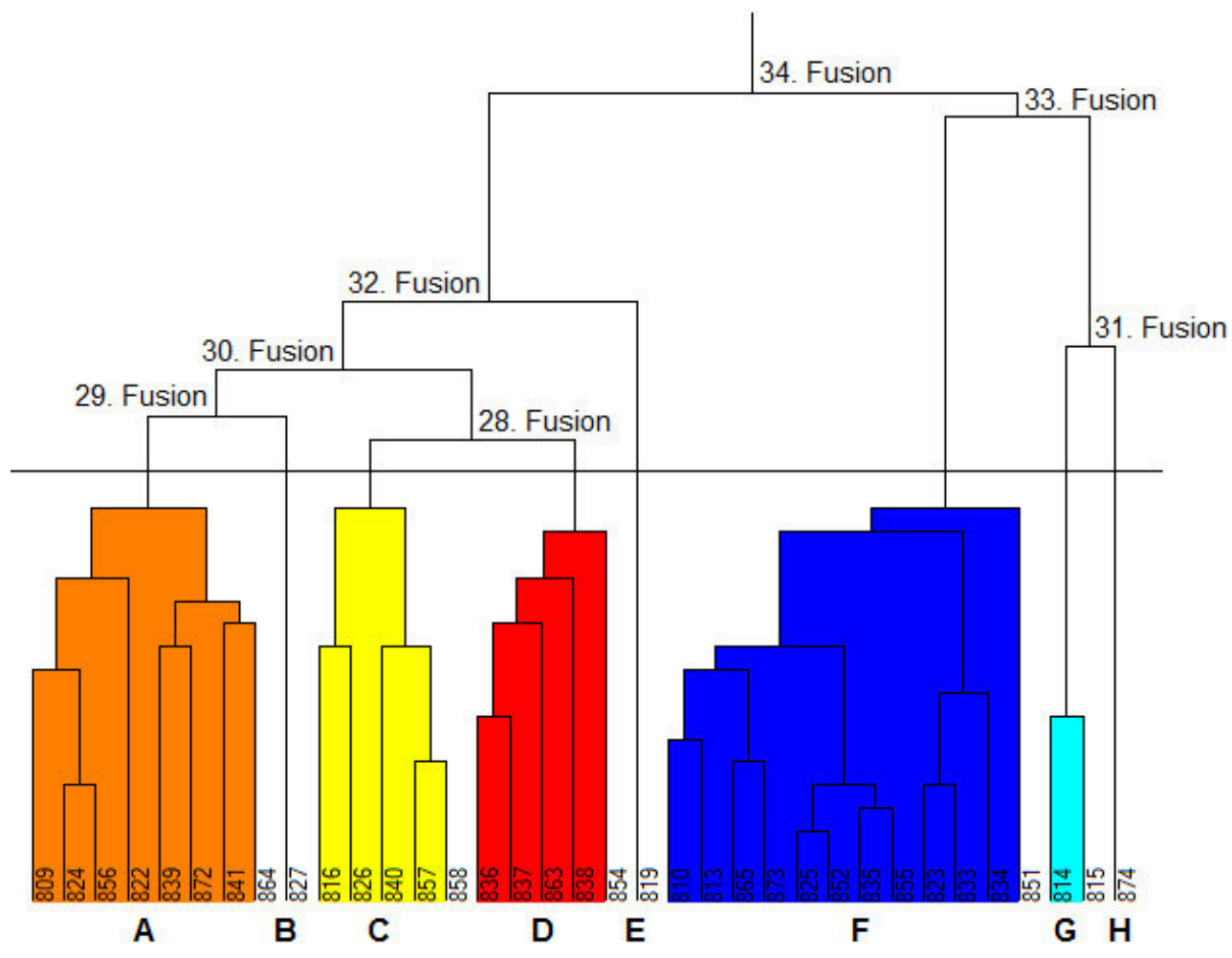

Abbildung A4. Dendrogramm der Clusteranalyse mit acht eingefärbten Dendremen. ALI-Korpus, Vokalismus (41 AK). $\mathrm{N}=35$, Messmoment $\mathrm{RIW}_{j k}$, Clustermethode Complete Linkage.

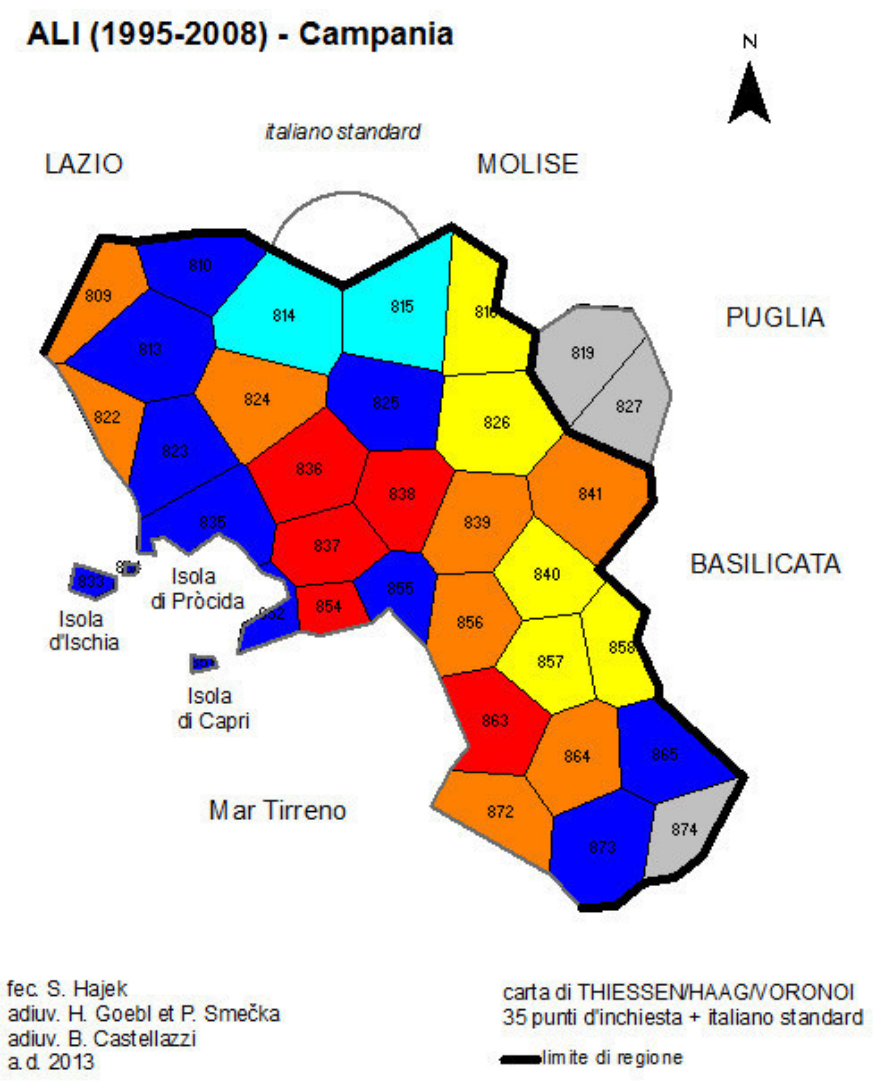

Karte A4. Räumliche Umlegung des Dendrogramms aus Abb. A4: Clusterkarte mit acht Choremen. Die Punkte der grau unterlegten Polygone bilden je ein eigenes Cluster. 
Legende, MINMWMAX, 6-fach

[1] von 24.73 bis $30.88(n=5)$

[2] bis $37.03(n=13)$

[3] bis $43.18(n=16)$

[4] bis $48.42(n=17)$

[5] bis $53.66(n=10)$

[6] bis $58.91(n=10)$

Summe der Elemente: 71

$\mathrm{MIN}=24.73$

$\mathrm{MW}=43.18$

$\mathrm{MED}=43.64$

$\operatorname{MAX}=58.91$

Häufigkeitsverteilung, MINMWMAX, 12-fach

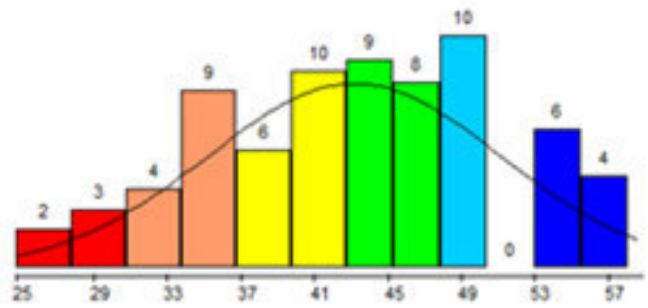

\section{ALI (1995-2008) - Campania}

LAZIO

italiano standard

MOLISE

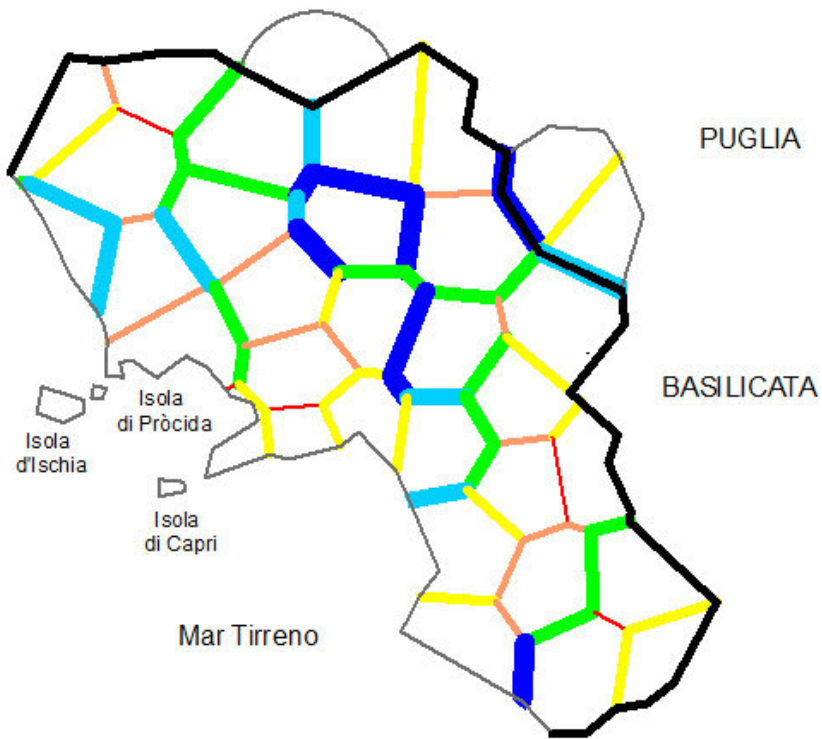

fec. S. Hajek

adiuv. H. Goebl et P. Smečka

adiuv. B. Castellazzi

carta di THIESSEN/HAAG/VORONOI 35 punti d'inchiesta + italiano standard -limite di regione

Karte A5. Schottenkarte zum ALI-Korpus, Totalkorpus (275 AK). N = 35, Messmoment RDW . $_{j k}$.

\section{Legende, MINMWMAX, 6-fach}

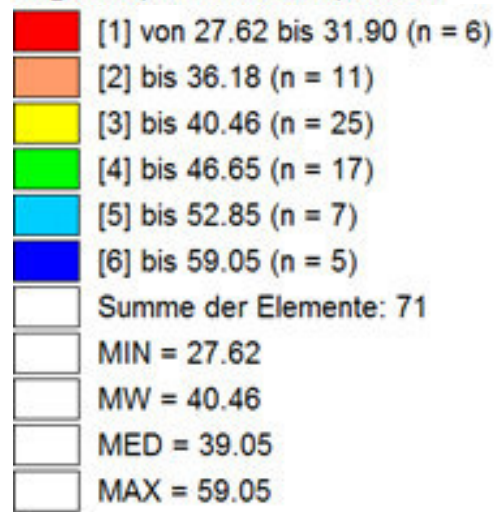

Häufigkeitsverteilung, MINMWMAX, 12-fach

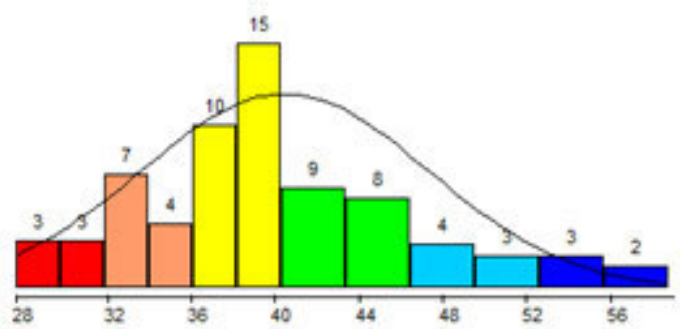

\section{ALI (1995-2008) - Campania}

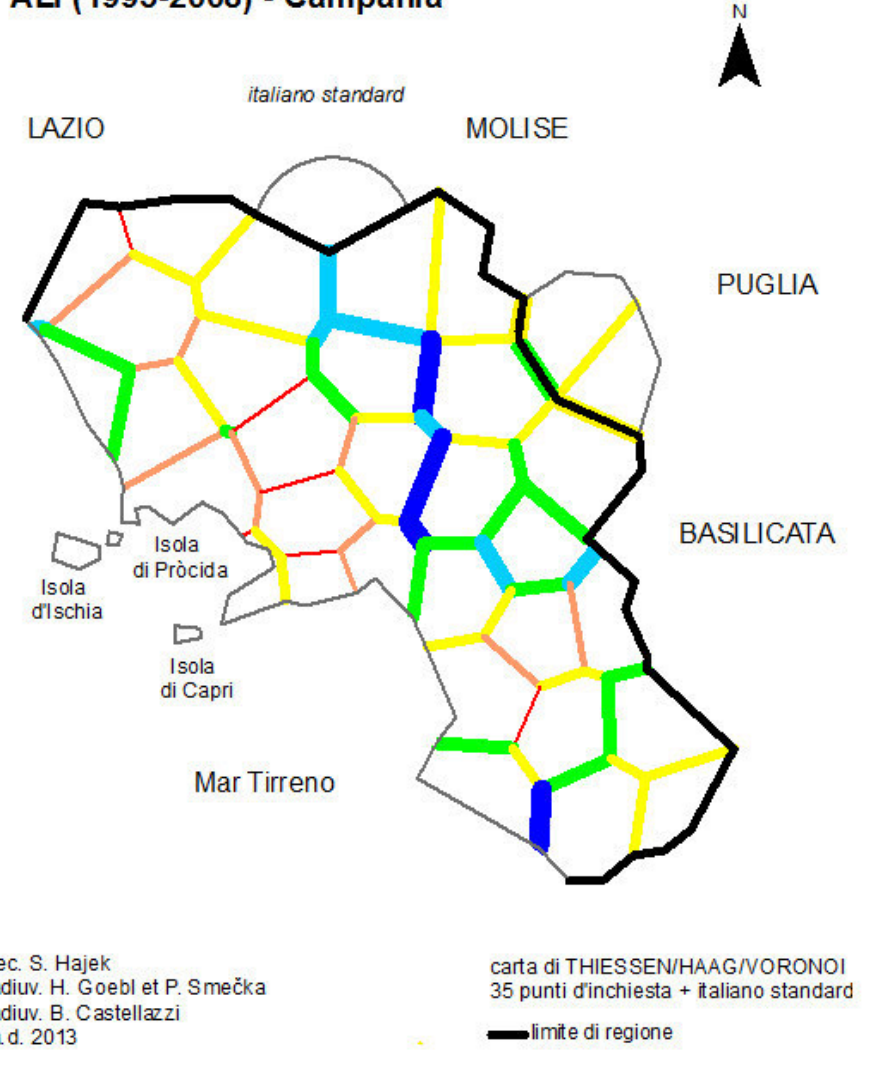

Karte A6. Schottenkarte zum ALI-Korpus, Lexikon (105 AK). N = 35, Messmoment RDW $j k$. 
Legende, MINMWMAX, 6-fach

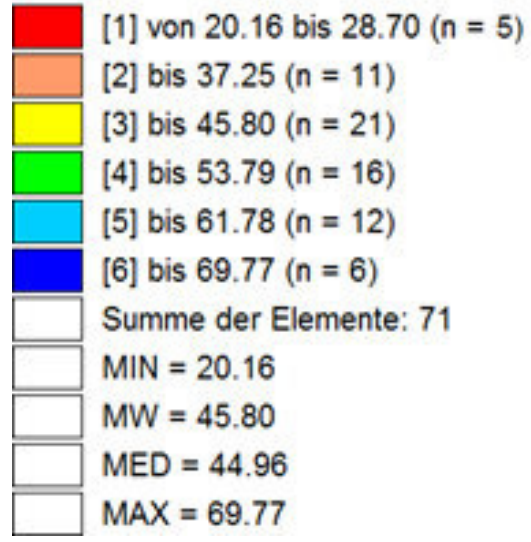

Häufigkeitsverteilung, MINMWMAX, 12-fach

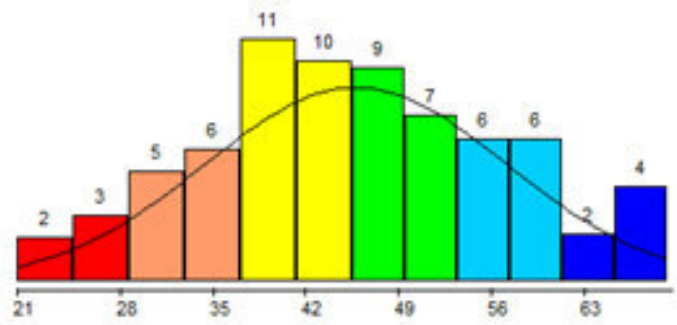

\section{ALI (1995-2008) - Campania}

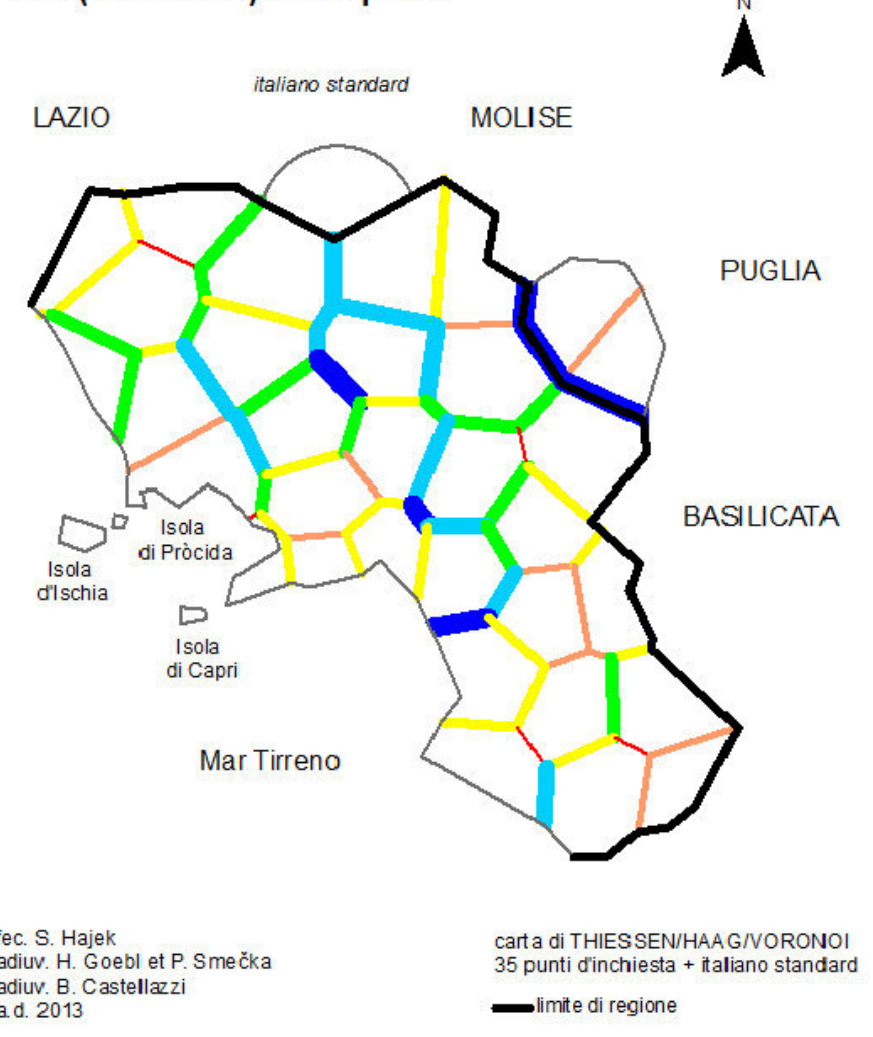

Karte A7. Schottenkarte zum ALI-Korpus, Konsonantismus (129 AK). N = 35, Messmoment RDW . $_{j k}$.

\section{Legende, MINMWMAX, 6-fach}

[1] von 9.76 bis $20.46(n=7)$

[2] bis $31.17(n=11)$

[3] bis $41.88(n=24)$

[4] bis $52.31(n=10)$

[5] bis $62.74(n=12)$

[6] bis $73.17(n=7)$

Summe der Elemente: 71

$\mathrm{MIN}=9.76$

$M W=41.88$

$\mathrm{MED}=41.46$

$\operatorname{MAX}=73.17$

Häufigkeitsverteilung, MINMWMAX, 12-fach

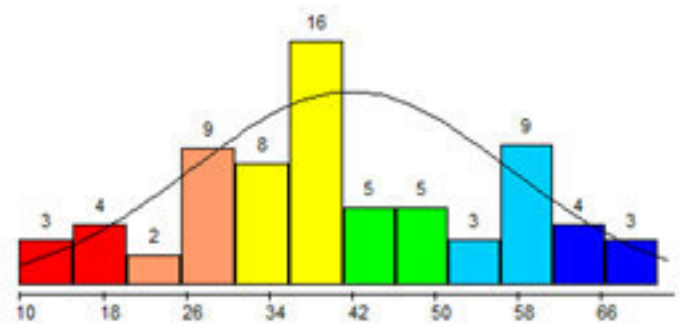

\section{ALI (1995-2008) - Campania}

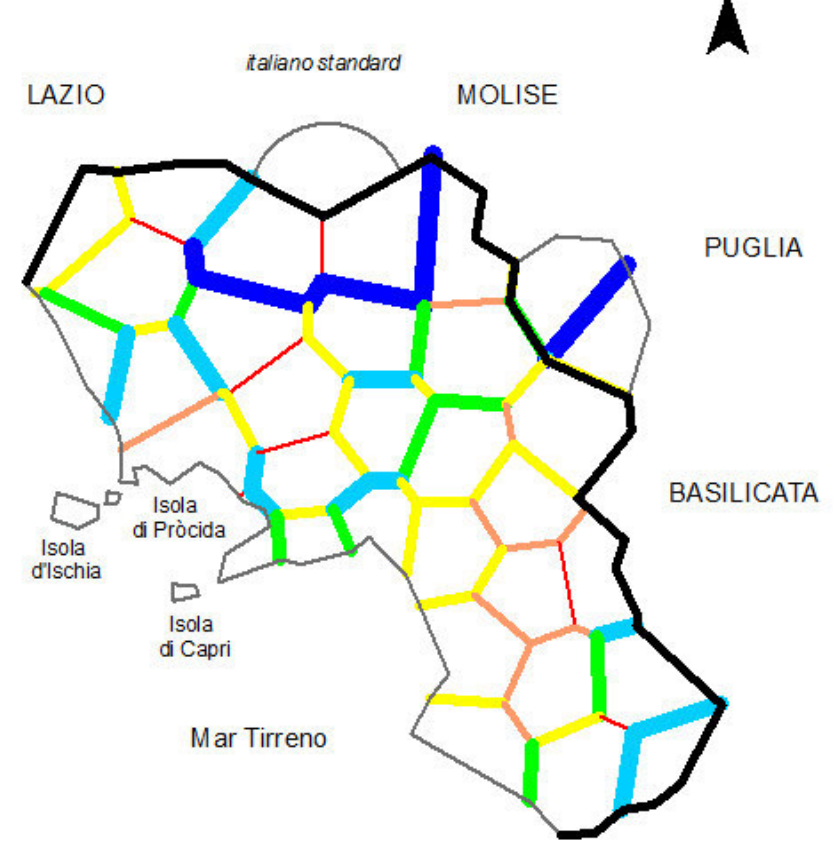

fec. S. Hajek

adiuv. H. Goebl et P. Smečka adiuv. B. Castellazzi

a.d. 2013

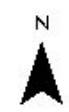

N

carta di THIESSENHAAGNORONOI 35 punti d'inchiesta + italiano standard limite di regione

Karte A8. Schottenkarte zum ALI-Korpus, Vokalismus (41 AK). N = 35, Messmoment RDW $j$. 
Legende, MINMWMAX, 6-fach

[1] von 57.45 bis $60.78(n=4)$

[2] bis $64.10(n=7)$

[3] bis $67.42(n=6)$

[4] bis $70.16(n=5)$

[5] bis $72.90(n=8)$

[6] bis $75.64(n=5)$

Summe der Elemente: 35

$\mathrm{MIN}=57.45$ (P. 814)

$\mathrm{MW}=67.42$

MED $=67.64$

MAX $=75.64$ (P. 835; 852; 855)

Häufigkeitsverteilung, MINMWMAX, 12-fach

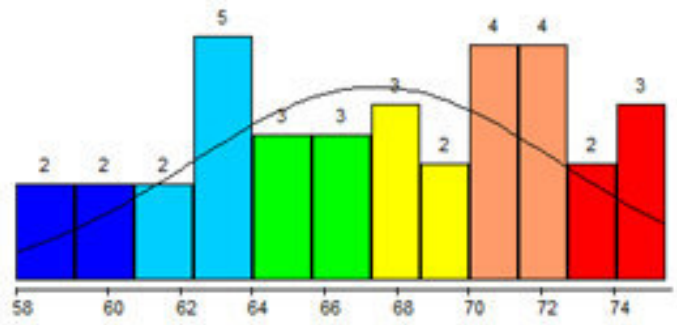

\section{ALI (1995-2008) - Campania}

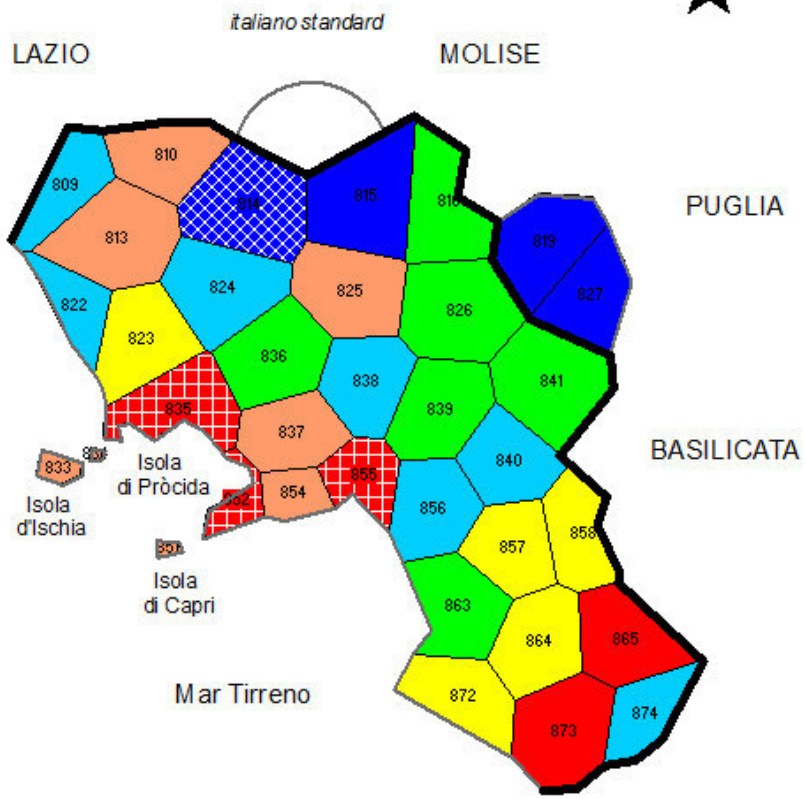

fec. S. Hajek

adiuv. H. Goebl et P. Smečka adiuv. B. Castellazzi a.d. 2013

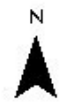

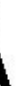

carta di THIESSENHAAGNORONOI 35 punti dinchiesta + italiano standard -limite di regione

Karte A9. Kennwertsynopse der Maxima. ALI-Korpus, Totalkorpus (275 AK). N = 35, Messmoment RIW $j k$.

\section{Legende, MINMWMAX, 6-fach}

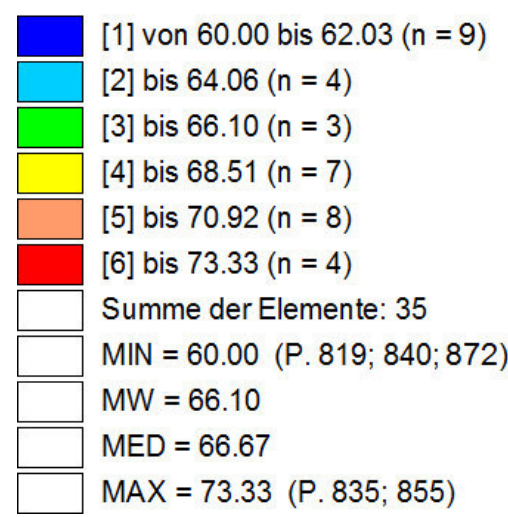

Häufigkeitsverteilung, MINMWMAX, 12-fach

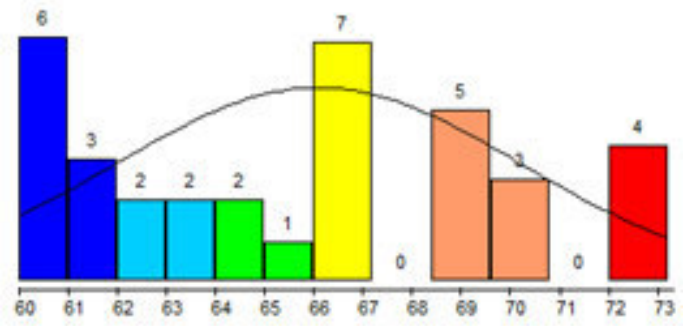

\section{ALI (1995-2008) - Campania}
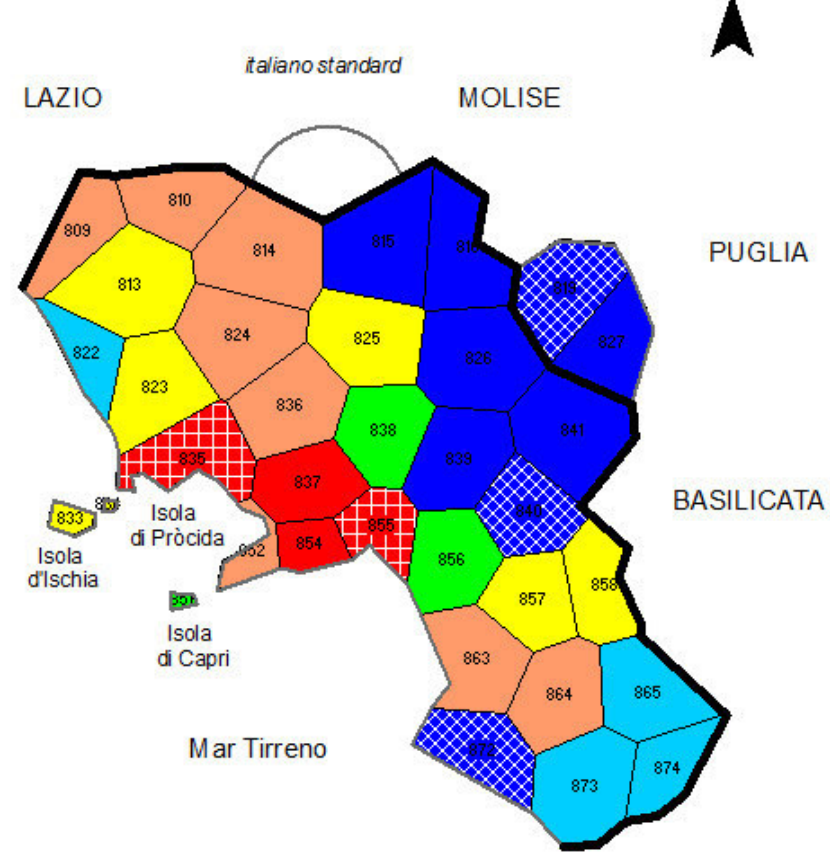

fec. S. Hajek

adiuv. H. Goebl et P. Smečka adiuv. B. Castellazzi a.d. 2013

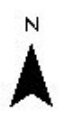

carta di THIESSENHAAGNORONOI 35 punti dinchiesta + italiano standard

limite di regione

Karte A10. Kennwertsynopse der Maxima. ALI-Korpus, Lexikon (105 AK). N = 35, Messmoment RIW ${ }_{j k}$. 
Legende, MINMWMAX, 6-fach

[1] von 55.81 bis $60.38(n=3)$
$[2]$ bis $64.95(n=5)$
[3] bis $69.52(n=9)$
[4] bis $72.96(n=7)$
$[5]$ bis $76.40(n=6)$
[6] bis $79.84(n=5)$
Summe der Elemente: 35
MIN $=55.81 \quad(P .814)$
MW $=69.52$
MED $=69.77$
MAX $=79.84$ (P. $865 ; 873)$

Häufigkeitsverteilung, MINMWMAX, 12-fach

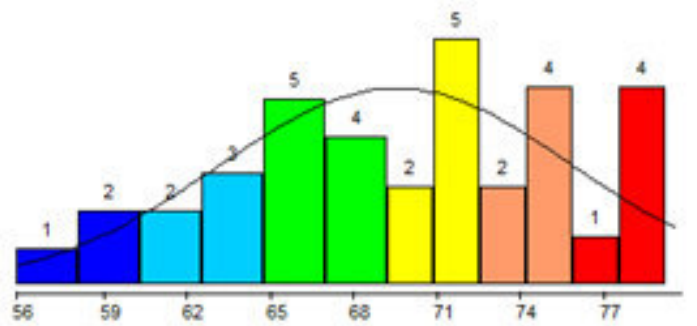

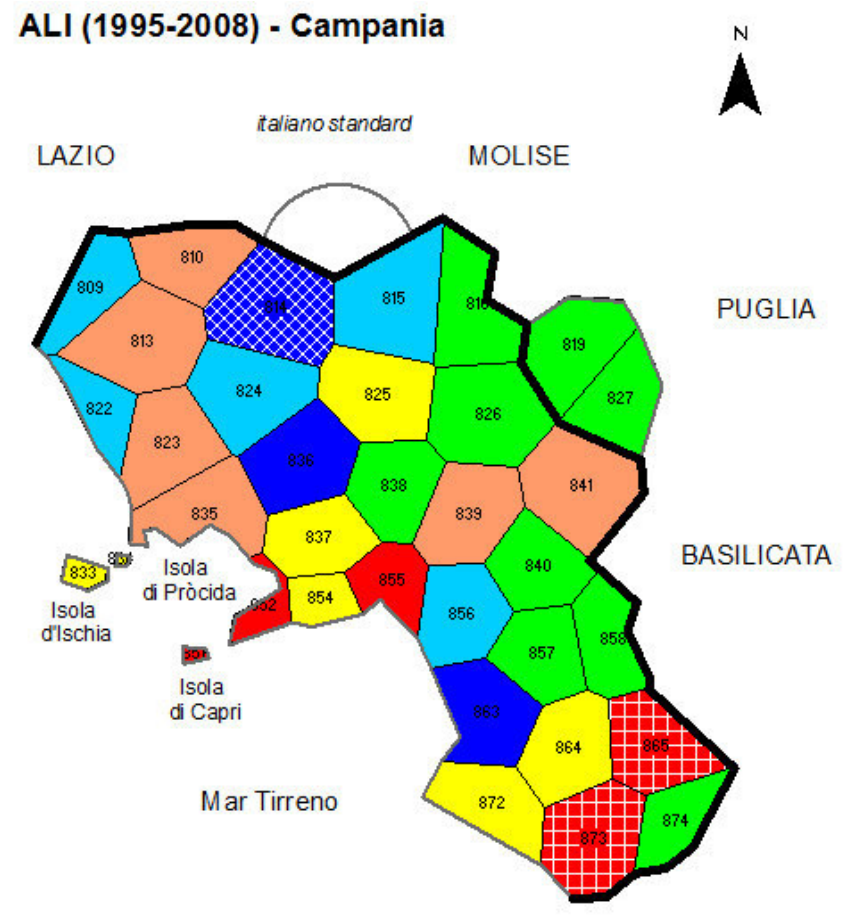

fec. S. Hajek

adiuv. H. Goebl et P. Smečka adiuv. B. Castellazzi a.d. 2013 carta di THIESSENHAAGNORONOI 35 punti dinchiesta + italiano standard

Karte A11. Kennwertsynopse der Maxima. ALI-Korpus, Konsonantismus (129 AK). N = 35, Messmoment RIW $j k$.

Legende, MINMWMAX, 6-fach

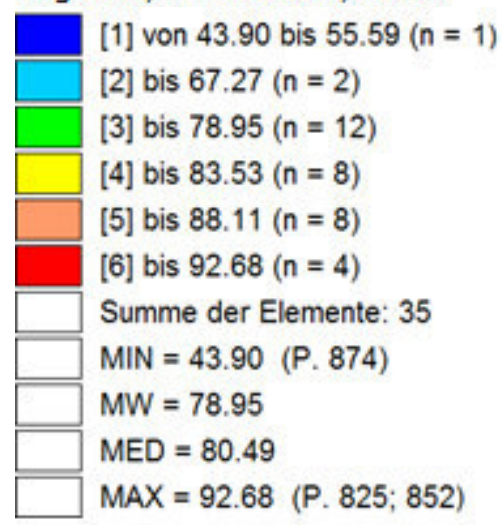

Häufigkeitsverteilung, MINMWMAX, 12-fach

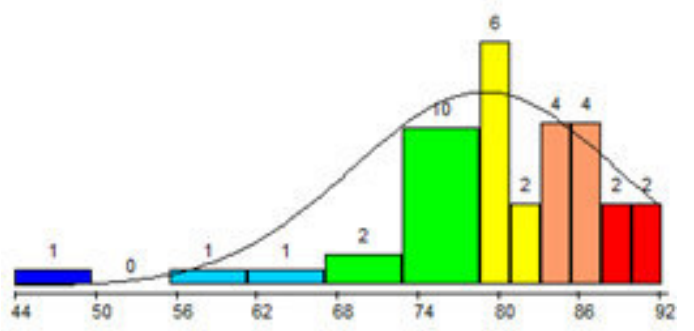

\section{ALI (1995-2008) - Campania}

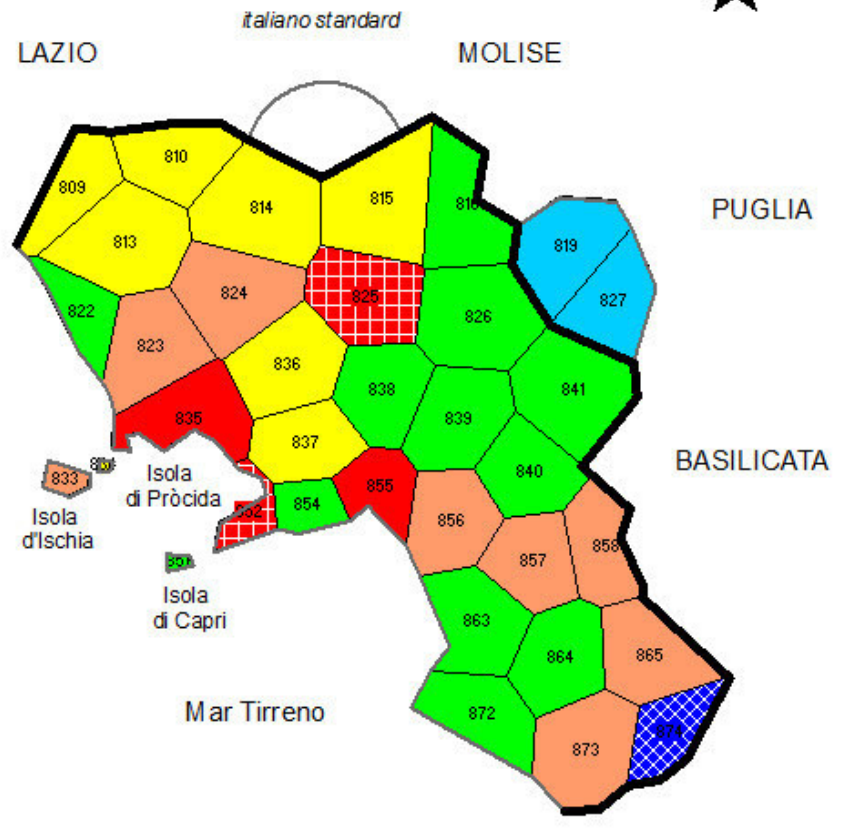

fec. S. Hajek

adiuv. $H$. Goebl et $P$. Smečka adiuv. B. Castellazzi a.d. 2013
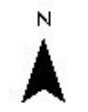
Legende, MINMWMAX, 6-fach

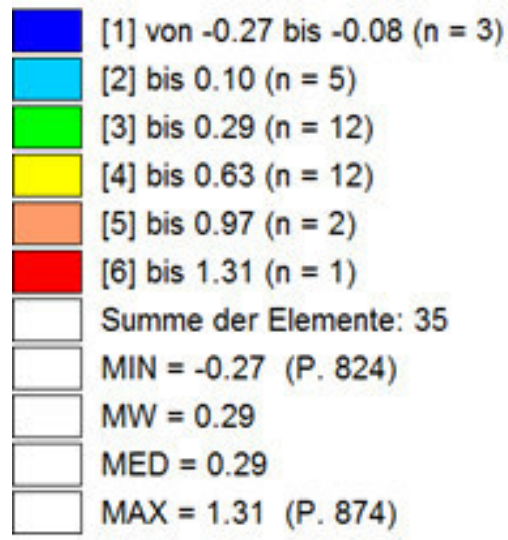

Häufigkeitsverteilung, MINMWMAX, 12-fach

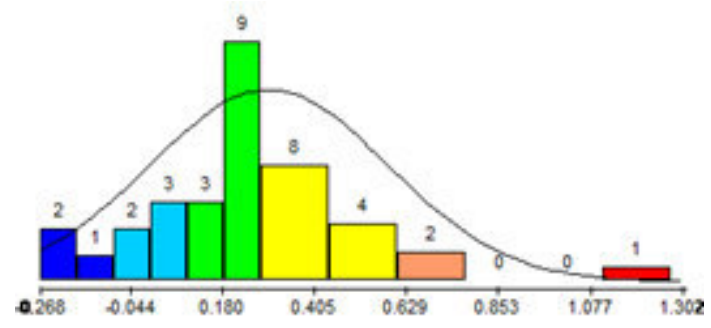

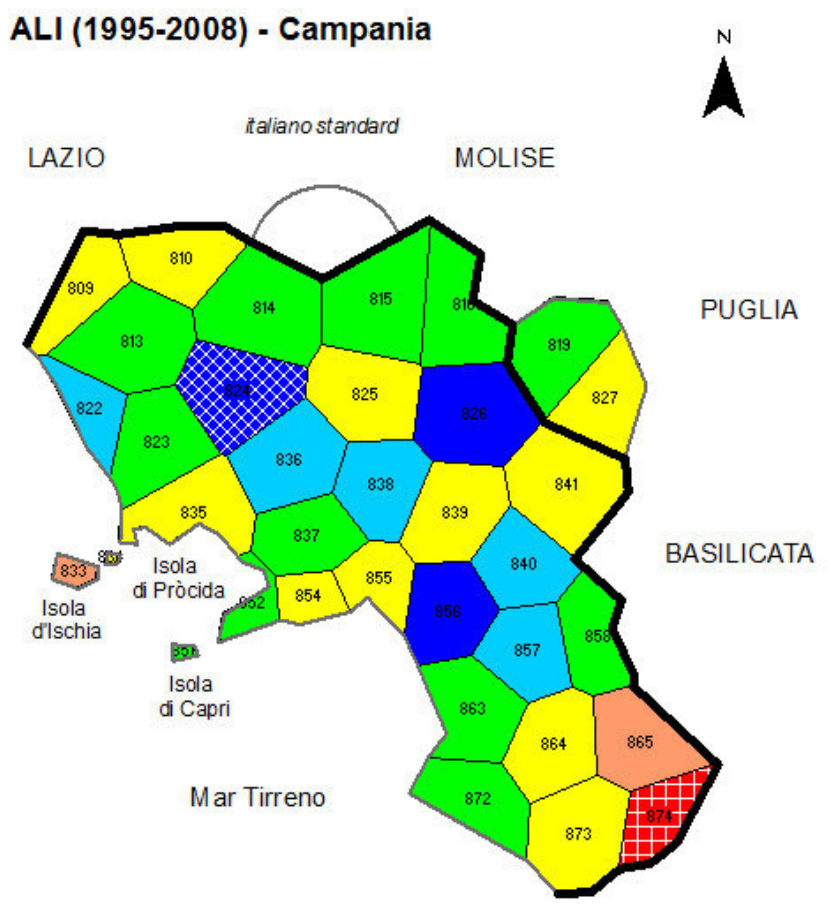

fec. S. Hajek

adiuv. $\mathrm{H}$. Goebl et P. Smečka adiuv. B. Castellazzi

carta di THIESSENHAAGNORONOI 35 punti d'inchiesta + italiano standard - limite di regione

Karte A13. Kennwertsynopse der Schiefewerte. ALI-Korpus, Totalkorpus (275 AK). N = 35, Messmoment RIW $j k$.

Legende, MINMWMAX, 6-fach

\begin{tabular}{l} 
[1] von -0.14 bis $0.02(n=3)$ \\
[2] bis $0.17(n=8)$ \\
{$[3]$ bis $0.33(n=10)$} \\
[4] bis $0.61(n=8)$ \\
{$[5]$ bis $0.89(n=4)$} \\
{$[6]$ bis $1.17(n=2)$} \\
Summe der Elemente: 35 \\
MIN $=-0.14 \quad(P .856)$ \\
MW $=0.33$ \\
\hline$\square$ MED $=0.31$ \\
\hline$\square$ \\
\hline$\square=1.17 \quad(P .874)$
\end{tabular}

Häufigkeitsverteilung, MINMWMAX, 12-fach

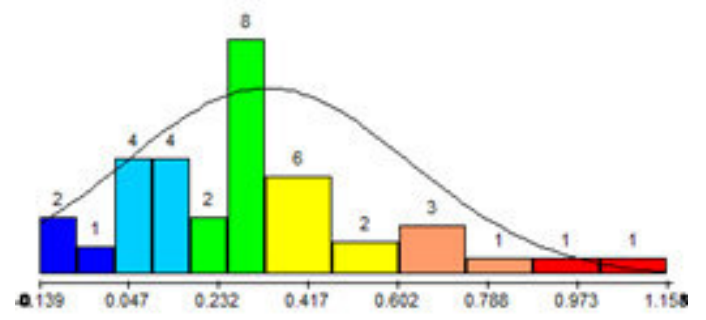

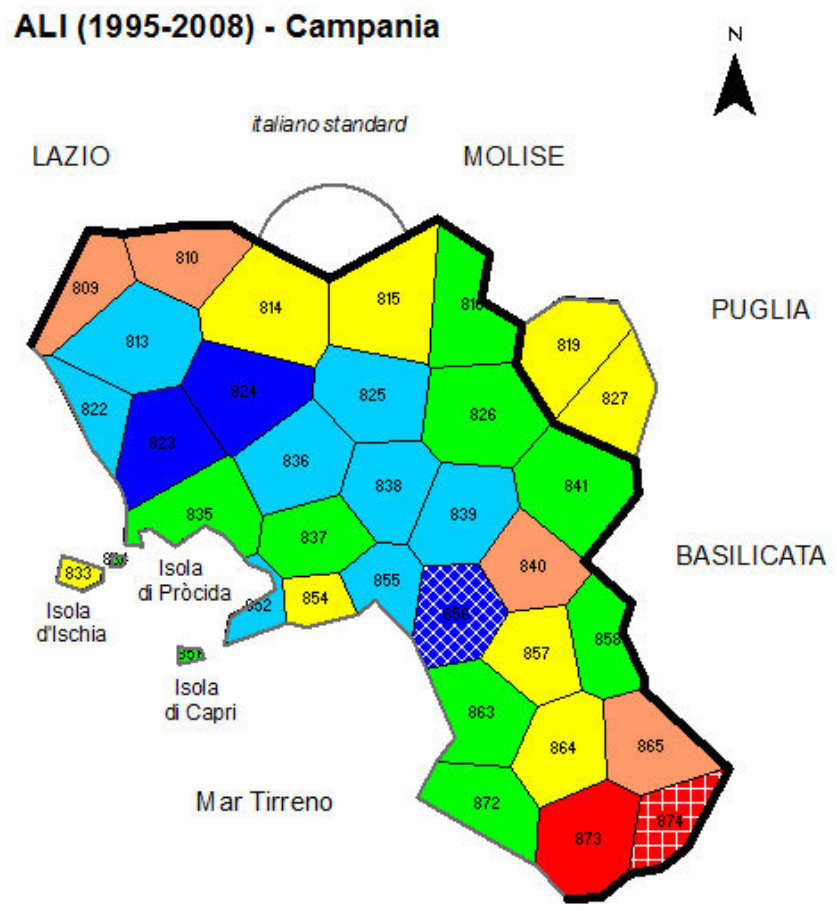

fec. S. Hajek

adiuv. H. Goebl et P. Smečka $\quad 35$ punti d'inchiesta + italiano standard adiuv. B. Castellazzi
a.d. 2013 carta di THIESSENHAAGNORONOI limite di regione

Karte A14. Kennwertsynopse der Schiefewerte. ALI-Korpus, Lexikon (105 AK). N = 35, Messmoment RIW $j k$. 


\section{Kartenteil}

Legende, MINMWMAX, 6-fach

[1] von -0.31 bis $-0.13(n=4)$

[2] bis $0.05(n=8)$

[3] bis $0.23(n=7)$

[4] bis $0.44(n=6)$

[5] bis $0.64(n=6)$

[6] bis $0.85(n=4)$

Summe der Elemente: 35

$\mathrm{MIN}=-0.31$ (P. 824)

$\mathrm{MW}=0.23$

MED $=0.16$

MAX $=0.85$ (P. 865)

Häufigkeitsverteilung, MINMWMAX, 12-fach

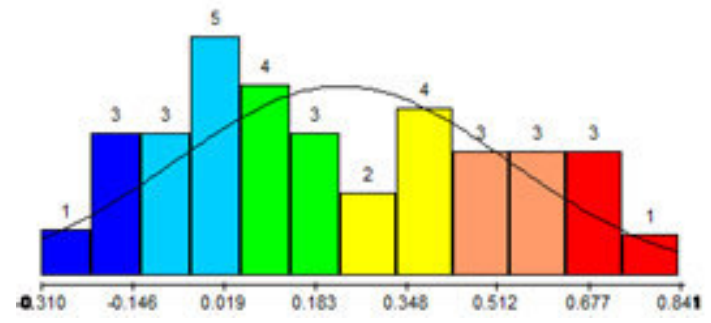

\section{ALI (1995-2008) - Campania}

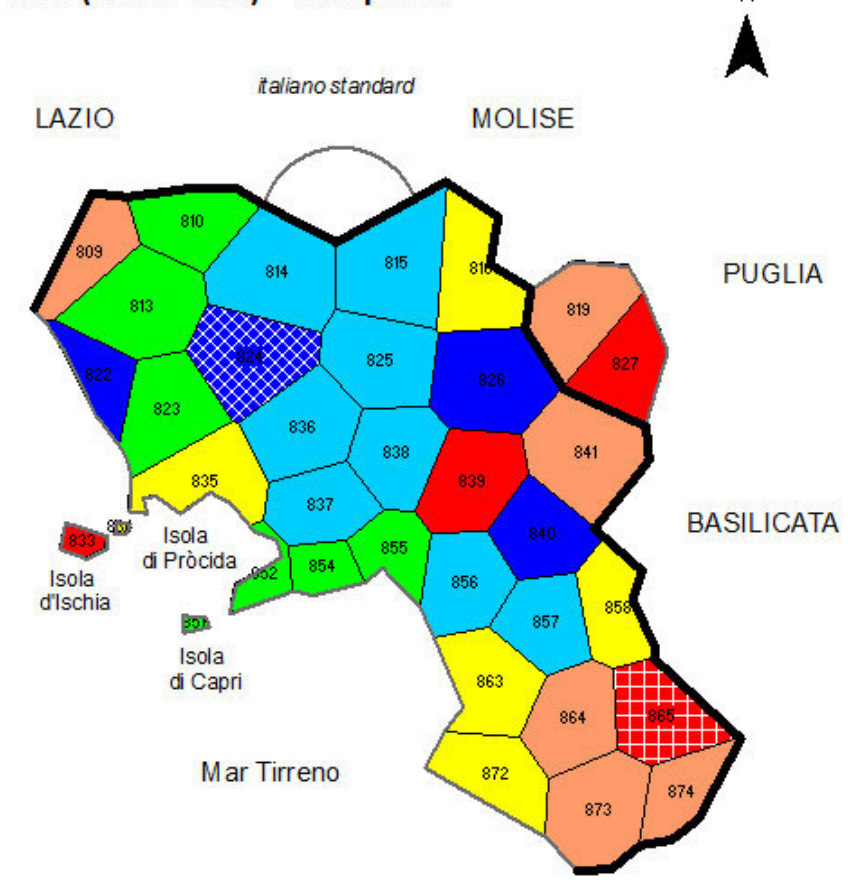

fec S. Hajek

adiuv. H. Goebl et P. Smečka adiuv. B. Castellazzi carta di THIESSENHAAGNORONOI 35 punti d'inchiesta + italiano standard - limite di regione

Karte A15. Kennwertsynopse der Schiefewerte. ALI-Korpus, Konsonantismus (129 AK). N = 35, Messmoment RIW jk $_{\text {. }}$

\section{Legende, MINMWMAX, 6-fach}

[1] von -0.95 bis $-0.61(n=2)$
$[2]$ bis $-0.27(n=9)$
$[3]$ bis $0.06(n=9)$
$[4]$ bis $1.09(n=13)$
$[5]$ bis $2.11(n=0)$
$[6]$ bis $3.14(n=2)$
Summe der Elemente: 35
MIN $=-0.95 \quad(P .841)$
MW $=0.06$
MED $=-0.08$
MAX $=3.14 \quad(P .815)$

Häufigkeitsverteilung, MINMWMAX, 12-fach

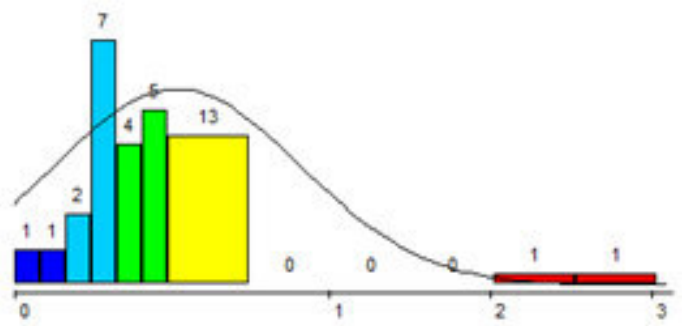

\section{ALI (1995-2008) - Campania}
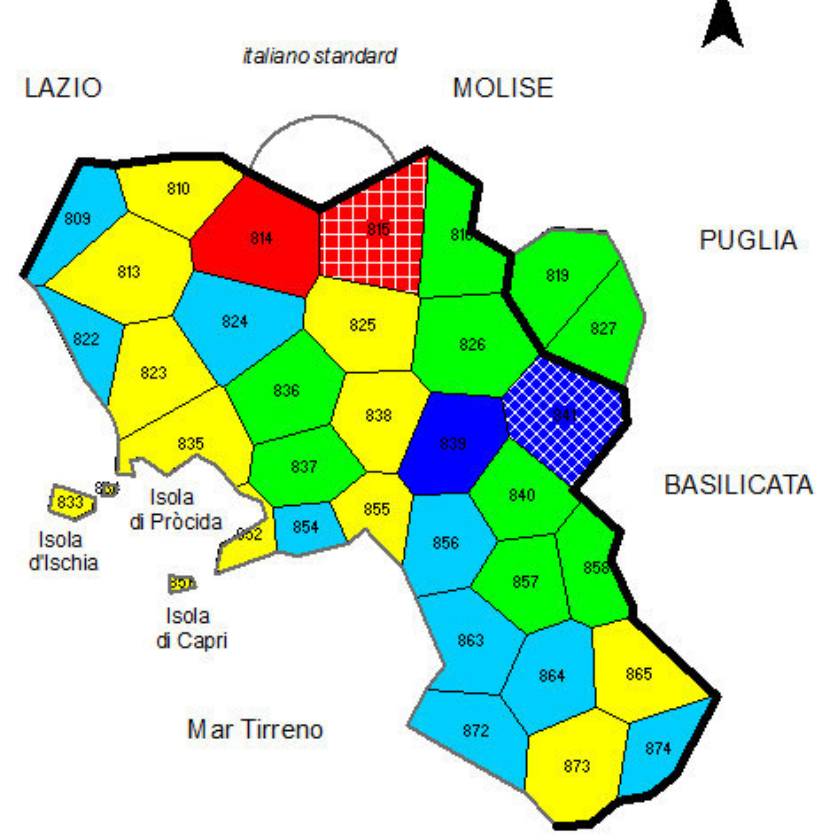

fec. S. Hajek

adiuv. $\mathrm{H}$. Goebl et $\mathrm{P}$ Smečka

adiuv. B. Castellazzi

carta di THIESSENHAAGNORONOI 35 punti d'inchiesta + italiano standard

limite di regione

Karte A16. Kennwertsynopse der Schiefewerte. ALI-Korpus, Vokalismus (41 AK). N = 35, Messmoment RIW R $_{j}$ 
Legende, MINMWMAX, 6-fach

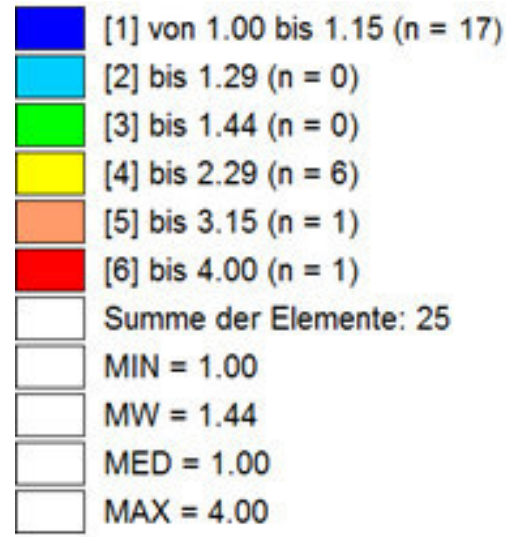

Häufigkeitsverteilung, MINMWMAX, 12-fach

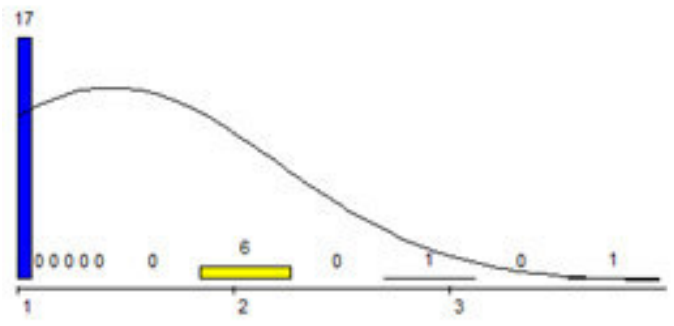

\section{ALI (1995-2008) - Campania}

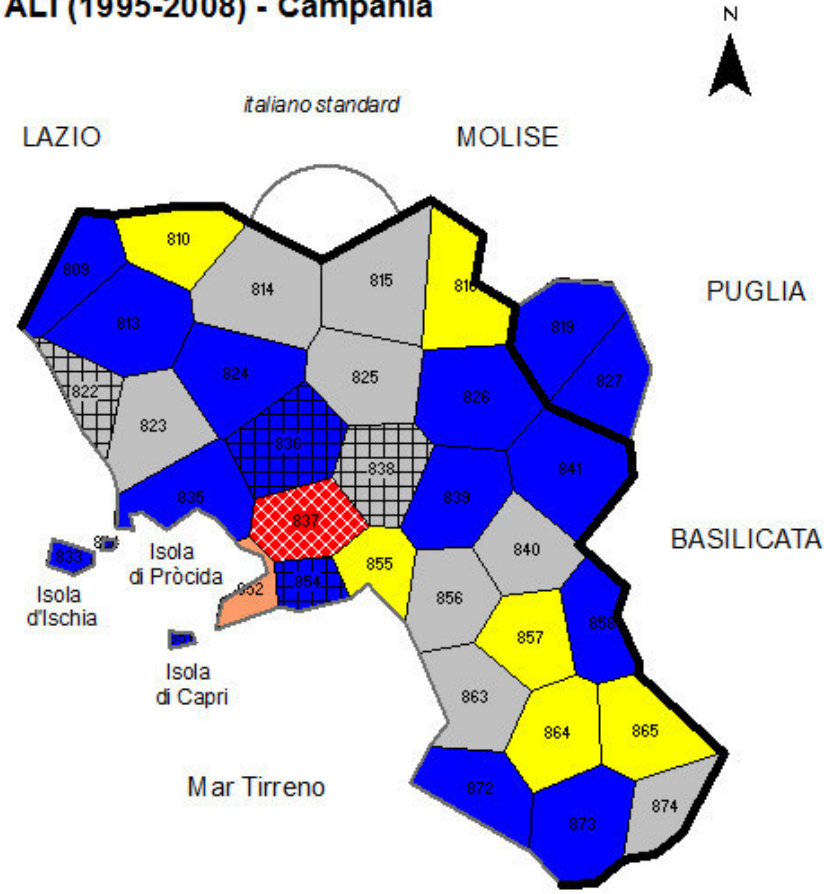

fec. S. Hajek

adiuv. H. Goebl et P. Smečka adiuv. B. Castellazzi a.d. 2013

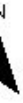

carta di THIESSEN/HAAGNORONOI 35 punti dinchiesta + italiano standard

Karte A17. Antipodenkarte der Maxima. ALI-Korpus, Totalkorpus (275 AK). N = 35, Messmoment RIW $j k$.

\section{Legende, MINMWMAX, 6-fach}

\begin{tabular}{l} 
[1] von 1.00 bis $1.60(n=6)$ \\
{$[2]$ bis $2.19(n=0)$} \\
{$[3]$ bis $2.79(n=0)$} \\
\hline$\square[4]$ bis $4.52(n=6)$ \\
{$[5]$ bis $6.26(n=1)$} \\
{$[6]$ bis $8.00(n=1)$} \\
Summe der Elemente: 14 \\
MIN $=1.00$ \\
\hline$\square$ MW $=2.79$ \\
\hline$\square$ \\
MED $=3.00$ \\
MAX $=8.00$
\end{tabular}

Häufigkeitsverteilung, MINMWMAX, 12-fach

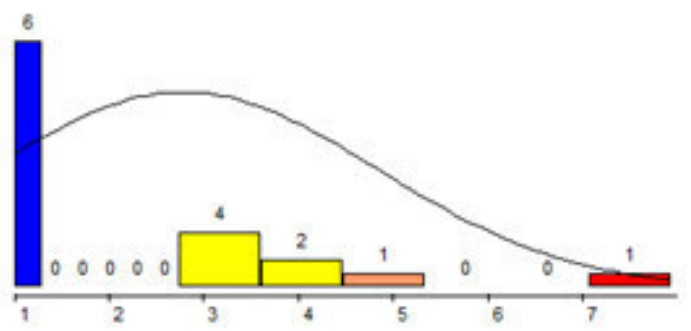

\section{ALI (1995-2008) - Campania}
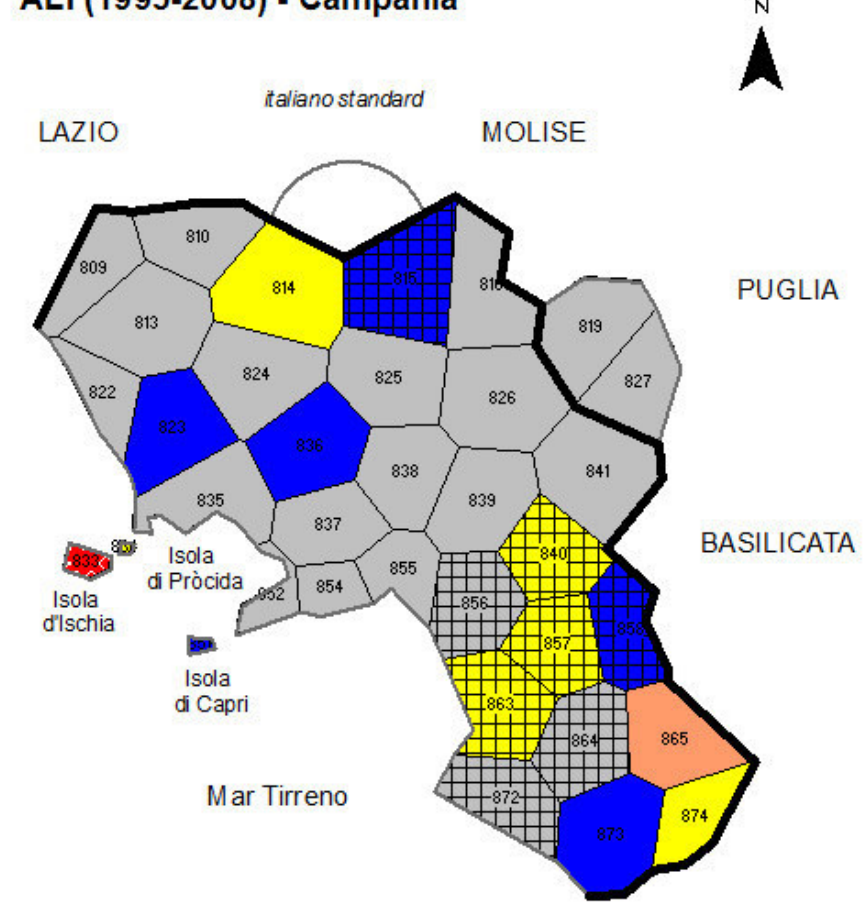

fec. S. Hajek

adiuv. H. Goebl et P. Smečka adiuv. B. Castellazzi

carta di THIESSENHAAGNORONOI 35 punti d'inchiesta + italiano standard limite di regione

Karte A18. Antipodenkarte der Minima. ALI-Korpus, Totalkorpus (275 AK). N = 35, Messmoment RIW $j k$. 
Legende, MINMWMAX, 6-fach

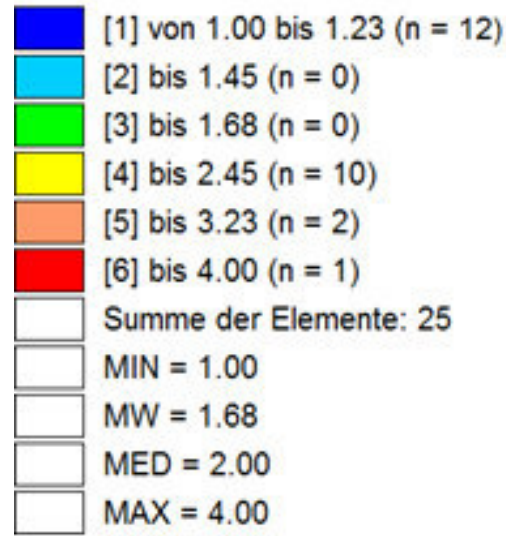

Häufigkeitsverteilung, MINMWMAX, 12-fach

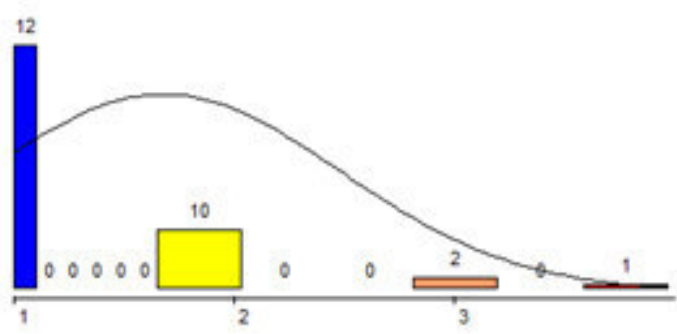

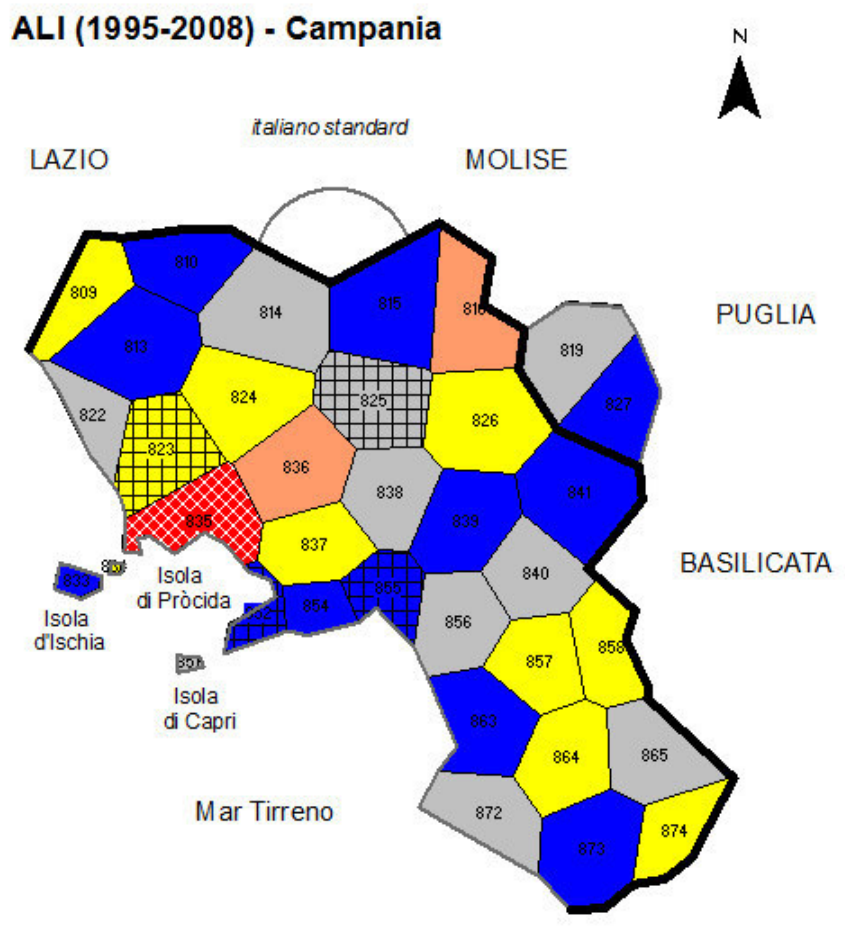

fec. S. Hajek

adiuv. H. Goebl et $P$. Smečka adiuv. B. Castellazzi a.d. 2013 carta di THIESSENHAAGNORONOI 35 punti d'inchiesta + italiano standard

Karte A19. Antipodenkarte der Maxima. ALI-Korpus, Lexikon (105 AK). N = 35, Messmoment RIW ${ }_{j k}$.

\section{Legende, MINMWMAX, 6-fach}

\begin{tabular}{l} 
[1] von 1.00 bis $1.46(n=8)$ \\
{$[2]$ bis $1.93(n=0)$} \\
{$[3]$ bis $2.39(n=3)$} \\
{$[4]$ bis $3.59(n=3)$} \\
{$[5]$ bis $4.80(n=1)$} \\
{$[6]$ bis $6.00(n=3)$} \\
Summe der Elemente: 18 \\
\hline$\square$ MIN $=1.00$ \\
MW $=2.39$ \\
\hline$\square$ \\
\hline$\square$ \\
$M E D=2.00$ \\
MAX $=6.00$
\end{tabular}

Häufigkeitsverteilung, MINMWMAX, 12-fach

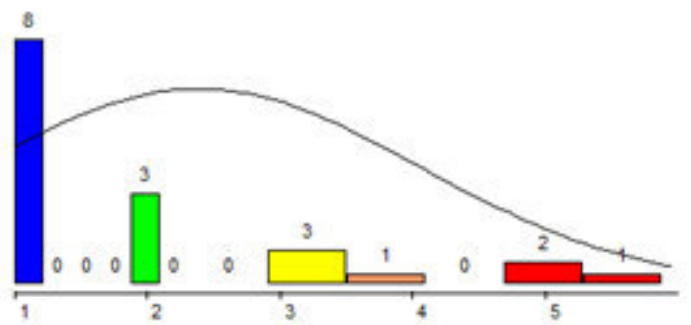

\section{ALI (1995-2008) - Campania}

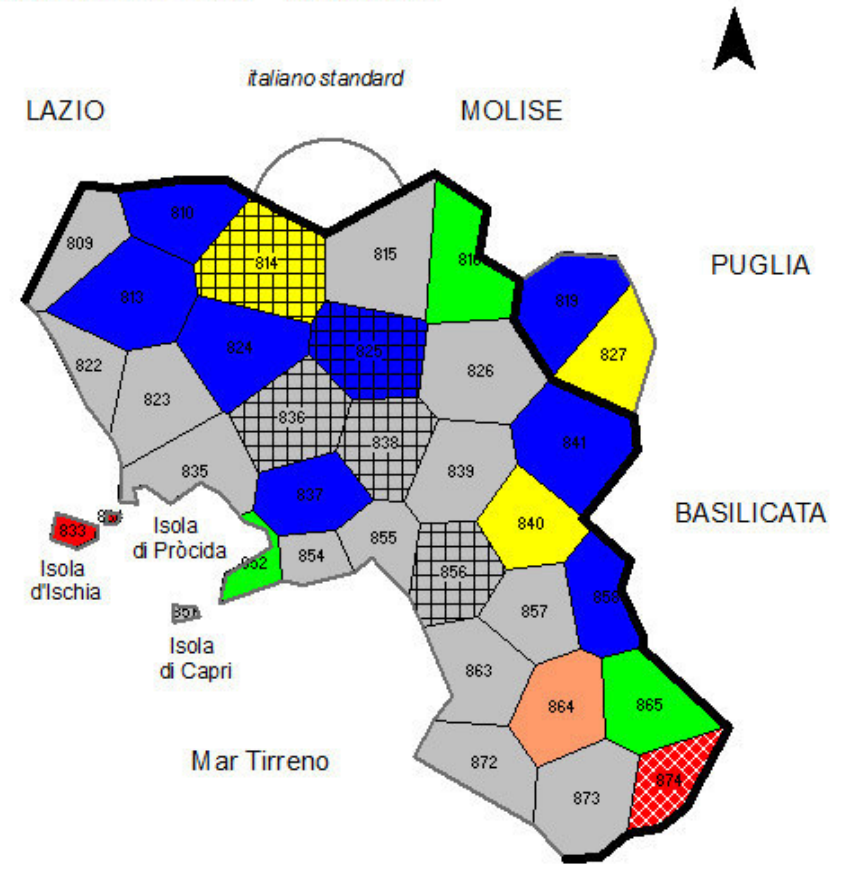

fec. S. Hajek

adiuv. H. Goebl et P. Smečka

adiuv. B. Castellazzi

a.d. 2013 carta di THIESSENHAAGNORONOI 35 punti d'inchiesta + italiano standard limite di regione

Karte A20. Antipodenkarte der Minima. ALI-Korpus, Lexikon (105 AK). N = 35, Messmoment RIW . $_{j k}$. 
Legende, MINMWMAX, 6-fach

\begin{tabular}{|c|}
\hline [1] von 1.00 bis $1.17(n=16)$ \\
\hline [2] bis $1.33(n=0)$ \\
\hline [3] bis $1.50(n=0)$ \\
\hline [4] bis $2.33(n=5)$ \\
\hline [5] bis $3.17(n=2)$ \\
\hline [6] bis $4.00(n=1)$ \\
\hline Summe der Elemente: 24 \\
\hline $\mathrm{MIN}=1.00$ \\
\hline$M W=1.50$ \\
\hline$M E D=1.00$ \\
\hline $\operatorname{MAX}=4.00$ \\
\hline
\end{tabular}

Häufigkeitsverteilung, MINMWMAX, 12-fach

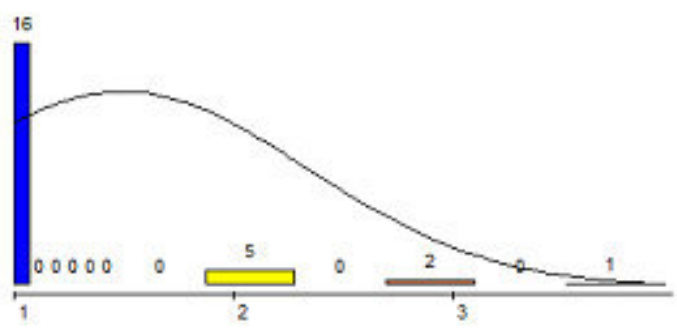

\section{ALI (1995-2008) - Campania}

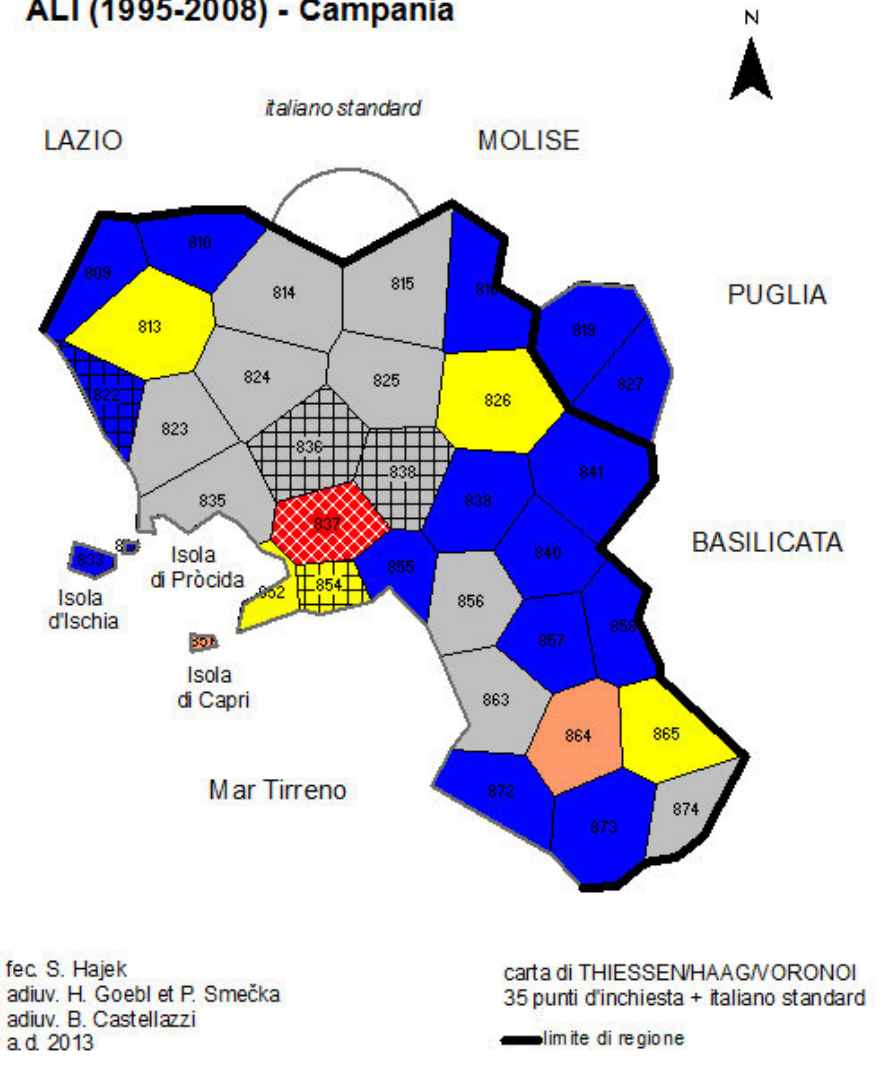

Karte A21. Antipodenkarte der Maxima. ALI-Korpus, Konsonantismus (129 AK). N = 35, Messmoment RIW $j k$.

Legende, MINMWMAX, 6-fach

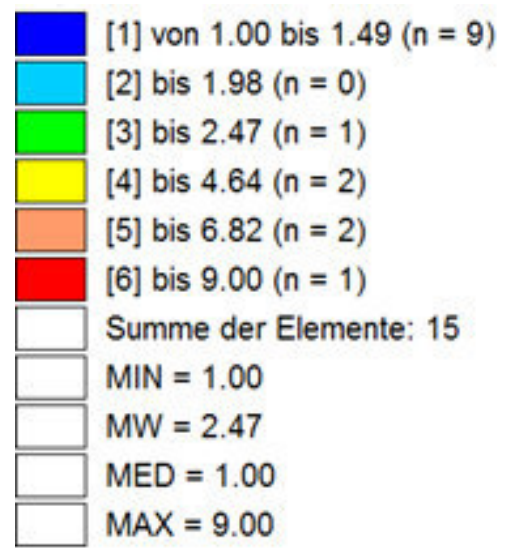

Häufigkeitsverteilung, MINMWMAX, 12-fach

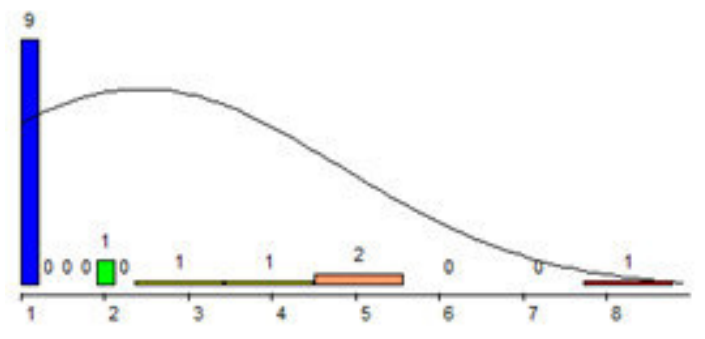

\section{ALI (1995-2008) - Campania}
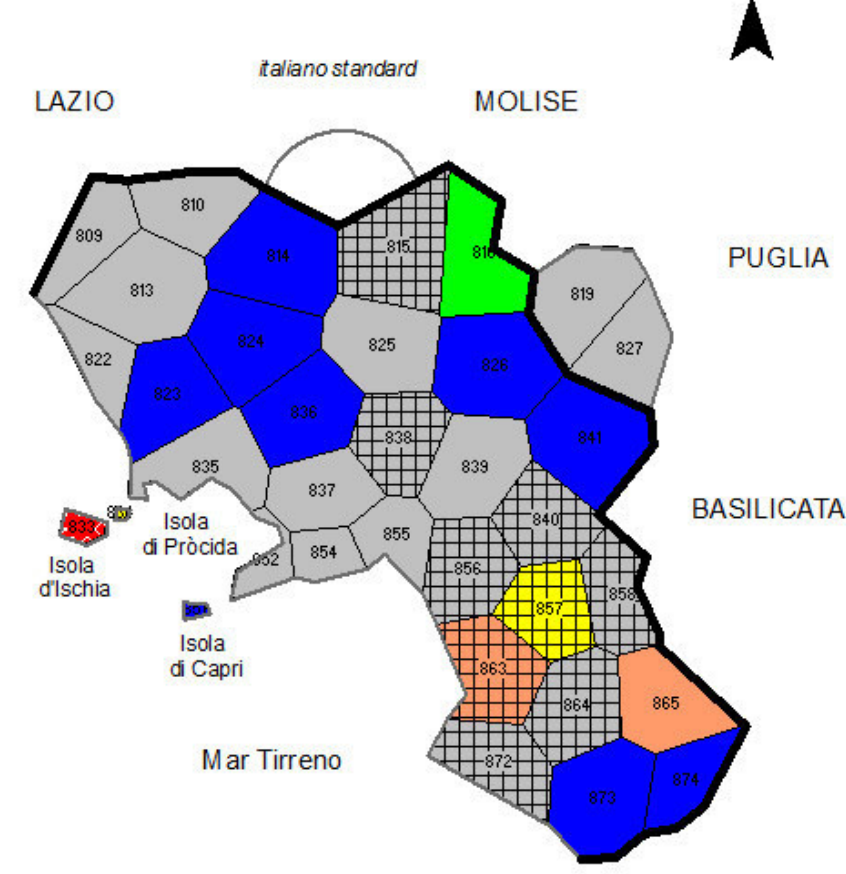

fec. S. Hajek

adiuv. H. Goebl et P. Smečka adiuv. B. Castellazzi a.d. 2013 carta di THIESSENHAAGNORONOI 35 punti d'inchiesta + italiano standard limite di regione

Karte A22. Antipodenkarte der Minima. ALI-Korpus, Konsonantismus (129 AK). N = 35, Messmoment RIW H $_{j}$. 
Legende, MINMWMAX, 6-fach

[1] von 1.00 bis $1.36(n=8)$

[2] bis $1.72(n=0)$

[3] bis $2.08(n=9)$

[4] bis $3.06(n=5)$

[5] bis $4.03(n=1)$

[6] bis $5.00(n=1)$

Summe der Elemente: 24

MIN $=1.00$

$M W=2.08$

MED $=2.00$

$\operatorname{MAX}=5.00$

Häufigkeitsverteilung, MINMWMAX, 12-fach

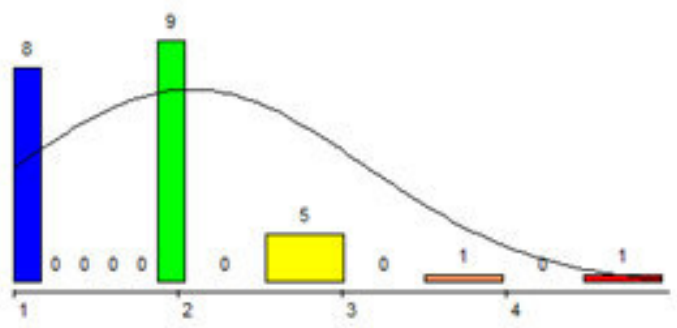

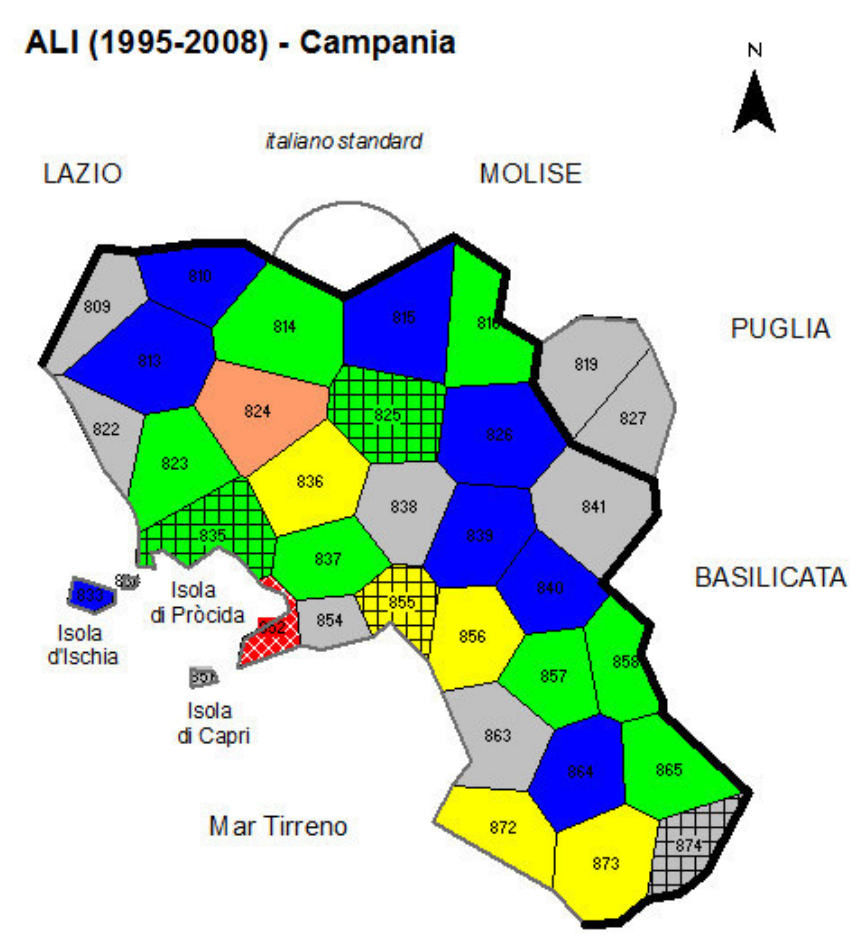

fec. S. Hajek

adiuv. H. Goebl et P. Smečka

adiuv. B. Castellazzi

carta di THIESSENHAAGNORONOI 35 punti dinchiesta + italiano standard limite di regione

Karte A23. Antipodenkarte der Maxima. ALI-Korpus, Vokalismus (41 AK). N = 35, Messmoment $\mathrm{RIW}_{j k}$.

\section{Legende, MINMWMAX, 6-fach}

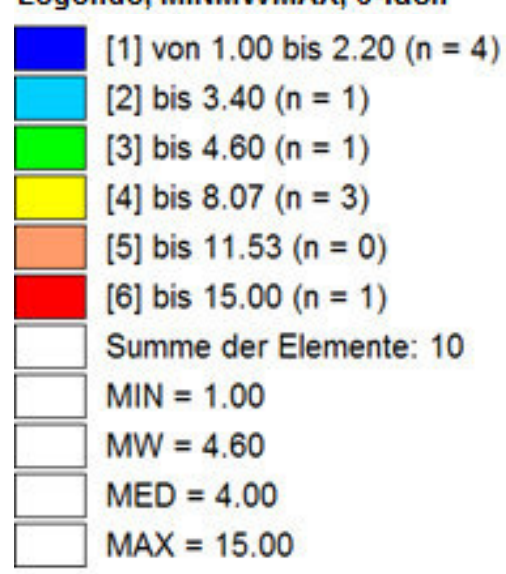

\section{Häufigkeitsverteilung, MINMWMAX, 12-fach}

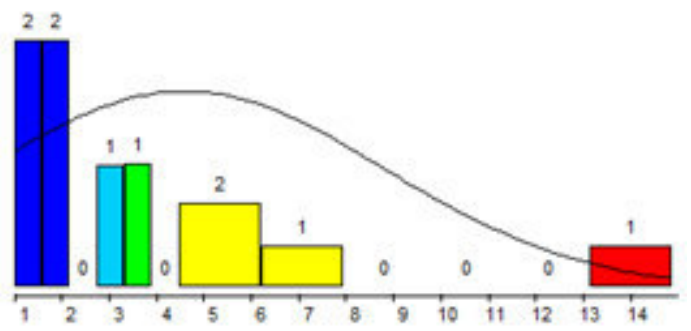

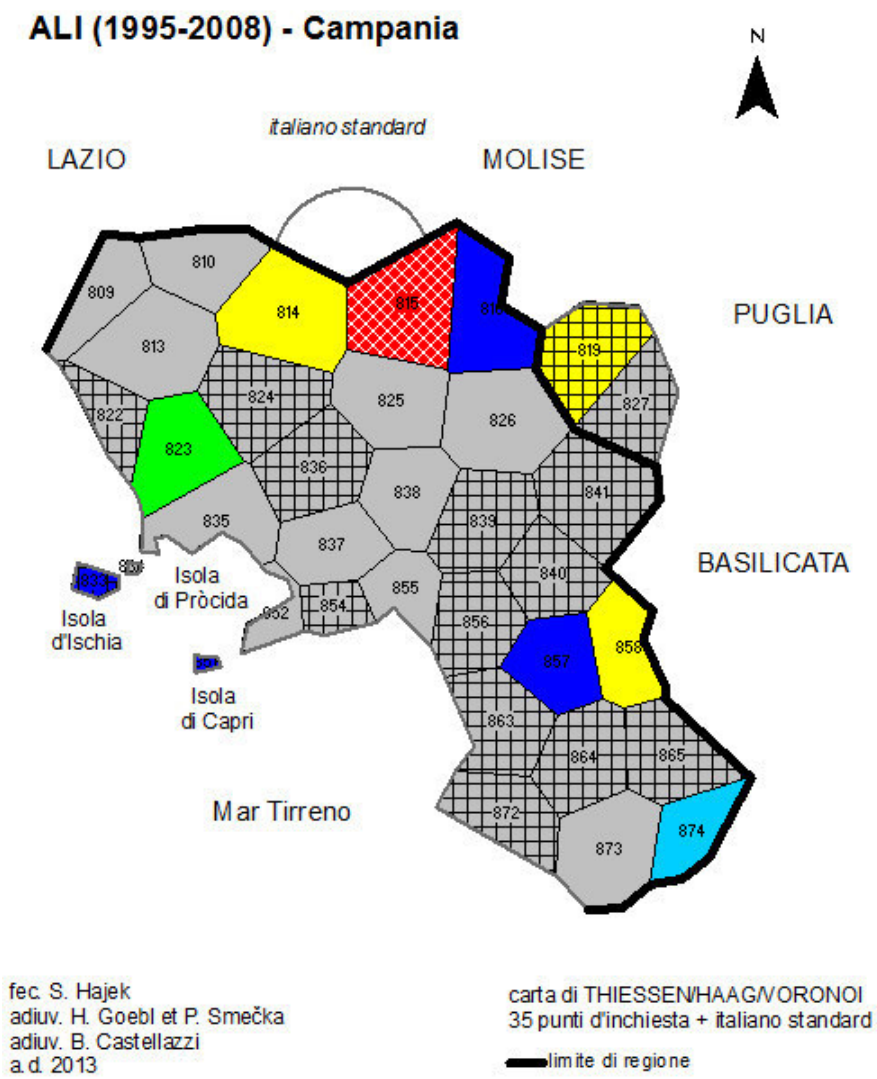

Karte A24. Antipodenkarte der Minima. ALI-Korpus, Vokalismus (41 AK). N = 35, Messmoment RIW $j$. 
Legende, MINMWMAX, 6-fach

[1] von 0.29 bis $0.40(n=2)$

[2] bis $0.51(n=4)$

[3] bis $0.62(n=7)$

[4] bis $0.68(n=9)$

[5] bis $0.74(n=9)$

[6] bis $0.79(n=4)$

Summe der Elemente: 35

$\mathrm{MIN}=0.29$ (P. 855)

$\mathrm{MW}=0.62$

$\mathrm{MED}=0.65$

MAX $=0.79$ (P. 837)

Häufigkeitsverteilung, MINMWMAX, 12-fach

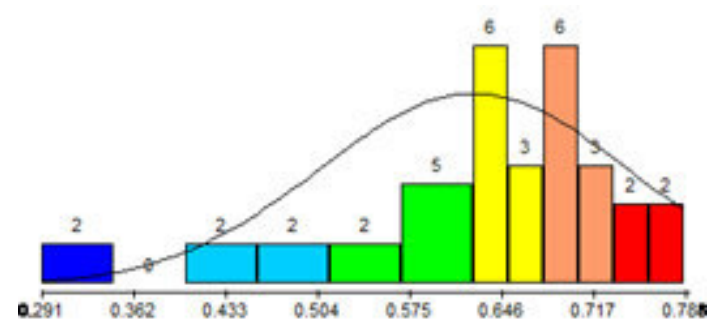

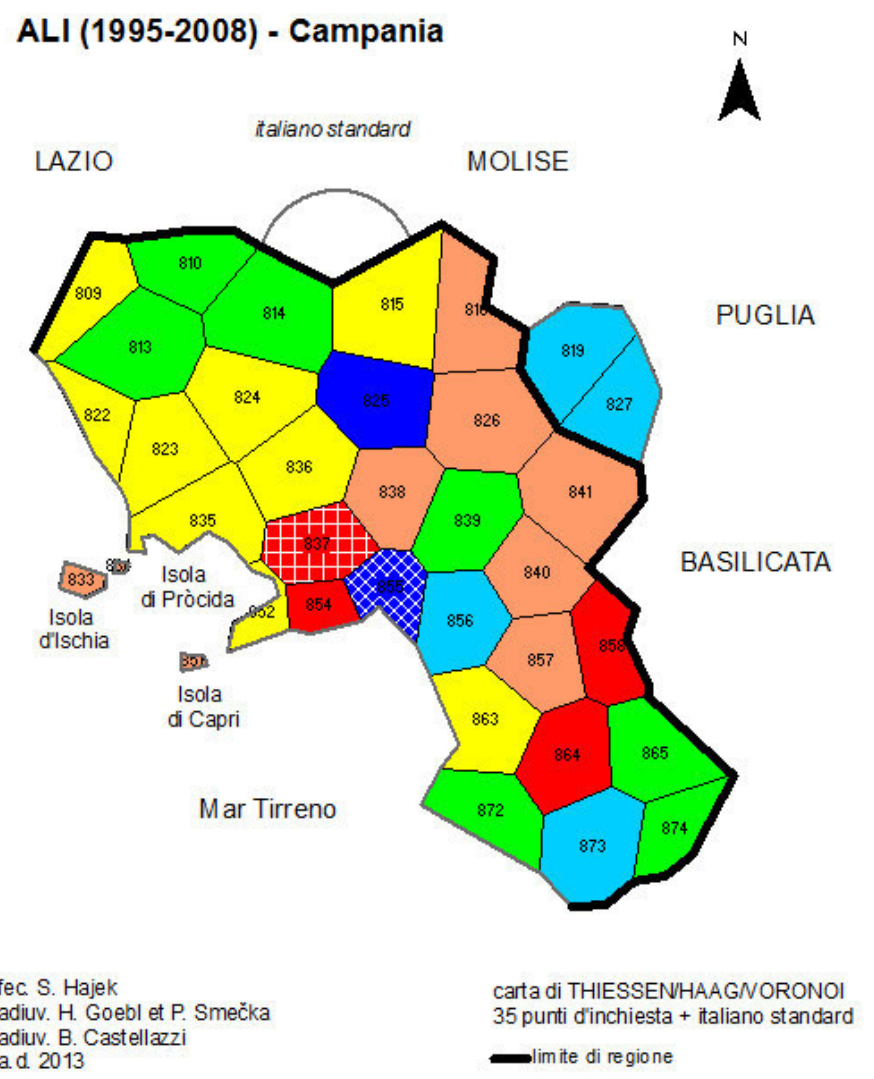

Karte A25. Korrelationskarte zum ALI-Korpus: Totalkorpus (275 AK, Messmoment RIW $j k$ ) und geographische (euklidische) Proximität. N = 35, Produktmoment-Korrelationskoeffizient nach Bravais/Pearson.

\section{Legende, MINMWMAX, 6-fach}

[1] von 0.46 bis $0.53(n=5)$

[2] bis $0.61(n=1)$

[3] bis $0.68(n=13)$

[4] bis $0.73(n=2)$

[5] bis $0.78(n=4)$

[6] bis $0.83(n=10)$

Summe der Elemente: 35

$\mathrm{MIN}=0.46$ (P. 856)

$\mathrm{MW}=0.68$

MED $=0.68$

MAX $=0.83(P .834)$

Häufigkeitsverteilung, MINMWMAX, 12-fach

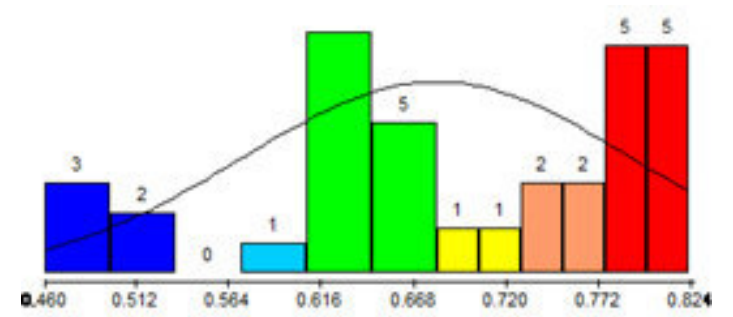

adiuv. H. Goebl et $P$. Smečka
adiuv. B. Castellazzi a.d. 2013

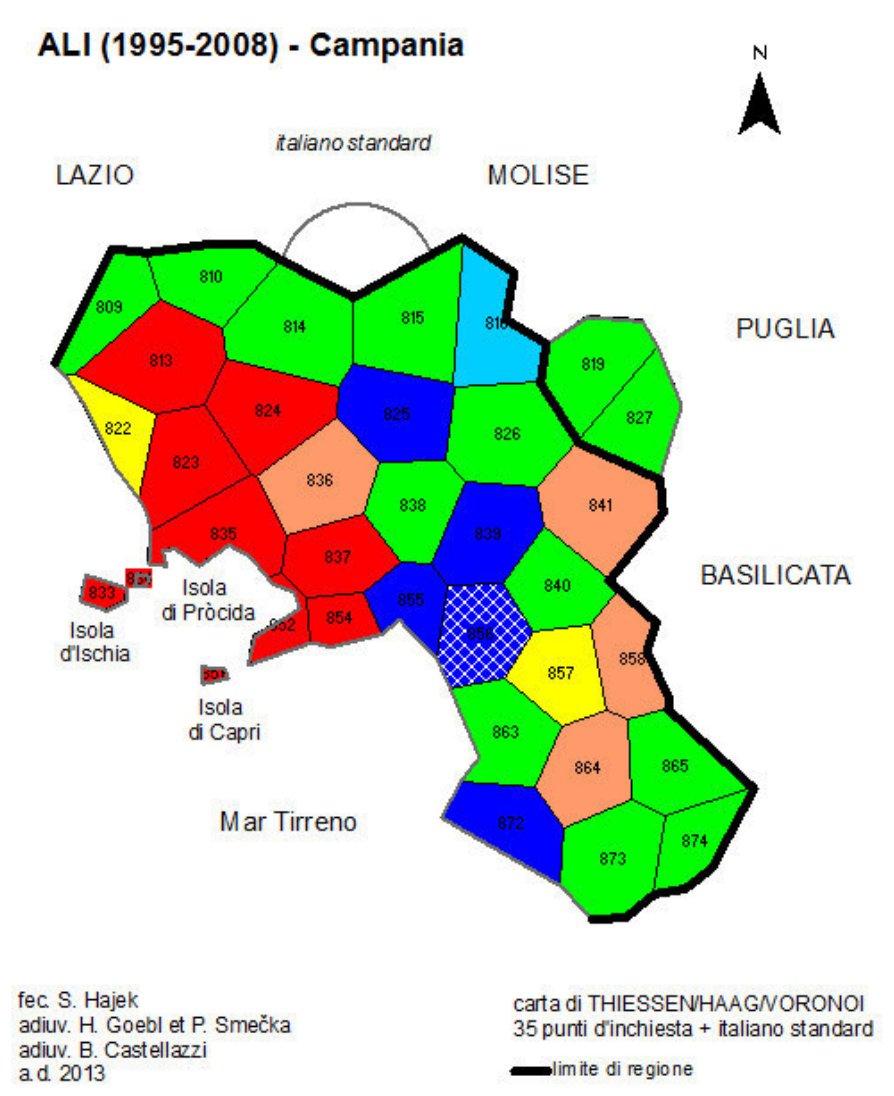

Karte A26. Korrelationskarte zum ALI-Korpus: Lexikon (105 AK, Messmoment RIW $_{j k}$ ) und geographische (euklidische) Proximität. N = 35, Produktmoment-Korrelationskoeffizient nach Bravais/Pearson. 
Legende, MINMWMAX, 6-fach

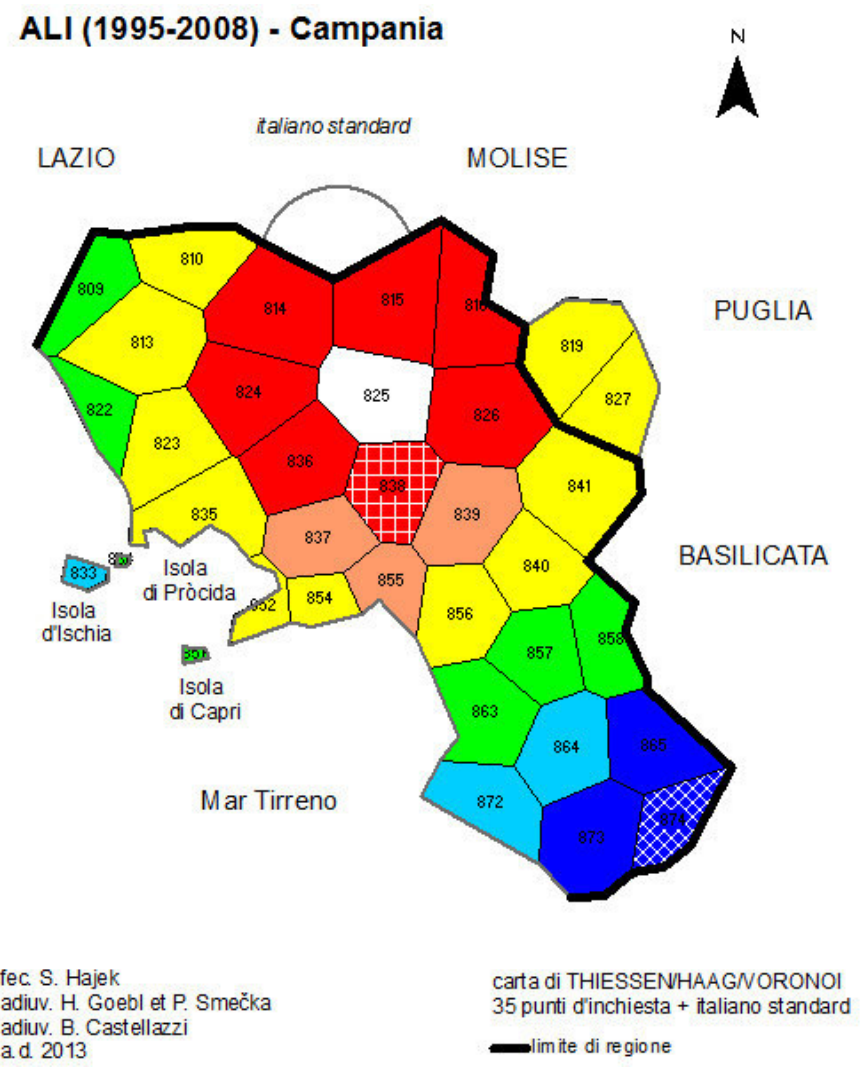

Häufigkeitsverteilung, MINMWMAX, 12-fach

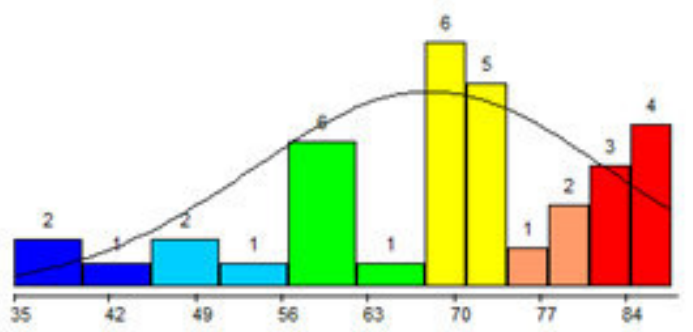

[1] von 34.23 bis $45.49(n=3)$

[2] bis $56.76(n=3)$

[3] bis $68.02(n=7)$

[4] bis $74.75(n=11)$

[5] bis $81.47(n=3)$

[6] bis $88.20(n=7)$

Summe der Elemente: 34

$M I N=34.23(P .874)$

$M W=68.02$

$\mathrm{MED}=70.28$

MAX $=88.20$ (P. 838)

Karte A27. Geographische (euklidische) Proximität zum Referenzpunkt Benevento (825). N = 35 .

\section{Legende, MINMWMAX, 6-fach}

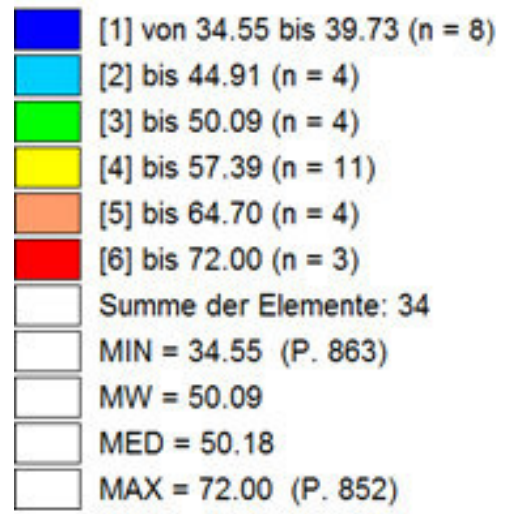

Häufigkeitsverteilung, MINMWMAX, 12-fach

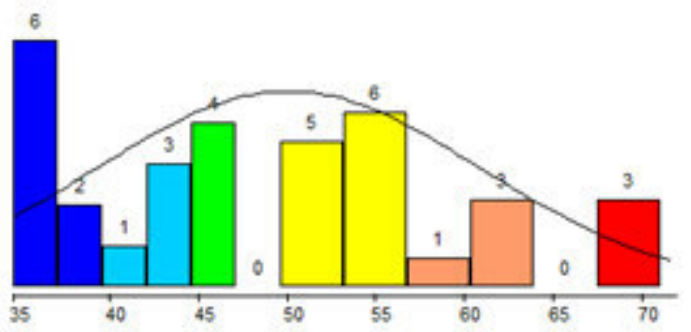

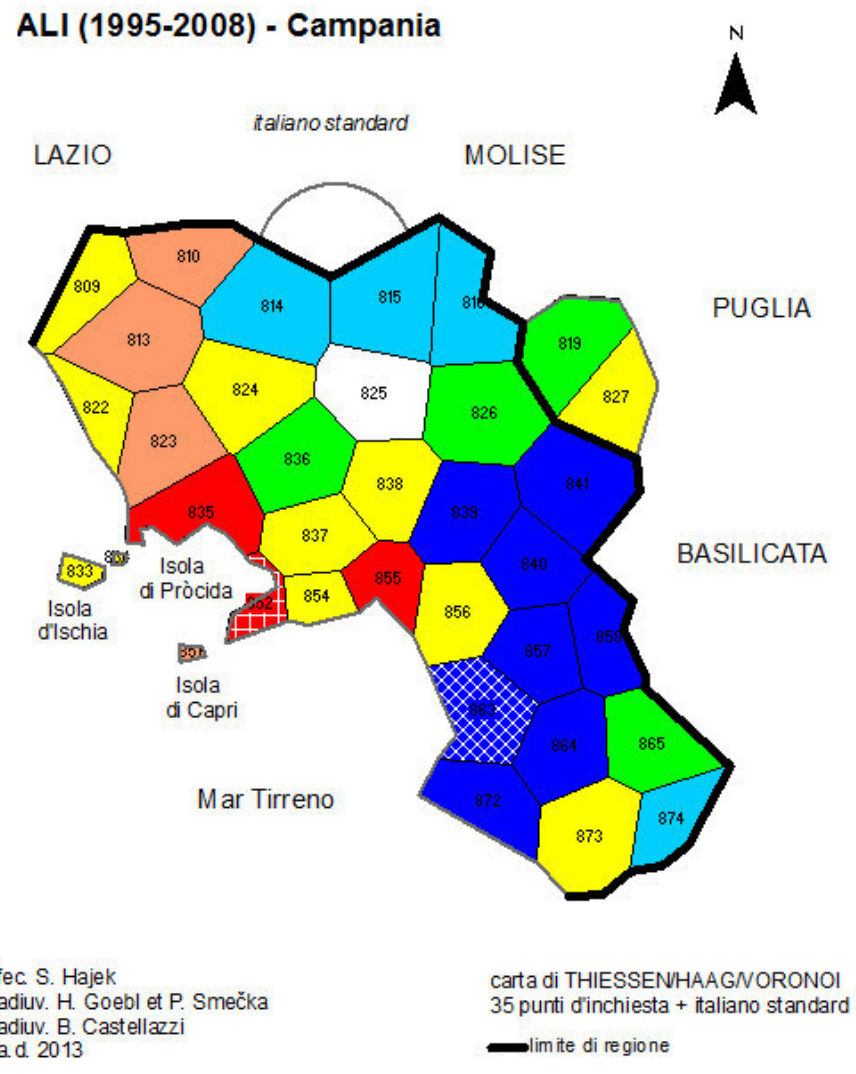

Karte A28. Sprachliches Ähnlichkeitsprofil zum Referenzpunkt Benevento (825). ALI-Korpus, Totalkorpus (275 AK). N = 35, Messmoment RIW $\mathrm{R}_{j k}$. 
Legende, MINMWMAX, 6-fach

[1] von 0.19 bis $0.32(n=2)$

[2] bis $0.45(n=3)$

[3] bis $0.58(n=9)$

[4] bis $0.65(n=9)$

[5] bis $0.73(n=9)$

[6] bis $0.80(n=3)$

Summe der Elemente: 35

$\mathrm{MIN}=0.19(P .855)$

$\mathrm{MW}=0.58$

MED $=0.61$

MAX $=0.80$ (P. 837)

Häufigkeitsverteilung, MINMWMAX, 12-fach

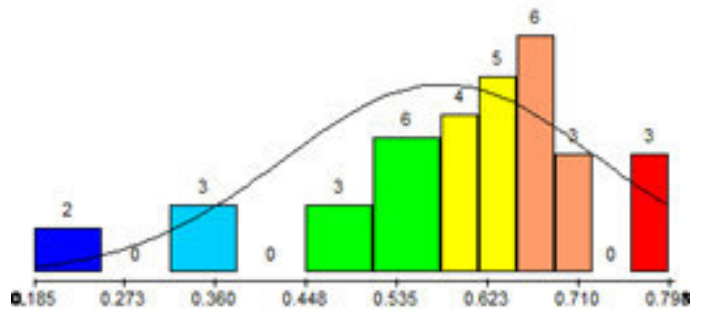

ALI (1995-2008) - Campania

$N$

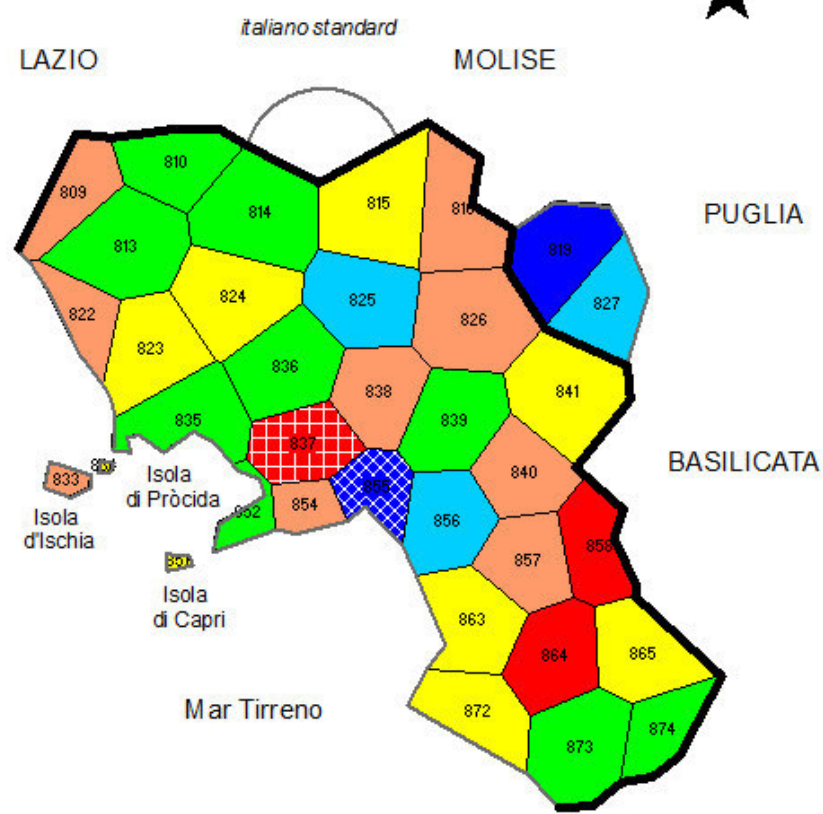

fec. S. Hajek

adiuv. H. Goebl et P. Smečka adiuv. B. Castellazzi

a.d. 2013

carta di THIESSENHAAGNORONOI 35 punti d'inchiesta + italiano standard

limite di regione

Karte A29. Korrelationskarte zum ALI-Korpus: Konsonantismus (129 AK, Messmoment RIW $_{j k}$ ) und geographische (euklidische) Proximität. $\mathrm{N}=35$, Produktmoment-Korrelationskoeffizient nach Bravais/Pearson.

Legende, MINMWMAX, 6-fach

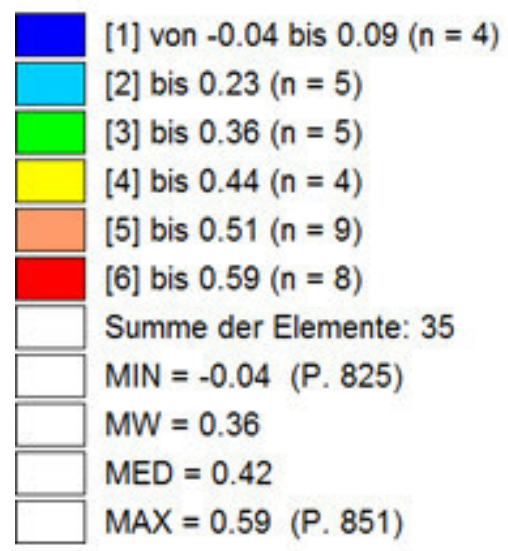

Häufigkeitsverteilung, MINMWMAX, 12-fach

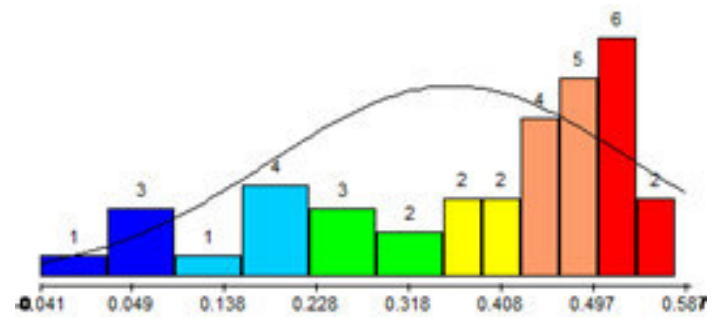

\section{ALI (1995-2008) - Campania}
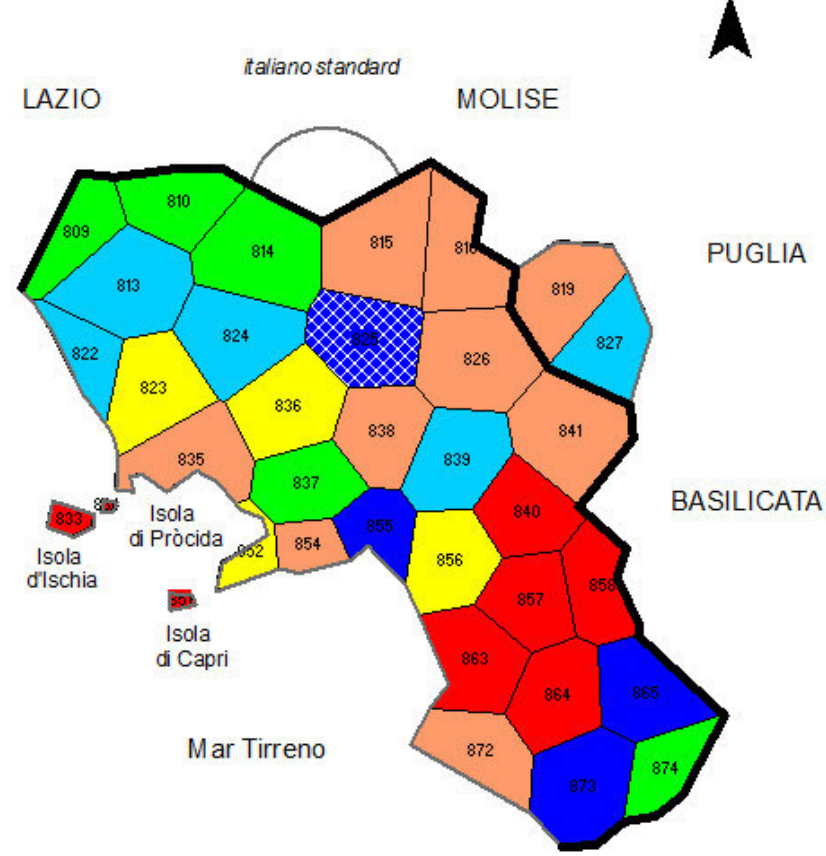

fec. S. Hajek

adiuv. H. Goebl et P. Smečka

adiuv. B. Castellazzi

a.d. 2013

carta di THIESSENHAAGNORONOI 35 punti dinchiesta + italiano standard limite di regione

Karte A30. Korrelationskarte zum ALI-Korpus: Vokalismus (41 AK, Messmoment RIW ${ }_{j k}$ ) und geographische (euklidische) Proximität. $\mathrm{N}=35$, Produktmoment-Korrelationskoeffizient nach Bravais/Pearson. 
Legende, MINMWMAX, 6-fach

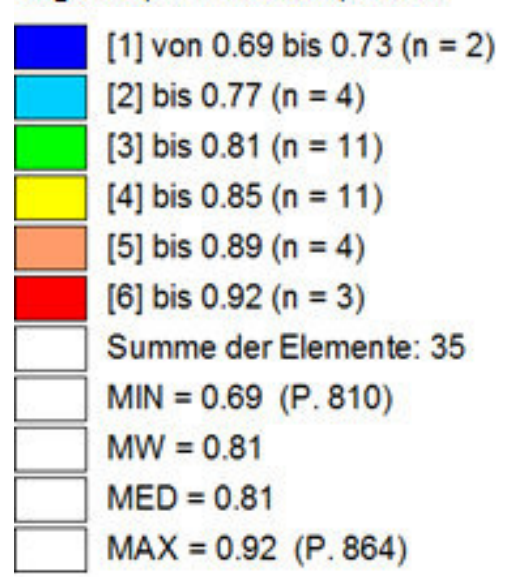

Häufigkeitsverteilung, MINMWMAX, 12-fach

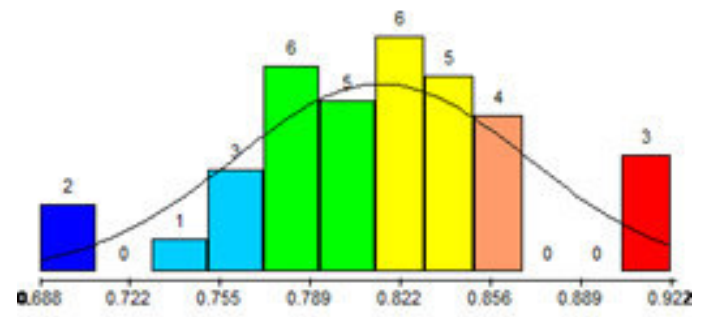

\section{ALI (1995-2008) - Campania}

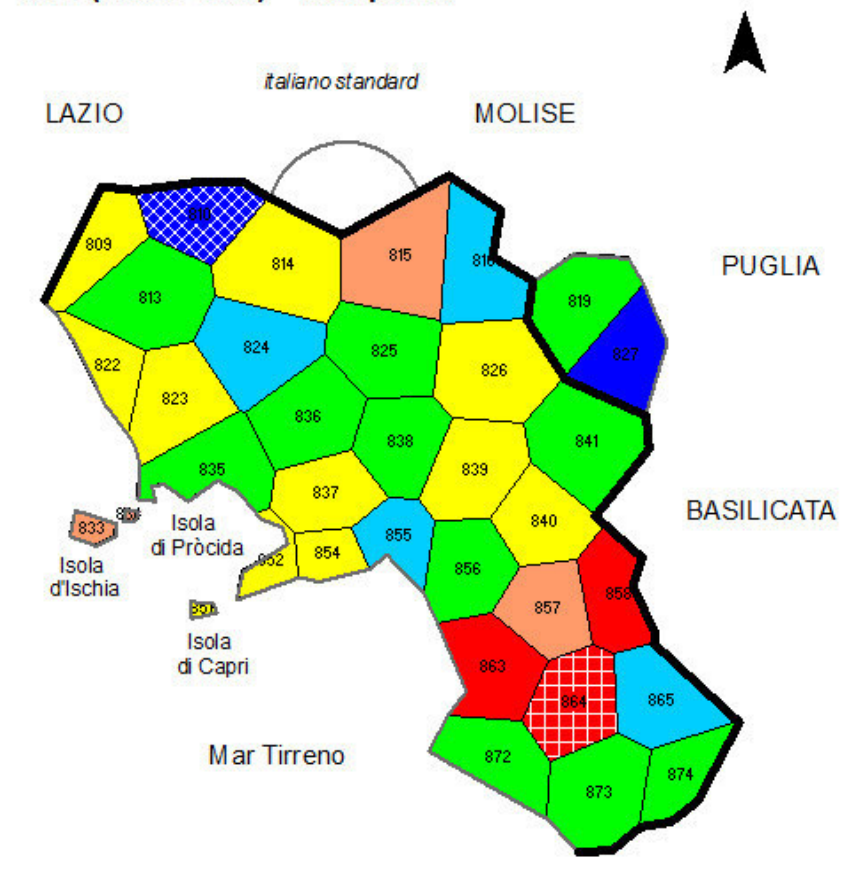

fec S. Hajek

adiuv. H. Goebl et P. Smečka adiuv. B. Castellazzi a.d. 2013 carta di THIESSENHAAGNORONOI 35 punti d'inchiesta + italiano standard - limite di regione

Karte A31. Korrelationskarte zum ALI-Korpus. Lexikon (105 AK) und Phonetik (170 AK). N = 35, Messmoment jeweils RIW $_{j k}$, Produktmoment-Korrelationskoeffizient nach Bravais/Pearson.

\section{Legende, MINMWMAX, 6-fach}

\begin{tabular}{|l}
\hline \\
{$[1]$ von 0.22 bis $0.36(n=1)$} \\
{$[2]$ bis $0.51(n=3)$} \\
{$[3]$ bis $0.65(n=13)$} \\
{$[4]$ bis $0.73(n=8)$} \\
{$[5]$ bis $0.80(n=6)$} \\
{$[6]$ bis $0.87(n=4)$} \\
Summe der Elemente: 35 \\
\hline$\square$ MIN $=0.22$ (P. 819) \\
MW $=0.65$ \\
MED $=0.66$ \\
MAX $=0.87$ (P. 834)
\end{tabular}

\section{Häufigkeitsverteilung, MINMWMAX, 12-fach}

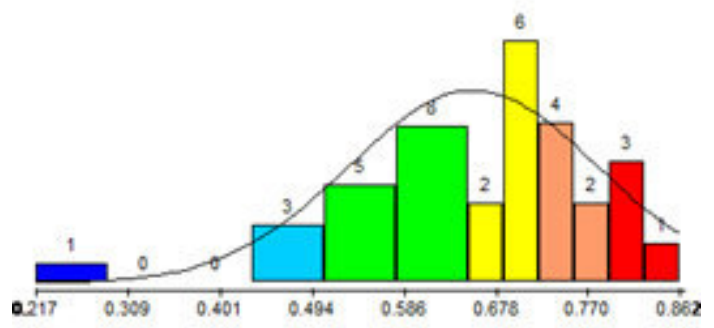

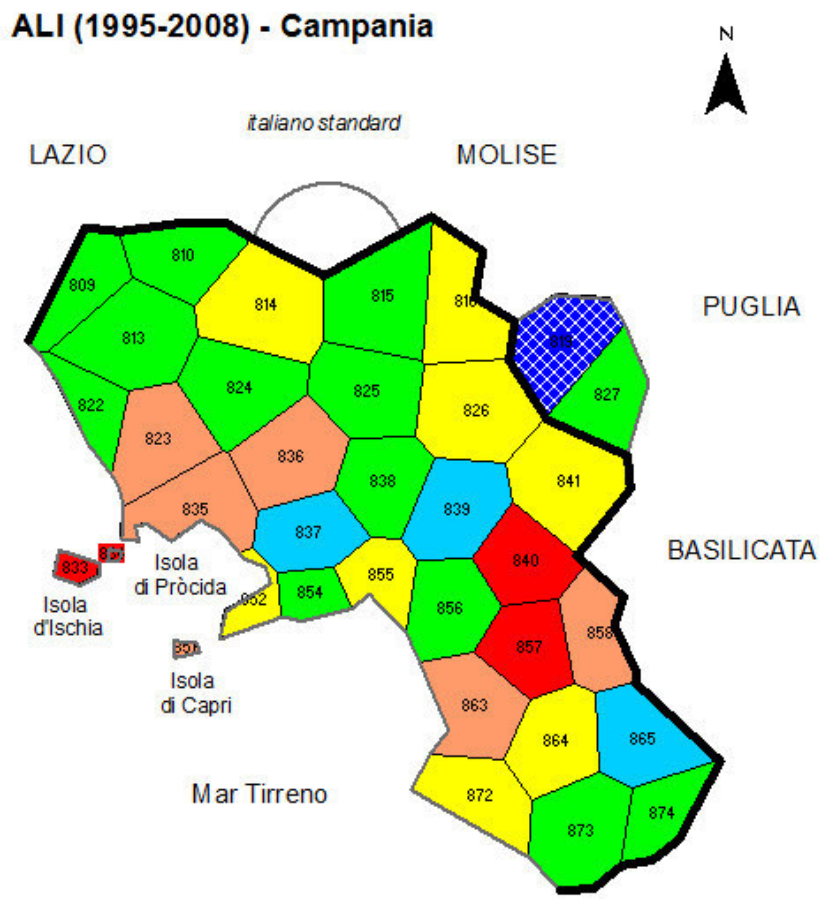

fec. S. Hajek

adiuv. H. Goebl et P. Smečka adiuv. B. Castellazzi a.d. 2013 carta di THIESSENHAAGNORONOI 35 punti dinchiesta + italiano standard limite di regione

Karte A32. Korrelationskarte zum ALI-Korpus. Konsonantismus (129 AK) und Vokalismus (41 AK). N = 35,

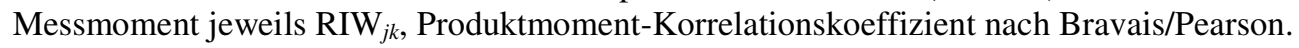


Legende, MINMWMAX, 6-fach

[1] von 27.65 bis $34.26(n=9)$
[2] bis $40.88(n=3)$
[3] bis $47.49(n=6)$
[4] bis $57.54(n=6)$
[5] bis $67.60(n=7)$
[6] bis $77.65(n=3)$
Summe der Elemente: 34
MIN $=27.65(P .857 ; 863)$
MW $=47.49$
MED $=46.47$
MAX $=77.65$ (P. 813)

Häufigkeitsverteilung, MINMWMAX, 12-fach

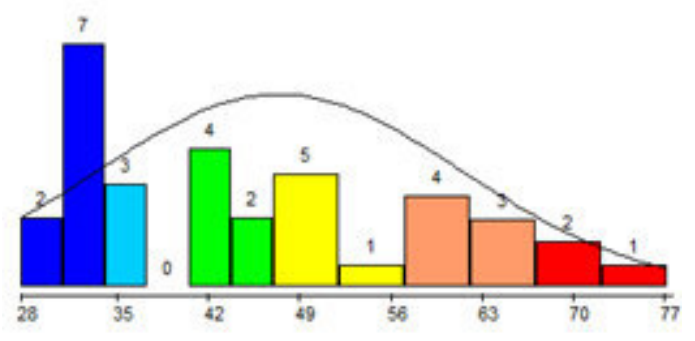

\section{ALI (1995-2008) - Campania}

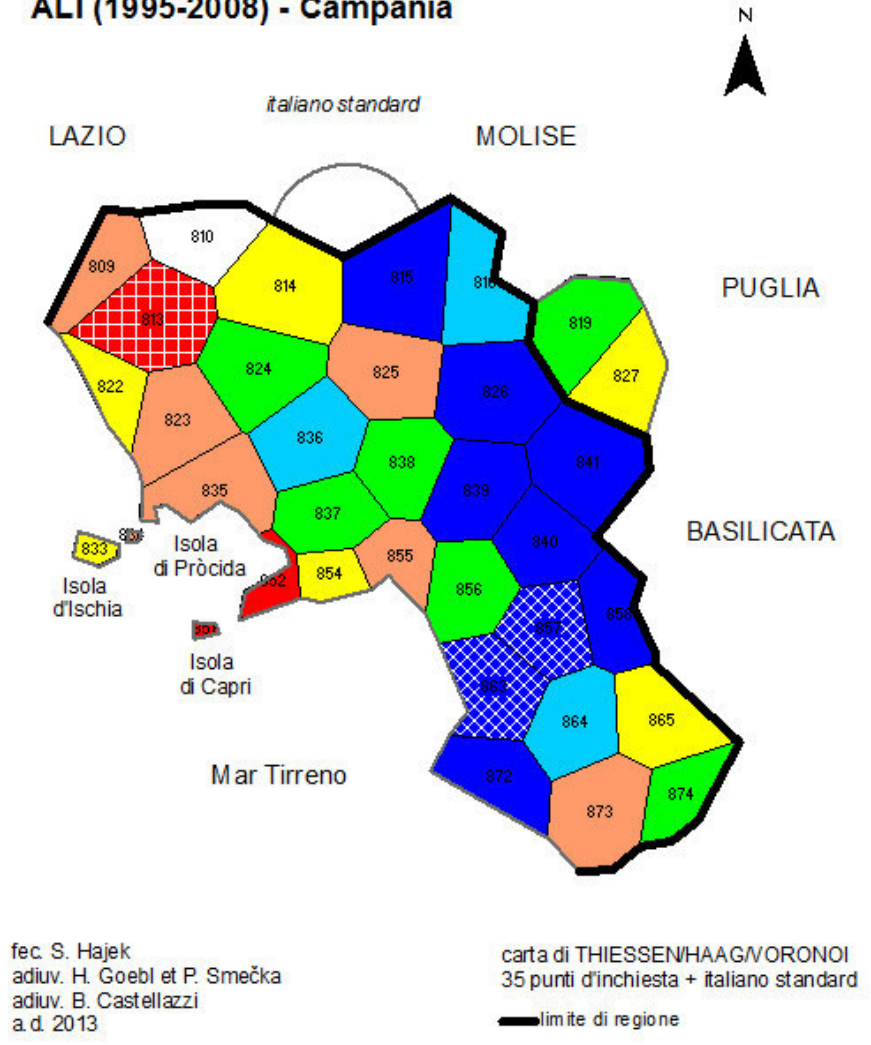

Karte A33. Ähnlichkeitsprofil zum Referenzpunkt Fontegreca (810). ALI-Korpus, Phonetik (170 AK). N = 35, Messmoment $\operatorname{RIW}_{j k}$.

\section{Legende, MINMWMAX, 6-fach}

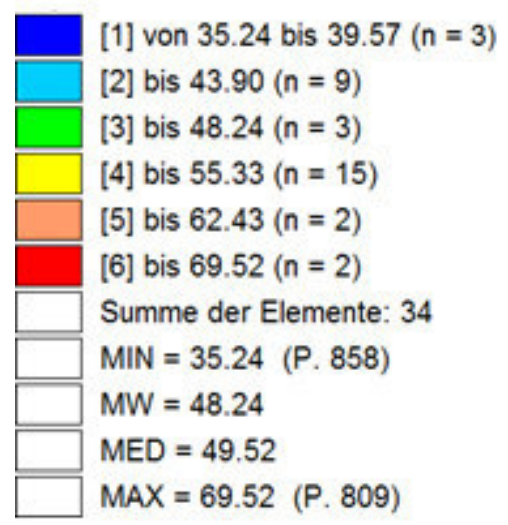

Häufigkeitsverteilung, MINMWMAX, 12-fach

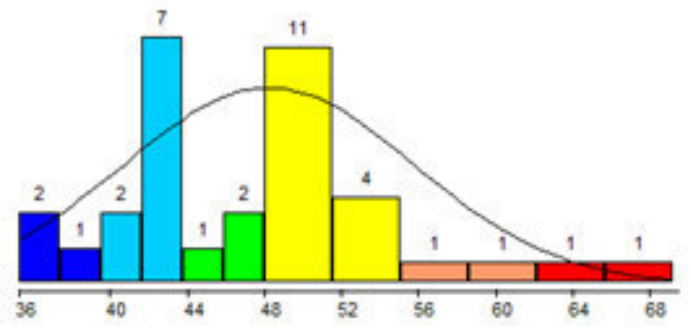

ALI (1995-2008) - Campania
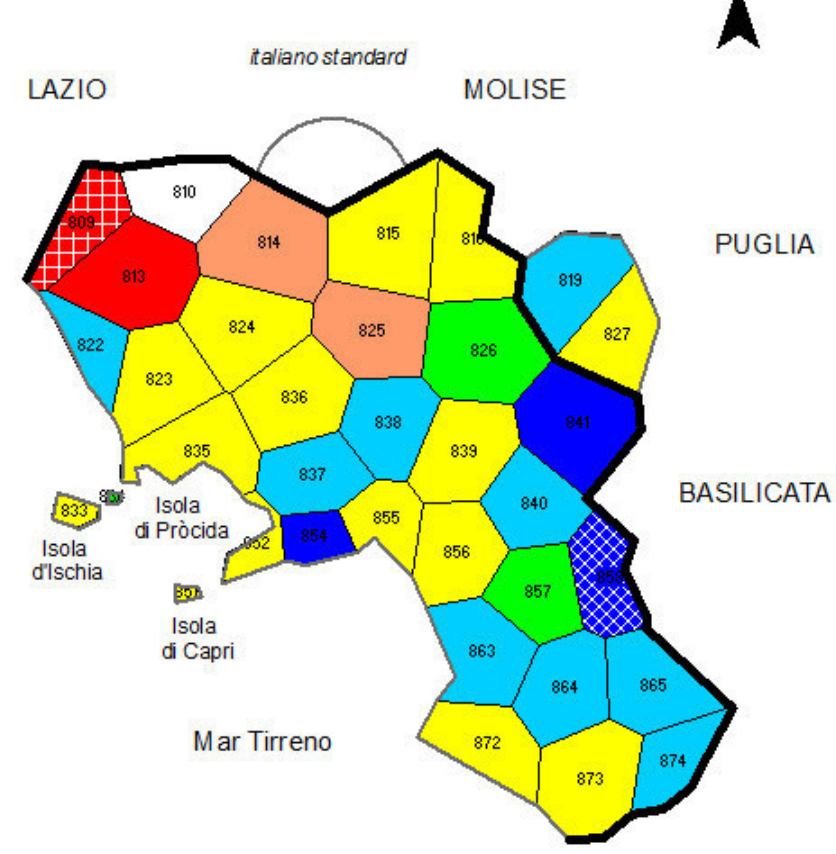

fec. S. Hajek

adiuv. H. Goebl et P. Smečka adiuv. B. Castellazzi a.d. 2013

carta di THIESSENHAAGNORONOI 35 punti dinchiesta + italiano standard limite di regione

Karte A34. Ähnlichkeitsprofil zum Referenzpunkt Fontegreca (810). ALI-Korpus, Lexikon (105 AK). N = 35, Messmoment RIW R $_{j k}$. 


\section{Kartenteil}

Legende, MINMWMAX, 6-fach

[1] von 22.48 bis $28.46(n=9)$

[2] bis $34.44(n=2)$

[3] bis $40.42(n=7)$

[4] bis $53.56(n=12)$

[5] bis $66.70(n=2)$

[6] bis $79.84(n=2)$

Summe der Elemente: 34

$M I N=22.48$ (P. 816)

$\mathrm{MW}=40.42$

MED $=37.98$

$\operatorname{MAX}=79.84$ (P. 873)

Häufigkeitsverteilung, MINMWMAX, 12-fach

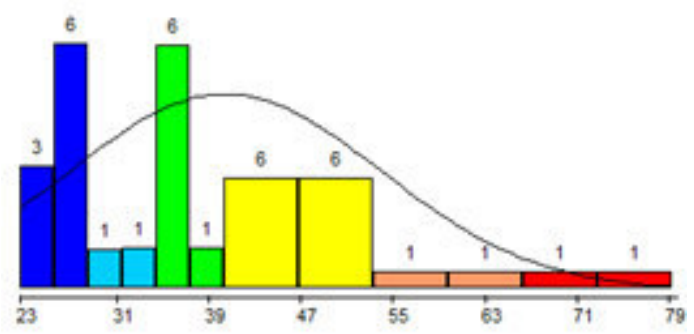

ALI (1995-2008) - Campania

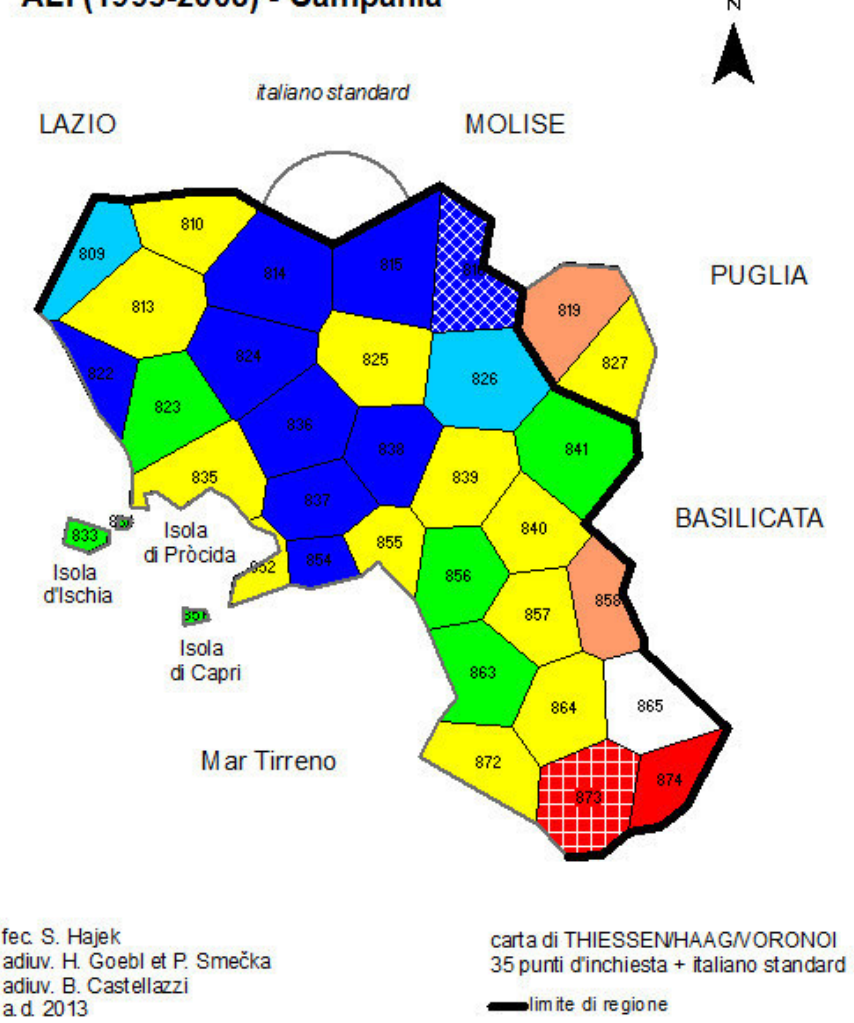

Karte A35. Ähnlichkeitsprofil zum Referenzpunkt Monte San Giacomo (865). ALI-Korpus, Konsonantismus (129 AK). $\mathrm{N}=35$, Messmoment $\mathrm{RIW}_{j k}$.

\section{Legende, MINMWMAX, 6-fach}

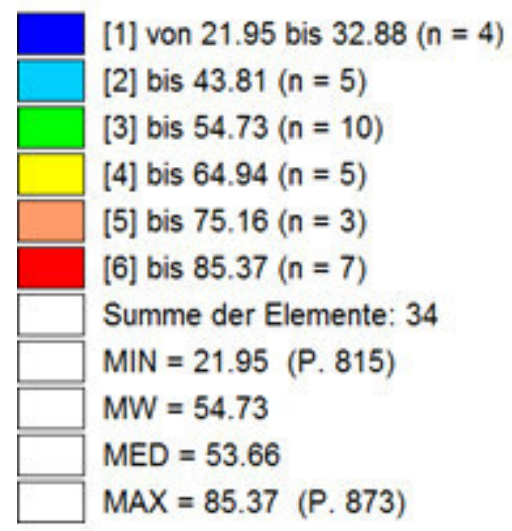

Häufigkeitsverteilung, MINMWMAX, 12-fach

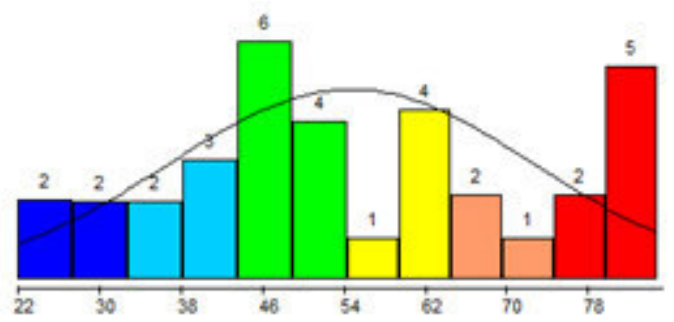

\section{ALI (1995-2008) - Campania}
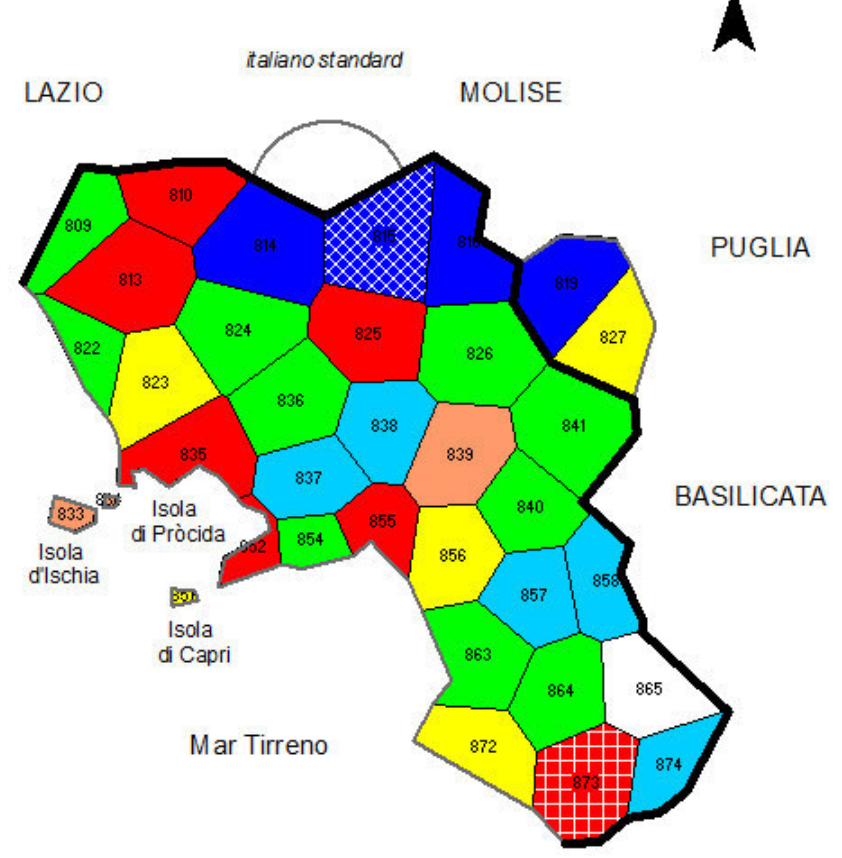

fec. S. Hajek

adiuv. $\mathrm{H}$. Goebl et $\mathrm{P}$. Smečka adiuv. B. Castellazzi a.d. 2013 carta di THIESSENHAAGNORONOI 35 punti dinchiesta + italiano standard -limite di regione

Karte A36. Ähnlichkeitsprofil zum Referenzpunkt Monte San Giacomo (865). ALI-Korpus, Vokalismus (41 AK). $\mathrm{N}=35$, Messmoment $\mathrm{RIW}_{j k}$. 


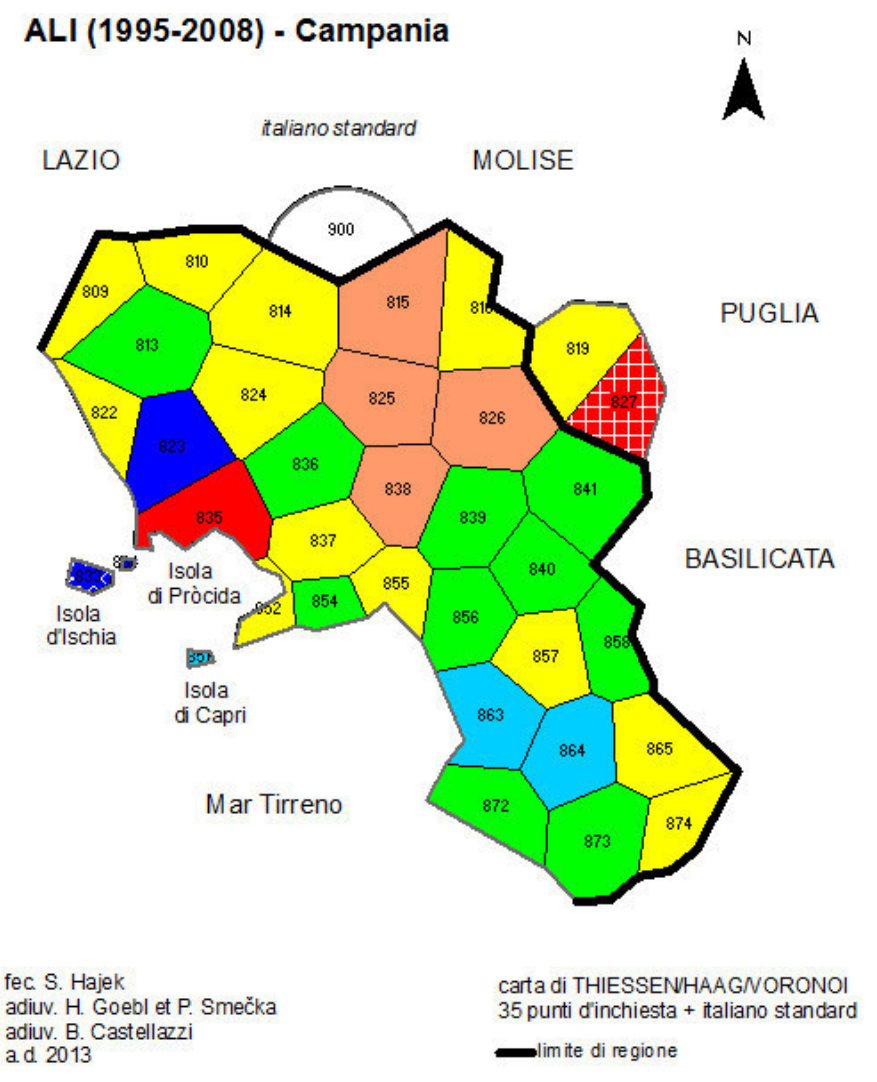

Häufigkeitsverteilung, MINMWMAX, 12-fach

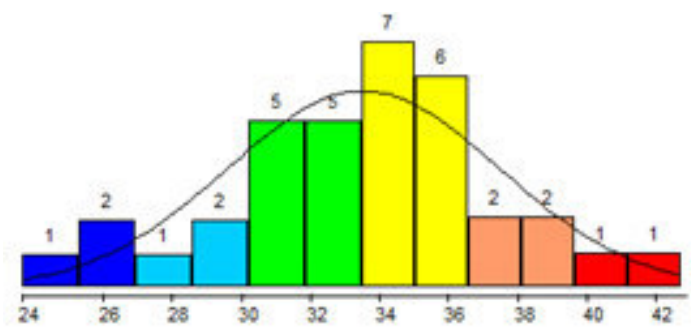

Karte A37. Synopse der Ähnlichkeitswerte zum Referenzpunkt italiano standard (900). ALI-Korpus, Totalkorpus (275 AK). N = 36, Messmoment RIW $j k$.

\section{Legende, MINMWMAX, 6-fach}

\begin{tabular}{l} 
[1] von 28.57 bis $31.18(n=4)$ \\
{$[2]$ bis $33.80(n=4)$} \\
{$[3]$ bis $36.41(n=12)$} \\
{$[4]$ bis $39.83(n=10)$} \\
{$[5]$ bis $43.25(n=1)$} \\
{$[6]$ bis $46.67(n=4)$} \\
Summe der Elemente: 35 \\
MIN $=28.57(P .851)$ \\
MW $=36.41$ \\
\hline$\square$ MED $=36.19$ \\
\hline$\square A X=46.67 \quad(P .835)$
\end{tabular}

Häufigkeitsverteilung, MINMWMAX, 12-fach

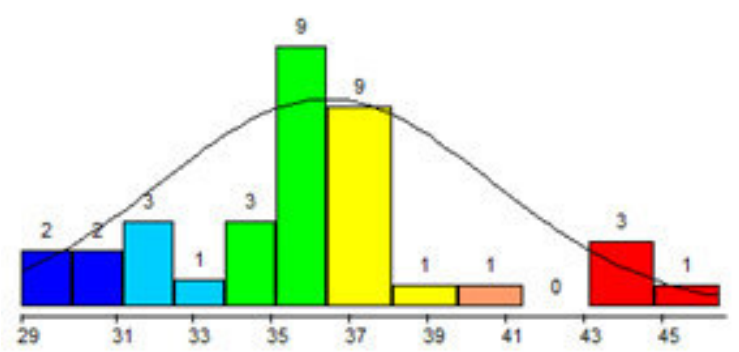

\section{ALI (1995-2008) - Campania}

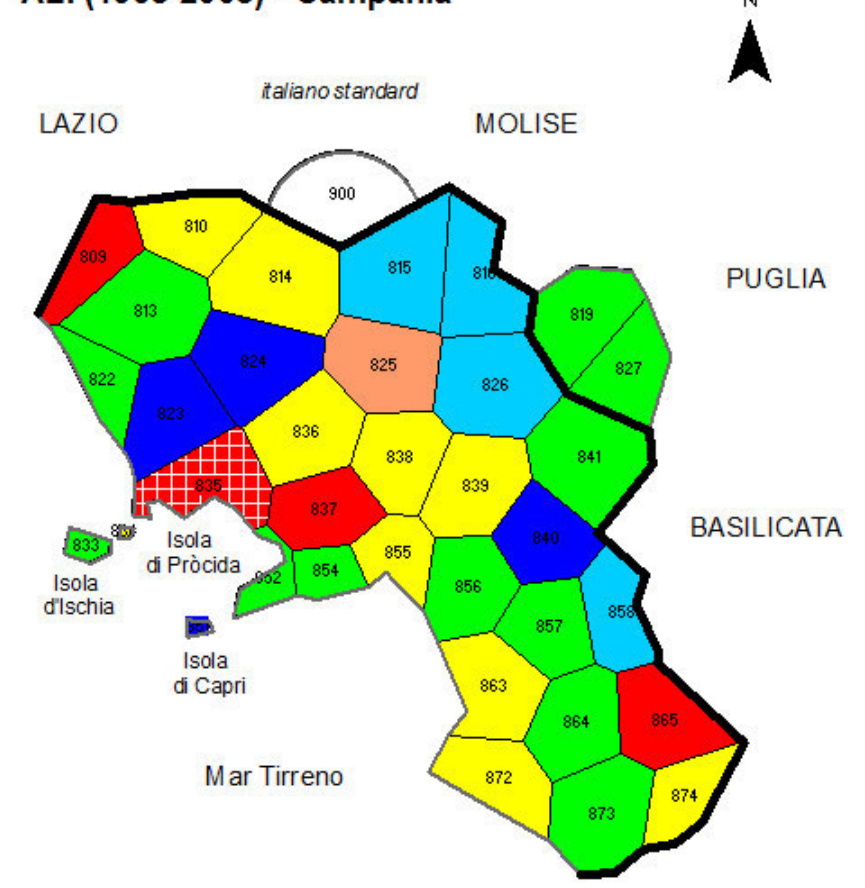

fec. S. Hajek

adiuv. H. Goebl et P. Smečka adiuv. B. Castellazzi a.d. 2013 carta di THIESSENHAAGNORONOI 35 punti d'inchiesta + italiano standard -limite di regione

Karte A38. Synopse der Ähnlichkeitswerte zum Referenzpunkt italiano standard (900). ALI-Korpus, Lexikon (105 AK). N = 36, Messmoment RIW $j k$. 
Legende, MINMWMAX, 6-fach

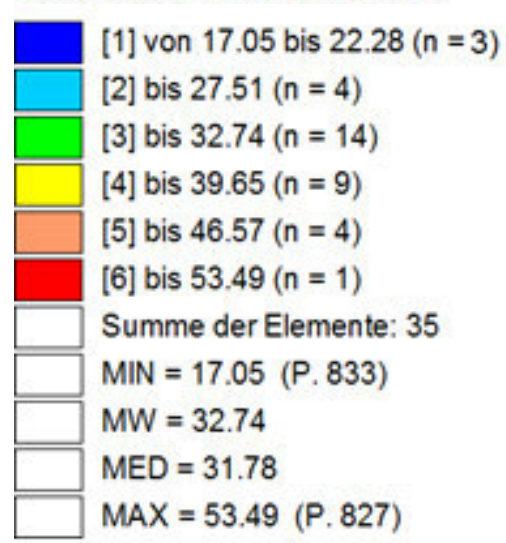

Häufigkeitsverteilung, MINMWMAX, 12-fach

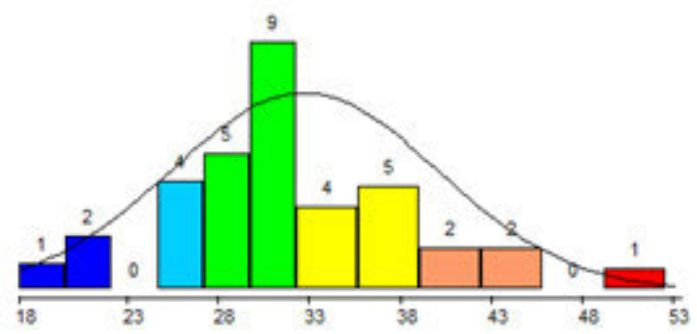

\section{ALI (1995-2008) - Campania}

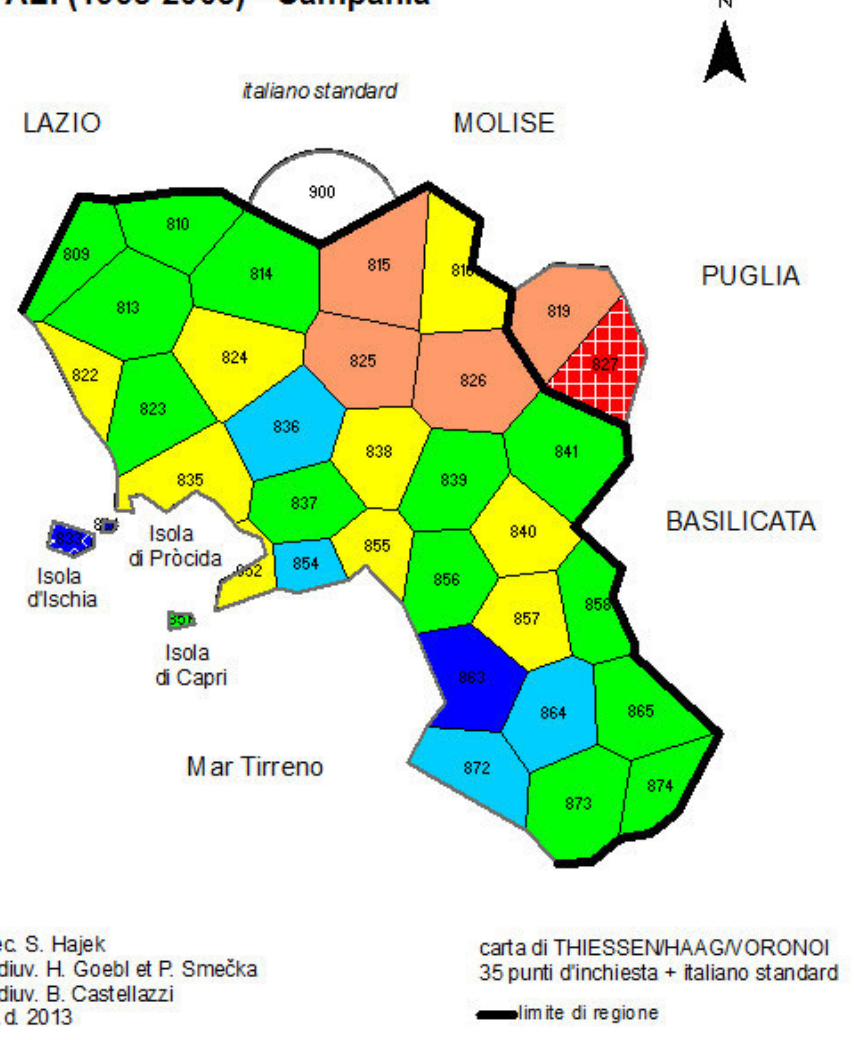

Karte A39. Synopse der Ähnlichkeitswerte zum Referenzpunkt italiano standard (900). ALI-Korpus, Konsonantismus (129 AK). N = 36, Messmoment RIW $j k$.

\section{Legende, MINMWMAX, 6-fach}

[1] von 14.63 bis $19.30(n=4)$

[2] bis $23.97(n=0)$

[3] bis $28.64(n=10)$

[4] bis $34.54(n=18)$

[5] bis $40.44(n=2)$

[6] bis $46.34(n=1)$

Summe der Elemente: 35

MIN $=14.63(P, 819 ; 823 ; 833)$

$M W=28.64$

$M E D=29.27$

MAX $=46.34(P .874)$

\section{Häufigkeitsverteilung, MINMWMAX, 12-fach}

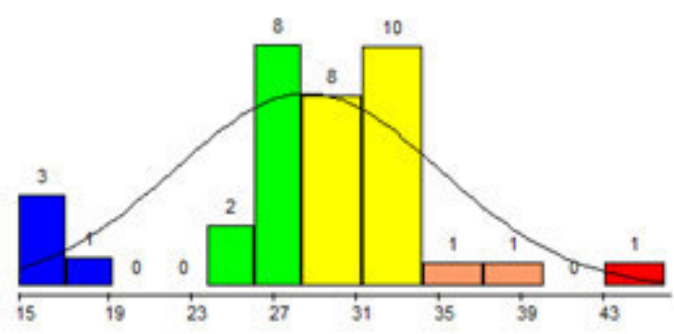

\section{ALI (1995-2008) - Campania}
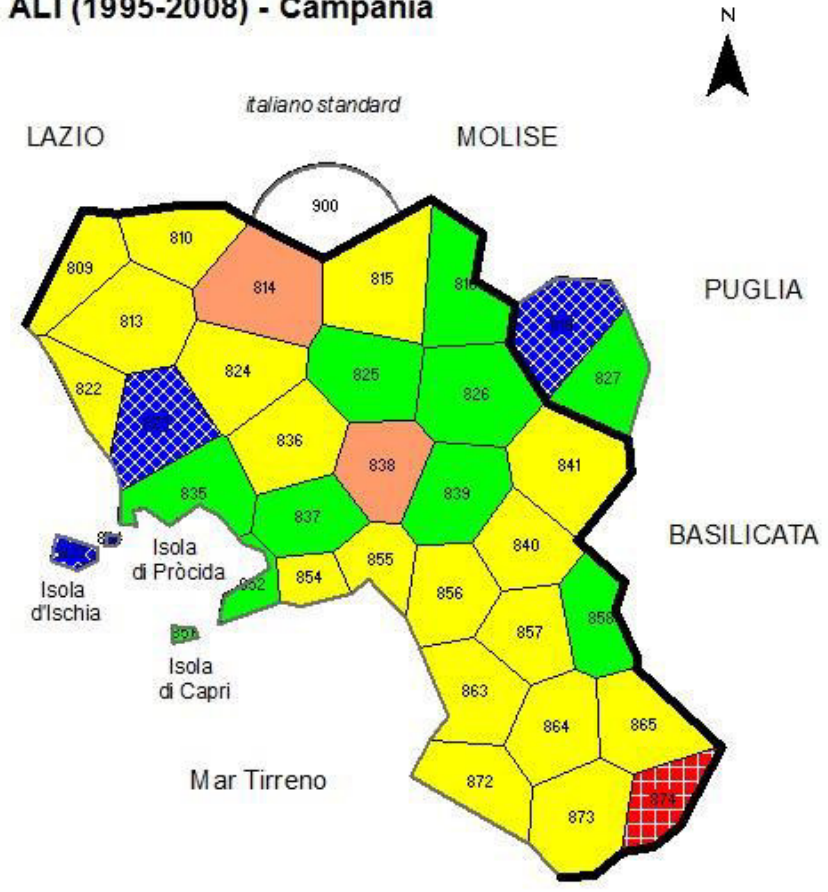

fec. S. Hajek

adiuv. H. Goebl et P. Smečka adiuv. B. Castellazzi
a.d. 2013
.

\section{A}

carta di THIESSENHAAGNORONOI 35 punti dinchiesta + italiano standard - limite di regione

Karte A40. Synopse der Ähnlichkeitswerte zum Referenzpunkt italiano standard (900). ALI-Korpus, Vokalismus (41 AK). N = 36, Messmoment RIW $_{j k}$. 


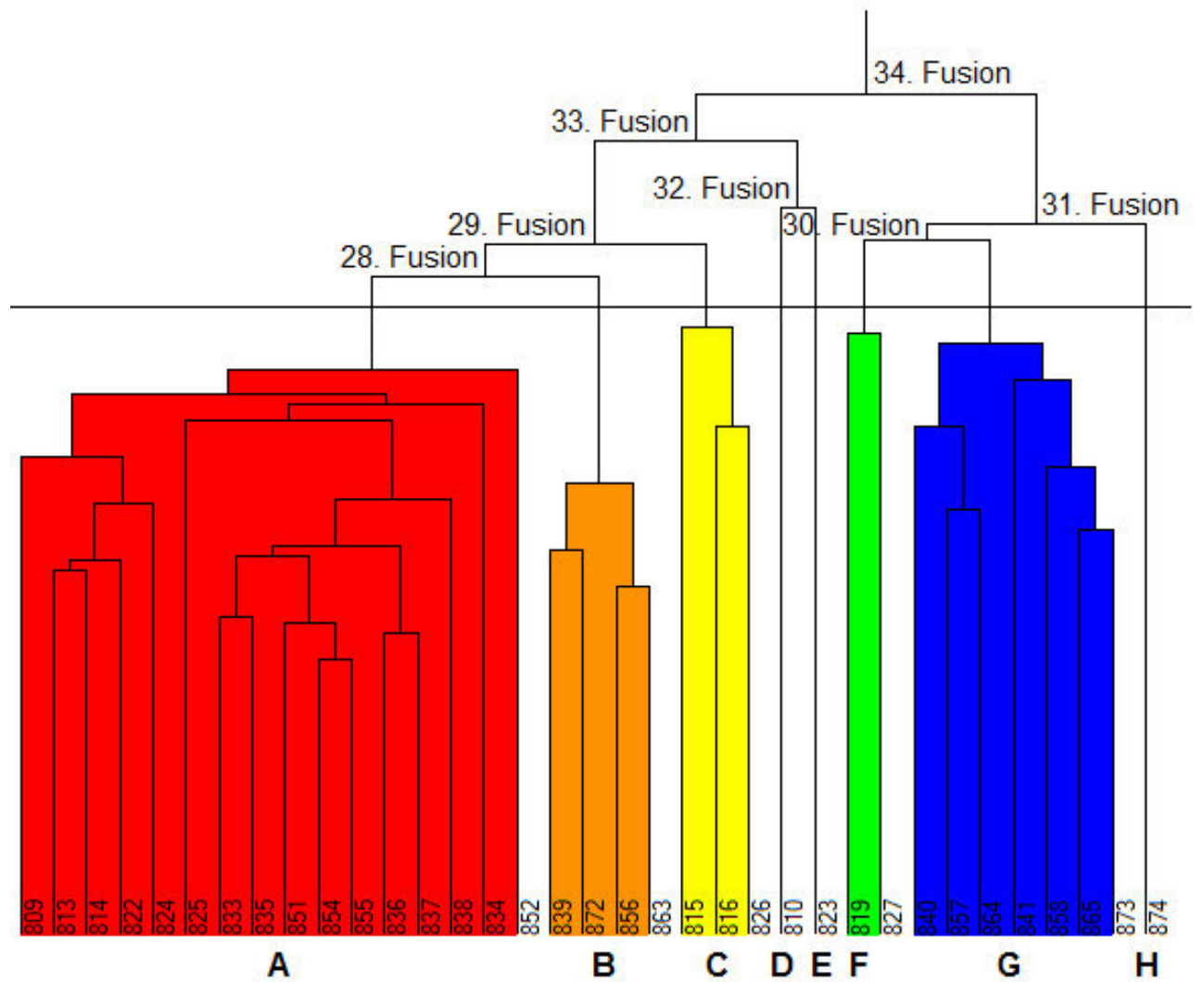

Abbildung A5. Dendrogramm der Clusteranalyse mit acht eingefärbten Dendremen. Vergleichskorpus, Totalkorpus

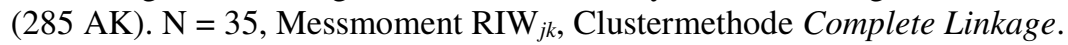

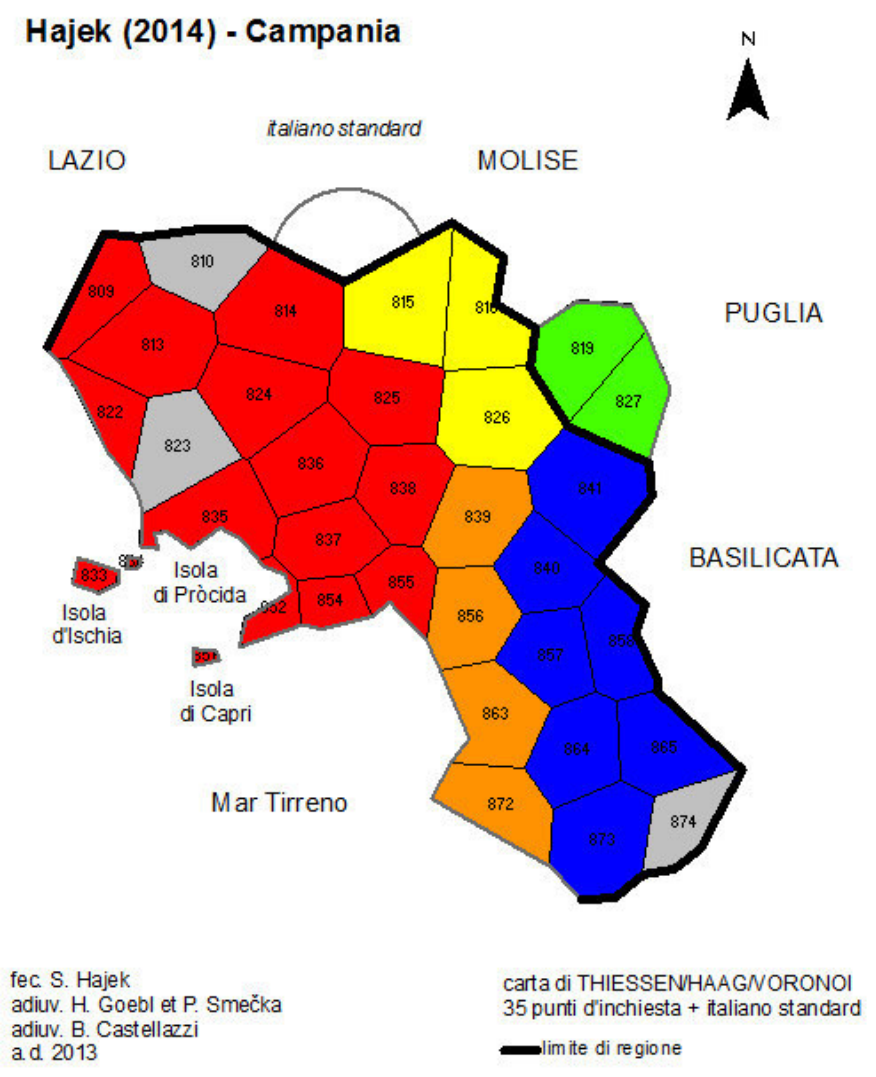

Karte A41. Räumliche Umlegung des Dendrogramms aus Abb. A5: Clusterkarte mit acht Choremen. Die Punkte der grau unterlegten Polygone bilden je ein eigenes Cluster. 


\section{Kartenteil}

\section{ALI (1995-2008) - Campania}
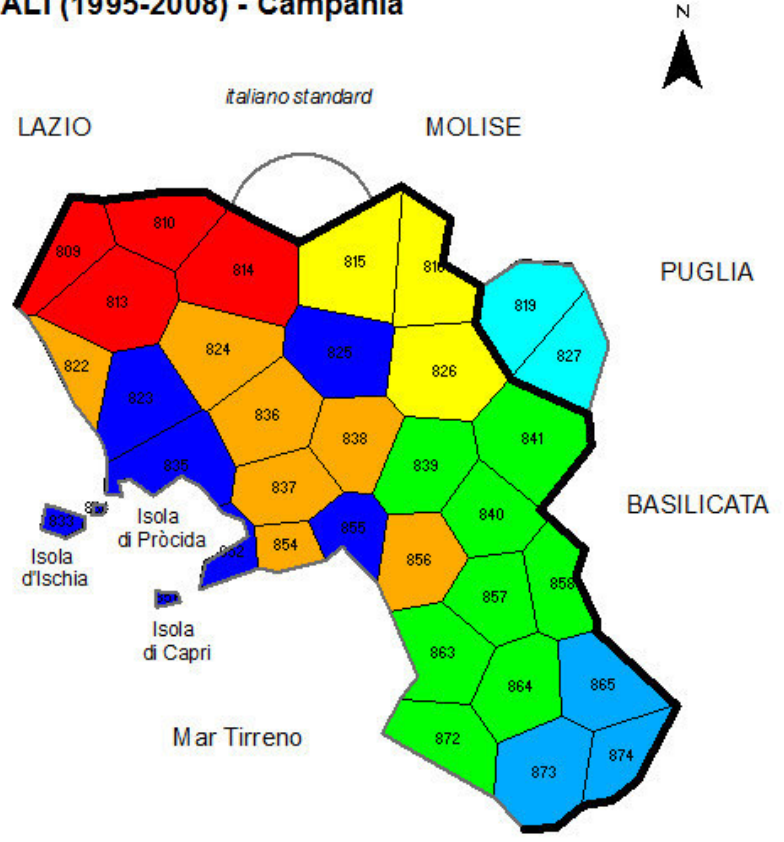

fec. S. Hajek

adiuv. H. Goebl et P. Smečka

adiuv. B. Castellazz

carta di THIESSENHAAGNORONOI 35 punti d'inchiesta + italiano standard

a.d. 2013

Karte A42. Räumliche Umlegung des Dendrogramms aus Abb. A1: Clusterkarte mit sieben Choremen. ALI-Korpus, Totalkorpus (275 AK). N = 35, Messmoment $\mathrm{RIW}_{j k}$, Clustermethode Complete Linkage.

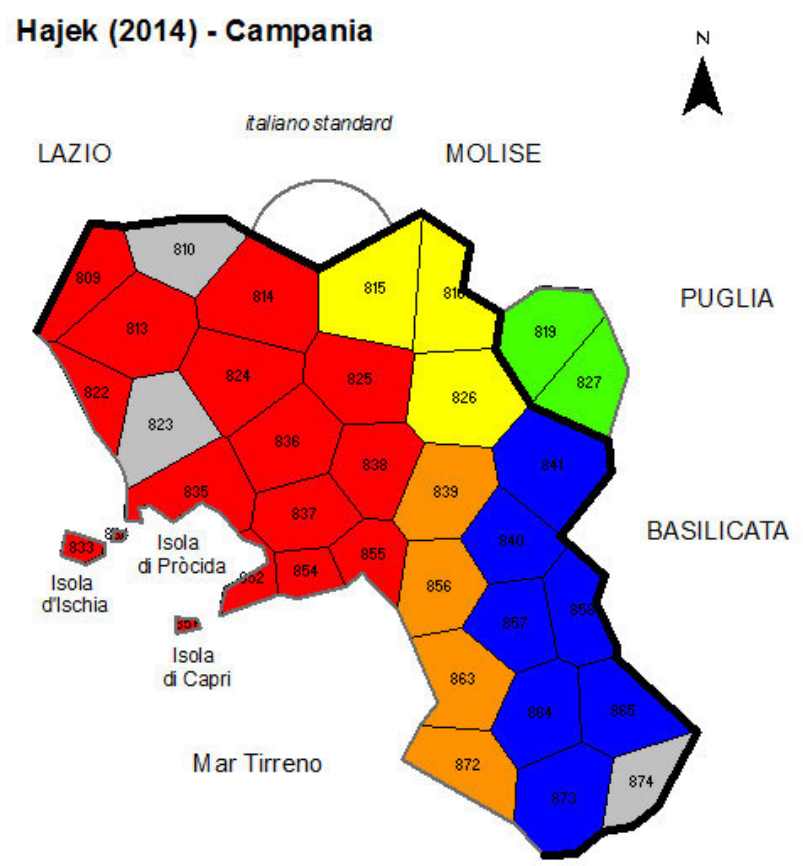

Karte A43. Räumliche Umlegung des Dendrogramms aus Abb. A5: Clusterkarte mit acht Choremen. Vergleichskorpus, Totalkorpus (285 AK). N = 35, Messmoment $\mathrm{RIW}_{j k}$, Clustermethode Complete Linkage. Die Punkte der grau unterlegten Polygone bilden je ein eigenes Cluster. 


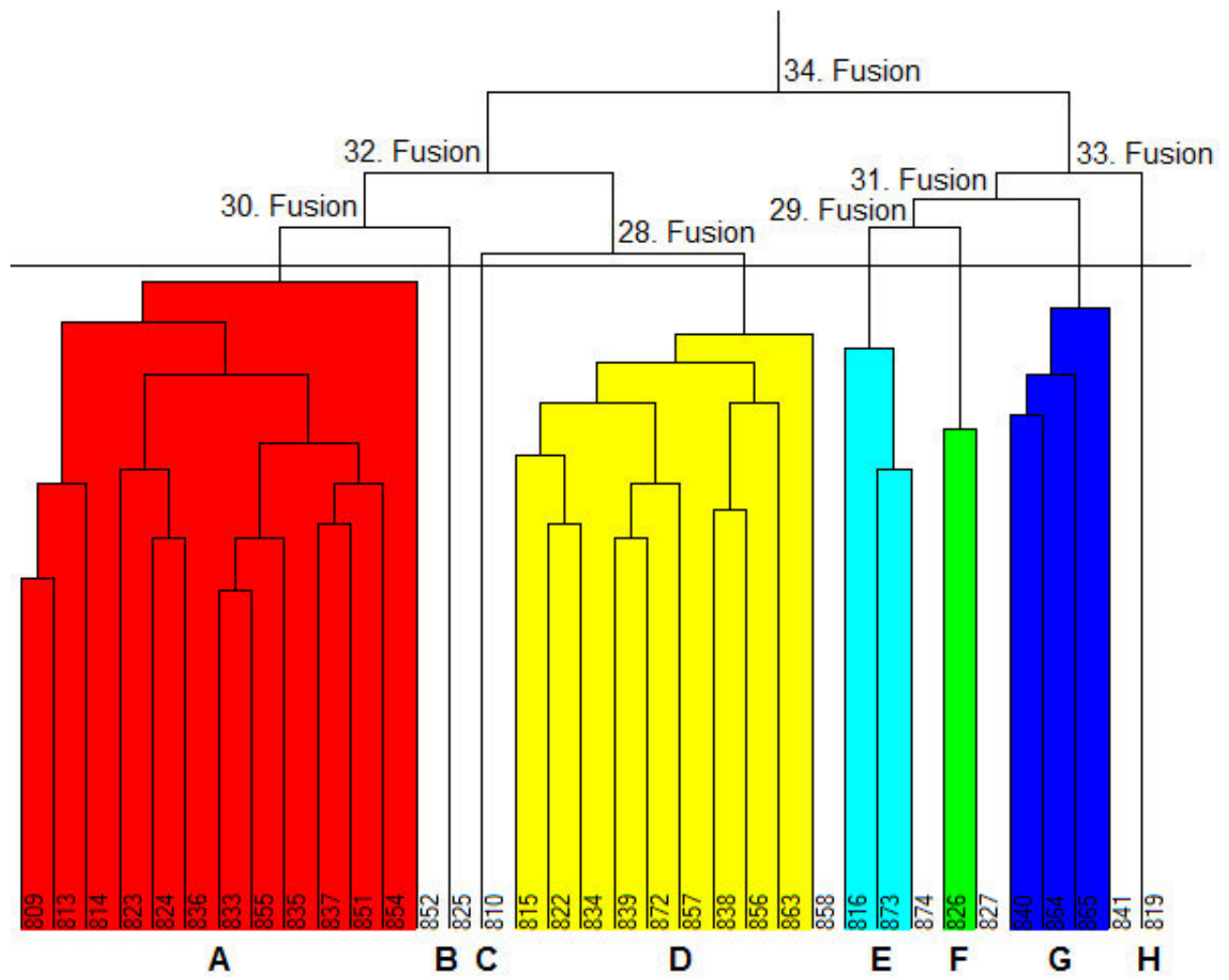

Abbildung A6. Dendrogramm der Clusteranalyse mit acht eingefärbten Dendremen. Vergleichskorpus, Lexikon (112 AK). N = 35, Messmoment $\mathrm{RIW}_{j k}$, Clustermethode Complete Linkage.

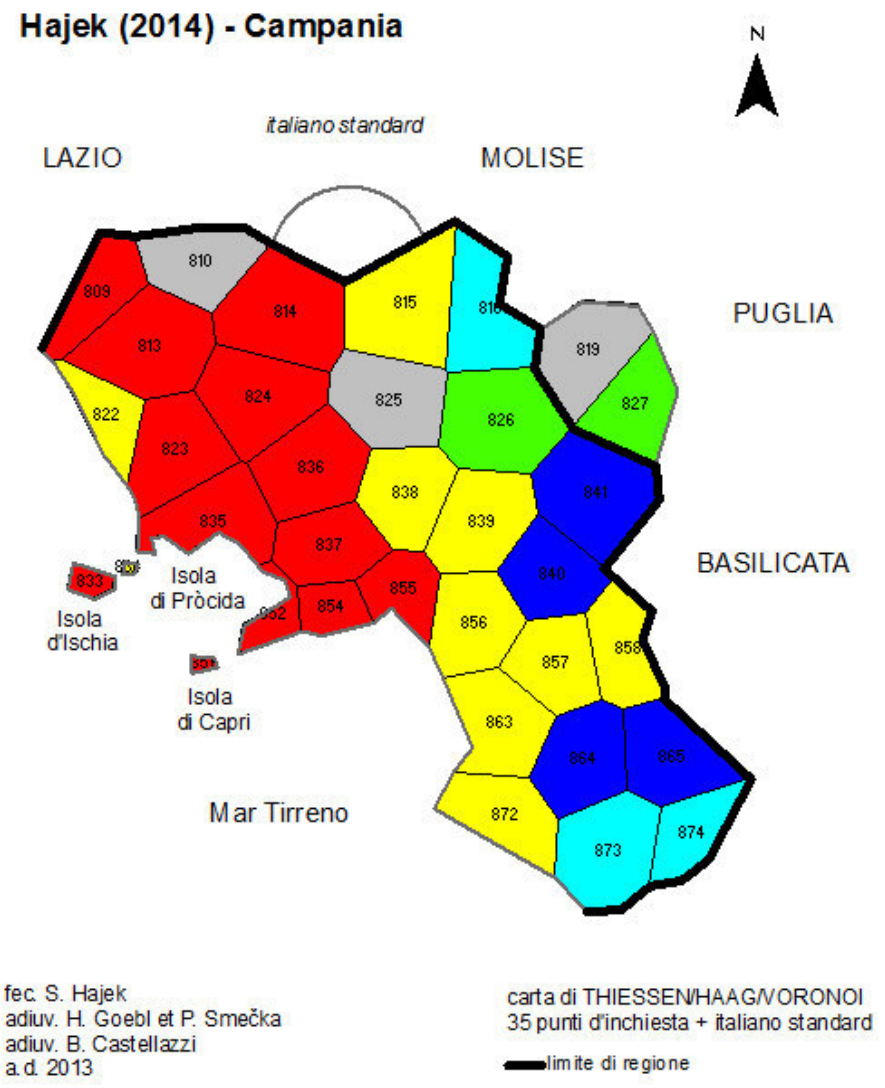

Karte A44. Räumliche Umlegung des Dendrogramms aus Abb. A6: Clusterkarte mit acht Choremen. Die Punkte der grau unterlegten Polygone bilden je ein eigenes Cluster. 


\section{Kartenteil}
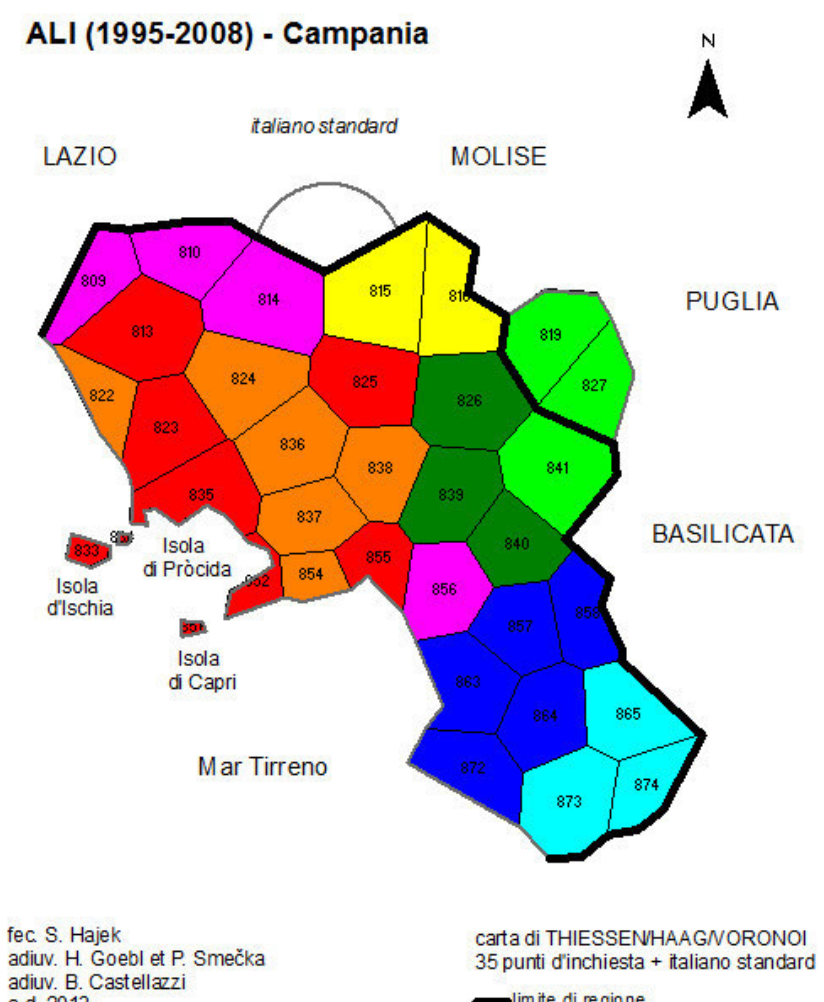

Karte A45. Räumliche Umlegung des Dendrogramms aus Abb. A2: Clusterkarte mit acht Choremen. ALI-Korpus, Lexikon (105 AK). N = 35, Messmoment RIW , $_{j k}$ Clustermethode Complete Linkage.

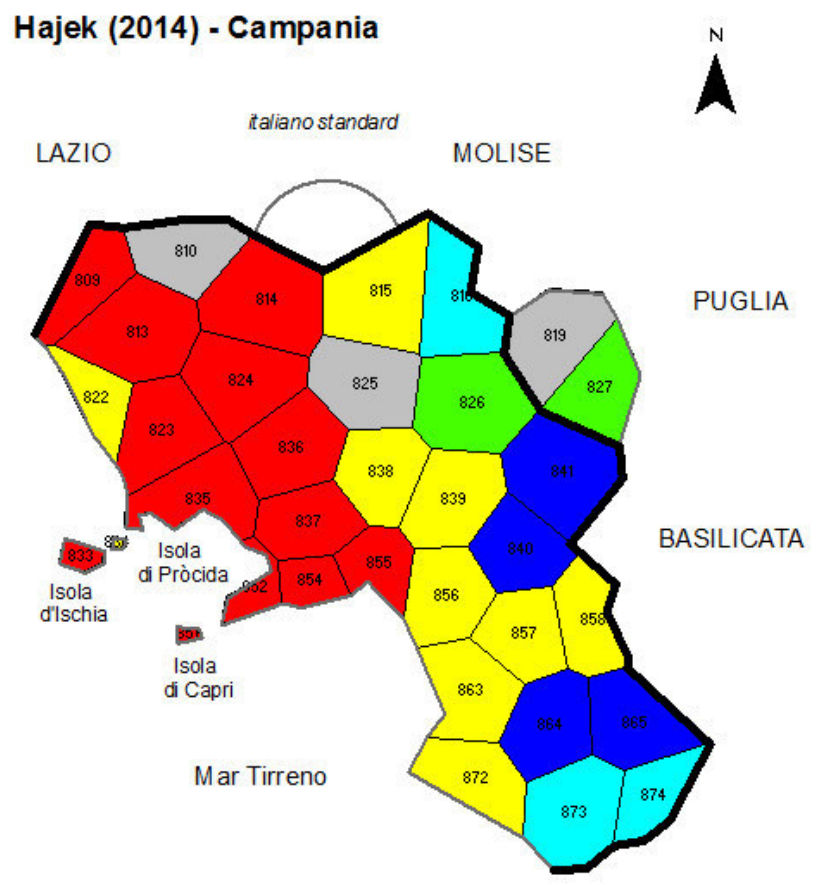

Karte A46. Räumliche Umlegung des Dendrogramms aus Abb. A6: Clusterkarte mit acht Choremen. Vergleichskorpus, Lexikon (112 AK). N = 35, Messmoment $\mathrm{RIW}_{j k}$, Clustermethode Complete Linkage. Die Punkte der grau unterlegten Polygone bilden je ein eigenes Cluster. 


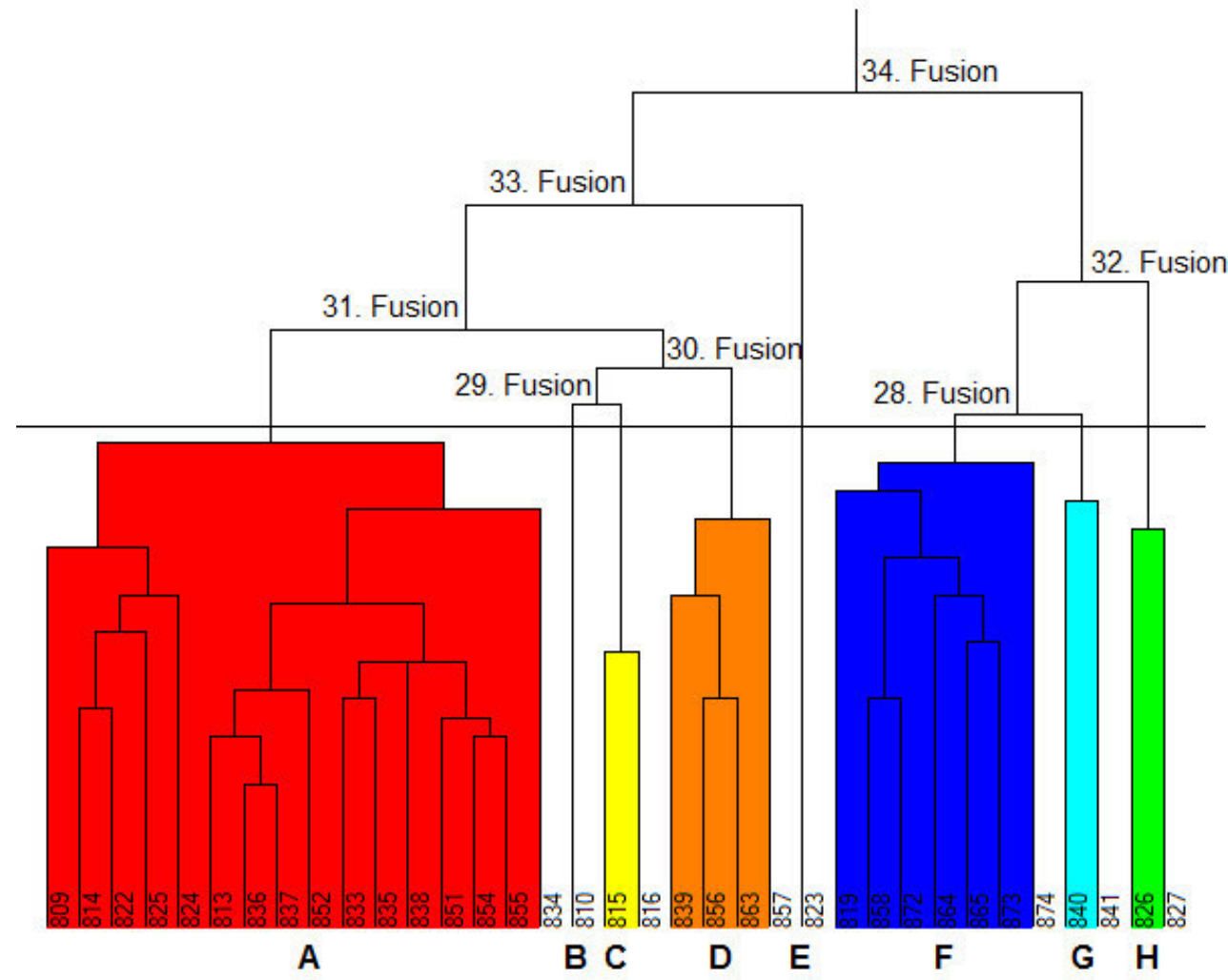

Abbildung A7. Dendrogramm der Clusteranalyse mit acht eingefärbten Dendremen. Vergleichskorpus, Konsonantismus (125 AK). N = 35, Messmoment RIW ${ }_{j k}$, Clustermethode Complete Linkage.

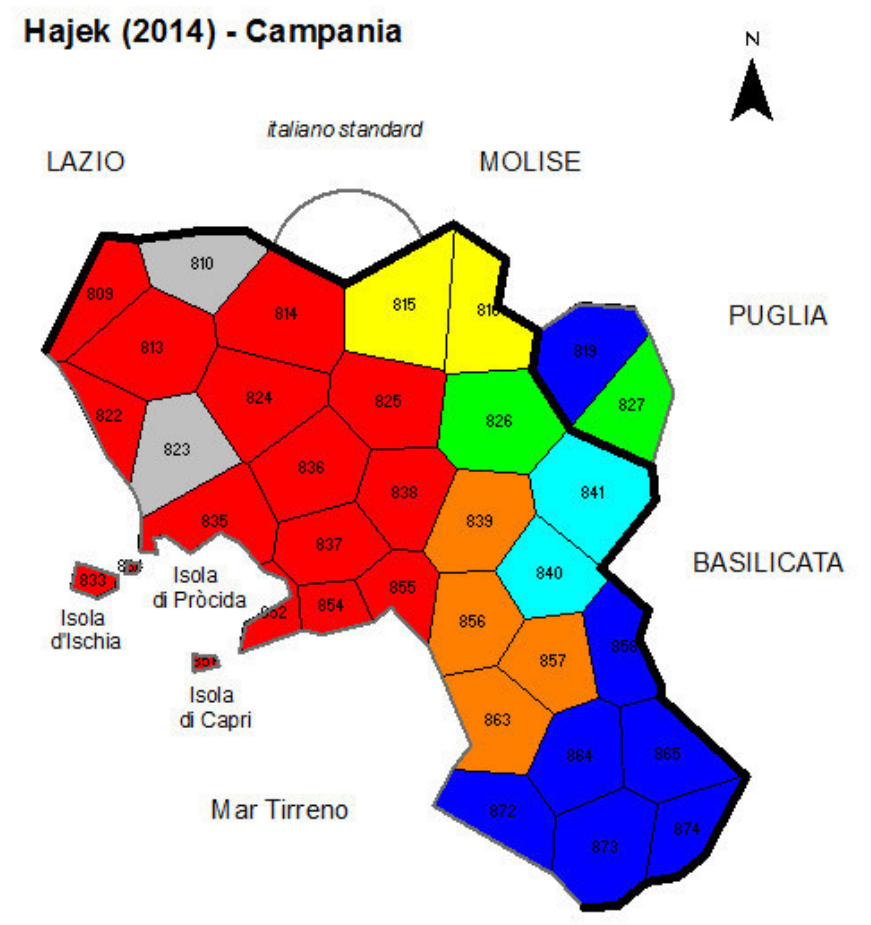

fec. S. Hajek

adiuv. H. Goebl et P. Smečka

adiuv. B. Castellazzi

a.d 2013 carta di THIESSENHAAGNORONOI 35 punti dinchiesta + italiano standard limite di regione

Karte A47. Räumliche Umlegung des Dendrogramms aus Abb. A7: Clusterkarte mit acht Choremen. Die Punkte der grau unterlegten Polygone bilden je ein eigenes Cluster. 


\section{Kartenteil}

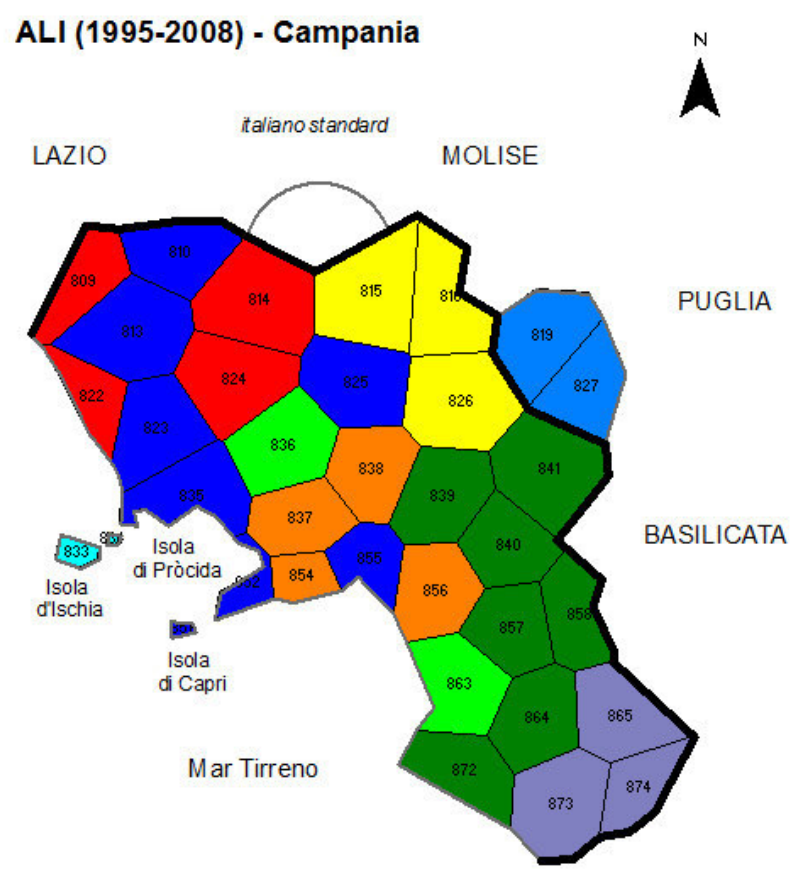

$$
\begin{array}{ll}
\text { fec. S. Hajek } & \text { carta di THIESSENHAAGNORONOI } \\
\text { adiuv. H. Goebl et P. Smečka } & 35 \text { punti dinchiesta + italiano standard } \\
\text { adiuv. B. Castellazzi } & \text { limite di regione } \\
\text { a.d. } 2013 &
\end{array}
$$

Karte A48. Räumliche Umlegung des Dendrogramms aus Abb. A3: Clusterkarte mit acht Choremen. ALI-Korpus, Konsonantismus (129 AK). Messmoment RIW $_{j k}$, Clustermethode Complete Linkage.

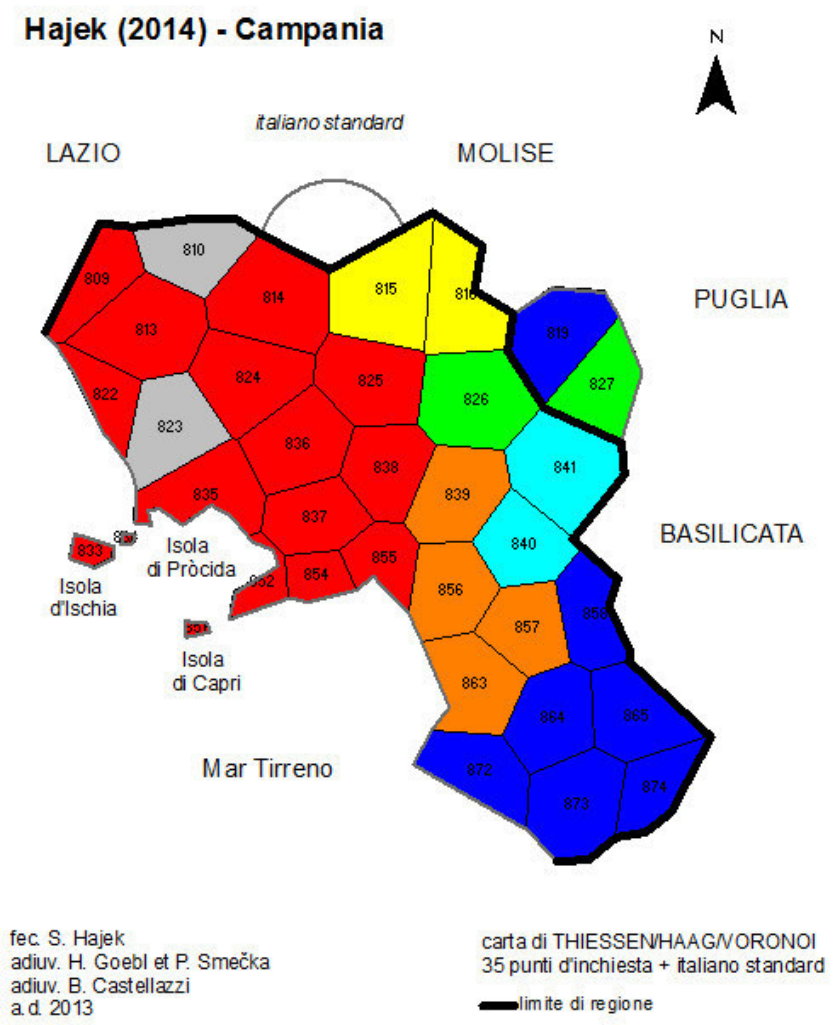

Karte A49. Räumliche Umlegung des Dendrogramms aus Abb. A7: Clusterkarte mit acht Choremen. Vergleichskorpus,

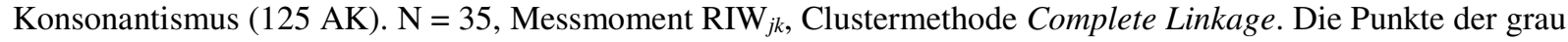
unterlegten Polygone bilden je ein eigenes Cluster. 


\section{Kartenteil}

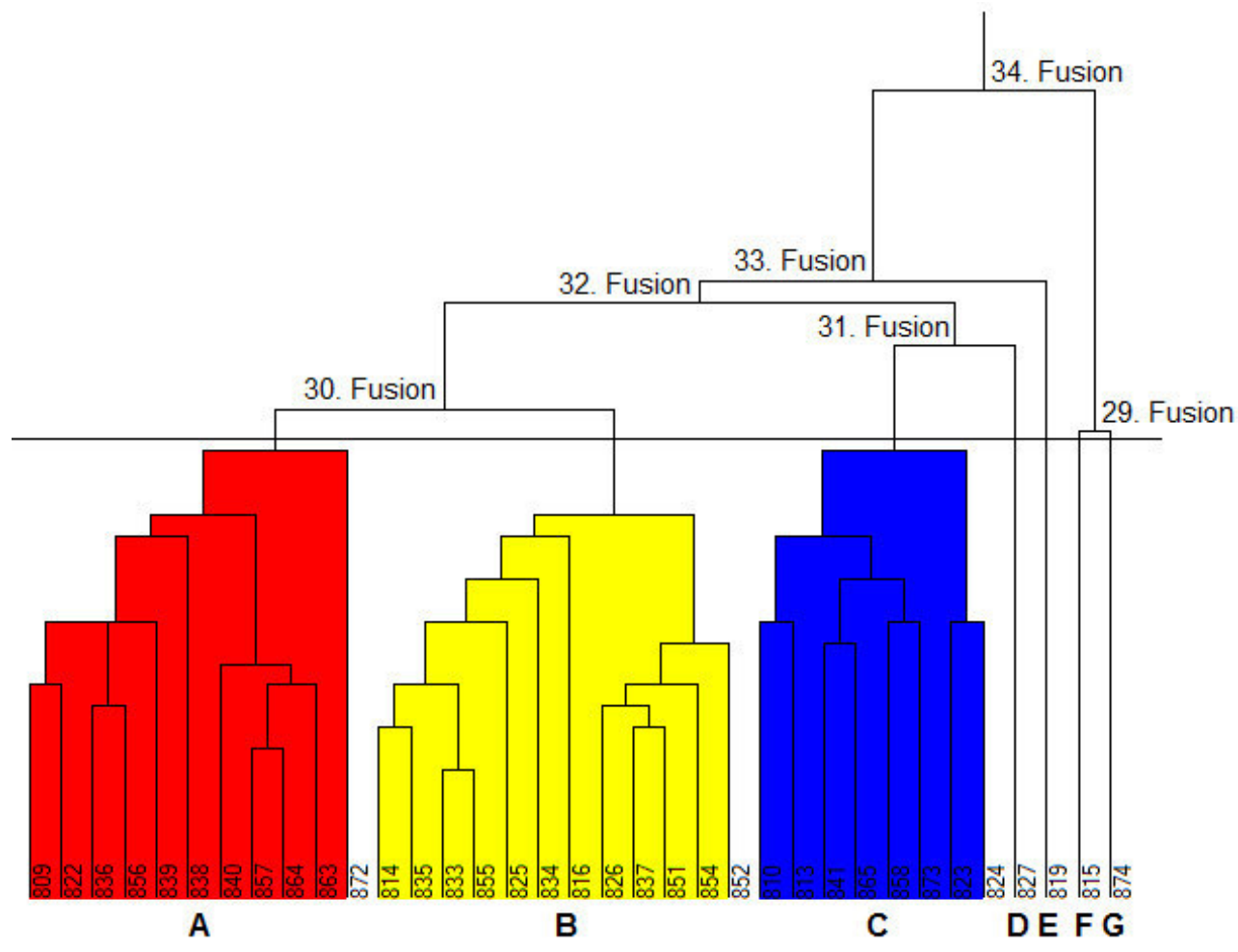

Abbildung A8. Dendrogramm der Clusteranalyse mit sieben eingefärbten Dendremen. Vergleichskorpus, Vokalismus (48 AK). N = 35, Messmoment $\mathrm{RIW}_{j k}$, Clustermethode Complete Linkage.

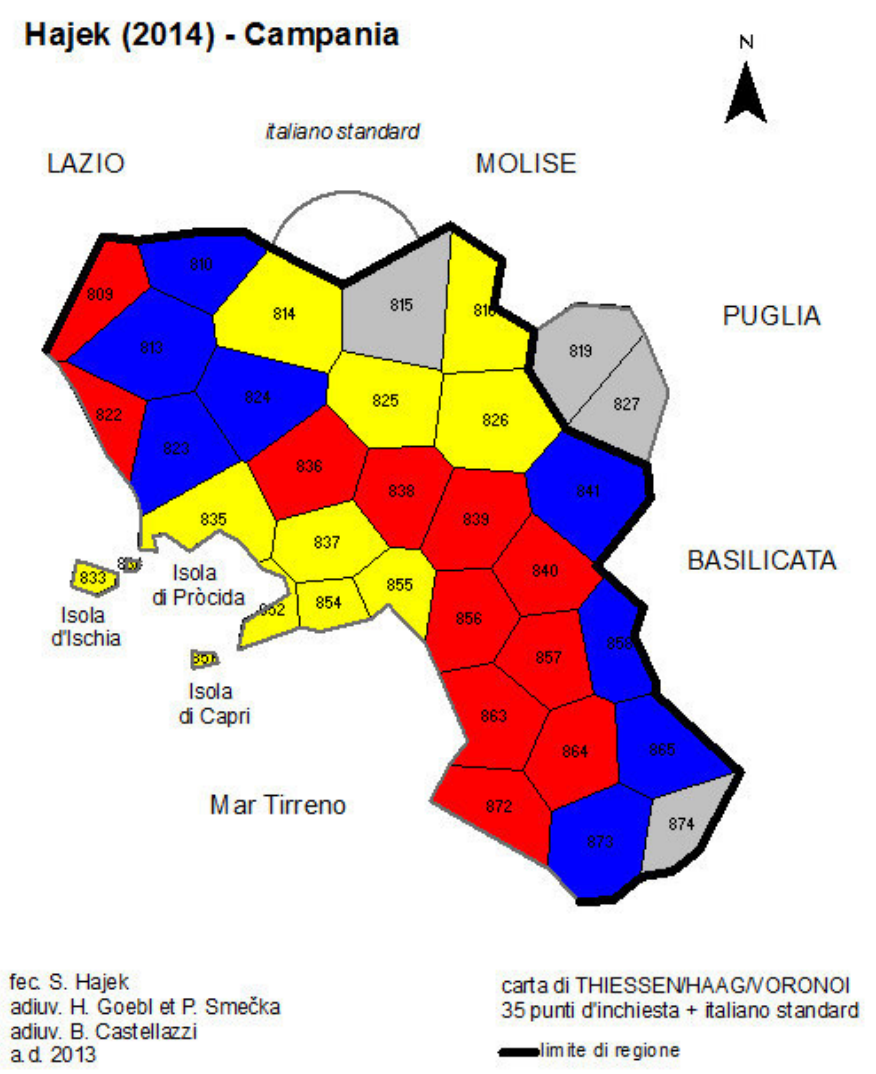

Karte A50. Räumliche Umlegung des Dendrogramms aus Abb. A8: Clusterkarte mit sieben Choremen. Die Punkte der grau unterlegten Polygone bilden je ein eigenes Cluster. 


\section{Kartenteil}

\section{ALI (1995-2008) - Campania}

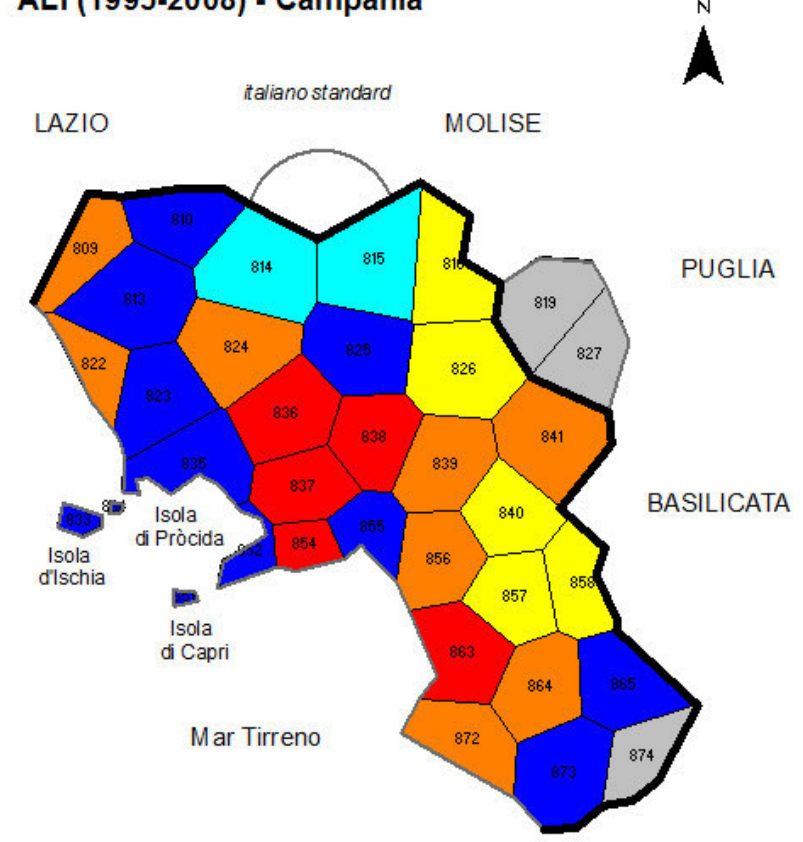

fec. S. Hajek

adiuv. H. Goebl et P. Smečka

adiuv. B. Castellazzi

carta di THIESSENHAAGNORONOI 35 punti d'inchiesta + italiano standard

a.d. 2013

Karte A51. Räumliche Umlegung des Dendrogramms aus Abb. A4: Clusterkarte mit acht Choremen. ALI-Korpus,

Vokalismus (41 AK). N = 35, Messmoment RIW $_{j k}$, Clustermethode Complete Linkage. Die Punkte der grau unterlegten Polygone bilden je ein eigenes Cluster.

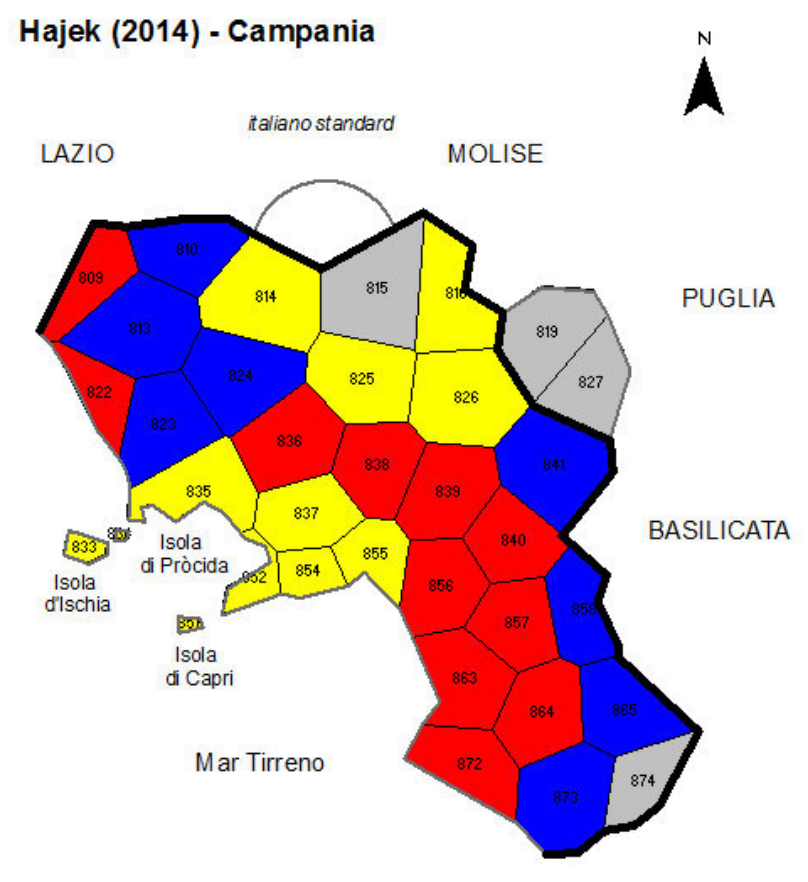

fec. S. Hajek

adiuv. H. Goebl et P. Smečka adiuv. B. Castellazz a.d. 2013 carta di THIESSENHAAGNORONOI 35 punti d'inchiesta + italiano standard - limite di regione

Karte A52. Räumliche Umlegung des Dendrogramms aus Abb. A8: Clusterkarte mit sieben Choremen. Vergleichskorpus, Vokalismus (48 AK). N = 35, Messmoment RIW ${ }_{j k}$, Clustermethode Complete Linkage. Die Punkte der grau unterlegten Polygone bilden je ein eigenes Cluster. 
Legende, MINMWMAX, 6-fach

[1] von 24.73 bis $30.88(n=5)$

[2] bis $37.03(n=13)$

[3] bis $43.18(n=16)$

[4] bis $48.42(n=17)$

[5] bis $53.66(n=10)$

[6] bis $58.91(n=10)$

Summe der Elemente: 71

$\mathrm{MIN}=24.73$

$M W=43.18$

$M E D=43.64$

$\operatorname{MAX}=58.91$

Häufigkeitsverteilung, MINMWMAX, 12-fach

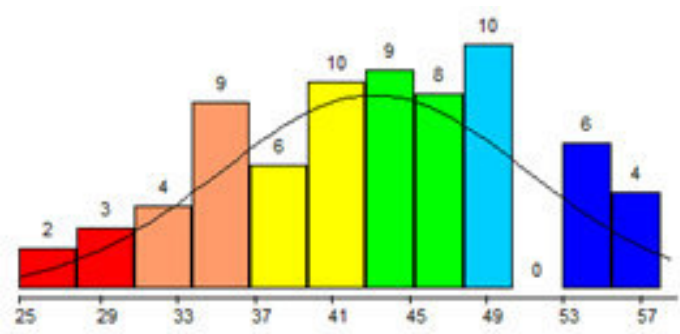

\section{ALI (1995-2008) - Campania}

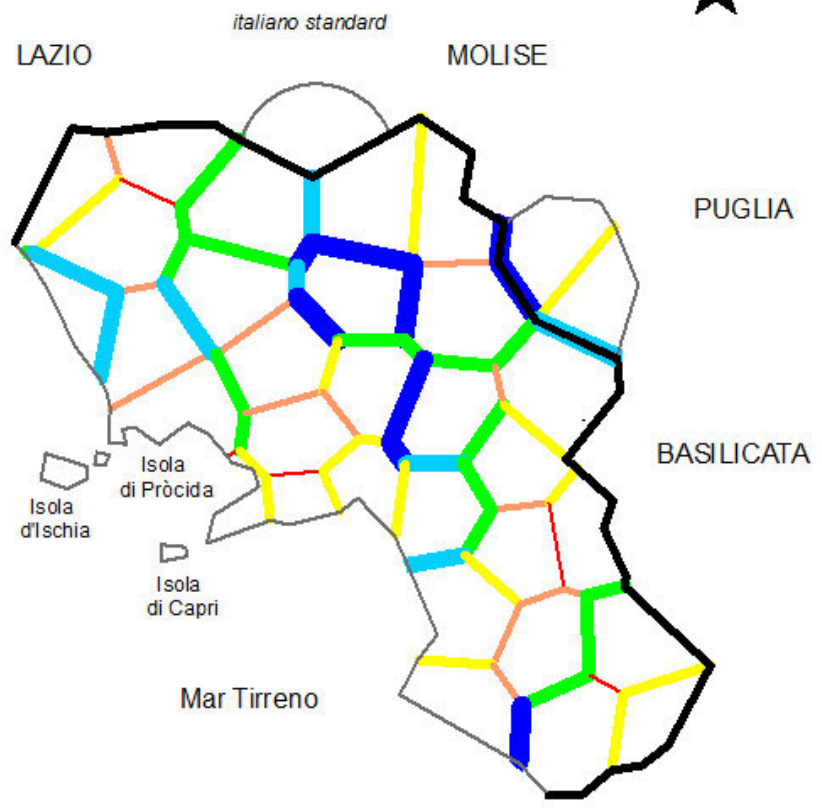

fec. S. Hajek

adiuv. H. Goebl et P. Smečka adiuv. B. Castellazzi

a.d. 2013
$\stackrel{N}{N}$

MOLISE

carta di THIESSEN/HAAG/VORONO limite di regione 35 punti d'inchiesta + italiano standard

Karte A53. Schottenkarte zum ALI-Korpus. Totalkorpus (275 AK), N = 35, Messmoment RDW $j k$.

\section{Legende, MINMWMAX, 6-fach}

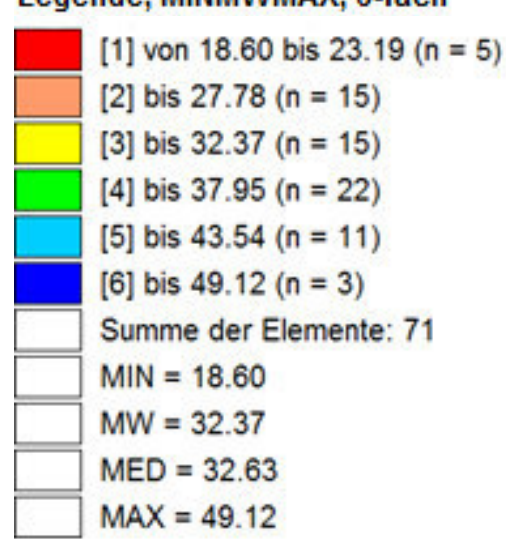

Häufigkeitsverteilung, MINMWMAX, 12-fach

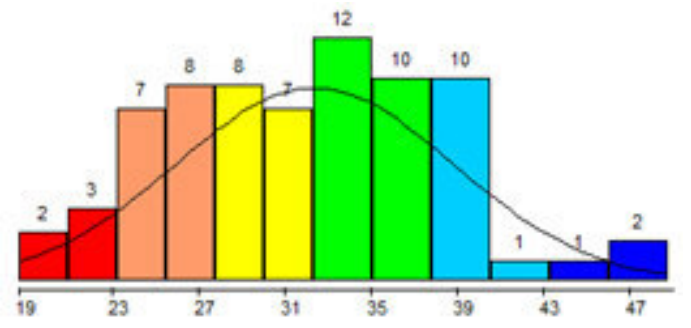

\section{Hajek (2014) - Campania}

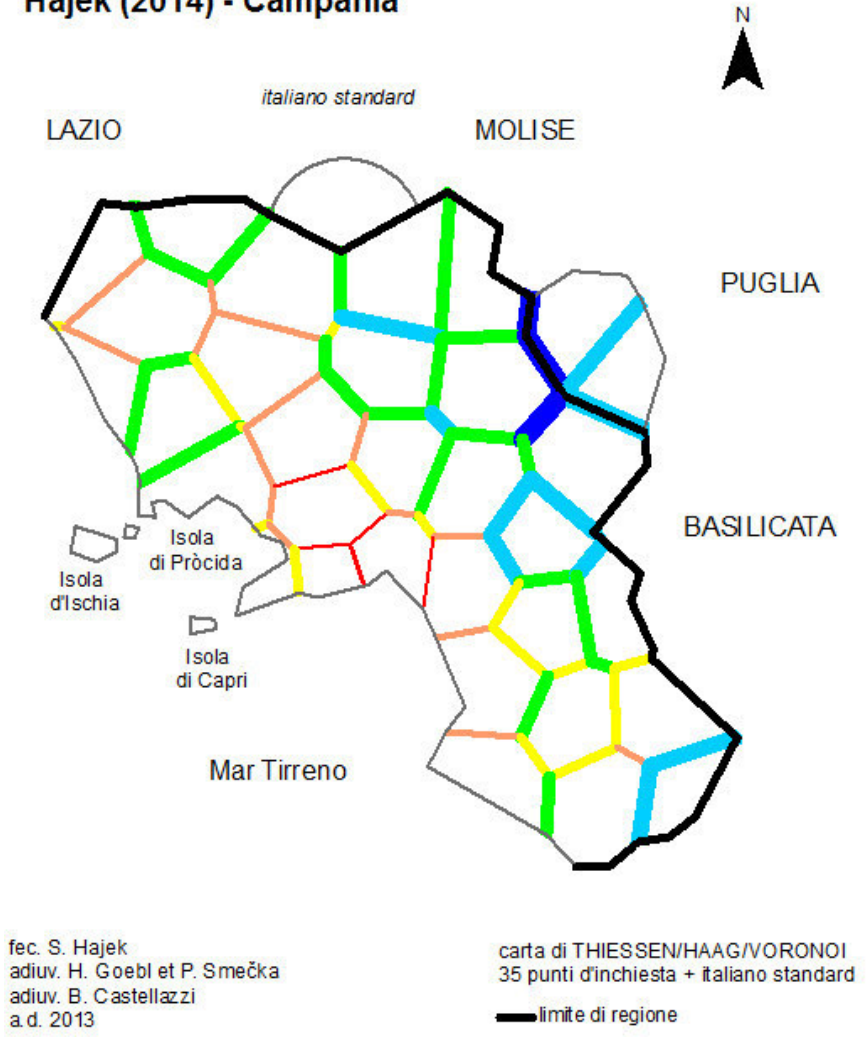

Karte A54. Schottenkarte zum Vergleichskorpus. Totalkorpus (285 AK), N = 35, Messmoment RDW W $_{j}$ 


\section{Kartenteil}

Legende, MINMWMAX, 6-fach

[1] von 27.62 bis $31.90(n=6)$

[2] bis $36.18(n=11)$

[3] bis $40.46(n=25)$

[4] bis $46.65(n=17)$

[5] bis $52.85(n=7)$

[6] bis $59.05(n=5)$

Summe der Elemente: 71

$\mathrm{MIN}=27.62$

$\mathrm{MW}=40.46$

MED $=39.05$

$\operatorname{MAX}=59.05$

Häufigkeitsverteilung, MINMWMAX, 12-fach

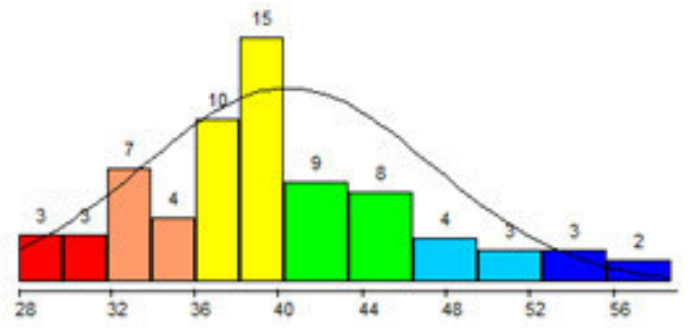

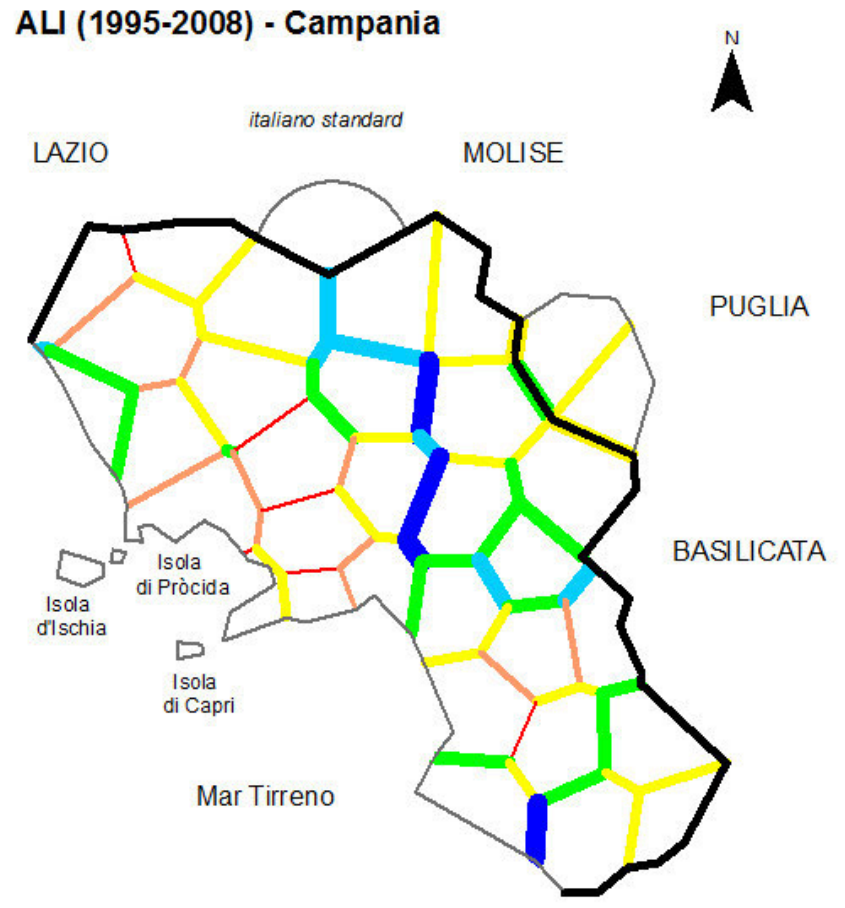

fec. S. Hajek

adiuv. H. Goebl et P. Smečka

adiuv. B. Castellazzi

carta di THIESSEN/HAAG/VORONOI 35 punti d'inchiesta + italiano standard -limite di regione

Karte A55. Schottenkarte zum ALI-Korpus. Lexikon (105 AK), N = 35, Messmoment RDW $j k$.

\section{Legende, MINMWMAX, 6-fach}

\begin{tabular}{l} 
[1] von 22.32 bis $26.55(n=4)$ \\
[2] bis $30.77(n=17)$ \\
[3] bis $35.00(n=16)$ \\
[4] bis $40.00(n=16)$ \\
[5] bis $45.00(n=15)$ \\
[6] bis $50.00(n=3)$ \\
Summe der Elemente: 71 \\
MIN $=22.32$ \\
MW $=35.00$ \\
MED $=34.82$ \\
\hline$\square M A X=50.00$
\end{tabular}

Häufigkeitsverteilung, MINMWMAX, 12-fach

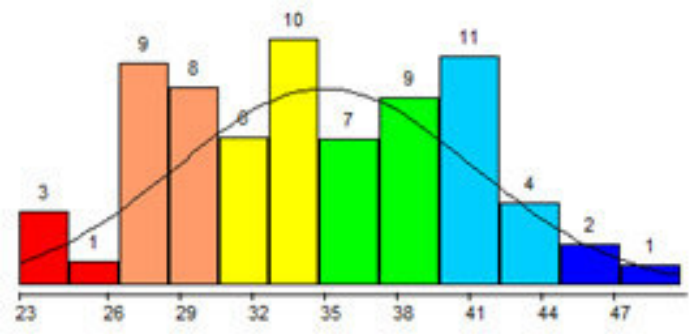

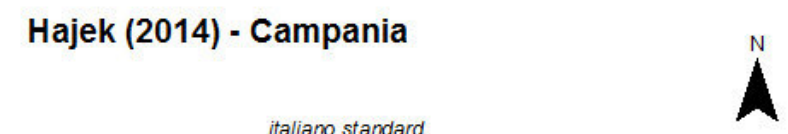

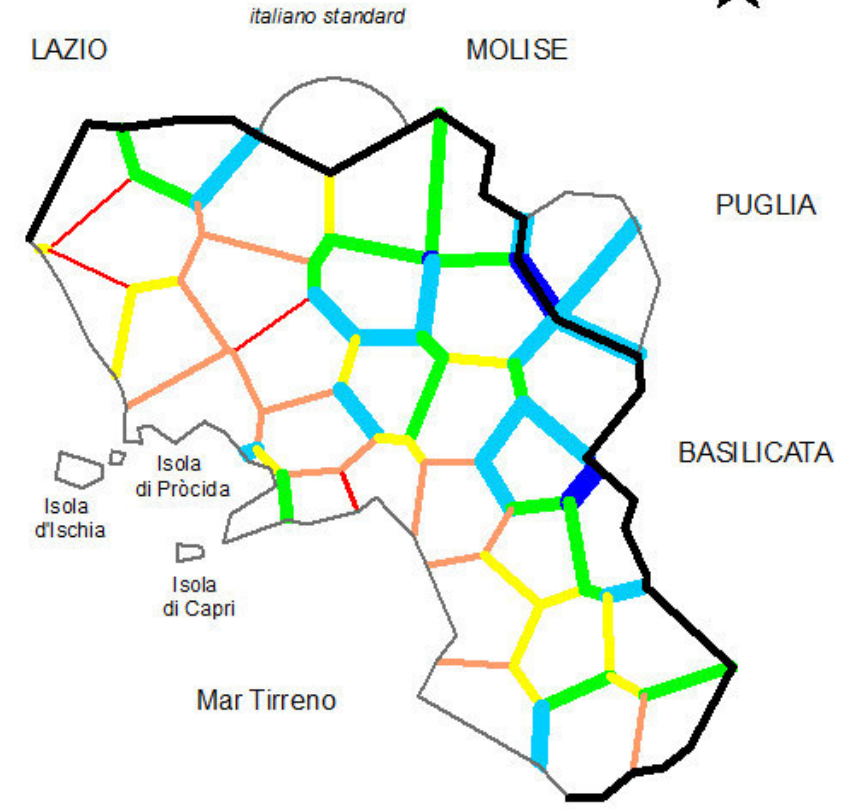

fec. S. Hajek

adiuv. H. Goebl et P. Smečka

adiuv. B. Castellazzi

carta di THIESSEN/HAAG/VORONOI 35 punti dinchiesta + italiano standard -limite di regione

Karte A56. Schottenkarte zum Vergleichskorpus. Lexikon (112 AK), N = 35, Messmoment RDW $j k$. 
Legende, MINMWMAX, 6-fach

[1] von 20.16 bis $28.70(n=5)$
[2] bis $37.25(n=11)$
[3] bis $45.80(n=21)$
[4] bis $53.79(n=16)$
[5] bis $61.78(n=12)$
[6] bis $69.77(n=6)$
Summe der Elemente: 71
MIN $=20.16$
MW $=45.80$
MED $=44.96$
MAX $=69.77$

Häufigkeitsverteilung, MINMWMAX, 12-fach

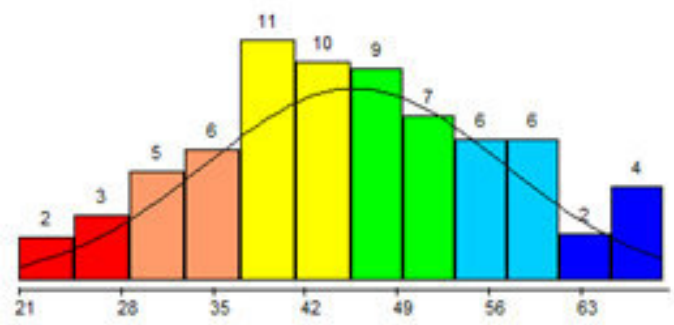

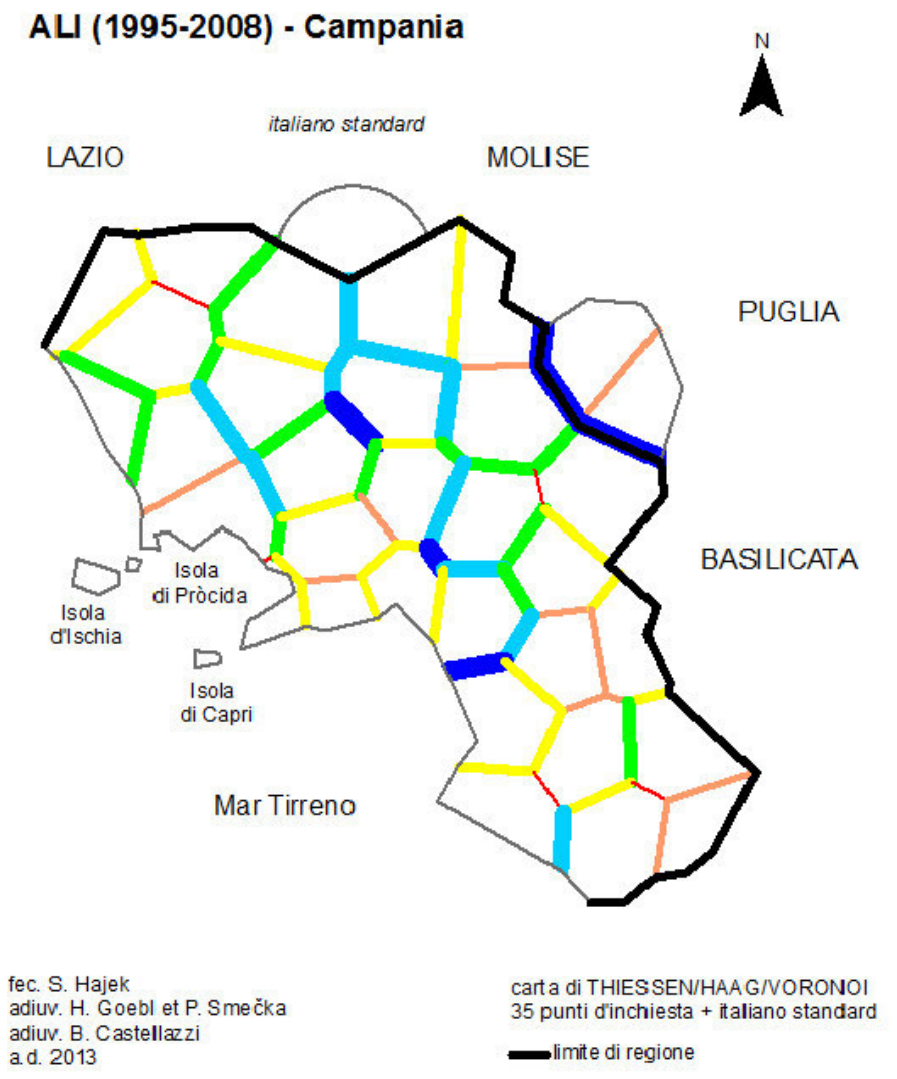

Karte A57. Schottenkarte zum ALI-Korpus. Konsonantismus (129 AK), N = 35, Messmoment RDW j $_{j k}$

Legende, MINMWMAX, 6-fach

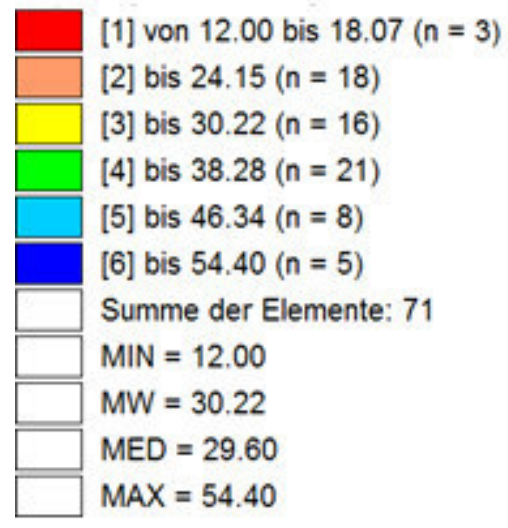

Häufigkeitsverteilung, MINMWMAX, 12-fach

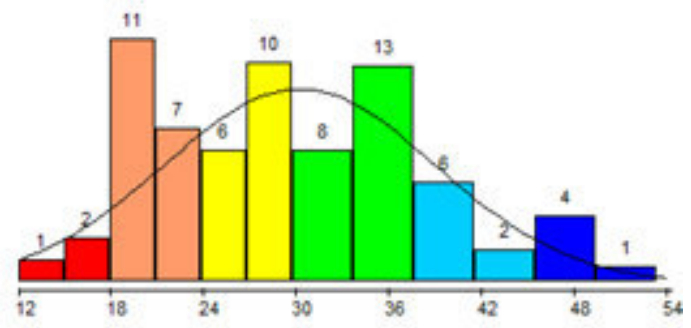

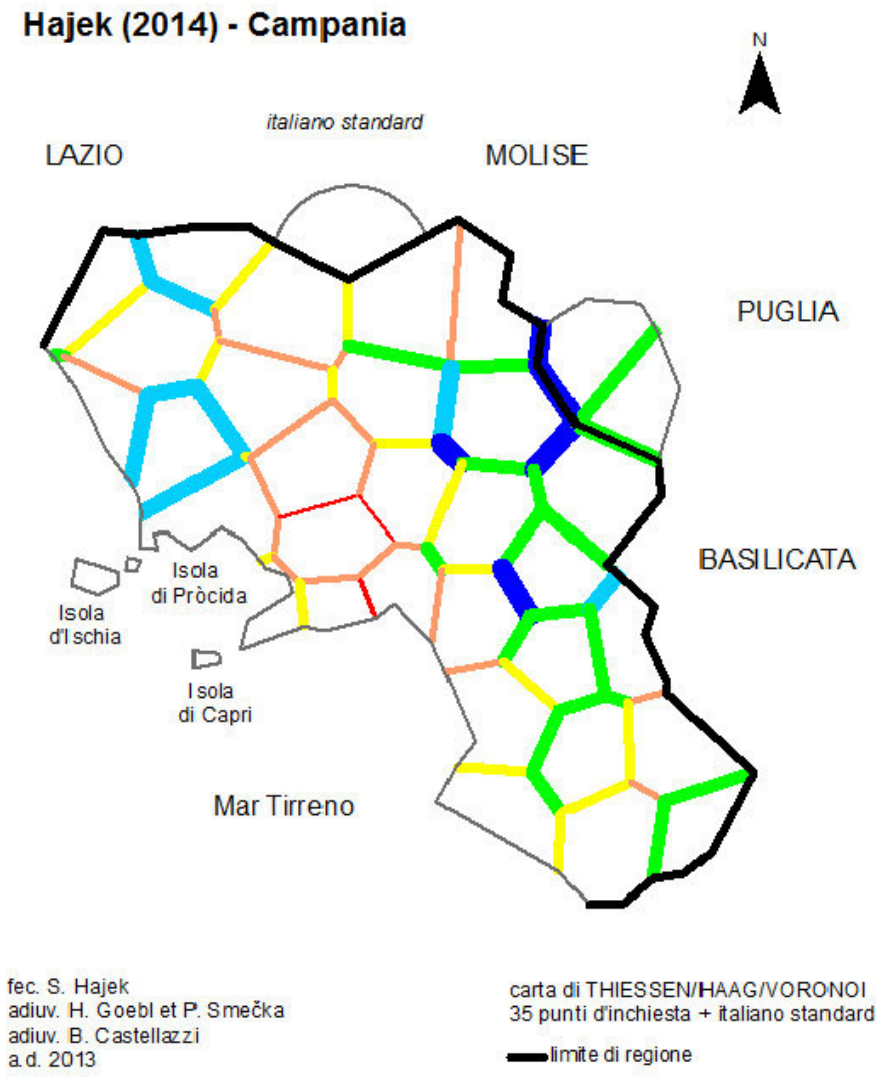

Karte A58. Schottenkarte zum Vergleichskorpus. Konsonantismus (125 AK), N = 35, Messmoment RDW $j$. 
Legende, MINMWMAX, 6-fach

[1] von 9.76 bis $20.46(n=7)$

[2] bis $31.17(n=11)$

[3] bis $41.88(n=24)$

[4] bis $52.31(n=10)$

[5] bis $62.74(n=12)$

[6] bis $73.17(n=7)$

Summe der Elemente: 71

$\mathrm{MIN}=9.76$

$M W=41.88$

MED $=41.46$

$\operatorname{MAX}=73.17$

Häufigkeitsverteilung, MINMWMAX, 12-fach

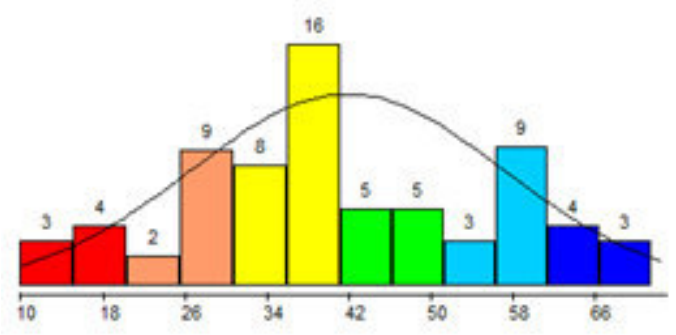

\section{ALI (1995-2008) - Campania}

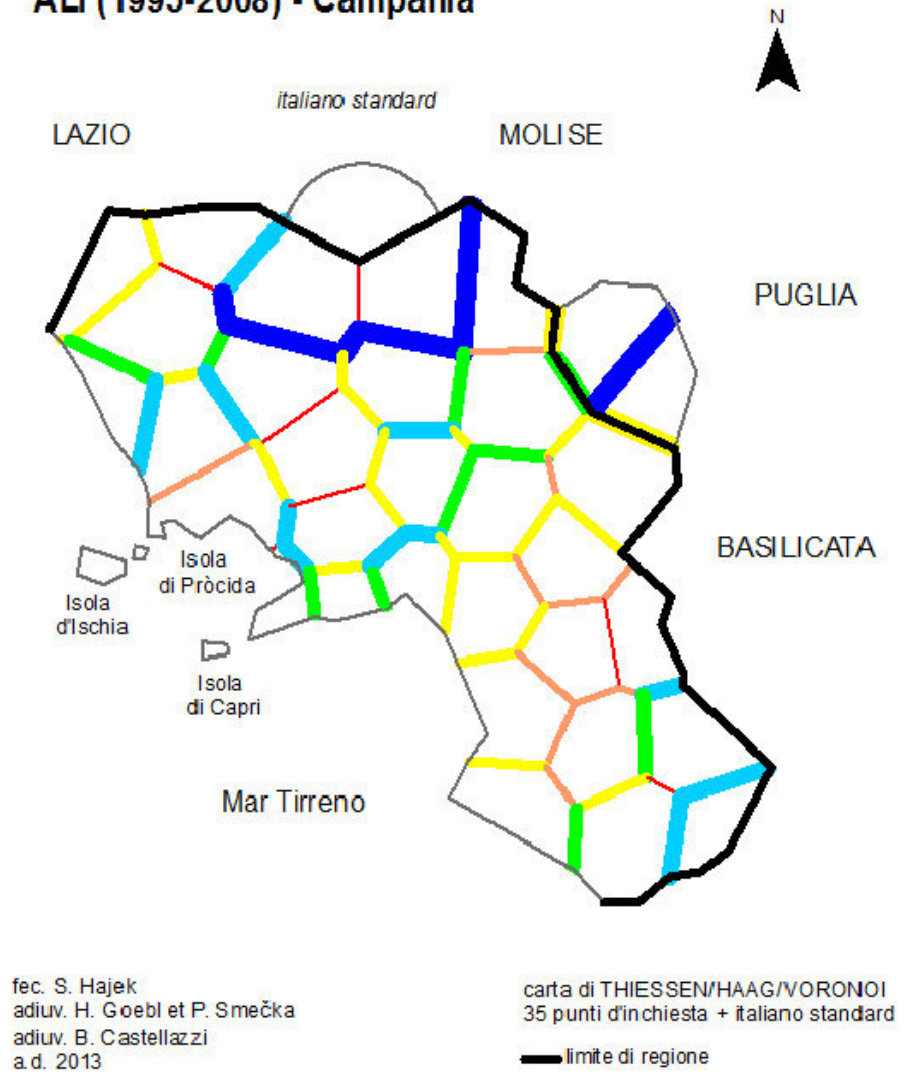

Karte A59. Schottenkarte zum ALI-Korpus. Vokalismus (41 AK), N = 35, Messmoment $\mathrm{RDW}_{j k}$.

Legende, MINMWMAX, 6-fach

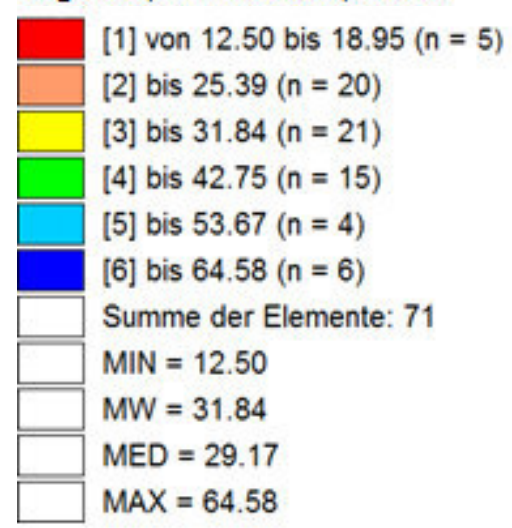

Häufigkeitsverteilung, MINMWMAX, 12-fach

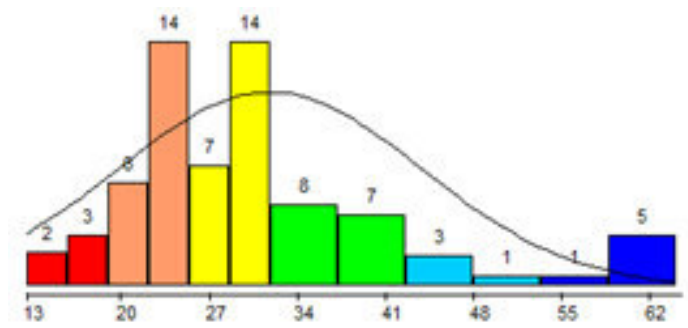

Hajek (2014) - Campania

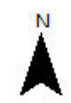

MOLISE

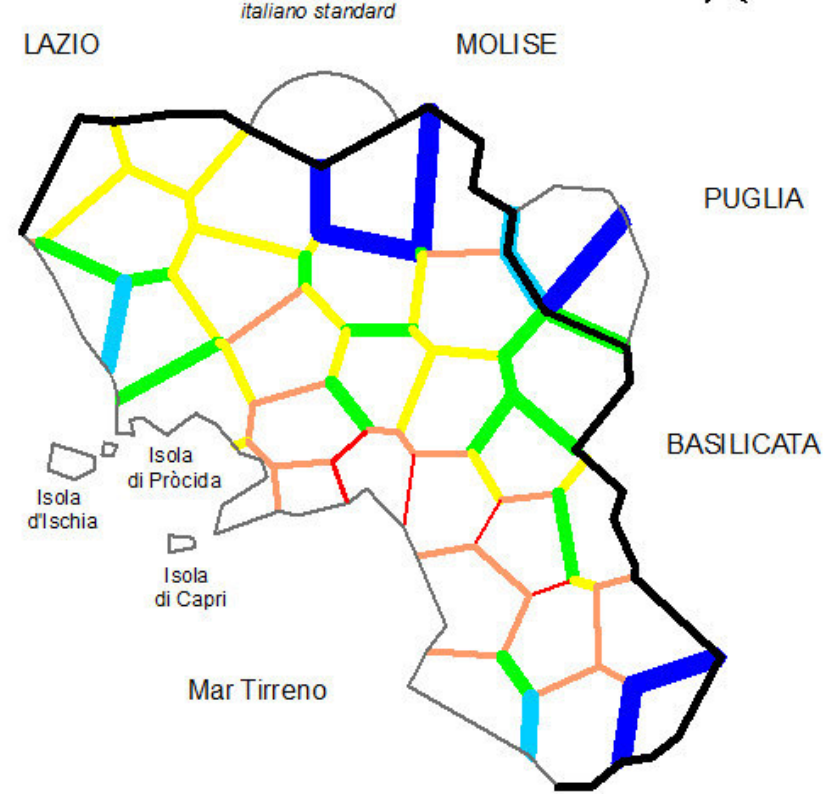

fec. S. Hajek

adiuv. $\mathrm{H}$. Goebl et P. Smečka

adiuv. B. Castellazzi

a.d. 2013 carta di THIESSEN/HAAG/VORONOI 35 punti dinchiesta + italiano standard -limite di regione

Karte A60. Schottenkarte zum Vergleichskorpus. Vokalismus (48 AK), N = 35, Messmoment RDW , $_{j}$. 
Legende, MINMWMAX, 6-fach

[1] von 57.45 bis $60.78(n=4)$

[2] bis $64.10(n=7)$

[3] bis $67,42(n=6)$

[4] bis $70.16(n=5)$

[5] bis $72.90(n=8)$

[6] bis $75.64(n=5)$

Summe der Elemente: 35

MIN $=57.45$ (P. 814)

$\mathrm{MW}=67.42$

MED $=67.64$

MAX $=75.64$ (P. 835; 852; 855)

Häufigkeitsverteilung, MINMWMAX, 12-fach

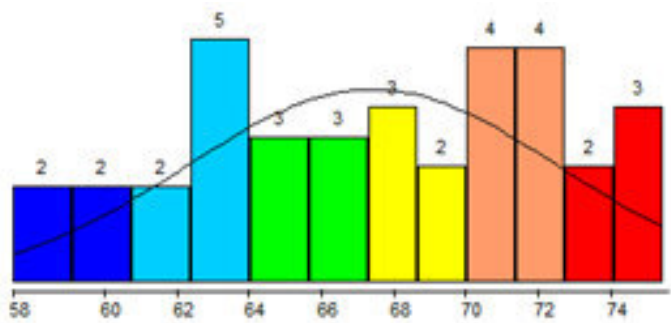

\section{ALI (1995-2008) - Campania}
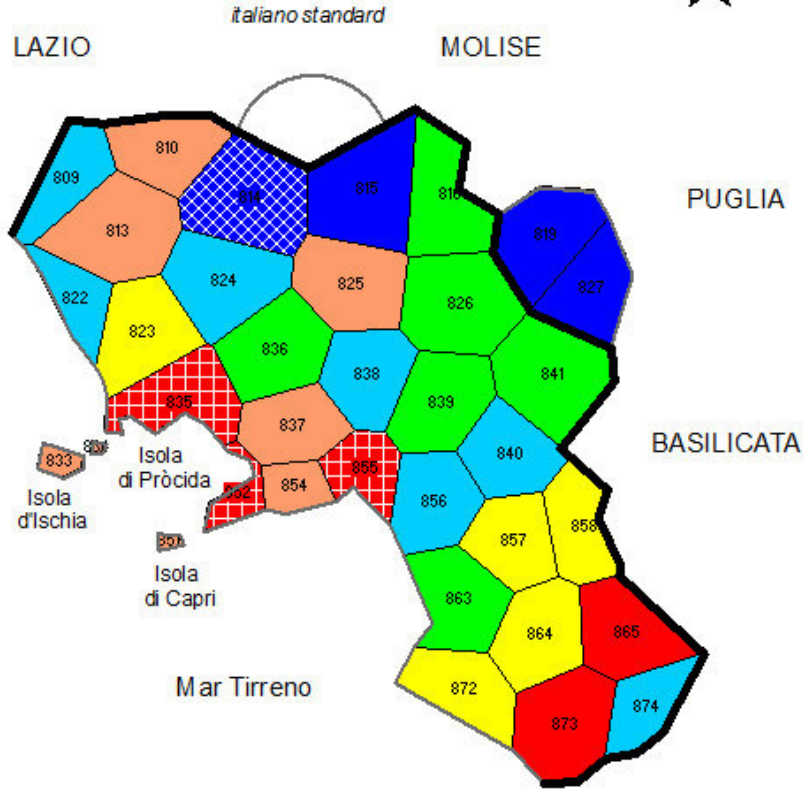

fec S. Hajek

adiuv. H. Goebl et P. Smečka adiuv. B. Castellazzi

carta di THIESSEN/HAAGNORONOI 35 punti dinchiesta + italiano standard

limite di regione

Karte A61. Kennwertsynopse der Maxima. ALI-Korpus, Totalkorpus (275 AK). N = 35, Messmoment RIW M. $_{j k}$

\section{Legende, MINMWMAX, 6-fach}

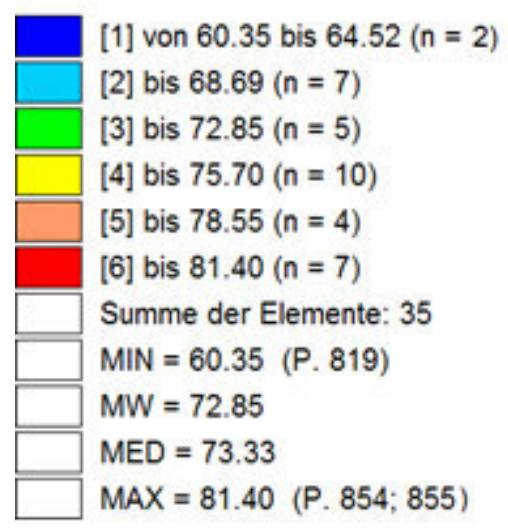

Häufigkeitsverteilung, MINMWMAX, 12-fach

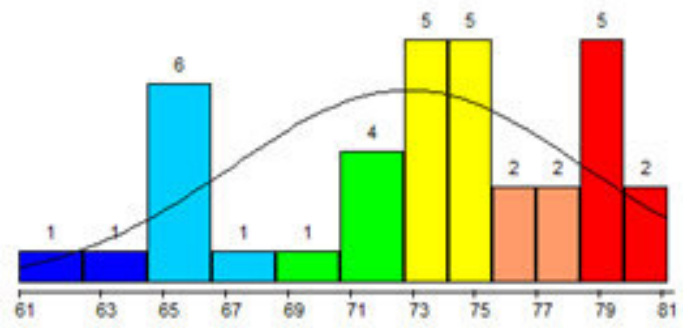

\section{Hajek (2014) - Campania}
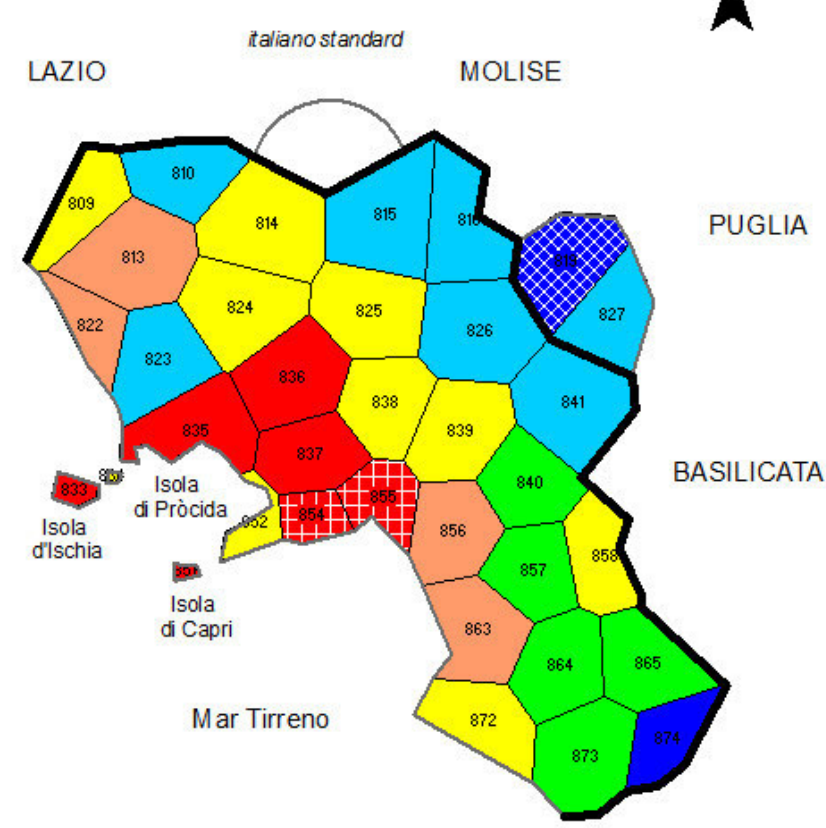

fec. S. Hajek

adiuv. H. Goebl et P. Smečka

adiuv. B. Castellazzi

a.d. 2013 carta di THIESSENHAAGNORONOI 35 punti d'inchiesta + italiano standard limite di regione

Karte A62. Kennwertsynopse der Maxima. Vergleichskorpus, Totalkorpus (285 AK). N = 35, Messmoment RIW . $_{j k}$ 
Legende, MINMWMAX, 6-fach

[1] von 60.00 bis $62.03(n=9)$

[2] bis $64.06(n=4)$

[3] bis $66.10(n=3)$

[4] bis $68.51(n=7)$

[5] bis $70.92(n=8)$

[6] bis $73.33(n=4)$

Summe der Elemente: 35

$\mathrm{MIN}=60.00$ (P. 819; 840; 872)

$\mathrm{MW}=66.10$

MED $=66.67$

MAX $=73.33$ (P. 835; 855)

\section{Häufigkeitsverteilung, MINMWMAX, 12-fach}

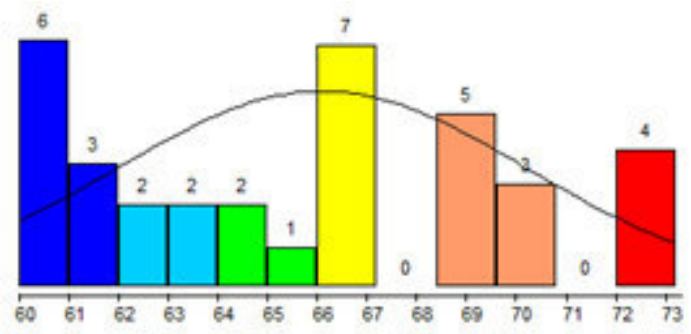

\section{ALI (1995-2008) - Campania}

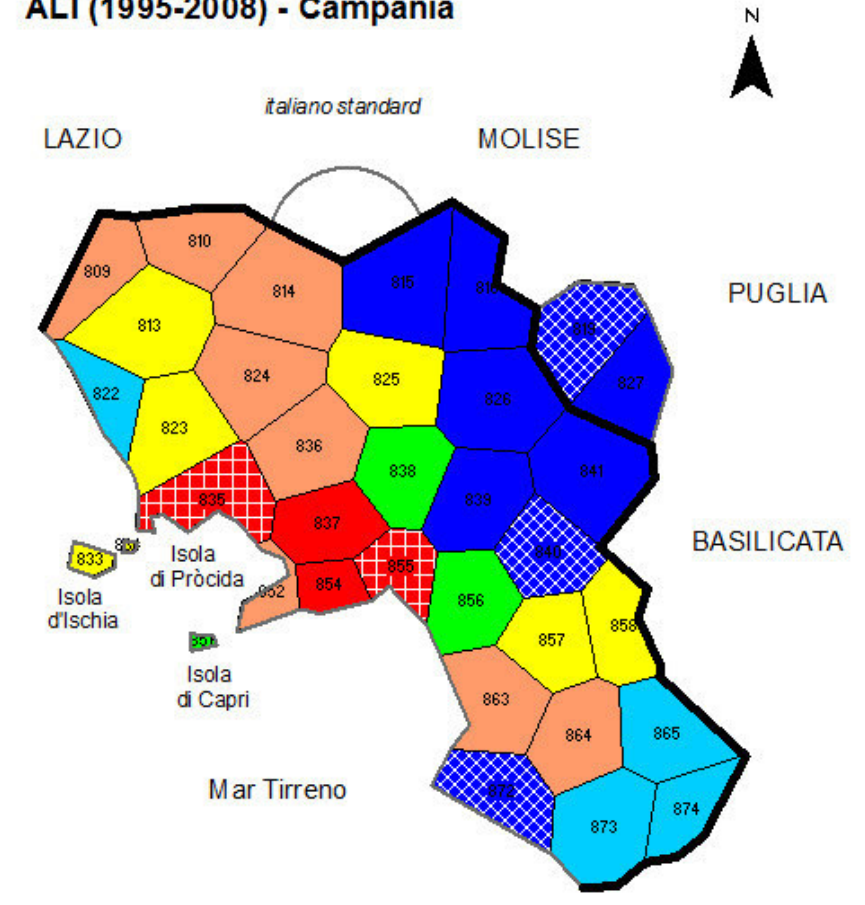

fec. S. Hajek

adiuv. H. Goebl et P. Smečka

adiuv. B. Castellazzi

carta di THIESSENHAAGNORONOI 35 punti d'inchiesta + italiano standard

-limite di regione

Karte A63. Kennwertsynopse der Maxima. ALI-Korpus, Lexikon (105 AK). N = 35, Messmoment RIW $j$.

\section{Legende, MINMWMAX, 6-fach}

[1] von 63.39 bis $66.19(n=5)$

[2] bis $68.99(n=4)$

[3] bis $71.79(n=7)$

[4] bis $73.75(n=7)$

[5] bis $75.71(n=5)$

[6] bis $77.68(n=7)$

Summe der Elemente: 35

$\mathrm{MIN}=63.39$ (P. 819)

$M W=71.79$

$M E D=72.32$

MAX $=77.68$ (P. 833; 854;855)

Häufigkeitsverteilung, MINMWMAX, 12-fach

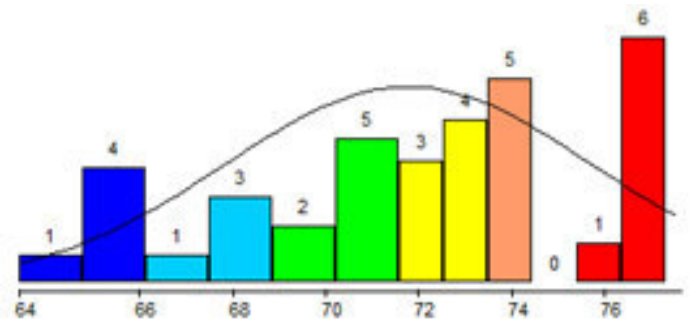

\section{Hajek (2014) - Campania}
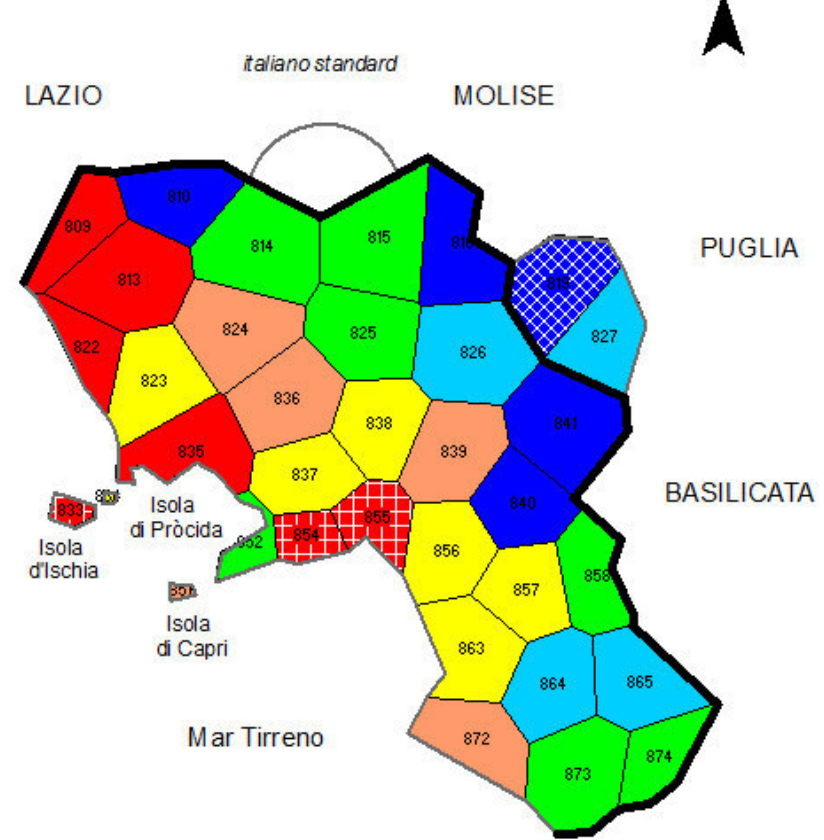

fec. S. Hajek

adiuv. H. Goebl et P. Smečka adiuv. B. Castellazzi a.d. 2013 carta di THIESSENHAAGNORONOI 35 punti d'inchiesta + italiano standard limite di regione

Karte A64. Kennwertsynopse der Maxima. Vergleichskorpus, Lexikon (112 AK). N = 35, Messmoment RIW . $_{j k}$ 
Legende, MINMWMAX, 6-fach

[1] von 55.81 bis $60.38(n=3)$

[2] bis $64.95(n=5)$

[3] bis $69.52(n=9)$

[4] bis $72.96(n=7)$

[5] bis $76.40(n=6)$

[6] bis $79.84(n=5)$

Summe der Elemente: 35

$M I N=55.81$ (P. 814)

$M W=69.52$

$\mathrm{MED}=69.77$

MAX $=79.84$ (P. 865; 873)

Häufigkeitsverteilung, MINMWMAX, 12-fach

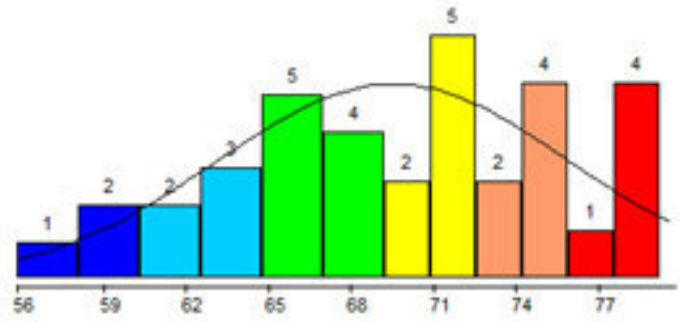

\section{ALI (1995-2008) - Campania}

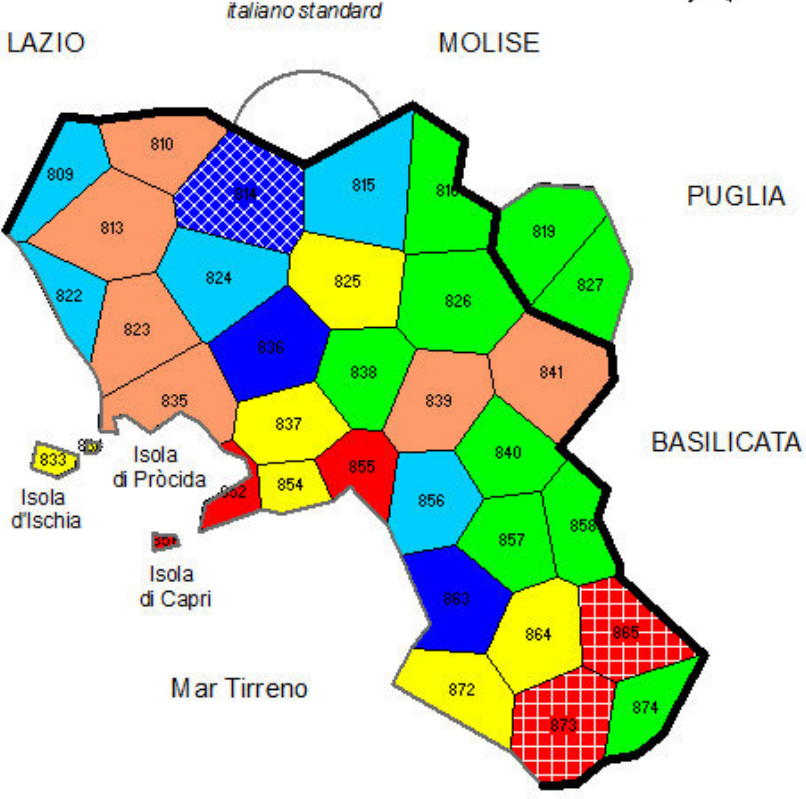

fec. S. Hajek

adiuv. H. Goebl et P. Smečka

adiuv. B. Castellazzi

ad 2013
$N$

PUGLIA

carta di THIESSENHAAGNORONOI 35 punti d'inchiesta + italiano standard - limite di regione

Karte A65. Kennwertsynopse der Maxima. ALI-Korpus, Konsonantismus (129 AK). N = 35, Messmoment RIW $j k$.

\section{Legende, MINMWMAX, 6-fach}

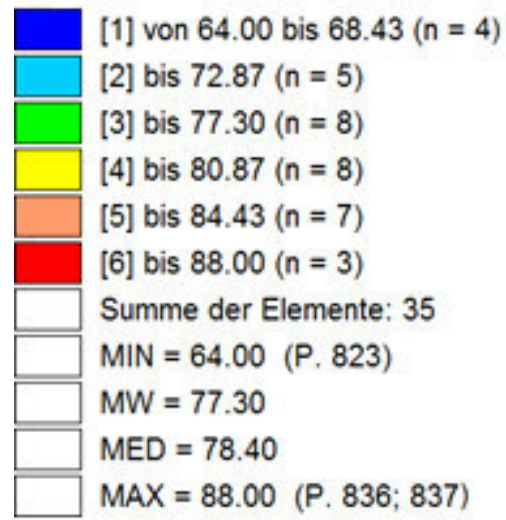

Häufigkeitsverteilung, MINMWMAX, 12-fach

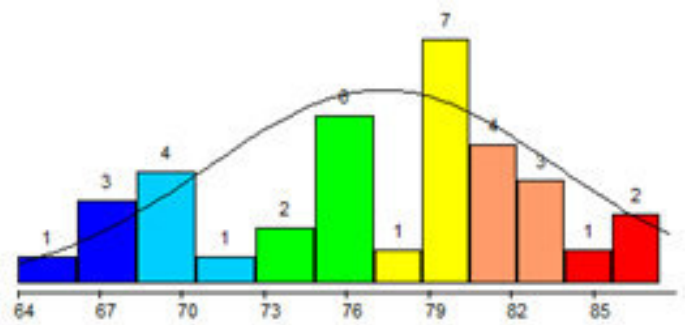

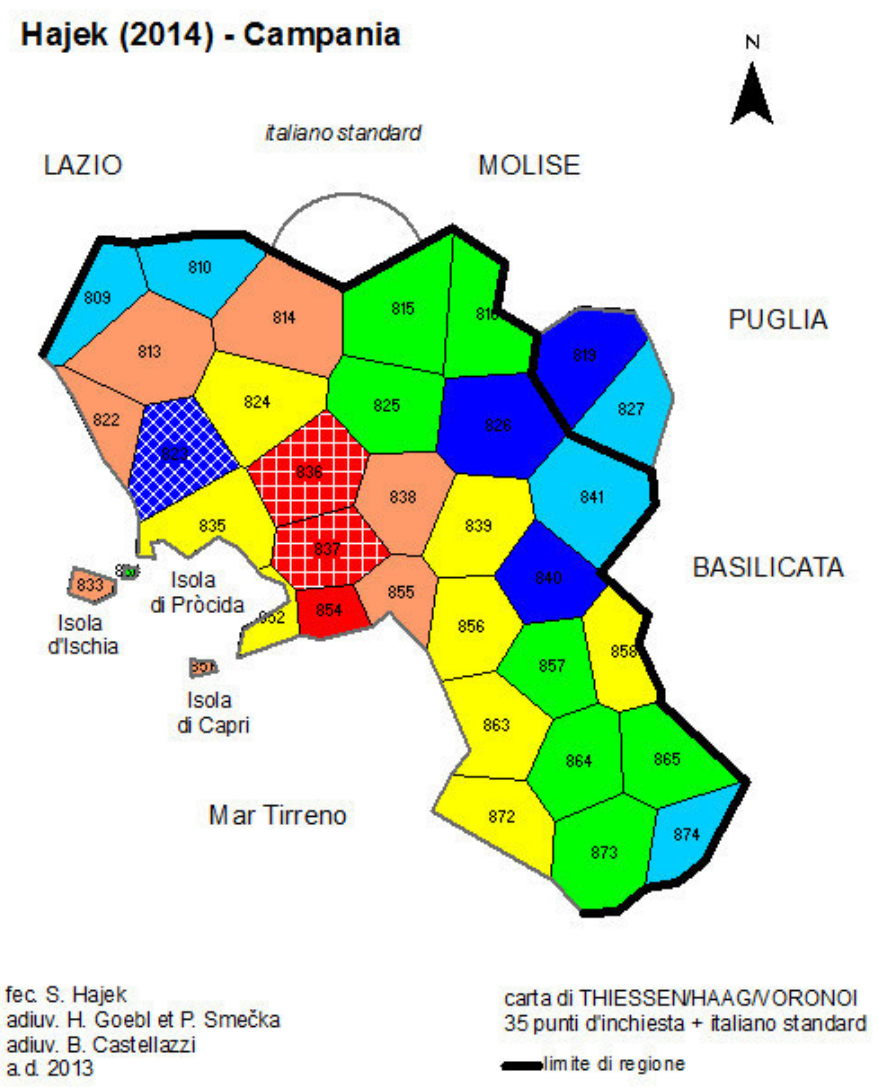

Karte A66. Kennwertsynopse der Maxima. Vergleichskorpus, Konsonantismus (125 AK). N = 35, Messmoment RIW M . 
Legende, MINMWMAX, 6-fach

\begin{tabular}{l} 
[1] von 43.90 bis $55.59(n=1)$ \\
{$[2]$ bis $67.27(n=2)$} \\
{$[3]$ bis $78.95(n=12)$} \\
{$[4]$ bis $83.53(n=8)$} \\
{$[5]$ bis $88.11(n=8)$} \\
{$[6]$ bis $92.68(n=4)$} \\
Summe der Elemente: 35 \\
MIN $=43.90 \quad(P .874)$ \\
MW $=78.95$ \\
MED $=80.49$ \\
\hline$\square M A X=92.68 \quad(P .825 ; 852)$
\end{tabular}

Häufigkeitsverteilung, MINMWMAX, 12-fach

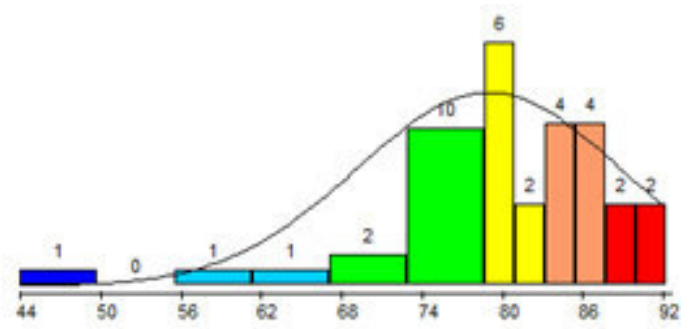

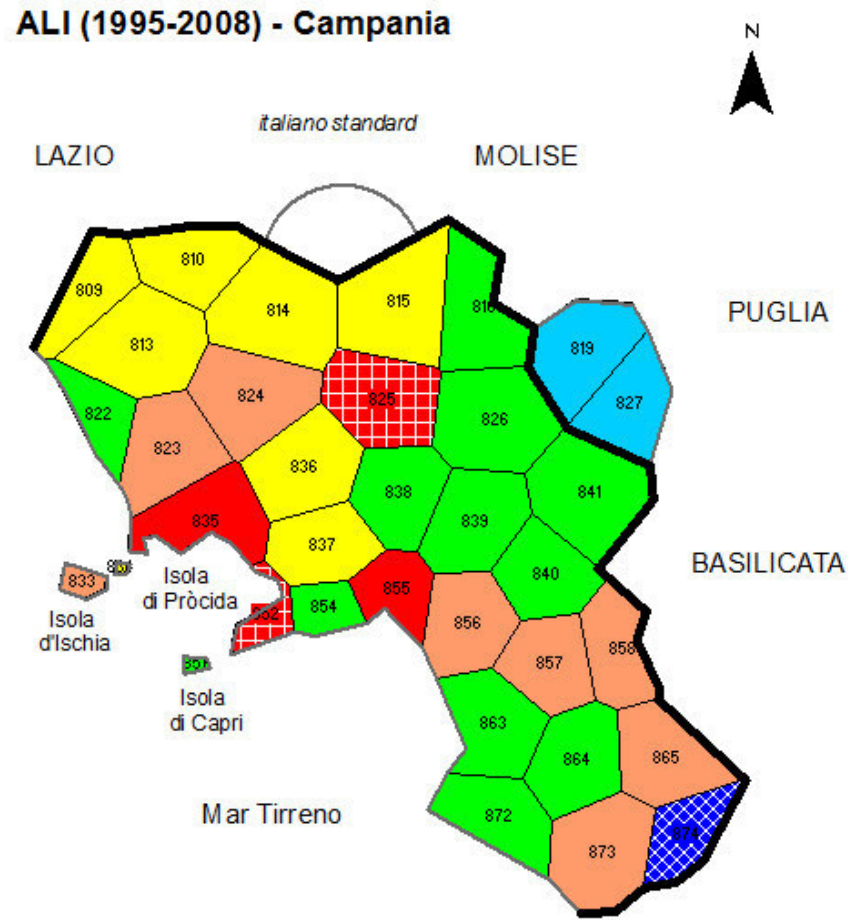

fec. S. Hajek

adiuv. H. Goebl et P. Smečka adiuv. B. Castellazzi

carta di THIESSEN/HAAGNORONOI 35 punti d'inchiesta + italiano standard -limite di regione

Karte A67. Kennwertsynopse der Maxima. ALI-Korpus, Vokalismus (41 AK). N = 35, Messmoment RIW H $_{j k}$

\section{Legende, MINMWMAX, 6-fach}

[1] von 54.17 bis $62.08(n=2)$

[2] bis $70.00(n=2)$

[3] bis $77.92(n=10)$

[4] bis $81.11(n=6)$

[5] bis $84.31(n=9)$

[6] bis $87.50(n=6)$

Summe der Elemente: 35

$M I N=54.17$ (P. 815; 874)

$M W=77.92$

$M E D=79.17$

MAX $=87.50$ (P. 833; 855; 856)

Häufigkeitsverteilung, MINMWMAX, 12-fach

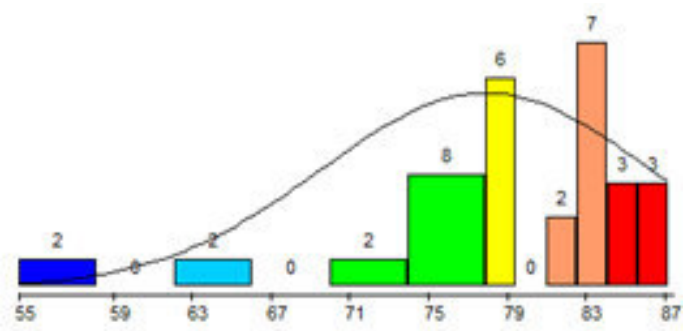

\section{Hajek (2014) - Campania}
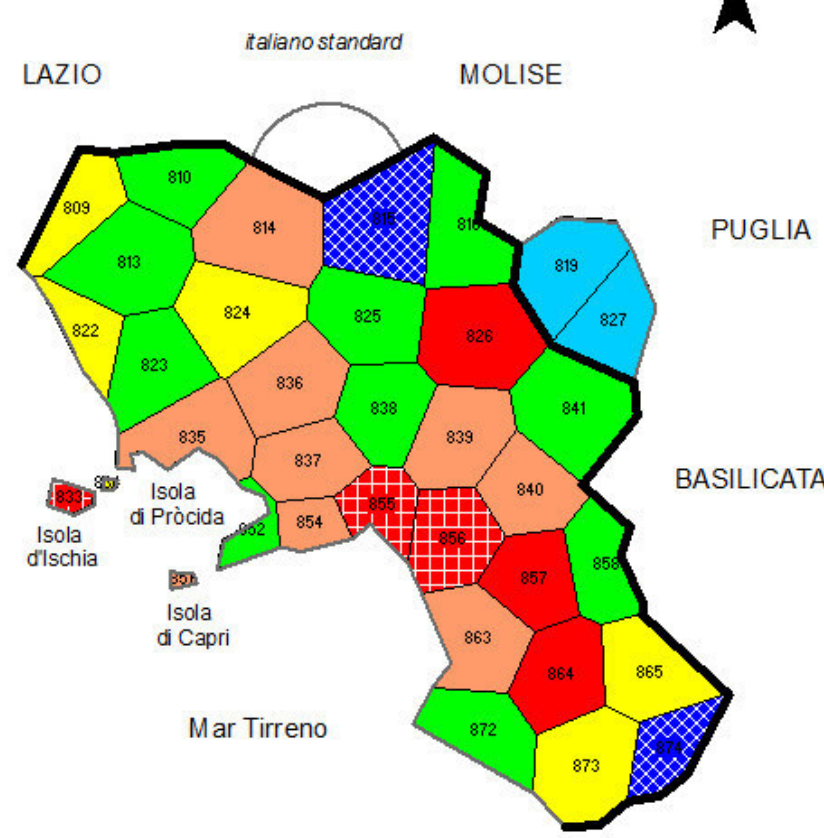

fec. S. Hajek

adiuv. $\mathrm{H}$. Goebl et $\mathrm{P}$. Smečka

adiuv. B. Castellazzi

a.d. 2013

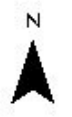

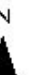

JGLIA

carta di THIESSENHAAGNORONOI 35 punti drinchiesta + italiano standard

limite di regione

Karte A68. Kennwertsynopse der Maxima. Vergleichskorpus, Vokalismus (48 AK). N = 35, Messmoment RIW jk $_{\text {. }}$ 
Legende, MINMWMAX, 6-fach

\begin{tabular}{l} 
[1] von -0.27 bis $-0.08(n=3)$ \\
{$[2]$ bis $0.10(n=5)$} \\
{$[3]$ bis $0.29(n=12)$} \\
{$[4]$ bis $0.63(n=12)$} \\
{$[5]$ bis $0.97(n=2)$} \\
{$[6]$ bis $1.31(n=1)$} \\
Summe der Elemente: 35 \\
\hline$\square$ MIN $=-0.27 \quad(P .824)$ \\
\hline$\square$ MW $=0.29$ \\
MED $=0.29$ \\
\hline$\square M A X=1.31 \quad(P .874)$
\end{tabular}

Häufigkeitsverteilung, MINMWMAX, 12-fach

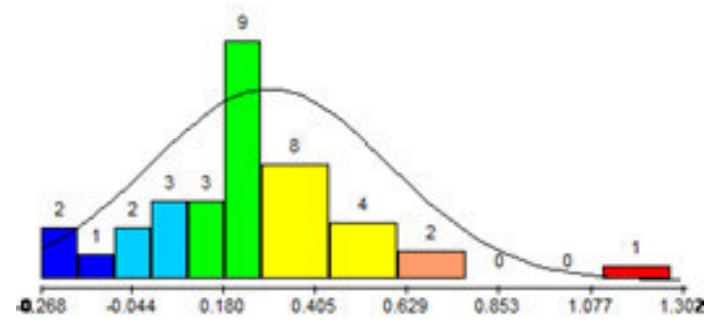

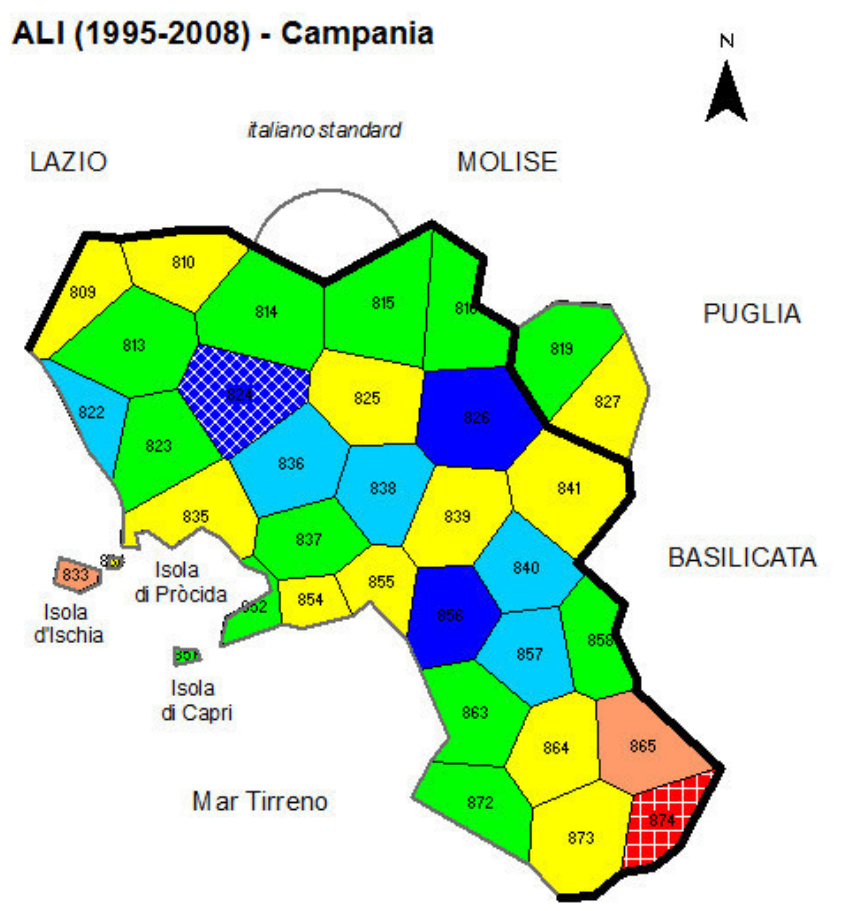

fec. S. Hajek

adiuv. H. Goebl et P. Smečka adiuv. B. Castellazzi

carta di THIESSENHAAGNORONOI 35 punti d'inchiesta + italiano standard limite di regione

Karte A69. Kennwertsynopse der Schiefewerte. ALI-Korpus, Totalkorpus (275 AK). N = 35, Messmoment RIW . $_{j k}$

\section{Legende, MINMWMAX, 6-fach}

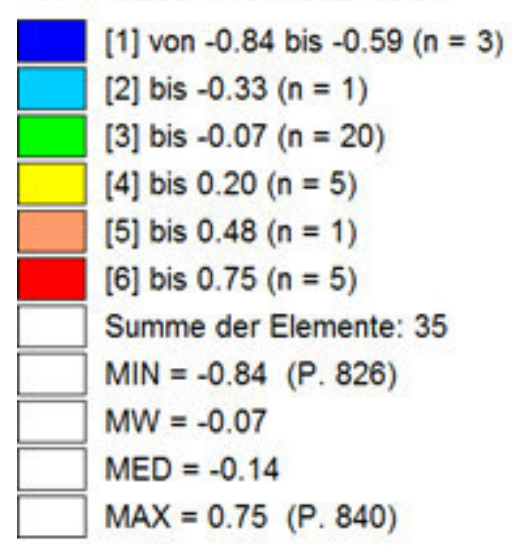

Häufigkeitsverteilung, MINMWMAX, 12-fach

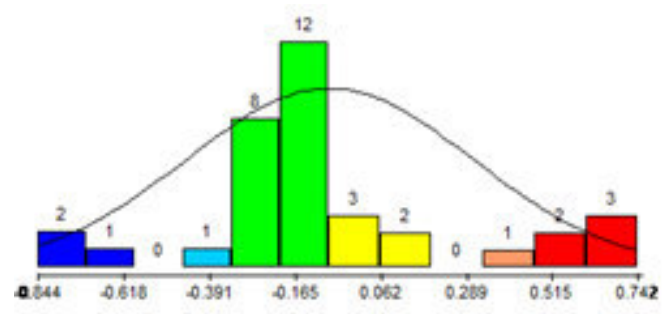

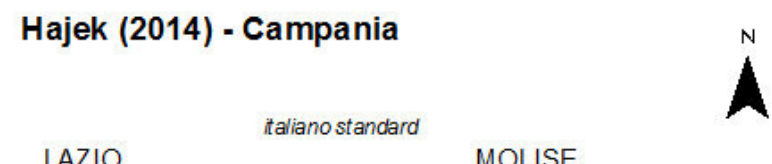

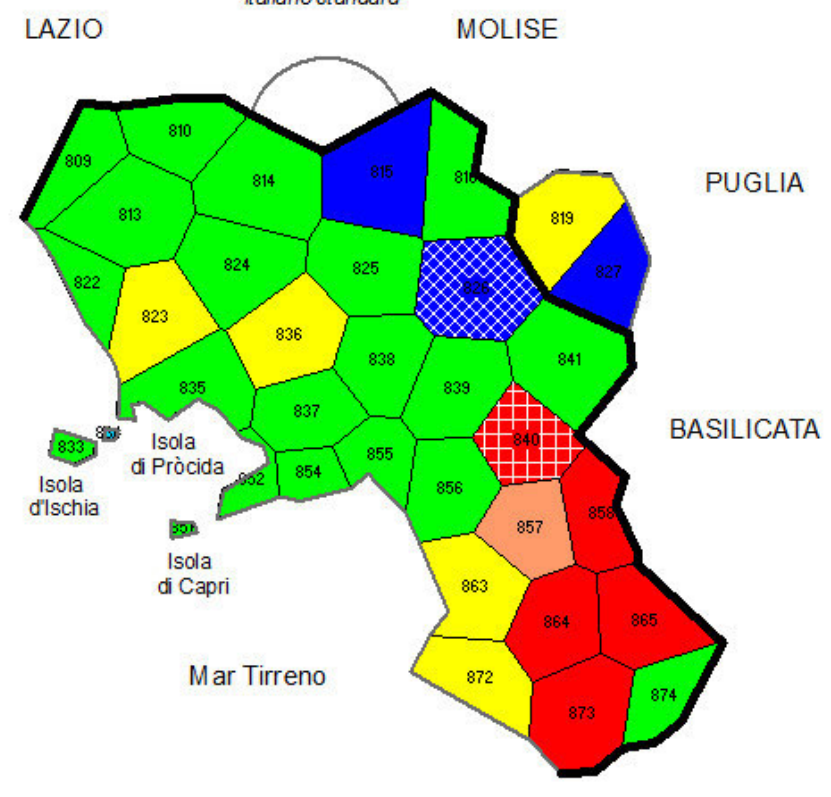

fec. S. Hajek a.d 2013

Karte A70. Kennwertsynopse der Schiefewerte. Vergleichskorpus, Totalkorpus (285 AK). N = 35, Messmoment RIW $j k$. 
Legende, MINMWMAX, 6-fach

[1] von -0.14 bis $0.02(n=3)$

[2] bis $0.17(n=8)$

[3] bis $0.33(n=10)$

[4] bis $0.61(n=8)$

[5] bis $0.89(n=4)$

[6] bis $1.17(n=2)$

Summe der Elemente: 35

$\mathrm{MIN}=-0.14$ (P. 856)

$\mathrm{MW}=0.33$

MED $=0.31$

$\operatorname{MAX}=1.17($ P. 874)

Häufigkeitsverteilung, MINMWMAX, 12-fach

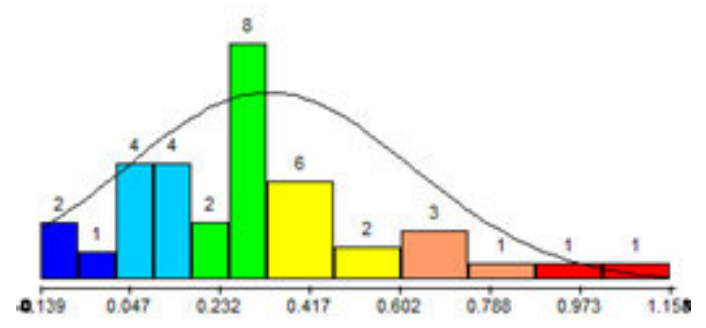

\section{ALI (1995-2008) - Campania}

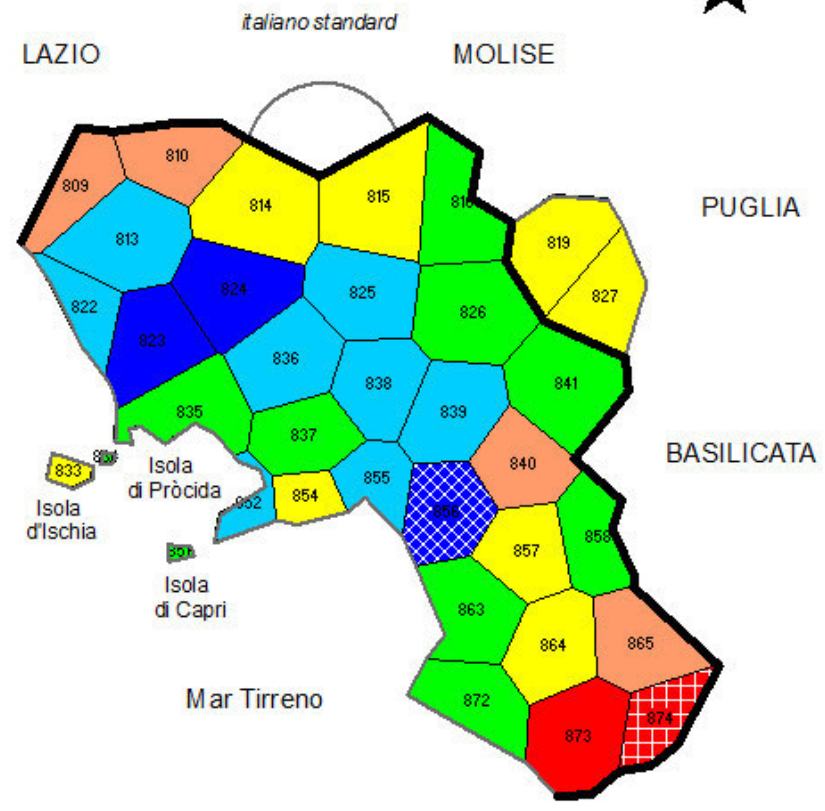

fec. S. Hajek

adiuv. $H$. Goebl et $P$. Smečka

adiuv. B. Castellazzi

a.d. 2013

carta di THIESSEN/HAAGNORONO 35 punti dinchiesta + italiano standard limite di regione

Karte A71. Kennwertsynopse der Schiefewerte. ALI-Korpus, Lexikon (105 AK). N = 35, Messmoment RIW $j k$.

\section{Legende, MINMWMAX, 6-fach}

[1] von -0.74 bis $-0.56(n=4)$

[2] bis $-0.38(n=5)$

[3] bis $-0.21(n=7)$

[4] bis $-0.02(n=11)$

[5] bis $0.17(n=5)$

[6] bis $0.35(n=3)$

Summe der Elemente: 35

$\mathrm{MIN}=-0.74$ (P. 826)

$\mathrm{MW}=-0.21$

MED $=-0.14$

$\operatorname{MAX}=0.35$ (P. 873)

Häufigkeitsverteilung, MINMWMAX, 12-fach

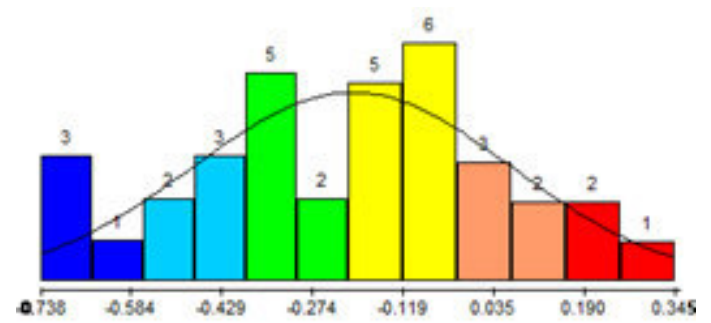

Hajek (2014) - Campania

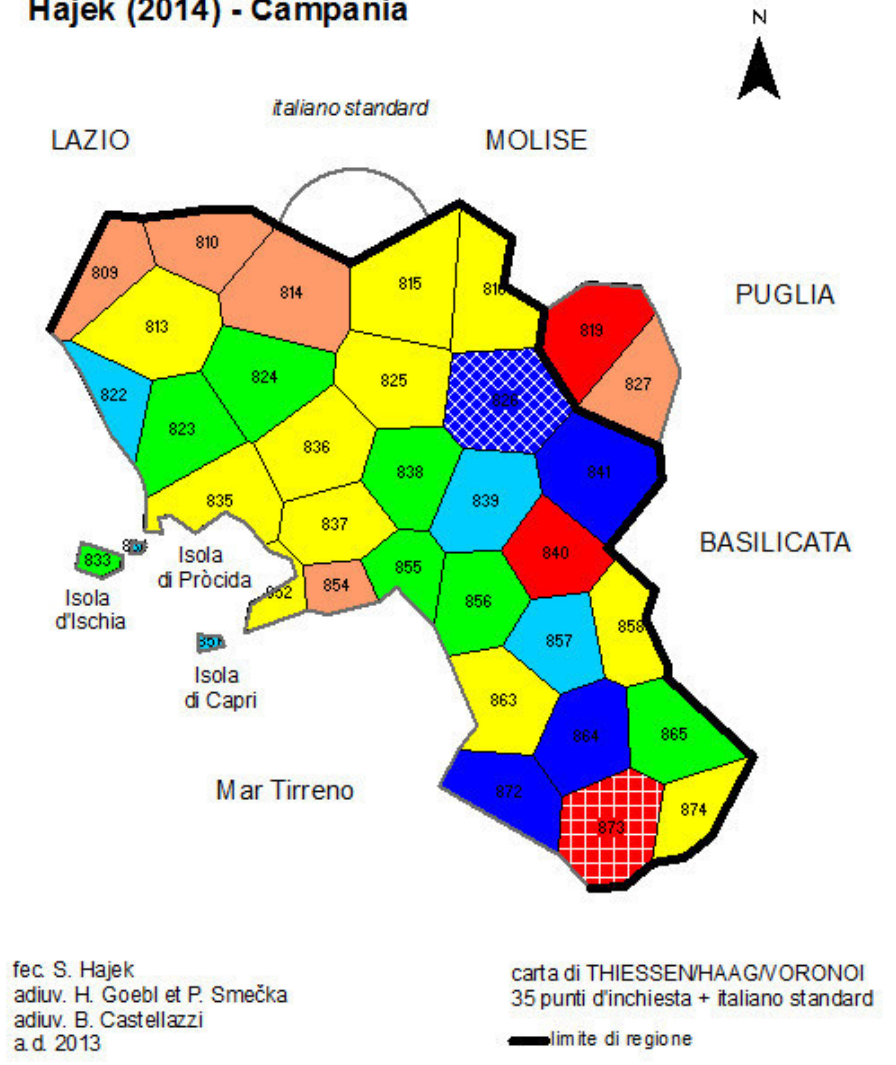

Karte A72. Kennwertsynopse der Schiefewerte. Vergleichskorpus, Lexikon (112 AK). N = 35, Messmoment RIW $j k$. 
Legende, MINMWMAX, 6-fach

\begin{tabular}{l} 
[1] von -0.31 bis $-0.13(n=4)$ \\
{$[2]$ bis $0.05(n=8)$} \\
{$[3]$ bis $0.23(n=7)$} \\
{$[4]$ bis $0.44(n=6)$} \\
{$[5]$ bis $0.64(n=6)$} \\
{$[6]$ bis $0.85(n=4)$} \\
Summe der Elemente: 35 \\
MIN $=-0.31 \quad(P .824)$ \\
MW $=0.23$ \\
MED $=0.16$ \\
\hline$\square M A X=0.85 \quad(P .865)$
\end{tabular}

Häufigkeitsverteilung, MINMWMAX, 12-fach

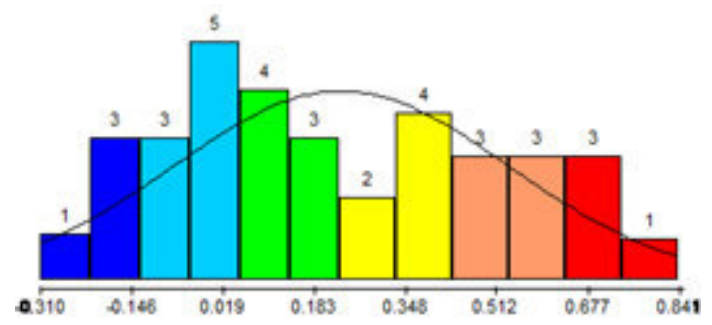

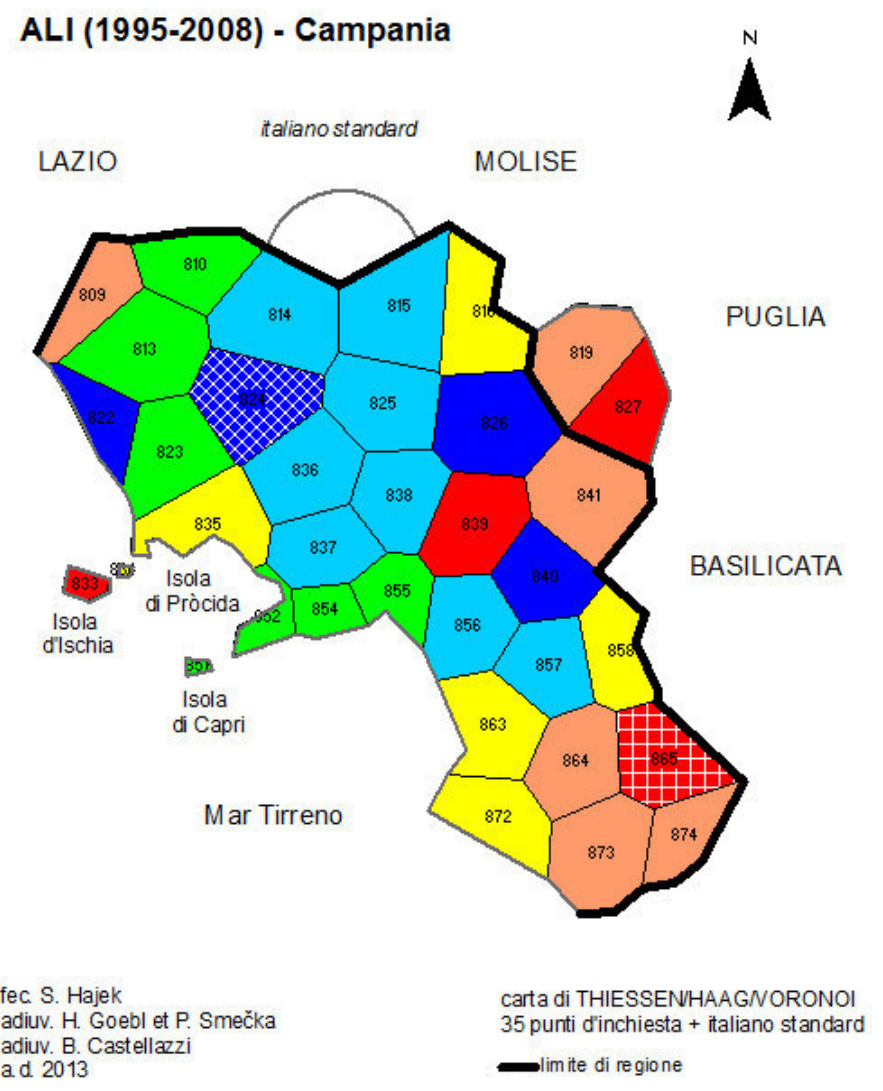

Karte A73. Kennwertsynopse der Schiefewerte. ALI-Korpus, Konsonantismus (129 AK). N = 35, Messmoment RIW $j k$.

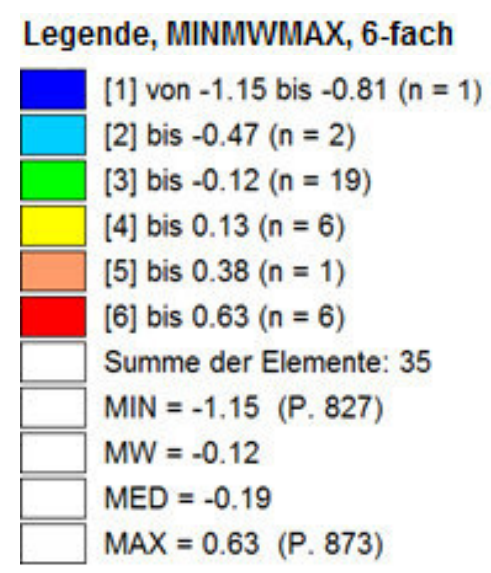

Häufigkeitsverteilung, MINMWMAX, 12-fach

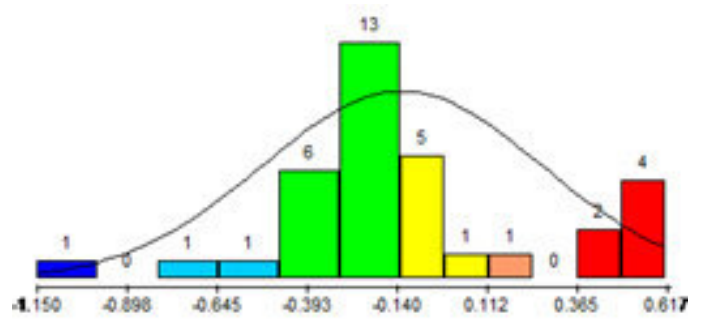

\section{Hajek (2014) - Campania}

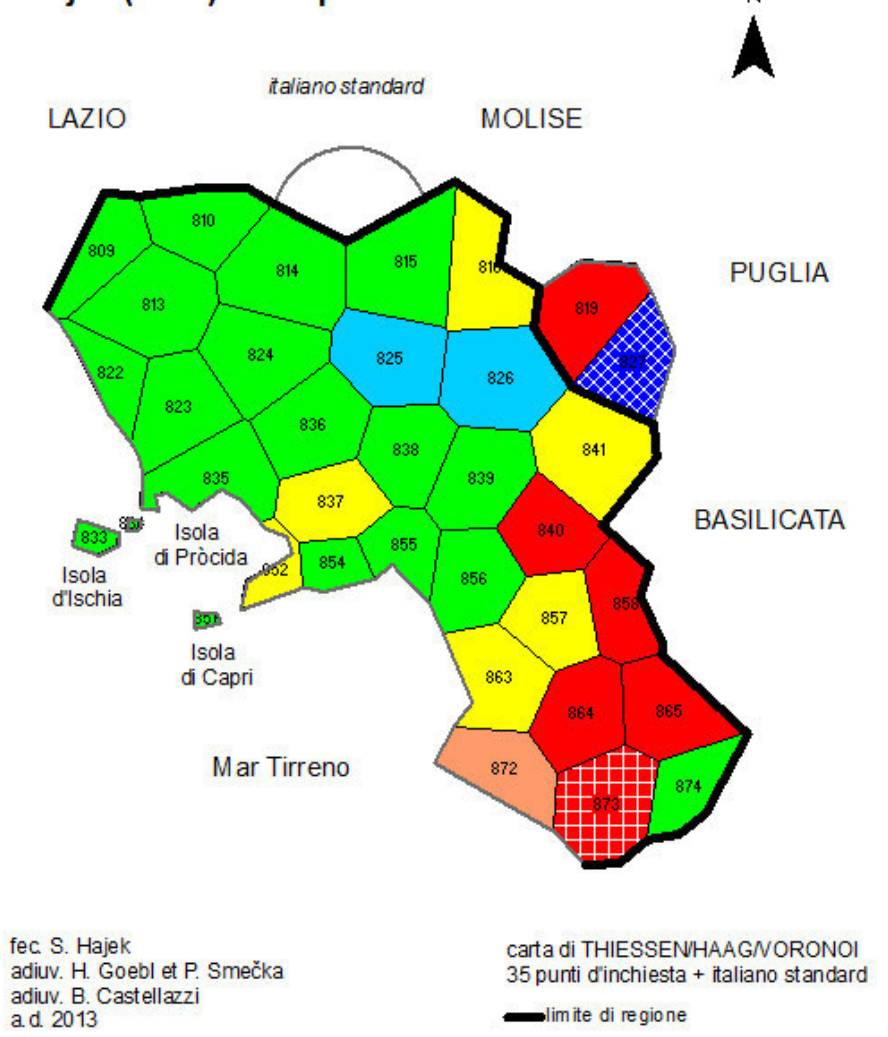

Karte A74. Kennwertsynopse der Schiefewerte. Vergleichskorpus, Konsonantismus (125 AK). N = 35, Messmoment $\mathrm{RIW}_{j k}$. 
Legende, MINMWMAX, 6-fach

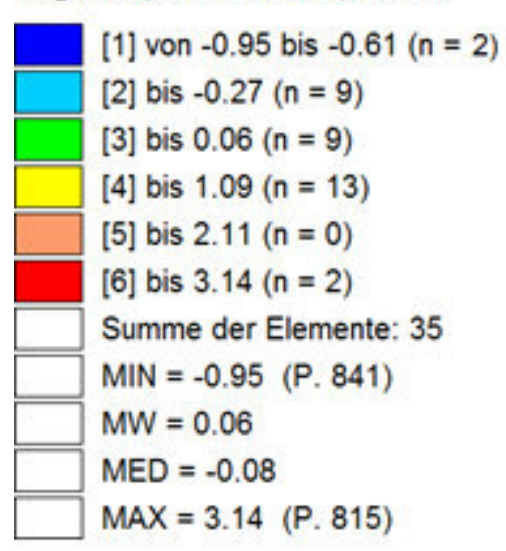

Häufigkeitsverteilung, MINMWMAX, 12-fach

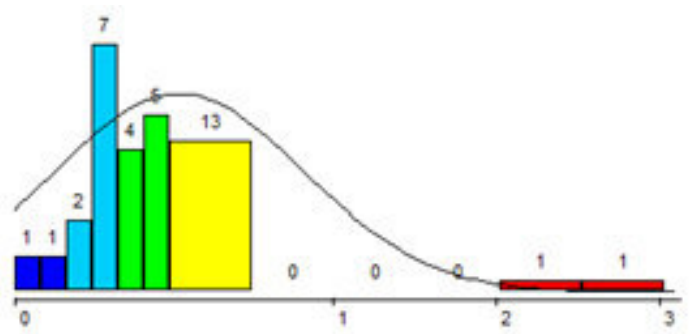

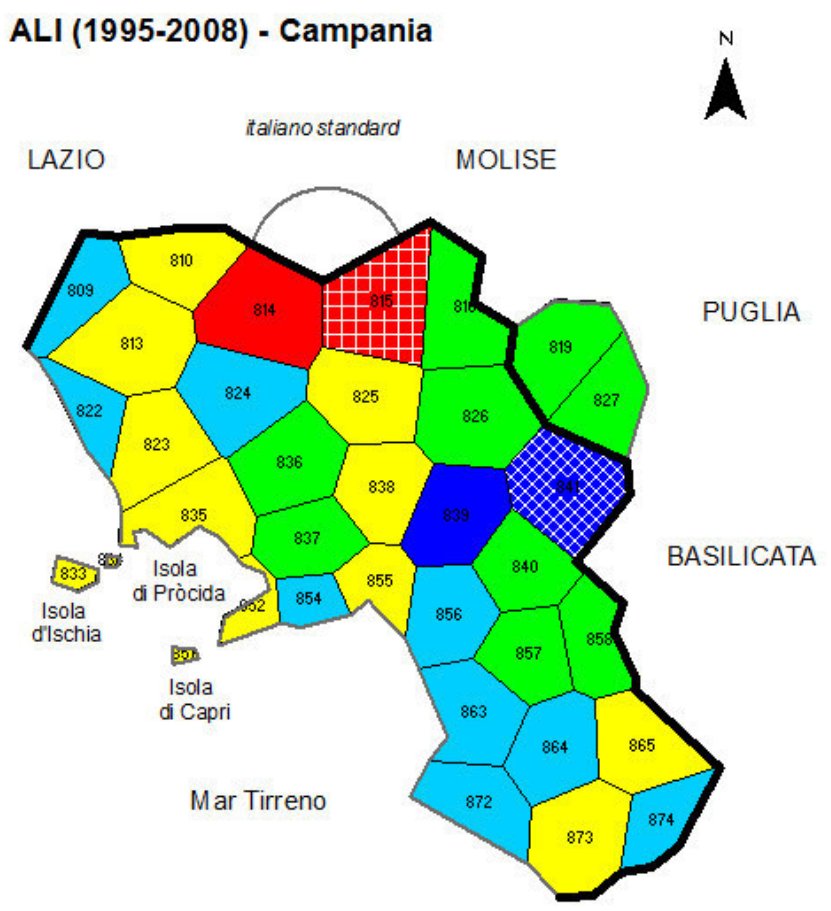

fec. S. Hajek

carta di THIESSENHAAGNORONOI a.d. 2013

Karte A75. Kennwertsynopse der Schiefewerte. ALI-Korpus, Vokalismus (41 AK). N = 35, Messmoment RIW ${ }_{j k}$.

\section{Legende, MINMWMAX, 6-fach}

[1] von -1.75 bis $-1.50(n=5)$

[2] bis $-1.25(n=5)$

[3] bis $-1.01(n=7)$

[4] bis $-0.53(n=16)$

[5] bis $-0.06(n=1)$

[6] bis $0.42(n=1)$

Summe der Elemente: 35

$\mathrm{MIN}=-1.75$ (P. 825)

$M W=-1.01$

MED $=-1.00$

$\operatorname{MAX}=0.42$ (P. 874)

\section{Häufigkeitsverteilung, MINMWMAX, 12-fach}

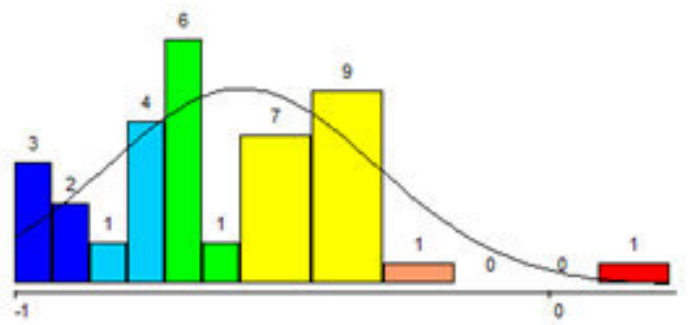

\section{Hajek (2014) - Campania}
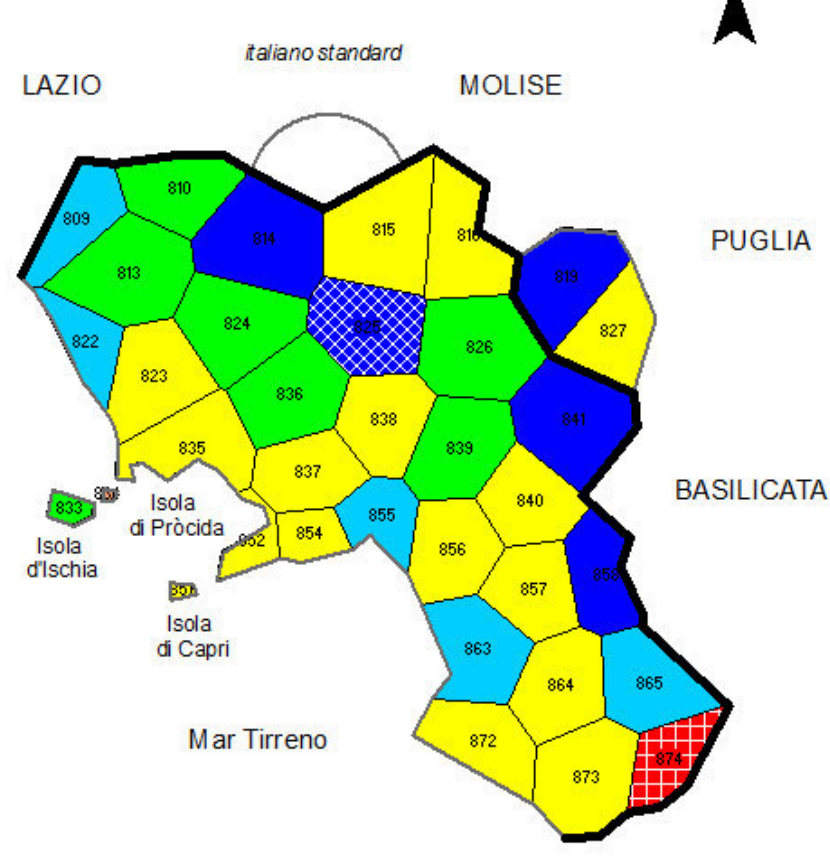

fec. S. Hajek

adiuv. $\mathrm{H}$. Goebl et $\mathrm{P}$. Smečka adiuv. B. Castellazzi

carta di THIESSENHAAGNORONOI 35 punti dinchiesta + italiano standard limite di regione

Karte A76. Kennwertsynopse der Schiefewerte. Vergleichskorpus, Vokalismus (48 AK). N = 35, Messmoment RIW $j k$. 
Legende, MINMWMAX, 6-fach

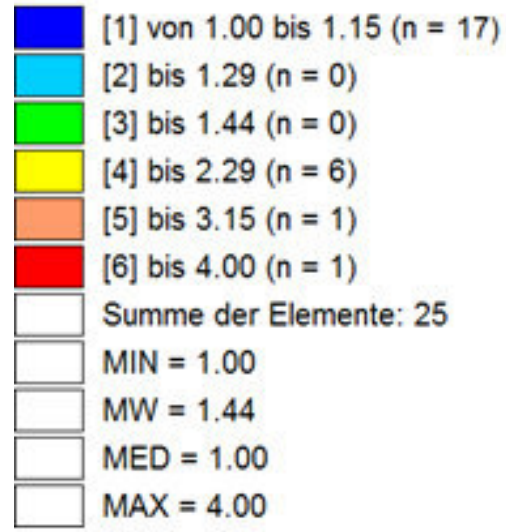

Häufigkeitsverteilung, MINMWMAX, 12-fach

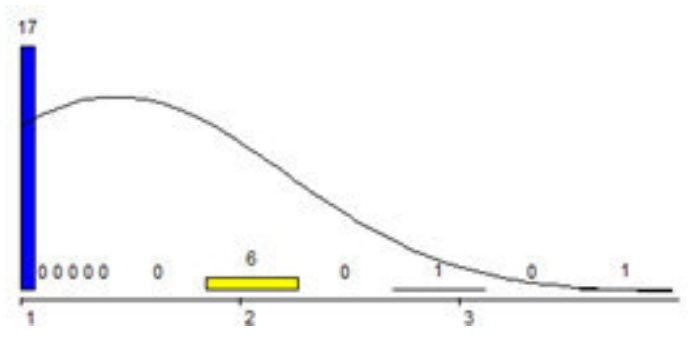

\section{ALI (1995-2008) - Campania}

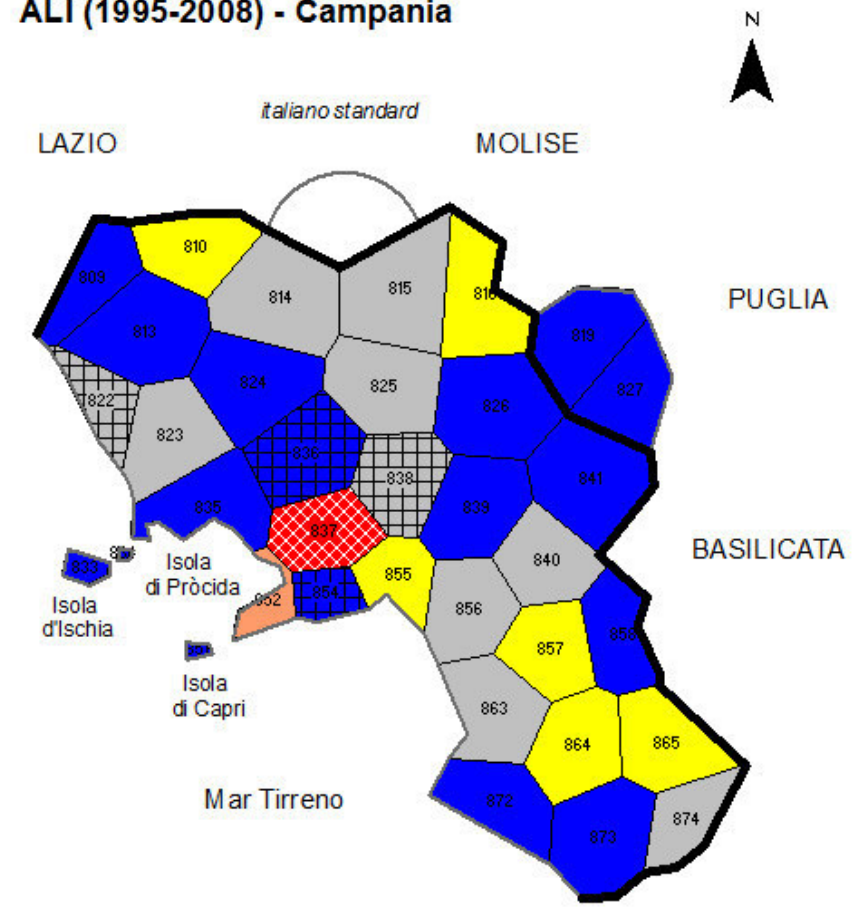

fec. S. Hajek

adiuv. $\mathrm{H}$. Goebl et $\mathrm{P}$. Smečka adiuv. B. Castellazzi a.d. 2013 carta di THIESSENHAAGNORONOI 35 punti d'inchiesta + italiano standard limite di regione

Karte A77. Antipodenkarte der Maxima. ALI-Korpus, Totalkorpus (275 AK). N = 35, Messmoment RIW $_{j k}$.

Legende, MINMWMAX, 6-fach
[1] von 1.00 bis $1.48(n=4)$
[2] bis $1.96(n=0)$
[3] bis $2.44(n=9)$
[4] bis $4.63(n=4)$
[5] bis $6.81(n=0)$
[6] bis $9.00(n=1)$
Summe der Elemente: 18
$\mathrm{MIN}=1.00$
$M W=2.44$
MED $=2.00$
MAX $=9.00$

Häufigkeitsverteilung, MINMWMAX, 12-fach

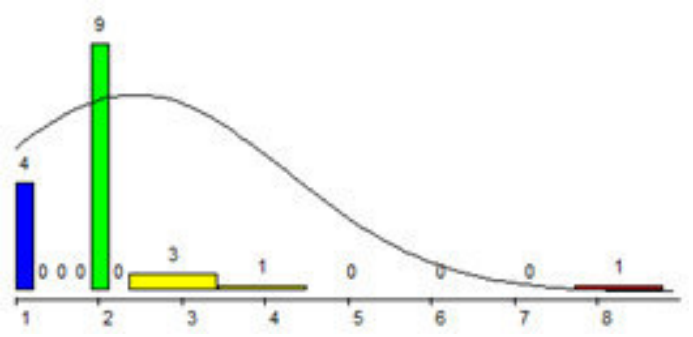

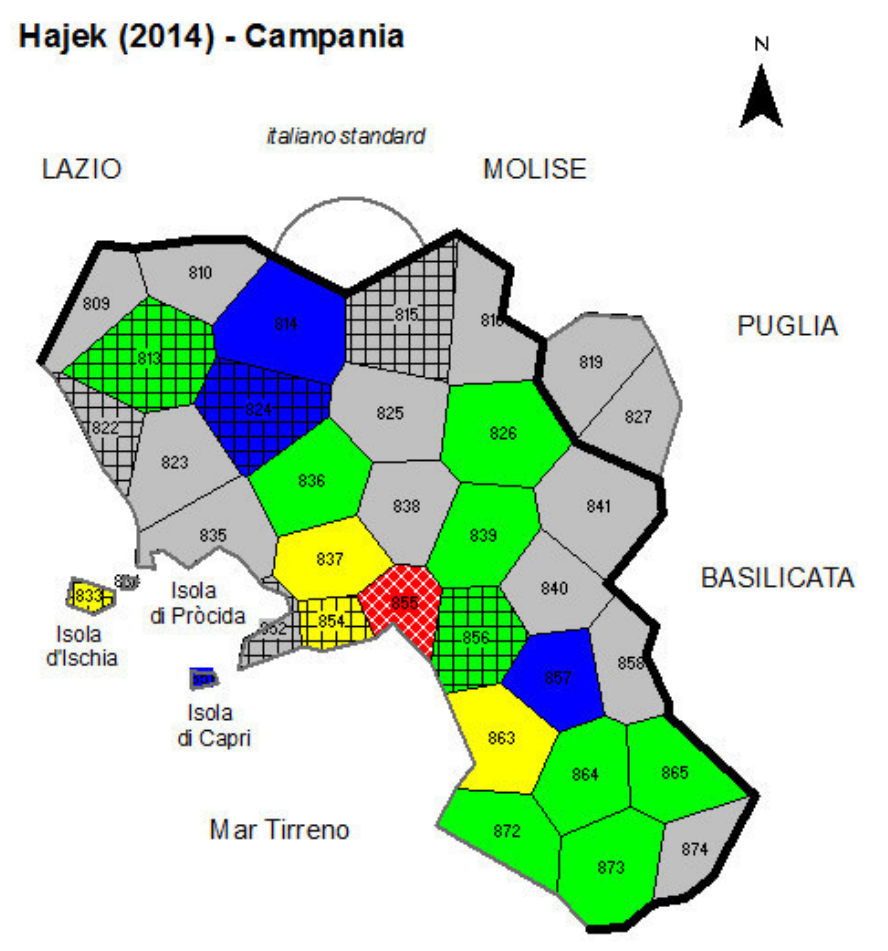

fec S. Hajek

adiuv. H. Goebl et P. Smečka adiuv. B. Castellazzi

carta di THIESSENHAAGNORONOI 35 punti d'inchiesta + italiano standard -limite di regione

Karte A78. Antipodenkarte der Maxima. Vergleichskorpus, Totalkorpus (285 AK). N = 35, Messmoment RIW ${ }_{j k}$. 
Legende, MINMWMAX, 6-fach
[1] von 1.00 bis $1.60(n=6)$
[2] bis $2.19(n=0)$
[3] bis $2.79(n=0)$
[4] bis $4.52(n=6)$
[5] bis $6.26(n=1)$
[6] bis $8.00(n=1)$
Summe der Elemente: 14
$\mathrm{MIN}=1.00$
$\mathrm{MW}=2.79$
MED $=3.00$
MAX $=8.00$

Häufigkeitsverteilung, MINMWMAX, 12-fach

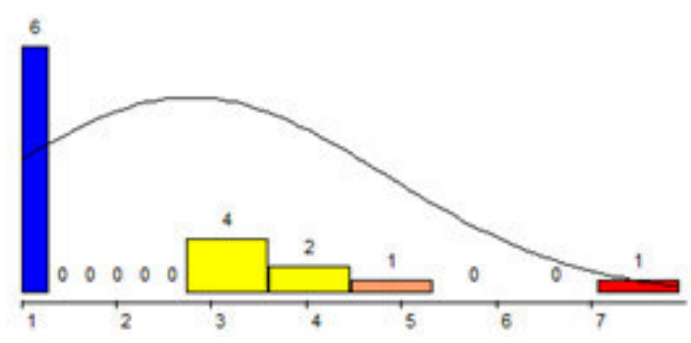

\section{ALI (1995-2008) - Campania}

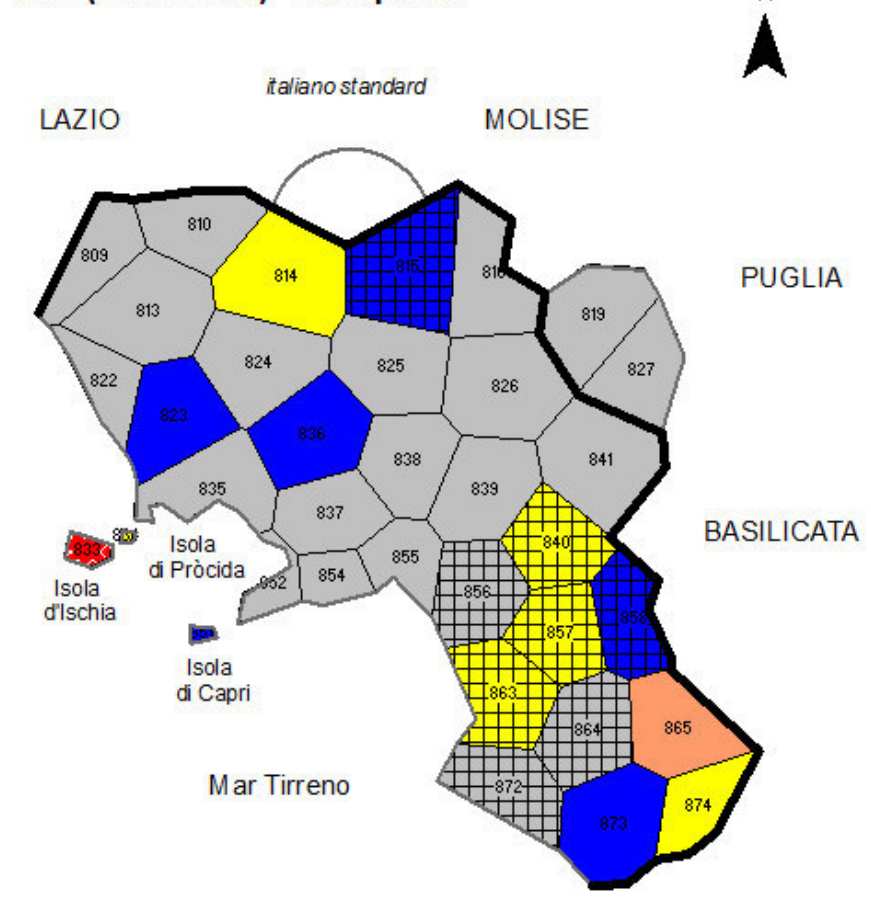

fec. S. Hajek

adiuv. H. Goebl et P. Smečka

adiuv. B. Castellazzi

carta di THIESSENHAAGNORONOI 35 punti d'inchiesta + italiano standard a.d. 2013

Karte A79. Antipodenkarte der Minima. ALI-Korpus, Totalkorpus (275 AK). N = 35, Messmoment RIW $j k$.

Legende, MINMWMAX, 6-fach

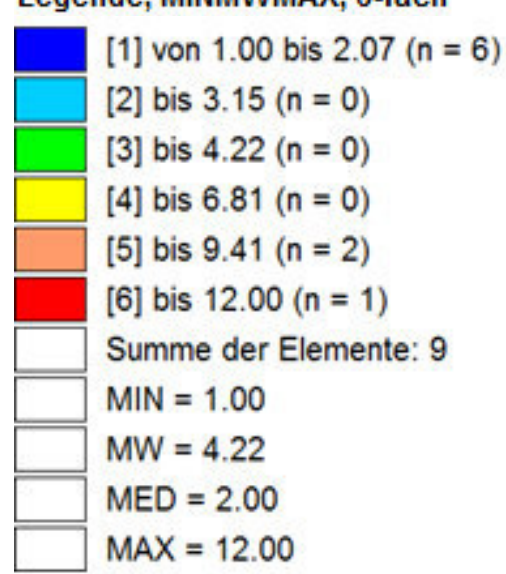

Häufigkeitsverteilung, MINMWMAX, 12-fach

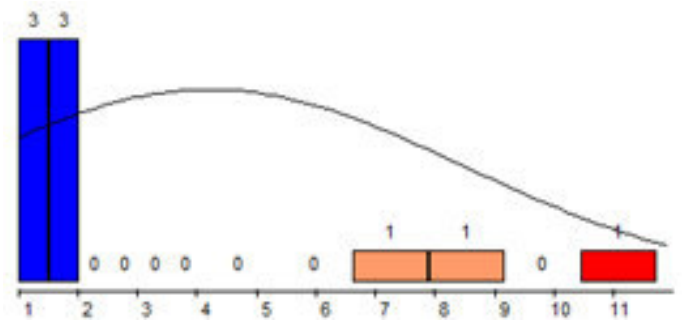

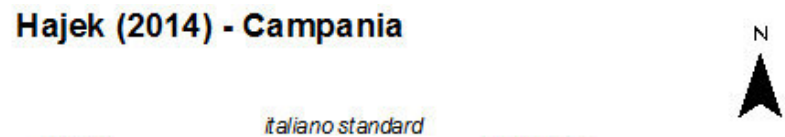

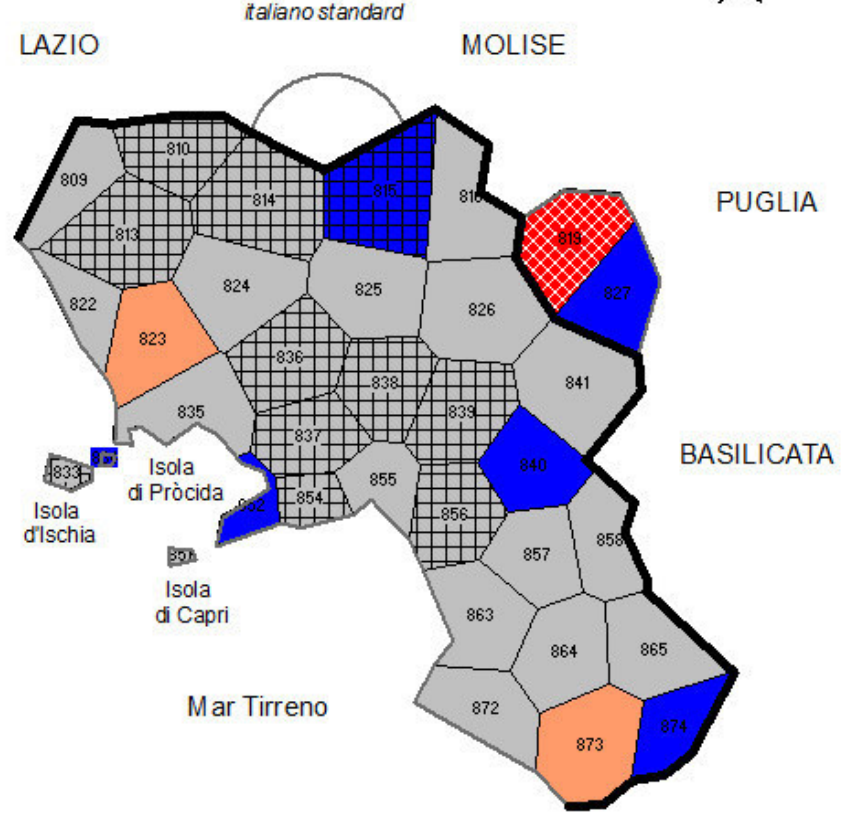

fec. S. Hajek

adiuv. $\mathrm{H}$. Goebl et $\mathrm{P}$. Smečka adiuv. B. Castellazzi a.d. 2013 carta di THIESSENHAAGNORONOI 35 punti d'inchiesta + italiano standard limite di regione

Karte A80. Antipodenkarte der Minima. Vergleichskorpus, Totalkorpus (285 AK). N = 35, Messmoment RIW M $_{\text {. }}$ 
Legende, MINMWMAX, 6-fach

\begin{tabular}{l} 
[1] von 1.00 bis $1.23(n=12)$ \\
{$[2]$ bis $1.45(n=0)$} \\
{$[3]$ bis $1.68(n=0)$} \\
{$[4]$ bis $2.45(n=10)$} \\
{$[5]$ bis $3.23(n=2)$} \\
{$[6]$ bis $4.00(n=1)$} \\
Summe der Elemente: 25 \\
MIN $=1.00$ \\
\hline$\square$ MW $=1.68$ \\
\hline$\square$ \\
\hline$\square D=2.00$ \\
\hline$\square$
\end{tabular}

Häufigkeitsverteilung, MINMWMAX, 12-fach

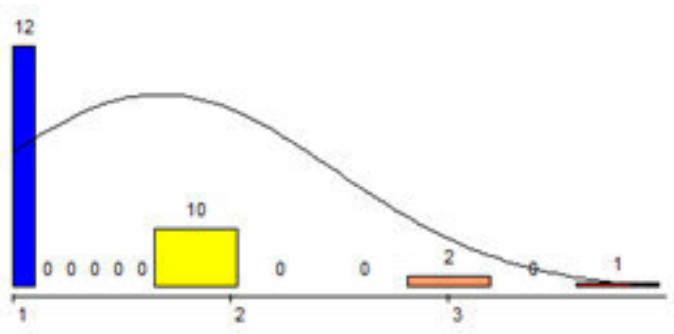

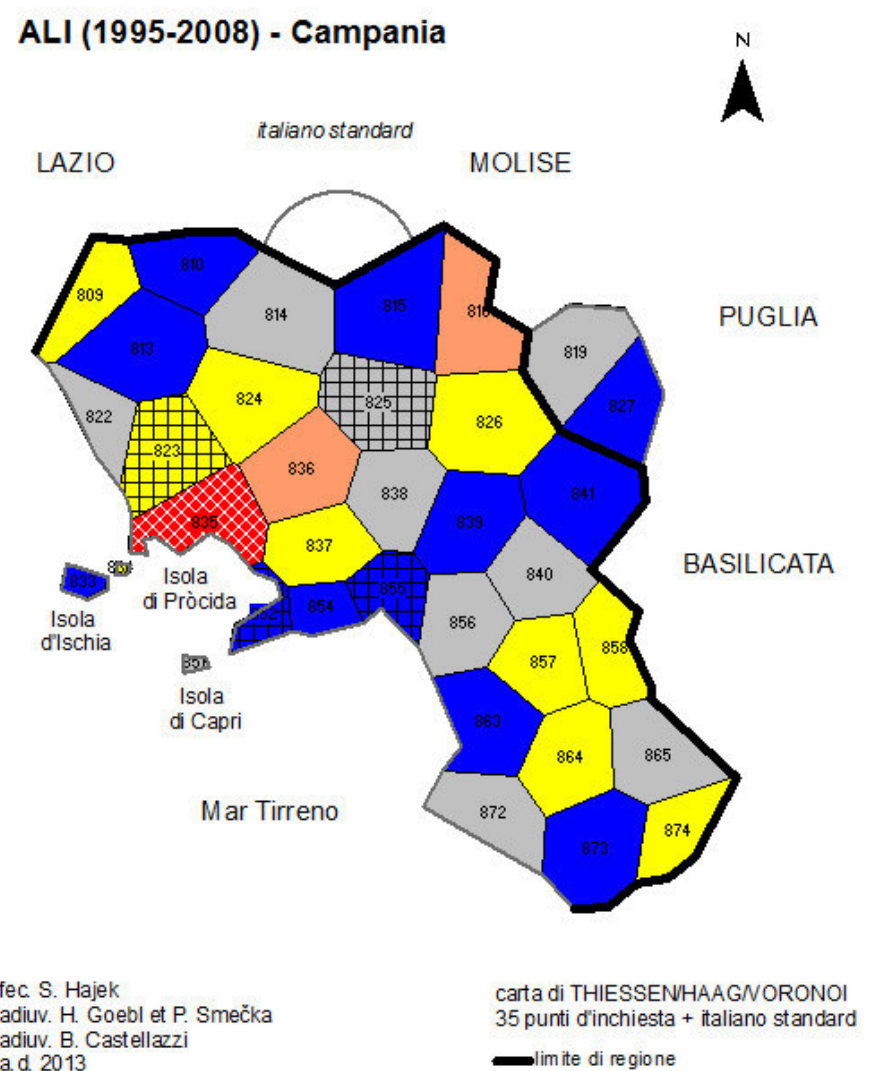

Karte A81. Antipodenkarte der Maxima. ALI-Korpus, Lexikon (105 AK). N = 35, Messmoment RIW $j k$.

\section{Legende, MINMWMAX, 6-fach}

\begin{tabular}{l} 
[1] von 1.00 bis $1.37(n=9)$ \\
{$[2]$ bis $1.74(n=0)$} \\
{$[3]$ bis $2.11(n=4)$} \\
{$[4]$ bis $3.07(n=3)$} \\
{$[5]$ bis $4.04(n=1)$} \\
{$[6]$ bis $5.00(n=2)$} \\
Summe der Elemente: 19 \\
MIN $=1.00$ \\
MW $=2.11$ \\
\hline$\square$ MED $=2.00$ \\
MAX $=5.00$
\end{tabular}

Häufigkeitsverteilung, MINMWMAX, 12-fach

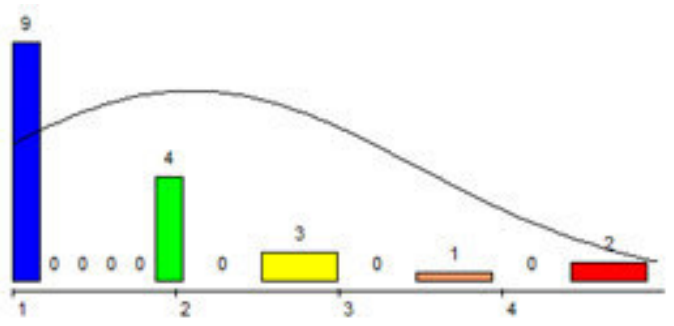

\section{Hajek (2014) - Campania}

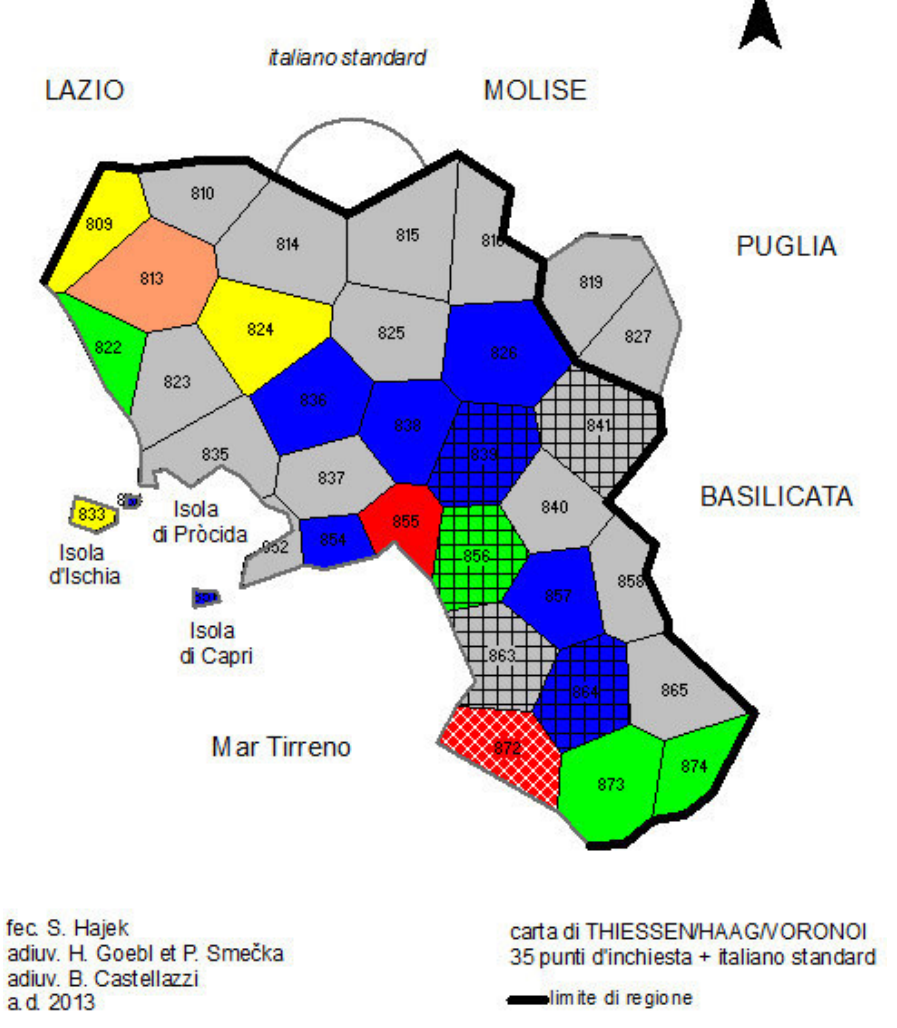

Karte A82. Antipodenkarte der Maxima. Vergleichskorpus, Lexikon (112 AK). N = 35, Messmoment RIW $j$. 
Legende, MINMWMAX, 6-fach

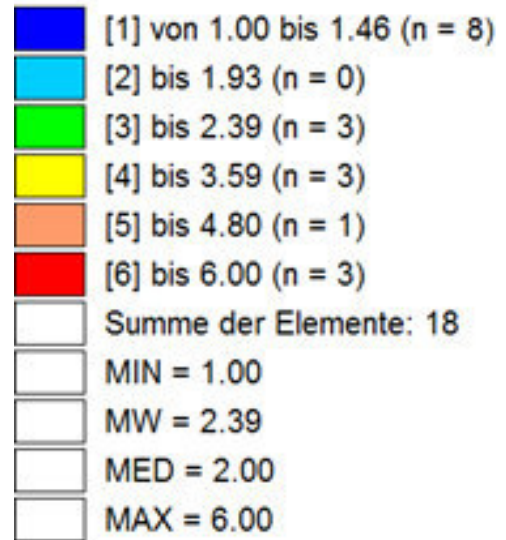

Häufigkeitsverteilung, MINMWMAX, 12-fach

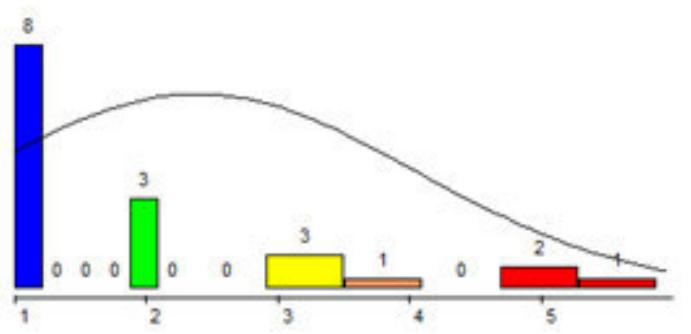

\section{ALI (1995-2008) - Campania}

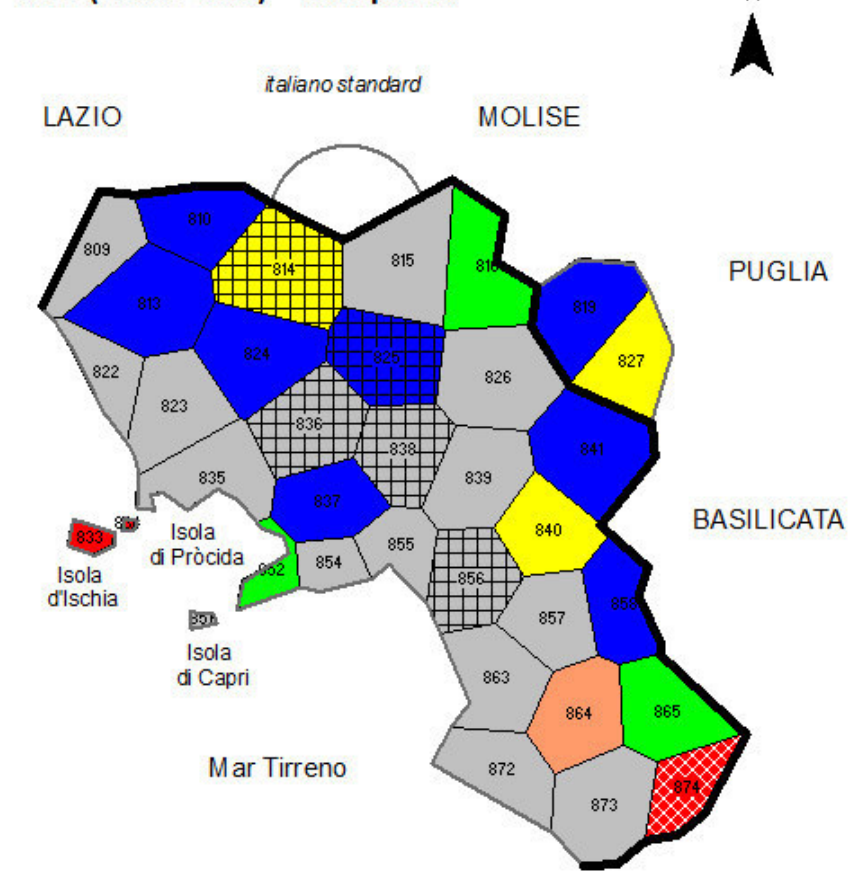

fec. S. Hajek

adiuv. H. Goebl et P. Smečka

adiuv. B. Castellazzi

carta di THIESSENHAAGNORONOI 35 punti d'inchiesta + italiano standard limite di regione

Karte A83. Antipodenkarte der Minima. ALI-Korpus, Lexikon (105 AK). N = 35, Messmoment RIW $j k$.

\section{Legende, MINMWMAX, 6-fach}

$$
\begin{aligned}
& \text { [1] von } 1.00 \text { bis } 2.03(n=2) \\
& \text { [2] bis } 3.07(n=4) \\
& \text { [3] bis } 4.10(n=1) \\
& \text { [4] bis } 5.73(n=1) \\
& \text { [5] bis } 7.37(n=0) \\
& \text { [6] bis } 9.00(n=2) \\
& \text { Summe der Elemente: } 10 \\
& \text { MIN }=1.00 \\
& M W=4.10 \\
& \text { MED }=3.00 \\
& \text { MAX }=9.00
\end{aligned}
$$

Häufigkeitsverteilung, MINMWMAX, 12-fach

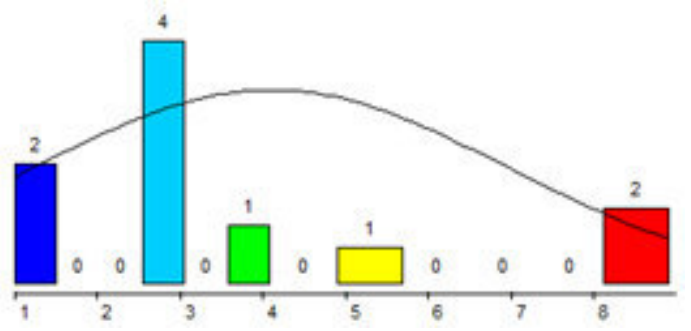

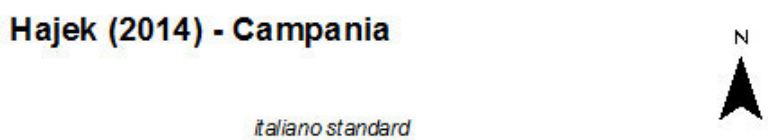

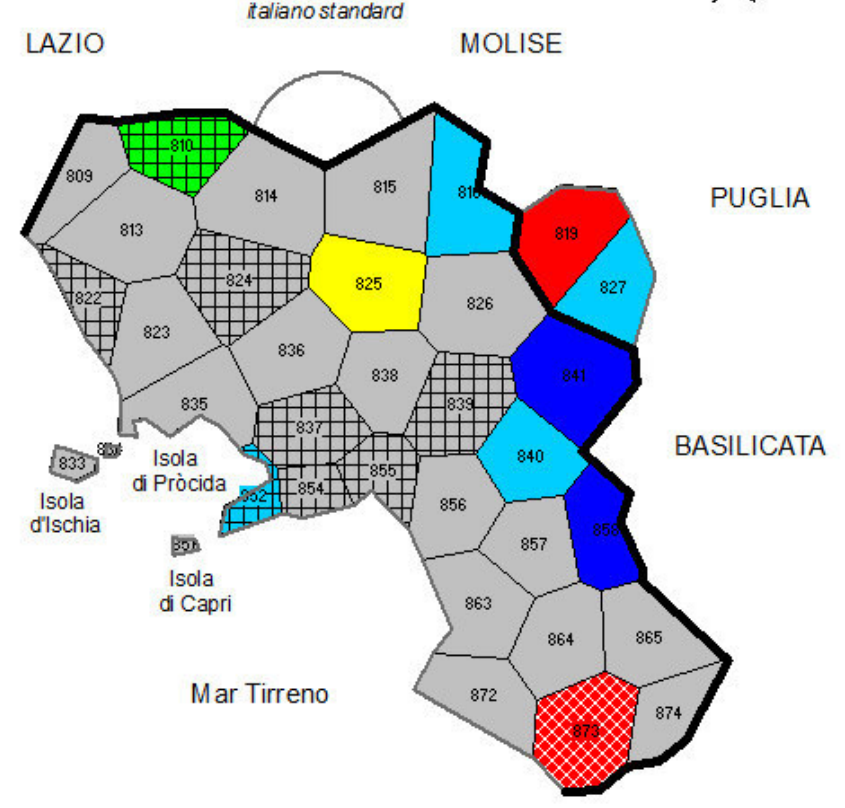

fec. S. Hajek

adiuv. H. Goebl et P. Smečka adiuv. B. Castellazzi a.d. 2013 carta di THIESSENHAAGNORONOI 35 punti dinchiesta + italiano standard - limite di regione

Karte A84. Antipodenkarte der Minima. Vergleichskorpus, Lexikon (112 AK). N = 35, Messmoment RIW jk $_{\text {. }}$ 
Legende, MINMWMAX, 6-fach

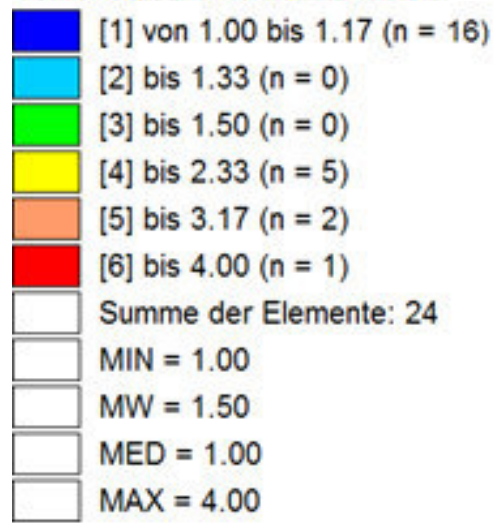

Häufigkeitsverteilung, MINMWMAX, 12-fach

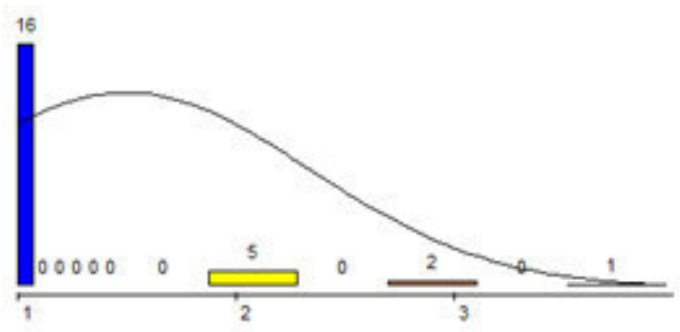

\section{ALI (1995-2008) - Campania}

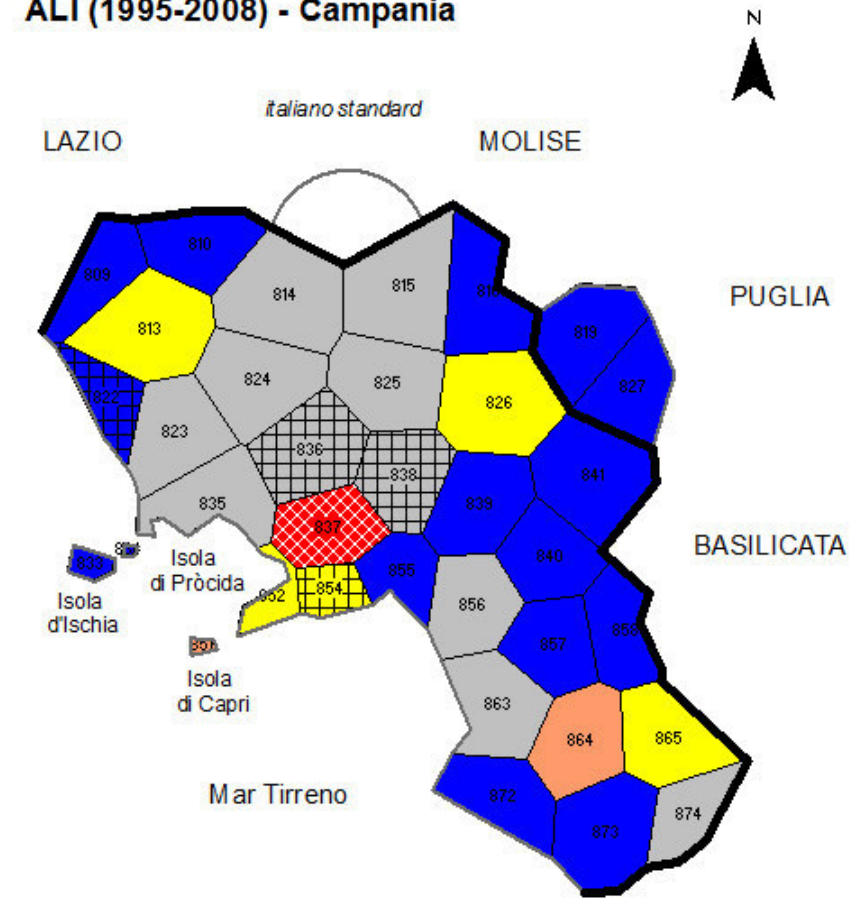

fec. S. Hajek

adiuv. $\mathrm{H}$. Goebl et P. Smečka adiuv. B. Castellazzi

carta di THIESSENHAAGNORONOI 35 punti dinchiesta + italiano standard lim ite di regione

Karte A85. Antipodenkarte der Maxima. ALI-Korpus, Konsonantismus (129 AK). N = 35, Messmoment RIW . $_{\text {. }}$

\section{Legende, MINMWMAX, 6-fach}

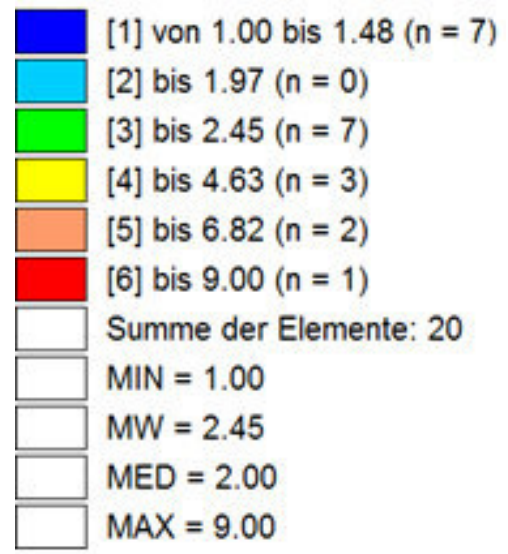

Häufigkeitsverteilung, MINMWMAX, 12-fach

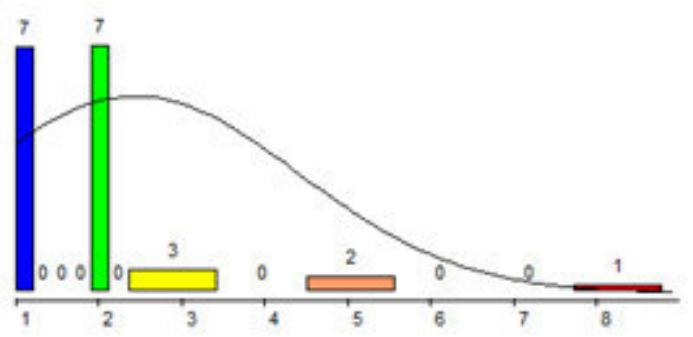

\section{Hajek (2014) - Campania}

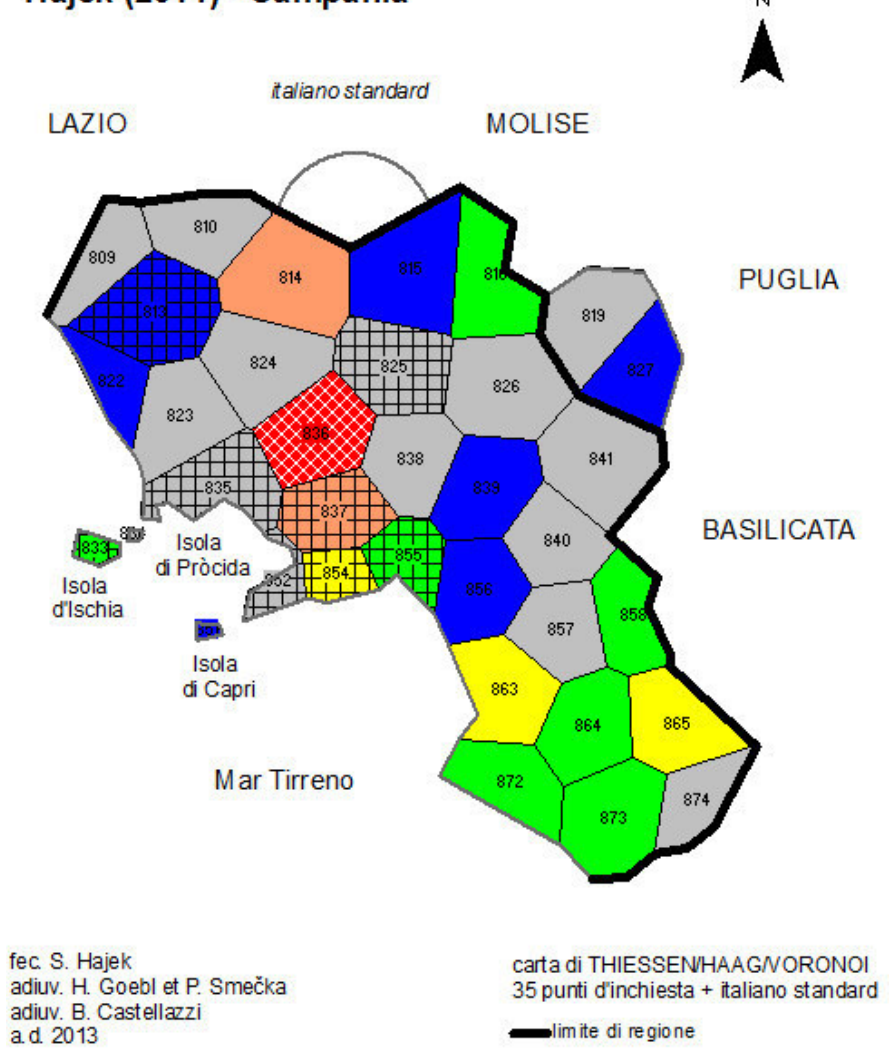

Karte A86. Antipodenkarte der Maxima. Vergleichskorpus, Konsonantismus (125 AK). N = 35, Messmoment RIW ${ }_{j k}$. 
Legende, MINMWMAX, 6-fach

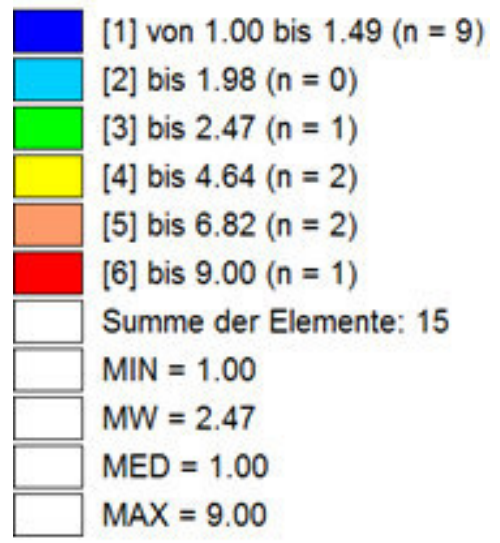

Häufigkeitsverteilung, MINMWMAX, 12-fach

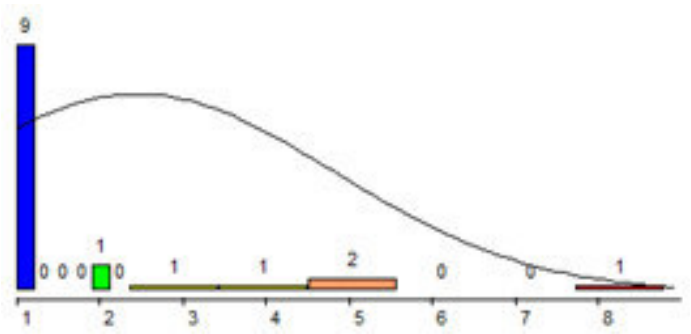

\section{ALI (1995-2008) - Campania}

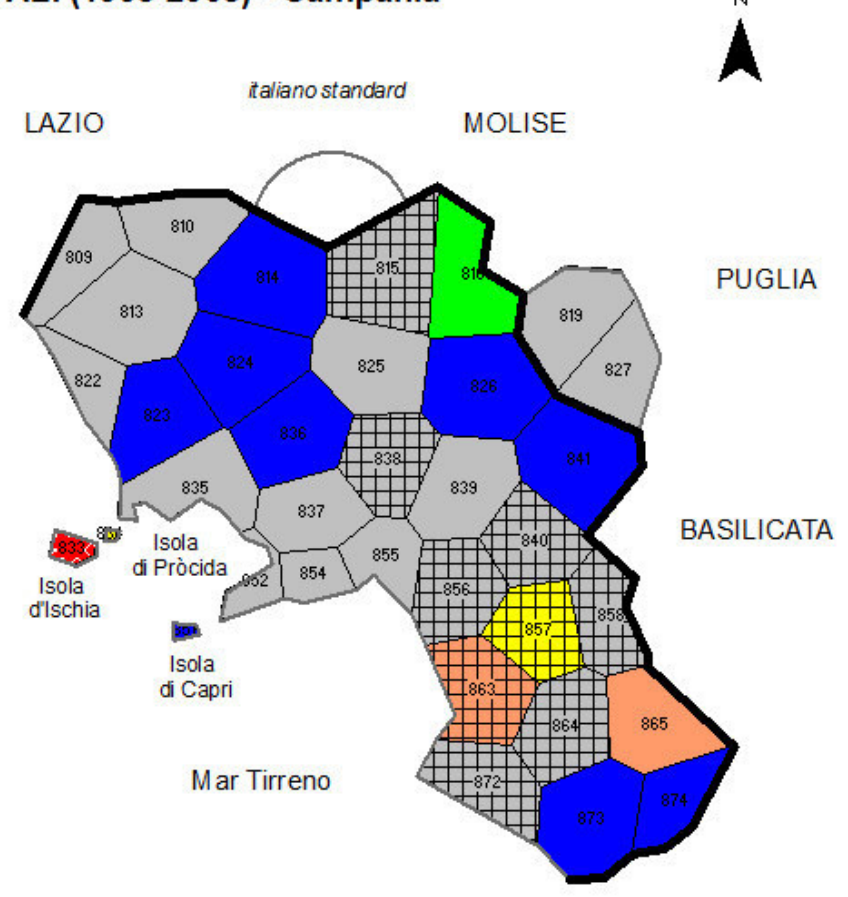

fec. S. Hajek

adiuv. $\mathrm{H}$. Goebl et $\mathrm{P}$. Smečka adiuv. B. Castellazzi a.d. 2013

carta di THIESSENHAAGNORONO 35 punti d'inchiesta + italiano standard limite di regione

Karte A87. Antipodenkarte der Minima. ALI-Korpus, Konsonantismus (129 AK). N = 35, Messmoment RIW , $_{j k}$

Legende, MINMWMAX, 6-fach

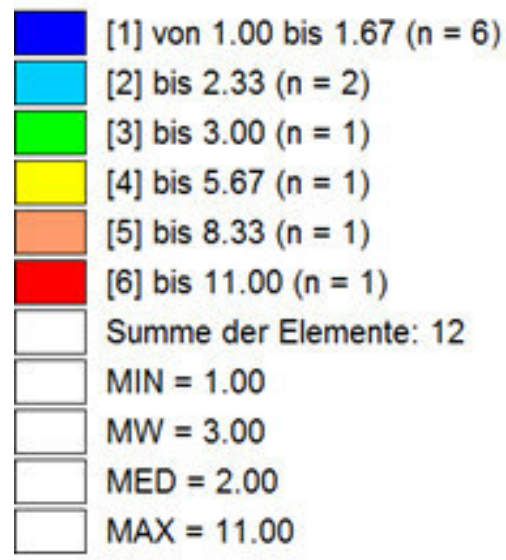

Häufigkeitsverteilung, MINMWMAX, 12-fach

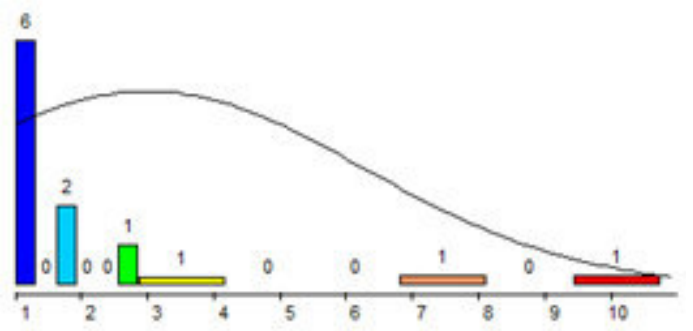

\section{Hajek (2014) - Campania}

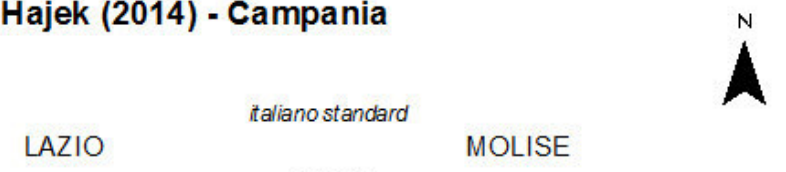

fec. S. Hajek

adiuv. H. Goebl et P. Smečka adiuv. B. Castellazzi a.d. 2013

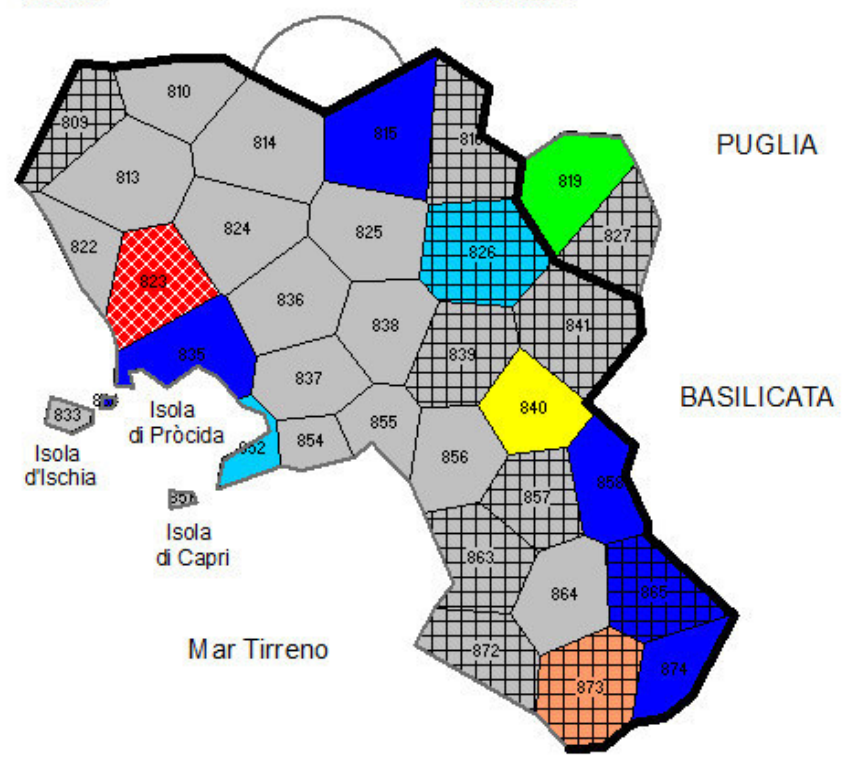

carta di THIESSENHAAGNORONOI 35 punti dinchiesta + italiano standard limite di regione

Karte A88. Antipodenkarte der Minima. Vergleichskorpus, Konsonantismus (125 AK). N = 35, Messmoment RIW $j k$. 
Legende, MINMWMAX, 6-fach

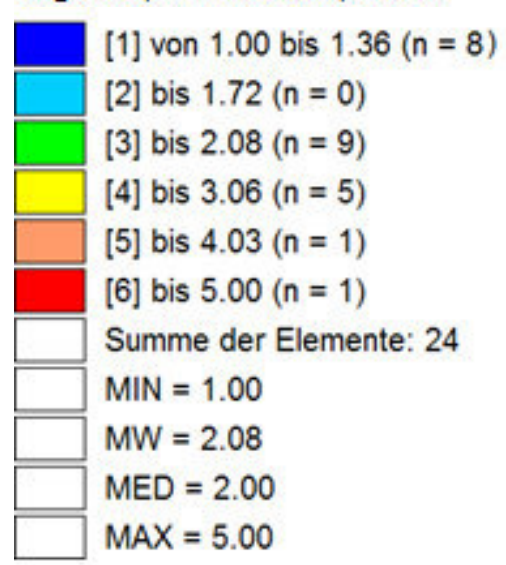

Häufigkeitsverteilung, MINMWMAX, 12-fach

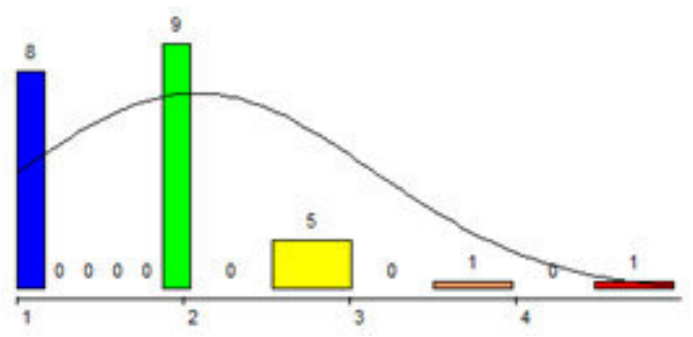

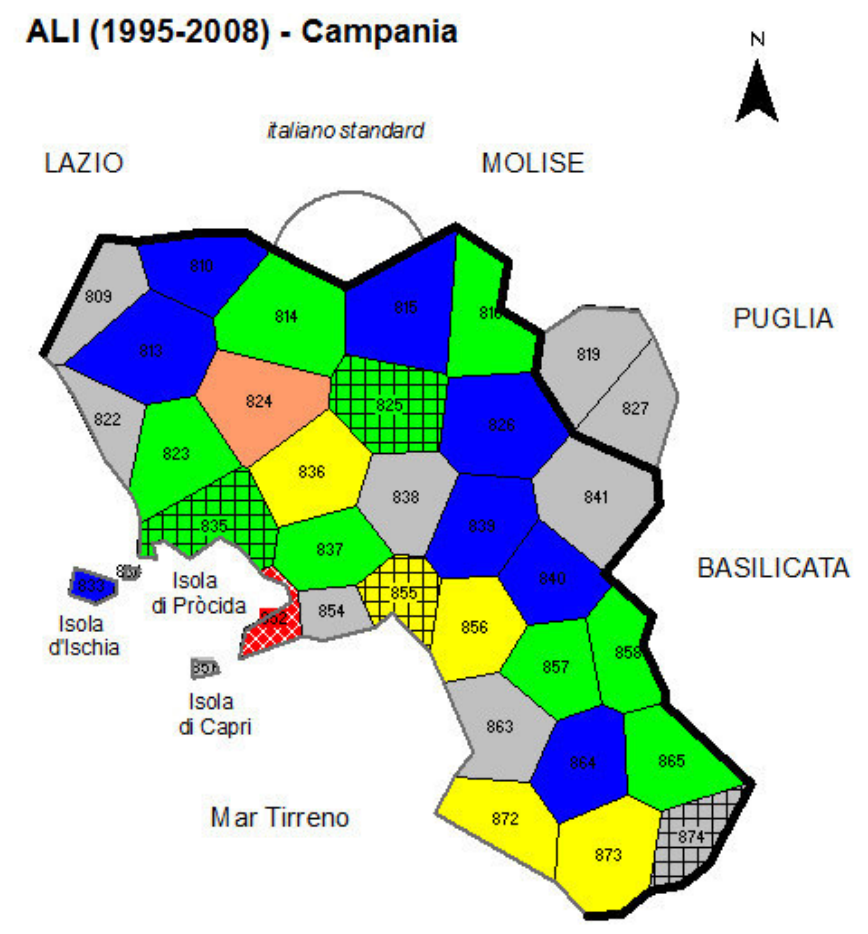

fec. S. Hajek

adiuv. H. Goebl et P. Smečka

adiuv. B. Castellazzi

carta di THIESSENHAAGNORONOI 35 punti dinchiesta + italiano standard limite di regione

Karte A89. Antipodenkarte der Maxima. ALI-Korpus, Vokalismus (41 AK). N = 35, Messmoment RIW $j k$.

\section{Legende, MINMWMAX, 6-fach}

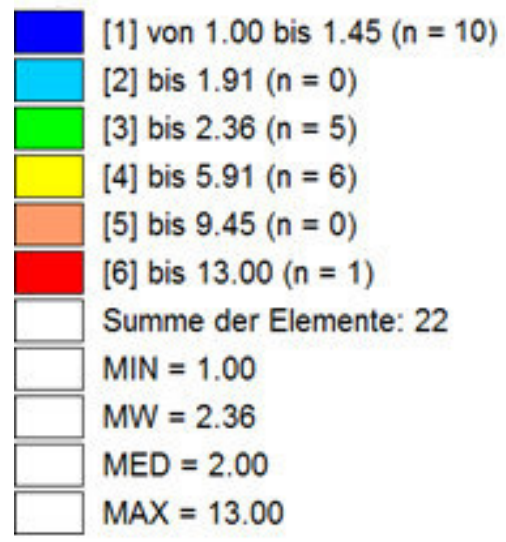

Häufigkeitsverteilung, MINMWMAX, 12-fach

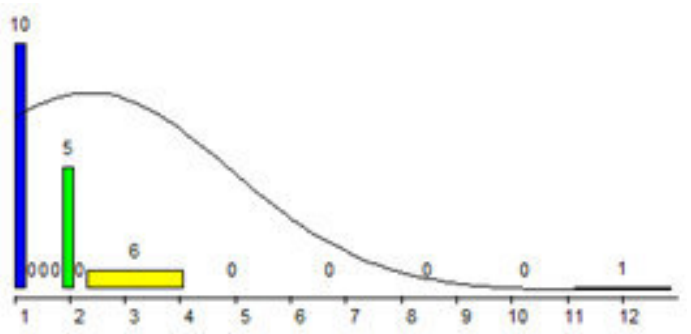

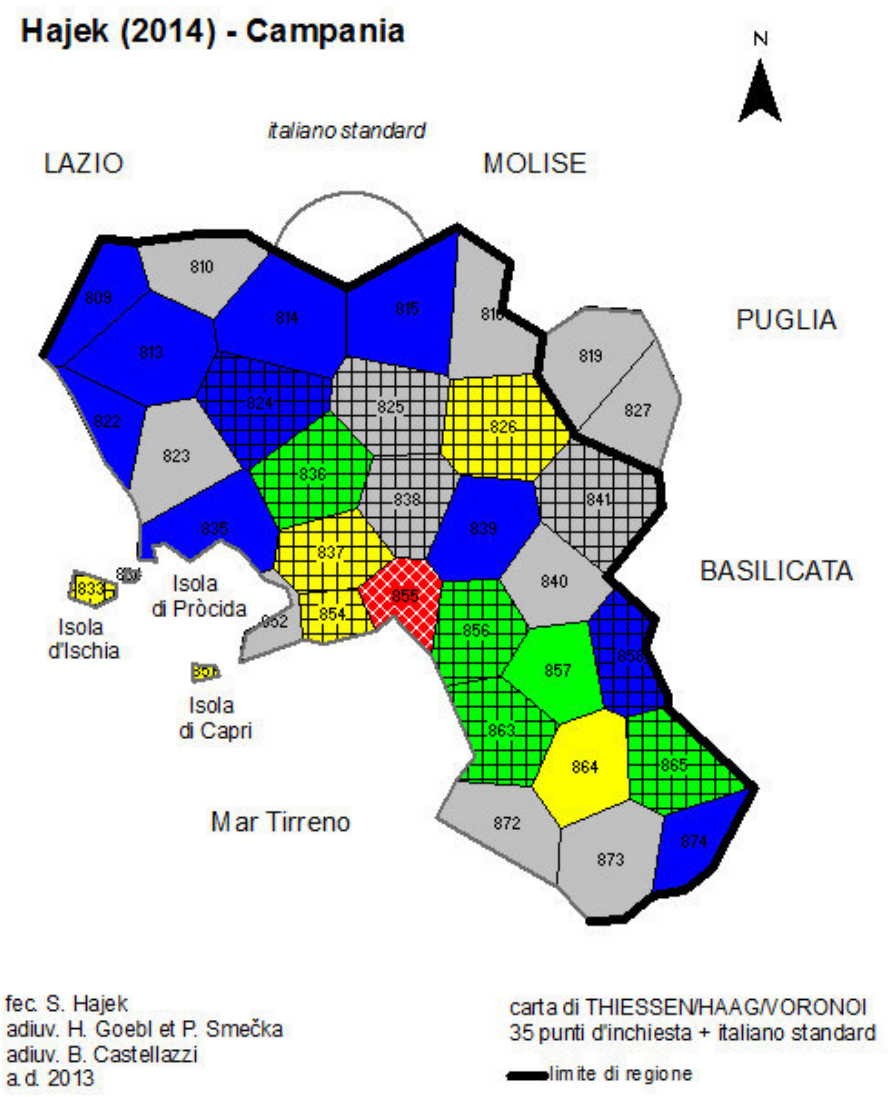

Karte A90. Antipodenkarte der Maxima. Vergleichskorpus, Vokalismus (48 AK). N = 35, Messmoment RIW $j k$. 
Legende, MINMWMAX, 6-fach

[1] von 1.00 bis $2.20(n=4)$

[2] bis $3.40(n=1)$

[3] bis $4.60(n=1)$

[4] bis $8.07(n=3)$

[5] bis $11.53(n=0)$

[6] bis $15.00(n=1)$

Summe der Elemente: 10

$\mathrm{MIN}=1.00$

$\mathrm{MW}=4.60$

MED $=4.00$

$\operatorname{MAX}=15.00$

Häufigkeitsverteilung, MINMWMAX, 12-fach

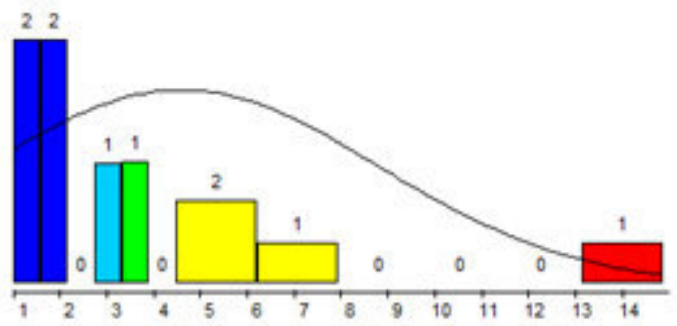

\section{ALI (1995-2008) - Campania}

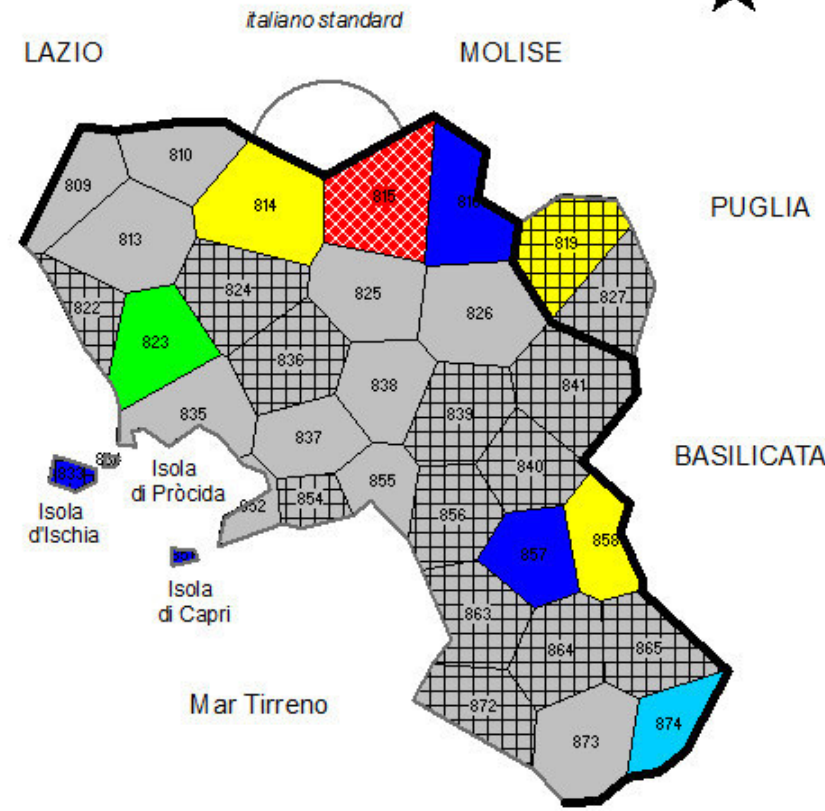

fec. S. Hajek

adiuv. H. Goebl et P. Smečka

adiuv. B. Castellazzi

a.d. 2013

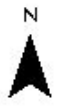

$\dot{1}$

carta di THIESSENHAAGNORONOI 35 punti dinchiesta + italiano standard

Karte A91. Antipodenkarte der Minima. ALI-Korpus, Vokalismus (41 AK). N = 35, Messmoment RIW ${ }_{j k}$.

Legende, MINMWMAX, 6-fach

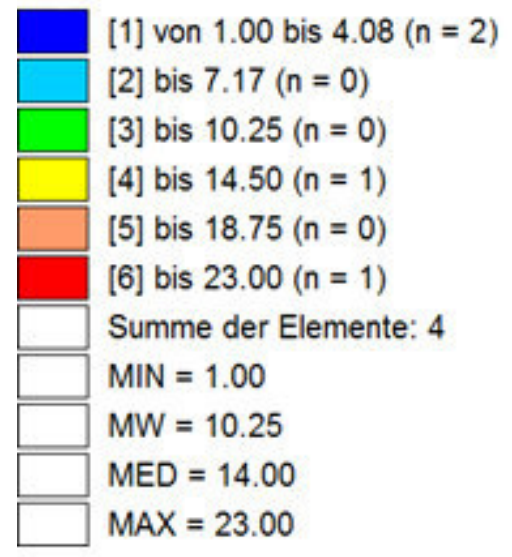

Häufigkeitsverteilung, MINMWMAX, 12-fach

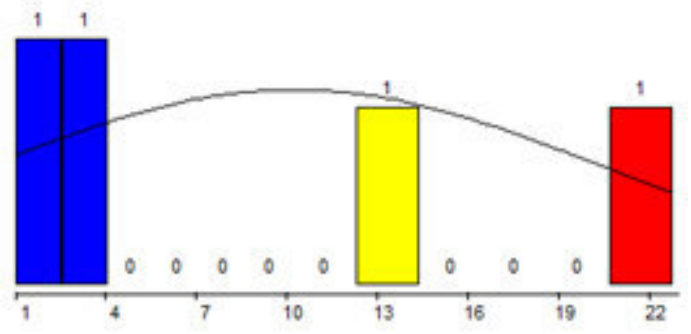

\section{Hajek (2014) - Campania}

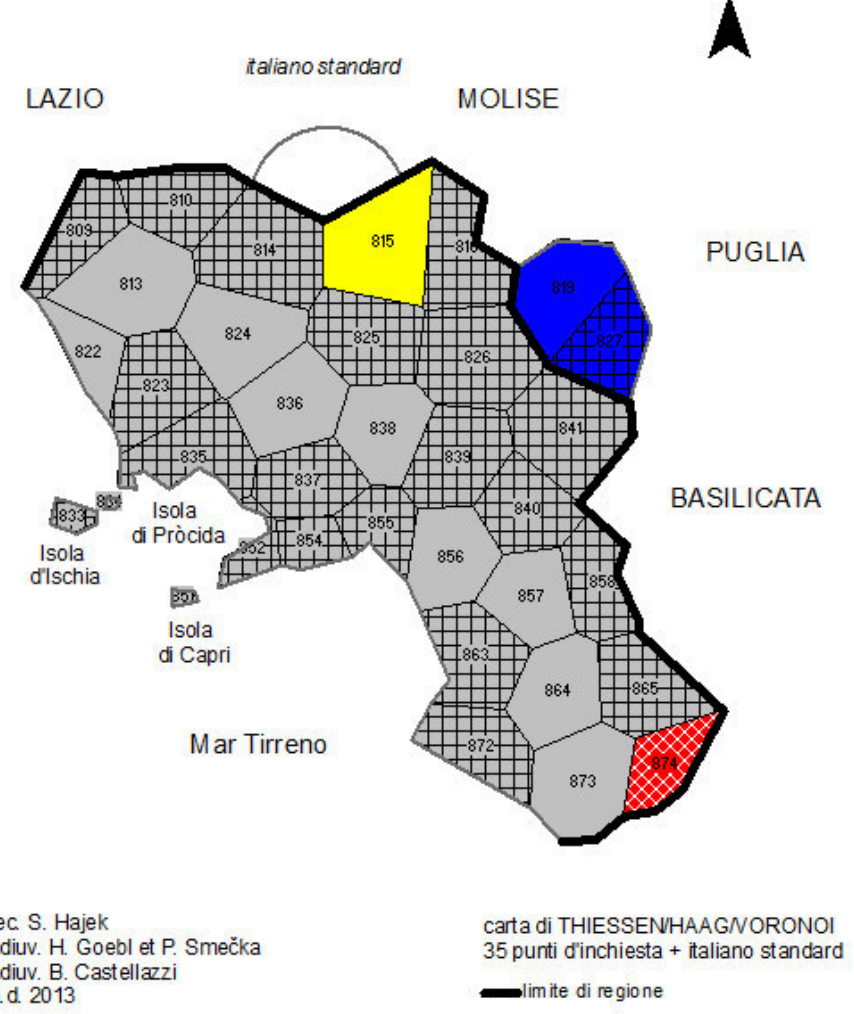

Karte A92. Antipodenkarte der Minima. Vergleichskorpus, Vokalismus (48 AK). N = 35, Messmoment RIW ${ }_{j k}$. 
Legende, MINMWMAX, 6-fach

[1] von 0.29 bis $0.40(n=2)$

[2] bis $0.51(n=4)$

[3] bis $0.62(n=7)$

[4] bis $0.68(n=9)$

[5] bis $0.74(n=9)$

[6] bis $0.79(n=4)$

Summe der Elemente: 35

$\mathrm{MIN}=0.29(P .855)$

$\mathrm{MW}=0.62$

MED $=0.65$

MAX $=0.79$ (P. 837)

\section{Häufigkeitsverteilung, MINMWMAX, 12-fach}

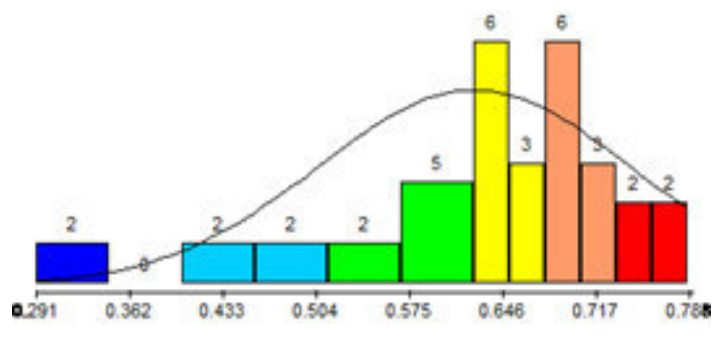

ALI (1995-2008) - Campania

$N$

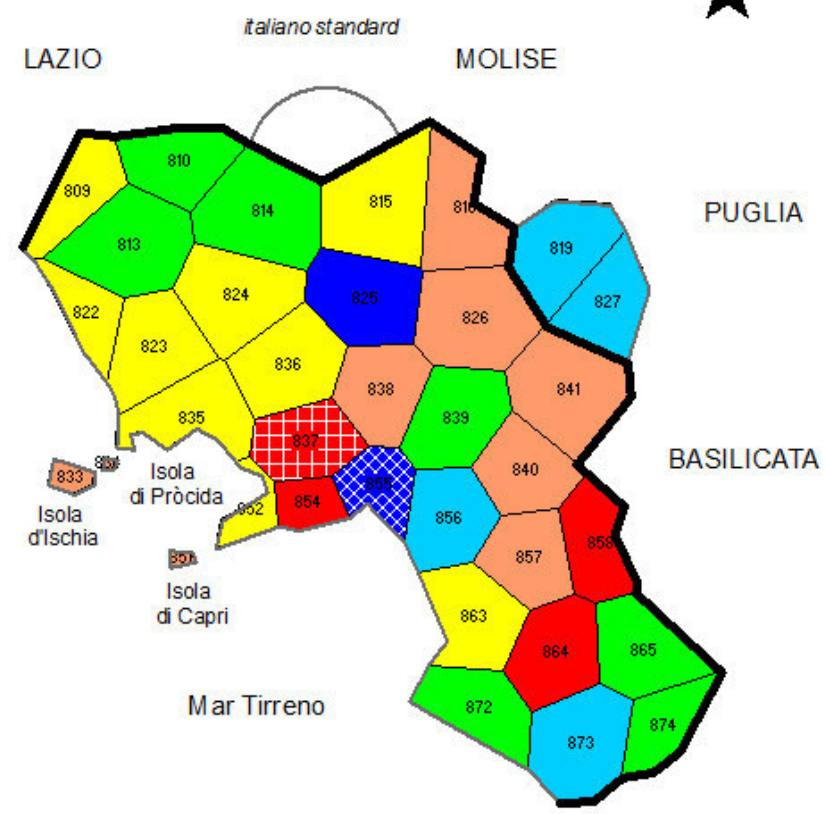

fec. S. Hajek

adiuv. H. Goebl et P. Smečka adiuv. B. Castellazzi

carta di THIESSENHAAGNORONOI 35 punti d'inchiesta + italiano standard -limite di regione

Karte A93. Korrelationskarte zum ALI-Korpus: Totalkorpus (275 AK, Messmoment RIW ${ }_{j k}$ ) und geographische (euklidische) Proximität. $\mathrm{N}=35$, Produktmoment-Korrelationskoeffizient nach Bravais/Pearson.

\section{Legende, MINMWMAX, 6-fach}

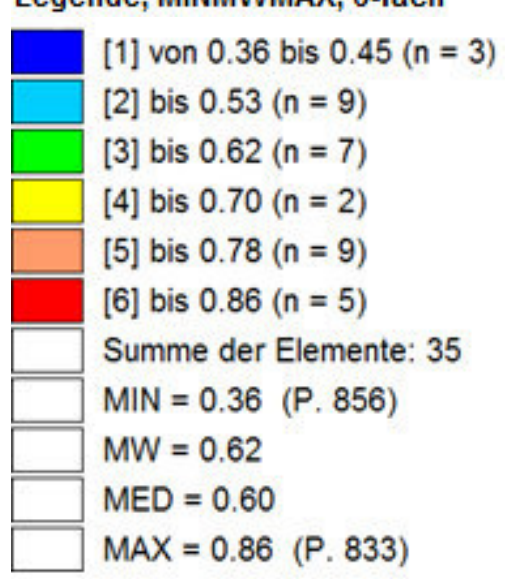

\section{Häufigkeitsverteilung, MINMWMAX, 12-fach}

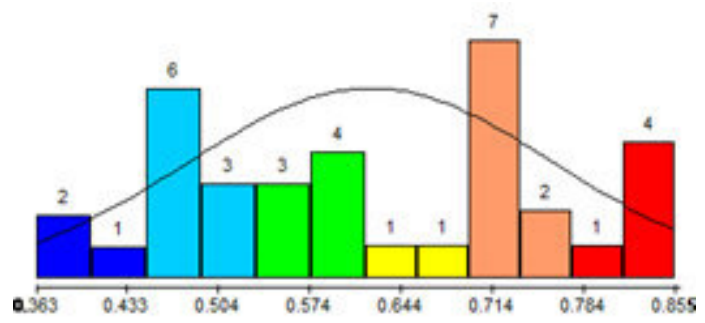

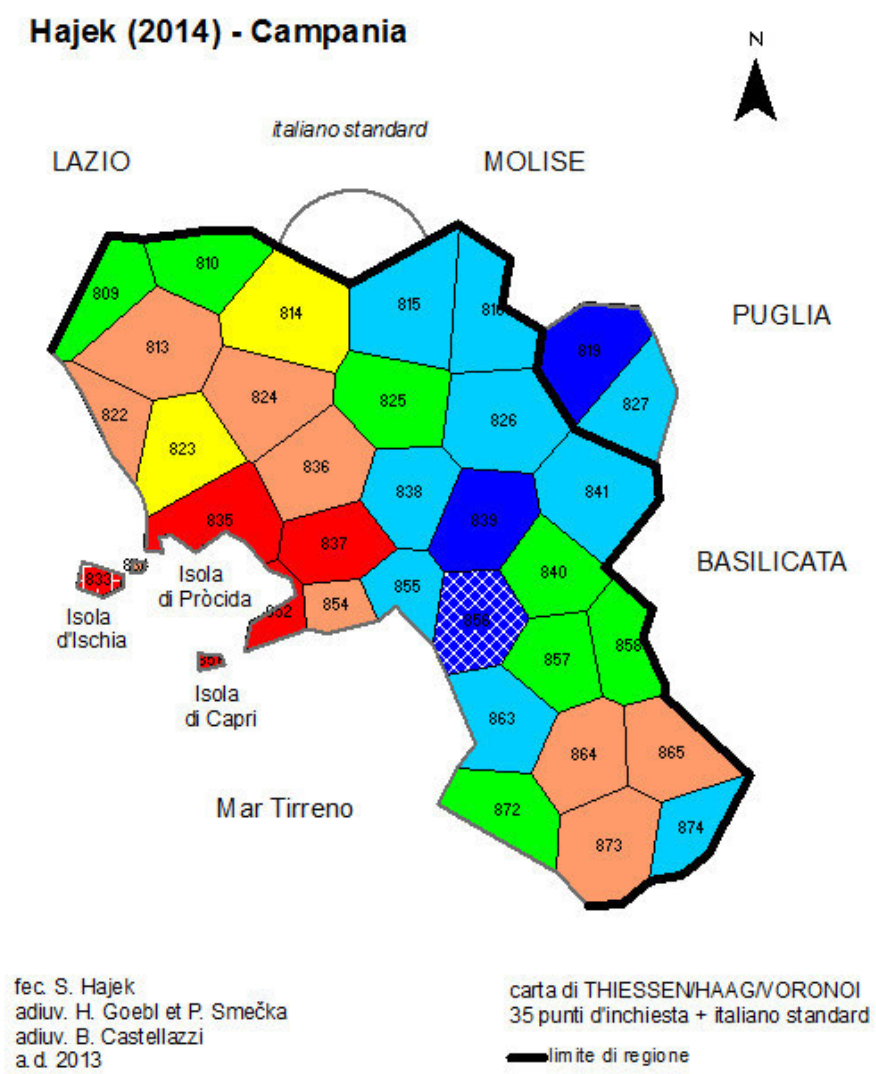

Karte A94. Korrelationskarte zum Vergleichskorpus: Totalkorpus (285 AK, Messmoment RIW ${ }_{j k}$ ) und geographische (euklidische) Proximität. $\mathrm{N}=35$, Produktmoment-Korrelationskoeffizient nach Bravais/Pearson. 
Legende, MINMWMAX, 6-fach

\begin{tabular}{|c|}
\hline [1] von 0.46 bis $0.53(n=5)$ \\
\hline [2] bis $0.61(n=1)$ \\
\hline [3] bis $0.68(n=13)$ \\
\hline [4] bis $0.73(n=2)$ \\
\hline [5] bis $0.78(n=4)$ \\
\hline [6] bis $0.83(n=10)$ \\
\hline Summe der Elemente: 35 \\
\hline $\mathrm{MIN}=0.46$ (P. 856) \\
\hline$M W=0.68$ \\
\hline $\mathrm{MED}=0.68$ \\
\hline $\operatorname{MAX}=0.83(P .834)$ \\
\hline
\end{tabular}

Häufigkeitsverteilung, MINMWMAX, 12-fach

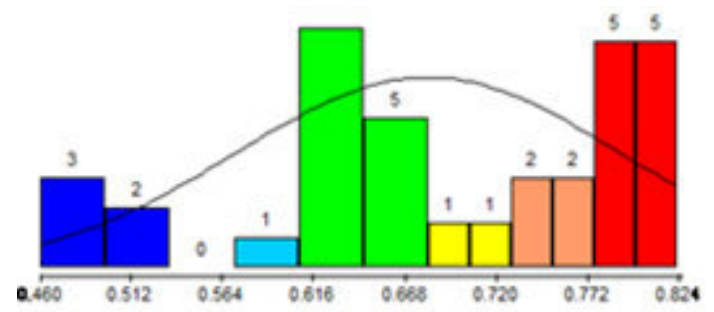

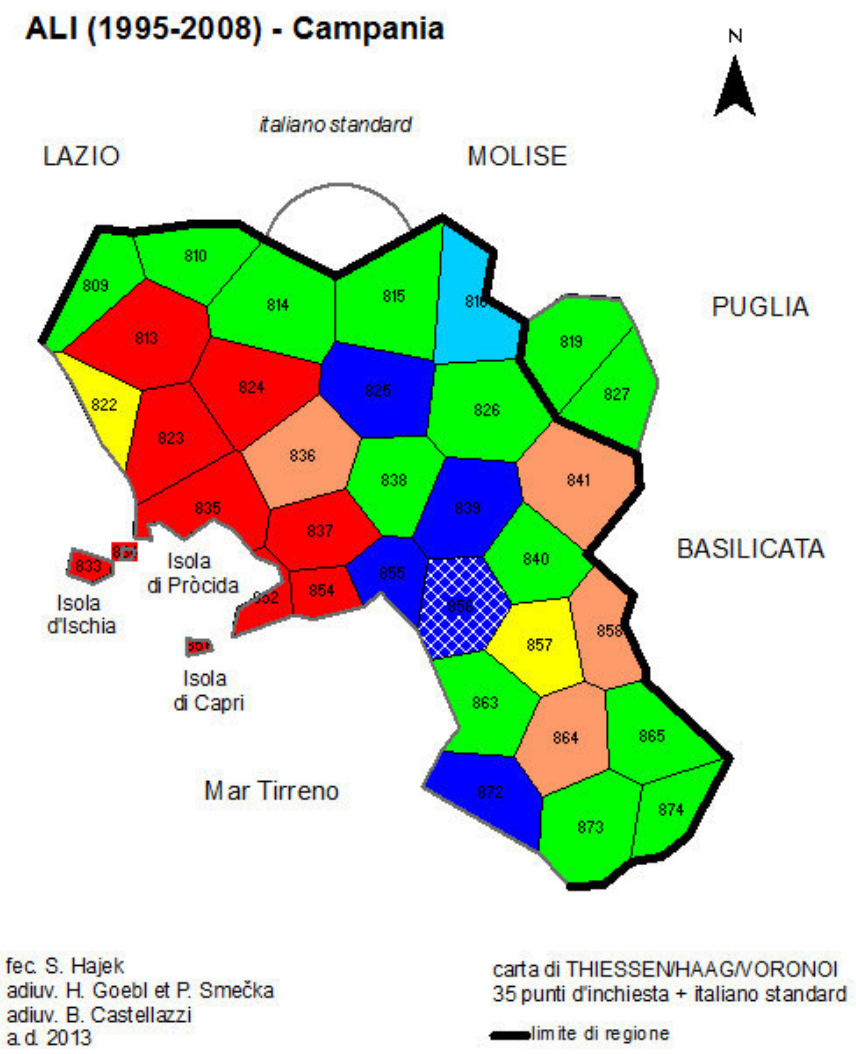

Karte A95. Korrelationskarte zum ALI-Korpus: Lexikon (105 AK, Messmoment $\mathrm{RIW}_{j k}$ ) und geographische (euklidische) Proximität. N = 35, Produktmoment-Korrelationskoeffizient nach Bravais/Pearson.

\section{Legende, MINMWMAX, 6-fach}

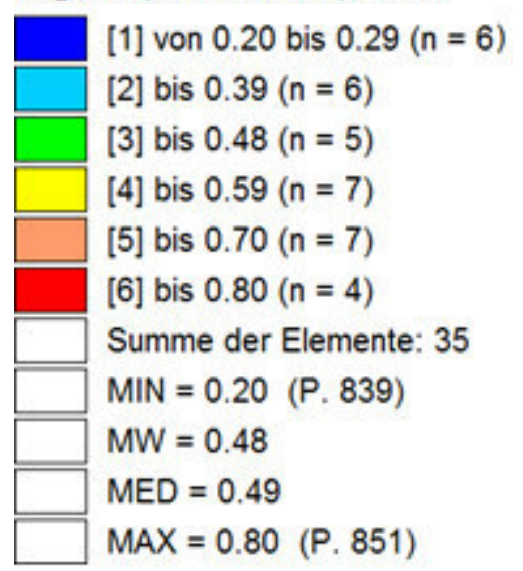

Häufigkeitsverteilung, MINMWMAX, 12-fach

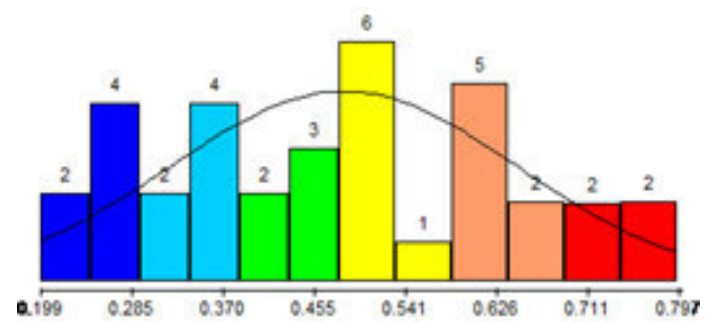

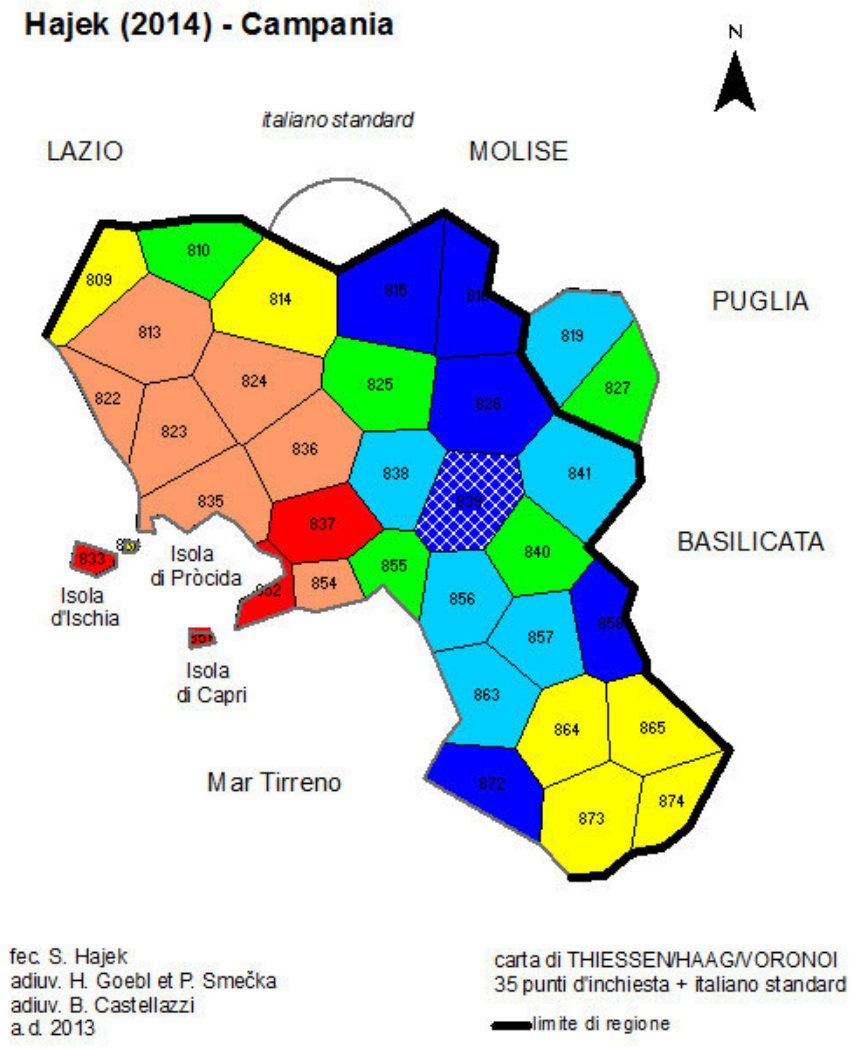

Karte A96. Korrelationskarte zum Vergleichskorpus: Lexikon (112 AK, Messmoment RIW ${ }_{j k}$ ) und geographische (euklidische) Proximität. N = 35, Produktmoment-Korrelationskoeffizient nach Bravais/Pearson. 


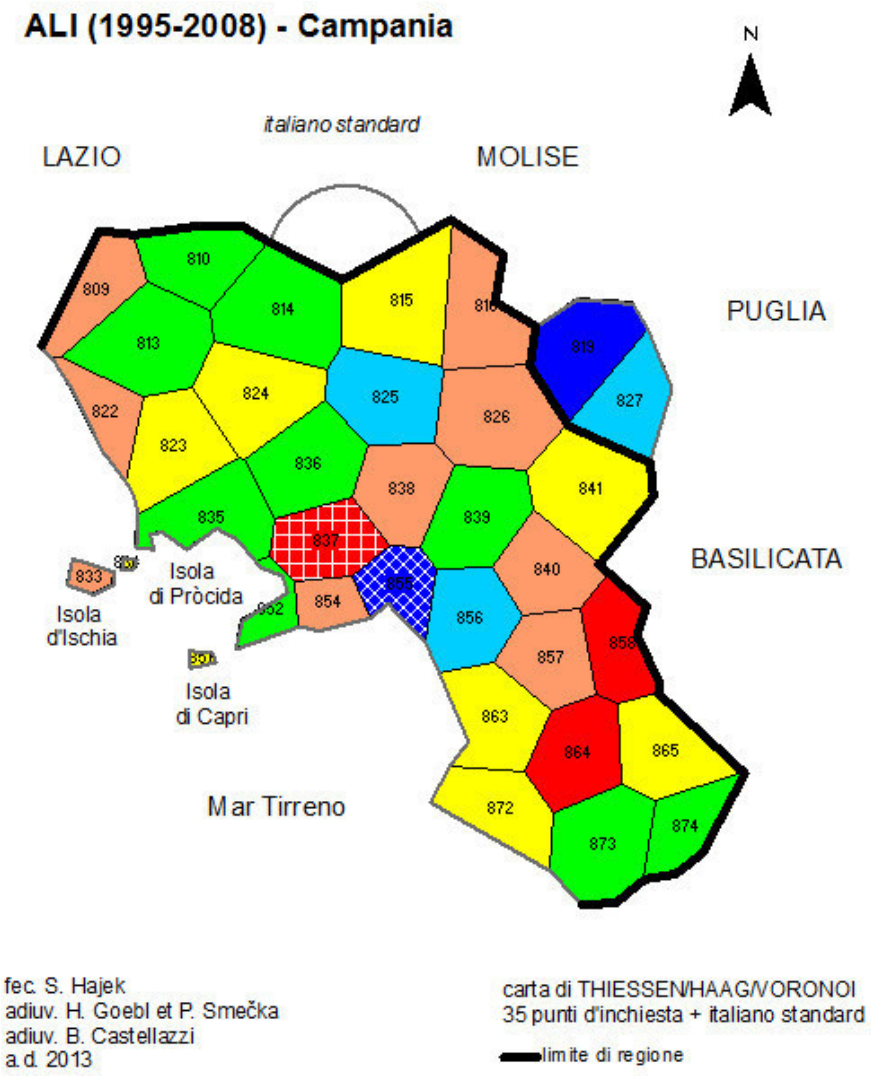

Häufigkeitsverteilung, MINMWMAX, 12-fach

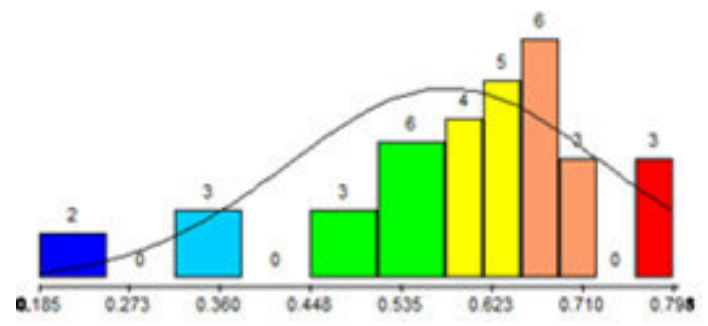

[1] von 0.19 bis $0.32(n=2)$

[2] bis $0.45(n=3)$

[3] bis $0.58(n=9)$

[4] bis $0.65(n=9)$

[5] bis $0.73(n=9)$

[6] bis $0.80(n=3)$

Summe der Elemente: 35

MIN $=0.19$ (P. 855)

$\mathrm{MW}=0.58$

MED $=0.61$

MAX $=0.80(P .837)$

Karte A97. Korrelationskarte zum ALI-Korpus: Konsonantismus (129 AK, Messmoment RIW ${ }_{j k}$ ) und geographische (euklidische) Proximität. $\mathrm{N}=35$, Produktmoment-Korrelationskoeffizient nach Bravais/Pearson.

\section{Legende, MINMWMAX, 6-fach}

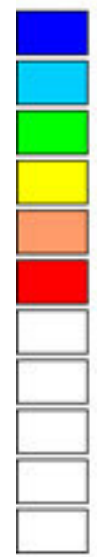

[1] von 0.24 bis $0.37(n=2)$

[2] bis $0.51(n=5)$

[3] bis $0.64(n=8)$

[4] bis $0.71(n=5)$

[5] bis $0.78(n=8)$

[6] bis $0.84(n=7)$

Summe der Elemente: 35

$\mathrm{MIN}=0.24$ (P. 856)

$\mathrm{MW}=0.64$

MED $=0.67$

MAX $=0.84(P .833)$

\section{Häufigkeitsverteilung, MINMWMAX, 12-fach}

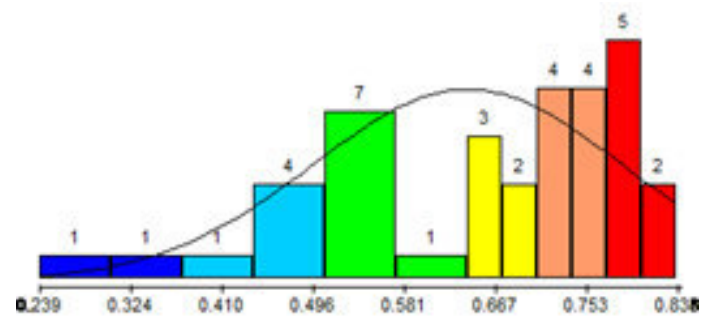

\section{Hajek (2014) - Campania}
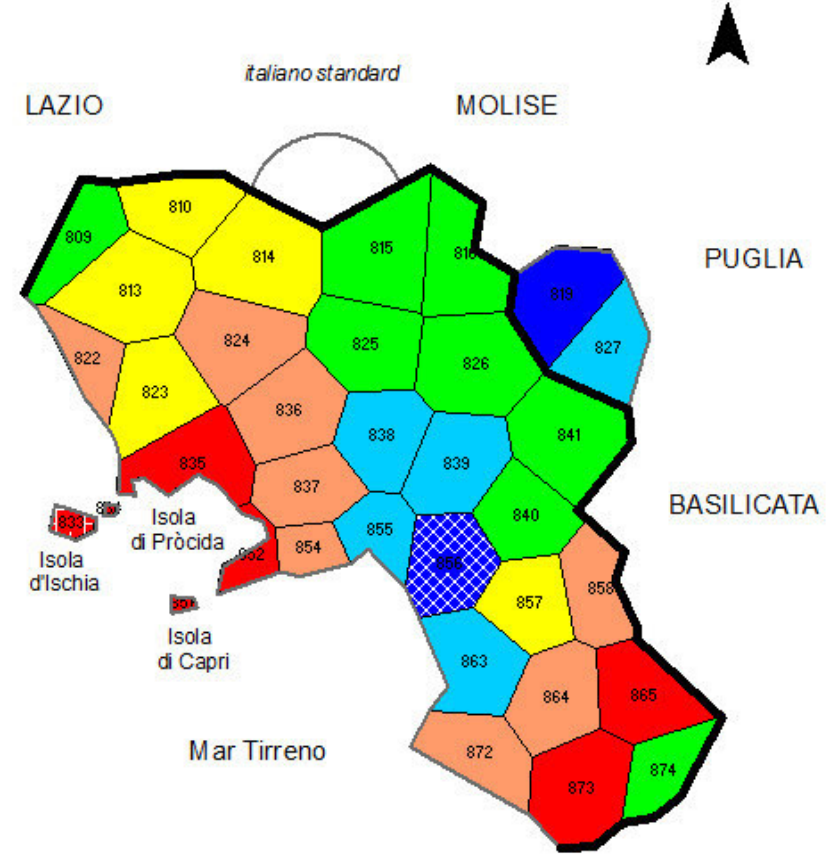

fec. S. Hajek adiuv. H. Goebl et P. Smečka adiuv. B. Castellazzi

carta di THIESSENHAAGNORONOI 35 punti dinchiesta + italiano standard - limite di regione

Karte A98. Korrelationskarte zum Vergleichskorpus: Konsonantismus (125 AK, Messmoment RIW ${ }_{j k}$ ) und geographische (euklidische) Proximität. N = 35, Produktmoment-Korrelationskoeffizient nach Bravais/Pearson. 
Legende, MINMWMAX, 6-fach

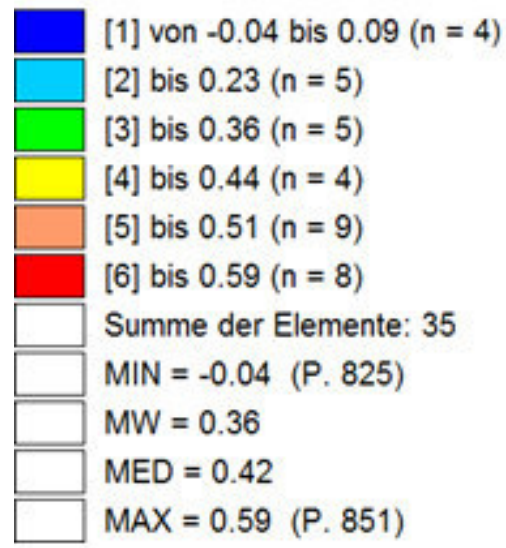

Häufigkeitsverteilung, MINMWMAX, 12-fach

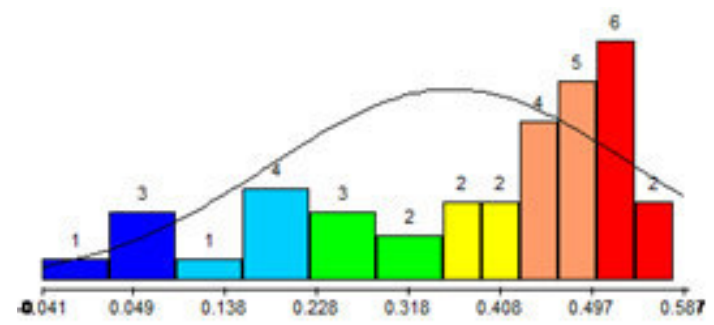

\section{ALI (1995-2008) - Campania}

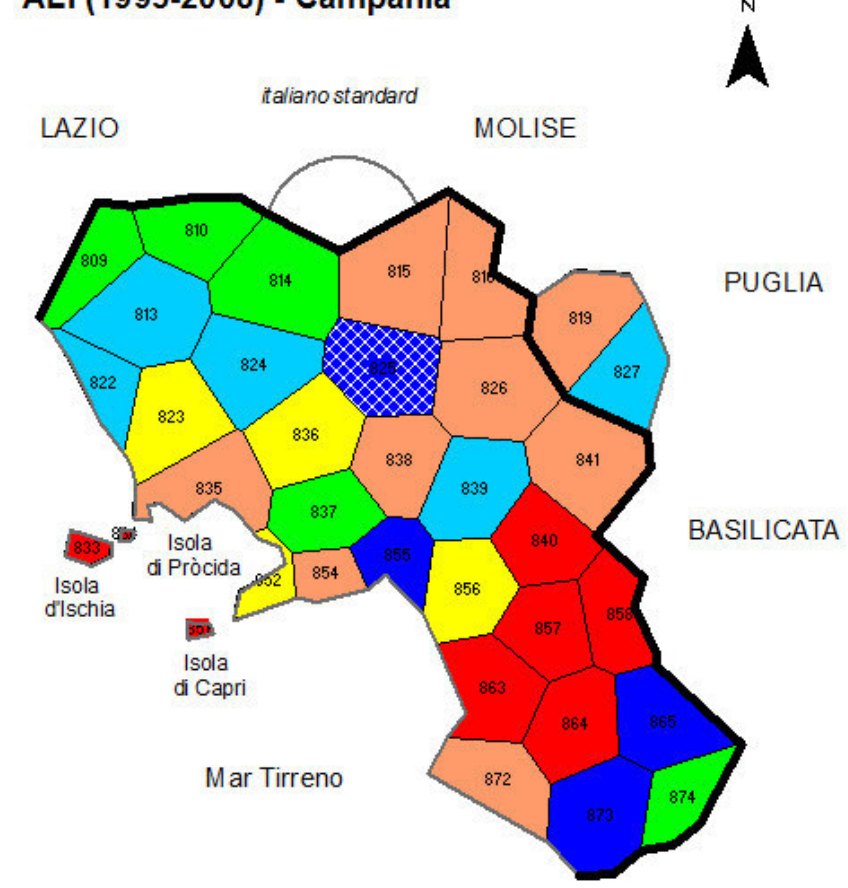

fec S. Hajek

adiuv. H. Goebl et P. Smečka adiuv. B. Castellazzi a.d. 2013 carta di THIESSENHAAGNORONOI 35 punti d'inchiesta + italiano standard limite di regione

Karte A99. Korrelationskarte zum ALI-Korpus: Vokalismus (41 AK, Messmoment RIW ${ }_{j k}$ ) und geographische (euklidische) Proximität. $\mathrm{N}=35$, Produktmoment-Korrelationskoeffizient nach Bravais/Pearson.

\section{Legende, MINMWMAX, 6-fach}

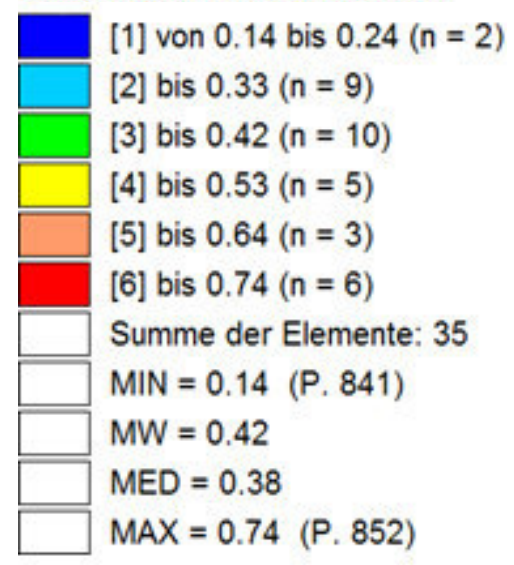

\section{Häufigkeitsverteilung, MINMWMAX, 12-fach}

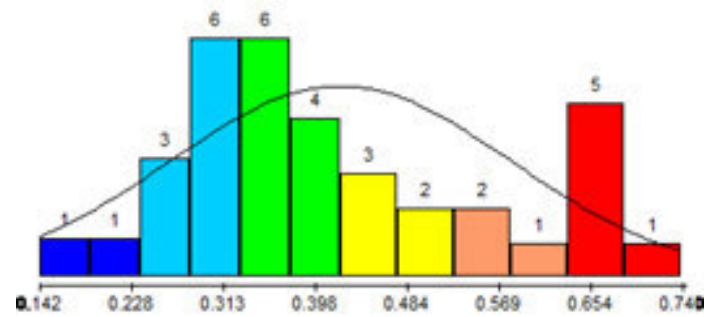

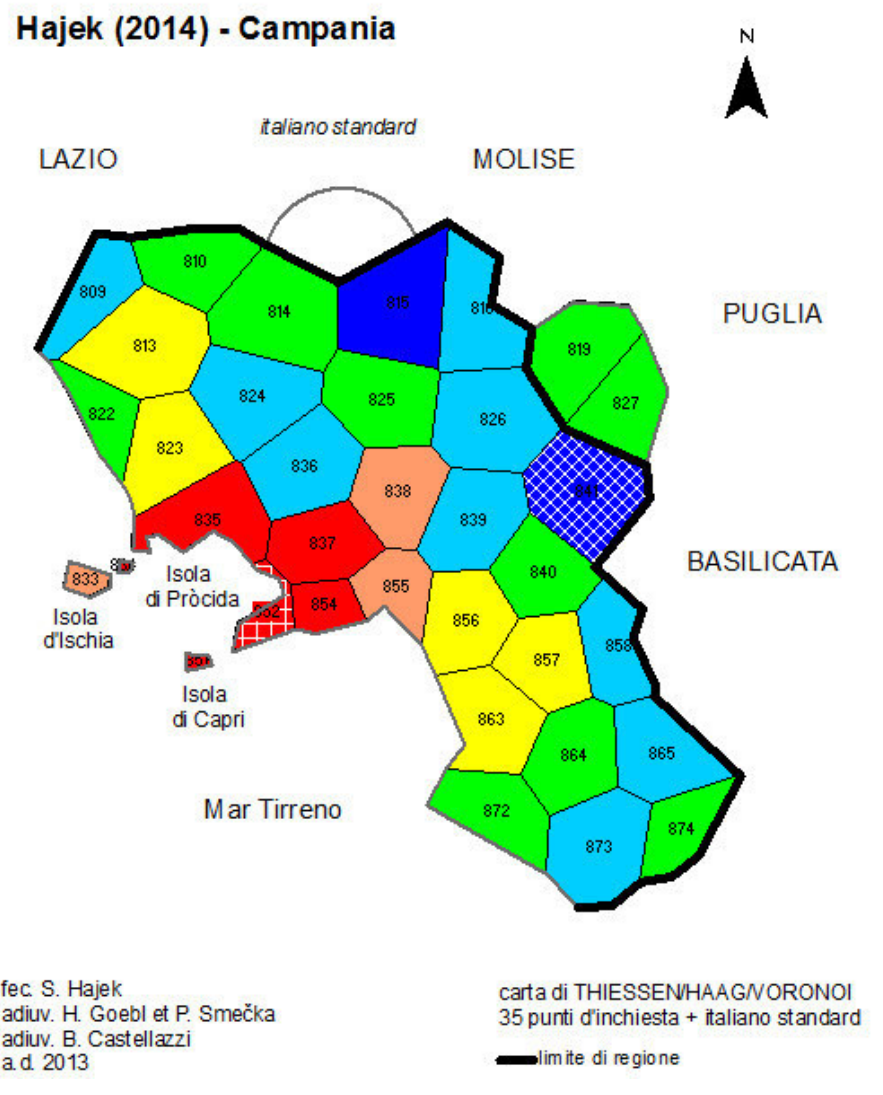

Karte A100. Korrelationskarte zum Vergleichskorpus: Vokalismus (48 AK, Messmoment RIW ${ }_{j k}$ ) und geographische (euklidische) Proximität. $\mathrm{N}=35$, Produktmoment-Korrelationskoeffizient nach Bravais/Pearson. 
Legende, MINMWMAX, 6-fach

[1] von 0.62 bis $0.67(n=5)$

[2] bis $0.72(n=4)$

[3] bis $0.77(n=8)$

[4] bis $0.82(n=8)$

[5] bis $0.87(n=8)$

[6] bis $0.93(n=2)$

Summe der Elemente: 35

$\mathrm{MIN}=0.62(P .834)$

$\mathrm{MW}=0.77$

MED $=0.78$

MAX $=0.93$ (P. 864)

Häufigkeitsverteilung, MINMWMAX, 12-fach

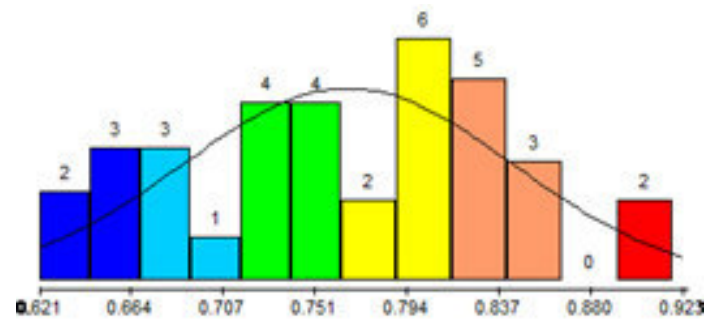

Hajek (2014) / ALI (1995-2008) - Campania

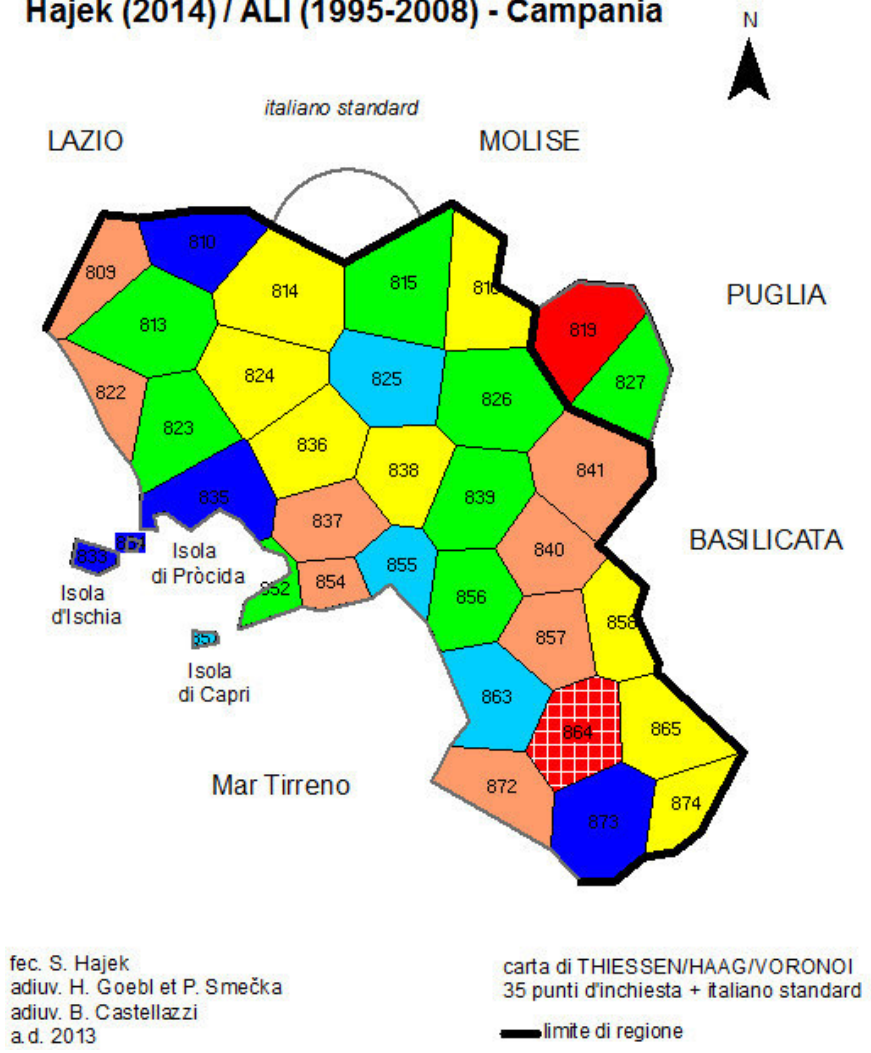

Karte A101. Korrelationskarte zu den Totalkorpora: ALI-Korpus (275 AK) und Vergleichskorpus (285 AK). N = 35, Messmoment jeweils RIW Rk $_{j k}$, Produktmoment-Korrelationskoeffizient nach Bravais/Pearson.

Legende, MINMWMAX, 6-fach

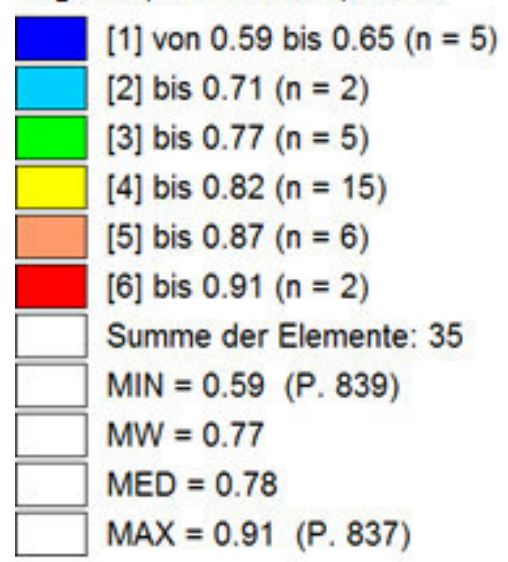

Häufigkeitsverteilung, MINMWMAX, 12-fach

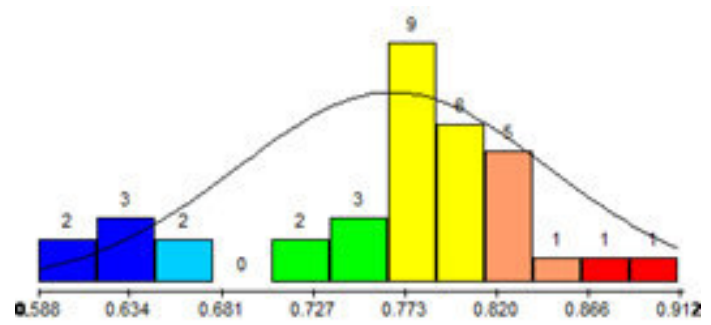

Hajek (2014) / ALI (1995-2008) - Campania

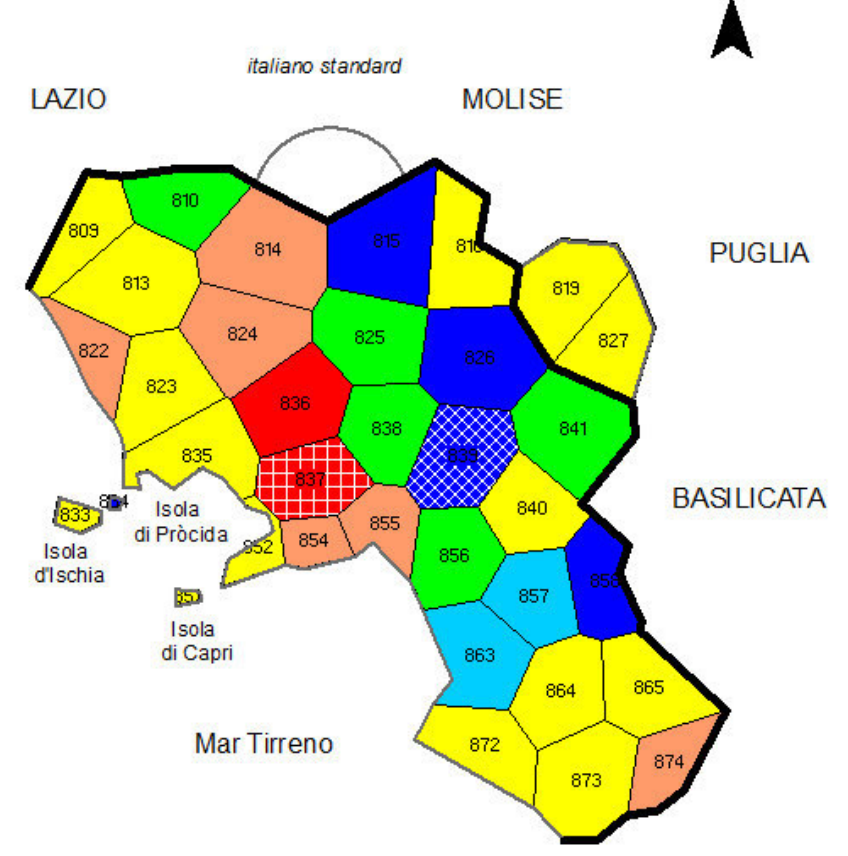

fec. S. Hajek

adiuv. H. Goebl et P. Smečka adiuv. B. Castellazzi

a.d. 2013 carta di THIESSEN/HAAG/VORONOI 35 punti dinchiesta + italiano standard -

Karte A102. Korrelationskarte zum Lexikon: ALI-Korpus (105 AK) und Vergleichskorpus (112 AK). N = 35, Messmoment jeweils RIW $_{j k}$, Produktmoment-Korrelationskoeffizient nach Bravais/Pearson. 
Legende, MINMWMAX, 6-fach

[1] von 0.48 bis $0.55(n=5)$

[2] bis $0.61(n=8)$

[3] bis $0.67(n=7)$

[4] bis $0.75(n=5)$

[5] bis $0.84(n=7)$

[6] bis $0.92(n=3)$

Summe der Elemente: 35

$\mathrm{MIN}=0.48$ (P. 835)

$\mathrm{MW}=0.67$

MED $=0.65$

MAX $=0.92$ (P. 864)

Häufigkeitsverteilung, MINMWMAX, 12-fach

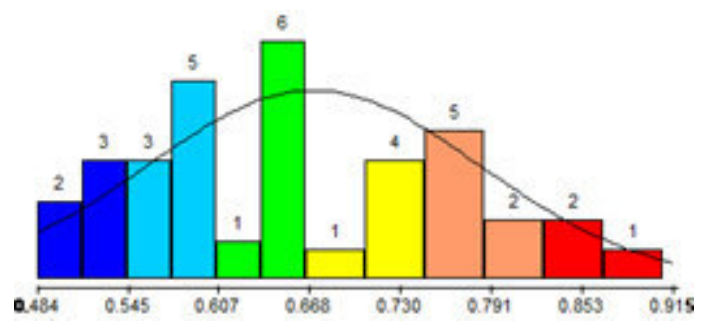

Hajek (2014) / ALI (1995-2008) - Campania

$\stackrel{N}{N}$

MOLISE

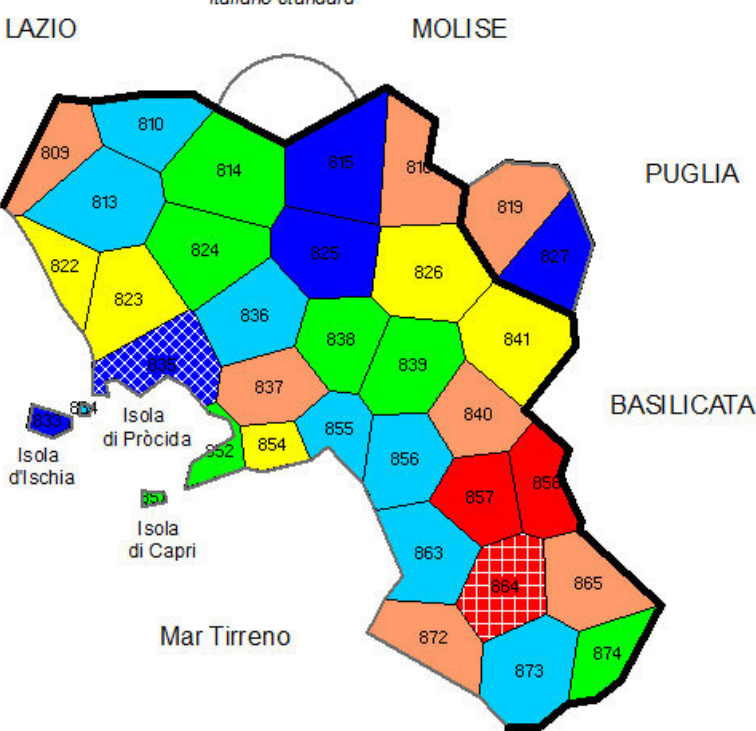

fec. S. Hajek

adiuv. H. Goebl et P. Smečka adiuv. B. Castellazz a.d. 2013

carta di THIESSEN/HAAG/VORONO 35 punti d'inchiesta + italiano standard -limite di regione

Karte A103. Korrelationskarte zum Konsonantismus: ALI-Korpus (129 AK) und Vergleichskorpus (125 AK). N = 35, Messmoment jeweils RIW $j k$, Produktmoment-Korrelationskoeffizient nach Bravais/Pearson.

\section{Legende, MINMWMAX, 6 -fach}

[1] von 0.05 bis $0.21(n=1)$

[2] bis $0.38(n=4)$

[3] bis $0.55(n=11)$

[4] bis $0.62(n=7)$

[5] bis $0.70(n=5)$

[6] bis $0.78(n=7)$

Summe der Elemente: 35

$\mathrm{MIN}=0.05$ (P. 814)

$M W=0.55$

MED $=0.56$

MAX $=0.78$ (P. 874)

Häufigkeitsverteilung, MINMWMAX, 12-fach

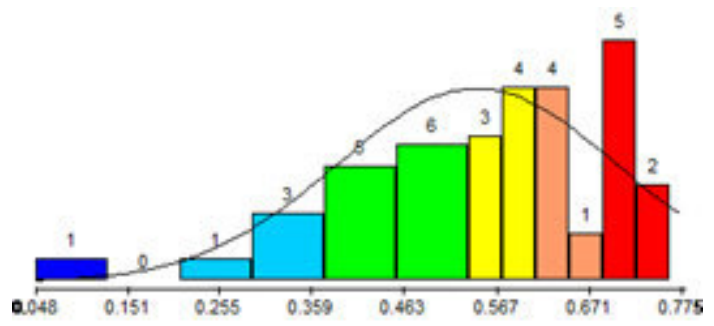

Hajek (2014) / ALI (1995-2008) - Campania
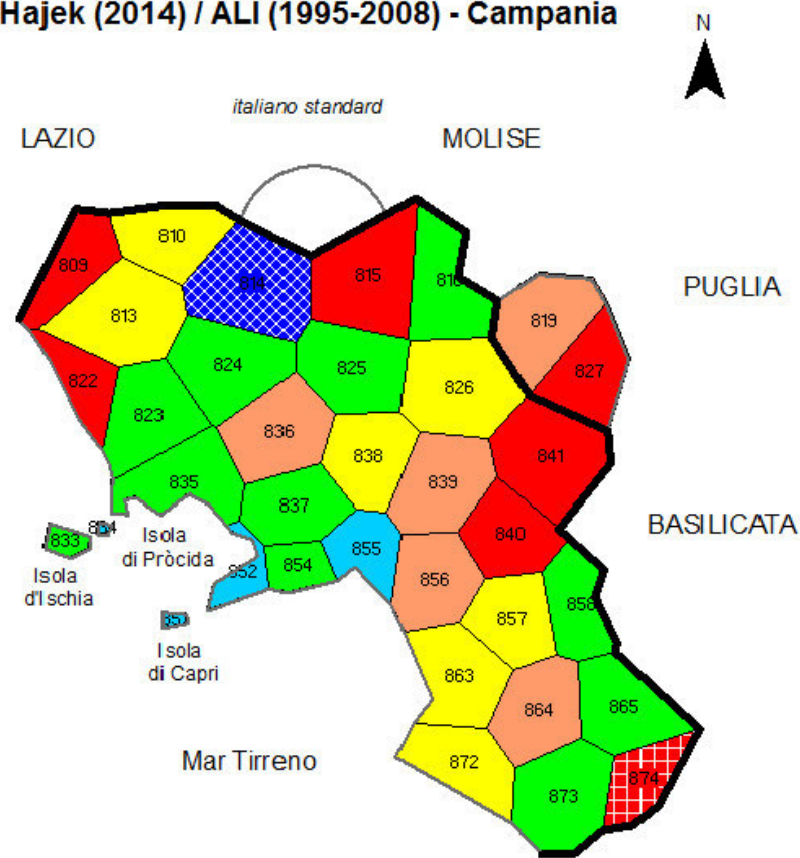

fec. S. Hajek

adiuv. H. Goebl et P. Smečka adiuv. B. Castellazzi a.d. 2013 carta di THIESSEN/HAAG/VORONOI 35 punti dinchiesta + italiano standard limite di regione

Karte A104. Korrelationskarte zum Vokalismus: ALI-Korpus (41 AK) und Vergleichskorpus (48 AK). N = 35, Messmoment jeweils RIW $j k$, Produktmoment-Korrelationskoeffizient nach Bravais/Pearson. 
Legende, MINMWMAX, 6-fach

[1] von 34.91 bis $39.96(n=11)$

[2] bis $45.01(n=1)$

[3] bis $50.05(n=4)$

[4] bis $58.58(n=11)$

[5] bis $67.11(n=3)$

[6] bis $75.64(n=4)$

Summe der Elemente: 34

$\mathrm{MIN}=34.91$ (P. 840)

$\mathrm{MW}=50.05$

MED $=51.27$

MAX $=75.64$ (P. 855)

\section{Häufigkeitsverteilung, MINMWMAX, 12-fach}

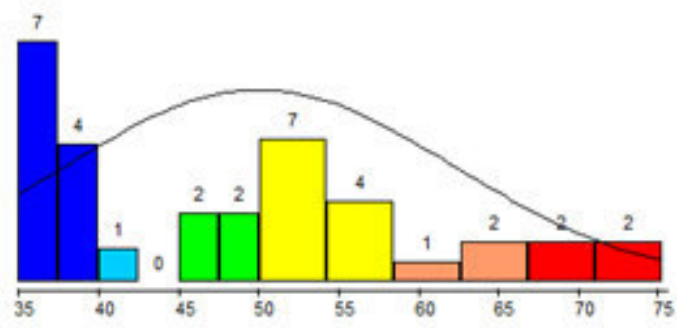

\section{ALI (1995-2008) - Campania}

LAZIO italianostandard MOLISE

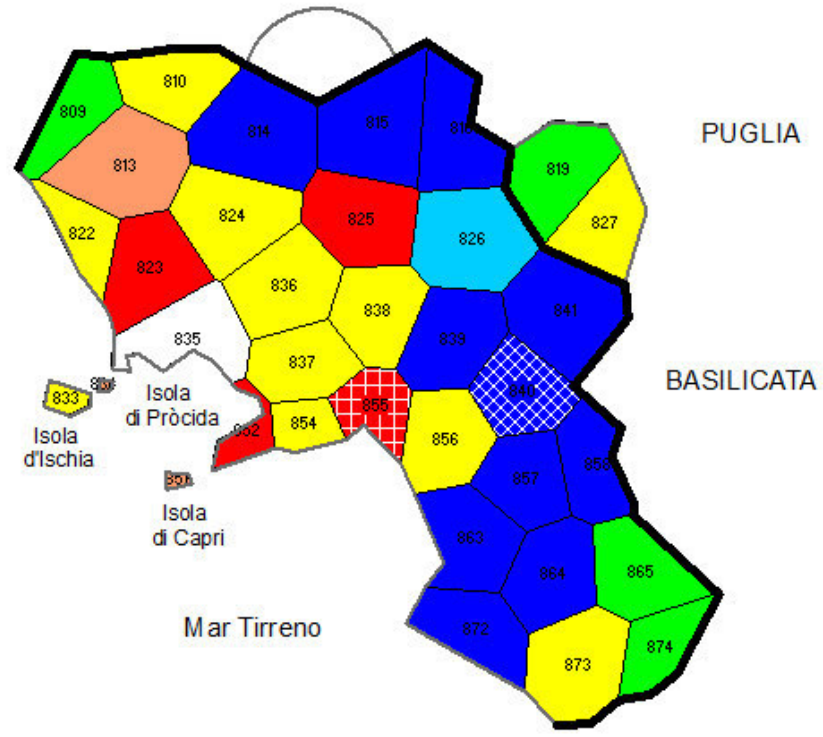

fec. S. Hajek

adiuv. H. Goebl et P. Smečka adiuv. B. Castellazzi a.d. 2013 carta di THIESSEN/HAAGNORONOI
35 punti dinchiesta + italiano standard limite di regione

Karte A105. Ähnlichkeitsprofil zum Referenzpunkt Neapel (835). ALI-Korpus, Totalkorpus (275 AK). N = 35, Messmoment RIW $_{j k}$.

\section{Legende, MINMWMAX, 6-fach}

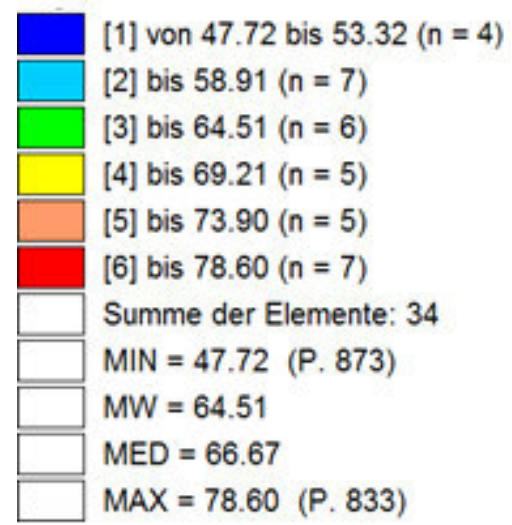

Häufigkeitsverteilung, MINMWMAX, 12-fach

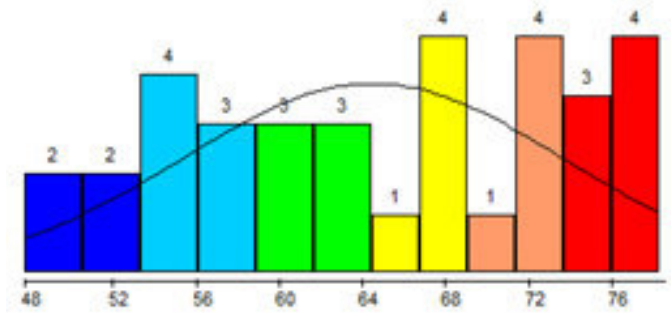

\section{Hajek (2014) - Campania}
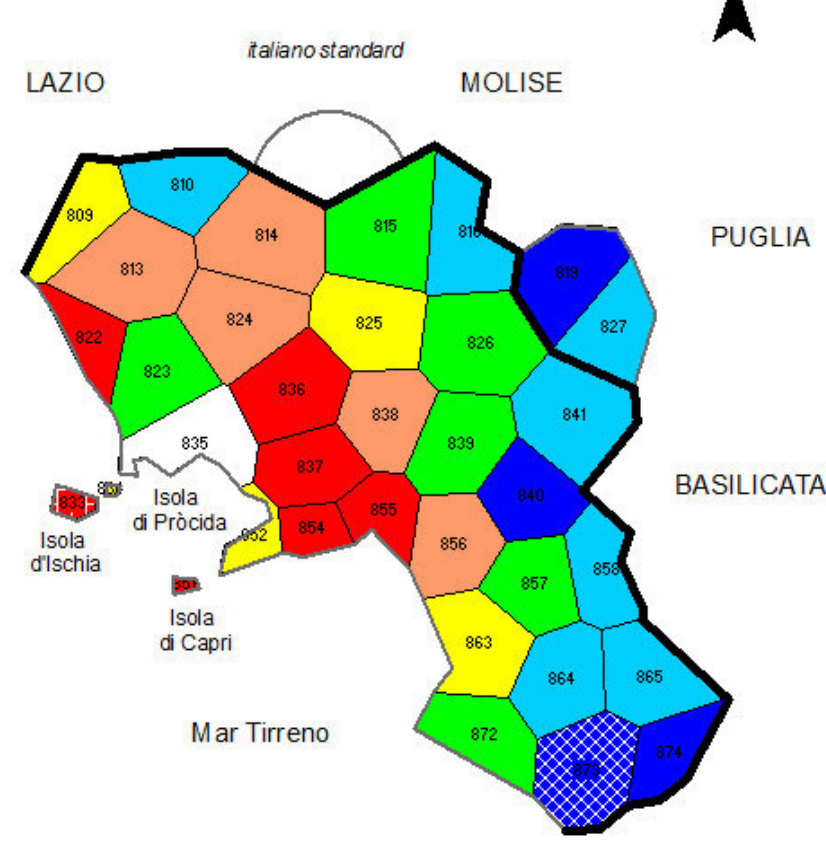

fec. S. Hajek

adiuv. H. Goebl et P. Smečka adiuv. B. Castellazzi a.d. 2013

carta di THIESSENHAAGNORONOI 35 punti dinchiesta + italiano standard limite di regione

Karte A106. Ähnlichkeitsprofil zum Referenzpunkt Neapel (835). Vergleichskorpus, Totalkorpus (285 AK). N = 35, Messmoment RIW $j k$. 
Legende, MINMWMAX, 6-fach

[1] von 39.05 bis $43.05(n=1)$

[2] bis $47.06(n=12)$

[3] bis $51.06(n=6)$

[4] bis $54.36(n=5)$

[5] bis $57.66(n=3)$

[6] bis $60.95(n=7)$

Summe der Elemente: 34

$M I N=39.05(P .852)$

$\mathrm{MW}=\mathbf{5 1 . 0 6}$

MED $=50.48$

MAX $=60.95$ (P. 816; 839)

Häufigkeitsverteilung, MINMWMAX, 12-fach

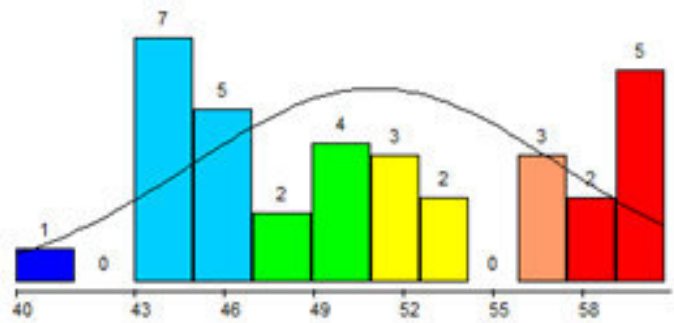

\section{ALI (1995-2008) - Campania}

LAZIO italianostandard MOLISE

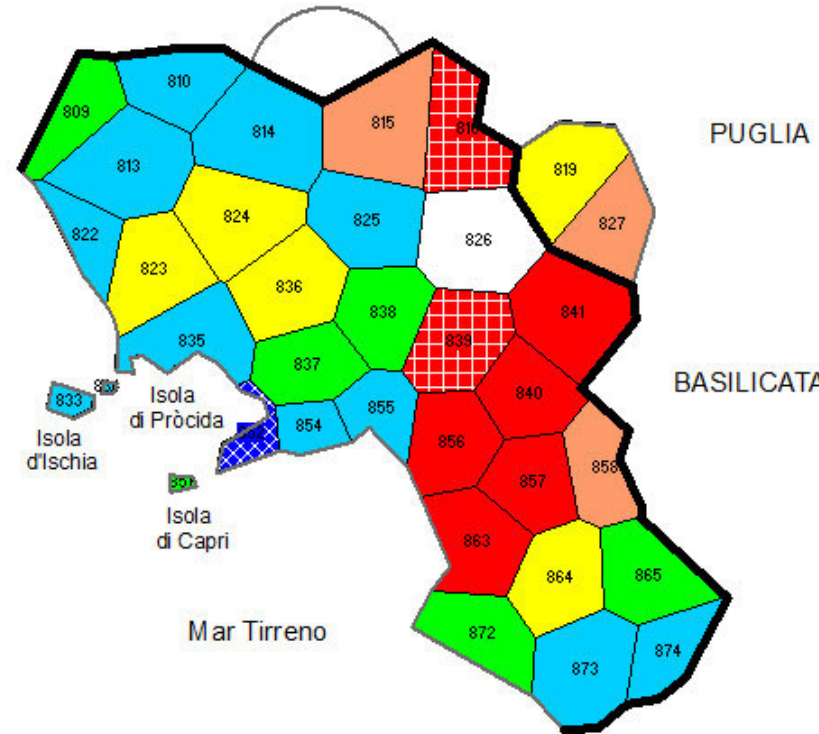

fec S. Hajek

adiuv. H. Goebl et P. Smečka

adiuv. B. Castellazzi

carta di THIESSENHAAGNORONOI 35 punti dinchiesta + italiano standard

limite di regione

Karte A107. Ähnlichkeitsprofil zum Referenzpunkt Melito Irpino (826). ALI-Korpus, Lexikon (105 AK). N = 35, Messmoment RIW $j k$.

$$
\begin{aligned}
& \text { Legende, MINMWMAX, 6-fach } \\
& \text { [1] von } 51.79 \text { bis } 55.20(n=3) \\
& \text { [2] bis } 58.61(n=3) \\
& \text { [3] bis } 62.03(n=8) \\
& {[4] \text { bis } 64.27(n=5)} \\
& \text { [5] bis } 66.51(n=11) \\
& \text { [6] bis } 68.75(n=4) \\
& \text { Summe der Elemente: } 34 \\
& \text { MIN }=51.79 \quad(P .810) \\
& \text { MW }=62.03 \\
& \hline \square \text { MED }=63.39 \\
& \text { MAX }=68.75 \quad \text { (P. 809) }
\end{aligned}
$$

Häufigkeitsverteilung, MINMWMAX, 12-fach

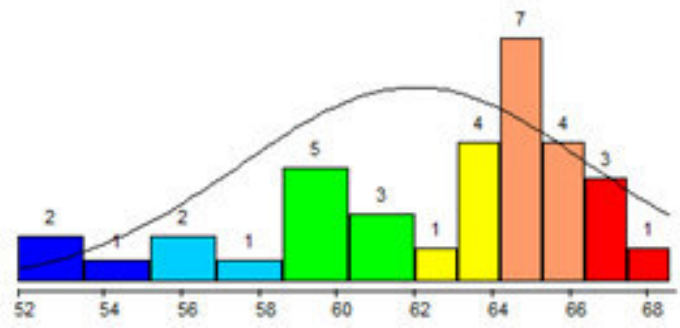

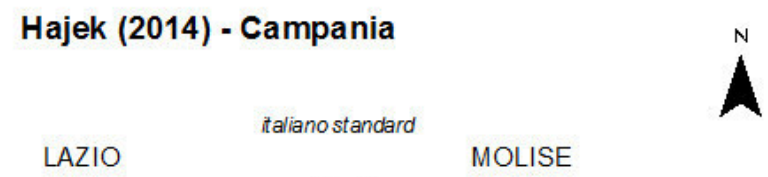

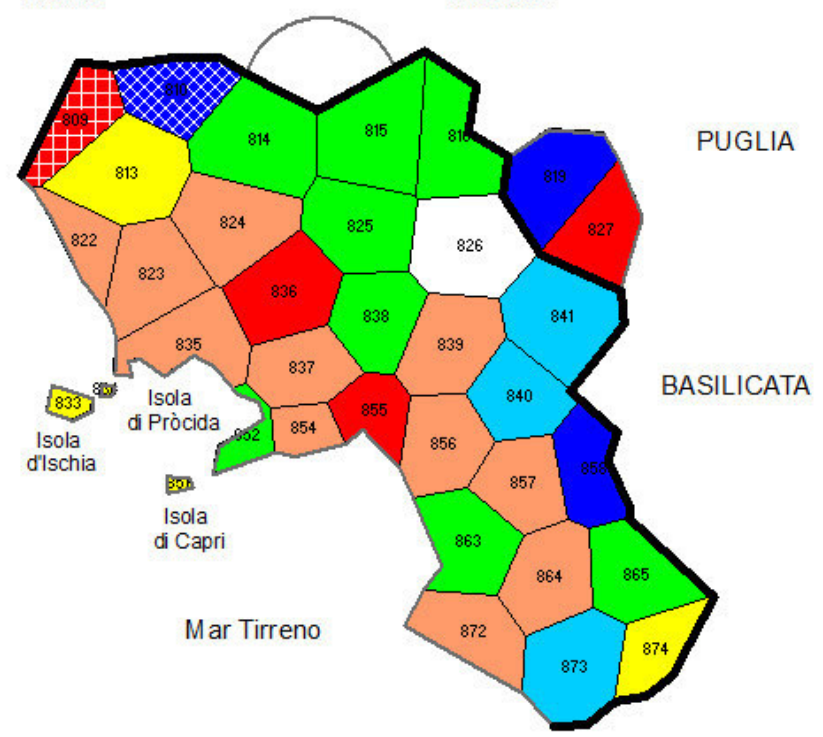

fec. S. Hajek

adiuv. $H$. Goebl et $P$. Smečka adiuv. B. Castellazzi

carta di THIESSENHAAGNORONO 35 punti d'inchiesta + italiano standard - limite di regione

Karte A108. Ähnlichkeitsprofil zum Referenzpunkt Melito Irpino (826). Vergleichskorpus, Lexikon (112 AK). N = 35, Messmoment RIW $j k$. 
Legende, MINMWMAX, 6-fach

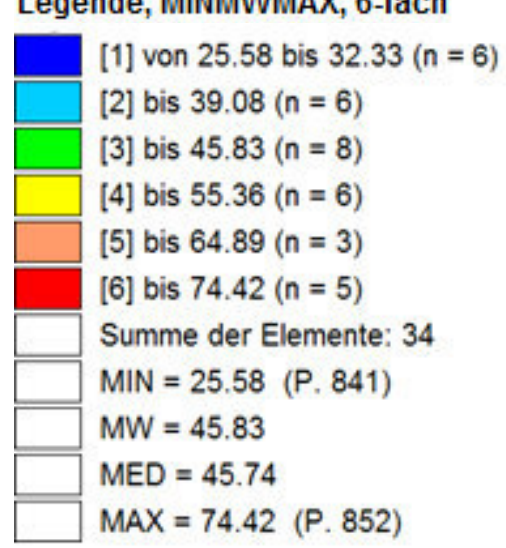

Häufigkeitsverteilung, MINMWMAX, 12-fach

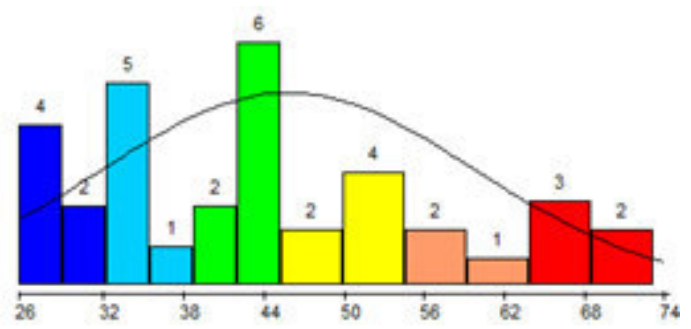

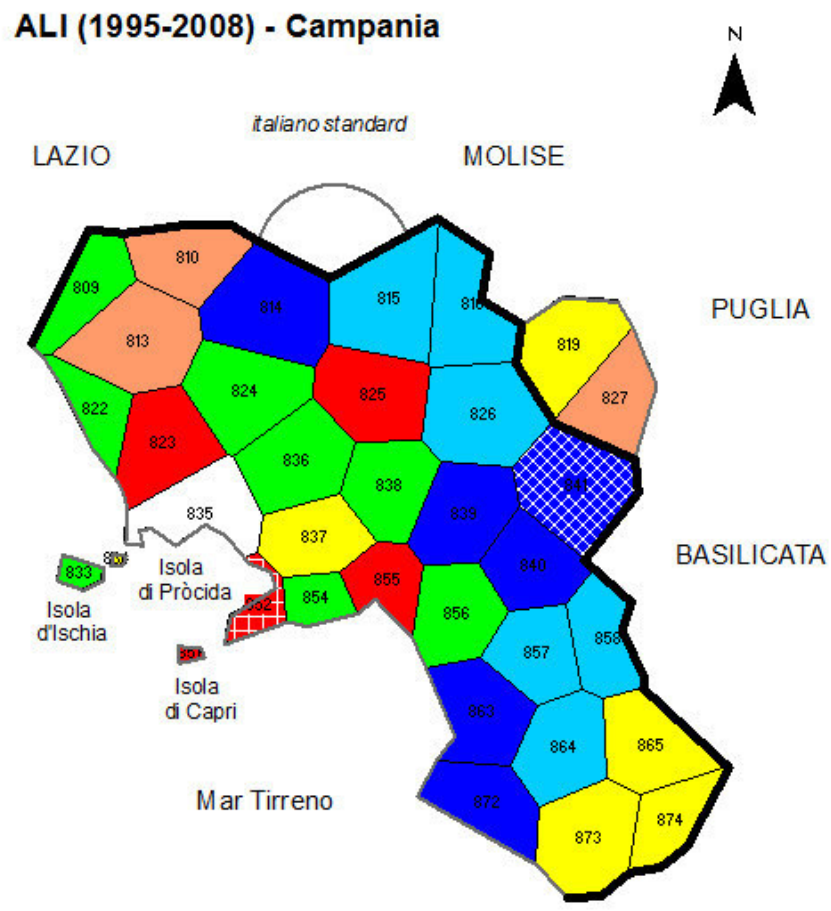

fec. S. Hajek

adiuv. H. Goebl et P. Smečka adiuv. B. Castellazzi

carta di THIESSENHAAGNORONOI 35 punti dinchiesta + italiano standard - limite di regione

Karte A109. Ähnlichkeitsprofil zum Referenzpunkt Neapel (835). ALI-Korpus, Konsonantismus (129 AK). N = 35, Messmoment RIW $_{j k}$.

\section{Legende, MINMWMAX, 6-fach}

[1] von 40.00 bis $48.15(n=6)$

[2] bis $56.30(n=4)$

[3] bis $64.45(n=6)$

[4] bis $69.90(n=3)$

[5] bis $75.35(n=5)$

[6] bis $80.80(n=10)$

Summe der Elemente: 34

$M I N=40.00$ (P. 873)

$\mathrm{MW}=64.45$

MED $=67.20$

MAX $=80.80$ (P. 833; 836; 851)

\section{Häufigkeitsverteilung, MINMWMAX, 12-fach}

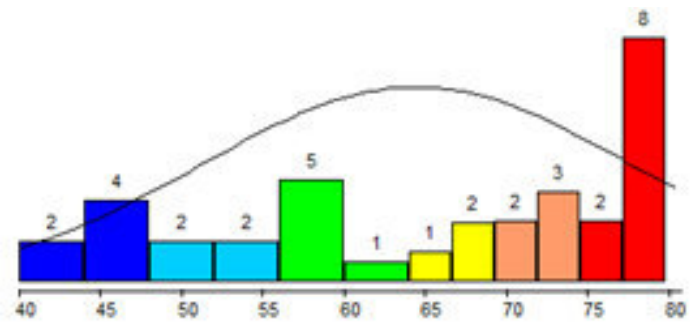

\section{Hajek (2014) - Campania}

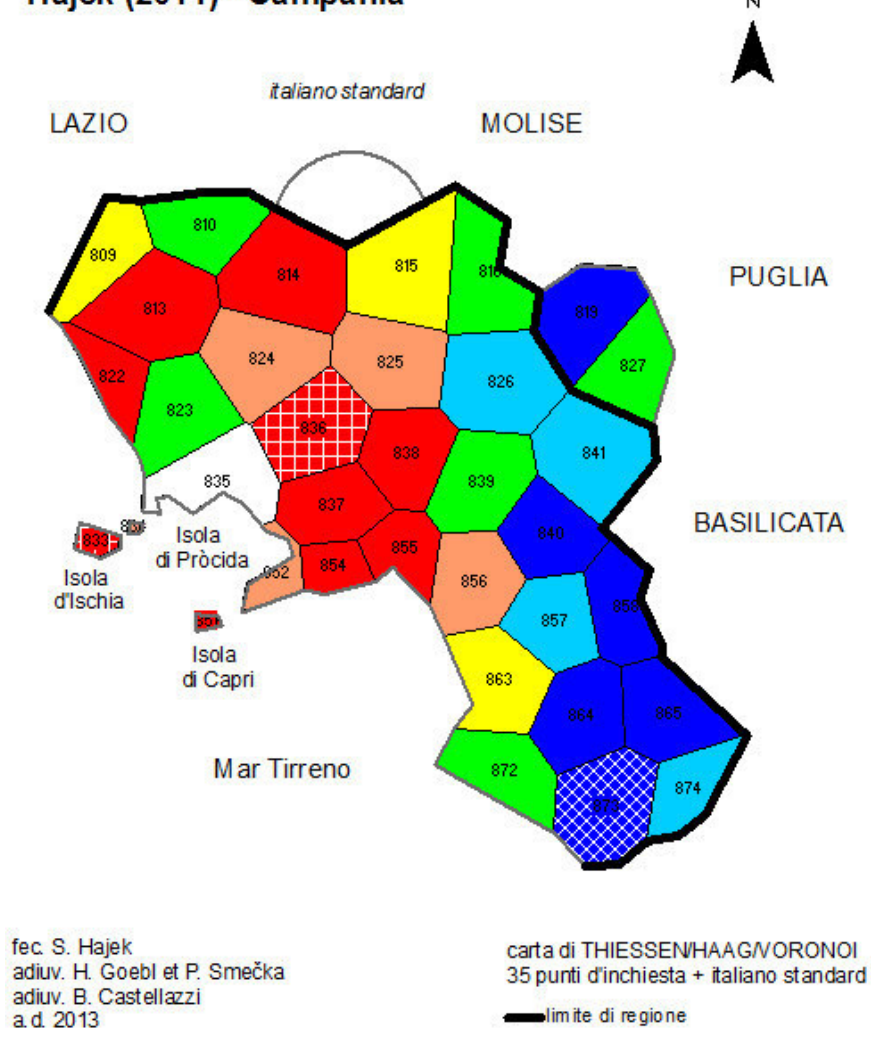

Karte A110. Ähnlichkeitsprofil zum Referenzpunkt Neapel (835). Vergleichskorpus, Konsonantismus (125 AK). $\mathrm{N}=35$, Messmoment RIW $_{j k}$. 
Legende, MINMWMAX, 6-fach

[1] von 14.63 bis $20.40(n=4)$

[2] bis $26.16(n=1)$

[3] bis $31.92(n=16)$

[4] bis $48.11(n=12)$

[5] bis $64.30(n=0)$

[6] bis $80.49(n=1)$

Summe der Elemente: 34

$\mathrm{MIN}=14.63 \quad($ P. 819)

$M W=31.92$

MED $=31.71$

MAX $=80.49$ (P. 815)

Häufigkeitsverteilung, MINMWMAX, 12-fach

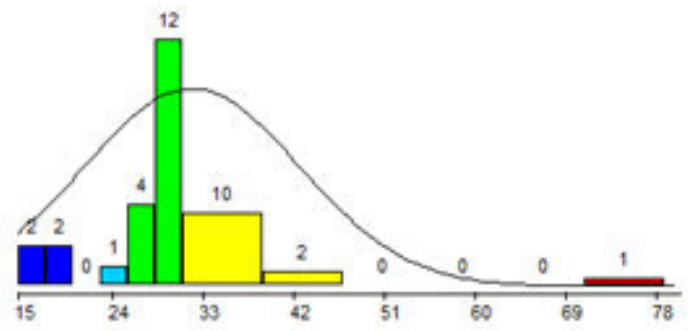

\section{ALI (1995-2008) - Campania}

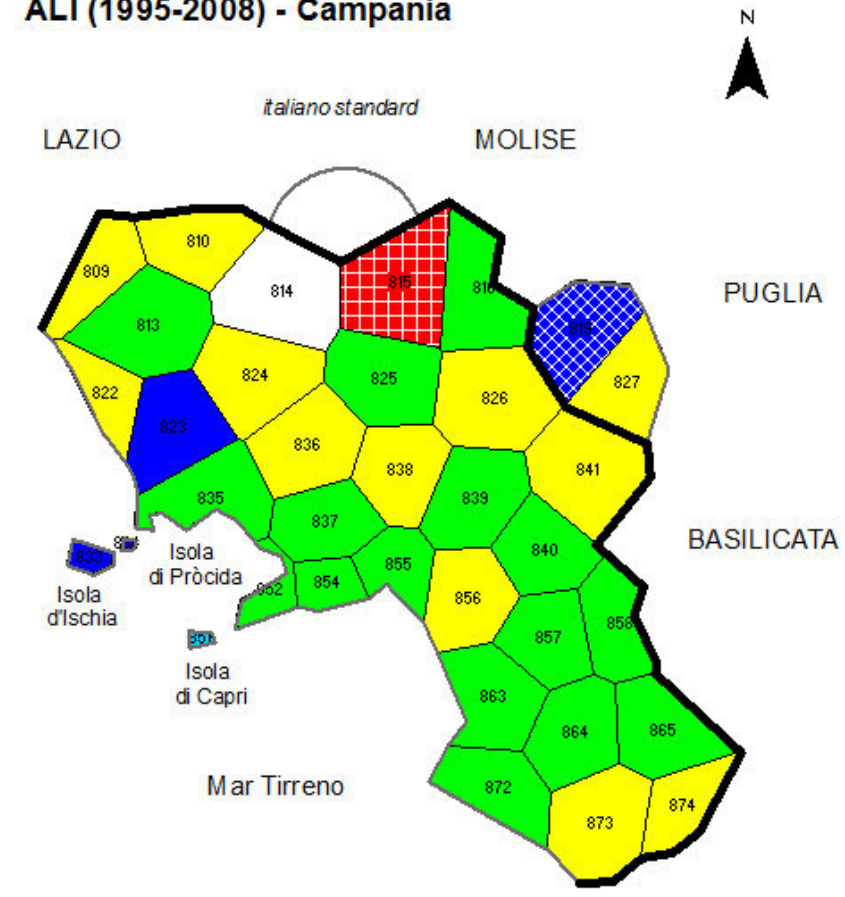

fec. S. Hajek

adiuv. H. Goebl et P. Smečka

adiuv. B. Castellazzi

a.d. 2013 carta di THIESSENHAAGNORONOI 35 punti dinchiesta + italiano standard

limite di regione

Karte A111. Ähnlichkeitsprofil zum Referenzpunkt Gioia Sannìtica (814). ALI-Korpus, Vokalismus (41 AK). N = 35, Messmoment RIW $j k$.

\section{Legende, MINMWMAX, 6-fach}

[1] von 33.33 bis $44.93(n=2)$

[2] bis $56.54(n=2)$

[3] bis $68.14(n=7)$

[4] bis $73.20(n=16)$

[5] bis $78.27(n=4)$

[6] bis $83.33(n=3)$

Summe der Elemente: 34

MIN $=33.33(P .874)$

$\mathrm{MW}=68.14$

MED $=70.83$

$\operatorname{MAX}=83.33(P .835)$

Häufigkeitsverteilung, MINMWMAX, 12-fach

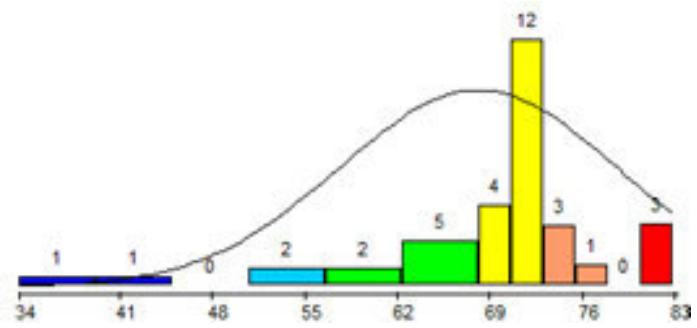

Hajek (2014) - Campania

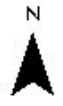

LAZIO \#alianostandard MOLISE

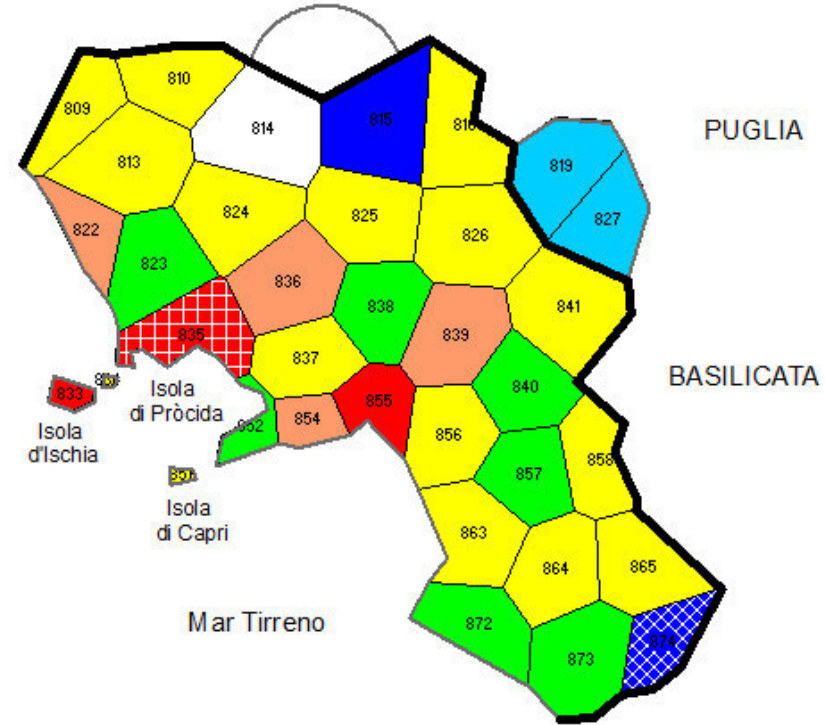

fec. S. Hajek

adiuv. H. Goebl et P. Smečka

adiuv. B. Castellazzi

a.d. 2013

carta di THIESSEN/HAAGNORONOI 35 punti dinchiesta + italiano standard limite di regione

Karte A112. Ähnlichkeitsprofil zum Referenzpunkt Gioia Sannìtica (814). Vergleichskorpus, Vokalismus (48 AK). $\mathrm{N}=35$, Messmoment $\mathrm{RIW}_{j k}$. 
Legende, MINMWMAX, 6-fach

[1] von 23.64 bis $26.93(n=3)$

[2] bis $30.23(n=3)$

[3] bis $33.53(n=10)$

[4] bis $36.65(n=13)$

[5] bis $39.78(n=4)$

[6] bis $42.91(n=2)$

Summe der Elemente: 35

$\mathrm{MIN}=23.64$ (P. 833)

$M W=33.53$

$\mathrm{MED}=33.82$

MAX $=42.91$ (P. 827)

Häufigkeitsverteilung, MINMWMAX, 12-fach

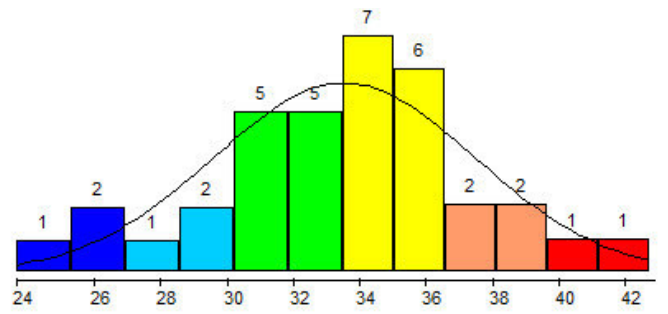

\section{ALI (1995-2008) - Campania}
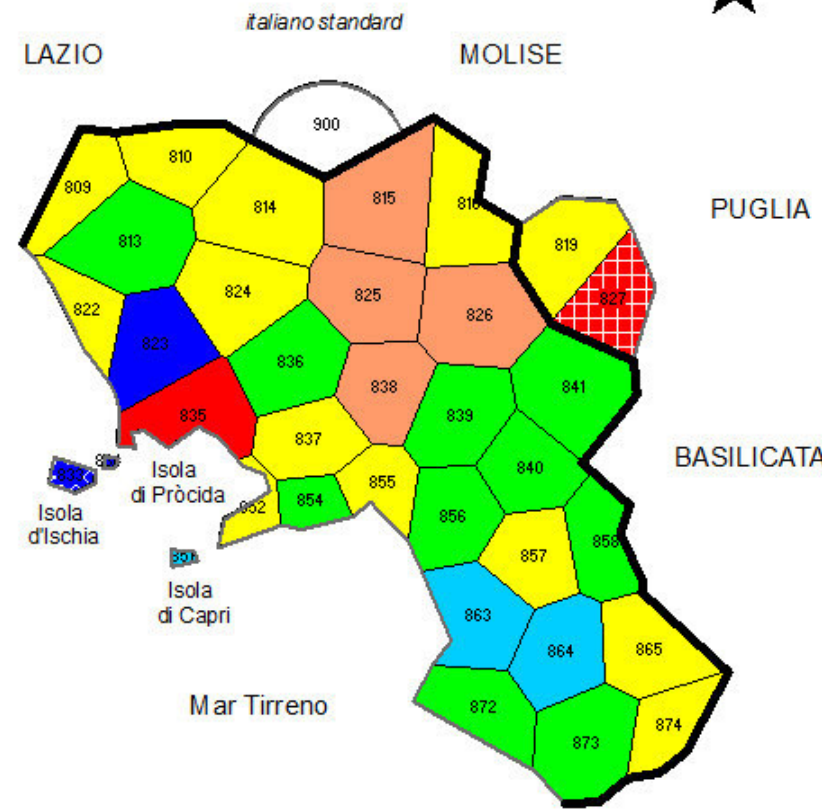

fec. S. Hajek

adiuv. H. Goebl et P. Smečka

adiuv. B. Castellazzi

carta di THIESSENHAAGNORONOI 35 punti d'inchiesta + italiano standard

limite di regione

Karte A113. Synopse der Ähnlichkeitswerte zum Referenzpunkt italiano standard (900). ALI-Korpus, Totalkorpus (275 AK). N = 36, Messmoment RIW $j k$.

\section{Legende, MINMWMAX, 6-fach}

\begin{tabular}{l} 
[1] von 34.74 bis $39.90(n=1)$ \\
[2] bis $45.06(n=5)$ \\
{$[3]$ bis $50.23(n=10)$} \\
{$[4]$ bis $53.60(n=9)$} \\
{$[5]$ bis $56.98(n=6)$} \\
{$[6]$ bis $60.35(n=4)$} \\
Summe der Elemente: 35 \\
MIN $=34.74(P .823)$ \\
\hline$\square$ MW $=50.23$ \\
\hline$\square$ MED $=50.53$ \\
\hline$\square A X=60.35(P .834)$
\end{tabular}

Häufigkeitsverteilung, MINMWMAX, 12-fach

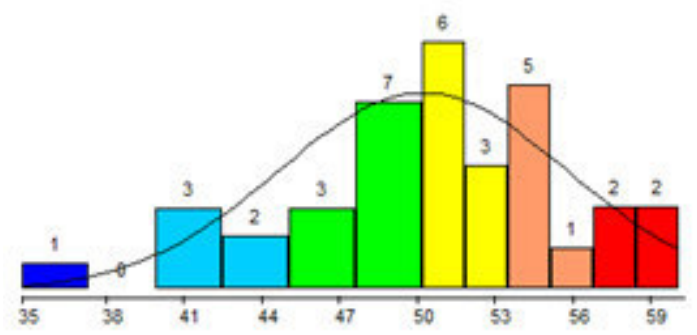

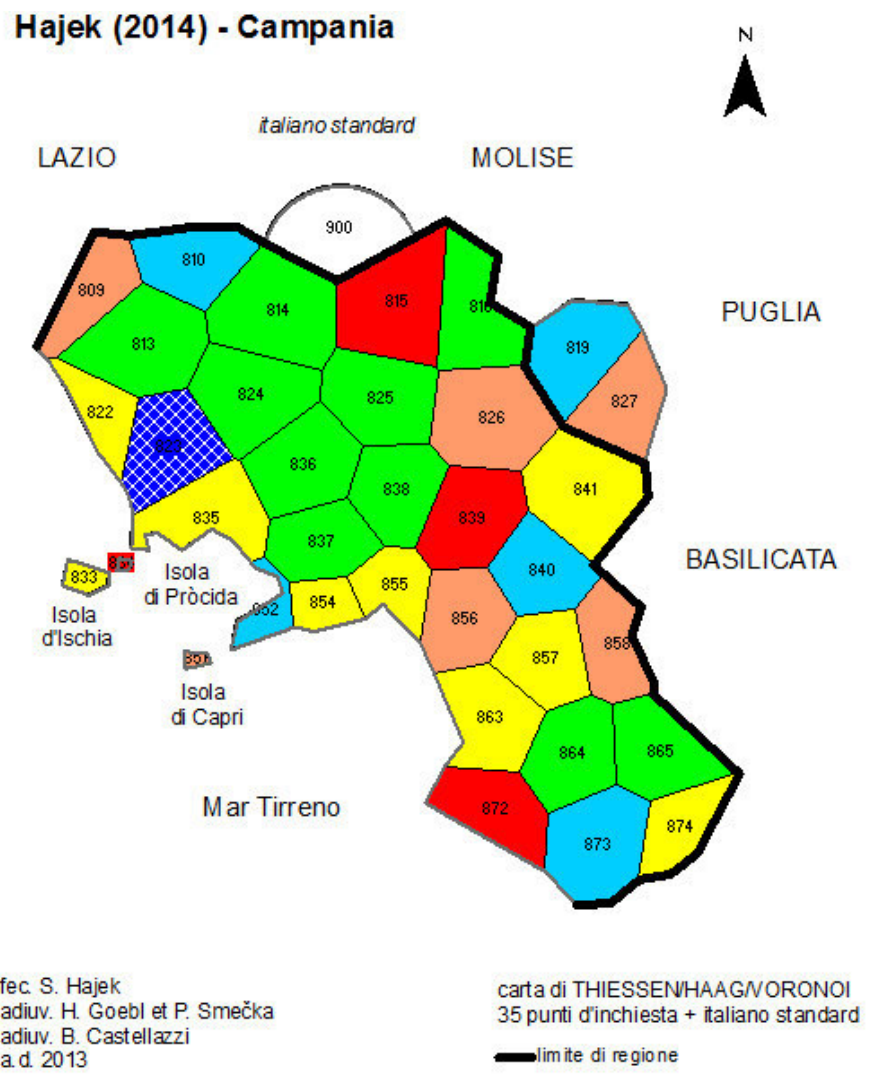

adiuv. H. Goebl et P. Smečka a.d. 2013

Karte A114. Synopse der Ähnlichkeitswerte zum Referenzpunkt italiano standard (900). Vergleichskorpus, Totalkorpus (285 AK). N = 36, Messmoment $\mathrm{RIW}_{j k}$. 
Legende, MINMWMAX, 6-fach

\begin{tabular}{l} 
[1] von 28.57 bis $31.18(n=4)$ \\
{$[2]$ bis $33.80(n=4)$} \\
{$[3]$ bis $36.41(n=12)$} \\
{$[4]$ bis $39.83(n=10)$} \\
{$[5]$ bis $43.25(n=1)$} \\
{$[6]$ bis $46.67(n=4)$} \\
Summe der Elemente: 35 \\
\hline$\square$ MIN $=28.57(P .851)$ \\
MW $=36.41$ \\
\hline$\square$ MED $=36.19$ \\
\hline$\square A X=46.67$ (P. 835)
\end{tabular}

Häufigkeitsverteilung, MINMWMAX, 12-fach

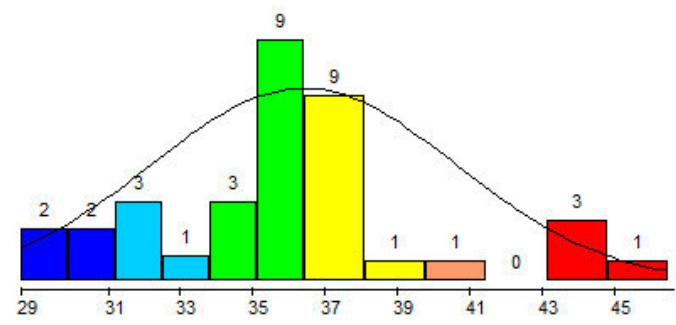

\section{ALI (1995-2008) - Campania}

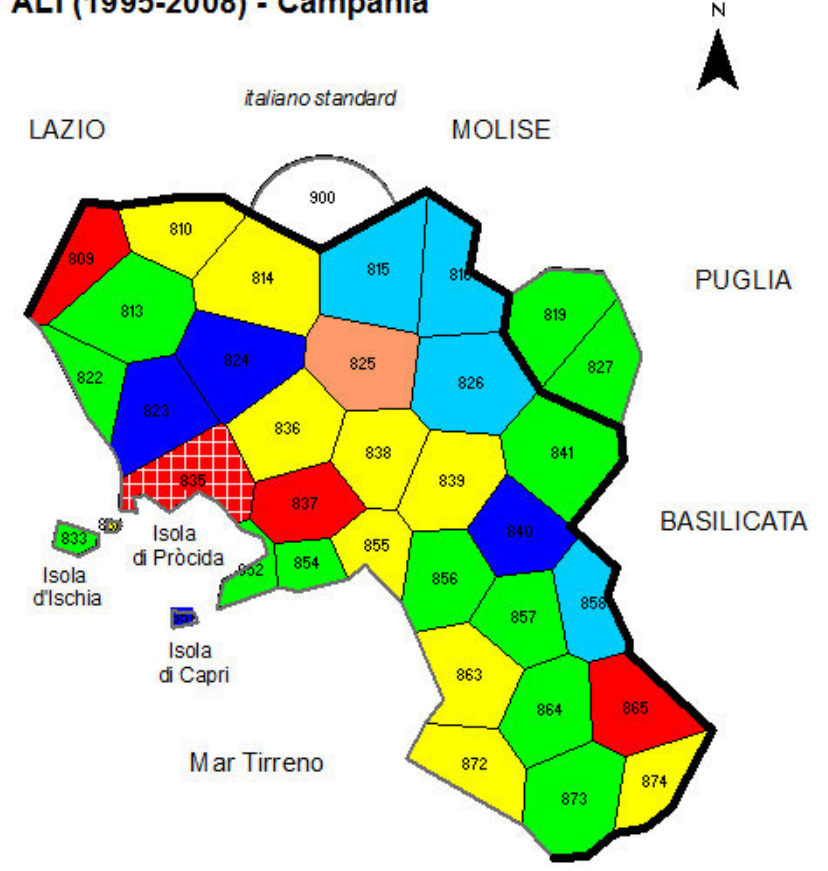

fec. S. Hajek

adiuv. $\mathrm{H}$. Goebl et $\mathrm{P}$. Smečka adiuv. B. Castellazzi

carta di THIESSENHAAGNORONOI 35 punti dinchiesta + italiano standard - limite di regione

Karte A115. Synopse der Ähnlichkeitswerte zum Referenzpunkt italiano standard (900). ALI-Korpus, Lexikon (105 AK). N = 36, Messmoment RIW $j k$.

\section{Legende, MINMWMAX, 6-fach}

[1] von 50.89 bis $53.98(n=10)$

[2] bis $57.07(n=0)$

[3] bis $60.15(n=10)$

[4] bis $65.99(n=7)$

[5] bis $71.84(n=6)$

[6] bis $77.68(n=2)$

Summe der Elemente: 35

MIN $=50.89$ (P. 819;823;840)

$M W=60.15$

MED $=59.82$

MAX $=77.68(P .834)$

Häufigkeitsverteilung, MINMWMAX, 12-fach

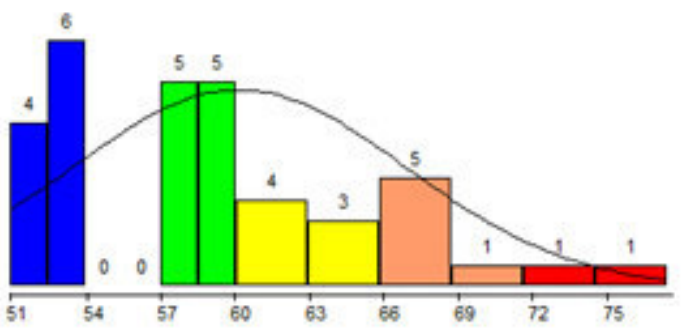

\section{Hajek (2014) - Campania}

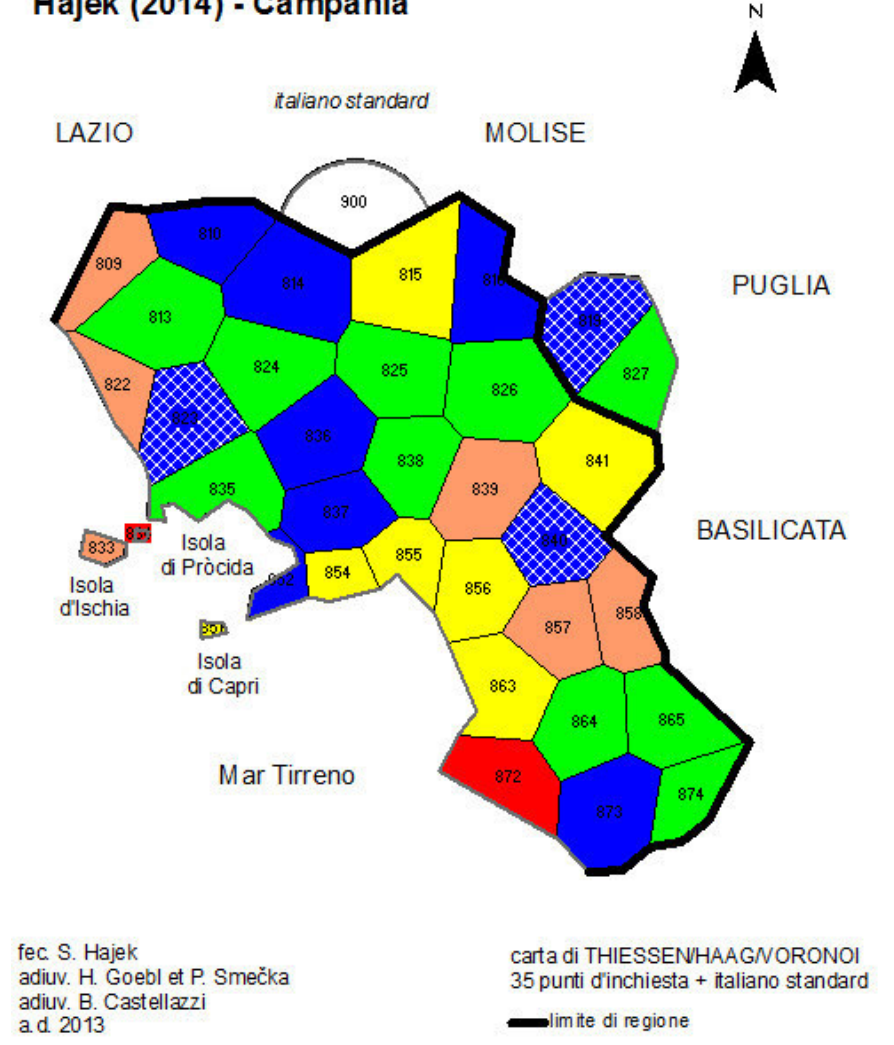

Karte A116. Synopse der Ähnlichkeitswerte zum Referenzpunkt italiano standard (900). Vergleichskorpus, Lexikon (112 AK). N = 36, Messmoment RIW $j k$. 
Legende, MINMWMAX, 6-fach

\begin{tabular}{|c|}
\hline [1] von 17.05 bis $22.28(n=3)$ \\
\hline [2] bis $27.51(n=4)$ \\
\hline [3] bis $32.74(n=14)$ \\
\hline [4] bis $39.65(n=9)$ \\
\hline [5] bis $46.57(n=4)$ \\
\hline [6] bis $53.49(n=1)$ \\
\hline Summe der Elemente: 35 \\
\hline $\mathrm{MIN}=17.05(P .833)$ \\
\hline$M W=32.74$ \\
\hline$M E D=31.78$ \\
\hline MAX $=53.49(P .827)$ \\
\hline
\end{tabular}

Häufigkeitsverteilung, MINMWMAX, 12-fach

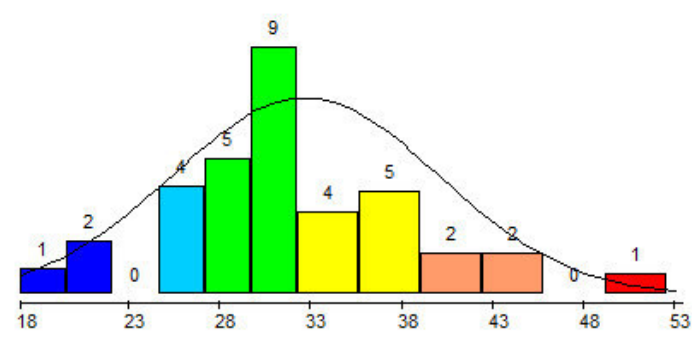

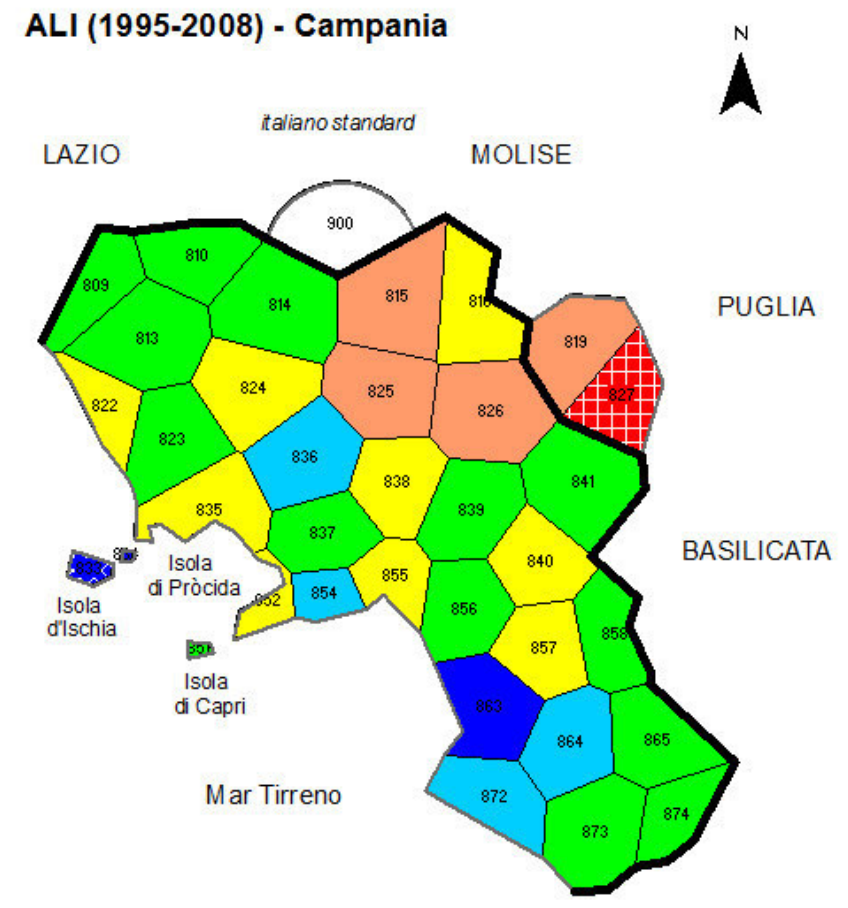

fec. S. Hajek

adiuv. H. Goebl et P. Smečka adiuv. B. Castellazzi

carta di THIESSENHAAGNORONOI 35 punti dinchiesta + italiano standard - limite di regione

Karte A117. Synopse der Ähnlichkeitswerte zum Referenzpunkt italiano standard (900). ALI-Korpus, Konsonantismus (129 AK). N = 36, Messmoment RIW $j k$.

\section{Legende, MINMWMAX, 6-fach}

[1] von 24.00 bis $32.12(n=1)$

[2] bis $40.24(n=2)$

[3] bis $48.37(n=13)$

[4] bis $53.04(n=12)$

[5] bis $57.72(n=4)$

[6] bis $62.40(n=3)$

Summe der Elemente: 35

$\mathrm{MIN}=24.00$ (P. 823)

$M W=48.37$

$\mathrm{MED}=48.80$

MAX $=62.40$ (P. 826)

\section{Häufigkeitsverteilung, MINMWMAX, 12-fach}

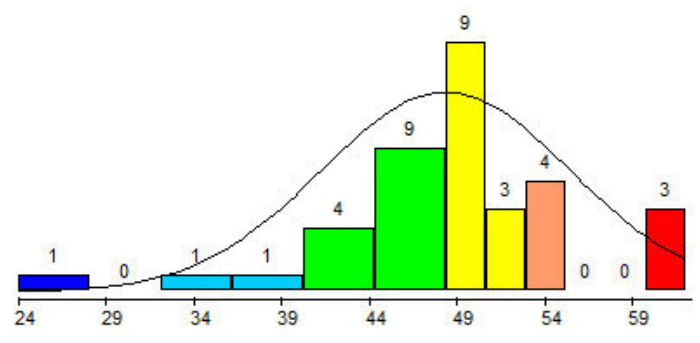

Hajek (2014) - Campania

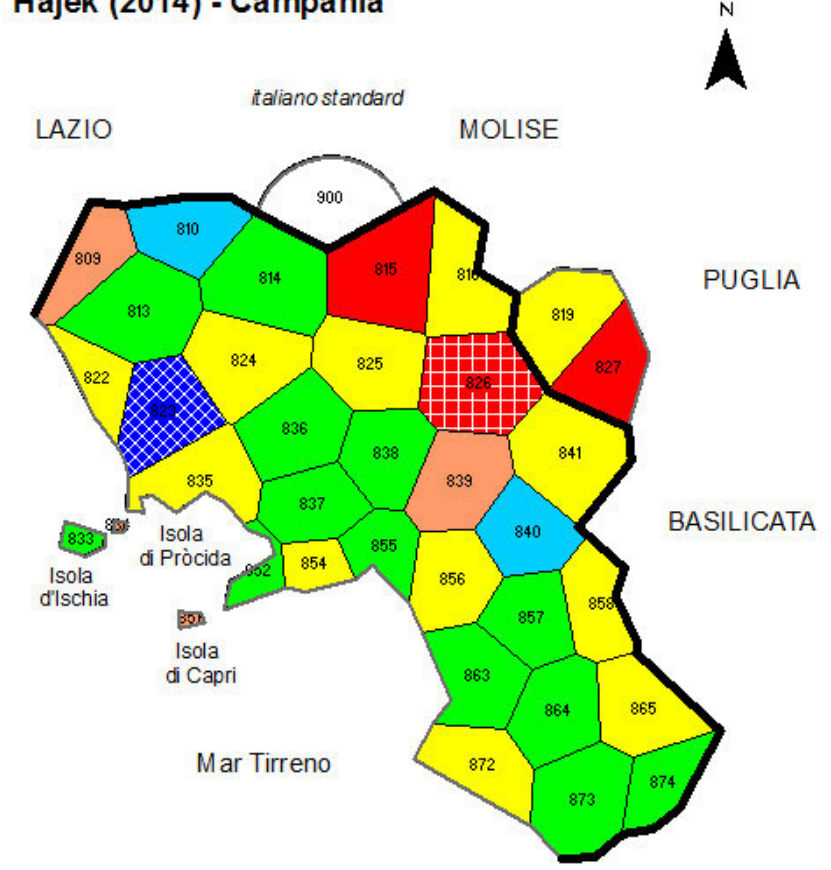

fec S. Hajek

adiuv. $\mathrm{H}$. Goebl et $\mathrm{P}$. Smečka adiuv. B. Castellazzi carta di THIESSENHAAGNORONOI 35 punti d'inchiesta + italiano standard - limite di regione

Karte A118. Synopse der Ähnlichkeitswerte zum Referenzpunkt italiano standard (900). Vergleichskorpus, Konsonantismus (125 AK). $\mathrm{N}=36$, Messmoment $\mathrm{RIW}_{j k}$. 
Legende, MINMWMAX, 6-fach

[1] von 14.63 bis $19.30(n=4)$

[2] bis $23.97(n=0)$

[3] bis $28.64(n=10)$

[4] bis $34.54(n=18)$

[5] bis $40.44(n=2)$

[6] bis $46.34(n=1)$

Summe der Elemente: 35

MIN $=14.63$ (P. 819; 823; 833)

$M W=28.64$

MED $=29.27$

MAX $=46.34$ (P. 874)

Häufigkeitsverteilung, MINMWMAX, 12-fach

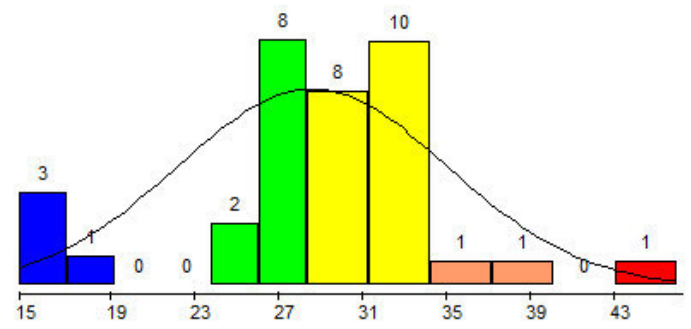

\section{ALI (1995-2008) - Campania}

$\stackrel{N}{N}$

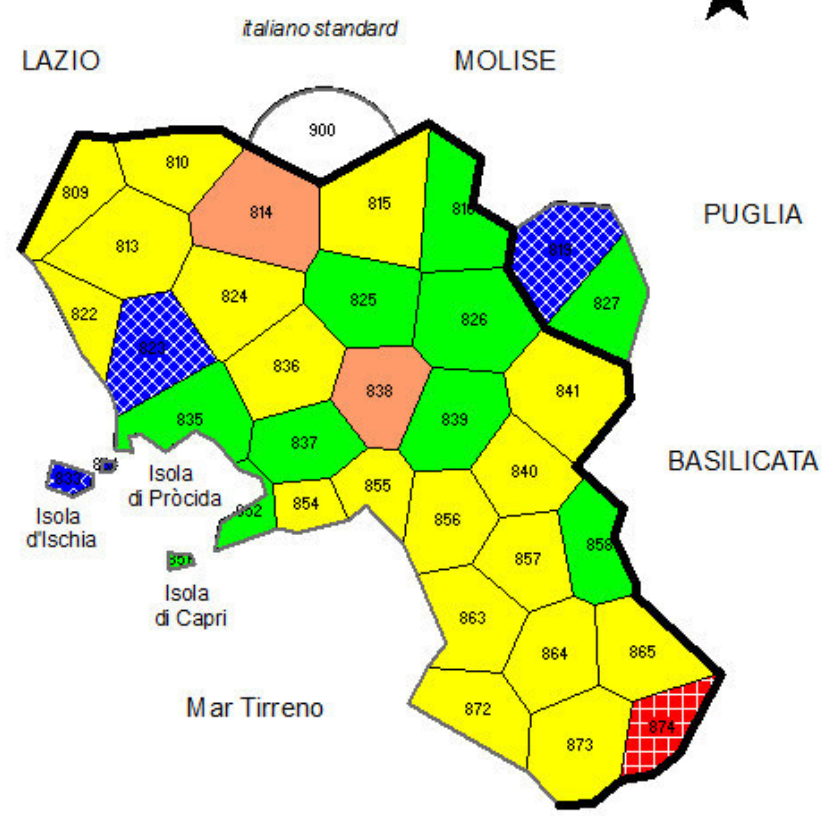

fec. S. Hajek

adiuv. H. Goebl et P. Smečka adiuv. B. Castellazzi a.d. 2013 carta di THIESSENHAAGNORONOI 35 punti dinchiesta + italiano standard

limite di regione

Karte A119. Synopse der Ähnlichkeitswerte zum Referenzpunkt italiano standard (900). ALI-Korpus, Vokalismus (41 AK). N = 36, Messmoment RIW $j k$.

Legende, MINMWMAX, 6-fach

\begin{tabular}{l} 
[1] von 16.67 bis $21.75(n=2)$ \\
{$[2]$ bis $26.83(n=5)$} \\
{$[3]$ bis $31.90(n=11)$} \\
{$[4]$ bis $41.41(n=15)$} \\
{$[5]$ bis $50.91(n=1)$} \\
{$[6]$ bis $60.42(n=1)$} \\
Summe der Elemente: 35 \\
MIN $=16.67(P .819)$ \\
\hline$\square$ MW $=31.90$ \\
\hline$\square$ MED $=31.25$ \\
MAX $=60.42(P .874)$
\end{tabular}

Häufigkeitsverteilung, MINMWMAX, 12-fach

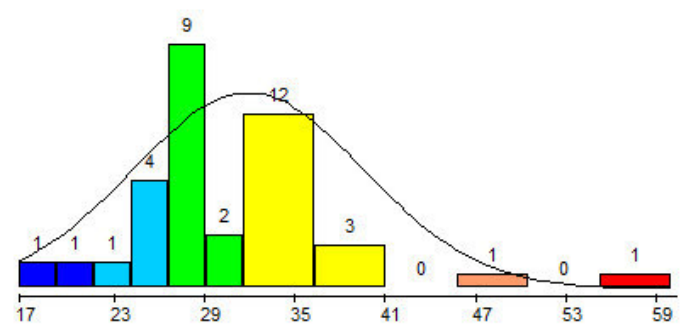

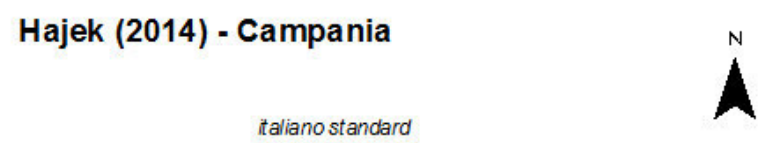

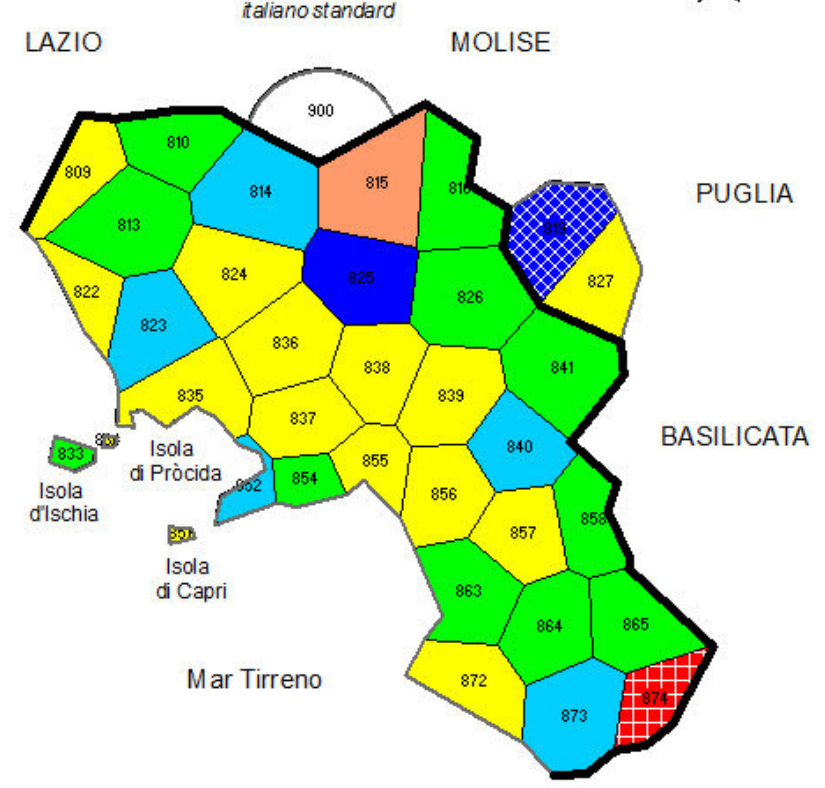

fec. S. Hajek

adiuv. $H$. Goebl et $P$. Smečka adiuv. B. Castellazzi

carta di THIESSEN/HAAGNORONOI 35 punti dinchiesta + italiano standard limite di regione

Karte A120. Synopse der Ähnlichkeitswerte zum Referenzpunkt italiano standard (900). Vergleichskorpus, Vokalismus (48 AK). N = 36, Messmoment RIW $j k$. 